THE EXTERIOR

\title{
OF THE HORSE
}


University of Pennsylvania

Annenberg Rare Book and Manuscript Library
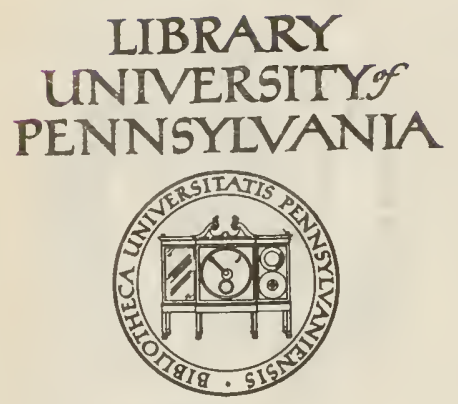

Rittmhouse Orrngy

VR 6.19 .1

$\rightarrow$ MI. EH

FAIRMAN

ROGERS

COLLECTION

ON

HORSEMANSHIP

1892

AS A MEMORIAL TO HER HUSBAND. 


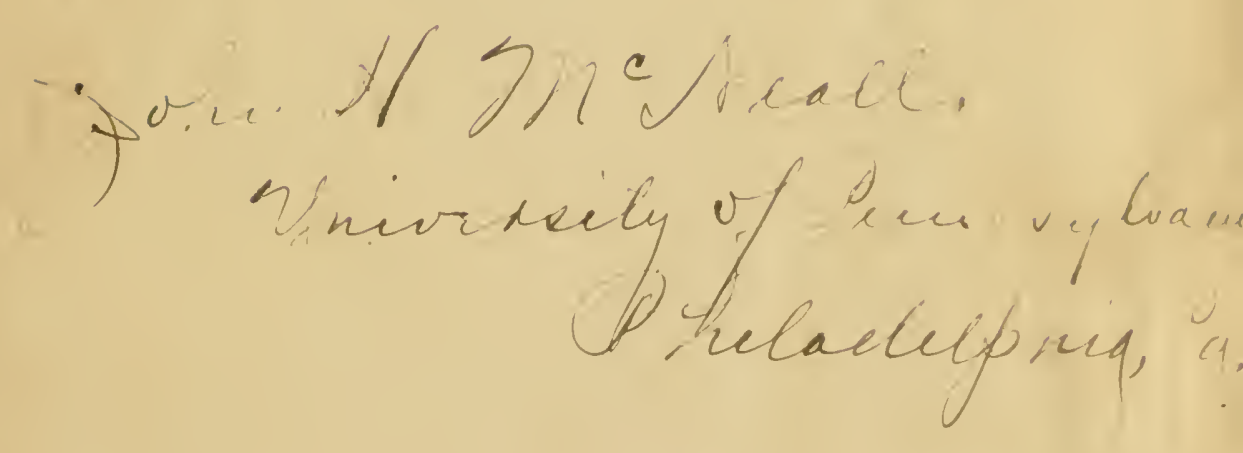




\section{University of Pennsylvania Libraries}

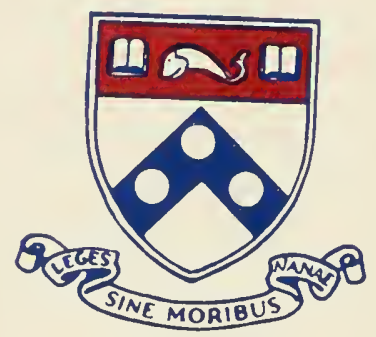

Annenberg Rave Book and Manuscript Library

$$
\text { Gift of }
$$

Mrs. John H. ḾcNeill 


\section{EXTERIOR OF THE HORSE.}

BY

\section{ARMAND GOUBAUX, AND GUSTAVE BARRIER,}

HONORARY DIRECTOR OF TIIE VETERINARY SCHOOL OF ALFORT, MEMBER OF THE ACADEMY OF MLDICINE AND OF THE NATIONAL SUCIFTY OF AGIICULTURF OF FRANCE,

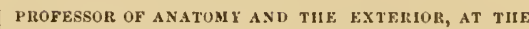
VETERINARY SCHOOL, AT ALFORT, MEMBER OF THE CENTRAL SUCIETY OF VWTERINARY MEDICINE OP

\section{SECOND EDITION,}

With 346 Figures and 34 Plates, by G. Nicolet, LIBRARIAN AT TIIE VETERINARY SCHOOL OF ALFORT.

TRANSLATED AND EDITED BY

\section{SIMON J. J. HARGER, V. M. D.,}

PROFERSOR OF ANATOMY AND ZOÜTECINICS IN THE VETERINARY DEPARTMENT OF THE CNIVFRSITY OF PENASYluatia.

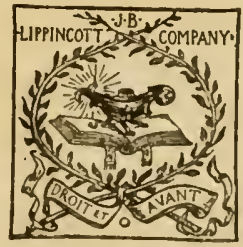

P II I I, $A$ D E, I, P H I A :

J. B. LIPPINCOT'T COMPANY.

LONDON : 10 HENRIETTA STREET, COVENT GARDEN.

1892 . 
Copyright, 1892, by J. B. LipPincott ConPanY.

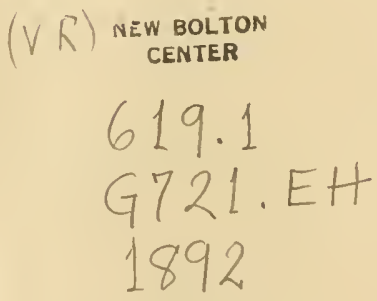

Printed ey J. B. Lippincott Company, Philadelfhia, U.S.A. 
TO THE

MEMBERS OF THE VETERINARY PROFESSION, AND ALL CONNOISSEUR OF THE HORSE, THIS WORK IS

\section{$D E D I C A T E D$}

BY THE TRANSLATOR. 
Digitized by the Internet Archive in 2009 with funding from Lyrasis Members and Sloan Foundation 


\section{PREFACE BY THE TRANSLATOR.}

Progress in veterinary science implies advance in investigation and the publication of books setting forth the results of that advance. Numerous volumes of veterinary literature have of late years appeared from the pens of both French and German writers; but in English there has been very little produced upon the subject; and Englishspeaking teachers, practitioners, and students constantly find themselves compelled to look to foreign writers for instruction on points connected with their vocation.

In no branch of this literature has this deficiency been more serionsly felt than in that which studies the horse exclusively from the exterior, considering his external form and characters with relation to his mechanical aptitude and his commercial value. Hence I was induced to fill this vacancy by the translation of Gonbaux and Barrier's "Exterior of the Horse."

In selecting this book, the French reterinary text-book par excellence, I was influenced no less by the reputation and standing of its authors than by the originality, exactness, and fulness of its treatment of the subject.

The difficulty of such an undertaking an be fully appreciated only through actual experience. I have endeavored as far as possible to avoil the use of French terms. In some instances, however, it was impossible to find English terms that wonld convey the exact meaning of the terms of the original text. Wherever I have retained the forcign terms, it has been done solely for the sake of brevity and simplicity.

No pains have been spared to make this one of the most complete books of its kind. The numerous plates and figures thoroughly elncidate the more diffienlt points of the text; and references are made to all the best Freneh, German, and Italian treatises on the veterinary science. One of my special aims hats been to adapt this book to the Encrlish-speaking realer. It contains valuable information for the practitioner, the student, the horseman, and the breeder. 
I take occasion here to acknowledge my obligation to M. Barrier and Messrs. Asselin and Houzeau for the loan of the plates and clichés, and also to express my gratitude to the friends who have assisted me in my work, and particularly to the publishers for their generous assistance, for the ability with which they have executed their portion of the undertaking, and for the interest they have manifested not only in this work, but also in all publications pertaining to veterinary science. Nor must I forget, finally, to express my obligations to Mr. E. R. Jones for his conscientious care in reading and correcting the pronf.

ShoN J. J. HARger.

205 North Twentieth Street, Philadelphia,

December 3, 1891. 


\section{PREFACE TO THE FIRST EDITION.}

Is the preparation of the work herewith offered to the public, our aim has been to sclect from the science which treats of the rational improvement of domestic animals-the science of zoötechnics-that chapter which bears upon the consideration of the external forms and the characteristics of the horse in their connection with his mechanical aptitudes and his commercial value.

This study, for which we have retained the name given to it by the founder of veterinary schools, merits a treatment very different from the theoretical and empirical one accorded to it by the majority of our predecessors. We have endeavored, therefore, on all important points, to base our opinions upon numerous careful rescarches pursued by ourselves in person; and from these data we have deduced, or by them confirmed, the principles of a judicious appreciation of the physical and moral qualities of the horse.

To our teaching colleagues, our associates, our pupils, and all others who have aided us in our task, we here acknowledge our deep gratitude. If we have not cited the names and treatises of all the authors who have written upon the exterior of the horse, it is beeanse we had determined, in the matter of bibliography and out of consideration for our readers, to abstain from all idle discussions and uninteresting controrersies. As for the rest, we think we have done them full justice in the numerous citations we have made from their works.

Our labors have been singularly facilitated by the friendly interest and generosity of our publishers, who will allow nothing to stand in the way of the successful completion of a book useful to seience, and, in partienlar, of one useful to the veterinarian.

We are indebted also to M. G. Nieolet, librarian to the veterinary school of Alfort, whose artistie skill has reproduced, among other suljects, with an exactness hitherto mnknown in works of this kind, the chatracteristics of the dental wear, the recognition of which is a matter of such great importance in determining the age.

$$
\text { Armang Goubaux, Gustave Barmer. }
$$

AlFort, March 15, 1884. 



\section{PREFACE TO THE SECOND EDITION.}

This second edition, in preparation for three years, has been the subject of a careful revision and of numerous alterations.

Some very notable improvements upon the first edition have been made.

A new plate upon the age, and fifty-three original figures, have been added.

The matter, while much condensed as a whole, has in many places been rewritten at great length.

Finally, by the emplorment of three varieties of type, we are enabled to indicate the degree of importanee of each subject treated, and to facilitate the use of the volume to those who can consult only the essential parts.

$$
\text { Armand Goubatx, Gustaye Barrier. }
$$

ALFORT, March 1, 1890. 



\section{CONTENTS.}

\section{SECTION FIRST.}

\section{PRELIMINARY IDEAS OF ANIMAL MECHANICS.}

C H A P T E R I.

PAGE

OBJECT, END, AND UTILITY OF THE Exterior . . . . . . . . . 1

CHA P T ER II.

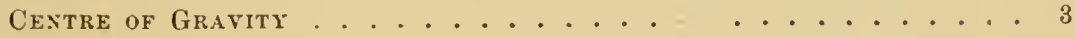

C H A P T E R III.

The Lever asd Muscular Mechanism . . . . . . . . . . 11

CH A P T E R I V.

The Ixchixed Plaxe

.................... 19

\section{SECTION SECOND.}

STUDY OF THE REGIONS.

8 1. Dirisioss of thr HoRse. . . . . . . . . . . . . . 21

ใ 2. SOME DEFINITIOXS . . . . . . . . . . . . . . . 31

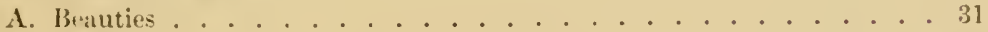

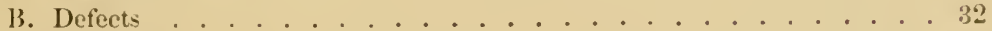
C. Blemishes . . . . . . . . . . . . . . 32

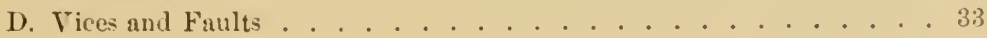

$$
\begin{aligned}
& \text { PART I. } \\
& \text { THE HEAD. } \\
& \text { CHAPTER I. }
\end{aligned}
$$

ANTFRIOR FACE . . . . . . . . . . . . . . . 36

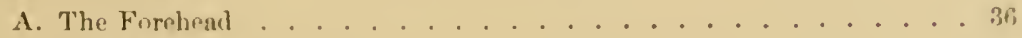

B. The Fite . . . . . . . . . . . . . . 38

C. Extremity of the Nuse ............... 40 
Lateral Faces .......................... 41

A. The Ear . . . . . . . . . . . . . . . . 41

B. The Temple . . . . . . . . . . . . . . 46

C. The Supra-orbit and the Eyebrows . . . . . . . . . 47

D. The Eye . . . . . . . . . . . . . . 4 48

E. The Cheek . . . . . . . . . . . . . 58

F. The Nostrils . . . . . . . . . . . . . 59

CH A P T E R I I I.

POSterior FACE. . . . . . . . . . . . . 65

A. Intermaxillary Space . . . . . . . . . . . . 65

B. Inferior Maxillary Kegion . . . . . . . . . . . 67

C. The Chin .................... 68

CHA P TER I V.

INFERIOR EXTREMITY . . . . . . . . . . . . . . 69

A. The Mouth and its Subdivision . . . . . . . . . . 69

1. The Lips . . . . . . . . . . . . . . . . . . . . . 69

2. The Teeth and the Gums . . . . . . . . . 73

3. The Bars . . . . . . . . . . . . . . 74

4. The Lingual Canal . . . . . . . . . . . . . . 75

5. The Tongue . . . . . . . . . . . . . 76

6. The Palate . . . . . . . . . . . 79

B. The Mouth in General . . . . . . . . . . . 79

CH A P T ER V.

Posterior Extremity. . . . . . . . . . . . 82

A. The Poll or Nape . . . . . . . . . . . . . . 83

B. The Parotid Region .... . . . . . . . . . 83

C. The Throat ................... 85

CHA PTER VI.

Head in General ................... . . . . 85

A. Harmonious Relations . . . . . . . . . . . . . 86

B. Length . . . . . . . . . . . . . . . . 87

C. Volume ........................ 87

D. Direction .................... . . 88

E. Forms ........................ 92

F. Attachments ........................ 95

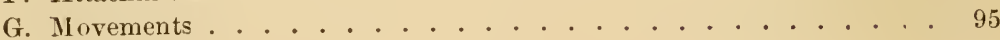

H. Expression .................. . . 96

\section{PART II.}

THE BODY.

CH A P T ER I.

SUPERIOR FACE . . . . . . . . . . . . . . . . . . 98

A. The Neck . . . . . . . . . . . . . . . . . . . 98

The Mane and the Forelock . . . . . . . . 109 
B. The Withers

C. The Back . . . . . . . . . . . . . . 116

D. The Loins . . . . . . . . . . . . . . 122

E. The Croup ..................... 123

The Haunch . . . . . . . . . . . . . . 142

\section{H A P T E R I I.}

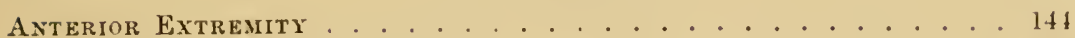

A. The Breat, or Pectoral liegion . . . . . . . . . . 144

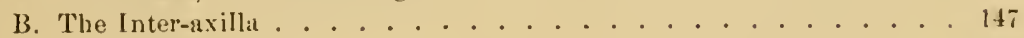

C. The Axilla . . . . . . . . . . . . . 147

\section{H A P T E R I I I.}

IYFERIOR FACE . . . . . . . . . . . . . . . . . 148

A. The Xiphoid Region. . . . . . . . . . . . . 148

B. The Abdomen . . . . . . . . . . . . . . 149

\section{CH A PTE R I V.}

Lateral Faces . . . . . . . . . . . . . . . 152

A. The Costal Region; Ribs; sides . . . . . . . . . . 152

The Chest in General . . . . . . . . . . . . 157

B. The Flank . . . . . . . . . . . . . . . 162

C. The Groin . . . . . . . . . . . . . . 167

C H A P T E V.

Posterior Extremity . . . . . . . . . . . . . . 168

A. The Tuil . . . . . . . . . . . . . . . 168

B. The Anus . . . . . . . . . . . . . . . . 174

C. The Perineum and the Mediun Raphé . . . . . . . . . . 175

C H A P T E R I.

Gexital Organs . . . . . . . . . . . . 176

\&1. Genital Organs of the Male . . . . . . . . . . . 176

A. The Testicles and their Enrelopes . . . . . . . . . 176

B. The Sheath and the I'enis ............ 181

\& 2. Genital Orans of the Female . . . . . . . . . . . . 184

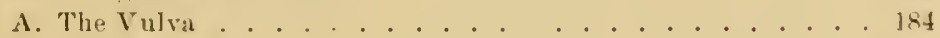

B. The Ilamme . . . . . . . . . . . . . . 186

\section{PART I I I.}

THE MEMBERS.

Genfral Considerations . . . . . . . . . . . . 186

1. Action of the Anterior Member . . . . . . . . . 1: 19;

2. Action of the Posterior Yember . . . . . . . . . . . 198

CHAPTER I.

ANTFRIOR IIEMHER . . . . . . . . . . . . . . 200

A. The Slunulder . . . . . . . . . . . . . . 201

13. The $\mathrm{Arm}$........................... 214 
C. The Elbow . . . . . . . . . . . . . . . . . . 219

D. The Forearm . . . . . . . . . . . . . . . . 221

E. The Chestnuts . . . . . . . . . . . . . . . . 227

F. The linee . . . . . . . . . . . . . . . . . 227

CH A P T R I I.

Posterior Member . . . . . . . . . . . . . . . . . . . . 237

A. The Thigh and the Buttock . . . . . . . . . . . . . 237

B. The Stifle . . . . . . . . . . . . . . . . . . . 244

C. The Leg . . . . . . . . . . . . . . . . . . . 246

D. The Hock . . . . . . . . . . . . . . . . . . . 253

E. The Chestnut . . . . . . . . . . . . . . . . . . 279

F. The Canon and the Tendons . . . . . . . . . . . . . 279

G. The Fetlnck . . . . . . . . . . . . . . . . . . 290

H. The Footlock and the Ergot . . . . . . . . . . . . . . 297

I. The Pastern . . . . . . . . . . . . . . . . . 298

J. The Coronet . . . . . . . . . . . . . . . 309

\title{
C H A P E R I I I.
}

THE Foot . . . . . . . . . . . . . . . . . 312

A. Organization . . . . . . . . . . . . . . 312

1. Internal Parts . . . . . . . . . . . . . . . 313

2. The Hoof . . . . . . . . . . . . . . 316

B. Properties and Mechanism . . . . . . . . . . . . . . . 322

C. Beauties . . . . . . . . . . . . . . . . . . . 327

D. Defects . . . . . . . . . . . . . . . . . 328

1. Of Volume and of Proportion . . . . . . . . . . . 328

2. Of Conformation . . . . . . . . . . . . . 329

3. Of the Axis . . . . . . . . . . . . . . 332

4. Of Quality of the Horn . . . . . . . . . . . . . . 334

E. Accidents occasioned by Shoeing . . . . . . . . . . . . . . 335

F. Diseases . . . . . . . . . . . . . . . . 336

\section{SECTION THIRD.}

\section{PROPORTIONS.}

\author{
PART I. \\ INTRODUCTION. \\ C H A P T E R I.
}

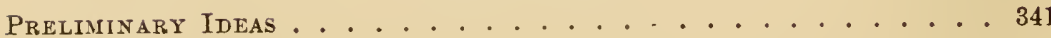

CH A P T R I I. 


\title{
PART I I. \\ OBJECT AND UTILITY OF THE PROPORTIONS.
}

CHA PTER I.

Points of View fron Which the l'Roportions ARE studied..... 357

A. Relation of Dimensions between the Parts . . . . . . . . . . . 358

B. Angulur Relations of the Osseous Segments . . . . . . . . . . 365

Theory of the Similitude of the Angles and the Parallelism of the

Bony Segments . . . . . . . . . . . . . 365

C. General Relations of the Ensemble, the Whole Organism . . . . . 385

D. Relations of the Organism with the Nervous System. . . . . . 397

\section{CH A P T E R I I.}

Isolated fafects of Beautiful Proportions upon the Animal MaCHINE . . . . . . . . . . . . . . . . . 404

A. Conditions of the Motor en Mode de Masse, or of Force . . . . . 405

B. Conditions of the Motor en Mode de Vitesse, or of Speed . . . . . . 407

C. Conditions of the Mixed Motor. (Combination of Force and Speed realized ). . . . . . . . . . . . 408

D. Excitability ; Impressionability ; Irritability . . . . . . . 410

\section{H $\triangle$ P T E R I I I.}

Restlt of Beattiful Proportions upon tiie Axmal Machine a . 412 Resistance to Fatigue : Endurance . . . . . . . . . . 412

CH A P T E R I V.

Definitive SYxthesis .

\section{SECTION FOURTH.}

\section{THE HORSE IN RELATION TO LOCOMOTION.}

\author{
PART I. \\ ATTITEDES AND MOVENEATS UPON PLACE.
}

C II A P T R I.

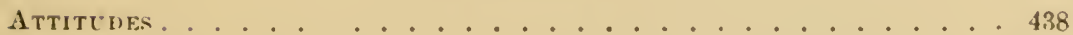

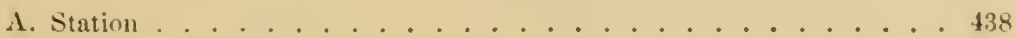

Axes, Equilihrium ...................... 442

a. Of the Anterior Mrubers ............... 443

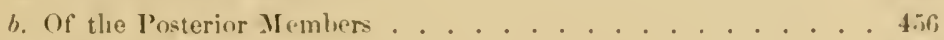

B. Lying Down or Decubitus . . . . . . . . . . . . 466 
C H A P T ER I I.

Movenents upon Place................. . . . 468

A. Rearing . . . . . . . . . . . . . . 468

B. Kicking ................. . . 470

PART I I.

MODE OF PROGRESSION, OR THE GAITS OF THE HORSE.

C H A P T E R I.

Generalitiles of the Galts . . . . . . . . . . . . 472

Analysis of the Gatts . . . . . . . . . . . . . 4 479

Systems of Notation of the Gaits . . . . . . . . . . . 490

Synthetic Study of the Mode of Progression . . . . . . 496

C H A P T E R I I.

The Gaits in Particular. . . . . . . . . . . . . 503

A. The Amble, Pacing . . . . . . . . . . . . . 504

Broken Amble ................ . . . 509

B. The Trot . . . . . . . . . . . . . 510

Broken Trot, Flỵing Trot . . . . . . . . . . . 522

liacking ................ . . . . 522

Skipping . . . . . . . . . . . . . . . 527

The Canter . . . . . . . . . . . . . . 527

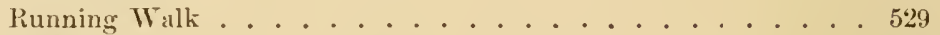

C. The Walk ... . . . . . . . . . . . 530

Backing . . . . . . . . . . . . . 542

D. The Gallop . . . . . . . . . . . . . . . 544

E. Leaping . . . . . . . . . . . . . . . . 569

Bounding and Bucking ............. . . 575

C H A P T E R I I I.

Defects in the GaIts ..................... . . 576

A. Defects existing in the Anterior Members alone . . . . . . . . 577

1. Dragging the Toe. . . . . . . . . . . . 577

2. Excessive Knee-Action . . . . . . . . . . 578

3. Immobilized or Pegged Shoulders. . . . . . . . . . 878

B. Defects existing in the Posterior Members alone . . . . . . . 579

1. String-halt . . . . . . . . . . . . . . 579

2. Rotating Hocks . . . . . . . . . . . . . . . 581

C. Defects dependent upon the Mnde of Association in raising the Anterior Feet and resting the Posterior . . . . . . . . . . . 582

Forging . . . . . . . . . . . . . . . 582

D. Defects existing separately or simultaneously in the Anterior or the Posterior Members . . . . . . . . . . . . . 584

1. Rocking . . . . . . . . . . . . . 584

2. Strain of the Loins . . . . . . . . . . . . . . 585

E. Defects existing indiscriminately in the Four Members . . . . . 586

1. Billarder, Paddling . . . . . . . . . . . . 586

2. Interfering . . . . . . . . . . . . . . 586

3. Lameness. . . . . . . . . . . . . . . 588 


\title{
SECTION FIFTH.
}

\section{AGE OF THE HORSE.}

\author{
PARTI. \\ THE 'TEETH.
}

CH A P T E R I.

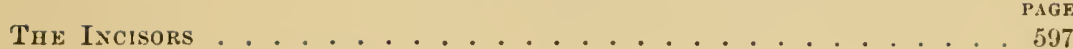

A. Of the First Dentition . . . . . . . . . . . 597

B. Of the Second Dentition .............. . . . 601

C. Structure . . . . . . . . . . . . . . 606

D. Details of the Dental Table according to the Age . . . . . . . 615

E. Direction ................. . . 616

The Tusks or Canine Teeth . . . . . . . . . . 619

CHA PTER II.

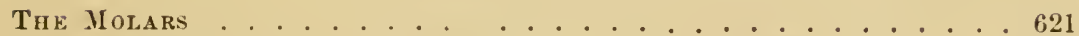

1. Supplementary Premolars .............. 621

2. Molars Proper ................ . . . 622

A. Of the First Dentition .................. 622

B. Of the Second Dentition . . . . . . . . . . . 625

C. Development and Structure............. 631

CH A P T E R I I I.

ERuption of the TeEth. . . . . . . . . . . . . 637

A. Of the Incisors . . . . . . . . . . . . 637

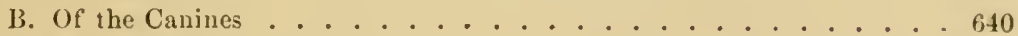

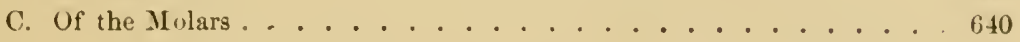

PART I I.

DETERMINATION OF THE AGE.

CH $\triangle$ P T E R I.

Duration of Life in the Horse . . . . . . . . . . . 642

C II A P T F R I I.

THE Parts to be Exanined for the Deternivation of the Age.

CII A P T ER I I I.

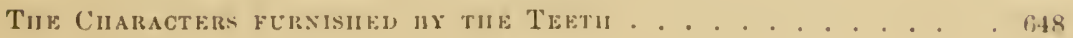




\section{PART I I I.}

Irregularities of the Dental Apparatus . . . . . . . . . 721

1. Number . . . . . . . . . . . . . . 721

2. Form . . . . . . . . . . . . . 726

3. Union of Two Teeth . . . . . . . . . . . . . . 726

4. Form of the Central Enamel . . . . . . . . . . . . 727

5. Depth of the Infundibulum and its External Dental Cavity . . . . 729

6. Defect of Length or Excess of Width of one of the Jaws . . . . . . 736

7. Excessive or Insufficient Wear . . . . . . . . . . . 738

8. Wear resulting from Cribbing . . . . . . . . . . . . 752

9. Employment of Fraudulent Means . . . . . . . . . . . 762

\section{SECTION SIXTH.}

Considerations Relative to the Description and Identification of THE Horse . . . . . . . . . . . . . . . 77

\section{H A P'TER I.}

The Conts. . . . . . . . . . . . . . . 771

1. Coats properly so called . . . . . . . . . . . 771

8. 1. Primitive Coats . . . . . . . . . . . 773

A. Simple Coats (Black, Sorrel) . . . . . . . . 773

B. Composite Coats (Isabella Bay, Mlouse-Color) . . . . . 775

C. Mixed Coats (Fox-Color) . . . . . . . . . 777

8 2. Derived Coats (Gray, White, Flea-bitten, Roun) . . . . . 778

8 3. Conjugate Coats (Piebald, Conjugate, Isabella) . . . . . . 782

Spotted or Marbled Coats . . . . . . . . . . 784

Synoptical Trable of the Coats . . . . . . . . . 784

2. Peculiarities of the Coats ............. 785

A. General. . . . . . . . . . . . . . 786

B. Of the Head . . . . . . . . . . . . . 794

C. Of the Body. . . . . . . . . . . . . 796

D. Of the Members. . . . . . . . . . . . . . . 797

Synoptical Table of the Peculiarities of the Coats . . . . 800

3. Causes of the Modifications of the Coats . . . . . . . . . 799

4. Indices furnished by the Coats and their Peculiarities as to the Qualities

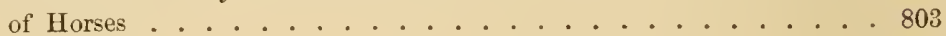

CH A P T E R I I.

Тне Неight. . . . . . . . . . . . . . . . . . 806

C H A P T ER III.

Certificate of Description . . . . . . . . . . . . 813 


\section{SECTION SEVENTH.}

\section{THE APTITUDES OR THE SERVICES.}

CHAPTER 1 .
A. Running-Horse
B. Steeple-Chaser . . . . . . . . . . . . 827
C. Trotters (in Harness or under the Saddle). . . . . . . . . . . 829

$8: \overline{0}$

\section{CHA P T E R I I.}

Horses of LuXurY . . . . . . . . . . . . . . . . . . 833

A. Coach-1Iurses (Large and Small Conch-Horses) . . . . . . . . . . 833

B. Saddle-Horses (Hacknes, Cub, Hunter, Double Pony, Pony) . . . . . 837

C H A P'T E R I I I.

Cavalry Horses . . . . . . . . . . . . . . . . 844

A. Staff Horses . . . . . . . . . . . . . . 845

B. Troop Horses . . . . . . . . . . . . 846

CH A P T E R I V.

Horses of Indestry and Commerce . . . . . . . . . . . 849

A. Slow Heavy-Draught Horses . . . . . . . . . . . . . . . 851

B. Fast Heary-Draught Horses . . . . . . . . . . . 852

\section{SECTION EIGHTH.}

\section{VICIOUS HORSES.}

\section{H A P T E R I.}

Whims axd Vicrocs Marits

1. Horses which loll the Tongue, domble it up, or continually protrude

it from the $M$ onth . . . . . . . . . . . . . . 859

2. Horses which strike the Lower Lip agrainst the Uper . . . . . . 859

3. Horses which rub the Lowrer Extremity of the Head against the Mun-

ger, or the Tail aguinst surrunding Oljects . . . . . . . . 860

4. Horses which shuke the II and or jerk the lanins . . . . . . . . . 860

5. Horses which grasp the Branches of the Bit with the Lower Lip . . . Sitl

6. Huxes which tear their Bhunkets with the Terth . . . . . . . s sil

7. Horses which reat one Ilind-Font upon the other . . . . . . . stil

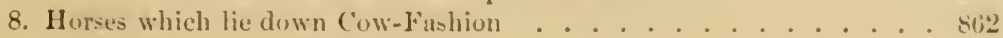


9. Horses which strip their Halters . . . . . . . . . . . 862

10. Horses which roll as soon as they are harnessed or when they return to

the Stable after working . . . . . . . . . . . 863

11. Horses which trot in the Stable . . . . . . . . . 863

12. Horses which paw in the Stable . . . . . . . . . . . 864

13. Horses which weave in the Stable . . . . . . . . . 864

14. Horses which eat Earth . . . . . . . . . . . . . . . . . . 864

15. Horses which have the Vice of "Wind-Sucking," or swallowing Air . 865

CH A P T E R I I.

Vices Properly so CALled . . . . . . . . . . . . . 869

8 1. External Manifestations Proper to each Vice . . . . . . . . 869

1. Balky Horses . . . . . . . . . . . . 869

2. Horses difficult to Approach or to Groom . . . . . . . 870

3. Horses difficult to Harness or to Mount . . . . . . . 871

4. Horses difficult to Shoe . . . . . . . . . . 871

5. Biters ................. 872

6. Horses which rear and strike with the Fore-Feet . . . . 873

7. Horses which back ............ 874

8. Kickers ................ . . 874

9. Timid Horses, Shyers . . . . . . . . . . . . . 876

10. Aversion to special Objects ........... . . 877

11. Runaway Horses . . . . . . . . . . . . . 879

8. General Causes of Vices . . . . . . . . . . 882

\section{CH A P T E R I I I.}

Choice of the Horse. . . . . . . . . . . . . . 886

1. The Seller. . . . . . . . . . . . . . . . 887

2. The Purchaser . . . . . . . . . . . . . . . 892

3. Examination of the Horse . . . . . . . . . . . . . 894

4. Horses mated or paired . . . . . . . . . . . . . . . 901

5. Horses which may be mounted or driven at will . . . . . . . . 903 


\section{LIST OF ILLUSTRATIONS.}

FIG.

1. Situntion of the Centre of Gravity in the Horse . . . . . . . . . 4 4

2. Determination of the Centre of Gravity . . . . . . . . . 5

3. Stability of the Equilibrium . . . . . . . . . . . . . 10

4, 5, 6. The Lever und Muscular Mechanism . . . . . . . . . . 12, 13

7. Lever of the First Cliss . . . . . . . . . . . . . . . 16

8, 9. Lever of the Second and Third Classes . . . . . . . . . . . 17

10: The Inelined Plane . . . . . . . . . . . . . . . . . . 19

11. Regions of the Horse seen in Profile . . . . . . . . . . . . 24

12. Regrions of the Horse seen in Front . . . . . . . . . . . . . 25

13. Regions of the Horse seen Behind . . . . . . . . . . . . 25

14. Regions of the Hore seen Laterally and in Front . . . . . . . . . . . . 26

15. Regions of the Horse seen Laterally and Behind . . . . . . . . . . 27

16. Superficial Structures viewed in Protile . . . . . . . . . . . . 28

17. Superficial structures viewed in Front . . . . . . . . . . . . . . 30

18. Superficial structures riewed from Behind . . . . . . . . . . . . 30

19. Regions of the Head . . . . . . . . . . . . . . . . . . . . 35

20. Vertical Section of the Eye of the Horse (semi-schematic) . . . . . . 49

21. Examination of the Eye . . . . . . . . . . . . 52

22. Fxamination of the Eye . . . . . . . . . . 53

23. Normal Eye . . . . . . . . . . . . . . 54

24. Examination of the Nustril . . . . . . . . . . 62

25. Interior of the Mouth (atter Bruneau) . . . . . . . . . . 70

26. Fxamination of the Muth ................ it

27. Bit of the Bridle .................... 80

28. Iirections of the Hend and the Neck . . . . . . . . . . . 8?

29. Direetions of the IIead and the Neck . . . . . . . . . 90

30. Directions of the Head and the Neck . . . . . . . . . . 92

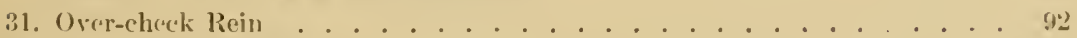

32. Nirection of the Neck . . . . . . . . . . . . 101

33. Direction of the $\mathrm{Neck}$. . . . . . . . . . . 103

34. Coxte . . . . . . . . . . . . . . . 124

35. The cuxa as a Bent lever . . . . . . . . . . . . . 124

36. Longth of the Croup . . . . . . . . . . . . 12ti

37. Openness of the lliorischial Angle . . . . . . . . . . 126;

38. Virtiations in the Inclination of the Ilium . . . . . . . . 13:2

3!. Variations in the Inclination of the Ischium . . . . . . . . . . . 133

40. Simultaneous Vurintions of the Ischium und the Ilinu . . . . . . . 134

41. Intluence of the Misplucenent of the Coxae as a whole . . . . . . 135 
I:LG.

42, 43. Convexity of a Curve . . . . . . . . . . . 153

44. Convexity of the Ribs . . . . . . . . . . . 155

45. State of the Hairs of the Tail . . . . . . . . . . . . . 170

46. Docked Tail, with the Hairs long . . . . . . . . . . . 171

47, 48, 49. Docked Tail, with the Hairs shortened . . . . . . . . . . . 171, 172

50, 51. Horse in the Act of Pulling . . . . . . . . . . 187, 189

52, 53. Limits of Extension and of Flexion . . . . . . . . . . 191, 193

54. Schemes of the Evolution of two Congeneric Members during the Phases of Contact and of Elevation . . . . . . . . . . . . . 194

55. Action of the Anterior Nember in the Trot . . . . . . . . . . 197

56. Action of the Posterior Member in the Trot . . . . . . . . . . 199

57. Length of the Shoulder . . . . . . . . . . . . . . 204

58. Length of the Shoulder in Relation with the Arm . . . . . . . . 206

$59,60,61$. Direction of the Shuulder . . . . . . . . . . . 207, 208

62. The Scapulo-humeral Angle. . . . . . . . . . . . . . . 209

63. Direction of the Arm . . . . . . . . . . . . . . . . 216

64. Scheme of the Muscular Incidences of the Straight and the Oblique Arm . 217

65. Compensation of the Straight Sloulder by an Oblique Arm . . . . . . 218

66. The Olecranon as a Lever-arm . . . . . . . . . . . . . . . 220

67. Form of the Knee . . . . . . . . . . . . . . 229

$68,69,150,151$. Direction of the Knee in an Antero-posterior Seuse . 231, 232, 450

70, 71. Direction of the Knee in Relation to the Median Line . . . . . . . 283

72. Scheme of the Direction of the Thigh . . . . . . . . . 241

73,74 . Length of the Thigh . . . . . . . . . . . . . . . . 242

75. Scheme of the Width of the Leg . . . . . . . . . . . . 249

76. Tendons and Tendinous Burse of the Hock . . . . . . . . . . . . . 254

77. Form of the Hock . . . . . . . . . . . . . . . 256

78. Scheme of the Rigidity of the Posterior Nember . . . . . . . . . . 259

79. Straight Tibia . . . . . . . . . . . . . . . 264

80. Oblique Canon . . . . . . . . . . . . . . 266

81, 82. Deviations of the Vertical Axis of the Hock . . . . . . . . 269

83. Capped Hock . . . . . . . . . . . . . . . . . 270

84, 85. Curb and Spavin .............. . . . 273

86. Spavin . . . . . . . . . . . . . . . 274

87. Jarde . . . . . . . . . . . . . . . . 275

88. Jarde upon the Dissected Hock . . . . . . . . . . . . 276

89. Jarde upon the Macerated Hock . . . . . . . . . . . . . . . . 277

90, 91. Different Views of the Dissected Hock . . . . . . . . . . . . 278

92, 93, 96, 97. Bones and Ligaments of the Canon, Fetlock, Pastern, and

Coronet . . . . . . . . . . . . 280, 291

94, 95. Width of the Canon ... . . . . . . . . . 285

98. Mechanism of the Articulation of the Fetlock . . . . . . . . . . . . . 292

99, 100. Scheme of the Length of the Pastern . . . . . . . . . 301, 302

101, 102, 152, 153. Direction of the Pastern . . . . . . . . 304, 450

103. Disadvantages from Excess or Insufficiency of the Obliquity of the Pastern 305

104, 105. The Pastern as a Lever . . . . . . . . . . . . . 306

106. Longitudinal and Median Section of the Foot . . . . . . . . . 314

107. Normal Foot before and after Maceration . . . . . . . . . . 315

108. Foot viewed in Front . . . . . . . . . . . . . . 316

109. Profile of the Hoof ................ . . . 317

110. Wall of the Hoof . . . . . . . . . . . . 317 
111. Inferior Face of the IIoof . . . . . . . . . . . . . . 317

112, 113. Antern-posterior and Transverse sections of the Hoof . . . . . 318

114. Interior of the Hoof . . . . . . . . . . . . . . . . 319

115. Trunsvere Section of the Hoof' (Posterior l'art) . . . . . . . . 319

116. Frog and Periople . . . . . . . . . . . . . . . 319

117. Hoot with Perioplic lsand detached . . . . . . . . . . 320

118. Views of the Foreffot . . . . . . . . . . . . . . 320

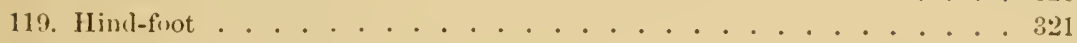

120. Foot with High Heels . . . . . . . . . . . . . . . 331

121. Font with Low Heels . . . . . . . . . . . . . . . 331

122. Foot, Pincald . . . . . . . . . . . . . . 333

123. Deformity of Hon from Laminitis . . . . . . . . . . . . . . 338

124. Keraphylloxele . . . . . . . . . . . . . . . . . 339

125. The Proportions, after Bourgelat . . . . . . . . . . . . 347

126. The Proportions of Eelipse, after Saint-Bel . . . . . . . . . . 351

127. The l'roportions of the Horse seen in l'rofile . . . . . . . . . . 360

128. The P'roportions of the Head viewed in T'rofile . . . . . . . . . . 362

129. The l'roportions of the Head viewed in Front . . . . . . . . . . . . . 36 ?

130. Comparative P'roportions of the Man und the Horse . . . . . . . . 364

131. Articular Angles, atter Morris . . . . . . . . . . . . . 366;

132. Anterior Member with the Oblique Segments inclined Forty-five Degrees to the Horizon . . . . . . . . . . . . . . . . 368

133. The sime in the Posterior Member . . . . . . . . . . . . 368

134. The drticular Angles upon a Drawing, from a Photograph of Fitz-Gladjator.

135. Toise

136. Mealsurement of the Inelination of the Segments . . . . . . . 375

137. The of the Arthrogoniometer . . . . . . . . . . . . . . 376

138. Arthrogoniometer for measuring the Articular Angles . . . . . . . 376

139. Value of the Articular Angles in the Fore Member . . . . . . . . . 381

140. Value of the Articular Angles in the Hind Member . . . . . . . . 381

141. Length of the Body . . . . . . . . . . . . . . . . . . . 388

142. Length of the Body not dependent upon that of the Vertebral Column . 390

143. Length of the Body as modified ly the Oblinuity of the Shoulder and the Croup . . . . . . . . . . . . . . 392

144. The Rissembler . . . . . . . . . . . . . . 440

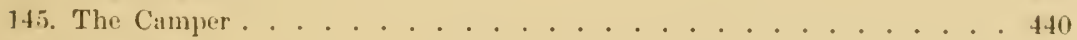

14\%, The Plues . . . . . . . . . . . . . . . . 41

147. Lines of Equilibrium of the IIorse viewed in Profile. . . . . . . 44

148. Scheme of the Lines of Equilibrim . . . . . . . . . . . 445

149. Nomal and Abmormal Axes of the Fore Member . . . . . . . . . 4t6

17it. Axes viewed in Front . . . . . . . . . . . . . . . . 4.1

155. Nommal Axis viewed in Front. . . . . . . . . . . . . 452

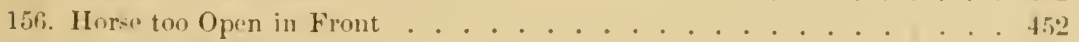

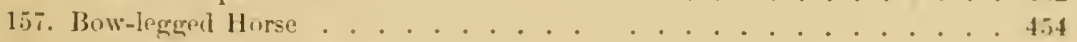

1is. Outbow-fented Horse . . . . . . . . . . . . . . . . . tist

15is. Horse Chosel in Front . . . . . . . . . . . . . . . 45is

$160.0 x-\mathrm{K} n$. . . . . . . . . . . . . . . . . . . . . . . . . . . . . . . . . . . .

161. Ifore Crossfunted in Front . . . . . . . . . . . . . 15is

1fi2. Seleme of the Axis of the IIind Member. . . . . . . . . . 456;

133. Normul and Abnormal Axes of the Hind Menber seen in P'rutile . . . 457 
FIG.

164. Axes viewed from Behind . . . . . . . . . . . . . . . 460

165. Horse too Open Behind . . . . . . . . . . . . . . . . . . . 461

166. Bow-legged Horse . . . . . . . . . . . . . . . . . . . . . 462

167. Horse Closed Behind . . . . . . . . . . . . . . . . . . . 463

168. Horse Cow-hocked . . . . . . . . . . . . . . . . . . . . 463

169. Rearing . . . . . . . . . . . . . . . . . . . . . . . . 4 468

170. Kicking . . . . . . . . . . . . . . . . . . . . 471

171. Scheme of the Morement of a Member during the Phases of Contact and Elevation . . . . . . . . . . . . . . . . 475

172. Exchange of Contact upon the Posterior Bipeds in the Walk . . . . . . 476

173. Instrument for Analyzing the Gaits (Marey) . . . . . . . . . . . . 4 480

174. Cylinder of liegistration . . . . . . . . . . . . . . . . . . . 480

175. Chaussure Exploratrice (Marey) . . . . . . . . . . . . . . . . 481

176. Bracelet Explorateur (Marey) . . . . . . . . . . . . . . . . . . 481

177. Registering Apparatus of Marey applied to the Horse . . . . . . . . . 482

178. Chaussure Exploratrice for registering the Gaits by Electricity . . . . . 484

179. Longitudinal Section of the sane . . . . . . . . . . . . . 484

180. Instantaneous Photographs of the Fast Gallop, after Muybridge . . . . . 487

181. Chrono-photograph of the Walk of a Man . . . . . . . . . . . . . 489

182. Chrono-photograph of the Leap of a Man . . . . . . . . . . . . . . 489

183. Movement of the Anterior Member of the Horse . . . . . . . . . . . 490

184. Lecon's Method of Notation of the Gaits . . . . . . . . . . . . . . . 491

185. Hodochronometric Scale of Vincent and Goifton . . . . . . . . . . . 492

186. Notation of the Running of a Man (Marey) . . . . . . . . . . . . . 493

187. Notation of the Walk of Two Pedestrians . . . . . . . . . . . . . 494

188. Notation of M. Lenoble du Teil . . . . . . . . . . . . . . . 4 495

189. Table for Artitieirl Notation of the Gaits . . . . . . . . . . . . 498

190. Mrodel for Notation of the Gaits (Marey) . . . . . . . . . . . . 500

191. Model for Notation of the Gaits . . . . . . . . . . . . . . . 501

192. Synopsis of the Notations of the Gaits of the Horse . . . . . . . . . . 502

193. The Amble . . . . . . . . . . . . . . . . . . . 505

194. Notation of Two Men Wakking . . . . . . . . . . . . . . . 506

195. Notation of the Marched Amble . . . . . . . . . . . . . . 507

196. Tril of the Amble, after Lenoble du Teil . . . . . . . . . . . . 507

197, 198. Displacements of the Centre of Gravity . . . . . . . . . . . . . 508

199. Trail of the Broken Amble . . . . . . . . . . . . . . . . . . 509

200. Notation of the Broken Amble . . . . . . . . . . . . . . . . 510

201, 202, 203. Trails of the Trot (Lenoble du Teil) . . . . . . . . . . . . . 511

204, 205, 206. The Leaped Trot . . . . . . . . . . . . . . . . 512

207. Kinematic Analysis of the Play of the Anterior Member in the Ordinary

Trot . . . . . . . . . . . . . . . . . 513

208. Kinematic Analysis of the Play of the Posterior Member in the Ordinary

Trot . . . . . . . . . . . . . . . . . 514

209. Tracing, Notation, and Reactions of the Trot . . . . . . . . . . 515

210. Notation of the Ordinary Trot in which the Phase of Suspension is not

Pereeptible . . . . . . . . . . . . . . . 516

211. Notation of the Marched Trot . . . . . . . . . . . . . 517

212, 213. Displacements of the Centre of Gravity . . . . . . . . 517,518

214, 215, 216. The Flying Trot of the Horse A be Edington . . . . . . . . . 524

217. Trail of the Flying Trot of the Horse Abe Edington . . . . . . . . . . 524

218. Notation of the same . . . . . . . . . . . . . . . . 525 
219. Notation of the Cinter in Front . . . . . . . . . . . . 528

220. Running Walk: Notation und Bases............ . . 529

22I. Trail of the Running Walk . . . . . . . . . . . . . 530

22:2. Kinematic Analysis of the Play of the Anterior Member in the Walk . . 531

223. Kinematic Analysis of the Play of the Posterior Member in the Walk . . 581

224. Tracing and Notution of the Walk, with Equality of the Lateral and Diag-

onal Contacts. . . . . . . . . . . . . . . . 533

$225,226,227,228$. Succession of the Contacts of the Walk . . . . . 534,535

229. Notation of the Ordinary Walk . . . . . . . . . . . 525

230. Walk, with Predominance of the Lateral Contats . . . . . . . . 536

231, 232, 233. Diverse Trails of the Walk . . . . . . . . . . 538

234. Backing . . . . . . . . . . . . . . 543

235. Backing, in the Horse attached to a Load . . . . . . . . . . 544

236. Diagonal or United Gallop . . . . . . . . . . . . . . 546

237. Lateral or Disunited Gallop . . . . . . . . . . . . . . 546

238. Kinematic Analysis of the Play of the Anterior Member in the Gallop . . 548

239. Kinematic Analysis of the Play of the Posterior Member in the Gallop . . 548

240. Tracings, Notation, and leactions of the Gallop of the Trained Horse . . 549

241. Notation of the Gallop in Three Times . . . . . . . . . . . 550

242. Notation of the Full Gallop . . . . . . . . . . . . . 551

243, 244, 245, 246, 247, 248, 249, 250. The Full Gallop, its Beats, Bases, and

Projection ................ . . 554, 555

251. Passage from Station into the Gallop . . . . . . . . . . . 555

252. Principal Trails of the Gallep (Barrier and Lenoble du Teil) . . . . . 558

253. Displacements of the Centre of Gravity . . . . . . . . . . . . . 560

254. Instantaneous Photographs of the Running Gallop of the American Iorse

Sallie Gardner (Muybridge) . . . . . . . . . . . . 564

255. Notation of the Running Gallop, from Instantaneous Photographs . . . . 565

256. Trail of the Gallnp, furnished by Sallie Gardner . . . . . . . . . . 565

257. Transition from the Walk to the Trot . . . . . . . . . . 568

258. Transition from the Trot to the Walk . . . . . . . . . . 5688

259. Transition from the Trot to the Gallop . . . . . . . . . . 569

260. Trunsition from the Gallop to the Trot . . . . . . . . . . 569

2fi1. Scheme of the Three Principal Varieties of Leaps . . . . . . . . . . . 570

262, 263, 264, 265, 266. Different Phases in the Execution of the Leap. . . . 571

267. Trail of the Icap over a Hedge . . . . . . . . . . . . . . 572

268. Yutution of the Leap uxce a Hedge . . . . . . . . . . 573

269. Instantaneous Plotograph of Inraught-IIorses moving a IIenry Load . . 57\%

270. Dintition of the IInr'se, as a whole . . . . . . . . . . . . 595

271. Deciduous Incisors viewed on their Anteriur Face . . . . . . . . 598

27.2. Deciduous Incisons (Profile and Dental Tables) . . . . . . . . . . 599

273. Decidurus Pineer . . . . . . . . . . . . . . . 600

274. Nannifiel Longitudinal section of a Suprior Virgin Pincer of the Fir-t

Jentition, seen in its .17rolus . . . . . . . . . . . . 600

275. Longritudinal sietion of the Jaws, slowing the Relutive Situation of the

Milk und Permunent lncisors . . . . . . . . . . . . cil

27i. Unworn 1uferior Piner of the seend Dentition . . . . . . . . 602

277. Superior Viren Ineisur of the Secund Dentition (Pincer) . . . . . . . d:03

278. Lungitudinal Section of a Permanent Ineisor that has been 1wed . . . 6,04

279. Eccentrie rund Longitudinal seetion of a Superion and Inferior l'ormanent

Intermedinte . 
FlG.

280. Longitudinal and Median Seetions of the Pincer, Intermediate, and Corner in each of the Jaws . . . . . . . . . . . . . . . . . . .

281. Series of I tongitudinal Sections of the Right Inferior Incisors of a Fiveyear-old Horse . . . . . . . . . . . . . . . . . . . . . . . . .

282. Schematic Section of the Dental Follicle of an Inferior Incisor of a Horse

283. Longitudinal and Median Sections of a Permanent Inferior Pincer (enlarged)

284. Radical Cementation of the Incisors of a Horse . . . . . . . . . . . .

285. Longitudinal Antero-posterior Section of an Inferior Pincer, etc.

286. Median and Longitudinal Sections of Ineisors, showing, 1st, the Growth of the Teeth at their Roots; 2d, the Progressive Wear of their Tables; $3 d$, their Length and Obliquity according to the Age; 4th, Obliteration of their Pulp Cavities ; 5th, finally, their Radical Cementation . . . . . .

287. Transverse Section of Inferior Right Pincer, showing the Different Layers constituting the Tooth, with their Relative Thickness (Magnified Five Diameters) . . . . . . . . . . . . . . . . . . .

288. Incisive Areades exposed to show the Progressive Inclination of the Teeth in Relation to the Plane of Meeting of the Jaws . . . . . . . . . . .

289. Ineisors exposed by their Anterior Face to show their Relative Inclination towards the Median Line

290. Double Inferior Right Canine Tooth in the Ass

291. Superior Right Canine Tooth

292. Longitudinal and Median Sections of the Canines

293. The Three Superior Deciduous Molars (Right Side)

294. The Three Inferior Deciduous Molar's (Right side)

295. Transverse Section of the Inferior Jaw, showing the Relation in the Alveolus of the Permanent and Deciduous Molars at the Moment of Eruption .

296. Transverse Section of the Superior Jaw, slowing the Relation in the Alveolus of the Permanent and Deciduous Molars at the Moment of Eruption 297. Superior Permanent Molar (Right Side, Virgin Tooth) . . . . . . . . 298. Superior Molar Arcade of the Right Side of a Horse Six Years Old Past . 299. Inferior Molar of the Second Dentition (Left Side, Virgin Tooth) . . . . 300. Inferior Molar Areade of the Left Side of a Horse Six Yeurs Old Past . . 301. Superior Right Molar removed from its Dentul Follicle . . . . . . . .

302. Inferior Left Molar removed from its Dental Follicle . . . . . . . . . .

303. Table of Superior and Inferior Molars . . . . . . . . . . . .

304. Inferior Left Molar Areade of a Very Old Horse, showing the Radical Cementation

305. Transverse Section of a Superior Left Molar (enlarged) .

313. Absence of the Inferior Corners . . . . . . . . . . . 725

314. Union of Two Superior Incisors . . . . . . . . . . . . . . 726

315. Fissure of the Infundibulum of the Ineisors . . . . . . . . . . . 727

316. Double Infundibulum of the Incisors . . . . . . . . . . . . 728

$31 \%$, 318. Superior and Inferior Brachygnathism . . . . . . . . . . . 737

319. Parrot IIouth . . . . . . . . . . . . . . . . 740

320. Reversed Parrot Mouth . . . . . . . . . . . 742 
321. Incisors of the Inferior Jaw tro short . . . . . . . . . . . T4t

322. Inferior Molar Areade of a Very Ole II ore, showing the Radical Cementation, as well as the lu*uflicient Length of the Middle Tecth . . . . . 745

323. light Molar Arendes of a Very Oht Horse . . . . . . . . . . 746

324. Bevelled Molars from Irregular Wear. . . . . . . . . . . . 745

325. Hypertrophy of the Fourth Right superior Molar . . . . . . . . . 750

326. Abuormal Wear produed by Cribbing . . . . . . . . . . . T55

327. Abuormal Wear produced by Cribbing . . . . . . . . . . . . 756

328. Alnormal Wear prodaced by Cribling . . . . . . . . . . . 757

329. Abnormal Wear produced by Cribbing . . . . . . . . . . . 759

330. Hippometer with Pedestal . . . . . . . . . . . . . . 808

331. Hippometer without Pelestal . . . . . . . . . . . . . . 809

332. Hippometric Cane . . . . . . . . . . . . . . . . 810

333. Rumning-Horse, Vermout, Wiuner of the Great Prize of Paris in 1864 . . 826

334. Steeple-chase Horse, Bois-Roussel, Winner of the French Derby in 1864 . 828

335. Trotter in Harness, Fazan, Russian Stallion of the Orloff Variety . . . . 831

336. 'Trotter under the Saddle, Bayadère, Anglo-Norman Mare . . . . . . . . 832

337. Large Coach-Horse, Lahore, Half-thoroughbred Anglo-Norman . . . . 835

338. Small Coach-Horse, Shang-Hai, Half-thoroughbred Anglo-Norman . . . 837

339. Hickney . . . . . . . . . . . . . . . . . . 838

340. Cob . . . . . . . . . . . . . . . . . 840

341. Hunter ..................... . . . . 841

342. Double Pony . . . . . . . . . . . . . . . . . 842

343. Pony . . . . . . . . . . . . . . . . 843

344. Slow Heary-draught Horse . . . . . . . . . . . . . . 851

345. Fust Heary-drught Horse . . . . . . . . . . . . . . . . . 853

346. Velocité, Percheron Mare of the Compagnie Générale des Omnibus . . . 854 


\section{PLATES.}

PLATE

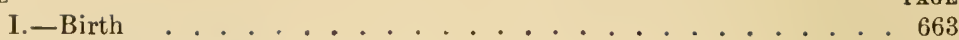

II.-About One Week . . . . . . . . . . . . 664

III.-One IIonth . . . . . . . . . . . . . . 665

IV.-Three Months . . . . . . . . . . . . 666 667

V.-Four Months . . . . . . . . . . . . 6667

VI.-Five Months . . . . . . . . . . . . . . 669

VII.-Ten Months . . . . . . . . . . . . . 671

VIII.-One Year ............... . . . 673

IX.-Sixteen Months . . . . . . . . . . 675

X.-Twenty Months ............... . 677

XI-Two Years . . . . . . . . . . . . . . . 679

XII._Rising Three Y'ears . . . . . . . . . . 681

XIII.-Three Years Past . . . . . . . . . . . 683

XIV.-Rising Four Years . . . . . . . . . . . 685

XV.-Four Years . . . . . . . . . . . . 687

XVI._Four Years Past. . . . . . . . . . . . 689

XVII.-Rising Five Years . . . . . . . . . . . 691

XVIII.Five Years . . . . . . . . . . . . 693

XIX-Six Years................. . . . 695

XX-Seven Years . . . . . . . . . . . 697

XXI.-Eight Years. . . . . . . . . . . . . . 699

XXII.-Nine Years .............. . 701

XXIII-Ten Years ............. 703

XXIV.Eleven Years .............. 705

XXV.Twelve Years ............. . . 707

XXVI.-Thirteen Years ............. 709

XXVII.-Fifteen Years .............. 711

XXVIIl-CSeventeen Years ............. 713

XXIX.-Nineteen Years ............. . 715

XXX_Twenty-rone Years . . . . . . . . . . 717

XXXI.-Thirty Years . . . . . . . . . . . 719

XXXII._Bégu._Nine Years . . . . . . . . . . 731

XXXIII._False Bégu._Fourteen Years . . . . . . . . 735

XXXIV.-Bishoping . . . . . . . . . . . . . . 769 
THE

\section{EXTERIOR OF THE HORSE.}

\section{SECTION FIRST.}

PRELIMINARY IDEAS OF ANIMAL MECHANICS.

\section{('II A P'TER I.}

OB.JECT, EXD, AND UTILITY OF TIIE FXTERIOR.

The term exterior of the horse seems to have been employed by veterinarians only since the close of the last century, dating from the period when Bourgelat published his book upon the extemal. form of the horse in 1768 , six years after the foundation of veterinary schools.

Before his time reterinarians and horsemen had entered but superfieially "upon the study of the forms of the horse. They harl limited themselves in their works to determining, sometimes by fignres, the principles relating to the proportions. These efforts, however, had pasised, sin to speak, muperceived, were lost among the publications of the times and drowned in the midst of the different writings of which the mumeroms veterinary treatises were emposed. Here, as in the other branches of veterinary science, Bontegelat was endeavoring to astablish prinoples to guide the pupils who flocked into his schools. If it be remembererl that this innovator wats an eminent master ats well ats a skilful horseman, we will not be astonished to see that he has reacherl with the greatest "ases, in his treative on the exteriore, if not. aboolute perferetion, at least that degrees of exaretuess which it was just to demand at that epoch from a man who turnerl everything into instruetion. Bourgelat more than all others was conscious of the great utility of the horse, and the necessity of preparing in a sperial manner 
the professional men whom he gave to the agricultural world. He desired that they should be well acquainted with and appreciate the qualities and the defects of this merchandise, which every day gained more importance and acquired a greater value. The inanguration of instruction upon the exterior dates from this period.

Its object is to enable the scholar to determine by a rapid exctmination of the form of a horse his relative commereial ralue in the service in. which he is to be cmployed. In $1837,{ }^{1} \mathrm{H}$. Bonley had already stated its object as follows:

"Given the external conformation of an animal, we determine the service in which he may be employed and estimate the amount and duration of the effects which his machinery is capable of producing." This study, we see, is only a branch of zootechnies, but differs from the latter in that it does not seek the conditions for the amelioration of the equine races. It is intended, rather, to be a guide in the choice of an animal at the sale. Its importance to the horseman is such that the necessity of forming a distinct course for its study and deroting to it extended investigations is understood. This study is, then, especially an applied science, and it is therefore indispensable before entering upon it to have a certain knowledge of anatomy, physiology, mechanies, physies, hygiene, zootechnics, and pathology.

In order to be able to understand it well, its theory should first be learned. A knowledge of the horse is a problem full of difficulties when its application is to be made to any given animal. It is only through constant habit that we can suceed in forming by a rapid examination a good judgment of his value as a beast of service. No doubt this result may be obtained without having undertaken anatomical and physiological studies. It is sufficient to possess what tradesmen call judgment, a glance of the eye; but this is only acquired by long practice. We all know what perfection in this respect is acquired by certain persons quite ignorant of the sciences which are applied to the exterior. The officers of our remounts, of our studs, even simple horse-dealers, astonish us sometimes by the rapidity with which they see in a horse the weak point, the defect, and the blemish; they have, moreover, that veritable tact of knowing how to adapt themselves, in their purchases, to the exigencies, modes, and fancies of the times. However, the time which it has taken them to obtain this result must be considered. Theoretical ideas have precisely the effect of shortening this time; they are, for beginners, aids which experience 
will allow them to dispense with, but without which they could not rise above this empirieal knowledge, appanage of the ignorant or of the coxcomb, who aleepts under the same title the true and the false, and who is incapalhle of distingnishing otherwise thim by the routine with which he proceeds.

If the knowledge of the horse is an art, it is expecially one which consists in observing, comparing, and judging according to positive information. Besides, it is necessiry, in order to reach perfeetion, to have observed much, to have put into practice that ficulty which makes the clinician, the comnoisseur, and the artist. It is when such an education is carried to a considerable extent that we suceed in seizing at once what good or defective qualifications the horse possesses, and that it is possible to form a just.conclusion by appreciating to what degree the good qualities exceed the bad.

\section{CHAP'TER II.}

CENTRE OF GRAVITY.

TuE simultaneous actions of the force of gravity upon all the molecules of a body may be considered as so many small parallel forees having the same purpose and the same direction, whose total sum is the weight of the boly, and whose result is applied to one point which is the centre of gravity.

The vertical pressure of the centre of gravity to the ground is called the line of gravitation (line of gravity, Raabe \& Bonnal). We have just seen that the result of these forees is equal to their sum, and that the position of its point of application depends upon the intensity of its components.

All the actions of the force of gravity being equal for each molecule of the same kind, if these molecules of a body are uniformly distributed,-in a wort, if the latter be homoreneous, - it will in all its parts be equally attracted ly this force. Therefore, nothing will be easier than to determine the eentre of gravity, especially if the bouly has a geometrical form. Special procerlures are employed to determine the location of this centre in a boly, whatever may be its form. We will not speak of this at present.

seldom, however, are bodies found in conditions sufliciently homegeneous for its determination to he simple. Certain parts are much more dense than whers, and therefore the force of gravity attrats them more. The result of this is that the centre of gravity, instead of heing situated in the middle of the boly, is drawn nearer, as has been seen, to the parts which weigh the most. This is observed in organized hodies.

Its Determination in Animals.-In animals new difliculties arike. The vital phenomena being only the phenomena of movenent, the material particles 
at each instant are displaced in different directions, and thus are modified the weight and rolume of the organs in which the molecular changes take place. Other displacements, mueh more considerable, indeed even more important from the point of view which concerns $u s$, are due to the actions of the organs, the different attitudes of the body, or the movements which are caused by locomotion. We understand, then, how difficult becomes the exact determination of the centre of gravity, and the great importance of sufficiently appreciating its

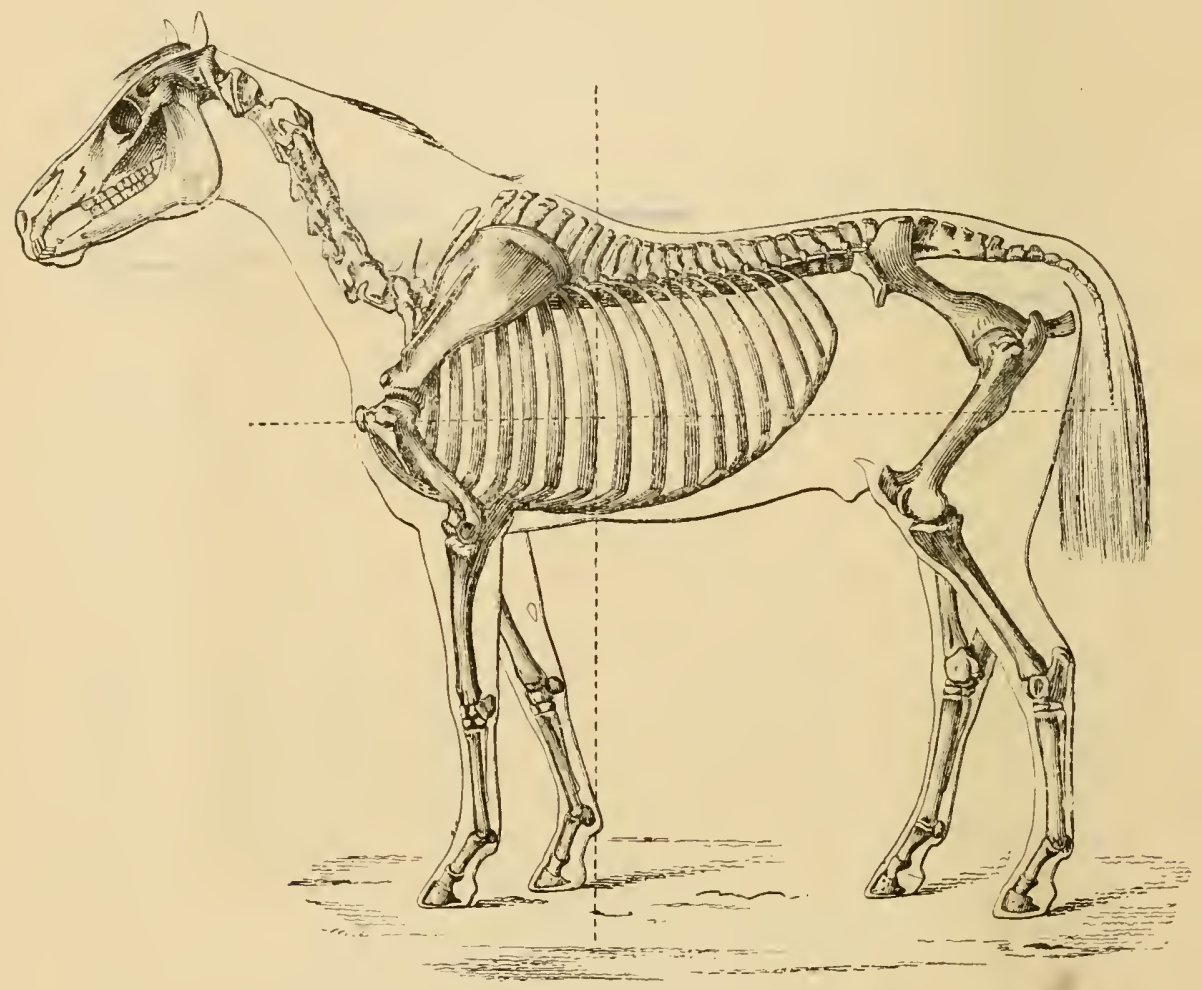

FIG. 1.-Situation of the centre of gravity in the horse.

displacements when it is a question of obtaining from it the conditions of equilibrium.

According to Borelli,' the eentre of gravity in the horse is situated in the middle of the height of the trunk, and the line of gravitation falls through the centre of the quadrilateral formed by the four members.

According to Professor Colin, ${ }^{2}$ it almost corresponds to the intersection of two ines, one of them (vertical) passing back of the xiphoid appendix of the sternum, the other (horizontal) separating the middle from the inferior third of

1 Borelli, De motu animalium, Naples, 1731, p. 126.

${ }^{8}$ G. Colin, Traité de physiologie comparée des animaux, se édition, Paris, 1856. t. i. p. 460. 
the body (Fig. 1). Further om, the same author adds: "It is chear that the position of the centre of gravity and the distribution of the weight of the body upon the members must vary very much according to the conformation of animals whose head, neck, abdomen, and (roup present such diverse proportions."

The position of the centre of gravity of the horse, as indicated by M. Colin, seems to us very nearly correct, at least judging from the experiments which we have conducted.

At first, it seems extremely probalble that this point is situated in the median plane of the body. In effecting a series of weighings bearing alternately upon both of the lateral bipeds of the same subject maintained an much as possible in an invariable attitude, we succeed in determining that the left lateral hiped, for example, supports a weight very nearly equal to that of the right lateral biped. On the other hand, if, from the example of XII. Rabe and Bomnal, ${ }^{1}$ we eonsider that the dorso-lumbar column $A B$, Fig 2 , measuring the interval comprisel be-

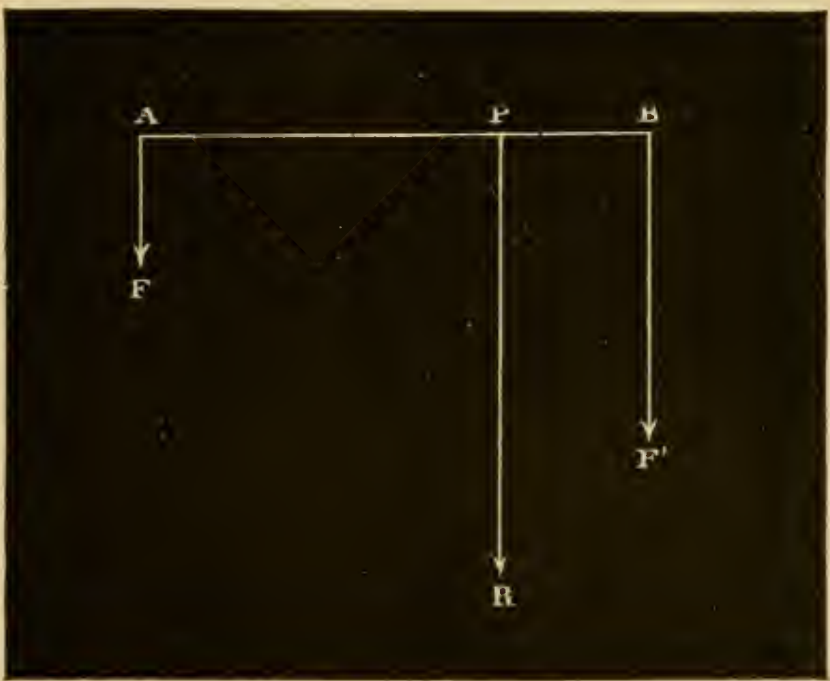

F)(G, 2.

tween the centre of the movement of the shoulder and that of the haunch,- that is to say, the length of the base of support of a well-formed hore, - is attracted by two parallel forces $F$ and $F "$, distributing the weight of the brdy npon the posterior and anterior hipeds, it will be easy to determine with considerable approximation the position of the joint $I$, through which passes the line of gravitation, - that is to say, the resultant of these two forces. It is known that this point divides the line $A \mathrm{~B}$ into two parts inversely proportional to the forces $F$ and $F^{\prime}$, in such a way that we have

$$
\frac{F^{\prime}}{F^{\prime \prime}}=\frac{P B}{P . i}
$$

1 Raabe et Bonnal, Détermination des lignes le gravilé du cheval, ete. In .Irohives vitirl. naires, 1 k 33, p. 538. 
Here are, in fact, the results which we have obtained by the aid of this procedure npon a saddle-horse of a fine form provided with good equilibrium, that measured $1.55 \mathrm{~m}$. at the withers and at the croup, and $1.53 \mathrm{~m}$. from the point of the shoulder to the point of the buttock. The subject, saddled and bridled, was weighed, the neck at 45 degrees and the head elevated. Its base of support, $A B$, was equal to $1.20 \mathrm{~m}$. As to the total weight, which was 445 kilogrammes, it was distributed thus:

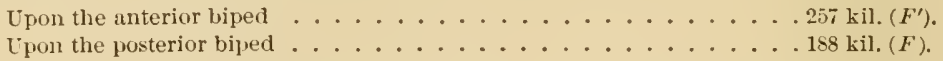

In the particular case of which we are speaking, the point $P$ divides the line $A B$, which unites the two forces, into two parts inversely proportional to their intensity. We have then

$$
\frac{F}{F^{\prime}}=\frac{P B}{P A} \text { or }=\frac{A B-P \cdot \mathrm{t}}{P \cdot \mathrm{t}}
$$

By the addition of the denominators to each of the two terms of this equation we obtain

$$
\frac{F+F^{\prime}}{F^{\prime}}=\frac{A B-P \cdot A+P A}{P A}=\frac{A B}{P A}
$$

whence

$$
P A=\frac{F^{\prime} \times A B}{F^{\prime}+F^{\prime}}=\frac{257 \times 1.20 \mathrm{~m}}{445}=0.69 \mathrm{~m}
$$

and

$$
P B=120 \mathrm{~m} .-0.69 \mathrm{~m} .=0.51 \mathrm{~m} .
$$

The line of gravitation then falls upon the horse submitted to the experiment at $0.51 \mathrm{~m}$. posterior to the anterior biped.

This is about the position which MAr. Raabe and Bonnal have assigned to it. The line of gravitation of the Arab mare upon which these horsemell experimented was situated $0.69 \mathrm{~m}$. in front of the coxo-femoral centre and $0.47 \mathrm{~m}$. from the centre of movement of the shoulder. The distance of its two centres of morement was $1.17 \mathrm{~m}$. instead of $1.20 \mathrm{~m}$. As to its bipeds, they weighed: the anterior, $270 \mathrm{kilogrammes-the} \mathrm{posterior,} 184$. In this case, the distribution of the weight, although analogous to that of our horse, differs from it, since in the latter the surplus weight of the anterior bipeds is only 69 kilngrammes, whilst in the mare it reached 86 kilogrammes. The more anterior position of the line of gravity in the latter is thus explained.

MII. Raabe and Bomnal have deduced with reason the practical importance of obtaining as precise a determination as possible of the centre of grarity. The ideal to be realized, when we think of placing a rlorsal burden upon a horse, should, in fact, consist in distributing this burden upon each biped proportionally to the weight which it bears in the natnral state. In these conditions the centre of gravity preserves its normal position and one of the lipeds is never relieved at the expense of the other.

In 1835, Morris and Baucher ${ }^{1}$ had already experimentally determined in the horse the disulacements of the centre of grivity, by changing the position of the head and neck, as well as that of the rider.

"With this purpose," says Morris, "M. Baucher, a horseman, and myself were going to the general mart of the Custom-House at Gros-Caillou to weigh horses upon scales of proportion with morable planks invented a few years ago. . . .

"The two weighing-machines were placed in such a manner that the anterior extremities rester upon the middle of the first and the posterior extremities upon the middle of the second. 
The two planks being exactly upon the same level, and belonging to weighing-machines of the same proportion, eould therefore be taken for two scules of an orlinary balance. We equipred a saddle-mare regulurly formed, althongh the hend and neek were stronger than the remuinter of the body, she was brilled and sadaled.

"The seales being abundoned to the weight of the mare held in a complete state of immobility, the head being in its ordinary losition, rather low than high, gave us the following results:

$\begin{array}{cccc}\text { Fore Extremity. } & \text { Hind Extremity. } & \text { Total Weight. } & \text { Ditlerence. } \\ 210 \mathrm{k} . & 174 \mathrm{k} . & 381 \mathrm{k} . & 36 \mathrm{k} .\end{array}$

"A fluctuation of from 3 to 5 kilogrammes was established, which settled alteruately upon the fore and hind extremities, on account of the movements produced by the organs of respiration.

"We lowered the hend so that the end of the nose reached the lerel of the chest. This movement uffected and the immobility obtained in this position, the fore extremity increased 8 kilogrammes, of which the hind was relieved.

$\begin{array}{cccc}\text { Fore Extremity. } & \text { Hind Extremity. } & \text { Total Weight. } & \text { Difference. } \\ 21 \mathrm{k} k & 166 \mathrm{k} . & 384 \mathrm{k} . & 52 \mathrm{k} .\end{array}$

"The head being ruised until the end of the nose was on a level with the height of the withers, the same precautions for immobitity being observed, the fore extremity displaced 10 kilogrammes of its weight upon the hind and then balanced itself, with the following resuls:

$\begin{array}{cccc}\text { Fore Extremity. } & \text { Hind Extremity. } & \text { Total Weight. } & \text { Difference. } \\ 200 \mathrm{k} . & 184 \mathrm{k} . & 384 \mathrm{k} . & 16 \mathrm{k} .\end{array}$

"The head, being returned to its former position, was drawn back upon the neck and elevated nomewhat by the action of the bridle. Ten kilogrammes were then displaced backward as fullow: :
Fore Fxtremity.
Ilind Extremity.
Total Weight. $3 \mathrm{~s} \mathrm{k}$. Difference.
$2 y \mathrm{k}$. $20 \% \mathrm{k}$. $18 \mathrm{z} \mathrm{k}$.

These results evidently prove that the more the head is raised, if not naturally, at least by the action of the hand, the more its weight and that of the neck are equally distributed upon the extremities, if the position be not forced.

"Ifter these experiments M. Butcher mounted the mare, and the two seules poised with the following weights:

$\begin{array}{cccc}\text { Fure Extremity. } & \text { Hind Extremity. } & \text { Total Weight. } & \text { Difference. } \\ 2 \pi \mathrm{k} . & 197 \mathrm{k} . & 418 \mathrm{k} . & 51 \mathrm{k} .\end{array}$

" The rider placel in an arademic position, his weight of $61 \mathrm{kilogrammes}$ was distributed as: follows: 41 kilogrummes upon the anterior members and 23 upon the posterior.

"Being sented in snch a manner that the upper part of the buly leaned backwarl, M. Baucher displaced 10 kilugranmes upwn the hind extremity. Then drawing the horse's heall bekwarl accorling to his methoul, he aguin churged the same with u weight uf 8 kilogrammes: Lotnl, 18 kilogrammes. In this pusition we ubtain:

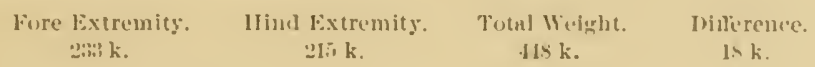

"By bearing entirely unon the stirrujs, the weight on the anterior nembers incrensel 1:2 kilogrammes.

"Ifterwarls we plneed u gray hore of a vicious disposition won the sonles, which, with diflerences alreudy well indicated in construction, furuished us with annlegrous results," 
In union with Bellanger, first veterinary flugelman, ${ }^{1}$ Morris instituted a second series in 1857 . The following are the results:

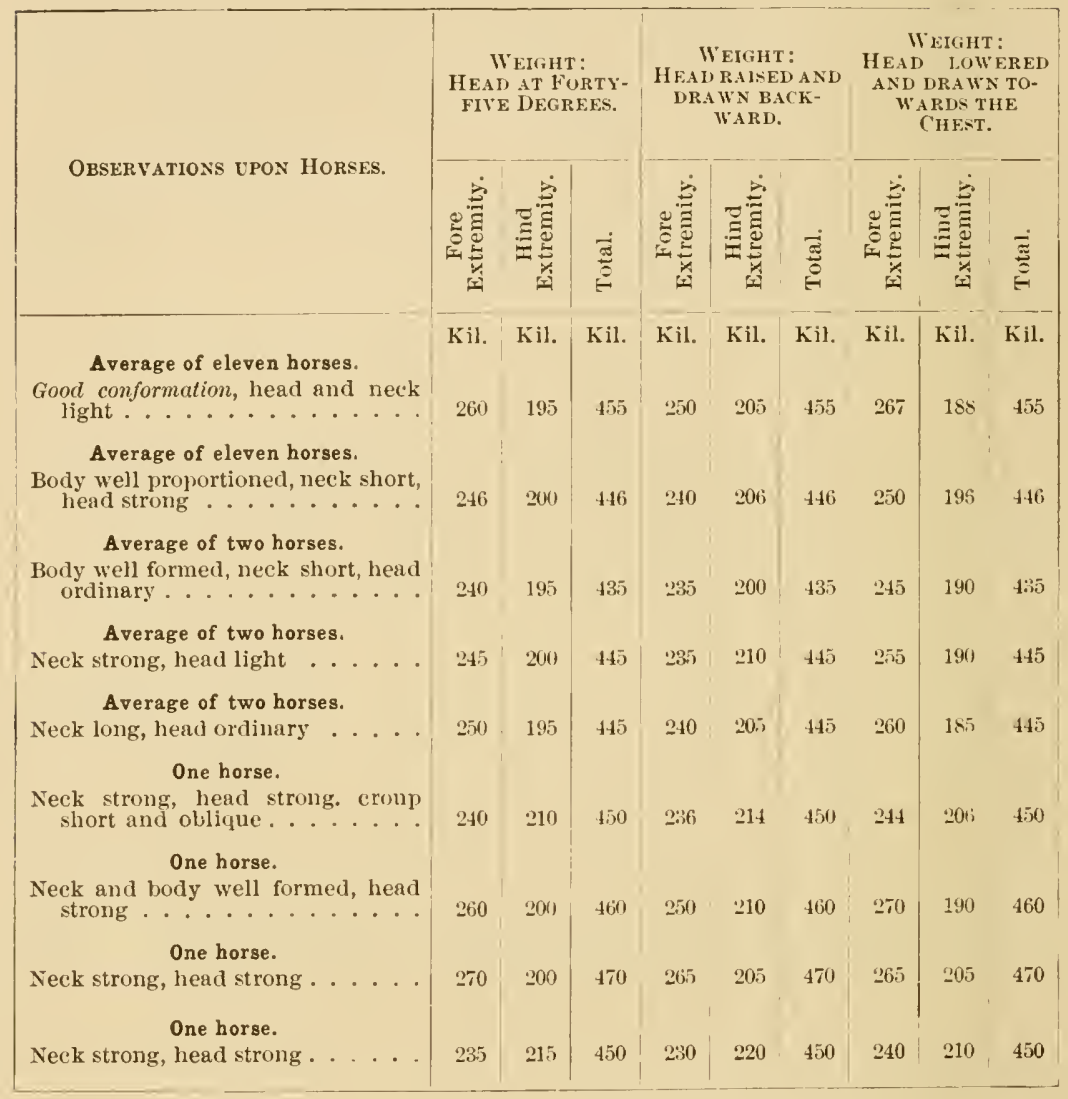

"It may be remarked, in considering these different weights," General Morris adds, "that the weight of the fore extremity is about one-ninth greater than that of the hind; that the change of the position of the head causes the weight of the fore extremity to differ from that of the hind by 10 kilogrammes; that long necks give more weight to the fore extremity than short and strong omes; that the fore extremity is heavier than the hind." M. Colin has repeated the first of these experiments upon two horses, and arrived at results entirely concordant.

Our Experiments.-We will say that most of these have been made upon fifty horses of different sizes and races, chosen from the hospital of the school at Alfort. 
We have also sought to appreciate the extent of the posterion and anterior displacements of the line of gracitation in other different conditions,-for example, with the mounted horse, according as the rider sits erect, leans forward or backwarl, or as he carries his head high or low. The displatements of this line are then determined, whether in front of or behind its average position, which oscillate hetween two and six centimetres, sometimes more, according to the case. Differences of weight, quite considerable, are equally produced in weighing both of the lateral bipeds when the head, the neck, the trunk, or the rider is inclined to one side, facts which show the inportance of the lateral displacements of the centre of gravity during locomotion, especially the work of dressing. But it is in horses high or low in front that the variations of the weight of the fore or hind extrenity assume importance. These have no longer the momentary or aceidental character of the preceding, and from this fact always involve, aceording to the case, a permanent surcharge of one of the two bipeds, anterior or posterior, and consequently their premature ruin. Their gravity angments in horses low over the withers when from the nature of their enployment they are obliged to carry burdens, as in the service of the saddle, the shafts, or the pack-saddle.

In order to prove this, we weighed sucessively several subjects, by placing them first upon the plank of a weighing-machine perfectly horizontal ; then we raised gradually sometimes the anterior quarters, sometimes the posterior, so as to obtain, at will, horses having the fore or hinl quarters low. The height was carefully noticed at the beginning of cach trial, and then it was known exactly how much the croup or the withers were raised or lowered. The results were then in all points comparable, since in all eases the observations were made upon the same subject. They were found to be in conformity with the theory, and may be considered as a corrohoration of the preceding experiments. Wi have chronicled them in the following tables:

1.-ELEVATION OF TIE HEIGIT AT THE WITHERS.

\begin{tabular}{|c|c|c|c|c|c|c|c|c|c|c|c|}
\hline 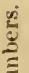 & $\stackrel{\mathscr{L}}{\stackrel{E}{E}}$ & $\stackrel{2}{2}$ & & \multicolumn{2}{|c|}{$\begin{array}{c}\text { DISTRIBETION } \\
\text { OF } \\
\text { WEIGIIT. }\end{array}$} & \multirow{2}{*}{ 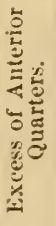 } & \multirow{2}{*}{ 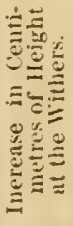 } & \multicolumn{2}{|c|}{$\begin{array}{c}\text { DISTIRIBITION } \\
\text { OF } \\
\text { WEIGIIT. }\end{array}$} & \multirow{2}{*}{ 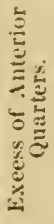 } & \multirow[b]{2}{*}{ Observations. } \\
\hline $\begin{array}{l}\frac{1}{0} \\
\frac{\omega}{5} \\
\end{array}$ & 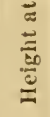 & 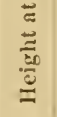 & $\begin{array}{l}\bar{y} \\
\bar{z} \\
\frac{3}{5}\end{array}$ & 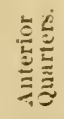 & 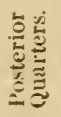 & & & 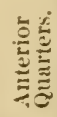 & 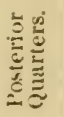 & & \\
\hline & M.C: & M1. & Kil. & Kil. & Kil. & Kil. & MI.C. & Kil. & Kil. & kil. & \\
\hline 1 & 1.47 & 1.52 & $4(x)$ & $2=0$ & 215 & $3 i$ & 0.10 & $24 \bar{i}$ & 20 & 25 & Common mare. \\
\hline 2 & 1.68 & $1.6 ! !$ & (6)8 & $3 \pi 1$ & 314 & (i) & 010 & 368 & $3: 20$ & 48 & l'ereheron gelding. \\
\hline 3 & 1.46 & 1.45 & $4: 3$ & 245 & 183 & (i2) & 0.11 & 234 & $1(x)$ & 4s & Commoll mare. \\
\hline 4 & 1.44 & 1. 5.5 & 314 & 184 & 130 & 54 & 0.11 & 175 & 139 & $34 i$ & 13arb. mure. \\
\hline 5 & 1.58 & $1.6: 3$ & 488 & 272 & 216 & 56 & 0.01 & 268 & 230 & 45 & Thornugh. horse. \\
\hline 6 & 1.62 & $1.1 i 1$ & $5 \geq 6$ & 308 & 218 & 90 & 0.06 & 306 & $2: 0$ & 86 & Sorman gelding. \\
\hline 7 & 1.65 & $1.66 \%$ & 570 & 310 & 200 & 50 & $0.04 ;$ & 3018 & $3 i 2$ & 46 & l'ercheron gelding. \\
\hline 8 & 1.65 & $1.6^{\circ} 2$ & 550 & 310 & 240 & 70 & $0.06 \%$ & 307 & 248 & $6-1$ & Sorman mare. \\
\hline 9 & 1.39 & 1.899 & $3: 30$ & 200 & $1: 30$ & 70 & 0.06 & 195 & 135 & (6) & Corsicnn gelding. \\
\hline 10 & 1.57 & 1.50 & 415 & 2601 & 185 & $7 j$ & 0.06 & $25 \overline{5}$ & $1(\%)$ & 65 & Irisle cols. \\
\hline 11 & 1.65 & 1.61 & 630 & $\because 70$ & $2(x)$ & 110 & $0.06 i$ & 2635 & $2(i 5)$ & $10 n$ & Bonlun. gelding. \\
\hline 12 & 1.51 & 1.53 & 4.55 & ans & 167 & 121 & 0.06 & 281 & 171 & 113 & I'ercheron gelding. \\
\hline 13 & 1.51 & $1.5: 3$ & 410 & 245 & $1(i)$ & 81 & $0 .(\mathrm{Mi})$ & 2311 & $1 * 0$ & 50 & Corsichn gevldiug. \\
\hline 14 & 1.59 & 1.60 & 465 & 260 & $2(1) 5$ & 55 & 0.063 & 250 & 215 & 35 & (iетmuл gelding. \\
\hline 15 & 1.15 & 1.20 & 235 & 137 & 98 & 39 & 0.06 & 125 & 110 & 15 & Fumale nsti. \\
\hline
\end{tabular}


2.-ELEVATION OF THE HEIGHT AT THE CROUP.

\begin{tabular}{|c|c|c|c|c|c|c|c|c|c|c|c|}
\hline \multirow{2}{*}{ 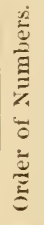 } & \multirow{2}{*}{ 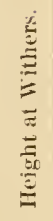 } & \multirow{2}{*}{ 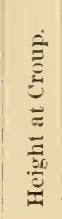 } & \multirow{2}{*}{ 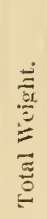 } & \multicolumn{2}{|c|}{$\begin{array}{c}\text { DISTRIBUTION } \\
\text { UF } \\
\text { WEIGHT. }\end{array}$} & \multirow{2}{*}{ 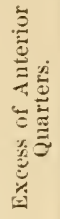 } & \multirow{2}{*}{ 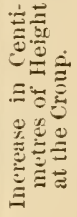 } & \multicolumn{2}{|c|}{$\begin{array}{c}\text { DistRIBUTION } \\
\text { OF } \\
\text { WEIGHT. }\end{array}$} & \multirow{2}{*}{ 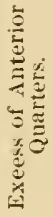 } & \multirow[b]{2}{*}{ Observations. } \\
\hline & & & & 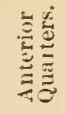 & 总总 & & & 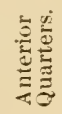 & 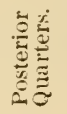 & & \\
\hline & M.C. & II.C. & Kil. & kil. & Kil. & Kil. & M.C. & Kil. & Kil. & Kil. & \\
\hline 1 & 1.47 & 1.52 & 46.5 & 250 & 215 & 35 & 0.10 & 258 & 207 & 51 & Common mar \\
\hline 2 & 1.68 & 1.69 & 688 & 374 & 314 & 60 & 0.10 & 38 & 308 & 72 & Percheron gelding \\
\hline 3 & 1.46 & 1.48 & 420 & 245 & 183 & 62 & 0.11 & 252 & 176 & 76 & Common mare. \\
\hline 4 & 1.44 & 1.45 & $31 \cdot 1$ & 184 & 130 & 54 & 0.11 & 186 & 12: & 58 & Barb. mare. \\
\hline 5 & 1.58 & 1.63 & 188 & 272 & 216 & 56 & 004 & 27 & 201) & 70 & Thorough. horse. \\
\hline 6 & 1.62 & 1.61 & 526 & 308 & 218 & 90 & 0.1 & $3 \%$ & 20 & 120 & Norman gelding. \\
\hline 7 & 1.65 & 1.66 & 570 & 310 & 260 & 50 & 0.0 & 31 & 25 & 54 & Percheron gelding. \\
\hline 8 & 1.65 & 1.62 & 550 & 310 & 240 & 70 & 0.1 & 31 & 23 & 80 & Nol \\
\hline 9 & 1.39 & 1.39 & 330 & 200 & 130 & 70 & (1). & 20 & 127 & 76 & Corsican gelding. \\
\hline 10 & 1.47 & 1.50 & 445 & 260 & 185 & 75 & 0.6 & 23 & 21 & 15 & Irish cob. \\
\hline 31 & 1.6 .5 & 1.61 & 630 & 370 & 260 & 110 & 0.1 & 37 & 258 & 114 & Boulon. gelding. \\
\hline 12 & 1.54 & 1.53 & 455 & 288 & 167 & 121 & 0.1 & 293 & 170 & 123 & Percheron gelding. \\
\hline 13 & 1.51 & 1.52 & 410 & 245 & 16 & 80 & 0. & $2 i$ & 150 & 110 & Corsican gelding. \\
\hline 14 & 1.59 & 1.60 & 465 & 260 & 205 & 55 & 0.8 & 26.5 & 200 & 65 & lding. \\
\hline 1 & 1.15 & 1.20 & 235 & 137 & 98 & 39 & 0.96 & 142 & 93 & 49 & Female ass. \\
\hline
\end{tabular}

Let us see now what is understond by the terms equilibrium and base of sippoit.

Equilibrium in mechanics is the state of a body induced by the forces

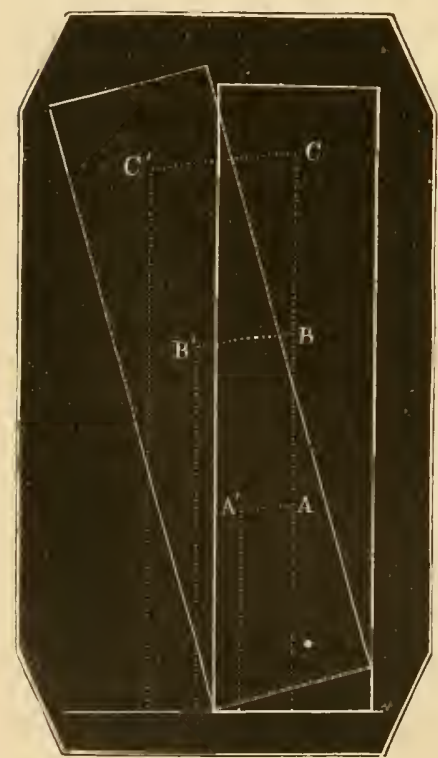

FIG. 3. which destroy one another or which are amnulled by a resistance (Littré).

In animals the body seldom rests upon the ground lyy a continued surface (decubitus). It is supported by four broken columns articulated from distance to distance and designated by the name of members. The polygon formed by the lines joining the four points which touch the ground at rest represents what is called the base of support. This polygon is sometimes a triangle; at other times the base of support is reduced to a line; finally it may be only a point. Whatever may be the form and extent of the base of support, it is necessary, in order to obtain equilibrium, that the line of gravitation does not meet the groumd ontside of this base.

The equilibrium will be so much more stable as the base of support becomes larger/ the centre of gravity placed lower, and the line of gravitation nearer the centre of the base. It will be mustable in the contrary conditions. In fict, in the solicl here represented (Fig. 3) it will be seen that if the centre of gravity is displaced from $A$ to $C$, having reached to the point $C$, the slightest oscillation of one side or the other, $C C^{\prime}$ for example, will cause the line of 
gravitation to come outsile of the base and prowoke a fall. Therefore, a lorse Waving a heavy body mounted upon long, slenter members drawn close to the median plane will be endowed with an equilibrimn relatively unstuble. As the base of support has the form of an elongated rectangle, with the horse at rest, the displatement of the eentre of gravity fom in front backward will be much less dangerous for the intergrity of its exuilibrium thin those which take place from sille to side, because the line of gravitation will be noved much easier from the base of support in the latter ease than in the former. This explains to us why falls during rapid paces searcely ever take plate upon a straight line, but are produced, on the contrary, in turning; why the ambling horse, which moves his members by lateral biperls, goes finster and falls more frequently than the trotting horse, which moves his members by diagonal bipeds; why the leaping horse, which displaces the centre of gravity guently, falls down-soroften; why sliding sideway's is more dangerous thim moving forward or backward, ete.

$\checkmark$ That instability of equilibrium gives the measure of speed has been justly faid. It is easy to acconnt for this. If, fiom the fact of its displacements, or from its situation being more or less raised, it is carried outside of the base of support, it will cause the members to be displacel with a greater rapidity to support the broly, ats the fall is more imminent.

The race-horse lengthens his body, extends his head and neck, and seems ahmost to lie down upon the ground in such a mamer as to bring, as much as prosible, the centre of gravity in advance of the movement. The lressed horse raises himself in a strong proportion in order to execute more easily the varied morements which at every justant his rider exacts from him. His paces are shortened, raised; his equilibrium is more stable, the displacements of his contre of gravity less extended but more numerous. On aceount of his acouired speed, and especially because of the instability of his equilibrium, the hippodrome-horse can seareely make progress upon a straight line; the slightest lateral displacement of the centre of gravity, a little sudden, eauses him to fall.

\section{(CHAPTER III.}

THE IAVER AND MISCTIAR MEUIIATII.

Tur: lever is defined as a "rigid and inextensible rod supported 11 mon a fixed puint." The form and nature of the substance of which this stalk is compused halve no importance from the print of view which concerns us. It is seen, then, that the hones of the skeleton are properly enomidered as hevers, sine they enter into the definition which we hatre just given.

Every lever nay be sulumittal to the action of soveral forces, but, whatever may be their number, we know that it is always asse ter reduce them to two. When it is a question of ascertaining the comblitions of the equilibriom of this machine, only two forees are nsually reengnimel. The former will be in regnililgrimm when the resultant of the forces which move it is ammulled by the reatetion of the point of support. If expulibrium does nest result, the effecet of the foreres is to determine a rotation of the stalk alromed the fixed point. 
Of the two forces which act mon the lever, one, which is called the power, is destined to equalize the other, which is called the resistance, or to overcome its action. The object of the lever is to favor one of these forces at the expense of the other. We will see later on what its consequences are. In the animal economy, these forces are represented by the muscles, and the levers by the bones.

For convenience of demonstration, we will suppose that the two forces which incite the lever are situated in the plane of the latter. In most instances it is not thus: the forces and the lever are placed in different planes.

An example will explain this better. suppose it to be a question of the adductor muscle of the arm. The lever upon which it is inserted is the humerus, the resistance which it must overcone is the weight of the member applied to the articulation of the elbow. It is then easy to determine that the huneral and vertical axis passing through the centre of this articulation, forms a plane in which the adductor muscle of the arm is not situated. If it were located there, it would determine flexion alone of that bone, which is not the case, since it promotes adduction.

Among the muscles of the members, it is only the direct extensors and fiexors that are situated in the plane of their respective levers. It is the same for the muscles of the spinal column. All the others act in different planes. This does not mean that the conditions of the equilibrium of the lever are not applicable to the former, but the developments into which we must enter in order to resolve particular cases would leal us too far away.

In mechanies, the moment of a force in relation to an axis is the product of the projection of this force upon a plane perpendicular to the axis, through the distance of this force to the axis.

When the idea of moment is applied to the study of the lever, it may be

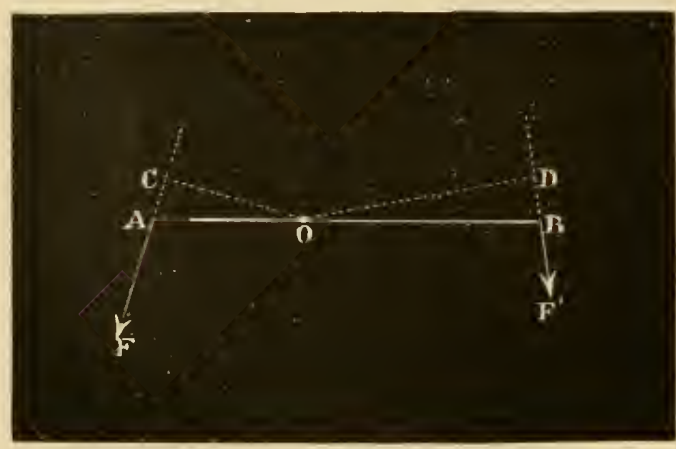

FIr. 4. defined thus: The product of the force by the arm of the lever, because the forces, being situated in the same plane, are themselves their projection ; as to the axis, it is supposed to pass through the point of silpport.

Suppose the two forces $F^{\prime}$ and $F^{\prime}$ inciting the lever $A B$ (Fig. 4). The whole system is situated in the plane of the action. The forces then project themselves following $F A$ and $F^{\prime} B$. Let us suppose now an axis perpendicular to this plane and piereing it at the point $O$. It is evident that the distances of these two forces to this axis are measured by the perpendiculars $O C$ and $O D$. The moment of force $F$ will be $F \times O C$; that of the force $F^{\prime}, F^{\prime \prime} \times O D$.

The perpendiculars $O C$ and $O D$ are called lever-arms extending from the point of support in the direction of the forces $F$ and $F^{\prime}$.

Whence it results that in the lever the moment of a force is the product of that force by its lever-arm. It is demonstrated in the same manner that the lever is in equilibrium when the moments of the two forces are equal. We will therefore obtain :

$$
F \times O C=F^{\prime \prime} \times O D \text {. }
$$


Whenee is produced:

$$
1 \frac{F^{\prime}}{F^{\prime \prime}}{ }^{\prime \prime \prime} \cdot
$$

That is to say, that the forces are to ench other inversely as the arms of their lever: great forre, small lever-arm, and, reciprocally, large lever-am, suall fince.

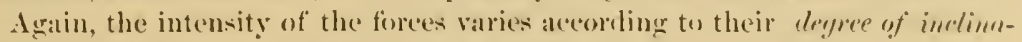
tion. The three following cases may present themselves:

1st. The jorce mulase a right angle with the lecer-alm.

It acts then with its maximum of intensity. This is, in fict, the calse where the lever-arm is the most consilerable; it is meatsured by the distances of the proint of application of the force to the point of relation.

2). The forre malies an arnte angle (Fig. j).

Let the force $r$ atet upon the lever $A U B$. If it acted perpendicuharly, jis lever-arm would be 10 . Now, 0.1 is $>$ than $O($, as oblicue II)on $1 F^{\prime}$ with reference to the perpenclieular $O{ }^{\prime}$; arm of the lever of F. Thus a eertain part of the foree employed in repelling the tixed point is lost for the movement of the print $A$. This is seen by alecomposing $F$ into two forees, $A E$ and $A H$, acting npon the point A, following the difretions indicaterl. $A I /$ is the gurntity em-

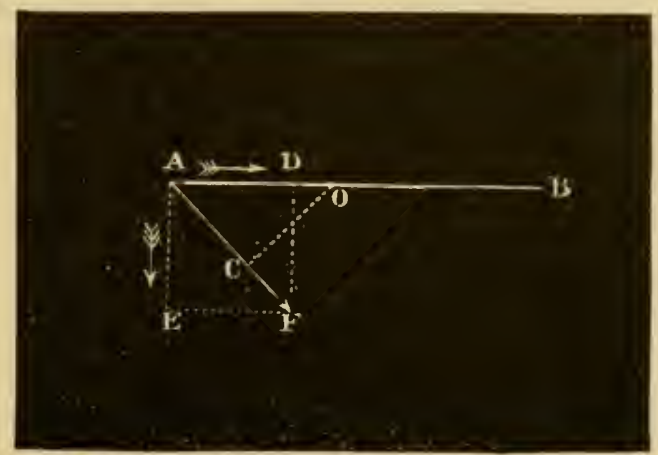

F16, 5 . ployed to repel the tixerl point.

It may be conceived that the more the angle formed hy the force with is lever-arm is acute, the greater will be the inerease of $A l l$ at the expense of $A E$, and the force utilized for the movement will thus be less. The disposable force will be nul] if $F$ becomes parallel to the arm of its lever.

3d. The foree mules an obture angle (Fig. 6).

In this ease the arm of the lever $O C$ is smaller than if $F$ were perpendicular to $O .1$, since it woulal he n.t itself. Thus a cerlain purt of $F$ is lest in drawing $A$ towarils $1 l$ ) at the expense of the movement. The more the inelination of $F$ is obtuse, the more the eompunell $A / l$ will intrense relatively to the compoment $A E$, alone useful for the inowement. The paralledism of $F$ with its arn would ('nuse, as in the preverling ('ase', tut al atumlmest of $t$; willout llere being any fussible movemeal.

Thus it results from the preceding remarks that every timse a force is not preplendieular to its lever-arm, a fart of its intensity will be

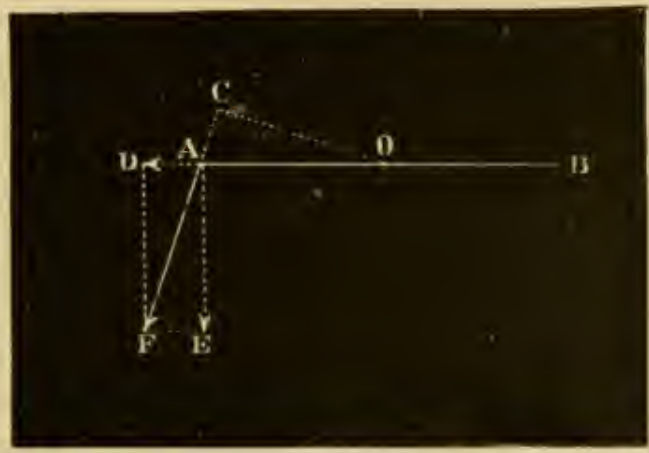

Fiเ. 6. attrating or repelling the point of support aceording to the nature of the angle formed. 
Muscular Mechanics.-These ideas can be at once applied to muscular mechanic's. A muscle which contracts tends to draw its two extremities equally towards its centre. Each one is usually inserted upon a distinct bone. The bones, however, are not all movable to the same degree. Whence it follows that every musele has a fixed and a mouble insertion, the latter being situated upon the bone which is displaced during the contraction.

As the muscles of the apparatus of locomotion are voluntary, the animal can at will change a movable insertion into a fixed insertion, and rice reva. In other terms, a muscle, for example, which extends from the head to the arm (mastoido-humeralis) can as well become a motor of the head as an extensor of the arm. It suffices that the other muscles contract in order to fix and render immovalle the head or the arm. The multiplicity of the muscular fibres is in proportion to the intensity of the contraction; their length, on the contrary, agrees with its extent. Or, if preferred, the volume of the muscles gives the measure of foree ; their length, that of speed.

It is, then, we believe, an error to think that the extent of the contraction of the muscles is not measured by the length of their fleshy portion, but by the length of the fibres which form them. This is only partly true, for in compound muscles, if the fibre be interrupted by aponeurotic or tendinous intersections, if it be shorter than in simple muscles, things oecur, so to speak, as if the fibre represented the length of the Heshy body. The extent of the contration is the result of several distinet actions which are addert to one, another to letermine the total effect. The intersections, therefore, only give greater support to the contraction of the fibre; they furnish it with greater resistance to the tractions of weight, for the museles in which they are encountered, besides their active rôle in locomotion, are still important passive agents in station.

In most instances, in the members especially, the muscles are applied along the length of the bones, and are found, on that aceount, in conditions very disadvantageous. Their manifest tendency towards proulelism with the lever-arm seems to have little connection with the theoretic ideas which we have just given, since a large part of their force is regarded as lost for movement.

This is of no account, however, and it is easy to determine that this disposition is, on the contrary, most fortunate, whatever may have been said concerning it.

Indeed, if the muscle at the beginning of its contraction acts with a defective incidence, this incidence becomes more and more favorable as the eontraction progresses, and the muscle will then profit, at the moment its action is most powerful, by the entire quantity of movement already acquired by overcoming the resistance. But if the insertion at the beginning be more perpendicular, the muscular aetion, instead of aequiring intensity, will gradually lose it, and the movement produced, while overcoming the resistance, will be less extended.

On the other hand, the tendency to parallelism determines in the members of animals those slender forms which we know are in accordance with speed. It is certain that the muscular interstices are much more considerable as the muscles are more removed from their bony columns and therefore more perpendieular to them. This is ohserved in animals with massive forms and slow morements. Here, the heaviness of the gait is due to the enormons size of the mass as well as to the feeble degree of the eontraction of the muscles.

It must not be inferred from this that for speed we should seek absolute parallelism of the muscles with their levers. It must be remembered that this 
parallelism is a linderance to the execution of the initial movement; hence the utility of the eminences which the bones of the members present, more particnlarly in the vicinity of their extremities. These projections, upon which the muscles are inflected or attached, have the effect of removing them from the bones and increasing the intensity of their action. Such is the rote of the great ses:moids, the supra-carpal bone, the olecramon, the coracoid procest, the calcatneum, the anterior tuberosity of the tibia, the patella, the trochanter, ete. Such is the advantage presented by the enlarged extremities of the bones of the members, and such the result of the inclination of the diflerent bones upon each other. These diverse dispositions retain the advantages of parallelism, whilst avoiding the manifest inconveniences at the beginning of the muscular action.

Again, the study of the lever teaches us that the paths described by the leverarms are in direct ratio to their length, since they describe circunferences which are to each other as their radii. If, consequently, one of the forces act upon an arm shorter than another, the arm of the latter will traverse a path much more considerable.'

In organisms it is very remarkable to find that the lever-arm of the muscles: is usually very weak, especially when the latter are charged with the production of speed. As Lecoq ${ }^{2}$ judiciously remarks, power aets in this ease with much less intensity, lout it may become much greater through the multiplicity of the muscular fibres, which, having only to produce a contraction slightly marked, ean be disposed obliquely and be much more numerous in the muscle. On the other hand, if the muscles have their insertion very far from the point of sup)port, their contraction, by removing them from this point, deprives the member of its slender form.

From what we have said above, ¿ propos of the inclination of the forces upon their lever-arms, it is easy to determine the force utilized at each instant of the muscular contraction. It is elearly seen that, according as a muscle is at the beginning or at the end of its contraction, there is a tendency to an :1p]roximation or a separation of the articular surfaces.

It is said that a muscle is at its moment when its traetion is exercised perpendicularly to the displaced bone; but a great many muscles cease their artion before reaching that position; they often only commence the movenent which is terminated by the intervention of other muscles. This takes place in the frexors of the metacarpus, for example, whose parallelism to the lever-arm is almost complete; if the flexors of the phalanges did not initiate the flexion of the metaciapus, these muscles could perhaps not produce it hy themselves.

In all the instances which we have just considered the mobile lione represents a lever upon which we always find the three fundauental points: the point of supuort and the points of application of the power and of the rexistanse.

The proint of support is nearly always situated on a level with the articulation with the fixed bone; this is also the entre of movement. The power is always applied at the mobile insertion of the motor muscle. As to the resistance. it is situated upon the lever, at that variable point where the weight or the obstacles to the displacenent of the mohile bone act, whaterer they may les. 
According to the relative position of these three points, we recognize three classes of levers.

In the one called the first class (Fig. 7 ), the fixed point $A$ occupies an inter-

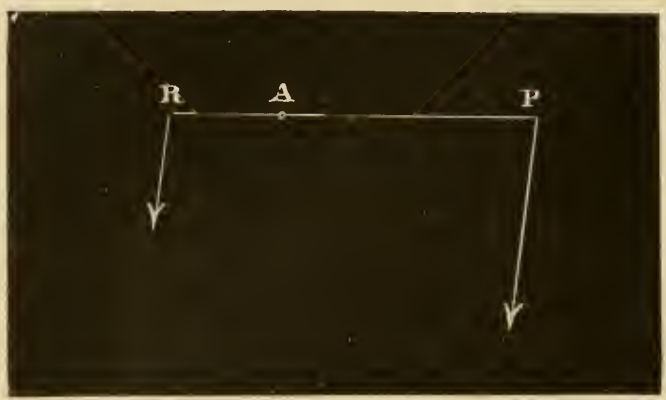

FIG. 7. mediate position to the two others, $P$ and $R$. It is called inter-fixed lever.

A certain number of muscles act 11 pon this class of lever. It is exemplified, for instance, in the extension of the head upon the neck. The fixed point (oecipito-atloid astienlation) is always situated, whatever may be the position of the hearl, between the resistance (centre of gravity of the lutter) and the power (occipital insertion of the muscles of the nupe of the neck).

The cervical ligament in our larger domestic species also equalizes the weight of the head by an analogous mechanism.

It is, however, not correct to consider the head as an inter-fixed lever at the moment of flexion, as some persons think. According to their view, in fact, the obstacles depend on the antagonists (extensor muscles) and the elasticity of the cervical ligament. These would be the elements of resistance, the weight of the head becoming, according to this opinion, an auxiliary of the power (flexor muscles).

No doubt it is sometimes thus when the head and neck are elevated, but things are very different when these regions are lirected towards the ground. The weight of the head then becomes to the flexors a veritable resistance to be overcome, and the lever is no longer of the first class; it is of the third, as we will see further on.

Besides, in order to understand the action of a muscle well, it is necessary to investigate it as if it alone were attached to the lever, withont regarding the manner of existence of the antagonistic ones. In most instances the latter do not oppose any resistance, but allow the former to execute the movement freely. The extension of the forearm, and that of the metatarsus, the femur, the pelvis, the spine, ete., take place throngh the mechanism of an inter-fixed lever in which the arm of power is, according to the case, the olecranon, the calcaneum, the trochanter, the ischial tuberosity, the spinous or transwerse apophyses of the vertebre. In the economy the lever of the first class appears to be more particularly reserved for extension. It is also the lever of speed, for the arm of power is never equal to that of resistance: the latter is always much longer.

In man, whose standing position is vertical, in whom falling forward is easy, on account of the particular situation of the organs, the lever of the first kind is, with good reason, to be considered as the lever of station. We shall see that in animals it is that of the second class in which this usage can be preferably recognized.

In the lever of the seeond class the resistance occupies the intermediate position (Fig. 8). The name inter-resisting is applied to it. In this case, whatever 
may be the respective positions of the there points, the lever-arm of power exeeds that of resistance, since $l$ 'A always rematins hypothetically longer than lid. This lever is, then, very truly that of force, but hats more disiallvantage conceruing the production of speed, for, the latter hering proprortional to the lever-arm, the path of the resistance will never be ats long as that of the power.

Several examplesareseen in animals. / It is well known that whilestamling the weight of the bondy tencls to elose all the articular angles of the members upon each other/

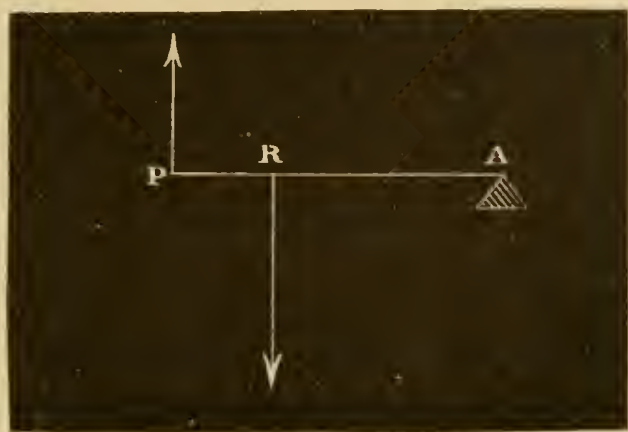

FIG. 8 . There are also observed, on the convex side or the summit of the latter, museles which are opposed to this closing, by acting as levers of the sceond elass. It is thus that the supra-spinatus, the coraco-radialis, the sul-spinatus, the subscapular, sustain the scapulohumeral angle. The insertions of these different muscles are all situated a little heyoml the articulation, which represents the point of application of the resistance to be wereome, whilst the point of support is placed at the articulation of the ellow. It is in the same mamner that the extensors of the forearm sustain the humero-rarlial articulation upon which are transmitterl the actions of the weight, that the suspensory ligament of the fetloek maintains this region, that the gastrocnemius and the perforatus muscles of the leg retain the calcanem, that the midille wluteal muscle prevents the closing up of the coxo-femoral angle. It will be nuticerl that all these muscles act as levers of the first class when the member: do not serve as a support, so that the organism has no need of interprosing new anatomical disporsitions in orcler to develop fores. The same levers aclapt themselves with the same pewere to different comditions in orrler to proctuce, aceoreling to the necessity of the movement, either force or speed.

Finally, a thirel case presents itself in the relative situation of the three fimdamestal proints of the lever. It is that in which the prower is placerl letween the resist-

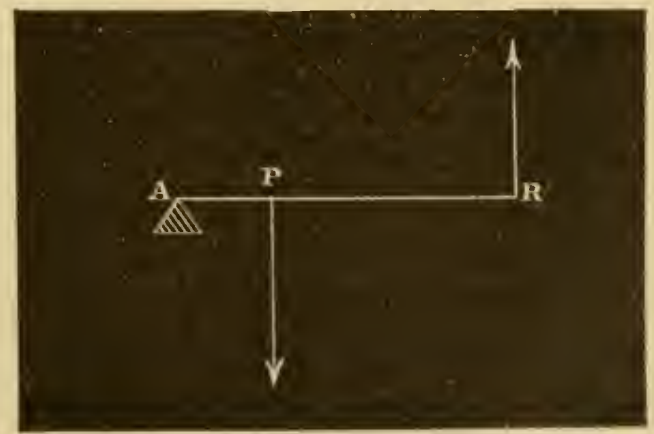

Fi⿳, 9. ance and the point of sulport.

This lever is designated the lemen of the thimd clesse, or inter-pmissemt (Fig. !)).

Here the arm of resistance is always hypothetically lomere than that of the power, and the velocity is inceressed at the cxpense of the force. Like that of the first elass, it ('an alsot be called the lewer of epeed. 
The economy offers numerous examples of this variety. All the flexor muscles act as levers of this kind. The large psoas muscle flexes the femur by this mechanism. The point of support is at the coxo-femoral articulation, the resistance (the weight of the member) is applied at the femoro-tibial articulation, and the power is exerted at the internal trochanter. The flexors of the leg, metatarsus, arm, forearm, metacarpus, phalanges, head, spinal column, etc., act upon levers of the third kind. We are right in saying that this lever is that of flexion in the same manner as that of the first kind is the lever of exteusion.

In the animal mechanism all the levers are not distributed in the same number. The manner of articulation of the bones and the function of the parts demand here the use of the inter-fixed lever, there that of the inter-puissant lever, and elsewhere that of the inter-resisting.

We have, however, a right to ask why the organism ntilizes two levers of speed, the first and the third class, since one of them may become that of force. We have seen, indeed, that the bones which act as levers of the first kind when the member is raised become the second kind during support, by the simple displacement of the fixed point and of the resistance. It cannot be thus for those which act as levers of the third kind. In other words, the lever of flexion cannot be of the first kind; it belongs especially to the third. For, were it otherwise, we should find in the sinus of the articular angles apophyses analogous to the olecranon, the calcaneum, the trochanter, the sesamoids, or the patella, peculiarities destined to substitute the lever of the first chass for that of the third. It is not difficult to see that the movement of flexion, already sufficiently limited by the interposition of the muscular masses occupying the articular sinus, would be almost impossible. The presence of these eminences on the opposite side of the locomotory angles does not cause any inconvenience, for the extension is never complete, and, were it so, it would place the two segments in prolongation with each other, which would not limit the normal movement. In flexion it is different; the concavity of the angles should be free in order that certain points of the movalile segment do not meet too soon the fixed segment and therefore limit its displacement.

In all the preceding cases we have supposed the muscular action isolated in order to analyze it better. It is, however, never thus. Every muscle which contracts to displace a bone is aided in its rôle by the contraction of one or more neighboring muscles. These latter have the effect of fixing the one of the two segments which should not be moved. Not one of the pieces of the machine is arranged in an immovable manner, since all are agencies to produce movement. It is then important, in order to avoid the discharge of force, that certain ones among them be immovable, and it is on this account that the contraction of a muscle is always assisted by that of a congener. This fact, most of the time difficult to determine, becomes most evident at the time of the production of the effort.

Finally, we remark that, if the organism frequently employ the lever, the simplest of machines, in the functions of its locomotive apparatus, this animal lever differs much from the ordinary one and, with still greater reason, from the mathematical. If we apply to it the laws of the latter, we simply arrive at a sufficient approximation of its action without seeking to establish any absolute principle.

With M. Mignon, ${ }^{1}$ we think that in the animal lever the point of support is

'Mignon, Mécanique animale, in Recueil de médecine vétérinaire, 1811, p. 67. 
neither invariable nor certain; the insertion of the forces neither well established nor very preeise; their intensity always approximative. Whatever may be the exactness of the idea which may exist in regard to volume, length, direction, the structure of the muscle, its angle of insertion, the arm of the lever which it mover, the amount of contractility-that is to say, the value of the force itselfescapes us.

"In the organized machine resistance is only a power disguised alone by the name. It is indeed weight at first, but it is also muscular contraction which opposes and resists the action of the lever. It is an unknown quantity to be orercome by another equally unknown."

Let us add that the forces of extension have their maximum of intensity at the beginning of their action, whilst those of flexion have it at the termination. This is explained by the diflerence of the result which they should prouluce $/$ The first resist the weight of the body at the same time that they overeme in locomotion the inertia of the regions situated below them, the second only have to raise the member to permit it to advance over the ground, and are nearly discharged from the role which the first fulfil during station. The insertion of the extensors is ordinarily more advantageous than that of the flexors, because these latter have but to employ velocity against the others, which should, in addition. levelop force.

\section{('HA P'TER I V.}

\section{THE INCIINED PLANE.}

THE inclined plane is, with the lever, the other of the two simple machines employed by the organism in the construetion of the locomotory apparatus.

It is known that in the inclined plane (Firr. 10) a solid, $O$, incited by the weight $F$, is drawn the length of this plane by a foree, $f$, which is calculated by the following formula :

$$
\delta=O F \sin F=\sin u \text {. }
$$

In wher workls, the force $f$ is the product of the weight of the body oby the sine of the angle of inclin:1tion of the plane.

The lareger this angle becoms's, the

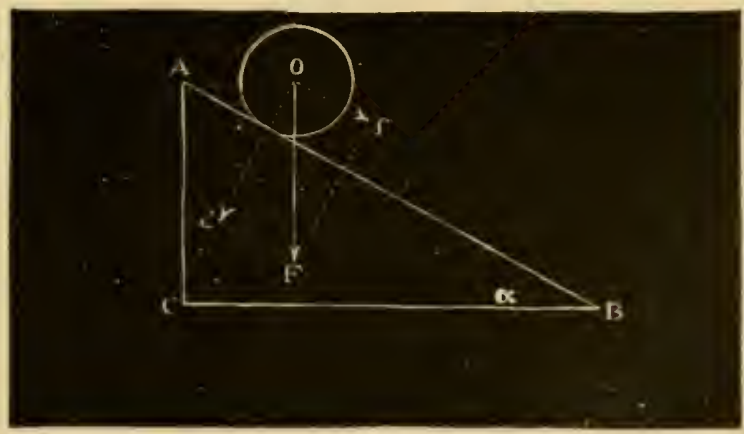

Fili. 10. more the component $f$ increases at the expense of the othere component, od, destroved by the rexistances

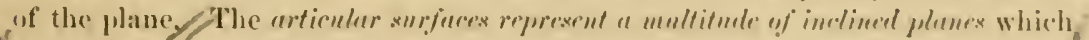
flecompose the weight of the mass apon the loug levers and the tendinous and ligamentous cords situated in the vicinity of the articulations. 
At the superior part of the members the articular surface is a eavity more or less deep. It may be considered as being formed by a succession of inclined planes whose inclination diminishes from the periphery to the centre. It thus disseminates the weight of the borly upon the head, which is adapted to it. The latter acts in the same nammer a second time, alternating the actions of the mast by disseminating them upon the ligaments at the same time as upon the bones. On a level with the secoml articulation of the members we find other inclined surfaces; these surfaces are multiplied towards the earpus and tarsus; finally, they are found in the articulations of the hand and foot.

Thus more and more the weight of the body is disiseminated upon the bony columms through the existence of these diverse inclinations, and the rolume of the bones decrenses in proportion to the efforts which they support.

Another mode of dispersion, again very remarkable, is that which M. Mignon ${ }^{1}$ calls the inclined plane of the segment, in contradistinetion to the preceding, which he names inclined plane of surface.

"In order to establish the existence of these planes in animal machinery," he says, "it is sufficient to observe that in the members the bony segments superpose themselves by being diversely inclined and by thus forming a series of angles at their reciprocal points of union. As these angles do not become closed, as the aetion of the weight is one by its direetion, - that is to say, revtical,- -and as the oblique segment, immediately inferior, receives this action, the latter is then transmitted in the direction of the osseons segment; and, since it has followed this inelined segment, it undergoes the influence of this oblique plane which eonducts and supports it; that is to say, it is decomposed into two parts, one of which is perpendienlar to the segment, the other parallel to it and follows its direction.

"The flexible supports upon which the segments or inclined planes act therefore become one of the elements of these planes.

"If we now examine the mechanical dispositions of the support, we find that the weight of the body is dispersed and attenmated upon a series of inclined planes, which receive, decompose, and transmit this weight; that the solid segments, more and more numerous, support that portion of the weight transmitted parallel to the plane and decompose it in their turn; that the flexible parts sustain like a spring the other portion of the weight perpendicular to the different planes; finally, that the levers and pulleys favor, aid, or increase the action of these springs which move and extend intelligent forces that graduate and measure in some mamner the entire influence claimed by the necessity of the moment.

"Such is the mechanical system, as simple as it is ingenunus, which concentrates or disseminates action, produces and directs it, increases or diminishes it, resists or combats it."

These primary ideas being well understond, we may now begin the particular study of the regions. 


\title{
SECTION SECOND.
}

\author{
STUDY OF THE REGIONS.
}

\section{$\S 1$. DIVISIONS OF THE HORSE.}

Most authors who have written upon the exterior, since Bourgelat, have adopted the division of the horse into fore extremity, borly, and hind extremity; others have preferred the anatomical division into trunk and members. All have areted under the influence of three good reasolls.

Horsenen, with Bonregelat, have only emsidered the saddle-hor:s', and have reganded it as a machine moder the rider, extending beyond him, in fiont and behind. For all those who pratise horemanship, the rider in the mamagement of his momnt has two resistances to orercome, two parts to direct: the fore port, - that is to say, all that part of the horse in fiont of him,- -and the hind pert, all that which is lrehind. The body is under him, he feeds its aretion directly, and it camnot eseape him. It is not thus with the fore and the hind perts, whose movernents are often far from being corvelative, and upon which le slould fix his attention.

The anthors who have prefered, comtrary to the precerling, the division of the horse into trumk and members, quickly perecived that the division of Bourerelat, whilst applyiug itself very well to the service of the sadelle, becomes defortive when applicel to the heary or the light dranght-lorse. It womlel le useless to insist "1pon this point. 'The contrarliction in the terms is still grrater whon it heremers a ynestion of studying the external (onformation of other domestic animals, such as the ox, the sherele, and the dong.

We will adopt the following divisum, beranse it is more erenemal and more convenient, and because this book is mot alone adelesised to hor:s'men.

Whatever may be the animal examined, or its service, it may always 
be divided into three parts: the head, the body, and the members; and the expressions fore extremity and hind extremity may be replaced to advantage by those of anterior quarters and posterior quarters.

The heerd and the body are the most important parts of the animal machinery, for they contain the organs that are indi-pensable to the maintenance of life.

The members, broken columns articulated from space to space, support the trunk and, by their movements, transport it from one place to another.

Besides these prineipal divisions, there are secondary ones; these are faces or planes which limit the animal in front, behind, above, below, and laterally.

The lateral faces, in ordinary language, are sometimes designated in a particular manner. Thus, horsemen often call the left side (mounting side) the near-side, in opposition to the right, which they call the off-side. As it is usually on the left side from which a rider monnts a horse, these expressions are only suitable for the traininghorse, and would be ont of place in all other cases.

Drivers also employ, for the same reasons, denominations which it is well to understand. One who drives draught-loorses is always stationed on the left of the team, and it is for this reason that this side is designated under the name of the side of the man, the right being ealled the off-side of the man.

In Paris and in a large number of departments there are reasons for the use of these expressions, but in certain localities, Finistère and the northern east, for example, they would be void of sense, since men often drive horses on the right side.

We have so far only indicated the primary divisions of the horse. Each of them is again subdivided into secondary regions, which we have consigned to the following synoptieal table as well as to the explanatory figures which are annexed to it.

In order to facilitate for persons little familiar with dissection a knowledge of the summary anatomical deseription which acempanies each region, we have, by guiding the artists in the exact representation of the forms of the horse, reprodnced Figs. 16, 17, and 18, indieating the various struetures. In faet, all the prominences-bony, ligamentous, tendinons, and muscular-which exist under the skin and may become apparent on the exterior are illustrated here. 
TABLE OF TILE REGIONS.

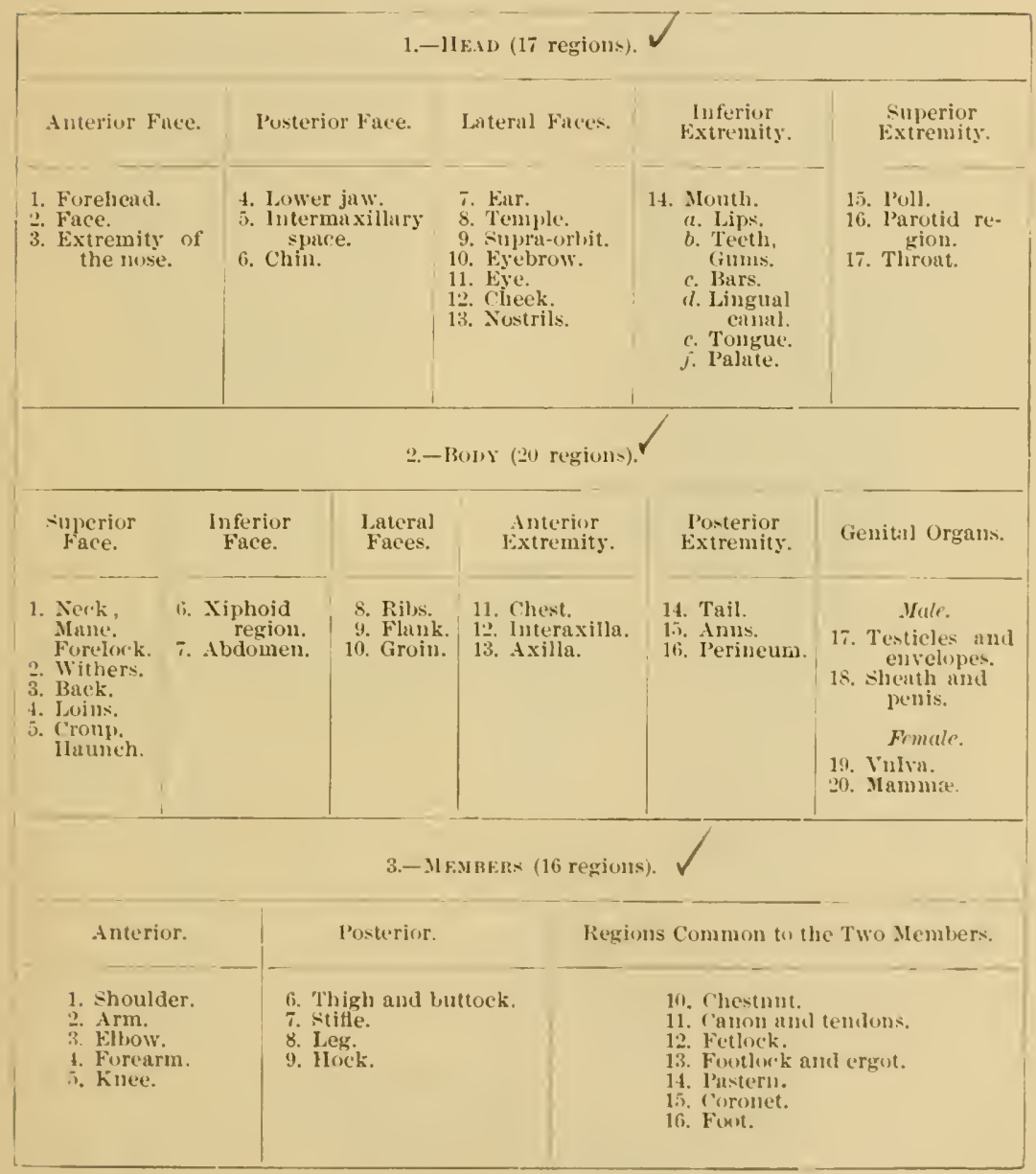



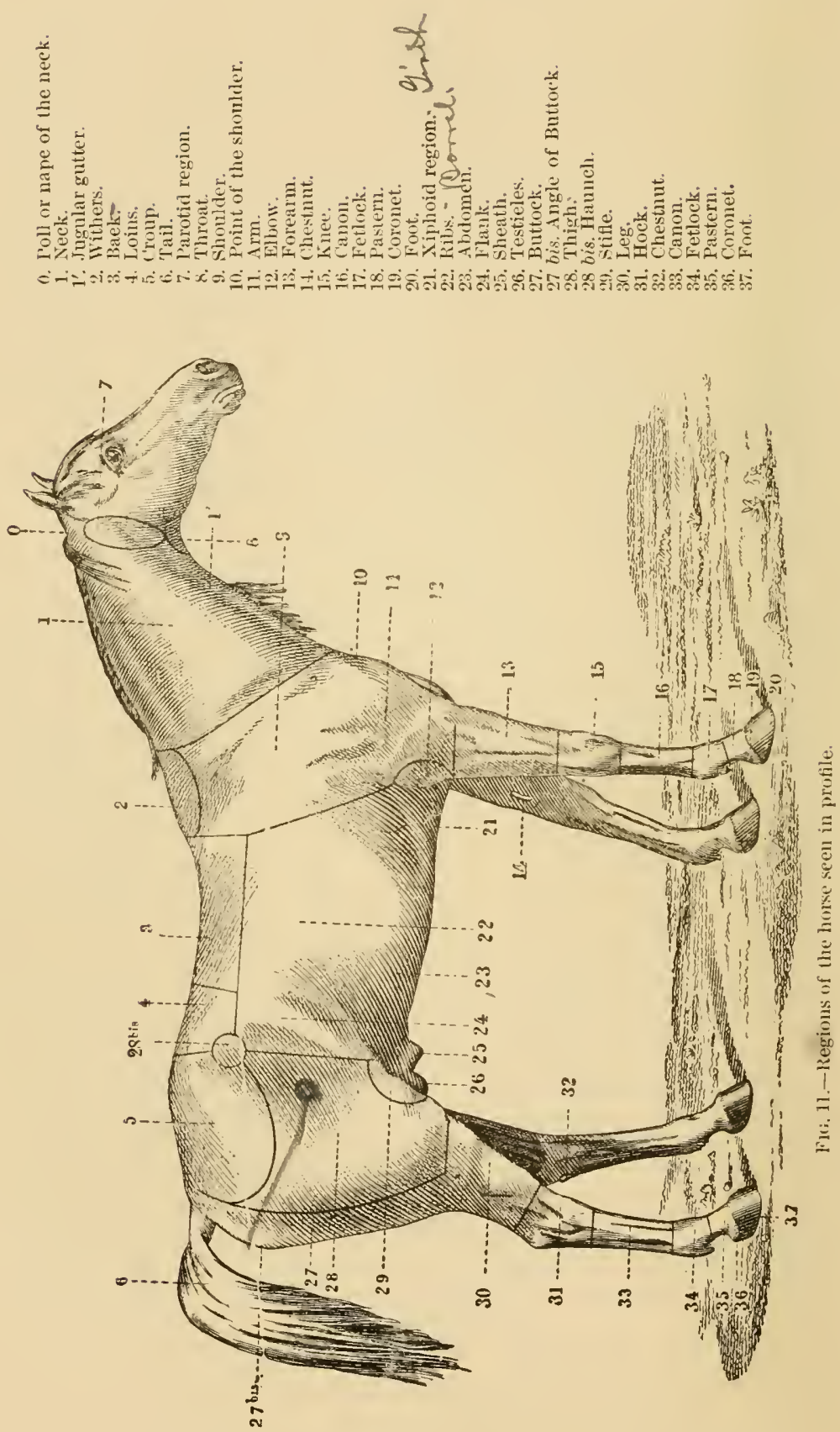


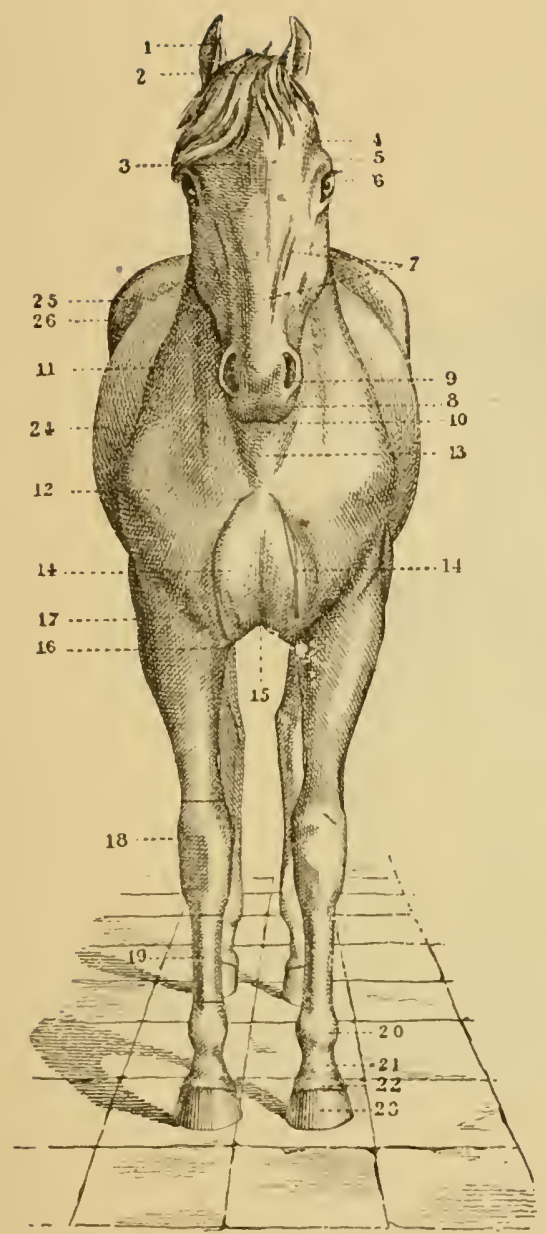

Firi. 12.-Rerions of the horse seen in front.

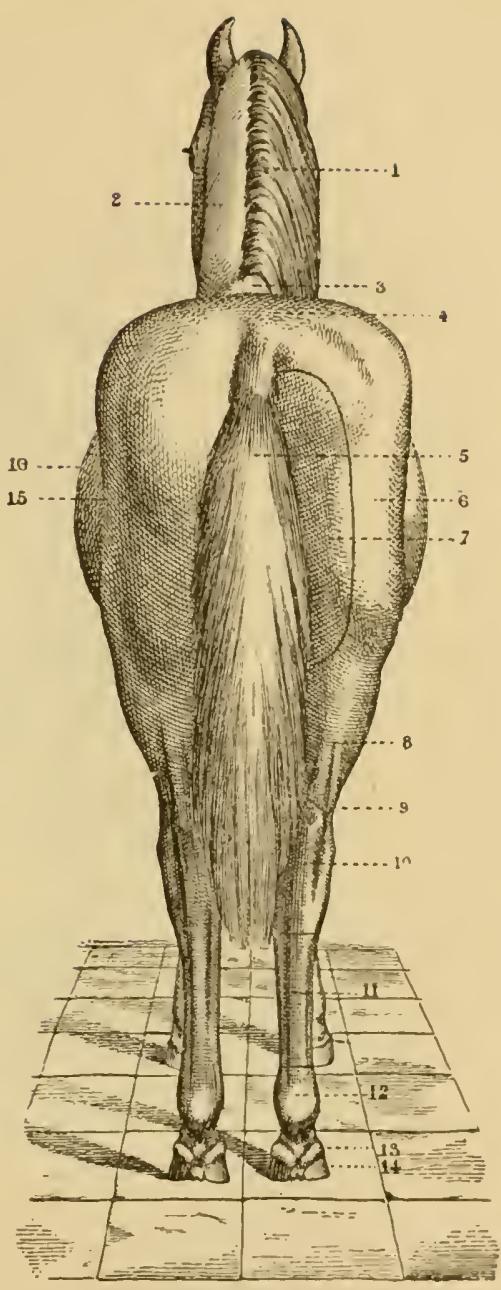

Fir. 13.-Regions of the horse seen behint.
1. Ear.
13. Nerek.
1. Mune.
2. Neek.
9. Point of the lrock.
2. Forelock.
14. ('hest.
3. Withers.
11. Hoek.
3. Foreherm.
1.). Interaxilla.
4. Croup.
4. Supra-srbit.
16. Axilla.
5. Tail.
11. (')
5. Eyebruw.
17. Forearm.
6. Thigh.
12. Fetloxk
18. Kunee.
7. Buttork.
corollet.
7. Finee.
19. Canoll.
$\therefore$ Cort of the bock.
1. Fint
15. F)ank.
$\therefore$ Extremity of the 20. Fetloek. nose.
9. Sinstril.
21. Paster1.
10. Superior lip.
22. Cormet.
11. Shoulder.
23. Fort.
12. Point of the shoul- 25. Hollow of the flank. der of of the arm. 26. Hanuch. 


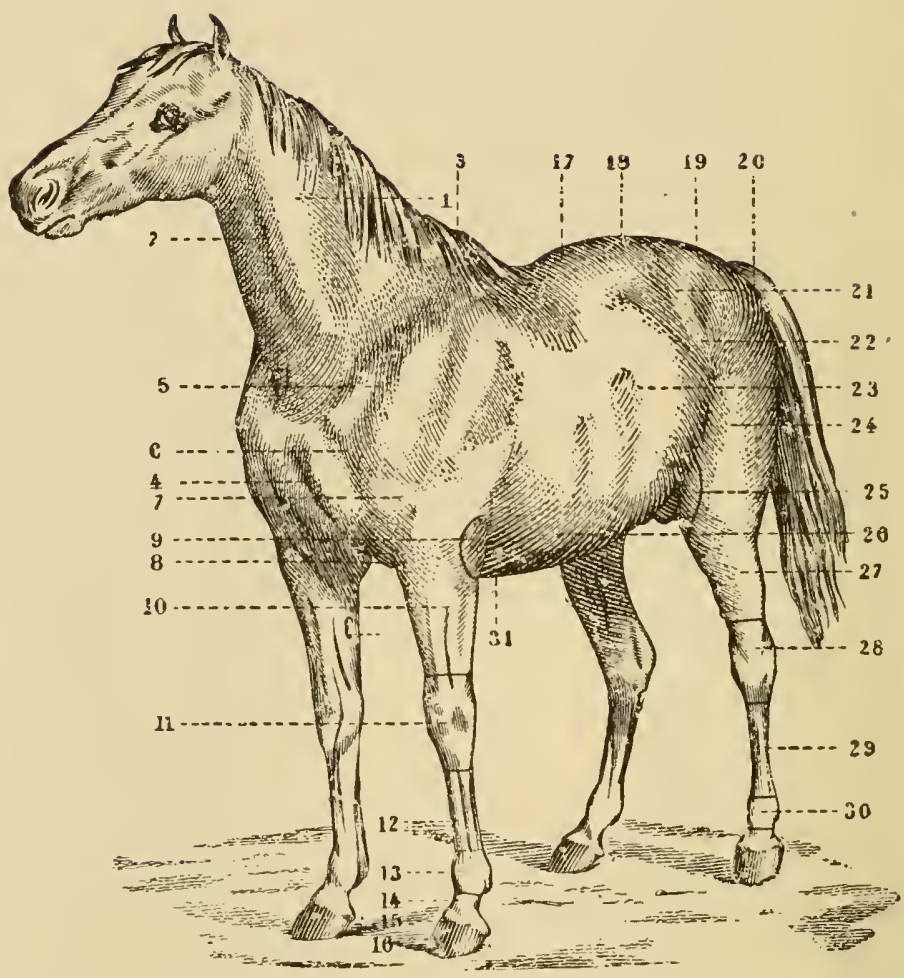

FIG. 14--Regions of the horse seen laterally and in front

1. Neck.

2. Jugular gutter.

3. Withers.

4. Breast.

5. Shoulder.

6. Angle of the shoulder.

7. Arm.

8. Axilla.

9. Elbow.

10. Forearrn.

11. Knee.

12. Canon.

13. Fetlock.

14. Pastern.

15. Coronet.

16. Foot.
17. Back.

18. Loins

19. Croup.

20. Tail.

21. Haunch

22. Flank.

23. Ribs.

24. Thigh.

25. Stifle.

26. Abdomen.

27. Leg.

28. Hock.

29. Canon.

30. Fetlock.

31. Xiphoid region. 


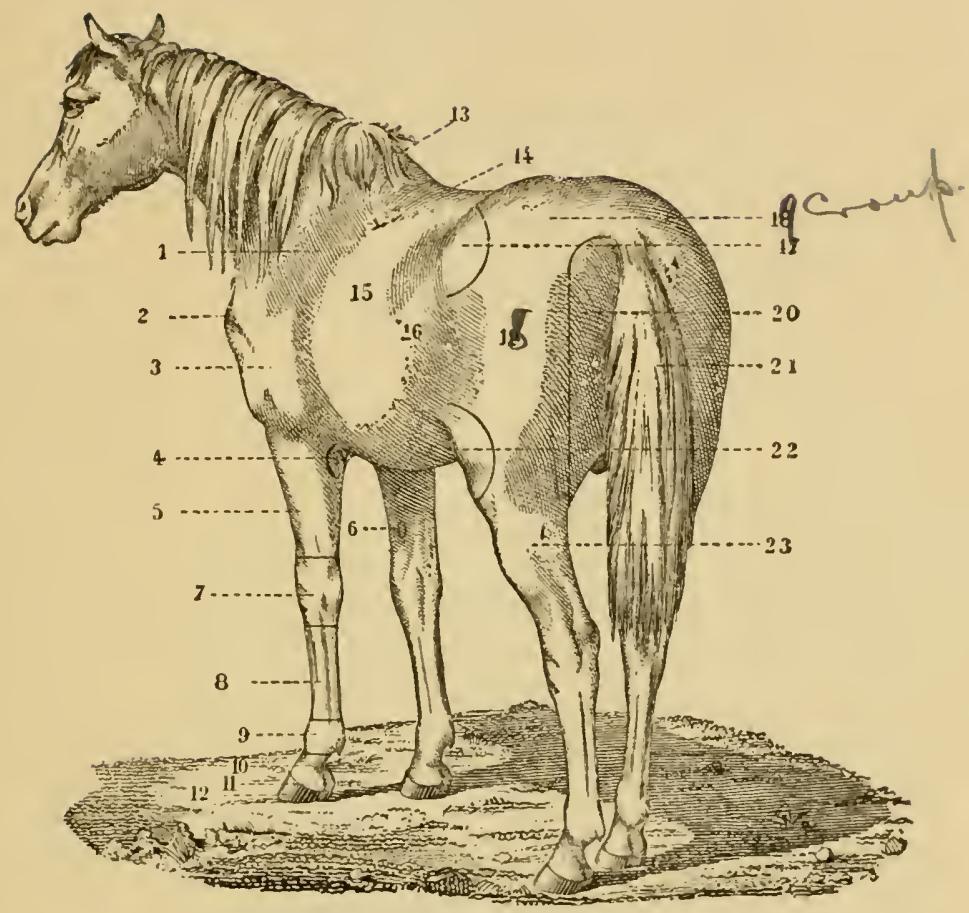

FrG. 15.-Regious of the horse seen laterally and behind.

1. Shoukler.

2. loint of the shoulder.

3. Arm.

4. Elbow.

5. Forenrm.

6. Chestnut.

7. Kinee.

8. Canon.

9. Fetlock.

10. 1'astern.

11. Coronet.

12. Foot.
13. Withers.

14. 13ack.

15. Ribs.

16. Flank.

17. llaumeh.

18. Thigh.

19. Croup.

30. Buttuek.

21. Tail.

22. Stifle.

2i. Leg. 


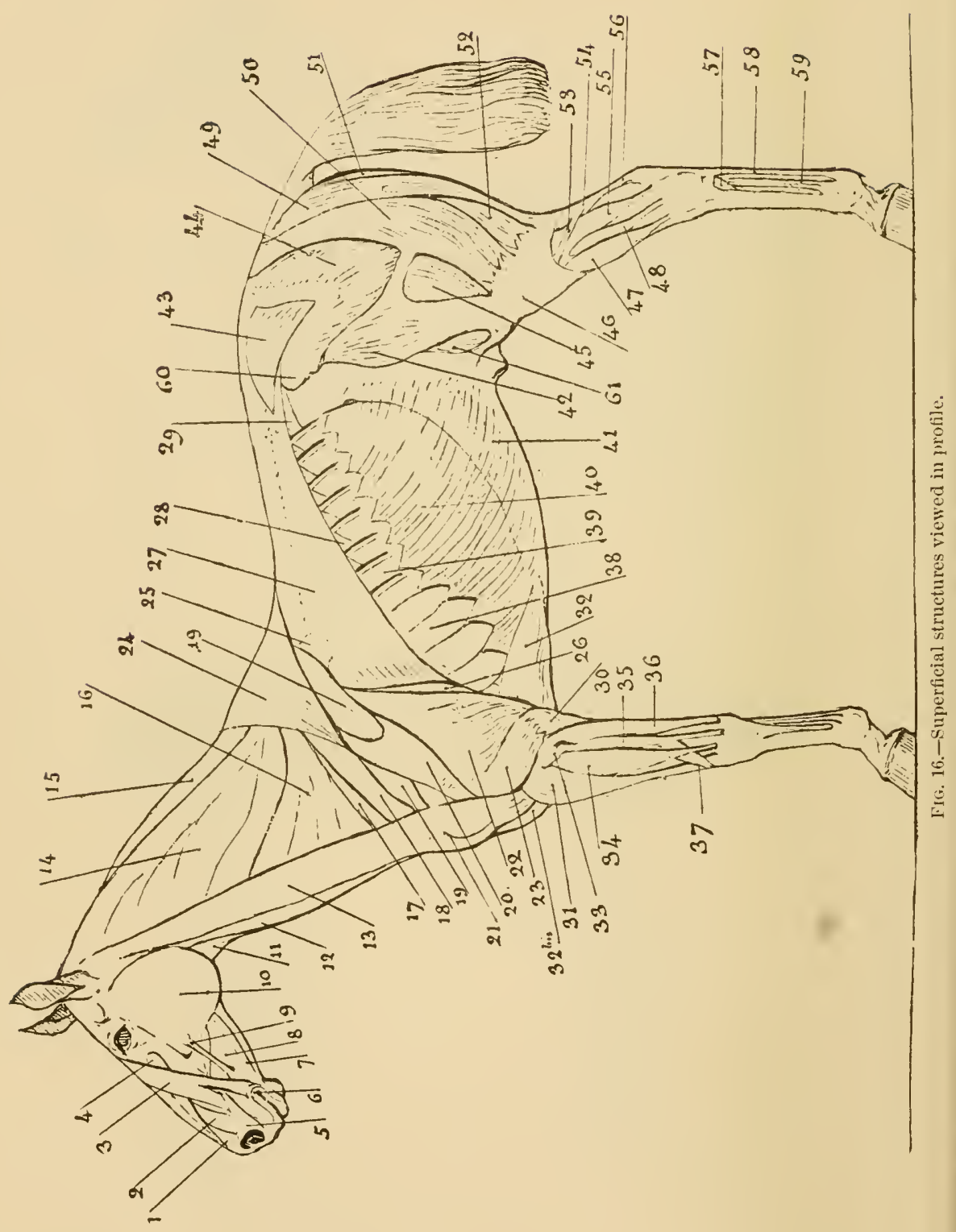



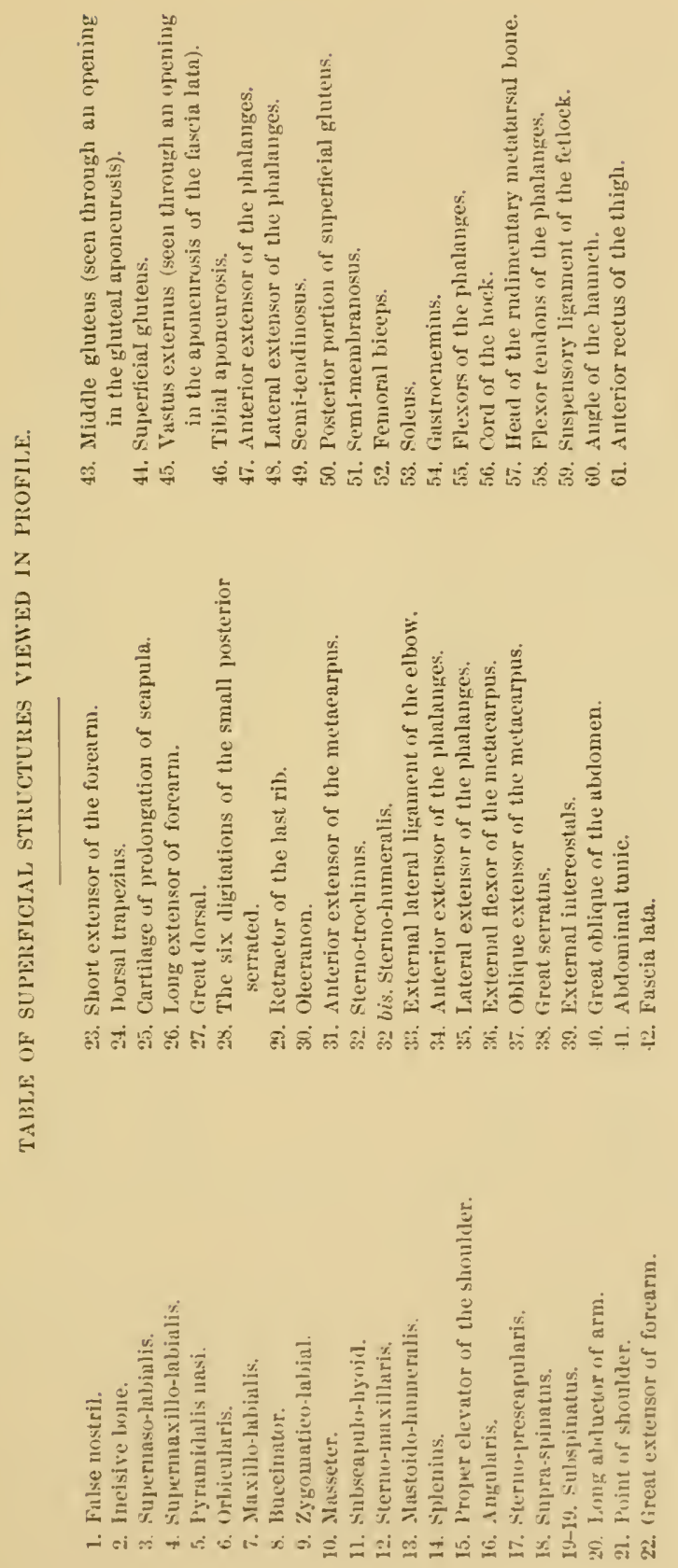


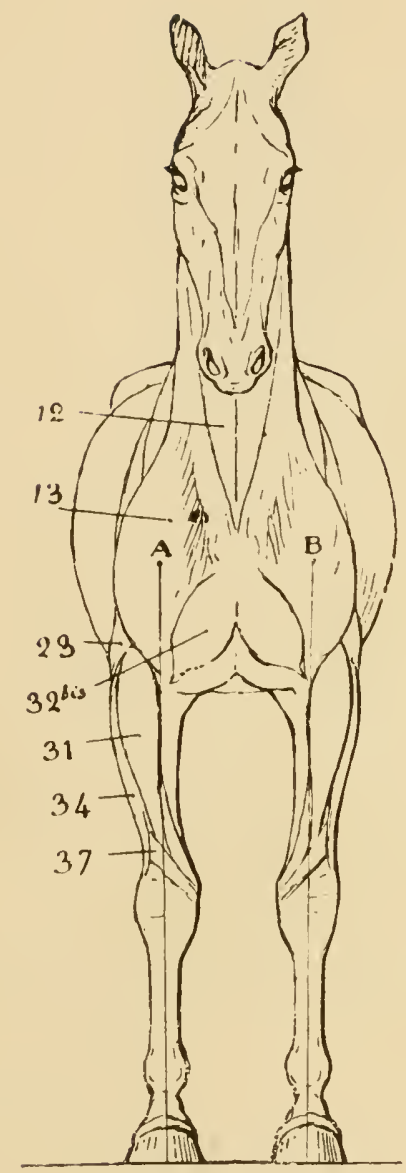

FIG. 17.-Superficial structures viewed in front.

12. Steruo-maxillaris.

13. Mastoido-humeralis.

23. Short extensor of the forearm.

31. Anterior extensor of the metacarpus. 32 bis. Sterno-humeralis.

34. Anterior extensor of the phalanges.

37. Oblique extensor of the metacarpus.

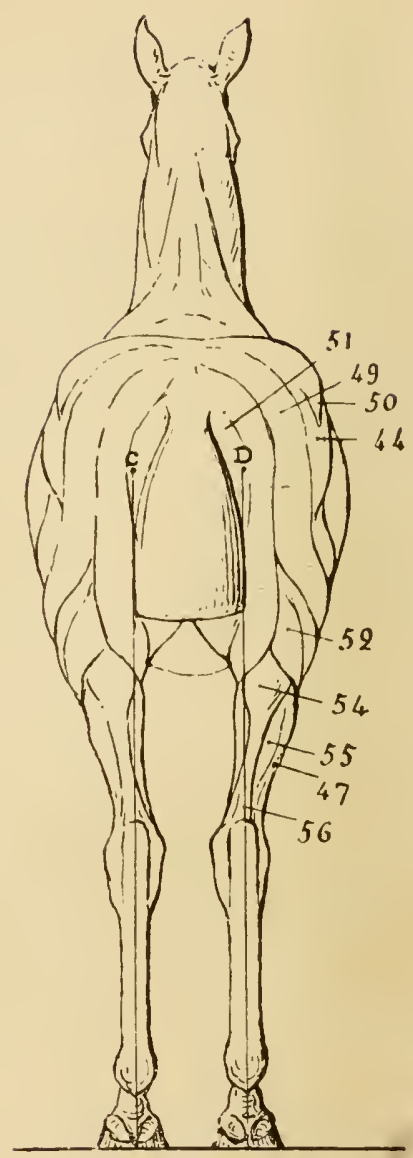

FIG. 18.-Superficial structures viewed from behind.

44. Anterior portion of superficial gluteus.

47. Lateral exteusor of the phalanges.

49. Posterior portion of superfieial gluteus.

50. Middle gluteus.

51. Semi-tendinosus.

52. Femoral biceps.

54. Gastrocnemius.

55 . Deep flexor of the phalanges.

56 . Cord of the hock. 


\section{\& 2. SomE Defixitoxs.}

In the language of the exterior, certain expressions are often employed whose signifieation should be exactly known. They are the following : Beauty, Defect, Blemish, Vice, Fault.

\section{A.-Beauties.}

Beauty, says Bonrgelat, resides in the fitness and the relation of the parts. 'This definition is incomplete, for it refers only to the proportions of the whole and excludes those of the parts taken separately. Indeed, it may be that the general hamony in a horse is defective, although some of the parts are absolutely beantiful; the whole may be composed of elements badly arranged, notwithstanding that eertain of them are not incompatible in subjects of the best conformation.

A more precise sense sfundel therefore be attached to the word Geantifinl, and we should assont that it indicates the perfect adaptation of the organ to its fimctivn, of the subject to the service for which he is destined. It is not that which pleases the eye, as is often understood by persons ignorant of these kinds of study, but that which is yualified as fit by the connoissem, the competent man. Beanty is therefore synonymous with fitness.//It is seen, then, that a becutiful region is a yood region, a beautiful horse is a goorl horse, the beauty of the whole results, as Bourgelat says, from the beanty and reciprocal fitness of all the parts. One of these may be beantiful withont the whole posicssing that quality.

This aceeptation of the word beantiful is applied generally as well as particularly, and it is the only one which shomld be aceepted when the woret is employed.

There is still another distinction to be astablished amomer the beanties: some are rebsolute, others are relutive.

Absolute benties are always somght for whatever may be the service, - the suldlle, or light or heavy traction. A spacions chest, large articulations, donse and voluminous muscles, regular expulihrim, and powerful attachmonts are absolute beanties to be exacted imbliserininately from all horses, for these charaters inclioute the strength and

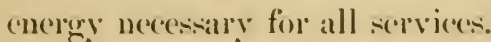

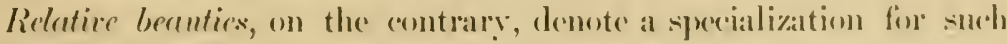

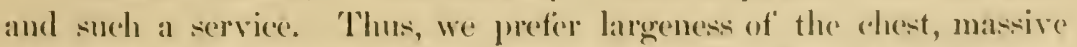
shmlders, voluminous museles, short, vienous members, a body close to the ground, wide loins, ete., in the slow and heary motors which 
must overcome resistance by the mass and the power of their effort; whilst we seek a more elevated and narrower body, a longer neck, a light head, long bones,-in a word, a smaller mass and more subtle and extended movements,-for the rapid motor. These are beanties relative to these two kinds of utilization, which would become prejudieial if insteal of being applied to one they were applied to the other.

\section{B.-Defects.}

The word defect is, in its etymology, the opposite of beanty. It eharacterizes the want of adaptation of the thing to the end for which it is destined.

Defects are absolute, relative, congenital, or acquired.

Absolute defects are eauses for the rejection of the horse, for they are injurious to every kind of utilization. Thus, a flat rostal region lessens the capacity of the chest, flat feet render the application of the shoe diffienlt and expose the foot to contusions of the heels and the sole; a retracted abdomen indicates a capricious appetite; slender members are soon ruined; small articulations diminish the extent of the movements; unstable equilibrium predisposes to falls, to excessive use of the members, ete. These are so many absolute defeets.

On the contrary, defects are relative when they only injure the employment of a horse for a determined service. A concave back is defeetive for the pack-saddle; a croup too oblique and a very large chest will not be suitable for the rapid gaits, whilst they are not prejudicial in the dranght-horse; the same is true of the low withers and the high withers, the horizontal croup and the donble eroup, ete. It is apparent, then, from these examples, that what is a beanty for one service may become a defect for another.

Congenital defects are those which the loorse possesses at birtlith acquired defects, those which are the result of his utilization.

A knec-sprung horse-that in to say, one whose knce is naturally displaced forward-is affected with a congenital defect; whilst, if this defeet be the result of usage, he is said to be possessed of an acquired defect. Most defects are malformations which the animal possesses at birtl, and are therefore of a congenital nature; however, there are a large number which he acquires through work.

\section{C.-Blemishes.}

It is difficult to give a good definition of the word blemish, because the first eondition to fulfil in order to define a thing is that the thing itself be defined in the literal sense of the word. At this present 
time the number and nature of the blemishes are far from being determined. Nothing is more absolute, nothing more relative; all depends upon the idea which is formed of them.

The words blemish, vice, and funlt are very often employed synonymously when applied to the horse. They alpear, however, to have a particular signifieation. /f fhus, by the term blemish is designated a eanse of depreciation superficial and apparent. I'iee and foult seem rather to convey in themsclves something concealed.

Among the nymerous definitions which aregiven of a blemishynt of Littré seems to us to be the most complete: "A blemish is a defect of whatever origin, pathological or otherwise, which has its seat in the skin or the suljacent parts, and which diminishes more or less the value of the horse."

As the word defect has another sense in the exterior; as, besides, it is of little importance to explain the variety of the origin of blemishes, since this origin may or may not be pathological, we will modify:? this definition in the following manner: A blemish is every apparent tiace of depreciation having its seat in the skin or in the subjacent tissucs. This trace need not be persistent. A horse may indeed be blemished to-day and not be so eight days hence. A very slight fall upon the knees sometimes leaves an immediate trace which then blemishes the sylject, while oftentimes soon afterwards nothing is visible.

Howerer it may be, we add that most usually the name blenish is given to cicatrices, tumors resulting from accidents, operations which the animal has undergone, or different diseases which have left apprarent flesions. Let us give some examples. A horse one of whose articulattions has been cauterized is blemished. A horse which presents enlarenenents around the hock is blemished. The same thing follows when blisters are applied to the walls of the thomax, and the hairs are not replated at the place of their applieation. A horse which after having been blerl hats antracted an inflammation of the jugular vein, with a consentive obliteration of the latter, is a blemished horse.

Blemishes, as may be conceived, are of more or less gravity, and diminish, on that aceomt, the value of the animal which posisesices them. There are some to which no impertance is attached. We will return to them in the examination of the regrions.

\section{D.-Vices and Faults.}

These two expresions have not alwars the same neaning in the langmage of the cexterior. In certain asses the word riee is symengmons with disease or defert, ats is secen, for example, in the first anticle of the 
law of August 2, 1884, which treats of the sale and exchange of domestic animals. This law gives, in fact, the enumeration of all the vices, faults, or diseases reputed redhibitory,-that is to say, which cause a cancelling of the sale or exchange. In other cases, vice results from the bad character of animal or from his imperfect education. A horse which bites, strikes, rears, and pulls backward without being induced to do so, is a vicious horse.

Generally there exists a certain gradation between vices and faults. Te the word viee is usually given the sense of a serioys moral imperfection; to the word fault, that of a slight moral imperfection; finally, to the word defect, that of a physical deficiency more or less serions. We repeat, however, that these three expressions are often employed in the same sense in ordinary language, although they are, as we have just seen, quite clearly defined.

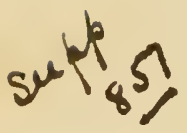

\section{PART I.}

THE HEAD.

Divisions.-Sitnated at the anterior extremity of the trunk, the head represents a resistance placed at the extremity of the arm of a lever formed by the neck, - a resistance whose relative sitnation, on account of the extensive movements which it executes, las a great influence in changing the position of the centre of gravity.

Studied as a whole, it presents for consideration four faces, a superior extremity, continuous with the neck, and an inferior, oceupied by the oral opening.

Each one of these primary divisions is subdivided into a number of regions enumerated in Fig. 19.

Faces.-1st. The anterior face presents successively, from ! above to below, the forchead, the face or nose, and the extremity of the nose.

$2 \mathrm{~d}$ and 3d. The lateral faces present the car, the temple, the supra-orbit, the eye, the musseteric region, the cheeks, and the nostrils.

4 th. The posterior face offers the branches of the inferior maxilla, the intermaxillary space, and the chin.

5th. Inferior Extremity.-This is entirely oceupied by the mouth, 
which comprises several secondary regions,-namely, the lips, the teeth, the gums, the bars, the lingual canal, the tongue, and the pralate.

6th. Superior Extremity.-It comprises the structures intermediary to the head and neck: above, the poll or nape; below, the throat or pharyngo-laryngeal region; on each side, the parotid region.

Such are the different regions of the head, which we will examine presently.

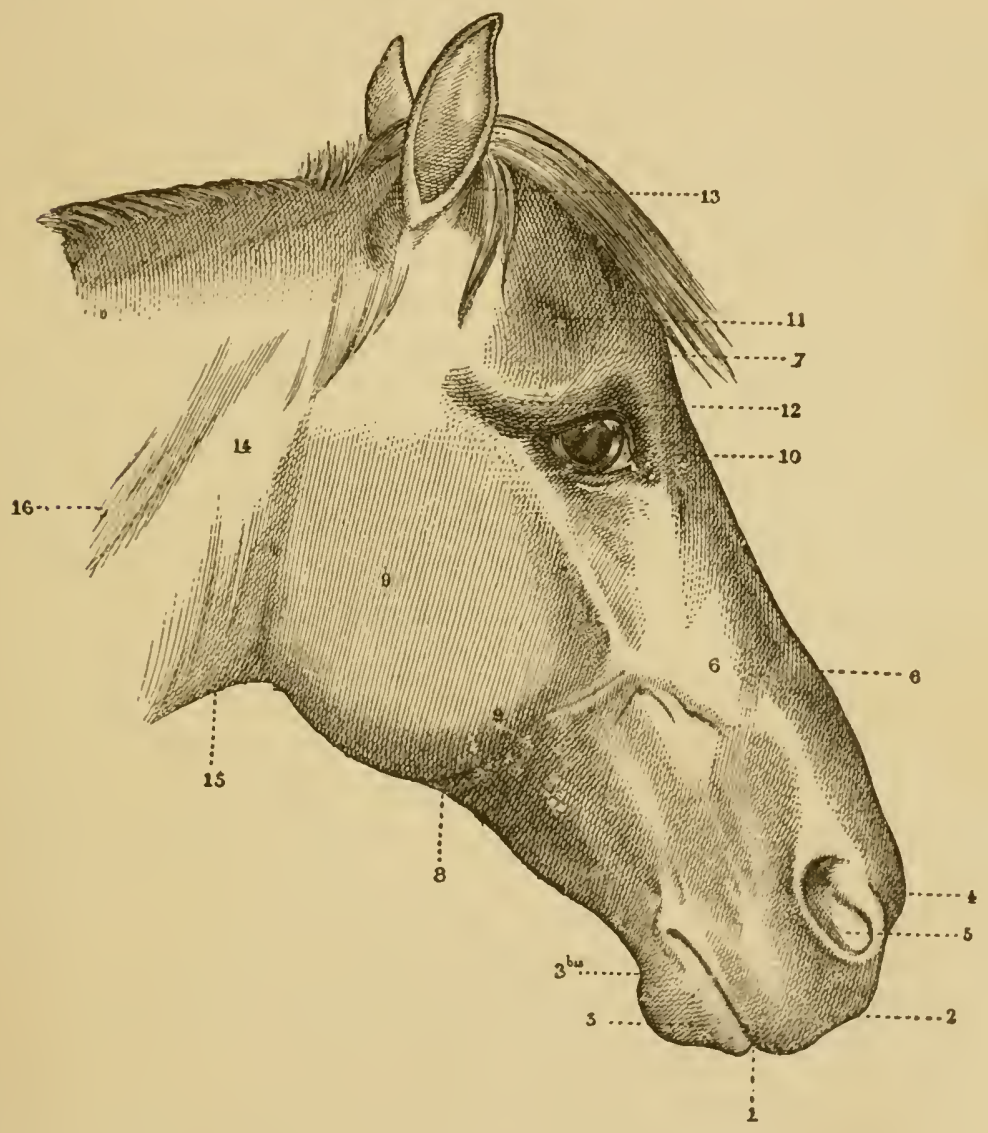

FIG. 19.

1. Mouth.

2. Superior lip.

3. Inferior lip.

3 bis, ('hin.

4. Extremity of the nose.

5. Nistril.
6-6. Face.

7. Forehend.

8. Inferior maxilla.

9. Clieeks.

10. lige.
11. Supranrbit.

12. Temples.

13. Ear.

14. l'arotial region.

13. Thront.

16. Neck. 


\section{CH A P TER I.}

ANTERIOR FACE OF THE HEAD.

\section{A.-The Forehead.}

Situation; Limits; Anatomical Base.-The forehead is that symmetrical region which occupies the superior part of the anterior face of the head. It is limited above by the external occipital pro- tuberance and the poll; below by the face ${ }^{1}$ on each side, passing from above to below, by the car, the temple, the supra-orbit, and the eye. It is partly concealed by a tuft of hairs, the forelock, floating over its surface.

It has for its osseons basis the anterior reflection of the occipital bone and the corresponding portions of the frontal and the parietal bones. On each side of the median line, where the frontal bone is directly covered by the integument, are the temporal fossæ, occupied by the temporal muscles, separated from the skin by the external and internal temporo-auricularis muscles. Whatever may be the general form of the forehead, there always exists over the temporal fosswe a convexity of variable volume which is due to these muscles; for the remainder of its extent the region is almost perfectly plane.

This region should be examined in relation to its width and its direction.

The width of the forehead is an absolute beauty. This is an incontestable fact upon which all are in accorl, but to which authors have very often given false interpretations. Most writers exert themselves to demonstrate that this width is in relation with the intelligence, and deduce from this the indication of its beanty. That this assertion may be established it is necessary to prove: 1st, that the width is in direct relation with the volume of the encephalon; $2 \mathrm{l}$, that the volume of the latter is proportional to the development of the intelligence.

Relative to the first proposition, we shonld not forget that the frontal diameter depends upon the volnme of the surrounding muscles as well as upon the amplitude of the frontal sinuses, filled with air and comprised in the thickness of the cranial parietes. We may even suppose that in most instances it is the resultant of both causes united, and, above all, of the latter, rather than of the actual capacity of the cranial eavity. What, then, becomes of the interpretation given above? Let the reader draw his own conclusion.

Concerning the second assertion, its explanation will be of but little 
more eonsequence. It is true that in the animal sale the development of the encephalon is in relation with that of the intelligence; but we are not justified to conclude with the positive assertion, that in isollated individuals of the same speeies this relation is still eonstant. Contradictory observations aganst the argment are numerous in man, in whom the ficets have been well studied. In the horse, such seem to be the facts by the eonemrence of the authors who have adhered to this theory. Vallon ${ }^{1}$ reports that at the great cavalry school at Saumur, where large numbers of vieious and unyelding horses from the army are sent, there are many which, eompared with others, are not deficient in the transverse measurement of the forehead. The intelligence, therefore, is not in enrstant relation with the width of this region. Some. sulyects, without doulst, are more endowed with this faculty than others; but it is a fiet which can only be proved by following the animals in their future career.

Among the Aralians the forehead is regarded as one of the four mincipal eharacteristics of the horse. This maxim is true, lut for reasons very different from these which they have involied.

Again, the forehead should be wide beeause its transwerse development indieates that of the temporal museles and of the frontal sinuses, dependencies of the respiratory apparatus. Theoretically, a strong muscularity of a certain region is always an absolute beauty, for not only does it inclieate a great aptitude for the excention of its particular function, but it is also a sign of muscular puisisanee of the locomotory system in general. For analogous reasons a spacious frontal sims is to be songht, as the climensions of one organ are proportional to those of the other organs in the same organic apparatus. From the principle that the function makes the organ it will follow that the more developed it be the more perfere will its function be.

It is for this reasom that spacious sinuses are an alsolute beaty, and not, as Merche ${ }^{2}$ thinks, becaluse their object is "the exaltation of" the semse of smell." The olfactory cells exist not in the mueous membrane of the sinuses, hut in the pitnitary membrane alonge the course of the first pair of enepplatie nervers.

In the young animal, at the forl and the colt, the forelieal is very prominent, from the faret that the sinuses have not alepuired the same (apareity that they will have, firm the absorption of bone, as the animal alvances in age. ${ }^{3}$

1 Vallon, ciurs d'hippolngie, t. i. p. 3n6.

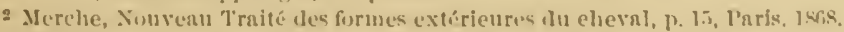

3 The vertical diumeter of the forshend is the alistuce between the externat ungle of the eye and the bnse of the corresponding ear; the transterse diameter is the distance from the base 
The direction of the forehead is closely related to the general form of the head, and varies with the race. It is straight when its surface is rectilinear in every sense ; concare when it is depressed in its inferior portion ; concex when the profile is arched from above to below. These diverse forms designate the head as square, flat, arched, or harefaced. We will return to this a propos of the general form of the head.

The form of the forehead is sometimes modified by the presence of small eminences known under the name of horns, from their analogy with similar appendages observed on animals of the bovine species. The horses which present this anomaly are rare. They are ealled horned in ordinary langnage. ${ }^{1}$

We will study, in the article on the robes, the peculiarities relative to the eolor and disposition of the hairs of the forehead.

Diseases and Blemishes.-The most common lesions of this region are cicatrices and excoriations resulting from falls, blows, and other tranmatisms. Among other affections more rare and more serions are tumefactions which result from diseases of the frontal sinuses. Sometimes cieatrices are situated on the middle or inferior part of its surface to either side of the median line, indicating that trepanning has been practised, with a view of giving exit to pus contained in the sinus. When these are observed, it is necessary to complete our examination by that of the nasal mucons membrane and the submaxillary lymphatic ganglia, because an insidious purulent collection of the sinuses may be a complication of glanders.

Merche, ${ }^{2}$ following Bourgelat and many others, mentions a fraud sometimes committed by horse-dealers attempting to mate horses intended for sale. It consists in producing a white coloration in the region of the forehead by canterizing the skin with a hot iron or with boiling water, ete. The hairs will soon become exfoliated and be replaced by those of a white color. This artifice can be easily detected by the fact that in the centre there is a dennded spot around which the hairs are less numerous than in the surrounding parts. (Bourgelat.) The proof of such a deception is much more detrimental to the reputation of those who employ it than to the value of the animals on which it is practised.

\section{B.-The Face or Nose (Fig. 19).}

Situation; Limits; Anatomical Base.-The face is a symmetrical region situated on the anterior surface of the head, limited above by the forehead, below by the extremity of the nose, and on each side by the eye, the cheek, and the nostril.

of one ear to that of the other. Their relative development gives three classes of foreheads: 1. Brachycephalic (square-headed), when the two measurements are nearly or quite equal: it includes the Aryan, African, Irish, and English (shire) horses; 2. Dolichocephalic (long-headed), when the vertical diameter is in excess, as in the Belgian, Frisian, German, and Percheron races; 3. Mesocephalic, which is intermediary between the two preceding. (Harger.)

1 A. Goubaux, Note sur les chevaux cornus, in Comptes rendus de la Société de biologie, 1852, p. 25.

2 Merche, Nouveau, Traité des formes extérieures du cheval, p. 16. 
The bones entering into its formation are the nasal anteriorly, and the lachrymal, superior maxillary, and incisive laterally. Three pairs of muscles oceupy the lateral moieties,- the supermaxillo-labialis, ${ }^{1}$ supernaso-labialis, and inferior palpebral or lachrymalis.

The study of this region is very interesting, becanse it circumseribes the nasal fossa, whose development is always in direet relation with that of the respiratory apparatus in general. A wide transverse diameter of the face is therefore its first condition of becuty as well as of utility.

The face is divided into three regions, a middle and two lateral.

1. Middle Region.-This must be studied as to its direction and its widtll.

a. The direction or form of the face or nose gives to the head particular names.

Thus, when it is straight or rectilinear from above to below, the head is called flat or square. When it is convex in the same sense, the head is designated as having a ram's nose or a Roman nose, if the convexity be limited to the face; when the convexity extends to the forehead as well as to the nose, the head is arched. Finally, when it is concave in the middle of its length, the head is likened to that of a rhinoceros, and is also called camel-nosed.

The various forms may be congenital or acquired. The latter are due to pressure on the nasal bones from the improper employment of the nose-band of the bridle or the halter. Fortunately, this does not interfere with the capacity of the nasal fossa, which are as capacious as in natural conditions. It will be otherwise, however, if this conformation be occasioned by fracture of the nasal bones, as we shall see further on.

Although the straight form or square head is the most agreeable to the eye, the other forms of the face do not imply anything derogatory to the development of the respiratory apparatus.

$b$. The width of the middle region can be easily determined by examining its anterior surface. The width is in all cases an index of the respiratory capacity, and should be in proportion to that of the forehead to preserve the harmonious relation of the integral parts. We cannot oppose too strongly the erroneous teaching of some authors who regard a convex face, under the pretence that it is narrow, as a predis-

1 This muscle, covering the maxillary sinuses below the eye, ean be easily ontlined. Its external borler is separated from the maxillary spine, with which it is almost parallel. by a space about twenty-five eentimetres in width. This space should be selected for trepanning, so as not to injure the muscle. (Harger.) 
posing eause of rocuing. This affection does not have its seat in the nasal fosse. Narrowness of the face is an absolute defeet.

2. Lateral Regions.-The lateral divisions present but little of importance. We will observe, nevertheless, that they do not present altogether the same conformation at different periods of the animal's life. Thus, they are more prominent in young horses, because the molar teeth are more deeply implanted into the alveoli of the superior maxilla; as age advanees and the teeth are eontinually worn, the latter are pushed from their sockets, and these regions appear more concave.

Diseases and Blemishes.-The blemishes of the face are:

1. Deformities consequent to fracture of the nasal bones from traumatisms receired by the parietes of this region. These fractures are rare, not only because the bones themselves possess a marked degrec of resistance, but also becanse the elasticity of the air contained in the nasal fosse to a great extent breaks the momentum of blows received upon their surface. Nevertheless there is danger of producing, either by the displacement of the bones or the consequent formation of a callus, a serious obstacle to the free passage of the air during ordinary respiration and particularly during exercise. Other deformities may exist upon the lateral parietes of the face. These are tumefactions which result from a chronic lesion of the mucous membrane of the maxillary sinuses, due to necrosis of a tooth or other alterations of a diverse nature, whose gravity varies with the cause.

2. Traces of Cauterization. - At the present time cauterization of the face is seldom practised. The Arabs employed it in the treatment of strangles and benign affections of the superior respiratory passages. With these exceptions, such blemishes indiate that the animal has been or is still suffering from a grave disease of the nasal cavities.

3. Cicatrices which are the result of traumatisms, excoriations, or thickenings of the skin cansed by the halter or bridle; finally, cicatrices of an angular or semicircular slape, arousing the suspicion that the maxillary sinuses have been trephined. These last are situated within the maxillary spine towards the internal angle of the eye.

When any of the blemishes enumerated are present, it is necessary to complete our examination by a minute inspection of the nasal sinuses, the molar teeth, and the submaxillary lymphatic ganglia.

\section{C.-Extremity of the Nose (Fig. 19.)}

Situation; Limits; Anatomical Base.-The cxtremity of the nose is sitnated at the inferior extremity of the fice, between the nostrils and above the superior lip.

Anatomieally it comprises for its base the anterior extremity of the septum nasi and the comma-shaped cartilages which encircle the internal alie of the mostrils. The external face of the latter is covered by the transversalis nasi muscle, which is separated on the median line from the fine integument of this region by the terminal teridon of the maxillo-labialis musele. 
All authors who have described this region have confounded it with the superior lip, whose organization is entirely different. They have, therefore, erred anatomically in saying that it has an extensive nervesupply, and physiologically none the less seriously in considering it as the principal organ of tonch in the horse. The superior lip fulfils the latter rôle. It follows from this that we will describe neither beanty nor defect of this region, excepting that it should be large as an index of the respiratory functions.

It is more important to assure ourselves that it is exempt from blemishes. When they exist, they are nearly always the result of falls which the animal has received. It is necessary, then, to examine with care the state of the incisor teeth, the lips, the gums, and the plumb-line of the extremities, to determine as nearly as possible whether the blemishes resulted from an accident or from a weakness of the fore limbs, the effect of usage. They are never prodnced by the application of the twitch, - a means of torture employed to clivert the attention of the animal, and which ean only be placed upon the superior lip, whaterer precaution in this respect be taken.

\section{CHA PTER II.}

LATERAL FACES OF THE HEAD.

\section{A.-The Ear (Fig. 19).}

Situation; Limits; Anatomical Base.-The ear is situated at the superior extremity of the lateral face of the liead, to one side of the forehead and the dependency of the mane known under the name of forelock, in front of the poll, above the parotid gland and behind the temple.

Anatomically, this region is easily visible, and has for its base the conchal and scutiform cartilares. These give attachment to ten pairs of muscles which endow the ear with movements either general or partial. The former carry it backward, outward, forward, inward, and rotate it on its adipose enshion. The latter (mastoilo-auricularis) are destined to move the concha so as to adjust the volume of air in the auditory chamber (hiatus) to sounds of different intensities.

Diverse beauties are recognized in this organ which are dependent upon its length, thickness, situation, direction, and movements.

1. Length.-As Bourgelat has remarked, some prefer a long ear, 
others a short one. He adds, with much prudence, that good judgment does not approve of an excess of length, and that this organ, being an integral part of the head, should be in proportion with it. It is a fact worthy of remark, that horses in which they are short are usually energetic and courageous. We must also add that small ears diminish the apparent size of the head, render the physiognomy more pleasant and expressive, and brighten the eye. In this respect the Aryan horse has greatly influeneed the English thoroughbred; the Boulonnais, the Flemish ; the Irish, the Percheron, ete.

2. Thickness.-The thickness of the ear denotes the quality of the race and of the subject. This is indicated by several other organs which in addition reveal clearly his origin. When the skin of the concha is thick, and garnished on the inside with numerous long hairs, when the subeutaneous connective tissue is abundant and obliterates the blood-vessels and nerves, we have evidences that the subject is common and lymphatic. A concha small, firm, and elastic, covered by a skin fine and adherent, with fine and scanty hairs in the interior, and blood-vessels well outlined, characterizes an animal of distinguished ancestry. This is so well known to horse-merehants that they never fail to tamper with the hairs of the ears of common horses in arranging their toilet prior to offering them for sale.

3. Situation.-The situation of the ear merits consideration. Its distance to one side of the median line, though dependent in part upon the development of the muscles of this region, allows us to appreciate, to a certain degree, the width of the cranial eavity. If this separation gives more expression to the head and presages greater intelligence, it is nevertheless necessary to guard ourselves against an error of which we have spoken, in according to this character more importance than it deserves. The same argument applies to ears situated too high; they have an unpleasant effect on the eye and are often an index of a timid and sulky disposition.

4. Direction and Movements.-It is considered a mark of beauty if a horse freely directs his ears to an angle of abont fortyfive degrees with the axis of the head. It is thus that they present themselves in active and energetic subjects: if, besides, they are short and well placed, they are designated as bold or cunning.

Ordinarily they are moved in varions directions to receive soundwaves, by means of which the animal obtains a direct knowledge of certain conditions of the exterior. Animals in which the ears are motionless are sluggish and indolent or, what is more serious, suffer from a variable degree of deafness. 
Let us refer to certain movements which have not been considered. These are forward and backward oscillations of the ears of some horses during work, and particularly during laborions efforts. At each step or at cach effort the animal carries the ears quickly forward, then backward to their primitive position, and repeats this action during the continuance of the work. We know of no appropriate expression to qualify these singular oscillations.

En résumé, the ear is beautiful when it is short, directed forward, well situated, clean, fine, covered by a thin and adherent skin, with few hairs in the interior of the eoncha.

Defects.-Ears long, thick, and transversely horizontal designate a horse as being lop-eared. This ungraceful earriage does not necessarily detract from the good qualities of the animal. There are many lop-eared horses none the less excellent for service. Nevertheless this defect is more common in lymphatic horses than in those of the finer races.

We speak also of horses whose ears are held in a horizontal direction and undergo, during locomotion, alternate elevations and depressions. It has been said of such, more picturesquely than properly, that they limp at the ear. This peculiarity may exist on the right, on the left, or on both sides simultaneously.

When the ear is thick, large, and decidedly pendulous, overhanging the parotid region, it is ealled suine-ear. This defect is no more grave than the preceding, but it is more unpleasant to the eye.

The ears are restless or uncertain when the animal kceps them in continual motion in the stable as well as during exercise. This is an evidence of a timid nature, impaired rision, or even total blindness. It seems that in the last two instances, as $\mathrm{H}$. Bonley ${ }^{1}$ has said, the animal endeavors to compensate for the loss of vision by turning the auditory apparatus in various directions; he endeavors to see by the sense of hearing.

In the language of horsemen, horses are skittish if they worry and fret at the least noise when they are driven into such or such a place in the stable or made to exeeute certain movements; it is often remarkable.

Finally, some horses carry the ears backward against the superior border of the neek. It is evidenee of a bad disposition and an inclination to strike or bite when approached.

Blemishes.-The blemishes of this region are numerous.

1st. It is quite common to obscrve dranght-horses whose ears are 
lacerated. They may become deformed, thickened, and acquire a faulty direction. Frectures of the conchal cartilage result ordinarily from blows inflicted by brutal drivers; they have no serions consequences.

2d. At the present time horses with the ears cropped in the middle of their length are almost unknown. We have met with only two instances. It appears, however, that this was the custom during the last century. Horses which had undergone this opcration were called crop-ected. If at the same time the tail had been amputated, they were designated by the term docked (J. B. Huzard). Vallon ${ }^{1}$ reports that this mutilation was formerly common in Algeria, and was employed by the Arabians in their military expeditions to establish proofs of ownership. Under other circumstances, amputation of the ears is sometimes effected by the application of the twitch, most often by brutal farriers, upon horses difficult to shoe or to dress. It will not be difficult to convince the reader of the danger which the employment of such procedures may occasion.

3d. It is not less rare to meet horses whose ears are split. This incision was made upon the left car of caralry horses under eight years of age, discharged from the French army. The purchasers did not delay to unite the two flaps. When the incision had existed for a long time, they freshed the edges with a cutting instrument and united them. Nothing more than a cicatrix persisted afterwards, which was often concealed by the hairs.

In Algeria, says Tallon, ${ }^{2}$ as in the states of the Mussulmans, it is the custom under certain circumstances to split the ears of colts. Wre (an therefore purchase, without fear, such horses as have been subjected to the operation. This is also practised on the Western prairies of the United States as a brand of ownership.

4th. We sometimes observe at the base of the ear dcnudations or circular cicatrices which result from the repeated application of the twitch to this region. It is to be feared, then, that the animal has been treated for a disease of long standing which required repeated dressing, or that he is difficult to shoe, harness, etc. Certain horses during the summer, as soon as they begin to perspirc, experience violent itching in the interior of the ear, which causes disordered movements of the head. Cleanliness, hycgionic precautions, and detarsive lotions are the remedics for the affection.

Let us now consider the fraudulent means employed to hide the defects and blemishes of this region. 
1st. The simplest and most harmless among them consists in clipping the hairs of the ears. In this part of the animal's toilet, the dealer carefully cuts the long and abundant hairs which exist in a normal state at the entrance of the concha and which act undoubtedly as organs of protection to the auditory apparatus. These hairs are less abundant in horses of the finer races, as stated above. It is also intended by this procedure to give lightness to the head, fineness to the ear, and distinction to the animal, characteristies which do not belong to common horses. This fraud-for it is a procedure whose object is to deceive the buyer as to the real qualities of the merchandise which is offered-is not easily detected except by those who are experienced with horses. This is so generally resorted to that certain dealers, very honest otherwise, are unwilling to expose horses for sale unless they have been thus prepared. When questioned as to this practice, they respond that, the parts being cleansed with difficulty, the removal of the hairs renders this more easy. We often find on the internal surface of the concha a thick layer of sebaceous matter-cermmen-which becomes irritating, provokes pruritus during the summer, and, at the same time, attracts insects. This material is most abundant in horses whose sanitary conditions are neglected. Particles of fodder and atmospheric dust will adhere to it, against the invasion of which the hairs thus shortened can offer no obstruction. In the army this enstom has been abolished.

2d. Another common means is the use of a hood, under the pretence of protection from inseets. It should always be removed, as it may hide the marks of the twitch, for example, if it be difficult to (shoe or harness the animal; or, again, a leaden ball suspended by a thread and placed in the interior of the ear to quiet nerrous subjects.

3d. When the ears are long and pendulous they can be made, by horsemen, to assume a good direction by means of a silk thread which is covered by the hairs of the forelock. Being thus adducted towards the median line, they may entirely hide this defect.

4th. Certain operations were formerly practised upon these organs, whose effect was to straighten them. They are not employed at the present time, but have been abandoned, not because of a moral view, but because they are recognized as being dangerous and inefficient. It is not rare to see horsemen attempt to shorten the ears by means of the car-cutter. This instrument is a sort of monld composed of two lateral halves, into which the concha is received. Whatever projects beyond the edges of the instrument is carefully removed with a bistoury.

We have not included deafness among the defects of the car because 
this infirmity is often difficult of appreciation, although it may oceasion great inconveniences in animals which are govemed by the voice of their master.

As M. Richard ${ }^{1}$ remarks, in deaf horses the ears are generally fixed, directed forward or laterally, vainly endeavoring to perceive sound. This attitude, by itself alone, does not permit us to recognize this defect at the time of sale. In most instances it passes unperceived, and is only observed after the animal has been worked for some time. Deaf horses are ordinarily docile, both in harness and in the stable, and respond quickly to all the indications of the bridle and bit. The Arabians, with almost self-love for their horses, urge them with the voice as well as with the hand, and reject those which are deaf as being fit only for the pack-saddle, and of little value as saddle-horses. Nevertheless, it is more prejudicial in draught-horses. Those that are mounted are more easily guided by the action of the bridle.

\section{B.-The Temple (Fig. 19).}

Situation; Limits; Anatomical Base.-This is a double region, more or less prominent, situated on the lateral faces of the head. It has for its anatomical base the exterior of the temporomaxillary articulation, and is limited below by the check, behind by the parotid region, and in front and above more or less directly by the ear, the eye, and the supra-orbit.

The principal qualifications which we scek here are its distinctness and its freedom from blemishes.

Diseases and Blemishes.-Demudations, excoriations, aud wounds of this region deserve to be taken into consideration. The first are the result of friction from disordered movements of the head, as in animals tossing themselves about when suffering from colic, vertigo, epilepsy, or grave diseases of the feet, when the animal assumes a prolonged decubitus, etc. The second, on the contrary, are the consequences of severer causes, as traumatisms of varions kinds, which may primarily or secondarily open the articulation, allow the escape of the synovial fluid, and produce a fistula. The last accident is serious, the horse being unable to masticate his aliment properly on account of the pain which the movements of the jaws produce. ${ }^{2}$ It is not astonishing that an affection of such a nature might be concealed by a hood which covers the ears to protect their interior from foreign bodies and insects. At any rate, the animal should always be uncovered during the examination, and such an alteration of the temple should never escape the attention of the observer.

1 Richard, Étude du cheval, 6e éd., p. 66.

2 A. Goubaux, Comptes-Rendus de la Société vétérinaire (séance du 27 avril, 1876). 
This is the region in which the first white hairs, common in old horses of a dark color, make their appearance. It is to be remembered, however, that we may find gray temples in younger horses as well as in colts and foals.

\section{C.-The Supra-orbit and Eyebrows (Fig. 19).}

Situation; Limits; Anatomical Base.-The supra-orbit is an asymmetrical depression situated above the eye, on the side of the forchead, and above the cheek and the temple.

This region, which corresponds to the most superficial part of the temporal fossa, is filled with a mass of adipose tissue more or less abundant. It indicates nothing as to the quality of the animal, but it permits us to make an approximate inference of his age. It is a well-known fact that in old horses the supra-orbits become hollow from the absorption of the fat which in the young animal completely occludes them. This fact is not so constant that very much importance can be attached to it.

Although the first condition does not lessen the real value of the animal, horse-merchants, in order to obliterate these cavities when empty, have endeavored to fill them by a very simple method which, in the majority of cases, occasions no inconvenience. It consists in making a deep puncture into the region with a large needle or the sharp blade of a knife until the connective tissue of the temporal fossa is reached. Having made the incision, the mouth is applied over the opening and the connective tissue is forcibly inflated with air. (A hollow needle would be more expeditions.) We have seen one instance in which an abscess complicated this operation.

To detect this deception, it is only necessary to make pressure with the fingers over the region, which will produce crepitation due to the passage of the air through the connective tissue.

Some authors have admitted a region of the eyebrows. Huzard the elder and Merche have absolutely denied their existence. Lecoq ${ }^{1}$ refutes with good reason the latter opinion by remarking that in the fotus the arches of the eyebrows are visible, in a very distinct manner, a little before the remainder of the body is covered with hairs. Later, they are confounded with the surrounding parts and lose, for this reason, all interest from a point of view of the exterior. We will not dwell any longer on this point. 


\section{D.-The Eye (Fig. 20 and Fig. 23).}

Situation; Limits.-The eye constitutes a double region situated upon the lateral planes of the liead, above the cheel and the face, below the supra-orbit, and on each side of the forehead.

Anatomical Base.-The essential part of the visual apparatus consists of a membranous sphere called the ocular globe, transparent in frout, whose interior is lined by a nervous membrane, the retina, sensitive only to luminous rays.

It is protected over its greater extent by a deep osseous eavity, the orbital cavity, to the bottom of which it is fixed; in front also by two mobile curtains, the cyelids, which complete the orbit in front and regulate the quantity of light which should be admitted into its interior. Ten pairs of muscles endow it with various movements ; finally, special organs of a glandular nature lubricate its anterior surface and protect it from the constantly desiceating influence of the atmosphere. Such, in a general way, is the organization of the ocular region.

1st. Essential Organs of Vision, or the Globe of the Eye.-This is a membranous envelope, completely closed, whose interior is filled with transparent substances of a variable density, known under the generic name of the media of the eye.

This sae, most bulging in front, is constituted here by a transparent, thick, and resisting expansion, the lucid cornct, covering one-fifth of its peripheric surface. Posteriorly it is composed of three layers, to which are assigned different functions. These are, proceeding from without to within :

$a$. The sclerotic (1), white, sometimes pigmented, fibrous, resisting, and thick, which is vulgarly often known under the name of the white of the eye, and which is visible from the exterior by its white coloration around the periphery of the cornea whenever the eyelids are separated from each other. Its external surface gives attachment to the motor muscles of the eye-globe. Its anterior elliptical opening is closed by the cornea by bevelled edges after the manner of the crystal fitting into the case of a watch.

$b$. The choroid (2), very thin, black, not visible from the exterior, which plays the rôle of an alsorbing surface for an excess of luminous rays, and converts the interior of the eye into a veritable dark chamber, into which the images of external objects are received to be appreciated by the retina.

This membrane, in front, where it is called the ciliary body, presents numerous radiating folds, the ciliary processes, which eircumscribe the edges of the crystalline lens (7). Through the ciliary ligament it gives attachment to the cireumference of the iris (t), an elliptical diaphragm pierced in its centre by an opening, the pupil (5).

The iris and the pupil are visible through the transparent cornea. The former divides the space anterior to the crystalline lens-anterior chamber-into two communicating compartments, an anterior (8) and a posterior $\left(8^{\prime}\right)$ practically obliterated. The coloration of its anterior face is of a yellowish-brown, but it may vary in different subjects; that of the posterior, on the contrary, is black, due to 
the presence of pigment called the "uvea," variable masses of which, called "corpora nigra," or "soot-balls," I are sometimes suspended from its edge into the pupillary opening.

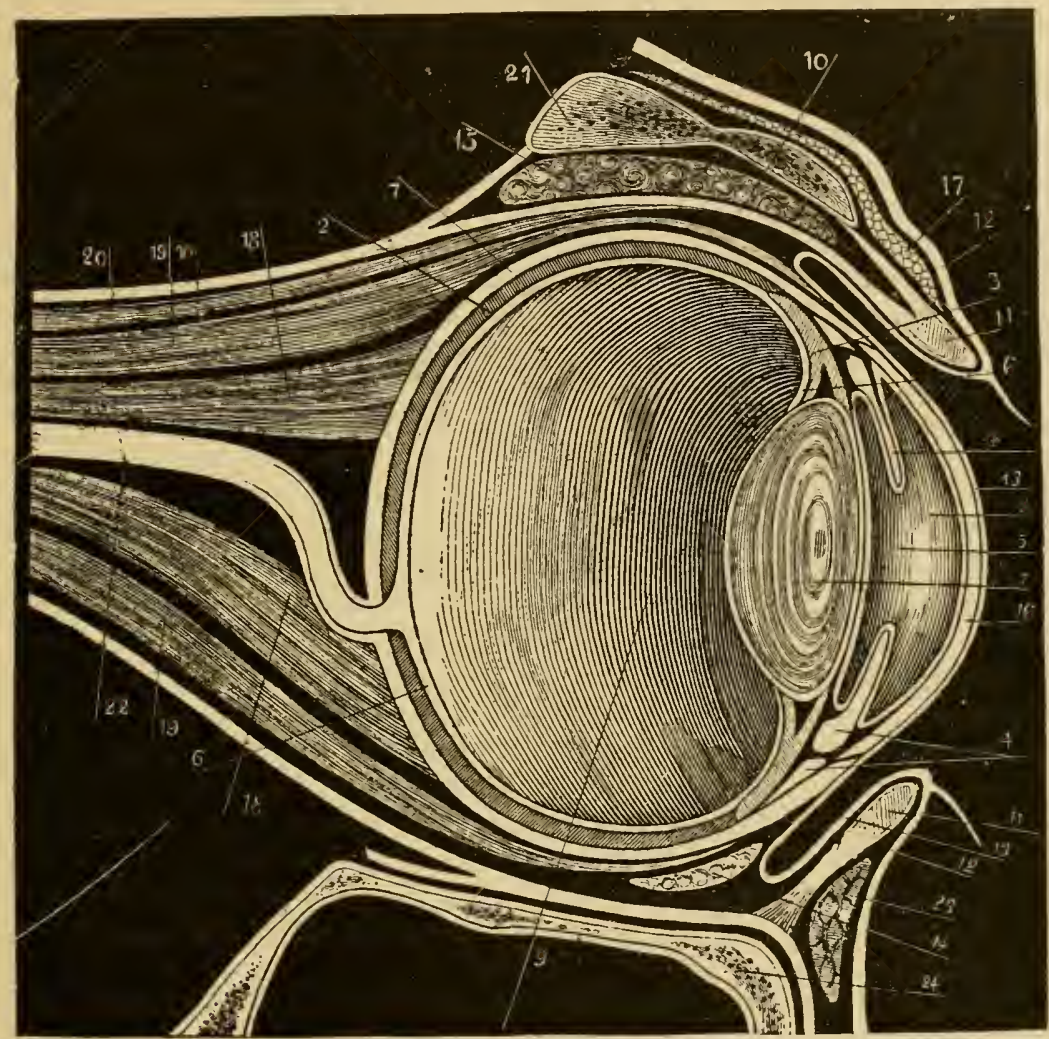

F1G. 20.-VERTICAL SECTION OF THE EYE OF THE HORSE (semi-schematic).

1, sclerotic; 2, choroid; 3, ciliary processes; 4, iris; 5 , anterior compartment, with the aqueous humor; 6 , retina ; 7 , crystalline lens; 8 , anterior chamber; $8^{\prime}$, posterior chamber : 9 , posterior compartment of the eye, with the vitreous humor; 10 , ocular sheath; 11 , tarsal cartilages; 12 , integument of the eyelids; 13 , conjunctiva; 14 , section of the small oblique muscle; 15 , lachrymal gland; 16 , cornea; 17 , transverse section of the superior half of the orbicularis muscle; 18. posterior straight muscle; 19 superior straiglut muscle; 20 , elevator of the superior eyelid; 21 , section of the orbital arch; 22 , optic nerve; 23 , transverse section of the inferior moiety of the orbicularis muscle; 24 , section of the floor of the orbit.

c. The retina (6), transparent, very thin and delicate, adherent to the choroid and its dependencies, which is an expansion of the optic nerve, and upon which the impressions of light are directly perceived.

Media of Refraction.- $a$. Crystalline Lens ( $\bar{\gamma})$.- This is a li-convex,

1 These are found in most eyes, and when not excessive, so as to obstruct the light, are not an unsoundness. (Harger.) 
transparent ${ }^{1}$ organ, more convex on its posterior face, and appears behind the pupil. It is closely applied against the posterior face of the iris, and divides the interior of the eye into two great compartments, an centerior (5) and a posterior (9).

b. Vitreous Humor (9).-It is a transparent, limpid, and gelatinous substance which occupies the whole of the posterior chamber.

c. Aqueous Humor (8).-The aqueous humor, slightly more dense than water, occupies the anterior chamber ( 8 and $8^{\prime}$ ) of the eye. It bathes both surfaces of the iris. It is under external as well as internal pressure, and readily escapes when the cornea is perforater.

The function of these three media of the eye is to concentrate the rays of light, by refraction, upon the surface of the retina, where they make an image. The lens, being more convex behind than in front; converges them for this reason and brings them to a focus on the anterior surface of the retina. Its relative position is thus necessitated by this function; if too distant from the retina, the image is formed anterior to the latter and is not perceived by that membrane; if too close, the rays converge posterior to the retina and the image really would tend to be formed outside of the ocular globe and again is not appreciated by this structure.

2d. Protective Organs of the Eye-Globe.-These include the orbital cavity, the eyelids, and the nictitans membrane.

a. The orbital cavity is a conical, deep cavity, surrounded by a fibro-osseous wall with an osseous opening in front. Its parietes are formed by the ocular sheath (10), conical and resisting, attached behind to the crest of the orbital hiatus, whose base is attached to the orbital opening and thence prolonged into the eyelids, whose base they constitute. Superiorly, the eye is only protected by the adipose cushion which forms the base of the supra-orbital region. Internally and inferiorly, the orbital cavity is osseous. The opening of the orbital cavity is circumscribed by the orbital process of the frontal bone (21) and a portion of the lachrymal and zygomatic bones (24). We also find on its floor and towards the internal side the lachrymal fossa and the superior orifice of the canal of the same name.

b. The eyelids, distinguished as superior and inferior, are two mobile musculo-membranous valves which protect the part of the eyeball exposed to the exterior. Their free border, more curved in the superior than in the inferior, presents the excretory orifices of the Meibomian glands as well as a series of tentacular hairs longer above than below, known under the name of eyelashes. The eyelids offer, besides, two commissures or angles,-a temporal or external, and a nasal or internal.

The external face is covered by an adherent (12) delicate skin provided with numerous short hairs. The internal face moulded on the eye-globe is covered by a delicate mucous membrane-the conjunctiva (13)-which is very sensitive to foreign bodies. The conjunctiva in the healthy animal is of a rosy color and becomes reflected over the choroid and the nictitans membrane, and is prolonged into the lachrymal canal. It becomes arrested at the edge of the cornea and its epithelial layer alone covers that structure. At the free border of the eyelids exists a cartilaginous lamina called the tarsus, on which the extremity of the ocular sheath terminates.

\footnotetext{
It sometimes has a bluish eolor, due to the reflection of the variegated colors at the posterior part of the choroid. (Harger.)
} 
The Meibomian glands, embedded in the deep face of the tarsus, secrete a sebaceous matter which prevents the escape of the tears in a normal state and obliges them to follow the natural passages in reaching the exterior.

The orbieularis palpebral musele approximates the two lids and the levator palpebra elevates the superior; the inferior is depressed by its own weight.

$c$. The membrana nictitans, or third eyelid (haw), is a nueleus of very mobile eartilage surrounded by adipose and connective tissue and the conjunetiva, situated at the internal canthus of the eye. It becomes continuous with the adipose tissue enveloping the oeular muscles. It has no inherent movements of its own, but mechanically protrudes when the eye is compressed, and liberates the latter from foreign bodies. It glides over the surface of the cornea when the eye is retraeted into its orbit, and can be easily rendered visible when the globe is compressed and drawn into the bottom of the ocular cavity.

3d. Apparatus of Lubrication of the Eye.-This apparatus comprises the lachrymal gland (15), situated between the orbital process of the frontal bone and the eyeball. It seeretes the tears. These are distributed over the surface of the cornea by the hygrophthalmic eanals, which open on the inner surface of the superior eyelid towards its temporal angle, and thence they gain the nasal commissure, where they open through the puncta lachrymalia into the lachrymal ducts. A small tubercle, the caruncula lachrymalis, a dependency of the eonjunctiva occupying the inner angle of the eye, directs them towards these two conduits, whence they pass successively through the lachrymal sac and the lachrymal canal to make their exit through the orifiee on the floor of the nostril, where they are liberated on the exterior.

4th. Apparatus of Locomotion.-The movements of the eye are protective and functional. The former have for their object the mechanical protrusion of the nictitans membrane upon the ocular surface by retracting the eye into the bottom of its orbit. It is accomplished by the posterior rectus muscle. The latter elevate, depress, deviate laterally, rotate the eye, and control the size of the pupillary opening of the iris to regulate the quantity of light which enters the eye. Elevation, depression, and lateral inclination of the eye-globe are executed by the contraction of the superior, inferior, external, and internal reeti muscles; rotation, by the superior and inferior obliques, muscles which are physiological antagonists. These museles are inserted posteriorily into the bottom orbital hiatus and anteriorily on the external surface of the sclerotie. Their anterior insertion can be exposed by making lateral traction on the eye-globe with a tenaculum.

Method of Procedure in the Examination of the Eye.Long ago, Bourgelat ${ }^{1}$ lad elearly indieated the preeautions to be taken in executing such an examination skilfully. It is, perhaps, needless to recommend that the head should be divested of all harness, more partieularly of blinkers, and that the surroundings should be such as not to obstruct the view or commmicate abnormal reflections to the eyc. The head is turned towards the entrance of the stable, and the eye is carefully inspected in semi-daylight to observe any pathological

1 C. Bourgelat, Traité de la conformation extérieure du cheval, 5e éd., p. 57. 
alterations. For this purpose the ophthalmoseope may sometimes be used with advantage. Then the animal is taken into broad daylight to sec how the eve aets under the influence of the solar rays. To determine simply the integrity of vision the following procedure is pur-

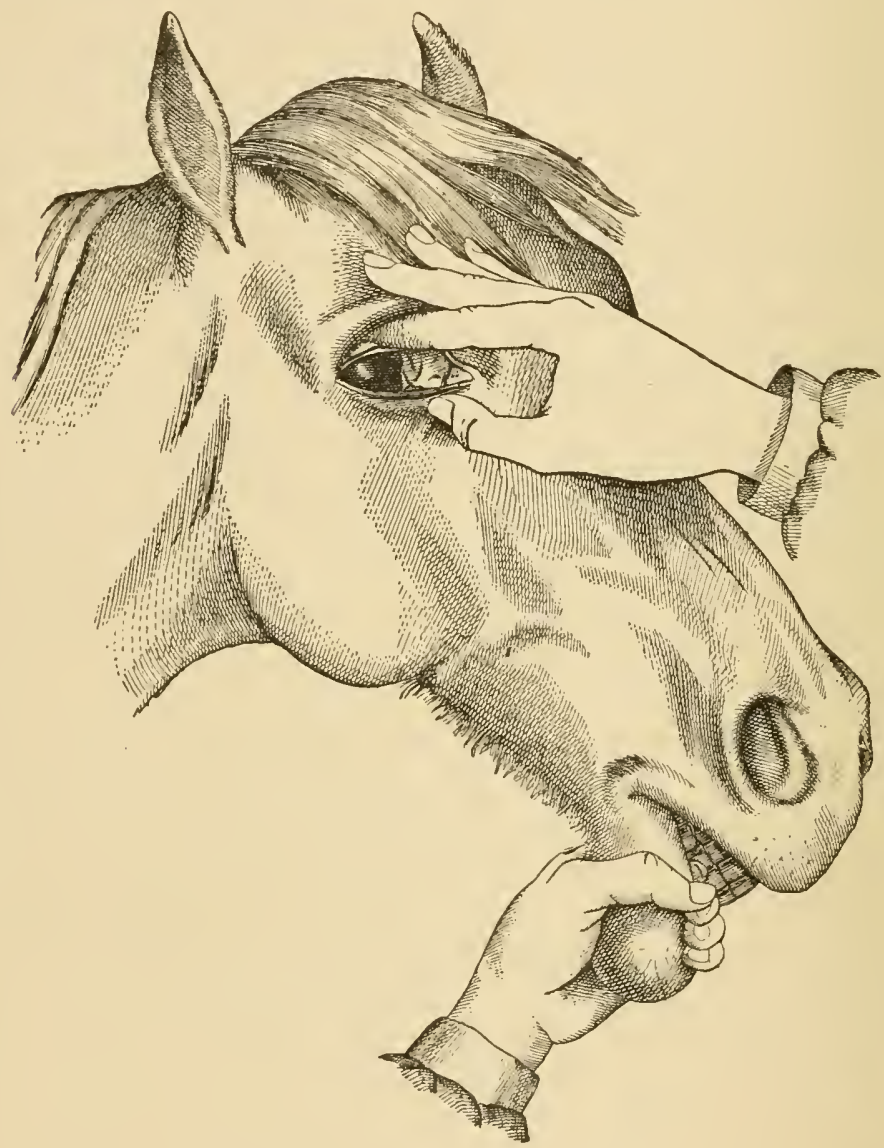

FIG. 21.-Examination of the eye.

sned: The observer places himself in front of the animal, strikes the side of the face lightly with the hand, and suddenly withdraws it in elevating it to a level with the corresponding eye. The latter, if vision is not impaired, will suctenly close from fear of being struck. If the sight is impaired or lost, the eyelids remain stationary. This manouvre is repeated with the opposite eye. The movements of the hand must not be too forcible, as excessive vibration of the air may even affect a blind eye, particnlarly in one-eyed horses. If it be desired to examine 
the conjunctiva, the nictitanous membrane, the lachrymal caruncle, the media, ete, with more eare, and the eyelids are not sufficiently separated, the following manipulation is employed (Fig. 21 and Fig. 22) : Having quieted the animal, one hand is placed upon the face to pre-

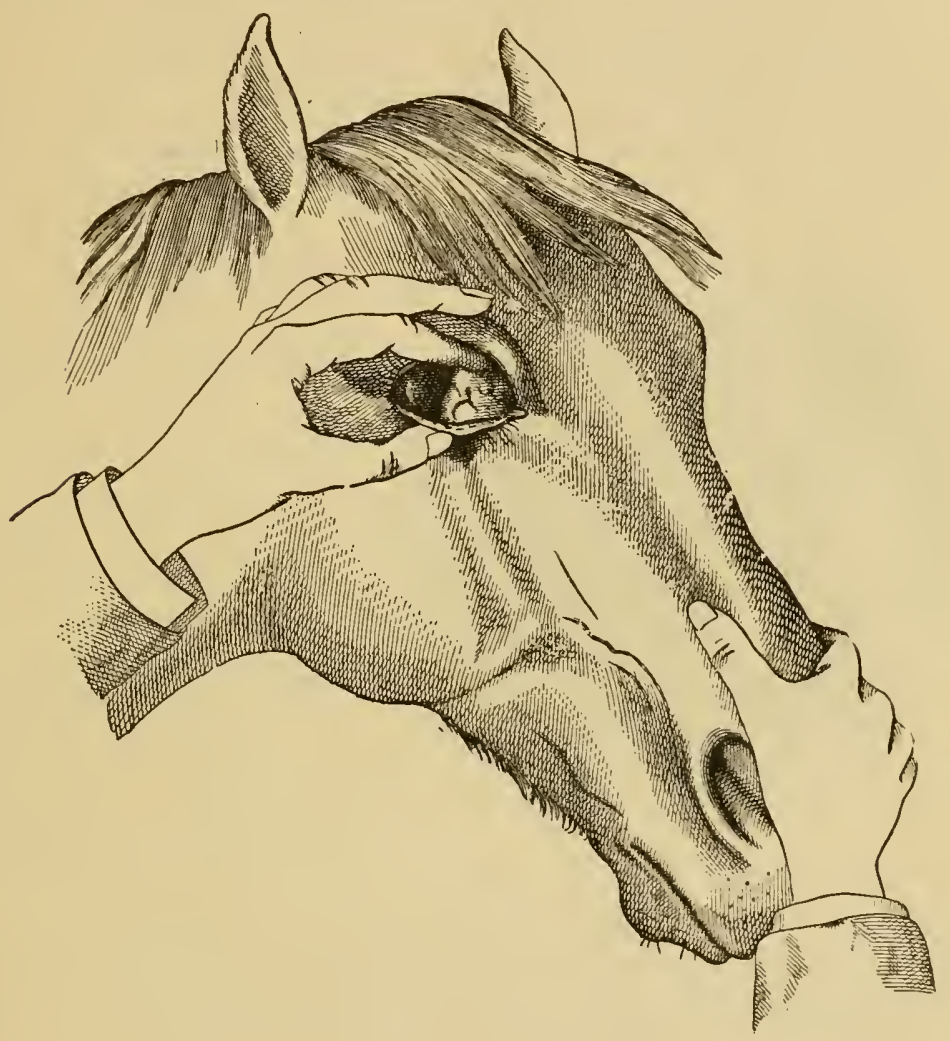

FIG. 22.-Examination of the ere.

vent his advaneing, or upon the inferior lip, if the head be held too low. Then, with the thumb and index finger of the free hand, the evelids are separated and the eye-globe is compressed into the orbital cavity. The nictitans will then protrude and expose a large area of the conjunctiva, and render pathological growths or foreign bodies visible.

Beauties of the Eye.-Whatever may be the physiologieal integrity of the eye, its absolute beauty resides in the following phenomena :

1. Its separation from the median line, which coincides with a wide forehead and a wide nose.

2. Its degree of prominence over the surrounding regions, which 
indicates a fulness of the oenlar eavity and the temporal fossa, the size and development of the muscular system in general, and the amplitude of the ficld of rision.

3. Its perfect equality with that of the opposite side.

4. Its decp coloration and the intensity of its reflection, a white or pale color being symptomatic of more or less serious diseases.

5. Its fieclom fiom blemishes of the comea and the tianspareney of the mediu. Alteration in these always manifests itself by an opacity and the appearance of

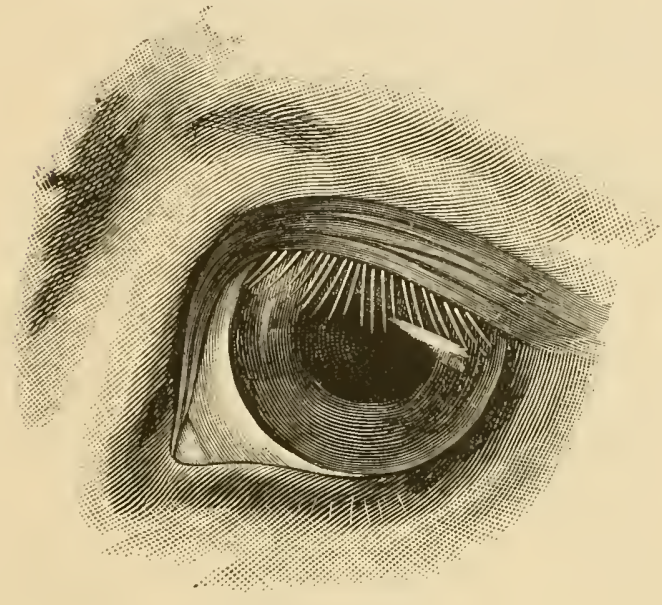

Fig. 23.-Normal eye. abnormal colorations, whenee results a variable degree of impermeability to light.

6. The extent and quickness of the morements of the iris, immobility indieating complete insensibility of the retina to the impressions of luminous vibrations. The pupil should contraet in the presence of light, and dilate in darkness, in order to proportion the retinal sensibility to the functional delieacy of this membrane.

7. A mean convexity of the comea, too much or too little characterizing a myopic, a hypermetropic, and not a normal eye.

8. The black coloration of the pupil, which denotes a perfeet transparency of the crystalline lens, and indieates the reflection of the black color of the choroid and the ciliary body situated behind.

9. The integrity, fineness, absenee of blemishes, and mobility of the eyelick, all other qualities of these organs indieating imperfections and functional impairment.

10. A rosy tint of the conjunctiva, its redness, paleness, and infiltration being symptomatic of a general or local inflammatory state, of a congestive state, or of profound organic debility.

11. The cleamess and little abundance of the tears, the dryness of the eyelids, the large development and good direction of the eyelasihes.

12. Finally, the viracity, changeableness, and frankness of the ex- 
pression, which denote the energy, the nobleness, and the distinction of the horse.

Such are the numerous beauties sought for in this region.

Defects.-The defects of the eye are not less important to consider. We mention :

1. The small eye, or pig's eye, in which the ocular globe is little developect, the palpebral opening narrow, and the eyelids thick. It accompanies, in general, a lymphatic temperament and a common ancestry. It is said to be an index of a predisposition to diseases of this region.

2. The concealed eye, ordinarily small and but little salient, but surmounted by a prominent and voluminous eyelid which partly conceals it, implies a sullen and treacherous disposition and a natural aggressiveness.

3. The bovine eye, or gross eye, characterized by an excessive convexity of the cornea, is very salient between the eyclids, little mobile, ungraceful, and without expression. It is often predisposed to myopia.

4. The hollow eye is seen only in old horses and in those deteriorated by age and hard labor. It is retracted into its orbit, covered by flabby eyelids, surmounted by a hollow supra-orbit, and often weeping.

5. The circled or bordered eye is one in whieh a portion of the selerotic around the edge of the cornea is visible throngh the palpebral opening. It is very unseemly.

6. The eyes are sometimes unequal in size, either from excess or deficiency of growth. When this disproportion is not congenital, it is a subject of apprehension, from always being a constant result of repeated attacks of periodic fluxion. The eye which has experienced repeated attacks of this disease is always the smaller. Its function is practically lost.

7. The myopic eye is very convex; it resembles much the bovine eve, save the volume, which is not exaggerated. It is observed most frequently in young animals, and renders them irresolute and liable to shy.

8. The hypermetropic eye is, on the contrary, not sufficiently eonvex. Such animals as possess it discern very poorly objects which are near, whilst those which are at a distance can be easily recognized. It predisposes them to stumbling and uncertainty of the limbs.

9. A wall-eye is one in which the iris is of a pearly-white color, being deprived of its pigment. Apart from the visual effect, it is none the less exeellent functionally. 
Diseases.-The diseases of the eye arc nmmerous and more or less grare. They are:

Numye is constituted by a slight opalescence of the cornea.

Albugo is a complete opracity of a variable area.

Lenema is a cicatrix of the cornea.

Gluncome is a greenish coloration of the vitreous humor. It is grave.

Cuturect is indicated by a partial or total opacity of the crystalline lens. It is a serious affection.

Amenrosis or gontte sereine is due to a paralysis of the retina. It may exist only on one or on both sides.

Hydropsy is an angmentation of the volume of the globe of the eye due to a hypersecretion of the aqueous humor.

Simple ophthalmia is an inflammation of the conjunctiva.

Periodic fuxion is a periodic inflammation of the whole eye, which terminates in the total abolition of sight by the formation of a cataract after a variable period.

Lippitude is an inflammation of the Meibomian glands and the free border of the eyelids. The eye often becomes covered with the secretion of these glands. It is called blear-eye.

Triehiasis consists of an inversion of the superior eyelashes against the octlar globe.

Eneanthis is a hypertrophy of the caruncula lachrymalis.

Melanotic deposits may form on the preceding structure; warts may grow on the eyelids.

Onglet is nothing else than an inflammation of the nictitans membrane. ${ }^{2}$

Blemishes.-The blemishes of the region of the eyes are denudations, cebresions, and rounds of the superciliary arches. They are the consequences of injuries received by striking the head against resisting objects, etc., or of diseases, as epilepsy, when the animal falls to the gromel or when he strikes his head against a wall during an attack of vertigo. Sometimes they are complicated by firctures of the orbital arches.

Under other circmmstances, the cyelids become the seat of abrasions, lacerations, or deformities of their free border,-e.g., ectropion and entropion. The deformity which follows periodic fluxion should be taken into scrions consideration. It has been olserved that the superior eyelid of the eye, after sereral attacks of this disease, becomes angular, from ocular atrophy, towards the nasal angle, which gives to the palpebral opening a triangular form instead of that of a regular oral.

Finally, all abuomal color's of the comea or the media of the eye constitute blemishes to which we must give the most serious prognosis.

I have often, in praetice, met with eyes affected with strabismus, -external, internal, and oblique. This was casily remedied by the simple section of the antagonistic muscle. (Harger.) 
Among these blemishes, many are the symptoms of grave diseases of the oeular structure.

These diseases have too often for their consequence the destruction of one or even of both eves. The animal is then suffering from partial or total blindness. Generally attempts are made to conceal this infirmity, and sometimes we meet with horses offered for sale, provided with an artificial eye made of hard rubber, which very much resembles that which nature provides. It is needless to say, however, that, with a proper examination of the eye, as before explained, this fraud will deceive only those who are unobserving or inexperienced. But it is not the same with those which are blind in both eyes or suffer from amaurosis, in which the eye presents all its normal characteristies. These conditions can also be detected by a scrupulons inspection of the parts. The retina not being sensitive, the iris will remain stationary even when exposed to intense light, and when at liberty the animal will run against surrounding objects. Such horses are uncertain on their feet and not withont danger as saddle-horses. Too much reliance eannot be placed on the word of the horse-dealer, and a thorough veterinary examination becomes a necessity to assure one's self of the integrity of the crystalline lens and the movements of the iris.

A blind horse will supply, with the other senses, the defieieney created by the cessation of vision. The ears are extended forward, and, at the least noise, are direeted forward and outward to perceire it. During progression, the elevation of the members is exaggerated, but their step is uncertain and the animal is predisposed to stumble. The carriage of the head is elevated to prevent falling, and the nostrils are mobile, as if to examine the surroundings by the odors which they exhale. He carefully smells and feels with the orbieular tentacles all objects presented to him. The eyes are wide open, the mouth is sensitive to the slightest indication of the reins, and the ears are quick to recognize the voices of those who lead him or approach him. As Vallon ${ }^{1}$ has written, he is susceptible of rendering good serrice if we understand how to use him and have the proper respect for him which his condition deserves. At work, as in the stable, it is necessary to place him alongside of one that is gentle and docile, beramse he anmot defend himself against the attacks of his neighbor. Workerl in file, he shonld not be placed in the lead. We may add that when he is worked in harness he should alwars have the same driver, or the same rider when used under the saddle. In all arses his master 
should not forget that he must at the same time see for the horse as well at for himself.

\section{E.-The Cheek (Fig. 19).}

Situation; Limits; Divisions; Anatomical Base.-The cheek is an almost plane surface, occupying the major portion of the lateral face of the head. It is limited in front by the temple, the eye, and the face; behind by the branches of the inferior maxillary bone; below by the commissures of the lips; and, finally, altogether above by the parotirl region.

The cheek has an area more considerable extemally than internally, where it forms the lateral parietes of the mouth. The latter surface is generally, thongh incorrectly, not examined, and we will describe it in connection with the mouth in general.

Its external surface is divisible into two regions: the one superior, the flat of the check, or the masseteric region; the other inferior, or the buccal region. Their separation is indicated by a vertical gutter in front of the masseter muscle, in which are situated the glosso-facial artery and vein and the duct of Stenon. In its lower half these three structures lie side by side, the artery being anterior and the duct directly against the border of the muscle; at its middle the duct passes obliquely forward over the side of the cheek, to penetrate it opposite to the anterior border of the third superior molar tooth.

Its base is formed by the masseter, buccinator, alveolo-labialis, zygomaticolabialis, and maxillo-labialis muscles, separated from the skin by the cuticularis colli. Their surface is covered by the sub-zygomatic plexus of nerves; the superior and inferior molar glands lie opposite to the corresponding teeth.

The five principal blood-vessels can be located from the exterior: the glosso-facial artery along the anterior border of the masseter muscle; the superior coronary on the side of the superior maxillary bone, about an inch and a half from its alveolar ridge, with which it is parallel; the inferior coronary between the branch of the lower jaw and the maxillo-labialis muscle; the transverse artery of the face parallel with the zygomatic crest; and the external branch of the maxillo-muscularis parallel with the curvature of the angle of the lower jaw.

Beauty.-The principal beauty to be songht for in this region consists of its distinct delineation, characterized by the fineness of the skin and the hairs, and the absence of connective tissue rendering the blood-ressels, the nerves, and the muscles distinctly visible through their thickness. Such we find it in horses which belong to the finer races. When it is excessive, it renders the head too sharp. In common horses, on the contrary, the cheek is round in the flat portion and flabby and thiek in the buceal portion.

Defects.-The most frequent defect of this region is called the granary, and is due to irregularities of the molar teeth. In this condition we remark on the exterior an elongated tumor, often lobu- 
lated, produced by the bulging of the cheek in consequence of the accumulation of aliment between the latter and the molar arcades. It is observed principally in old horses. Horse-merchants always take the precaution to cleanse the mouth of such horses with vinegar and water before they are presented for sale, in order to mask the fetid odor which it exhales. The employment of these manœurres, however, is insufficient for those who examine carefully the condition of the teeth, on the one part, and pouch in the cheek on the external surface, on the other. The latter, on account of its continual distention, is not closely applied upon the molars, but remains flabby, pendulons, and presents longitudinal ridges. We can understand that this defect of itself does not depreciate much the value of the horse, but that its gravity depends upon the eause whieh produces it and the means which remedy it.

Blemishes.-The blemishes of the cheek are traces of setons, indicating that the animal has been treated for an affection of the eyes or of the nasal cavities. A seton improperly applied to this region may produce paralysis of the corresponding lips by injuring the branches of the sub-zygomatic plexus of nerves; the former is then drawn to the side opposite to that of the paralysis.

A salirary fistula, following an accidental opening of the duct of Stenon, may be found on the maxillary fissure or the side of the face. A transparent, limpid liquid escapes from the opening, perhaps in jets, when the food is masticated on that side. It is a serious accident, on account of its long continuation, the inefficiency of its treatment, and the malnutrition which results from the loss of the saliva.

\section{F.-The Nostrils (Fig. 19).}

Situation; Limits; Form; Divisions.-The nostrils are the external orifices of the nasal fossæ, and the only passage through which the air can enter the lungs in solipeds, which respire only through the mouth in ordinary conditions. Designated as right and left, and situated at the inferior extremity of the head on each side of the median line, they are limited, internally, by the "tip" of the nose; below, by the superior lip; and, externally, by the cheek and the face. The form of the orifice is auricular or crescent-shaped, extending from above to below, and slightly from without to within. They present two lips, wings, or alce, and two commissures.

Anatomical Base.- $a$. The internal ala or lip, flattened and thin at its free border, which is convex, is turned down ward and outward, and is constituted centrally by the nasal cartilage, whose flat portion, with the one on the opposite side, forms the cartilaginous plate of the extremity of the nose. The latter, covered externally by the transversalis nasi muscle and the skin, and internally by soft skin and mucous membrane, is prolonged downward and outward through the inferior commissure, to terminate in the external ala. 
b. The external wing or ala of the nostril is concave. Its inferior extremity contains a hard and resisting body, which is the termination of the curved portion of the preceling cartilage. In the remainder of its extent it is soft and flexible, formed only by skin and muscles.

The muscles are all dilators. In some mammiferous aquatic animals, as the hippopotamus and the seal, there are constrictors to prevent the entrance of water into the respiratory apparatus. In terrestrial animals, on the contrary, the closure is prevented by the rigility of their fibro-cartilage.

$c$. The commissures are formed by the junction of the alæ. The inferior is round, concave, and continuous posteriorly with the floor of the nasal fossa ; the superior is smaller, acute, and is continuous, with a dependency of the skin called the false nostrit. The latter is a cul-de-sac formed by a reflection of skin on the inside of the nostril, whose bottom lies at the angle of the incisive and nasal bones. It exists only in the domesticated animals, as the loorse, ass, and mule, and admits of the introduction of the finger. ${ }^{1}$

Around the margins, as are all the natural openings, it is covered by soft, thin, and adherent skin, continuous with the nasal mucous membrane. It is covered by two kinds of hairs : the one short, fine, and numerous; the other coarse, long, and scanty. The latter, very deeply implanted and provided at their bulb with a norve-filament, are organs of tactile sensation to the animal analogons to the moustaches of carnivora. 'They are more or less abundant, according to the quality of the race. The habit of entting them with the scissors, singeing, or extracting them entirely, with the view of giving lightness to the head, is to be reprimanded.

Beauty.-The absolute beauty of the nostril resides in its width and in its separation from the lips, because it is proportional to the eapacity of the respiratory apparatus. In solipeds, bnecal respiration is prevented by the development of the soft palate. All the air which enters the lungs must pass through the nostrils, whose amplitude should therefore be in relation with the former. It follows, then, it priori, that the greater these orifices are the greater will be the volnme of air which enters the lungs during inspiration; that consequently the development of the lungs will always be correlative to the dimensions of the nostrils, and vice verse. There is no exception to this rule, and the reverse has never been observed in nature. Small nostrils are an absolute defect, and associate themsclves with a chest that is narrow and lout little spacions.

Movements.-The movements of the nostrils are almost imper-

1 On the floor of the nostril, anterior to the mucous membrane, is the orifice of the lachrymal canal. It is rounl, excavated, punchct-out, and resembles a glanderous chancre, for which it must not be mistaken. In the mule and in the ass it is situated on the superior commissure. It is usually single, but may be double or even triple. 
ceptible in normal conditions and at rest. They dilate slightly during inspiration and becone relaxed again during expiration. It is not thus during exercise ; their movements are accelerated in proportion to the efforts executed. Other circumstances, as the age, the temperature, and the seasons of the year, modify their frequency and often their rhythm. The causes of irregular dilatations of the nostrils or of excessive rapidity of their movements should be carefully determined. These are always srmptomatic of pulmonary emphysema or of some other grave affection of the respiratory organs. The examination in this case will, therefore, include that of the lungs, the trachea, the larynx, and, if need be, that of the other organic apparatus, if the acceleration be due to their diseased condition.

Examination of the Interior of the Nostrils.-The examination of the interior of the nostrils is made as follows: Let us suppose the animal to be held by the bridle or simply by a halter whose strap is passed through the mouth. Taking, for example, the nostril on the right side (Fig. 24), the inferior lip is seized with the left hand and the bulb of the right thumb is placed under the internal wing in order to remove it from the external, which is separated by means of the index finger. With this simple manœuvre it is usually sufficient to inspect the state of the mucons membrane over a large part of its area. If it dlo not suffice, an assistant will hold the head, and both hands are used ; the internal ala is seized by the right hand and the external by the left hand, the head being so held towards the light as to expose the largest surface of the uasal fossa. In some cases reflected light from a mirror may be utilized.

It is necessary to recall certain normal anatomical dispositions :

The skin which covers the alæ of the nose, preserving its characteristics, is reflected into the nostrils to form a cul-rle-sac known under the name of the false nostril, and becomes continuous with the pituitary mucous membrane. The hairs with which its free surface is provided are destined to arrest partieles of dust held in suspension in the air, which are obnoxions to the respiratory organs, ancl which, when inhaled into the more sensitive portions of the apparatus, ealse irritation.

At the inferior part of the nostril, on the floor and a little anterior to the point of continuity of the skin and the mucous membrane. is found the external orifice of the lachrymal duct, giving exit to the tears in their passage through exeretory apparatus and offering such characteristics that it cannot be mistaken for a pathological alteration. It is ordinarily single, but may be double and even triple. Its form is round, its edges perpendicular, eommonly ealled puncherout, and the liquid which exudes is limpid and transparent.

A eartilaginons septum, the septum nasi, separates the nasal fosse into right and left. It is covered by the mucous membrane and is related to a lamina 
of fibro-cartilage covered by mucous membrane, and extending from the superior turbinated bone to the deep face of the internal ala. In a physical examination this lamina must be unrolled, for it is often the seat of pathological alterations.

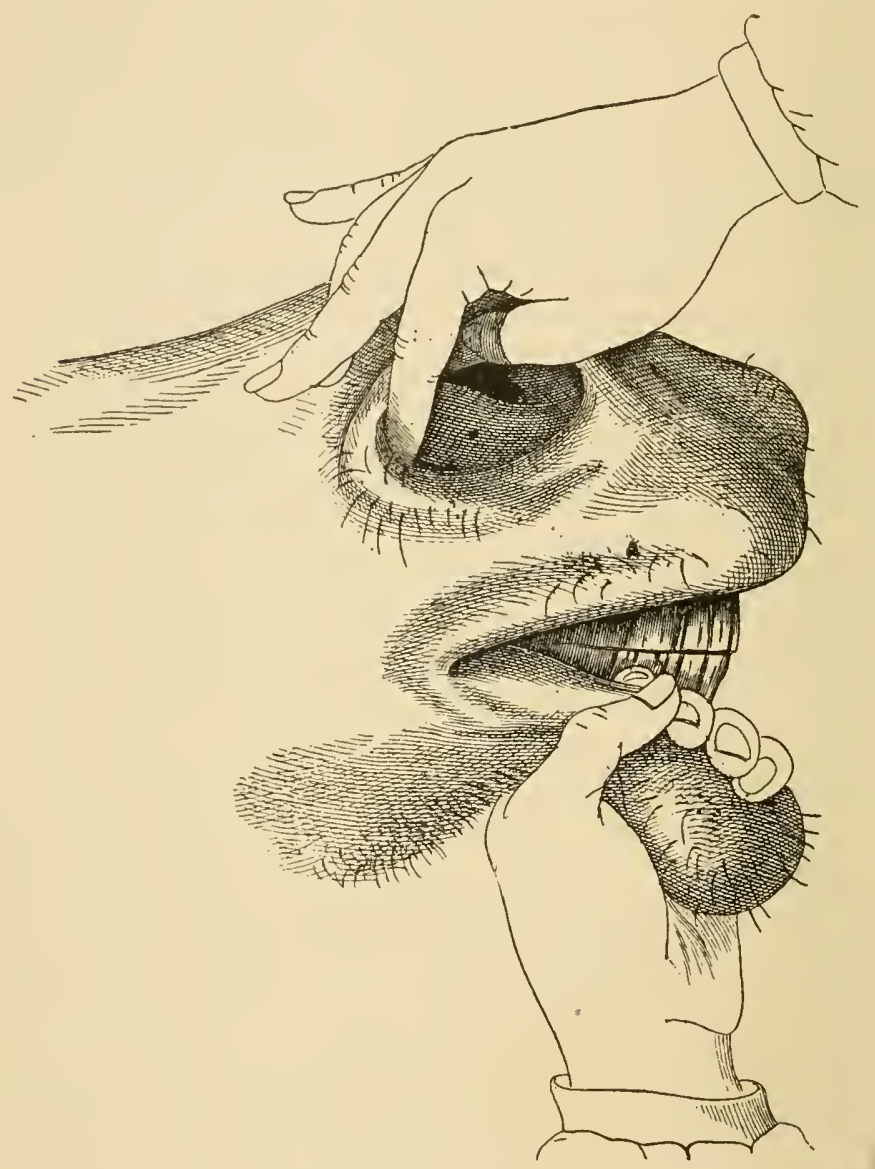

FI(i. 24.-Examination of the nostril.

State of the Mucous Membrane.-The nasal mueous membrane, in a state of health and of rest, is of a rosy color. After a certain amount of exereise, it becomes bright red, more or less intense, according to the plethora of the subject. It is paler and more follieular upon the branch of the aforesaid lamina of eartilage. Let ns only indicate here that in a pathologieal state it may be pale yellow, leaden as in glanders, infiltrated, and may present on its surface ulcerations, pustules, small red spots, petcehia, ehaneres, deeortications, cicatrices, tumors, ete. All these symptoms pertain to diverse diseases eoneern- 
ing which we eannot ocenpy ourselves in this book. Let us limit ourselves to saying that the most serions of all is farey-glanders, which should be particularly observed, and in the diagnosis of which the minute examination of the maxillary lymphatic glands must not be neglected.

It is not rare to meet wounds in the region of the nostrils, which are found mostly in stallions, and involve the mucous membrane and the cartilage.

At other times we find finger-nail marks which have been made on the pituitary membrane during the examination by inexperienced persons or those muable to control the animal.

Normal Liquid of the Nostril.-We have seen above that the normal liquid of the nasal fossæ is clear and transparent, from the fact that it results from the continnal discharge of the tears. In certain horses, when the atmosphere is cold, and much more in those whose lungs are emphyssematons, we find the presence of a flaky discharge which adheres to the hairs of the nostrils, and designates the latter, according to horsemen, as being firosted.

In pathological phenomena the liquid receives the name of discharge, and assumes certain characters which depend upon particular diseases. It may be :

1st. Adherent or not to the alre of the nose.

2d. Thiek, tenacions, or clotted.

3d. White, reddish, yellowish-green, sometimes streaked with blood.

4th. Inodorous, fetid, gangrenons, or from caries.

5th. Unilateral or bilateral.

In all cases the examination of the nostrils should be completed by that of the lymphatic ganglia.

Entrance and Exit of the Air.-The expired air merits also to be taken into consideration. It is of little utility to appreciate its quantity, either by placing the hand in front of the nostril, or, when the atmosphere is cold, by considering the two cones of rapor which escape. It is more interesting to assure onrselves of the regularity and equality of the colmm of air at its exit from the orifices, for it may meet obstructions of a diverse nature in its passage, as polyps, tumors, deviations of the nasal septum, ete. Some authors report that certain tradesmen, to mask the dischlarge, have placed a sponge into the diseased eavity. This fraud is very easily discovered, and requires no further explanation. In a state of good health the expired air is inodorous; the bad odor with which it is contaminated proves a disease of the lungs, earies of the superior molars, and, finally, prolonged 
stasis of pus in the guttural pouches or in the frontal and maxillary sinuses. If there is doubt as to the veritable cause of this odor, the animal is made to cough by compressing the larynx with the hand, and standing to one side of the animal to avoid being contaninated by the expectorated matter. He is also made to snort by touching the sides of the median septum of the nasal fosse, which will immediately provoke such an effort and render the discharge visible if there be any.

It is important to add that the air should pass in and ont without making any sound; if a somd is perceived, the animal is affected with roaring.

Roaring is acute and chronic. The former is temporary, the second permanent. It is a defect which nullifies the contract of his sale in some Continental countries. (Law of August 2, Article 2, 1884.)

Cysts of the false nostril, between the layers of the integument which are placed in apposition to form it, are observed in some horses. We have seen several examples, and never have we remarked the least interference with respiration.

We have proof of paralysis of one or of both nostrils. In the latter case the animal will find it an impossibility to trot, from the fact that the parietes of these openings are collapsed upon themselves and offer an obstacle to the introduction of the air. ${ }^{1}$

Expression of the Nostril.-Let us remark that the nostril is one of the principal organs of expression of the physiognomy. According to its state of contraction, dilatation, flaccidity, or crispness, it manifests in a thousand ways the sensations which the animal experiences. Now it is surprise, fear, anger; now joy, pleasure, anxiety, and suffering. Persons who are experienced with horses will soon become familiar with the expression of the organs, which defies all description from the multiple shades in which it is manifested. We will return to this again, a propos of the head in general.

Blemishes.-The blemishes of this region are situated upon the alie of the nostrils, the nasal fosse, the appendices of the turbinated bones, and result from bites or lacerations. These may be produced accidentally in dranght-horses by the hook which is often placed at the extremity of the shaft, when the animal is tied to a ring surmounted by a hook, or when, in turning the head, the nostrils strike against any sharp object.

1 A. Goubaux, Mrémoire sur les paralysies locales (Recueil de médecine vétérinaire, année 1848, p. 229). 
Formerly the nostrils were slit to diminish the sound of neighing. The practice is still exercised upon the ass in the Orient. ${ }^{1}$ We have several times repeated this operation upon the horse withont producing any modification of the somnd. The procedure is therefore inadequate.

To recapitulate :

1. The nostril should be large and clear.

2. The mucous membrane, rosy at rest, more or less red after exercise.

3. The liquid which it discharges, clear and transparent.

4. The air which is exhaled, inodorous.

5. Inspiration and expiration should be noiseless.

\section{CH A PTER III. \\ POSTERIOR FACE OF THE HEAD.}

\section{A.-The Intermaxillary Space.}

Situation ; Limits ; Anatomical Base.--The intermaxillary space is a symmetrical and triangular-shaped cavity, situated at the posterior face of the head, comprised between the two branches of the inferior maxilla. It is limited above by the throat, below by the chin, and on each side by the borders of the maxillary bone.

Its anatomical base is the body of the hyoid bone and the muscles which attach to it, the inferior face of the tongue, and the intermaxillary lymphatic glands; on each side, about an inch from the internal alveolar ridge, and underneath the glands, is the sublingual artery. The skin is fine, covered with hairs ordinarily longer than those in other parts of the body ; the connective tissne is abundant.

Beauties and Defects.-The principal structures which offer themselves for consideration in this region are the lymphatic glands. These should be small and movable without adhering to the surrounding tissue. It is observed that in all diseases of the nasal sinuses, the nasal fossa, and the mouth, these ganglia bccome voluminons, painful, more or less adherent, and approach the corresponding branch of the inferior maxillary bone. In glanders they are decidedly adherent to the latter and to the base of the tongue.

It is not only the inspection of these organs which requires our 
consideration, but we shall also examine the plainness, the width, and the depth of this region.

It is plain or clean when all the structures which enter into its composition are distinct and can be outlined with the fingers. When the connective tissne is abundant the contour of the parts is not discernible and the whole region is full or thick. Such is its structure in lymphatic horses raised in low and moist districts.

The depth is related to the cleanness and the absence of connective tissuc.

The width of the intermaxillary space denotes a corresponding separation of the branches of the maxilla and a large development of the respiratory apparatus, since the larynx is partly lodged in that space, and thus protected from the movements of flexion of the head upon the neck. It is erroneous to believe that in horses in which the head is arched, this region is narrow, and that these are therefore much more predisposed to roaring. Exclusive of the general form of the head, it is true that there are certain subjects in which the intermaxillary space is wider than in others. Professor Dupuy, ${ }^{1}$ in 1829 , has taken measurements of sixteen horses of different types, and proved a maximum width of $0.119 \mathrm{~m}$., and a minimum of $0.087 \mathrm{~m}$. In two horses which were roarers, the measurements were $0.079 \mathrm{~m}$. and $0.063 \mathrm{~m}$. ; hence it was belicved as conclusive that the narrowness in the latter was due to a defective development of the maxilla and an insufficient separation of its branches, causing compression of the larynx. We cannot dispute the figures of Dupuy, but they are very exceptional.

The skin of the intermaxillary space in common races is furnished with long, stiff, coarse, and abundant hairs, which make the head appear heavy and voluminous. Some are in the habit of singeing or extracting them, so as to render the head smaller, to disguise the race.

Diseases and Blemishes.-The general discase known under the name of strangles is often followed by considerable inflammatory swelling of this region and the formation of enormous abscesses of the lymphatic ganglia, of which we have spoken above. When the latter do not have their normal characteristics, it is said that there is a gland in the region, or that the animal is glanded. Great importance must be attached to this tumor, for it may be a symptom of a more serious disease, glanders.

\footnotetext{
1 Dupuy, De la fluxion vulgairement appelée périodique on Recherehes historiques, physiologiques et thérapentiques sur cette maladie, auxquelles on a ajouté des considérations sur le cornage, la pousse et la section des nerfs pneumo-gastriques, 8ro, Paris, 1829, p. 114.
} 
As consequenees of these alterations, we may find denudations, excoriations, and cicatrices resulting from the application of medicines or from operations, as incising an abscess with a view of causing the disappearance of the swelling. Formerly excision of the gland was practised in horses over five years of age, in which the gland was enlarged. Végèce had already considered this operation uscless, the gland being only a symptom and not the disease itself. Strange to say, it has again been revived in some modern publications.

\section{B.-The Inferior Maxillary Region (Fig. 19).}

Situation; Limits; Anatomical Base.-The inferior maxillary region is a double area, having for its base the rectilinear branches of the inferior maxillary bone. It is limited internally by the intermaxillary space, externally by the cheek, anteriorly by the chin, and posteriorly, more or less distinctly, by the parotid region. Its internal face presents the course of the glosso-facial artery and vein and the excretory duct of the parotid gland,-Stenon's duct. These three structures pass around the maxillary fissure, where they can be easily distinguished through the skin and where the pulse is counted. On the inner side the duct is superficial and the artery deep.

The two rami of this bone circumscribe a $\mathrm{V}$-shaped space with the apex forward, which corresponds to the intermaxillary space, and whose width, as stated above, constitutes an absolute becuty. They are not of the same thickness at all periods of life, and some persons attach enongh importance to this to judge of the age of the animal by their examination alone. In young animals the molar teeth are deeply implanted into their alveoli, and the maxillary bone, for this reason, is of much greater thickness. Conversely, as the teeth are pushed from their alveoli, whose sides will then approach each other, there is an absorption of bone, the maxilla becomes thinner and the posterior border acute. This phenomenon ean be utilized in determining the age, the border becoming sharp when the animal is about thirteen years old. This, however, is not absolute, and too much importance should not be attached to it. Descriptive anatomy has shown numerous individual differences.

Animals of a lymphatic temperament and with large skeletons have thick maxillary bones. This is very marked in Shetland ponics. In horses of a nervous or a nervo-sanguinary temperament they are thin and fine. It indicates nothing but a race characteristic, and does not influence the qualities of the animal.

In animals belonging to the common races this region, like the 
intermaxillary space, is covered with long and abundant hairs, which it is the custom to singe, cut, or extract. This practice is called to make the jue or the hairs of the jaurs.

Diseases and Blemishes.-These are osseous tumors, the result of blows which the animal has received or of injuries which are inflicted by the extremities of the shafts. Again, we may find enlargements of the bone sometimes accompanied by necrosis and fistulæ emitting an extremely disagreeable odor. The latter lesions are caused by diseases of the inferior molar teeth. Finally, this region may be the seat of salivary fistulæ upon the course of the excretory canal of the parotid gland, most frequently on a level with the point where the duct is inflected around the maxillary fissure.

These diverse alterations have a great tendency to assume a chronic form, and are always followed by deformities quite persistent, which blemish the animals for a more or less long period.

\section{C. - The Chin (Fig. 19).}

Situation; Limits; Anatomical Base.-Symmetrical and situated in front of the intermaxillary space and the branches of the lower jaw, and behind the tuft of the chin, the chin, upon which rests the curb of the bit, corresponds almost to the point of union of the two branches of the maxillary bone. The symphysis is manifested externally by a slight erest, a gutter, or a simple convex surface.

These diverse conditions, with difficulty appreciated from the exterior, have caused this region to be named round or sharp, two conformations upon which buyers also attach too much importance. The impression of a portion of the harness or of the curb upon the skin depends much less upon the anatomical disposition of the parts than the degree of natural sensibility of the subject. It is casy to moderate the action of the curb by protecting the latter with a leather enshion and by regulating the quantity of traction exercised on the reins ascording to the sensibility of the animal.

Denudations and wounds are the ordinary consequences of immoderate pressure sustained by the chin of very irritable horses, as from the curb, or other traumatisms. There are also blemishes of the chin, which are not without interest in that which concerns special utilizations of the animal. 


\title{
CHA PTER IV.
}

\author{
INFERIOR EXTREMITY OF THE HEAD.
}

\section{A.-The Mouth (Fig. 25).}

Situation; Divisions.-The mouth is a complex region which occupies the inferior extremity of the head and represents the entrance into the digestive apparatus. It is elongated from before to behind, and comprised between the two jaws. We recognize in it the following parts, which we will first study: 1 , the lips; 2 , the teeth and the gums; 3 , the bars ; 4 , the lingual canal; 5 , the tongue; 6 , the palate. We will afterwards pass to the examination of the mouth in general.

\section{x. The Lips (Figs. 19, 25, and 26).}

Situation; Limits; Anatomical Base.-The lips are two movable musculo-cutaneous curtains, placed at the entrance of the mouth, whose opening they limit.

They are distinguished as superior or anterior and inferior or posterior.

Physiologically, they are organs necessary to the prehension of food, and they serve as auxiliaries in mastication. The inferior lip, in relation to the exterior, to a small degree supports the bit, whose impulses are, in a certain measure, first received by it.

The superior lip, the more mobile, is limited above by the extremity of the nose; on the sides by the cheek and the nostrils; by its free border, finally, it is in contact with its congener. The inferior lip is limited behind by the chin and laterally by the cheeks.

The lips present for study two faces, external and internal; two commissures, right and left; and two borders, free and adherent. Each is composed of three layers,-an external or cutaneous, an internal or mucous, and a middle or muscular,-besides blood-ressels and nerves. The muscular layer is constituted by the orbienlaris oris muscle and the muscles of the face which attach to it. The arteries are the superior and inferior coronary, passing through the centre of their substance.

The external face of each lip is covered by fine and very adherent skin, provided with two kinds of hairs: the one consisting of long, stiff, and scattered hairs, called tentacles, and deeply embedded in the subcutaneous tissue and even in the muscles; the other, very fine, short, and numerous, belonging to the ordinary hairs of the coat. The former are provided with a nerve terminal at the base of their papilla, which makes them delicate organs of tactile sensation for the animal. To a large degree these supersede the function of the hand in quadru- 
mana. The external face offers on the median line of the superior lip a small gutter more or less distinct, and on each side an elevation more or less prominent. This gutter is the representative of the nasal gutter, very pronounced in man and some other animals. This lip is, besides, longer, larger, more movable, and more constricted at its base than the inferior. In the latter, on the contrary, the median gutter is absent, to be replaced by some semicircular folds on a hemispheri-

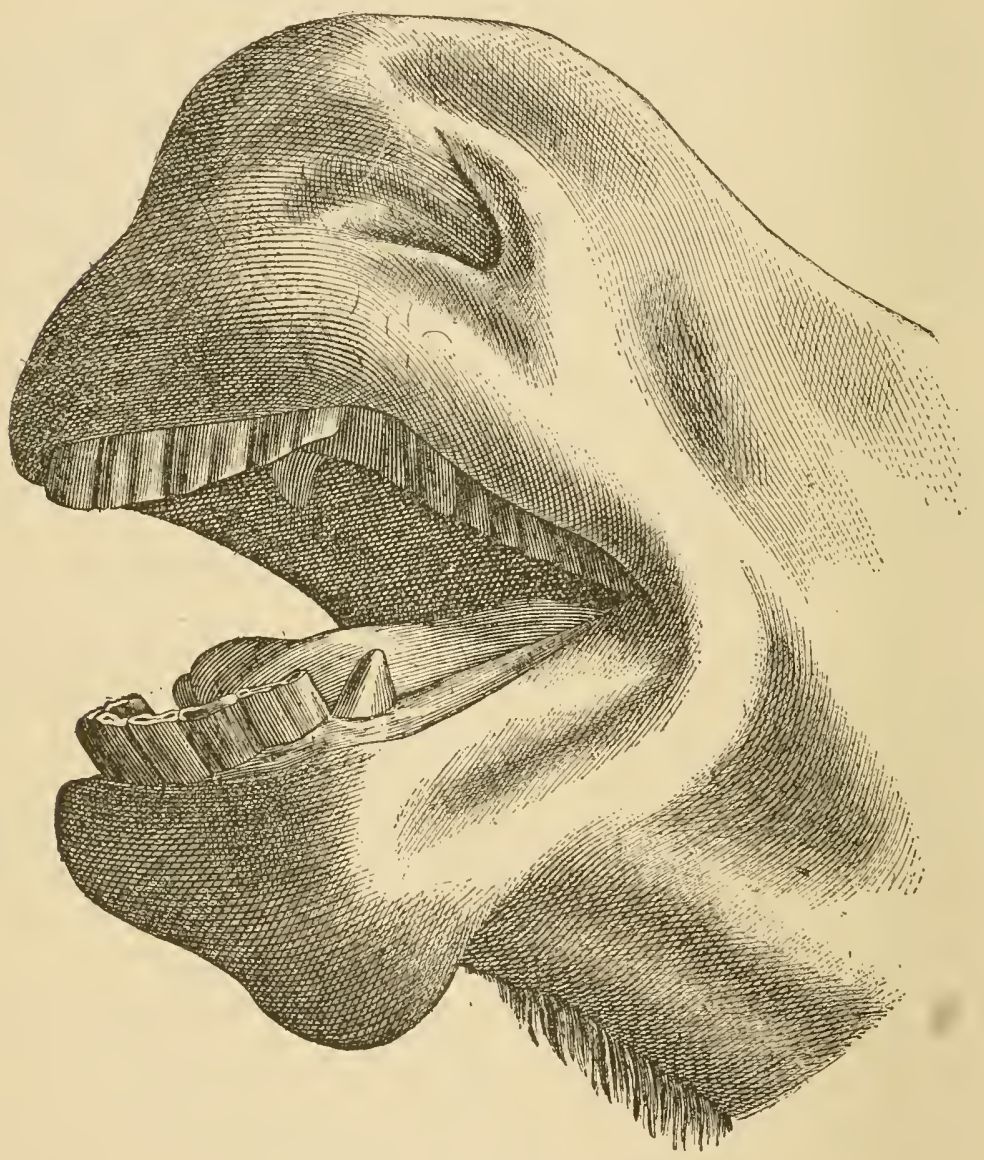

FIG. 25.--Interior of the mouth (after Bruncau).

cill eminence, more or less developerl, to which has been given the name of tuft of the chin, and whose base is the mento-labialis muscle.

The internal face of each lip, concave in every sense, is covered by the buecal mneons membrane, smooth, shining, of a rosy color in good health, and sometimes marbled, due to a deposit of black pigment. This layer becomes reflected on the incisive and inferior maxillary bones, to become continuous with the gums, and lies in eontact with the anterior face of the incisor teeth. It 
contains large numbers of salivary glands in the thickness of the submucous tissue. The connective tissue which unites it to the adjacent parts is sufficiently loose to allow of an abuudant serous effusion.

The free border of each lip is thin and bevelled, lies in contact with its congener, and is the point of continuity between the skin and the mucous membrane.

The adherent border is marked in the interior of the mouth by a gutter at the point of continuity of the mucous membrane with the gums. Externally, it is not delimitated from the adjacent parts, with which it becomes continuous.

The commissures are the points where the two lips become continuous, slightly round and quite thick, they are perfectly closed in ordinary conditions.

Their volume appears much larger in young than in old animals, because the direction of the incisor teeth, upon which their internal face rests, beeomes more and more horizontal with the progress of age. Also, the head in old horses seems to be tapering at its inferior extremity.

The lip, like the nostril, the eye, and the ear, is a most remarkable organ of expression. When it is eurled up, relaxed, lowered, elevated, or inclined, we have so many variations which affect the whole physiognomy. When we study the expression of the horse under the influence of pain, fear, pleasure, or. distress; when we observe his attitude as he attempts to snateh or bite somebody or one of his companions; when we observe the lips in certain diseases; when we translate the language of the stallion as he seents the mare, or the animal as he passes through the death-agonies, then ean we see how perfect the expression is and how it varies in each circumstance.

It is well known, also, that the physical qualities are in direct relation with the faculty of expression of which the lip is capable. The horse which is of a sanguine temperament, with a nervous system that is well developed, cnerotic, and easily stimulated by external causes, presents a high development of this region. The common horse, on the contrary, has a lip which is thin, soft, flabby, immobile, and withont expression. The skin which covers it is thick and the hairs long, eoarse, and abundant.

3 The lips should approximate themsdres easily by their free border to keep the mouth constantly closerl, in order to avoid a continuous eseape of saliva. Nevertheless, it is not always thus, fiom the fact that the animal is "reined up too high," or that one of the lips may be paralyzerl. In the first instance, the mouth remains ofyen from the fatigue of the museles induced by the unnatural position of the head; in the second, there is great diffieulty in the prehension of food, the constant loss of saliva is deleterious, and the physiognomy loses all its 
expression. If the paralysis be unilateral, one of the lips is drawn to one side by the muscles which still preserve their nervous influenee. If it be bilateral, the affected lip becomes pendulous. It is this whieh we sometimes see in the inferior lip of old horses and much more rarely in the young. This state is more often associated with a profound debility of the organism and an atony of the muscular system in general, than as a veritable paralysis, or at least as a complete inertia of the organ.

Nevertheless, the defeet in question may be congenital. Delphine, an old brood-mare in the stud of Pin, suffered from paralysis of the inferior lip, and all her progeny inherited the same infirmity; yet she wis possessed of great energy and good breeding, and was not ineonrenienced in the least (Richard). ${ }^{\text {? }}$

Certain horses, whether in harness or under the saddle, at rest or during exercise, have a continual and convulsive movement of the inferior lip which is very ungraceful to the eye. In the language of horsemen, it is said that they beat the lip.

Again, some hor'ses continually attempt to seize the branches of the bit with the lower lip, a vieious habit eapable of ehanging its good direction. It is remedied in several ways, either by the application of a leather lip-strap to the bridle, by bending the branches of the bit backward, or, finally, by shaking the reins lightly at each new attempt of the animal, to compel him to let go.

The commissures of the lips, aecording as they are situated more or less high, designate the mouth as being well, too much, or not enough cleft. This does not constitute a serious defect, because the bridle can always be so adjusted as to prevent the bit from exerting excessive pressure against the first molar tooth or the angles of the mouth.

Most anthors since Bourgelat lave contended that the inferior lip ean prevent the pressure of the bit upon the bars by opposing too great a resistance or interposing itself between the two. The former then offers considerable resistance to the bit, and the animal becomes hard-mouther. M. Richart ${ }^{2}$ has amply refuted this assertion in pointing out the feeble resistance which the orbieularis muscle is able to offer against the bit, and in demonstrating that hard mouths result ordinarily from the inexperience of the rider in using the reins or the inaptitude of the horse to exeeute certain movements.

On the inferior lip there exists sometimes, on each side of the median line, a tuft of long eurly hairs, which are ealled, from the 
analogy of their form and position, moustaches. This peculiarity is also more rarely observed on the superior lip.

Diseases and Blemishes.-Diverse diseases, which may ordinarily prevent the sale of the animal, are observed in the region of the lips. Besides paralysis, of which we have spoken, farcy ulcers are sometimes observed here over the course of the lymphatics. Ulcers of variola also affect this region, attacking young animals principally. These latter ulcers may be situated upon the external surface of the lips, along their free border, as well as in the interior of the buccal cavity, and around the alæ of the nostrils. Their gravity is of little consequence, and with care and practice we are enabled to distinguish them easily from the preceding, which are characteristic and serious in the extreme. Besides these alterations, the lips are the seat of swellings which disfigure the parts because they extend into the surrounding tissues. Such are cedematous effusion due to anasarea, the prolonged ingestion of certain plants, as buckwheat, for example, or the accidental application of vesicants, as when the animal rubs a surface which has been blistered for a therapeutic purpose.

The most common blemishes of the lips are excoriations and cicatrices, resulting from the application of the twitch. These are always an indication of a vicious habit of the animal, difficulty in shoeing, or of his having been subjected to a surgical operation requiring frequent dressings. It is not rare to meet with cuts or lacerations along their free border. These wounds suggest falls, and it is important to examine with care the condition of the extremity of the nose, the incisor teeth, the gums, and the limbs, to inform oursel res as to the cause which has produced them.

In old horses it is quite common to see thickenings or lacerations of the one or the other commissure, occasioned by repeated and violcnt traction on the bit or by a bit which is too narrow and improperly adjusted. These render the complete closure of the month impossible, and may prove to become obstacles to the prehension of liquids. The pain which they cause may, for a certain time, incapacitate the animal for service.

Let us say, in conclusion, that we often see in horses affected with immobility particles of hay or straw adhering to the commissures of the lips and remaining there without provoking the least movement of the jaws. It is then said that he smokes his pipe.

\section{The Teeth and the Gums.}

The teeth are organs of osseous appearance, implanted in the alveoli of the maxillary and ineisive bones. They assist in the prehension and mastication of the aliment, and are distinguished from their use as incisors, eanines, and molar's.

The relation of the tecth to the determination of age is so important to recognize that we will devote to it a special chapter. (See Age.) We will content ourselves for the present by saying that their minute examination should be made at the sime time as that of the mouth, and include their integrity, soundness, length, direction, and the regularity of their surface.

The mucous membrane which surrounds the teeth and aids to fix 
them into their alveoli is called the gums. These offer little of interest. In young horses they are rosy, thiek, and adherent, but as the animal grows older they become pale and retracted from the teeth. Alimentary matters may penetrate between their dental surface and the teeth, excite inflammation, and become the origin of periostitis or of caries of the bone.

\section{The Bars (Figs. 25 and 26).}

Situation; Limits; Anatomical Base.-The bars, occupying the inferior interdental space on each side, include that portion of the inferior maxilla between the canine and first molar teeth, and are covered simply by the mueons membrane. In the mare, in which the tushes are undeveloped, the bars are longer, and extend from the corner incisor tooth to the first molar. They support the canon of the bit.

Most authors have pretended that the conformation of the bars is of great importance relative to the pain which the horse feels as a consequence of the pressure of the bit; that if they be clecated or sharp, the pain is intense, and, on the contrary, feeble when they are round ; finally, that the form of the bit should be adapted to the one or the other of these dispositions. We repeat here what we have already said above as to the bars: with equal sensibility it is eertain that on the sharp bars the pressure will be more intense, but the difference which we observe in the sensibility to the action of the bit resides not so much in the conformation of the parts as in the natural sensibility and irritability themselves, - all peculiarities of this region. As M. Sanson ${ }^{1}$ has justly said : when sharp bars accompany a nervous and irritable temperament, it is to this alone that a false or spoiled month, as well as the fuults of rearing or rumuing away, must be attributed. Most lorses whose mouths have been abused with the bit by inexperienced riders or drivers present round and depressed bars. When the mucous membrane is thiekened and the sensibility is blunted, they are ealled calluses.

The bars may be the seat of wounds sufficiently grave to prevent the use of the animal for a variable period of time. Due to forcible traetion on the bridle, these may terminate in caries, fistula, and exfoliation of a part of the bone which forms their base, and leave a permanent deformity.

To recapitulate, the fineness of the bars constitutes the principal beauty to be songht for in their examination.

1 A. Sanson, Nouveau Dictionnaire pratique de médecine, de chirurgie et d'hygiène vétérinaires, t. ii. art. "Bouche." 
4. The Lingual Canal (Figs. 25 and 26).

Situation; Limits; Anatomical Base.-The lingual canal is generally described as the space comprised between the branches of the inferior maxilla, in which the tongue is situated. It is a kind of gutter the sides of which are covered by the mucous membrane of the mouth. Anteriorly, where its inferior wall is formed by the body of the aforesaid bone, it is single; posteriorly, it divides into two branches comprised between the sides of the rami of the same bone and side of the fixed portion of the tongue.

At the anterior extremity of these lateral divisions is the lingual crest formed by the superior border of the sublingual gland, covered by mucous membrane, and presenting a series of orifices of the excretory duets,-dueti Riviniani.

Underneath the mucous membrane covering the lateral faces of the tongue is the duct of Wharton, the excretory canal of the maxillary salivary gland. It opens upon the superior face of the body of the maxilla on each side of the frenum of the tongue by means of an enlargement called the barb or barbillon, whose function is the protection of the canal against the entrance of alimentary matters.

Depth.-The lingual canal, which we must examine in regard to its depth, should be proportional to the volume of the tongue. If the latter be not in relation with the capacity of the gutter which contains it, the result will be a vicious position of the bit; in the one ease the tongue will entirely support the action of the bit, whilst in the other the latter will rest exclusively upon the bars. We must say, to speak the truth, that nothing has been demonstrated to establish this opinion. The width of the canal is always in relation with the volume of the tongue, and, should it be otherwise, the bit will experience neither more nor less diffienlty, as we shall show further on.

We think, also, that there is neither becuty nor defect to be appreciated in this region. We may, however, observe an inflemmation of the canal of Wharton from the introduction, through the barls, of particles of forage proving very often to be pieces of brome-grass. This affection is noticed most frequently in old horses with irregular teeth, and nonrished on old Burgundian hay, in which this grass is abundant. It is accompanied by intense congestion of the barb, and perhaps a discharge of pus from its orifice.

It was formerly believed that the barbs could prevent the animal from drinking. It is surprising that this opinion was even shared by Bourgelat, who considered these organs simply as excrescences of the mucous membrane. At present, many persons in the rural distriets are imbued with this prejudice, and, employ horsemen and empiries who practice its ablation. It is easily understood 
that this barbarous operation facilitates the penetration of foreign bodies into the salivary canal, the entrance to which is thus no longer protected.

\section{The Tongue (Figs. 25 and 26).}

Situation; Limits; Anatomical Base.-The tongue is an organ of prehension and mastication of the aliment, of gustation and deglutition, placed in the lingual cancl, and which completely fills the mouth when the jaws are in apposition. It is related above to the hard palate; in front, to the incisor teeth and the lips; on each side, to the bars, the molar tecth, and the cheelss; and behind, to the soft palate.

The principal structures entering into its organization are five pairs of muscles.

Anatomically, it is divided into two portions : anterior, or free, and posterior, or fixed. The free portion is spatula-shaped and flattened from above to below. A fold of mucous membrane of a triangular form is detached from the middle of its inferior face and attached to the body of the inferior maxillary bone. This is the fronum, or anterior pillar of the tongue. It limits to a certain degree the movements of this organ.

Its examination, which should be made at the same time as that of the teeth, is conducted as follows, supposing the operator to stand on the left side (Fig. 26): The left hand seizes the inferior lip or is placed upon the anterior face of the nose to steady the head. The right hand seizes the tongue; the middle and index fingers are introduced between the lips into the mouth on a level with the bars, and the organ is grasped. Being thus held between these two fingers above and the thumb and annularis below, it is withdrawn from the mouth and, with its adjacent parts, carefully inspected. 'To examine the base of the tongue, it is necessary to stand in front of the head and allow the light to shine into the buceal eavity.

These manneuvres must be practised with the greatest gentleness. Excessive traction will be painful to the animal and make him insubordinate; it may also cause a rupture of the stylo-glossus muscle, which we have several times proved by dissection, ${ }^{1}$ as woll as the genio-glossus and the fronum. On account of the pain which is produced, certain dealers, without doubt, do not hesitate to practise this barbarous act on horses suffering from immobility, to make them timid and cause them to "back."

1 A. Goubaux, De quelques pratiques barbares anxquelles on a recours pour examiner la bouche du cheval, pour déterminer son àge, pour le faire reculer, ctc. (Journal de l'école de Lyon, 1866, p. 335.) 
The movements are clevation, depression, extension, retraction, and lateral inclination. Each changes the form and volume of the organ; it becomes wider, thicker, concave or convex, etc.

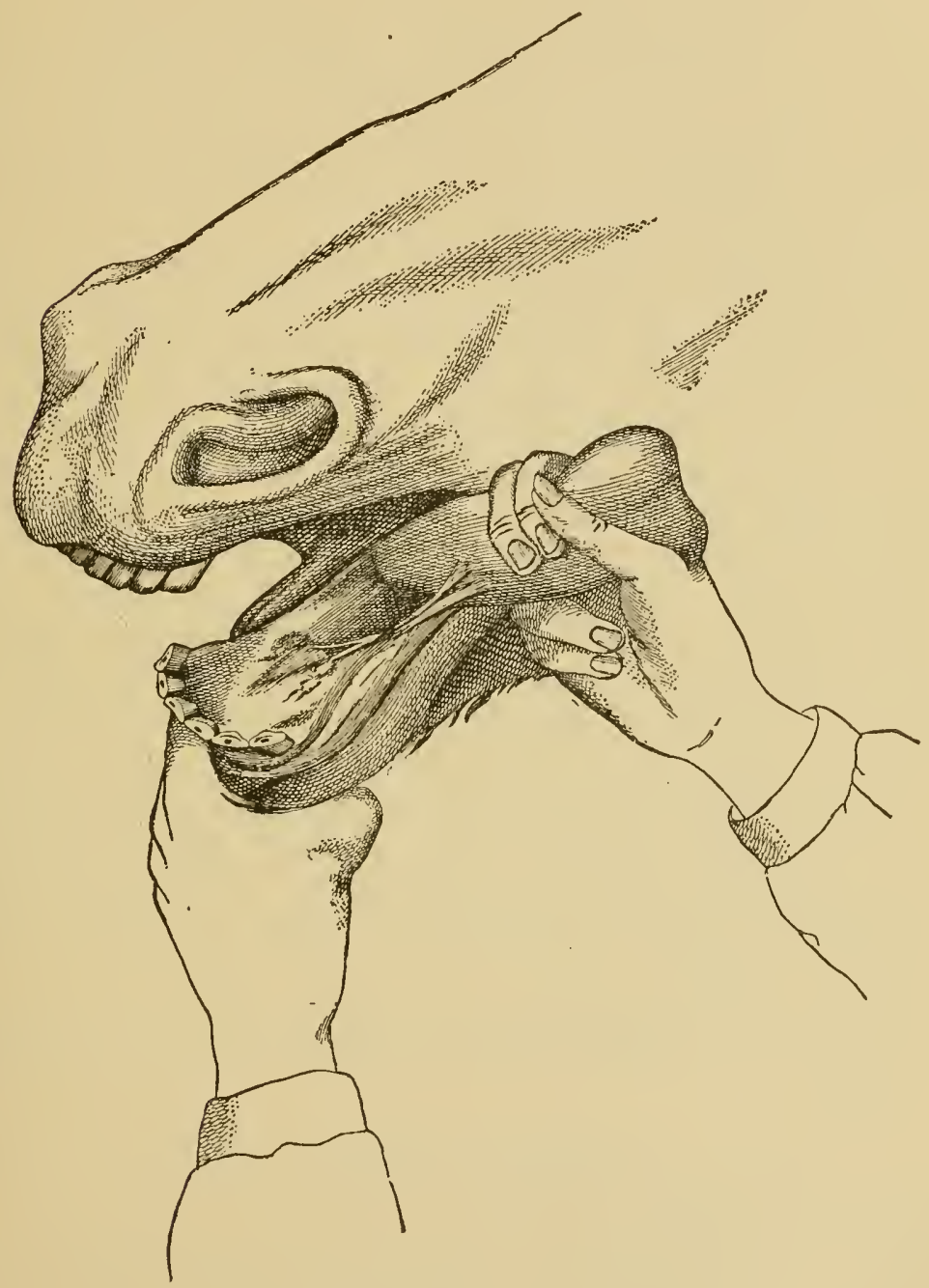

FIG. 26.-Examination of the mouth.

The volume, in general, is proportional to the eapacity of the buccal cavity. We have never observed, except in very old horses, that the thickness of this organ caused it to project beyond the bars, become the sole support of the shank of the bit, and lessen, for this reason, 
the sensitiveness of the mouth. The differences of sensibility, which are quite common, proceed from another canse. We have already spoken of this a propos of the bais and the chin.

In a normal state, the tongue shonld always be kept in the interior of the bnecal cavity. It helps to support the bit and, in eoncert with the lips, it receives its first impression. Some horses have the bad habit of doubling the tongue within the mouth by recurving its free extremity above or underneath the bit. This can be readily detected by scparating the lips from each other, and is remedied by tightening the curb-chain.

The integrity and entireness of the tongue should never escape the attention of the veterinarian. When a horse, tied with the reins of the bridle, or with a strap passed through the mouth, becomes frightened, he will throw himself violently backward and support the weight of the body entirely by the mouth, the point of attachment. Then, if the means of attachment does not break, the tongue may be sufficiently compressed by the bit or the strap to be eut transversely. We know of an instance of this kind in which the free portion was completely separated and fell to the gromd. This is always a grave accident. If the scetion be incomplete, mastication is slow and imperfect; if it be complete, death may be the consequence, as it was in the instance mentioned above. A horse should, therefore, never be attached to the reins of the bridle or to a strap passed through the mouth.

The tongue may become lacerated or cut, more or less deeply, on its lateral borders from irregularities of the molar areades, which are denticulated in old horses. These wounds are very painful and prevent the animal from masticating his food. The remedy is the dressing of the teeth.

There are some horses whose tongue, during work or at rest, protrudes from the month and becomes pendulous; this is called lolling the tonguc. ${ }^{1}$

In other cases it is alternately protruded and retracted in a manner which simulates the movements of a serpent's tongue; hence the appropriate designation, serpentine.

Both of these eonditions are ungracefnl, deleterions from the constant loss of saliva which conld be utilized in digestion, and finally the organ ceases to give the same point of support to the bit which it furnishes in ordinary cireumstances.

1 I have seen an instance in which this was temporarily prevented by the application of a rubber band to its free portion, the effect of which, however, was an almost complete section of the organ. (IIarger.) 


\section{The Palate (Fig. 25).}

Situation; Limits; Anatomical Base.-The palate, which forms the anterior or superior wall of the buccal cavity, has for its osseous base the superior maxillary, incisive, and palatine bones. These are separated from its mucous membrane by a thick layer of erectile tissue, most abundant anteriorly. It is limited in front by the superior incisors; laterally, by the superior molars and the superior interdental spaces; behind, by the attachment of the soft palate. Only a portion of it is visible in the examination of the cavity of the mouth. Its surface is of a rose color, sometimes pigmented in different portions of its area. It presents transverse arches, with the eoncavity behind disposed symmetrically on each side of the median line, and separated from one another by transverse furrows.

With the exception of the width, which is most marked in the finer races, the palate has no appreciable beauty or defect.

The thickness varies according to the age and the plyysiological conditions. The palate may become congested and inflamed, projecting beyond the table of the incisor teeth and thus preventing mastication. This state is vulgarly termed lampas. It, however, is not pathological, but physiological, due to the irritation of dentition.

Huzard ${ }^{1}$ the elder has long ago shown the uselessness and cruelty of the practice of removing the swelling of this region by excision with the knife or by canterization with the actual cantery. These barbarous procedures impede mastication and tend more to diminish than to increase the appetite, as is shown by the animal's willing but ineffectual attempts. They are still performed at the present time by farriers and empirics, who call it burning the lampas. Scarifications practised for the same reason are not without accidents. They are made posterior to the third bar of the palate and not less than an inch from the edge of the gums of the molar teeth, so as not to puncture the palatine artery.

\section{B.-The Mouth in General.}

All the sccondary regions which we have studied in the preceding chapter should be in harmony with one another, so that, as a whole, they may fulfil their functions. The mouth, indeed, requires examination not only from a physiological point of view, but from that of the exterior also, in that it is the organ in which is lodged the instrument to guide the animal, called the bit. père.)

${ }^{1}$ Bourgelat, Traité de la conformation extérieure du cheval, 5e éd., p. 81. (Yote de Huzard 
The Bit. - This instrument (Fig. 27) is composed of a cylindrical piece of metal, wood, or rubber, straight, curved, or broken, and two branches, to which the reins, bridle, and curb-chain are attached. The former, called the canon or bar of the bit, or the bitting, rests upon

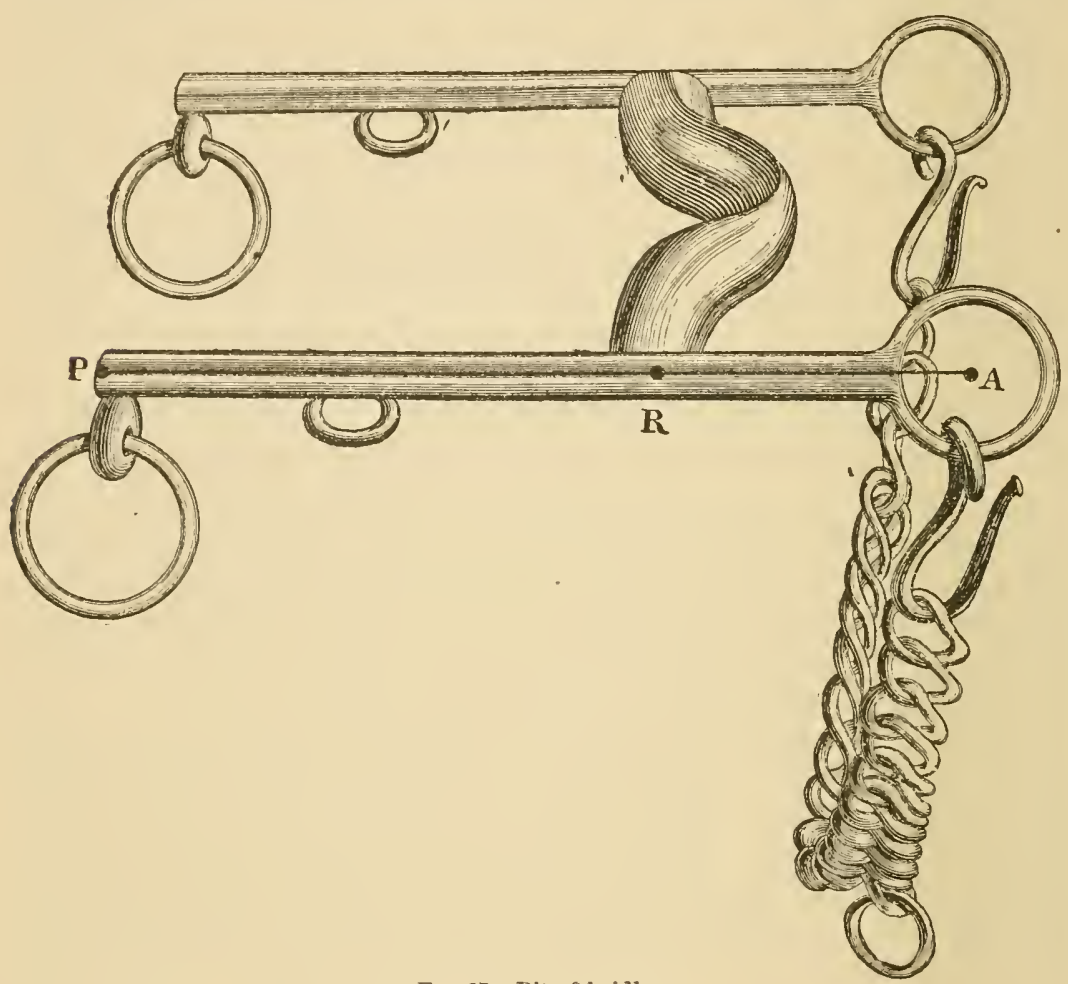

FIG. 27.-Bit of bridle.

the tongue and the bars; the latter prevents deviation and increases the power.

The bit plays the part of a lever of the second class, in which the curb $A$ is the fulcrum or point of attachment, $P$ the point of application of the power, and $R$ the place where the resistance is overcome by pressure upon the bars. PA representing the power-arm of the lever, it will be at once perceived that the longer the branches of the bit the more powerful and energetic is its action. The latter augments, with the diminution of the arm of resistance, the distance from the eanon to the attachment of the eurb, $A R$; also, if the bit be grooved instead of round, or if the free portion of the tongue be large and the pressure on the chin of increasing force, its effect will be more intense. 
Functionally, the bit is, therefore, an apparatus of restraint which, by its pressure, more or less severe, on the bar's and the chin, causes pain of variable intensity.

Temperament of the Mouth.-The animal will react in consequence of this pain, and Bourgelat designated the temperament of the mouth as the particular mode or intensity of this reaction; in other words, as the special effect of the different sensations transmitted by the bit to the mouth.

Thus, the mouth is qualified as being steady, true, or normal when it supports the bit with freedom, without uneasiness, pain, or fear; when it neither struggles nor yields too easily to the action of the hand.

The mouth is sensitive, tender, delicate, or easy when it perceives the most delicate impressions of the hand and responds to them with promptness.

It is strong, hard, and thick when it yields only to energetic traction on the reins.

A spoiled mouth is one which reacts falsely towards the indications of the bit, whatever may be its sensibility otherwise.

Finally, the firesh month or the active month is that which relishes the bit, chews it without cessation, and appears slightly frothy from the continual agitation which the movements communicate to the saliva.

These different qualities of the mouth can only be judged by the utilization of the animal, but they should not be neglected on that account. In a general way it is always necessary, in the selection of a horse, to seek the most complete information possible and not omit any tests, if such be necessary. Overweening vanity is too often the cause of the most singular mistakes. We cannot insist too much upon the importance of examining all parts of the mouth, and of censuring those individuals who confine themselves to an inspection of the teeth with a view to a knowledge of the age alone.

Internal Face of the Cheeks. - We will now refer to the internal face of the cheeks, whose external conformation we have already studied. It does not constitute a particular region by itsclf, but it limits laterally the mouth external to the molar treth, ats the lipss do in front of the incisor teeth. It merits, nevertheless, some consideration, because it presents the round tubercle at the termination of Stenon's duct, opposite to the anterior border of the third molar tooth.

Wounds or lacerations of the mucous memlirane, the result of dental spiculie from irregularitics of the molars, often exist here, partienlarly in old horses. They may produce inability to masticate, 
the remedy for which is apparent. The subjects presenting these lesions are poorly nourished, their mastication is inconplete, and frequently food aceumulates between the molar arcades and the internal face of the rheeks, producing a peculiar distention (granary) on the exterior, which we have previously deseribed.

Method of Action of the Bit.-The bit should be considered as a check which arrests, as a power which masters, and, above all, as a means of communication between the horse and he who directs him. The physical impression which it causes varies from the slightest sensation to the most intense pain.

If the intensity of its effect is not properly measured with the degree of sensibility and the intelligence of the subject, it produces effects opposite to those which are desired; it provokes an energetic and often stubborn defence, in which the man is not always victorious, and which may not be without danger to his person. If, on the contrary, the mechanical effect of the bit be in proportion to the sensitiveness of the mouth, so as to be a simple indication for the horse to surmise what is required of him, and, if necessary, to teach him by the pain that he must obey a will superior to his own, then it becomes a means of education entirely rational and utilized in his dressing for various purposes. It becomes an intermediary agent between two intelligences whose communication is thus possible. It translates ideas and information from the language of the master into that of his servant; and, little by little, the latter will comprehend this language, although it varies according to the purpose for which the animal is employed, as the saddle, light carriage, or heavy traction. It is important that the dressing should begin early and under a patient, firm, able, and experienced master.

The bitting is the name given to the method by which the bit is most conveniently adjusted to the mouth of the horse.

\section{CHAPTER V.}

POSTERIOR EXTREMITY OF THE HEAD.

THE posterior extremity of the hear comprises three regions, of which one, serving to unite the had with the neck, is double. They are: the poll or nape, the parotid region, and the throat. 
A.-The Poll or Nape (Fig. 19).

Situation; Limits; Anatomical Base.-The poll or nape occupies the summit of the head. It is limited laterally by the eur and the parotid region, anteriorly by the forehead, posteriorly by the crest of the neck and the mane.

This region, which corresponds anatomically to the occipito-atloid artieulation, has for its hase, on the median line, the funieular portion of the nuchal ligament, separated from the surface of the atlas by a synovial bursa ; on each side are eight pairs of muscles disposed in several layers. Over the side of the atlas, corresponding to the two foramina, at the base of its transverse process, are the two prineipal blood-ressels, the retrograde and occipito-muscular arteries, separated from each other by a space of about two inches. The skin which covers it is ordinarily protected by the mane, which is usually cut to lodge the head-piece of the halter or bridle.

Diseases and Blemishes.-The veterinarian must thoroughly assure himself of the fineness and freedom from disease of this region; for, on account of the movements and the disposition of the muscles into layers, filtration is favored, and all diseases in this location assume an unfavorable aspect. ${ }^{1}$ Wounds of the poll result sometimes from a misfitting bridle or halter and from contusions, consequent on the animal's rearing and striking the poll against resisting bodies. The most common result of these is fistula with necrosis of the tendons, nuchal ligament, and even the bones. This is extremely serious and often fatal; sometimes a cicatrix alone betrays the disease. A less serions disease is a synovitis and dilatation of the above-mentioned bursa. The swelling is usually bilateral.

No one but the most ignorant would buy horses with such blemishes without observing them. We know of instances in which the hood was employed to cover the parts. An abnormal sensibility of the poll is always indicative of a previous or now-existing disease, which can be demonstrated by passing the hand over this region.

\section{B.-The Parotid Region (Fig. 19).}

Situation; Limits; Anatomical Base.-The parotid region, like the gland which forms its base, derives its name from its proximity to the ear. It is linited above by the ear, below by the

1 A. Goubaux, Note sur quelques lésions de la région de la nuque, chez le cheral (Arch. Fétér., 1877, p. 137). 
throat, behind by the neck, and in front by the temple and the check. The extcrnal face of the parotid glanel is separated from the skin by the farotido-auricularis and cuticularis colli muscles; underneath, it lies anainst the pharynx, larynx, guttural pouches, blool-vessels, and nerves, and is traversed obliquely from below upward, and from without to within, by the jugnlar vein; the superior extrenity embraces the base of the ear, and the inferior is lodged in the angle of mion of the jugular and glosso-facial veins.

Beauties and Defects. - These are purely conventional and vary according to taste. 'The region, to be beantiful, it is said, should he light and depressed in order that the movements of the head may be free and extensive; if too much excavated relative to the surrounding parts, the movements will be too easy, the saddle-horse will be able to defend himself against his rider, and the head is mal-attached; if too salient over the regions which confine it, the horse becomes diffieult to guide and direct, the movements are neither free nor extended, and the head is again mul-cettached.

These arguments do not rest on any given physiological rationale. It suffices to recall the anatomical disposition of the articulations and the museles to understand that these eonformations are arbitrary and render the contradietory thoories valueless. A moderate depression of the parotid surface is simply agreeable to the eye in that it makes the head appear to be better attached, and, for this reason, deserves the preference aceorded to it.

Diseases and Blemishes.-It is of more utility than the preceding to determine the presence or absence of diseases and blemishes. We observe here tumefactions due to melanotic tumors, to alterations in the gland itself, as parotiditis, to diseases of the structures which surround it, as the guttural pouches, or to lesions of the surrounding veins. Parotid abscesses are often complieated with salivary fistulæ, which allow the eseape of saliva and produce malnutrition. The hood is again called upon by unscrupulous dealers to hide these conditions.

Let $1 \mathrm{~s}$ also mention denulutions, cicatrices, and traces of the cautery, as well as other blemishes which result from the employment of a means of treatment of diseaties of the larynx, the gland, or the facial vein. In such cases it is necessary to determine whether or not the animal is a roarer or suffers from an obliteration of the juxular vein. (Fee Neck.)

In conchusin, let as mention the barharous usage which consisted in conlpression of the parotid region with a farrier's pincers in loorses suffering from violent attacks of colic, the caluse of which was attributed to pain and engorgement of the parotid glands. In similar circumstances it was also the custom to beat and open the grands to quiet the animal. This operation, dangerous as well as absurd, often terminated in gangrene and its inevitable consequence, the death of the patient. We have proof of such an example. 


\section{C.-The Throat (Fig. 19).}

Situation; Limits; Anatomical Base.-The throat oeenpies the bottom of the curvature of the head upon the neck, or the sine of the eervieo-cephalie angle. It is limited behind by the inferior border of the neek, in front by the submaxillary space, and laterally by the parotid region. It is a single region, which corresponds to the inferior face of the larynx and the origin of the trachea, which are separated from the internal face of the skin by the muscles. It is bordered inferiorly and on each side by the two glosso-facial veins.

Its absolute beauty eonsists in its large transverse diameter, becanse the larynx, whose diameter is related to that of the throat, belongs to the respiratory apparatus, the capacity of which should alwars be extensive. Its narrowness is, therefore, an absolute defeet, because it signifies lungs of small eapacity.

In examining a horse, the larynx is generally eompressed with the hand to determine the eough, the eharacter of which has an important clinical aspect. All horses, however, are not equally sensitive to this manipulation. In eertain animals it is necessary to employ both hands to obtain this result, and in others it is entirely impossible to exeite a cough.

The character of the cough indicates the condition of the respiratory organs. Provoking a cough sometimes causes the ejection of a discharge which has been fraudulently concealed. As soon as such is visible it is jucicious to examine the nostrils and at the same time observe any movements of deglutition. In some rare cases of glanderous ulceration of the larynx and trachea, the expectorated matters are thrown into the mouth and immediately swallowed. Abadie, of Nantes, who has first called attention to this fact, advises in these cases the opening of the mouth of the animal and allowing the secretion to run out.

The blemishes of the throat are depilations, excoriations, and cicatrices, indicating the use of revulsives employed in diseases of the larynx and pharynx.

\section{CHA P TER VI.}

\section{HEAD IN GENERAL.}

WE have studied in the preeeding chapters the different regions of the head, as to their situation, form, beauty, defects, discases, and blemishes. In other words, we have employed a system of analysis in endeavoring to point out the physical and anatomical characters, the integrity, imperfeetions, and good qualities of each region in particular. 
This study will not be complete without a glance at the different parts is a whole, purposely reserved for a special chapter. This synthetical study will cnalle us to perecive much more easily the harmonious relations which should exist among them; it will furnish us also with an oppertunity of examining the head, as to its length, volume, direction, general form, attachments to the neck, morements, and their influence upon the displacement of the centre of grovity, and, finally, the cixpression.

\section{A.-Harmonious Relations of the Head.}

M. Richard ${ }^{1}$ was the first to insist, with detail, upon the fact that the relation of construction of the different regions scems to be much more intimate in the head than in any other portion of the body. It is, he says, not rare to see, for example, a very beautiful hock associated with a defective haunch, a good sloulder with a defective croup, withers well made with loins concave and badly attached, a narrow chest with limbs strong and well formed, ete.

Inharmonious proportions are infinitely less common in the head. Thus, large nostrils, well-situated eyes, ears widely separated, and a large intermaxillary space coexist nearly alwars with a wide forehead; whilst a narrow forehcad implies, in most horses, large ears, placed high and approaching each other, eyes but partly open, small nostrils, and a narrow intermaxillary space. The fineness and mobility of the ears and of the eyelids, the amplitude of the nostrils, the thinness of the lips, the vivacity of the eyes, and the intelligent expression of the physiognomy, are beauties which ordinarily coexist.

It follows, then, that a good or a bad conformation of one part naturally permits a good or a bad disposition of another. Beanty of the forehead is not associated with narrowness of the nose; that of the nostrils with narrowness of the intermaxillary space; the intelligent expression of a beantiful eye with stupidity of the remainder of the face.

In a general way, it is correct to say that the beauties and defects of the head correlate themselves in a manner almost absolute; but we must remember that there are some subjects in which these relations are defective. Therefore, in selecting a horse, such a desirable quality as a wide forehead should not of itself be regarded as conclusive of general excellence. If the harmony be in nature, it is often destroyed by man, who modifies the natural conditions of existence of the domestic animals. 
A propos of the proportions, we will again revert to this subject. For the present we will only indicate the harmonious relations of the head without ignoring the possible digressions or exceptions to this principle, which is really less absolute than M. Richard has been willing to admit.

\section{B.-Length of the Head.}

Since the time of Bourgelat, all have been generally in accord as to the classie length of the head : that the height of the body measured from the withers to the ground, or the distance between the angle of the shoulder and the hip-joint, shonld be two and one-half times the length of the head. If these distances were more than two and onehalf times the vertical diameter of the head, it was too short; if the reverse was true, it was considered too long.

When it has an appropriate length, it is carried with grace, responds easily to the action of the bit, and does not overburden the anterior members. A head too long is too heary, displaces the centre of gravity forward, restrains the movements of the anterior extremities, bears heavily on the reins, and diminishes to such an extent the speed and usefinness of the animal. If too short, it becomes lighter, more movable, and favors rapidity of movement by the removal of the centre of gravity from the anterior limbs.

These are reasons of so little value that an excess or a deficiency in length can be compensated by a short or a long neck. In the saddle-horse, the head should be short; if too long, it displaces the centre of gravity forward, and throws too much weight on the fore limbs. In the dranght-horse, however, this objection disappears and is rather favorable to traction. We have seen many excellent horses which, according to the measurements indicated by Bourgelat, had this region very long or very short. In such instances, the length of the head is to be considered as to its harmonions development with the other portions of the body, which vary with size and race, rather than by its influence upon the real qualities of the animal.

\section{C. - Volume of the Head.}

The volume of the head is represented by different names, which also express its coexisting peculiarity of construction. It is called fine when the osseons processes, the muscles, and subcutaneous blood-ressels and nerves are well ontlined. This is an index of a good constitution, and is a reliable sign of good brecding; whereas, indistinctness of these 
component parts and an abundance of comnective tissue always denote a soft, hrmphatic tomperament and a common ancestry.

The head is termed gross or coarse when it is defective from an excess of all its dimensions, owing its volume more particularly to the great development of its bony framework. The objections to this conformation are the same as to that of the long head. It is admissible, however, with the same restrictions that we made when speaking of the length of the head. In the dranght-horse it is not a defect, because his power depends, in a great measure, upon his weight, and not so much upon the rapidity and extent of his movements; also because it tends to fix the anterior part of the body when the muscles eontract.

The head is designated fleshy or plain when, in addition to grossness, there is an almost complete effacement of the blood-vessels, nerves, and osseons and musenlar protuberances in conseguence of the thickness of the skin and subentaneous tissue, as well as of the diminution of the bony proeesses themselves. It reveals a weak eonstitution, a lymphatie temperament, and all the predispositions to which the latter is heir.

It is called senile or sharp when it appears emaciated from atrophy and absorption of the adipose tissue and of the muscles. The eminences of the bones, such as the maxillary spine, become quite conspienous, the supra-orbit is hollow, the eye is deeply embedded in its orbit, the cheek flat, the face depressed over the maxillary sinuses, and the skin seems attached to the bones. In a word, it presents all the characteristics of arlvanced age and exhaustion from extreme usage.

It must not be confounded with the senile head pioper, of which we will speak further on.

\section{D.-Direction of the Head.}

The long axis of the head may assume three principal positions relative to the vertical line: the oblique, the horizontal, and the rertical. The last two qualifieations are not to be taken literally, but as expressing an approximation to the vertical and horizontal positions.

The head has a good as well as a natural direction when it extends oblicuely from above to below, from before to behind, and forms, with the ground surface, an angle of abont 45 degrees. The horse is thereby enabled to distinguish perfectly objects placed before him; he is enabled to aroid them, and is less likely to stmmble and fall. It is also necessary to add that the bit has a suitable point of support upon the bars, since the insertion of the reins or the lines is more perpendicular to the branches of the lower jaw, which represent the arm of a 
lever. But then there are other reasons of a purely mechanieal nature (Fig. 28).

We represent by the lines $A B$ and $A C$ respeetively the direetions of the head and the neek. The former being very movable, admitting of extension and flexion, we represent the direction of the extensors and flexors by the dotted lines $C e$ and $C d$, in order to show at what angles they are inserted npon their lever-arm, the head. It is to be remarlied that when the obliquity of the head is earried to an angle of 45 degrees, the extensor's and the flexors have an incidence approaching a perpendieular direetion, which they will not have when the head has any other inclination.

The animal respires more easily (the larynx being neither in a state of compression nor exaggerated extension), responds more promptly to

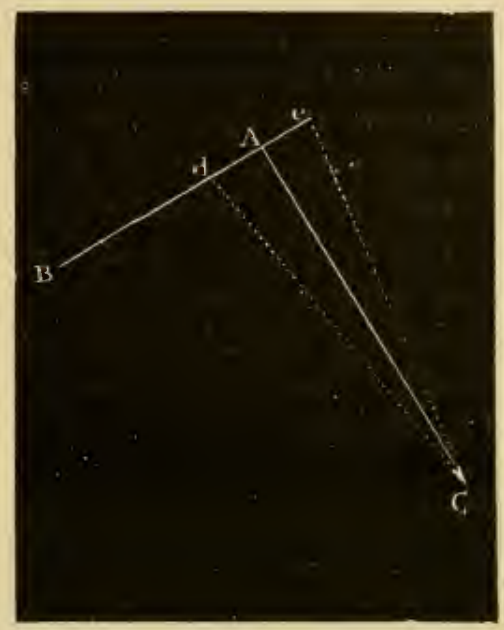

FIG. 28. the bit, is more readily controlled, and executes with greater facility any movements of the head which may be demanded.

When the head is earried horizontally, the centre of gravity is elevated and displaced forward and the stability of the equilibrium is lessened. The larynx and trachea are placed in a straight line, facilitating the entrance and exit of air. The body being then in a state of unstable equilibrium, the hind limbs, which are principally concerned in locomotion, ean more easily displace the centre of gravity, the fore limbs, in order to avoid falling forward, move more rapidly, and locomotion is thereby increased. ${ }^{1}$

This position is not maintained at rest, but only during exereise, and more especially in horses which are ewe-necked and in young saddle-horses at the beginning of their dressing, when they are not yet habituated to the action of the bit. This attitude is expressed by saying that the animal carries his head towards the scent.

If there are some advantages in horses carrying their heads in this

1 It is a well-known fact that in our fastest trotting horses the height of the posterior extremities exceeds that of the withers. This excess is an additional aid to the displacement of the centre of gravity by the hind limbs, according to the prineiple enunciated, and hence farors an increas of speed. An opposite conformation will diminish speed. (Harger.) 
position relative to the increase of speed, of which we will speak later, there are at the sime time some disidvantages. The horse cannot so easily recognize oljects immediately about him; he camnot appreciate as well the nature of the surface over which he travels, aud is more likely to stumble and fall. The most serions defect which this direction entails is that the bit camnot act perpendienlarly to the bars. All the traction exercised on the bit tends to retract the commissures of the lips and carry it against the first molars. The teeth may now grasp the bit, the animal may beeome nncontrollable, and is then said to have taken the bit.

It is to be remarked, from another point of view, that in the horizontal position of the head the extensors attach at an obtuse angle, an incidence unfaromble to contraetion; the attachment of the flexors, on the other hand, is at an acute angle, also a less favorable incidence (Fig. 29, A).
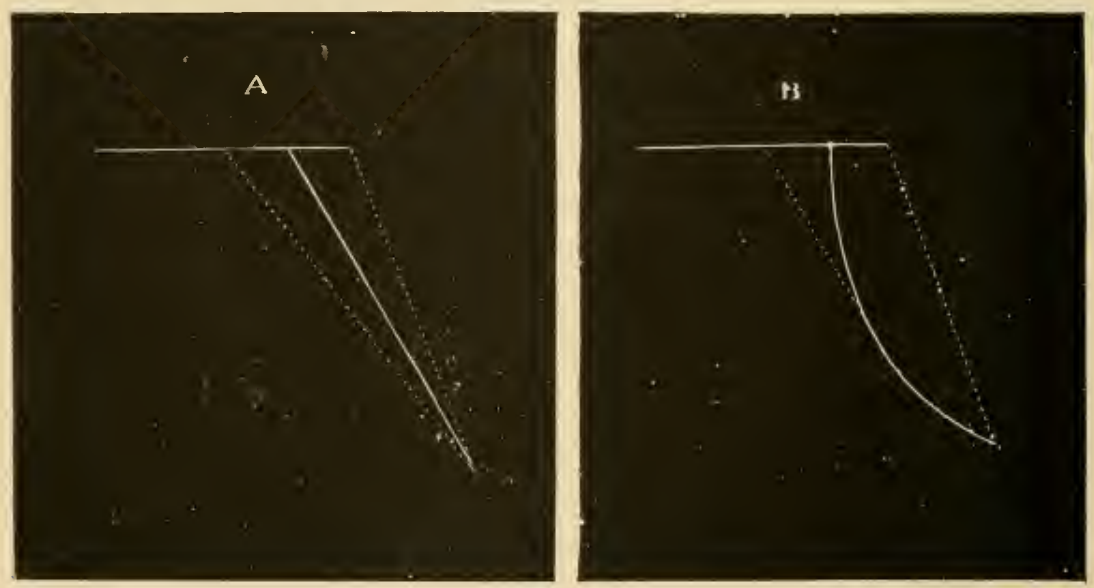

FIG. 29.

This earriage of the head, when habitual, is nearly always aeeompanied by a concavity or reversing of the neck. In such cases, as Professor Lesbre ${ }^{1}$ thinks, the articular relations between the atlas and the axis will assume the normal condition most appropriate for the execution of all the movements. These would be extremely limited in extension if the cervical axis did not enrve itself. Anatomy also explains that lateral inclination of the head in such an elevated attitude becomes almost impossible, because its production 
requires a mean position of contact of the articular surfaces. Finally, the reversing of the neck, which is the consequence, renders the insertion of the muscles, now approaching the perpendicular direction, less defective, and at the same time increases the power of the mechanical action of the nuchal ligament (Fig. 29, B).

It is sometimes impossible to prevent the animal from holding the head in this position. The remedy consists in the nse of the martingale, a strap of leather of suitable length extending from the bit to the girth of the saddle. This apparatus is frequently added to the harness simply as an ornament. In saddle-horses this faulty direction can also be prevented by the nse of a martingale with rings at its extremity, through which the reins pass, and which act as a pulley to keep the latter in their proper position, and thus prevent the elevation of the head.

When the head is held in the vertical position the centre of gravity is carried backward and downward. The line of gravitation approaches the centre of the base of support, whence ensues a state of stable equilibrium, more diffienlty in displacing the centre of gravity, and less quickness of movement. This position of the head is objectionable in driving-horses and in running-horses, whilst in dranghthorses it is not.

A vertical head is always accompanicd by an arched or swan neck, the appearance of which is agreeable to the eye. Besides having the defect which we have indicated, the head is not in a good position for seeing distinctly objects beyond a certain distance. The field of vision does not extend far enough ahead to enable the animal to avoid obstacles which may be in his path. Also, like those which carry the head in extension, he is apt to stumble and fall, but for opposite reasons.

In this direction of the head the incidence of the extensors is acute and that of the flexors obtuse (Fig. 30, A). Here again the neck is incurvated or arched to preserve the normal relation of the articular surfaces of the occipito-atloid articulation and render at the same time the insertion of the muscles more perpendicular to the arm of their lever (Fig. 30, B). This vertical direction is less objectionable in the saddle-horse than in any other. In horses which present it the steps are short and the flexion of the knees (knee-action) is more marked. They are more sensitive to the bit, and quite manageable if the conformation be not exaggerated.

When excessive, however, it constitutes a serious defect, as when the head is oblique from abore to below and from before to behind, and its inferior extremity approaches the sternum. The effect of the backward 
displacement of the centre of gravity has here reached its highest
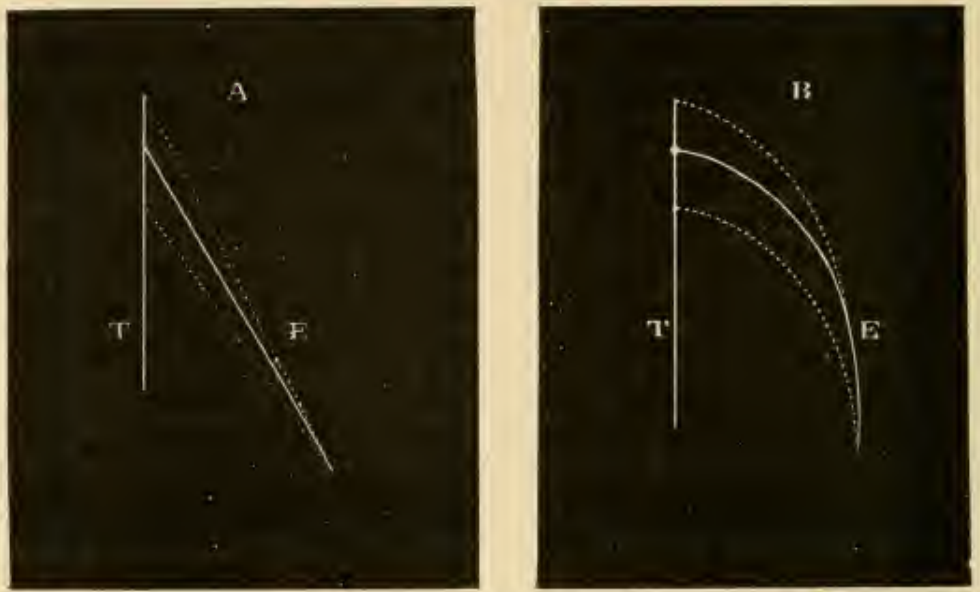

FIG. 30 .

limit; according to the usual expression, the horse arehes his neck to

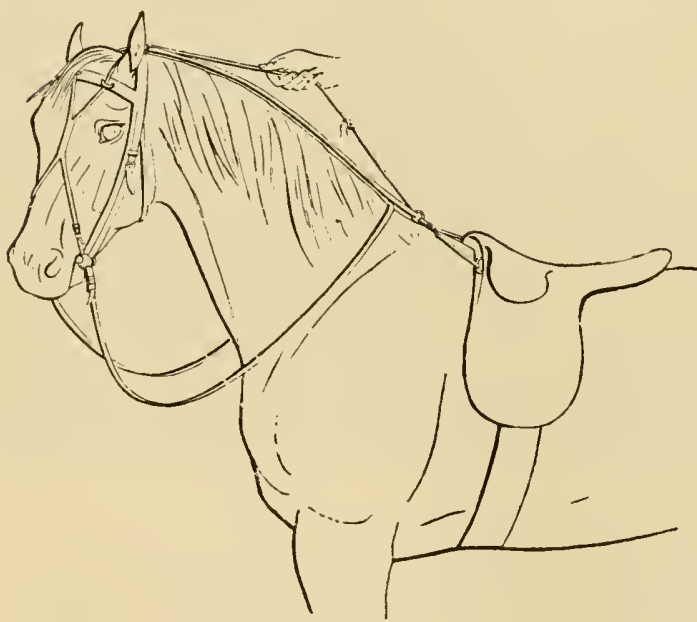

FIG. 31 .

his breast, cannot see the surrounding obstacles, and removes his head entirely from the control of the hand.

In certain subjects the branches of the bit are said to touch the pectoral region. This has not ret been proved by our observation. If it be true it can be remedied by limiting the excessive flexion of the head upon the neck by means of an over-

check, - a system of straps extending from the saddle to each side of the bit and inflected over the poll (Fig. 31).

\section{E.-Forms of the Head.}

At the beginning of the chapter we compared the general form of the head to that of a quadrangular pyramid, in order to establish the 
different subdivisions and facilitate their deseription. This comparison is not sufficient to specify elearly certain conformations which must be described, and to which have been given particular names.

1. The head is ealled straight when its anterior face is rectilinear in every sense. It is accompanied ordinarily by a wide forehead and nose, large nostrils, wide separation of the ears, the eyes, and of the branches of the lower jaw, exceeding fineness of the skin, of the eyelids, and of the lips, and a high faculty of expression. It is the type of absolute beauty ; it indicates the nobleness of the animal, his purity of blood, his energy, and his kindness of temperament. It is found in Aryan and thoroughbred horses and their descendants of mixed breed. It is the one most highly appreciated.

2. The conical head is that which is much contracted at its inferior extremity. It is regarded as a defect, becanse it presents, it is said, all the characters opposerl to those of the preceding form. This is true in many cases, and some who designate the beanty of the head by saying that the horse should be able to drink firom a glass, little suspect that they indicate precisely the defective point; the animal is nearly always incapable of performing work requiring force and energy. Yet we have known, for several years, excellent horses which had the conical head. Old subjects, from senile atrophy of the maxillary bones and the change in the direction of the incisor teeth, sometimes acquire this form of head.

In a general examination it is necessary, therefore, to assure ourselves that the forehead and nose are wide, the jaws well separated; in a word, that the head dues not present one of the more exceptional forms of which we will speak immediately. In the latter the anterior surface of the head is characterized by a curvature more or less marked, which may be concave or conrex. These have received special names.

3. The head is arched when the profile of its anterior face is convex.

t. It is called hare-faced when the convexity is limited to the region of the forehead.

5. It is designated ram's head when the convexity is limited to the nose.

De Curnien also described the hurdy-gurdy head, so named on accomnt of its resemblance to the profile of that instrument. It presents " a curve, more or less pronounced, extending without interruption from the poll to the lips ; it ordinarily has considerable expression and inclicates a pure line of descent." It is not necessiry to dwell upon this variety, as all its characteristies correspond to those of the archer form. 
The concexity of the head, whatever may be its extent and degree, is not very desirable, on aceount of its inelegance and the habitual narrowness which accompanies it.

For a long time, more especially during the last century, the convex head was very much in demand. But it was believed that horses which presented it had narrow nasal cavities and intermaxillary spaces; that they were particnlarly predisposed to become roctrers. By judicions crossing, attempts were made to canse its disappearance from the races in which it was most common,- - those of the north of Europe, Normandy, Limousin, Spain, Algeria, ete. To-day it is quite rare and is ceasing to be a distinct race peculiarity. Most authors have considered it as characteristic of a deficient development of the cranial cavity and the respiratory apparatus, and as indicating a predisposition to grave diseases. M. de Curnieu remarks that "it represents the extreme of degeneration; the horse possessing snch a shaped head is the idiot of the species, and is found in the poorest parts of England, Germany, and Normandy."

6. The head is snub-nosed when its anterior face is concave, or when the coneavity is limited to the inferior part of the forchead. It is common among the Irish race, as the Irish cob and the Shetland pony, and in the Corsican and Sardinian ponies. Ordinarily short, wide, and in relation with the development of the respiratory apparatus, it is incorrect to believe that it is an objectionable characteristic. Nothing justifies this belief. It gives the animal a certain air of aggressiveness and independence; it is often allied with marked robustness, great energy, and a series of other good qualities of the race in which it is observed.

7. The head is compared to that of the rhinoceros when the concavity exists only at the inferior extremity of the nasal bones. It was formerly observed in the Ardenmaise horse and is a good conformation, although perhaps disagreeable to the eye. It may be congenital or acquired: congenital, when it is present at birth; aequired, when it is the result of pressure or of fracture of the nasal bones, as we have remarked in the chapter on the nose. It only becomes a defect in the latter case when, from displacement or the formation of a callus in the nasal fosse, it becomes an obstruction to respiration.

The relative value of these different forms is by no means ahsolute, and each one has numerous exceptions. We have known horses with arched heads, which, during several years, performed extremely laborious scrvices. In others, the width of the maxillary space by our measurements was as great as that in subjects with 
straight heads. It appears to us very hazardons to believe that this conformation predisposes to roaring, and the facts which we will relate seem to prove that the observations made during the last century have been mal-interpreted. 'The lesions of chronic roaring do not reside in the nasal cavities. Among horses with straight heads roaring seems to be as common as among those in which they are convex; finally, it should not occasion surprise to find roaring more common in some races than in others, this resulting not so much from an anatomical defect as from a physiological weakness transmitted by heredity. This conformation is really only defective when accompanied by a veritalble narrowness of the cranial cavity, the forehead, nose, nostrils, or maxillary space. In other cases it is perfectly reconcilable with services which exaet foree and vitality. The same argument is true as to glanders, to which horses with arched heads were, incorrectly, said to be more predisposed than others.

\section{F.-Attachments of the Head.}

Attachments of the head is the name given to the mode of union between that part of the body and the neek. The head is said to be well attached when there exists a slight depression in front of the transverse apophysis of the atlas, extending from the poll to the throat. When its union with the neck forms a graceful curve, the movements are easy and extended. This is preferable in the saddle-horse and those used for light purposes. It is to be noticed in the finer races as well as in mixed breeds, in the English horse, the true Arabian, the Anglo-Norman, the Tarban horse, etc.

The head is poorly attached, or unfastened, when the parotid grooves are too much accentuated. Often, with this arrangement, the neck is long and slender, the muscles of the members slightly developed, the loins depressed, the chest narrow, and the animal lacks strength and endurance. The head is plastered on when the parotid groove is effaced. The subject is then heary on the bit and appears unsightly. This condition is most oljectionable in the saddle-horse.

\section{G.-Movements of the Head.}

The movements of the head play an important part in the execution of the different functions which it fulfils. It contains, first, the organs of smell, sight, hearing, and taste. We can add to these the sense of touch, although the latter belongs also to other regions. Whence it follows that the head is obliged to assume different attitudes in order 
to place the organs of which it is the seat in the best conditions to establish their proper relation with the external world. The most interesting movements for us to study, however, are those whose object is to modify the position of the centre of gravity while standing or walking. The head occupies, in fact, at the anterior part of the trunk, a position which also allows it to oscillate like a veritable pendulum at the extremity of the cervical stalk. It may be raised or lowered, remain in the axis of the borly, or be displaced laterally, backward, or forward; in a word, the centre of gravity can be moved upwarl, downward, forward, backward, sideways, raised from the base of support or drawn to it, removed from the centre of this base, forced ont of it, or again drawn back. These multiple actions are produced still more freely by the head when it is attached to a long neek, in which ease its movements are easier and more extended. Therefore, all the influence which it exercises upon locomotion can be understood, since it can, according to the will of the animal, change rapidly the conditions of stability or instability of the equilibrium; in a word, modify the speed.

Not only do we speak of its extensive displacements, the effect of which is understood at first sight, but we also make allusion to its partial movements upon the neck.

According to our researches, the centre of gravity of the head is situated on the median line, at the intersection of a transversal plane, which passes posterior to the last superior molar tooth, and of a horizontal plane tangent to the palatine arch. Should the head be extended, it becomes a mass of about fifteen to sixteen kilogrammes, which will carry it, from this fact alone, in advance of the cervical lever, and which will tend to deviate the line of gravitation in front of the base of support. This is the attitude which it assumes in the race-horse when he is rumning at finl speed. When it becomes flexed, reverse effects are produced; when it is directed to the side, the corresponding anterior member will at once be overburdened, and the other as much disburdened. This is sufficient to explain the importance of these total and partial displacements. We will, besides, have occasion to return to the subject when describing, in their proper place, the gaits, the attitudes, and the movements which the animal performs.

\section{H.-Expression of the Head.}

The face of the horse is certainly the part of the body upon which the sensations and the passions which he experiences show themselves 
most clearly. When this filculty of expression is carried to a high degree, he is said to have figure and expression.

The parts which are most particularly charged with the manifestations of the different internal states of the anmal are: the eyes and the eyelids, the ears, the nostrils, the lips, and the month. These organs, through the different attitudes which they take, depict, by turns, gentleness, vivaeity, anger, sadness, depression, joy, pain, fear, frankness, courage, ferocity, aggression, savageness, indifference, stupidity, emmui, ete. Ordinarily, the fueulty of expression of the head is in direct relation with the purity of the race, the quality of the animals, their energy, and their intelligence. But it is a gross error to believe that it is possible to appreciate the qualities of a horse from an examination of his physiognomy alone. The latter, like that of man, ean deceive, perhaps still more, for it has not the same mobility and shades; its language is less familiar to us; its most powerful auxiliary (gesture) and its best interpreter (speech) is wanting. Besides, if the features of the face are quite well understood, through edneation and habitual intercourse, as regards horses of the same species, they become much less comprehensible when it is a question of different species having between them only limited relations.

Man reads upon the face of his fellow-man sentiments which he feels; long observation and habit are indispensable to him, on the contrary, in order to understand the expressive manifestations of the horse.

Besides, we should not be deceived about their valne; for in some select subjects in which the head clearly reveals the greater part of the internal passions, the mass of the body will often deprive it of expression.

The ability of the buyer will consist, then, in the prudence with which he guards himself against the premature inferences that can be drawn from their absence.

It must not be forgotten that he who exhibits the animal for sale is greatly interested in showing qualities which the horse has not, or has only in a feeble degree, and can by a kind of special preparation-the fear of blows, the blows reeeived, the introduction of a piece of ginger into the anus, etc.-give him an appearance of vivacity or energy which, unfortunately, will be only temporary. 


\title{
PART II.
}

THE BODY.

\author{
CHA P'TER I. \\ SUPERIOR FACE OF THE BODY.
}

\section{A. - The Neck.}

Situation; Limits; Anatomical Base.-The neck is a single region, flattened from side to side, sitnated at the anterior extremity of the trunk and supporting the head. Free on its lateral faces, it is limited in front and above by the poll, the parotid region, and the throat; behind and below by the withers, the shoulders, and the brecist.

It has for its osseous base a bony axis formed by the cervical vertebre, sustained superiorly by the two portions of the nuchal ligament and enveloped completely by numerons and voluminons muscles. The trachea, the esophagns, the arteries, the veins, the lymphaties, and, finally, the nerves leading to the head, occupy its inferior border. The mane adorns its superior border.

This region is an important one to study, becanse it constitutes at the anterior part of the trunk the arm of a lever more or less long, whose extremity gives attachment to the head, which is a kind of resistance that follows all its displacements and coneurs with it to modify the sitnation of the centre of gravity during progressive movements.

Divisions. - Whatever may be the particular form of the region of the neck, it may be represented as a pyramid flattened from side to side, the buse of which corresponds to its posterior and the summit to its anterior extremity. Its periphery presents, besides, two faces, a right and a left, and a superior and inferior border.

1. Lateral Faces.-Each of the lateral fuces is traversed over its entire length by a round thickening corresponding to the cervical vertebre covered by the museles, the most superficial of which is the mastoido-humeralis. Above this enlargement is an irregularly-triangular 
surfice, on which are seen, in fine and well-bred horses, the digitations and direetions of the muscles mnderneath the skin. Below, it presents a longitudinal depression along the side of the trachea, known under the name of jugular grtter. The width of the latter diminishes from before to behind; its depth varies with the subject aceording to the form of the neek, the muscular development, etc. In those animals in which the neck is stag-like, or reversed, this gutter is more superfieial. Whatever may be its disposition, it lodges under the skin a large superfieial vein, the jugular, which becomes immediately very apparent when the circulation of the blood is interfered with by any obstacle, as the pressure of too small a collar, for example.

2. Borders.-The inferior border is thick and rounded, because it has for its base the trachea. Its width from side to side is in relation with the ealibre of this eonduit and the amplitude of the lungs. It constitutes, therefore, a mark of absolute beauty.

The superior border, thinner than the preceding, supports the mane. Its thinness is a matter of beauty and is to be songht for ; but, in some old horses, especially stallions, it beeomes invaded with adipose tissue, which renders it so heavy that it eannot sustain itself and falls to one side. Such a condition is ealled lop-neck, or fallen-neck, an ungraceful disfigurement which makes the application of the collar diffienlt, and is accompanied by deep transverse folds, which are always hard to cleanse, and in which colonies of acari often take refuge. ITe have seen some animals in which these furrows were sufficiently deep to bury the hand when the head was extended.

The region of the neck should be examined as to its form, direction, or carriage, rolume, length, mode of attachment to the head, and its morements.

Form.-The neek is ealled straight, or pyramidal, when its borders are rectilinear and its lateral faces nearly plane or but slightly rounded, according to the age, the sex, the volume of the museles, ete, of the animil. The head is then well supported and well directed. It is arehed when its superior horder deseribes a convexity more or less pronounced throughont its entire length. In this ase the head is ordinarily earried in a vertieal position, and presents the defectiveness of which we have already soken. If the convexity be limitel to the anterior part it is designated sman-meck, by reason of analogy to the neck of that bird, whose graeeful curvature it imitates. This form modifies, like the preceding, the carriage of the head, but the vertical direction which the latter shows is less pronomned. Finally, the neck is reversed, or ene-nectied, when its superior border is coneave, which implies a proportional con- 
rexity of the inferior border. Many horses showing this conformation have, in front of the withers, a distinct depression. Most of them also hold the head in a horizontal direction, as we have indicated.

In a general way, all these forms are so much more compatible with the velocity of the gait the more the head is carried in advanee of the base of support and, consequently, as the cervical trunk is less convex along its superior border. The pyramidal and reversed forms remove the head farthest from the body and denote the greatest speed. On the contrary, the arched and the swan-neck, by their tendency to curve the vertebre in the shape of an $\mathrm{S}$, diminish the length of the neck, move the centre of gravity backward, and are more favorable to its elevation and depression as well as to the lateral displacement of the trunk. They also offer advantages in the saddle-horse, in which grace, brilliancy, rapidity, and extent of movement are preferred.

These conformations can be acquired by means of mechanical contrivances and appropriate dressing. All horsemen are in the habit of making the necks of their horses supple by obliging them to execute progressively the movements of extension, flexion, and lateral inclination. The utility of such suppleness is easily understood, since this kind of functional gymnastics has no other purpose than to habituate the animal to use this balance-so powerful and so useful-with dexterity and rapidity, and thus overcome the resistance of the head. We shall, farther on, see that these cervical gymmasties, carried to an extreme, will prove prejudicial in certain cases, while, when well employed, their efficacy becomes incontestable in certain others.

Direction or Carriage.-Independently of the particular forms which it assumes, the neck also carries itself in several directions relative to the vertical line. We shall consider three varieties:

1st. The vertical, or, more properly, an approximation to the vertical. In this attitude, which constitutes a point of beanty and indicates energy, the head is easily sustained, the animal is easy on the reins and the bit, and the movements of the shoulders are free and extensive (Fig. 32).

Let $m m$ and $O B$, for illustration, represent the directions of the shoulder and the neck respectively. The extensor muscles and the mastoido-humeralis will be schematically represented by the lines $B m$ and $B n$. The latter, it will be plainly seen, has a more eonsiderable length, and therefore a greater amplitude of contraction to elevate the scapulo-humeral angle and increase the are described by the forefoot. We see, moreover, that the weight of the head, represented by the line 
$B R$, indicating the direction of the force of gravity, is exerted at the end of the cervical lever at a very acute angle, an incidence which diminishes the intensity of the force of gravity. This explains why horses arrying the neck in this position are not hard-mouthed; the

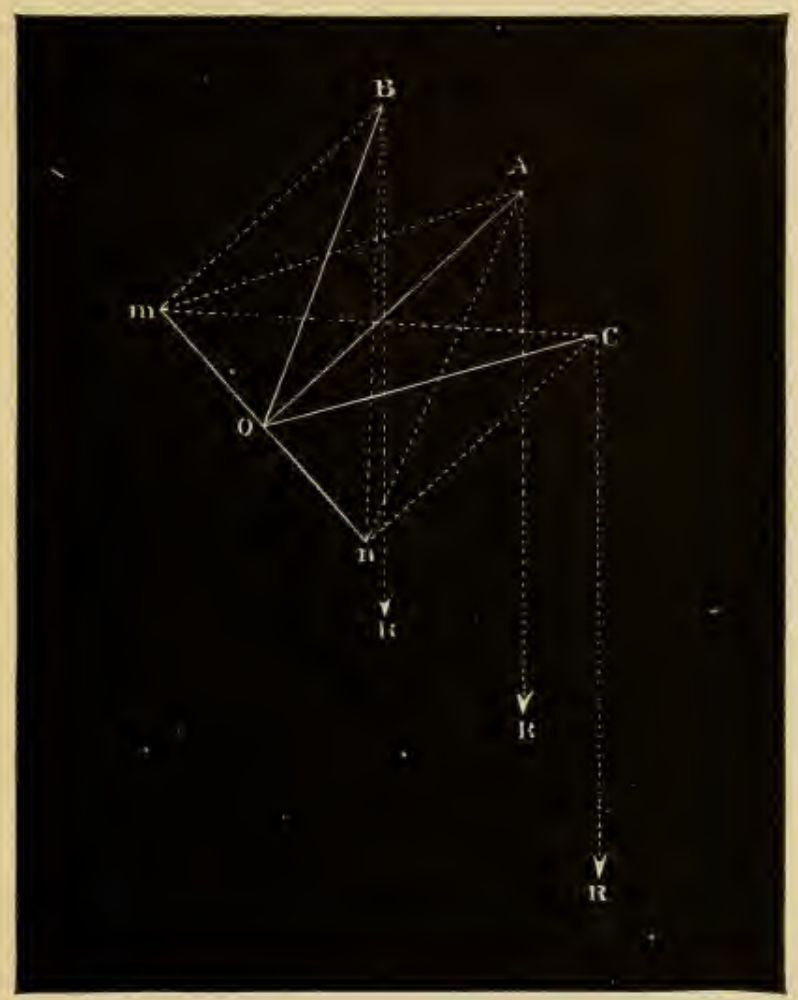

FrG. 32.

head seems to weigh less at the end of the cervical stalk, in consequence of the slightly-perpendicular incidence of the line of gravitation.

Finally, we eall attention to the favorable insertion of the extensor muscles, $\dot{B} m$, which are in excellent condition to resist the weight of the head and to earry it backward in order to give freedom to the action of the anterior limbs. Horses with necks thus formed are well qualified for all the brilliant movements of tossing and balancing the head in the riding-school and in the parale.

2d. The Horizontal. - We observe this direction in animals that are deficient in energy, in the common races, and in those which are 
fatigned. "If the last," sayrs H. Bonley," "are prevented, by the resistance of the reins, from inclining the head towards the ground, they continually toss it up and down, and by this oscillating movement case the muscles and relieve themselves of the fatigue which this position ercasions." We also see horses that are attached to heary loads assume this attitude occasionally, for reasons which we have seen when speaking of the direction of the head.

Whatever may be the circumstances under which we observe it, the animal always has a hard mouth, and his gait is shortened. We must except, here, the race-horse, whose neck is held horizontally when he is urged to his utmost speed, but assumes another position under ordinary circumstances. All these facts are explained by the mechanical considerations employed above.

Let, for example, $m n$ and $O C$ be the relative direction of the shoulder and the neck (Fig. 32). It is plain that the mastoido-humeralis is shortened, and therefore has a limited degree of contraction. Nevertheless, its insertion in the shonlder is much more perpendicular than in the preceding direction, whence it results that the muscle will be more powerful as regards the intensity of its action. We understand from this fact how it is that horses which become exhausted during a long journey carry the neck in this direction. Moreover, the line of gravitation, $C R$, of the head tends to become more and more perpendicular with the cervical axis, which gives to the head a greater power of resistance and explains why these animals are always hardmonthed.

The head thus held displaces, besides, the centre of gravity forward, relieves the posterior extremity of the body from a portion of the weight sustained by it, and exacts a smaller expenditure of force in the propulsive efforts of the hind limbs.

3d. Finally, the neck may assume an intermediate direction,- that is to say, an obliquity of abont 45 degrees. We see again, by inspecting Fig. 32, that in this instance the advantages and disadvantages of the two preceding directions are about equally distributed. The muscles have a mean length, and their incidence with the shonlder is favorable, the step is snfficiently extended, and the head is neither too light nor too heary on the rein. In a word, for good service, this is the numal position assumed by most horses, the golden mean to which it shonld be reduced.

Volume.-The volume of the neek should not be too large.

1 H. Bouley, Dictionnaire pratique de médeciue, de chirurgie et d'hygiène vétérinaires, $t$. vi. art. "Encolure." 
It is important that the latter should be harmonionsly proportioned to the other parts of the body, and only by practice are we enabled to judge of the characters which denote this harmony. Thus, it may be slender or thick, two conformations intimately associated with an excess or a deficiency of its length. However, in stallions the neck aequires a development which must not be considered as a defect. The effect of castration is a diminution of the thickness of this region to a notable extent.

Length.-The length of the neck, which is measured from the middle of the anterior border of the shoulder to the anterior extremity of the transverse process of the atlas, is correlative to its volume, which should be neither excessive nor defieient, under penalty of destroying the usefulness of the animal.

Let us see what happens when the cervical lever is lengthened or shortened on this or on that side of its normal dimensions. Let (Fig. 33) $m n$ and $O C^{\prime}$ be the relative directions of the shoulder and the neek;

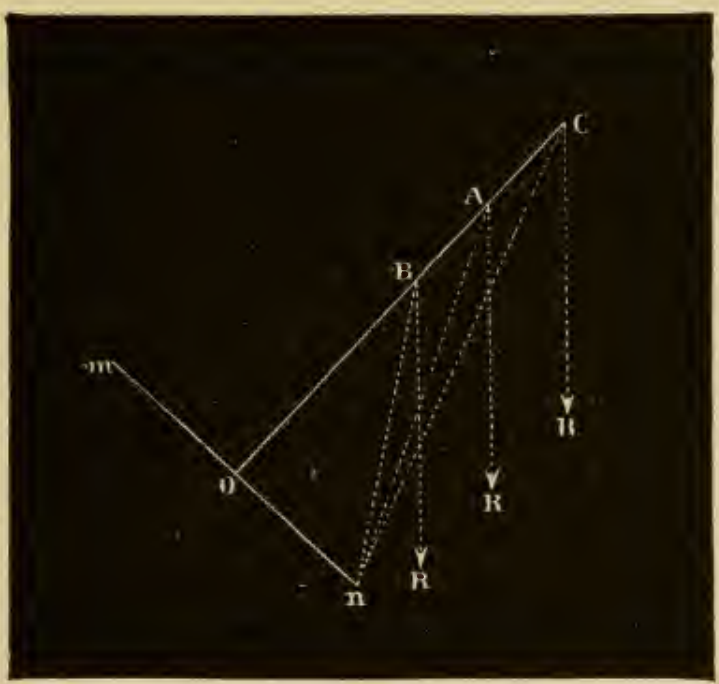

FIG. 33.

let, on the other hand, $O C, O A$, and $O B$ represent the lengths of the neck gradually decreasing.

1st. When the length is proportional, $O A$, it allows a sufficient extension in the movements of the shoulder and in the displacement of the centre of gravity ; the heal is not too heary on the bit, and the cervical trunk possesses suppleness and a mean power of mobility. If to this quality be added a good direction and a high carriage, we will find the conditions most favorable for all gencral services. 
The proper length of the neek cannot invariably be determined mathematically, as Bourgelat has pretended when he assigned to it the same length as that of the head. Although this relation may be constant, we find some compensations correcting the errors in the one sense or the other, and altering the external beanty no more than they influence the good qualities of the animal. We will return to this in disenssing the proportions.

2d. When the neck is too long, $O C$; its greatest disadvantage lies in overburdening the anterior portion of the body and in bringing the centre of gravity too far forward. It frequently becomes defective, besides, by reason of its slender and emaciated appearance. Finally, it renders the head heary because it increases the length of the lever of this resistance, $C R$.

Nerertheless, nature often brings compensations which remedy the undue length of the neck and give to it the characteristics of a veritable beauty. This consists, first, in its elevated attitude, which does not permit of excessive weight on the anterior quarters, by displacing, to a proper degree, the centre of gravity backward. There is, in consequence, a firm, energetie, and powerful muscularity, which gives sufficient volume and counteracts the slender appearance. The smalluess and lightness of the head diminishes the force of the resistance, $R$, in its relation with the abnormal length of the cervical lever. This compensation, joined to a direction approaching the vertical, contributes to render the head lighter on the reins, becanse the line of gravitation in this case is applied at the extremity of the neck with an ineidence more or less acute.

It is useful to remark, also, that the length of the neck denotes a correlative development of the muscles, $C n$, elevators of the scapulohumeral angle, and therefore a large extent of contraction and a long swing to the forefoot. The insertion of the museles on the shonlder being more perpendicular, their action will be for this reason more energetic. In addition, the neck, by lengthening itself, becomes more movable and acquires a greater influence upon the displacement of the centre of gravity. These are its real advantages in the race-horse, whose neck is not really beautiful unless it is long, very muscular, carried high, and provided with a light head.

3d. Finally, the neck may be too short, $O B$. In this case it presents advantages as well as disadvantages, aceording to the purposes for which the animal is intended. In driving- and saddle-horses, especially the latter, it lacks suppleness and mobility, is generally thick and massive, and renders the animal less subject to control. 
It is essentially defective in the race-horse, because its movements are slow and have but a limited action on the displacements of the centre of gravity. Let us add that the paee lacks amplitude by reason of the defect in the length of the elevator muscles of the shoulder. Horses having short neeks owe their speed less to the extent of the movements of the limbs than to their frequent repetition in a given time.

It is not the same in the draught-horse, in which the work is effected altogether by his weight and the energy of his efforts. A short neck can be redeemed by a firm and powerful museularity, which will furnish a large surface for the support of the collar and will, at the same time, indieate great power. The brevity of the cervieal lever will be compensated again by its horizontal tendency, because the elevator museles of the seapular angle profit by a more perpendicular insertion, without which the anterior displacement of the centre of gravity of the head would overburden too much the anterior members. In a word, the gait will be slow, whilst the energy of the effort will be carried to its maximum if, as we have said, the region lias very vigorous museles.

From the preceding considerations, we must conclude that each kind of service demands a determined length of the neck: that for extreme speed we must have a neck of long dimensions, well carried, and supporting a light head; that for great and powerful efforts we need weight and musele,- - that is to say, a large quantity of contractile elements and these in a voluminons mass; finally, for ordinary speed and energy, the neek should have intermediate proportions.

In all cases it must not be forgotten that between the medium and the extremes there is a whole seale of intermediate forms which are neither excessive nor deficient, and that when the neck attains either extreme there are still certain compensations for it perfeetly compatible, if not with absolute beauty, at least with energy and vigor.

Attachments.-Those lines which mark the limits of the supe $\frac{1}{1}$ rior and the inferior borders of the neck constitute what are called its attachments.

A propos of the head, we have already spoken explicitly of the superior attachment. We know that there is a slight furrow on the external face of the parotid gland ; that the larynx and pharyx are asily lodged in the space between the rami of the inferior maxilla; that the nape of the neek, the parotid gland, and the throat, ats al whole, appear to present between the head and the neck a slight constriction, whose rounded and graceful profile enables us to surmise the 
perfect freedom of their reciprocal movements. When these conditions are not fulfilled, the lead is said to be plastered on, or malattached; its movements are not so easy, as we observe it, more especially in short and thick necks.

"The inferior attachments of the neck," say's H. Bouley (loc. cit.), "should be marked on each side by the slight relief which constitutes the anterior border of the shoulders; on each side of the tracheal border by the angle of union of the jugular gutters converging towards each other above the point of the sternum; finally, towards the withers by a depression in front of the summit of this region, generally not well marked. In these conditions the neck has a good origin: it is well attached. In other words, it harmonizes with the anterior parts of the trunk, of which it is a continuation. The facts are not the same when the neck is meagre and thin, and its inferior border forms with the chest a very pronounced angle; when the demareation between it and the shoulders is established in an abrupt and salient manner; when, finally, the depression in front of the withers is deeply marked. In such cases we say that the neck is malattached, or, better, that it is stuck into the thorax, a very striking expression, which conveys an exact idea of this defective conformation."

Since we are speaking of the inferior attachments of the neek, we will describe a peculiarity which is sometimes met with, and to which, for a long time, the name of cut of the spear has been given. "The cut of the speetr," says Garsault, " "is a hollowness quite deep, which is seen in Turkish and Spanish horses at the junction of the neck and the shoulder, sometimes higher and sometimes lower. This is considered as a very good mark, the canse of which is told in a fable, which sars that an excellent Turkish stallion received a stab from a spear in that part, and that all his descendants-he having been placed in the stud-inherited this mark of honor."

I Lafosse, in his "Dictionnaire d'hippiatrique," observes with truth that this peculiarity is present as often on the left as on the right side, and that it is not hereditary. Special rescarches have demonstrated that it consists simply in a congenital atrophy of one of the digitations of the angularis muscle of the scapula. The atrophied branch leaves a depression which extends to the level of its insertion on the corresponding transverse process of the cervical vertebra.

Movements.-Considered in its relation with the locomotory 
functions, the neck represents a balance which supports the head at its anterior extremity, and whose displacements carry it upward, downward, backward or forward, and to one side, at the will of the animal. Remarkably mobile, from the fact of the numerous pieces which form its osscous base and the powerful muscles which move them, this balance plays the greatest rôle in most of the attitudes taken by the animal machine in movement.

We have already seen its influence upon the stability of the situation of the centre of gravity. (See Experiments of Morris and Bancher, page 6.) This influence is still more apparent when the animal rises, lies down, kicks, prances, walks, trots, gallops, leaps over obstacles, ete. Under all these circumstances the neck is carried first to the side opposite to that part of the body which is to move first; then it liberates successively all those parts which will continue this movement or terminate it. Its displacements are always proportional to those of the entire body ; very quickly depressed in kicking, elevated in prancing, moving from side to side in walking, and forward and backward in the gallop. When the movement has a certain degree of uniformity, and is accompanied with great speed in a straight line, the neck accuires then a relative fixity after being extended forward enough to induce the members to move with a celerity in accordance with the rapidity of the gait. We see this, for example, in the fast trot or the gallop.

Some important practical deductions can be drawn from these facts, which may be employed in directing horses, as well as in equestrianism.

If the rider desires the horse to move the left anterior foot when it is in repose, it is only necessary to make traction and urge him forward in such a manner as to increase the weight on the right fore member. If it be desirable to make him change the feet while he is galloping, it is only necessary to disburden this or that member by drawing the neck to the opposite side. If the animal be required to leap over an obstacle, the neck is raised to facilitate the half-prance which preredes the leap. If, on the contrary, the object be to prevent him from falling on his knees, the head is forcibly raised in order to prevent the centre of gravity from being displaced outside of the base of supjourt.

It will be sufficient for us to point out a few instances, in orler to demonstrate the importance of the cervical region in the varions movements, so that we may be able to apply them intelligently in practice.

Diseases and Blemishes.-The blemishes of the neck are cicatrices, which have, aceording to their situation, different significations. We observe them 
ordinarily on the lateral faces, along the eourse of the jugular gutter, and on the borders.

On the lateral faces there are sometimes traces of setons, which occupy the superior third of its length. These are very significant, because they indicate that the animal has been treated for disease of the eyes, the nasal sinuses, or the encephalon, as vertigo.

Along the course of the jugular rein there are traces of firing and linear cicatrices, which suggest that the horse has been affeeted with inflammation of the jugular vein, or that he has undergone a serious operation in this region. It is important, then, to determine if one of these veins is not obliterated. To ascertain this it is sufficient to make pressure with the thumb over its course at the inferior part of the neck, in order to prevent the blood from descending towards the heart. The slight shake of the hand will refleet the waves of the column of blood to the upper extremity of the gutter when the vein is intact. The contrary effect will show that the vessel is obliterated and the circulation is re-established by collateral ressels. If the obliteration exists only in one of the jugulars, the inconvenience is not so great, because the eireulation is still sufficiently active through the one of the opposite side. When, however, the obstruction exists on both sicles, the animal is unfit to perform rapid service, because the collateral veins are insufficient for the afferent cireulation, and congestion of the component parts of the hear is the eonsequence. Moreover, the jugular vein being the ressel selected for phlebotomy, we are not able, under this circumstance, to have recourse to it in cases of emergeney.

Very frequently the bleedings, of which one of the veins has been the seat, leave their trace on the skin. A very small longitudinal cicatrix indicates the spot where the tissues have been involved by the fleam of the operator. At other times these traces are more apparent, manifesting themselves by raricose clilations, simple or multiple, along the course of the vein, at the level of the places where it had been punctured. This condition is called varicose.

Along the inferior border we recognize cicatrices resulting from tracheotomy, - that is to say, the artificial opening of the trachea for the prevention of asphyxia when the natural air-passages are occhded or have an inadequate calibre. It is necessary, in a case like this, to exereise the animal in every possible way to determine whether he is or is not a rourer. A horse that carries a tracheal tuhe permanently will almost completely lose his value, and should not be purehased.

We observe, also, along the inferior border of the neck, surfaces flattened from before to behind, arising from fractures of the eartilaginous rings of the trachea, or from a congenital deformity of the conduit, which infringe on its sides, and always diminish, in the same proportion, its internal calibre. Oceasionally, difficulty of respiration arises in consequence of this affection, and we should fully satisfy ourselves as to the manner in which respiration is effected in horses with such a deformity.

Finally, the superior border of the neck may present cicatrices following deep abscesses with necrosis of the nuchal ligament, a disease which requires a long time to reeover from, and which should never be passed unobserved. These blemishes are ordinarily oceasioned by the use of a collar too small or improperly fitted.

From the same causes appear calluses and corus along the anterior border of the shoulder, or in the vicinity of the superior border of the neek. 
The diseases of the neck are affections of the skin, as surfeit and mange along its superior border; inflammation of the jugular veins, thrombi and phlebitis; lesions of the osophagus and trachea; inflammation of the lymphatic ressels, lymphangitis, followed by knotted indurations along the course of the ressels; and, finally, lesions of the cervical ligament.

We cannot enter into long details in this connection without going beyond our province. Suffice it to say, that most of these diseases continue a long time, and are difficult to eradicate, on account of the situation, the structure, and the movements of the region in which they are found.

The Mane and the Forelock.

Situation; Limits. - The mane and the forelock are formed by the horse-hairs which occupy the superior border of the neck and extend forward to the superior extremity of the head between the ears, and backward to the withers.

a. The mane is to the neck of the horse, says H. Bouley (loc. cit.), what the capital is to the column which it sumounts; it beautifies the neck by concealing, under its undulating tufts, the angularity of the superior border, and thus gives to the latter a more graceful aspect.

Its abundance varies according to the race, the sex, the age, the state of the genital organs, and the animal himself. In well-bred horses and in foals it is fine, silky, and not abundant, while it is coarse, long, and stiff in common horses and most plentiful in adults. Thus, it appears more bushy in the stallion than in the gelding or in the mare. This state of the mane and its color denote nothing absolute and have very little signification In this respect the individual differences are so mumerons that all inferenees as to the pecnliarities of the animal's character thus deduced are uncertain as well as delusive.

We habitually separate, with the scissors, the mane from the forelock at the level of the nape of the neek, where the head-stall of the bridle rests.

The mane is said to be single when all the hairs which compose it fall on one side of the neck, regardless of their length. In saddlehorses it is turned towards the left side so that the rider may seize it in mounting the horse. In the ease of draught-horses, which invariably occupy the same position relative to the pole, the one attached on the left side (near horse) has the mane on that side; the one on the right side (off horse) carries it on the right side. This detail, however, is often neglected.

The mane is double when naturally parted in the middle, one-half falling to the right and the other half to the left side. Thus, being 
exposed in the eentre, it is soiled by particles of fodder and dust. It is difficult to preserve cleanliness, and the parts beome the seat of such affections as herpes and psoriasis, which persist with so much tenacity that it is sometimes impossible to eradicate them completely.

In their natural condition, as we have already mentioned, the hair's fall from their own weight. They are in certain cases cut so as to assume an erect direction and form a sort of erest on the median line, outlining the eonvexity of the neek more distinctly and making the latter appear heavier. Such is the custom with ponies and small horses, and particularly those in which the neck is reversed, with the view of rendering its appearance more agreeable to the eye. To-day this is the fashion even in the teams of the wealthy.

Among the ancients it appears to have been the eustom to cut the mane as a sign of mourning. To render it thicker and longer, the Arabs of Algeria, aceording to Vallon, ${ }^{1}$ also employed this method for from one to four years, and sometimes even throughout the life of the animal.

The hairs of the mane, like those of the tail, are ordinarily straight. One of our associates, Mercier, has communicated a remark on this subject, which was also believed by the Arabians: that it is in the white or gray horses with frizzled or eurly hairs in which melanotic tumors are always found in the interior of the boty, although none may have any apparent trace on the exterior, particularly under the tail and around the anus. This remark, the correctness of which we have verified a number of times, both on the living subject and in the cadaver, is very important because of the dangers to which animals affected with melanosis are predisposed.

There are neither diserses nor blemishes of the mane. It is therefore erroneous to attribute to this appendage what properly belongs to the superior border of the neek.

b. The forelock is nothing more, properly speaking, than the superior extremity of the mane. It consists of a tuft of hairs varying in length with the animal and the race, which escapes between the ears in floating meshes, overshadowing the forehead and the eves. Ordinarily, in the English thoroughbred horse it is light, fine, and silky. In the Arabian horse it is, on the contrary, long and heary. In common horses it is long and coarse. Like the mane, it may be single or double. All proportions being preserved, it is most developed in Oriental horses. It the same time that it is an ornament to the 
head, it protects the eyes from insects and excess of light. It acts, perhaps, also as a protection to the organs contained within the cranial eavity against the solar rays, and in horses much exposed to the sun its removal is injudicious.

The mane and the forelock sometimes attain extraordinary dimensions. We have seen well-bred and common horses in which the former descended to the level of the knees and the latter to the inferior extremity of the nose. With certain exceptions, these appendages are not allowed to reach so great a length; they are dressed by means of a comb or a brush. Sometimes it is desirable to render the mane, which was primitively double, single. This may be accomplished by removing a portion of the hairs by extracting them with the currycomb and continually brushing those remaining to the same side, the right or the left, as may be desired, according to the fancy of the owner. If, instead of proceeding as we have just indicated, scissors were employed to remove the superabundant hairs, these would again grow and remain straight. We have known a horse which, in consequence of the want of skill of the person who had arranged the mane, had the latter falling to the right, while on the left the hairs were upright like a brush, giving them a very ungraceful appearance.

\section{B.-The Withers.}

Situation; Limits; Anatomical Base.-The withers comprise a single region situated on the superior face of the trunk, behind the crest of the neck, in front of the back, and between the two shoulders.

This region has for its anatomical base the five or six dorsal vertebre which follow the first. Their summits, enlarged and tuberous, support a nuclens of permanent cartilage, to which are attached the corresponding portions of the nuchal and dorso-lumbar ligaments, very much widened.

On each side are the cartilages of prolongation of the seapula, and the muscles to which it gives attachment. The spinous processes offer a large surface laterally for the attachment of the trapezius, the rhomboiclens, the splenins, the great and small complexi, the small anterior serrated, the ilio-spinalis, and the transterse spinous muscles, arranged in so many superposed layers.

The anatomical complexity and elevated situation of the wither: afford an explamation of the gravity of wounds and diseases of this locality. The superposition of the muscles allows of easy filtration of pus into the surrounding parts.

Beauties and Defects.- The beauties of the withers reside in the form, elevation, extent, and freerlom from blemishes thereof.

1. Form.-This qualification indicates that they should be well outlined, and that the smminit should be formed only by the tissues which 
constitute their essential base. As H. Bouley ${ }^{1}$ remarks, the superior border, under this definition, shonld alone present the inert parts, as the bones and ligaments. At the base, on the contrary, the thickness denotes a large development of the muscles which separate it from the internal face of the scapular eartilages.

The abundance of the subcutaneous and interstitial ronnective tissue, the rolume and non-compactness of the muscles, as well as the development of the musenlar system in general, are the principal factors in the production of the lateral diameter of the region. Let us add, also, that it always has this aspect in an ordinary degree when its prominence over the surrounding parts (shonlder and back) is not very marked. Such withers are called course, thick, and low. They are found in horses with great assimilative powers, thick skin, stiff and coarse hairs, abundant connective tissne, voluminous and flabby muscles, lymphatic temperament, and strong and massive forms.

On the other hand, an ordinary stature, a slender, fine, and distinguished form, prominence of all the external anatomical eminences, a fine skin, an energetic nature, and dense and firm muscles always accompany well-defined withers. This form is the most desirable; it indicates the race, the temperament, and, in a word, the distinction of origin, and all the qualities of the animal so characterized.

When the latter peeuliarity is extreme, the withers are called sharp. This conformation, which is often seen as a consequence of emaciation from old age or excessive labor, is an attribnte of those animals which become very lean when subjected to severe work, and accompanies a general deficiency of musenlar development. As Vallon ${ }^{2}$, has remarked, it is particularly defective in cavalry horses, for it exacts the use of a very narrow and elevated areade of the saddle in front, differing much from the ordinary model, and which is not always at our disposal in a campaign. Such animals are difficult and expensive to harness, give the rider an uncomfortable position, and are exposed to traumatisms of this region from the pressure of the saddle during a long march. They necessitate the continued obscrvation of the veterinarian and those who mount them.

2. Height and Extent.-The examination of the height is not less interesting from the double relation of its utilization and its direction. Writers are not in accord as to the exact sense which should be attached to the word height when applied to the withers. In the

1 H. Bouley, Nouveau Dietionnaire pratique de médecine, de ehirurgie et d'hygiène vétérinaires, t. viii. p. 72 .

2 Vallon, Cours d'hippologie, t. i. p. 339. 
first edition of this book we have wrongfully consislered that the height of the withers should be viewed from their elevation in relation to the eroup and the adjacent parts.

In view of the eritieism which this opinion has received, we reeognize to-day that the relative height of the eroup is not germane to the subject which we now have under eonsideration, but to the respective heights of the anterior and the posterior extremities of the body. We will discuss this in the chapter on proportions, as to the dimensions of the body as a whole (see Height und length of the body; Horses high and low in front).

By the height of the withers should be meant, therefore, only the height of the eminence formed by this part of the body above the adjoining regions, such as the shoulders, the back, and the superior border of the neck. By extent we are to understand the total dimensions of the withers antero-posteriorly ; in a word, the degree in which it is prolonged towards the region of the baek. This cireumstanee, dependent in a large measure upon the length and inclination of the spinous processes, neeessarily enables the latter to play the part of the long arms of the levers of the extensor muscles of the vertebral column, and is therefore a favorable eondition for the development of speed.

The height or elevation of the withers depends, on the contrary, upon several diverse canses, which we must determine. Among them we mention :

a. The well-defined form, or the thickness, of which we have already spoken, which concur to modify the obliquity of the lateral faces in consequence of either the lowness or the prominenee of the entire region, as the ease may be.

b. The length and obliquity of the shoulder, whieh tends to cover, to an extent more or less considerable, the sides of the apophyses of the first dorsal vertebra.

c. The absolute length and vertical direction of these processes, whieh, by their summits, exceed to a variable extent the border of the scapular eartilages.

d. Finally, the morle of suspension of the thorax between the anterior members, the effect of which is to produce a more or less marked projection of the summits of the spinons proeesses above the superior border of the shoulders.

The age, the sex, and the state of the genital organs have equally their influence. Poorly delineated in the foal and the young animal, the withers beeome more prominent towards the fifth, sixth, or seventh 
year, the period when the bones have attained their full length and the body its complete development. In the mare it is less prominent than in the gelding or the stallion. In the latter, however, in which the anterior portion of the boxly is more extensively developed, it appears usually thick, museular, lore, and efficed.

The relative influence of all these aunses it is easy to comprehend. One may operate alone or several may be combined, and the height of this region should not be attributed exclusively to one alone, as the sole length of the spinous processes, for example, which hippotomists until the present time have asserted withont offering any proof to substantiate the claim. Taking eognizance of this relation, we have endeavored to prove, by numerous researches upon the living animal and the cadaver, that this opinion is well founded. It is true that we have frequently found an excess of the length of the spinons process of the fifth dorsal vertebra (the eulminating point of the region) in horses with high withers, but we have also, all things being equal otherwise, none the less often seen this process only equal to and even shorter than the others. Moreover, we can affirm that this excess of length is not uncommonly met with in horses in which the region appears depressed.

The spinons processes are, therefore, subject to great variations in animals not dissimilar in appearance These variations may attain five centimetres in the one case or the other.

It hecomes evident, then, that other influences must assist in the determination of the prominence of the withers. They are those which we have enumerated above. Among them the most important, doubtless, is that which refers to the morle of suspension of the thorax betureen the anterior members. As to this assertion, our researches leave not the least doubt. We daily meet horses which have the same length of the ribs, the shoulder, and the spinons processes, the same inclination of these processes and the scapula, and the same state of muscular development, in which, nevertheless, the summit of the withers does not, to the same degree, project beyond the top of the shoulder. How can we explain this fact, unless it be due to differences in the degree of the elevation of the trunk in its attachment to the anterior extremities? As a proof of this enunciation it has been ascertained, in similar instances, that the distance from the inferior surface of the thorax to the ground angments in direct ratio with the projection of the spinous processes above the scapular cartilages.

Let us remark, in passing, that in practice it is almost impossible to establish the relative rôle which is exercised by the one or the other 
of these eauses to which the height of the withers owes its variations; whether it be due to the length and vertical position of the apophyses or to the lowering of the thorax. But what is well demonstrated by experience is that the best type of withers in a horse is that which is as salient and as much prolonged backward as possible; especially if the horse be expected to perform service at a rapid pace, ${ }^{1}$ and also for work under the saddle.

It is not very important to determine the real eause of the prominence of the withers. What is essential to know is that increased height in most instances means a lengthening of the arm of the lever of the spinal and cervieal muscles and an increased freedom of movement of the anterior extremity of the body, two conditions, either of which favor's the muscular contraction and movements of the anterior limbs, the rotation of the scapula, and, consequently, the movements of extension and flexion. These reasons suffice to justify the preference which is accorded to this conformation.

It is well known that horses with low and thick withers have ordinarily insufficient action and too much clumsiness of the movements of the fore limbs. The shoulder rotates but little, the animal is predisposed to forging and interfering, and is unfit for service at a rapid gait. He supports the head insufficiently and is heavy on the bit.

Apart from the foregoing objections, there is still another factor which aggravates this defect. This is the difficulty of maintaining the satdle in place, it having a constant tendency to slide forward and to make direet pressure on and bruise the tissues underneath. Hence result wounds and inflammatory affections, the effeets of which are so often incurable. The nse of the crupper is an insufficient preventive against such lesions, and may itself become a cause of pathological conditions, from its continued traction at the base of the tail.

Let us close by saying that beauty of the withers not only involves the mechanical advantages which we have already considered, but it is also a sign of the noble qualities and the distinction of its possessor. It endows the surrounding regions with other important qualities, such ats are indiated by the length of the shoulder and the height of the (hest, and thus presents itself as one of the essential qualifications of this locality. Whenever the chest is deep, and the shoulders long and oblique, it is clearly recognized that the withers are elevated, well attached, and extended well barkward, the general harmony presuming that, in most instances, the development of one of the clements of an

1 'This is not invariable. Among our speediest trotters we find some in which the withers are high, and others in which they are low. (Harger.) 
anatomical region coexists with that of the others, whatever may be their number. With respect to the horse, however, it is necessary to guard ourselves against such an absolute generalization ; it is essential to remember that the shoulder or the thorax can give this region a prominence in which the withers do not really assume that importance which might be supposed from a point of view of the exterior. Such, at least, have been the deductions made from onr own olsservations.

Diseases and Blemishes.-The withers, in consequence of their prominence, situation, and anatomical complexity, are exposed to numerous lesions of variable gravity. Blows, chafing, bruises, and bites are among the eauses which may lead to swellings, wounds, or abscesses with profound complications of necrosis and caries of the bones, the muscles, and the ligaments. These affections, known under the generic name of evils of the withers, render themselves apparent, in the majority of instances, by an extraordinary exaggeration of the sensibility, abnormal enlargement of the part, cicatrices, or fistulous tracts discharging pus, which leave their evideuce by soiling and decorticating the adjiacent skin.

Horses in such a condition are not rarely offered for sale, and we know of two instances in which the dealer eleverly concealed the tumefaction and the fistula, of which it was the seat, with a blanket.

It is more common to meet animals which offer accilental white markings or cicatrices more or less large, where the skin is denuded, thin, and more easily excoriated by the contact of the harness. The presence of these cicatrices furnishes, besides, the evidence of a pre-existing disease implicating the muscles or the bones of the withers and the shoulder, which may result in some irregularity of the gait. They have an important bearing in an examination for soundness in the purchase of horses.

Other blemishes may also result from the application of blisters or the actual cautery. They have their principal value, however, when the affection for the cure of which they have been applied has not yet disappeared. Such diseases are liable to return or become angmented under the persistent action of the causes which produced them.

3. The freedom from blemishes, in a general way, as related to the physiological appearance, is, therefore, as indispensable to our study as the form, the elevation, or the extent.

\section{C.-The Back.}

Situation; Limits; Anatomical Base.-This single region, situated on the superior part of the trunk, is limiterl anteriorly by the withers, posteriorly by the loins, and laterally by the ribs (sides).

It has for its osseous base the eleven or twelve posterior dorsal vertebre and the superior extremity of the corresponding ribs. These bones give attachment to the different muscles which fill the costo-vertebral grooves, - the great dorsal, the small anterior and posterior serrated, the ilio-spinalis, the transverse spinous, and the intercostals. 
Its uses are of primary importance, beeanse it receives the saddle and the weight of the rider. It transmits to the anterior part of the body the efforts of propulsion, which are commmicated through the loins by the posterior limbs. The back therefore fulfils, by its conformation, diverse requirements which we will describe.

Direction.- The back may present several directions. It is straight when it describes almost a horizontal line from before to behind. A straight back is a sign of great strength, for all the weight which the region supports is borne by the bones and tends to efface the rachidian arch. The saddle will, in this conformation, rest in a good position.

The back is convex (or the animal is roach-backed) when it is slightly arehed, prominent, and sharp near the region of the loins. Snch a conformation increases the eonditions of solidity to external pressure, in which the preceding form is deficient, on aceount of this arch being exaggerated. It is incorreet to associate this condition with flat ribs and a narrow chest. Convexity inereases the reactions of the back and shortens the gaits of the animal. The eonstituting vertebre in this disposition are related in such a manner that all pressure made upon them from above to below is supported more by the bones than by the ligaments which unite them, whenee less elasticity and flexibility in executing its varions functions. The convex back, besides, is generally shorter than the other forms, and does not permit suffieient freedom to the extension and flexion of the posterior members in taking long and rapid steps. It is therefore a contra-indication of rapid locomotion. Horses in which it is observed are predisposed to forging; that is to say, the fore and hind feet touch each other when their speed is increased.

The convex back, for these reasons, is a defect in saddle- and driving-horses; in those performing, on the contrary, slow and heavy work, it is of no consequence.

When the dorsal region is concave from before to behind, the animal is designated as sway-backed or hollow-backed. This conformation, congenital or acquired, is more fanlty than the preceding, and any load borne upon it tends to effice the areh formed by the vertebre of this region. Instead of the latter offering a resistance, from their mutual contact, to the weight which they support, such weight is ahnost entirely sustained by the ligaments. This fact makes the vertebral column become rectilinear or, when exaggerated, convex along its inferior border. The ligaments which maintain the dorsal arch normally are therefore submitted to constant traction during service, particularly if a weight be superarded to that of the viscera. Wre have often observed in old horses more or less voluminons cxostoses disposed in a 
series along the common inferior vertebral ligament. In our opinion, these should be attributed to the violent and continuous pressure of the saddle or the harness. If this be true, it is easily pereeived that these excrescences on the body of the vertebra are most common in animals which, instead of having this region straight, have it strongly concave.

The first ill effeet of this concavity is an overtaxing of the vertebral ligaments due to the displacement of the bones, - a condition which communicates to the rachidian column a greater flexibility than is physiological. The result is that the transmission of the impulsive action of the hind limbs communicated to the anterior part of the body is incomplete. The region lacks sufficient rigidity, and a certain part of the force is wasted, to the detriment of the speed, since its effect is to deviate the vertebræ from their normal rectitude.

Sway-backed horses are not adapted to work which exacts much force and resistance of the back. They cannot be employed as hunters, runners, or cavalry horses, but should be reserved to draw vehicles, one with four wheels being preferred.

With M. Bouley ${ }^{1}$ we believe, nevertheless, that it is necessary to discriminate between a real concavity of this region and that which is only apparent,-a condition sometimes existing in horses capable of the greatest exertion. The latter appears to be due to a concavity of the superficial surface of the back alone, to a peculiar curvature formed by the series of spinous processes, which may be shorter in the middle of this region than in front or behind. It is a veritable anatomical anomaly. In this case the arch of the vertebre themselves is in a normal condition and fulfils all its funetions. This remark should consequently be taken into account, and a positive judgment should not be expressed unless the proof is apparent.

It has also been said of horses thus formed that the reaction of the back is less hard than that of the average horse,-a fact which has recommended them to favor as saddle-horses. Some anthors, as Curnieu, Eugene Gayot, and Vallon, assert that this last fact is due to a different order of phenomena, which lead to a suppleness and ease of the movements. These result, in this view, not from any peculiar condition of one region alone, but from the conformation of the body as a whole. The latter interpretation is true, but it does not destroy the validity of the other. One isolated cause may pioduce the same effect as several others combined.

${ }^{1}$ II. Bouley, Nouveau Dictionnaire pratique de médecine, de chirurgie et d'hyygiène vétérinaires, t. v. p. 130. 
We believe that the more flexible and elastic the vertebral column is the more it will disperse the effects of concussion from violent exertion or accidents. The back will at any time lose this quality as soon as the alternative efforts which elevate and depress it are enacted in an irregular manner. Let us recall the regular movements of the rope-dancer; nothing more graceful and of better rhythm. But would they have the same rhythmical character if, for example, he attempted to jump without regularity upon his rope? Evidently not!

This comparison applies to a certain degrec to our subject. In locomotion the weight of the body, whencver it tonches its base of support, calls into activity the elasticity of the vertebral column, which describes oscillations whose amplitude is proportional to its elasticity, its degree of tension, and the energy of muscnlar contraction. If, for one reason or other, these oscillations are excessive, whenever the feet come into contact with the surface upon which the animal moves, an evident antagonism of forces will result, leading to a succession of rebounds, which render the reactions still more exaggerated, even more so than if the back had an opposite conformation. Here is, we think, the eanse of the divergence of opinions which we have spoken of.

Horses of this type frequently have very feeble reaction when their gait is rhythmical and perfectly regular, as in the ordinary trot or the gallop; but the reactions become marked as soon as the oscillations of the vertebral column cease to be in accord with the movements of the foot in tonching the ground, as in trotting or rumning at great speed.

Sometimes the line of the back is oblique from above to below, and behind to before, instead of being horizontal, concave, or convex. Such a form is called dipped. This direction, dne to a more or less marked elevation of the croup above the withers, entails an unequal distribution of the body-weight upon the four extremities. The centre of gravity is carried towards the fore limbs, increasing by so much the weight which they support. We shall hereafter have something further to add in respect to the objections which exist with regard to this type of structure when we come to treat of the axial measurements of the body.

Form.-In horses whose musenlar system is very highly developerl, there exists on the median line of the back a longitudinal line or furrow, which is slightly surmomnted laterally by the environing parts on account of the volume of the muscles situated in the costo-vertebral gutters. This characteristic marks that kind of back which is called double. It is a peculiarity observed in heavy and woll-muscled animals whose ehest is wide, the back somewhat encave, and the withers low.

Many subjects which present it at the time of purchase may not 
retain it throughout their whole life. Under the influence of the work to which the animal has been submitted, and poor and innutritious alimentation, the double back often becomes single and the muscular organization in general loses its volume and its high degree of development.

Conversely, the erest of the back beemes prominent and stands out in relief over the surromnding museles in subjects emaciated from the ravages of age, or in those of a certain natural conformation whose chest is narrow, the back slightly convex, the withers high, and the muscles less voluminous. In the latter form the region is predisposed to become sharp, and is more exposed to wounds from the saddle or the harness.

Length.-The length of the back is in relation with the depth of the chest and the rapidity of the gait. Its measurement, which requires some judgment, is usnally combined with that of the loins. The typical back is regarded as equal in length to the distance between the dorsal angle of the seapula and the external angle of the ilium or the haunch. The determination of how much of this distance belongs to the loins is of little practieal utility, but it should be as small as possible. A long back implies a corresponding length of the thoracic cavity whose superior wall it forms. We know that it is indispensable to seek, for any kind of work, those anatomical dispositions which imply the development of the respiratory apparatus. Such development requires a proper separation of the anterior from the posterior members; and this separation is in relation with rapidity of locomotion, in that it is the expression of the length of the muscles which pass from the trunk to the superior part of the limbs, as the psoas, great dorsal, and pectoral ; also of those which oceupy the eosto-vertebral gutters, whose function is the extension and propulsion of the vertebral eolumn. Again, it enlarges the base of support and leaves a sufficiently large area underneath the trunk, circumscribed by the four feet, for the movements of the posterior limbs. The latter are thus less liable to come in contact with each other, and so to produce that disagreeable sound called forging.

These advantages, however, are often diminished by the following associated imperfections, which the shortness of the loins camnot always rectify.

The dorsal column being long, tends to alter its direction under the impetus received from the posterior extremities during the movements of progression. A certain part of this impulsive force is therefore necessarily lost at the expense of propulsion. Further, from the angmented flexibility and diminished solidity of the vertebral column, 
its depression, to an exaggerated degree, is rendered more easy, and the back may even become concave under the pressure of excessive weight. Long-backed horses are more predisposed than others to fracture of the vertebre during surgical operations in the recumbent position.

As to the short back, it presents the elements of great strength and solidity, transmits the action of the hind limbs with greater force, and rarely becomes sway-backed; but, conversely, it lacks flexibility of movement, diminishes the capacity of the thoracic cavity, and limits the play of the posterior limbs. The animal is predisposed to forging as soon as he is obliged to lengthen his steps, unless the loins, by an excess of length, preserve the required proportions of the dorso-lumbar region as a whole. Under these circumstances this defect is apt to be obscured by one that is more grave, as we shall see further on.

Most anthors who have written of this subject pretend that shortness of the back constitutes its first beauty. H. Bouley ${ }^{1}$ has very judiciously asserted that this proposition is too absolute. A very short back is not desirable except in animals destined to carry heary weights, as the shaft-horse, the pack-horse, the mule, the ass, and the saddlehorse. In the last, from which speed is exacted, a deficiency in the length of the chest should be compensated by the arching of the ribs and their increased projection backward. As to the diminished stride of the legs, it may be redeemed by the multiplicity and rapidity of their movements. An elevated carriage of the head, throwing the weight upon the hind and liberating the fore limbs, tends to prevent forging. Moreover, by judicious handling, the short-backed saddlehorse can be taught, little by little, to elevate the anterior members quickly enough and sufficiently far in advance, so that they will not be touched by the posterior.

The same considerations are applicable to animals other than saddlehorses, in which a long back would be deemed preferable, with the presumption that the dorso-lumbar spine be well directed and strongly muscled.

Width.-The width is also one of the qualities of the back to be considered. It is in relation with the transverse diameter of the chest and the volume of the ilio-spinalis muscles. When the back is norrow, the ribs are often flat, the thoracic cavity deficient in space or rolume, the spinal crest too prominent, and the parts are predisprosed to wounds and abrasions from the harness or the saddle. Thus narrowness of the back, for these reasons, may become a positive defect. 
Diseases and Blemishes.-Various lesions resulting from a defective pattern or vicious application of the harness or the saddle are sometimes observed in this region. Such are denudations, excoriations, bruises, corns, cysts, abscesses, and fistula which exist on the median line, or the lateral parts. Their gravity varies according to position and the anatomical structures of the parts involved. Cure is difficult in proportion to their closeness to the median line. Benign as they may appear at the beginning, there is always danger of complications which may prevent the animal from working for several months. The presence of cicatrices or of white hairs are the indelible evidences which follow lesions of this nature. Finally, we sometimes find the marks of blisters or of the actual catery, which will indicate that the animal has been treated for some one of these diseases.

\section{D. -The Loins.}

Situation; Limits; Anatomical Base.-This symmetrical region, situated behind the back and in front of the cromp and the haunches, and limited on each side by the flank, has for its base the six lumbar vertebræ (sometimes only five), whose costiform processes continue posteriorly the costo-vertebral gutter. This gutter is covered by the transverse spinous and the ilio-spinalis muscles, the anterior extremity of the gluteal muscle, and the aponeurosis of the great dorsal muscle.

We will examine this region as to its length, width, foim, direction, and attachments.

Width.-The width of the loins is directly proportional to the development of the costiform apophyses of the lumbar vertebræ, and corresponds in some degree with that of the muscles named above. A wide loin is regarded as a feature of absolute beauty.

Length. - Whatever may be the work the animal is destined to perform, the loins should be as short as possible, a condition of solidity important to recognize, because the lumbar vertebre have no support laterally, being simply articulated the one with the other. Its shortness also favors the transmission of the impetus given by the posterior limbs, because it lessens the elasticity and mobility of the structures through which the force of impulsion must pass. As to the relation of the entire length of the dorso-lumbar region, the back should be long and the loins short, especially in saddle- and pack-lrorses. This point cannot be impressed too strongly.

Form. - As in the back, the form of the loins is dependent mainly upon that of the muscles. The median line is indicated by a crest or a gutter. In the former case, they are single, and should be well muscled; in the latter, they are double. When the crest is very high, the loins are called sharp, which is a sign of weakness and fecble resistance.

Direction.-As to their direction, the loins are usually straight, and their comrexity is observed only in old horses, or in those abused 
by excessive labor, in whieh the spinal column has been injured by the weight and muscular traction which the region has sustained. In gravely-diseased animals they are often arched and have lost suppleness.

Attachments. - The loins should become insensibly united to the croup and the back. When they are mal-attached, there exists in front of the former a depression of variable depth, which gives them such names as low, weak, false, and dipped. Besides, they are often long, narrow, and feeble, peculiarities detracting from their strength.

Examination.-At all times, in eonducting an examination of the horse, veterinarians are in the habit of pressing on the loins to determine by their flexibility the state of the health of the subject.

This practice should be executed with some precautions. Taking a position at the side of the animal, with the back towards his head, the hand is passed downward over the back, and the loins are pinched on the median line by making gentle pressure with the thumb and index finger. Under this influence the animal, when in a state of health, will extend the spine, or flinch. In those suffering from weakness or certain few diseases of this region, as osteoporosis, or in those of a nervous temperament, the sensitiveness may be much exaggerated In horses suffering from fever or some other diseases, the region will remain perfectly rigid. In a general way, its sensitiveness affords an index of the health of the animal. Certain nervous subjects will resist this manipulation by biting or kicking; in order to avoid this, the head should be raised and the position of the clinician should not be too close to the body. Others will yield to the first attempt, but resist a repetition by stiffening the parts.

Diseases and Blemishes.-The wounds of this region are of the same nature as those of the back. They result nearly always from a misfitting harness or its improper application. The posterior part of the saddle frequently bears on the origin of the loins and wounds them on the median line. These wounds are always painful and slow to cicatrize, and may prevent the animal from working for a long period. In olden times they were designated under the name evils of the loins.

Strain of the loins, which is sometimes observed, is a much more grave affection, but we will speak of it under the defects of the gait.

It manifests itself as a great weakness of the posterior quarters, which is must apparent during locomotion, and renders its rictim unfit for active service.

The blemishes are traces of blisters or the firing-iron, more or less extensive, proving an old cauterization for a serious disease, principally strain of the loins. There may also be excoriations, white markings in horses of a dark color, or cicatrices of the same nature as those which we have indicater in the region of the back.

\section{E.-The Croup.}

Situation; Limits.- The croup is a single region situated on the median line of the superior surface of the body. It is bounded in front by the loins, behind by the teil, and on each side by the thigh and the superior part of the buttoek. 
Although, from an anatomical and physiological point of view, the croup constitutes the first segment of the abdominal limb, yet, on account of its close relationship with the other parts of the back, we prefer to regard it, for our present purpose, as the terminal portion of the trunk giving attachment to the hind limbs. Solidly united with the vertebral column by bones and muscles, it

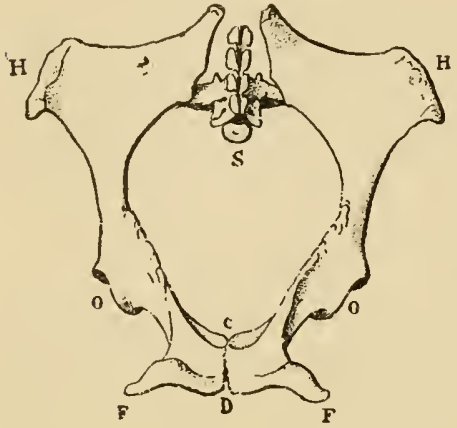

Fig. 34. helps to form the periphery of the pelvic cavity. Accordingly, we shall not, in this discussion, separate it from the other regions of the body with which it is so intimately associated.

Anatomical Base.-It has for its base the two coxæ, $H F$ (Fig. 34), firmly united on the median line, $C D$; anteriorly they articulate with the borders of the sacrum, $S$, and are immovable excepting for a certain amount of elasticity. These bones are covered by a large mass of muscles, some of which extend to the femur and to the tibia. On the side is the coxo-femoral articulation, $O$, in which the head of the femur takes part, and which supports this region upon the posterior members.

Considered from a point of view of animal mechanies, the coxa can be represented (Fig. 35) by a bent lever, $H O F$, composed of two arms: the one anterior, $H O$, formed by the ilium, ex-

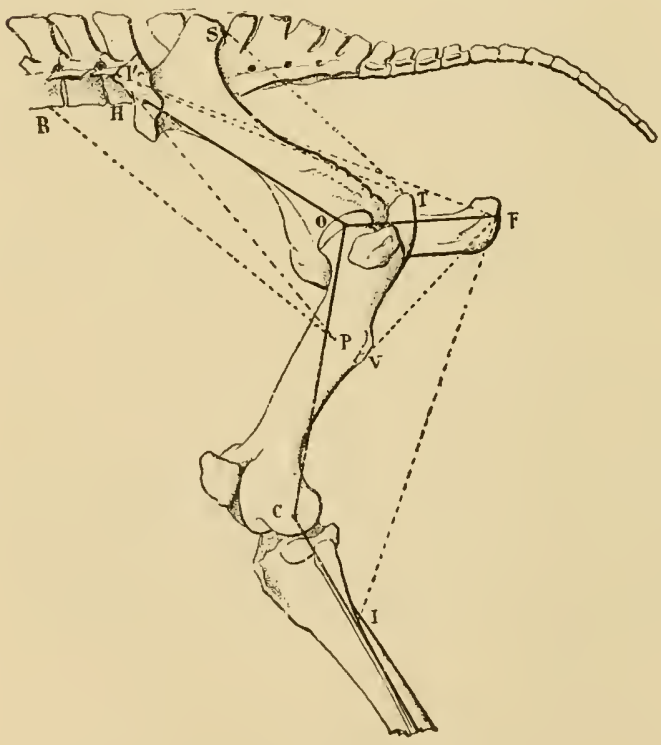

FiG. 35 . tending from the external angle of the haunch, $H$, to the centre of the coxo-femoral articulation, $O$; the other, $O F$, formed by the ischium, extends from the centre of the hip-joint to the ischiatic tuberusity or the point of the buttock, $F$.

These two bones form a a very obtuse angle, $H O F$, whose mean extent, as determined by our researches, is from 140 to 145 degrees, but which may vary ten degrees in either direction, according to the individual. We will call it the ilio-ischial angle.

It rests by its summit, $O$, upon the head of the femur, at an inclination varying according to the individual; sometimes it is inclined forward, and then the line of direction, $H F$, tends to become more horizontal; sometimes it tends to an opposite inclination. 
Finally, the femur not always having the same obliquity, it forms with the ilium and the ischimm two angles, $H O C$ (ilio-femoral) and $F O C$ (ischio-femoral). for this reason more or less closed or open.

It will be perceived that the femur surmounts the centre of the articulation, 0 , by the great trochanter, $T$.

Among the groups of muscles we recognize

1st. The gluteal muscles, TH, TS, carrying the femur backward when their fixed point is $H$, or elevating the ilium when $T$ is the fixed point.

2d. The flerors of the femur, $H P$, principally the psoas, $R P$, advancing the thigh when $H$ is their fixed point, and depressing the ilium when $P$ becomes the fixed insertion.

3d. The ischio-tibial (femoral biceps, semi-tendinosus and membranosus), $F I$ and $F I^{\prime}$, extending the femur and flexing the tibia, have as their fixed point $F$ or $S^{\prime}$; when $I$ or $I^{\prime}$ is the fixed point, the ischium swings downward or upwart.

The remaining muscles are all similar in function to those already studied.

We obscrve, therefore, that there are in this region two principal groups of muscles. The first, $P H$, flex the femur, carrying it forward; the second, $T H$, $F I, F V$, more voluminous, extend this region. When the femoral insertion is fixed these muscles are capable of producing the same movements of the croup. The flexors, $H P$, swing the coxa downward and forward; the extensors rotate them backward. They can thus contribute directly or indirectly in supporting the dorso-lumbar region.

The eroup must be studied with regard to its length, width, thickness, direction, muscular development, and particular forms.

Length.-The length is measured from the external angle of the ilium (haunch) to the ischiatic tuberosity (buttoek). Bourgelat considered it equal to the distance comprised between the summit of the hear and the commissures of the lips. These dimensions appear to correspond in most horses of a regular conformation, except in thoronghbreds, in which the croup is relatively longer on account of the exceptional smallness of the head.

The length of the coxr is, withont dispute, the most important condition of the beunty of the croup in animals adapted to any rapid service. Whilst it is not a necessity in dranght-horses, it nevertheless arlds to their usefulness and beanty. Among Arabians this quality is much appreciated. "As to the horse whose eroup is as long as his back and loins mited, you can safely ehoose him eren with your eves closed ; such a horse is a blessing !" 'This is one of their maxims. 'The principal idea which this metaphor teaches is that the long croup should always be preferred, to the exclusion of all others.

The reason for this preference is readily perceived. The great development of its antero-posterior diameter corresponds relatively with the length of the muscles of the eroup, notably those of the 
gluteal region, the principal extensors of the femur. They, in connection with the other extensors of the hind limb, communicate to the body a greater impulse, which carries it forward by a sudden and forcible opening of all the locomotory angles and a straightening of the whole limb. The greater their length the more they will be capable of shortening during contraction, and, consequently, the greater will be the foree which the hind limb possesses.

This impulsion, besides, will have greater power, because the insertion of the muscles will have an incidence approaching the perpendicnlar. The line $C D^{\prime}$, which represents the direction (Fig. 36), is less oblique to $B C$ (or $(' O)$ than the line $C D$.

Again, the length of the croup is concomitant with that of the ischio-tibial muscles, $A B$ and $A^{\prime} B$, which flex the tibia or rotate the coxæ backward during rearing or progressive novements in which they

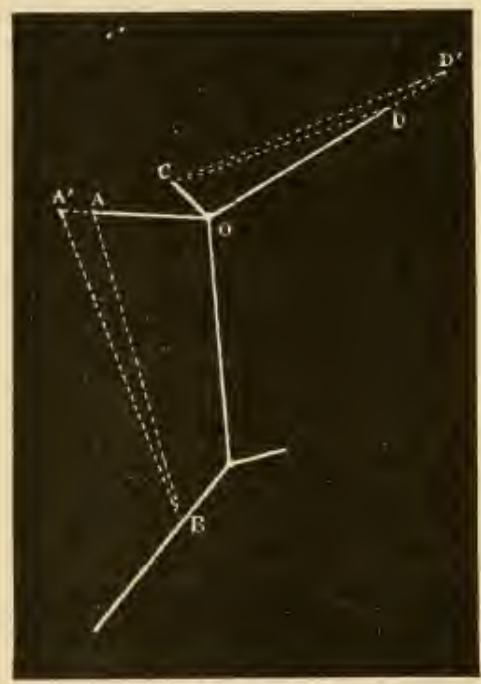

FIG. 36.

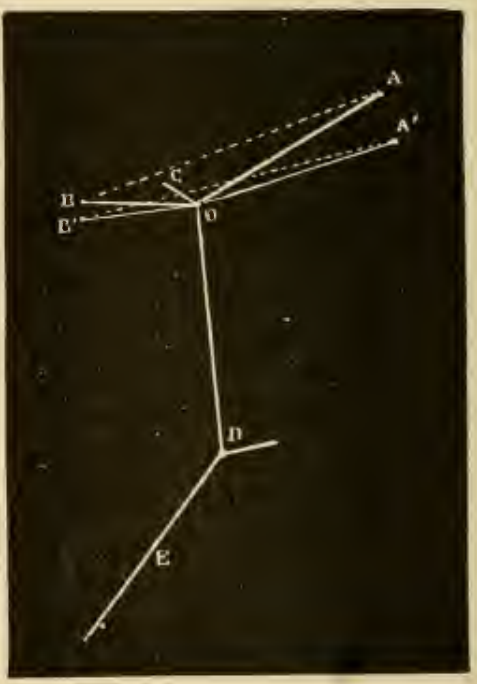

FIG. 37.

are concerned, as the gallop or leaping. Not only the length but the angle of incidence is also modified.

This is not all. It is also instructive to inform ourselves as to how the length of the croup is produced, for there are three principal factors which enter into its formation,-1st, the degree of openness of the ilio-ischial angle ; $2 \mathrm{~d}$, the length of the ilium; and, 3d, the length of the ischium.

The openness of the ilio-ischial angle, according as it is more or less large, separates correspondingly the angle of the hannch from the 
point of the buttock, and makes the croup long or short. This is illustrated in Fig. 37. The lines $A B$ and $A^{\prime} B^{\prime}$ are of unequal lengths, whilst they support angles whose sides are exactly equal; nothing but the inclination of these lines has changed. It follows from this that if the increase of the length of the cronp can exist withont influence upon the real length of the ilium and ischium, it modifies, nevertheless, the direction of the region in such a way that it tends to become, in general, more horizontal. We will return to this subject hereafter.

It is curious to observe that in our larger quadrupeds the line of direction of the croup always passes perceptibly above the centre of the coxo-femoral articulation, whilst in our smaller species, as rodents and carnivora, for example, the ilim and the ischium standing more nearly in the same line, and making a less angle the one with the other, this line passes almost throngh the centre of the joint. The ilio-ischial angle, in this respect, seems more marked, or, if it be preferred, the angle is the more effaced as the volume of the body becomes less and the nimbleness of the movements greater. Thus it augments in size gradnally from the horse and the ox to the pig ; from the pig to the smaller ruminants ; and, finally, from the latter to the carnivora and the rodents. This relative openness, or largeness of the angle, with the corresponding modifications in the length of the muscles, and of their incidence with the osseons levers, and the play of the angles of locomotion in the posterior extremity, seems specially adapted to the execution of the gallop and leaping.

Whatever may be the interpretation, it is well known that in horses of great speed this angle is more open than in dranght-horses. In animals used for rapid services, this conformation has the preference. It is manifested externally by the relation of the centre of the articulation with the line of direction of the croup.

The length of the croup, however, is due, more than to aught else, to that of the ilium and the ischium, the ilio-ischial angle remaining the same. These offer some important individual differences. Thus we

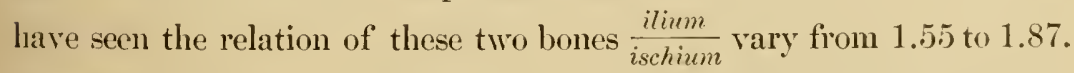
The ratio angments in fast-trotting horses, and diminishes in hunters, saddle-horses, and draught-horses. The length of the iliun determines that of the muscles attaching to it, and favors the amplitucle of the femoral extension, whilst that of the ischium fixes the vertebral column when the flexors act, and facilitates the rotation of the pelvis downward and backward. 
Here are some very suggestive figures which show these dimensions relatively in certain species other than the horse: We have found the relation to be 0.57 in the swan; 0.87 in the turkey; 1.22 in the hare and the rabbit; 1.30 in the lion; 1.50 in the eat; 1.60 in the greyhound; 1.56 in the goat. In the ox it is only 1.24 : it is smaller than in the horse.

In all animals in which the anterior part of the body has no direct support, as in birds, or is comparatively heavy, as in the larger ruminants, or, again, when the natural mode of progression is galloping or leaping, the ratio diminishes in consequence of the relative increase of the ischium.

The result is apparent. It is easy to determine the proportions of the two levers constituting the coxa, by the distance comprised betwcen the centre of the articulation and the point of the buttock. This factor is at least useful, if not indispensable, in estimating the locomotory aptitude of the animal.

To recapitulate: the length of the croup is in close relation with the production of speed. The ilio-ischial line is an insufficient indication, and often the somree of error. We shonld primarily strive to estimate the length of the bones which eonstitnte that line, and shonld attach only a secondary importance to the line of direction ; or, in other words, to the openness of the angle which they form.

Thickness.-Authors have said but little upon the thickness of the croup, a point which should, nevertheless, be taken into consideration. We may define it as the distance comprised between the antero-posterior axis of the coxæ and the summit of the sacral spine.

The interval between the sacrum and the coxæ is greater at the outlet than at the inlet of the pelvic cavity, on account of the inclination of the axis of the eroup and the horizontal tendency of the axis of the sacrum. It varies singularly in different subjects, owing to the peculiarities of the form of the sacral spine and the general direction of the sacrum itself. This bone may often be curved in draught-horses, while it is ordinarily more or less rectilinear in animals possessed of speed, notably the English thoronghbred and his deseendants. The more it is depressed the smaller will be the coxo-sacral interval, or the less the thickness of the croup.

When it is straight, on the eontrary, this interval angments, and the line which marks the profile of the cromp contrasts more strongly with the ilio-ischial line. The region then appears horizontal.

Numerous muscles, among then the ischio-tibial muscles, charged with the rotation of the pelvis and the fixation of the spinal colnmn, attach to the sides of the sacral spinc. Its straightness, also indieating 
the thickness of the croup, is, therefore, in relation with the length of the muscles, the extent of rotation of the coxæ, and, consequently, the aptitude for galloping and leaping. This straightness may at the same time be considered, in horses of rapid movement, as an index of great power and strength in the upper part of the hind quarter.

Width. - The width is the distance between the external angles of the ilia, but depends also upon the separation of the points of the buttock.

In the skeleton, the interval between the external angles of the ilia always slightly exceeds the length of the ilio-ischial line; in other words, the pelvis is wider than long, the excess varying from two to seven centimetres, according to our measurements.

In the living animal it is otherwise on account of the thickness of the muscles which cover the ischiatic tuberosity; the length of the croup becomes equal to, and sometimes exceeds, its width in heavy horses from two to five centimetres.

The development of the transverse diameter of the region varies evidently with the race and the conformation of the animal, but is, in general, an index of the volume of the muscles, and, eonsequently, of their contractile power, the fibres or contractile units being more numerous in a wide croup than in any other. Such a eroup is, therefore, an absolute beauty, and a most desirable feature in a horse, no matter for what service he is intended; but it is especially desirable in horses used for heavy work, in which the greatest possible effort is exacted. It is even more desirable in broodmares.

The separation of the haunches is far from furnishing, though it be so regarded, the best criterion for judging of the true width of the croup. Horses having an equal measurement over the haunches may have, in reality, ilia very different in their transverse diameter. It is not rare to meet some subjects whose haunches are less separated than most others, but whose pelvic measurements and iliae surfaces are considerably larger.

We have convinced ourselves that these individual differences depend upon the following eauses:

1st. The degree of inclination of the iliac surfaces from above to below. 2d. The degree of concarity of the external iliac fosse.

The first cause effects a lowering of the external angle of the ilium in relation with the summit of the croup, and brings it towards the median plane of the body, a circumstance which, it is true, diminishes the distance between the hamehes, but which exercises no influence in any manner upon the peripheral surface of the bone for muscular attach- 
ment. An apparent narrourness of the croup, due to this cause, may exist, all things being otherwise normal, so markerl as to diminish the transverse diameter of the cronp by more than six centimetres.

As to the degree of concavity of the external face of the ilium, its influence is easily understood. It augments thereby the surface destined for muscular insertion. Let us confine ourselves by saying that it is often much more pronounced than can be determined from the exterior.

The practical conclusion to be drawn from these statements is simple: to judge well the width of the eroup, it will suffice to consider the transverse dimension of the cavity of the pelvis. With equal length of the ilium, preference is to be given to the horse in which the sides of this region are inclined, - that is to say, a great difference of level between the haunch and the summit of the croup is desirable, the separation of the haunches remaining the same.

Two objectionable consequences may result from excessive width of the croup and a too marked inclination of its sides. Too widely separated from the median line, the coxo-femoral articulations require too large a base of support, and consequently produce exaggerated lateral oscillations of the posterior part of the body during locomotion. From this results an ungraceful swaying of the buttocks, which has been called the rocking of the horse; whence results a loss of force and time proportional to the extent of these movements and the excessive oscillations of the centre of gravity. The conditions of locomotion require the centre of gravity to move in as straight a line as possible, because force is required to displace it from that line. In dranght-horses this defect is of no importance; in animals used for other purposes it is detrimental, and a mean obliquity of the sides of the croup is preferable.

Other defects, not less serious, may result from an excessive inclination of the lateral parietes of the croup, as is seen more particularly in the form in which it is designated shrup. Here the base of support is narrow and the hind limbs do not have their necessary freedom of movement during rapid locomotion; they approach each other, the abduction is limited, and the animal will interfere or forge. Let us add that such a croup lacks strength and beanty, and is often accompanied by a narrow chest, sufficient eause to render the animal unfit for for some kinds of work.

The absolute narroness of this region is at all times regarded as a defect.

Direction.-The direction of the croup has been the theme of extensive discussions among authors who have written upon the exte- 
rior. More recently, our learned colleague, M. Neumann, ${ }^{1}$ has, in a full review of this subject, endeavored to offer diverse criticisms on certain views which we supported on this point in our first edition. These criticisms have induced us to make a careful revision of this part of our book, and we have conducted numerous experiments, the results of which are given in this edition. We are convinced that the divergence from our opinion regarding the direction of the croup, held by some writers, is much less reasonable than our crities imagine. They do not sufficiently consider the sources of error, and the compensations and exigencies demanded by the nature of the work which the animal must perform. Very often qualities or defects which belong to other elements of the conformation are attributed to the direction of the croup ; finally, it is common to see persons who choose as a standard of excellence such or such an inclination which has given good results in some instances, without reflecting that different purposes also require peculiar anatomical conditions, which endow the mechanism with a peculiar aptitude.

The discussion into which we now enter will furnish the proof of what we have said.

First, how is the direction of the croup manifested?

Certain writers think, incorrectly, that it is indicated by a curve on the median line of the body extending from the termination of the loins to the origin of the tail. This line denotes only the degree of convexity of the sacral spine and the curvature of the sacrum. It is altogether independent of the general direction of the coxr, and influences but little the form of the region.

The axis of the croup, in our opinion, corresponds almost exactly with a line uniting the angle of the haunch to the point of the ischium and passing some distance above the coxo-femoral articulation ; we will call it the ilio-ischial line.

We are prepared to assert that the direction of this line depends upon two principles, as follows:

1st. It may depend upon the dimension of the ilio-ischial angle.

2d. It may depend upon the more or less inclined position of the coxæ without variation in its angle.

a. Influence of the Dimexsion of the Itio-ischial Axgle. - Two canses are capable of modifying the size of this angle; they may act alone or simultancously. It may be the inclination of the ilium alone which varies, or that of the ischium, or, finally, that of both, which may vary at the same time.

Let us examine each of these cases in particular.

1 G. Neumann, Sur la direction de la croupe; in Revue vétérinaire, 1887, p. 521. 
1st. Tariations in the Inclination of the Ilinm.- When the ilium approaches the revtical (Fig. 33), the cronp) $A^{\prime} B$ is more oblique and shorter than the croup $A B$.

The length of the gluteal muscles $A^{\prime} C^{\prime}$ is diminished; nevertheless, this incidence is more favorable than that of $A C$, whether for the extension of the fenur or the support of the vertebral column. The advantages which follow from this incidence are more efficacious than is generally believed. Are they not evident in the draught-horse, for example, when he endeavors to move his load? The effort inclines his croup and closes proportionally his articular angles, which otherwise are more open. Is it not the immediate consequence of this variation to alument the intensity of the muscular contraction, by rendering the insertion more perpendicular to the bony levers on which they act? If, therefore, from this rircumstance the animal approaches a conformation which saves him from exerting

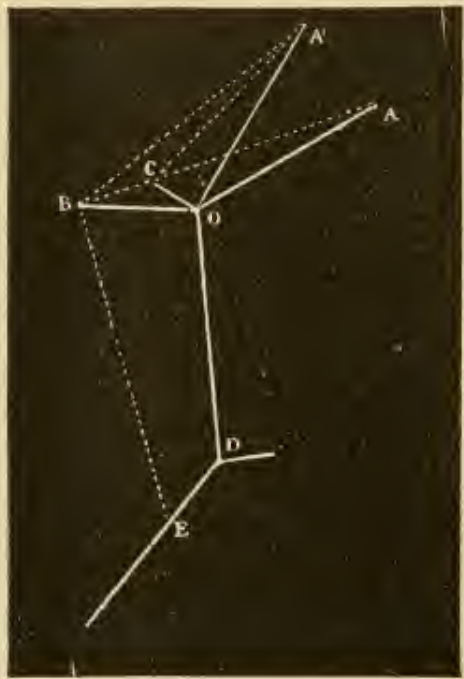

FiG, 38 . all his efforts during traction, he will realize a certain economy of force which must not be overlooked.

The coxo-femoral angle, $A^{\prime} O D$, being very obtuse, the weight of the body will distribute itself more perpendicularly upon the bones; the muscles $A^{\prime} C$ and $B E$, charged to support the spinal column, will expend less force.

From an opposite point of view, if the coxo-femoral angle, $A^{\prime} O D$, become more obtuse, it places the femur in a position much closer to its limit of extension. (See Generalities of the Members.) It follows, then, that if the coxa, by its uprightness, increase the dimension of the angle $A^{\prime} O D$, which is already large, this bone can only pass through a limited distance during the act of extension, hecause at the moment of the propulsion of the trunk the posterior limit of the femoral play is reached much more quickly. The movements of the femur will, on the contrary, be much more extensive with the angle $A O D$ less obtuse and approaching the ilium towards the horizontal direction.

If the ilium be lowered, the results are precisely of an opposite order. We will, therefore, not pass further into details.

The following conclusions are derived from the study of this mechanism (Fig. 38) :

With the oblique ilium, the gluteal muscles are shorter, but better inserted for intensity of power ; the fixation of the spine is more easy ; the movements of extension and flexion lack amplitude; and the impulsion is transmitted more vertieally. Foree is inereased and speed is diminished.

With the ilium horizontal (that is to say, less upright), the mechanical conditions are the opposite of the preceding; the muscles are long; the 
femoral movements extensive; impulsion is transmitted horizontally, but the general structure is not adapted to inerease the fixation of the spinal column. Velocity is increased at the expense of force.

The first conformation, therefore, should exist in horses which are employed to carry burdens or pull heary loads; the second is found in those which are adapted to rapid locomotion with little or no weight to carry, those whose value depends upon their qualities of speed.

2d. Variations in the Inclination of the Ischium.- I'hen it is the ischium which is lowered (Fig. 39), the eroup, $A B^{\prime}$, is more oblique, and appears longer. The length of the ischio-tibial muscles, $B^{\prime} E$, diminishes, but they have an incidenee of insertion more favorable, whether for the rotation of the coxæ, in view of fixing the spinal column, or the flexion of the leg during progression.

The coxo-femoral angle, $A O D$, does not vary, and the extension of the femur preserves its amplitude, provided the ilium, $A O$, remain well directed.

The force of propulsion, at the same time, continues to be transmitted in its proper direction, $O A$.

Nevertheless, the distance, $B^{\prime} E$, between the ischium and the tibia diminishes, which can only be compensated by an increase in the femoro-tibial angle, $O D E$, thus giving to the bones a more vertical direction, such as is often seen

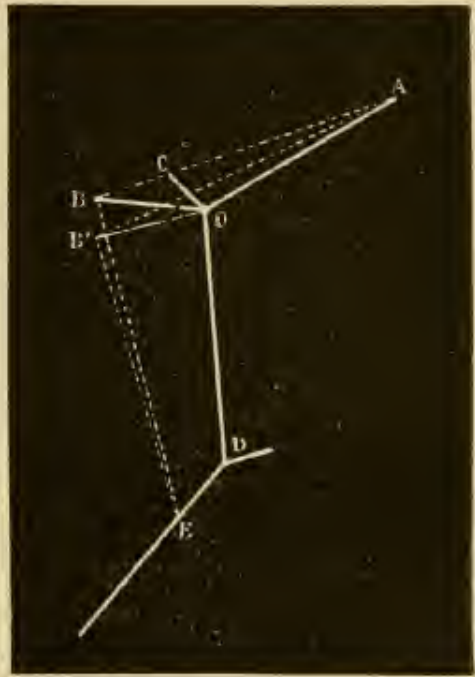

FIG, 39. in thoroughbred horses, in which the tibia is ordinarily but little inclined.

The gluteal muscles, $A C$, do not vary.

What are the conclusions from these statements? Simply this: that the obliquity of the croup, due only to the lowering of the ischinm, or, if it be preferred, of the point of the buttock, firvors again force at the expense of speed, but in a mamer less prejuelicial than in the preceding ease, since the femoral amplitude, as well at a good direction of the force of impulsion, are preserved.

This conformation, if it be not exaggerated, will be excellent for most ordinary services, because it corresponds more uniformly to the mean requirements of power, resistance, and velocity demanded firom the horse of to-day.

3d. Simultaneous Variations of the Ischium and the Ilium.-If the angle, $A O B$, instead of preserving its mean dimension, becomes smaller 
by the approximation of its two sicles, so as to become $\left.A^{\prime}\right) B^{\prime}$, the results atre as follows (Fig. 40):

The apparent length of the cromp, $A^{\prime} B^{\prime}$, will be diminished, although the dimension of the levers $O A^{\prime}$ and $O B^{\prime}$ do not change. The distance between the

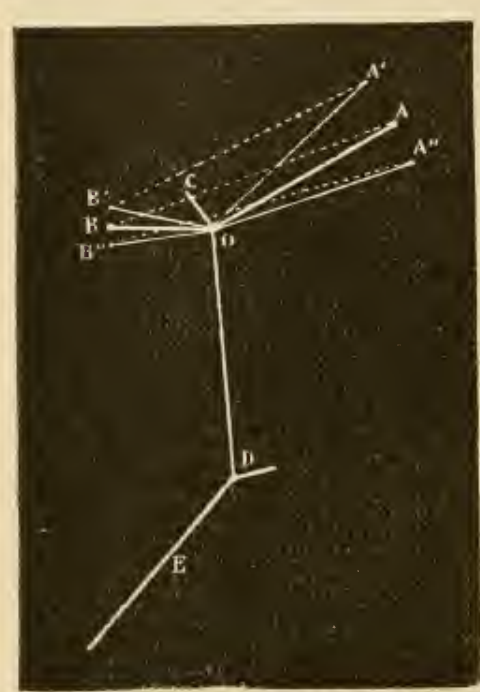

FIG. 40. print of the ischium and the tibia becomes longer.

The coxo-femoral angle, $A^{\prime} O D$, being larger, the impulsive force of the femur will he reduced, because it is transmitted ton vertically. This is the principal disadvantage of this conformation.

The fixation of the dorso-lumbar spine is easy and powerful, on account of the greater obliquity of the ilium and the perpendicular incidence of insertion of the gluteal muscles, $A^{\prime} C$.

Such a eroup appears short and poorly defined; the animal lacks mobility and develops a vertical impulsion; the region possesses great strength, and he is well fitted to execute the gallop or leap, on account of the length of the buttock, but he is without great speed. TIs have known many horses whose croup had these characteristics, and which performed ordinary work satisfactorily.

In the olposite conformation, $A^{\prime \prime} O B^{\prime \prime}$, the croup will appear longer, but will have a tendency to weakness from the horizontal direction of the ilium.

The movements of the femur will be more extensive, the angle $A^{\prime \prime} O D$ being smaller.

The impulsion will be better transmitted than in the preceding case.

Finally, the buttock will be shorter.

Feebleness of the croup and loins, greater propulsion from behind, and little aptitude for the gallop and for leaping are the principal characteristics of this form. The gait will lack neither amplitude nor grace, but the weight on the back nust be reduced to a minimum. The subject will perform good service as a carriage-horse or for light traction.

An interesting remark to be made in passing is, that in the three varieties, $A B, A^{\prime} B^{\prime}, A^{\prime \prime} B^{\prime \prime}$, the general direction of the croup is not sensibly modified, while the conditions of force, strength, and speed are all of different orders. We shall return to this point later.

b. INFLUANCE OF THE Misplacemext of the Coxa as A 
WhoLE.-The pelvis, as a whole, may incline more or less towards the horizontal or the vertical line.

Although these misplacements are more rare and less marked tlan these of the individual bones, such general misplacements are nevertheless sometimes observed.

The ilio-ischial angle in such eases is ordinarily more closed than is normal, owing to a diminished obliquity of the ischim. The forward and backward rotation of the coxie can thus be accomplished withont pereeptibly modifying the direction of the floor of the pelvie earity.

This rotation, in one direction or in the other, modifies the obliquity of the croup (Fig. 41) more than the partial variations to which we have alluded.

When the coxce are rotated backurd, $A^{\prime} O B^{\prime}$, the combined result, a straightening of the ilimm and lowering of the ischimm, is both farorable and unfarorable. Velocity is diminished and force increased. The (roup and loins are strengthened, and the power for traction increased. The femoral impulsion is reduced because it is applied too vertically. This conformation, when it is exaggerated, disturbs the axis of the members by placing the latter under the trunk; it is altogether ineompatible with great speed, but is not detrimental to slow work which requires great force.

An inverse displacement, $A^{\prime \prime} O B^{\prime \prime}$, naturally means opposite results. The muscles are longer, their play is

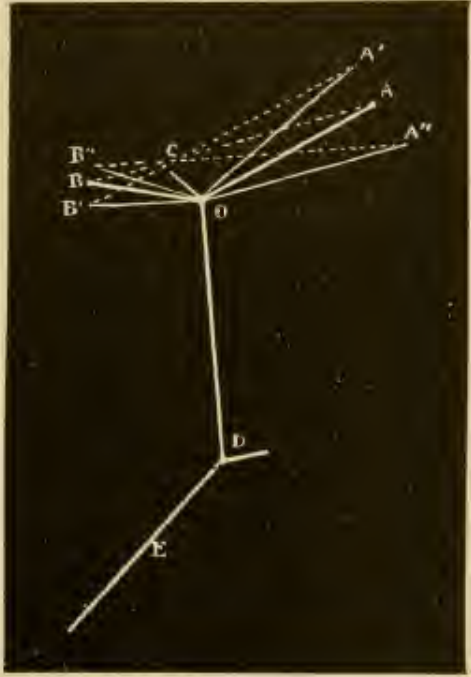

FIG. 41. augmented, the transmission of the motor impulse is more horizontal, but the regions above are weakened.

As soon as the horizontal direction passes beyond certain limits, the hind limbs tend to rest posterior to their vertieal axis, and the extension and flexion of the femur become insufficient. There is a tendeney towards a disposition analogons to that in the ox, whose loins are weak, not only on aceount of their great length, but also in conserquence of the conformation of the croup, whose inclination is but faintly marked. 
General Considerations relative to the Direction of THE CROUP. - If the reader is not already discouraged by having followed us in the minute analysis which we have given, he will now recognize that the terms horizontal croup and oblique croup only have a relative signification, always more or less vague, unless they are somewhat arbitrarily defined. He will know that such or such a croup is not necessarily well directed, from the statement that the ilio-ischial line is oblique or horizontal, as the case may be. He will then understand the distinctions to be made in the two factors, the ilium and the ischium, which occupy such an important relation in the modification of the general direction of the coxx. Finally, he will perceive that each special aptitude of the horse is associated with a particular inclination of the one or the other of these factors.

The modern horse must respond, by his conformation, to multiple purposes. The two principal, which embrace all the others, require the animal to employ either force or speed. The muscular forces, however, which in the two cases are intrusted with the double result, must, for the production of the one or the other, act according to a mechanism entirely different as to its mode of construction. Whence we meet certain qualifications, absolute for speed, while those for force may be absent, and vice versa.

In this region of the croup, any osseous inclination which implies long gluteal and ischio-tibial muscles, a large femoral extension, and a transmission of the motor impulse as horizontally as possible, should be considered as the three factors which exemplify the best conditions of speed.

The distinctly-horizontal croup has an inclination of 20 to 30 degrees, a low ilium inclined 25 to 30 degrees, a horizontal ischimm, and an open ischio-ilial angle. The animal thus conformed will have, if the femur be well directed, a coxo-femoral angle of 105 to 110 degrees. This increases the are of oscillation of the thigh, the limit of which during extension passes well beyond the vertical line of the members. We know, in fact, that the impulsive force especially is only utilized during progression after the moment that the direct axis of the member has passed beyond the rertical line passing through the centre of the coxo-femoral articulation.

Such a horse, however, becomes incapable of carrying, without great fatigue, a heavy weight on his back; light jockeys, therefore, are necessary for the rumning-horse; the vehicle which he draws must also be very light. Constructed for rumning, and carrying only his own weight, his speed will be extreme; more than this should not be 
demanded of him. How many of his likeness appear on the turf which are capable of astonishing speed for a short distance, but which cannot maintain it when the distance is increased, being overburdened by the weight which they must carry!

Let us change the data of this problem. Let us exact from the motor the production of a force of the greatest possible intensity, whether it be for carrying a leavy weight or drawing a heary load. ¿pon what will be based the influence of the direction of the croup in such a case?

With M. Nemmann, ${ }^{1}$ we respond that it depends, so to speak, exclusively upon the inclination of the croup and the coxo-femoral structures, or, if it be preferred, the position of the ilium under the dorso-lumbar arch. Here the length of the muscles and the extent of the movements are a secondary consideration; it suffices to overcome the intensity of the resistance. Consequently, any anatomical disposition whose effect is to furnish to the pieces of the skeleton a part of the effort required from the muscles, or which gives incidences of insertion to them more favorable to their contraction, must be regarded as being in eonformity with the adaptation of the subject to this variety of labor.

A strongly-oblique croup, inclined 40 to 45 degrees, with an oblique ilium inclined 45 to 50 degrees, and with a low ischium, will well fulfil these conditions. A large coxo-femoral angle, which will be the eonsequence, will place the coxæ as a strong support underneath the vertebral column and render the muscles able to sustain the latter, even if it be heavily charged. To exact the least speed from such a horse will be in opposition to physiological laws; he can only emplor his force at a slow pace.

Between these two extremes there are numerous intermediary types, which may, with sufficient ease, be grouped into three categories, as follows:

1. Saddle-horses, which are obliged to move a more or less heary weight carried on their back, at a sufficiently great velocity, whether at the trot or the gallop. Those which are destined for the turf should have a croup approaching the horizontal ideal of 25 degrees, but with a more oblique ilium (30 degrees), for the purpose of giving solidity to the structures anterior to it. Trotters ${ }^{2}$ are benefited by a somewhat

1 G. Neumann, loc. cit., p. 527 .

2 In the American trotting-horse the obliquity of the croup is subject to the greatest rariation. In some it is horizontal, in others oblique. In the mare sunol, three-year-old, record $2.10 \frac{1}{2}$, it is extremely oblique. In such cases the mechanical disadvantage is compensated by an excessive length of the ischio-tibial muscles and those of the thigh and leg in gencrul. (Harger.) 
more oblique direction of the ilimm (35 degrees). As to hunters and cavalry horses, used exclusively mder the saddle, and from which great strength of the loins and posterior quarters, but less speed, are demander, their croup should have an intermediary position between the oblique croup of the draught-horse and the horizontal one of the thoroughbred. The ilium should incline 35 degrees, and the ischium be slightly lowered, in such a mamer that the ilio-ischial line shall preserve this intemediate relation.

2. Driving-horses, employed on the track or as animals of luxury, whose exclusive gait is the trot, without any weight on the back, can, without disadvantage, have a horizontal croup. This is appreciated as a quality of beauty and fashion as well as for its mechanical adrantages in rapid locomotion.

3. In dranght-horses for fast, heary work, or mixed motors, combining at the same time force from their bulk and their muscular power, and a certain speed from their relative muscular activity, mited with the length of the segments, a croup slightly more inclined than that of the cavalry horse or the trotting-horse will fitfil the required conditions.

Errors in the Estimation of the Direction of the Croup.The deep situation of the coxo-femoral structure, the large mass of muscles which cover and conceal it, more or less, and, finally, the complexity of the function which it fulfils as an apparatus of station, impulsion, and locomotion, render its study particularly difficult. Without a trained eye, capable of observing and often inferring the anatomy through the external form, errors are not only possible but frequent, even with experts. Some prefer the horizontal and others the oblique direction, while still others have no preference between the two directions, but assert that the inclination of the coxa alone is without effect on the locomotory aptitude.

Nevertheless, here, as in all other circumstances, the correct method of selection is regular and scientific. Each direction offers advantages which correlate with some determined exigency or need; each one also has its expediencies with regard to the qualities of speed or of force which it is desired to obtain. The difficulty lies in establishing the kind of conformation which is suitable to each special case.

In order to accomplish this, a thorough examination of the parts is required, irrespective of special appearances. Nothing, for example, produces such a deceptive appearance of horizontality in the croup, as the slight prominence and small convexity of the superior line and the horizontal direction of the ischium and the sacrum. Conversely, a depressed ischium and sacrum and a superior surface curved and 
oblique, seem to augment the inclination of the coxr. As we have scen, it may, nevertheless, be that in the two cases the obliquity of the ilium is equal and even more horizontal in the one which appears the more oblique. Hence it is especially the direction of the ilium which it is necessary to take into consideration in the determination of the conditions of force and strength of the regions in front of the croup, and particularly its characteristics of length, width, and thickness, which we have already detailed. A certain intuition which not every one possesses is necessary to appreciate these, and hence the errors of jullgment which are so common.

II. Richard ${ }^{1}$ has good reason to criticise persons who make no difference, in their selection for speed, between the horse with a horizontal croup and one in which it is oblique, and asserts that compensations can equalize their mechanical aptitude, if not in blood, at least in structure. Tallon ${ }^{2}$ has not expressed a different opinion in advaneing that an oblique croup is capable of forcibly propelling the body and of communieating to it great speed, provided the anterior part of the trunk is low and light. The length of the locomotory segments, the degree of the openness of the articular angles, the position of the limbs under the trunk, the muscular development, the race, the energy, and many other factors of speed, can accompany a (roup with an oblique ilium, and would be more or less defective in subjects with a horizontal croup. It is incorrect to connect a special aptitude, whatever it be, to the conformation of one region alone, and much more so to pretend that it depends exclusively upon one particular osseous inclination. We will not dwell on this point.

Modifications in the Direction of the Crodp resulting FROM LABOR.-The direction of the croup is not always congenital; it is often modified by the manner of utilization or work.

Young animals which are attached to heary loads too early, and those which are employed in monntainous districts for traction or as animals of burden, will have, in time, a croup more and more oblicue. On the contrary, in the saddle- or the pack-horse which are placed in service prematurely, this region tends to become more horizontal.

Muscularity.-Besides the qualifications, length, wilth, thickness, and direction, which we recognize in this region, it is also necessary that the muscles be firm, dense, well outlined, and well developed.

Withont these qualifications the region will be entirely deficient in

1 Richard (du Cantal), Etude du cheval de service et de guerre, 6e éd., p. 215, Paris, Is82.

3 Vallon, Cours d'hippologie, tome i. p. 406, Puris, 1863. 
power. This is a common defect in many horses of a sluggish and lymphatic temperament and raised in low, marshy districts.

Forms.-The different forms of the croup are dependent upon :

1. The dimensions, length, and width.

2. The direction of its large axis.

3. The direction of its superior line.

4. The muscular development.

5. The movements.

The deseription of these which we have already given above will allow us to notice them rapidly in review.

1. In relation to its dimensions, the croup can be long or short, wide or narrow. When the launches and the points of the buttocks are in planes which tend to be parallel, and at the same time the region is long and wide, the horse is said to be square behind, a qualification which is to be admired, because it gives force and velocity. ${ }^{1}$ When the croup has a certain width in front but is narrower behind, it takes the names almond-shaped, mule-like; the horse viewed from behind appears narrow, pointed.

2. In relation to its great axis, we know that the croup may be oblique or horizontal. These terms are applicable to these directions when the latter exist in an ordinary degree; when they are not exaggerated. It often happens that they become faulty from an excess or a deficiency in the one sense or the other.

Too horizontal, it lacks force, renders the animal incapable of supporting the least weight on his back, and alters the vertical axis of the posterior limb by displacing the latter too far backward. Too oblique, it acts prejudicially to this axis by placing the limb too far under the trunk, transmits the force of impulsion ineffectively, and predisposes the back to disease from undue strain. It is then ealled low, cut-off', slanting.

3. Direction of its Superior Line.-When the sacral spine is prominent, so that the sides slope strongly outward, downward, and backward, as is remarked in certain strains of horses in the south of ecntral France, the croup is designated sharp or mule-like. This conformation, quite common in the barb-horse of Andalusia, becomes defective only when it is accompanied by a narrowness of the posterior quarters, lessening the strength of the parts and the velocity of the gait.

The eroup is called hen-tailed when it presents a more or less distinet depression anterior to the base of the tail. In such animals the

${ }^{1}$ A. Rivet, Guide pratique de l'acheteur de ehevaux, 1877. 
latter is badly carried ; the aspect which it presents gives it the name of rabbit's tail; it is observed in certain Frisian and German horses with slanting croups.

4. The development of the muscles of the cronp varies according to the race.

When the median line presents a longitudinal gutter, limited on each side by an elevation of the gluteal museles, the croup is double; its lateral diameter is then nearly always large. It is a eharacteristic of great force, and is observed in dranght-horses of a lymphatic type. It must be considered as being detrimental to the production of speed, becanse it surcharges the posterior extremities and occasions excessive lateral displacements of the centre of gravity.

When, on the contrary, the sacral spine projects above the surrounding muscles, otherwise well developed, the eroup is said to be angular. This conformation, which renders the lines and the contour of the region more apparent, is not a defeet, but denotes great power of the bony levers. If, however, it results in a disappearance of the harmony between the bones and the muscles, and the latter are weak and poorly developed, the preceding advantages will be absent.

"If the muscles of the croup of the mare appear sunken, so that the base of the tail is well detached and the abdomen somewhat pendulons and projecting on each side, we can presume that she is pregnant; a slow and heavy walk confirms this presumption" (Captain Rivet).

5. Finally, in relation to its movements, we remark that the eroup should propel the trunk without swinging from side to side. If this condition be not fulfilled, the region is said to be oscillating, and if it is more exaggerated, the animal rocks himself.

In the first ease, the region lacks propulsive force; in the second, the gait is ungraceful and deprived of speed.

"In the pregnant mare, nine times out of ten the muscles attaching to the summit of the croup on each side of the base of the tail will tremble when she walks" (Captain Rivet). This condition is due to al relaxation of the sacro-ischiotic ligament, a fact which we have demonstraterl.

Diseases and Blemishes.-Certain authors assert that the coxo-femoral articulation is quite frequently the seat of a peculiar strain, against which cauterization, setons, and vesicants are employed (Vailon, Merche).

This disease, consigned to-day to the list of maladies whose names have 
encumbered ancient veterinary medicine, serves as a pretext for a treatment of which the region sometimes bears the traces, and which is too often the proof of the uncertainty into which a lameness whose seat is unknown sometimes leads the veterinarian. Be that as it may, it will be necessary to examine carefully the other regions of the posterior member in which the coxo-femoral articulation presents evidence of such disease.

The blemishes of the croup are not numerous. They are due to excorittions and wounds which result from continued friction, caused by a misfitting or a vicious application of the crupper.

The muscles of the croup, with those of the thigh and buttock, sometimes become the seat of atrophy, which, manifesting itself by a considerable reduction in their volume, places the osseous apparatus in relief. ${ }^{1}$

This atrophy of the croup, whether of nervous origin or otherwise, is always due to a prolonged inactivity of the muscles, and is sometimes rebellious to treatment. It depreciates the value of the animal, especially when it is the manifestation of a local paralysis.

\section{The Haunch.}

Situation; Limits; Anatomical Base.-The haunch, an asymmetrical region, is situated upon the antero-external part of the croup, with which it becomes more or less confounded, according to the subject. It is for this reason that its study as a distinct region is somewhat difficult.

It is limited below by the fank and the anterior crural region, above by the loins and the croup, and has for its principal base the external angle of the ilium and the muscles which attach to the latter.

Related in front to the hollow of the flank and behind to the croup, it forms, in horses of a coarse conformation, a large eminence which then receives the qualification well detached. If its prominence be due to the meagre development of the surrounding muscles, as is sometimes seen in lean and poorly-developed subjects, in the angular croup of certain Norman horses, and in many with oblique croups, it becomes defective and renders the animal too angular. We are familiar with the old jest alluded to by De Curnieu, in which the jockey tries to hang his hat on the haunch of a horse which is very meagrely developed in this respect. ${ }^{2}$

When prominence of the haunch is not due to a vicious conformation of the croup, it simply appears ungraceful to the eye and has no influence upon the qualities of its possessor.

In other instances, the haunch may show an opposite defect; it is not sufficiently salient, and then becomes effreed, low, dropped, or sumken.

I H. Bouley, Nonveau Dictionnaire de médecinc, d'hygiène et de chirurgie vétérinaires, t. viii. p. 517 .

2 De Curnieu, Leçons de science hippique générale, 1855, t. i. p. 248. 
This is the usual form which it exhibits in very fat horses, or in those whose croup is of insufficient width. We have sufficiently discussed this defect and will not return to it here.

From the preceding statements it follows that it is scarcely possible to draw any indications of importance from the mere examination of the haunches. Nevertheless, this is not the view taken by (ertain hippotomists. The reason for this difference of opinion lies in the following considerations. Bourgelat first described this region as having for its base the whole of the ilium, including that part of the body extending from the external angle of that bone to the coxo-femoral articulation. Many of his disciples, following his example, have made use of such expressions as long, short, narrow, wide, straight, and oblique haunches, terms which are still used in the veterinary world, but whose meaning is hard to determine, if we take them in their literal sense.

It is easy to see that it is illogical to make such a distinction as to separate the anterior part of the coxa from the posterior, to call the one part a haunch and the other a croup, to examine separately structures which are so intimately united and so harmonionsly blended in their nature and their anatomy. Accordingly, to avoid those repetitions and confusions which otherwise would not fail to spring up in our minds, the haunch is best regarded as only a secondary region of the eroup, interesting us by reason of its particular forms, and, more especially, its blemishes. These are the reasons why we have imitated those of our predecessors who have not accepted the distinction established by Bourgelat.

Diseases and Blemishes.-The haunch may be the seat of excoriations and wounds of more or less gravity, and sometimes accompanied by severe complications. They are always found on horses which have been injured by passing through narrow door-ways, on those which have to keep the recumbent position for a long time after surgical operations or during serious diseases, upon a bed with insufficient litter, or, finally, in those which, suffering from violent attacks of colic, throw themselves on the ground.

In other cases, the haunch is the seat of hermatomata (blood-tumors), cysts, abscesses, bruises, partial or total fractures. The latter are followed by marked deformities of this region; one haunch is lower than the other, from the fact that the detached portion is carried downward and forward by the contraction of the muscle of the fascia lata and the small oblique of the abdomen. The lameness which exists at the outset of such an aceident disappears at the expiration of a certain time, but the deformity will always persist. An animal which presents it is called hip-shot; it has received a stroke from a broom.

"Finally, it is possible that in young horses the centre of ossification which forms the tuberosity of the external angle of the ilium may become detached by the force of muscular contractions, as when the animal is forced 
into a restrained position for the performance of a surgical operation, castration, for example; thus may be produced an accident which, if it is not a fracture properly speaking, simulates it by its deformity and by its results." 1

\section{CHAPTER II.}

ANTERIOR EXTREMITY OF THE BODY.

\section{A.-The Breast, or Pectoral Region.}

Situation; Limits; Anatomical Base.-The breast is a symmetrical region situated at the anterior part of the trunk, and limited in front by the inferior border of the neck, behind by the axille and the inter-axillary region, and on each side by the arm.

It has for its main osseous element the anterior extremity of the sternum, on which are inserted the stemo-hyoideus, sterno-thyroideus, sterno-maxillaris, and sterno-humeralis muscles, and these are separated from the internal face of the skin by an abundance of connective tissue. It contains the plate vein, situated in the gutter formed by the adjoining borders of the sterno-humeralis and mastoido-humeralis muscles, which can be located easily from the exterior, and on which phlebotomy is sometimes practised.

Form.-The configuration of the exterual surface of the pectoral region varies according to the subject, from the fact that the volume of the above-mentioned muscles leaves the trachelian appendix of the sternum more or less prominent. But little attention need be given to this prominence. Nevertheless, if it is very marked, the region is qualified as sharp. Sometimes the breast presents two deep depressions situated within the seapulo-humeral angles; these depressions are due to a meagreness of the muscles or to a change in the direction of the scapulo-humeral angle. This peculiarity is very conmon in horses which are poorly developed, and the breast is then deseribed as hollow, or sunken.

Width.-The width is the principal element to be considered in the examination of the breast, and, as Bourgelat has said, it should be proportional to the volume of the body or the general development of the animal. 
Iost authors have advanced the opinion that its width is proportionate with that of the chest. In our opinion, it is easy to see in this assertion the false interpretation of the fact (for the most part very well established) that narrowness of the breast aceompanies a thorax of little eapacity and slender limbs.

It might be supposed, indeed, that there onght to be a certain relation between this narrowness and the space enclosed by the first two ribs. This is, however, an error which we have exposed by more than fifty observations made upon the living subject and completed afterwards upon the eadaver. We have never found marked differences in this respect among subjects of the same size, whatever may have been the width of the breast. This is due to the simple reason : it is not at the anterior extremity that the dimensions of the chest vary, but rather in the middle and posterior regions. Also, the differences in the width of the peetoral region are the result of eauses other than the separation of the anterior ribs. We must attribute them to the varying thickness of the pectoral muscles which form its base. It is also true that this region can aceidentally become narrow in animals whose thorax is spacions. It is only necessary to place them in bad hygienie conditions, or to give them improper food and injudieionsly-chosen work, to convince ourselves that emaciation causes a diminution of its width.

It is physiologically true, however, that the general development of the respiratory apparatus is directly proportional to that of the museular srstem. The functional activity of the muscles causes an angmentation of their volume, and their contractions produce an increase of the amount of oxygen consumed. No lungs, no muscles; and, conversely, dense and vigorous muscles require a spaeious thorax; whence it follows that the width of the peetoral region, owing to the volume of its museles, should coincide with a certain degree of respiratory power. If, therefore, this region is narrow, it becomes desirable to determine to what cause this narrowness is due, whether to that of the thorax direetly, or to the animal's " condition."

The size being equal, the breast of the English thoroughbred horse is less wide than that of the heary coach-horse, whilst he is enclowed with a ehest equally if not more spacions. In this case the harmonions development of the loeomotory apparatus must also be considered; the power of the museles, insteat of being the effect of their thickness, is due to their length; and the sternum appears more prominent than it does in a horse with thiek muscles. Besides, these muscles are dense, firm, and habituated to repeated energetic and extensive contractions. 
There are, therefore, two elements to be considered in the width of the pectoral region: whether it depend solely upon the volume of the peetoral muscles, or if to this eause is also adcled a well-developed thoracie eavity. In the former case, the width of the breast will vary aceording to the general condition and health of the animal; in the latter, its variations, whatever they may be, cannot be presumed to be dne to narrowness or feeble development of the thorax.

The width should not exceed certain limits; for when these limits are passed width of the breast becomes a defeet, since it gives too large an area to the base of support. Horses endowed with speed should be well open in front, but their openness must not be excessive, beeause the lateral displacements of the centre of gravity ean only take place at the expense of the velocity of the gait.

The English thoroughbred is not too open in front, whilst his chest, which appears narrow, is high and salient in such a way that the extremity of the sternum is prominent and gives attachment to long muscles.

Dranght-horses can, without being defective, be very open in front. The lateral oscillations of the centre of gravity, being only prejudicial to velocity, do not diminish the energy of his efforts. His power depends upon his mass, and he demands, therefore, firm and voluminous muscles. From this point of view we may regard a wide breast as an absolute beauty, or as a point of great merit, because it gives to the trunk the volume which is necessary for it to have in order to overeome easily, but slowly, heavy resistances.

When the breast is very narrow, it is said that the horse is closed in front. In all such cases, this conformation, the opposite of the preceding, is defective. It indicates a feeble development of the muscular system, and very often respiratory organs of small amplitude. If such animals offer some appearance of energy when they are exercised, they are generally incapable of enduring continuous and laborious work.

Narrowness of the breast, as well as its width, may be congenital or acquired. When it is congenital, it is observed in those subjects which, at birth, show themselves to be defective in the development of the muscular and the respiratory systems. When it is acquired, on the contrary, it is consequent upon a state of emaciation, exhaustion, diverse chronic diseases, and, in general, a profound debility of the organism. In this case, the extremity of the sternum becomes salient, the points of the shoulders project forward, and leave between them and the sternohumeralis muscles two deep depressions which terminate inferiorly the jugular gutters. 
Blemishes.-The most common blemishes of the breast are traces of setons, but these need not arouse any apprehension, because people are in the habit of inserting these counter-irritants for the most trifling causes. More or less extensive cicatrices or denndations are also met here, which result from the application of revulsives and blisters in the treatment of diseases of the respiratory apparatus.

Finally, in draught-horses it is common to observe excoriations or cicatrices which extend from the inferior border of the neck to the anterior border of the shoulders, following the direction of the collar. These have no important significance, and are even utilized by the horse-merchant to indicate to the buyer a proof that the animal settles freely into the collar.

\section{B. - The Inter-axilla.}

Situation; Limits; Anatomical Base.-The inter-axilla is a symmetrical region limited in front by the breast, behind by the xiphoid region, and on each side by the axillary space. It responds to the inferior border of the sternum and to the origin of the sternohumeralis and sterno-aponeuroticus muscles.

Having a variable conformation, concave or convex, according to the volume of the muscles, it presents nothing remarkable as regards the exterior. Setons are applied in this region, to which, in the majority of cases, no more importance need be attached than to the cicatrices which follow them.

\section{C.-The Axilla.}

Situation; Limits; Anatomical Base.-The axilla corresponds in situation with the point of junction of the supero-internal extremity of the forearm with the trunk.

Limited in front by the breast, behind by the elbow and the riphoid region, internally by the inter-axilla, and externally by the forearm, the axilla has for its anatomical base the sterno-aponeuroticus muscle and the muscular interstice situated between the adjoining borders of the sterno-humeralis and mastoidobumeralis, in which the vein of the axilla (brachio-cephalic trunk) is lodged. The skin is soft, pliable, and mobile.

Little importance is attached to this region, viewed from the exterior. Nevertheless, in certain thin-skinned and fat horses whose skin in the axilla offers numerous folds, it presents, during the summer and after a long march on dusty roads, excoriations, accompanied by redness and great sensibility, which may prevent them from performing their duties for several days. This aceident, frequent in cavalry horses, and generally of no gravity, is callect fraying of the axille.

We may also allude to bloodletting from the brachio-cephalic vein, which is sometimes followed by a thrombus.

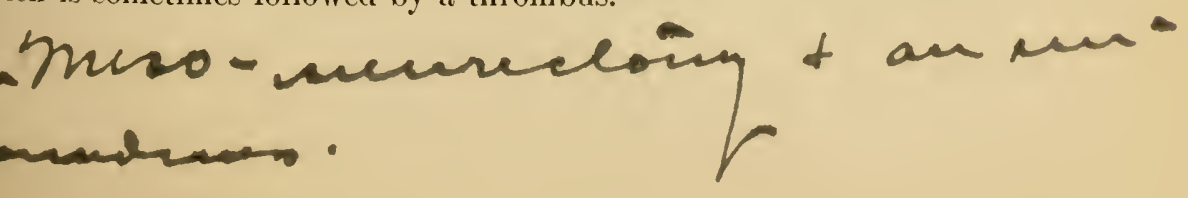




\title{
CH A P'T E R I I I.
}

\author{
INFERIOR FACE OF THE BODY.
}

\section{A.-The Xiphoid Region.}

\section{Situation; Limits; Anatomical Base.-The xiphoid re-} gion corresponds to the inferior part of the sternmm and the xiphoid eartilage (a tract whose approaches are flattened from above to below), at the level of which usually passes the girth of the saddle and the bellyband, when the thorax is properly suspended between the anterior members and the abdomen has a good conformation. If the withers are low or elevated, or the abdomen like that of the greyhound, these bands must be carried either forward or backward of their proper place. It is then understood without diffienlty that the situation of the latter must be ehanged aceording to the cireumstanees.

Limited anteriorly by the inter-axilla, posteriorly and on the sides by the abdomen and the ribs, and laterally by the elbow and the ribs, this region is more or less plainly marked, aceording to the subject, by a slight concavity which insensibly passes into the neighboring regions, and especially into the abdomen. It is of no great interest with respect to the information which it furnishes, but is, nevertheless, the seat of blemishes as well as of wounds.

The blemishes are excoriations, eicatrices of variable sizes, and traces of revulsives and blisters, recent or remote, applied for therapeutic purposes in serious diseases of the respiratory organs. The diseases of the thoracie eavity which require the employment of such means may not leave any permanent alteration of the organs affeeted, but, at the same time, it is necessary to examine the thoracie organs carefully, as well as the movements of the flank.

The wounds are generally catsed by a harness which is misfitting or improperly applied. In saddle-horses, a girth whose tension is severe will, if it be too stiff, too wide, soiled, or exert unequal pressure, irritate the skin and rencler it extremely painful. It is then necessary to use one which is narrower, or made of softer material, as cotton, or lined with silk. In draught-horses the same wounds are caused by the pinching of the skin between the girth and the belly-band. These denudations disippear never to return when use is made of one wide girth, upon which one more narrow is fastened by means of two keeps.

Other means, such as sheepskin with the wool on, and soft pads, are insufficient, irritating, and difficult to keep clean. 


\section{B.-The Abdomen.}

Situation; Limits ; Anatomical Base.-In external anatomy this region corresponds to the inferior surface of the abdominal cavity.

It is ciremmseribed in front by the xiphoid region; behind by the sheath and the scrotum in the male, and in the female by the mammary glands; on each side by the ribs, the flank, and the groin.

The structures which form its base are, proceeding from without to within, the skin, the pamniculus carnosus, the tunica abdominalis, the abdominal muscles, and, finally, the peritoneum, the serous membrane which covers the parietes of the abdominal cavity, and the contained organs.

Beauties and Defects.-It is important to consider the region of the abdomen, for by its volume and its weight it influences locomotion. By certain other characteristies it gives information as to the qualities of the animal and its state of health or of disease. We shall now discuss it as to the two following points, intimately associated with each other : the volume and the form.

Volume.-In a state of health the abdomen is elastic and yields to digital pressure. It angments in volume after a meal and diminishes in a measure when digestion is completed. It should be proportional to the size and the type of the horse.

It varies according to the breed. Though larger in some and smaller in other strains, it is not on this account disproportional, comparatively speaking. In animals used for slow or rapid work, its vertical diameter, measured from the middle of the back, is most generally equal to the length of the head. It is always more voluminous in the light saddlehorse, the product of a half-breed and a pure-blooded animal, or of the latter stock alone, except during the period of training.

It is, perhaps, most exact to consider, with M. Eug. Gayot, the rolume of the abdomen as beautiful whenever this region continues the external form of the thorax,-i.e., when the latter becomes insensibly continuons with the arch described by the ribs and the flank. Its inferior line, when viewed in profile, should describe a graceful curve from the stermum to the inguinal region. In this ease it can be presumed that digestion and assimilation are well performed, beeause the amplitude of the abdominal cavity corresponds to the volume of the enclosed viseera, which is in relation with their functional activity, particularly when the diet consists of aliments of good quality.

When the abdomen is defective throngh lack of volume, it indicates an animal with impaired assimilation, whose digestive functions 
are irregular and incomplete, unless this state be due to the mode of alimentation, or to the special functional grmuastics to which the race-horse is submitted.

A too voluminous abdomen denotes an animal of a ravenous appetite, of common breeding, or reared in low and damp countries with coarse, very aqueous, and innutritions food. Being compelled to take a large quantity of these aliments in order to obtain the necessary nutritive material, the horse submitted to this regimen has a distended stomach and intestines which, pressing against the posterior face of the diaphragm, compress the heart and the lungs. The muscles remain feeble, flabby, and little developed; the skin becomes thick and the hairs coarse; the form is thick and clumsy, and the constitution soft. The step is heavy, the respiration constrained by the weight of the intestinal mass. The pace is impeded by the lowering and forward displacement of the centre of gravity, and this fact renders the horse unable to execute even the least laborions efforts for any length of time.

In young horses, from the nature and the quantity of the substances which they ingest, the abdomen is ordinarily voluminous. They receive little grain, and their diet consists principally of dry forage and of grass which they obtain in pastures. In broodmares the abdomen is also more developed, either from the fact of gestation or from the peculiarities of their food.

We do not believe, as some veterinarians do, that the volume of the abdomen has any influence upon the disposition of the horse. If certain subjects are irritable, whimsical, gentle, or quiet, their disposition pertains to their inherent nature, and not exchusively to the conformation of such or such a part of the body. In fact, the exceptions to the rule proposed by the reterinarians we have alluded to are so frequent that it is not necessary to give this matter any further attention.

Form.-The abdomen, of which the form is in elose proportion to its volume, is generally cylindrical in those animals that are well nourished.

If its inferior line, instead of describing the graceful curve of which we have spoken, passes obliquely hackward and upward, as we observe it in greyhounds, it is called greyhound-like.

The horse which presents it is lauk, deficient in the volume of the bowels and of the body, which possess poor assimilation ; too much air passes underneath the abdomen; the digestive functions are imperfect. Arrived in the stable after a long drive, he stands back from the manger, sulks over his food, reads the newspaper, according to the language of horsemen, and is incapable the next day of resuming lis work. 
This condition must not be confounded with that retraction of the abdomen which is temporarily the result of training in the horse, or of an exclusive diet of oats for those required to perform laborious services.

If, on the contrary, the inferior line of the abdomen is very convex, descending abruptly backward from the sternum, it is spoken of as dropping, pendulous, or cou's belly. This is a conformation indieating, ats we have seen, a horse with a ravenous appetite, sluggish, without activity, and predisposed to be sway-backed and short-winded. In breeding distriets where the forage is nutritious and fattening, as in the Talley of Ange and in the Cotentin, it is not necessary to hesitate over a roluminous abdomen when the conformation of the chest is good, and particularly in the case of mares which are pregnant, and that of foals and colts. Diet and exereise will soon cause its disappearance. The skill of the buyer consists in selecting under adverse cireumstances, often with little to enlighten him, the animal which, in spite of a heary abdomen, will with proper care assume a light, graceful, and stylish appearance. ${ }^{1}$

Diseases and Blemishes.-The diseases and blemishes of the abdomen it is important to recognize. They are:

1. Edema, or a serous infiltration of the connective tissue, an enlargement of variable area, which is soft (but not hot or fluctuating) and yields (pits) to the pressure of the finger. It results often from prolonged rest in the stable, and sometimes also follows traumatisms, castration, or the application of irritating substances used with a therapeutic object.

2. Exomphalus, or umbilical hernia, very common in colts, which consists of a subcutaneous swelling from a protrusion of a portion of the intestines through the umbilical opening, whose obliteration after birth has not taken place. This affection is very rare in adults, because it is treated at an early period, and becanse it reduces itself spontaneously as the vertical diameter of the abdominal carvity increases.

3. Ventral hernia, which only differs from the preceding in that the rupture of the parietes through which the abdominal organ passes is accidental, and may be situated upon any part of the abdomen, instead of being natural and occupying always the position of the umbilical opening. It is due to rupture of the muscular and fibrous parietes of the abdomen. When the solution of continuity extends to the skin and the intestines protrude, it is called an erentration. The two terms do not carry the same importance. Although they are only different degrees of the same accident, yet, in relation to their gravity, they are not comparable.

4. Traces of setons, which certain practitioners prefer inserting in this region rather than in the axilla or inter-axilla, so as not to interfere with the application of the girth and the belly-band. They have no importance.

1A. Rivet, Guide pratique de l'acheteur de chevanx, p. 7 . 
5. Excoriations following vesicants or revulsives. These should induce the buyer to examine with care the state of the lungs, for these agents are sometimes intentionally applied here to divert the attention from the place which shonld more particularly require their application.

Let us say, finally, that in some instances the abdomen may be distended, tympanitic, and painful to pressure. These symptoms indicate acute or chronic inflammation of the digestive viscera, or the peritoneum, or the presence of diverse profound lesions which we shall here only hint at.

\section{CHA PTER I V.}

\section{LATERAL FACES OF THE BODY.}

\section{A.-The Costal Region; Ribs; Sides.}

Situation; Limits; Anatomical Base.-The region of the ribs is situated upon the lateral parts of the trunk, below the back, behind the shoulder and arm, in front of the flank, and above the xiphoid region and the abdomen.

It has for its base the last twelve ribs, which are not concealed by the shoulder, and which are covered by the great dorsal, the great serratus, and the great oblique muscles of the abdomen; the intercostal muscles, external and internal, fill the spaces which exist between them.

Movements.-In the normal state, the ribs execute regularly alternative movements of elevation and depression, more or less extensive according to the state of respiration and the numerous circumstances which modify its rhythm. These movements, especially perceptible under the skin of emaciated horses, are of two kinds: the first movement takes place during inspiration, and is explained by an augmentation of the intercostal spaces and the rotation of the ribs forward and their abduction from the median line; it corresponds to the dilatation of the thoracic cavity and the lungs; the second movement, coinciding with expiration, consists in the approximation of the ribs and in their rotation backward and inward; it corresponds to the contraction of the thorax and the compression of the lungs.

Form.-Slightly flattened towards its superior part, and much more rounded as it is examined more posteriorly, this region presents two opposite conformations. The ribs are called round when they describe, as a whole, a well-defined convexity from above to below; they are flat in the contrary disposition.

Beauties.-The due curvature of the ribs, their definite separation from each other, and their full development in length are three absolute beauties, or points of excellence, to be desired in all horses, whatever 
may be their service. In explaining the reasons for this, we will show the inconveniences resulting from their flatness, their nearness to each other, and their want of length.

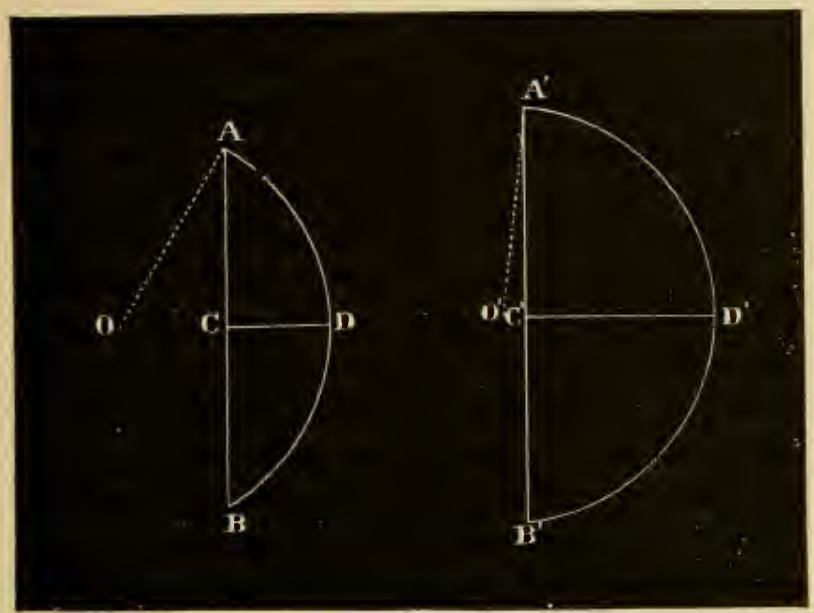

FIG. 42.

1st. The normal curvation of the ribs is in direct relation with a large transverse diameter of the thoracic cavity, and, consequently, with the development of the respiratory apparatus.

Before proceeding further, let us determine what is understood by the convexity of a curve. It is the relation which exists between the height of its arch and the length of its chord, supposing, be it well understood, that we are speaking of a regular curve. In other words, a curve is much more convex when it forms a greater projection upon a shorter chord. Thus, the two ares $A D B, A^{\prime} D^{\prime} B^{\prime}$ (Fig. 42), although belonging to two circumferences of the same radius $\left(O A=O^{\prime} A^{\prime}\right)$, have not the same convexity relatively to the chord which unites them, for the ares and their chords are different, and their relations, $\frac{C D}{A B}, \frac{C^{\prime} D^{\prime}}{A^{\prime} B^{\prime}}$, are not equal. Igain, the curve $A O B$ (Fig. 43 ) is more convex than the curve $A O C$, although its height be equal, because the ratio $\frac{O R}{A B}$ is greater than the ratio $\frac{D E}{A C}$

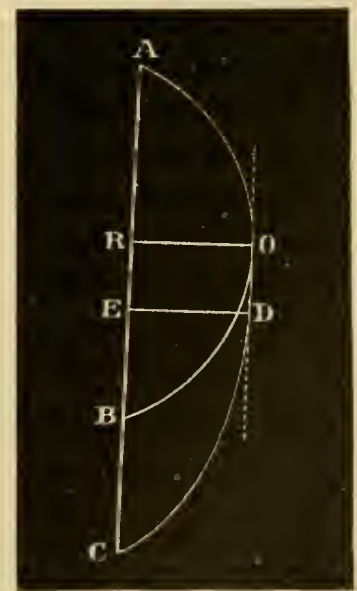

FIG. 43.

Therefore, because two curves have the same projection upon their chord, it must not be concluded that their convexity is the same, this condition being realized only when the chords are equal.

What we have just applied to the arcs can be extended to the ribs, although 
complete similarity may not be possible, on account of the irregularity of their curvature and the variations of their length and form.

Henry Cline long ago demonstrated ${ }^{1}$ that the more the pectoral cavity deriates from a cylindrical form the more its eapacity is diminished. It results from this that the rib which presents the greatest curvature will also be the one which circumscribes the greatest space. Depress a cone or cylinder, and the reduction of their volume is in proportion to the flatness of their surface. The thorax may be regarded as a flattened cone; and this is why we say : for an equal length of the ribs, the chest can never gain in height what it has lost in width; or, in other words, the convexity of the ribs is the first beanty, or point of structural merit, to be songht for in a good conformation of this region.

2d. This is not all; the ribs, as structural elements of the costal region, should also be long, for this length of ribs constitutes, for an equal width of the chest, the thoracic measurement in the vertical sense. The volume of a solid depends upon the relation which exists between its three dimensions; to be large, it is necessary that the dimensions should all be as large as possible.

It is, however, interesting to know that the rib can make up by its length for the lack of chest-volume occasioned by its loss of convexity. This proposition, which appears to be contradictory, in principle, to that which we have just given above, is, however, very logical, as we shall see.

In the preceding case we supposed the length of the rib invariable, and only made its curvature variable. In the present case we investigate the problem under its two aspects by modifying its data to find the compensations, if any exist. This method can be illustrated by the following comparison: Is there for two horses, the one having very round ribs and a low chest, the other, less convex ribs and a very high chest, any compensation in respect to the thoracic capacity?

Nearly all anthors answer this question in the affirmative, and, theoretically speaking, they are correct.

Let us suppose the two ribs $A O B$ and $A D C$ (Fig. 44). Let us also remember that they have not the same convexity, since the ratio $\frac{O R}{A B}$ is greater than $\frac{D E}{A C}$, which indicates that the first is more curved than the second.

A glance at the figure shows that not only does the rib $A D C$ circumscribe a surface equal to that of the rib $A O B$, but one that much exceeds the latter. Here, then, are two animals having the same width of the chest and a different convexity of the ribs, for which there is more than a compensation. Another

I Henry Cline, Traité sur la forme des animaux, published in the work of M. G. Lefèvre de Sainte-Marie: De la race bovine courte corne améliorée, dite Kace de Durham, Paris, 1849, p. 325. 
form of rib, $A O G$, might be found, for example, circumscribing a narrower chest for which there would be a proper compensation.

such are the results which can be deduced from an examination of the figure.

But unfortunately for the position of those who defend this opinion, there is here much difference between theory and practice; and sinec, after all, we must view the horse as he is, and not as we desire him to be, we must say that the ratio existing between the height of the ehest and its wilth does not vary to a great extent. In thirty-six horses of different races, measured in this respect, we have seen this ratio range between 1.125 and 1.468 ; it should have a mean of 1.273 .

It follows from this that the compensations offered by the chest in its height are

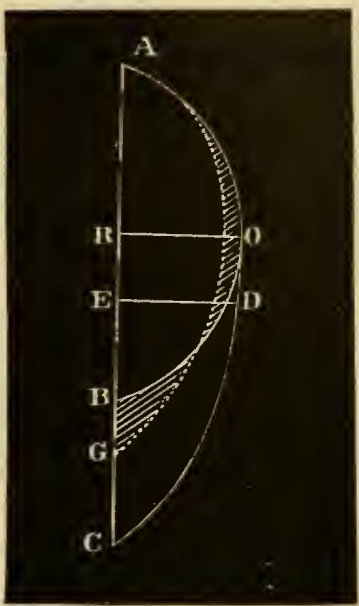

FIG. 44. not as valuable as we were at first sight tempted to believe, because of the harmonions relations which exist between the two diameters of the thorax. A flat rib is in most instances short; a round one is more often long; the thoracic eavity but little developed in one sense has many chances of being small in another; this is especially the reason why a flat side should be rejected.

It would always be in defiance of the most elementary observation to say that the existence of pectoral compensations is to be absolutely denied. Such compensations are possible theoretically, and in practice they do exist; but they are rare and very limited. If a large number of horses be measured, some are found having the same conformation and the same wilth of the chest, with a difference of only two or three centimetres in the height of the latter. Less commonly, horses are secn which present a diminution of, perhaps, one or two centimetres in the width of the chest, but which redeem themselves by an excess of three or four centimetres, at most, in the height. But these last are exceptions so diffienlt to meet that we have reason to doubt whether the internal mensurations of the thorax would, in faet, give the proof of a real compensation.

It is always true that the ribs, even if deficient in convexity, are still capable of eireumseribing a spacious thoraeic eavity, upon the sole condition that they are long and their flatness is not very marked. The essential point is to know when the defect will be compensated and when it will not be. This is a point which demands great praetical skill, and 
"1pon which many connoisseurs are led into error. We think that we are giving gool advice to beginner's in recommending them always to disapprove of the flat rib, whatever may be its apparent length. In the presence of such a conformation they should not neglect to assure themselves, by a more complete examination of the other regions, of the state of development which the respiratory organs present. This is, in our opinion, the easiest and most positive means of recognizing the compensation, if any exists.

Besides, the roundness of the chest-wall, often more apparent than real, may lead superficial observers into error. The volume of the muscles which cover the thoracic walls and the abundance of fat and subcutaneous tissue may have the effect of making the parietes of the chest appear more round than it really is, and of concealing the essential bony pieces which constitnte its base and limit its internal cavity.

3d. The width of the intercostal spaces is a beanty, or point of excellence, of no less importance. When the ribs are well separated, the thoracic walls present a large surface, extending from before to behind, and circumscribing a deeper cavity. Their separation from each other coincides also with their great projection backward, and it is easily understood that the latter gives the measure of their projection forward during inspiration. The movements of the different parts of the thorax shonld be as extensive as possible, in order that the lungs may have sufficient freedom of action. Large intercostal spaces support strong inspiratory muscles, and, therefore, imply great possible displacement of the pectoral walls.

To recapitulate, the beauty of the ribs resides:

1st. In their great curvature from the shoulder backward.

2d. In their length, or in the vertical extent of the thoracic perimeter.

3d. In their strong projection backward.

4th. Finally, in their separation from each other.

Defects.-Ribs that are flat, short, little inclined backurard, little separated, characterize a horse which is short-winded and withont power, whatever may be his breed, his stature, his temperament, or his origin.

In ordinary language, this vicious conformation is expressed by saying that the false ribs are short and the hoop-ribs are but little descended, or that the animal has need of ribs.

Diseases and Blemishes.-a. Horses which have suffered from a prolonged sickness, and which for this reason have assumed the decubitus for a long time, sometimes present a flatness of the one or the other region of the ribs. 
$b$. Those which have been affected with a serious pneumonia or a pleurisy, and to which repeated applications of revulsives and blisters have been made, often show along the inferior surface of the region denudations accompanied by large discolorations of the skin or the hairs. It is important, in examining such animak, to observe attentively the character of the cough and the movements of the flank, in order to be assured that these affections no longer exist.

c. At other times there are cicutrices situated at the level and in front of parts covered by the suddle, and due to setons inserted for a therapentic purpose. These counter-irritants are directed vertically, or are slightly oblique from before backward and from above to below. When they are observed, or their traces are found, we should inform ourselves more completely as to the reasons for their application, and the present conclition of the horse, according to the manner indicated below.

d. Heavy draught-, light draught-, and saddle-horses offer also, on the parts which receive pressure and friction from the shafts, the pole, the traces, the saddle, and the girth, depilations, wounds, cicatrices, and sit-fasts, known under the name of corns, which are the result of wounds occasioned by these pieces of the harness.

$e$. Finally, bony tumors may be seen npon the course of one or several of the ribs. These are traces of old fractures, usually situated upon the middle parts of the region. Nearly always they are complieated by contracting adhesions with the lung, through the existence of a localized inflammation of the pleura which eovers the internal surface of these bones. Likewise, as Lecoq says, we have reason to fear, especially when several ribs have been fractured, that a superrening affeetion of the chest may be aggravated by this cause.

\section{The Chest in General.}

We have now examined separately the regions which eoneur to form this vast eavity, and we shall next investigate it as a whole with regarl to the correlation between its dimensions and its beauties.

Defluition; Limits; Anatomical Base; Usages.-The chest is that part of the body which corresponds to the bony cage designated under the name of thorax. Bounded above by the withers and the back; in front by the neck: and the breast; on each side by the shoulder, the arm, the axilla, and the ribs; below by the inter-axilla, the xiphoid region, and the abdomen; and, finally, behind by the abdomen and the flanks, it has for its osseous base the following parts:

a. On the median line and above, the bodies of all the dorsal vertebra.

b. Laterally, the ribs and the interenstal spaces.

c. Inferiorly, the superior face of the stermum and the cartilages of prolongation of the ribs.

d. Behind, the diaphragm, convex in front and pierced by three openings, traversed by the aorta, the nsophagus, and the posterior vena cava.

Open in front to afford passage to the trachea, the resophagus, and the vessels of the head and anterior members, as well as to the important nerves, it has in general the form of a cone, with the base posterior and trunciterl obliquely from above to below, and from behind to before; it is depressed upon its lateral factes.

Its functions are complex and of three kinds: 
Through the bony parts, it is primarily an apparatus of protection to the central organs of respiration and circulation. By the mobility which it possesses, it constitutes the most important agent in the respiratory mechanism. Finally, by its resistance, its connections with the spine, and the extent of its skeletal surface, it plays an important rôle in locomotion by furnishing numerous points of attachment to the muscles which belong to the superior sections of the thoracic members. To fulfil this last purpose, its first pieces are short, strong, straight, and but slightly movable, for their action would be very much disturbed by their relation with the shoulder and arm. The last pieces, on the contrary, are curved more and more, narrower, removed from the median plane, and leave a wide space at the posterior part of the pulmonary lobes.

Beauties.-Although the chest-wall is far from being observable over its whole extent from the outside, it is possible to judge of its capacity with much precision. This knowledge is of the greatest importance, for it furnishes information upon the essential elements of the value of the horse.

The chest may be called beautiful when it is high, wide, and long. Let us see the meaning which should be attached to these three words:

1st. Height.-This is measured from the summit of the withers to the inferior surface of the xiphoid region; this line, then, marks the true vertical diameter of the thorax, that diameter being greatest at the spinous process of the fifth dorsal vertebra, which forms, as we have seen, the culminating point of the withers.

This dimension must not be confounded with the depth, which is measured from before to behind; it is to be regretted that some hippotomists have changed, in this connection, the meaning of a term established by long usage. ${ }^{1}$

In speaking of the ribs, we have said that this height, with the corresponding width, is directly proportional to the length of these bony arches. When this height is ronsiderable, the chest is said to be well descenderl, an epithet which depicts its sitnation relative to the ground.

We must remember, morcover, that the extent of this thoracic dimension is one of the conditions of pectoral amplitude. It should, however, not be forgotten that this factor alone is insufficient to the development of the thoracic capacity; the curvature of the ribs must also be taken into the reckoning. Leaving ont of the account the length of the fifth dorsal spinal apophysis, the height of the chest is nothing else than the chord of the arch represented by the ribs. Mere height of the chest has no longer any importance but for the coexistent

1 The depth of a thing, says Littré, is the extent of this thing, considered from uts entrance to its bottom. The entrance of the ehest is situated between the first two ribs; its bottom is the diaphragm. Therefore, lere, depth is synonymous with length. 
curvature of the ribs. In fact, it is known that by depressing a cylinder its capacity can be reduced without diminishing its surface.

It is not correct to believe that the height of the chest is always proportionate to the height of the withers. We have already shown that the length of the spinal apophyses of this region is subject to numerous variations, and that the prominence of the withers often depends upon the mode of suspension of the trunk between the anterior members.

A horse whose chest has a good height should, according to MI. Gayot, ${ }^{1}$ measure a greater distance from the top of the withers to the interior face of the sternum than from this point to the ground. The first distance wonld exceed the second thirty centimetres in well-formed saddle- and driving-horses, with a height of about one hundred and sixty centimetres, whilst it might not be more than fifteen or twenty centimetres in animals of an inferior conformation.

We must acknowledge that we are still ignorant of the exact proportions. Not only is the distance between the ground and the xiphoid region not equal to the height of the chest, but the latter is always several centimetres greater; the difference may even be twenty centimetres. Our measures have been made with the aid of the metrical standard and the compass of depth upon more than fifty horses of all varieties,-slow and rapid workers, saddle- and race-horses, etc.; they have been taken upon common horses, Percherons, Bonlonnaise, Belgians, Bretons, Normans, Berrichons, Andalusians, Barbs, Tarbans, and English thoroughbreds.

It is scarcely necessary to add that this height must be examined from the side of the chest; it wonld be impossible to appreciate it aceurately by viewing the region from any other direction. The chest, to be high and well descended, should extend well below the summit of the elbow.

2d. Width.- The width of the chest is the result of the currature of its osseous parts. It is measured from the middle ribs to those which correspond to them upon the opposite lateral plane. To do this, the observer is stationed in front of the animal, so as to see the profile of the ribs and the degree in which they project beyond the shonlders on the right and the left. The roundness of the ribs is also judged by viewing the horse obliquely, either in front or behind.

It is not necessary to refer here to the advantages of a large trans-. verse development of the thoracic cavity, but we would caution the

I L. Moll et Eug. Gayot, La connaissance générale du cheval, Paris, 1861, p. 137. 
reader against certain ideas which are too absolute, and which exist among horsemen. Some prefer the eylindrical chest for slow and heary motors; they reject it, on the contrary, for rapid services, in which they would prefer the elliptical form. The latter form, whilst giving equal space within the chest, tends to limit the lateral displacements of the centre of gravity, and thus facilitates the velocity of the gait. Others insist that there is sufficient compensation between the two forms, but consider width of clest as a beauty, or point of merit, in all cases.

We have seen, when speaking of the ribs, that a high chest is spacions only on account of its proportional wilth, but the relation between the vertical and the transverse diameters varies less than is generally thought. The development in one direction very often carries with it a correlative development in the other. The digressions which seem to contradiet this principle are more apparent than real, for the condition of the body has much influence upon the external dimensions of the ehest. Take a horse in good health, vigorous, well proportioned, and subject him to excessive work and insufficient food, and measure his chest when emaciation has reached its extreme limits. Not only is he unrecognizable in his general form, but his narrow thorax and his flat rils have modified the correlation of his two thoracie diameters, and we shall be astonished to find it to be 1.4 , when, for example, it was 1.2. When the animal is ill eared for, when good nourishment and moderate exereise no longer maintain the harmonies of the economy, all the functions are diminished, especially those of respiration and circulation. The chest tends to becone contracted, at the same time that the muscles become smaller, for the lungs are less active in the animal which is emaciated.

To make a contrary experiment, take the same horse and entirely change his conditions of existence; his chest will reassume its form, according as its muscles anyment in volume, density, and energy.

The training which animals destined for the race-con'se undergo, and that which results from the special labor to which work-horses are subjected, constitute, again, important canses of a development of fulness of the chest. In the horse, as in man, muscular gymnasties have the effect of increasing the thoracie perimeter. If we were not convineed of this fact in practice, our purchasing officers would every day refuse horses whose chest is not perfect at the moment of the sale. Our remounts take them because they know that this defeet will partly disappear after sufficient exereise.

Thus, in our opinion, amplitude of all the thoracie diameters shonld 
be desired, whatever may be the service required, for they are correlative to one another. The variations, in this respect, are so insignificant that they do not deserve to be taken into consideration. The English thoroughbred horse differs essentially in his form from the heavy dranght-horse, but the relations of the three dimensions of his chest are sensibly the same as in the latter when both have a spacions lung. All proportions considered, the rilo scems perhaps a little longer and less convex; what tends especially to make it appear thus is the particular nature of the tissnes and muscles which cover it.

3d. Depth or Length. - The length of the chest is measured from before backward, from the angle of the shoulder to the middle part of the last rib. It is easily appreciated by examining the horse in profile. It depends upon: 1st, the width of the intercostal spaces; $2 d$, the degree of projection of the ribs behind.

The chest may be deep without the back acquiring an immoderate length.

In fact, ribs very much arched and strongly oblique behind and below cause the thoracic cavity to encroach in a certain proportion upon the abdomen. Nevertheless, as the width of the intercostal spaces is in direct ratio with the length of the dorsal region, it follows that a long chest is incompatible with a short back. The English horse presents a rery fine chest when he is well formed, and he generally transmits this beanty to his descendants as well as to the offspring of his crosses with our native horses.

Defects. - When the chest is deficient in height, the horse is said to be too far from the earth; he has no chest, no xiphoid region ; too much air passes under his abdomen; he is wanting in girth; his sides or false ribs are short; his hoops are not low enough. When the chest is wanting in width, it is said to be narrow; it is short, on the contrary, when it is wanting in length or depth.

Finally, when it is deficient in its three dimensions, the animal lacks or has no insides.

In describing the inherent beanties of a large development of the chest we have, at the same time, demonstrated the inconveniences of its defects; it is, therefore, not necessary to return to the latter here.

To recapitulate, the chest, to be beautiful, or ideally perfect, should be high, wide, and long.

The relation cxisting between its different diameters varies but little in horses of the same race.

The differences depend in most instances upon the state of fatness or emaciation of the animals, or upon improper exercise and training. 
In a general way, the chest is or is not spacious, the harmony of the whole implying only that an increase in one direction is ordinarily followed by an augmentation in the others.

It is from this point of rieu, especially, that animals differ in regard to their thoracic capacity.

Exceptions are always found. Certain horses are deficient in one or another of the diameters, most often in the width.

In such cases compensations are possible, but within a very small limit. They are always very rare and rery difficult to estimate.

We must not, then, allow ourselves to be misled by appearances; we should form our judgment on a complete examination of the respiratory apparatus.

\section{B.-The Flank.}

Situation; Limits; Anatomical Base.-The flank is a donble region, situated behind the ribs, in front of the haunch, the thigh, and the stifle-joint, below the loins, and above the abdomen, with which it is continuous. Its principal base is the small oblique muscle of the abdomen, with a portion of the great oblique and the transverse.

Divisions.-Three divisions are recognized, more or less distinct according to the individuals and the conditions in which they are placed; the names which have been given to them indicate quite accurately the special configuration which they present.

The first, external to the lumbar region and in front of the haunch, is called the hollow of the flank, becanse it presents a depression so much more distinct as the intestinal mass is heavy and farther remover from it. It is very pronounced in horses with a pendulous or cow's abdomen.

The second division, or coid of the flank, corresponds especially to the fleshy part of the small oblique muiscle of the abdomen. It forms a rounded relief, oblique, downward and forward, which extends from the angle of the ham the the cartilaginous circle of the false ribs.

Finally, the third division, the most inferior of all, known by the name of the morable portion of the flank, is united to the stifle-joint by a very mobile cutaneous fold, and becomes insensibly continuous with the abdomen.

Three things are to be examined in this region: its form, its extent, and its movements.

1st. Form.-When the flank is well formed, its hollow is but little observed, its cord is scarcely prominent, and its movable part continues regularly with the external surface of the abdomen and the last ribs. A flank of this description is seen in animals that are well fed and in a proper state of flesh. 
When its concarity is too deep, it is said to be hollou, as may be observed in horses that are indolent, of a lymphatic temperament, and of large form and pendulous abdomen. It is also seen in meagre animals, and in those which are poorly nourished, or which have been obliged to endure great fatigue or a long period of sickness.

It is called corded when its cord or middle part projects above the two others, through the simultaneons effect of the depression of one and the retraction of the other. This state is noticed under the same eireumstances as those which cause the hollow flank, of which we have just spoken.

Then the inferior part of the flank becomes abruptly continuous with the abdomen, and appears as if pushed back towards the sublumbar region, it is said to be tucked up. Some authors also call it a greyhound flank when it becomes a permanent retraction, the tucking up being, in their opinion, only a transient disposition, always disappearing under an appropriate regimen. The greyhound flank, on the contrary, constitutes a veritable defect, being "an indication that the animal does not eat enough, which is the fault of a poorly-developed appetite; it is impossible to repair in a just measure the waste caused by the action of the apparatus of locomotion, and as, by a singular contradiction of nature, greyhound horses are nsually endowed with great energy, they are exposed to an early rum if they are not used with care, since the losses which they sustain are only slowly repaired." 1

Finally, if the flank unites the three preceding vicious conformations, -if, in other words, it is hollow, corded, and tucked up, - the animal is said to be thin, poor.

21. Extent. - The extent of this region is estimated by its width, measuring from the angle of the haunch to the last rib. This measurement should be as small as possible, and a flank of this kind is said to be short or narrow. Let us see the reasons for this.

Most hippotomists assert that the width of the flank is in direct relation with the length of the loins, and that the measure of the one gives correctly that of the other. This assertion can be considered only as relatively true, for the reason that the last rib, on account of its projection backward, does not end where the lumbar region begins. No doubt the width of the flank will, to a certain degree, depend upon the great or small extent of the loin, for the rib comes more or less near to the haunch. In order that this last proposition should become rigorously true, it would be necessary that the length of the loins

${ }^{1}$ II. Bouley, Nouveau dictionnaire pratique, etc., t. vii. p. 54, art. "Flanc." 
should correspond always to the width of the flank, which, as we have just stated, is not the case.

A more exact relation then remains to be establislied: it is that this width is the consequnence of the depth of the chest first, and the length of the lumbar region afterwards. The latter varies much less than is generally believed in horses of the same size and race. It is quite otherwise with the former. When speaking of the chest, we have seen that the different depths of this cavity depend especially upon the degree of backward projection of the ribs, supposing a constant length of the back. The shortness of the flank indicates a deep chest, short loins, and well-developed muscles; it is in these features that its beanty resicles. All are in accord upon this point. Horse-dealers do not fail to show, loy placing two fingers flat npon the region, that the animal has only turo fingers' width of flunk.

It seems useless to detail the disadvantages of a contrary conformation. It is evident that too much area is a defect, indicating, at the same time, the mobility and lack of solidity of the loins and the want of capacity of the chest. In this case the flank is said to be long.

3d. Movements.-Composed exclusively of soft structures, and attached to the last rib, whose movements, normal or abnormal, it follows, the flank is indeed, as has been said, the true mimor of the thoracic eavity.

In ordinary conditions, when the horse is at rest, it rises and falls, alternately recedes from and approaches the median line, as the air enters the lungs or is expelled from them. During inspiration its cord is effaced, its hollow is depressed, its inferior part enlarges, descends, and is confounded with the hypochondriac circle. During expiration, on the contrary, its cord is quite apparent, its hollow is less deep, its movable part ascends, is retracted, and increases the prominence of the false ribs.

These movements should be executed regularly, slowly, without any jerks, and should succeed each other at almost equal intervals. Let us, however, notice a very correct observation of J. Girard, ignorance of which might lead one into error : after six or seven equal respirations a longer one occurs.

The number of respiratory movements of the flank varies according to the age, the seasons, and the physiological condition ; but its mean may be estimated at twelve or fourteen to the minute. It increases with excreise according to the duration, extent, rapidity, and intensity of the efforts which the animal has been obliged to make. We have determined it to be eighty-seven after a gallop of about half an hour. This number 
is always much greater immediately after than during the exercise. This results from the fact that the thorax furnishes numerous points of attachment to the muscles of locomotion, and thus loses its rigidity during work, precisely in the measure necessary to assure pulmonary oxygenation and avoid asphyxia. After a race, on the contrary, the muscles which extend from the thorax to the members no longer act, and the ribs need preserve no longer the same fixity; the respiratory movements are now as much accelerated as they were before separated.

All horses do not have exaggerations of the respirations in the same proportion after exercise; some become breathless much more quickly than others. We shall explain this fact when we discuss the depth of the ehest. However it may be, the horse which remains "winded" a long time after exertion lacks endurance, is said to be panting, or short-breathed, and nsually has a narrow chest and a tucked-ıp flank.

Examination of the Flank.-We often limit ourselves to a superficial examination of this region, but this practice is wrong, for it is one of the most important regions of the surface of the horse's body. To avoid any doubt as to the regularity of its movements, two examinations should be made: the first in the morning and when the horse is at rest, and the next after a certain amount of exercise. It will be well in both (ases to give the animal several handfuls of oats.

These are the reasons for this procedure: at rest and in the morning the respiratory movements are less frequent; the horse is not excited, and at this time he presents the most regular and most normal manifestation of his functions. After light exercise, the respiratory morements are increased, and those of the flank are more numerous and more intense, and sometimes reveal respiratory diseases which would have remained unperceived had not the organs themselves, so to speak, been obliged to show, by a greater activity, their physiologieal imperfections or their pathological alterations. Finally, the few handfuls of oats which the animal eats have the effect of turning his attention away from the persons or things which surround him.

In summer it will also be well to free him from all insects which may torment him.

The observer should place himself in such a position as to view the flank obliquely, in order to distinguish better its profile. He may he stationed either in front, one metre from the shoulder, or behind, and at the same distance from the eroup; the eye will then follow with (are and ease the oscillations of the lower part of the flank at the level of its attachment to the cartilages of the false ribs. The examination 
will be made successively upon the two flanks, for it is sometimes accomplished better on the one side than on the other. The purely anatomical explanation which has been given for this is not sufficiently satisfactory to arrest our attention here.

It will be possible, with the aid of these precautions, to determine the modifications of number and rhythm of the movements without much difficulty. However, it is necessary to have a certain amomit of practice and possess some knowledge of the different diseases which may affect this region, for it is a question of slight variations, sometimes scarcely apparent, the appreciation of which requires the co-operation of an expert.

Among the most common alterations of the flank there is one which is quite compatible with all the apparent signs of health, and which frequently escapes detection up to the moment of sale; it is that due to pulmonary emphysema, an alteration which produces characteristic lesions in the lungs, consisting of an infiltration of air into the parenchyma of those organs. This lesion, clearly proved, is redhibitory, and nullifies the contract of sale or exchange, according to the terms of Article 2 of the law of August 2, 1884.

The expiratory movement in the emphysematous horse is double, and is separated by a short interval of time (hence called double time), during which the flank suddenly expands, and stops for an instant, to continue again its former expiratory movement.

This double expiratory effort is more or less apparent according to the stage of the discase. However this may be, as soon as the discase has been detected, the animal should be made to congh by compressing the origin of the trachea. If the congh is dry, slight, abortive, and several times repeated; if the nostrils are much dilated after excreise; if they are both covered in cold weather with a grayish discharge adhering to the ala; if the chest has an abnormal resonance on pereussion ; if the movements of the flanks cause the entire body to move, particularly the anus; if labore dbreathing is rapidly developed in warm weather, the respiration lond, the anxiety extreme, ete., the existence of a very advanced case of emphysema may be positively affirmed.

Unfortmately, these characteristics are far from being always evident at the time of the sale, and they very often pass unperceived by inexperienced persons. By placing such animals in special conditions of alimentation, by submitting them to a particular mode of treatment in which arsenious acid plays an important part, merchants an sometimes conceal the discase, or, at least, mitigate it in a notable degree. The purchaser cannot be too exacting as to the integrity of 
the movements of the flank, nor too much discredit all the more or less specious reasons which the seller never fails to give, in such eases, in opposition to any unfavorable assertions concerning the horse.

$\checkmark$ Diseases and Defects.-The flanks may be the seat of tumors of diverse nature. Sometimes these are indurations of the skin, a kind of callosities produced by the ring of the breeching in shaft-horses; at other times they are abscesses, which are caused by the continual rubbing of that part of the harness. They may be the result of a ventral hernia, a portion of the intestine being expelled from its eavity on account of a rent in the abdominal walls. Finally, they are due to the presence of farcy-buds or lymphatic cords which cross the flank to reach the ganglia of the inguinal region.

"The frequent expulsion of gas from the anus, which takes place in emphysematous horses, has induced iguorant horsemen to make an artificial fistula above or upon the side of the anus, by which they pretend to relieve the lorse of the great quantity of air which he has in his body. At present this ridiculous operation, which formerly annulled the redhibitory action in regard to horses upon which it had been practised, is abandoned." 1

The special object of this procedure, of which we have seen snme examples, was to prevent the noisy expulsion of gas through the anus by giving it a more direct outlet, in order to conceal to a certain extent the severe emphysema of which it is one of the symptoms.

\section{C. -The Groin.}

Situation; Limits; Anatomical Base.-The groin, which until now has not been comprised among the regions of the exterior, nevertheless deserves to be pointed out, on account of the examination which should be made of it.

It corresponds on each side to the cutaneous fold extending from the abdomen to the thigh, and has for its base the inferior inguinal ring, which, as we know, gives passage, in the male, to the testicular cord and the external puclic vessels, and, in the female, to the mammary nerves and vessels. The superficial inguinal ganglia are also seen here on the side of the abdomen; much more deeply, and on the side of the thigh, the elongated group of deep inguinal ganglia, less directly explorable than the preceding; finally, the part is covered by a fine skin, with downy hairs, oily to the touch, usually black and very pliable.

Limited in front by the abdomen, behind and externally by the superior and intermal extremity of the thigh, internally by the scrotum, or the mammce, this region presents, properly speaking, neitler beauties nor defects. We need only assure ourselves of the absence of blemishes.

In undertaking its exploration, some precautions must be taken, especially in irritable horses. In examining the right side, for instance, the observer, after having warned the animal, will station limself 
opposite the flank, apply his left hand to the croup, and with his right seek the inguinal ring, taking care to avoid being injured by the posterior member. If the horse is very sensitive, and attempts to rear, bite, or kick, an anterior member or the left posterior should be raised. The manouvres are of the same nature, but of an inverse order, when the groin of the opposite side is explored.

The principal alterations which are observed in this region are enlargements known by the name of glands, which involve the superficial inguinal lymphatic glands, and whose presence often coincides with the existence of a glanderous diathesis. It will be prudent in such a case to examine the corresponding member, as well as the surface of the body, and, particularly, the course of the lymphaties, to see if no other symptoms of farey exist, such as cords and buds.

Inguinal hernia is sometimes observed in the groin, which enlarges the testicular cord and no longer permits the different parts which compose it to roll under the fingers. We will refer to it again when treating of the scrotum.

\section{CHA PTER V.}

\section{POSTERIOR EXTREMITY.}

\section{A.-The Tail.}

Situation; Limits; Anatomical Base.-The tail is a long, flexible appendix, situated at the posterior extremity of the trunk, limited in fiont by the croup, below by the anus, and laterally by the point of the buttock.

This appendage is an ornament to the horse in the same manner as the mane, and is of great utility in protecting him against insects.

It has for its base the coccygeal vertebrx, as well as the four pairs of coccygeal muscles, which cover their surface. These muscles endow it with movements of elevation, depression, and lateral inclination; the skin which covers them, and which is very adherent, is furnished with long hairs over its whole surface, except upon its inferior face and at the level of its base.

Two divisions are recognized in this region,-the stump and the hairs.

Attachment and Carriage.-The tail should be strong at its origin, commeneing high up on the croup, and be harmoniously supported during locomotion. It is then said to be well attached and well carried. When it does not present this uniformity of eharacter, it is 
called badly attached, or badly carried. Often in very energetic horses, during work, it is eoneave superiorly, and even retroverted forward, which is expressed by saying that it is of trumpet form. Some persons eall it rabbit's tail, planted as in an apple, when it originates almost horizontally from a very oblique eroup.

It is easy to understand that its attachment and its carriage depend upon the direction of the croup. When the latter is horizontal, the animal carries this organ with elegance; with an oblique eroup, on the contrary, the tail is poorly sustained, being applied against the buttock.

According to its good or its vicious position, adnurers of horses draw, in a manner entirely empirieal, an accurate conclusion as to the energy and vigor of the animal. The explanation of this opinion is found in the fact that when the elevator muscles are well developed and have a dominant action over the depressors, it is an excellent sign in subjeets whose general museular system is strongly developed. As horses of the finer races have the sacrum reetilinear from before to behind, whilst those of the common races have it usually convex in the same direction; as, besides, this direction of the bone has an influence upon that of the eroup, and, therefore, upon the carriage of the tail, we must guard ourselves against forming the conclusion that the beautiful attitude of the latter is in all cases the expression of great energy.

Formerly, dealers and owners frequently attempted to remedy the ungraceful carriage of the tail by excising a part of the depressor muscles so as to allow the elevators their full degree of ation; this procedure was simplified by amputating a more or less considerable portion of the stump. This was the operation on the tail after the English fashion; the animal which had undergone this operation was said to be docked in the English style; it gave him a certain degree of distinction. Cutting the depressor muscles alone, the stump being spared, was ealled nicking; the horse was then nicked.

This eustom is very old, for Hartmann ${ }^{1}$ reports that the council of Calchyd, meeting in England towards the end of the eighth century, prohibited the practice of thus docking horses, on the ground that it was a barbarous enstom. ${ }^{2}$ There is no donbt that from this usage was deriver the nickname Caudati, which was given to the English in the thirteenth eentury. ${ }^{3}$ The procedure did not long prevail in England before it passed into Germany. ${ }^{4}$

1 Hartmann, Traite des haras, p. 274.

2 Journal de Paris, année 1757, Nos. 201 and 216.

3 Dufresne. Glossar, word "Caudati."

${ }^{4}$ Neue Kriegsbibliothek, Breslau, 1771, svo, 6th part. 
It is not in place here to speak of the different accidents which may be the consequence of docking; they are quite numerous, and more or less serions. It is sufficient to say that the operation is not ahrays without danger.

Many docked horses carried their tails either to the right or to the left side, like certain terrier dogs. This resulted from raising the tail upon the croup after the operation, and maintaining it there by supporting it by its superior face upon a pad of straw. The latter often became disarranged during locomotion, was displaced backward and forward upon the eroup, and rendered the cicatrization irregular.

State of the Stump.-The stump has the form of a quadrangular pyramid, whose summit corresponds to the free extremity; its inferior face is normally ahways devoid of hairs.

The tail whose stump is intact is called entire; it is said to be docked when a portion has been amputated from the latter. We should not neglect to note the one or the other of these conditions when a description of the animal is required.

Some persons attach importance to the development of this part, because it is generally in harmony with the other muscles of the body. It is also customary to raise it at the time of the sale, and to estimate the vigor of the animal according to the degree of resistance which it opposes. As H. Bouley affirms, "the information furnished by this measurement of force seldom leads into error." 1

State of the Hairs.-When the tail is entire, its stump, intact, naturally carries all the hairs which it can support. At present the horse is said to have a full mane and tail when they

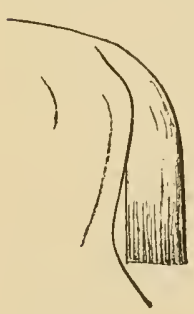

FIG 45. have not been shortened. In such eases, their abundance and their length vary much according to the race and the subject. It is known that in Arabian horses the hairs of the tail often touch the ground; in others, they usually stop more or less below the hock; they are always disposed in a point inferiorly, like the bristles of a brush.

It is rare that they are preserved in this state. They are usually shortened in different ways; they are divided transversely, sometimes on a level with the chestnuts or the point of the hock, sometimes towards the fold of the buttock. In the description, this kind of section should be indieated in the following manner: entire tail, shortened hairs. All race-horses are thus treated 
(Fig. 45). The tail is then more easily turned up, it soils the rider less, and is much less liable to catch the reins, an accident often serious on account of the energetic kicking which it at times provokes.

As soon as the stump has been shortened, it is plain that a certain number of hairs are wanting; the horse can no longer be described as having a full tail. Special designations have been employed which recall the particular disposition of the hair upon the horse's tail.

When, for example, after amputation practised upon the stump, the remaining hairs preserve their entire length, the tail is like a broom (Fig. 46), on account of the aspect it presents; inferiorly it terminates in a tapering point, like a paint-brush, as in horses with full mane and tail. When it is too long, it is sometimes shortened with the knife, but its form is preserved. It is usually allowed to have its full length in draught-horses.

If, after the amputation of a portion of the stump, the hairs are cut transversely at the level of the fold of the buttock, or slightly below, the tail, still quite

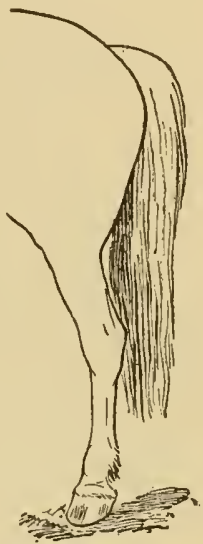

FIG. 46. long, is called banged. Such is the eustom adopted in the army, and in horses performing light work, coach-horses, ete.

At present it is becoming more and more fashionable to have the tail very short in certain horses kept for pleasure, principally Irish cobs, race-horses, and ponies. It then scarcely extends beyond the point of the buttocks.

Three principal forms are given to the tail by the manner in which the hairs are cut; besides, it has not the same aspect on the animal
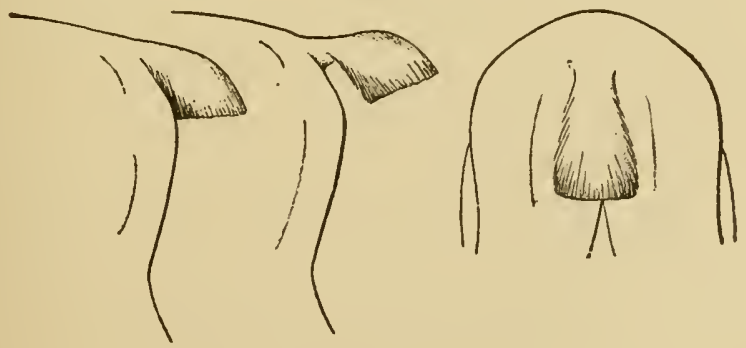

FIG. 47.

when at rest as when at work, in profile as behind, as is shown by the figures. It is called a short tail when the hairs have been cut off perpendicularly to the stump and close to the latter (Fig. 47). 
Sometimes the hairs are cut obliquely from below upward and from behind to before (Fig. 48).

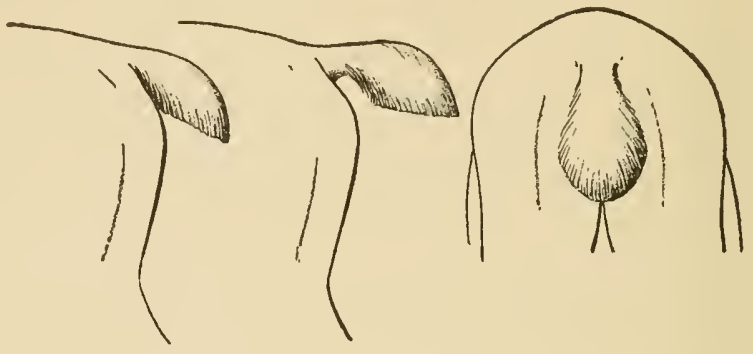

FIG. 48.

Finally, the tail is called bushy when the hairs, a little longer than the stump, are excised obliquely, as in the preceding form, but following a convex curve, which is insensibly continned on each side to join the root of the stump. When well supported, it resembles the brushes which bakers use to clean loaves of bread (Fig. 49).

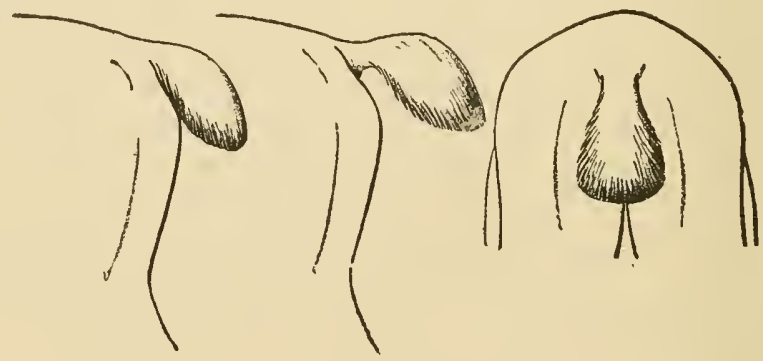

FIG, 49 .

Formerly, the name chb-tail designated one whose stump, with the hairs removed in the middle, ent very short, presented upon the sides two long locks which were allowed to flow freely. The origin of this appellation being much disputed, and, besides, being of little interest, we will say nothing more about it. This form of tail is no longer fashionable. However, Lecoq reports that it is still sometimes seen in tow-path horses. ${ }^{1}$

Finally, the horse is said to be rat-tailed when the hairs, thinly scattered, render the partly-denuded skin of the stump visible. Although a proverb asserts that never does a horse with rat-tail leave his master in trouble, this peculiarity should always be considered as an inconven- 
ience, on aceount of the function devolving upon this region, especially in broodmares; it is rejected in services of luxury, on account of the ungraceful appearance which it gives to the animals.

We have already said, in speaking of the mane, that horses with a gray or white coat, with curled woolly mane, always have melanotic deposits in the interior of the body. This state of the mane is extended also to the tail, and constitutes a cause of depreciation so much greater as it is more accentuated, for melanotic tumors often eause the most serious complications.

Merehants have the habit of plaiting the tails of their horses when the hairs are very long, principally in those of heavy draught, before they present them for sale. This practice, intended to give greater apparent width to the posterior part of the trunk and to make the posterior quarters appear more prominent and vigorous, is generally accompanied by a small fraud, which consists in introducing a piece of ginger into the anus. Suddenly the animal feels very energetie, a feeling which he manifests by the elevated earriage of his tail and the vivacity of his movements. We will return to this eustom when speaking of the animal at the sale.

A more serious fraud, the employment of which, however, is rare, is the application of a false tail to horses with a rat-tail, for example, or in the case of a pair of horses in which this region is dissimilar. If any doubt is entertained as to this manœuvre, it may always be detected by umplaiting the tail and withdrawing the straw and other accessories which jockeys employ when the horse is to be sold.

When the tail has been the seat of operations practised by dealers, it is useful, at the time of buying, to be guaranteed as to the possible results. On two oceasions we have seen animals die of tetanus following amputation of this organ, performed by the seller.

In relation to its movements, the tail, during work, should be earried high and remain immobile. If it is agitated in a jerking way, the animal switches the organ, as seen in urinating, ticklish mares when the posterior parts of their bodies are touched or approached. Care should then be taken against kicks and bites; the attitude of the cars and the expression of the physiognomy afford information conceming the intentions of the animal.

Let us remark, in eonelusion, that the horse threatened or struck from behind instinetively depresses the tail between the buttocks. It is often sufficient to seize him by this appendage and exereise upon the hairs strong traction from above downward, to prevent him from rearing. 
One of the most frequent diseases of this region is pruritus, occasioned by the uncleanliness of the skin of the stump, sometimes by the presence of intestinal worms (oxyures), or the itch, which is manifested by depilations, excoriations, and eschars, more or less extensive. These affections always begin by a peculiar straightening of the hairs, which should attract the attention of the purchaser; otherwise they are not serious.

The crmpper quite frequently canses wounds when it is not well fitted or padded, especially in animals low in front, in which the saddle and harness have a tendency to slip towards the withers. These lesions are also observed on horses of a good conformation which are harnessed without the breeching, and which are required to descend steep hills. However caused, these wounds sometimes make it impossible for the animal to endure the crnpper. We have seen them so deep that they could take the place of nicking. Generally it is sufficient to increase the thickness of the crupper or to discontinue the use of this part of the harness, to enable the sores to heal at once.

We shall further on speak of cicatrices, longitudinal or transverse, traces of docking or nicking; of fistulæe which require a long time to heal, and which complicate these operations; finally, of melanotic tumors, sometimes ulcerated, which cause a black, fetid, and unclean discharge.

\section{B.-The Anus.}

Situation; Limits; Anatomical Base.-The anus is the posterior orifice of the digestive tube. Situated underneath the tail and above the perineum, it has for its base the most posterior muscular fibres of the rectum, surrounded by a strong sphincter, related on the sides to two retractor muscles (ischio-anal). Its skin is fine, pliable, oily, devoid of hairs, and black even in white horses; we can sometimes find, however, as in the vieinity of other natural openings, pinkish surfaces deprived of pigment, called leprous spots. Internally it is covered by the reetal mueous membrane.

In vigorous and healthy horses the anus forms a rounded projection, firm, depressed, and folded at its centre like the mouth of a purse; it is described as prominent. In animals weakened by age, work, and sickness, it appears sunken, soft, and sometimes gaping. It shows, in this ease, its mucons interior, and becomes powerless to retain the frecal matters, which-poorly moulded, on account of the general atony of the digestive tube-are expelled with much gas during loeomotion or while the animal is taking a deep inspiration. This state is characterized by giving the animal the epithet evacuator.

Diseases and Blemishes.-The anus is especially to be examined in regard to its celterctions.

Let us speak first of the melanotic tumors in certain white or gray horses, the volume of which is an obstacle to the expulsion of the excrements. These 
tumors soon soften, ulcerate, and acquire a repulsive aspect and an unpleasant odor, and they lead to fatal results whenever sufficient inflammation is excited.

Anal fistulce were quite common at the time when the operation of docking the tail was more usually practised, of which they constituted one of the complications. It was not less frequent to find here other fistula which were voluntarily made, under the name of whistle, or nightingale, with the object of relieving horses affected with emphysema, in which the expulsion of gas through the anus is almost constant. As we have shown on a previous page, this practice has long since fallen into disrepute, and is now only the appendage of a gross empiricism.

In certain horses a particular larva is sometimes found, attached strongly to the margin of the anus by the hooks of its cephalic appendix; it is that of the Estrus homorrhoidalis, which comes from the stomach and is expelled from the digestive tube to perform its metamorphosis.

There is another larva, that of the Hippobosca equina, or horse-tick, better known under the name of flat $f y$, or spider-fly, because of its special form. These larvæ are seen under the tail, on the sides of the anus, and on the genital organs, particularly in Oriental horses. They are flat, resistant to pressure, and very adherent to the above-mentioned parts. These flies sometimes emigrate to animals which are not accustomed to them, and excite the horses to such a state of agitation that they are suddenly seized with fright, run away, and demolish everything in their way. It is only necessary to remove the cause of this agitation as soon as it manifests itself, in order to avoid with certainty such formidable dangers.

\section{C. - The Perineum and the Median Raphé.}

The perineum is a single region comprised between the anus and the external genital organs.

In the male it extends from the posterior part of the scrotum to just below the anus. Situated at first between the thighs, then between the buttocks, it is in relation anatomically to the corresponding part of the urethra and to the perineal aponeurosis which covers the latter. Its skin is black, or sometimes marbled, from the presence of leprous spots, which peculiarity should not be omitted in the description of the horse.

It offers neither beauties nor defects for consideration ; it should be perfectly distinct and exempt from cicatrices, which might be the result of a dangerous operation, urethrotomy, practised in the treatment of calculus of the blarder, or the consequence of blows reccived by the animal.

In the mare this region is much smaller; it corresponds only to the narrow space situated between the vulva and the anus.

Some authors have regarded it as extending to the manms, whose situation is quite similar to that of the testicles. But eren if we should observe this analogy, the study of the perineum, with regard to the exterior, would not gain in importance.

As to the raphe, as its name indicates, it is a kind of eutaneous 
thickening which marks the median line, from the sheath and the testicles, or the mammæ, to the anus. It is shown in the form of a small crest, more or less prominent according to the subjects, is a simple peculiarity of the regions upon which it is observed, and, therefore, is devoid of all interest.

\section{CHA PTER VI.}

GENITAL ORGANS.

THE examination of the genital organs should not be neglected, either for the purpose of ascertaining their good conformation in animals which are destined for reproduction, or for simply proving their state of licalth or of disease.

\section{§1. Genital Organs of the Male.}

These comprise, with respect to the exterior, the testicles and the penis, to which are annexed the protecting coverings, dependencies of the integument, known under the name of enveloping tunics for the former and sheath for the latter.

\section{A.-The Testicles and their Enveloping Tunics.}

The organs which secrete the semen, the reproductive fluid of the male, are two glands, situated on each side of the median line, in the inguinal region, and between the thighs. They constitute, as a whole, an irregularly-rounded mass, divided in its middle into two almost equal lobes, by a slight groove, a sort of raphé, which behind is contimnons with the perineal raphé, and in front is prolonged upon the inferior surface of the sheath.

1st. The Enveloping Tunics.-The testicles are surrounded by several superposed envelopes, which are, proceeding from the superficial to the deep parts :

a. The scrotum, or the skin (but the whole double sac, composed of all the enveloping tunics, is also spoken of as the scrotum).

$b$. The dartos, very adherent to the latter, and forming for each testicle an independent inusculo-elastic sac.

c. The sub-dartoid connective tissue, a more or less dense layer, which separates the dartos from the following tunic.

d. The cremaster or tunica erythroüdes, a striated muscle which is attached to 
the external surface of the fibrons tunic, and determines the rapid ascending movements of the testicle.

$e$. The fibrous tunic, which surrounds the serous sac in which the testicle is suspended.

f. Finally, the vaginal tunic or sheath, a diverticulum of the peritoneum, covering the inner face of the fibrous tunic and surrounding the testicle as well as its suspensory cord.

The development of the testicnlar envelopes varies according to diverse circumstances, such as the degree of descent of the testicles, the state of health or of disease, rest or exereise, the temperature, the race, etc.

Contrary to the general opinion, they are always formed at birth, at which time occurs the commencement of the descent of the testicles; but they soon disuppear, to reappear towards the end of the first year, following, consequently, the migration of the organs which they protect.

These tmics, thin, soft, unctuons, and shiny in fine and well-nourished subjects, are thick, coarse, dull-colored, and rongh in common horses. The scrotum or skin is, with few exceptions, almost hairless, of a black color, or only covered by some dorny hairs. Nevertheless, in light-colored animals it is sometimes deprived of pigment in certain places, and then offers white or red spots of a variable area, to which is given the name leprous spots.

2d. The Testicles. - Suspended at the extremity of a cord constituterl by the vas deferens, blood-vessels, and nerves, these glands consist of ovoid masses depressed laterally, and related by their external face and superior border each to an elongated organ, the epididymis, enlarged at its two extremities and formed by an indefinite number of convolutions of its excretory canal. They float freely in their envelopes, but are neither in the same horizontal plane nor in the same transverse line: the left is always more inferior and more posterior than the right. The two testicles are, therefore, so disposed that they can approach the median line without being mutually compressed during the adduction of the thighs, between which they are situated. It is apparent how painful to the animal and dangerous to these organs such friction and compression would be if frequently repeated.

The excmination of the testicular region requires some precautions, particularly in irritable and sensitive horses.

Let us suppose that this examination be practised upon the left testicle.

The head is maintained in an elevated position by an assistant ; in addition, the anterior right foot may be raised. This being done, the 
surgeon stations himself opposite the croup of the same side, places the left hand upon the dorso-lumbar region, being careful not to stand in the line of action of the corresponding posterior member, and goes, with the right hand, in search of the testicles, having previously earessed the parts which surround the region.

When these organs are well developed, lie in the scrotum, and are consequently visible and tangible firm the exterior, the horse is entire, ${ }^{1}$ and is also called stallion; he is called gelding after emasculation. Emasculation is performed for various reasons, most usually with a view of completely destroving the function of these organs.

The testicles, in the entire male, slould be well down, rounded, almost equal, firm, and rolling under the pressure of the fingers, without showing any abnormal sensibility. They are larger in the adult animal than in the colt, and in Arabian, Barb, and Andalusian stallions than in those of other races. In hot weather they may become somewhat flabby and pendulous. When they are small and retracted towards the inferior orifice of the ingninal canal, soft, or altogether pendulous, they indicate a horse that is degenerated, without energy, without vigor, and unsuited for reproduction.

The gelding las the testicular envelopes flattened and almost indistinguishable from the posterior part of the sheath of the penis. There always exist on each side of the median line, at the place where the testicles have been, two linear cicatrices, slightly excavated, which present the same characters in all emasculated animals, and which are rlue to the excision of these glands.

A horse may have been subjected to an operation destroying his reproductive faculties, and still have his testicles in the serotum. This operation, known under the name bistoumage, is nothing else than a subcutaneous torsion of the testicular cord, which is soon followed by a complete atrophy of the organ due to the obliteration of the bloodvessels which nourish the testicle.

Although very little practised upon the horse at present, bistournage leaves traces which 'an be easily recognized: the volume of the testicle is no more than that of a large walnut; it ocempies an elevated situation, and is no longer movable in its envelopes, in consequence of the adhesions which are established under the influence of the inflammatory phenomena consequent upon the torsion.

When the testieular envelopes present the characters recognized in the gelding, and there exists on the surface no appreciable cieatrix;

¿ Technically, the word horse signifies the entire male. 
when, besides, the animal neighs fiequently, has an ereetion of the penis at the approach of mares, and shows himself endowed, in appearance at least, with all the instincts and aptitudes of the most vigorous entire male, it is certain that he has not been castrated by bistournage, or otheruise, but that his testicles have not made their normal deseent, and either float in the abdominal cavity or remain lodged in the inguinal camal. In either case the horse is called a cryptorchid ${ }^{1}$ or an enorchid. ${ }^{2}$ Very often he is called an anorchid, ${ }^{3}$ but this is an improper designation, because it indicates the absence of the testicles instead of simply expressing their irregular situation.

In ordinary langnage a cryptorchid is called a rirlgeling. In scientific langnage we do not advocate the use of this expression, which originated from the horseman, but which is not confined to him, if we may judge from the favor which it has met among a certain class of individuals.

Whatever terminology may be used, it is none the less true that that eryptorchism does not always exist on both sides at the same time. It is quite common to find it inilateral, but it is an error to believe it affeets the right side oftener than the left. Since 1847 we have established the falsity of the foundation of this opinion; it is useless to prolong our remarks on this question.

Cryptorchids have always been regarded, with good reason, as being tronblesome and dangerous to their companions as well as to their attendants. They often interfere with the manœurres of cavalry by kicking and biting, or unfasten themselves in the stable during the night, and mount the mares which they get access to. They are very arlent, and perform copulation readily, althongh this act appears to fitigne them extremely. We have not succeded in getting them to repeat it on the same day. Finally, it shonld not be forgotten that these animals are sterile whenever the two testicles remain in the abdominal cavity; their semen contains no spermatozoa. This secretion has the same charaeters in those animals in which the glands are arrested in the inguinal canal, as we have several times proved; but we will not assert that it is always thus.

The importance of the preceding facts is clearly demonstrated by the two following instances:

One of them, given by H. Bouley, Jr., has reference to the remarkable Rivière-

\footnotetext{
1 From $\kappa \rho \dot{\pi} \tau \omega, 1$ conceal, and op $\rho \chi s$, testicle.

2 From $\dot{\epsilon} \nu$, in, and $\partial_{\rho} \iota \varsigma$, testicle.

s From $\dot{\alpha}$, taken away, and $\dot{\rho} p \nmid \varsigma$, testicle.
} 
Rouleau lawsuit, which was so much discussed in Parisian veterinary circles more than half a century ago. ${ }^{1}$

It concerned a horse sold and guaranteed as entire by Mr. Rivière to Lady Rouleau, in which the two testicles, eath harely as large as a small hen's egrg, were lodged in the inguinal canal. Bouley, $\mathrm{Jr}$., in his report, effected an annulment of the sale by specifying:

1st. That the testicles had acquired only about one-fifth of their normal size, and that they were atrophied, and, consequently, able to fulfil only imperfectly their functions.

2d. That, in this respect, Lady Roulean had been deceived into buying as an entire horse one that was imperfect, having a defect in his organization which she had not been able to recognize, and which diminished his value and rendered him unable to perform the service for which he was purchased.

In the presence of these conchusions, and upon the concordant opinion of three other experts named by the court, Rivière agreed to dissolve the bargain, took back his horse, and the affair terminated.

The second example is that of Cloture, the cryptorchid horse, of remarkable form and qualities, which took twice in succession the purse in the races at the Champ de Mars. Bonght some time afterwards by the administration of the governmental studs, he served, at Pompadour, forty mares, without succeeding in impregnating a single one!

In order to prove the existence of cryptordiclism, it is sufficient, as Henry and Symphorien Bouley verified in 1852 in the ease of cloture, to determine whether the inguinal region does or does not carry the permanent cicatrix of eastration. It is proper to say, however, that, by frandulent means, this cicatrix can be initated, thus giving to snch a horse the appearance of one that has becn castrated. The only method which can then be cmployed is to lead the animal to the mare, in order to produce an erection of the penis, and to permit a collection of the seminal fluid, which should be subjected to a microscopic examination. ${ }^{2}$

Diseases and Blemishes._- When the testicles, their envelopes, and the corls do not present the normal character's we have indicated above, there is reason to eonsider them diseased, and the prognosis which shonld be given is in most instances very grave. The diseases of the testicular region are numerons and varied; we will only review them in passing.

\section{They are:}

1st. Edema, simple infiltration of the connective tissue of the envelopes, a condition which may be the result of prolonged and complete idleness in the stable, or it may be the manifestation of a local affection or of a grave constitutional disease.

1 Bouley, Jr, Recueil de médecine vétérinaire pratique, 1832, p. 457.

2 Goubaux et Follin, Mémoire sur la cryptorehidie, in Recueil de médecine vétérinaire, annee 1856, p. 820 . 
2d. Orchitis, acute inflammation of the tissues of the testicles, whose multiple causes often give rise to serious complications.

3d. Sarcocele, which is usually one of the terminations of chronic orchitis, and consists in a more or less pronounced induration of the gland. It forms a voluminous tumor, insensitive to pressure, complicated at times by hydropsy of the vaginal sheath, and accompanied by a considerable enlargement of the cord. Sarcocele, by its weight, inconveniences the animal considerably; but this would be of little import if it were not frequently one of the manifestations of glanders or the sign of a cancerous state. As the differential diagnosis is difficult, and as there is always apprehension of the presence of a glanderous diathesis, it will be prudent to condemn animals which are thus affected, more particularly if they are intended for reproduction.

False sarcoccle is a similar condition, which has its seat in the testicular envelopes. Its prognosis is sometimes as serious as that of the preceding.

4th. Hydroccle, which is an acute or a chronic dropsy of the raginal sheath. The latter form is particularly serions in that it predisposes to hernia, occasions great pain, and causes atrophy of the testicle. It is quite frequently a complieation of sarcocele.

5th. Varicocele, varicose dilatation of the veins of the envelopes, of the cord, and of the gland itself. It is very rare in the horse.

6th. Carcinoma, which affects the substance of the testicle and causes a gradual atrophy of the latter. This tumor is one of the forms of what is called sarcocele.

7th. Cysts, distinguished as dermoid or as serous, according to their nature; they are rare, and are located in the testicles, the envelopes, or the cord.

Sth. Champignon, scirrhous cord, an indurated tumor of the extremity of the cord, which follows castration on one side or the other, and has no tendency towards cicatrization; it presents a deep fistula leading to the interior of the parts and discharging an abundance of pus. It is a common diseased state, and is grave on account of its complications.

9th. Finally, hernia, called inguimal or testicular, due to a displacement of a portion of the intestine into the vaginal sheath. It is acute or chronic, according to its duration and symptoms. The violent colics which accompany the acute form will always prevent the animal from being offered for sale. It is not the same with the chronic form, examples of which are quite frequently met in stallions.

The old law of redhibitory vices comprised chronic intermittent hernia among the diseases capable of causing the annulment of the sale; the law of August 2, 1884 , does not include it.

However, a horse suffering from chronic hernia should never be purchased; at some period he may succumb to a strangulation of the hernial intestine, an accident always to be feared, because there is always a possibility of its occurrence.

\section{B.-The Sheath and the Penis.}

To the organs charged with the secretion of the semen is annexed an apparatus of exeretion, the penis, which serves at the sime time for copulation and for the emission of the urine. This organ is protected 
as well as maintained in its normal situation by a cutaneous fold, the sheuth, which we will examine first.

1st. The Sheath.-The sheath is to the penis what the serotum is to the testicles.

Constituted by the skin, which, doubled upon itself from before to behind, forms a kint of pouch open in front, it is destined to contain the free portion of the penis in a state of non-erection. Between the layers of the integument which forms the base exists a fibro-elastic expansion, called the suspensory ligament of the sheath, a dependency of the abdominal tunic, to which it is attached on each side. The skin in its interior is deprived of hair, irregularly folded upon itself, soft, and unctuous from the numerous sebaceous glands, called the preputial glands, which secrete a sebaceous material of a strong and disagreeable odor, known by the vulgar and improper name of coom.

The sheath is entirely effaced at the moment of erection of the penis. Its development varies according to the animal: in the stallion it is ample and generally little soiled by its secretion ; in the gelding it is smaller, and its narrow opening sometimes prevents the protrusion of the penis during micturition. There may result, in such a case, as Leeoq has remarked, lyperseeretion by the sebaceous glands, irritation from the urine, and even ulcerations difficult to heal, which may extend to the penis.

Warts, or papillomata, are in certain cases observed on the sheath. They are regarded as contagious, although no irrefutable proof of this bas as yet been given.

Edema of the sheath depends upon a prolonged retention of the penis within it, upon the contact of the urine, or upon the presence of an excess of the sebaceous secretion. It disappears readily under the influence of exercise and cleanliness.

Finally, melanotic tumors are met here, which by their volume sometimes prevent the protrusion of the penis and interfere with the exit of the urine.

There are some horses which produce during locomotion, particularly in the trot and the gallop, a sound, always disagreeable, called the sound of the frog. It ceases ordinarily at the end of a certain time during the exereise. Some persons have incorrectly attributed it to the churning of the liquids and gases confined in the cæcum, a part of the large intestine remarkably developed in the horse. We long ago made the remark that it is never heard in mares. Franconi, our classmate and friend, informed us one day that it could be made to disappear by packing the sheath with oakum. We have since verified the efficacy of this ingenious means, the action of which is understood without difficulty, knowing the mechanism by which this sound is produced. During locomotion the sheath is alternately raised and lowered, and at the same time the penis executes in its cavity more or less extensive to-and-fro movements. There results from this the formation of a vacuum and the entrance of external air, which oceasions this 
particular sound. Its intensity appears to depend upon the flaccidity and the disproportion of volume of the parts concerned in the mechanism of its production; its absence is due, on the contrary, to a more complete coaptation of these same parts, which exists in those animals in which this sound is not produced.

2d. The Penis.-The penis is the male organ of copulation. It represents an erectile shaft, constituted prineipally by the corpus avernosum, and supports along its entire length the urethral canal. In the study of the exterior of the horse, however, we shall occupy ourselves only with the free portion of this organ, which in a state of relaxation is contained within the sheath, and appears externally only at the moment of erection, when the blood distends and elongates it.

It then appears covered by a fine, unctuons, ghistening skin, sometimes rosy and marbled in the places deprived of pigment. Limited at its bise by a sort of circular cul-de-sac, it has an almost cylindrical form, excepting at its free extremity, where it suddenly enlarges. The latter, known under the name head of the penis, and notched below and behind (sub-urethral notch), is hollowed in its middle by a shallow excavation which surmounts a round eminence formed by the extremity of the corpus cavernosum, and in the centre of which opens the urethral tube, projecting about one or two centimetres. Above the latter is the urethral sinus, a spacious bilocular cavity, often filled with hardened sebaceous matter (the beun), which may compress the urethra and interfere with micturition.

It is the erectile tissue of the urethra, altogether independent of that of the corpus cavernosum, which composes the head of the penis. At the beginning of erection the latter alone is dilated so as to give the necessary rigidity to the organ to penetrate the genital passages of the female. As soon as the penis is inserted, the urethra dilates and gives to the free extremity of the organ the aspect of a mushroom or the nose of a watering-can, as is seen in the stallion immediately after the ejaculation of the semen.

Under ordinary conditions the head of the penis is not visible at the entrance of the sheath : it is concealed by the folds of the skin. It is incorreet for painters and sculptors to represent this part almost with the same disposition as that which it affects in man.

The penis of the entire horse is more voluminous and more firm than that of the gelding ; but in this respect it differs much in different animals. These variations have not, as is generally believed, any influence upon the qualities of horses which are destined for reproduction; it is the same with those variations which concern the head of the penis, which is often very different in different stallions of the same race, the same form, and equal ardor.

It is more important to assure onrselves that the penis moves with ease in the interior of its protecting envelope. The stallion has quite frequent erections; it is eommon even to see him masturbate, either in the stable or at rest when he is harnessed. When these erections orenr, 
the penis emerges from the sheath with more or less rapidity, and increases in volume, in length, and in tension.

In this condition it is easy to determine the state of the parts and to judge as to their good conformation. This annot be done during micturition, for the penis is only partly protruded.

Erection in the gelding is, on the contrary, rare; the eopulative organ is confined to its narrow sheath. If it be not protruded at the time of micturition, the animal urinates into his sheath, an injurious fiunt, on account of the irritation which the retention of the essentially putrefactive products determines there. In horses ancelessly groomed the desiceated sebaceous matter after a time occasions an inflammation of the skin which the simplest hygienic measures coukd prevent.

We have sometimes observed melanotic tumors upon the penis. They give rise, by their softening, to ulcerations, from which eseapes a blackish, disagreeable discharge; by their volume they also produce compression of the urethra and obstruct the free passage of the urine.

At other times blood-tumors (humatoma) exist in the corpus cavernosum, resulting from blows received by the penis during erection, or produced by the efforts of the stallion in mounting. Veritable wounds are occasioned sometimes from these calses, whose prognosis is much more serious because there is always danger from hemorrhage or from resultant complications of gangrene necessitating the amputation of the organ.

Finally, all animals having ulcerations at some point of the penis should be rejected. These are sometimes the expression of the most serious contagions disease, maladie du coüt, or dourine, which is most common in Oriental horses. The ulcerations must not be confounded with the pustules of equine roriola, which resemble the former very much, and upon the differential diagnosis of which our distinguished associate, Professor Peuch, has especially insisted. ${ }^{1}$

Paralysis of the penis is peculiar to jaded stallions degenerated from old age. The organ is then not contained in the sheath ; it is said to be pendulous.

Flabby, infiltrated, swollen, purplish, and cold, it oscillates in every direction during locomotion, and is continually exposed to wounds ancl contusions. It is necessury then to place the penis in a leather sheath, acting like a suspensory ligament, which is maintained in situation by leather straps fastened around the loins.

\section{§ 2. Gexitar, Organs of the Female.}

\section{A.-The Vulva.}

The vulva is the only part of the genital apparatus of the female which directly concerns us in this connection; most anthors have added a description of the mamme, and we will not change the established custom.

The vulva constitutes the external orifice of the genito-urinary

1 F. Peuch, Note sur le horse-pox simulant la dourine, in Revne vétérinaire, annce 1880. p. 297. 
apparatus in the female. This orifice, sitnated below and at some distance from the anus, has the form of a vertical chink, in which can be recognized two lateral lips and two commissures, the one inferior and the other superior.

The lips (labice) are in apposition, the one against the other, in ordinary conditions. The skin which covers them is fine, unctnous, devoid of hairs, usually black, and very adherent. It beeomes continnons, at their free border, with the internal mucous membrane.

Of the commissures, the superior is acnte; the inferior is rounded, and shows, when the labiæ are separated, a single globular organ, the clitoris, a veritable penis in miniature, lodged in a mucous fold which constitutes a sort of prepuce, of a rosy color, sometimes black or marbled.

During the period of heat (menstruation) the vulva is slightly open, swollen, warmer, more sensitive, and all the parts covered by mucous membrane are bright red. From the inferior eommissure there is a moderate discharge of liquid, which agglutinates the lips. The animal frequently ejects a small quantity of urine, which is followed by several convulsive protrusions of the clitoris. She is then very excitable, difficult to approach, inclined to kicking, and provoked by the least touch. She is called pissy when this condition is habitual ; orariotomy (removal of the ovaries) may sometimes remedy this; at other times it is without effect.

Mares which have been pregnant generally present longitudinal folds upon the external face and inferior part of the lips of the vulva. These folds increase with the frequency of parturition. In old and very emaciated mares the vulvo-anal region is strongly excavated, a fact which may render the introduction of the penis somewhat uncertain.

In certain cases fillies are ringed in order to prevent copulation when they run in pasture with males. This operation consists simply in approximating the lips of the vulva by means of metallic threads inserted transversely from side to side and disposed in superposed rings, or simply in proteeting the vulvar opening by means of a wire netting.

Althongh this practice opposes a copulation by preventing the introduction of the penis, it fails with those animals that are inclined to accomplish this aet to satiate their imperative desires, and, on this account, it is not free from danger. The stallion in his efforts sometimes wounds the lips of the vulva, lacerates them with his teeth, or commits an error of place nearly always fatal to the female, without considering the wounds which may be inflicted upon his own organs. 
There are neither beauties nor defects to be indicated in this region. It should especially be free from blemishes.

Wounds, lacerations, bites from the stallion, pustules of horse-pox, and ulcerations symptomatic of maladie du coït are observable in this region. The last are of a very grave prognosis. Ruptures of the superior commissure are nearly always due to difficult parturition. According to J. B. Huzard, the presence of warts, or papillomata, on account of their hereditary character, should exclude the mare from the stud. ${ }^{1}$

\section{B.-The Mammæ.}

The mammar, special to the mare, are two glands endowed with the secretion of the milk. They form two hemispherical eminences placed in the inguinal region and separated from each other by a median groove. Each of them presents in its central part a small protuberance, the teat, or nipple, whose free extremity has in its middle a shallow depression, at the bottom of which open two excretory ducts which commence in the interior of the organ.

But little developed in the filly and in the mare which has never been pregnant, they acquire a considerable volume towards the end of gestation; they preserve it after parturition during the period of suckling, but reassume their primitive characters afterwards.

The diseases of the mammary glands are few ; let us mention more especially melanotic deposits, of which they are sometimes the seat in gray or white mares.

Linear cicatrices, which result from the cuts of the whip-lash, frequently given in this region, are, as in the sheath of the male, quite frequently found here.

Finally, their surface often shows corded lymphatics from farcy, because of the abundance of the lymphatic vessels which emerge from them.

\section{PART III.}

THE MEMBERS.

General Considerations.-The members, limbs, or legs are the supports and the natural motors of the trunk. They represent four articulated columns, secrmented, piece by piece, sitnated upon the lateral faces of the body, in front and behind the centre of gravity, and distinguished, for this reason, as anterior and posterior.

The segments which compose them diminish in volume, in periph- 
eral surface, and, in general, in inclination from above to below, but at the same time they augment gradually in number, compactness, and resistance. Surrounded in their superior sections by voluminons and powerful museles, they are, as it were, reduced inferiorly almost to skin and bone. These are fortunate dispositions, whose effect is to disseminate and attenuate the combined actions of the weight and the velocity, and to furnish an adequate surface for the attachments of the museles, all preserving to the centre of gravity all the elevation compatible with the extent of its displacements, and conferring upon the trunk gracefulness, harmony, and elegance of support. If the members were covered with muscles throughout their entire length, their weight would be excessive, and the step heary and slow on account of the volume of the extremities and the consequent lowering of the centre of gravity.

During locomotion these motor columns are alternately elevated from the ground; they receive the body-weight which falls on them, and impress it with the needed impulsive force, and are then lifted, projected in adrance, and again touch the ground.

Function.-The function of the anterior limbs is very different from that of the posterior.

The Anterior members, situated in advanee of and close to the centre of gravity, and bearing consequently more weight than the others, have a secondary office, being principally endowed with the

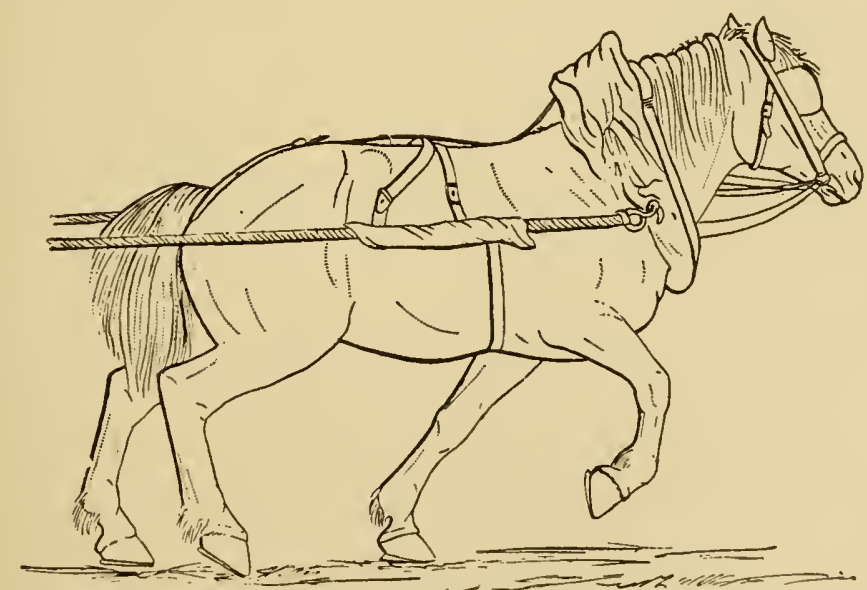

FIG. 50.-From an instantaneous photograph of the author's.

function of support and dispersion of concussion. Their propulsive action is not very marked, excepting at a slow pace and when the animal moves a heary load. Under these circumstances (Fig. 50) the body. 
strongly inclined forward, gives the fore-legs an oblique direction backward, which permits them to push against the collar, to which the shoulders are energetically applied. It is by the extension of all their articular angles, previonsly semi-flexed, that the fore-legs accomplish this result. When they are directed obliquely and in an inverse direetion, as is seen sometimes at the beginning of the effort of traction, the force which they exereise upon the trunk, and therefore against the collar, is at its minimum. Traction forward can be favorably executed only when the foot, directed backward, is fixed against the roughnesses of the ground. This is observed in the draught-horse as he mores his load; when the soil, the point of support, gives way, the feet suddenly glide backward.

Aside from these functions, the anterior member is, as all admit, nothing more than a column of support and an apparatus of dispersion and compensation. From its mode of attachment to the trunk and the disposition of the segments composing it, the fore-leg is adapted in a remarkable manner to this double function. Fixed to the side of the thorax by means of museles and aponenroses, it has all the articular angles quite open, except that one of them, the radio-metacarpal, is even entirely effaced. It opposes to the body-weight and to the locomotory reactions resistances, more particularly mechanical, whose passiveness eases the muscular strain. The bones, the ligaments, and the tendons, more than their muscular portions, resist the pressure and coneussion of locomotion.

The posterior members are widely different in construction and function. Much less of a support to the trunk, and well situated in relation to the centre of gravity, they are articulated solidly with the coxre withont endangering their integrity. By the inclination of their different segments, they push against the trunk at a given moment when the former are straightened, one piece upon the other ; thus the angles are obliterated, and the hind-legs eommunicate to the body the needed force or velocity. The muscles, being obliged to contract in order to oppose the tendency towards elosing of the angles of locomotion, are more voluminous and numerous than those of the fore-leg; they are therefore able to sustain without fatigue the part of the bodyweight which the osseous framework intrusts to them.

They are therefore, first of all, the agents of propulsion. They act with the greatost effieacy and power against the trunk, to which they are attached, at the moment when their line of direction (a line which unites the superior centre of movement to the foot) points obliquely downward and backward. Inelined in an inverse direction 
during the beginning of the effort of traction, they can only support that portion of the body and take a position to prepare themselves for the effort which they are to execute the following instant. Besides, this phase is of a very short duration, and the backward obliquity soon manifests itself. The latter exists already at the end of a certain period when the eanon is still inclined forward. The phase cannot be expected in the draught-horse, as we shall clearly see if we reflect upon the fact that the body of the animal is continually inclined forward during the efforts of traction. In-

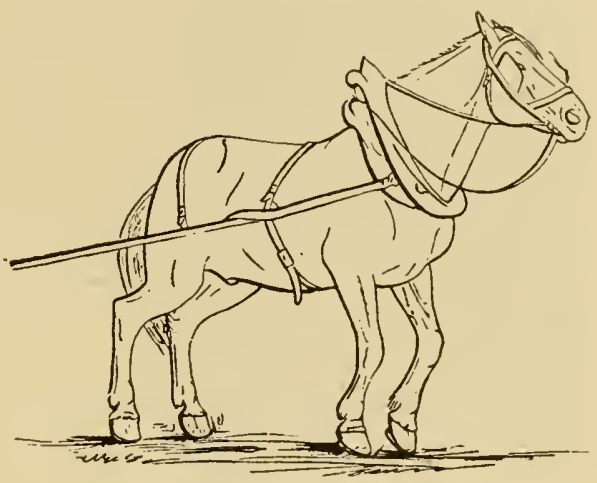

FiG. 51. stantaneous photographs place this matter beyond a doubt (Fig. 51). ${ }^{1}$

Mechanism of Impulsion. - Whichever of the members we examine, the impulsive force which they develop at a certain period in their acting as a support results invariably from a more or less forcible extension of the bony segments at the moment when the members are supported against the trunk or the collar. It is an interesting and important fact that we ean prove scientifieally that this process of extension is the conjoint function of most of the muscles belonging to the limb which originates the impulse. Many of the flexors are capable of contributing to this end, either because they cross over several articular angles and attach to the convex side of one of them, ${ }^{2}$ or because they originate from the trunk and coneur to straighten the inclined levers upon which they terminate. ${ }^{3}$ As to the abductors and adductors, they can, by acting simultaneonsly, perform the role of extensors. The other muscles maintain the osseous levers in their proper plane as compared with the median plane of the body, and prevent their ontward or inward displacement after the manner of the ropes which fix the mast of a ship.

I See, for further details and interesting discussions by modern authors. H. Bonley, Nonveau dietionnaire de médecine, de chirurgie et d'hygiène vétérinaires, tome i., art. "Allures," p. 360, Paris, 1856; G. Colin, Physiologie eomparée des animaux, t, i., p, 448, 3e cil., l'aris, 1ss6: G. Neumann, Du tirage du eheval, in Rec. de mém. et observ. sur l'hyg. et la méd ét. milit.. année 18.6; ibic., Sur les éléments de l'impulsion, in Revue vétérinaire, année 1886, p. 528; G. Chenier, eontribution à l'étule des actes locomoteurs, in Écho des soc, et assoc. vétér., Juin, 1866.

2 Snch are: the flexors of the metacarpus, of the phalanges, of the forearm, of the metatarsus, the ischio tibial muscles, ete.

${ }^{3}$ Such are: the psoas, the superficial gluteus, the great dorsal, etc. 
We are therefore convinced that during propulsion there is no antagonism of forces, but solely the use of the powers intended to produce an elongation of the members according to a definite plan. To become convinced of this, it will be necessary only to examine the muscles of one's own leg, semi-flexed, just before it becomes extended in order to straighten the body; all the structures are rigid because they all appear to contract in unison, so as to overeome the antagonistic forces.

On the other hand, mechanical dispositions of great power and the arrangements of the muscles and tendons in the hind limbs of the horse associate the articular angles in such a manner that one of them camnot be extended without producing a simultaneous opening of the others. It follows from this that all the forces which are exerted at one point are transmitted at the same time to the adjoining parts and canse them to move successively one upon the other. This process of force-accumulation gives an explanation to some of those spasmodic movements, -string-halt,—so sudden and so energetic, of which the posterior members are the seat.

\section{Articular Movements; Orientation or Relative Position of the Angles of Locomotion; Limited Positions of the Osseous Segments.-The articular movements, being closely} subordinate to the extent of the oscillations of the segments which accomplish them, here offer us an opportunity for general considerations concerning which we should say a few words.

It must be admitted, to begin with, that amplitude of joint-action must increase in a ratio with the initial displacement of the bony levers as studied in thcir condition of rest when compared with the line of their regular axis.

But the effectiveness of this play depends upon another consideration of primary importance. It is indispensable that the line of direction of the segments of the member should hold certain determinate relations with the vertical line passing through their centre of movement. In other words, it suffices not that the articular angle which they form be well opened, but it is also necessary that the angle be well located for progression. This condition is realized whenerer the angular displacement of the branches of an angle of locomotion tends to separate the two extremities of the member to which it belongs, following a very oblique line rather than the vertical or some analogons direction. When such a relation does not exist, the locomotory columns passing over too little surfice at each step, are not properly extended in a forward movement, but are merely elevated, and the 
impulse transmitted to the trunk is no longer a trajectory approximating the horizontal, but becomes a short eurve.

The inclination of the osseous segments should therefore supply. this double purpose: it should augment the effectiveness of the articular play without diminishing its extent.

Each of the locomotory segments, when viewed alone, presents for study (Fig. 52) a limit of extension, $A$, and a limit of flexion, $B$; in a word, the line or space of oscillation, $A B$, marking the limit of opening and of closing the angle, beyond which it cannot extend, by reason of the resistance offered by the articular surfaces and the tension of the ligaments.

Anatomy, through the researehes

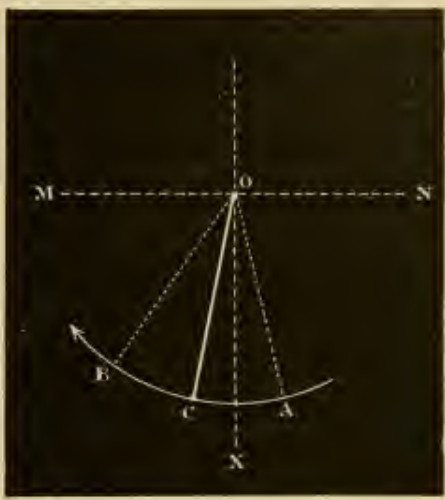

FIG. 52 . of Vincent and Goiffon ${ }^{1}$ upon the eadaver, has determined the extent of this space, $A B$, in a very satisfactory manner; but it becomes a diffieult problem when it is a question of the precise location of the angle $A O B$ in relation with the vertical line $O X$, or, what amounts to the same thing, to fix the limited positions $A$ and $B$,-points which indieate the limit of the oscillation of $O C$ in the living animal.

It is in this direction that investigations should now be pursued. It is possible, indeed, that if we could recognize the exact position of these limits in horses of speed, it would become easy to determine the most desirable inclination of the bony levers. Evidently this inclination should assume the direction $O C$, bisecting the angle $A O P$. In this ease alone the space of oseillation will reach its greatest possible limits ; for the extremity $C$, being equivalent from $A$ and $B$, admits of equal flexion and extension, the greatest of each that is posible. All other inclinations diminish the one or the other of these movements.

We have presented the only accessible observations that have been made on this subject, excepting orly the incomparally accurate researches which MM. Marey and Pagès ${ }^{2}$ have undertaken with the aid of instantaneous photographs of horses in locomotion.

\footnotetext{
1 Vincent et Goiffon, Mémoire artificielle des principes relatifs a la fidèle représentation des animaux, t. ii., Paris, 1779.

2 Pagès, Analyse cinématique de la bocomotion du cheral, in Comptes-liendus de l'Aradimie des sciences, 1885, p. 702; Warey et Pagès, Analyse cincimaticpe des allures du cheral, in Comptes-Rendus, 1886: ibld., Nouvements du membre pelvien chez l'homme, l'éléphant et le cheval, in Comptes-liendus, 1587.
} 
Unfortunately, these experiments have only determined the limited positions in the walk, the trot, and the slow gallop, and leave us still ignorant of what these positions are in extreme speed. Nevertheless, from the facts already acquired, an important proposition can be deduced : that the limit of extension of the locomotory segments occupies, in hor'ses of speed, a point, A, quite close to a vertical line passing through their centre of mocement.

According to the angles considered, this point is situated either in advance of the rertical line mentioned (angles with the sine posterior), or behind it (angles with the sine anterior). But it is apjarent that the farther the limit of extension passes beyond the vertical line of the centre of movement the more will the angle of these segments, when it is opened, be favorable to the augmentation of the obliquity of the member, and consequently the more will it tend to increase the amplitude of the step or the extent of the movement.

It would follow from this that the most favorable inclination of an osseous lever is that which removes it the least from the vertical line $O X^{Y}$ during flexion, and consequently that which tends to approach it to this same line while the animal is standing still. In this case the direction of the segment will be more closely related to the bisecting line $O C$, which is associated, as we have seen, with the largest space of oscillation.

In the preceding statements we have viewed an isolated locomotory segment, as it is moved freely under the horizontal line $M N$, without the intervention of foreign influences. This has permitted us to indicate to the best advantage the direction of the segment associated with a large and effective oscillation.

In natural conditions, however, this arrangement is not so simple, since the locomotory angles are formed by bones which are articulated in twos or in threes. It is therefore in place to inquire whether, under these cireumstances, the extreme limits $A$ and $B$ remain always the same with relation to the vertical line $O X$ through the centre movement.

It is easy to assure ourselves of the contrary. These positions depend upon the inclination of the segment with which the one under consideration is articulated. The maximum value of the articular angle may be similar, and, for the sake of the argument, we may say equal; but the orientation of this angle being different, the extreme positions $A$ and $B$ are displaced either forward or backward of the vertical line, according to the obliquity of the adjacent segment. This will necessarily result in differences in the utilization of the articular movements in forward locomotion. 
Let us suppose the two segments $O C$ and $O C^{\prime}$ to have different obliquities when compared with the vertical line $O X$ (Fig. 53).

Let, on the other hand, $C O B^{\prime}$ be the maximum extension of the angle $C O B$.

The angles, in extension, being equal, for anatomical reasons, to the segment $O C^{\prime}$, the limit of extension of $O B$ will be $B^{\prime \prime}$. A simple inspection, however, shows that $O B^{\prime \prime}$, being less inclined upon $O X$ than $O B^{\prime}$, will also be less favorably directed than $O B^{\prime}$ in relation witl the vertical line $O X$. Therefore, the orientation $O D$, bisecting the angle $C O B$, is more favorable than the orientation $O D^{\prime}$ bisecting the angle $C^{\prime} O B$.

It can only be alleged that the angle $C^{\prime} O B$, since it is more open while the horse is standing still, should be the same in action, but if it were thus the conditions would no more be equal, and consequently no

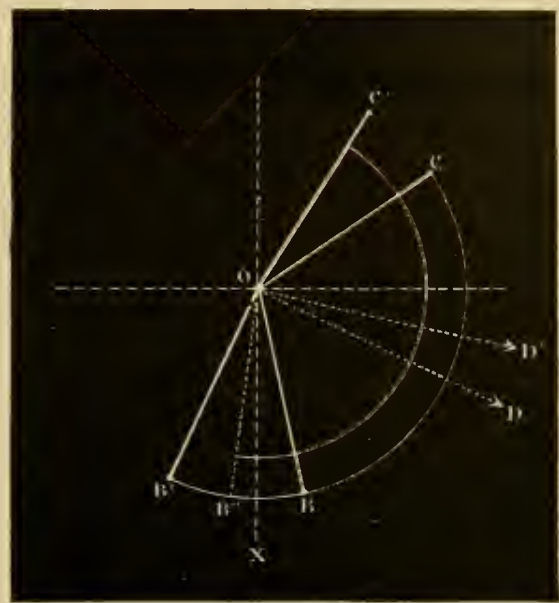

FIG. 53. more comparable. The condition of the maximum opening of the angle $C^{\prime} O B$ changing, it can be assumed that in the same manner the angle $C O B$ is caused to vary. Moreover, anatomy teaches that there exists for these two angles a maximum separation, practically the same, but dependent upon the disposition of the articular surfaces and the ligaments limiting their displacement. The sole difference which distinguishes them is that in repose their branches are unequally inclined.

\section{Mode of Evolution of the Members during Progression.} - The mode of evolution or oscillation of the members during progression involves quite a complex analysis, but we must be able to explain its general features in order to understand some subsequent phenomena.

Let us examine this oscillation in the walk, a mode of progress in which the body is never entirely disconnected from the ground.

The foot, now elevated from the ground and now in contaet with it, passes through two principal phases : one of elevation, ${ }^{1}$ during which it is in the air, and one of contact, during which it supports a portion of the weight of the body. During this evolution, the line of direction of the member appears to oscillate alteruately around, two points situated at its superior and its inferior extremities; the foot, the inferior extremity, is the point of the phase of contact; the superior, the centre of movement of the shoulder or the croup, is that of

1 The reader must have a clear conception of the meaning of the terms elevation and contact, because they are frequently employed in the following chapters. 
the phase of elevation. When the first is stationary on the ground, the second, or superior point, describes an are of a circle and is carried forward by the force of impulsion, and vice versa.

At the moment when the foot, $D$ (Fig. 54), is ready to leave the ground, the line of direction, $H^{\prime} D$, is inclined downward and back-

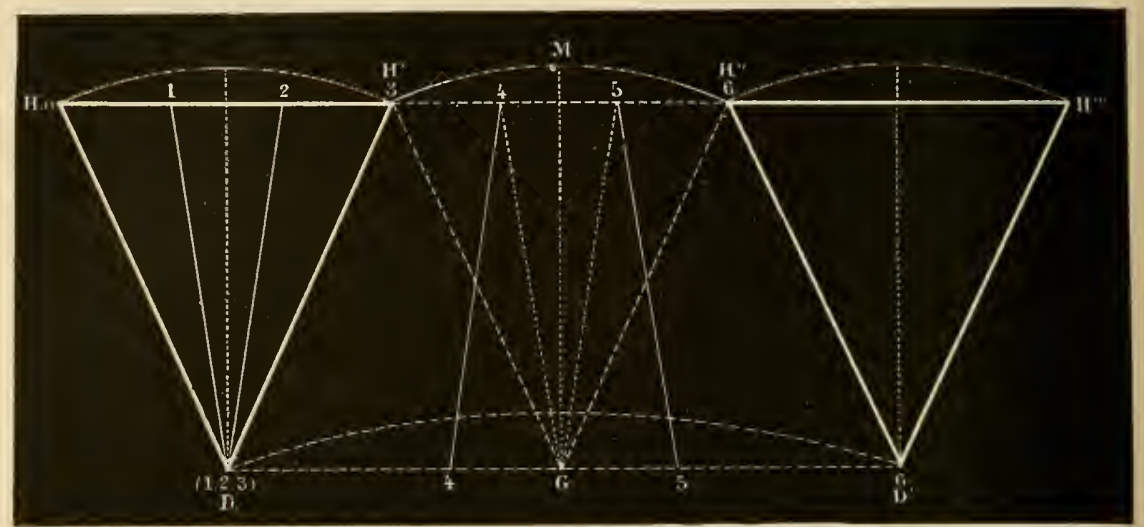

FIG. 54,-Schemes of the evolution of two congeneric members during the phases of contact and of elevation.

ward. It is then advanced, describing an are of a circle, and when it reaches the point $D^{\prime}$, where it again touches its support, the line of direction, $H^{\prime \prime} D$, is reversed.

In the same half of the body (anterior or posterior) the phase, $D D^{\prime}$, of elevation of one nember coincides always exactly with the phase of contact, $H^{\prime} H^{\prime \prime}$ of the other. The successive positions of one member, whatever they be, are therefore directly the reverse of those of its congener. As to the relative velocities of the transmission of the body and of the feet, they are different, but always in simple relation. The foot, in the same space of time, passes over a distance, $D D^{\prime}$, double that of the centre movement $H^{\prime} H^{\prime \prime}$. Its velocity is therefore twice as great.

Many years ago Captain Raabe ${ }^{1}$ and M. Colin schematically represented the oscillations of the extremities in the following manner:

Let us suppose that we examine the evolution of the posterior pair of limbs.

The centre of the croup, $H$, during the phase of contact, describes a uniform movement in advance which carries it from $H$ to $H^{\prime}$, it being supported by the right posterior limb, $D$. At this instant $H^{\prime}$, the right leg, is elevated, $H^{\prime} D$, and

1 Raabe, Examen du Traité de l'extérieur du cheval, de Lecoq, et de la Physiologie, comparée, de M. Colin, Paris, 1857. See, besides, the plates in the Traité de Phystologie, de M. Colin, t. i. p. 445, 3e éd., Paris, 1886. 
the posterior left, $G$, on the contrary goes to rest on the ground, $H^{\prime} G$, at a distance, $D G$, equal to a thalf-step. or hall 8 rench

While the latter, $G$, passes through its phase of contact, the centre of the croup passes through the space from $H^{\prime}$ to $H^{\prime \prime}$ and describes the arc $H^{\prime} H^{\prime \prime}$ equal to that described by the right, because, in the normal gait, the steps are equal.

Arrived at $H^{\prime \prime}$, the left member, $G$, becomes elevated, $H^{\prime \prime} G$; the right, on the other hand, is now placed on the ground, $H^{\prime \prime} D^{\prime}$, to renew its phase of contact at a distance, $G D^{\prime}$, equal again to a half-step.

During its progression, the right foot, therefore, proceeds from its initial position $D$ to attain its final position $D^{\prime}$. It consequently passes through the arc $D D^{\prime}$, while the centre of the croup only passes over the space $H^{\prime} I^{\prime \prime}$, which is exactly one-half of the distance $D D^{\prime}$.

$H^{\prime} H^{\prime \prime}$ is parallel to $D D^{\prime}$, for the isosceles triangles $G H^{\prime} D$ and $G H^{\prime \prime} D^{\prime}$ are equal, since $G D$ and $G D^{\prime}$ are equal. Again, the analogous angles $G D H H^{\prime}$ and $D^{\prime} G H^{\prime \prime}$ being equal, the lines $D H^{\prime}$ and $G H^{\prime \prime}$ are parallel.

Therefore, $H^{\prime} H^{\prime \prime}=D G=\frac{D D^{\prime}}{2}$.

When one of the members has passed successively through the two phases of contact and of elevation, the body effects what is called a complete step, the two pairs of members (anterior and posterior) being jointly concerned. During this evolution it can be seen that the centre of movement, $H$, and consequently the centre of gravity, has progressed from $H$ to $H^{\prime \prime}$, or, what is equivalent, through a space which is equal to the line $D D^{\prime}$, equal to the distance passed over by one of the feet, a distance completed in two attitudes, $H D, H^{\prime \prime} D^{\prime}$, identical and suceessive.

It follows from these statements that the length of the step will be measured by the separation of $D D^{\prime}$, comprised between the successive imprints left upon the ground surface by the same foot.

But for an accurate analysis (such as is often necessary) the division of the step into the two principal phases of contact and elecation, above mentioned, is insufficient. It is necessary to subdivide each into a number of equal secondary divisions called periods. All veterinary writers, with Captain Raabe, recognize at present the following six periods (see Fig. 55) :

\footnotetext{
Phase of period, from 0 to $1 \ldots$ Commencement of the contact.

Phase of contact. $\{2 \mathrm{~d}$ period, from 1 to $2 \ldots$ Middle of the contact.

(3d period, from 2 to 3 ... Termination of the contact.

Phase of elevation $\left\{\begin{array}{l}4 \text { th period, from } 3 \text { to } 4 \ldots \text { Lifting of the foot. } \\ 5 \text { th period, from } 4 \text { to } 5 \ldots \text {. Fiddle of elevation. }\end{array}\right.$

or of extension. $\left\{\begin{array}{l}5 \text { th period, from } 4 \text { to } 5 \ldots \text { Niddle of elevation. } \\ 6 \text { th period, from } 5 \text { to } 6 \ldots \text { Resting of the foot. }\end{array}\right.$
}

Systematic Analysis of the Play of the Members.-The general scheme of the evolution of the members, which we have given, has permitted us to prove a certain number of facts, and to 
formulate these into intelligible propositions. As a whole, the conclusions which have been deduced are exact; but if we endeavor to make a more minute analysis of these phenomena we shall find that they are not so easily worked out.

Strictly speaking, the limb of a horse cannot be compared to a long lever which alternates by turns round its inferior extremity when the latter is related to the surface of support, or its superior when it is lifted. In other words, the displacements of the leg are not assimilable to those of an oscillating pendulum, as Captain Raabe and his disciples have supposed.' 'They result from a series of partial movements which influence each other mutually and give to the articular centres very complicated trajectories. The recognition of these secondary actions offers interest from a point of view of the particular mechanical role fulfilled by each region. It is necessary to make some remarks concerning this statement.

MII. Marey and Pagès, ${ }^{2}$ in their recent and valuable researches with the aid of chrono-photography (see Generalities upon the Gaits), have been enabled to register the sucessive positions of the different bony segments of locomotion and the relative duration of their revolution during the execution of the two principal phases of contact and of elevation of a complete step.

Let us see what interpretations can be given to the phenomena indicated by these original investigations. Take, for example, the movements of the members in the ordinary trot; like MM. Marey and Pagès, we will choose, among the numerous positions affected by these apparatus, a certain number of attitudes well characterized by the extension and flexion of some segments, or by important modifications of the articular trajectories.

\section{Action of the Anterior Member (Fig. 55).}

A. Phase of Contact.-The anterior member (which during this phase arrives at $a$ state of rest in an attitude of extension whose degree varies with the extent of the pace and the nature of the gait) should successively fulfil two very distinct rôles, of which the purposes are, first, to deaden the shock of concussion against the soil, and next, to extend itself. After this process is over, it again prepares to elevate itself.

1 These views have been demonstrated in a recent work entitled L'art équestre, par M. Barroil, p. 21 et suiv., Paris, 1887. Chez Rothschild.

1 Marey et Pagès, Analyse cinématique des allures du cheval, in Comptes-Rendus de l'Academie des sciences, 27 Septembre, 1886; ibid., Mouvement du membre pelvien chez l'homme, l'éléphant et le cheval, in Comptes-Rendus, 18 Juillet, 1887. 
1. Attenuation of Concussion.-This is effected during the movement from 0 to 2 by the diminution of the two extreme angles (the scapulo-humeral and metacarpo-phalangeal) placed at the extremities of the rigid radio-metacarpal segment. The fetlock is strongly

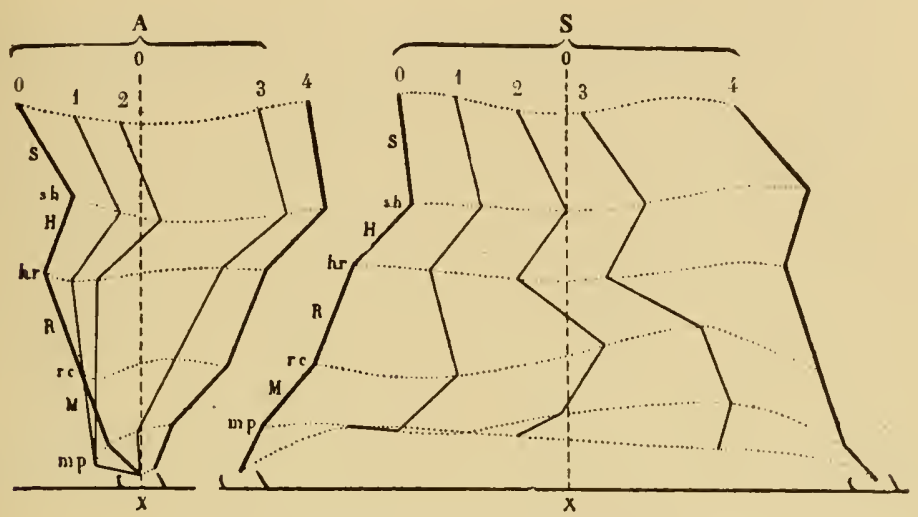

FIG. 55.-Action of the anterior member in the trot.
A. Phase of contact.
$S$. Phase of elevation.

lowered and the radio-metacarpal segment pivots forward upon the pastern, which is horizontal and immobile. During the second period, from 1 to 2, the closure of the scapulo-humeral angle is most marked.

2. Extension of the Member.-Extension takes place in a progressive manner from 2 to 3 (Fig. 55). The line of direction of the member becomes vertical, elongated, and at the termination is directed downward and backward. The angle of the fetlock and that of the elbow are onened : the first by the gradual straightening of the pastern, which pivots on the coronet and becomes vertical; the second by the forward rotation of the radio-metacarpal division, which pivots upon the first phalanx. As to the angle of the shoulder, it becomes slightly augmented by the forward rotation of the scapula. It is now observed that during this period the member can fulfil a function of impulsion, particularly when the resistance to progression is considerable, as in strong traction, for example.

Preparation for Elevation.-Elevation is manifested during the movement from 3 to 4 (Fig. 55). The pastern continues to rotate in advance, carrying with it the foot, which pivots upon its toe. The radio-metacarpal angle beeomes slightly flexed, while that of the shoulder continues to augment. At the moment of elevation nearly all the articular angles have reached their maximum extension.

S. Phase of Elevation.-During this phase the foot leaves the 
ground, is carried forward, and finally establishes a new point of contact. Directed obliquely downward and backward at the beginning, the member is directed in an inverse sense at the termination. It therefore successively becomes shortened, elongated, and finally assumes a new point of contact.

1. The shortening manifests itself more particularly during the motion from 0 to 2 (Fig. 55). It is characterized at first by the maximum flexion of the pastern producing a closure of the angle of the fetlock, of the canon, and of the forearm, resulting in a diminution of the angle of the carpus and of the elbow. Arrived at the point 2, the angle of the fetlock already begins to open in consequence of the straightening of the pastern. As to the shoulder, it contributes, by its backward rotation, in the shortening of the limb and in closing the scapulo-humeral angle, though only to a small degree.

The diminution of the length of the member is therefore progressive, and passes from below upward by a greater and greater flexion of the articular angles.

2. The elongation, which commences at 2 (Fig. 55) by the extension of the fetlock, is continued to 3 by that of the metacarpus, by the opening of the angle of the elbow, and, finally, by that of the shoulder. These phenomena are not all simultaneous. They are due to a gradual and successive extension of the pastern, the canon, and the arm, and the lengthening of the inferior extremity of the member commences before the shortening of its superior part has reached its maximum.

The preparation to touch the surface carries the anterior member to its limit of extension. The radio-metacarpal angle is effaced; those of the elbow and the shoulder now attain their maximum separation. As to the pastern, it extends obliquely downward and forward; the foot is resting in the same axis.

\section{Action of the Posterior Member (Fig. 56).}

The posterior member, being an agent of attenuation, impulsion, and ambulation, offers attitudes analogous to those of the anterior.

A. Phase of Contact.-Like its homologue, this member arrives in station in a state of extension whose degree varies with the length of the pace and the nature of the gait. During this phase it also deadens the concussion against the ground and develops the force of impulsion; having accomplished these, it again prepares for a position of station.

1. The attenuation of the concussion is effected from 0 to 2 by 
the descent of the fetlock and the closing of the coxo-femoral and the femoro-tibial angles.

These articular phenomena are due : to a sudden horizontal direction of the pastern, which pivots upon the os corona, produces a lowering

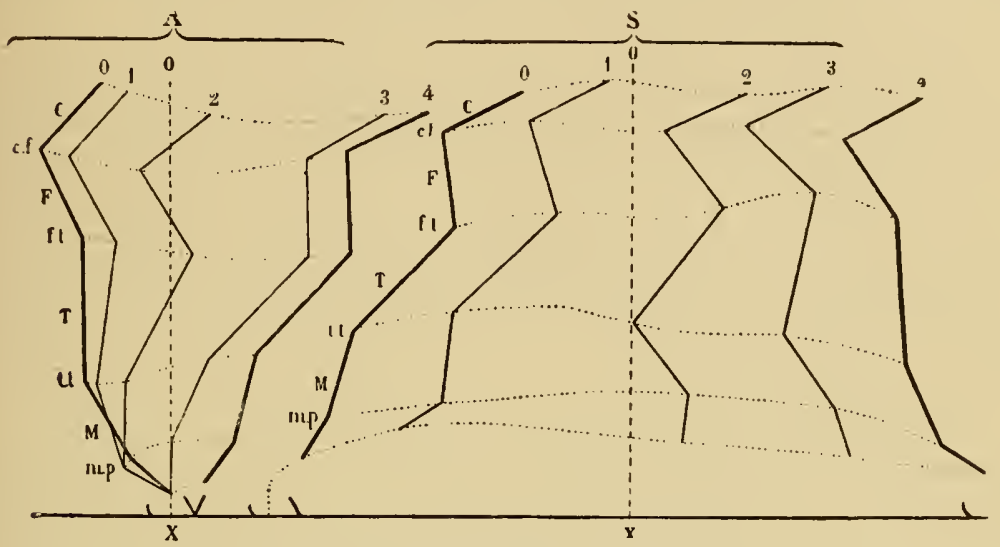

FIG. 56.-Action of the posterior member in the trot.

$A$. Phase of contact. $\quad$ S. Phase of elevation.

of the fetlock, and straightens the canon; to the forward rotation of the tibia upon the tarsus, which lowers the femoro-tibial articulation; finally, to a greater obliquity of the femur, which results in a lowering of the coxo-femoral angle.

2. The development of the impulsive force is effected principally from 2 to 4 (Fig. 56), during which movement the foot is on the ground. In this space the line of direction of the member becomes directed obliquely downward and backward, and the latter beeomes elongated progressively by the almost simultaneous opening of all its angles. This takes place first at the pastern, which rotates forward upon the os corona, becomes vertical, and opens the angle of the fetlock; the canon is now extended and opens the angle of the tarsus; finally, the superior extremity of the tibia is directed more obliquely forward, and the inferior extremity of the femur is carried backward, thus opening the angles of the femoro-tibial and the coxofemoral articulations.

The preparation for elevation succeeds the periorl of impulsion and manifests itself at 4 (Fig. 56); the hoof and the pastem pivot in advance upon the toe, whence a slight flexion of the fetlock: the canon is now rotated backward at its superior extrenity, and the movement also produces a feeble closure of the tibio-metatarsal angle. 
S. Phase of Elevation.-In these phenomena the foot leaves the soil, oscillates forward, and then assumes a point of contact. The line of direction of the member is first inclined backward, and afterwards obliquely forward. The posterior column, like the anterior, should successively become shortened, elongated, and prepare itself for station.

1. Shortening.-This process presents the following stages: $a$. Maximum flexion of the pastern and slight flexion of the canon and the thigh, producing a marked elevation of the foot and a maximum flexion of the fetlock, which, however, is only feeble in the hock, the stiflc, and the hip (0 to 1 ). b. Very marked flexion of the canon and the femur, with an accentuated closing of all the articular angles except that of the fetlock, which commences to open itself by the extension of the phalanges ( 1 to 2 ).

2. Elongation of the Member.-The elongation commences by the extension of the fetlock, to be continued by that of the hock and the stifle from the sole influence of the extension of the tibia on the tarsus (2 to 4). The coxo-femoral angle has now reached its minimum size.

Before the foot again reaches its point of contact, the angles of the stifle, the hock, and the fetlock have reached their limit of extension almost entirely under the influence of that of the leg, which itself has attained this limit of movement. The pastern, which now tends to become horizontal (4) again, thus carries the hoof far in advance.

All these are conditions of strncture more or less closely allied to the production of force or speed, and these we shall examine in the pages that follow. We shall also demonstrate that the animal motors can be submitted with the greatest accuracy to the same scientific analyses, according to mechanical principles, as the inanimate motors which are the production of human ingennity.

\section{CHA PTER I.}

ANTERIOR MEMBER.

THE anterior member comprises several regions which we describe in the following order: the shoulder, the arm, the forearm, the elbou, the knee, the canon, the fetlock, the footlock, the ergot, the pastern, the coronet, and the foot. 


\section{A.-The Shoulder.}

Several authors have intentionally united the description of the shoulder with that of the arm, because of the fact that, in relation with the exterior, there exists between them no definite line of separation, and that, in relation with their functions, they are intimately united. There is, nevertheless, no more reason for confounding these regions than there is for uniting the croup with the thigh, the back with the loins, or the neck with the head. We shall therefore study them separately.

Situation; Limits; Anatomical Base.-Situated between the neck and the sides of the thorax, the withers and the arm, the shoulder occupies, without any precise demarcation, the lateral and anterior region of the chest.

The scapula is flat and triangular, and is provided with a strong spine on its external surface and a wide cartilage of prolongation at its superior border. It thus forms the osseous base of the shoulder, and gives attachment to two kinds of muscles, which, with respect to the anterior member, can be distinguished as extrinsic and intrinsic. Besides, this bone participates by its inferior extremity in the formation of an articulation very mobile and at the centre of the movements of the arm.

The extrinsic muscles originate from the vertebræ, the ribs, and the sternum. Viewed only as to their action upon the shoulder, their function is to fix the latter to the trunk and regulate its displacements.

The intrinsic muscles embrace and sustain the seapulo-humeral arthrodia, and act exclusively upon the arm, except three which extend to the forearm (the long and short flexors and the great extensor of the forearm). These intrinsic muscles determine most of the movements of the humerus, and carry this bone into extension, flexion, abduction, and adduction. They also oppose the closing of the articular angle during station, and maintain in proper relation the two bones which form it.

Form.-It is difficult to assign a geometrical form to the shoulder on account of its intimate connections with the thorax, the neck, the withers, and the arm. In lean subjects, the most salient parts of its conformation are very markedly delineated underneath the skin: in front, its anterior border projects from the base of the neck; above, its cartilage is indieated by a curve parallel with the superior line of the withers; on its external face a longitudinal crest, formed by the acromion spine, extends from above to below; behind, a less marked furrow separates it from the thorax; in front and below, a round, voluminous eminence, improperly called the point of the shoulder,

1 It is formed, in fact, by the superior extremity of the humerus, and merits much more appropriately the name point of the arm, under which Bourgelat described it. 
forms the summit of the seapulo-humeral angle and indicates cxternally the origin of the region of the arm; finally, immediately behind this angle, and upon the external surface of the great extensor of the forearm, is found what is termed the blemish of the shoulder. An ordinance of sanitary police, of the 31st of Angust, 1842, preseribed that all horses suspected of suffering from contagious diseases should be marked in this region by a square brand.

In fat and well-muscled horses these prominences of the shonlder are almost completely effaced; the external face, the anterior border, and the articulation become rounded and insensibly confounded with the adjoining regions; the form of the shoulder must be surmised rather than perceived, unless it is revealed while the animal is exercised at a more or less rapid gait, in which event its movements will inform us as to its general form, its dimensions, and its direction.

Movements.-When, during the walk, the anterior member leaves its point of contact with the ground, it becomes shortened, directed forward, and all the articnlar angles close themselves by the flexion of the segments which form them, and the foot is elevated a certain distance above the soil. But if the shortening were manifested oniy in a vertical direction, it is easy to understand that the foot would arrive at precisely the same point which it previously occupied without, of course, commmicating any propulsion to the trunk.

In order to give amplitude ${ }^{1}$ to the step, it is indispensable therefore that the bones be carried forward, and that the displacements begin at the superior extremity of the limb (the scapula) and terminate with the foot, one piece being moved upon the other.

The shoulder is the region whence proceed the initial movements when the member is adranced.

In this phenomenon the shoulder is slightly elevated by means of the surrounding museles; its humeral angle rotates forward while its superior border is carried downward and backward, and the extent of this movement is directly proportional to the length of the museles which produce it.

The elevation of the humeral angle is effected principally, through its connection with the humerus, by the strong mastoido-humeralis muscle which expands over the anterior surface of the articnlation. It is aided in this action by

1 We designate under this name the linear displacement of the inferior extremity of the member in advance of its vertical axis, the result of the successive movements of the angles and bones which compose it. This displaeement is equal to one-half of the oseillation of the motor column, which is, metaphorieally speaking, not unlike a body swinging to and fro in the man. ner of an artieulated pendulum, but with this difference, that here the muscular contraction replaces the weight which alone causes the latter to oscillate. 
the sterno-humeralis, directed obliquely outward, downwarl, and backward; finally must be added the serratus magnus, which draws the dorsal angle of the scapula downward and backward, as well as the dorsal trapezius.

As soon as the member has completed its extension the elevation of its superior border, and consequently the lowering of the articular angle, is effected by the trapezius, the rhomboideus (the proper elevator), and the angularis on the one part, and the sterno-trochineus and the sterno-prescapularis on the other, and the member is again brought into its primitive position. These two movements, intimately associated, are executed actively by the muscles above named, and passively by the weight of the body.

The scapular play, it is needless to say, should be as easy, supple, and extensive as possible. Nevertheless, there are some horses whose shonlders, though regularly constructed, are unable to rotate with sufficient freedom, and this limitation markedly restricts the movements of the member. Such a shoulder is vulgarly called pegged. (See Defects of the Gaits.)

Length.-The most important phenomenon in the construction of the shoulder is its length, or, in other words, its development from the summit of the withers to its point.

Two factors enter into the production of this dimension: the height of the spinous processes of the first dorsal vertebra above the scapular cartilage, and the length of the shoulder properly so called. But as the variations of one of the elements of this region are not always correlative with those of the other, it follows that the real length of the shoulder is not strictly given by the distance from the summit of the withers to the point of the arm. This restriction being established, let us view the assigned limits of this length and the advantages which follow its marked development.

Bourgelat was the first one to mention that the distance comprised between the summit of the head and the commissure of the lips equals almost exactly the measurement of the shoulder from the withers to the insertion of the neck on the breast. ${ }^{1}$ This is an observation which is quite accurate, as has been testified by some of the very best authorities on such subjects, notwithstanding the active opposition which it has received from the generality of hippotomists. Those who, like ourselves, have taken the pains to verify by numerous measurements the exactness of this fact, Colonel Duhousset among them, have somewhat modified it by saying that the entire length of the head equals the distance from the summit of the withers to the point of the shoulder. It is thus, at least, in the more beatiful and perfect 
horses, whatever may be the service to which their conformation adapts them. The exceptions are much less numerous than is generally believed. Nevertheless, such variations, although not very

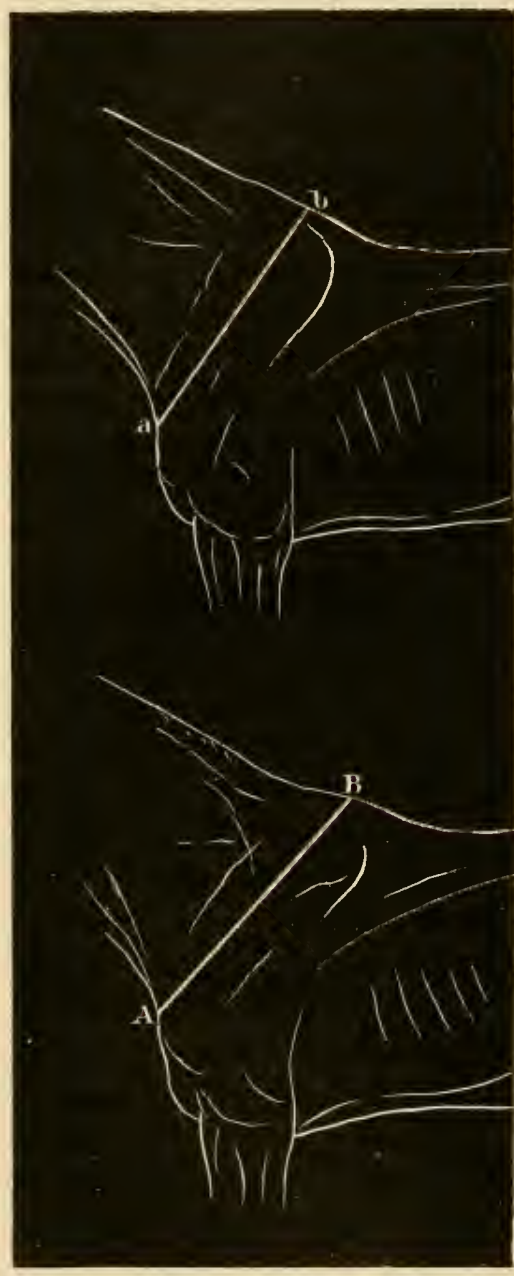

FIG. 57. marked, do exist, and the experienced eye will recognize a shoulder that is long or one that is short (Fig. 57).

The length of the shoulder, in order to appreciate it accurately, should be viewed: (1) in the absolute; (2) in relation to the arm.

1. Absolute Length of the Shoulder.-It is neeessary, for various reasons, that the shoulder should be as long as possible.

First, its length necessitates a correlative development of the intrinsic muscles, the extent of whose contraction is directly proportional to the movements effected by the humerus.

Secondly, the degree of amplitude of the rotation of the scapula in relation with the movements of the member as a whole, and the arc described by each extremity of this bone and taking place around a definite centre, are more extensive as the length of this region in(reases. The value of high withers lies in the length of its muscles, for long shoulder-muscles correspondingly augment this scapular movement.

Thirdly, besides being in relation with the vertical diameter of the chest, an ample length of the muscles has a disposition to render the shoulder more oblique,--another beanty whose value in horses possessed of speed we will presently explain. A long shoulder, as it is 
applied vertically or obliquely upon the sides of the thorax, has a tendency of itself to elevate or to lower the centre of gravity by angmenting or by diminishing the total length of the member in this proportion, at those times when the anterior extremity of the body is being displaced. The centre of gravity, however, in order to be in accordance with the laws of equilibrium and of speed, should have a farorable position and not be too elevated. Furthermore, a shoulder can profit by its length only when it is correspondingly inclined; otherwise, the reactions will be hard and the animal withont action in consequence of the defective orientation of the superior angles of the member.

There is an idea, very generally prevalent, that, in the draughthorse, marked lengtl of the shoulder constitutes a defect rather than an advantage. This is an error which the partisans of such a theory could very easily demonstrate by making some practical measurements upon the very best specimens of dranght-horses. In them, also, the head is the measurement of the shoulder. The great length of this region is in all cases, in our opinion, the first and most important element of its beauty and perfection. There are, without doubt, dranghthorses with short shoulders capable, nevertheless, of very effective service, and the disadvantages of this defect in them do not have the same importance which they would have in the race-horse. In the dranght-horse, amplitude of the movements is secondary; the essential qualities reside in the resistance which can be overcome by the power of his muscles and the proper incidence of their insertions. To say that the length of the scapula and its muscles, in these slowmoving animals, is defective and incompatible with the power of the muscles, is to advance a principle which is entirely incorrect and without proof.

2. Length of the Shoulder in Relation with the Arm.On general principles the shoulder and the arm should be long absolutely, in order to be favorable to velocity; but, with the same total length of these two segments, it is necessary that the former be long and the latter short. This becomes apparent from the following demonstration :

Let us represent (Fig. 58) the two shoulders, $A B, A B^{\prime}$, and the two arms, $C D, C D^{\prime}$, having the same reciprocal inclination and giving the same total sum, $A B+C D$ being equal to $A B^{\prime}+C^{\prime} D^{\prime}$ by hypothesis.

From our estimations, the relation $\frac{A C}{A D}$ is equal to $\frac{1}{5}$; we have preserved the same relation for $\frac{A C^{\prime}}{A D^{\prime}}$, the conditions in both cases being therefore comparable. 
Let us suppose now that the extensors of $C D$ and those of $C^{\prime} D^{\prime}$ are shortened through the same space $\left(C E=C^{\prime} F\right)$, a phenomenon which, however, in

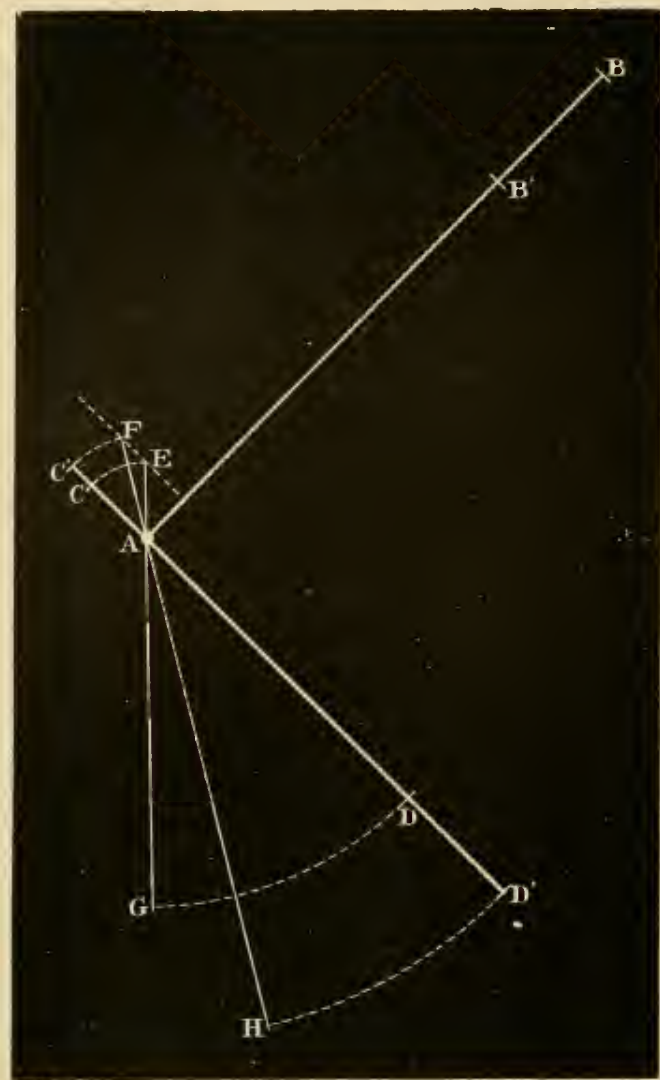

FIG. 58 . reality does not oceur, since the muscles are of different lengtlis. The arm $C D$ will be carried to $E G$, while $C^{\prime} D^{\prime}$ will be displaced to FH. Whence it follows that the point $D$ will reach a situation more advanced, $G$, in relation with the limit of extension, than the point $D^{\prime}$, which will describe the are $I^{\prime} H$ always smaller than the are $D G$ under the speeial proposition with which we started $\left(\frac{A C}{A D}\right.$ equalling $\left.\frac{A C^{\prime \prime}}{A D^{\prime}}\right)$.

The angular displacement of the short arm, $C D$, is therefore more extensive for an equal contraction or shortening of the muscles than that of the long arm, $C^{\prime \prime} D^{\prime}$.

In addition, the extensors of the shoulder $A B$ are longer than those of the shoulder $A B^{\prime}$. Consequently, the muscles of the latter are obliged to shorten themselves more for the production of the displacement $D G$, which the extensors of $A B$ will effect without fatigue.

Finally, as the effort of a muscle varies according to certain conditions, among others with the resistance to be displaced, it follows that the shoulder $A B$ will produce the extension of the arm $C D$ more easily than $A B^{\prime}$ that of the arm $C^{\prime} D^{\prime}$, since the former is shorter and consequently less heavy than the latter.

Thus the length of the shoulder in comparison with that of the arm should be as great as possible, for the reason that it effects a greater displacement of the humerus with a more feeble muscular contraction. 
Direction.-Another element in the beanty of the shoulder of the race-horse in particular resides in its obliquity.

This direction is indicated by an imaginary line which passes from the summit of the withers through the centre of the scapulohumeral articulation. Observation has demonstrated that this line passes a little posterior to the scapular spine.

Marked obliquity of the shoulder has always becn considered a beauty, or point of excellence, in close relation with the production of speed; while in its relation with the development of force it is comparatively indifferent. Nothing is more easy of comprehension.

Let us represent (Fig. 59) $O A$ and $O A^{\prime}$, two shoulders of unequal obliquities, and $O B$, the humerus on which they operate. Let us sippose, also, that $A O B^{\prime}$ be the maximum opening of the angle $A O B$.

All things being equal, the limit of extension of the humerus on the shoulder $O A^{\prime}$ will be carried to $B^{\prime \prime}$, since, from the anatomical union of the two regions, the angle $A^{\prime} O B^{\prime \prime}$ is equal to the angle $A O B^{\prime}$. (See Generalities on the Mem-

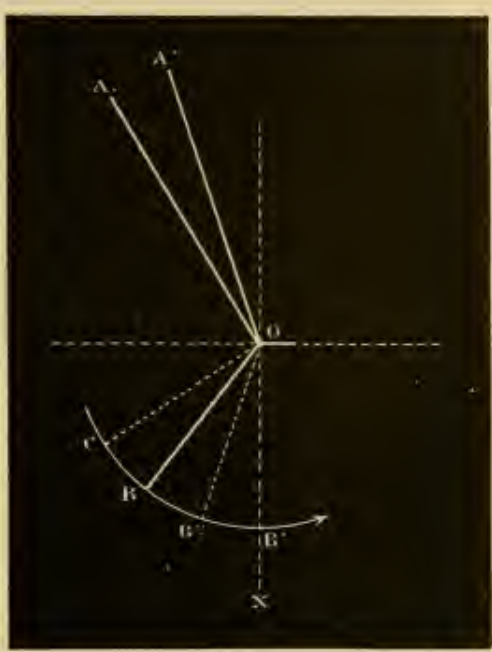

FIG. 59. bers, p. 194.) $O B^{\prime \prime}$ being more distant from the vertical line than $O B^{\prime}$, will also be less favorably directed than $O B^{\prime}$ in relation with the vertical direction $O . \mathrm{I}_{\text {. }}$

The orientation of the scapnlo-humeral angle is therefore most favorable to progression when the shoulder is oblique; the inferior segments of the member are further advanced, and such a shoulderespecially if it be long-will be eapable of producing a much more extensive revolution of the humerus $B B^{\prime}$.

If, instead of becoming larger from the straightening of the shoulder, the scapulo-humeral angle remains the same $\left(A^{\prime} O C=A O B\right)$, it is correct to assume that, from an equal functional shortening of the muscles, the humerus $O C$ will be carried less in advance than the humerus $O B$.

Such are the reasons which operate in fivor of a great obliquity in horses of speed; but this is not all.

If we study the movements of the shoulder, viewed separately, the fact becomes evident that, for an equal elecation of its extremity, it will 
be carried much more in advance when it is inclined than when it is straight.

Let us represent by $A B$ and $A^{\prime} B^{\prime}$ (Fig. 60) these two different directions; by $B M$ and $B^{\prime} M^{\prime}$ two vertical lines drawn from the superior extremity of each

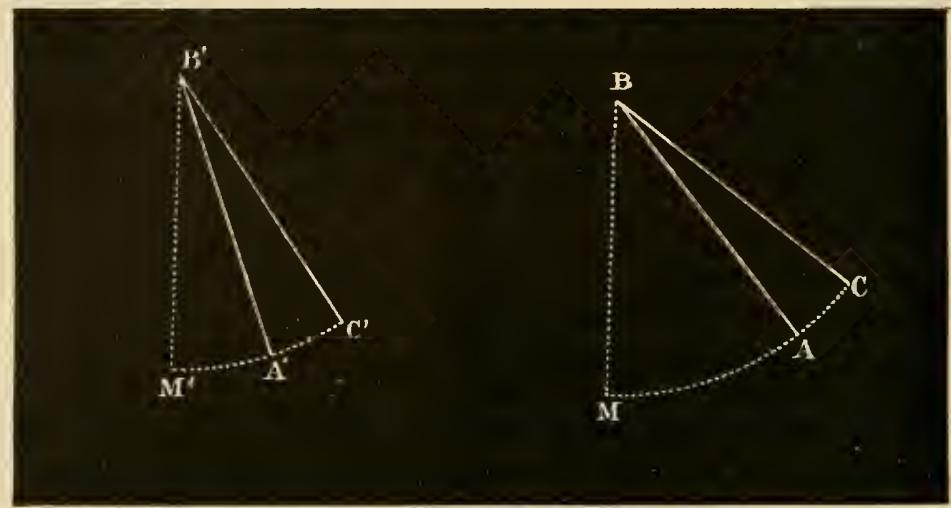

FIG. 60.

shoulder; finally, by $A C$ and $A^{\prime} C^{\prime}$, equal amplitudes of the two scapular oscillations. It is assumed, by hypothesis, that $A M>A^{\prime} M^{\prime}$. Whence it follows that $A M+A C$ is $>A^{\prime} M^{\prime}+A^{\prime} C^{\prime}$, or, in other words, that $M C$ is $>M^{\prime} C^{\prime}$.

Therefore, for an equal are described by the point of each shoulder, the more inclined will carry the lower or distal extremity to a position the more anterior. This will also allow a greater extension of the humerus, and the forearm will reach for-

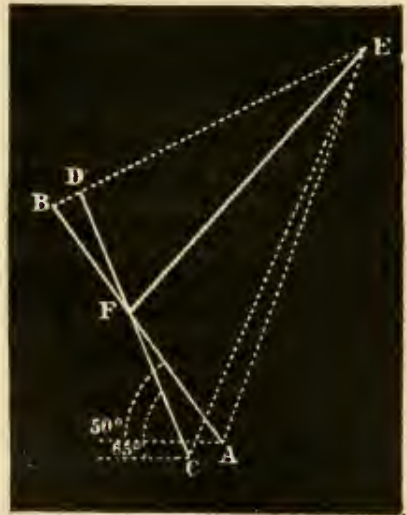

FIG. 61. ward to a point more in alvance. It is certain, a priori, that a straight shoulder is capable of a greater oscillation forward, buit it must be remembered that the degree of the scapular movements is the result of the functional shortening of the elevator muscles of the point of the arm. This shortening alone gives the moasure of rotation, a measure which we know is proportional to the muscular length. We have sufficiently dwelt on this particular point is propos to the neck without again making reference to it here.

Another advantage of an oblique shonlder lies in the perpendicular ineidence of the muscular insertions (Fig. 61). 
The line $A E$, which indicates the direction of the elevators of the shoulder $A B$, is more perpendicular to this segment, and consequently more powerful than is its homologue $C E$, which is attached to the shoulder $C D$. But it can be seen that the mechanical inconveniences resulting from the latter conformation will be mitigated to a certain degree by a more horizontal direction of the neck $E F$. It is also observed that horses with straight shoulders, and which have to employ great force, carry their necks very low, so as to increase the power of the muscles by giving them the best ineidence, and to enable the centre of gravity to be more easily displaced forward.

The Scapulo-humeral Angle.-The obliquity of the shoulder, an element to be desired for velocity, tends to effect a reduction of the dimension of the scapulo-humeral angle. This ciremstance would, consequently, restrain the extent of play of the latter, if the humerus, by a more vertical position, did not preserve a normal separation of these two segments.

Whatever may be the value of this direction of the humerus, it never attains such a degree as to give to this angle the same obtuseness which the other angles of locomotion have, excepting the coxo-femoral. Normally, in running- and trotting-horses, the scapulo-humeral angle is much more acute than any of the others. The consideration of this fact alone is, however, not sufficient to establish our position. It is necessary that the arm itself have good direction; in a word, that the angle remain vell situated in relation to the vertical axis of the member.

Our measurements have shown us, in fact (Fing. 62), the angles $A O D$ and $A O C$, is well as the angles $B O D$ and $B O C$ :

It may be said that a large seapulohumeral angle ean coexist with an oblipue shoulder, and, vice versa, a small one with a straight shoulder.

It can be understood by this time why so many beantiful or idleally perfect shoulders fail to fulfil the expec-

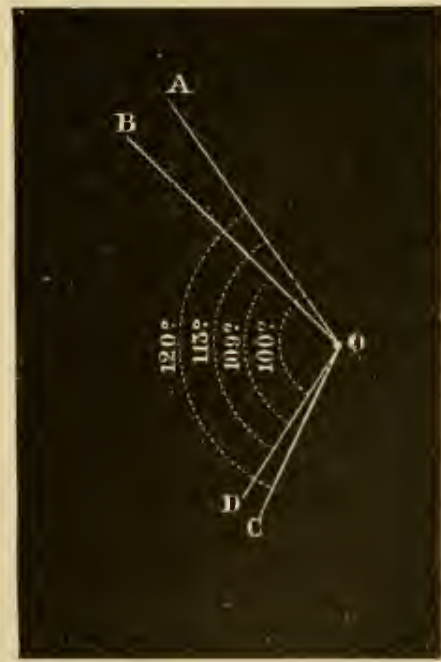

FrG. 62. tations which are based upon them, and how, also, the inclination of the arm constitutes, to a certain point, a compensation for a straight shoulder. In the latter case, the aninial may still be capable of great 
speed, but he does not receive the benefits which should result from the fixation of the seapulo-humeral angle in advance. Whenever the anterior nember is advanced, the point of the shoulder is not sufficiently elevated to permit the other segments to attain their maximum degree of movement. As a natural consequence of this, the gait is deficient, the feet are but little elevated from the ground, the steps are short, and the movements rapid.

The scapulo-humeral angle in horses of the best conformation is not 90 degrees (as is generally but ineorrectly supposed); and, a fortiori, the inclination upon the horizon of the two segments eonstituting it is more than 45 degrees. In the articular angles, the axes of movement of the branches should meet in the probable centre of the articulation. The central point of the scapulo-lunmeral muion is not, as has been commonly believed, the point of the arm (the summit of the trochiter and trochin). Its situation is more posterior, and corresponds externally to the convexity of the great trochanter over which the tendon of the sub-spinatus muscle glides. It is at this point that the axes of the scapula and the humerus meet, and the angle formed by these lines ean be measured in the living animal when the bones are placed in their normal position in relation with the median line.

Our measurements have given us 5.5 degrees as a mean inclination of the scapula in horses possessed of speed, and 65 to 70 degrees in those used for slow and heary work. The beantiful models of rapid draught-horses do not differ sensibly, in this relation, from the champion of the race-course, and we do not hesitate to affirm this fact in opposition to those obstinate partisans of the oblique shoulder, who value it only in the race-horse, and declare it a defect in the draught-horse. The unpublished observations on this topie which Professor Laulanié has kindly communicated to us, although less numerous than ours, fully corroborate our own. According to our distinguished colleague, the mean seapular inclination is 57 degrees, the extreme measurements varying from 50 to 66 degrees.

The scapulo-humeral angle has been determined by us to have a mean dimension of 115 degrees, and we have seen it vary from 110 to 130 degrees in all types of horses.

Résumé.-It results from the preceding statements that the direction of the shoulder is in intimate relation with the speerl. It is desirable to have it as much inclined as possible, because its obliquity will admit of a greater extension of the humerns; it will permit the member to be raised higher and to complete the extension before plaeing the foot on the soil; it will more strongly project the foot, and will be 
compatible with a favorable orientation of the seapulo-humeral angle; finally, it will give suppleness, style, and amplitude to the gait, and at the same time will attenuate those reactions whose effects are as injurious to the rider as to the horse himself. Scapular obliquity usually acconpanies elevated withers and great depth of thorax. It gives to the horse a mark of distinction which denotes the nobleness of his race.

All other directions of the shoulder are antagonistic to veloeity from the fact that their elements are diametrically opposite to those of the conformation we have described. These disadvantages, however, disappear, as before stated, in slow and heavy work for which foree alone is required.

To conclude, from these remarks, that the shoulder of a heary Percheron is defective because it is not straight, would be wrong; and those who will endeavor to prove it by real measurements will reeognize that, in the very best speeimens of this class, this region, nevertheless, will show a marked inclination. Without doubt, in such cases, the most beautiful and perfeet shoulder is that which offers the greatest surface for the adaptation of the collar. It is a serions mistake to suppose that an inclined seapula does not furnish the elements of this large surface, for it excludes nothing favorable to muscular power.

It has also been said that, in the presenee of such a shoulder, the application of the collar is against the seapulo-humeral artienlation only; whence a certain amount of pain during the efforts of extreme traction, bruises of the sensitive parts, wounds, ete. These are objections which have value only when the shoulder is too sharp, emaciated, or poorly muscled, and consequently leaves the articulation too much in relief; but if it become defective for this reason alone, the defects must not be attributed to the obliquity. If the muscles be well developed this hinderance will disappear, especially if the preeantion be taken to elevate the attachment of the traces. It seems useless to repeat so often the aphorism, the harness is made for the horse, and not the horse for the harness. Nevertheless, how few harness-makers seem to appreciate this fact, but prefer to choose the collar without taking the measurement of the shoulders!

The inclination of the scapular segment having a marked influence only upon the speed, the straight shonlder is accepter in the motor which works exclusively from the weight of the mass. In a rapicl motor, these defects will increase whenever the height orer the withers is low, and, particularly, when the latter conformation is due to the low attachment of the trunk between the anterior members. Their free movement being already prevented on account of the 
defeetive direction of the shoulder, these members will be advanced with much more diffienlty, as they will be required to support a greater portion of the body-weight. Under these circumstances, if the animal be able to perform good service at the gallop or the trot on level roads, he becomes dangerous in descending hills or on rough roads, and is predisposed to stumbling and falling when he increases his speed.

Finally, the shoulder merits our attention from a point of view of the modifications which may supervene in its direction. Aecording to the mode of subsistence or the employment of the region, it becomes straight or inclined, oblique or straight, as it was at first. A long time ago, Ch. de Sourdeval, in the Journal des Haras, had already reeognized the influence of the attitudes which animals assume to obtain their nomrishment. This accurate observer has proved that the shoulder becomes more vertical in those which are obliged to eat from the ground, or which are maintained in pasturage, whilst it becomes more oblique in those which are fed in the stable and reeeive their food from a high manger. Besides, a majority of horsemen think that a proper dressing of the saddle-horse in the riding-sehool will incline the scapular segment to a notable degree, and that the continuous pressure of the eollar will straighten the shoulder of the dranght-horse. This is also our opinion.

Position.-It suffices not that the shoulder be long and well directed, it should also be properly placed against the vertebral column,- that is to say, so situated as to maintain a proper separation between itself and the cronp. When this condition is not fulfilled, the vertebral column is too long, lacks force, transmits the impulsive action of the posterior limbs feebly, and becomes sway-backed as a consequence. 'This defeet, very common in draught-horses, is nearly' always accompanied and complicated by a vicions direction and insuffieient length of the scapula, which is then ealled short, straight, or forward. We ean determine that it is not so by measuring the distance between the dorsal angle of the scapula and the angle of the haunch. In a natural conformation this distanee is about equal to the length of the head, while in disproportionate suljeets it may measure onefourth or even one-third more. (See Proportions, length of the body.)

Volume or Muscular Development.-The volume of the muscles of the shoulder is an indispensible element of its beauty, whatever may be its relative function. This qualifieation has different degrees, dependent upon the race, the temperament, and the mode of rearing and subsistence. The muscles of the English thoronghbred are 
more remarkable for the density, fineness, and cleanness of their fibres than those of the heavy Percheron, in which they are voluminous, short, and separated by an abundanee of connective tissue. In the one case, the muscles communicate to the region a long, slender, and graceful appearance; in the other, it is the mass, the rolume, the power. We should never demand a nuscular development which changes all in all the conditions of its intended utilization.

When the osseous eminenees of the shoulder, especially its seapular spine, its point, its tuberosity, its dorsal angle, and its cartilage of prolongation, form a prominenee somewhat marked, which allows us to surmise the situation of these parts, it is ealled well outlined. This is the form which it presents in all horses belonging to the finer brects.

When, on the contrary, the same reliefs are very apparent underneath the skin, from the effeet of a commencing emaciation or muscular atrophy, as is observed in horses exhausted by fatigue or privations, it is called meagre or lean, and expresses a certain feebleness of the locomotory apparatus. When, finally, this emaciation is such that the seapula ean be almost eompletely outlined under the integument by its reliefs and its general configuration; when the situation of the superand sub-spinati muscles is manifested by a deep depression; when the scapnlar cartilage is delimited above by a prominent curve from before to behind; when, in a word, the region as a whole overhangs, so to speak, the adjacent parts of surrounding regions, as the neck, ribs, withers, back, it is called atrophied.

Conversely, if the muscles, instead of being deficient in bulk, exeeed a volume compatible with their special service, a volume demanded, besides, for general harmony ; if, for example, they affect, in the saddlehorse, a volume which would be sought for in the dranght-horse, they will render the movements clumsy by surcharging the anterior part of the body, oppose themselves to the complete extension of the anterior member, and diminish the force of propulsion engendered by the hind limbs in rapid locomotion. In these conditions the shoulder receives the appellations of massive, fleshy, thick, charged with too much muscle, ete.

Diseases and Blemishes.-These are denudations and excoriations, due to a mal-fitting collar, which may terminate in smooth or radiating cicutrices formed by a portion of the skin which is deprived of its hair, thinner, irritable, and much less resisting to friction. The seat of these womds is at the level of the anterior borders of the shoulders, where they appear flat and circumscribe the base of the neek. Horse-dealers never fail to point to these as a proof that the horse is free in the collar. Of but little gravity in themselves, they constitute, nevertheless, a cause of depreciation in view of the increased sensitiveness 
which they give to the parts and the difficulties which are afterwards cxperienced in the application of the collar.

At other times, this region may be the seat of cold abscesses, disabling the horse for a variable period during their formation. These are sometimes true fibromata, from the induration of the subcutaneous connective tissue. Of a chronic character at first, they soon become so sensitive to the pressure of the collar as to render the most docile horse intractable.

The most serious of these tumors are those at the point of the shoulder, from the fact of the enormous volume which they may aequire, the dangers which their extirpation presents, and the difficulties experienced in healing the consecutive wounds, which are always more or less deep. They are caused by the pressure of a collar badly adjusted, insufficiently padded, or too heary.

It is not necessary to confound these tumors with diffuse enlargements of the scapulo-humeral articulation, as, for instance, with the particular affection known under the clinical but improper names sprained shoulder, shoulder-slip, which is accompanied by a lameness in which the anterior member is markedly abducted when it is extended, instead of moving in a direction parallel to that of the body. This movement, which is called moving, is due to the immobilization of the arm upon the shoulder or the sides of the thorax, and is a symptom of diverse lesions of the ligaments, the muscles, the bones, the blood-vessels, or the nerves. Although this phenomenon may be quite rare, the point of the shoulder none the less often carries the evidence of the treatment employed to combat it. Such are the marks of cauterization, setons, rowels, and blisters, which oceasion decortications, accidental white spots, or cicatrices of a particular form upon a more or less extensive area of this region. The gravest blemishes, above all, are traces of the actual cautery, except in the Barb horses, in which this therapentic agent is always applied as a means of prevention against diseases of the articulation. It is important, in such eases, to examine carefully the inferior portion of the corresponding member, for the scapular lesion may be a feint for another disease, or, what is more frequent, an indication of an error of diagnosis.

Let us mention, also, paralysis of the shonlder and atrophy of the super- and sub-spinati muscles, which are sometimes observed, but which produce no lameness.

\section{B.-The Arm.}

Situation; Limits; Anatomical Base; Form.-The arm, slightly detached from the trunk, is situated between the shoulder, with which it is confounded, and the forearm, from which it is separated by an oblique furrow in front.

Limited in front by the breast and the axilla, behind by the sides of the thora.t, and lower down by the elbow, it contains for its osseous base a long and voluminous bone, the humerus, surrounded by two sets of muscles: the first, coming from the shonlder, the neck, the side of the thorax, and the sternum, moves this region in every direction; the second, extending to the forearm and the foot, regulates the movements of the inferior segments of the member.

Movements. - When the thoracic member is carried forward, as in walking, the humerus is first flexed, then its inferior extremity 
deseribes an are of a eirele forward to increase the opening of the scapulo-humeral angle. It is not, as our distinguished colleague, M. Chénier, ${ }^{1}$ has said, that the humeral extension is terminated at the end of the phase of contact, but it is at the end of the elevation, when the foot is being placed on the ground, that the two bones (humerus and scapula) attain their maximum separation. The same phenomena are true of the member of the opposite side; the angle is closed by the approaching of its branches until the step is about to be terminated, when the arm is extended.

Length.- We will not consider the details of this particular element as we did in the ease of the shoukler. The arm should be as long as possible, relatively, in order to give greater length to its muscles which attach to the radius, and to permit its inferior extremity to describe an are of a larger circle. But its length will be defective when it becomes excessive, - that is to say, disproportionate relative to that of the shoulder. In this instance, as we have seen (see Fig. 58), the are whieh it describes is not angmented. The foot will pass over a smaller space of the ground surface; the movements are not executed with freedom; the animal is disposed to stumble and fall, at least, if the shoulder be not long and oblique. It is therefore apparent that, in relation with the latter region, the arm should be short to give the necessary extent and rapidity to its oscillations. Aecording to our measurements, confirmed by those of MIM. Colin and Duhousset, the distanee between the point of the shoulder and the centre of the humero-radial articulation should be equal to one-half of the length of the head in draught-horses. In rapid motors, like the trotter or the running-horse, it is, on the contrary, nearly always longer.

It is important to recognize this dimension from a point of view purely artistic, beeause seulptors and painters, says Colonel Duhousset, ${ }^{2}$ have committed grave errors from antiquity even to the present time. Nearly all represent the humerus too long, placing much too high the point of the arm, which should not extend beyond the level of the extremity of the sternum.

While an exaggerated length of the arm constitutes a defect which is not always compensated, its shortness also produces deficiencies of an inverse order, and both are hinderances in that which concerns the rapid gaits. If too short, it accomplishes an insuffieient extension; its muscles contract feebly, and restrain the movements of the forearm; the

${ }^{1}$ G. Chénier, Analyse de la première édition du présent ouvrage, in Écho des sociétés et associations vétérinaires, année 1882.

2 E. Duhousset, Lecheval, Paris, 1881, p. 67. 
elevation of the anterior members, when the animal is in locomotion, becomes exaggerated,-an elevation which is executed at the expense of the length of the step. Whence a loss of time which, insignificant as it may be at each step, eventually determines a marked diminution in the total quantity of speed.

Direction.- The direction of the arm is indicated by an imaginary line which joins the convexity of the great trochanter to the centre of the external lateral ligament of the elbow.

It should fulfil the principal elements, as follows: to allow to the scapulo-humeral angle, already reduced by the obliquity of the scapula, a sufficient magnitude, and not to alter the direction of the rertical line in relation with the radins.

We estimate, from our researches, that a mean inclination of 60 degrees is favorable to the development of velocity. When the inclination passes beyond these figures, it must be compensated by an augmentation of the seapular obliquity. In the draught-horse, whose scapula is more straight, the humerus does not suffer by becoming more oblique. In the more active dranght-horse it is intermediary between the two preceding types.

The data furnished by instantaneous photographs of animals in locomotion $^{1}$ show that the limit of extension of the humerus is very

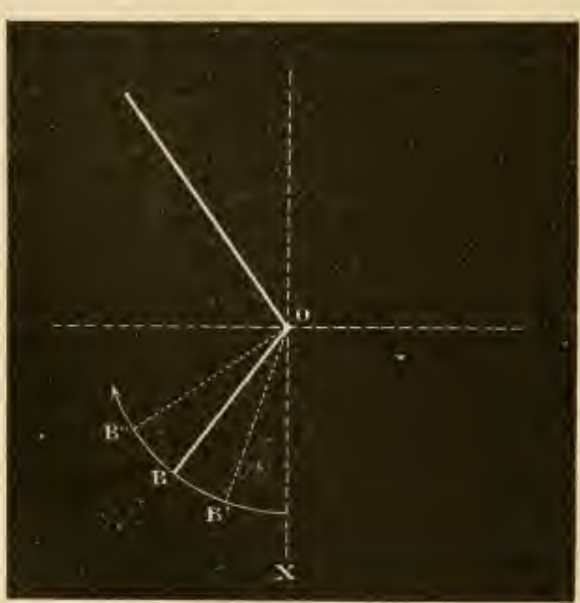

Fig. 63. close to the vertical line passing through the scapulo-humeral centre.

Theoretically, therefore, the arm should not be too straight at repose, - that is to say, in such a position that the line of direction of the member is too close to the vertical line passing through the centre of the suspension of this nember to the trunk. When the conformation is thus, the extension of the humerus is necessarily limited, and such an arm cannot profit by the advantages of a long shoulder. It is true (Fig. 63) that the segment $O B^{\prime}$, for example, must pass through much less space to

I See the figures of MM. Marey and Pagès, reproducing the details of the oscillation of the members in the gaits. 
reach the vertical axis $O X$ than the segment $O B$, supposed to be well directed. With the latter, however, the forward oscillation will be greater, and it will correspond better with a long shoulder, which, as we know, determines the degree of its displacements.

If it be too oblique, on the contrary, as $O B^{\prime \prime}$, it does not bring the humero-radial articulation sufficiently in advance to permit the forearm

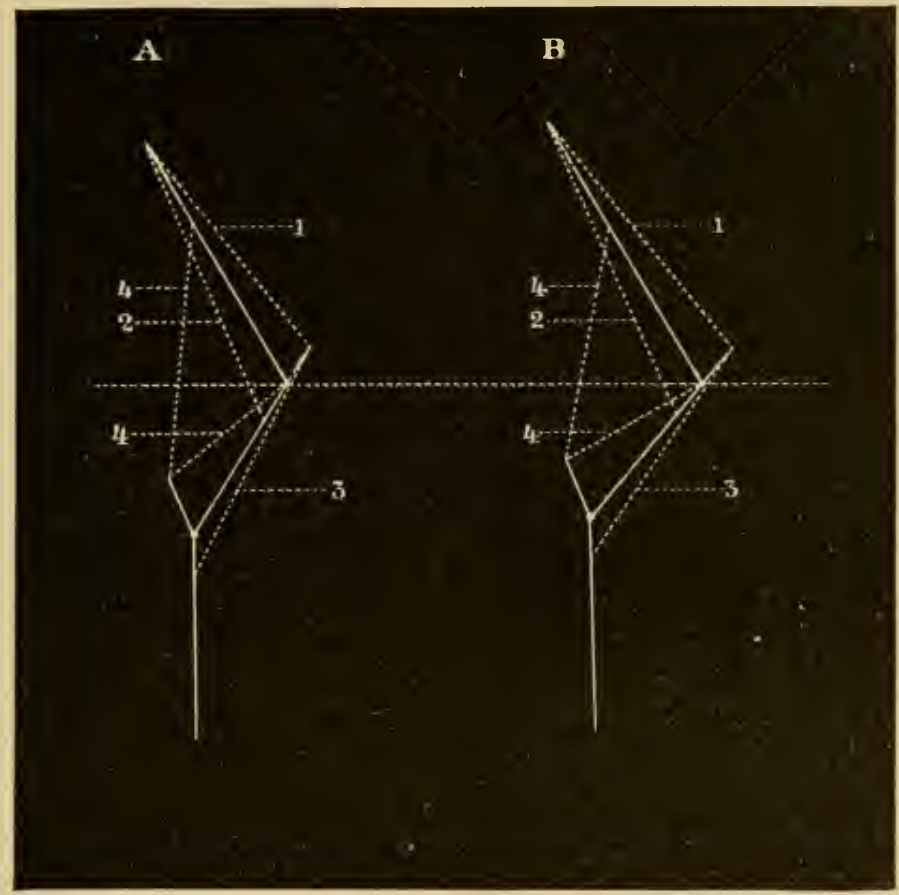

FIG. 64,-Scheme of the museular incidences in the straight arm, $A$, and in the oblique arm, $B$.

1, Extensors of the humerus; 2, flexors; 3 , flexors of the forearm ; 4 , extensors.

and the canon to evolve themselves completely. It obliges the horse to multiply his movements and elevate the members excessively, instead of being advanced without describing too great a curvature, $\rightarrow$ a losis of both time and energy.

But a very oblique arm gives a better insertion for the muscles: than a straight one, as can be demonstrated by an examination of the two diagrams $(A$ and $B$ ) of Fig. 64 , upon which are inclisated the flexors and the extensor's of the humerus and the radius; its muscles, however, are shorter. It is also not disadvantageous in horses from which great force is exacted.

The degree of brachial inclination, on the other hand, having an 
inflnence on the value of the scapulo-humeral angle, it may be asked if, for velocity or speed, a straight shoulder will not in a measure be compensated by an excess of obliquity of the arm. In other words, is it rational to prefer (Fig. 65) an angle $A O B$ to an angle $C O D$, both

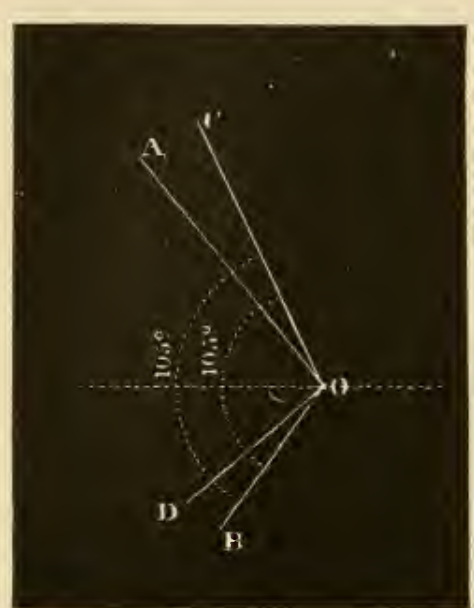

FIG. 65. having the same dimension? Evidently it is: to a straight arm an oblique shoulder; this is the law, and for several reasons already known. We will recall them: An oblique shoulder will augment the elevation and extension of its point, from the same quantity of muscular contraction; whence it follows that the inferior extremity of the member will be carried more in advance of its primitive position. As the straightening of the humerus also tends to the same result, the two acting in unison will increase the total amplitude of the movement.

If, on the contrary, the conditions be the reverse, if the arm be very oblique and the shoulder straight, the scapulo-humeral angle, although equal to the preceding, will be restrained to a less separation of its branches, because the extremity of the shoulder and the humeroradial articulation will remain too far backward in order to give to the forearm and the eanon the ease and the time to be carried sufficiently far in advance.

To recapitulate, the inelination of the humerus should not be exeessive in rapid motors, and the conditions of a good orientation of the seapulo-humeral angle must be found in the obliquity of the shoulder.

This explains why certain subjects, well marked in appearance in relation with their articular angles, do not confirm the conclusions which are based upon them. It suffices not (as we have seen on page 191) that the angles may have freedom of action, but it is also necessary that this action may be effected in the direction of the movement. If their orientation in relation with the vertical line of the centre of movement is defective, all the mechanical advantages for the accomplishment of our aim, speed, are lost.

These considerations, upon which we have purposely insisted, are not applicable to services which only exact strength. We will except, however, the rapid draught-horse, in which the elements of force seem 
to be dependent on the phenomenon of speed. The inclination and the disposition of the articular angles will also very often enable us to judge the amount of thoroughbred blood in such animals. It is, by no means, not the same in slow draught-horses. We frequently meet in them a straight shonlder supported on an oblique arm. The obliquity of the humerus in such cases is not a defect, for it fivors the power of the muscles by rendering their insertions more perpendicular. The shortness of the step, the inevitable consequence of such a conformation, offers nothing of special interest, since, in motors of this nature, the ultimate purpose does not consist in the extent but in the power of the effort produced.

Direction of the Arm in Relation with the Median Plane of the Body.-The long axis of the arm, in order that its displacements may be effected properly, should be almost parallel to the median plane of the body. If its inferior extremity is directed too much outward, the whole member is deviated in the same degree, the relation of the vertical lines is disturbed, and the foot is turned inward. This is called cross-footed. If, on the contrary, the elbow be deviated inward, the inferior part of the limb is turned outward (see crookedlegged horse). We will again refer to these à propos of the axes.

Muscularity.-The development of the muscles is an absolute beauty. It is preferredly appreciated by the prominence and width of the olecranon muscles (extensors of the forearm), which oceupy the triangular space between the scapula and the humerus, and by the relief formed by the humeral biceps in front of this region.

Diseases and Blemishes.-The region of the arm is, in most instances, exempt from these lesions. Contusions and, more rarely, fractures, the result of kicks received from other horses, when they are worked in file, running in pasture, in public exhibitions, or during transportation on railroads, are the principal alterations of this nature which are observed in this region. Rupture of the fibres of the coraco-radialis muscle is sometimes a cause of lameness.

\section{C.-The Elbow.}

Situation; Limits; Anatomical Base.-The elbow, situated between the arm and the forearm, and in front of the xiphoid region, has for its base the superior extremity of the cubitus, a voluminous apophysis called the olecranon. It gives attachment principally to the extensors of the forearm.

The elbow offers for consideration three elements: its length, a good direction, and its freedom from blemishes.

Length.-The osseous process which forms the olecranon repre- 
sents the arm of a long lever for the muscles to which it gives attachment. Charged to maintain, during station, the summit of the humeroradial angle continually tend-

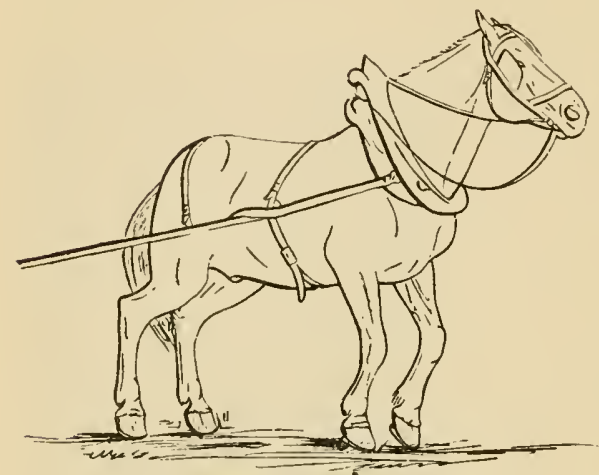

Fig. 66.-Reproduction from an instantaneous photograph. ing to become closed from the pressure of the bodyweight, and to produce extension of the sime angle in the propulsion of the trunk (Fig. 66), and, finally, to bring the antilurachial region into its primitive position, during locomotion, these muscles act so much the more favorably as the arm of the lever in question is longer and more curved backward. Preference should therefore be given to an elongated and prominent elbow, rather than to one which, in a word, eneroaches much upon the arm.

Direction.-The direction of the elbow is related to that of the arm. It is considered fine or beantiful when it oceupies a plane parallel to the axis of the body, and when, besides, this plane is sutfieiently separated from the lateral faces of the thorax. The elbows are then said to be well separated and well directed.

If, from the feeble development of the museles which separate the anterior limb from the ribs, the region in question, although always parallel to the median plane, is too close to the thoracic walls, the horse has the elbows on the body. It then lacks vigor, energy, and amplitude of the breast.

When the elbow is turned outrard, the inferior extrenity of the member is deviated inward, which characterizes the animal as being pigeon-toed; if, on the contrary, the elbow is turned obliquely inward, the foot is directed ontward, and the animal is said to be outhon-footed.

Each one of these directions is vicions, becanse it renders the movements of locomotion mngraceful, clisturbs the vertical axis of the members, predisposes them to premature ruin, even inchuling the effects from speedy cut and interfering.

Freedom from Blemishes.-Wounds of the region of the elbow may be the consequence of the improper application of the belly-band, when the horse is worked in the shafts, particularly of two-wheeled vehicles or the cart.

Most frequently they are due to the mode in which the decubitus is effected. 
Certain horses have the habit of lying down like a cow, - that is to say, of maintaining the anterior members flexed under the chest. It results from this that the heels of the shoe come into direct contact with the point of the elbow, irritate and bruise the skin, and cause the formation of a more or less voluminous tumor called shoe-boil, so named from the agent which acts as the exciting cause. A tumor of this kind is sonetimes sensitive to the touch, and necessitates suspension from work. At other times shoe-boils are not harmful, except as being ugly blemishes. We have had under our observation for several years a horse which performed very active service and carried on each elbow a shoe-boil of the volume of a man's head.

As soon as any excoriation of the skin of this region is perceived, it is necessary to observe the position of the animal in the decubitus, and, if required, to shorten the heels of the shoe, or simply the one on the internal side, which alone is most usually the cause of the "boil ;" or, again, we may protect the foot with a leather boot.

We may here mention fractures of the olecranon; these are followed by a permanent deformity of the elbow, the extremity of the bone being displaced upward by the contraction of the extensor muscles of the forearm. Even after the fracture is repaired, this injury causes a lameness the nature of which can always be detected by careful observation.

\section{D.-The Forearm.}

Situation; Limits ; Anatomical Base.-The forearm, situated between the arm and the knee, is related, above and behind, to the elbow.

Two bones constitute its base: the radius and the greater portion of the cubitus. These bones are surrounded by two sets of muscles, which all act upon the metacarpus or the phalanges; the one, the anterior, compressing the extensors of these regions, and the other, the posterior, forming the flexors of the same. Indirectly, through the ligaments, they can also move the forearm, and carry it into extension or flexion, according to the muscles which act. They operate for the most part upon levers of the third class, and hence play their prineipal rôle in the production of velocity; rarely do they concur in an active manner in the support of the body, a function provided for by the special mechanical conformation of the parts.

Form.-The forearm, as a whole, has the form of a cone, depressed from side to side towards its base or superior extremity, whose volume is in relation with that of the muscles just named.

Its external face is separated from the arm and the elbow by a furrow, witl an inferior convexity, due to the prominence of the extensors of the forearm upon the superior extremity of the antibrachial muscles, extensors of the metacarpus, and phalanges. A gutter, extending along the external border of the radius, and in its lower part, separates the anterior from the posterior muscles.

The internal face is devoid of muscles over the greater portion of its extent, and the skin is applied almost directly against the radius. The internal subcutaneous vein of the forearm, on which phlebotomy is sometimes practised, crosses this face a little obliquely from below to above. Finally, in the lower third of 
this region, we meet a horny excrescence to which has been given the name chestnut. It is small in animals of fine breeding.

The anterior and posterior faces, convex from side to side, are covered by muscles; their thickness is proportional to the volume of the latter.

Movements.-The forearm, from the mode of mion of its two bones with themselves and with the humerus, can execute only two principal movements : extension and flexion.

The first, whose extent is directly proportional to the length of the bones concerned and the degree of opemness of the humero-radial angle, carries the knee forward and upward, and enables the anatomical foot to be moved in advance. This is accomplished just before the foot touches the ground.

The second takes place principally during the latter half of the phase of contact, as is shown by instantaneous photographs. It contributes, therefore, in a certain measure to the impulsive forces, since in this period the member, as a whole, is directed obliquely downward and backward.

Beauties. - In order to be in the most favorable conditions for the production of velocity, the forearm should be long, wide, thick, and well directed.

Length. - The length of the antibrachial lever should be considered from two different points of view : the one considers the absolute length; the other, its length as compared with that of the canon.

a. Absolute Length.-The absolute length of the forearm should be as great as possible, for the reason that the are which this segment describes by its extremity is proportional to its length; also, because this length implies a corresponding length of the muscles which cover it. It is upon these two factors that the velocity, in so far as it is produced by the structures of this region, principally depends.

If the forearm be short, its oscillation, it is true, will be more rapid, but the distance passed at each step will be less. It can only preserve the velocity by a greater frequency of the movements, at the expense of a loss of time and more fatigue. Again, the knee being more elevated, the whole limb will be raised rather than projected forward; the animal will trot upon place, but with a short forearm the movements will be more brilliant, easy, and harmonious, and the horse is said to have high lineerection. In the cavalry horse, or in those used in riding-schools and parades, this is, without doubt, a matter of beanty, but perfection in this respect makes the horse more manageable, and is therefore a useful qualification. A horse with a high linee- 
action will be less disposed to stumble, will more easily overeome obstacles in his way, and will be fitted for special varieties of work, but will never be possessed of great speed.

Horses provided with long forearms move their members closely along the ground, and thus offer less safety to the rider on uneven roads. An intelligent handling and a rational training will nearly always cause a disappearance, or at least an attenuation, of most of these disadvantages of a long forearm.

b. Length in Relation with the Canon.-Nearly all authors agree that the radio-metacarpal segment should owe its length to the forearm or its superior section, and not to that of the canon. In other words, from a point of view of speed, the conformation should be such as to present a long forearm and a short canon.

The relative length of these regions varies in a small proportion when they are measured in a large number of lorses of the same height at the withers. But the few centimetres by which these figures differ are sufficient to produce a very marked effect on the value of the movements at the extremity of the member.

Professor Neumann ' was the first one to remark that if the metacarpus be considered just before the foot is raised, when the region is inclined downward and backward, it will be seen that the latter plays the rôle of a lever, upon the superior extremity of which the weight of the body is decomposed into two secondary forces: the one, perpendicular to the canon, tends to carry the knee forward; the other, parallel to this segment, indicates the intensity with which the foot presses against its point of support, the ground. The latter force, antagonized by the resistance of the soil, offers but little of interest to us in the present discussion. The former force acts behind on the arm of a lever, the metacarpus, antagonized in front by the extensor muscles of this region. It follows, then, that the shorter this arm the less will be the effect of the force in question and the less the fatigue of these muscles in combating the tendency to flexion.

A member with a long forearm will support the body more easily during contact for a longer time without a greater expenditure of force, and will incline itself more before being raised from the ground, a condition which will enable the foot to describe a larger are and increase the length of the step.

If the inferior extremity of such a forearm, having reached its limit of inclination, be now flexed, it will describe, for an efual angular displacement, a greater quantity of movement, and the latter is always proportional to the speed acquired, which is itself in direct

$1 \mathrm{G}$. Neumann, De l'avant-bras du cheral et de l'influenee de sa longneur sur la rapidité des \&llures, in Journal de médecine vétérinaire militaire, t. xi., anmẻe 1573, 1574, p. 157. 
ratio with the distance passed over in a unit of time; but the extension of the canon taking place after the flexion of the forearm, the quantity of movement of the latter will tend to angment that which the antibrachial muscles will communicate to the canon, in order to faror the rapid and extensive projection of the inferior part of the nember.

It is, therefore, also necessary to seek for a great development of the forearm in the parts where the muscles are situated, since the degree of musenlar shortening gives the measure of the angular displacements of the bones. For this reason it is preferable to have a short canon in relation with the forearm. From a point of view of locomotion, it is just to say that, of these two segments, the one is active and the other passive; the first, by its mobility, overcomes the inertia of the second.

Finally, with a short forearm, the displacement of the knee is effected upward instead of its being projected forward in the direction of movement. The arm of the lever (radius) of the resistance (weight of canon) diminishes, whilst the intensity of the power (flexors of the radius) remains the same, which favors so much the latter and gives to it more ficcility to elevate the knee. With a long radius, the arm of the lever (radius) of the resistance (weight of the canon) augments, and the power (extensors of the metacarpus) remains invariable, a condition which farors this bone again and disposes it more favorably for the extension of the canon. This is the reason why, in the first ease, the knee-action is exaggerated, the members badly employed and not properly advaneed ; also why, in the seeond ease, the knee is not unduly elevated, the segments being at the same time well projected forward. The animal thus acquires more speed withont inereasing the rapidity of his efforts and without compromising the integrity of the locomotory apparatus.

Width.-It suffices not that the forearm should merely be long, but it should also be wide, this wideness being an indieator of the volume of the muscles.

This width is measured from before to behind below the elbow, viewing the horse in profile, at a point always a little superior to the widest part of the tibial region, and at the level of the most prominent portion of its anterior muscles; it is, finally, on the same level as that of the tibial region at the point where the latter receives the insertion of the fold of the buttock.

The forcarm has such a conformation in well-formed horses, which qualifies it wide, muscular, well muscled. 
The tendons which terminate, under such conditions, the posterior radial muscles are short and thick; they are well separated from the canon and farorably disposed to fulfil their function of support in relation to the fetlock. The antero-posterior diameter of this region should be considerable,-in the dranght-horse more than in any others, since it is in relation with the contractile force of these muscles, provided they are dense, firm, and poor in adipose and connective tissues.

When the forearm offers dimensions opposed to the preceding, it is defective by reason of its small volume, and is called slender. The slender forearm characterizes ordinarily a horse without energy, with long, disproportionate limbs, vulgarly called weedy; he lacks strength and firmness, and, in general, is defective in most instances in the other regions.

Thickness.-The thickness, in close relation with the width, is measured from side to side, viewing the region from in front. It is recognizable by the prominence which the anterior antibrachial muscles form externally. It is desirable to have the thickness as extensive as possible, for the reasons which we have previously indicated. It may be remarked, ncvertheless, that the forearm does not lave the same muscular development in the thoroughbred horse as in the draughthorse; the region appears flat in the former, whilst it scems rounded in the latter.

Direction.-The direction of the forearm is as important a characteristic of its beauty as its length and its breadth. It should be vertical when the horse is examined in profile, and parallel with the median plane of the body when he is viewed in front. The vertical axis in this case is not altered, and the members are well placed to support the weight of the body.

If the inferior extremity of the region be directed forward or backward, outward or inward from the vertical line, the direction is vicious; certain parts of the limbs become exhausted and prematurely ruined, to which we will again refer in speaking of the linee and the vertical axes, because any deviation of this nature, altering the vertical position of the segment, demands an increase of function of the muscles equivalent to the part of the weight which is no more supported by the bones themselves.

It is not without interest to present here the details of the rôle which the direction of the arm plays in the effective utilization of the antibrachial movements. The angle formed by the two segments depends upon the more or less marked degree of inclination of the humerus. When the latter approaches the horizontal, this angle is so 
much more elosed than when the bone in question is more vertical. In order that the horse may have speed it is necessary that the forearm be not only long but that it be also enabled to become flexed to a large degree, so as to give the greatest possible amplitude to the step. The more vertical the arm the better will this condition be fulfilled. Such a disposition will, besides, favor the opening of the humero-radial angle during the propulsion of the trunk, another qualification which all the articular angles of rapid motors possess. Here observation confirms the theoretical data presented in discussing the arm. In racehorses the latter region is not inclined, a disposition which, as we have seen, is not incompatible with an extensive closing of the scapulohumeral angle, since the oblicurity of the scapulum counteracts the disadvantages which result from a vertical humerus.

These slight variations in the direction of the bones and the mode of opening of the superior articular angles of the members contribute to explain the contradictory results which are observed in race-horses of the best appearance as to conformation. Very difficult to appreciate, these variations often pass unperceived and lead the observer into error as to the importance of their effects.

These, nevertheless, may sometimes be quite considerable, as we shall presently see.

Let us suppose, for an instant, that a horse be able, at each step, to open the scapulo-humeral angle and close the humero-radial, each to a greater degree than in another horse. Let us assume, also, to make use of round numbers, that this feeble amplitude of two degrees is manifested upon a lever only one metre in length. We know that the distance passed over by the extremity of this lever for each degree will be:

$$
\frac{2 \pi R}{360}=\frac{2 \times 3.1416}{360}=0.017 \mathrm{~m} .
$$

This will signify that each step of this horse will be 34 millimetres longer than that of the second horse. These $3 t$ millimetres will give him an increase of 22 metres and 644 millimetres over a distance of 4000 metres travelled at a fast gallop (the step measuring 6 metres); at a fast trot (the step being 3 metres), an increase of 68 metres.

Thus, the influence of the articular angles merits to be taken into consideration, in that they can determine the amount of speed which a given animal is able to employ. As it has been well remarked, we must take cognizance of only a very feeble angmentation for a very short lever, as in the example which we have chosen. What might have been the results if, instead of calculating them upon two degrees, we had estimated them upon four, six, or eight, as it frequently exists? 
Diseases and Blemishes.-These are wounds, the result of kicks upon this region from other horses, but which are only grave when they interest the internal face of the region, where the bone, as we know, is directly subentaneous and not covered with muscles. In this situation they are often complicated by fractures of the bone.

At other times, synovial dilatations, which proceed from the upper extremity of the region of the knee, may exist here, but these appear upon the forearm only when they have reached a large development. Those of the humero-radioeubital articulation are extremely rare, and, in our experience, we have seen only two examples. They manifest themselves posterior to the external lateral ligament of this joint, and can be clearly seen when the nember is placed upon the ground. They then aequire a volume equal to one-half of that of a hen's egg, and disappear altogether when the limb is raised.

Finally, let us mention the wounds which are located upon the external lateral ligament of the humero-radial articulation. The external side of the joint forms a prominence, projecting above the level of the surrounding surface, which is continually being bruised, and receives most of the pressure when the animal assumes the decubitus for a long time upon a bed with insuffieient litter. These wounds are very grave, for they may be complicated by an opening of the articulation and terminate in the death of the animal.

The defects of direction, true blemishes, we will study with the vertical ares of the members.
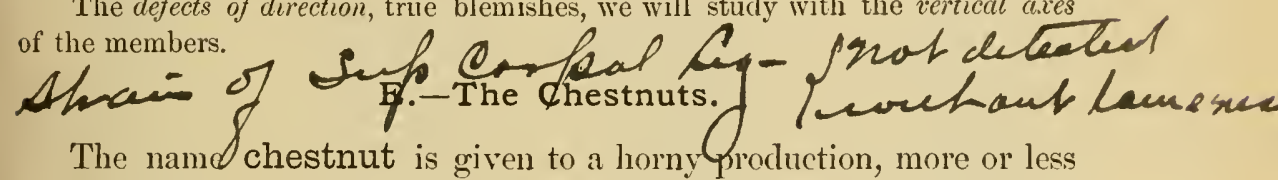

The namd chestnut is given to a horny froduction, more or less voluminous, according to the race, situated upon the middle part or the inferior third of the internal face of the forearm.

But little developed in the finer races, it is large in common horses, in which it is habitually cut or peeled off in arranging the animal's toilet before presenting him for sale.

The absence of the chestnuts in the anterior members has been observed, but it is a very rare fact. (The chestnuts are the rudiment of the nail or hoof of the internal digit or thumb.)

\section{F.-The Knee.}

Situation.-The knee, corresponding to the wrist of man, comprises all the radio-carpo-metacarpal articulations. It is at this region that the anatomical foot commences. It is also the region where the anterior member is almost completely divested of its muscles, and is constituted by nothing but the bones, the tendons, and the ligaments.

Limits; Anatomical Base.-Limited above by the forearm and below by the canon, this region has for its osseous base the seven carpal bones arranged in two suporposed layers. One of these bones, the first and the most external of the four of the superior row, also called the supra-carpal, is situated somewhat 
without the region, and forms behind a more or less pronounced elevation under the skin.

Several special ligaments, short, strong, and numerous, unite the bones of the same row to one another; others maintain the two rows in contiguity, or concur to fix the one or the other to the forearm or the canon; finally, the common ligaments, which are mueh longer and more resisting, and common to all the carpal articulations, appear to assume the rôle of insuring general solidity of the whole region.

Among the last, two are lateral, funicular, which circumscribe the carpus within and without, and extend from the tuberosities of the radius to termiuate on the head of the rudimentary metacarpals; the other two are capsular: the one, the anterior, is thin, more particularly charged to sustain the synovial membrane of the joint and to furnish gliding surfaces for the tendons which pass over the anterior surface of the knee; the other, the posterior, much more fibrous, extremely thick and resisting, fills up all the irregularities on the posterior face of the carpal bones and transforms this face into a veritable sheath, the carpal sheath, which is completed posteriorly by the supra-carpal bone and an arch of fibrous tisssue, in which are lodged the flexor tendons of the phalanges. This ligament, one of the most powerful in the organism, is prolonged at its inferior extremity by a strong band to constitute the check tendon, which is inserted into one of these tendons (that of the deep flexor), and plays a mechanical but important rôle in supporting the fetlock and maintaining its angle.

Three synorial membranes lubricate the articular surfaces and facilitate their movements. They are everywhere firmly surrounded by the ligaments as well as the extensor tendons of the foot, excepting at certain places where they are more feebly supported, and become the seat of abnormal dilatations. We will refer to these in discussing the blemishes.

The anterior face of the carpus is traversed from above to below by two principal tendons, which are maintained there by means of special synovial sheaths: one of them is that of the anterior extensor of the metacarpus, the other that of the anterior extensor of the phalanges.

The external face is traversed by the tendon of the lateral extensor of the phalanges; the internal face by that of the internal flexor of the metacarpus.

Finally, upon the posterior face of the region is located the rast carpal sheath, whose synorial membrane covering its walls and reflected upon the two tendons of the flexors of the phalanges, ascends on the posterior face of the radius to about its inferior fourth, and descends against the metacarpus to the lower limit of its superior third. Althongh strongly surrounded above by the muscular cone of the flexors of the metacarpus and the antibrachial aponeurosis, below and in its middle portion by the carpal arch, it nerertheless becomes apparent, when it is the seat of abnormal distentions in the form of tumors, whose exact characteristics and situation we will indicate farther on.

The movements of the canon on the forearm mechanically excite those of the knee; they consist of flexion and extension.

The first is produced when the foot is elevated from the ground and before it is advanced to eomplete the step. It is worthy of remark that the inferior extremity of the member, instead of moving in its own plane, is deviated outward in consequence of the obliquity of all the articular surfaces, and is not thus exposed to come in contact with the posterior face of the forearm. 
The second only takes place when the member, sufficiently relieved from the weight it supports, is projected forward to complete the step and assume its contact. It has attained its extreme limit as soon as the two segments are placed in a straight line, as they were during station.

As to the displacements which the carpal bones undergo, the one upon the other, their importance is considerable in relation with the distribution of the quantity of force upon the metacarpal surfaces. Their multiple facets, indeed, represent so many inclined planes which deaden the concussion and disseminate it upon the powerful ligaments which unite these bones.

Form.-The anatomical details which we have summarily reviewed are indispensable in order to conceive an exact idea of the external aspect of a wellconstituted knee.

The skin, in horses of the finer and more nervous races, is thin, covers all irregularities of the region, and shows its contour with the most perfect details. Also it is in these that the characters of a beautiful conformation cin be best studied.

Viewed on the anterior face (Fig. $67, A$ ), the knee appears slightly rounded from side to side, and a little wider above than below. It offers on its middle an

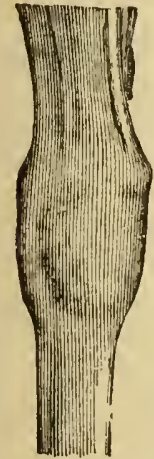

A

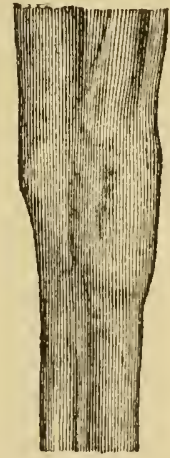

B

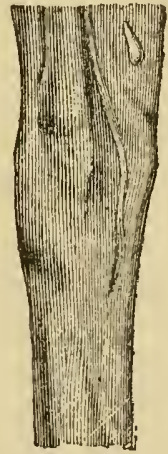

c

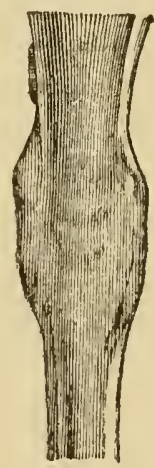

D

F1G. 67.

elongated eminence, the termination of the tendon of the anterior extensor of the metacarpus. 'Two curved lines circumscribe it on the sides: the intermal, very marked, comnences at the tuberosity of the radius; the external begins almost on the same level, but makes a less salient angle; both terminate quite abruptly at the canon below the head of the rudinentary metacarpal bones.

Examined in profile from the external side (Fig. 67, B), its anterior line, almost straight, continues that of the forearm; two eminences, scarcely marked, modify it slightly and indicate the relief of the two rows of earpal bones. Its posterior line, on the contrary, presents a very pronounced angle, formed by the supra-carpal bone, below, which it curves obliquely forward upon the tendons. Between these two lines there are two prominences which indicate the external tuberosity of the radius, above, and the head of the corresponding splint bone, below. The branch from the tendon of the lateral extensor of the phalanges joining that of the anterior extensor is detached below the latter. 
The profile of the knee from the inner side (Fig. $67, C$ ) is very much similar to that which is seen from the outer side. It presents the internal radial tuberosity, well ontlined, the internal metacarpal vein, and the head of the internal splint bone.

Finally, viewed from behind (Fig. 67, D), the lines which circumseribe it on the side are similar to those which we have deseribed in connection with the anterior face, while in its middle it is traversed by a voluminous conical eminence formed by the insertion of the flexors of the metacarpus upon the supracarpal bone. This relief, slightly depressed below the latter at a point called the fold of the knee, is contimous inferiorly, without any sharp demareation, with the flexor tendons of the phalanges.

Beauties.-The knee, in order to be beautiful, must be fine, thick, wide, well situated, well directed, and free fiom blemishes.

Fineness.-This quality is one that, in a general manner, is desirable in all the articulations. It denotes that they are formed only of those parts which should constitnte them. It resides in the apparent prominence of all the normal osseots reliefs, the ligaments and the tendons, which implies a thin and delicate skin, a small abundance and great density of the connective tissne which covers these structures. All horses belonging to the more distinguished races are noted for this peculiarity; those of the common races present it in a small degree, and in nerveless and lymphatic animals it is absolutely defective; the articulations in the last are always more or less poorly defined.

Thickness. - The thickness of the knee is its diameter from side to side. It is particularly desirable, becanse the lateral diameter is in relation with the transverse development of the articular surfaces, with the volmme of the earpal bones, and, consequently, with the firmness of the step and safety of the gait. When this region is narrow, the animal is liable to stumble and to a premature ruin of his limbs, which are too feeble to support the weight of the body beyond a certain rate of speed.

Width.-The width is measured from before to behind, for the extent of the knee measures more in this scuse than from one side to the other. A large width always indicates the antero-posterior development of the articular surfaces and a decided prominence of the supra-carpal bone.

The effect of the first of these factors is to rencler the carpal bones more resisting, to angment the movements of flexion and extension, at the same time that it makes the inferior extrenity of the radius appear larger, a disposition which separates the muscles from their parallelism with the bones and faror's their action. The second only implies a longer arm of the lever for the flexors of the metacarpus. 
The knee is called calf's knee when it is defective in its width, its thickness, and in the effacement of all the bony prominences; it denotes a general feebleness of the member, the volume of an articulation being correlative also to that of the regions which confine it.

Height. - The height of the knee above the ground depends on the relative length of the forearm and the canon. We have seen that a long forearm gives a great advantage in the function of long antibrachial muscles, and it is for this reason that preference should be given to a knee well descended and situated very low. In this connection, all other things being equal, saddle- and carriage-horses have the knee higher than draught-horses, a fact which can be easily ascertained by actual measurement. Their canons are longer, their body is less close to the ground. Nevertheless, tnis does not change the prineiple which has just been laid down. The latter applies only to those subjects whose conformation is comparaicle, and to no others.

Direction.-The vertical direction of the forearm and of the canon is without doubt one of the principal conditions of the strength and endurance of the anterior members. So true is this that everything in the carpal articulations is so arranged as to determine this mode of superposition of the osseous segments. Such is, however, not always the direction of the knee: sometimes it is deviated forward or backward from the vertical line; sometimes it is within or without this axis. Hence grave defects of the axis of the member, to which are given particular names.

Thus, the horse is called orer in the linees, kneesprung, when this region is curved forward (Fig. 68).

This condition is also distinguished as acquired and eongenital: acquired or accidental when it is the result of fatigne and excessive wear and tear of the parts; congenital, on the contrary, when it exists fiom the time of the animal's birth.

The first case is a serious condition, indicative of the muscular weakness of the part, of its worn-ont state, or

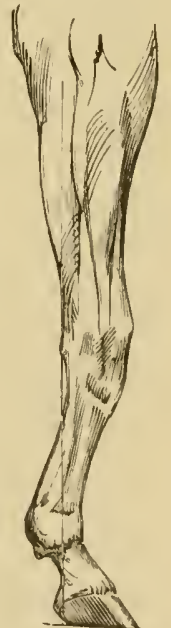

FIG. 68. of the contraction of the posterior tendons; such a horse is utterly unsteady on his feet, is positively unsafe to ride, and may fall on his knees at any moment, as is shown by the indelible scars with which they are usually disfigured.

In the second (ase the defect is only apparent, and in no way interferes with a firm and steady grip of the ground or with the freedom of movements. 
"In this class," says H. Bouley, "we even find horses whose knees arch forward to such an extent, when they are standing still, that we wonder how they manage to hold themselves up; and nevertheless, even laboring under such an exaggerated form of this defect, they never stumble when once they have been started. The reason of it is that the remarkable attitude of these animals does not bespeak any weakening in the powers of their extensor muscles, as it does in the horse that has become knee-sprung through hard work and old age."

Custom alone enables us to distinguish true or acquired sprung knees; let us add that it is also revealed by the trembling of the knees when the horse is in a resting posture, as well as by the habitual presence of hard or soft blemishes upon the inferior regions of the members.

If, contrary to what we have seen, the knee deviates towards the

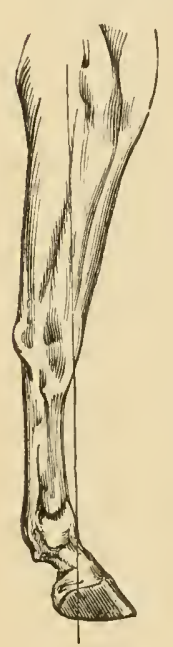

Fig. 69. back of the vertical axis (Fig. 69), it is termed effaced, sunken, hollow, or sheep-knee.

This defect, characterized by a concavity of its anterior face and a more distinct prominence of the supracarpal bone, has not, so far as we know, the importance, as regards speed, which some would attach to it. It necessitates, without doubt, a somewhat more extensive contraction of the flexors of the metacarpus, to bring that region into the attitude required by normal flexion, whence a loss of time in the execution of the movements. This loss of time and of muscular force, which result from it, are insignificant and can hardly be appreciated. Such a conformation is vicious, rather in so far as it causes a continual tension of the posterior ligamentous apparatus of the carpus and the check tendon of the perforans, a tension which tells likewise upon the lateral ligaments and becomes further increased at every instant of contact with the ground, when the animal is moving at great speed. These excessive tractions, injuring the articular ligaments, will eventually bring about the formation of osseous deposits at the points of their insertion upon the bones, or clse a permanent induration of the check tendon and the suspensory ligament of the fetlock.

Considerations of a similar nature are applicable to a knce which deviates to the inner side of the vertical axis, and which is styled ox-knee, from its analogy to that of the animal whose name it bears (Fig. 70). Very convex upon its internal face and concave externally,

1 H. Bouley, Nouveau Dictionnaire pratique de médecine, de chirurgie et d'hygiène vétérinaires, t. viii. p. 201. 
it is no longer compatible here with a miform distribution of the bodyweight upon the metacarpal region, becanse the articular surfaces in the horse's carpus have a slant different from that of the carpal bones in the ox. The inward deviation has a tendency to increase in the state of rest and at the time of contact with the ground during locomotion; the outer half of the bones is overloaded, while the internal lateral ligament is stretehed to its utmost. Hence, for this reason, first and foremost, do we look upon this anatomical conformation as a vice of the greatest importance in carriage- or in saddle-horses, the latter in particular.

Moreover, during the act of flexion, it exaggerates the movement of abduction of the metacarpus, which, on the contrary, under ordinary normal conditions, is always very slight. At every stcp the animal throws the canon outside of the vertical axis, wastes a certain amount of time in bringing it back to its normal attitude, and uses his limb in a most ungraceful style, described by H. Pouley as "a kind of all-over-the-shop gait, displeasing to the eye of the true connoisseur." Finally, the necessary consequence of this form of the knee is the ontward deviation of the inferior part of the member, notably the hoof. We will return to this in speaking of the outbowfooted horse. (See Axes.)

When the region of the carpus deviates to the external side of the vertical axis it is the seat of a grave defect, which is denoted by the limb being convex on the external side and concave inwardly, as well as by a convergence of the two hoofs (Fig. 71). This conformation is not common, but, like the preceding, it canses unsteadiness in the "grip" of the ground and a straining of the ligaments. In this case it is the internal surface of the articulations which is overloaded, and the external lateral ligaments that are subjected to the abnormal tension;

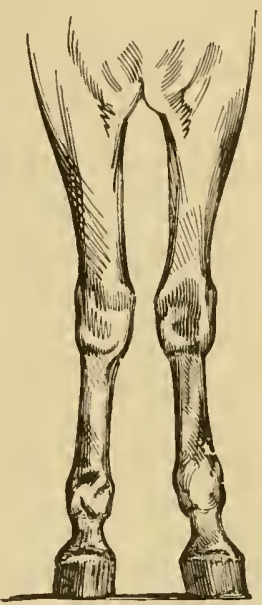

FIG. 70. and for this reason blemishes are the speedy result of this form of the knee. Besides, as the toe of the hoof is turned inward, the horse is pigcon-toed and exposed, consequently, to all the evils of this defect, particularly interfering.

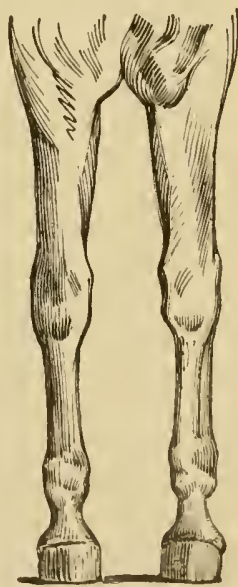

FIG. 71 particilary interfering. 
Clearness of Outline.-It is not sufficient that the knee be "dry," wide, thick, well located, and set in the right direction, but it is absolutely indispensable that the outline be perfeetly clear, 一that is to say, neatly defined in its external lines, whether viewed from the front or from the side. Any deformity, even a slight one, should be considered grave, for it is a sign of the weakness and the nltimate ruin of the limb in which it is noticed.

Diseases and Blemishes.-H. Bouley ${ }^{1}$ has described the diseases and the blemishes of the knce in his usual happy style. We will therefore limit ourselves to condensing here what he has written on this subject.

1. Recent Lesions and Diseases.-First among these are denudations, excoriations, and more or less deep wounds of the skin of the anterior surface of this region, the result of falls, and the gravity of which varies with the nature of the soil, the velocity of the gait, and the weight of the burden which the animal carried at the time. These lesions, as well as the scars they leave behind, are, as a rule, somewhat circular in shape, on which account the horse thus disfigured is said to be crowned. The cicatrices which succeed them usually have quite a regularly circular form, and designate the animal that presents them crowned. It is important to ascertain whether they are the result of a lack of steadiness in the anterior limbs or due to accidental falls. It is likewise necessary to find out if the lesion of the knee has affected only the skin and the subcutaneous connective tissue, or if, on the contrary, the synovial burse have been involved, for the gravity under these diverse circumstances is not the same. In general, superficial wounds are not accompanied by any great difficulty in walking, while the deep ones, those which have brought about the opening of the articulations, are extremely painful, and make it impossible for the animal to press his hoof on the ground.

Sometimes injuries or falls have determined no other consequences than a simple excoriation of the epidermis and the hairs thereon, which latter will grow again with their natural change of color. At other times the region is more or less contused, without a loss of substance, and the extravasation of blood or serum underneath the skin will oceasion the formation of abscesses capable of rendering the subjects incapable of service for some time.

2. Chronic Lesions and Diseases.-In this category are arranged numerous lesions and affections, which, in most instances, are tantamount to true blemishes. They involve the skin, subcutaneous connective tissue, the articular and tendinous synovial bursæ, and the bones. Let us examine them rapidly.

a. Skin.-We have seen that the horse styled crowned may receive upon the anterior surface of the knees injuries of greater or less importance; but the skin only preserves permanent traces when it has been affected in its essential parts. The most trifling of these after-results are those which proceed merely from a modification of the hair-follicles. Where these follicles are the new hair grows white, and thus bears witness of the fall which has taken place. In other 
eases the integument has been injured more deeply or even partly destroyed, and then no new hairs grow when the cicatrization has been completed. In the eyes of the connoisseur the horse is no less blemished in the one case than the other, whether he has an abnormal white spot upon the knee or an indelible cicatrix deprived of hairs; he is considered weak upon his limbs, predisposed to repeated falls, and, consequently, much depreciated from a commercial point of view, although, at times, the blemish may be altogether accidental. We should, therefore, beware of the so-called recipes which horse-merchants never fail to recommend tor the reproduction of the hairs. More especially should we be on our guard against the fraudulent means used by certain individuals for the purpose of concealing from the eyes of too credulous buyers a blemish which battles all such attempts. Some have been known to go so far as to blacken the denuded spot with a particular blacking; others cover it rather skilfully with false hairs, which they temporarily keep in due position by means of a thin coating of dextrine! As may be readily inagined, all these expedients are of such a nature as not to deceive the attentive and experienced observer.

Fissures known under the name of mulculders are met in the region of the fold of the knee. They are grave in so far as they cause much pain, and are often very tedious to heal.

$b$. Subcutaneous Connective Tissue.-It is not rare to observe more or less abundant effusions into the subcutaneous connective tissue as the result of contusions of the knee. The anterior face of this region is then seen to present a voluminous, fluctuating, and non-inflammatory tumor, whose walls, at first thin, soon become indurated and irregularly thickened; this constitutes the hygroma, or cyst, of the knee. It sometimes becomes inflamed and very painful. As a general rule, it interferes with locomotion only in a mechanical manner, and is nothing more than an eyesore.

Indurated tumors of the connective tissue have the same origin; they differ from hygromata in the fact that they are not fluctuating and that they can be much more easily dissolved.

c. Tendinous and Articular Bursæ.-A complex articulation like the knce, endowed as it is with such extensive movements, is sure to give signs of fatigue in the long run, by synovial dilatations at the level of the most mobile parts,- - that is to say, at the points where the gliding apparatus must needs have displayed an excessive and almost incessant functional activity. Indeed, that is what is observed in the radio-carpal and interearpal articulations, in spite of the powerful union which protects them.

Hydropsy or hydrarthrosis of the first manifests itself by the presence of two tumors, soft and fluctuating when the limb is semiflexed, and tense and convex when it is in extension. The one is situated immediately above the supracarpal bone and against the radius; the other forms at the upper part of the anterior surface of the knee. They correspond evidently, therefore, to the portions of the synovial membrawe which are feebly supported; pressure applied upon the lateral tumor is distinctly transmitted to the anterior, a fact which indicates the close relation which they bear to each other.

Hydrarthrosis of the interearpal joint is shown, when the foot is in contact with the ground, by the appearance of two or three nodosities of the size of a hazel-nut or a walnut, between the extensor tendons of the phalanges and of the metacarpus, almost over the middle of the anterior surface of this region. 
When the articular dilatations of the knee are very old, their wall becomes indurated and even ossified. This constitutes, in the latter case, one of the varieties of hooped knee, of which we will speak farther on.

The dilatations of the tendinous synovial bursce are of two varieties: they appear either along the course of the flexor tendons or along that of the extensors. Larger than the preceding, they may acquire very great dimensions. It sometimes happens, at least with the second variety, that they communicate between themselves or with the articular capsules, ${ }^{1}$ an important peculiarity, which should warn us against the danger of opening them.

Hydropsy of the carpal sheath, better known under the name of carpul or tendinous thorough-pin of the hnee, is manifested by the formation of two tumors posterior to the carpus, between the radius and the flexor muscles of the metacarpus. Each one of these is ovoid in shape; the internal is ordinarily smaller than the external, and both extend higher up than the articular dilatation. Inferiorly, the tendinous dilatation is prolonged below the knee by a soft, elongated, and irregularly-lobulated swelling, which follows the course of the flexor tendons, and transmits its fluctuation and palpation to the two superior culs-de-sac, thus giving evidence of its communication with them. This is a circumstance which is never noticed in the articular synovial dilatation.

The synovial dilatations of the tendinous burse situated upon the anterior capsular ligament of the carpus present analogous characteristics. They consist of elongated tumors, from one to three in number, located under each of the extensor tendons, and always perfectly distinct at the beginning of their formation. In advanced stages they become diffused over the anterior surface of the knee, and may communicate among themselves and with the articular synovial membranes; their parietes become indurated and, in some places, ossified. They might be easily confounded with the cysts, wheh are always more superficial, were it not for their relative situation with the tendinous cords.

d. Osseous Apparatus.-Not even the osseons apparatus is exempt from the traces of the wear and tear resulting from age or from excessive work. Exostoses appear, in time, upon the anterior surface of the carpal bones and upon their articular edges, at the points which correspond to the insertions of the ligaments. These osseous tumors of the knee have received the generic name of osselets. Their formation begins at the head of the rudimentary metacarpal, preferably on the internal side, and then they gradually extend, little by little, to the pieces of the two rows. When they are thus generalized, it has been the custom to say that the knee is hooped, a very appropriate expression, which conveys to the mind the idea of the alterations of which the region is the seat, These osselets, like the tendinous and articular dilatations, are grave blemishes; they disfigure the animal, produce a deviation of the forearm and of the canon, and, finally, often give rise to a rebellious and, very often, persistent lameness of variable intensity.

As the regions situated below the knee and the hock offer but few differenees in their anatomy and their external appearance, we will study them with the posterior members.

1 I have examined a large uumber of articulations and have not once verified such a condition. (Harger.) 


\section{CH A PTER II.}

\section{POSTERIOR MEMBER.}

WE have already stated the reasons for uniting the description of the croup with that of the trunk, and need not return to them here.

The regions of the posterior members correspond to those of the anterior, with some unimportant variations consequent upon the particular mode in which these parts execute their movements.

Thus, the thigh is the counterpart of the $a r^{\prime} m$; the stifle, of the elbow; the leg, of the forearm; the hock, of the knee. Such are the diverse regions which it remains for us to examine.

\section{A.- The Thigh and the Buttock.}

Situation; Limits; Anatomical Base.-We deem it advisable to combine the thigh and the buttock in one description, since there is so close a relation between them.

We will merely consider the latter as that part of the former which is charged with the flexion of the tibia, the extension of the femur, and the rotation of the coxa.

The thigh is the region where the posterior member becomes separated from the trunk. It is limited above by the croup and the haunch; below, by the leg and the stifle; in front, by the flank; inwardly, by the groin (in both sexes), the sheath and the serotum in the male and the mammary glands in the female; behind, finally, it is altogether free, and is simply in relation with the trunk and the hairs of the tail.

Its anatomical base consists of the femur and of numerous muscles which, originating in adjoining regions, terminate here, or, on the contrary, are detached here to terminate on the sections immediately below it,- -viz., the leg and the foot.

Form. - The thigh offers for study two surfaces and two borders.

The external surface is slightly rounded, according to its length and its width, in a horse in good condition. It forms, in such cases, below the croup, an almost vertical plane, which blends off below with the corresponding surface of the leg, and, in front, with the side of the flank. But hard work and insufficient food render the muscular interstices and the natural prominences of the skeleton very apparent: the femur is indicated by a thick longitudinal elevation, in front of which the muscles appear hollow, in consequence of the contraction of the flank; the ischiatic tuberosity and the trochanter become very salient, and leave between them a deep furrow which separates the superficial gluteus muscle 
from the posterior ischio-tibial muscles, and which is known under the picturesque name of furrow of misery.

The internal surface, called the flat of the thigh, is also more or less convex. It is traversed above in its direction and from back to front by a large vein, the saphena, on which phlebotomy is sometimes practised. This vein is accompanied by a small artery bearing the same name and covered over with a net-work of nerve-branches and of lymphatic vessels, whose situation it is important to remember from a surgical point of view.

The anterior border of the thigh is constituted by a voluminous muscular mass, the crural triceps, whose function it is to extend the leg. Over the middle and inferior portion of this border attaches a musculo-cutaneous fold, which is called the fold of the stifle, and spreads over from the side of the flank to the anterior surface of the stifle-joint.

As to the posterior border, it represents by itself the sub-region of the buttock or the brecching, and has for its base the ischio-tibial muscles. It describes, beginning at the base of the tail where it becomes continuous with the croup, a regularly-curved line, which becomes concave inferiorly and disappears at the posterior border of the leg. The most salient point of this graceful curve has received the name of point or angle of the buttock; it is due to the prominence of the ischiatic tuberosity of the coxa. On the other hand, the fold of the buttock is the most concave portion of this line, and corresponds about to the centre of flexion of the tibia on the femur. It is worthy of remark that in very emaciated subjects the point and the fold of the buttock are always strongly marked, while they are scarcely indicated in those that are in good condition, particularly in the heavy draught-horse, whose muscular system is voluminous.

Viewed from behind, the thigh is thicker as its muscular masses are more developed and as the animal belongs to a race of a more lymphatic and less nervous temperament.

Movements.-This region, in relation with the movements which it executes, is most interesting to study. It describes two principal movements, whose centre is the coxo-femoral articulation : these are extension and flexion. Their maximum amplitude is about 30 degrees.

During flexion, the femur is displaced angularly to begin the step. It reaches its limit of flexion a little before the foot arrives on the ground, so as to allow the full extension of the tibia, which has not yet been completed at the moment that the femoral flexion is accomplished.

During extension, the phenomena have an inverse order: the femur moves backward, thus strongly opening the eoxo-femoral angle; its obliquity is changed in direction; it becomes vertical or even inclined backward and downward when the limb is abont to rise. The extension of the thigh takes place during the last phase of contact and ceases as soon as the foot has left the ground to accomplish a new step. The muscles which execute it are more numerous and stronger than those which produce flexion; a fact not to be wondered at, since these 
muscles have to displace the body-weight as well as to overeome the inertia, while, in the second case, they only raise the member and project it forward. The energy and the extent of their contraction will determine the intensity and amplitude of the femoral force which, in concert with the stifle and the hock, communicates to the trunk the initial impulsion, the action, as it is customary to say.

Direction. - The direction of the thigh cannot be suital)ly described unless we understand well the signification which it is necessary to accord to this word.

In animal mechanics, osseous segments have an axis of form which is not always their axis of movement. The latter being defined as the imaginary line which connects the two probable centres of movement, it is clear that it will differ from the axis of form whenever the articular surfaces are situated in front, behind, without, or within the axis of the latter. This has already been noticed in the case of the humerus, and is evident here again in the consideration of the femur. The axis of form of this bone follows almost exactly the direction of a line connecting the trochanter with the fossa which exists between the trochlea and the external condyle; the axis of movement, on the contrary, joins the centre of the coxo-femoral to the centre of the femoro-tibial articulation, and crosses the first by reason of the fact that the head of the femur occupies the internal side of this bone instead of being situated directly at its superior extremity.

In spite of the difficulties which, in the living animal, hinder the determination of this fact, we may obtain the result in an approximate manner by seeking the two points indicative of the two aforesaid articular centres; these are, on the one part, the concarity of the trochanter, and, on the other, the middle of the length of the external femoro-tibial ligament. The line joining these two points will constitute the axis of movement of the femur. In many subjects, the horse being supposed to be in equilibrinm, it is almost vertical; in others, it falls to a slight extent obliquely forward and downward; finally, there are some in which it is oblique in an inverse sense, - that is to say, downward and backward.

The direction of the thigh should satisfy the four principal requirements which follow :

1st. Give to the coxo-femoral angle, already reduced by the horizontal direction of the croup, a sufficiently wide opening.

2d. Permit of an extensive separation of the branches of the femoro-tibial angle, while allowing, at the same time, a feeble obliquity of the leg.

3d. Not alter the vertical axis, which implies the tangeney of the hock to the vertical line falling from the point of the buttock.

4th. Finally, maintain the stifle in a certain state of separation from the median plane.

We estimate, from our researches, that a mean inclination of 80 degrees fulfils all these desiderata in rapid motors. The obliquity in 
the slow draught-liorse may be more aceentuated, since the eva is less horizontal, but this modification is rarely observed. Ordinarily, in these horses, the femur is straighter at the same time that the eroup is slanting, which thus increases this angle instead of diminishing it, so as to place the inferior parts of the member in a less defective position in relation with the vertical axis.

Examinations of instantaneous photographs teach us that the limit of extension of the crural segment is situated but slightly posterior to the vertical line passing through the centre of the coxo-femoral articnlation.

In principle, therefore, the thigh should not be too straight when the animal is normally at rest,- - that is to say, when the line of direction of the femur becomes confounded with the vertical line which extends from the centre of suspension of the limb upon the trunk. (See Vertical Axes.)

When it is thus (Fig. 72, $A B$ ), the degree of extension of the femur is necessarily limited, the animal lacks action, and is incapable of utilizing the advantages of a long croup. Besides, his vertical axis becomes vicious, and the hock and the foot carried too far baekward, render him camped behind. As to the muscles, the gluteals, $H A$, the extensors of the leg, mn, and the ischio-tibial muscles, Go, are short; the flexors, $i H$, alone are long.

When the femur, on the contrary, is too oblique, as $C D$, it is the flexion that is unduly limited. The are which the foot describes at each step is too short; the member, stationed too much under the trunk, works upward, and loses a part of its extension power in raising the body instead of projecting it forward, whatever may be the greater length of the gluteal muscles, $H C$, of the ischio-tibials, $G o^{\prime \prime}$, and the extensors of the leg, $m n^{\prime \prime}$.

On the other hand, the degree of inclination of the thigh being capable of modifying the value of the coxo-femoral angle, it may be questioned whether, for velocity, the obliquity of the croup wonld not be capable of compensating the excess of obliquity of the crural segment in such a manner as to leave to this angle the same opening and, consequently, the same degree of play.

This compensation, as we have seen above, is possible, but only within very narrow limits, because the orientation of the articular angle soon becomes defective; its bisecting plane assumes too horizontal a direction. Here, as in the arm, the principle is: to a horizontal croup should correspond a straight thigh.

On the other hand, if it be necessary that the femur should pre- 
serve a suitable and efficacious opening of the coxo-femoral joint, it is no less obligatory that it should give a proper direction, as well as a

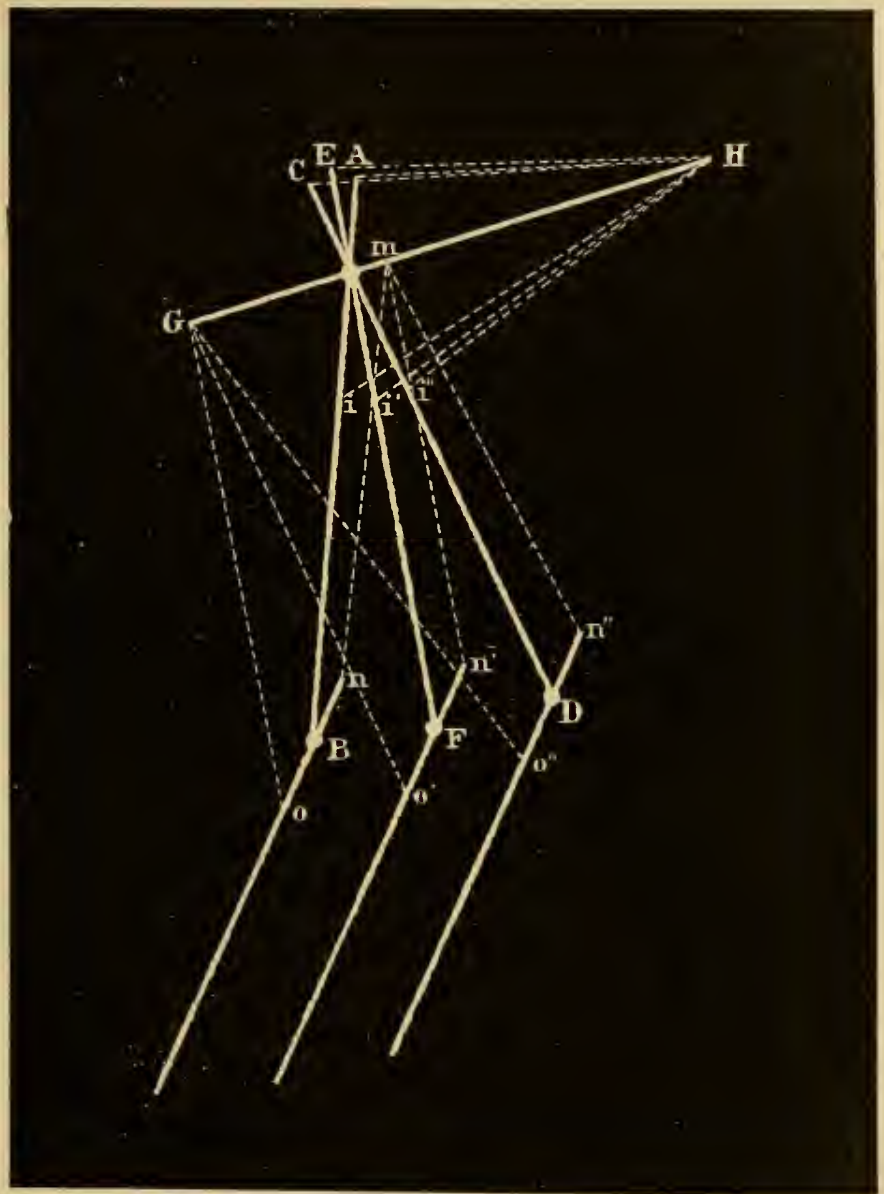

FIG. 72.

wide opening, to the angle which it forms with the leg. Observation demonstrates, in fact, that the femoro-tibial angle always has a wider opening in rapid motors; this is the factor which prevents the tibia from assuming an excessive inclination which would place it in a position disadvantageous to its movements of extension and flexion and its effectiveness in progression.

We therefore believe that a somewhat oblique thigh fulfils all these diverse requirements. It is the kind of thigh which is best for long strides, extensive and effective propulsive movements, and a normal 
relation with the vertical axis. This is very different from the classical teachings of a certain school, that all the superior segments of the nembers should incline at an angle of 45 degrees with the horizon!

Finally, one more point of excellence in the thigh consists in its being well away from the median plane towards its inferior extremity. The region of the stifle, of which we will soon speak, will not, in this case, be exposed, in rapid locomotion, to come in contact with the abdominal parietes. If this separation, however, be too marked, it will cause an outward deviation of the inferior parts of the limb. Many horses, close behind and outbow-footed, owe the faulty direction of their posterior extremities to this canse. (See Vertical Axes.)

Length.-The length of the thigh, it can be plainly seen, must be in close relation with the amplitude of the oscillations of which it is capable; besides, it governs the degree of the displacements of the tibia. In our opinion, it should be computed from the coxo-femoral articulation to the inferior part of the stifle. But its variations manifest themselves principally at the level of its posterior border. They are usually characterized by different expressions. Thus, such a buttock is said to be long or well descended (Fig. 73), which constitutes for this

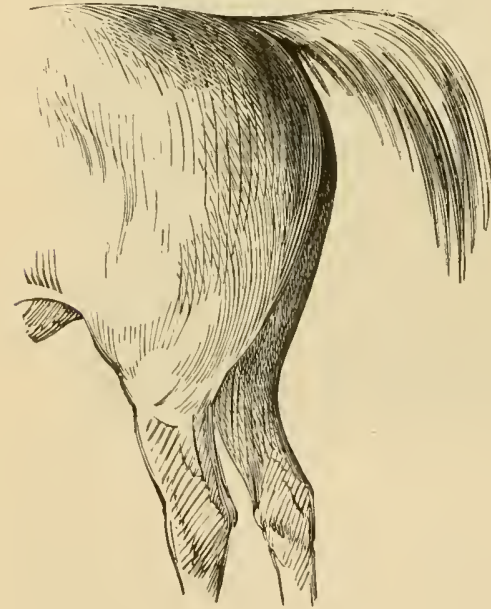

Fig. 73.

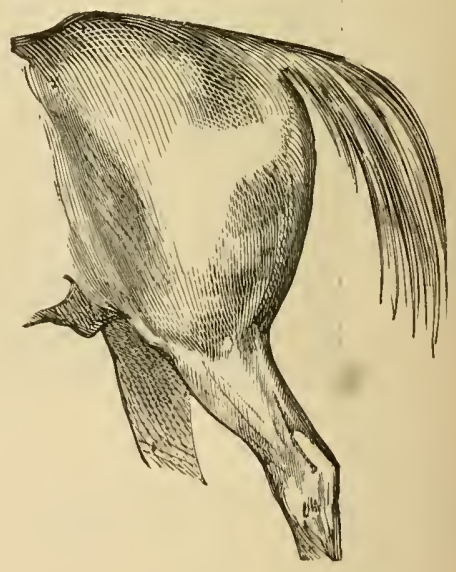

Fig. 74.

region a beauty of the first order, and of which the English thoroughbred, especially, offers a remarkable example.

When the thigh is deficient in length, it renders the buttock round and short (Fig. 74), a defect which may also be due to too small a femoro-tibial angle. The buttock is also named sulient when its point 
is prominent in a horse in good condition, which signifies an easy rotation of the coxae on the posterior members.

Width and Thickness. - The width of the thigh is measured by a horizontal line which crosies it underneath the coxo-femoral articulation. Its thickness, on the contrary, is appreciated, from side to side, either by viewing the animal from behind or obliquely from in front.

It is almost superfluous to dwell upon the importance of these two dimensions, which show the muscular development of the region and, consequently, the impulsive foree of the hind extremities. A thigh lacking sufficient thickness is designated as sharp; when this deficiency affects the whole thigh, and is accompanied, moreover, by a lack of width, the thigh is styled flat, lean, or is ealled a frog's thigh; among horsemen the animal himself is known by the name froggy, by reason of the striking weakness of his hind quarters.

The beautiful muscularity of the thigh can be summarized in a word: the animal is well rumped and strong-limbed; his buttock is well firmished; his muscles are firm, dense, and elastic.

Peculiar Markings.-The external surface of the thighs often presents cauterization brands, practised for the purpose of distinguishing subjects, of recognizing their breed, and of testifying of their purchase, or of any prizes they may have obtained.

Up to a recent date, horses in the French army were marked upon the left thigh as follows: with a grenade, if used by riflemen; a C, by the cuirassiers; a $\mathrm{D}$, by the dragoons; an $\mathrm{H}$, by the lussars; an $\mathrm{A}$, by the artillery ; a huntinghorn, by the chasseurs; a cross, by the lancers; a $\mathrm{T}$ and an $\mathrm{E}$, for the transportation horses, etc. This practice having sometimes occasioned extensive sloughing of the integrment and disfigured the animals, these marks were subsequently made upon the side of the neck, where they were more or less concealed by the mane. Ultimately the accidents to the operators, the pain occasioned by the branding, and the complications and the blemishes resulting therefrom led to the adoption of a much wiser method, the marking of the hoof, which is alone practised nowadays.

Nevertheless, in spite of the numerous disadvantages of the hotiron brand, some large corporations have thought it advisable to preserve it. The Paris General Omnibus Company's horses are all marked with a number upon the left side of the neck; those of the Paris "Petites Voitures" (or light-stage) Company, on the contrary, are marked on the hoof: There are cases in which one of the thighs bears likewise peeuliar markings. Somctimes we find a number, sometines a date, and at other times various letters, very often al P'on horses that have won prizes; again, figures of a special form, as in 
the case of many Russian, Hungarian, and Andalusian horses, or those of certain studs.

Diseases and Blemishes.-The diseases of the thigh and the buttock consist in general of wounds, abscesses, and bloor tumor's, which are the result of blows, knocks, fials, or other purely accidental causes. There is, nevertheless, an important one for which we should keep a sharp watch; this is an infammation of the lymphatic ressels on the flat of the thigh. An examination of the course of these vessels reveals a hard, cylindrical, sometimes bosselated, cord, prainful or painless to the touch, and of variable volume, which goes right up to the inguinal lymphatic glands in the groin. This elongated tumor, known unler the name of corded lymphatice, is very often the symptom of glanders-furey, and, for this reason, its existence is an ugly symptom. In other cases this condition is the consequence of diseases of the foot or of the inferior regions of the member. Whatever its cause may be, its presence always demands a most searching examination of the part by those who propose purchasing the animal.

Let us also indicate the varix and thrombosis of the superior part of the saphena vein, comparatively insignificant though they be, and, finally, the more or less numerous wounds and cicatrices which are the result of the cuts of the whip applied to this region.

The thigh is a favorite spot, even as the breast, the axilla, the ribs, the sides of the neck, etc., for the application of setons. Traces of these indicate that the horse has been affected with chronic diseases of the foot, such as grease, cunker, etc., or that these issues have been employed as counter-irritants against grave alterations of the encephalon or the spinal cord. Not infrequently, either, the external surface of the thigh shows marls of cautery in the vicinity of the coxofemoral articulation. These reveal former cases of lameness where the seat of the malady has remained unascertained and all other methods of treatment have proved ineffectual. Their presence demands a minute examination of all the inferior regions of the member, even of the hoof. Many are the chances of locating the true cause of the lameness in those parts.

\section{B. - The Stifle.}

Situation; Limits; Anatomical Base.-The stifle corresponds to the femoro-patellar articulation, and is comprised between the inferior extremity of the thigh and the superior part of the leg.

Externally, its outline represents two rounded, unequal eminences, one abore the other. The upper, more voluminous, and due to the anterior crural muscles, overhangs the lower, which is smaller, and is caused by the patella. Below the latter there exists a slight depression.corresponcling to the patellar ligaments and the patellar adipose cushion. Finally, the cutanenus fold, known under the name of foll of the stifle, extends from the superior prominence of which we have spoken to the surface of the flank in the direction of the hypochondriac region.

The stifle, in relation to its conformation, offers neither special points nor defects for consideration. It is important, above all, that its essential parts can be distinctly outlinerl. Its distance from the 
ground is ordinarily equal to that of the ellow, in swift horses as well as in others, whatever may have been said to the contrary.

Whilst the neatness of outline of this region is a quality to be desired, its direction should not escape a careful examination. With good reason, a stifle which lies close to the abdomen, and is slightly deviated ontward, is preferred to one that is low, deviated inward, or even parallel to the median plane. The first direction, indeed, indicates great length and a beautiful obliquity of the thigh and great case in exeeuting the movement of flexion of this segment. In the second ease, the stifle is liable to strike the abdominal parietes, a drarback which must needs have a certain importance in the modification of the rapidity of the gait, confining as it does the forward displacement of the thigh, the more so as it often coineides with a femur which is short and not sufficiently oblique.

Nevertheless, too great a separation of the stifles will be defective, in so far that it will surely superinduce an outward deviation of the inferior part of the members and render the animal outbou-footed. We will return to this point à propos of the axes.

Diseases and Blemishes.-The stifle presents varions affections which deserve our attention. They are:

1st. Synovial dilatations, a kind of thorough-pins, which appear in the form of a soft tumor, more developed internally than externally, at the level of the patellar ligaments. They manifest themselves by a round, sometimes lobulated, fluctuating enlargement of a variable volume. When the distention is of large dimensions, the synovial membrane is bulged out above the patella underneath the extremity of the crural triceps muscle, where it forms a more or less accentuated swelling. Its prognowis is then rather serious on account both of the difficulty which is experienced in obtaining its resolution and of the lameness of the horse.

2d. Exostoses, located on the anterior surface of the patella, and resulting most frequently from external violence.

3d. Superficial or else deep wounds, inflicted by knocks or blows. They have no gravity so long as the skin alone is involved; but the immerliatc consequence of such causes may be fracture of the patella, - a rare accident, fortunately, for it incapacitates the animal for work for a long time and induces nearly always a permanent lameness.

4th. Displacements, called luxations of the patella, common in young horses, and vulgarly designated under the name of foal's cramp. This bone, according to some, is supposed to be thrown out of its cavity of reception,- that is to say, altogether dislocated towards the outer side of its trochlea ; acenrding to others, it is supported, or rather held, by the very salient eminence which is formed by the superior extremity of the internal lip of the femoral trochlea.'

I See, for more details, Bulletin de la Société centrale de médecine vétérinare, séances du 11 Aout et du 27 Octobre, 1881. (MN. Bouley, Chuchu, Cagny, Nocard, Trasbot, Weber.) 
The latter opinion is nowadlays most generally aecepted. Be this as it may, the accident occurs but once, or again its reproduction may be intermittent and frequent, the bone becoming alternately dislocated and reduced spontaneously at the end of a variable period. In either ease a very intense lameness supervenes, the chief diagnostic character of which consists in the attitude of the member, which remains in a state of foreed extension, and ean only be carried forward by a very marked abductive movement. A horse in such a state is, of course, not in a condition to be sold, unless, however, the sale should be made during the interval of two displacements of the patella, as we have had occasion to observe several times.

5th. Traces of blisters and cauterization denote that the region has been treated for one of the diseases of which we have just spoken, principally synovial dilatations.

\section{C. - The Leg.}

Situation; Limits; Anatomical Base.-The leg is the intermediate region between the thigh and the hoek; the stifle and the buttock are also its upjer boundaries.

Two bones form its resisting, osseous base: the tibia and the peroneus. The latter is so rudimentary in the horse that it is hardly of any aceount so far as animal mechanics are coneerned. The tibia, on the contrary, strong and prismatic, is situated obliquely from above downward and from before backward under the femur, to which it is joined by a very movable articulation.

Two groups of powerful muscles eover it in front, on the back, and on the ontside. Its internal face alone is subcutaneous, and therefore more exposed to traumatisms. The function of the anterior tibial muscles is the flexion of the canon and the extension of the phalanges upon each other and upon the metacarpus. The role of the posterior tibial muscles is precisely the reverse: with the exception of one, the popliteus, they are all extensors of the metacarpus or flexors of the digital region. They are, in a great measure, concealed extemally by the inferior extremity of the ischio-tibial muscles which cover them. Lastly, most of them beeome inflected over the back part of the hoek, - that is to sily, the summit of the tibio-tarsal angle,-and by this very fact help to prevent the closing of this angle when the member is standing still.

External Form.-The tibial museles, like those of the antibrachial region, have this peeuliarity, that above they are constituted by a fleshy body, and below they are continued by a shorter or a longer tendon, destined to transmit their action to the canon or to the phalanges. The result of this is that the region, considered as a whole, presents a somewhat pyramidal or conical form, wider above than below, and eompressed from one side to the other. Four faces may be reeognized on this region, two of which, the external and the intermal, especially merit our attention.

The external face, almost plane superiorly, and confounded with the most deelivitous part of the thigh and the buttock, shows quite distinctly the outlines of the muscles that we have mentioned above. Inferiorly, there is a change in its appearance near the hock: the external tuberosity of the tibia may be discerned in front, the anterior border of the ealcanens behind, and hetween these two eminences a depression which is called the hollow of the hock. It is 
limited in front by the tibial crest and behind by the tendon of the gastrocnemius and perforatus muscles (cord of the hock, incorrectly called the hamstring tendon), which is inserted on the summit of the calcaneus.

The internal face, almost plane and subcutaneous, is traversed by the saphena vein, which is accompanied by the artery of the same name and several lymphatic vessels, voluminous but not visible in the normal state. The very lowest extremity of this face displays in relief the internal tuberosity of the tibia, as well as the corresponding portion of the tendo Achillis, and, between these two, the concavity already indicated under the name hollow of the hock.

Movements. - The leg, owing to its mode of articulation with the thigh, is the seat of two principal movements, flexion and extension.

During the former, the leg is carried upward and backward; the femoro-tibial angle is closed in proportion to the length of the flexor muscles. Flexion commences in the latter part of the phase of contact, and is completed a little after the raising up of the foot. It does not entail much fatigue on the agrents which execute it, as they have only to overcome the weight of the member to be raised.

As soon as the thigh has effected its forward movement, the leg rapidly completes its own, and the amplitude of the are of a circle thus described by its inferior extremity depends always (apart from the length of the tibia itself) upon the degree of flexion which it effects and the distance at which the foot was raised above the ground. If the foot is not raised high enough at the moment when it is to come down on the ground, the hoof will be in contact again before the leg has had sufficient time to attain the maximum degree of extension of which it is capable. Indeed, it is evident that the length of the step is in direct ratio with that of the tibial extension.

Length.-The length of the leg is measured from the inferior part of the stifle to the fold of the lrock. It is always equal to that of the forearm, and should be as extensively developed as possible in rapid motors. Upon it depends, indeed, the extent of the movements undergone by its inferior extremity, at the same time that it implies a proportional length of the muscles which belong to this region; moreover, as these muscles are destined to move the canom, it follows that, for these two reasons, a long leg is indispensable to the velocity of the gait.

If it be too short, the foot passes over less surface at each step; the animal can only preserve his speed by dint of multiplying his movements and increasing his fatigue. It is needless to say that this conformation offers nothing objectionable in slow motors, from which nothing more is expected than wreat muscular power.

The length of the leg descrves, likewise, to be studied in relation 
with that of the canon. In this connection, all author's are agreed that a short canon at the extremity of a long leg constitutes a great point. But why? No onc has explained it. Still, it is easy to account for it. The reasons are of the same nature as those which have been explained in connection with the forearm.

Here, also, the metatarsus, at the time of contact, plays the part of a lever, at the superior extremity of which the weight of the body is decomposed into two sceondary forces : the one, perpendicular to the canon, tending to carry the hock backward; the other, parallel to this segment, showing the intensity with which the foot presses against the ground. The latter force, destroyed by the resistance of the soil, is for us void of interest. As to the former, it has the metatarsus for its lever-arm, while the extensor's of this region are its antagonists. The shorter this arm will be, the less will be the museular foree required to counteract the tendency to flexion. Not only this, but, during the impulsion, the extension of the canon will equally be effected without any greater expenditure of force.

A canon which is short relatively to a long leg describes a less extensive are of a eircle, and is less heavy. These are additional reasons why the tibial muscles will have to contract with less intensity and to a smaller degree in order to produce the same effect.

On the other hand, the metatarsus is covered only by tendons, -in other words, by inert cords, simple agents of transmission. The tibia, on the contriry, is surrounded by the fleshy portion of the muscles, contractile organs, whose shortening gives the measure of the osseous displacements. Large dimensions should, therefore, be looked for in this region, which, it may be said, constitutes the active part of the segmented pendulum represented by the tibia and the metatarsus. The length of the canon not compensating the shortness of the leg, since its rôle in locomotion is absolutely passive, there is the best reason to select one that is short in relation with the leg when the object is to combine the best conditions for speed. This consideration in the draught-horse is of no importance.

Width.- The width of the leg is recognized at its superior extremity from before backward, and at the level of the enlarged portion of the cxtensors. It is always somewhat inferior to that of the forearm.

It indicates the development of the muscles in this zone, and we know that the volume, density, and compactness of the muscles are, in the superior sections of the nembers, qualities of the first order. A horse with a leg thus museled is called strong-limbed; the calf of 
the leg is well outlined and powerful. In the opposite conformation, the leg is lean, flat, or frog-like, from analogy with that of the familiar batrachian. That is a grave defeet, particularly in the draught-horse.

The leg should also be wide in the vicinity of the tarsus. The caleanean cord must be distinctly separated from the tibia, for then the probabilities are that this separation is due to the length of the calcaneum, that arm of the lever of the muscles which produces the impulsion, the extenșion of the hock.

Nevertheless, let no error be committed here; the separation in question may depend upon another factor: a more or less accentuated inclination of the tibia upon the canon.

It is evident, from the mere examination of the diagrams of Fig. 75 , representing two tibix, $O M$ and $O N$, differently inclined upon their respective canons, that the wider leg is also the more inclined of the two, $O M$, although its calcanean lever, $O C$, may be absolutely of the same length as that, $O D$, of the straight leg, $O N$.

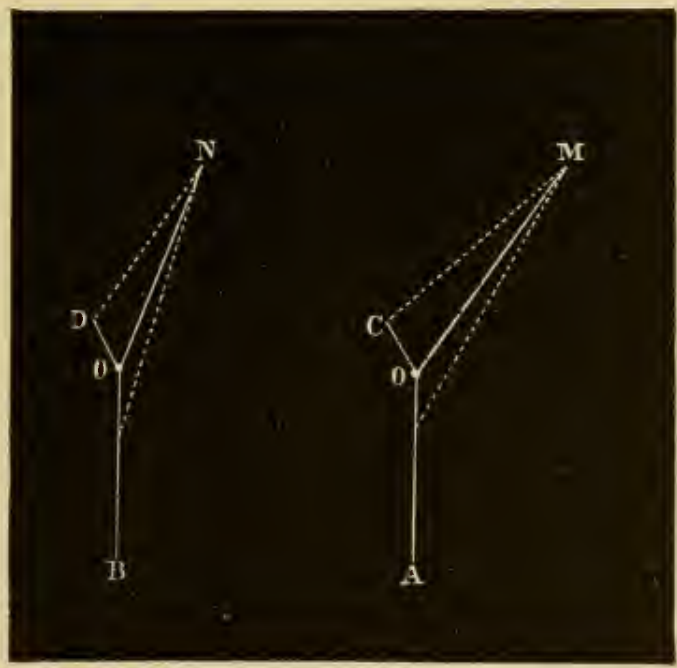

FIG. 75

It is therefore requisite, at all times, to take into consideration the direction of the tibia in estimating the value of the width of the inferior part of the tibial region.

Thickness.-In order to estimate properly the muscular development of this region, it is necessary to consider its thickness, -in uther words, its transverse diameter. This can be appreciated by examining the horse obliquely from in front, or by viewing it from 
before or from behind. The reliefs of the anterior muscles in either of these positions should be plainly marked and strongly convex outward. When the leg possesses but little thickness, it then lacks force, and is qualified thin, leun, flat, as we have seen above.

Direction. - The direction of the leg is as important a qualification with regard to the development of force as to the production of speed, for it favors the muscular action and facilitates the play of the articular angles, according to its obliquity. It is measured by a line joining two points situated the one above, the other below, the two external tibial tuberosities, superior and inferior respectively.

The direction of the leg, like that of the thigh, should fulfil two principal requirements :

1st. It should not alter the regularity of the vertical axis, which axis affects the verticality of the canon and the tangency of the hock to the vertical line which falls from the apex of the buttock.

2d. It should secure a large opening and the proper direction of the femoro-tibial and tibio-tarsal angles.

A mean inclination of 65 to 70 degrees, aceording to our researches, fulfils very well these conditions in swift horses. Indeed, instantaneons photographs demonstrate that the limit of extension of the tibial section is situated very nearly on the vertical line which passes through the centre of the coxo-femoral joint. Remembering this disposition, as well as the fact that the femur is capable, during flexion, of surpassing posteriorly the vertical line through its' centre of movement, it is only natural that the obliquity of the tibia should be more marked than that of the femur.

When the leg is ton straight, which is rare, its degree of extension is necessarily limited, and the step is short, whatever may be the length of the thigh; the foot, being too far forward, causes the horse to be under himself behind. When it is too oblique, the flexion, on the contrary, is reduced, and the hock, being carried too far backward, produces the opposite defect, and the animal is said to camp behind.

In speaking thus, we have supposed the direction of the femur and the metatarsus to be invariable, for it will be understood that the former of these segments, by modifying its inelination, might re-establish the normal axis of the limb. But given a proper obliquity of the femur, and, besides, the vertical direction of the canon as necessary, the position of the tibia has a direct influence upon the axes and the degree of aperture of the femoro-tibial and tibio-tarsal angles. Shonld it become more vertical, it widens the angles, lengthens the member, raises the trunk, diminishes the stability of the equilibrimm, and 
favors speed; should it become more inclined, it closes the angles, shortens the member, draws the body down to the gromnd, and favors the muscular insertions and the production of force.

It is easy to understand that the more the tibia is inclined on the femur the more perpendicular is the insertion of the muscles upon their lever-arm and the more effective are their eontractions. These two segments are never so oblique upon each other as to form a right angle, even when the member is in station. Although normally very obtuse, the more closed the femoro-tibial angle is the more favorably is it disposed for all the manifestations of force. It renders the buttock shorter without preventing it from being strongly museled; it diminishes the height of the animal withont interfering with an increase of its bulk. Besides, is not this the form which this angle assumes when the draught-horse is called upon to move his load and to display great force? Does he not incline the croup, the thigh, the leg, and the canon, close all the angles, bring the body to the ground, correct the museular insertions, and, in a word, adapt his locomotory apparatus to the new conditions which are imposed on him?

In the rapid motor, the angle of the stifle should offer a greater amplitude. If, indeed, on the one hand we should seek in the abdominal limb for a certain horizontality of the croup with a view of augmenting the power and extent of the contraction of the muscles, the case is quite different with the inferior segments, the femur, tibia, and canon, which require but little obliquity to move one upon the other with a great amplitude when the foot is raised from the ground. It is for this reason that the femoro-tibial angle is much more open in the rumning-horse than in any other. A tibia exeessively inclined in relation with the femur would not reach its limit of extension quickly enough; too much time would be taken up, and the extension would not be terminated before the foot had tonched the ground again. We have seen in discussing the thigh that the femoro-tibial angle is about 145 to 150 degrees in horses endowed with speed. This is a quality which we have recognized in the best running-horses, and whieh we will give only as a simple datum on which our judgment can be based, for this angle varies according to the type of the horse examined.

In order to subserve speer, it is neeessary, besides, that the tibiotarsal angle be very wide, another condition which implies a small inclination of the direction of the leg. The ranon can then be more strongly flexed, pass over more space, and take a long stride, particularly if the tibia be long and well muscled. MForeover, when the foot gets on to the ground again, the extension of the hock is at its full on 
account of the degree of elosing which its angle has attained, and also because the extensor muscles of the canon are in a more favorable position to contract with intensity.

A small tibio-tarsal angle depends upon one of two causes: an excessive obliquity either of the canon or of the tibia. In the first case, a portion of the force is expended in raising the trunk upward instead of propelling it forward. In the second ase, the tibia, being too much inclined and too mueh direeted backward, cannot execute its movements upon the femur with sufficient freedom, and limits the gracefulness and velocity of the locomotion.

The tibio-tarsal angle, according to our measurements, oscillates about 156 to 160 degrees in the most beautifully constructed runninghorses. It is never 136 degrees, as affirmed by the partisans of the theory of the parallelism of the segments, not even in the draughthorse, in whieh the angle is smaller, and in which, in truth, its examination is of no importance.

In this respect our observations are absolutely in accord with those of our colleague, M. Laulanié.

Diseases and Blemishes.-The diseases of this region, few as they are, are nevertheless capable of presenting characters of exceptional gravity. We will cite :

1st. Wounds caused by kicks from other horses, received during work, outdoor exercise, or in the stable. These wounds generally appear on the internal and the anterior faces of the tibia. They are less grave upon the external surface, because here the bone, protected by the muscles, is less predisposed to fractures. The intense lameness which accompanies these injuries usually prevents the animal from working or being presentable for sale.

2d. Osseous tumors, of about the size of a hen's egg, sometimes observed on the internal faces of the two tibix, deserve the greatest consideration on the part of the buyer. Although their presence may be related to a simple external violence, yet they are often the sign of a veritable callus, - that is to say, of the work of consolidation which has taken place at the point where the bone has been fractured in consequence of more or less intense trumatisms. Experience has demonstrated that incomplete fractures of the bone, imperfectly consolidated, may be rendered complete under the influence of muscular contraction alone. It is advisable, therefore, to defer the purchase of a horse which presents this blemish.

3d. Lastly, let us mention the lameness due to rupture of the tendon of the flexor of the metatarsus. This tendon, an integrant part of the muscle in question, extends from the inferior and external extremity of the femur to the supero-anterior extremity of the canon; it plays a most important mechanical rôle, in so far as it establishes an intimate connection between the morements of the metatarsus and those of the thigh. This tendinous cord, under the influence of the energetic efforts made by the animals to free themselves from their bonds when placed under such restraint as is used by the blacksmith in shoeing a vicions 
subject, or when their limbs get entangled in the traces, when they are down on the ground, or again under the influence of a forcible gliding backward of the foot, etc., may not withstand the straiu and may become ruptured. The simultaneousness which at first existed between the movements of the two above-named segments at once disappears. The flexion of the canon is no more synchronons with that of the thigh; the former sometimes remains pendulous or swings backward, and the tendo Achillis (rord of the hock) becomes relaxed and thrown into folds when the animal walks. As to the position of the limb in station, it is normal.

This lameness, which must not be mistaken for a symptom of fracture of the tibia, in spite of its appearance, is ordinarily not serious ; it simply incapacitates the animal for his work for six or seven weeks.

4th. We need only mention, in terminating, the excoriations which are rather frequent upon the legs of kicking horses. They are common on the internal face in those subjects that struggle and kick to disengage themselves when the nembers have been displaced over the shaft or the pole of the vehicle or the traces of the harness. The presence of these wounds, or their traces on the skin, should be a warning to the intending purchaser of some bad and vicious disposition in the animal which is offered to him.

\section{D. -The Hock.}

Situation; Limits; Anatomical Base.-The hock, in the horse, is analogous to the knee. It corresponds to the tibio-tarsometatarsal artieulations, supports the bones of the leg, and forms the centre of the chief movements of the foot.

Functionally, it is, more than any other, a region of dispersion of concussion as well as of propulsion. It is upon this region that the efforts of the extensor muscles which propel the body are concentrated; it is on this point that the reactions of locomotion bear at the moment when the body, moving with great relocity, and projected forward, strikes the ground; finally, this is the region on which, in the act of rearing, all the weight of the body presses down with such great force.

Under these different aspects its study is full of interest, as much in relation to animal mechanies as to that of pathology.

Let us examine with some detail the parts which eompose it.

The Bones.-The tarsus of the horse is composed of six small bones, sometimes seven, from a want of fusion of the median and small cuneiforms in one of them. Among these bones there are two whose volume and function are quite peculiar; these are the astragalus and the calcaneus. The first presents a very movable articular trochlea, or pulley, which is opposed to the inferior extremity of the tibia; the second, more salient and elongated, is situated behind the preceding, continues, by its direction, the canon, and forms a powerful arm of a lever for the extensor muscles of the metatarsus.

Underneath these two principal bones are found the four others, flattened from above downward, with numerous facets. They are very solidly united to the 
calcanens and the astragalus, the three pieces of the metatarsus, and play the rôle of dispersing agents for the weight of the body in movement.

Ligaments. - The bones of which we have spoken are joined in a most intimate manner to the adjoining structures, the tibia and the metatarsus, by capsular and funicular ligaments, which allow perfect freedom in the tibio-tarsal hinge.

Among these ligaments, two lateral, external and internal, unite the extemal and the internal tuberosities of the tibia to the head of the corresponding rudimentary metatarsal bones. They are elongated, rounded, unelastic, tortuous according to their length, and take successive attachments on the lateral surfaces of the bones which lie in their course.

Two capsular ligaments of unequal resistance protect the tarsus in front and behind. The anterior, somewhat thin and stronger ontwardly, extends from the anterior edge of the inferior articular surface of the tibia to the surface of the tarsal bones and the canon. It protects the synovial membrane in front. The posterior affects a general analogous disposition as to its attachments, but it is thin and membranous in its superior part in order to yield easily to morements of flexion, whilst in its centre and inferiorly it is reinforced by a plate of fibrocartilage, which serves as a gliding surface for the tendon of the deep flexor of the phalanges. It keeps in position the articular synovial membrane behind.

Articular Synovial Membranes.-Of the five tarsal articulations, only one is interesting from an external point of view. This is the tibio-astragaloid, which is lined by a special synovial membrane. Although this membrane is firmly maintained on the sides by the lateral ligaments, and in front and behind by the capsular ligaments described above, nevertheless, it presents certain weak spots which may possibly yield under the influence of the interarticular pressure from an excess of synovial secretion. These spots are three in number: the one

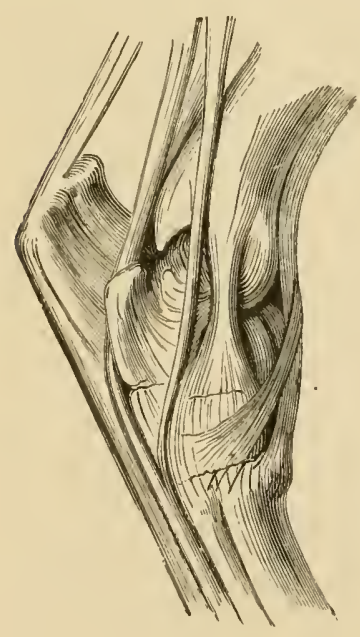

FIG. 76. antero-intermal, where the ligament is not protected by the anterior tibial muscles, the other two posterior, and situated above the reinforeing fibro-cartilage of the posterior ligament. Pressure applied to any one of these swellings will cause the liquid to flow into the others, a fact which demonstrates conclusively enough their intercommunication.

Tendons and Tendinous Bursæ.-The tendons of the various muscles glide over the bones and the ligaments of the hock by means of synorial bursæ, of which it is necessary to say a few words.

In front and on the outside, the anterior capsular ligament is maintained by the tendons of the anterior extensor of the phalanges and the flexor of the metatarsus, which is held by a fibrous aponeurosis in the bend of the hock; their movements are effected through the intervention of the underlying connective tissue.

On the ontside is the tendon of the lateral extensor of the phalanges, which a bursa of its own enables to glide through a duplicate of the external lateral ligament.

On the inside we find the tendon of the oblique flexor of the phalanges (Fig. 
76) having almost the same disposition along the internal lateral ligament, while below, supplied also with a special synovial bursa, the cunean tendon of the flexor metatarsi passes obliquely backward over the internal face of the hock; this, when in a state of abnormal distention, is capable, according to Bouley, ${ }^{\prime}$ of simulating a spavin by the enlargement that it forms under the skin at the very point where a spavin is located.

Finally, at the back, the tarsus is transformed into a fibrous envelope known as the tarsal sheath. Its anterior wall is constituted by the posterior ligaments of the hock; it is completed behind by an areh of fibrous tissue extending from the posterior border of the caleaneus to the inner side of the tarsal bones. It gives passage to the perforans tendon through the medium of a synovial membrane. The latter extends from the inferior fourth of the tibia downward to about the superior third of the canon. When this synovial membrane becomes dilated it forms two hernice superiorly in the hollow of the hock, one on the outer and the other on the inner side, posterior to the corresponding culs-de-sae of the tibioastragaloid articulation. It is also prolonged downward along the flexor tendons in the shape of a tumor of variable size, sometimes simulating curb.

The summit of the calcaneus also presents a little synovial gland, where the tendon of the gastrocnemius muscle is attached, to facilitate its gliding upon the aforesaid bones during extension and flexion of the metatarsus. This bursa, being very firmly sustained over its periphery, is not liable to beeome distended and form external dilatations. It is different, however, with the bursa which facilitates the play of the superficial flexor of the phalanges over the summit and along the posterior border of the calcaneus, and which almost entirely covers this surface. This tendon, after winding around that of the gastrocnemius, widens, becomes inflected orer the head of the calcaneus, almost completely enveloping it, and is then continued in the region of the canon. Now, it is for a distance of about five centimetres along the perforatus tendon in front of the summit of the calcaneus that the enlargement manifests itself when, from excessive seeretion of the synovial fluid, this membrane becomes distended.

External Conformation.-The hock is a centre of movement, whose perfect integrity is so important, as affecting the usefulness of the animal, that the eye should know and recognize its normal form in its least details.

This region is divided into four faces: an anterior, a posterior, and two lateral.

a. Anterior Face.-The anterior face (Fig. 77, A) corresponds to the summit of the tibio-tarsal angle; it has received the name of fold of the hock, and shows, on each side, the profile of the lateral fuees. It presents, outwardly, above and behind, the summit, $a$, of the calcanens; below this, the external tuberosity of the tibia, $b$; finally, below, the eminence, $c$, formed by the base of the calcaneus, the enboid and the head of the external rudimentary utetatarsil bone. On the inside, it offers the very prominent intemal tuberosity of the tibia, $d$; lower down, the internal tubercle of the astragalus, $e$; finally, altogether below, the prominence of the head of the internal metacarpal bone, $f$; in its 
middle is visible the tendons of the flexor metatarsi and of the anterior extensor of the phalanges, $g$; inferiorly, the groove, $h$, of the pulley of the astragalus; inwarlly, the saphena vein crosses this face obliquely from above to below, $i$; finally, still on its internal part, the unsustained portion of the articular synovial membrane, $k$.

b. Posterior Face.-This face (Fig. 77, B) is angular and constituted from albove downward: by the $\operatorname{cord}, l$, and the point of the hock, $a$; the posterior border, $a^{\prime}$, of the ealcaneus and the perforatus tendon. But, viewed from behind, the loock also presents: the profiles of the lateral faces, $b, n, c$, and $d, e, f$ (the same letters as in the preceding figure); the hollow of the hock, $m, m$, and the chestnut, $o$.

c. External Face.-This face is limited in front by a line which has, in its middle part, a summit, $h$ (Fig. $77, C$ ), corresponding to the astragaloid trochlea; behind, the line, forming the profile of this same face, is very angular at the level of the summit of the calcaneus, $a$, at a point known, in external anatomy, under the name of the point of the hock. Between the latter and the canon are seen successively: the posterior border of the calcanens, $a^{\prime}$; then the tendon, $t$; above the point of the hock is detached, very prominently, the cord of the hock, l, in front of which is seen a deep depression, $m$, called the hollow of the hock. This face, for the remainder of its extent, is undulated in its middle by three superposed processes: the superior is formed by the infero-external

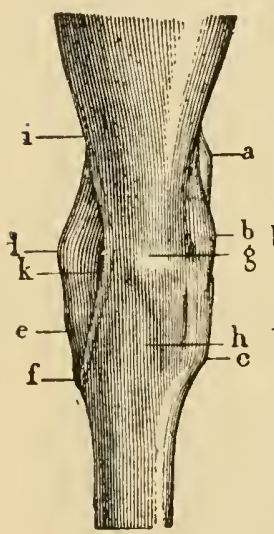

A

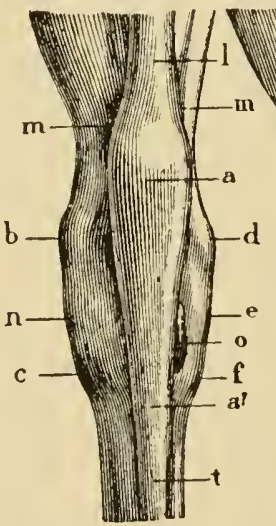

B

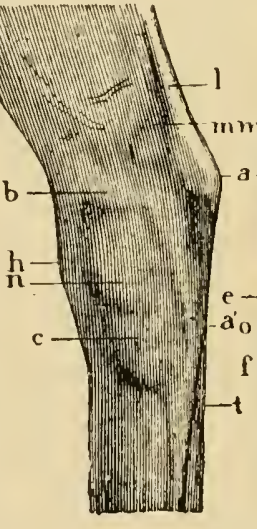

C

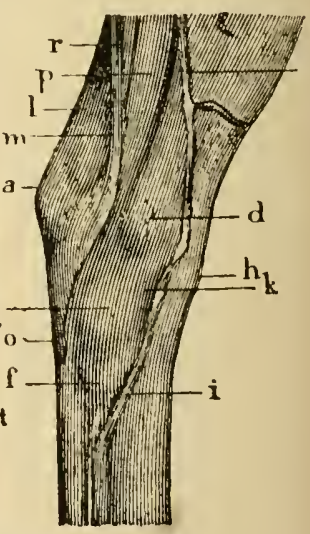

$\mathrm{D}$

FIG. 77.

tuberosity of the tibia, $b$; the middle one, more effaced, is constituted by the base of the calcanens, $n$; the inferior, $c$, corresponds to the cuboid and the head of the external rudimentary metatarsal bone.

d. Internal Face.-The internal face offers almost the same peculiarities as the external. It shows anteriorly the convexity due to the astragalus, $h$ (Fig. $77, D)$; posteriorly, the point, $a$, the cord, l, and the hollow, $m$, of the hock; in the centre and from above downward the infero-internal tuberosity of the tibia, $d$, the internal tubercle of the astragalus, $e$, and, finally, the large cuneiform and the head of the internal rudimentary metatarsal bone, $f$. But on this face are seen, besides: the muscular portion of the deep flexor of the phalanges, which 
is well outlined, $p$, over which are located numerous venous branches, $r$; the saphena vein, $i$; the chestuut, $o$; and, finally, the point, $k$, where the articular synovial is unsustained.

Such is the conformation which the normal hock presents when it is examined on its four faces. We have insisted much upon this, in order that the beginner may not mistake for ineipient blemishes normal eminences and depressions which are only the indications of one of the primary qualities of this region, its neatness of outline.

Examination of the Hock.-The blemishes of the hock, as soon as they become apparent, modify at once the neatness of its lines, which cannot deceive the attentive and educated observer ; it is not the same, however, with the student. We would therefore advise the latter to examine the region with eare in front, between the fore-legs, and behind, in order to determine the form of the profile of the lateral faces; then to view it from the side, to see the profile of the anterior and the posterior faces. When he has aequired a certain skill, he can attempt a more complicated but more rapid examination, which is called oblique or three-quarters, either in front or behind. The complexity and the greater rapidity of the oblique examination are readily understood, since, in such a case, the eye endeavors to appreciate, with the same glance, the two adjacent faces of the region.

Some persons claim that it is ridiculous to examine the hock by viewing it from between the fore members; others remark the same of those who, not contented with seeing with minuteness, insist, moreover, on feeling with their hands, the better to ascertain the facts. Such deference for the spectators' opinions would be very injudicions, and, moreover, a very bad example for beginners whose many-minded teachers are already so numerous. We are not aware that any one ever became possessed of science by intuition; in order to know a thing a man must have given himself the trouble of learning it.

Now, this book is especially prepared for the student, whom it is necessary to impress with this great truth, -namely, that, in the purchaze of horses, "he who does not open his eyes opens his purse wide!" Open your eyes wide, therefore, until you have aequired absolute certainty concerning what yom are examining, and by no means refrain from feeling with your fingers if needs be. We will never regret too much precaution in such a case, if we can thereby avoid committing an error; and in any case the purehaser will not be the party who will complain of it.

Whatever precautions may be employed, a careful examination of the hock always requires certain preparatory conditions in the animal. 
He must stand in such a manner that each of the four members supports its own share of the body-weight and lies in its natural axis. If this little detail is neglected, the eye will be deceived as to the true dimensions of the region and camnot compare the one side with the other, as we shall see in a future chapter.

Movements.-The hock is the seat of only two extensive movements, that of extension and that of flexion. The plane of these movements, on account of the obliquity of the astragaloid trochlea, is slightly oblique ontward, a disposition which, coinciding with a certain obliquity of the femur, permits the member to be extended without being restrained by its contact with the abdominal parietes.

There are, besides these principal movements, others, very limited, consisting of simple gliding of the contiguous bones, whose effect is to attenuate the locomotory reactions, and which are, in the case of the hock, an apparatus of dispersion analogous to that of the knee.

When leaving the state of repose, the foot is always more abducted in flexion than in extension, and both are exeented with the most perfect regularity. When, however, the articulations of the member are diseased, whether those of the leg or those of the hock, as deduced from the obscrvations of Rigot and from our own, flexion is sudden, jerking, exaggerated, and sometimes so extensive that the anterior face of the fetlock almost touches the parietes of the abdomen. This phenomenon constitutes string-halt or dry sparin; but the hock offers no trace of external deformity. We will again revert to this on the subject of the gaits.

Finally, when, at the moment of contact, the points of the calcanei are turned ontward by a sort of rotation, of which the foot is the centre, the horse is said to have rotating hocks. (See Graits.)

The Hock as a Centre of Amortissement and Impulsion.-This region is one of the most energetic centres of impulsion in the posterior member. It is by its aid that the tibio-tarsal angle can suddenly open in order to project the body forward at the end of the phase of contact.

The quantity of movement of the body, after being first disseminated upon the bones and the ligaments of the coxo-femoral articulation, and secondly upon those of the femoro-tibial union, is then transmitted to the tibio-tarsal articulation, where, a certain portion having alrearly been destroyed, it is again dispersed upon the tarsal bones and their ligaments. The combined action of the weight of the body and its velocity results in a diminution of the tibio-tarsal angle as well as of the other angles in the superior part of the member. In the hock, as 
elsewhere, the extensor muscles hinder this closing of the angle by acting in the mamner of a lever of the second class, or that of force. The canon, which is a portion of the arm of this lever, takes its point of contact upon the soil by means of the foot, and receives the weight of the body upon the astragaloid pulley, while the power, represented by the gastrocnemins and the perforatus muscles, maintains the equilibrimm of this weight by strong tration upon the extremity of the calcaneus.

A fact here strikes the mind of whoever considers the nature of this power, that it has to overcome at every moment a resistance of more than 100 kilogrammes! It is its relative feebleness; it is the small volume of the fleshy body of the gastrocnemius and the perforatus muscles, and even of the perforans, which can also sustain the tibio-tarsal angle; it is the small volume of these agents, compared with the powerful muscles of the croup and the thigh, which Professor Lemoigne justly regarls as a key to the rigidity of the member,-a key without which all the other extensors would be deprived of their fulcrum or point of support. ${ }^{1}$ It seems that there exists here an enormons contradiction between the means at the disposal of the organism and the effects which it is to produce.

This inconsistency is only apparent, and disappears as soon as we examine the mode of proceeding by which the extension of the hock is effected. By reason of the comnections which exist between the femur and the calcanens, through the interven-

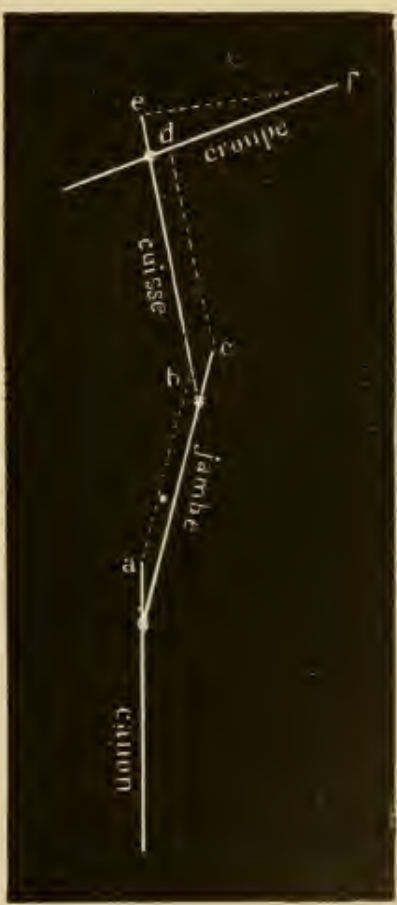

FIG. 7S. tion of the cord $a b$ (Fig. 78), the opening of the femoro-tibial angle cannot take place without producing coincidently and in the same proportion the opening of the tibio-tarsal angle.

As the opening of the former may depend upon the straightening of the femur or of the tibia, under the influence of their proper extensors, $e f$, $e d$, it follows that all muscular traction exerted on the summit, 
$e$, of the trochanter, or on the summit, $c$, of the patella, is communicated also in the same sense and with an equal intensity to the summit, $a$, of the calcaneus.

It is thus that, in spite of their distance of separation, the extensors of the femur and of the tibia participate in an indirect manner in the extension of the canon,- - that is to say, in the maintenance of the tibio-tarsal angle, owing to the mechanical role of the cord of the hock. This remarkable synergy or correlation in the extension of the articular angles of the posterior limb explains the vigor, precision, and suddenness of the propulsive movements of this member during locomotion. It also accounts for the true action of the gastrocnemins, the perforatus, and part of the tibial aponeurosis, which thus become agents of transmission in common with the muscles of the croup, the stifle, and the leg, enormous muscles, acting together and simultaneously to overcome the inertia of the body and to propel the latter forward.

Thus the organization of this cord responds admirably to the function which is allotted to it. Being composed of two voluminous tendons, that of the perforatus and that of the gastrocnemins, twisted one upon the other, reinforced by a thick lamina of the tibial aponeurosis, and, finally, attached to the summit of the calcaneus, this cord acts, besides, almost perpendicularly to the extremity of one of the longest lever-arms in the economy. The tarsus, from the number of its bones, the smallness of their dimensions, the strength of their means of union, the tennity of their movements, becomes finally the instrument which receives the force, transmits it, attenuates it, disperses and decomposes it without inconvenience to the living machine, on condition, however, that this base be constituted according to the mechanical principles which we are about to explain.

Beauties.-The lock, to be well formed, shonld be neatly outlined, lean, wide, thick, well openerl, and well dirceted.

Neatness of Outline.- The hock is said to be neat and nicely cut out when it reproduces exactly the shape which we have described above. It is, in this case, exempt from blemishes, and its hollow is very pronounced.

Leanness or Dryness. - This region is, moreover, qualified lean or dry when all its normal elevations and depressions are well marked and covered by a fine, supple skin, adherent to the adjacent parts. The neatness of outline indicates the somdness of the pices of the tarsal apparatus; its leamness, on the contrary, implies the pureness of the breed, the fincness of the constitution, and the energy and excitability of the individual. In subjects of a lymphatic tem. erament, as 
in those of the North of France and some of the districts of the West, the skin and the hairs are thick, the subentaneons connective tissue abundant, and all the osseous reliefs more or less effaced. These animals frequently have a fut, full, doughy hock. We must not confound this state with an absolutely blemished condition of the parts, for we should thereby frequently be liable to discard many excellent horses, in which, on account of the race, the climate, and the soil, it is impossible to obtain the dry hock which is usually observed in horses of meridional countries, above all in the finer races.

Width.-The width of the tarsus is an absolute quality, but in order to appreciate the same it is indispensable that the members be stationed in their normal axis. It is measured from the point to the fold of this region. It will be readily understood that, if the canon be placed well under the trunk, for example, this dimension will appear more considerable in eonsequence of the diminished obliquity of the calcaneus upon the tibia. It is precisely on account of this possible error, resulting very frequently from a defect in the vertical axis or a variable obliquity of the leg, that deception as to the width of the hock may arise, and the latter is not always-far from it - the expression of the length of the. calcanens, even as many think. With H. Bouley, we should recommend the intending purchaser not to be satisficd with the one dimension indicated above. He should, moreover, appreciate the distance comprised between the cord and the anterior profile of the leg on the one part, and the perforatus tendon and the anterior profilo of the canon on the other. In other words, it is absolutely necessary to ascertain the width of the hock above, in the middle, and below. If these three conditions are not fulfilled the region camnot be qualified wide, for it is eminently defective from the very disproportion of its parts.

It is ordinarily at the inferior extremity, at the level of its base, that the region shows an abnormal narrowness, owing to which it is styled strungled. The tarsal bones of the lower row are, in this ease, not in relation, in their development, with the dimensions of the astragalus, the tibia, and the ealeaneus; ahove all, with the last, which lowes none of its power and acts, by this very reason, with so much more force upon the ligaments which unite it to the metatarsal lever, of which it really constitutes the superior extremity. Such a hock, therefore, beromes blemished very soon, and should he rejected for very severe services expected from the saddle- or the dranght-horse.

When the region is deficient in width orer its whole area. it is called slender, narrow. This is, we believe, a serions defert, although 
there are some anthors who excuse it, and even class this form of hock among the good conformations. We can only admit one thing or the other: either the width is an absolute beanty or it is a defeet. If the former of these opinions be adopted, it is plain that the same qualities cannot be attributed to the narrow hoek as to the wide hock, which is exactly the reverse. This is, nevertheless, what the authors of whom we speak have done, unknown to themselves, although the inconsistency of such a theory is at onee apparent.

The width of the hoek, in reality (we suppose it well directed and well opened), implies :

1. The separation of the caleanean eord, which, in its turn, depends upon both the volume of the posterior muscles and the length of the calcanens (superior width).

2. The antero-pusterior diameter of the tibio-astragaloid articulation and, here again, the length of the caleaneus (middle width).

3. Finally, the antero-posterior development of the inferior row of tarsal bones (inferior width), which is tantamount to saying that a wide hoek commands a well-muscled leg; a well-direeted tarsal cord in relation to the arm of its lever, which is, in addition, powerful of itself on aceount of its great length; large artieular surfaces secmring, conseguently, much amplitude to the movements of extension and flexion; finally, a solid union with the metatarsal eolumn, whose width is evidently correlative.

The slender, narrow hoek presents a eonformation precisely the opposite. It is, therefore, for inverse reasons, lefective, which is indeed confirmed by observation. A strange sophism would be committed, unknown to himself, by the man who would argue the usefulness of so powerful a hoek associated with a weak croup and bad loins. ${ }^{1}$ The solidity of one region, it is true, can sometimes exaggerate the feebleness of another; but this is not the case in the example under consideration. If sueh a croup or such loins transmit the impulsion badly, what will the impulsion be with a narrow hoek? The two defeets will be superadded to each other without any chance of compensation !

Thickness.-The thickness of the hock is measured from one lateral face to another. It is appreciated by examining the region in front, behind, or obliquely, if one has more experienee and a more practised eye. Like the width, we must view it above, in the middle, and below, in order to assure ourselves that there is a proper correlation 
between the development of each of these secondary parts. The thick hoek merits this name and is truly beautiful only on cundition of its great transverse diameter at the level of the tibia, the astragalus, and the superior extremity of the canon.

The tarsal thickness indicates that of the leg, of the canon, of the fetloek, and of the pastern. It bespeaks perfect steadiness and equilibrium in every part of the hind limb; while its brealth las the entire command of the extent of the movements, the latter taking place backward and forward and vice verse.

It is evident, however, that this thickness in the dranght-horse, for example, should not be compared to that of the thoroughbred, two types essentially different. In the one, the bones are voluminous, short, and the muscles powerful; in the other, the bones are long, relatively slender, and the muscles long. If each requires, with equal propriety, wide and thick articulations, absolute beanties applying to all services, still it is necessary that the proportions and the general harmony should not suffer thereby.

Extent of the Tibio-tarsal Angle.-As the hock is practically only one articulation, the summit of an angle, it is not useless to inquire if its degree of openness is capable of influencing the functions of the parts, and if this angle, once determined, can owe the separation of its branches to a greater or lesser inclination of the one or the other of them. In other terms, what is the value of the tibio-tarsal angle, and what is its orientation on the member to be in the most farorable attitude for the development of force or the display of velocity?

Most writers have endeavored to answer this question by advaneing theoretical views insufficiently based on facts. Hence their writings contain numerous contradictions. We think we have been more logieal in studying first very beantiful models, with a view of reasoning afterwards more easily in the particular cases which present neither an absolute beanty nor a veritable defect, and which are so often met in practice.

Iismissing for a moment the obliquity of the leg, let us remark that the angle of the hock molergons more or less the influence of the three metatarsal directions, as follows:

a. The eanon remains vertical.

b. It is oblique forwarl and downward.

c. It is oblique backward and downward.

We will suppose, in each of these instanees, the point of the hork tangent to a vertical line which would start from the point of the buttock, as we remark it in the member with a normal axis. (Sce Axes.)

a. The Canon, Vertical.-The eanon in this case is tangent 
throughont its entire length to the previously-cited vertical axis. This position of the member is the most favorable to the proper execution of its locomotory function, as we will verify ì propos of the vertical axes. It belongs, besides, to all properly-eonformed horses, whatever may be the service for which they are destined.

The tibio-tarsal angle, moder this premise, can be more or less open according to the situation of the tibia which constitutes its superior branch. Whence, consequently, there follow two secondary propositions with regarl to the direction of the latter segment.

1st. The Tibia, Straight. - IV e will designate thus a tilia whose obliquity is little marked (abont 65 to 70 degrees). The hock which corresponds to it is ealled straight; the angle which it forms is very

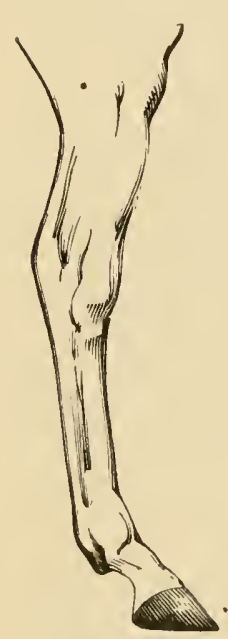

FIG. 79. open (Fig. 79). A similar conformation is favorable to velocity or speed, for it allows long strides, during which the ealcanens beemes more and more perpendicular to the muscles that have to move it. Besides, the foot, on arriving on the ground, is more strongly flexed upon the leg, which gives the hock a more energetic and extensive impulsion.

Rumning-horses ordinarily have this region thus disposed; their tibio-tarsal angle is abont 15.5 to 160 degrees, as we have already seen in treating of the leg.

The observer is easily deceived as to the witth of the straight hock on aceount of the direction which the caleaneus here affects. On that aceount it is necessary to observe the length of this bone during walking. But it is an error to believe that this hock, implying but little inclination of the tibia, necessarily violates the vertical axis by placing the limb more under the trunk. It suffices, to convince ourselves of the contrary, to observe the thoroughbred horses, which have in nearly all instances a marked opening of the tibio-tarsal angle, and to make measurement;, as we have done, upon their articular angles; it will then be rerified that their axes are perfectly normal on account of the suitable direction of the eroup and the thigh.

The straight hock, which it seems should produce much fatigne to the animal from the little perpendicularity of its cord upon the alcanens, is precisely so disposed in order that the deficient muscular contraction may not interfere in a great measure. As H. Bouley ${ }^{1}$ has 
remarked, "when the pieces of a freshly-dissected hock are moved, it is easy to recognize that, towards the limits of its movement of extension and flexion, the angle opens and closes by a sort of springlike action, which cannot be better compared than to that of the blade of a pocket-knife upon its handle. The articulation, being once opened, the two segments will remain in this state of extension by the very fact of the manner of coaptation of their surfaces of contact, and the intervention of a muscular force to maintain them vertically is not at all necessary."

The straight hock, finally, possesses this advantage from a point of view of speed, that it is usually associated with long posterior members capable of taking long steps. Supposing the lengths of the crural, tibial, and metatarsal segments to be equal, it is evident that their superposition, in a more or less vertical manner, will give a more considerable total height to the member than if these pieces are joined in a more oblique manner. Whence it follows that a horse having his bones thus articulated will have his locomotory apparatus more developed relatively to the body, and hence will be endowed with greater speed.

2d. The Tibia, Oblique.--The first effect of such a direction is the closing of the tibio-tarsal angle, allowing less freedom to the movements of flexion than if this angle were more open. Another effect is a more perpendicular insertion of the cord of the hock, which places the latter in the best conditions for the proper utilization of its force. The last result is a lessening of the total length of the posterior member and a proportionate diminution of the aptitude of the organism in relation to speed.

Thus conformed, the animal is closer to his base of support; the hock is strong, and its muscles well disposed; but the step is shorter on account of the smallness of the tarsal angle and the diminished length of the member. All things being equal otherwise, the gait will be less rapid, unless it makes up by the repetition of its movements for the space and time lost at cach stride, which will fatigue the animal and wear him ont more quickly ; but if the step lacks amplitude and the member length, the muscles may be more voluminous, the body developed, and the total mass considerable. The animal being then capable of the most cnergetic efforts at a very slow pace, the quantity of movement $(\mathrm{me})$ produced will not be less, because it will displace a greater weight with more feeble velocity. Poorly adapted for the turf, he will be excellent for traction, provided that his conformation has been modified in the sense which we have indicated. 
The hoek with a small angle, which we will call common, beeause it is ordinarily met in horses for light-draught and rapid hearydranght services, is, in our opinion, more favorable to the production of force. Does this mean that the straight look is defective for all laborious services, and that it is only observed in long-striding horses? By no means. It is rather frequently seen in our heary, lymphatic horses, which our measurements have proved; it should not, in such eases, be considered as defective unless it at the same time lacks width, which is not rare, or unless its deficiency is not compensated by a muscular and powerful leg.

b. The Canon, Oblique forward and downward.-This conformation, in which the canon is deviated in advance of the verti-

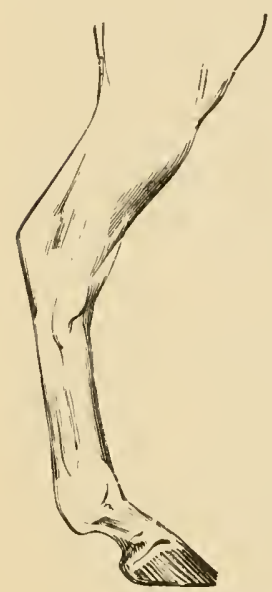

FIG. 80 eal line falling from the point of the buttock, has caused the hock to be qualified elboved or angular (Fig. 80).

This hock, says H. Bouley, "always appears wide in its superior part, hecause its angularness results in a separation of the calcanens from the tibia and, consequently, places the calcanean cord at a greater distance from the latter bone; whence a widening of the cxternal surface. This bending of the region, besides, also laas the effect of placing the arm of the calcanean lever in the most favorable condition for the prodnction of force.

"But, by the side of these advantages, real disadvantages present themselves, which give ample reasons for considering this conformation as being defective. First, the column of support below the tibia being situated obliquely, it results that the pressure of the weight of the body, instead of being transmitted to the ground by the bones exclusively, as in the vertical position of this segment, eauses a strain, proportionate to the degree of the obliquity, on the ligaments which unite the tarsus with the metatarsus as a whole, and imposes upon them an alnormal function. In addition, these ligaments, during locomotion, are subjeeted to all the greater strain, becanse the muscular force finds, in the direction of the talcanean lever-arm, more favorable conditions for its development. These are two canses which fatigue the apparatus of the hock more and hasten its premature ruin. Experience bears witness to this 
effect. Nothing is more common than to witness, at the base of elbowed hocks, the development of osseons tumors, which are the expression of the excess of its function, to which such hocks are predisposed from the very fact of their defeetive conformation. We can understand that this defect will tend to become more exaggerated when the hock, instead of corresponding to the rertical through the buttock, is situated farther under the centre of gravity. Horses whose hocks are angular are often animals of superior quality so far as energy for work is conecmed, and are, consequently, predisposed to ruin themselves so much more quickly, as the apparatus npon which they apply their force possesses less favorable conditions for resistance."

The learned author of this quotation might have added that the angular hock, by drawing the inferior part of the member towards the centre of gravity, by causing an exaggerated closing of the tibio-tarsal angle and too great a stretch of the foot forward under the trunk, determines, besides, an overloading of the posterior members prejudieial to their functions. It augments the work of the extensor museles of the metatarsus during station, diminishes the amplitude of the step by restraining the movement of flexion, and, finally, expends to no purpose a part of the effort of impulsion to elevate the trunk instead of carrying it directly forward.

Such a hock should, for these reasons, be rejected in spite of its apparent width, for it is the result of an imperfection in the axis of the member which will soon ruin it.

c. The Canon, Oblique downward and backward.-This direction of the canon places the posterior member in the attitude which is called camping, and which alproaches somewhat that of the animal when he urinates. We will have occasion to return to this in discussing the axes. Let us say, for the present, that it places the members in a very unfavoralle condition to fulfil, with ease, their functions as columns of support and as agents of impulsion, relatively to the trunk. It removes them ton far from the centre of gravity, transfers a corresponding portion of the body-weight upon the anterior members and the loins, and renders the impulsion more feeble and less extensive; it predisposes to gliding backward, fatigues the animal more, leads to sway-backedness, etc. (See A.res.)

We must not confound this conformation with that which is proper to a straight hock. The femoro-tibial and tibio-tarsal angles, in the latter ease, are open, but the natural axis of the limb is preserved, while, in the horse camping behind (only fiom the hock down), the tibia remains very oblique, whilst it leaves the tibio-tarsal angle very 
large and disturbs the normal axes. Whence it follows that this angle is badly disposed for the functions of its branches during locomotion, and even tends to resist the efforts intended to draw them towards each other during station. Its bisectrix, if prolonged to the ground, meets the latter at a point insufficiently distant from that where the hind feet effect their contact, and the eonsequence then is that the angle is quite as barly opened for the production of speed as for that of force.

Direction of the Hock.-The direction of the hock must be studied from two different points of view : in relation with the median plane of the body and in relation with the axis of the member.

1st. Direction Relative to the Median Plane.-Relative to the median plane of the body, the hock can assume three situations, -namely :

It is parallel and thus well directed.

It is deviated inward and qualified close or cow-hocked.

Finally, it is deviated outurard, which renders the horse open behind.

In order to have its normal direction, the hock should be parallel to the median plane, for its branches are flexed and extended upon each other in a plane equally parallel, not to speak of the normal deviation which the inferior part of the member affects during flexion. In this case the impulsion given by the posterior limbs is transmitted, without lateral oscillations, to the spinal column, whose direction it follows, and there is no waste of force in the projection of the body. The play of the extremities is easy ; the ficet are not predisposed to interfering; their contact with the ground is uniform ; the gait is free, regular, brilliant, and the tarsal apparatus will withstand a prolonged service.

When the hocks are close or crooker (Fig. 81), their points, when viewed from behind, converge, and the inferior part of the members is deviated outwald. The horse is then designated rou-hockerl, or clowehammed; his movements are without elegance, althongh the conformation is often associated with very great qualities.

If, on the contrary, the points of the hocks (Fig. 82) are diverging, the lower part of the member is turned inward ; the animal is open, or too open behind, in view of the great separation of the two calcanei.

We will cxplain, when treating of the axes of the members, the disadvantages of these defects, which give to such subjects the most ungraceful gaits imaginable.

2d. Direction Relative to the Axis of the Member.-In 
order that the tarsal apparatus may fulfil its functions well, it is not enough that it should be in a plane parallel to the axis of the body, but it is also necessary that the median line of the member divide it into two very equal moieties. If this condition be not realized, the

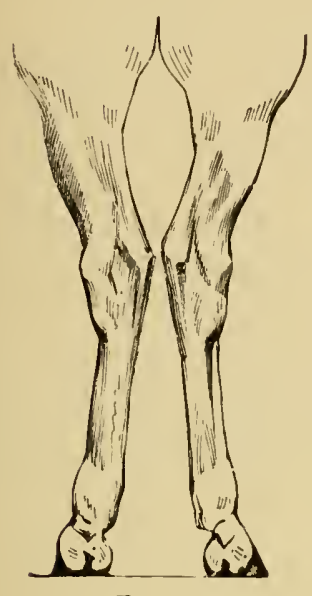

FIG. 81 .

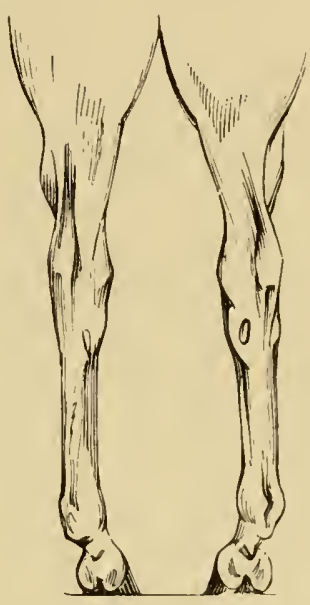

FIG. 82.

region of the hock is displaced inwardly or outwardly, and becomes the seat of irregularities in its contact more or less prejudicial to the integrity of the locomotory machine.

When the hocks are strongly eonvex on their internal face from above to below, they are most ordinarily angular in front, and the animal is close behind.

The deviation opposite to the latter, and common in horses too open behind, consists in a rather strongly-marked concavity of the whole of the internal surface of the member, in virtne of which the calcanei become very diverging, while the two howfs, nearer each other than they should be, converge and even tonch each other in the region of the tocs. A horse offering this conformation conld be called bourlegged, on account of its analogy to the aipert of the man whose legs are thus direeted. In both forms the hock does not give the natural impulsion to the body, and the members move in a very ungraceful mumer. (See Axes of Members.)

Diseases and Blemishes.-The alterations of which the hock may be the seat, salys H. Bouley, ${ }^{1}$ are numerons, varied, and often of extreme gravity. They may affect any of the constituent parts of 
this complex apparatus: the bones, the synovial membranes, the ligaments, the tendons and their sheaths, and, finally, the subentaneons tissue. The skin itself is sometimes affected, but only in a mild degree, as compared with the intrinsie pieces of the region.

The number and gravity of these lesions are readily explained by the important role of the hock in the function of locomotion.

Following the method of H. Bonley, we will study them by passing from withont to within. They exist, in fact, upon the skin, the connective tissue, the tendons and their bursa, the bones, and the tibiotarsal articular synovial membrane.

a. The Skin.-The point of the hock is quite frequently the seat of denudations and excoriations, whose presence should attract the attention. Such wounds, by reason of their locality, are often an index of the vicious character of the amimal, or of his irritable disposition. They result from blows, kicks, kicking, and are particularly common in irritable mares which are continually urinating. They are sometimes followed by accidental white markings in subjects with dark-colored extremities; at other times by cicatrices of a variable configuration, visible on the outside, covered by the surrounding hairs, or fraudulently hidden by a colored coating.

Traces of cauterization, in points or in lines, which are seen on blemished hocks should induce one to ascertain whether the affection for which the cauterization has been employed has entirely disappeared, or whether the region is improved in a manner to permit of a better utilization of the animal.

It is in the fold of this hock that the most serious cutaneous lesions are observed. They consist of transterse fissures, known under the vulgar name of sallenders, occasioned by external irritation, con-

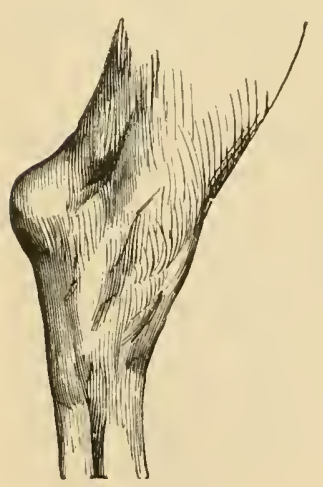

FIG. 83. tinual friction, or the application of a vesicant. Primarily benign, sallenders soon becomes complicated in consequence of the incessant movements of the parts, and also other causes, such as the humidity, the elevation of the temperature, uncleanness, etc. It then becomes a wound, rebellious to eicatrization, with thick, indurated borders, covered with scabs, and always very painful during the hot seasons.

b. Connective Tissue.-The subcutaneous connective tissue at the point of the hock, under the influence of contusions and repeated frictions, becomes infiltrated with serum, and forms at the end of a certain time a soft, fluctuating, sometimes codematous, non-inflammatory tumor designated under the names capped hock and capellet ${ }^{1}$ (Fig. 83).

Capped hock is nothing else but hygroma of the summit of the calcaneus. Its greatest inconvenience is the deformity of the point of the hock, but it occasions no lameness. It constitutes none the less quite at

1 ". The first of these names is without doubt derived from the fact that the tumor has been compared to a small eap adorning the head of the culcaneus." (H. Bouley.) 
serious blemish in pleasure-horses, on account of the deformity which it produces and the tenacity with which it resists the means employed for its resolution. It must not be confounded with the purely accidental cedema of this part in horses standing in the stable for a long time, which disappears promptly under the influence of exercise.

c. Tendons and Tendinous Synovials. - We will mention, in passing, the rupture of the tendinous portion of the Hexor metatarsi, of which we have already spoken in the article on the leg, and which gives rise to a lameness of a special character.

We will also name an accident,-an exceptional one, indeed,-luxation of the calcanean attachment of the perforutus. In the two known cases, the tendinous portion of this muscle had ruptured its insertion on this bone from a very violent effort of traction, was dislocated externally to the point of the hock, and produced so visible a deformity that the animal could not have been offered for sale.

It is the same with the ossification of this caleanean cap, as well as of a portion of the tendon itself, which we have observed, on one occasion only, in an old horse that was sacrificed for dissection, and whose hock we deposited in the Department of Collections at the Alfort School.

These lesions have no other interest than their rarity. A different ease, however, is that of the abnormal dilatations of the synovial sheaths which facilitate the glicling of the tendons in the region of the hock. These are, on the contrary, most common, always very grave (some of them at least), with regard to the depreciation in the value of the animal. They are known under the generic name of tendinous hygroma or tharough-pin.

The most serious among them is undoubtedly that of the tarsal sheath, which, for this reason, has received the name of tarsal or temlinous thorough-pin. It is characterized by subcutaneous tumors, which appear at the superior or at the inferior part of the hock, at the points where the synovial meubrane has no support. The superior dilatation is situated in the hollow of the hock, immediately in front of the tendo Achillis or cord, and along its course. More salient on the internal side, it is sometimes bilobed, and may reach the inferior fourth of the leg. When it is very voluminous, pressure exercised upon it will not force the liquid to the anterior face of the hock, because the tarsal sheath does not communicate with the articulation; but such pressure, being transmitter to the swelling at the inferior part of the hock, renders them more apparent.

These tumors, less developed than the preceding one, and less distinctly outlined in conserquence of the thickness of the walls of the sheath, follow the course of the flexor tenclons to the superior third of the canon.

"Tarsal thorough-pin," says H. Bouley, "is susceptible of acquiring enormous dimensions, particularly on the internal side. It has been seen to he enlarged in such proportions that the space between the two members was no longer sufficient for their normal movements, and the skin over its surfice was excoriated from the constant friction against the opposite bock during the movements of locomotion."

The synovial bursa which facilitates the gliding of the expansion of the perforatus upon the summit of the calcaneus is also capable of becoming dilated to an abnormal degree. Although very strongly attached here, it can yield to the pressure of the liquids from within, forming along the cord of the hock an 
elongated, cylindrical tumor, ordinarily of a small volume, and about ten centimetres in lengtls. This is called calcanean hygroma.

H. Bouley observed with justmess that the synovial cul-de-sac which permits the gastrocnemius tendon to glide upon the summit of the calcaneus, during the movements of extensive flexion, is so powerfully supported by the expansion of the perforatus that it is absolutely impossible for it to dilate in the form of external enlargements. He adds, with equal accuracy, that this synovial cannot in any manner give rise to the tumor which we have studied above under the name of capped hock.

Finally, it is also possible to meet hydropsy of the small bursa which facilitates the gliding of the cunean tendon of the flexor of the metatarsus over the surface of the internal lateral ligament. It presents a small, soft, fluctuating tumor of the size of a large bean, situated in front of the point where the exostosis of a spavin usually forms and for which it is sometimes mistaken. This dilatation has received the name of cunean hygroma, on account of its location in relation with the tendinous branch under which it is developed.

d. Articular Synovials.-It is rather common to meet upon the astragaloid pulley and in the corresponding grooves of the tibia more or less deep multiple striæe or fissures, perfectly regular, and all of them parallel to the lips of the astragalus. These strice of the articular surfaces are most common in old horses. They are, without doubt, due to some slow and obscure irritation of the tibio-tarsal joint, and correspond probably to a special irregularity of its movements; but clinicians at present have not determined in a precise manuer the external symptoms of this variety of lesions, which should consequently be investigated. (See Defects of the Gaits: String-halt.)

The most serious alteration of the tibio-astragaloid articulation is consecutive to a hydropsy of its synovial membrane. The synovia, under the influence of an excessive functional activity on the part of this membrane, is secreted in larger quantity in the articular eavity, and, in the long run, exercises pressure from within which, little by little, dislocates the parietes of the articular cavity. But as the latter are not equally sustained everywhere, the places which offer the least resistance to the internal pressure are distended beyond their physiological limits and produce a hernia, by forming under the skin three tumors whose position is stationary, whose volume and tension alone change aceorling to the intensity of the alteration. These three tumors constitute what is called articular thorough-pin of the lock.

The first of these is located in the fold of the hock and a little to the internal side. It molifies the profile of the anterior face of this region by the presence of an abnormal curve, yielding, and always more tense to the finger when the member is on the ground.

The other two articular dilatations are situated behind and above the lateral ligaments, between the tibia and the perforans tendon. They have a viriable volume, which ranges from that of a walnut to that of a child's head; the internal is most frequently larger than the external, which is sometimes absent. The presence of one of these constantly coexists with that of the anterior swelling, and that is what we might expect, since all three are only diverticula of the same cavity. Pressure exercised upon one of them is communicated to the others.

The synovial dilatations are, in general, less grave than the osseous tumors. 
They may for a long time remain compatible with the liberty of the movements. They (the articular especially) lame the animal only in cases of abundant hypersecretion of synovia and excessive tension on the surrounding tissues. Their parietes, in long-standing cases, become thickened and calcified in places, restraining greatly the tarsal movements. When the calcification is very extensive, it constitutes a false anchylosis of the articulation, which renders rapid locomotion absolutely impossible.

e. The Bones.-The osseous blemishes in the region of the hock have received different names. They are: curb, spavin, and jarde.

1st. Curb.-Curb (Fig. $84, B$, and Fig. $85, A$ ) is a periostitis of the inferointernal tuberosity of the tibia, which is developed under the influence of external violence or excessive strain of the articulation. It is characterized by the formation of osseous layers, which are disposed in regular strata upon the tibial tuberosity, over the surface covered by the attachment of the internal lateral ligament.

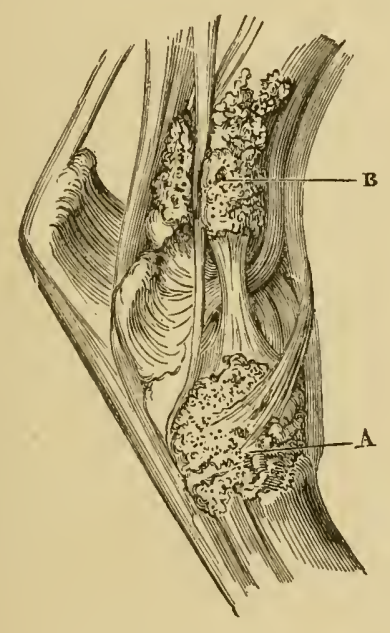

FIG. 84,

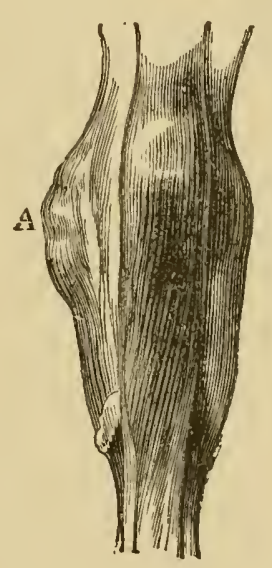

Fig. 85.

This formation offers a Iongitudinal groove in which the tendon of the oblique flexor of the phalanges glides and manifests itself extemally by a curve, more pronounced than in a normal state, when this face is viewed from in front, behind, or obliquely. At the beginning, it is often difficult of recognition from its fecble dimensions, which render the comparison of the two hocks necessary. Unless they are both blemished, it is generally easy to determine the presence of such a neoplasm, for it is exceptional that the two enlargements should be absolutely identical in relation to their form and volume. Curb only occasions lameness during its formation; when it is once developed, the lameness disappears. Nerertheless, there are some which from the volume which they attain cover up the margin of the tibial articular surfaces and interfere, more or less, with the freedom of the movements; in such cases they are all the more grave, as they are rebellious to all means of treatment.

2d. Spavin.-The term spavin should be reserved to denote a periostitis at the lower and internal part of the hock (Fig. St and Fig. 86, 1 ). It involves 
most usually certain bones of the tarsus and of the metatarsus covered by the expansion of the inferior extremity of the internal lateral ligament of the articulation, - that is to say, the head of the rudimentary metatarsal bone, a small

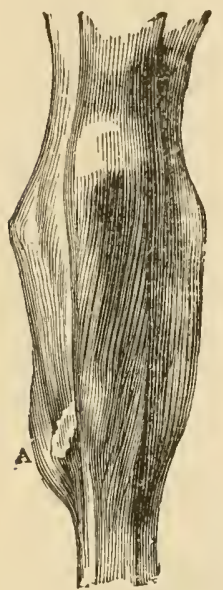

FIG. 86 . portion of the principal metatarsal, the cuneiforms, the scaphoid, and even the base of the astragalus. Frequently, however, it is much more circumscriber, which has led $\mathbf{H}$. Bouley to speeify as metatarsul, or low, the spavin which is situated at the upper extramity of the canon, and as tarsometatursal, or high, that i hich affects the bones of the tarsus as well as those of the metatarsus.

The first is manifested externally as an exaggeration of the eminence formed by the head of the internal splint bone, or, agaim, when it is more anterior, by the greater volume of the tuberosity of insertion of the flexor muscle of the metatarsus. Sometimes it is complicated by a splint on the canon, in consequence of the abnormal ossification of the interosseous ligament which unites the rudimentary to the principal metatarsal bone. Whatever may be its exact seat and its volume, which are susceptible to variation, metatural spavin ordinarily occasions only a temporary lameness, which ceases, in most instances, after a certain lapse of time, when the work of ossification is completed.

As to tarso-metatarsal spavin, its gravity is very different and its frequency much greater. It constitutes, in fact, a kind of exostosis which solders the inferior bones of the tarsus to one another and to the metatarsus. It is at first limited to the periphery of the articular margins, but progressively invades the articular surfaces themselves. The latter complication, whose evil effects are easily understood,-in one word, true anchylosis,--does not always exist, even in the case of very voluminous exostoses. We have examined the articular surfaces in a number of instances in old horses, and found them still intact. Such a lesion does not, as can be perceiverl, completely annihilate the movements of the tarsal articulations, and, consequently, lessens the gravity of the prognosis which may have been deduced from it.

Bone sparin, at the beginning of its formation, and before the appearance of the external tumor, determines a lameness, generally very intense, upon the nature of which it is almost impossible to decide with certainty. The lameness which follows has no pathognomonic character, even when it is accompanied by the jerk of string-halt. It is only at the end of a certain time that the exostosis is manifested in profile upon the internal side of the hock. Its volume and its seat are, in such cases, very variable. Som times scarcely distinct, sometimes very well defined, it projects inward, forwad, or backward from the articulation. In rather frequent cases the lameness at this period diminishes in intensity or disappears entirely ; but in most instances it persists and remains in relation with the extent of the tumor. Its characteristics are no longer the same; the animal suffers less pain and the limp seems to be due more to the mechanical difficulties which the tarsal bones experience in their displacements. However it may be, it is apparent that the gravity of the prognosis varies with the nature of the articular lesions, the obstacles offered to locomotion, and the persistence and tenacity of the rational symptoms to which the blemish is heir. 
3d. Jarde.'-Jarde (Fig. 87) is not, as every one wrongly belieres, an osseous tumor, reproducing identically, upon the external side of the hock, the enlargement which a spavin forms on the internal side of the same region. It is simply a more or less extensive periostitis of the head of the erternal rudimentary metatarsal bone. This lesion is very often complicated by a splint, as in the case which we represent (Figs. 88 and 89); at other times, and this is perhaps the most frequent circumstance, nothing is found but a tumor developed at the superior and external side of the canon,-that is to say, a simple splint. This is at least the opinion which we have acquired as the result of our researches for a period of observation extending over more than forty years, in conditions altogether exceptional in so far as the abundance of the specimens studied was concerned.

Jarde is never situated at the same height as spavin; it is always lower, which already implies that the external tarsal bones are not the seat of it. Besides, it remains confined outwardly or posteriorly, and does not extend forward as spavin does; finally, it is rather inclined to descend along the rudimentary metatarsal than to ascend upon the cuboid or the base of the calcaneus, additional reasons which mili-

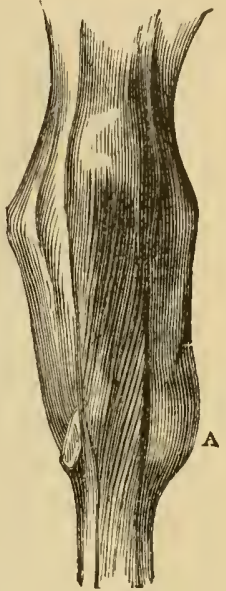

FIG. 87. tate in favor of its metatarsal origin. It should, therefore, neither in location, lesions, nor gravity, be considered as the homologue of spavin.

We also sometimes meet, on the outer side of the hock, a tumol localized on the base of the calcaneus, the scaphoid, the cuboid, and the head of the external metatarsal bone,-a tumor sufficiently circumscribed to merit a special name other than that of osteophyte, of which we shall speak farther on. (It could be called external spavin.)

In 1852, M. Gillet ${ }^{2}$ represented the true jarde with great exactness, although, by a singular deference for the erroneous opinions of his predecessors and his contemporaries, he would not abide by his own observations alone. His drawing, altogether similar to our own (Figs. 88 and 89), differed, for good reasons, from all the other more or less fantastic representations which have been made of the blemish in question. We will add that it is rery rare to meet lesions of this nature, and we are certain not to be contradicted upon this point by those who have taken the trouble to search for them.

The anatomical facts explain why the periostitis of which we speak can really only take its origin upon the liead of the external splint bone and not otherwise. It is necessary first to recall that exostoses resulting from usage appear only at points of insertion of the large articular ligaments. It is at these points that tractions and irritations are conveyed to the periosteum and inflame it. The irritation, spreading little by little, invades ultimately all the bony surfaces covered by these ligaments. It is according to this process that curb, sparin, and exostoses of the bodies of the vertebræ are produced; this same process we shall find again as the primary factor in the formation of splints or

1 This is the "curb" of English authors.

2 Gillet, Des Tares osseuses des membres du cheval, in Recueil de mémoires et observations sur l'hỵgiène et la médecine vétérinaires militaires, t. ir. p. 317, chez Dumaine, Paris, 1852. 
exostoses of the canon. The formation of a jarde is no exception to this principle.

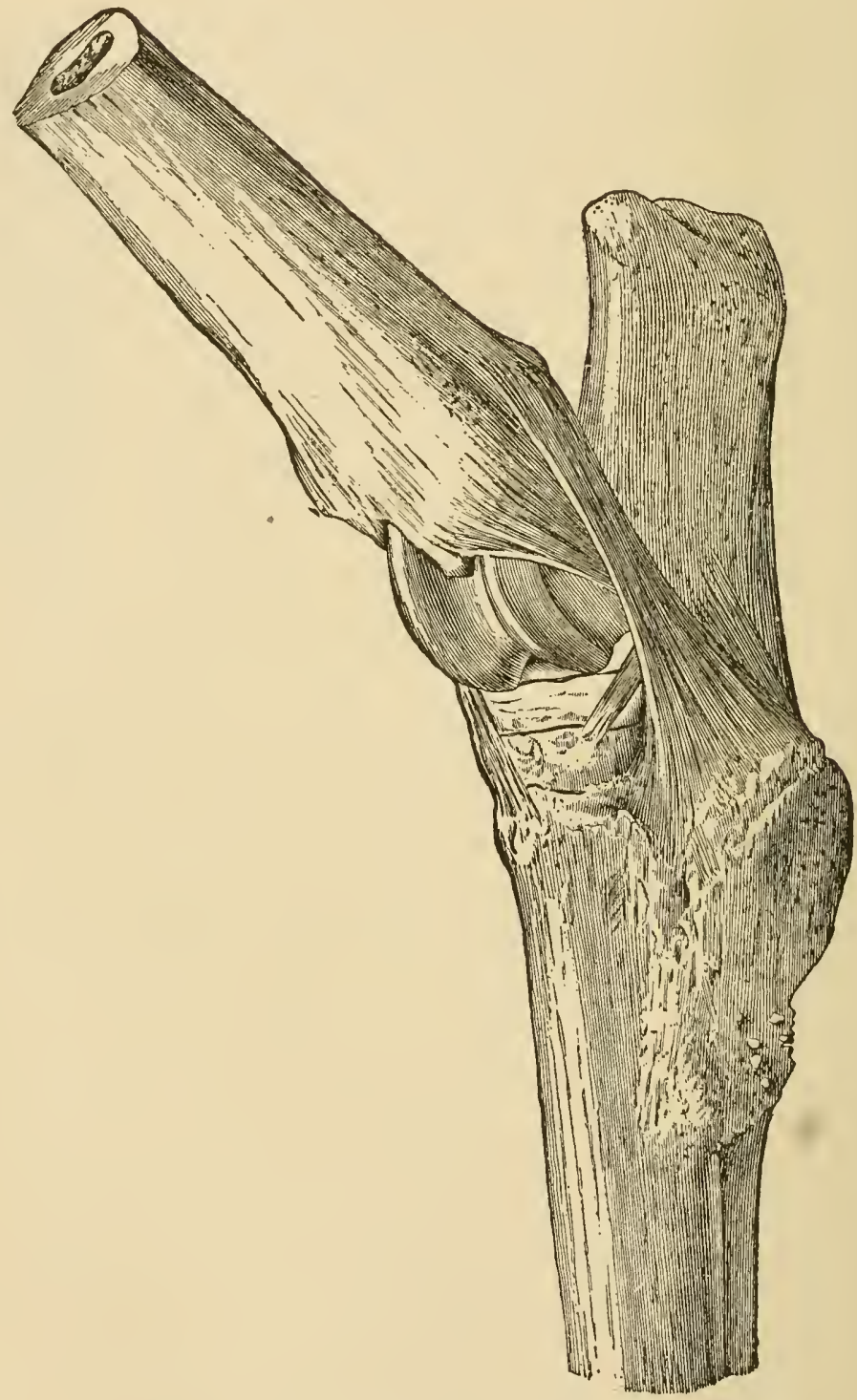

FIG. 88.-Jarde upon the dissected hock.

It commences at the head of the external metatarsal bone (Fig. 90), 一that is to say, at the inferior insertion of the powerful calcaneo-metatarsal ligament, $b$, so much more exposed to traction on its component fibres as the efforts which 
produce it are exerted at the extremity of a calcaneus longer and more oblique upon the tibia. Hence it has always been considered as coexistent with angular

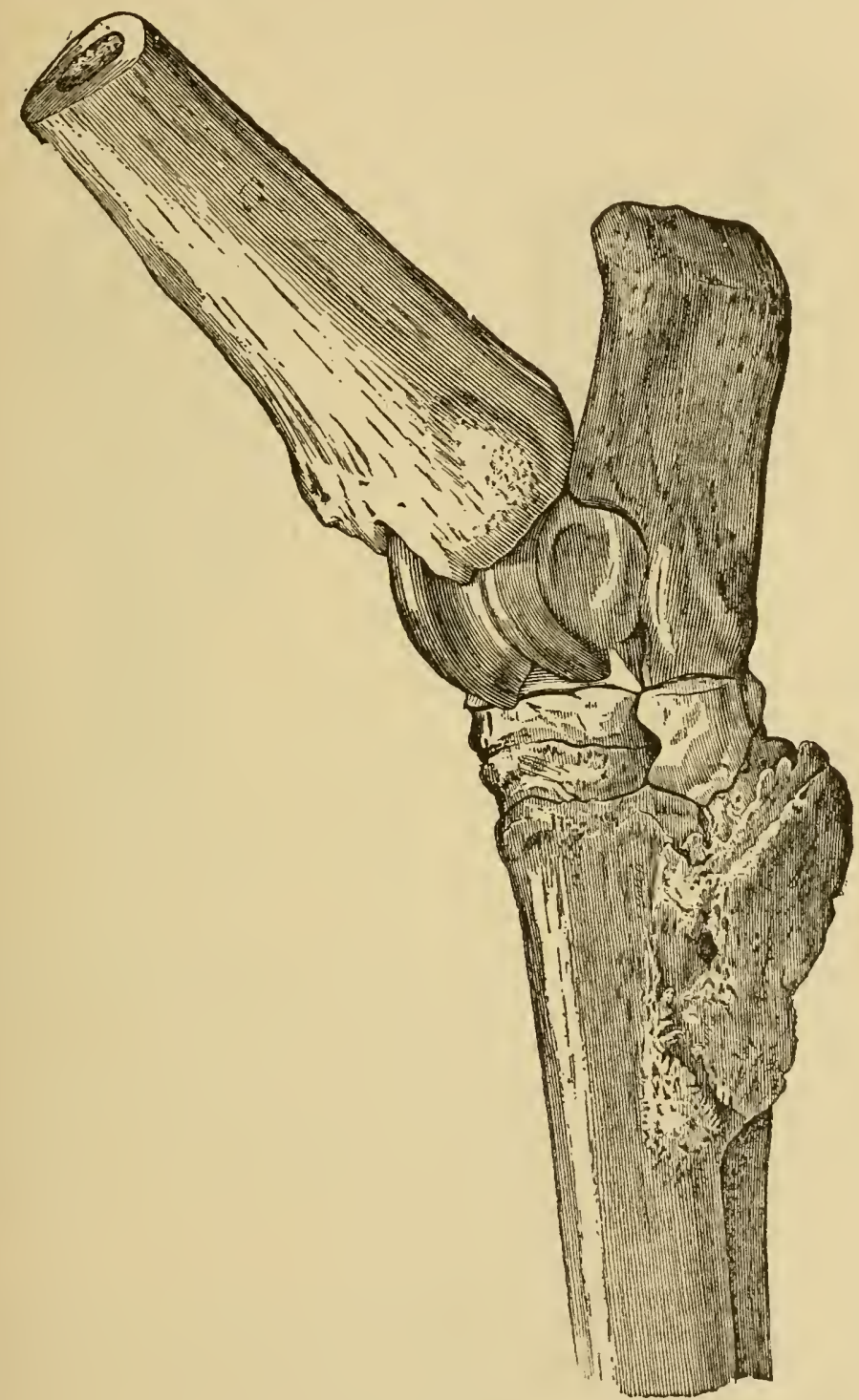

FIG. 89.-Jarde upon the macerated hock.

hocks. The tumor, once formed, has no tendency to ascend; it remains localized at the place which we have just indicated, or, perhaps, is complicated by a splint upon the tract of the interosseous ligament, which unites the principal metatarsal to the corresponding rudimentary bone. With regard to its seat, it mily 
be defined as a periostitis of the calcaneo-metatarsal ligament, $b$ (Fig. 90), and the external tibio-tarsal, $a$ (Fig. 91), and spavin as that of the astragalo-metatarsal, $b$ (Fig. 91), and the internal tibio-tarsal, $a$ (Fig. 90), ligaments.

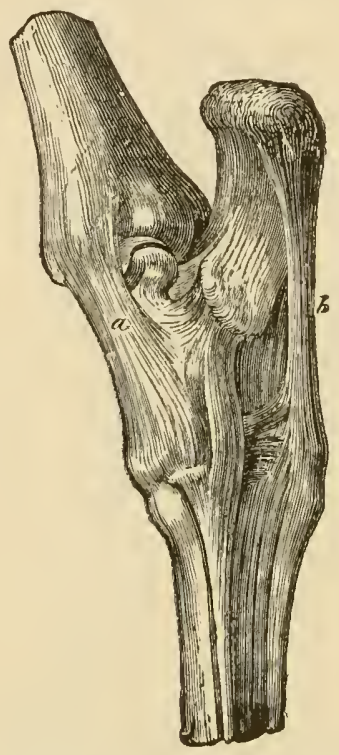

FIG. 90.-Dissected hock viewed inwardly and posteriorly.

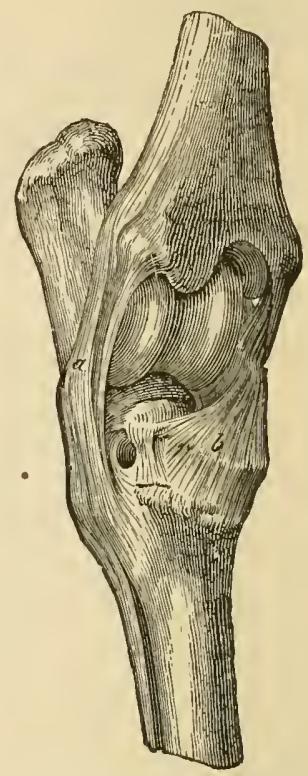

Fig 91.-Dissected hock viewed inwardly and in front.

Whatever may be its situation, it occasions a very characteristic deformity of the profile of the base of the hock. The line which passes from the summit of the calcaneus to the fetlock, instead of being perfeetly straight, describes, on the contrary, a eurve with the convexity posterior, at the level of the head of the splint bone and most frequently a little below. The enlargement is also perceived upon the hock viewed from behind or obliquely. When the jarde assumes the form of a splint, it sometimes elevates the suspensory ligament of the fetlock by developing in the posterior gutter, which serves as a cavity of reception for the latter. In this ease it is the line of the tendon which loses its rectitude and becomes more or less convex behind.

Before leaving this subject, we should warn our readers against a tendency which is quite general among horsemen, particularly in the army: it is the mania of jardes, if we may use such an expression. Many jardes exist often only in the imagination of those who speak of it, and who, to a certain degree, cannot inspect a horse without seeing this lesion. The head of the external metatarsal bone, in our opinion, has not always the same configuration; it is sometimes very angular, and may, in this case, alter externally the posterior profile of the tarsus,-above all, if the hock is cow-hocked,--without justifying thereby a conclusion of the existence of a blemish, because the structures still are and will remain perfectly normal. 
A jarde is far from offering the same gravity as spavin. This is simply due to the fact that it never terminates in anchylosis of the inferior tarsal articulations; the latter remain absolutely intact.

The lameness which it determines, when the work of ossification has been completed, depends upon the want of freedom experienced by the small metatarsal arthrodia or the compression of the suspensory ligament of the fetlock and the flexor tendons.

Osteophytes.-The hock does not always present so clear a delimitation of its osseous blemishes; in old horses it is quite frequently the seat of disseminated bony deposits whose point of origin may be in the thickness of the anterior capsular ligaments, that of the lateral ligaments, or again in that of the articular and tendinous synovial membranes. This condition, as we have seen, is the ultimate complication of synovial dilatations, and, consequently, is nothing remarkable. The normal profiles of the hock, in such instances, are completely changed. At the level of these osseous tumors the region presents more or less voluminous, hard, and irregular reliefs, which have a great tendency to join and eventually encircle the tarsal apparatus. These are always conclusive evidence of ruin and of usage driven to its utmost limits.

\section{E.-The Chestnut.}

The chestnut, o (Fig. 77, $B$ and $D$ ), in the posterior member, is situated on the inferior part of the internal surface of the hock. It responds anatomically to the small cuneiform, and is sometimes wanting. Huzard the elder has mentioned its absence, and we have also verified it in several instances. In such a case the description of the horse should mention the fact. As in the anterior member, its area and volume vary in a great measure according to the race; it has, besides, nothing of special interest.

(The chestnut, anatomically, is the rudiment of the hoof of the fifth digit or thumb, which it represents. Its absence is most frequently noticed in meridional horses, probably the descendants of the African horse, which, of all the equine races, is the most closely related to the ass. It is smaller in well-bred horses.-Harger.)

\section{F.- The Canon and the Tendons.}

Situation; Limits; Anatomical Base.-The canon is the region of the members which extends vertically from the knce or the hock to the fctlock.

Its anatomical base consists of the three metatarsal or metacarpal bones, the tendons of the different motor muscles of the phalanges, and a very strong ligament, known, on account of its functions, under the name of the suspensory ligament of the fetloek. 
Of these three bones, one, the principal metatarsal or metacarpal, is much more developed than the other two, which are altogether rudimentary. The latter (Fig. 92) are united to the sides of the principal bone by means of a very resisting interosseous ligament which ossifies with age, save at its two extremities.

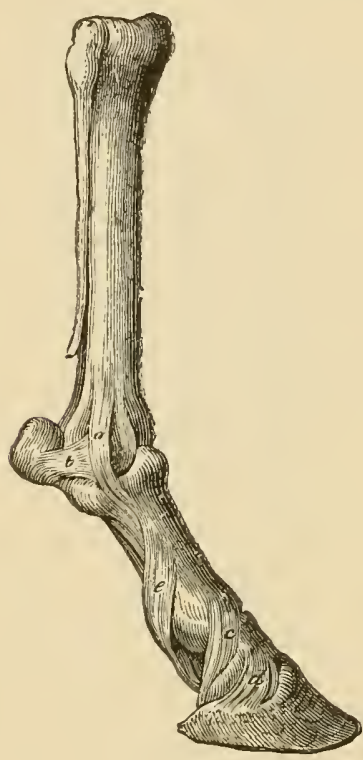

F1G. 92.

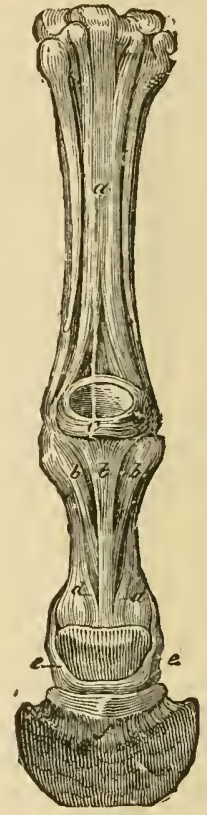

FIG. 93.

The superior part, or the head of these small styloid bones, is articulated by two diarthrodial facets with the extremity of the median bone of the canon; their inferior extremity, slightly dilated and button-shaped, almost free and tangible to the finger, is united by a fibrous ligament to the region which we will study as the ergot.

Thus constituted, the canon is articulated above, through the intervention of its component parts, with the lower row of carpal or tarsal bones, from which it receives and transmits impressions; below, the middle bone forms with the first phalanx a very movable joint, which is completed, behind, by the two sesamoid bones.

No muscles worthy of attention exist in this region. The tendons of the extensor museles of the phalanges are found on its anterior surface, and those of the flexors, perforans, and perforatus on the posterior. We must mention, besides, the carpal and the tarsal check tendons, fibrous, unelastic laminæ, which emanate from the posterior ligament of the carpus and the tarsus, and terminate, after a more or less extensive course, in the deep flexor tendon of the digit.

Two large synovial membranes exist, one above, the other below, upon about a third of the length of the canon. The superior we have already studied: it belongs to the carpal or the tarsal sheath. The inferior will be studied with the 
fetlock : it is that of the metacarpo- or metaturso-phalangeal sheath, also called the great sesamoid sheath. They both facilitate the gliding of the flexor tendons of the phalanges, the first against the posterior face of the hock or the knec, and the second over the angle of the fetlock; both permit, besides, the movements of the two cords upon each other.

Finally, against the posterior face of the principal boue of the canon, in a sort of gutter formed by the splint bones, is loctged the vast ligamentous brace of the fetlock, $a$ (Fig. 93), which is bifid inferiorly and terminates upon the sesamoid bones.

It is not without interest to note, in passing, a somewhat infrequent fact of which science, nevertheless, has a certain number of examples; we refer to the existence of supernumerary digits' ${ }^{\prime}$ on the internal face of the canon of one, two, or all four of the members of the horse at one time. This anomaly consists in the abnormal and almost complete development of the internal digit, which, in ordinary conditions, is simply represented by the corresponding but aborted metatarsal or metacarpal bone.

The external digit occurs much more rarely. Professor R. S. Huidekoper has observed a very remarkable case in a Texas horse. The animal had, in all, ten hoofs, three on each anterior member and two on each posterior. The anterior supernumerary digits were formed each of three phalanges; their hoofs descended almost to the ground. The supernumerary digits on the posterior members existed only on the internal side; their phalanges were rudimentary and their horny covering only reached to the middle of the pastern. ${ }^{2}$

\section{Rôle and Action of the Canon.-The canon is a locomotory} lever which plays a most important rôle in progression, station, and impulsion. Let us examine it rapidly from these diverse relations.

It is primarily the seat of two principal movements, flexion and extension.

The first, much more pronounced in the anterior member, elevates the foot and places the canon in a favorable position to accomplish the second, which it is desirable should be as extensive as possible. The length of the forearn and that of the tibia are, as we know, in relation with the amplitude of these displacements.

The movement of the canon in the two members is of an inverse order, on account of the opposite positions of the articular angles. When that in the anterior member is extended, it simply passes over the ground, places itself in prolongation with the radius, arrives thus on the soil, and preserves this attitude as long as the foot remains on the ground. In the posterior member, its extension commences a little before the foot is in station, and continues during the whole period that

1 Supernumerary digits constitute simply an example of the law of reversion to the pentadactylous or five-toed type of the foot of the ancestral forms of the horse, as the co-hippus, in which four digits exist. (Harger.)

${ }^{2}$ R. Huidekoper, Note communiquée. 
the foot is on the soil in such a monner that, at its termination, when the foot is elevated, the tibia and the metatarsus are in a straight line. It is apparent from this that the anterior canon, in this action, is especially utilized as an organ of support, whilst the posterior becomes a veritable agent of impulsion.

This region, however, only fulfils a passive rôle in locomotion. It is an inert lever having no influence in itself upon the movements which follow or precede it, since it is traversed in its length only by tendinous cords, organs of transmission, and not by contractile muscles. It is the same during station: its vertical direction and its inertia make it a veritable column of support for the weight of the body, whose total pressure accumulates upon it. It is therefore very appropriately disposed to fulfil this end. Besides being vertical, it also has an almost cylindrical form; its median bone has parietes of great thickness ; the tissue which constitutes it is extremely compact ; finally, by the concurrence of the rudimentary bones attached to its lateral faces, it angments the area of the superior articular surface and serves as an important apparatus of breaking concussion in virtue of the double articulation which is found there and the obscure movements which are produced there.

Its tendinous cords, even, and the posterior ligament, from their peculiar relations, present a special disposition to serve with efficacy as an apparatus of support. The carpal or tarsal check tendon relieves the former by displacing a large share of the weight upon the bones, while the obscurely muscular nature and the mode of intererossing of the fibres of the suspensory ligament of the fetlock ${ }^{1}$ make this ligament a veritable elastic brace, which disperses the effects of the weight in such a measure as to render them compatible with the resistance and integrity of the tissues.

Finally, the action of the canon in relation to the impulsion is not the same in the two members. This function, as we have seen, is more particularly imparted by the posterior members. The extensor muscles of the metatarsus are also provided with more powerful leverarms. The calcaneus, by its length and by the prominence which it forms above and behind the centre of the tibio-tarsal articulation, places these muscles in very favorable conditions relative to the intensity of force and the rapidity of speed.

1 From the point of view of comparative anatomy, the suspensory ligament of the fetlock is, in fact, only a modified musele which has its full development in the species whose hand and foot approach, by the number of their digits, the eonformation which is observed in man. Thus, it occurs in quadrumana, carnivora, rodents, and many of the insectivora. 
Form.-The canon is subdivided into four faces: an anterior, a posterior, and two lateral. They offer some slight differences according as they are examined in the anterior or in the posterior biped.

Viewed from in front, the region is rectilinear in its length, rounded transversely, and widest towards its extremities.

The lateral faces are flat, and leave the parts under the skin, which we already recognize, tangible to the eye and finger,-namely, in front, the borders of the principal metacarpal or metatarsal bone; behind and above, under the hock or the knee, the eminence of the corresponding rudimentary bone; below and a little above the fetlock, the button of this bone; posteriorly and in the middle part, a groove augmenting in depth and width down to the fetlock, which separates the suspensory ligament from the principal canon bone; it is in this groove that hernice or dilatations of the synovial membrane of the metacarpoor metatarso-phalangeal articulations appear; more posteriorly, the suspensory ligament of the fetlock, whose prominence increases from above to below; then a second groove, less deep than the preceding, separating this ligament from the flexor tendons, and lodging the synovial dilatations of the great sesamoid sheath; finally, the cord of the flexors, known in the exterior under the name of tendon, strong and resisting, which falls perpendicularly from the supra-carpal bone or the calcaneus upon the fetlock.

The tendon, an eminence rectilinear from above to below, narrow and round from side to side, forms exclusively the posterior face.

The skin of the eanon, as well as the layer of the subcutaneous connective tissue, is more or less thick, according to the fineness of the race. These minute but important details which we have described are not observed in all subjects. They are the characteristics of horses of fine breeding and of good qualities.

The hairs on the posterior face are always longer, more abundant, and coarser than the others, except in animals of the finer races, the Aryan or the English thoroughbred, for example.

Coarse, sluggish, and lymphatic horses are remarkable, on the contrary, for the abundance and the length of these hairs, which are only the origin of those of the footlock. Horsemen and many horse-owners have the habit of cutting, clipping, or singeing them, in the preparation of the animal for sale, in order to give to the members an appearance of fineness and of good qualities; they are spared in draught-horses to make the limbs appear more voluminous. We will again have occasion to return to this practice in diseussing the toilet.

Beauties and Defects.-The canon, in order to be becutiful, must be vertical, short, wide, thick, fine, and neat of outline; its posterior part, or the tendon, must also be fine, unblemished, firm, and well detached. It is defective in opposite conditions.

Direction.- We have only one word to say on the subject of the direction of the canon, which should be perpendicular to the ground 
in order to duly sustain the body-weight, particularly in the anterior members, in view of their function and their closer situation to the centre of gravity. The least displacement forward, backward, outward, or inward makes the horse appear deficient in the axes; its articulations in certain regions are surcharged; their constituent parts and the ligaments which nnite them show signs, in the long run, of the conenssions, of the violent tractions, a necessary consequence of the mode of superposition of the locomotory segments. Finally, the muscles themselves, supposing that the articulations are sound, are obliged to display more force in order to maintain the bones in a good direction, which in normal conditions elaim but little of their co-operation to preserve their equilibrium. The deviations of the canon are less prejudicial to the integrity of the locomotory apparatus when they are confined only to the posterior members; the animal is not less defective for this reason; only the effects of these alterations are slower in manifesting themselves. We will return to ali these facts when we discuss the direction of the axes.

Length.-The absolute length of the canon merits to be taken into consideration in the case of rapid motors. It has not much importance in the draught-horse.

In well-formed subjects, whatever may be the race to which they belong, the metatarsus is always longer than the metacarpus. We will say that, all things being equal, the latter are constantly longer in animals of speed, when compared in this relation to those of the draught-horse. With equality of form, the canon of the draughthorse is shorter than that of the thoroughbred; the body of the former is nearer to the ground and more voluminous than that of the latter, which, to use the comparison, appears, to a certain degree, mounted on stilts. It is easy to verify this statement by measurements which we ourselves have been careful to make before abandoning the classical opinion which claims that race-horses have their hocks as low as possible. We see, then, all proportions being of course considered, that their canons are always longer than is believed. Hence these animals possess more speed, for necessarily they embrace at each step a longer expanse of space.

The relative length of the canon should be studied with regard to the region which surmounts it, the leg or the forearm.

We know already that the length of the broken radio-metacarpal or tibio-metatarsal lever in rapid motors is due to the development of the superior bone, the radius or the tibia. It is necessary, therefore, that the canon be in such cases short. When it is thus, we know that 
the muscles experience less fatigne and contract to better advantage. A short canon is less heavy, oscillates more freely, unfolds itself more, and does not necessitate the same elevation of the member above the ground to reach the limit of its movements. Hence it is advisable to seek, in the pendulum under examination, a great extent for the display of what we have already designated its active function; in its passive function the canon is inert, being incapable of accelerating or slackening the movement which is communicated to it. (See Forearm and Leg.)

Width and Thickness.-The width of the canon is measured from before to behind, considering the animal in profile. It proceeds from the separation of the principal bone of this region from the flexor tendons of the phalanges, which procured also to the latter the designation well detached (Fig. 94). It is due, in the anterior members, to the volume of the antibrachial muscles; in the posterior, to the width of the

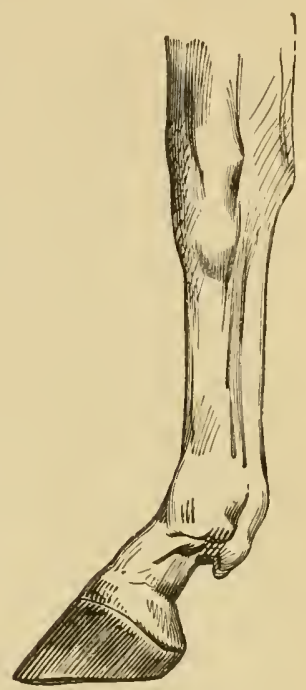

FIG. 94. hock, which carries the summit of the calcaneus more behind. In each of the members it results, besides, from a more or less marked prominence of the sesamoid bones behind the fetlock articulation.

Is it necessary to say now that this width is an absolute quality for all kinds of services? Evidently not, since it is itself derived from other good points which we have already described, such as the volume of the muscles, the width of the articulations, and the length of the lever-arm. If, however, in theory, the width of the canon in the anterior member coincides generally with that of the fetlock, it is possible, notwithstanding the development of the latter, that the former may be deficient from excessive narrowness at its superior part.

The flexor tendons, being then too strongly tensed in the fold of the knee by the tarsal sheath, descend obliquely upon the sesamoids by gradually separating from the metatarsus, a

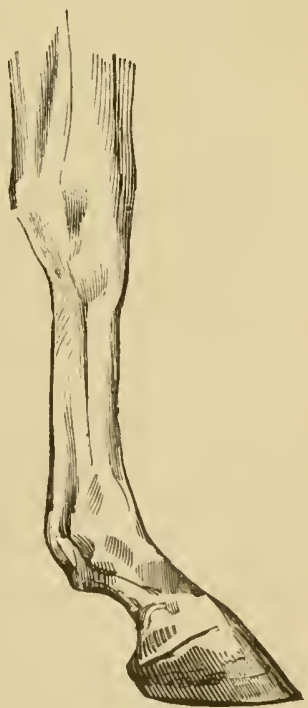

FIG. 95. vice of conformation which renders the tendons $u$ eak, less effective 
(Fig. 95). The horse affected with this fault appears slender in its build, which, in fact, lacks strength. Horse-dealers, in order to conceal it, leave the hairs at the upper part of the canon in arranging the toilet, while below they cut them off very closely, a deceitful procedure which it is easy to detect.

The tendon in the posterior members is never weak, thanks to the particular disposition of the tarsal sheatl.

The thickness of the canon is measured, on the contrary, from side to side, viewing the parts either in front or behind. This dimension, which indicates the transverse development of the principal bone, and, consequently, that of the regions between which it is placed, is always greater in the fore-limbs, columns of support, than in the hind, agents of impulsion. This is a fortunate adaptation of a part of the locomotory apparatus destined to fulfil such different functions.

A thick canon, therefore, constitutes an absolute beauty, which denotes great strength of the members; and because this is not the same in the well-bred as in the common horse of equal forms, because the meagreness of the canon in the former is not indicative of any weakness, it does not follow, as several authors have advanced, that such a conformation is not to be taken into account. H. Bouley has very forcibly elucidated how unwise this theory is, by saying, "The bones of the canon should be developed proportionately to the mass which they support." This conception is important. The slenderness of this region not only implies its feebleness of support, but it also involves that of the adjoining bones and of the tendinous apparatus which is annexed to it. A slender canon means a narrow knee; the phalanges, the sesamoids, and the tendons lack proper development. In these conditions, the members wear away in a very short time, and so much more quickly as the body is heavier, as the animal is endowed, from his race, with greater energy. It is common to meet this defect in horses of poor conformation which are the product of injudicious selections or crosses. (H. Bouley.)

When the region lacks width and thickness, the canon is called meagre, narrow, slender; when to these characters is added an excessive length, the animal is said to be mounted upon matches; finally, this same horse has nothing under his knee when the tendons are not sufficiently developed, while the member is qualified well cast when the tendons of the flexors are strong and well separated from the bones which constitute its lever-arm.

Fineness.-The fineness of the canon is characterized by the thinness of the skin and the spareness of subjacent connective tissue, 
which expose to external view, in all their details, the bones, the suspensory ligament, the tendons, and the blood-vessels. This state indicates a noble ancestry; it is found in horses of the distinguished races and those of their race which show their lineage.

This quality can habitually be perceived by a glance of the eye ; but many also endeavor to appreciate it by passing the hand over the lateral faces of the region, a manner of procedure which has primarily the advantage of betraying the existence of blemishes. It is necessary to attract the animal's attention before practising this manipulation upon the posterior members, in order to avoid his kicking or biting.

In common subjects, even in the best, the skin is thick and the connective tissue abundant. When carried to the extreme, these characteristics cause the canon to be spoken of as round and the tendons as fleshy, defects essentially prejudicial in pleasure-horses, in which the distinctness of the lines and the fineness of their extremities are the indispensable conditions of their value, while in draught-horses no importance is attached to them.

Density.-The firmness of the tendons denotes the density of the tissues, the energy, the quickness of movement, the blood, the race, and the resistance of the constitution. This is ascertained by the scnse of touch and not by striking the cord of the flexors with the foot, which some persons practise to judge of it as well as of the solidity of the member. It is easy to comprehend that such a method can give no positive information, since it is the surprise and not the weakness of the parts which causes the horse to flex the limbs.

Neatness of Outline.-This neatness-that is to say, the absence of blemishes-is the most important qualification to be realized in the examination of the canon. It is indispensable that to the inspection and to the touch the outline should be normal; that the ridges and grooves of this region, which we have described, should be quite marked without any alteration.

Diseases and Blemishes.-First among these are skin u'ounds resulting from contusions and kicks given or received by the animal. When these are the result of the repeated contact and friction of the opposite feet during locomotion they receive the name speedy-cut, and the animal is said to overreach himself, strike himself, eut himself. We will again return to them when treating of the defeets of the gaits.

It is not rare, either, to see blood-tumors, hot abscesses, and inflammatory enlargements of the subcutaneous tissue or of the lymphatic vessels on the internal face of the canon. Lymphangitis of a malignant type, often symptomatic of a glandero-farcinous diathesis, has a favorite seat in this region. Let us also indicate the enormous indurations of the skin and the subjacent connective tissue, 
very common upon the posterior members and completely deforming the regions between the hock and the hoof. These indurations, known under the name of fibrous elephanticsis (Trasbot) on account of their analogy with elephantiasis in man and of the aspect which they give to the members, are sometimes complicated by lesions of the bones. In spite of their hardness, their volume, and the pressure exercised on the organs which they cover, they do not occasion very great inconvenience in walking and permit the utilization of the animal at a slow pace. They are rebellious to all treatment, and the very means employed to combat them have no other result, in most instances, than the development of an activity analogous to that which is observed in similar cases in the formation of neoplasms, which may have with them, according to our colleague, Professor Trasbot, a closely-related origin.

We will also cite the hard and indolent enlargement of the tibial aponeurosis at the point where it terminates on the tendons of the extensor muscles of the phalanges. This induration, which is located at about the superior third of the anterior face of the hind canon, is susceptible of ulceration under the influence of friction, and seems more particularly confined to English thoronghbred and other horses of great speed.

Eczema (grease, water in the legs), a chronic affection of the skin, somewhat scarce to-day, consisting of an abundant and fetid exudation on the very lowest part of the member, may ascend to the posterior region of the canon when it is of long standing. Although not disabling the animal from work, this should nevertheless be considered serious, from the uncleanliness which it engenders and the care which it necessitates.

Contusions and ruptures of the tendons of the canon are frequent in the anterior members, while in the posterior they are, so to speak, at least from our own experience, almost unknown.

Designated under the name over-stretching, or, better, strains of the tendon, they result from traction or partial lacerations of the tendinous fibres during the violent efforts of locomotion at great speed. This alteration of the tendons or of the structures situated more deeply (check tendon) is followed by a more or less acute inflammation accompanied at the beginning by a severe lameness and succeeded soon by an enlargement, which renders the organs knotted and always very sensitive. The symptoms, at the end of a certain period, ameliorate, but the swelling and the lameness persist, while the contraction of the tendons and the consecutive deformity of the angle of the fetlock take place. For these reasons, over-stretching is a grave accident. It depreciates so much more the value of the animal as he is intended for pleasure and parade, and as it is necessary to employ the most energetic means of trcatment against it, such as tenotomy or the actual cautery, whose indelible traces have all the characteristics of the most permanent blemishes.

It is vulgarly said of the hippodrome horse which meets with the accident on the race-course, that he has snapped a tendon or that he is brolien down.

The most common blemish of the canon, involving the bones themselves, manifests itself by the presence of osseous tumors, known under the name of splints.

These exostoses, in the majority of cases, have their seat on the interosseous ligament which unites the rudimentary metacarpal or metatarsal to the principal bone of the canon. Those which exist on the anterior face of the latter are the 
result of contusions and have little gravity ; they are in most instances absorbed spontaneously, are much more rare, and only appear accidentally at all periods of life.

Splints occur more often upon the anterior members than upon the posterior, and on the internal side than the external. This is due to their cause of development. They proceed, in fact, from tractions exerted on the interosseous ligament under the influence of the vertical pressure which is exercised on the head of the splint bones during rapid locomotion. As long as these small bones are not soldered to the principal bone in consequence of the normal ossification of their ligament of union, they tend to glide up and down in a measure proportional to the weight which they sustain. Whence results rupture of the ligamentous fibres, which is propagated to the periosteum, irritates the latter, and causes a periostitis with the appearance of one or more tumors upon the tract of the metacarpal or metatarsal synarthrodial articulations.

It is easily understood from this that the formation of splints is a disease more frequent in young horses used too young, and without moderation, for heary work, than in old horses, in which the process of co-ossification of the bones of the canon has already been completed. It can also, without difficulty, be perceived that they should be more common on the anterior limbs, nearer to the centre of gravity, which receive, more especially, the effect of the quantity of movement at great speed. Finally, it is equally easy to explain their habitual presence upon the internal side if we only recall : first, that the weight of the body presses more upon the internal side of the articulation; second, that the pressure sustained by the bones is proportional to the area of compressed surfaces. Now, in this connection, it is to be remarked that, all proportions being considered, the articular surfaces of the internal metacarpal or metatarsal bones are larger than their homologues of the external side; whence it follows that these bones are more disposed to glide against the median piece which supports them than the external, and, consequently, to lacerate their interosseous ligament.

Splints, the volume of which varies from that of a small hazel-nut to that of a hen's egg, are characterized externally by the relief which they form underneath the skin, and by a sensation of hardness which is conveyed to the hand on palpation. They are readily perceived if the canon be viewed from in front. ${ }^{1}$

Their disposition is very variable: sometimes only one exists (simple splint); sometimes there are two, situated almost on the same level on each side of the region (pegged splints); at other times there are several in succession from above downward, upon the same face, and of an almost uniform volume (chain splints); finally, there are some which, in relation to size, form a decreasing series from above downward, on the one side or the other (spindle-shaped splints).

Whatever may be their form, these tumors are more grave as they are situated towards the carpal or the tarsal articulations, or are developed in the posterior gutter destined to lodge the suspensory ligament of the fetlock. In this case they cause an evident constraint and induce too often a persistent lameness. Most ordinarily a splint lames a horse, only at the first, when the inflammatory process of the periosteum is still in full activity. The lameness disappears as soon as the tumor is quite developed.

${ }^{1}$ The buttons of the rudimentary metatarsal or metacarpal bones should not be mistaken for splints. 
Fractures of the canon, though rather common, are, so far as our study is concerned, absolutely deprived of interest. We should, nevertheless, mention some: they are those of the rudimentary metacarpal or metatarsal bones. Resulting from traumatisms, they give rise to a complication, similar to the formation of a splint, at the point of union of the two osseous segments.

As to the synovial dilatations of the canon, they properly belong to either of the regions between which the canon is situated. The superior have already been pointed out with the knee; they are due to an abnormal distention of the carpal sheath. The inferior, known under the name of windgalls, consist of a hydropsy of the synovial membrane of the metacarpo-phalangeal articulation, or of the great sesamoid sheath, and will be studied with the fetlock.

Finally, there are also found, along the length of the canon, traces of actual cautery of varying area and configuration, which indicate, according to their situation, that the animal has been treated for disease of the osseous apparatus, the tendons, or the synovial membranes. In spite of these markings, the alterations of which they are the evidence may not have disappeared, and it is wise, consequently, to submit the member which presents them to a minute examination. In any case, the horse has none the less lost at least a part of his value, for he is blemished, and so much more gravely as the treatment to which he has been subjected has been less efficacious.

\section{G.-The Fetlock.}

Situation; Limits ; Anatomical Base.-The fetlock is situated between the canon and the pastern. It supports, at its posterior part, a horny production, the ergot, and a tuft of hair to which has been given the name of footlock.

It has for its anatomical base the metacarpo- or the metatarso-phalangeal articulation, which results from the apposition of the inferior extremity of the principal bone of the canon and the superior extremity of the first phalanx, complemented behind by the great sesamoid bones (Fig. 96).

These bones are united by numerous ligaments : an anterior or capsular ; two lateral funicular, $a$; a posterior, the suspensory of the fetlock, which has already been mentioned, and whose two branches terminate upon the sesamoid bones, $a$ (Fig. 97); finally, the group of inferior, $b$ (Fig. 97), and lateral, $b$ (Fig. 96), sesamoid ligaments, short and strong, which fix these bones to the first phalaux and the canon. The two sesamoid bones are, moreover, intimately united to each other by means of a fibro-cartilaginous mass which transforms their posterior face into a pulley, $c$ (Fig. 97), upon which the flexor tendons of the phalanges glide.

This ligamentous apparatus, of great strength, is, in addition, reinforced by the extensor tendons of the phalanges in front, and by the flexor tendons belind, which also fulfil the rôle of suspensors like the superior sesamoid ligament, whose function they supplement.

Three distinct synovial membranes exist in the region of the fetlock: one articular and two tendinous.

The first, firmly maintained in front and on the sides, can become dilated 
behind and above, between the canon bone and the suspensory ligament of the fetlock; behind and below, upon the sides of the first phalanx.

The largest of the tendinous synovials, posterior to the articulation, subserves the gliding of the tendons against the sesamoid pulley; it is known by the name

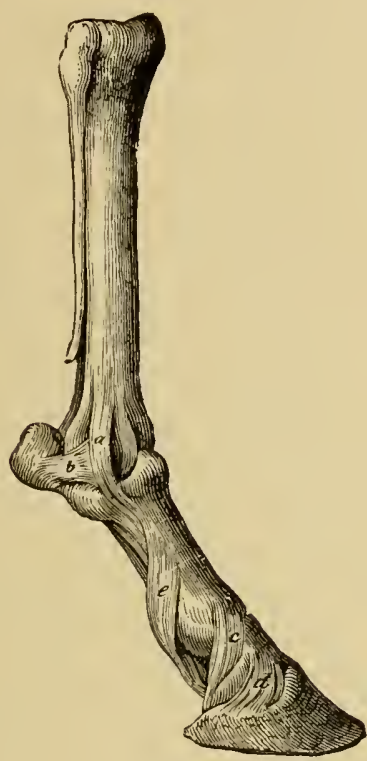

Fig. 96.

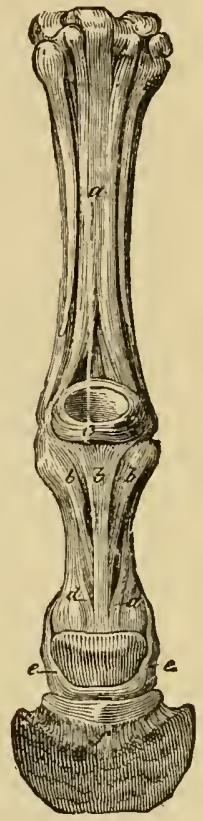

FIG, 97.

of great sesamoid sheath. Extending from the inferior third of the canon to the superior part of the second phalanx, and unequally sustained by the surrounding tissue, it sometimes forms a dilatation on each side, above the fetlock, between the suspensory ligament and the flexor tendons. It presents, also, along the length of the pastern, two weak points, of which we will only make mention, and whose enlargement is always much less marked than that of the preceding.

The second and the smallest of the tendinous synovials is found in front, underneath the tendons of the extensors of the phalanges, and permits their gliding upon the anterior face of the capsular ligament. It is extremely rare that it communicates with the articular synovial membrane. It is susceptible of becoming distended over its whole periphery, unsustained by the tendons, and even of rupturing its parietes into the surrounding connective tissue under the influence of internal pressure.

Mechanism of the Articulation of the Fetlock.-By reason of the oblique direction of the first phalanx and of its superior articular surface, which play, with regard to the weight of the body, the rôle of an inclined plane, the principal bone of the canon eonstantly 
tends (Fig. 98) to press on the sesamoid bones, $A$, and tends to effeet a closing of the angle $P B C$.

The ligamentous apparatus, however, and the tendons which exist

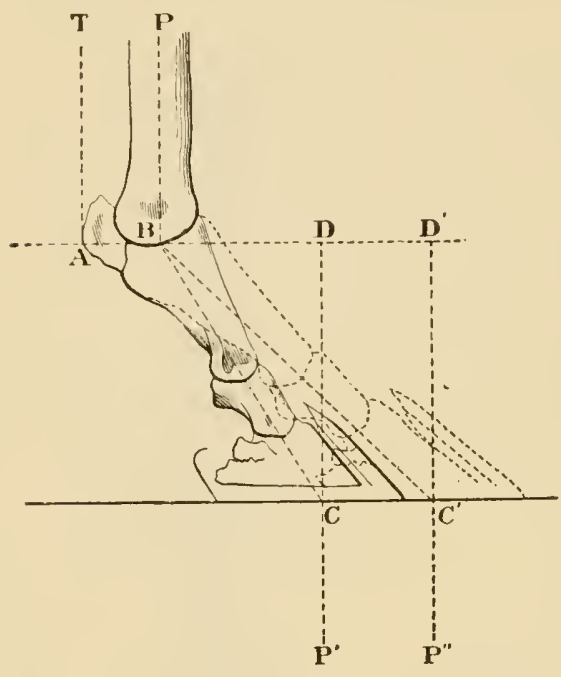

FiG. 98. behind this angle, constantly resist this tendency and, by their tenacity as well as their elasticity, transform the articular joint into a veritable elastic spring admirably adapted to the sustentation of the body, the dispersion of the reactions, and the impulsion of the mass.

The suspensory ligament of the fetlock, being resisting and elastic, thanks to the few muscular fasciculi which enter into its composition, yields more or less, according to the intensity of traction which it undergoes, to the lowering of the great sesamoids, and through its attachments upon the bones of the canon distributes upon the latter a portion of the pressure of the weight of the body, in such a measure as is eompatible with their integrity.

As to the cord $T$, of the flexor tendons, though much less elastic, it acts in the same manner upon the extremity of the lever-arm $A B$, in order to limit to some extent the movement of descent of the fetlock and prevent the elasticity of its suspensory ligament from being strained beyond its limits. But as it is continuous, superiorly, with the fleshy portion of the corresponding muscles, and as an intermission in the action of all these contractile organs is necessary, there exists, behind and below the carpal and the tarsal articulations, a strong ligamentous band emanating from the posterior capsular ligaments of the latter, which permits the flexor tendons to perform the rôle of passive organs of suspension, by giving them a function completely independent of their respective muscular portions. The carpal and the tarsal chech ligaments therefore transfer to the superior part of the canon bone the remaining pressure of the body-weight which has not been eompletely overcome by the elasticity of the suspensory ligament of the fetlock. Hence their force of resistance is in relation with the intensity of the tractions which they must support, and it is for this reason that the 
carpal check tendon always has a greater volume than its homologue in the posterior member.

The function of the fetlock is deduced from the preceding considerations. It is a veritable elastic mechanism or spring, which constitutes, for the weight of the body, an apparatus of sustentation and an apparatus of dispersion; it relieves the muscles charged with the support of the body, at the same time that it prevents, by its elasticity, the effects of the concussion of the latter against the ground.

External Form.-Viewed in front, the fetlock forms a spheroidal relief circumscribed laterally by two convex lines which are continuous above and below with the lateral faces of the canon and of the fetlock. Viewed in profile, it is limited, on the contrary, in front by a coneave curve which continues symmetrically the profile of the anterior face of the adjoining regions, while, behind, it presents a salient angle whose superior branch is tangent to the tendons, and whose summit corresponds to a tuft of hairs, the footlock, containing in its centre the horny production ealled the ergot. A fine skin with short hairs covers it and, to a certain point, enables one to conjecture its anatomy in highly-bred horses. In horses of the common races, on the contrary, the external details are more or less masked in consequence of the thickness of the integument and the quantity and coarseness of the pilous production. The region is also, in such eases, the object of special care on the part of dealers, which consists in removing the hairs of the footlock in order to give to the animals an appearance of fineness and distinction which they do not in reality possess. We will again return to this in the chapter on the toilet.

Beauties.-The fetlock, like all the articulations, in order to be beautiful, should be wide, thick, well directed, fine, and free from blemishes.

Width.-The width is given by the extent of the antero-posterior diameter, and is appreciated, consequently, by examining the horse in profile. It depends upon two elements: the volume of the inferior extremity of the canon and that of the sesamoid bones (Fig. 98); whence it is apparent that it should be ample, for it is proportional to the firmness of contact of the members, to the extent of the morements, and, finally, to the length of the arm of the lever $A B$, whose development favors the action of the suspensory apparatus of the tendons and of the suspensory ligament of the fetlock. When the articulation is narrow, the tendon is close to the canon, the animal has little firmness of step, lacks force, and is ruined all the quicker as the members are weaker as columns of support in relation to the body. 
Thickness.-The thickness is the transverse diameter. It indicates the large development, from side to side, of the inferior extremity of the eanon and of the eorresponding part of the first phalanx. It is necdless to insist upon the advantages of these peculiarities; it stands to reason that they denote large articular surfaces, and firmness and sureness of the step, important conditions to exact whatever may be the service.

The fetlock which is defieient by laek of width and thickness, by lack of volume, in a word, is called small, round; the animal is also said to have thin, light wrists, to be wanting in the wrists, to have weak pins, ete.

Direction.-To the two preceding qualities it is important to add a third,--that is, the good direction of the segments which coneur to the formation of this artieulation. We know already that one of them, the eanon, should be vertieal; as to the other, it implies a certain obliquity whieh we will determine when we treat of the pastern. Suffice it to say for the present, that this obliquity would be greatly exaggerated if it attained only 40 or 45 degrees with the horizon; in any well-conformed horse it attains at least 5.5 degrees.

When the branches of the spring represented by the fetlock straighten themselves one upon the other, their angle becomes more and more obtuse and even tends to become effaced. The animal is then said to be straight in the members, in the fetlocks. In certain eases, however, the deviation of the segments is sueh that their obliquity takes place in a sense inverse to that which they normally affeet; the summit of the articular angle is direeted forward while its sine looks backward. This is a somewhat eommon deformity to which the name knuckling has been given. We will treat of this with the pastern and the axes of the members.

At other times, an accidental, momentary deviation results from fatigue, and exists only in the fetlock of the posterior members, which are suddenly projected forward when the animal stands still and reassume their proper situation as soon as he steps out again. This singular attitude, which is manifested also in the stable, is expressed by saying that the horse is at roost.

Finally, when this deviation, instead of being parallel to the median plane, in front of or behind the axis of the member, is sitnated in an oblique plane, outward or inward, in relation to the median plane of the borly, the horse is qualified splay-footed or parrot-toed. It is a vice of the axes of the members which we will study in a future ehapter.

Fineness.-The fineness or dryness of the fetlock implies a 
delicaey of the skin and of the hairs which cover it, spareness of the subeutaneous conneetive tissue, and the precise and clean delimitation of all its parts. It is considered as an index of quality, temperament, energy, and vigor. When it is not thus the region is called puffy. In this respect, horses of the finer races approach those of the common races aceording to the condition they are kept in. We have known a rather large number which, working in low and moist countries, or upon muddy and filthy soil, had in the long r'un aequired long and abundant hairs and more or less thickened extremities.

Absence of Blemishes.-The fetlock is clean when it is exempt from blemishes and from diseases. The rationale of this beauty will be apparent from what follows.

Diseases and Blemishes.-From the situation which the fetlock occupies, numerous diseases, acute and chronic, as well as accidents, may affect it, which depreciate the animal in different ways.

The skin, first, is often the seat of excoriations, contusions, and wounds, most frequent on the inner side, and resulting generally from injuries which the subject inflicts ou himself during locomotion. It is then said that the horse overreaches, interferes, cuts himself, strikes himself; he is usually affected with a defective axis of the parts, and ordinarily has an ungraceful gait. (See Defects of the Gaits.)

Like the knee, the fetlock becomes more or less gravely lacerated on its anterior face in consequence of falls upon hard and irregular soil.

At other times it presents cicatrices, callosities, or traces of the actual cautery in points or in lines of a variable extent and configuration.

The integument sometimes, but more rarely, offers an abundant, fetid exudation, which transudes from warty excrescences called fici, and agglutinates the scattered hairs over the diseased surface. This disease, known under the names of water in the legs, grapes, fici, and grease, etc., is an index of a soft constitution and a lymphatic temperament, dependent most often upon bad hygiene. It is regarded as grave on account of its chronic state, its tendency to ascend into the region of the canon or descend towards that of the foot, of the putrid odor which it gives off, and of the tenacity which it offers against all means of treatment.

The connective tissue is frequently the seat of redema, cysts, hematoma (blood-tumors), abscesses, lymphangitis, fistulous uounds, etc., occasioned by very diverse causes, to concern ourselves with which would be beyond our province, the acute character of all these affections being given.

It is not the same, however, with cystic tumors, which are met either on the internal or on the anterior face, and which proceed nearly always from repeated contusions during locomotion. The eyst on the anterior face, sometimes very voluminous, produces an abnormal convexity of the region, when it is viewed in profile. This swelling is indolent, uniformly fluctuating and somewhat tense, whatever may be the attitude of the member, which permits it to be diagnosed from a synovial dilatation. It is not serions, but constitutes a lecided blemish in pleasure-horses, in consequence of the deformity which it entails. 
The cyst on the internal face, always much smaller, lies upon the tract of the internal lateral ligament of the metacarpo- or metatarso-phalangeal articulation. Its symptoms are the same as those of the preceding, but the blemish which it occasions is less grave.

A propos of the canon, we have spoken of the enormous indurations of the subcutaneous connective tissue which Professor Trasbot designates under the name of fibrous elephantiasis of the members. In the region of the fetlock they acquire at times colossal dimensions. H. Bouley ${ }^{1}$ has seen some that extended from the inferior half of the canon to the hoof, which they enveloped like a hood. Measuring more than a metre in circumference, they touched the ground behind, with the foot in station, and rubbed, in walking, against the opposite member, into which they had made a deep cut. Two tumors of this nature, of which Prudhomme ${ }^{2}$ has given the description, weighed twenty-one kilos. and twenty-seven kilos. respectively. The deep base of these enlargements is ordinarily formed by extremely-developed regetations from the periostenm.

The most common lesions of the fetlock, those which indicate at a glance the excessive function of this articulation and the premature wearing away of the member, are without doubt the tendinous or articular synovial dilatations, which have received the generic name windgalls.

One of these dilatations, however, that of the synovial bursa, facilitates the gliding of the extensor tendons over the superficial surface of the anterior capsular ligament of the articulation, and could with equal propriety be called anterior windgall. In relation to its development, it is alsolutely identical with the others.

It must not be confounded with the anterior cyst of which we have spoken above. Like the latter, it determines an abnormal swelling upon this region according to the degree of the synovial hydropsy ; but what will always permit it to be differentiated from the preceding is its relative situation with the tendon. In the first case, the tendon is never located upon the surface of the tumor; in the second, on the contrary, it is most usually the reverse, unless, under the effect of extreme distention, the somewhat weak parietes of the synovial membrane allow some of the contents to escape into the interspaces of the surrounding connective tissue. Before things have gone so far, however, over the middle of the anterior face of the tumor is seen a vertical gutter which renders it bilobed, and which is due to the compression exercised by the anterior extensor tendon of the phalanges. Rarely does the anterior windgall of the fetlock communicate with the articular synovial. Still, such a communication may be present (Rigot), and it is easy of appreciation, for other lateral dilatations will be found coexisting with it, pressure on which is integrally transmitted to the former (Bouley).

The true windgalls are of two varieties: articular and tendinous. It is important to be able to distinguish them.

Articular windgalls appear above the fetlock in the form of two small, round tumors, one on each side, tense when the member is in station, and softer when it is elevated. They are situated exactly in the angular space comprised between the border of the principal canon bone and the corresponding branch of the suspensory ligament of the fetlock. It is only when they have attained a large

1 H. Bouley, loc. eit., p. 580.

2 Prudhomine, Recueil de médecine vétérinaire, 1844, p. 589. 
volume that there appears, against the first phalanx, in the fold of the pastern and on each side, the outline of two other tumors, always much smaller, whose fluctuations are transmitted to the preceding. We have seen that these are the points of the synovial membrane which are only feebly supported.

Tendinous windgalls, formed within the great sesamoid sheath, are more voluminous and ascend higher than the articular, behind which they are located. Their exact position is the space comprised on each side between the suspensory ligament and the tendons; it is the point which corresponds to the superior culsde-sac of the sheath in question. Below the fetlock there are two other smaller tumors, in the fold of the pastern and along the latter border of the flexor tendons; they communicate with the superior, but are only visible in a state of extreme dilatation of the sheath.

The parietes of windgalls in time become thickened, indurated, and ossified. The accumulation of a large quantity of synovia in their interior renders the movements less easy, and occasions painful pressure upon the surrounding tissues; and, in consequence, the articulatiou itself becomes deviated from its normal direction owing to the mechanical restraint which it experiences and the pain which it causes during station.

The tendinous cords, relieving themselves instinctively, so to speak, from their habitual tension, retract and tend to produce, little by little, a more or less complete effacement of the angle of the fetlock, a complication always grave by reason of the vicious axis of the members which it occasions, knuckling. It is then that the articular extremities, deprived of their apparatus of dispersion, manifest the violence of the concussions which they experience during locomotion by the appearance of osseous formations upon their periphery. The exostoses, whose formation is exciter under the influence of these causes on the anterior and the lateral faces of the fetlock, have received the name osselets.

Generally speaking, the chronic diseases of the region, which we have enumerated, are compatible with the normal function of the joint. But the hard indurations of the tissnes and the formation of osseons vegetations around the articular margins produce a certain restraint of the movements. In spite of the variable stiffness of the members, the animal is still utilizable. A decided lameness, save in exceptional cases, appears only after a long time, when, for example, the synovial membranes are very distended and the articular surfices notably altered.

\section{H.-The Footlock and the Ergot.}

The footlock is a tuft of hairs situated behind the fetlock, around the ergot. Properly speaking, it merits but little attention when a horse is examined for soundness. It is small and formed of hairs of fine texture in the finer races, while in the common races, whose pilous system at the inferior part of the member is, in general, thick, coarse, and very extensive, especially if the subjects inhabit low and damp localities, it presents the opposite characters. It is not rare to see, in these, the hairs of the footlock touch the soil and often ascend to the posterior part of the knee.

Many horse-merchants, in doing up the huirs, do not fail to cut the 
footlock to the form of that in the English thoroughbred, in order to give to their horses an appearance of fineness and quality which they do not really possess.

The ergot is a more or less voluminous horny production, which oceupies the posterior part of the fetlock in the middle of the hairs of the footlock.

In relation to comparative anatomy, by reason of its situation, its connections, and the structures which form its base in some species, it is considered as the vestige of an aborted digit. It is, however, without interest from an external point of view.

Like the footlock, it aequires quite a great length in common horses. It is sometimes seen to divide under the influence of desiceation, and in the end is shed off. When it is too voluminous, it is ent when the hairs of the footloek are being arranged, a useless practice in well-bred animals, for with them it always has very feeble dimensions.

The ergot, in spite of its apparent insignificance, plays none the less a certain rôle of protection, in loeomotion at great speed, in relation to the posterior part of the fetlock, which the violence of the reactions tends to lower to the ground. It is common to see on the race-course, after a race, horses whose ergots are covered with blood from their use, an evident proof that the fetlock must go down to the gromnd at each time of the contact. It is always, in this case, the diagonal biped upon which the lorse gallops that is most injured, a result easy of explanation, sinee the feet which constitute this biped support, in suceession and singly, all the weight of the body multiplied by the veloeity of the locomotory movements.

\section{I.-The Pastern.}

Situation; Limits.-The pastern is situated between the fetlock and the coronet; it is the narrowest part of the member of the horse, and owes without doubt to this charaeteristie the name wrist, by which it is also designated in ordinary langnage.

Anatomical Base.-Its osseous base is formed by the first phalanx, which gives to it, consequently, its oblique direction from above downward and behind forward. We have made mention above (see Fetlock) of all the mechanieal advantages which depend upon the inclination of the superior articular surfaces of this bone; others will be noticed when we discuss the obliquity of its great axis. We will also revert to them in deseribing the function of the pastern as an inelined plane reeeiving the weight of the body and transmitting it to 
the hoof, besides disseminating it in part upon the environing retentive apparatus.

The first phalanx is united behind to the sesamoid bones; above, to the principal bone of the canon through the medium of ligaments which we have already enumerated. (See Fetlock.) Inferiorly, it is firmly articulated with the second phalanx by the lateral ligaments, $e, c$ (Fig. 96), which are common also to the articulation of the foot.

These means of union are completed, anteriorly, by the tendon of the anterior extensor of the phalanges; posteriorly, by the cord of the flexors, separated from the inferior sesamoid ligaments, $b, b, b$ (Fig. 97), by the inferior eul-de-sac of the great sesamoid sheath.

Movements.-The pastern is the seat of two movements, flexion and extension. Each of these modifies the opening of the metacarpoor metatarso-phalangeal angle, which, in a state of repose, can be considered as in an attitude of extreme extension. They have, however, not the same value. Almost insurmountable anatomical obstacles, as we have seen, hinder a greater extension; these reside in the presence of the suspensory ligament and the flexor tendons upon the summit of this angle; a fortunate disposition, in virtue of which the bones maintain their function in sustaining the body, without being exposed to too violent effects from the tractions of the extensive displacements of the latter. The flexion of the pastern, on the contrary, has, so to speak, no definite limits. The articnlar morement is eapable not only of cansing a disappearance of the primitive angle, but even of giving it a disposition inverse to that which it occupied at first. In this case, the obstacle to the closing of the new angle is entirely mechanical; it is due to the presence of the sesamoid bones and the soft tissues, which interpose their thickness between the canon and the phalangal segment.

At the moment of the contact, when the body-weight is thrown on the member, the fetlock is pushed backward and downward, and the pastern tends to become horizontal. It then gradually becomes straightened upon the canon until towards the termination of this phase. The two segments are now almost in a straight line. The pastern then becomes strongly flexed, elevates the foot, and is finally placed in prolongation with the canon to commence again the phase of contact with the ground. These diverse attitudes have been aecurately recorded by MIM. Marey and Pagès by means of instantaneous photographs. ${ }^{1}$

Form.-The anterior face of the pastern is slightly constricted in its middle, particularly in horses in which this region is somewhat

1 Marey et Pagès, Analyse cinématique des allures du cheval, in Comptes-Rendus des séances de l'Académie des sciences, Paris, 27 Septembre, 1866. 
long; the posterior face, less extensive, and known under the name fold of the pastern, is the centre of the movement of flexion of the hoof upon the phalanges; finally, the two lateral faces, almost subeutaneous, are crossed from above downward, and from before backward, by a ligament of constraint which the suspensory of the fetlock sends to the tendon of the anterior extensor of the digit. The skin which covers this region is more or less thick according to the race; the hairs also have a variable abundance and texture.

Beauties.-The pastern should be wide, thick, of medium length, well directed, fine, and free from blemishes.

Width and Thickness.-The width is measured in an anteroposterior sense, viewing the animal in profile; the thickness, on the contrary, is appreciated from side to side, examining the subject in front.

Great importance is attached to the development of both of these dimensions. The width gives the measure of the volume of the first phalanx and of the tendons which pass over its two faces. The thickness indicates the transverse development of the articular surfaces, which, we know, is correlative to that of the fetlock and that of the coronet. Now the principal condition to be realized in the solidity of the members of the horse is the volume of the bones and the ligaments which unite them, in order to maintain their locomotory angles; we judge of it, therefore, in relation to the body, as a whole, keeping in view the thickness of the segment and the abundance of the hairy productions which cover them.

Length.- To assign an absolute length to the pastern would oblige us to enter into too many minute details, as the excess or the deficiency of this element can be, and quite frequently is, compensated by a more or less oblique direction of the phalanges under the canon. The varions differences in this respect can be quickly recognized by the practised eye. We will therefore refer to them only to show the advantages and the disadvantages dependent upon these variations, with regard to the particular service which a horse is destined to perform.

A horse whose pasterns are too long is called long-jointed; he is short-jointed in an opposite sense. Each of these conformations is regarded as an absolute defect, if it be not compensated, in part at least, by a proper direction, as we shall sce farther on.

Until now, and for convenience of demonstration, the phalangal segment was considered as an almost rigid column extending from the fetlock to the ground. 
This view, too absolute in its character, has been recently opposed by our colleagne, MI. Pader, ${ }^{1}$ who has pointed out with reason the articulation of the foot-that is to say, the last inter-phalangal articulation, and not the hoof-as the centre of the movements of rotation of the phalangal lever upon the soil.

This statement being made, the phalangal segment may be represented schematically, during station, by the angular lever $A O B$ (Fig. 99), which rests by its point, $B$ (fixed point), upon the third phalanx, and receives at $O$ (fetlock) the weight of the body, $O R$, transmitted through the canon, $O C$.

The muscular action, $M$, exercised upon the sesamoid bones, $A$, must therefore, at each instant of the contact, in order to maintain the equilibrium, antagonize the force, $R$, and counterbalance it, so that the fetlock, $O$, where it is applied, may remain in its normal situation.

Let us now draw, from the point of support, $B$, the perpendiculars $B F$ and $B E$ upon the direction of the two forces, $M$ and $R$; these lines, it is seen, are the respective lever-

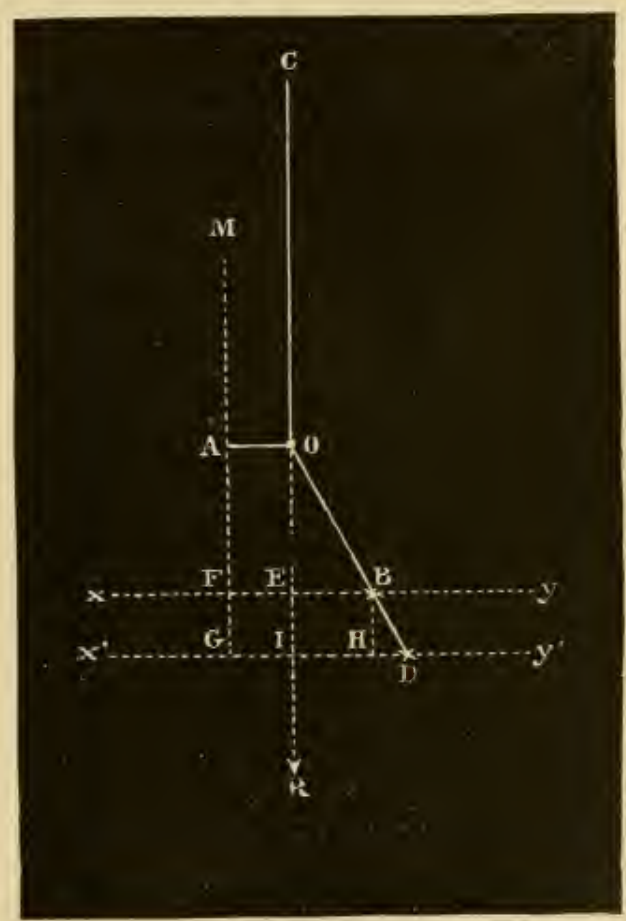

FIG. 99. arms of each of these forces, and it will be seen that here, as in all levers of the second class, the arm, $B F$, of the power overcomes that, $B E$, of the resistance.

It is known, besides, that a lever is in equilibrium when the movements of the two forces are equal.

Whence, since equilibrium does exist, we have the following formula: $M \times$ $B F(\mathrm{mom}$. of the force $M)=R \times B E$ or $I H(\mathrm{mom}$. of the force $R$ ).

This being laid down, let us now lengthen the pastern, and make it $O D$, for example.

The new arms of the lever will be $D G$ and $D I$. Both will be lengthened by the same quantity, $H D$, which will necessarily disturb the equilibrium, for the arm of resistance will have angmented, relatively, by a greater quantity than that

1 Pader, De la ferrure normale, in Bulletin de la Soc. cent. de méd., vét. aunée, 1858, p. 497. 
of the power. The absolute augmentation, however, being equal for both, the preservation of the equilibrium will demand that the power or the muscular contraction be more intense to counterbalance the resistance, or the weight of the body, whose arm has lengthened beyond the limits required by the mechanism of the parts.

Whence it follows that the elongation of the pastern increases the force $R$ at the expense of the force $M$, beeause its effect is to lengthen the arm of the lever by the same quantity, instead of in an inverse ratio to the forces which move them.

During locomotion, when the foot has reached the ground, it is no longer the first two phalanges that constitute the phalangal segment, as M. Pader ${ }^{1}$ believes, but

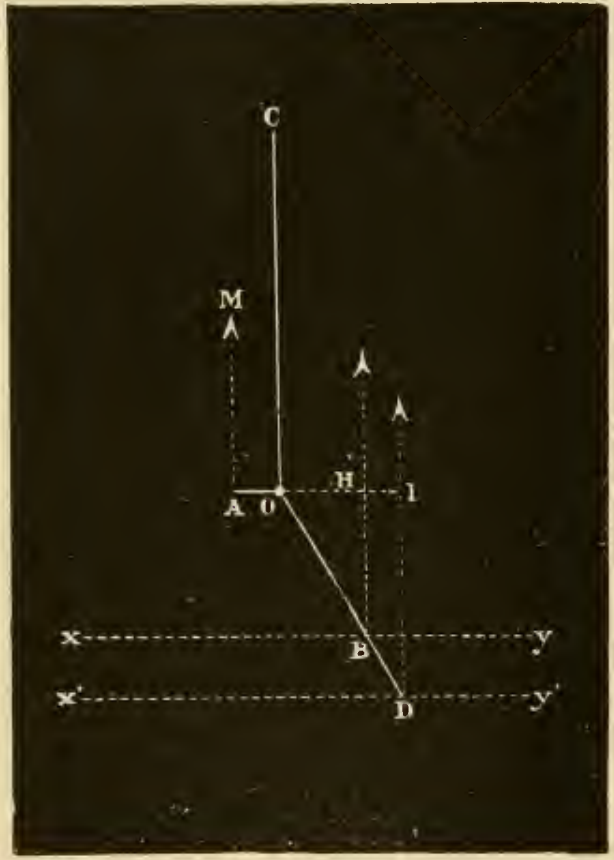

FIG. 100. it is the entire digital region, the hoof included.

These form, it is true, a broken lever romposed of two pieces (1st, the first two phalanges; $2 \mathrm{~d}$, the hoof), but their suceessive movements, always in the same direction, are so elosely associated as to give to the total displacement a unity analogous to that produced by a rigid lerer, $O B$ (Fig. 100), extending from the soil, $B$, to the fetlock, $O$.

With a quantity of movement that varies aecording to the weight of the body and the velocity of the gait, the extremity, $B$, of this segment comes, at each step, in contact with the ground, $x y$, which necessarily reacts in proportion to the action which it communicates to the hoof. It is easy to convince ourselves that this action is also modified by the variations in the length of the digital region.

Let the line $B H$ represent the force which, acting at the extremity, $B$, of the lever, $B O A$, tends to rotate it around the point $O$, and, consequently, to close the 
angle $B O C$, by antagonizing the muscular action, $M$, which is exercised at the extremity, $A$, of the same lever. In this case, the fetlock becomes the fixed point or fulcrum and the lever belongs to the first class.

Let us determine, as above, the arms of the lever of the forces, $B H$ and $A M$, by inserting from the fixed point a line perpendicular to their direction; these arms evidently are $O H$ and $O A$.

Now let us lengthen the lever $O B$ to $O D$, and we will see that the arm of the force, $B H$, becomes $O I$, while that of $A M I$ will always remain $O A$.

Thus, the longer the pastern the more the reaction of the soil against the weight of the body augments and fatigues the tendons and the ligaments which are inserted, at $A$, upon the sesamoid bones. The canses which tend to angment the length of the phalangal region are very significant, exception being made, of course, of the dimensions of the bones.

First among these we will place the elongation of the boof, resulting from the normal growth of the horn in a horse whose shoe is not sufficiently often reset; secondly, the error of the farrier in not sufficiently paring the foot; finally, the tendeney which farriers or proprietors have, according to their interests, of applying too thick a shoe in order not to have the trouble or the expense of resetting them at proper intervals, as often as the state of the hoof requires it.

Deficiency of the length of the pastern evidently has inverse drawbacks. The short-jointed horse surcharges his bones beyond measure; he lacks suppleness in consequence of the insufficiency of the fetlock as an apparatus of dispersion, and has, from this fact, hard reactions; besides, he is more predisposed to osseous blemishes of the bones of the members, as ring-bones.

The inconveniences of the long joints and the short joints have not, by far, the same importance in the anterior as in the posterior members, on account of their unequal distance from the centre of gravity. It is beyond a doubt that the anterior extremities, incomparably more loaded than the posterior in the sustentation of the body, show more quickly and more gravely the injurious consequences of these defects. In fact, experience has demonstrated this; blemishes of the anterior members are more common than those of the posterior, and the part which the pastem takes is more marked in the former, this region being always longer in the fore than the hind limbs, and also more oblique, doubtless on account of their proximity to the centre of gravity.

Direction.--The direction of the pastern is intimately allied to its length,- - that is to say, a long pastern is in most cases too horizontal, 
while it becomes more vertical when it is too short. In the first ease, the horse is low-jointed; in the second, he is qualified straight-jointed (Fig. 101 and Fig. 102).

The close relationship which associates long-jointedness with lowjointedness is easy of comprehension, the pastern becoming less and less a column of support, and

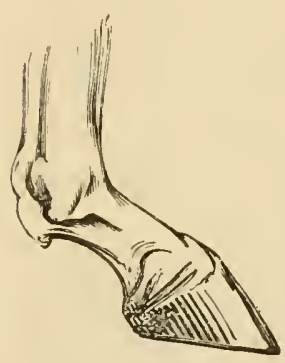

FIG. 101.

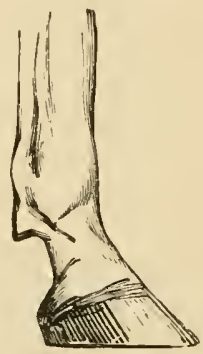

FIG. 102 more and more an elastic spring in proportion as its length increases. We have seen above that the arm of the lever of resistance (weight of the body) elongates and imposes greater efforts upon the muscles and the ligaments. A spring also gives all the more as it is more elastic and as the pressure which it supports is greater. This is precisely what takes place in a long-jointed pastern, which is at the same time nearly always lou-jointed, because it is relatively weak and flexible under the weight and the reactions of the body.

Some horses, nevertheless, are exceptions. Either from the great resistance of the fibrous ligaments or the tendons to traction, the mode of articulation of their bones, a greater energy of their muscles, an intensity of action which is more effective from the length of the arm of the lever and the perpendicular incidenee of insertion, or, finally, for some other cause, these animals redeem the excess of the length of the pastern, and mitigate the evil effects by a less oblique direction. These instances, however, are rare, which is nothing but natural, as we have just seen.

Most authors who define the direction of this region estimate it at about 40 to 45 degrees, in such a manner as to form with the fetlock an angle of 130 to 135 degrees. Vallon and M. Lemoigne are the only ones, to our knowledge, who seem to have measured this inclination with some care upon the living horse or upon the skeleton. Aside from the purely theoretical idea that the pastern should have a direction intermediary between the absolutely vertical and the horizontal, it has been believed to be good logic to recommend a mean obliquity of 45 degrees, without perceiving that this argument is funlty, first of all, in its premises, since it is not based upon facts.

The mean obliquity, in our opinion, oscillates around 60 degrees upon the horizon, in the anterior members, and 65 degrees in the pos- 
terior, which are always more vertical to the fetlocks. An inclination of 45 degrees is not observed in well-formed horses provided with good axes; it constitutes, on the contrary, a low-jointedness quite marked.

Let us now see the disadvantages which accrue from an excess or an insufficiency of obliquity ; they are of the same nature as those which follow an excess or an insufficiency of length. There are several ways of explaining this :

Let us first regard the pastern as an inclined plane of surface and of segment in the decomposition of forces parallel to the weight.

Suppose

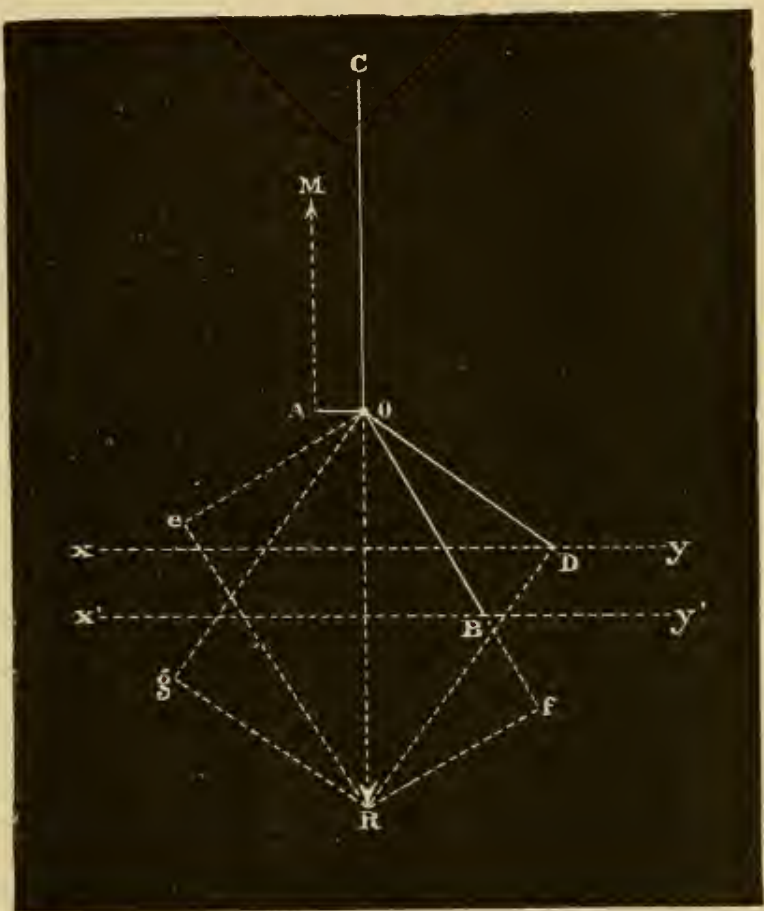
and $O D$ (Fig. 103) are two pasterns of the same length, but unequally inFIG. 103. clined upon the canon $O C$. From the fact of this inclination, the weight of the body, which we will represent in quantity and direction by the line $O R$, is decomposed, at the level of the fetlock $O$, into two forces, one of which is parallel to the phalangal region, and is overcome by its own resistance; the other is perpendicular to the preceding. The latter is exerted upon the sesamoid bones, and tends to lower the angle of the fetlock against the summit of which the tendons are applied.

These two components of the resultant $O R$ are, by constructing the parallelogram of forces: for $O B, O e$ and $O f$; for $O D, O g$ and $O D$. They indicate, for each inclination, the rôle which is intrusted to the bones and the museles. The sole inspection of the figure shows that with the pastern $O B$ (straight-jointed), the component $O f$ exceeds $O e$, and therefore likewise $O D$, which corresponds to it in the other ease. 
Therefore the straight joint surcharges the bones and relieves the muscles $A M$, which antagonize the force $O e$, while the long joint favors the bones at the expense of the tendons which it exhausts.

The pastem plays a no less important part as a lever, whatever way we examine it.

Being still given the two pasterns $O B$ and $O D$ (Fig. 104), of the same length, but unequally inclined upon the canon $O C$ : They form with the great

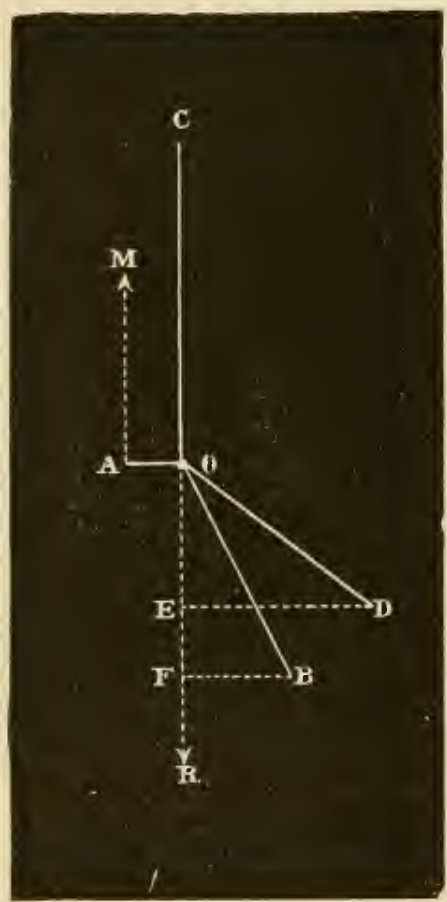

FIG. 104.

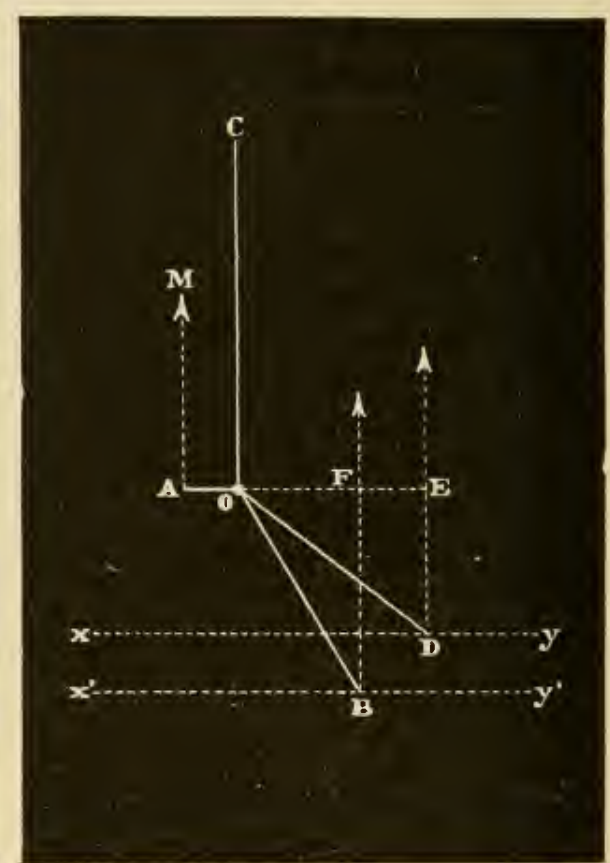

FIG. 105.

sesamoids, $A$, two angular levers, $A O B$ and $A O D$, of the second class, whose point of contact or fulerum is on the ground at $B$ and $D$, whose resistance, $R$, is at $O$, and whose power, $M$, is at $A$.

It is apparent that by drawing the perpendiculars $B F$ and $D E$ from the points of contact upon the direction of the force $R$,-that is to say, the arms of the lever of resistance for each of these inclinations,- this force will act at the extremity of an arm longer in the case of the low-jointed pastern than in that of the straight-jointed one.

The obliquity of the phalangal lever, therefore, obliges the musdes $A M$, whose lever-arm remains invariable, to make more energetic 
contractions, in order to maintain the equilibrium of the fetlock which receives the weight of the body, whose lever-arm has augmented.

Finally, the results are identical when the animal machine, moving at great speed, strikes the ground at each step of the gait.

When the levers $A O B$ and $A O D$ (Fig. 105) are of the second class, the power is always applied at $A$, the fulcrum is at $O$, while the resistance becomes the reactions, $D E, B F$, of the soil against the weight of the body, which are perceived at the points $B$ and $D . \quad B y$ drawing the perpendiculars $O F$ and $O E$ from the fulcrum, or point of relation, upon the direction of the vertical forces $B F$ and $D E$, it is found, as in the preceding figure, that the greater the inclination of the pastern the more the lever-arms $O E$ and $O F$ augment at the expense of the arm, $O A$, of the muscles, $A M$.

This implies that the obliquity of the phalangal region renders the reactions of the soil against the quantity of movement with which the body is animated at great speed more laborions and fatigning for the tendons.

It results from the preceding that the inconveniences of low-jointedness are of the same value as those of long-jointedness, and hence it follows that they will be superadded to each other in horses suffering simultaneously from these two defects. The same may be said of the straight and the short-jointed pastern.

These conformations, nevertheless, do not offer the same gravity in all services. The long and oblique pastern renders the horse more supple and more pleasant to ride; it enables him to disperse more easily the violent reaction of locomotion at great speed, and it wonld be very desirable in the saddle-horse, the driving-horse, and the racehorse, were it not a source of danger to the integrity of the tendons. The short and straight pastern is strong; it has no very prejudicial influences against heavy-draught services, but it renders the reactions hard and jeopardizes thereby the integrity of the osseous apparatus; hence it unfits a horse for the riding-school or for fast riding.

To recapitulate, numerous disadvantages and sometimes advantages may accrue from a pastern erring in its length and in its direction. If both sides be compared, it will be seen that it is injudieions to extol too much any one of these conformations in preference to that which we have indicated as the beantiful: the long, low, straight, and short joints" will always constitute defects.

Neatness of Outline and Freedom from Blemish.--The pastern is called neat when its skin is thin, the subcutaneons connertive tissue rather scarce, the hairs delicate and short; the boncs and the tendons are then apparent in their special form and direction. 
Here, also, neatness is a charaeteristic of quality and distinction, which the thoroughbred horse presents in the highest degree. Common horses, like the dranght-horse, have this region more or less thick, and the hairs of the footlock almost cover its posterior face. It is the custom to cut these hairs in the lighter variety of horses which are somewhat lymphatie and lack in breeding, so as to make the members appear more slender and render the form and ontline of the extremities more apparent. This procedure is not practised in heavy horses, in which these hairs fulfil the role of protecting organs against mud and dust.

The neatness of outline of the pastern implies, as in the other regions, the absence of diseases and blemishes.

Diseases and Blemishes.-MIny diseases are observed upon the pastern or extend there from other regions: such are contusions, excoriations, superficial wounds of the skin, cuts, fissures, collosities, nedema, abscess, grease, lymphangitis, fibrons elephantiasis, ete. We will only mention them in passing.

However, there are some diseases and blemishes whose seat is entirely confined to the pastern.

Let us cite first the effects of halter-cast, a transverse or oblique wound which is occasioned in the fold of the pastern by the friction of too long a strap fastening the horse to the manger. This aceident is produced when the animal, in endeavoring to rub the mane with one of the posterior biperls, or the pastern of one of these with the teeth, carries the posterior member forward, which then becomes entangled in the halter-strap. The latter, strongly tensed by the inverse actions of the neck, which is straightened, and of the foot, which is carried backward, moves to and fro over the skin, whence result more or less profound wounds.' Sometimes the animal loses his equilibrium, falls down, and twists the neck, which determines a permament deviation of the latter. ${ }^{2}$ Such a mishap can also be produced under other circumstances, when, for example, the horse is tied to a post, or to a cord with a fetter fixed to one of the anterior pasterus; when he is cast for the purpose of undergoing a surgical operation; when he is obliged to eat from the ground, and being in harness, accidentally entangles one of the members in the reins, ete. The symptoms and the gravity of this accident vary aceording to the qualities of the rubbing body, its hardness, the intensity of the friction, and the nature of the lesions. We will not expatiate on these. Let us merely say that a eicatrix follows these lesions, which, in most instances, is permanent, and upon which the hairs are not replaced. At times, the cicatricial tissue is so abundant that the region remains permanently enlarged and deformed; the movement of flexion of the foot is rendered less easy and the skin is much more sensitive to causes capable of irritating and excoriating it. Finally, there are cases in which cicatrization never follows, and the wound con-

1 H. Bouley, Nouveau dictionnaire de médecine, de chirurgie et d'hygiène vétérinaires, $t$. v. p. 662.

2 This accident. caused by the struggles of the animal, often gives rise to wryneck or partial luxation of the cervical vertebræ. 
tinues to discharge. The latter is then converted into an incurable fissure, often with an eezematous condition of the surrounding parts.

Fissures on the pastern are more grave than in any other region by reason of the movements and the difficulty of maintaining the wound which they occasion in a proper state of cleanliness.

The soft tumors which are observed here are synovial dilatations belonging to the great sesamoid sheath, or to the articulation of the fetlock. They appear on each side of the flexor tendons, but usually do not acquire a large volume. However it may be, they accompany windgalls, and only show themselves when the latter are largely developed.

Linear cicatrices are met on the lateral planes of the pastern, indicating that the animal has been subjected to neurotomy for a chronic discase of the organs contained in the hoof, or for osseous tumors of the coronary region. It is therefore necessary to ascertain if the malady against which the treatment has been employed has disappeared.

Exostoses of the first phalanx receive the name of osselets. Some incorrectly call them ring-bones, this appellation being reserved for the osseous tumors of the coronet or of the complementary fibro-cartilages of the third phalanx. The osselets may or may not cause lameness, according to the restraint which is experienced by the tendons or the articulation; they generally result from hard usage, and occur more frequently upon the anterior members, upon short and straight pasterns oftener than upon any others. Sometimes they result from blows, and are even the consequence of fractures of the first phalanx, accompanied by the formation of a callus.

Finally, let us mention traces of actual cautery, in points or in lines, used as a means of treatment against osseous tumors, indurations of the skin, or all other chronic affections of this region. These blemishes are, however, in most instances, only an extension of those which are dependent upon the cauterization of the fetlock or the coronet. When they are present, it is imperative to examine with care the adjoining parts of the member in order to assign to these blemishes their just value in the depreciation they canse to the animal.

\section{J.- The Coronet.}

Situation; Limits; Anatomical Base.-The coronet, a region rather difficult to delimitate, is situated between the pastern and the hoof.

Its anatomical base is that part of the second phalanx not contained in the horny case, covered anteriorly by the tendon of the anterior extensor muscle of the phalanges, posteriorly by that of the deep flexor, and laterally by the superior portion of the complementary fibro-cartilage of the third phalanx as well as by the glomes of the plantar cushion.

Rounded from side to side on its anterior face, wider below than above in consequence of the presence of the eoronary band, and depressed on its posterior face at the level of the concavity which separates the two bulbs of the aforesaid cushion, the coronet also presents on each side the tuberositics which give attachment to the lateral ligaments of the first inter-phalangal articulation. It is 
covered by a thick skin provided with hairs more or less abundant and coarse, according to the fineness of the animal.

Before presenting a pleasure-horse for sale, they usually clip his hairs in order to give to the members a certain appearance of lightness. But neither horses of the finer races nor heavy-draught horses are, as a rule, subjected to this practice, becanse in the former the hairs are short and fine, and in the latter they constitute an apparatus of proteetion of which it is unjust to deprive the horse.

In the army it is prohibited to dress the hairs over the parts corresponding to the pastern, in order to protect them as mueh as possible against the injuries so frequent during the manœuvres.

Beauties. - The only points of this region are the width, the fineness, and the freedom from blemishes.

The first implies a correlative width of the phalanges and the firmness of the member. The second consists in the thinness of the skin and the delicacy of the hairs; it indicates the ancestry, the temperament, the energy, and the vigor of the horse. As to the third, it implies a perfect regularity of the parts and the absence of diseases and blemishes.

Diseases and Blemishes.-The coronet, like all the other inferior regions of the members, shows numerous alterations which involve either the skin and the subcutaneous connective tissue, the tendons, or the bones. Their gravity necessarily depends upon the nature of the lesions, their location, their period of existence, and the interference which they offer to the locomotory function.

These are first calks, deep wounds of the skin, of a variable extent, which result from the contact of the feet in some circumstances, as on the race-course or in leaping over obstacles, for example.

Grease or water in the legs, already cited in the description of the canon, the fetlock, and the pastern, often begins at the coronet, whose hairs it agglutinates into small pencils of a bristly aspect which is quite peculiar, and which is vulgarly compared with a comb.

Contusions and other tramatisms produce, at times, deep alterations of the lateral cartilages, the tendons, the glomes of the plantar eushion, or even the skin, and give rise to a partial necrosis of these structures, known under the generic name quitter. A quitter may be tendinnus, cortilaginous, or cutaneous, according to the tissue involved. In general, they should be considered as being grave, for they incapacitate the animal from service for a long time and compromise his very life by the complications which accompany them. (See Fot.)

The anterior fice of the coronet is sometimes the seat of an afiection called crapendine, which is characterized by a peculiar modification of the secretory function of the coronary band, which becomes fissured and cracked after the manner of the bark of an old tree. (See Foot.) 
The osseous tumors of the region have received the name ring-bone, and are located on the anterior and the lateral faces. Clinically, they are distinguished as coronary and cartilaginous, aecording as they are developed upon the second phalanx or in the thickness of the lateral cartilages of the foot. ${ }^{1}$

They are usually, to whichever variety they may belong, the consequence of violent percussions received by the bones during locomotion, or of contusions of the cartilages. They also follow inflammatory conditions of a diverse nature, such as abscesses of the coronet, tendinous or cartilaginous quitter, the prick of a nail, etc.; finally, they are frequently sequelæ to fractures, in which case it is observed they are persistent. Short-jointed horses, young horses with a precocious constitution, which are subjected to laborious work, and full-grown horses which are employed in severe labor on the pavements of large cities are much more predisposed to such formations than others. The influence of heredity has been recognized for a long time ; certain families of horses, from injudicious selections or crossing, invariably transmit these blemishes to their descendants.

Ring-bones are recognized by a hard, resisting tumefaction, which covers the anterior or lateral faces of the coronary region, and manifests itself as an abnormal convexity when the animal is examined from in front or in profile. Although the enlargement is most often apparent to the eye, it is sometimes concealed by the thickness of the integument and the abundance of the hairs; it is therefore necessary to complete the examination by the use of the hand, especially in horses whose coronet is not very distinct in its outlines.

A ring-bone most usually at its beginning oceasions lameness; but when the tumor is once formed the lameness disappears, unless the exostosis has reached the contour of the articular surfaces.

Knuckling also appears as a complication of old ring-bones; to this symptom may be added contraction of the hoof, due to the deviation of the coronary band.

These exostoses always constitute a serious blemish, but the degree of the gravity nevertheless varies. It is clear that the depreciation of the value of the animal is greater as he is one of luxury or a rapid motor, and as the interference with the locomotory functions is more pronounced. Many horses are but little depreciated even by a voluminous ring-bone which is not accompanied by lameness, or whose lameness does not interfere with their utility as draught-horses. It is entirely different with pleasure-horses, in which the perfectness of conformation and the cleanness of the members form one of the essential conditions of their aequisition. Finally, these exostoses are, from their hereditary tendency, an absolute reason for condemning such horses as are destimed for breeding purposes.

The coronet rather frequently presents on its surface traces of the actual cautery in points or in lines. We will repeat here the advice we have so often given in such cases: it is necessary to ascertain by a minute examination that the diseased processes against which this treatment has been employed have really disappeared. Certain horse-dealers, indeed, have applied, with fraudulent intent, the actual cautery upon the member for the concealment of a lameness whose seat is more or less distant from the cauterized parts.

Let us remark, in terminating, that there is a partienlar variety of scabies or mange affecting the inferior extremities of the members of the horse; it is quilified symbiotic or chorioptic mange, because it is calused by an acarus named sym- 
biotes or chorioptes spathiferus. It resides in the coronary band, the fold of the pastern, and the footlock, which are soon covered by an abundant scurfy desquamation of the epidermis and gradually deprived of their hairs. This mange is benign, in consequence of its very slow spreading and the little tendency of the acarus towards migration; it passes easily from one anterior or posterior member to the other, whilst it is more rarely seen to be communicated from one anterior member to the corresponding posterior. However it may be, this variety of mange occasions decided itching, which prevails during the night or after work and induces the animal to rub and bite himself. From this symptom, it disturbs their rest, worries them unnecessarily, and exposes them to wounds which are to be dreaded on account of their situation. It is only contagious from horse to horse, and not at all from horse to man.

\section{CHA P'T E R I I I.}

THE FOO'T.

Definition.-The foot, in its relation to eomparative anatomy, is all that part of the member which is below the forentm or the leg.

This definition, on the contrary, much more limited so far as the exterior is concerned, is bere applied only to the extremity of the members whieh rests upon the ground, the nail, properly so called, the horny box, vulgarly known under the name of the hoof, which contains and protects living, sensitive tissues of variable texture and properties.

Distinction.-Four in number, the feet are qualified fore or hind, according to their relative situation with the centre of gravity. All have the same general organization; they differ, nevertheless, in several external characters which we will soon explain.

In each biped, anterior or posterior, they are distinguished as right and left; their conformation otherwise is absolutely identical.

\section{A.-Organization of the Foot.}

The foot has always been considered as onc of the most important regions to study. This will be the better appreciated when we learn the part it plays in station and in locomotion, the influence of its beauties and defects npon the aptitude of the animal for diverse services, and, finally, the gravity of its diseases.

Nore than twenty-two centuries ago, Xenophon said that the members are the very first parts to be examined in the horse: "A house camnot serve any purpose, however perfect it may be in its superior 
parts, if it has not a good foundation; it is the same with a warhorse; he will be good for nothing if, being perfect otherwise, he has bad legs (members); for he is unable to use whatever good points he may have.

\section{"In the examination of the legs, look first at the foot!" "}

This is the same idea which is reproduced, in our days, in the forms of aphorisms in all treatises on the exterior:

"No foot, no horse!" said Lafosse.

"No foot, no horse!" repeat the English.

Bracy-Clark has only translated the thought of Xenophon when he said, "Incerta basis instabile æedificium !"

The foot is formed by a certain number of internal parts, covered by a modified skin admirably adapted to its special functions, as well as by a horny envelope known nnder the name hoof. Let us examine them rapidly.

\section{Internal Parts of the Foot.}

These parts are complex and numerous; their relation can be clearly recognized in a vertical and antero-posterior section of the organ (Fig. 106).

Three bones form its osseous base and permit it to accomplish its various movements. These are: the third phalanx or pedal bone $(a)$; the second phalanx, or coronary bone $(b)$; finally, the navicular, or small sesamoid bone $(c)$, situated behind the preceding and complementing the articulation which the other two form.

Short, strong ligaments consolidate the joint on the sides, while two wide fibro-cartilaginous plates, lateral cartilages of the third phalanx, intimately united to this bone, seem like two elastic and diverging springs, placed on the outside and on the inside of this boue, to prevent it from descending or rocking too suddenly in the hoof at the moment when the latter strikes the ground.

Two strong, expanded tendons terminate upon the third phalanx : the anterior (d) carries it into extension; the posterior (e) permits, on the contrary, the flexion of this bone upon the os coronæ; it glides over the inferior face of the navicular bone by means of a synovial sheath designated under the name small sesamoid sheuth (better called the navicular sheath).

Finally, a voluminous fibro-elastic cushion $(g)$, called the plantar cushion, bifurcated behind and pointed in front (Fig. 107, $B: d)$ ), is placed under the flexor tendon, to which it serves as a flexible buffer when the foot has reached the ground. All pressure upon the hoof from below upward tends to depress it and force it against the lateral parts, where it is maintained by the two elistic cartilages indicated above.

Cutaneous Envelope of the Foot.-This is the skin, modified in its functions and external characters, which covers the surface of all these organs. The proof of this can be easily obtained by maceration of the hoof, or the artificial removal of the hoof and the hairs of the digital extremity, in order to see

1 Xénophon, De l'Équitation, traduction du baron de Curnieu, chap. i. p. 7. Paris, 1810. 
the integuments in direct continuity with the living parts which might, at first the integuments in direct continuity with the living of an entirely different organization
siglit, be mistaken for tissues consisting of a
Let Fig. 107 represent, by $A$, the normal foot before maceration; by $B$. the same

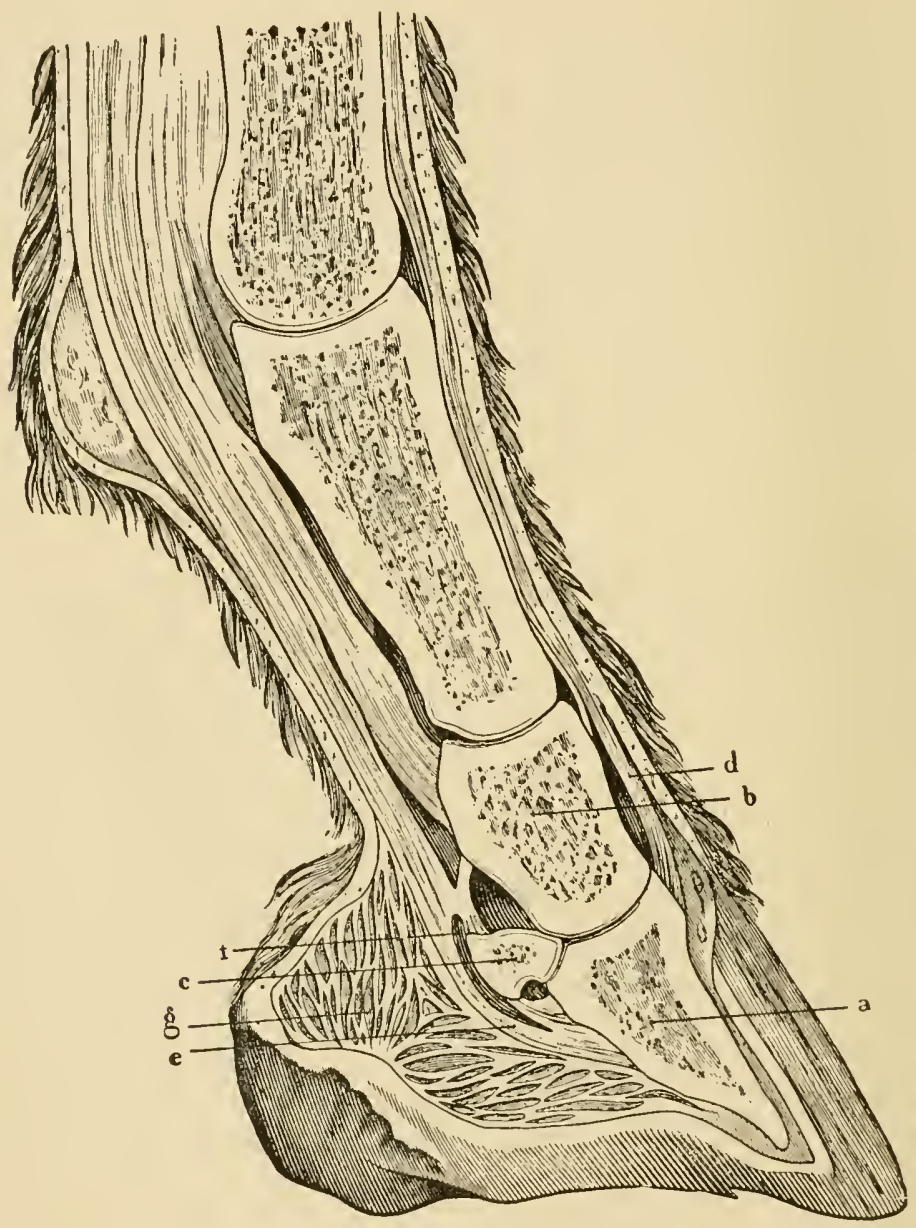

FIG. 106.-Longitudinal and median section of the foot.

foot after prolonged soaking in water. The epidermic productions, the horn and the hairs, naturally detached, leave the cutaneous covering intact.

The latter, vulgarly known under the name fleshy enrelope, flesh of the foot, is remarkable for its great vascularity and the abundance of its nerves. Hence it is very susceptible of congestion and inflammation as soon as the hoof, which surrounds it, has lost its physiological properties. All its lesions, of whatever nature they may be, are always accompanied by intense pain, the tumefaction of the living parts becoming impossible, incased as they are in a resisting, almost inextensible, envelope. 
The cutaneous envelope of the foot, also called the keratogenous membrane, is subdivided into three important regions. These are :

$a$. The coronary band or cutidure (Fig. 107, $B: a$ ) is an enlarged, circular band or ridge, crowning superiorly the living parts and terminating behind

B

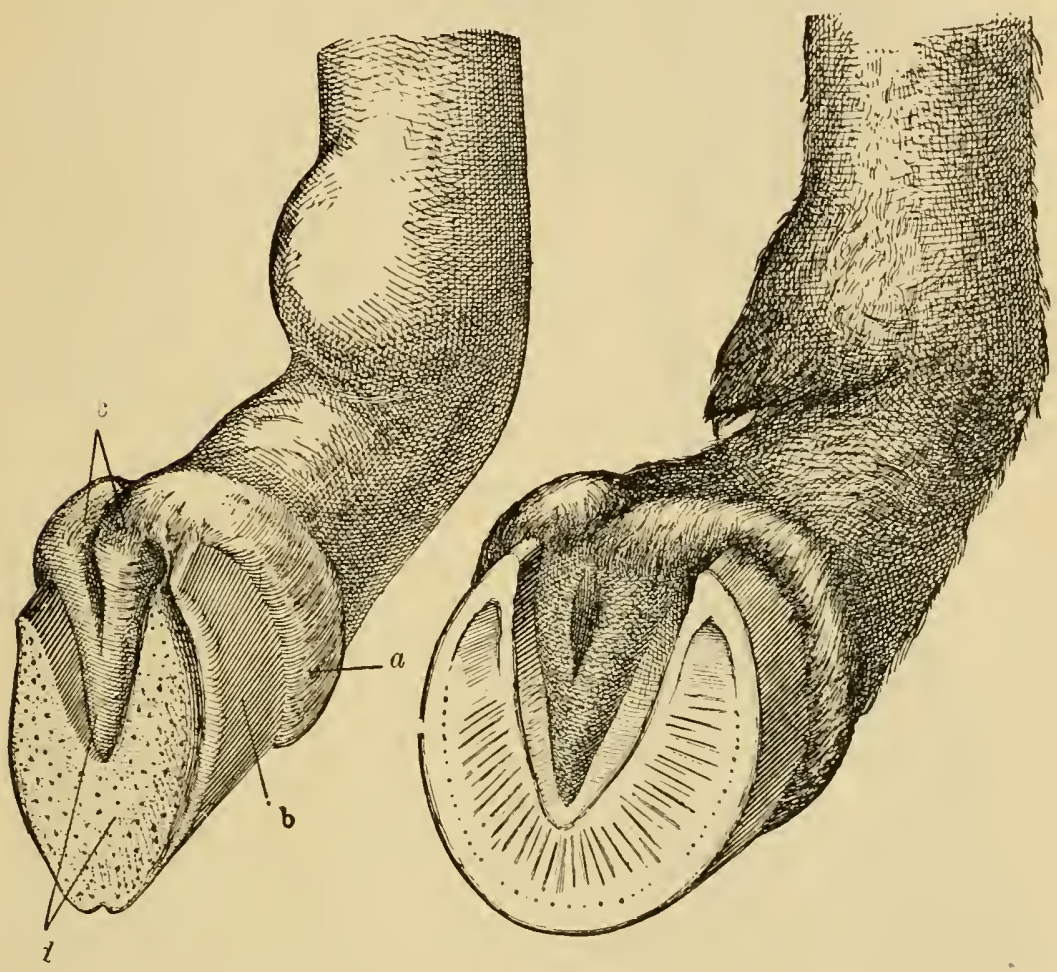

A

FIG. 107,-A. The normal foot before maceration. $B$. The foot after maceration.

by a continuity with the glomes, $c$, of the plantar cushion. It offers along the entire length of its superior border a much smaller secondary convexity, known uncler the name of perioplic band, to which are intrusted special functions.

It is covered over the remainder of its surface by a multitude of filamentous prolongations, papilla, easily perceived when immersed in water. These penetrate, by so many foramina, the superior border of the wall. Endowed, physiologically, with the elaboration of the latter, the cutidure constitutes also, by its villosities or papillæ, very rich in nerve filaments, a veritable organ of tactile sensation for the horse, which can thus recognize, with all the perfection desirable, the quality of the surface upon which his font rests.

b. The podophyllous, laminated, or lamellar tissue (Fig. 107, $B: b$ ) comprises the whole periphery of the cutaneous envelope situated below the coronary band. This tissue, which owes its name to the numerous lamina or longitudinal leaves which it presents, also forms a whitish, soft horn, composed of 
laminse intimately united to the horn which descends from the coronary band. This adherence of the two horny productions is so strong that it resists the most

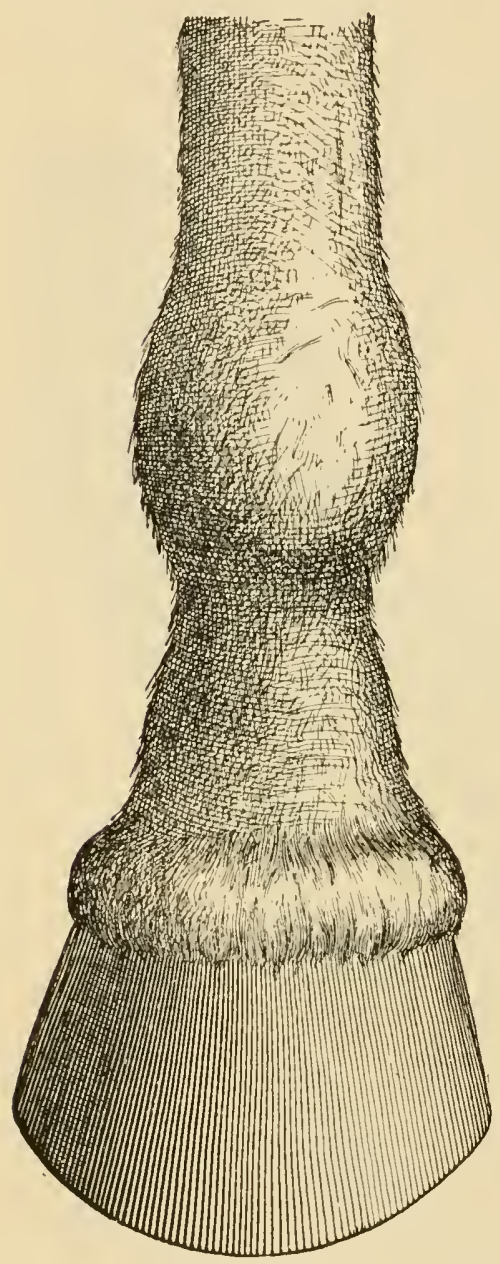

FIG. 108,- Foot viewed in front. prolonged maceration. Behind, the laminæe are reflected into each of the lateral lacunæ of the plantar cushion, and are in relation with that part of the parietes of the hoof which is called the bars.

$c$. The villous or velvety tissue (Fig. 107, $B: d$ ), whose aspect approaches that of a bushy sod, in consequence of the innumerable villosities over its surface, covers the whole of the plantar surface of the third phalanx and the plantar cushion or fleshy frog. Like those of the cutidure, these papillæ are received into the numerous foramina of the subjacent horn which is produced by the most superficial layer of the velvety tissue.

\section{The Hoof.}

The hoof, as we know, is the external liorny envelope of the foot, or, more properly speaking, the nail of the horse. Its form is that of a cone with its base downward and the summit truncated obliquely from above to below and from before to behind (Fig. 108). Its conical disposition, however, being always very slight, is only very apparent when it is examined from in front or behind. Viewed in profile, it has more the form of a cylinder, as has been remarked by Bracy-Clark ${ }^{1}$ (Fig. 109).

Concave below, cleft behind, and bordered superiorly by the skin of the coronet, the loof is composed of three distinct pieces intimately united to one another. These pieces can be separated the one from the other by prolonged maceration or boiling; they are designated under the names wall, sole, and frog. We must enter into a special study of each in order to understand the mechanism well.

a. The Wall.-The wall or paries forms, as its name indicates, the circumference of the hoof, and includes all that portion of the horny ease which is visible when the foot rests upon the soil. It represents a large erescent of horn, curved on itself (Fig. 110), placed against the anterior face of the foot on which

1 Bracy-Clark, Recherches sur la construction du sabot du cheval. 
it is moulded, and folded from behind forward at its extremities. The latter terminate in a point, converge towards each other by encircling the frog, and unite at the point of the latter. ${ }^{1}$

The wall is divided into several important regions bearing various names (Figs. 109 and 111).

The toe, $a$, is

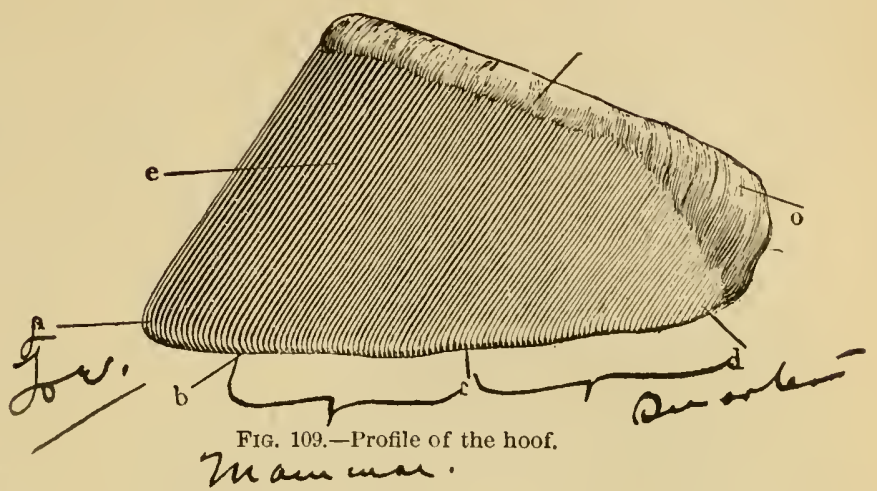
the median and anterior fifth of the circumference.

The mamme, $b$, include the fifth on each side of the toe.

The quarter, $c$, also double, constitutes the posterior fifth of the lateral sur-

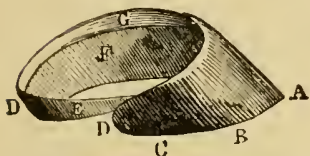

FIG. 110.

face, immediately behind the preceding.

The heel, $d$, situated altogether behind, corresponds to the point where the wall becomes inflected inward to constitute the bars.

Finally, the bar or stay, $e$ (Fig. 111), visible only on the raised foot, is the reflected portion representing the extremities of the wall, placed between the frog and the sole.

The wall offers for study, also, besides these subdivisions, two faces and two borders.

The faces, distinguished as external, $e$ (Fig. 109), and intemral, $q$ (Figs. 112 and 113), diminish gradually in height from the toe to the extremity of the hars.

1 This statement is entirely erroneous, because the bars do not extend beyond the posterior two-thirds of the lateral faces of the frog, which I have repeatedly observed. (Harger.) 
The first, convex transversely, rectilinear from above to below, is smooth, polished, and shiny. It is more oblique anteriorly than on the sides, which are themselves unequally inclined and incurvated. The internal quarter is always more straight and less round than the exterual.

The second, coneave from side to side, is eovered by numerous longitudinal laninæe, $q$, of white horn (keraphyllous tissue), which are solidly dovetailed into those of the podophyllous laminre on the pedal bone.

As to the borders, the inferior (Fig. 111), the longest, rests upon the ground,

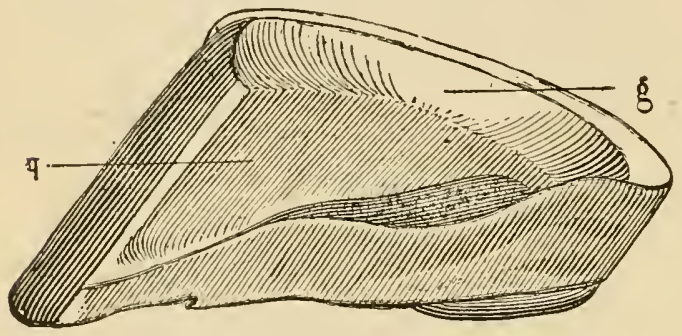

FIG. 112.-Antero-posterior and vertical section of the hoof (internal face). whose friction and wear it sustains, particularly at the tree and the mamme, in the unshod foot. On the contrary, bearing upon the superior face of the shoe in the domesticated horse, this border is removed by the farrier at each shoeing; and the latter should, in this connection, endeavor to imitate the natural conditions of wear and tear.

Its thickness diminishes from the toe to the heels, and then augments suddenly at this point to form the bars. Finally, it is intimately united along its whole periphery to the contour of the sole.

The superior, thin and oblique, shorter than the preceding, and bounded exteriorly by the periople, $p$ (Figs. 109 and 117), is transformed, inwardly, into

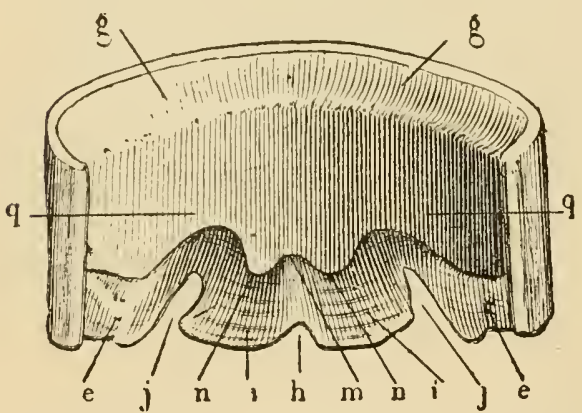

FIG. 113.-Transverse section of the hoof (anterior part). a semi-cylindrieal gutter, $g$ (Figs. 112 and 113), which traverses its entire length and lodges the coronary band. It is at the region of this gutter, called the cutigeral cavity, which becomes effaced towards the region of the bars, that the parietal horn is elaborated by the cutaneous thickening in question.

b. The Sole.-The sole is a large horny plate (Fig. 111), deeply notched behind for the reception of the frog, which occupies the inferior face of the foot. Concave inferiorly and convex superiorly, it fills the interval which exists between the inferior border of the wall, the bars, and the point of the frog.

Its superior or internal face (Fig. 114, a) is studded with porosities in which are embedded the numerous papillic of the velvety tissue, and receives the pressure of the third phalanx.

The inferior, $f$ (Fig. 111), exeavated, arch-like, and in contact only with the inequalities of the ground in the wild horse, is hard, dry, and scaly. 
Of the two borders, the external or anterior describes almost a semi-circumference, and unites intimately with the inferior border of the wall. The internal or posterior, on the contrary, much less extensive, simulates a re-entering angle, like the letter $\mathrm{V}$, whose sides are adherent to the bars and the frog.

c. The Frog.-The frog is a wedge or pyramid of soft horn, which covers the plantar cushion, whose form it reproduces. Lodged in the angle formed by the bars and the posterior border of the sole, it is seen to be single in front and bifid behind; two faces and two extremities are thus assigned to it.

The superior or internal face, $b$ (Fig. 114), is the reverse of the inferior face of the plantar cushion; it presents, consequently, a marked relief on the median line, known under the name frog-stay, $m$ (Figs. 113 and 115), and on each side two gutters, $n, n$, converging in front, which respond to the branches of the plantar cushion. Like the sole, it is covered by a large number of perforations, which receive the corresponding villosities of the velvety tissue.

The inferior or external face (Figs. 111 and 116), much more

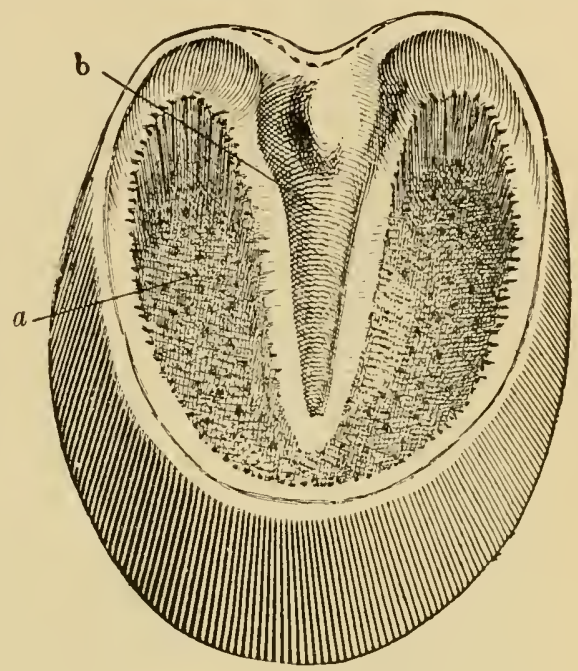

FIG. 114.-Interior of the hoof. important with regard to the exterior, is hollowed in its middle by a cavity, $h$, called the median lacuna, separating the two branches, $i$, $i$, from each other. Between each branch, $i$, and the har are the lateral lacunx, $j, j$ (Figs. 111, 113, and 115); finally, the body of the frog is the point of juncture of its two branches.

In the wild state, the inferior face of

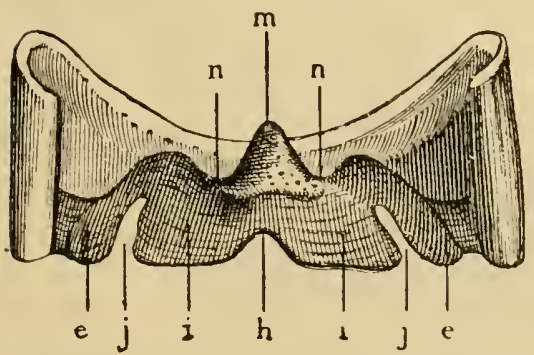

Fig. 115.-Transverse section of the hoof (posterior part).

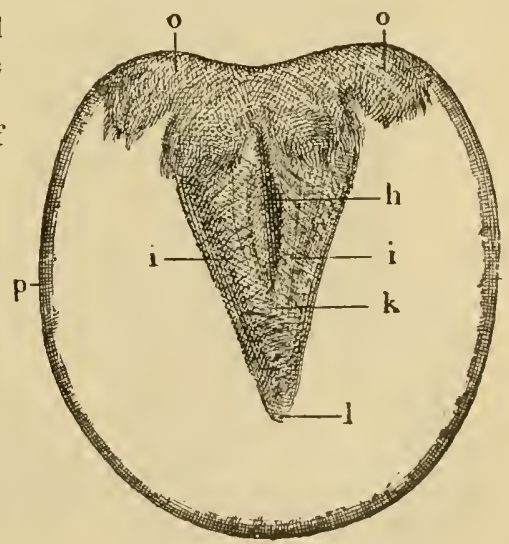

Fig. 116.-Frog and periople.

the furuncular branches, in conditions of nature, is upon the same level as that of the heels and the bars; it consequently rests upon the ground, as can be 
rearlily observed by the examination of the transverse sections represented in Figs. 113 and 115, practised upon unshod feet.

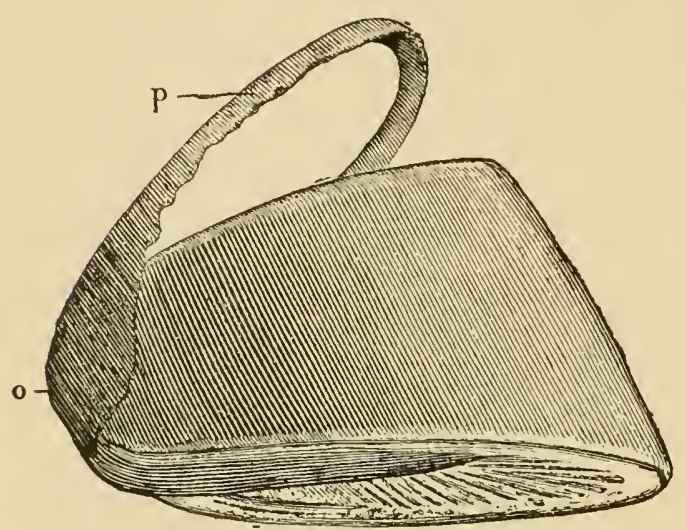

Fic. 117.-Hoof whose perioplic band is detached.

The frog, at its anterior extremity, terminates in a point (Figs. 111 and 116), which is lodged in the summit of the re-entering angle of the sole.

Its posterior extremity bifureates and terminates by two enlargements, $o, o$ (Figs. 109,116 , and 117), called the glomes, which overhang the heels and become continuous along the superior border of the wall by a thin, soft, flexible band of hom, $p$, little pervious to water. The latter production, known under the name of periople, and secreted by the perioplie band of whieh we have already

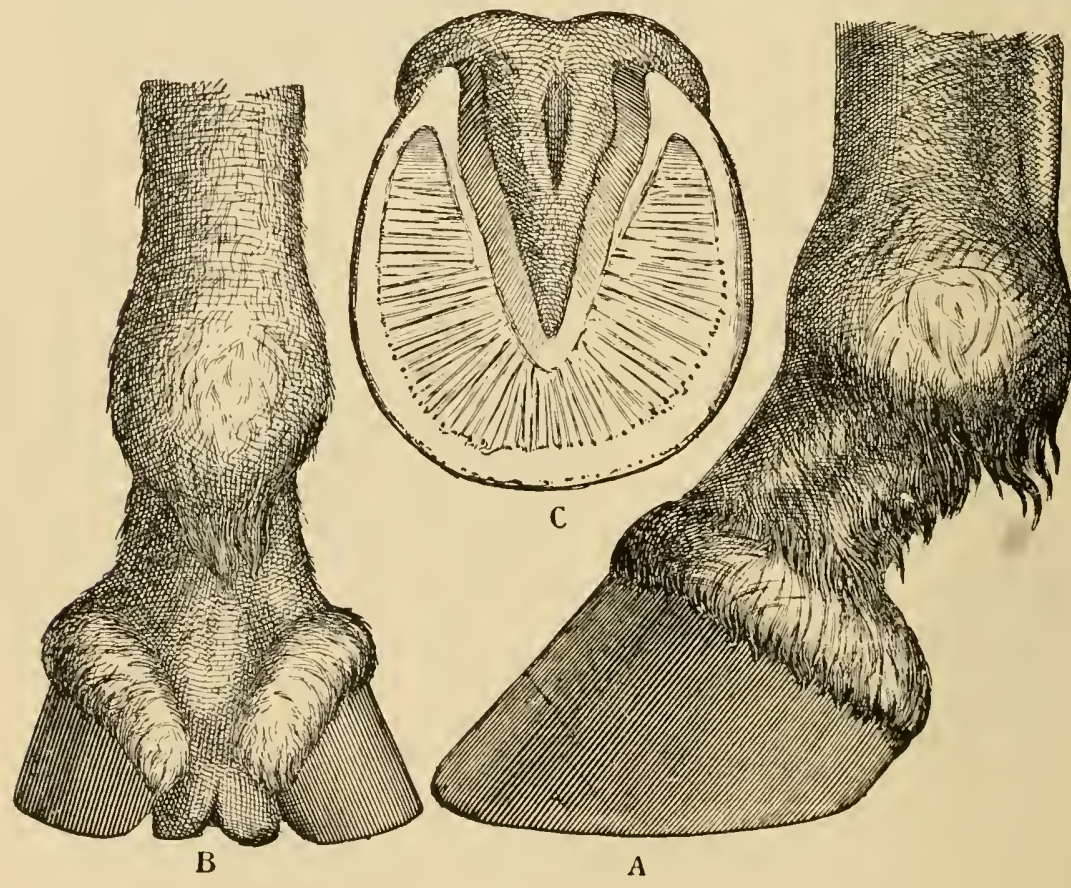

FIG. 118.-Fore-foot.
A. Profile.
B. Posterior view.
C. Inferior face.

spoken, is nothing else than the prolongation of the cutaneous epidermis upon 
the hoof, for which it forms a sort of protective varnish against the variations of dryness and moisture.

Such is, in a summary manner, the anatomical construction of the foot of the horse. Let ns now see the peculiarities concerning this organ if it be cxamined in the two sorts of members.

Differences between the Fore- and Hind-Feet; the Left and the Right.-These differences are secondary, altogether superficial, and do not modify the preceding details which bear on the general organization.

The fore-foot (Fig. 118, $A, B, C$ ) is more round, more spread out, less concave, and a little wider than the hind; the heels are less separated; the wall, in profile, is more oblique; the frog is less long, but more voluminous, thicker, and closer to the ground.

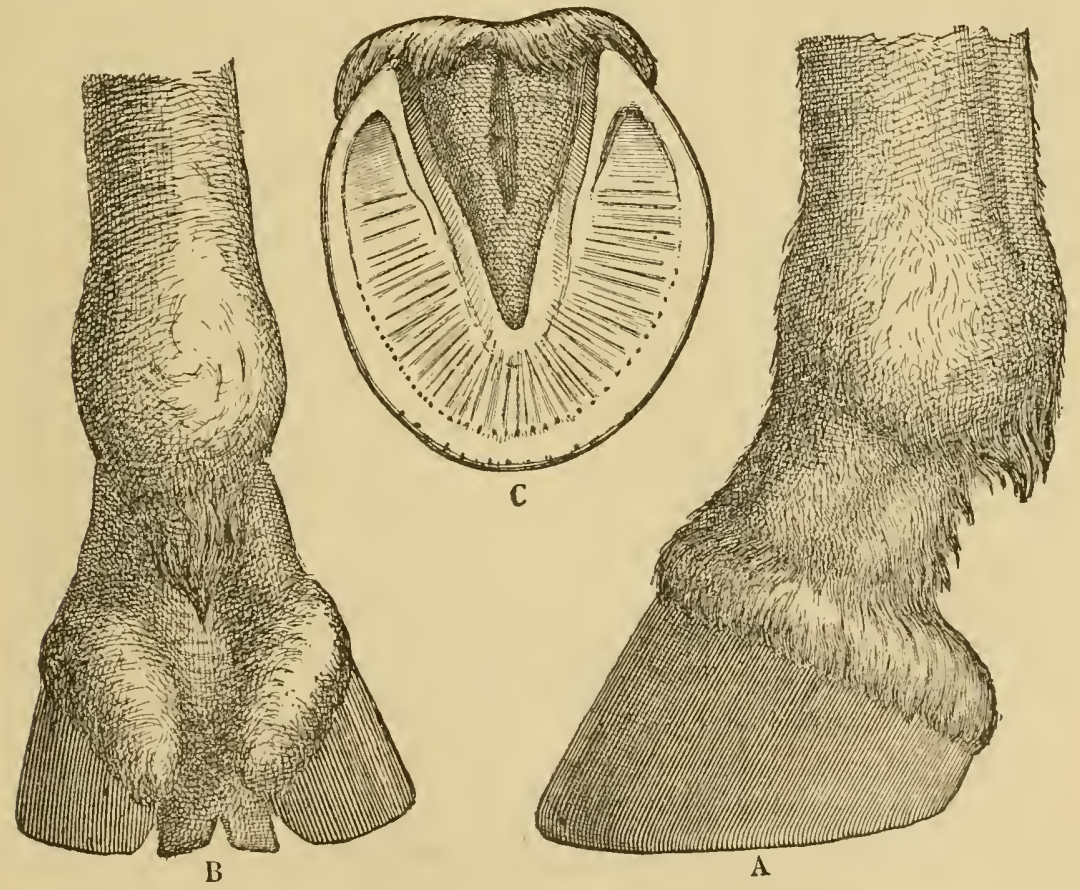

FiG. 119.-Hind-foot.

A. Profile. B. Posterior view. C. Inferior face.

The hind-foot (Fig. 119, A, B, C), on the contrary, is oval, concave, with higher and more separated heels, and a more vertical wall; the branches of the frog are less thick and more separated; the bars, finally, are somewhat stronger.

Nothing is more easy than to distinguish a left from a right foot, 
whether they belong to the anterior or the posterior biped : the external side of the wall is constantly more inclined and more convex than the internal; also, the inferior border of the wall is always rounder and stronger on this side than on the other.

\section{B.-Properties and Mechanism of the Foot.}

The foot of the horse, such as we have described, is an organ which enjoys certain properties inherent both to the nature and disposition of the tissues which compose its internal parts and to these same qualities possessed by the horny envelope. It is on account of these properties that the foot can fulfil, with all the desirable perfection, the important functions which devolve upon it.

The Horn: Properties.-The horn is a hard, compact, resisting, elastic, and tenacions substance, which is softened by contact with water or the influence of dampness, and hardens by evaporation. It is very combustible, and gives origin, when burning, to abundant fumes of a characteristic odor and a carbonaceous adherent matter which protects the living tissues against the action of the heat.

a. Origin.-The diverse regions of the cutaneous envelope (keratogenous membrane, flesh of the foot) of the foot do not contribute in the same manner to the formation of the horn. As our colleague, M. Arloing, judicionsly remarked, some are keratogenous and others keratophorous. Upon the first (coronary band, velvety tissue, perioplic ring) is imposed the elaboration of the nail, properly so called; upon the second (podophyllous tissue) more particularly devolves the rôle of support, consolidation, and union. Analogons to a sort of physiological cement, the latter establishes the relation and adherence between the horn and the living parts. Its production is represented for this purpose by the white, horny laminæe situated on the deep face of the wall, to which we have made reference above under the name keraphyllous tissue.

Thus the wall, the sole, and the frog are formed by the keratogenous regions of the ungual matrix.

b. Structure.-Under the microscope, the horn appears constituted by a great number of parallel tubes, rectilinear (wall, sole) or undulating (frog), which originate from the vascular papillis of the cutidure or the velvety tissue by enveloping them in the most intimate manner. Altogether comparable to hairs of a large calibre placed side by side, these tubes are composed of a multitude of horny (epithelial) 
cells, disposed concentrically around the axis in numerous layers in an imbricated manner. The most superficial of these layers affect a different disposition: the cells become perpendicular to the direction of the tube instead of remaining parallel, and in this manner is formed the intertubular horn, a veritable cement substance which agglutinates the hair cylinders to one another.

c. Color.-The horn cells, being epithelial in nature and formed from the cells of the epidermis of the skin, the hoof assumes a white or black coloration according as the parts which form it are or are not provided with pigment. When the skin of the coronary band is red, the wall is white for an equal extent; in the opposite case, it remains black. The same considerations are applicable to that of the sole and the frog.

d. Consistency.-The consistency of the nail is in direct relation with the degree of humidity of the horn, and this humidity is obtained by the foot either from the surrounding atmosphere or from its own tissues.

The temperature of the soil, the quality of the pasture, the hygrometric state of the air, the season of the year, the nature of the climate, are so many causes whose influence is evident and which it is needless to dwell upon.

Likewise, the horn becomes more supple and softer as it is examined closer to the living tissnes; it is, on the contrary, more resisting, brittle, and difficult to cut as it is more distant. The superficial parts of the frog, the sole, and the wall, the inferior border of the latter, are always excessively dry compared to the deeper parts of these structures.

These diverse conditions of the hoof, when existing in extremes, offer serious evils from the double point of view of the preservation of the foot and the use of the animal. We will revert to this in the chapter on defects.

Growth and Wear of the Hoof.-New lavers of horn are incessantly secreted at the level of the villous papillie of the keratogenous apparatus, pushing down the older layers to repair the loss occasioned by use. It is clear that each portion of the hoof grows according to the direction of its own fibres: the wall in its height, the sole and the frog in the sense of their thickness.

This growth is effected slowly. It requires about eiglit months for the production of a completely new hoof. All loss of substance to the wall is therefore reproduced very slowly; whence the lesson is taught that we should avoid this loss as much as possible. 
In the wild horse the continual growth, always compensated by a proportional loss from wear, does not induce a deformity of the nail; but the case is different in horses which we utilize as motors, on account of the shoe, which restrains the elasticity of the foot and disturbs the normal growth of the hoof. In such cases the wall may acquire an excessive length if the farrier does not take the care to shorten the whole extent of its inferior border to the limits required by the natural wear. As to the sole and the frog, their mode of exfoliation is such that their thickness never becomes excessive ; they become dried, cracked, and peel off spontaneously in more or less voluminons scales.

The secretion of the horn is exaggerated by certain influences, as the external temperature, the state of health or of disease, the nourishment, etc. We know that the process is more active in warm than in cold eountries, in summer than in winter, in the healthy animal, abundantly nourished, than in the diseased animal, suffering from bad hygiene and an insufficient alimentation. This is so true that the hoof itself often testifies, by the unequal zones of which it is the seat, of the physical conditions or suffering which the horse has endured.

Certain rammy or circled hoofs have in most instances no other origin.

Elasticity of the Foot.-The digital extremity of the equidæ, below the pastem, is disposed so as to disperse or break the concussions and the pressure which it receives during locomotion at the moment when the body, at great speed, comes in contact with the ground. Not only is the quantity of movement with which the body is animated dispersed and decomposed by the inclined planes of surface and of segment, but it is destroyed also by the intervention of the elasticity of several organs which we will recognize. It is therefore already considerably lessened when it arrives at the hoof, where it meets several elastic apparatus, whose mole of functional activity we must rapidly review. These apparatus are: the perforans tendon, the lateral cartilages, the plantar cushion, and the diverse parts of the nail (the wall, the sole, and the frog).

The first effect of the contact of the foot with the soil is the displacement of the third phalanx from above to below in the interior of the horny covering (Fig. 106). This movement of the bone is comteracted by the mechanical action of three very evident causes: anteriorly and peripherally, by the adherence of the podophyllous and keraphyllons tissues; above and laterally, by the resistance of the lateral cartilages; finally, below, by the presence of the plantar aponeurosis and the plantar cushion. 
The remarkably solid union between the hoof and the sensitive tissues is due, above all, to the intimate dovetailing of the sensitive laminæ with the horny laminæ. ${ }^{1}$

These two sets of lamine, however, are not simply placed in juxtaposition in a parallel manner, but they interdigitate with one another by the numerous secondary prolongations which they offer on their lateral faces and which are disposed after the manner of the barbs of a feather upon its stalk. This construction admits of a very slight gliding of the keraphyllous laminæ of the wall upon those, soft and flexible, of the podophyllous tissue, whence, in consequence, the first decomposition of force at their level.

Besides, the werge formed by the third phalanx not only descends parallel to the wall, but describes a sort of vertical rotation, from the pressure transmitted by the second phalanx to the navicular bone. This pressure is first exercised upon the plantar aponeurosis, e, which maintains the articular angle, and, secondly, upon the elastic plantar cushion situated immediately below. Following this, there exist also at this place two new structures whose elasticity, now called into activity at the moment of the contact, notably diminishes the intensity of the reactions.

But the phenomena do not cease here. The plantar cushion, strongly compressed from above to below by the wcight of the body, tends to depress the plantar arch at the same time that it elongates transversely, where it is maintained by the two lateral cartilages. The latter, flat, wide, supple, and very elastic, overlap behind the superior border of the wall and sensibly separate from each other under the influence of the eccentric pressure which they receive from the plantar cushion. They are therefore opposed, in their turn, to the rotation of the third phalanx in the interior of the hoof.

Thus, little by little, the internal parts of the foot decompose the reactions of the weight, by changing their form and relative situation, and, finally, by concentrating their action upon the diverse parts of the hoof, especially the frog, the quarters, and the sole.

The sole is flattened and becomes less concave inferiorly; its

\footnotetext{
1 M. Pader has recently called attention to the remarkable manner in which the horny case is attached to the living parts. According to him, in a horse of medium form, the laminac of the foot being supposed to have an area of a square decimetre, the total surface of the principal ancl secondary laminx, which he has had the patience to compute, shombl attain alont one square metre! It ean then be readily understood how this system of dovetailing of the lamina is calculated to insure the intimate union of the horn and the flesh, to decompose the concussion, at times enormous, which the ungual extremity receives, and to distribute uniformly the pressure upon the whole of the internal face of the wall.
}

(See, for more details, Bulletin đe la Soc. cent. de méd. vétér., année 1SsS, 1) 191.) 
peripheral bordcr expands more and presses against the wall, whose thin and narrow extremities are thus feebly scparated from cach other.

The frog is depressed to the same degree; its median lacuna enlarges; its branches are forced outward and press against the bars propped against them after the manner of two springs.

Finally, the wall reacts in an opposite direction to the simultancous pressure of the lateral cartilages, the sole, and the frog. Its superior border and its quarters expand.

The elasticity of the hoof is manifested, therefore, by a slight movement of scparation and approximation of its heels, whose amplitude is the greater in proportion as the frog is larger and more related (froy pressure) to the ground, conditions always realized in a state of nature (Figs. 97 and 99).

Hence rational shoeing should never be an obstacle to the opening of the posterior cleft of the foot at the moment of the contact and to its closing during the elevation.

The farrier, when paring the foot, must imitate the natural usage and respect that which nature spares: it strongly rounds and shortens the toe, and the mammæ a little less; it affects the sole only at its anterior circumference, without weakening too much its union with the wall; it rounds more outwardly than inwardly the sharp border of the latter ; removes from the sole, the frog, and the bars only that which is eliminated spontaneously. The foot which has undergone natural usage has been adapted to locomotion, and bears flatly from the mammæ to the heels. ${ }^{\text {? }}$

Preservation of the Form of the Hoof.-The hoof, in a state of nature, the Commission d'hygiene hippique also says, preserves its form and its qualities under the following conditions:

1st. Its elasticity is complete when the frog is in full relation with the ground.

2d. Its constant use maintains a proper length and a regular axis.

3d. The sole has all its thickness, all its strength, and prevents contraction of the heels.

4th. The hairs of the coronet cover and protect the cutidure; the varnish of the wall (periople) protects the horn against alterations of dryness and humidity.

5th. Finally, the moisture of the soil, the dew, and the freshness

1 Manuel de maréchalerie, rédigé par les soins de la Commission d'hygiène hippique, p. 105. Paris, 1870.

2 Loe. cit, p. $\bar{j} \bar{s}$. 
of the pasture maintain it in a state of humidity favorable to the preservation of its form.

\section{C.-Beauties of the Foot.}

The volume of the foot is susceptible of variation in notable proportions without being necessarily considered defective. English horses, as well as those of Algeria and Central France, generally have a small, hard, and resisting foot. Those of the common races, and of a lymplatic temperament, raised in low and damp districts, on the contrary, have this region more voluminous. It should, in all cases, be proportional to the height of the horse, his weight, his conformation, and his special aptitudes. The width of the hock, measured from the point to the bend of this articulation, equals that of the hoof from the toe to the heel, or at least very nearly, in a beautiful draught-horse. It is always more considerable in pleasure-horses, whose feet are nevertheless well formed.

"The unshod foot of a horse bred on favorable soil and sufficiently exercised is a type of beauty and perfection. Compared to the foot that has been shod, it is large, strong, as wide as long, and in proper equilibrium ; it constitutes a solid support.

"Viewed in firont, it is narrower above than below, more expanded externally than internally, and of equal height at its quarters.

"Tieved in profile, the line of the toe has a mean inclination ${ }^{1}$ the height of the heels is equal to at least one-half of the height of the toe.

"Fieved firom bchind, the heels of the standard foot are well separated, equal, of the same height, and fall vertically to the ground, especially the internal, which is sensibly more vertical than the external.

"Tricued from bclow, its sole is hollow and thick, the frog strong, healthy, and quite hard; the bars neither too straight nor too much inclined; the toe and the mamme of the wall and the sole are perceptibly worn from usage.

"The horn of the standard foot is black or dark gray; the wall, smooth and shiny, shows its fibrous structure." 2

Such are the characters of the virgin foot which we have represented in the text. ${ }^{3}$

1 Ahout 50 degrees for the front feet and 60 for the hind.

2 Commission d'hygiène hippique, loc. eit., p. 56.

3 See, for more details, Mathieu, De la face inférienre du sabot, chez le cheval vicrge de ferrure, in leencil de médecine vétérinaire, aunée 18̄6, p. 761. 


\section{D.-Defects of the Foot.}

Most authors have unnecessarily increased the list of defects of the foot, by comprising in it a certain number of conformations which are nothing else than the expression of a discased state very common and very variable in its manifestations: contraction of the hoof.

The foot of the horse may be defective under four different conditions which receive special appellations:

1. By Defect of Volume and of Proportion: Foot large, small, narrou, and unequal.

2. By Defect of Conformation: Foot flat, full, pumiced, with bunions, with high, low, sloping heels.

3. By Defect of Axis: outbou-foot, cross-foot, club-foot, crooked foot, pincaid foot.

4. By Defect of Quality of the Horn: Foot soft, dry, brittle, with weak heels.

Let us rapidly examine each one of these defects in particular.

\section{Defects of Volume and of Proportion.}

Large Foot.-An excess of the volume of the foot has serious inconveniences in the fast horse on account of its weight, its width, and the weight of the shoe.

The step is heavy and awkward; the reactions upon the gromnd are too violent. The horse is liable to stumble, pull the shoes, and interfere; he is more predisposed to contusions of the sole and congestion and inflammation of the vascular tissues; the horn is often brittle and retains the nails poorly. Finally, a larefo foot is a characteristic of slow, Iymphatic horses, and always indicates the absence of fine breeding and good qualities.

These objections disappear in the slow dranght-horse, which, from the nature of the pace, is firmer on his feet, and jeopardizes to a less degree the integrity of the apparatus of support.

He must have a wide-webbed shoe, with the toe well elevated, without garniture on the inner side (not projecting beyond the wall), and slightly projecting on the outer side.

Small Foot. - A foot too small, in spite of its neatness and lightness, is chiefly defective from the excessive reduction which it causes in the width of the base of support. Its horn is thin and ordinarily dry and brittle. The foot is easily bruised, contracted at the hecls, becomes painful after prolonged exercise, and is always more 
or less sensitive. It is particularly seen in the meridional races, upon very active and energetic subjects. It is the more defective as it is more disproportionate with the volume of the body and the height of the animal.

A semi-covered shoe with a good garniture-that is to say, projecting beyond the border of the wall more than nsual externally and internally-eases the foot much. ${ }^{1}$

Narrow Foot.-This variety of foot differs from the preceding by the meagre development of its transverse diameter as compared to its antero-posterior diameter. Its toe acquires an exaggerated length, which angments, consequently, that of the pastern to the detriment of the tendons, as we have already seen. (See Pastern, page 301.) It is also, like the small foot, subject to contraction,-that is to say, approximation or narrowing of its posterior parts ; its shoeing is similar to that of the small foot.

Unequal Feet.-The inequality of the volume of the feet would be, withont donbt, more rationally studied in the chapter on the discases, for it is rarely congenital. Be it as it may, such a conformation should be considered grave by reason of its eause. It is always the smallest foot which, in this case, is the first to become diseased on account of its relative weakness. Among the cliseases of which it may be the seat, contraction of the quarters and the heels oceupies, withont contradiction, the first rank. It can be obviated in a certain measure by applying a more covered (wider-webbed) but lighter shoe to which is given garniture proportional to the reduction of the volume of the hoof; it will be advisable to employ small nails.

\section{Defects of Conformätion.}

Flat Foot.-This foot is thus named on account of the flatness of its plantar surface. It is ordinarily large, spreading, with an oblique wall, low heels, very inelined bars, and a volmminons frog. It offers more difficulties in shocing than one is tempted to believe. The farrier should apply a covered shoe sufficiently light and concave, in order that it may not press on the sole, always very little arched; he will spare the heels and dress the frog only superficially; the toe should be well raised up and the heel flat, never thickened; besides, the farrier should drive the nails at a suitable inclination, so that they may not be

1 The French system of shoeing is entirely different from and, it would secm, inferior to the American. 
too shallow or enter the vital parts; two conditions which require great tact on his part.

For the pleasure-horse, the Charlier shoe, the English shoe, or the French shoe arljusted after the English manner, with a plate of leather or India-rubber under the sole to protect it, should be employed.

The flat foot is, indeed, predisposed to contusions of the heels, the sole, and the frog; it is unsightly from its form and its volume; its great width causes the horse to interfere; it takes a bad grip of the pavement.

Full Foot.-This defect is only an exaggeration of the preceding. Here, the sole does not have the least concavity; it is almost a perfeet plane over its whole surface. This foot is also more exposed to contusions, and requires a very wide shoe applied with small nails in order to aroid pressing on or pricking the sensitive tissue.

Pumiced Foot.-In the pumiced foot, not only is the sole not a plane surface, but it is bulging inferiorly, and surpasses the inferior border of the wall almost over its entire periphery. The difficulties of properly shoeing such a foot inerease proportionally with the degree of the defect. The farrier, in fitting the shoe, if he is not very skilful, alters the axis of the member, deforms the axis of the foot and diminishes the security of its contact with the ground.

This vice of conformation does not consist in a simple defect of the hoof alone; it extends also to the third phalanx, whose inferior face is plane or convex. A horse with pumiced fect ean doubtless render good service, but as soon as the shoes are removed he cannot perform labor, the plantar surface not being protected from the incessant contusions which are produced by the roughnesses of the soil. He should therefore be reserved for the farmer or for soft roads.

Foot with Bunions.-The foot is thus designated (though incorrectly) when there exists upon its inferior face, at the level of the quarters, more or less voluminous eminences (bunions), due to an abnormal conformation of the third phalanx in the corresponding region. This defect most often accompanies full and pumiced feet, and is more frequently observed on the internal side than on the extcrnal. It predisposes the sole to bruises from the convexity of which the latter is the seat, and exacts the most accurate and careful shoeing. The web of the shoe, indeed, should be wide and so adjusted in regard to the tumor that it can be protected with tar and oakum maintained by a plate of leather. If the animal lose the shoe on the road he will soon fall lame.

Feet that are flat, full, pumiced, and with bunions are peculiar to 
the anterior members; the sole of the posterior supports less weight and is always more concave.

Foot with High Heels. - This conformation (Fig. 120), common in some horses in meridional France (also in the so-called Arabian horses), does not result, as might be believed, from an excessive height of the wall at the heels. The sole here is hollow and the frog elevated from the ground. The pastern, from the fact of this bad direction of the foot, becomes straight, renders the animal straight-jointed, and displaces most of the weight on the toe. Many horses are high-heeled from the neglect of the farrier to lower the hecls before resetting the shoe, and hence in the long rum they become hoof-bound. Such cases are not difficult to

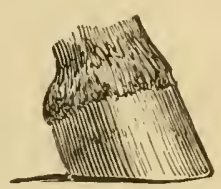

FIG. 120. remedy; it suffices to pare off the heels regularly and give them a proper height. If the defect is congenital, we must content ourselves with the foot such as it is, and only endeavor to prevent the increase of the defect in the shoeing, by employing a shoe thin at the heels.

Foot with Low Heels.-This form of the foot (Fig. 121) is open to objections of an inverse order. The weight of the body bears upon the hecls, which, ordinarily weak and sensitive, are thus easily bruised and contused. There results, besides, a more marked inclination of the pastern, which fatigues the tendons, and this so much more as the toe is longer and the horse longer-jointed. The shoeing, in this case, should aim at restoring the foot to its normal axis and,

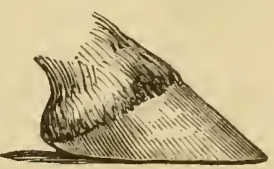

Fig. 121. at the same time, protect the posterior part of the heels. It is with this object in view that we recommend a semi-covered wide-heeled shoe; nor should the heel ever be thickened, as is the usual tendency to recommend. It is better to raise the heels by interposing between them and the shoe one or two thicknesses of leather, of India-rubber, or again, by the application of the English patents; in a word, of elastic pads incapable of producing contusions. If the frog is well developed, it will be judicions to alternate the covered-hcel shoe with the bar shoe.

Foot with Sloping Heels. - The heels in this conformation are much inclined forward and acquire an abnormal length, a disposition which leads to all the evil results of a low- and long-iointed pastern.

The indication, therefore, is to shorten the font over its whole area, particularly towards the toe and the mammæ. Precaution in paring it 
must, however, be employed, for the toe is not as long as it might appear. The latter should be shortened as much as possible. The shoe should be closely fitted at the toe and well sunk into the wall at this point; its extremities also must be kept somewhat long. Plates of leather under the heels or the English patents, by tilting the hoof forward, will contribute to re-establish its normal axis.

Low and sloping heels are phenomena peculiar to the forc-fect.

\section{Defects of the Axis.}

Outbow-footed.-The outbowed foot is that in which the toe is turned ontward; it is more frequently observed in the posterior members than in the anterior. We have already seen that this conformation is associated in most instances with a deviation of the part of the member below the knee or the hock; but it may also be due to a mere change in the axis of the foot. In either case the hoof will soon show the effects of this vicions direction of its axis. The internal quarter, pressed towards the median line, and eonsequently more surcharged, has a tendency to contract and press upon the living tissues below. The animal, besides, almost invariably strikes the opposite member with this quarter, as is well known. This is the principal accident which the farrier is called upon to prevent. Paring the external quarter more will ease the internal, which is always weaker; the axis will thus be regulated in the greatest measure possible. The shoe must not project beyond the wall at the external mamma or at the internal quarter; the heels should be of equal length and width. It is only after several shoeings that certain feet may be straightened. ${ }^{1}$

Parrot-toed Foot, Cross-footed.-This is a defect diametrically opposed to the preceding, and has inverse deformities. Here it is the toe which is turned inward, and much more frequently in the fore- than in the hind-foot. The internal quarter is stronger and relatively more prominent than the external, the heel of which is contracted and bruised quite easily. The horse, in this case, interferes with the mamma. Hence, before the shoe is adjusted, the internal mamma and the anterior part of the corresponding quarter must be well rasped off; so as to lower that side of the foot. The shoe will have to be closefitting on the inside, well "garnished" and slightly covered on the outside; the garniture of its heels should be equal on both sides.

Crooked Foot.-The crooked foot is that in which the hoof is

\footnotetext{
1 This defeet is so obstinate to treatment by shoeing beeause it is often dependent upon anatomical alterations of the phalanges and their articular surfaces, which cannot be modified.
} 
inclined tis the one side or to the other. This defect, rarely congenital, depends rather upon improper shoeing. In the first ease, it is eaused by a vicious axis of the superior parts of the member, and very often accompanies the outbowed and the parrot-toed foot. At other times it is observed in a horse simply too close or too open in front or behind. In the seeond case, it is due to excessive paring by the farrier of one of the two quarters.

Howerer it may be, the evil effects remain the same; the lower side bear's the most weight; the soft parts here are compressed and bruised, and the quarter becomes tilted to one side. The shoeing should endearor to re-establish gradually the normal axis, by sparing the deformed quarter, protecting it with the wide-hecled, projecting shoe, if this be possible, and, finally, by lowering the normal quarter.

Foot Pincard or Rampin (Fig. 122).- Some make a difference between the pineard and the rampin foot. Still, these two are only degrees of the same defect, eharacterized espeeially by the foot touching the ground only with the toe. This disposition allows the heels to acquire a great height. This defect is peculiar to the hind feet, where it is in reality only an exaggeration and continuation of the attitude which these members affect during the efforts of violent traction. It often coexists

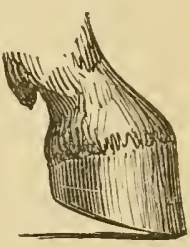

FIG. 122. with a low-jointed pastern. The rampin horse wears his shoe very rapidly, but only at the toe; his shoeing is expensive, and he is exposed to fissures of the wall ealled toe-cracks, on account of the excess of weight which this region of the foot must support. We believe, with Lecoq, that most of the corrective measures resorted to in the shoeing only aggravate this defeet. Let us say, nevertheless, that we are in the habit, in order to cure it, to save the heels and employ the pincard shoe, with corks on the heels, whose length is in relation with the distance of the foot from the ground.

Club-Foot._-"There is not much aceord," says Lecoq," "upon the true meaning of this word as applied to the foot of the horse. Some, comparing this malformation to the same species of deformity existing in the human subject, designate by the term club-foot any foot that is strongly deviated outward or inward. This is a very rare eondition, sinee, as Girard has observed, a horse thus eonformed, not being able to render any service, is promptly saerificed. Others designate under the name club-foot all the deformities of the horse's foot in 
which the coronet as well as the fetlock are strongly displaced forward, from the retraction of the ligaments and the tendons primarily, and the elongation of the heels secondarily. This defect sometimes exists to such a degree that the anterior face of the wall touches the ground at each step.

"When a club-foot is of long standing, a modification of the articular surfaces of the phalanges takes place, and the disease is then incurable. If, however, the aceident is recent and due especially to contraction of the flexor tendons, the horse still has some value, for the operation of tenotomy can sometimes straighten the foot, though the member may not entirely regain its original strength."

\section{Defects of Quality of the Horn.}

Soft Foot.-The foot is thus characterized when the horn is soft, without consisteney, and yielding to pressure. The wall and the sole, in spite of the large volume of the loof, are thinner than in ordinary conditions. Hence such a foot is difficult to shoe.

The elinches of the nails easily tear through the soft horn and will not hold the shoe. The foot is easily prieked in driving the nail, on accomnt of the thinness of the wall. Finally, the horse is sulject, for the same reason, to contusions of the sole, contusions which are so much more frequent as the foot is heavy and the knee-action high. The shoeing consists of a light, semi-covered shoe, to be nailed on with thin nails.

Dry Foot.-The dry foot is one whose horn is hard, dry, and brittle. The latter grows slowly and breaks readily when the foot is unshod or when too heavy nails are employed in fastening the shoe. Exposed to the same accidents as the soft foot, it must be dealt with in the same cautions way.

Broken Foot.-The foot is ealled broken when more or less extensive areas of the wall along its plantar border are broken or chipped off, so as to interfere with the regular distribution of the nails.

In the unshod horse, the best hoof is susceptible of breaking accidentally, but most often this defeet depends upon a poor quality of the horn, which is too soft or too brittle. It is more serious than is believed, on account of the extreme eare which it demands from the farrier. The nail-holes of the shoe ean only be placed at those points where the wall is still intact. The nails must not be driven too elose to the edges under the penalty of breaking the horn still more. The latter cireumstance would necessitate too many shoulders or tongues on 
the shoe, sunk into the horn at the toe or the mammæ, to supply the insufficiency of the nails.

The broken hoof is sometimes restored to its normal form by the application of gutta-percha at the points where this is necessary. It is then possible to apply a normal shoe provided with an ordinary number of nail holes equally distant from each other. It is not rare to see an animal whose foot has thus been treated offered for sale; at times cren the nails at the level of the broken parts are simply riveted on the shoe at these places and the irregularities filled with guttapercha or some other coating. The examination of the hoof can therefore never be too minute.

Foot with Weak Heels.-This is a variety of the low-heeled foot, in which the posterior parts are defective by reason of an insufficient consistency of the horn, and are consequently predisposed to contusions of all kinds. The shoe, in such cases, should protect the parts which lack strength, without bearing on them, either by means of a wide-heeled shoe, or, if the frog be well developed, the application of a bar shoe.

\section{E.-Accidents occasioned by Shoeing.}

The conditions of domestication of the horse make it necessary for those who employ him to protect the four hoofs by a shoe, a sort of incomplete metallic sole, destined to insure them against the excessive wear of the horn, which would otherwise soon impair their functional usefulness.

Shoeing, farriery, is the art which consists in the methodical application to the foot of the shoe or the protecting apparatus of which we have spoken. It is, in most instances, not very difficult to perform this operation, but there are some cases in which, either from the incompetency and unskilfulness of the farrier or the conformation of the foot itself, shoeing causes more or less grave accidents, in regard to which we must confine ourselves to a simple enumeration.

Pricking.--Pricking is the penetration into the sensitive tissues of a nail which is driven too closely by the farrier. Again, it can be eaused by the division of a flawy nail, of which one segment enters the living tissues (the quick), while the other issues on the onter side. Its gravity varies with the length of time the nail remains in the soft parts. If the nail be drawn ont again immediately, it is without gravity; if, however, the direction of the nail be not recognized, it may lead to serious complications. The nail should be removed and not reinserted. 
Pricking is sometimes eoncealed by the farrier, who rivets the nail upon the shoe at the level of the seat of injury.

Compression by the Nail.-This condition is produced when the nails are driven too deeply (too soft), -that is to say, too elose to the sensitive tissnes, which are thus more or less compressed. This accident happens quite often in soft or weak feet, in consequence of the thinness of their horn. It is easy to perceive this aceident by making the horse trot, and to remedy it by removing the shoe immediately.

Compression by the Shoe.-Compression of the sole occurs when the shoe, which is badly fitted, bears in some places on a weak or thin sole. Compression also takes place when the farrier has pared the sole too much or draws the shoe too tightly. Certain defective fect (flat and pumiced feet) are more particularly predisposed to this accident.

Heated Sole.-The sole is called heated when it has been subjected for ton long a time to the contact of the red-hot shoe; it is the more predisposed as it is less concave.

Burnt Sole.-The sole upon which has been applied for too long a time a shoe simply red is, on the contrary, qualified burnt. In the preceding case the abundant carbonaceous layer formed by burnt horn has protected the foot against the injurious effect of the heat. Here, there is very little charring of the horn, which permits the heat to penetrate quickly and deeply into the living tissues.

The burnt sole is rebellious to treatment.

Excessive Paring of the Foot.-When the font is pared ton much it aequires an exaggerated sensibility from the excessive thimness given, by the farrier's knife, both to the sole and the inferior border of the wall.

Cuts from the Hoof-Knife and the Butteris.-These are aceidents produced by unskilful or unintelligent employment of these instruments of farriery. Their gravity is in relation with the depth, the nature and the seat of the wounds which result from them. They are sometimes complicaterl by red cxerescences, excessive granulations of the subjacent tissue, known under the name of cherries.

\section{F.-Diseases of the Foot.}

"These numerous and varied diseases," says J. Girard," "ean be produced by prolonged travelling on dry, hard, rough, and stony roads; by concussion, the contact of external bodies and even of one 
foot with the other; by the deviation of some of the superior regions or articulations ; and, finally, by the shoeing."

In all diseases of the foot the horse, when exercised at a walk or the trot, does not make a free and equal contact with the ground upon the whole of the plantar surface of the foot; certain movements are precipitated, others are effected in preference upon the toe, upon one quarter more than the other, or again upon the heels.

We must confine ourselves, not to go beyond our domain, to the enumeration of the principal of these diseases, by simply mentioning in what they consist.

Contraction of the Foot.-Contraction of the foot (hoof-bound) is the more or less marked contraction of the foot in its posterior parts.

It is distinguished as true and false, according to the form which it assumes.

In true eontraetion the diminution of the lateral diameter affects the quarters as well as the heels, which are always very high; and hence such a foot is qualified mule's foot. As a consequence of the compression, the sole becomes more concave and the frog, in a great measure, becomes atrophied.

It is nearly always acquired, and occurs more frequently in meridional horses than in any others. The causes are numerous, but all can be traced to one of two factors: desiccation of the horn or interference with its normal elasticity.

In false contraction, known under the name contraction of the heels (narrow heels, compressed heels, etc.), the hoof preserves its ordinary form, except in the region of the heels, which are more or less drawn towards each other without attaining the excessive height which they assume in true contraction.

Inflammation of the Frog, Thrush.-These are two inflammatory conditions of the frog, which are accompanied by a separation of the horn, with a blackish, purulent, and very fetid discharge, emanating from the median and the lateral lacunie, principally from the former, especially when in feet in which it is prolonged between the two heels.

Canker.-In canker the horn of the frog first, and then that of the sole, softens, separates, and, finally, is shed, thus exposing the living tissues, whose papillæ, very hypertrophied, form fleshy vegetations, often voluminous, known under the name fici. These alterations of the keratogenous membrane, which have a tendency to spread to the surrounding healthy tissues, discharge an abundant caseous secretion of a very fetid odor.

Seams.-Seams (cracks) are longitudinal fissures of the wall, which extend from the inferior border to the coronary band or to the vicinity of the latter.

They are called complete when, involving the entire length and thickness of the wall, they extend to the podophyllous tissue; they are qualified incomplete in the contrary case.

Relatively to their seat, they are distinguished as follows: quarter seum, the complete fissure of the quarter, which is more common in the anterior members, and on the internal side more than the external side.

Seam of the toe (toe-crack), fissure of the toe; it occurs more frequently in the hind- than the fore-foot, and as it seems to divide the foot into two lateral moieties, the animal is, on this account, sometimes called cloven-footed. 
Seam of the bars affects the latter and breaks their continuity. This is one of the accidents of the foot most rebellious to treatment.

We will also say, in this connection, that seams or cracks are sometimes concealed, in animals offered for sale, either by a coating of gutta-percha, putty, wax, or simply hoof ointment. They are called barred when, as a means of treatment, their borders are approximated by the aid of special iron clasps.

Corns.-Corns are contusions of the sole in the region comprised between the wall and the bars. They are common in feet with low and weak heels, especially in contracted feet.

They are called dry when the horn which covers them is of a yellowish color and stained with blood.

A corn is moist when the exudation of blood and serum, in consequence of the bruising, is more abundant, renders the horn softer, and even separates it over a small area from the tissues below.

Finally, it is called suppurating whenever the alteration, not confined to a simple ecchymosis, has occasioned inflammation and suppuration of the subjacent tissues.

Bruised Sole.-Bruised sole is an accident of the same nature as that of corns. It only differs from the latter in that it consists of a contusion of a more or less large area of the sole at the quarters or at the toe. According to the objective characters of the horn, it is also qualified dry, moist, or suppurating.

Concussion of the Hoof.-Ancient veterinarians have designated under this name a localized congestive state of the keratogenous membrane of the foot resulting from external violence, most frequently the blows of the farrier's hammer.

This alteration differs only from that of laminitis in that it is due to the influence of purely local causes. Anatomically speaking, they are identical.

Laminitis.-Laminitis (founder) is, primarily, a congestion of the keratogenous apparatus in the region of the toe and the mammæ.

Under the pressure of the serous and sanguineous exudation which results therefrom, the podophyllous tissue (flesh of the foot), tightly compressed between the wall and the third phalanx, becomes extremely sensitive, which obliges the animal to walk upon the heel, or even renders all support by the foot impossible. The founder, in this case, is called acute, for it is accompanied by phenomena generally very intense.

If the temperature fall, the symptoms ameliorate, and inflammatory phenomena gradually invade the tissues previously congested, the keratogenous mem-

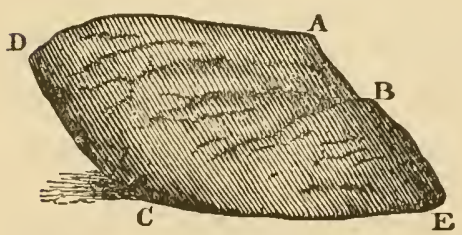

FIG. 123. brane, at this level, becomes the seat of an abnormal and exaggerated secretory function, characterized by a profound deformity of the hoof and a decided alteration in the form and relation of the internal osseous structures. It is this which constitutes chronic founder or laminitis.

The foot, in such cases, assumes an oral form and the wall is decidedly rammy; its toe acquires an enormous thickness and becomes convex; its heels are high and touch the ground first in locomotion. The sole, compressed by the plantar border of the third phalanx, loses 
its concavity; it presents, towards the toe, a swelling in the form of a crescent; its peripheral border, finally, is separated from the inferior border of the wall at the toe and the mamma by a voluminous wedge of podophyllous horn. The latter may be solid, or it may contain an internal cavity (seedy-toe), filled by a reddish, dry, porous mass formed by the residue of the serous and bloody exudate from the podophyllous tissue, which the farrier at times fraudulently endeavors to conceal with the shoe.

Seedy-Toe.-This condition is not always due to founder, because the cavity by which it manifests itself may exist under the sole as well as under the wall. 'This allows us to distinguish two varieties of seedy-toe: that of the sole and that of the wall. The first is much less grave than the second; it is occasioned by strong contusions of the velvety tissue; percussion of the sole over this region is resonant as soon as the cavity is formed.

False Quarter.- "False quarter is especially characterized by the absence of the wall at the quarter, in consequence of an operation or an accident sacrificing the coronary band. While it lasts there is nothing in this region but the horn secreted by the podophyllous tissue." 1 The foot is, in this case, quite frequently restored by a false quarter made of gutta-percha.

Avalure and Circles.-By the term avalure is meant the normal descent or growth of the horn, from the fact of the continual formation over the whole periphery of the cutidure. It becomes morbid, pathological, when it takes place in an irregular manner only over a portion of the wall, or over the whole area, which qualifies it entire or partial; the animal then grows a new foot or a new quarter. According to the case, it is called: complete, when the growth of the horn which corresponds to it extends to the inferior border of the wall; incomplete, when this growth has not yet reached this border; irregular, if it takes place more rapidly at one point than at another. Under these diverse circumstances we have altered nutrition of the coronary band manifesting itself in the form of circles (rammy foot), which often surround the whole wall, sometimes one of the quarters, and which occasion a marked soreness in the foot from the compression which they exercise upon the sensitive parts. The circled foot (Fig. $124)$ is frequently a symptom of ehronic founder and, in general, of all the diseases in which the keratogenous membrane is extensively involved.

Keraphyllocele.-Keraphyllocele is a horn tumor of a cylindrical or conical form, which exists on the internal face of the wall, particularly at the toe; it compresses and atrophies the vaseular tissues.

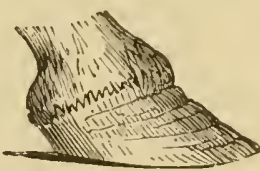

Fig. 121.

It is qualifierl fistulous or solid according as it contains, or does not contain, an internal cavity. Its mode of formation resembles in all respects that of the wedye of horn in chronic laminitis; it consists, in fact, of a localized congestion of the porlophyllous tissue, followed by a liypersecretion of the corresponding lamine. Among its causes we may recognize either a slight founder, a seam, or most frequently violent contusions of the wall, consecutive, for example, to the blows of the farrier's hammer when he sets the tocclip.

Quitters.-This term designates a partial necrosis of some of the tissues 
entering into the construction of the inferior part of the members. Quitters are divided as follows:

The cutancous is that of the cutidure or coronary band, and may be considered as a veritable furuncle.

The tendinous is the necrosis, in small fragments, of the aponeurotic, ligamentous, and tendinous tissues of the phalangal region.

Furuncle of the frog consists in a partial necrosis of the plantar cushion or fleshy frog.

Finally, cartilaginous quitter is nothing else than a slowly-progressive necrosis of the complementary fibro-cartilages of the third phalanx. This is much the gravest on account of its complications and its duration.

Calk. - Calk is a wound, a contusion of the coronary band, at the toe, the quarters, or the heels, which the animal inflicts himself by the contact of the shoe of another foot during locomotion. It belongs to the caiegory of grave diseases.

Crapaudine or "Mal d'Ane."-This affection, thus named because it is more common in the ass than in the horse, develops first at the toe upon the perioplic band, then upon the cutidure, and originates essentially from a chronic inflammation with perverted secretory functions of these two structures. It seems to be, as $\mathrm{H}$. Bouley believed, of the same nature as canker, and as a sort of exfoliation of the periople, with this difference, nevertheless, "that the secreted product, instead of remaining diffluent, concretes after its formation," I and constitutes, at the seat of the disease, a rugous surface, laminated lougitudinally and transversely, varying in severity and extent according to its period of duration.

We have deemed it needless to enter into more details as to the diseases of the foot, since their diagnosis, their prognosis, and their treatment belong entirely to the jurisdiction of the veterinarian. The foot is the veritable foundation of the animal edifice, which should always be remembered in the purchase of a horse. It is a region in relation to which one camnot be too fastidious. Is it defective? is it diseased? One can then foretell the speedy wcaring out and ruin of the animal, as well as considerable expenses of shoeing and treatment. On the contrary, is it duly constituted? is it healthy? Every day the aninal will resume, without discomfort, the work of the day before; he will never be incapacitated from work, for it is in the inferior regions that the member's begin to blemish, and all the more slowly as the extremities are better conformcd. Hence, in what concerns the diseases, we have only defined them and indicated their seat, not so much for the student to understand them as to direct his attention to certain parts of the hoof more predisposed than others to lose those characters which constitute the desirable points in these parts.

1 H. Bouley, Nouveau Dictiommaire de médecine, d'hygiène et de chirurgie vétérinaires, t. iv. p. 552 . 


\title{
SECTION THIRD.
}

\author{
PROPORTIONS.
}

\section{PART I.}

INTRODUCTION.

\section{CHA P T ER I.}

\section{PRELIMINARY IDEAS.}

Definition.-The word proportions, in its most general acceptation, signifies agreement and correlation when it is applied to the different parts of one whole. Considering it from the point of view which concerns us, this meaning should still be preserved, and, in the exterior, the study of the proportions endeavors to point out with precision the agreement of the regions with each other and with the body as a whole.

Agreement or Relation of the Regions.-The bodies by which we are surrounded are composed of elements, simple or complex, possessing a kind of reciprocal connection with one another, from which results the particular state in which these bodies appear to us.

As to living beings, they are a collection of organs whose action conspires to a sole end, the manifestation of that special mode of activity which is called life. These organs, when we study only that which is apparent to us from the exterior, show us relations of length, width, thickness, direction, development, etc., which canse the animated machine to present itself to us in a form always similar in its general features, but, on the contrary, infinitely varied in its details. It is on account of these general proportions, constantly the same and easily recognized in each individual of the same species, that we distinguish, 
at first sight, for example, a horse from an ass or a zebra. But the opponents of the relationship theory affirm that these characters cannot be compared; it is the disposition, the attitude, the appearance, the color, the presence or the absence, etc., of such or such parts, much more than the dimensions, which impress us at first. To make this assertion is to recognize implicitly the relations of the many parts of the organic collection, from which procecd the differences shown. The proportions of the ass are not more similar to those of man than those of man are to be confounded with those of the monkey; and so long as these species exist, we shall find in their external form the relations, more or less comprehensible, which their regions disclose at the present time. In different individuals these vary but very little, and in the same race they are not, as has been said, essentially rariable, for the features of resemblance become purely illusionary; we know, on the contrary, that they are used as a principal foundation for all classifications whose object is the methodical description of the different ethnic groups.

Harmony and Discord; Proportion and Disproportion. -When the mind examines any living form whatsoever, a conception, a production of its own activity, it always experiences in the presence of the one or the other a series of sensations which convey to it an agreeable or a disagreecuble impression. We are not affected in the same way by the reading of a literary composition, at the sight of a picture, a statue, an object of art, the recital of a dramatic adventure. The association of ideas, words, facts; the musical power of a sentence; the rhythm of discourse; the elevation of sentiment; the combination of geometrical lines, color, objects, or scenes described,-all these conditions of persons and things excite our sensibility differently, please or fatigue us according to the manner in which they are expressed and the aptitude of the person whom we wish to appreciate them.

In the same manner, the sight of a horse pleases or displeases us by the elegance of his form, the expression of his physiognomy, the vigor, the gracefulness, and the elegance of his gaits. Beautiful nature, like a fine book, manifests in every one a sentiment of physical and moral pleasure in proportion to the degree of impressionability and special culture which the observer possesses. Sympathy or antipathy, emotion or indifference, such are the results by which the correlation of things is manifested to our senses; by which, in other words, the harmony or discord of these relations is indicated. In ordinary language everything that is in harmony or concordance is called proportionate; evcrything that is not so is disproportionate, although in many 
instances the arrangement of the parts is different. In this respect, it is plain that the type of a handsome draught-horse approaches as near perfection, in its way, as that of a fine race-horse. Both satisfy in the same degree, although in a different way, the requirements of the true connoisseur, for both are the expressions of a perfect adaptation to the end desired.

Proportions are then good or barl, perfect or defectire; the subject in which they are found is well formed, correct in his lines, has a handsome form, becutiful symmetry, beautiful lines; or he is in two pieces, inluarmoniously constructed, ranting in form and in symmetry.

The Agreeable, the Beautiful, and the Good.--But," Bourgelat" says, "it is just as certain that all eyes have not the power to judge well, though, as it is a fact that all men indiscriminately believe that they have the right of judging. However, the decisions formed upon the knowledge of certain established and demonstrated rules are the only ones which should be held as the law ; for every judgment which has for its foundation only fancy, prejudice, inclination, a purely customary and imperfected notion of the thing, is only a selfconceited and often false opinion, denied by some, accepted by others, and sometimes even soon abandoned by him who has conceived it."

Thus the distinction between the agreeable and the beautiful in things pertaining to the horse has for a long time, as we know, been very clearly established; between that which pleases the eye and that which signifies energy, vigor, a perfect adaptation of the motor to its end; between that which is self-conceit, prejudice, mode, and that which is reason or demonstrated truth, science.

What, then, are the qualities which impress the laity,-that is to say, the mass of people, ignorant of the facts of which we speak? Elegance of. form, gracefulness of attitude and movement, roundness of the lines, indicating an easy, graceful action, and implying the absence of effort in the movements; vivacity, mobility, a certain gentle look of distinction in the physiognomy, which admits the predominance of moral perfection over the purely physical instincts. The animal which performs a laborious work contracts his muscles, stiffens his spine, extends his members, and shows under his skin a multitude of angular projections, straight or broken lines, which suggest vigor, energy, power, but which always indicate hard labor. Hence it is that we dwell, in preference, unknown to ourselves, on the spectacle of this energy in the state of rest, for as soon as it

1 C. Bourgelat, Traité de la conformation extérieure du cheval, 5e éd., p. 194. 
becomes visible, the grace, calmness, ease, which before pleased, will disappear. A round croup, flattened haunches, a sway back, a "fat," thick withers, an arched neck, slim canons, small feet, and a slender head will give more pleasure to the majority of inexperienced eyes than long, projecting lines, even a little roughly so, well-marked muscles, strong members, a spacious chest, broad articulations, large nostrils, etc.

All eyes do not see in the same way, nor even appreciate forcibly what is simply agreable. With greater reason the horsemen are rare who are capable of appreciating the beauty of which Bourgelat speaks; not the arbitrary, which varies with individuals and their artistic temperament, but the useful, which should be understood as synonymous with fitness, and which consists essentially in the adaptation of the organs to their function; that which results from the harmonious proportions of the parts and communicates to the whole a combination of qualities which renders it good, and not that which makes the same agreeable only to the senses. This beauty, to be appreciated, demands a certain intuition, much culture, study, acute observation, and judgment; we will refer to this at the end of this work.

\section{CHAPTER II.}

HISTORICAL.

Now that we know what difficulties are comprised in the study of proportions, it is not surprising that all horsemen have endeavored to establish the basis of these proportions the more safely to lead their pupils to a knowledge of the horse. But, among the many authors, those are few in number who have really produced upon this subject anything original. Many criticisms not founded upon facts, any amount of commentaries, and often much injustice are, unfortunately, the arguments of those who have entered the arena after the masters whose researches they have had neither the patience nor the courage to investigate carefully.

Abou-Bekr-Ibn-Bedr.-A veterinarian of distinction, Abou-Bekr, son of Bedr, has given in his book, "Le Nâcérî," all the questions referring to the science and the treatment of the Arabian horse. We find in this important 
work, which dates from the first third of the fourteenth century of the Christian era, the first vague, incomplete, and indeed incorrect indication of the measurements concerning the proportions of the horse. We will confine ourselves to this mention. ${ }^{1}$

Grisone.-The origin of the idea of proportions is therefore wrongly attributed to an Italian veterinarian of the sixteenth century, Frederico Grisone, ${ }^{2}$ a very imperfect idea, too, for he attempts in his book, which treats especially of horsemanship, rather to determine the qualities of the parts than to express their relations; he indicates the characters which, according to his opinion, should constitute beauty; besides these characters being in several respects very disputable, and in others very erroneous, we do not see that he has felt the necessity of comparing the regions with one another, and of expressing their relations with positive data. The establishment of the proportions, such as they are understood at the present time, does not therefore belong to him.

Bourgelat.-To Bourgelat, then, belongs all the praise of this attempt. He says ${ }^{3}$ that, "since beaty resicles in the fitness and agreement of the parts, it is very necessary to observe their particular and respective dimensions; and, to acquire a knowledge of the proportions, we must institute a lind of measurement which may be indiscriminately common to all horses.

"The part which can be used as a basis of proportions for all others is the head. Let us measure its length between two parallel lines, one tangent to the nape of the neck, or to the top of the forelock, the other tangent to the extremity of the superior lip, by a line perpendicular to these two parallel lines; we will thus obtain its geometrical length. Divide this length into three parts, and give them a particular name which can be applied to all heads, as, for example, that of prime. . . But all the parts which we shall consider, either in their length, height, or thickness, cannot constantly have either a whole prime, a prime and a half, or three primes; subdivide each prime into three equal parts, which we will name seconds; and as this subdivision is not sufficient to furnish us with the correct measure of all the parts, we will again subdivide each second into twenty-four points."

The geometrical length of the head is then divided into 3 primes, 9 seconds, or 216 points. Now, as this region may be defective in proportion, Bourgelat had to seek for another unit of measure in the height and in the length of the body, which, in the well-formed horse, are equal to two and one-half times the length of the head. By dividing one or the other of these dimensions into five equal parts, and by taking two of these parts, he then established a unit of measure such as the head would give if it were well proportioned.

This being laid down, let us now detail the law of Bourgelat, - that is to say,

For more details, see: 1. Le Nâcéri ou Traité eomplet d'hippologie et d'hippiatrie arabes, translated from the Arabian by M. Perron, t. ii. p. 96, Paris, 1859, chez Bouchard-Huzard; 2. Le Livre de l'agriculture d'Ibu-al-Awam, translated from the Arabian by J.-J. Clément-Mullet, t. il., 2d part, p. 33, Paris, 1866. This manuseript is older than the preeeding. M. Clement-Mullet wrote it in the twelfth eentury of our era.

2 Frederieo Grisone, Ordini di cavalcare et modi di conoseere le nature de eavalli, emendare i vitii loro, et ammaestrargli per l'uso della guerra et commodita de gli huominl, Veuetia, 1558, p. 5 .

${ }^{3}$ C. Bourgelat, loc. eit., p. 199. 
the ressumé of the rules which, according to his opinion, constitute the foundation of the beautiful proportions of the horse's body. ${ }^{1}$

\section{1st. Three geometrical lengths of the head give:}

The entire height of the horse, ab (Fig. 125, A), counting from the forelock to the ground upon which he rests, provided that his head be well earried.

\section{2d. Two heads and a half equal:}

The height of the body, $c d$, from the top of the withers to the ground. inclusive.

The lcngth of this same body, ef, from the point of the arm to the point of the buttock

\section{3d. A whole head gives:}

The length of the neck, $c g$, from the summit of the withers to the posterior part of the poll. The height of the shoulders, ch, from the top of the withers to the point of the elbow.

The thickness of thc body, $i j$, from the middle of the abdomen to the middle of the back.

The width of the body from one side to the other, $k l$ (Fig. 125, $B$ and $C$ ).

4th. A head, $b b^{\prime}$, measured from the top of the forelock to the commissure of the lips, will equal (Fig. 125):

The length of the croup, of, from the angle of the haunch to the point of the buttock.

The width of the croup or of the haunches, $m n$ (Fig. 125, $B$ and $C$ ).

The height of the croup, pq (Fig. 125, A), taken from the summit of the latter to the patella, the leg being at rest.

The postero-lateral lcngth of the legs or tibial region, $q r$, from the patella to the centre of the tibio-astragaloid articulation.

The perpendicular height, $r s$, of the same articulation above the ground.

The distance from the summit of the withers to the insertion of the neck into the chest, cl.

5th. Twice the length of the croup, $b b^{\prime}$, gives almost:

The distance from the point of the patella to the summit of the withcrs, $u c$.

The distance from the point of the elbow to the summit of the croup. hp.

6th. Two-thirds of the length of the head will equal: to outside.

The width of the breast, $v x$ (Fig 125, B), from one point of the arm to the other, from outside

The horizontal length of the croup, $y z$ (Fig. 125, A), between two verticals, one of which touches the point of the buttock, and the other passes through the summit of the croup and touehes the point of the patella.

The thirds of the hind quarters and of the body, taken together, $c z$, to the perpendicular line from the withers touching the elbow.

The anterior length of the leg, $u w$, taken from the tuberosity of the tibia to the fold of the hock.

7th. The half of the head is the same as:

The horizontal distance from the point of the arm to the vcrtical line from the summil of the withers and from the clbow, $e e^{\prime}$.

The width of the ncck, $m n$, viewed laterally and taken from its insertion at the intermaxillary space, or from the throat, to the root of the first hairs of the mane, upon a line which forms with the contour of the poll two equal angles.

\section{8th. The third of the head gives:}

The height of its supcrior parts, op (Fig. 125, B), from the summit of the forelock to the line which passes through the most prominent points of the orbits.

1 II Fig. 125, which is an exact reproduction from the large plate of the book of Bourgelat, we have omitted all the more confusing lines; it has also seemed neeessary to us to change the letters and somewhat modify the expressions of the original description in order to render the ideas more intelligible to the reader. Finally, we have omitted paragraphs 6 and 7 of the proportions of the founder of the veterinary sehools, because the measurements which are given there are only a repetition of those mentioned in paragraph 2. 
HISTORICAL.

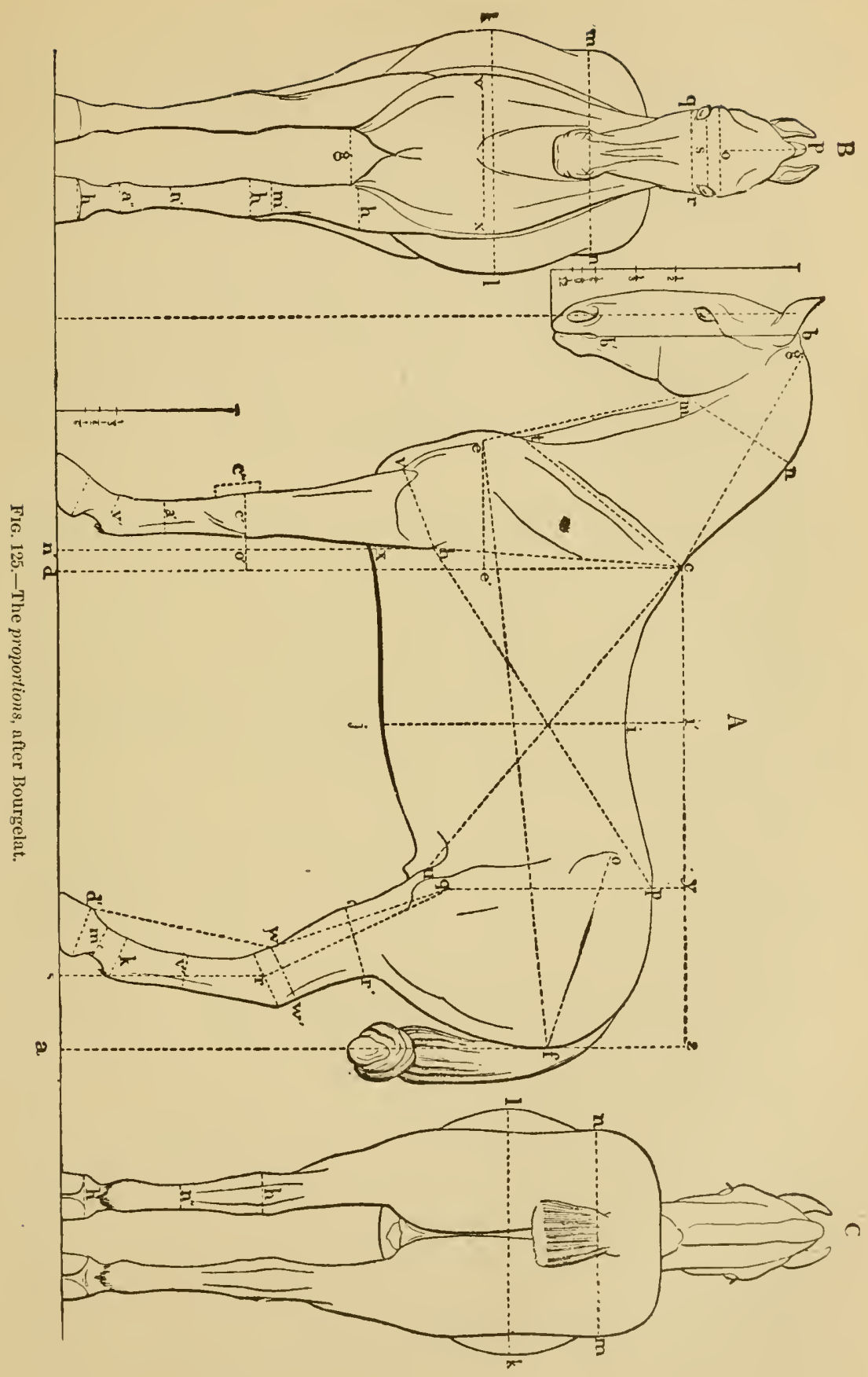


The width of the head, gr, below the inferior eyelids.

The lateral willth of the forcarm, $v$ (Fig. $125, A$ ), taken from its origin in front to the point of the elbow.

\section{9th. Two-ninths of the head give:}

The rertical clevation of the point of the elbow above the sternum, $h x$.

The depression of the back, $i i^{\prime}$, in relation to the summit of the withers.

The lateral wudth of the lcgs, vw', close to the hocks.

The opening, $g$ (Fig. 125, B), or rather the distance betwcen the forearms, from one axilla to the other.

\section{0th. One-sixth of the head equals:}

The thickness of the forearm, $h$ (Fig. 125, $B$ ), seen in front, at its origin, from the axilla to its external contour horizontally.

The width of the coronet of the anterior fect, $h$ (same figure), either from one side to the otler or from before to behind.

The width of the coronet of the postcrior fcet. $h$ (Fig. 125, C), from one side to the other only.

The width of the posterior fetlocks, $k$ (Fig. 125, A), from in front to behind.

The width of the knce, $h$ (Fig. 125, B), seen in front (measure a little large).

The thickness of the hocks, $h$ (Fig. 125, $C$ ) (measure a little small).

\section{1th. One-twelfth of the head gives:} thicker.

The thickncss of the anterior canon, $n^{\prime}$ (Fig. 125, B); the posterior, $n^{\prime \prime}$ (Fig. 125, C), is a little

\section{2th. One-ninth of the head equals:}

The thickness of the forearm in its narrowest part, $m^{\prime}$ (Fig. 125, B).

The thickness of the posterior pasterns, $m^{\prime}$, seen laterally (Fig. 125, $A$ ).

13th. The height of the elbow from the fold of the knee (Fig. $125, A$, below) is the same as:

The height of this same fold to the ground, o' $n^{\prime}$ (Fig. 125, A).

The height of the patella above the fold of the hock, qw.

The distance from the fold of the hock to the coronet, $w d^{\prime}$.

\section{4th. One-sixth of the preceding measure (13th) gives:} length.

The width of the canon of the forcfoot, $a^{\prime}$ (Fig. 125, 1 ), viewed laterally in the middle of its The width of the anterior fetlock viewed in front, $a^{\prime \prime}$ (Fig. 125, B).

15th. One-third of the same measure (13th) is almost equal to: The width of the hock from the fold to the point, $r$ (Fig. 125, A).

16th. One-quarter of the same measure (13th) gives:

The width of the knce seen laterally, $c^{\prime}$ (Fig. 125, A).

The length of the knee, $c^{\prime \prime}$ (Fig. 125, A).

17th. The space between the eyes from one angle to the other, $s$ (Fig. 125, $B$ ), equals :

The width of the leg or tibial region seen laterally at the level of the fold of the buttock, r' $r^{\prime}$ (Fig. 125, A).

\section{8th. One-half of this interval between the eyes gives:}

The width of the posterior canon scen laterally, $v$ (Fig. 125, A).

The width of the anterior fetlock seen laterally, $v^{\prime}$ (Fig. 125, A). $125, A)$.

Finally, the difference of the height of the croup in rclation to the summit of the withers, py (Fig. 
Bourgelat adds that "these are, in the horse, nearly all the parts corresponding through reciprocal dimensions. The eye which is experienced in these different data will recognize them without the use of the hippometre, the compass, or the scale upon the parts whose defects he wishes to judge by the measurement with as much facility as the painter reduces his sketch in making from an ordinary figure one that is colossal."

Bourgelat's work is almost entirely contained in the preceding data; contrary to the accepted opinion, it is based upon a profound knowledge of the horse, as well as upon observations as positive as those which are daily recorded by purely descriptive sciences, as anatomy, for example.

Still, the first and most frequent of the criticisms made against the founder of veterinary schools is his having acted under the inspiration of his own ideas and borrowed from other sources than from nature itself. How can we, indeed, uphold the bad expression, the ugly form, of the model upon which he has traced his geometrical lines? This model, known to-day by the name the Bourgelat horse, with his Roman nose, his arched neck, and massive, straight shoulder, rounded croup, flattened haunches, round buttocks, angular hock, and long canons, appears to have aimed at the establishment of a special and new type, very different, however, from that which he had mentally devised. The beholders failed to see all the beauty and accuracy contained in that rough scheme which Vincent's pencil produced under the very eyes of the master. Disagreeably impressed by the whole work, they missed the harmony of the important lines, they objected to the minuteness of the measurements, and looked upon it as a work of pure imagination, without reflecting that the most gifted imagination is powerless to create such combinations.

It is true Bourgelat did establish his laws according to his own idea of the beautiful horse, but he has obtained the proportions from a real type, which still exists, and which by a unanimous acknowledgment connoisseurs also consider the type of beauty.

That there are exaggerations, inaccuracies, in his system is incontestable. Is not this the danger of all inventors, and does it follow from this that we should discredit any of the truths that are offered? Bourgelat has attempted to determine the agreement of the parts with one another and with the whole; this is his main idea; to have seen and appreciated these relations is his merit; finally, he has found some which will live and which slow the results to which a correct idea, supported by a good judgment and an exceptional talent, may lead.

But we do not think that we call, following the example of Professor Baron, ${ }^{1}$ blame him for having estimated all the external measurement of the body by only one and the same unit: the length of the head. According to our colleague, the length of this region should only be used to measure the longitudinal axes, its width the transverse, and its thickness all that which, in the body, is an element of thickness. Truly, this logic appears a little exclusive. In practice it results in this: a single rule being insufficient, three are necessary. Instead of simplifying a rule already too complex, we increase the difficulties threefold at the time when it is so important to point out, in passing, the exceptions and the deviations that are of some interest. To understand the regional relations, one single common measure is sufficient, the head or any other part, 
it matters little which. The head has been rightly selected, because this unit is easy to be obtained, and its individual variations in the same race are more rare than those of the other regions. It is just as convenient to compare the different dimensions of the horse, with the head, and to find their harmonious combinations, as to rletermine the relations of height, width, and depth of a room, for example, by the same yard measure.

Bourgelat has been criticised for the minutix into which he has entered, notably, of the width and the thickness of the articulations and the members, the separation of the eyes, etc. But would he have fallen into this error if he had not especially worked to guide artists in the realization of their works? No doubt he forgot that the more minute his measurements became the more liable they were to show what was erroneous in them, for if the generality of horses are in conformity with his principal rules, they are notably different from the secondary as soon as dissimilar types are in question. This is the very reason why these rules have been successfully opposed, and without difficulty, by most horsemen. It seemed, in fact, a deduction from the ideas of Bourgelat, that there was but one single type of beauty for the horse, while it is evident that the type is multiple. To attempt to apply the same scale to the heavy-draught horse and to the race-horse, and assert it beforehand as infallible, was the obligatory consequence that his opponents were sure to draw from Bourgelat's forgetfulness, and to make the most of against him. He believed that his rules had an absolute value, whilst they are essentially relative to some particular types.

His other great fault is to have misunderstood the compensitions which exist between these regions. In assigning such precise limits to what he believed to be the ideal beauty, he has tacitly declared defective all that was not in conformity with his measures, a logical deduction of his system. The head, for example, was in his opinion either proportionate, too short, or too long. In these latter cases it was to be rejected, whatever might be the length of the neck. Still, we have seen that a neck which is too long redeems a small head; a neck that is short and massive ameliorates in the same manner the effects of a head that is too large. It follows from this that the defects of certain regions are capable of compensating those of some others, always on condition that these last, by agreement with the preceding, are of a reverse order in their results.

Another criticism which can be made against Bourgelat lies in his having absolutely ignored, so to spcak, the relations between the angles of the osseous segments of the members. He has occupied himself with little more than the relations of length, width, and thickness of the parts, without considering the desirerl angles of locomotion which tend to an increase of speed. This is a regrettable omission in this sense, that if the founder of veterinary schools had thought of it with the same intelligence that he showed in the establishment of his horse-measuring rules, science would have possessed at least some correct ideas upon this subject, which would have prevented General Morris from inventing, asicle from all positive observations, his theory upon the similitude of angles and the parallelism of the bony segments.

Finally, Bourgelat has also omitted to speak of the relations of the body as a whole with the nervous system, another important consideration which might have caused him to speak of the interesting question of the blood,-that is to say, of the moral qualities, transmissible by heredity, which endows the horse with the highest qualities of the choicest families of the species. 
Saint-Bel.-Saint-Bel, ${ }^{1}$ the founder of the veterinary school of Saint-Pancras, endeavored to propagate the principles of Bourgelat in England. He thought that Eclipse, that extraordinary and always unconquerable horse, would be for English scholars the best type of the conformation of the beautiful horse, and he prepared with great care the scale of the proportions of this noble animal.

We do not know what instruments Saint-Bel made use of to measure Eclipse. It is certain that he indicates accurate measurements alongside of others that are altogether impossible. Perhaps he employed the tape-measure. If this were so, the incompatibilities of several of his assertions may be explained. However this may be, we have shown in our drawing the head of Eclipse, such as this horse should have had in order to be regularly conformed.

The length of the head is supposed to be divided into twenty-two equal parts, which are used as a common measure for all parts of the body (Fig. 126) :

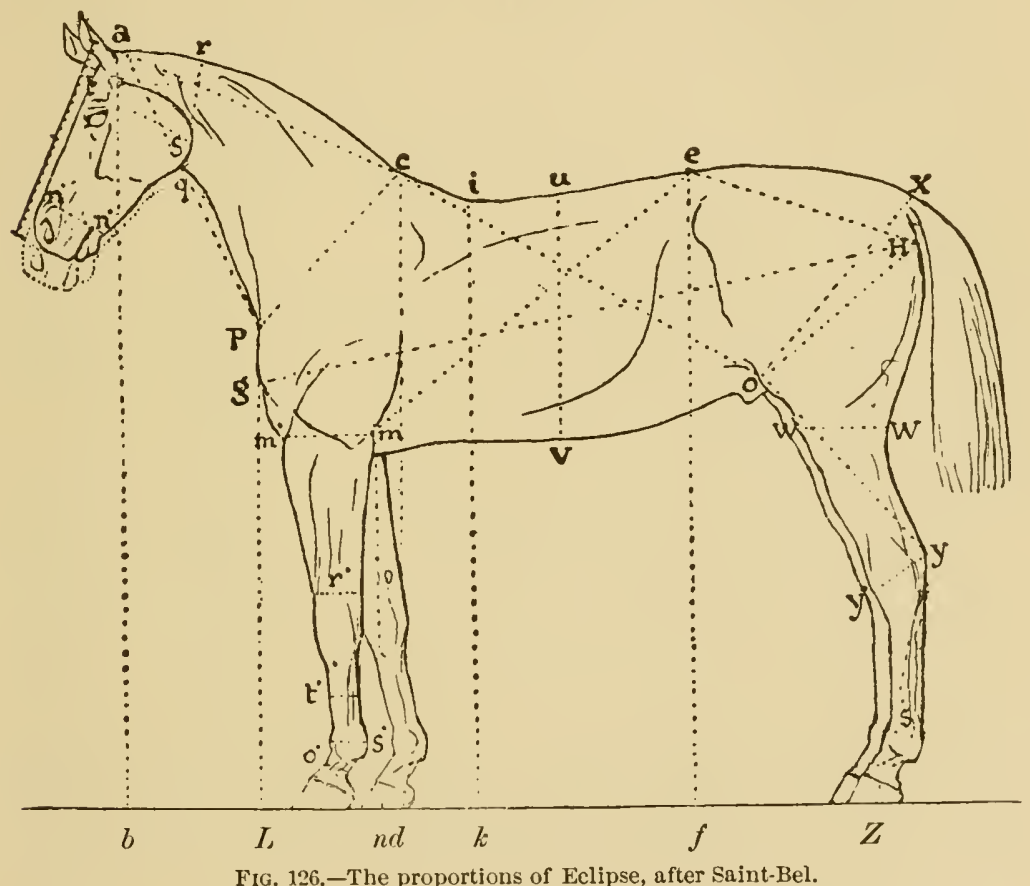

1st. Height of the poll from the ground $(a b) \ldots \ldots . . .3$ heads and 13 parts.

$2 d$. Height of the withers from the ground $(c d) \ldots \ldots . . .3$ heads.

3d. Height of the croup from the ground $(\epsilon f) \ldots . . . .3$ heads.

4th. Whole length of the body, from the point of the shoulder

to that of the buttoek $(g h) \ldots \ldots . . . .3$ heads and 3 parts.

5 th. Height of the body at the level of the centre of gravity (ik) 2 heads and 20 parts.

6 th. Elevation of the chest ahove the ground (?) . . . 2 heads and 7 parts.

7 th. Height of the perpendicular falling from the point of the shoulder upon the hoof $(g l) \ldots \ldots . . .2$ heads and 5 parts.

8th. Height of the perpendieular from the point of the elbow to the ground $(m n) \ldots \ldots \ldots . \ldots . \ldots . \ldots$ head and 19 parts.

1 William Youatt, II istory of the English Thoroughbred Horse. 
9th. Distance from the summit of the withers to the stiflejoint $(c o) \ldots \ldots \ldots . \ldots . \ldots 1$ head and 19 parts. 10th. Distance from the summit of the eroup to the elbow (em) 1 head and 19 parts. 11th. Length of the neck from the withers to the top of the head $(c a) \ldots \ldots . . . . . . .1$ head and 11 parts. 12th. Length of the neck from the top of the head to its insertion in the chest $(a p) \ldots \ldots . \ldots 1$ head and 11 parts.

13th. Width of the neck at its union with the ehest $(c p) \ldots . .1$ head.

14th. Width of the neck in its narrowest part $(q r) \ldots \ldots$. . 12 parts.

15th. Width of the head taken above the eyes $(s t) \ldots . . . .12$ parts.

16th. Thickness of the body between the middle of the back and the middle of the abdomen $(u v) \ldots \ldots . . .1$ head and 4 parts.

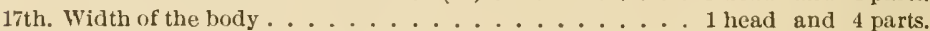
18th. Distance from the top of the eroup to the point of the buttock $(e h) \ldots \ldots \ldots . . \ldots 1$ head and 4 parts. 19th. Distance from the root of the tail to the stifle-joint $(o x) \ldots 1$ head and 4 parts. 20th. Distance from the stifle-joint to the point of the hock (oy) 1 head and 4 parts. 21st. Distance from the point of the hock to the hoof $(y z)$. . 1 head and 4 parts. 22d. Distance from the point of the buttock to the stiflejoint $(o h) \ldots \ldots . . . . .20$ parts. . . . . . . . . . . . . . . .

23d. Width of the croup .............. 20 parts.

24th. Width of the anterior members at the level of the elbow

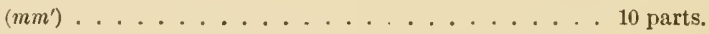

25 th. Width of the posterior members at the level of the fold of the buttock $(w w) \ldots \ldots . . . . .10$ parts. 26th. Width of the hock at the level of its fold $\left(y y^{\prime}\right) \ldots \ldots$ parts. 27th. Width of the head above the nostrils $\left(n^{\prime} n^{\prime}\right) \ldots . . .8$ parts. 28th. Distance from the internal angle of one eye to that of the other ...................... 7 parts.

29 th. Separation of the anterior members ....... 7 parts. 30 th. Width of the anterior face of the knees . . . . . . 5 parts.

31st. Width of the anterio member above the knee $\left(r^{\prime}\right) \ldots \ldots 5$ parts.

32d. Width of the hocks (anterior face) . . . . . . . 5 parts.

33 . Width of the fetlock $\left(s^{\prime}\right) \ldots \ldots \ldots . . . . . .4$ parts.

31 th. Width of the anterior face of the coronet . . . . . . 4 parts.

35 th. Same width, but a little lower ......... . . $41 / 2$ parts.

36 th. Width of the member in its narrowest part $\left(t^{\prime}\right) \ldots \ldots$. . 3 parts.

37 th. Width of the posterior pastern (anterior face) .... $23 / 4$ parts.

$38 \mathrm{th}$. Width of the anterior pastern $\left(o^{\prime}\right) \ldots \ldots . . . . . . .2 \frac{1}{4}$ parts.

39 th. Width of the anterior canon .......... $23 / 4$ parts.

40th. Width of the anterior and posterior canons upon their anterior face .................... $13 / 4$ parts.

Vallon.-Vallon ${ }^{1}$ also attempted to indicate proportions, but he has not been more successful than the English, especially in what concerns the length of the body, which he considers to be three heads in the saddle-horse, which is incorrect. Here are the measurements which he gives for a horse of $1.60 \mathrm{~m}$.:

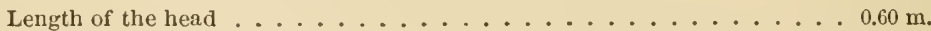

Length of the neck (a herd and a fifth) . . . . . . . . . . . . . .

Height of the horse from the withers to the ground (two and two-thirds

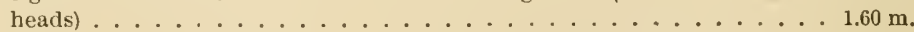

Height of the chest from the withers to the xiphoid region (a head and a quarter) ........................... $0.75 \mathrm{~m}$.

Length of the anterior members from the passage of the girth to the ground (a head and about a third). ........................ $0.85 \mathrm{~m}$.

Height of the posterior quarters from the top of the eroup to the ground (a

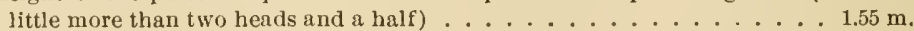

Length of the body from the point of the shoulder to the point of the buttock (three heads) ........................ $1.80 \mathrm{~m}$ 
If, with these proportions, the head is square and light, the forehead wide and long, the eye large, placed far from the ears, the withers elevated and extending backward, the loins short and straight, the croup, the shoulder, the leg, and the forearm long and well muscled, the canon short, the pastern of medium length and properly inclined, the articulations wide, the articular angles well oriented, the muscular system dominant and firm, the foot irreproachable, the horse has, as a whole, good proportions.

"As to the work-horse," he ardds, "he should not be in all respects similar to the cavalry horse. The fore-quarters need not be as light nor the shoulder as long and oblique, the withers as elevated; the chest should be spacious, the members shorter, the muscular system more strongly developed, the degree of the temperament (blood) less sanguinary.

"The proportions which suit the horse of $1.50 \mathrm{~m}$. the best are the following:

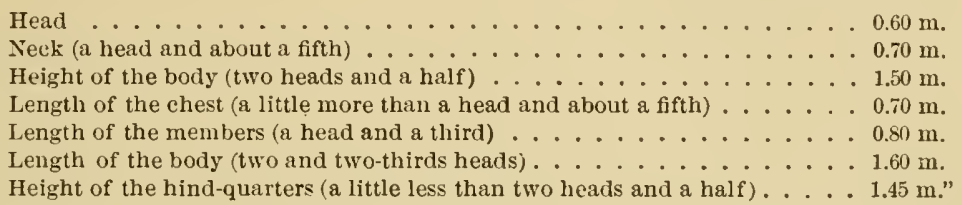

The preceding measures do not differ much in principle from those of Bourgelat, which they reproduce, as a whole, under another form. Their points of difference consist, in our opinion, in errors or at least exaggerations, the evidence of which will be seen when we present our own ideas concerning this.

M. Richard.-To our regret, and contrary to our custom, we are here forced to oppose one of the most distinguished horsemen, who, in France, contributed much to bring discredit upon Bourgelat's system. We mean M. Richard, whose opinions on other questions are in most instances in conformity with ours.

The principal objection to this recommendable writer proceeds from the point of view in which he regards the horse. Starting out with the idea that this animal has become for man a generator of force and speed, he cannot conceive that an attempt could be made to impose limits to the mechanical beauties of the horse-machine, which he would wish to realize. This manner of reasoning, although very just in principle, has led M. Richard into numerous exaggerations; because beauty resides principally in the harmony of the parts, and not in the extreme development of some of them, considered as more particularly advantageous for the proper action of the whole. If the disproportion results from the number of the defects, it may also become the consequence of a functional discord of the relations.

Now, it is with the beauties of the horse as with all other things analogous to them through utilization; the motor in question must be benefited by them, for otherwise they become useless or detrimental. It being granted that large wheels are for a vehicle one of the first conditions of speed, of what use would they be if their eleration gave it such an instability that it could be used only upon special roads, or turn only in certain curves? In the same way, it is acknowledged, in an absolute manner, that a long forearm, long legs, a long 
croup, and a very oblique shoulder are elements indispensable to the velocity of the gait; now, increase these beauties of the forearm and the leg in an exaggerated degree and you will make your horse taller; do the same thing with the croup and the shoulder, you will lengthen his body, and if you do not develop in the same proportion the chest, the abdomen, the neck, the head, the articulations, etc., you will have made, according to your fancy or talent, a giraffe, a dromedary, or an elephant, but you will no longer have a horse,- - that is to say, a special motor adapted to our needs, to our civilization; because you will have destroyed the pre-existing harmony of the regions. That is what MI. Richard has misunderstood, and which caused him not only to disregard the opinions of Bourgelat, but also to shower upon him those harsh criticisms which fell with equal force upon his followers, the members of the Board of Education.

Here are, besides, some extracts which abundantly prove that we lave not exaggerated his thoughts :

"The model horse of Bourgelat, constructed in accordance with his method, cannot fulfil the conditions required by reason and by a good locomotor. How, indeed, eau we accept limits to the development of certain regions, especially when the very excesses would always and without exception be a desirable beauty? How is it possible to limit the width of the forehead, the height of the cranium, the development of the withers, the height of the chest, that of the shoulders, or their obliquity? Shall we ever find a fetlock or a forearm that is too wide, the latter too long, a knee too much developed, a tendon too neatly outlined? Can we fix the limits to the width of the hock, to that of the leg, to the length of the croup and that of the ribs?

"He who wislues to study the horse according to his destination will be couvinced, as we are, that it is contrary to reason to establish by arbitrary measures (there can be no others) limits to the development of such or such region of his body. We understand perfectly that the artist should have data to direct him in the perfection of his work, the forms of which are regulated by taste and fashion, but the mechanic must obey only the laws of mechanies; he can judge of the qualities of the machine only from the invariable rules upon which these laws are established."

\section{And still further :}

"Physiology and mechanics united, in accordance with the observation of facts, teach us that a square head is generally beautiful. Its masticating muscles are usually quite prominent. Its nostrils are very mobile, very wide, very dilatable. Large eyes, wide open, bright, and placed low, a large forehead, and a well-developed cranium are its characteristics. Such a head is always to be recommended, whatever may otherwise be the indications of the proportions, which prove absolutety nothing if they are contrary to beauty. If, on the other hand, a horse has his neck well muscled, to execute well all the movements, without an excess of fatty or cellular tissue; if he has very high withers, and here we know no limits; if he has a short back and short loins, very wide and with strong muscles; if his croup is long and well muscled, high and well-inclined shoulders; if the chest is very deep and the ribs long, well arched, and rounded; if the flank is short, the forearm very long and wide; if the knee is strollg, the tendon extremely detached, the fetlock wide, the pastern short and of the desired degree of inclination; if the buttocks are prominent and furnished with strong, long, well-marked and well-descended muscles; if the leg and the hock are wide, whatever may be the excess of their width, take no account of proportions whose value nothing justifies ; you will always be sure of having found the model horse."

M. Richard does not perceive, in the two quotations which we have just made, that, more than all others, he has the idea of proportions, the name of which irritates him so much. He speaks of the excess of certain beauties, without thinking that the excess of things is judged only by comparing them with one another, or by appreciating how they exceed the dimensions and the mean limits which they ordinarily possess. If that particular thing cannot be too wide, or this one too long, it follows that another one can be right, or even too narrow and too small. Now, the excess, the sufficiency, and the deficiency are qualities 
impossible to be determined if the relations of the parts have not been studied, and if there be not for them certain mean terms of comparison. To say that a region is too long, exactly normal, or too short, is to express that, relative to its ordinary beautiful length, it is proportional or disproportional; it is therefore tantamount to admitting good or bad proportions. There exist, therefore, certain standard dimensions which must be known in order to be able to base one's judgment.

Without any doubt, it would be contrary to reason to establish by arbitrary measures the limits of development of any region. But the great error in our esteemed colleague's argument lies in not proving what he asserts. The measurements are arbitrary only when they proceed solely from the self-conceit of him who invents them; in all other cases they are as real as the things from which they are taken.

M. Richard has advanced exactly, with regard to Bourgelat, that of which he has accused the latter: a pure theory. He has not taken the trouble to study this author closely. If he had attempted this, would he ever have written the following passage?

"But we will go still further. We mean to prove in two words that a horse which would display the most rigorous proportions advanced by this author might be very badly conformed and in very bad condition as regards strength and speed. We wish to show still further that, in order to remedy his vice of conformation, we are forced to do the contrary of what is prescribed by the founder of veterinary medicine.

"Suppose that a horse which is in conformity with the proportions of Bourgelat has very long and corded flanks and a very short croup, which is often observed; this horse will have weak loins, and his gait will be shortened for want of length in its croupal muscles. What shall we do now, if we wish to give this horse the qualities of strength in which he is wanting and which the acknowledged proportions would indicate as excellent? We will lengthen its iliac bones, which Bourgelat condemns, so as to diminish a part of the surplus length of the loins; we will also lengthen the ischiums to carry the point of the buttocks farther backward. We have no other means of remedying the evil and making a good horse from a bad type of construction of the loins and the croup. To arrive at this essential result, what shall we do? We will do the opposite of what is prescribed by the proportions of Bourgelat: we will lengthen the body of the horse by lengthening the croup in front and behind through a greater predominance of the buttocks. The proportions of the whole, like those of the individual regions, are therefore contrary to physiological and mechanical laws as well as to those of reason. Then, as we have said, written, and taught for more than fifteen years, the proportions of Bourgelat, which have always been considered as the key to the basis of all the principles established by this author, are falscly founded; we eannot repeat too often that they should be condemned as a material error, fatal to the progress of science, fatal to the perfecting of our races of horses, especially cavalry horses."

In the face of such assertions, without proof, we must acknowledge that this verdict is very severe. M. Richard takes for granted precisely what he should at first have commenced to demonstrate,-namely, that a croup such as Bourgelat requires would be very short. But it would have been easy for him to ascertain the contrary by measuring this region upon subjects selected by himself as well formed in that part of their body. Then he could have proved that a croup whose length is equal to the distance comprised between the top of the head and the commissure of the lips is not too short, that, consequently, this proportion was not poorly founded, and should not be condemned as a material error and one fatal to the progress of science. M. Richard's objections, very judicious theoretically, we repeat, fail when practically applied, for the same reason: want of deliberation. To what would they be reduced if it were settler that Bourgelat had taken his measurements upon horses in which they showed 
themselves really irreproachable? To nothing, since upon these subjects the shoulder, the cromp, the forearm, the neck, the leg, etc., would exactly enter into the conditions of length, width, and thickness required by his contradictor. And yet this is the very merit, we do not say of all, but of many, of the proportions of the founder of veterinary schools, and M. Richard would not have failed to recognize it if he had seriously undertaken to verify, with compass in hand, the assertions of the former. This is the reason why, when we take literally the data of an author, without taking account of the almost inevitable exaggerations to which he is naturally inclined, one is easily led to draw from them wrong conclusions, to overlook the good in order to see only the weak points, and present these as the only result which this theory can attain.

Most certainly we would ourselves deserve this reproach if we should not now make prominent the correct and truly practical idea which is apparent in II. Richard's criticisms. This distinguished horseman desires principally to call the attention of the observer to the absolute beauties of the horse, beauties which we should never oppose, since they are the best index of the conditions of strength and speed, attributes which should never be limited, for they are fundamental qualities of the animal machine, elements indispensable to its proper action. If the eye is impressed with a want of harmony in the whole, it is not to the fulness of the chest, the length of the croup, of the forearm, of the leg, the obliquity of the shoulder, the height of the withers, the width of the articulations, etc., that this defect is to be attributed; it is due to the weakness, the bad conformation, of the other regions. The disproportion should be considered especially as characterizing the predominance of defects, and not as being derived from excess of the beauties. A horse is defective not because he is too well formed in some of his parts, but because he is not enough so in others. A kind of correlation of development exists between all the organs; if one of them acquires dimensions somewhat considerable, others follow it, so to speak, in the same measure; and this is what justifies to a certain extent the words of M. Richard, when he asserts that he does not understand how we can limit the width of the forehead, the height of the cranium, the development of the withers, the height of the chest, and the length of the shoulders; when he defies us in some way to find too wide a fetlock, a forearm too long, a knee too much developed, a tendon too much detached; when he rejects the limits imposed to the width of the hock, that of the forearm and the leg, the width of the croup and that of the ribs. The giraffe-, dromedary-, or elephant-horse is not possible, even in driving to extremities M. Richard's exaggerations, on account of those very organic correlations of which we have just spoken. This has been mentioned only to show the consequences which may be the result of the a priori in matters concerning the horse. We get to believe that facts are overthrown by words, and the more readily so, as we are encouraged in it by the mass of those who content themselves with admiring facts through the eyes of others. 


\section{PART II.}

\section{OBJECT AND UTILITY OF THE PROPORTIONS.}

Now that we have demonstrated the existence of the relations existing among the different parts of the body, it will be easy to understand what result can be reached by seeking for the proportions of the horse. The question at issue is to express in simple terms the relations of the regions in such a manner as to establish the elements of beauty which should here be looked upon as a reflection of perfection. Such a study is most fruitful for one who wishes to succed promptly in dereloping his "eye" and his judgment; it is not less useful for the artist anxious to impress his works with the stamp of accurate imitation.

We do not wish to say by this that imitation is the supreme aim of art and that the merit of artistic productions lies infallibly in their accuracy. It is far from our intention to compare the artist to a photographic apparatus : this would be the ignoring of his personality, of the very passion with which he sees the things of his domain; it would be the very negation of his talent. His work should, principally, reflect movement and animation, the emotion he felt in the presence of the subject which he wished to reproduce. He will be pardoned for the want of physical resemblance in his conceptions, whilst he will always be blamed for his want of sentiment or his absolute indifference. But if we have been able to say with reason in this respect that sincerity in art can replace truth, it is not less evident that the artist who is at the same time accurate and sincere in his reproduction will constantly excel him who has only one or the other of these qualities. It is on this account that the study of proportions is of the greatest necessity to him.

\section{CHA PTER I.}

POINTS OF VIEW FROM WHICH THE PROPORTIONS ARE STUDIED.

UNTIL now, under the head of proportions, we have only treated of the relations of length, of width, and of thickness of the constituent parts of the body, and even this has been done in a very incomplete manner. This too exclusive view is certainly insufficient for one 
who wishes to analyze minutely the horse as a machine productive of force and speed. It is necessary, besides, to inquire into the relations of direction which the osseous segments may affect among each other, to determine in what manner they are articulated, and what rules govern their most extensive and regular action.

We should then examine the whole body with regard to its larger dimensions, its general harmony.

Finally, we should determine in what measure the nervons system, this ultimate regulator of all activity and of all vital manifestation, is in functional equilibrium with the machinery which animates and directs the animal with absolute power.

These four important questions will be the subject of the present chapter.

\section{A.-Relation of Dimensions between the Parts.}

We have not to deal with long and slender or with short and thick forms only, - that is to say, with two extreme conformations between which there might exist a mean one related as much to the first as to the second. In reality, the types of conformation, varying with the conditions of existence and the kinds of utilization, are much more numerous. He who intends to make an artistic reproduction of them, or who wishes to choose them with a view to some special purpose, should therefore be acquainted with the characters proper to each, and seck for their differences.

Nevertheless, certain common characters always inite them, which establish their relationship, their analogies, and their resemblance. It is these qualities, easily found in the great majority of horses, which, hereafter, we propose to consider.

But an important observation should first of all be made with reference to the documents of which we are abont treating. It is, that they constitute only mean data capable of directing and aiding the artists or amateurs who are making their début. We cannot see in them absolute ideas beyond which everything is false. They are only beacons, landmarks of reference to be consulted, which, whilst showing general harmonions relations of the form of the horse, will cause gross errors, regrettable mistakes, and opinions filsely founded.

Since Bourgelat's time, several observers, besides Saint-Bel and Vallon, have endeavored to establish the relations of the dimensions which should exist between the parts of the horse's body.

Professor Colin, ${ }^{1}$ a long time ago, indicated the mean length of

1 G. Colin, Physiologie comparée des animaux domestiques, lère éd, t. i p. 252, Paris, 1855. 
the bony segments of the members. Our colleagues, M. Neumann ${ }^{1}$ and Professor Lemoigne, ${ }^{2}$ of Milan, have confirmed, on their part, the results published by M. Colin; we will say the same about our own personal researches. ${ }^{3}$

But Colonel Duhousset is indeed the man who, in Franee, is the most interested in the measurements of all the regions of the horse. We have had the pleasure of guiding him in his first attempts and investigating, afterwards, the correctness of his observations. These are published in a pamphlet, from which we have borrowed the greater part of the following details. ${ }^{4}$ After the example of Bourgelat, M. Duhousset has chosen the head as a unit of measure, and considers its length from the poll to the extremity of the upper lip. This dimension, as well as those of which we will hereafter speak, is obtained by the aid of a compass of thickness, and not by the tape-measure system, in order to avoid the causes of error inherent to the prominence of the parts whose outlines this measure would have to follow. It is also well that the animal be placed in normal equilibrium, and that his head, a little raised, should as nearly as possible be parallel to the direction of the slope of the shoulders.

We will annex to our deseription the following drawing (Fig. 127), a reproduction of a photograph on which the subject is shown absolutely in profile, a position which in no way alters the reciprocal relations of the parts ${ }^{5}$ the animal here represented was as high as he was long.

"The length of the head almost exactly equals the distance:

1st. From the back to the abdomen, No (thickness of the body).

2d. From the top of the withers to the point of the arm, $I E$ (shoulder).

$3 d$. From the superior fold of the stifle-joint to the point of the hoek, $J J$.

4 th. From the point of the lock to the ground, $J K$.

5th. From the dorsal angle of the scapula to the point of the haunch, $D^{\prime} D$.

6 th. From the xiphoid region to the fetloek-joint, $M I$; above this latter for large horses and race-horses; below and in the middle, in small horses and in those of medium size.

7 th. From the superior fold of the stifle-joint to the summit of the croup in subjects whose coxo-femoral angle is large; this distance is always less in other cases (G. and $B$.$) .$

1 G. Neumann, Des aplombs chez le cheval, in Journal de méd. vét. milit., t. viii. p. 352.

2 A. Lemoigne, Reeherches sur la méeanique animale du cheval, in Ree. de méd. vét., année 1877, p. 81.

3 See, besides, J. Kiéner, Journal de l'agrieulture, année 1881, t. ii. p. 341. (He treats there of the relation of the widths of the anterior and posterior canons.)

4 E. Duhousset, Le eheval, p. 63 et suiv., Paris, 1881.

5 In measuring a horse from a photograph, it is neeessary to take him absolutely in profile. Without this preeaution the regions are not shown perpendieularly upon the same plane; the length and the height of those which are more distant from the observer appear shorter in relaion to those which are nearer. 


\section{"Two and onc-half times the head gives:}

1st. The height of the withers, $H$, above the ground.

2d. The height of the top of the croup above the ground.

3d. Very often the length of the body from the point of the arm to that of the buttock, although for a long time Bourgelat's type has been rejected as a purely conventional type, short and massive. Our drawing, which is two heads and a half in length and in height, is that of a horse which is often seen.

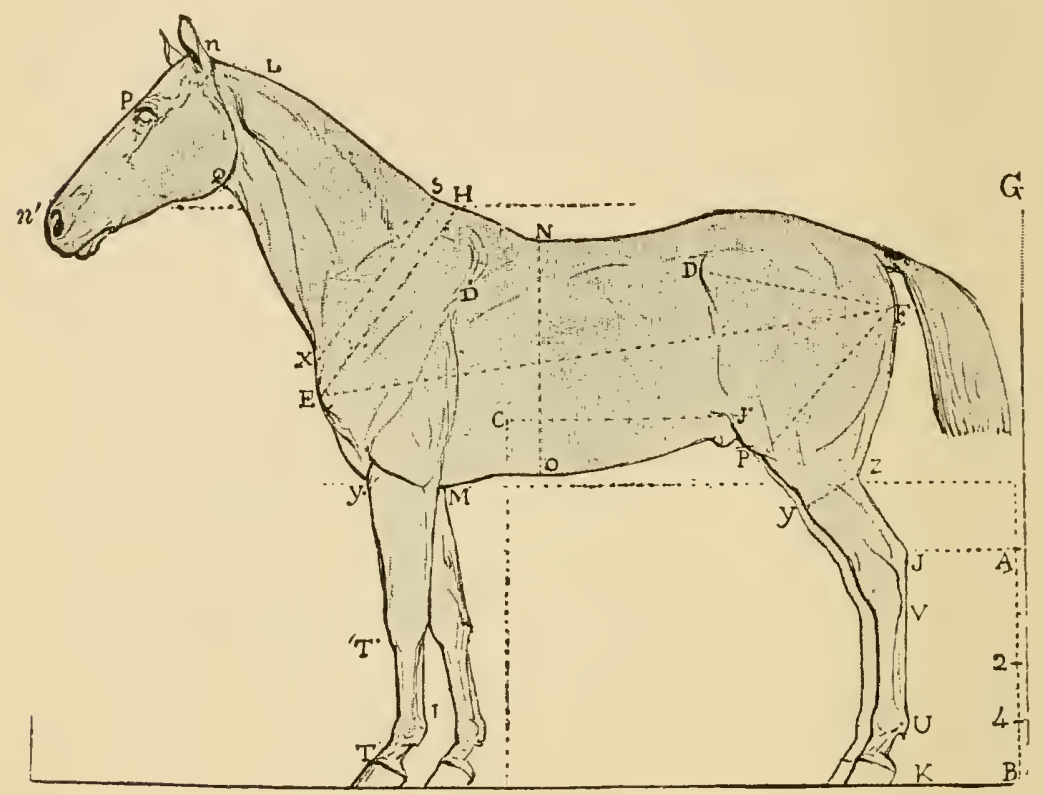

FIG. 127.-The proportions of the horse seen in profile.

"The length of the croup, from the point of the haunch to that of the buttock, $D F$, is always less than that of the head: this varies from 5 to 10 centimetres. As to its width from one haunch to the other, it often exceeds only very little its length (often it is equal to the latter) (G. and B.). horse:

"The croup, $D F$, exists quite accurately in length four times in the same

1st. From the point of the buttock to the inferior part of the stifle-joint, FP.

$2 d$. In the width of the neck at its jnferior attachment, from its insertion into the chest to the origin of the withers, $S \boldsymbol{X}$.

3 . From the insertion of the neck into the chest to the angle of the lower jaw, $I Q$, when the head is held parallel to the shoulder.

4th. Finally, from the nape of the neck to the nostril, $n n^{\prime}$, or to the commissure of the lips.

"The measure of one-half of the head will also guide us very much in the construction of the horse, when we know that it is frequently applied to several of his parts,-namely:

1st. From the most prominent point of the angle of the lower jaw to the anterior profile of the forehead, above the eye, $P Q$ (thickness of the head).

2d. From the throat to the superior border of the neck, behind the poll, $Q L$ (attachment of the head). 
3d. From the inferior part of the knee to the coronet, $T T$.

4th. From the base of the hock to the fetlock, $V U$.

5th. Finally, from the point of the arm to the articulation of the elbow (approximate length of the arm)."

The proportions of the head are also of great importance to artists, who, in this respect, depend entirely too much upon the inspiration of the moment. We always borrow from M. Duhousset-whose graphic precepts appear to us to be the nearest to the real form-the indications which he recorded in an unpublished work upon this subject; we will add to them, in passing, our personal researches.

"Althongh it is very difficult," says he, "when we speak of measurements taken upon the living horse, to form anything but approximations, still we think we are very near the truth when we give the following results which proceed from our numerous observations. The head which we present is that of a horse which is frequently seen as a medium between the pleasure-horse and the dranght-horse." In this respect, it will not be uninteresting to accompany with figures the two drawings upon which are found the measurements we are speaking of:

HEAD VIEWED IN PROFILE (FIG. 128).

Length, $A B$, from the poll to the end of the lips.......... $0.60 \mathrm{~m}$.

Thickness, $C D$, from the angle of the lower jaw to the anterior face (half a

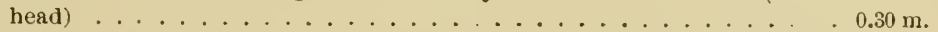

This line passes through the middle of the eye and is taken perpendieu. larly to the profile of the anterior face. It is seen in many common horses, especially in the heary-iraught horses; in tiner subjects it is a little short?r (G. and B.).

Width, $I H$, of the neek in its narrowest part (half a head) ..... $0.30 \mathrm{~m}$.

It is frequently greater, which is noticed whenever the superior attachments of the neck are wanting in neatness of outline. This is seen in lymphatic and draught-horses, and in those which are excessively corpulent (G. and B.).

Distance, $O R$, from the internal angle of the eye to the smperior conmissure of the nostril (G. and B.) (half a head) . . . . . . . . . $0.30 \mathrm{~m}$.

It is greater in the common head and in one which is too long.

Distance, $A O$, from the poll to the internal angle of the eye . . . . . . $0.22 \mathrm{~m}$.

This distance is equal to the thiekness of the head $(P Q)$, taken perpendicularly to the profile of the anterior face, and passing the level of the maxillary fissure and the maxillary spine.

Again, it is equal to $Q O$, from the internal angle of the eye to the maxillary fissure; and to $P G$, from the midale of the face to the eommissure of the lips (G. and B.).

The distance, $P E$, from the midale of the face to the maxiliary spine is about one-sixth of the total length of the head ................ $0.10 \mathrm{~m}$.

The line $B E$, considered from the end of the lips to the maxillary spine is equal:

To $E F$, from the maxillary spine to the cxternal auditory hiatus, visible only upon the skull.

To $H G$, from the insertion of the throat into the intermaxillary space to the commissure of the lips, G. and B.).

To $Q R$, from the maxillary fissure to the superior commissure of the nostril (f. and B.).

To $Q B$, from the maxillary fissure to the end of the lips (G. and B.).

To $O D$, from the intermal angle of the eye to the curved portion of the border of the lower jaw, provided the line $C D$ be in proportion ( $G$. and $B$.).

Finally, very often to $O I I$, from the internal angle of the eye to the insertion of the throat into the intermaxillary space ( $(\mathrm{r}$. and $\mathrm{B}$.). 
A very frequent equality is that which exists between the distances: $O B$, from the internal angle of the eye to the end of the lips.

$A H$, from the nape of the neck to the insertion of the throat into the intermaxillary space.

And $H B$, from the latter point to the end of the lip.

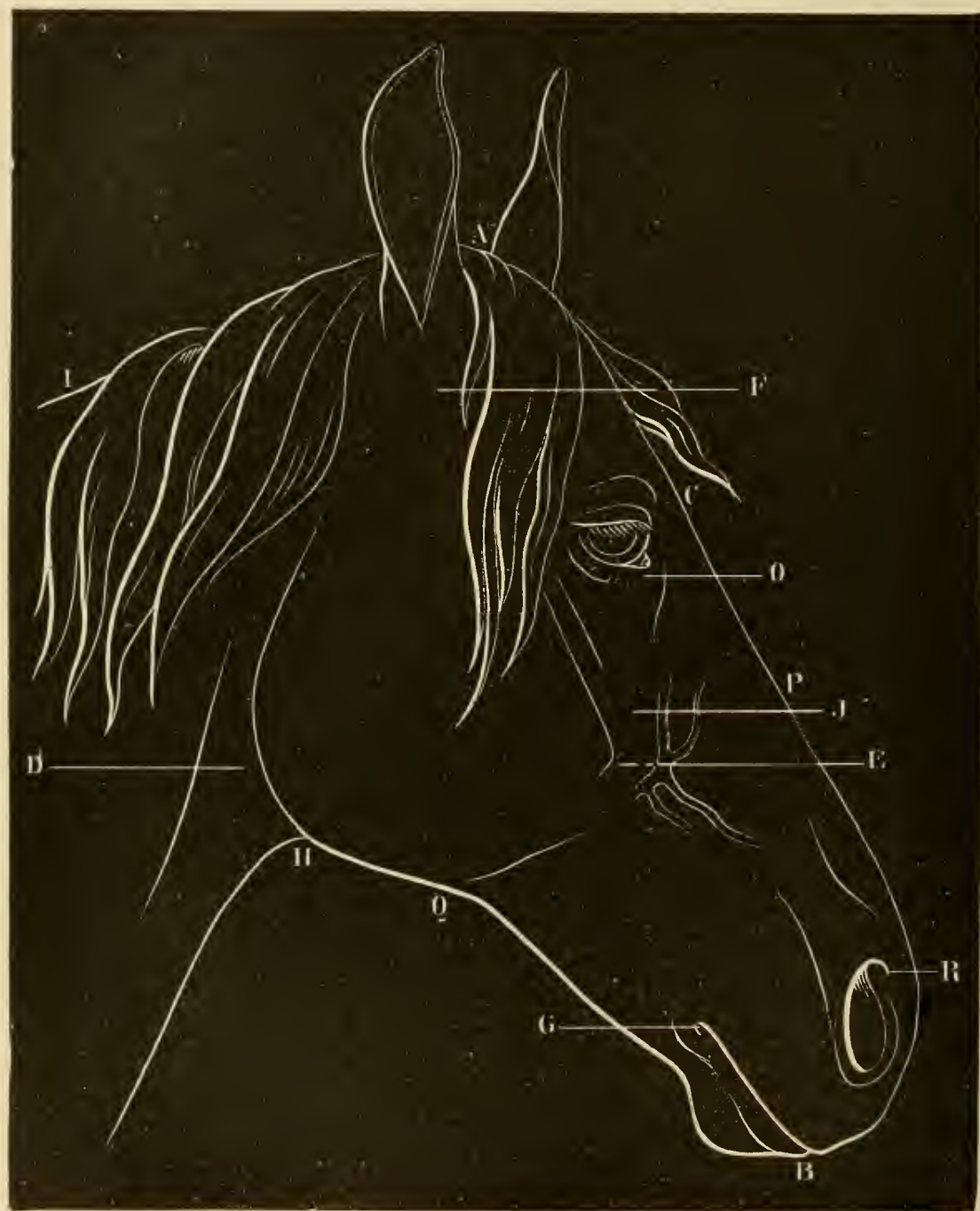

FIG. 128.-The proportions of the bead viewed in profile.

HEAD VIEWED IN FRONT (FIG. 129).

M. Duhousset adds that if, in order to continue our examination, we regard the head in front, we find its greatest width in $A B$, extreme points of the orbital arches. 
This width is 22 centimetres.

It is also equal to:

$A C$, from one areh to the poll.

$A D$, from one arch to the middle of the face.

$D E$, from the middle of the face to the end of the lips.

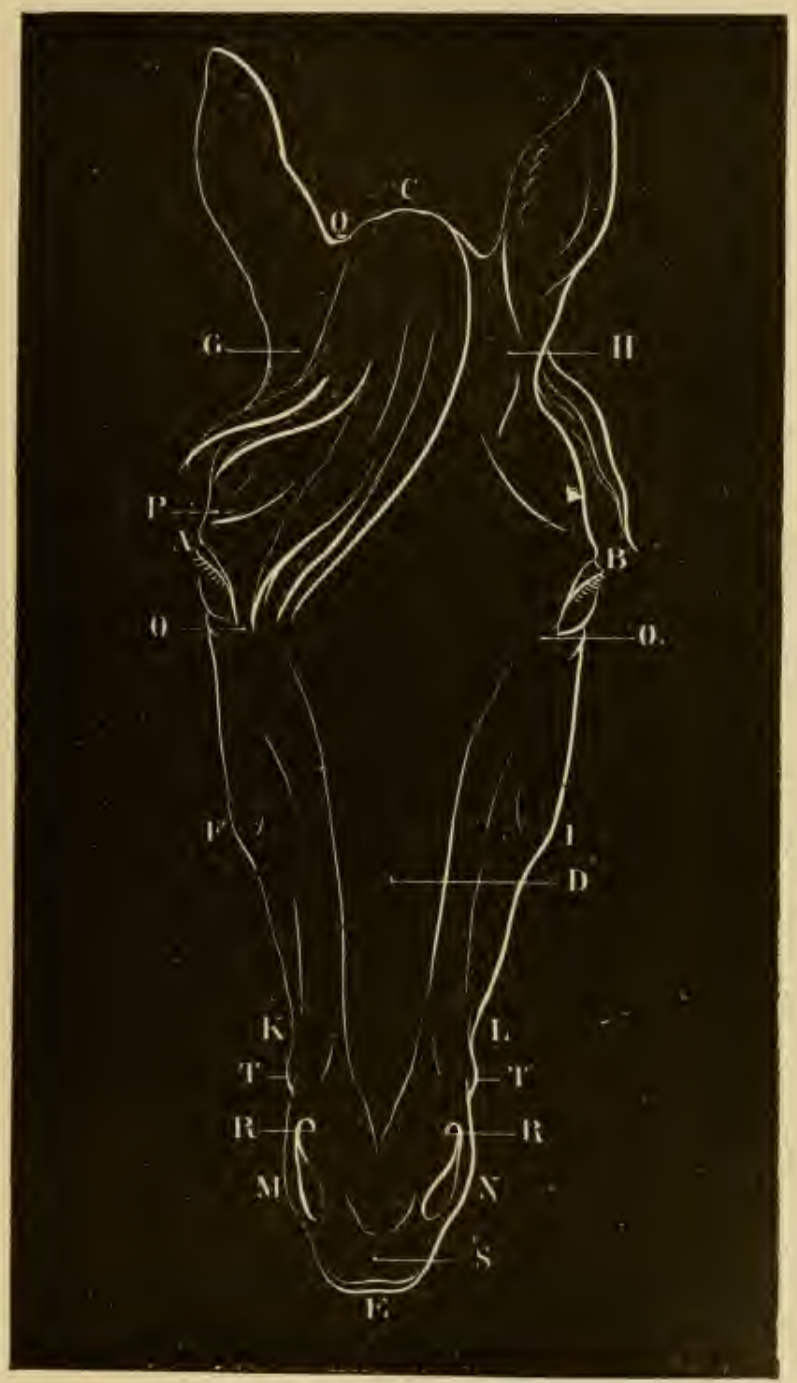

FIG, 129.-The proportions of the head viewed in front.

From the auditory hiatus, $G$, to the maxillary spine, $F$, it is the same distance as from this point to the end of the lips, $E$, and still better to the end of the teetli.

The line $G C$, from the auditory hiatus to the poll, equals one-sixth of the head, or 10 centimetres; the line $A G$, from the orbital arch to the auditory hiatus, is a little longer and measures 12 centimetres. 
The distance $F I$, comprised between the two maxillary spines, is 18 centimetres.

It is of the same value as:

$O O$, distance from one internal angle of the eye to the other (G. and B.).

$F R$, distance from the maxillary spine to the superior commissure of the corresponding nostril (G. and B.).

$F P$, from the maxillary spine to the supra-orbit (G, and $B$.).

From the auditory hiatus, $G$, to the tip of the ear, approximate length of this latter organ (G. and B.).

And $P Q$, from the supra-orbit to the insertion of the ear upon the poll (G. and B.).

From the poll to the internal angle of the eye, $\mathrm{CO}$, the distance is equal to that from this last point to the commissure of the lips, $O T$, and from the maxillary spine to the superior lips, $F S$ (G. and B.).

The separation, TT, of the two commissures of the lips is almost the distance from the superior border of the orbital arch to the base of the ear or to the auditory hiatus.

In a state of rest, the external limit of the separation of the nostrils does not exceed the width of the knee; the same distance often exists between the base of the ears, in quietude, over the region of the poll. We have intentionally represented in the figure the latter directed in different directions, in order to show that when the external part of the ear is turned back-

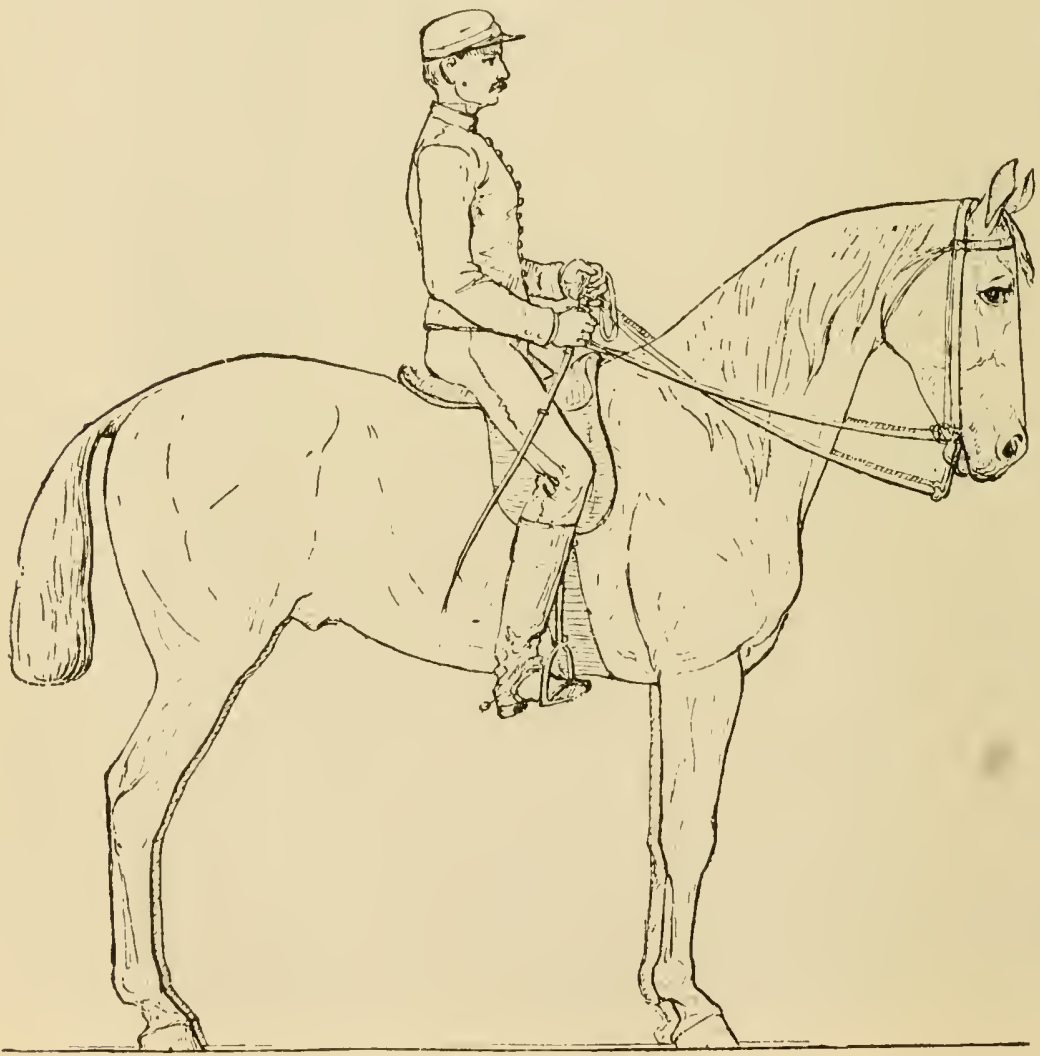

FIG. 130.-Comparative proportions of the man and the horse.

ward, it none the less preserves its accolade form, more or less marked according to the fineness of the subject, and characterizing at rest the internal curve of the ear.

The limit, $M N$, of the lips exceeds very little that of the nostrils; in many heads displaying harmonious proportions, this distance is one-half of $A B$. 
As to that which concerns the comparative proportions of man and horse, the reader may gather information from Fig. 130, which represents a man of $1.70 \mathrm{~m}$. mounted upon a horse of $1.60 \mathrm{~m}$. The latter is in the position of rassembler, ready to begin the step. ${ }^{1}$

\section{B.-Angular Relations of the Osseous Segments.}

Besides the relations of length, width, and thickness which exist between the different regions of the body, it is also important to know the relations of direction possessed by the different bony regions superposed one upon the other to form the members. These relations, as we have seen, have an influence upon the production of speed and force.

From this mode of superposition, angles are produced upon the course of the various bones, whose summit always corresponds to the centre of movement of an articulation, and whose sinus is either in the anterior or the posterior part of the particular region.

But as the bones of the skeleton have a variable external configuration, and as their axis of figure does not always terminate in an articular centre,-witness the femur, whose surfaces of contact with the pelvis and the tibia are situated internal to and behind the median line of the bone,-it follows that we ean logically determine the angles of locomotion only after having previously ascertained the axis of movement of each of their branches. Now, the latter are obtained by simply uniting to each other the artieular centres, which are at the same time the centres of rotation of the said branches. All researehes not founded upon this experimental mode are therefore at once eondemned as being vitiated by arbitrariness and error. The analysis of the following theory will give the proof.

Theory of the Similitude of the Angles and the Parallelism of the Bony Segments.-More than half a century ago, in 183.5, Captain Morris, ${ }^{2}$ later commanding general of the Imperial Guard, published a pamphlet in which was expressed the opinion that in all well-formed horses the same articular angles had a uniform opening or size and the osseous segments inclined in the same direction,-were parallel. Again, these bony segments were inclined at an angle of 45 degrees to the hoirzon. Whence it follows that the head, the shoulder, the thigh, and the pastern on one hand; the ncek, the humerus, the croup, and the leg on the other, in order to eombine the conditions of beauty, were

1 For further details, see E. Duhousset, Etude sur les proportions du cheval, d'après sou ossature, in Illustration, nos. des 18-25, Aont et ler Septembre, 1883. l'Eperon. 
regarded as having the same inclination, the same parallelism, and, finally, forming, two by two, angles of 90 degrees.

Such, in substance, is Morris's theory, by the aid of which he was led to construct the horse whose type he gives at the head of his treatise,

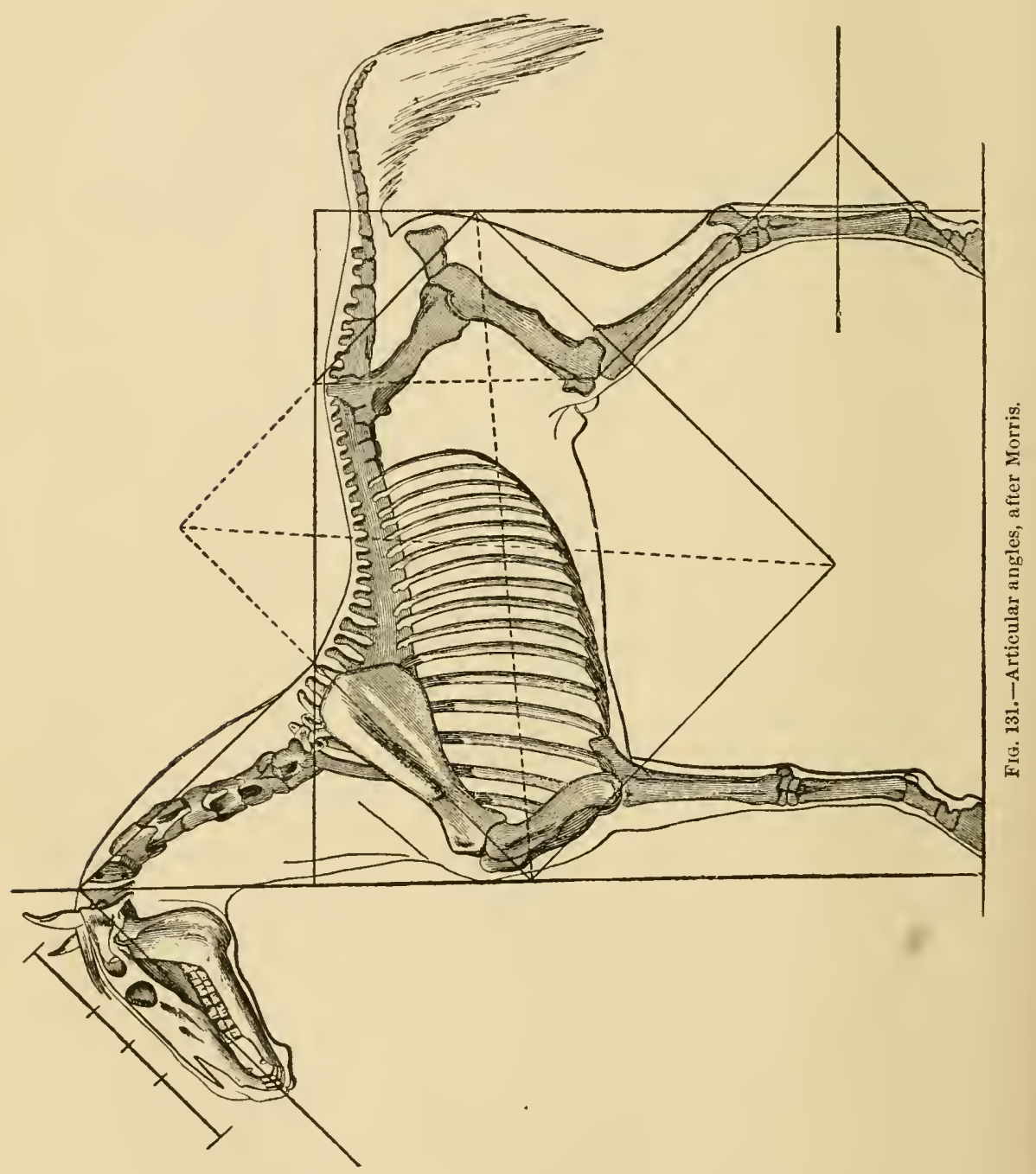

and which we eonsider it our duty to reproduce with the most scrupulons accuracy (Fig. 131). It is sufficient for us to look at this drawing to see that the author himself duly appreciated the maxim of Descartes, which he recommends to the attention of his readers: "He who 
wishes to know the truth should, at least once in his life, doubt all that he has been taught." It will be acknowledged that the general might have been better inspired; not only was he satisfied to doubt, but he never learned what he represented!

Still, it is upon this horse that he traced his geometrical lines. It is true that he himself admits that the directions considered are not strictly those of the bones, but those of the regions whose base they form. With such a reservation we may conceive that the most inventive mind has a free field and may persuade itself into believing in the ohjective reality of its conceptions, whatever may be their exaggerations.

We would not oblige the reader to formulate an opinion upon the theory of the similitude of the angles and the parallelism of the bony segments if the views of General Morris had not found partisans, even among men of great merit. His arguments in favor of his doctrine are (the expression is not too strong) absolutely unintelligible. As to the theory of the similitude of the angles, taken in itself, it has no scientific value, since common sense and facts are opposed to it. Its only merit consists in having drawn horsemen's attention to a question formerly completely ignored.

The most judicious criticism of it that we know of is that of our colleague of the school of Toulouse, Professor Neumann. ${ }^{1}$ We will review his principal arguments, which, in all points, are the same as ours.

And first of all, since the ideal conditions of speed imply certain angles and certain inclinations of the bones, how is it that these conditions are applicable only to the horse and not to other animals as swift as the horse, for example, the hare, the dog, the gazelle, etc.? Whence comes this exception to the laws of nature, which always show us organisms adapted in the same manner to the same needs? It being granted that long members and a tall form are especially necessary to produce speed, in order that they may be able to move extensirely under the body ; it being granted, on the other hand, as a deduction of this principle, that animals with long members have all their articular angles very open, we do not see why the horse, so very similar to them with regard to locomotion, should have been endowed with a particular and contrary disposition residing in the closing of his angles and the parallelism of his bony segments. A priori, the theory of Morris presents itself, then, for examination as an exception to the natural laws of speed, which should already aronse our apprehensions against its consequences.

Let us pursue the purely theoretical objections which result from its application to the construction of the horse; this M. Neumann has very fortunately attempted; we will resume our colleague's reasoning and confirm it with our own observations.

In subjects which are well formed the length of the anterior and the p. 352 .

1 G. Neumann, Des aplombs chez le cheval, in Journal des véterinaires militaires, t. viii. 
posterior members is about equal; the excess of the height at the withers over that at the croup results most usually from the projection of the spinal apophyses above the scapular cartilages.

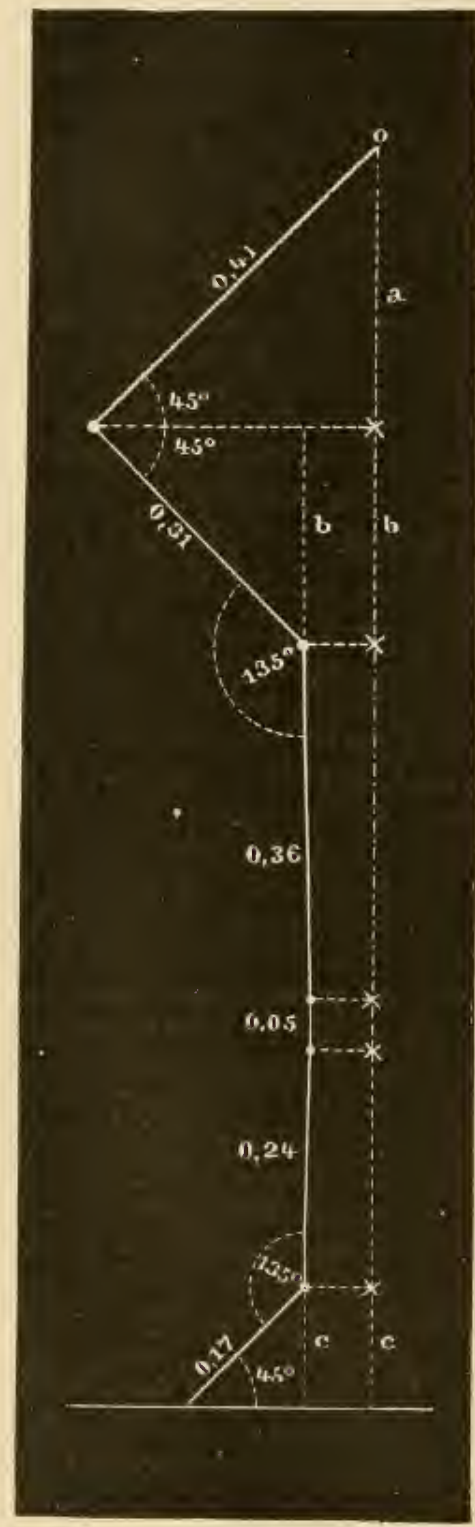

FIG. 132.

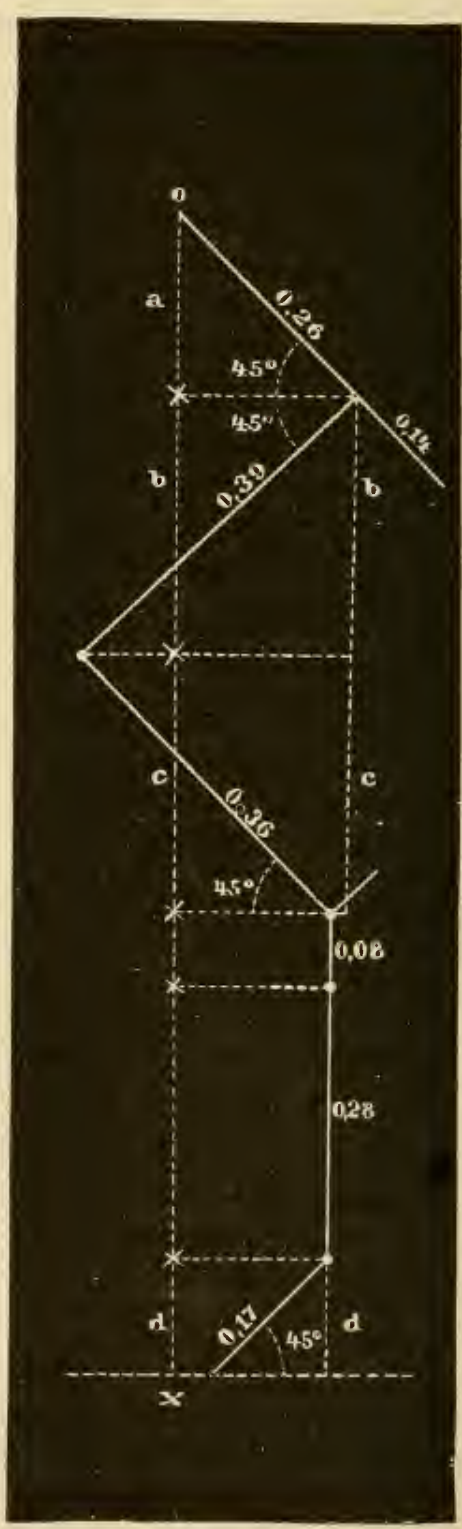

FiG. 133.

This being admitted, let us represent (Fig. 132) the anterior member of a horse of medium height with the oblique long segments inclined 45 degrees to 
the horizon, as aftimed by General Morris. Again, let us give to each segment its medium length, such as has been determined by the concordant observations of MIM. Colin, Neumann, Lemoigne, and our own,-namely :

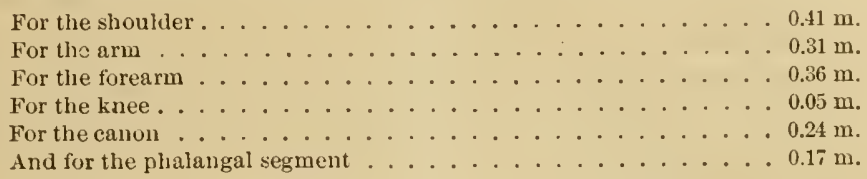

Then project each region upon the vertical line o.t, which means nothing else than the height of the member above the ground.

Finally, calculate the sides $a, b$, and $c$, which belong to the right-angled isosceles triangles having for hypothenuses the recognized length of the shoulder, the arm, and the phalanges.

We will have:

$$
a=\sqrt{\frac{(0.41)^{2}}{2}}=0.28991 \mathrm{~m} .
$$

From which results

$$
2 a^{2}=(0.41)^{2}
$$

Likewise, we will have:

$$
b=\sqrt{\frac{(0.31)^{2}}{2}}=0.21920 \mathrm{~m} \text {. and } r=\sqrt{\frac{(0.17)^{2}}{2}}=0.11313 \mathrm{~m} \text {. }
$$

Add the values of $a, b$, and $c$ thus obtained to those of the vertical segments which are projected in their actual length; add to them $0.12 \mathrm{~m}$. for the projection of the cartilage of prolongment, the thickness of the shoe, the hoof, the articular cartilages, the skin, etc., and we will obtain the following results:

VERTICAl, HEIGHT, Ox, OF THE ANTERIOR MEMBER ABOVE THE GROUND.

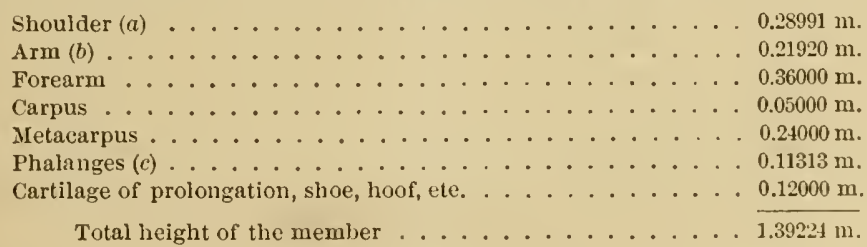

The same calculations are applied to the posterior member according to the following medium length (Fig. 133):

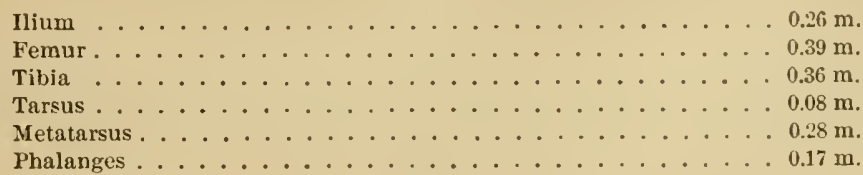


VERTICAI, HEIGIIT, OX, OF THE POSTERIOL MEMBER ABOVE THE GROUND.

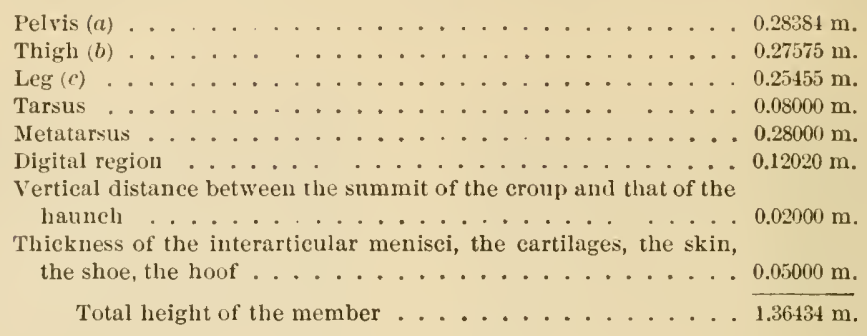

Whence it follows that if the locomotory segments of the horse were really inclined, as General Morris asserts, a subject of medium size would measure only $1.39 \mathrm{~m}$. at the withers and only $1.26 \mathrm{~m}$. at the croup. Besides, the summit of his withers would be 12 centimetres higher than that of the croup! Medium horses so small, or withers so prominent, are no longer seen! What is the conclusion? Evidently that the articular segments are not inclined 45 degrees to the horizon and that the angles are more open than the theory asserts.

On the other hand, M. Neumann adds, "Since some kind of mathematical accuracy is the principal merit of this eonception, is it not strange that, in a practical question, ideal lines, which are left to the appreciation of those who wish to apply them, are established as a foundation? For, if the direction of the region by itself be considered, it is seen-to speak of the sloulder alonethat this direction may vary from five to six degrees upon the same subject, according to the line which one wishes to obtain. Each region is not so well delineated. It does not offer points of delimitation so precise and so invariable that the lines which may be taken as a basis shall be the same in all horses which are marle an object of comparison; and, if these lines are not the same, of what use can they be in that comparative examination of the subjects which is necessary to the establishing of a theory?

"An oblique croup will necessarily correspond to an oblique shoulder; a horizontal croup to a straight shoulder; so that draught-horses which, in the opinion of connoisseurs, would be well adapted to their service, would present, on the contrary, a very defective conformation, if such a theory was to be the guide; to an oblique croup (that of the race-horse) would correspond an elbowed hock (that of the draught-horse); the anterior and the posterior pasterns should have the same clirection, whilst it is well known that the latter are nearly always straighter than the former; and many other details upon which we do not wish to insist."

Thus, from a purely theoretical point of view, the conception of the similitude of the angles and the parallelism of the bony segments is unsupportable, nor is it less so if we endearor to verify it experimentally.

In orler to do this, as we have said at the beginning, it is necessary to determine with the greatest care the external landmarks of the axcs or centres of rotation aronnd which the osseous levers turn. 


\section{The Determination of the Articular Angles.-Several at-} tempts have already been made to gain a knowledge of the articular angles of the horse. Vallon ${ }^{1}$ and Dandet ${ }^{2}$ have, indeed, indicated in their works angular openings in opposition to the ideas of General Morris, in vogue at the time among all horsemen. But these observers no doubt lacked sufficient instruments, judging from the conclusions to which they were led, and which otherwise fail in accuracy. They do not relate in their writings either their method or the class of horses they experimented upon. Some of their ideas are even so far from being true, that we are tempted to believe that in many cases they depended only upon the accuracy of their eyesight. However it may be, and though their researches were of so little account, it was already praiseworthy to invalidate in their time, as they have done, the classical opinions of the day.

In this way they made it easier for their followers to obtain the general acceptation and the ultimate triumph of ideas for which they had, so to speak, paved the way.

Little by little the theory of Morris fell into disrepute, unable as it was to stand the slightest investigation, and it would have remained thus if some observers of merit had not very recently attempted to set it up again.

And yet, as early as 1865, Professor Alexis Lemoigne, ${ }^{3}$ of Milan, published his researches upon the articular angles, with the intention of determining the direction of the final resultant of the horse's efforts in the act of pulling. This is what they consisted of:

Our learned colleagne, in his measurements, made use of the tapemeasure, the hippometer, the plumb-line, and the goniometer, provided with a spirit-level.

First of all he sought to establish with great accuracy, upon the skeleton, the axis of rotation of the bones, - that is to say, the centres of movement forming the mathematical summit of the angles of locomotion. We lave, on our side, verified M. Lemoigne's principles; they are absolutely precise. Here is the résumé. The reader can more easily fullow this review by consulting Fig. 134, which represents the copy of a photograph of Fitz-Gladiator.

\section{a. Anterior Member :}

1st. Scapulo-humeral Axis.-Its point of external localization, upon the living animal, is situated about at the level of the convexity of the great trochanter.

1 A. Vallon, Cours d'hippologie, Saumur, 1865.

2 Daudet, Traité de locomotion du cheval relatif à l'équitation. Saumur, 1864.

3 Alexis Lemoigne, in Giornale delle razze degli animali utili e di medicina veterinaria, fascie. 11 et 12, Naples, 1865 ; ibid., in Reeueil de médecine vétérinaire, ammée 1877, pp. 81 et 208. 
2d. Humero-radial Axis.-Point of extemal localization : at the humeral insertion of the external lateral ligament of this articulation.

3d. Radio-carpal Axis-Point of external localization: a centimetre below the external and inferior tuberosity of the radius.

4th. Metacarpo-phalangeal Axis.-Point of external localization: at the superior insertion of the corresponding lateral ligament of the articulation.

We have intentionally omitted, as of little importance to our subject, the intercarpal and the interphalangal axes also established by M. Lemoigne.

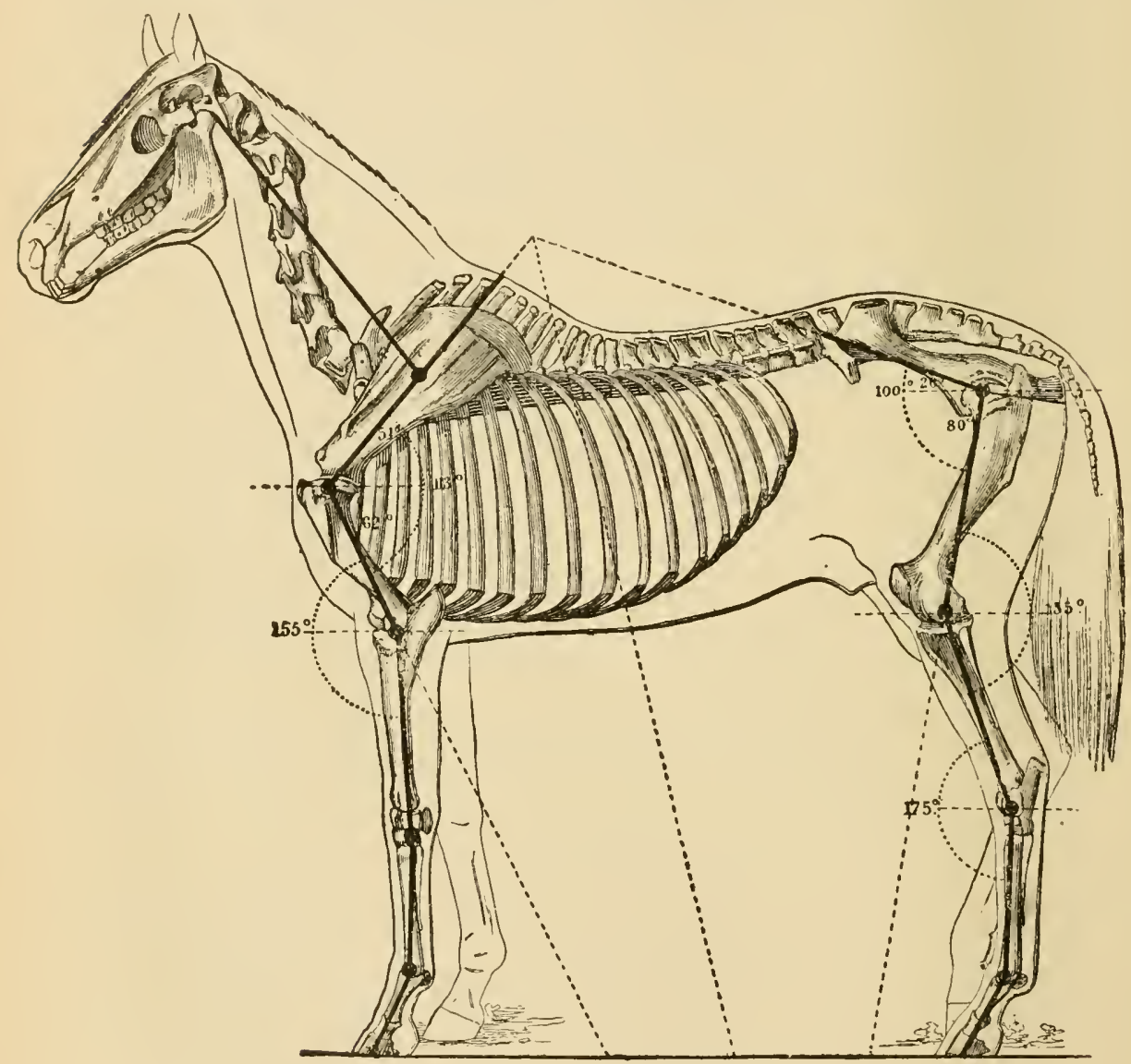

FIG. 134.-The articular angles upon a drawing from a photograph of Fitz-Gladiator.

\section{b. Posterior Member:}

1st. Coxo-femoral Axis.-Point of external localization: a little below and behind the convexity of the trochanter.

2d. Femoro-tibial Axis.-Point of external localization : a little below the superior insertion of the corresponding lateral ligament of this articulation.

3d. Tibio-tarsal or Metatarsal Axis.-Point of external localization : centre of the astragalus. 
4th. Metaterso-phalangal Axis.-Point of external localization: at the superior insertion of the corresponding lateral ligament of the articulation.

All these points of localization-the points where the centre of rotation can be located externally - can with a little practice be easily recognized in the living animal. But it is indispensable that this habit should be acquired by numerous experiments; otherwise, those who explore and measure are exposed to almost inevitable mistakes. Nor are all subjects suitable for such an experiment; there are some that must be absolutely rejected: those whose state of obesity conceals not only from sight but also from touch those external points of which we have been speaking.

These restrictions being established, we will suppose that upon a chosen subject all the articular centres have been marked with a colored pencil or chalk. In order to obtain the imaginary axes of movement of the osseous levers it will be sufficient to join these points by straight lines.

This direction should be determined accurately in a special manner for the shoulder, the coxa, and the phalanges, which are connected with only one articular centre. All the other regions are indeed placed between two of these centres, and therefore as soon as the latter are discovered their direction is known.

It is M. Lemoigne's opinion, as well as ours, that the line of direction of the shoulder starts from the scapulo-humeral centre, and superiorly divides the dorsal border of the scapnla at about two centimetres behind the line of the scapular spine.

That of the ilium extends from the coxo-femoral centre to the angle of the haunch, which it divides in its middle.

Finally, that of the phalanges extends from the metacarpo- or metatarso-phalangal centre to the ground, and remains almost parallel to the anterior profile of the digital region.

The animal being placed and maintained in its normal equi-

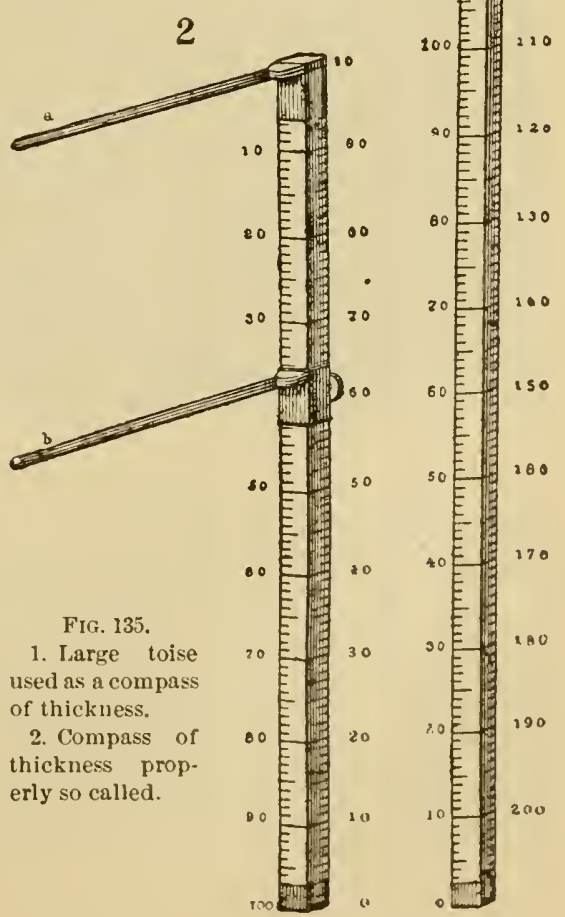


librium, the top of the goniometer, M. Lemoigne says, is placed in juxtaposition "to the external determining point of one of the axes of" rotation; an arm of the instrument is directed in such a manner that its line of direction passes through the external determining point of the axis of rotation which is immediately superior; the other arm is placed in a perfectly horizontal direction,-which is ascertained by means of a spirit-level,-and the degrees of the angle thus formed between the horizontal and the osseous segment whose inclination is desired are then counted. . . ."

By taking these precautions, and by the greatest care, MI. Lemoigne has been able to determine the following figures, which represent, upon fourteen subjeets, the mean of the inclinations of the osseous levers and the angles which they form.

TABLE A.

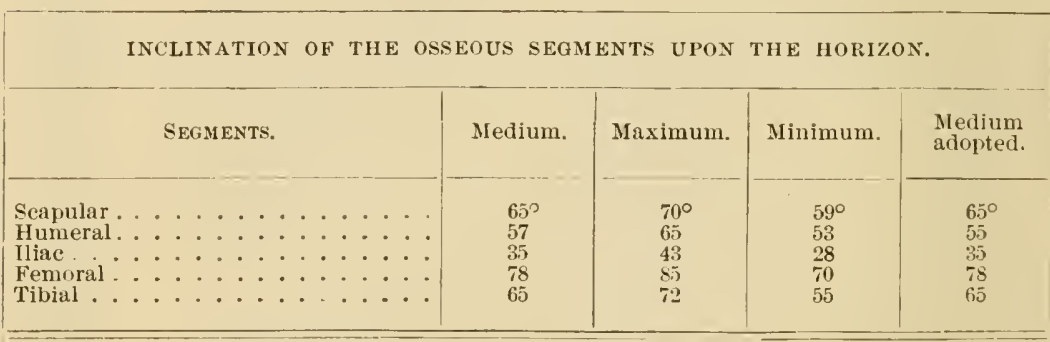

OPENING OF THE ARTICULAR ANGLES IN STATION.

\begin{tabular}{|c|c|c|c|c|c|c|c|c|c|c|}
\hline SEGMENT & TS. & & & & & & Medium. & Maximim. & Minimum. & $\begin{array}{l}\text { Medium } \\
\text { adopted. }\end{array}$ \\
\hline $\begin{array}{l}\text { Scapulo-humeral } \\
\text { Humero-radial } \\
\text { Metacarpo-phalaingal } \\
\text { Ilio-femoral } \\
\text { Femoro-tibial : }: \text {. } \\
\text { Tibio-metatarsal : } \\
\text { Metatarso-phalangal }\end{array}$ & 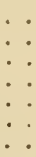 & $\begin{array}{l}\dot{ } \\
\dot{.} \\
\dot{ }\end{array}$ & 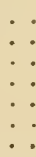 & 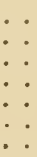 & $\begin{array}{l}: \\
: \\
: \\
:\end{array}$ & $\begin{array}{l}: \\
: \\
: \\
: \\
: \\
: \\
:\end{array}$ & $\begin{array}{l}121^{\circ} \\
148 \\
158 \\
117 \\
144 \\
15^{\prime 2} \\
158\end{array}$ & $\begin{array}{l}130^{\circ} \\
157 \\
170 \\
130 \\
15] \\
158 \\
165\end{array}$ & $\begin{array}{l}116^{\circ} \\
137 \\
152 \\
100 \\
138 \\
148 \\
150\end{array}$ & $\begin{array}{l}121^{\circ} \\
145 \\
158 \\
117 \\
144 \\
150 \\
158\end{array}$ \\
\hline
\end{tabular}

We, too, have attempted to determine the standard inclinations of the articular segments of the horse, and this we have done upom nearly a hundred subjects of different conformations.

For this purpose we have constructed (Fig. 135) a toise (1) and a compass for measuring thickness (2). Each of these instruments is composed of a strong, square rule bearing two graduations disposed in an inverse sense from each other, upon which glides by gentle friction a gange, $B$ and $b$, which may be held in position by means of a pressure-screw. By raising the rod $A$, the large rule forms a standard, 
and is used to measure the height ; by turning the gauge $B$, after having rompletely withdrawn it, it becomes a compass of thickness to moasure the great lengths. As to the compass of thickness properly so called, merely turning it will transform it into a small toise.

On the other hand, in connection with M. Vignardon, principal of the department of physies and chemistry at the Alfort school, we have constructed a goniometer hy the use of which we can dispense with the spirit-level, an instrunent very difficult to use on an irritable horse.

Suppose, for example, we are measuring (Fig. 136) the inclination of the segment, $A B$, upon the horizon, $X Y$. To do this, it will be sufficient to estimate the angle, $B A P$, formed by this segment with the vertical line, and deduct 90 degrees from the angle obtained. It is quite easy to arrive at this result by employing the following instrument, which we intend to designate lyy the name arthrogoniometer, on account of its use.

It is composed (Fig. 138) of a compass of precision, made of wood, whose branches are $0.65 \mathrm{~m}$. long, and which at the same time is used as a compass of thickness.

Upon one of these branches a semicircular piece of copper, very accurately graduated, well centred, and having a radius of $0.20 \mathrm{~m}$., is fixed by means of movable screws. The centre of

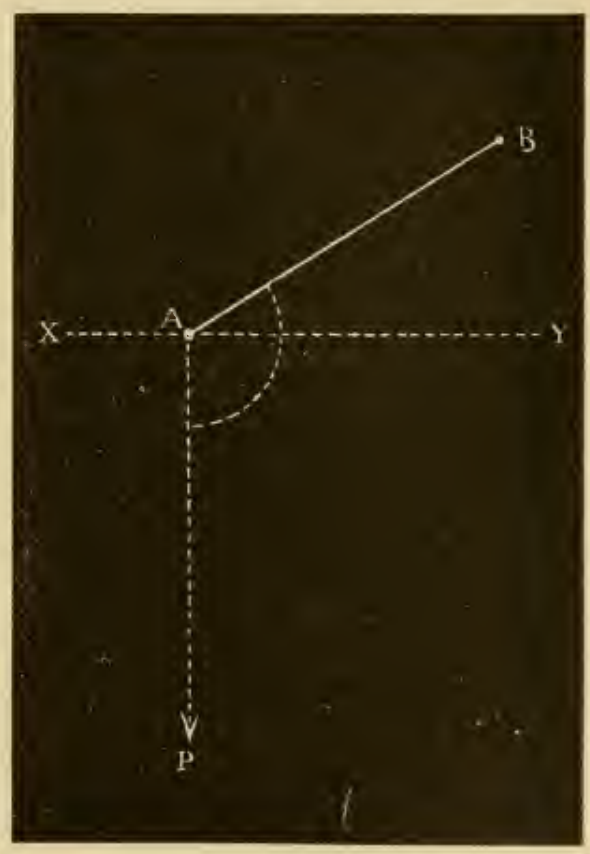

FIG. 136. this circle corresponds to the axis of rotation of the branches, an axis upon which a small metallic roul $0.10 \mathrm{~m}$. long is screwed perpendicularly, upon which freely slicles a hollow cylinder supporting a plumb-line.

In order to use the arthrogoniometer, we stand the horse in his normal equilibrium, and then place the articulation of the instrument over an articular centre, as, for example, the scapulo-humeral (Fig. 137). The observer stations himself about fifty centimetres from the animal; he is careful not to touch the latter, and recommends the assistant to hold his land over the eye of the corresponding side, so that the horse may not be frightened by the examination 
abont being made. This ilone, the operator places the instrument in such a position that the branch of the compass to which the half-circle is fitstened is perfectly tangent to the plumb-line. Then he gently moves the other branch until it has the direction of the osseons segment the inclination of which he desires to obtain. Having again proved the correet position of the apparatus, he reads upon the half-circle the value of the angle contained between the two branches, and deducts 90 degrees from this angle to obtain the desired inclination.

If, on the contrary, we simply desire to measure an articular angle, the plumb-line is needless. It is unfastened from the sliding cylinder, and the two

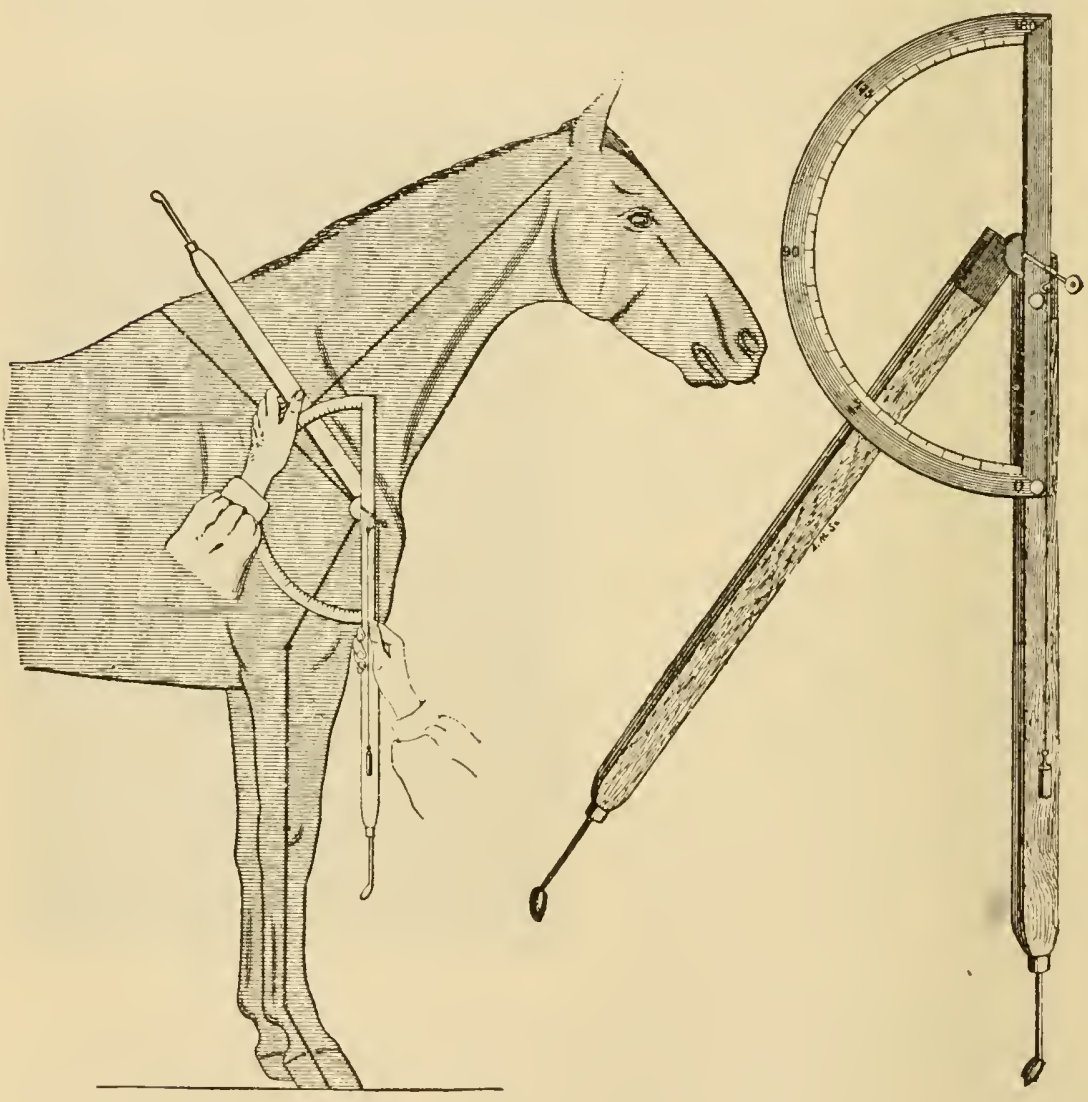

Fili. 137.-- Ise of the arthrogoniometer for measuring the articular angles.
Fig. 138,-Arthrogoniometer for measuring the articular angles.

arms of the arthrogoniometer are placed in the prolongation of the two axes of movenent whose separation we desire to determine. For the metacarpo- and netatarso-phalangal angles an ordinary compass is used, which is afterwards applied upon an appropriate protractor in order to obtain the angle contained. Although, in reality, the metacarpus and the metatarsus are not absolutely ver- 
tical, a sufficient approximation is nevertheless obtained by consiclering them so to determine the inclination of the anterior and the posterior phalanges.

By operating in this way and with great care npon a large number of subjects destincd for different services, but of irreproachable comformation for their kind, we have succeded in obtaining the angles and the inclinations given in the following table:

\section{TABLE B.}

INCLINATION OF THE SEGMENTS OF LOCOMOTION UPON THE HORIZON AND THE VALUE OF THE ARTICULAR ANGLES IN FAST HORSES.

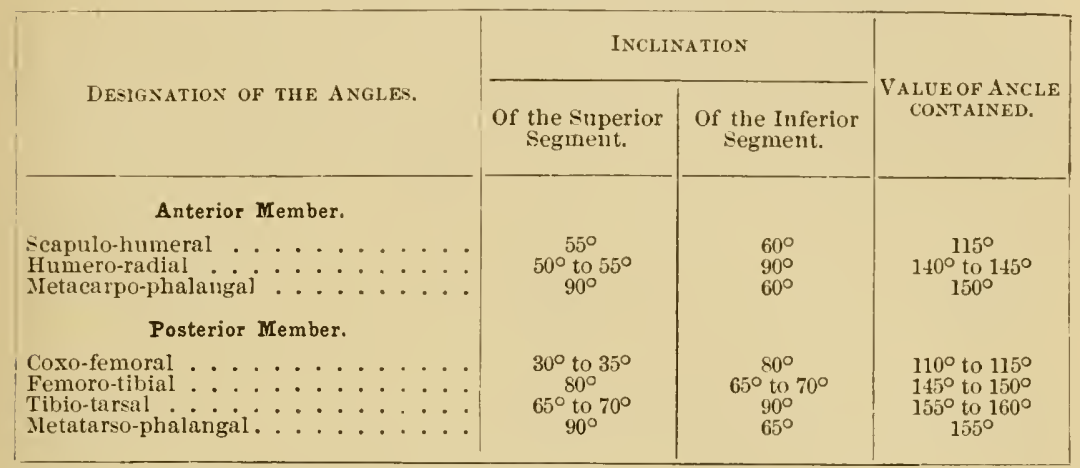

Notwithstanding the improvement which is obtained from the employment of the arthrogoniometer, the measurement of all the angles of locomotion in the same horse was none the less a long, delicate, and often dangerous operation. It was necessary to place the horse in equilibrium, and thus maintain him during the entire duration of the experiment,-that is to say, for nearly an hour.

In order to gain time and operate with more aceuracy, we have recently conceived the idea of applying photography to the measurement of the articular angles. This proceeding, which is more precise, more convenient, also gives more security to the observer. ${ }^{1}$

It consists in this :

Wafers (white or black, according to the color of the horse) are fastened to the sin over each articular centre. Others are also placed on the withers, the haunch, and the hoofs, which are used as marks to indicate the direction of the extreme segments of the members (shoulder, croup, phatlanges). Different measurements are then taken: the height at the withers and at the croup, the length of the body, length of the head, etc.

This being done, the horse is placed in the direction of an axis marked out

${ }^{1}$ G. Barrier, Sur un nouveau procédé de mensuration des angles articulaires, in Bulletin de la soc. cent. de méd. vétér. (Recuteil de médecine vétérinaire, annce 1885, 1).224). 
upon the ground. On the other hand, a photographic apparatus is stationerl upon another axis perpendicular to the first. As soon as the animal is placed in a good position, and his members are in their normal equilibrium, the photograph is instantaneously taken.

The photographic proof thus obtained is in some measure a mathematical reduction of the silhouette, or the profile of the subject, and the measurements previously taken upon the latter, then compared to the corresponding dimensions of the photograph, show exactly the ratio of the reduction effected. To avoid the eauses of error inherent to the slight alteration of forms due to the lenses, the photographic apparatus is placed at a certain distance, in such a manner as to obtain as small an image as possible.

Upon this image the wafers serve as so many points of determination or landmarks which it will be sufficient to join by straight lines to obtain the real direction of the osseous segments. It only remains now to estimate with a protractor the inclination of each line, as well as the angles which are firmed by their union. With this new process we can measure quietly, at our ease, without fatigue, without danger, and whenever convenient. The measurements are all comparable, since all the angles of the same subject have been photographed at the same time, and since on different horses we operate constantly under the same conditions.

The results obtained are very analogous to those already indicated.

What we have said with regard to each region, concerning the osseous inclination and the angular relations, excuses us from entering here into more minute details relative to the numerous variations which are observed in subjects according to their adaptation.

We will not speak of draught-horses used for slow work, in which the service at a walk requires only bulk and muscle; their scapulohumeral and coxo-femoral angles are always more open; the others, on the contrary, are more closed. When the reseatches of M. Lemoigne appeared, Professor Neumann was the only one who submitted them to a judicious analysis; and as the eriticisms which he opposed to them have an important value and may equally oceur to the mind of the reader, it is our duty to give an aceount of them, inasmuch as they apply to us also who have, since the beginning, sided with our Milan colleague.

M. Neumann has reasoned upon these things in a purely mathematical light, and, in this respect, no objection ean be made to his deductions. But the case is entirely different if the researches of M. Lemoigne and our own are considered as a rery accurate means of obtaining information upon the different inclinations of the bones of fast lorses. It is no longer a problem to know if these inclinations can be calculated with strict precision, a precision which it is impossible to realize in the researehes which have animal mechanies for their object; it practically resolves itself into this: It 
being granted that the angular relations of the osscous levers hare an immediate influence upon the development of speed (we think that we have shown this a propos of the regions), is it possible to extimate these relations with more accuracy than a single glance of the eye wonld give, and, this being so, are the centres of rotation obtained by the processis indicated above sufficiently precise to allow comparatire obserrations to be made upon different subjects and afterwards to reason in a general manner upon the results obtained?

Well, there is no doubt but the question, brought down to these limits, is susceptible of a positive solution; and however approximative this solution may be, it will always be better than the state of ignorance in which the observer was previously, or than the often erroneous appreciations suggested by our senses. Let us sce, besides, the eriticisms of M. Neumann, which, without contradiction, we ourselves would have presented if our colleague had not previously formulated them. ${ }^{1}$

First, it is certainly not demonstrated that the articular angles are always of the same geometrical kind for the same bonc; that they possess a centre and only one; that the position of this centre is always the same in relation with the external surface of the bone; finally, that the supposed axis of rotation is perpendicular to a crosssection of the latter. Nor is it established, either, that the axes passing through the centres of rotation, perpendicularly to the plane of movement, invariably meet the same anatomical points of the external surface of the bones. All this is true, but the variations among different animals are less marked than M. Neumann scems to believe. We will go further, for we have sought to determine it, and say that these variations, already so minute in the hybrids (mule, hinny), or in subjects of the same genus (ass), are recognized with extreme difficulty and are even unappreciable, so feeble are they, among the representatives of the same species. Therefore, although these objections are applied to possible and even probable errors, they are of little value as concerns definite results, and may be neglected without great inconvenience.

This is not the case in the search for the points of external data, or location of the axes of rotation in the living animal. Errors of one, two, or three centimetres, either above or below the point indieated, are easily committed, which lead without a doubt to solutions

I G. Neumann, Quelques observations sur la mécanique auinale, à propos des reclerches de II. Alexis Lemoigne, in Recueil de médecine vétérinaire, aunée 1877, p. 489. 
entirely erroneous. This is not, however, an irrefutable argument. At every moment, in physiological experiments, we find ourselves face to face with such difficulties, and notwithstanding the failures, notwithstanding the errors every day, these experinents are renewed, and seience constantly goes on reaping benefits from them. Must we say, then, that this idea should be renounced? Must we reject beforehand and with determination the facts acquired for this reason alone, that they may have been hadly collected, wrongly studied, wrongly interpreted, or that they are simply approximative? Certainly not; this would prove a deplorable state of the scientific mind.

Far from us be the thought of drawing this conclusion from the criticisms of M. Neumann. Our distinguished colleague (and he is to be praised for this) has signalized the danger ; he las appealed to corroborating observations; he has shown and demonstrated with proof the inevitable errors into which investigators incompletely prepared would fall, and we cannot too warmly approve his aim. All eyes are not apt to see well, all hands are not skilled in exploring, all horses are not suitable for this kind of study. Let it be well noted that if the results obtained by two observers do not agree in an absolute manner, if even their differences appear exaggerated, it is not less certain that these results, for each of them, can still be compared, for the chances are great that whatever error is committed is repeated everywhere the same way. In M. Lemoigne's opinions and in ours the differences are insignificant; we are in accord as to his articular angles. In table $B$ (page $37 \bar{T}$ ) we gave only the angular relations of the bones in fist horses, - that is to say, in animals with an oblique shoulder, a straight arm, a horizontal eroup, and a straight $\operatorname{leg}$; this shows why our scapulo-humeral and humero-radial angles are a little more closed and our tibio-tarsal angle a little more open, and even then the opening of the last results, perhaps, from the fact that in all our estimations we have considered the eanon as vertical.

Let us try now, as M. Neumann has done above in order to refute the theory of General Morris, to estimate, with our angles, the vertical height of the members of a horse of medium size.

Let the anterior member be represented schematically with its axis of movement (Fig. 139). The heights $a, b, c$ of the segments which do not themselves lie parallel with the vertical line are the sides of as many rectangular triangles, whose hypothenuse and one of the adjacent angles are known. It is then easy to calculate them by vulgar trigonometrical formulie, and we have:

$$
\begin{aligned}
& a=0.41 \mathrm{~m} . \sin .60^{\circ}=0.35507 \mathrm{~m} . \\
& b=0.31 \mathrm{~m} . \sin .55^{\circ}=0.25394 \mathrm{~m} . \\
& c=0.17 \mathrm{~m} . \sin .60^{\circ}=0.14722 \mathrm{~m} .
\end{aligned}
$$


POINTS FROM WHICH THE PROPORTIONS ARE STUDIED. 381

Add the values of $a, b, c$, thus obtained, to those of the vertical segments, those which lie parallel in their actual length with the vertical line; add to this

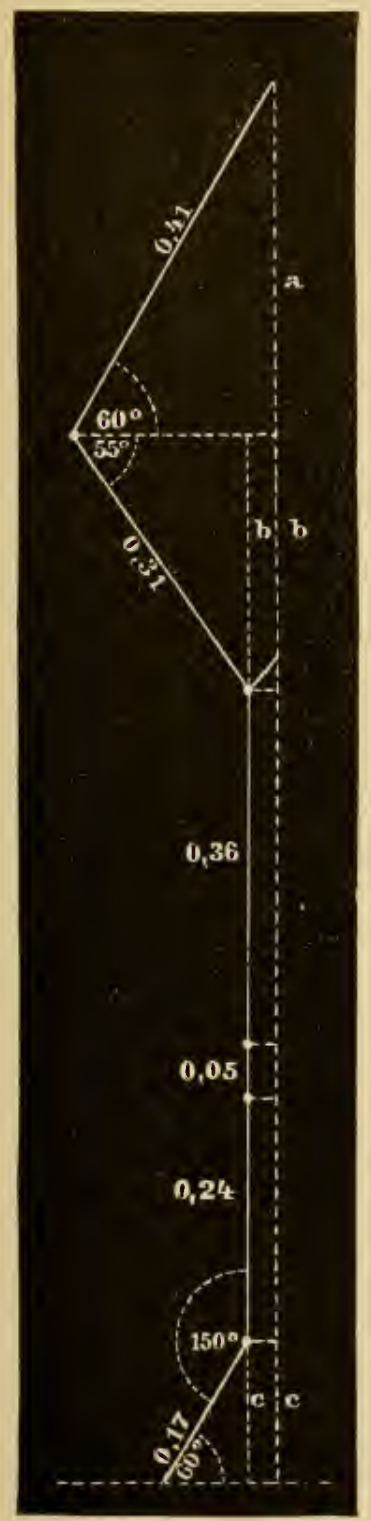

FIG. 139.

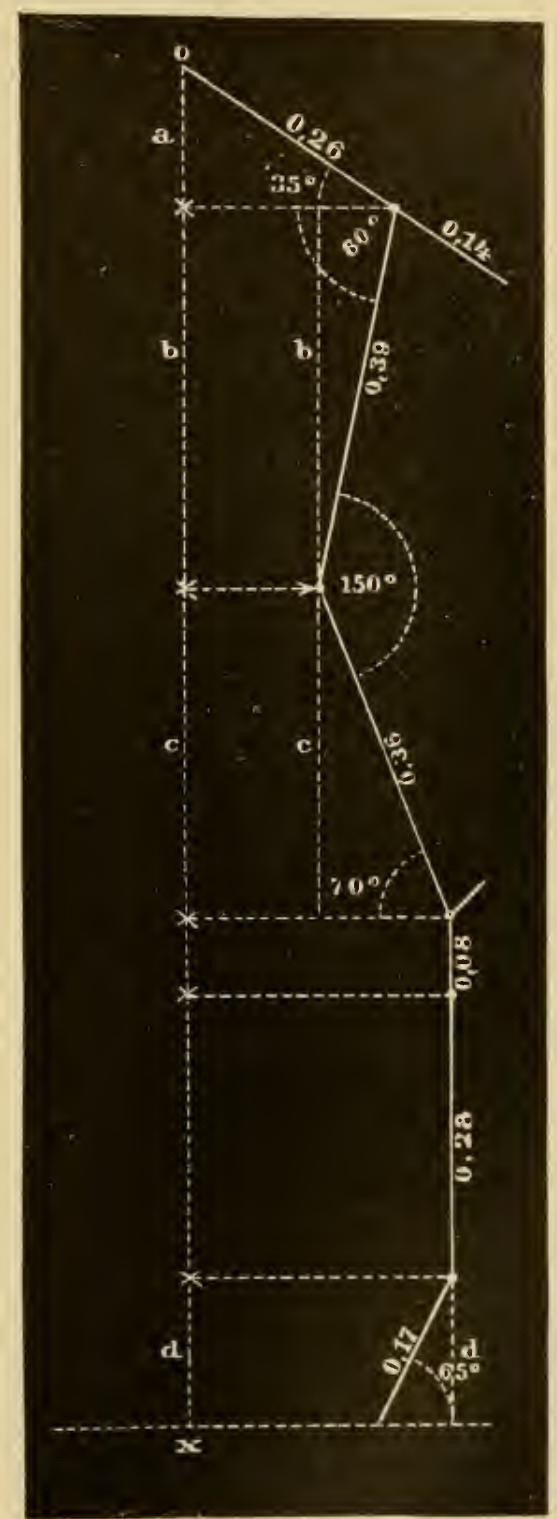

FIi, 140 .

$0.12 \mathrm{~m}$. for the prominence of the scapular cartilage, the thickness of the shoe, hoof, articular cartilages, skin, etc., and we will obtain the following results : 
VERTICAL HEIGHT OF THE ANTERIOR MEMBER CALCULATED FROM THE NORIAL LENGTH OF THE SEGMENTS AND THE REAL ARTICULAR ANGLES WHICH THEY FORM WITH EACH OTHER.

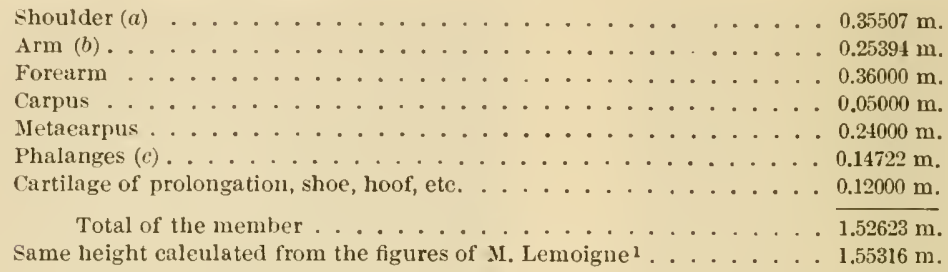

The same calculations applied to the posterior member (Fig. 140) give for the values of $a, b, c, d$ :

$$
\begin{aligned}
& a=0.26 \mathrm{~m} . \sin .35^{\circ}=0.14912 \mathrm{~m} . \\
& b=0.39 \mathrm{~m} \cdot \sin .80^{\circ}=0.38407 \mathrm{~m} . \\
& c=0.36 \mathrm{~m} \cdot \sin .70^{\circ}=0.33828 \mathrm{~m} . \\
& d=0.17 \mathrm{~m} \cdot \sin .65^{\circ}=0.15407 \mathrm{~m} .
\end{aligned}
$$

VERTICAL HEIGHT OF THE POSTERIOR MEMBER CALCULATED FROM THE NORMAL LENGTH AND INCLINATION OF THE SEGMENTS.

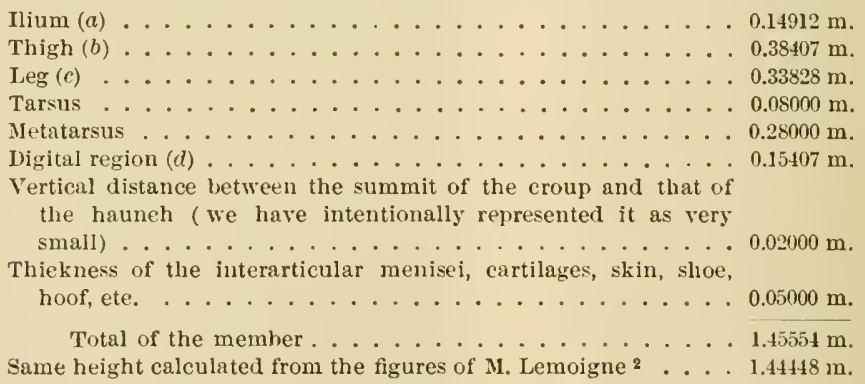

Thus, by taking M. Lemoigne's measurements as well as our own as a base, we suceed in reconstrueting the members with their nomal medium height, which proves the relative precision of our observations.

\section{Influence of the Inclinations of the Bones upon Speed.} -The degree of opening of the locomotory angles of the horse have a marked influence upon the development of speed. With regard to the superior regions of the members, we have not failed to mention and to indicate, for each bone, the value of the inclination which it should

i Here the shoulder and the phalanges are a little less inclined than they should be, which makes the member a little longer.

2 Iere the femur and the tibia are a little more inclined than they should be, whicl makes the member a little shorter. 
possess. It would therefore be fastidions to reproduce here all the details into which we have entered; our point of view now is much more general.

We will limit ourselves to the following short résumé:

1st. The articular angles are alternately closed and opened during locomotion.

Their elosing should dispose their branches in such a manner as to shorten as much as possible the whole nember in order to prepare it for an attitude of considerable extension.

Their opening, lengthening the locomotory column, should pernit the inferior extremity of the latter to acquire an extreme position, as far removed as possible from the original position, in order that the step may have a great length and the impulsion be of long duration.

2d. The extent of the articular action is intimately dependent upon the respective position of the osseons segments during the regular station. In principle, the original separation of these latter increases it, and their approximation diminishes it.

3d. In order that the articular action may produce the greatest amount of useful effects, it must be accomplished in such a mamer that the two extremities of the member may be separated, at the time of extension, in a very oblique direction and not according to the vertical or any other direction approaching the vertical. It is under these conditions that the length of the step and the impulsive power acquire their highest limit. It is in this case also that the impulsion is most efficaciously transmitted, - that is to say, following a trajectory close to the horizontal, having a forward movement and not an npward one.

4th. The degree of inclination of the locomotory segments is therefore capable of influencing the action of the articular angles in two ways: either by modifying its extent or modifying its efficacy. The obliquity of these segments should therefore satisfy this donble requirement,-viz., increase the efficacy of the articular action without diminishing its extent.

5th. To do this we know that the superior segments, the shoulder and the cromp, little movable, should rather tend towards the horizontal, in order to acquire more length without increasing beyond measure the height, to fareilitate the forward and backwarl movement of the inferior regions, and give then the freedom of extending themselves effectively to pass over the ground or communicate the impulsion.

This horizontality of the shonlder and the croup naturally implies 
in fast horses a more marked closing of the superior angles. In draught-horses these angles should be more open, because greater rigidity of the members is required in pulling.

6th. We have also seen that the inferior segments, much more movable, are all the better for having, when at rest, only a slightly oblique inclination, which brings them nearer to the rertical line passing through their centre of movement, because then the action of their articular angles develops the greatest amount of motion.

7 th. Observation and theory agree in proving that the locomotory segments are far from having an inclination of 45 degrees to the horizon in beautifully-formed horses, and from being parallel with one another in the members of the same biped, as the theory of General Morris would require.

8th. The similitude of the homologous angles does not seem to be established either, nor even necessary to the most favorable static and dynamic conditions.

The tendency to the equality of the following angles should, however, be recognized : the scapulo-humeral and the eoxo-femoral, the humeroradial and the femoro-tibial, the metacarpo-phalangal and the metatarsophalangal.

9th. All things being ecfual, the fast horse has his locomotory angles, the superior and the inferior, less open than the draught-horse, on account of the greater inclination of his shonlder, his croup, and his pasterns.

On the contrary, the other angles are more open and the segments a little longer, especially the canons.

10th. The angular relations of the locomotory segments are of importance in the production of force only in so far as they realize better static conditions and favor muscular incidenees.

Now, how shall we judge of the closing of the articular angles without having recourse to the use of mechanical instruments? This is certainly one of the most delicate points, and one which demands great practice and great accuracy of sight. It is, however, possible to give some hints capable of gniding one in this respect.

Thus, the elosure of the seapulo-humeral angle can be estimated by the obliquity of the shoulder and the elevation of its point.

The coxo-femoral angle can be approximately estimated by the horizontality of the croup. Many common horses, as has been seen, present the length of the head between the summit of that region and the superior fold of the stifle-joint; it is, on the contrary, very rare to 
fiud this in well-formed race-horses. In our opinion this difference results only from a smaller coxo-femoral angle in the latter.

A proper opening of the superior angles being once determined, nothing remains to be done but to ascertain the perfect regularity of the equilibrium, in order to judge of the inferior angles. And, sure enongh, if the inclination of the shonlder be good, it is evident that the humero-radial joint will be found in advantageous conditions, provided the forearm be almost vertical, and the fetlock-joint and the foot be well placed in relation with the vertical line.

Likewise, the position of the croup being ascertained to be right, it is evident that the direction of the leg will beeome correct also, from this fact alone, that the hock will ocenpy its normal position with respect to the plumb-line which is tangent to it.

The correct opening of the superior angles of the members, therefore, commands that of the inferior, on condition that the locomotory columns be regularly disposed for the support of the body, and that the osseous segments have maintained their proper length.

\section{C.-General Relations of the Ensemble, the Whole Organism.}

The word ensemble, when not employed as synonymous with regularity, harmony, beautiful proportions, signifies the totality of the animal machine acting as one generator of force or speed, irrespective of the parts which compose it.

It is by restriction, and incorrectly, that the large divisions, lines, or dimensions of the whole are called ensembles; we will therefore seldom use this latter expression, which seems to refer rather to the details, while its true acceptation gives it a much more general sense.

Several horsemen criticise and take pleasure in ridiculing the ingennous comparison which has been formed between the horse and an ordinary machine; it is to be regretted that they have neither felt nor understood analogies in which they no doubt would have found the solution of more than one difficult problem.

From a didactic point of view it is, indeed, convenient and allowable to compare the horse to a vehicle, for the reason that it is always more simple to make an examination upon a scheme than upon the thing itself, especially when the latter is complicated. Whatever may be the essence, nature, and position of the motor relatively to the vehicle, the latter, to fulfil effectually the end to which it is destined, should comply with certain conditions of height, length, and width, maintain certain relations between what we may be allowed to eall its 
inert part, the frame, and its active part, the wheels. These are the relations which it remains for us to determine by applying them to the horse. We will see in them at the same time the most general and the most important characteristies of his conformation.

Height. - The height of an animal is the elevation of its body above the ground, the members having the altitude they usually take during station. It is measured from the withers or from the croup, two external points easily found when we are careful to take the necessary precautions. (See Height.)

Observations show that these points are situated upon the same horizontal line or upon different levels. In the latter case, the horse is said to be high or low in front according to the corresponding height of the croup. There results evidently from this an abnormal distribution of the weight of the body upon the four extremities; this, at least, is the result of our measurements and our weighings.

A lowering of some centimetres at the withers usually causes a surcharge of the anterior members, and therefore modifies the conditions of the equilibrium and the velocity of the gait. These drawbacks increase in proportion to the burden earried on the back, which is often added to the subject's own bulk. Lastly, the region of the withers is more exposed, on account of its prominence, to contusions and wounds caused by the harness.

Inverse effects accompany the diminution of the height over the croup. The hind-quarters, sureharged in their turn, are wanting in action, and are obliged to use greater efforts; the hocks are soon ruined.

But these different disadvantages, with their grievous consequences, manifest themselves only when the inequality in the height of the two bipeds is very marked. When it is slight, it is but little pereeived in practice. Besides, it has not the same importance in all services. The eavalry horse, the pack-horse, and the dray-horse, always heavily loaded, will show the effects of being low in front much sooner than the race-horse, the coacher, the trotter, or the light dranght-horse. These latter, on the contrary, in which speed is the main quality, suffer much more from a defeet in the hind-quarters; an excess of height of the croup over that of the withers is a farorable disposition in them, whilst an equality of the height of the two bipeds is the best conformation in the others.

Many horses of good breeding and of great speed have the croup considerably higher than the withers; this conformation is even very much appreciated by horsemen, especially in hunters and 
steeple-chasers. It should not he forgotten, however, that in such cases the overloading of the anterior members is compensated by the relative lightness of the fore-cyuarters and the power and great length of the hind-quarters. Here, as with the hare, according to M. Richard's ${ }^{1}$ comparison, the posterior members are carried far under the trunk, their footprints are much beyond those of the anterior, the hind-quarters are strongly built, the croup and loins are vigorous and well supported, the dorsal spinous apophyses are long, and the shoulder very oblique. There is then truly a compensation.

One point which should be insisted upon in passing is, that we never see subjects three heads in height. The most exceptional in this respect only reach two heads and three-quarters, whilst the happy medium reaches but two and a half heads, aceording to Bourgelat's judicious remark. ${ }^{2}$ Those which very much exceed this figure, as well as those which do not attain it, should be considered disproportionately built; these last are more seldom seen. Let us cite an example of this kind, oceurring in our observations, which is quite remarkable, and in which the height at the withers was only two heads and one-third.

The height is an organic sum composed of two elements, the body and the members, between which harmony does not always exist. Then there results one of the defects of construction most prejudicial to a good functional aetivity of the living machine. We will soon have occasion to return to this.

Length.- The length of the body is considered from the point of the shoulder to that of the buttock, the animal being in the normal position. Bourgelat rightly assigned to it two heads and a half in well-formed horses. Our best types nowadays are still constructed aceording to these incontestable measurements.

Perhaps this dimension is subject to variation more than the preceding; we insist upon this, however, that its variations remain constantly below three heads, even in subjects reputerl to be long by the greater number of horsemen and artists, - English horses, for example, which are usually shorter than others.

M. Duhousset ${ }^{3}$ says that nothing is easier than to be mistaken by a superficial observation. To prove this, we place before the eyes of the reader a drawing of the two horses in Fig. 141. No. 1 is taken firom a photograph having exactly two heads and a half in the two

1 A. Richard, Etude du cheval, etc., p. 149

2 Cl. Bourgelat, loc cit., p. 203.

3 E. Duhousset, Le Clieval, p. 69. 
measurements, height and length. No. 2 is this type lengthened only

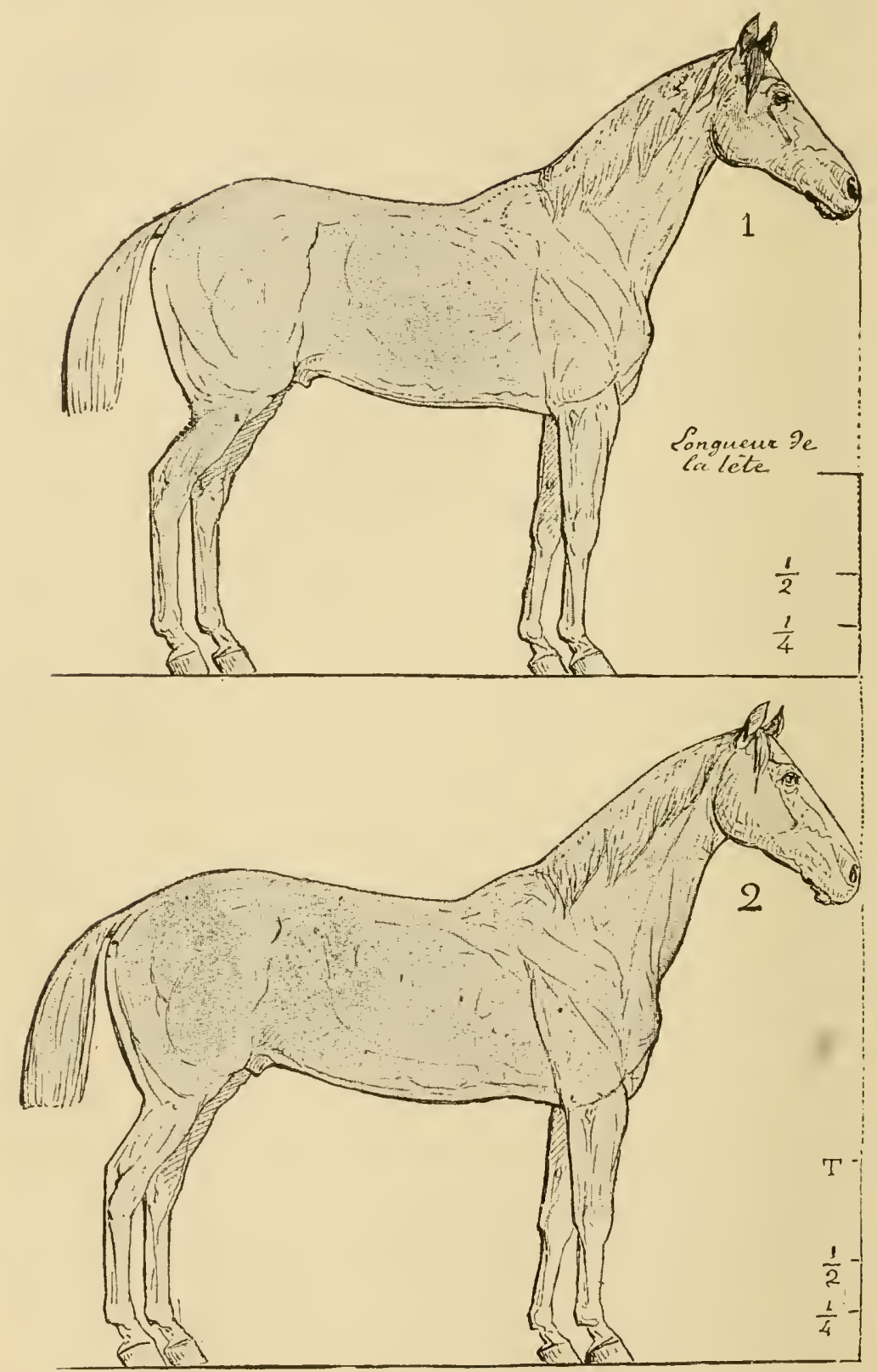

FIG. 141.

by one-fourth of the length of the head. It is evident that the first 
will appear short, but the second will always have the appearance of a long animal ; however, that the minimum difference is accurate may be verified by the nse of the complass. According to this, we may inagine the still greater apparent difference which would be produced by this second horse if the length compared with the height had been three heads instead of two and three-fourths.

One of the most extraordinary horses, in this respect, which we have measured was two heads and four-fifths long ; it is needless to add that it was entirely defective in other respects. Horses which do not reach two heads and one-half in length are far from being common; still, we have noticed several examples.

However this may be, it is important to recognize the fact that the pure and simple consideration of the length of the body is insufficient to form an opinion as to the shortness of the dorso-humbar column, a sine quâ non condition of his strength and aptness to properly utilize the impulsive action of the hind-quarters. This results from the length being an organic sum whose elements are: 1st, the length of the spine; $2 \mathrm{~d}$, the length, the direction, as well as the relative situation of the shoulder and the croup. It is plain that the point of the shoulder and that of the buttock will be still more distant from each other as they belong respectively to regions longer, more inclined, and more separated.

The question, then, is to determine in what way the spinal column is covered by these regions. Now, the scapulo-iliac distance comprised between the dorsal angle of the scapulum and the angle of the haunch furnishes a rather convenient means of obtaining this result. This distance, as we have already seen in speaking of the shoulder (page 2033), is equal to that of the head in all beautiful horses. If it is found to exceed this, we may infer that it depends either upon the excessive length of the loins or the position of the shoulder and the croup. As the disposition of these may be easily appreciated, since they occupy a superficial position, it follows that, all things being equal, the horse which has the greatest separation between the dorsal angle of the scapula and the haunch will also be provided with the longest spine, and will be the most predisposed to become sway-backed.

But an excess of length does not always imply a like formation of the vertebral column. De Saint-Ange ${ }^{1}$ has explained this judicious remark by means of an ingenious graphic demonstration, of which the scheme of Fig. 142 is only the reproduction. The subjects Nos. 1 and 
2 have the same total length; they differ only in the dimensions of the back and loins; in the first, they are long, $m n$; in the second, they are in good condition, op. In the latter the total length, $A D$, depends,

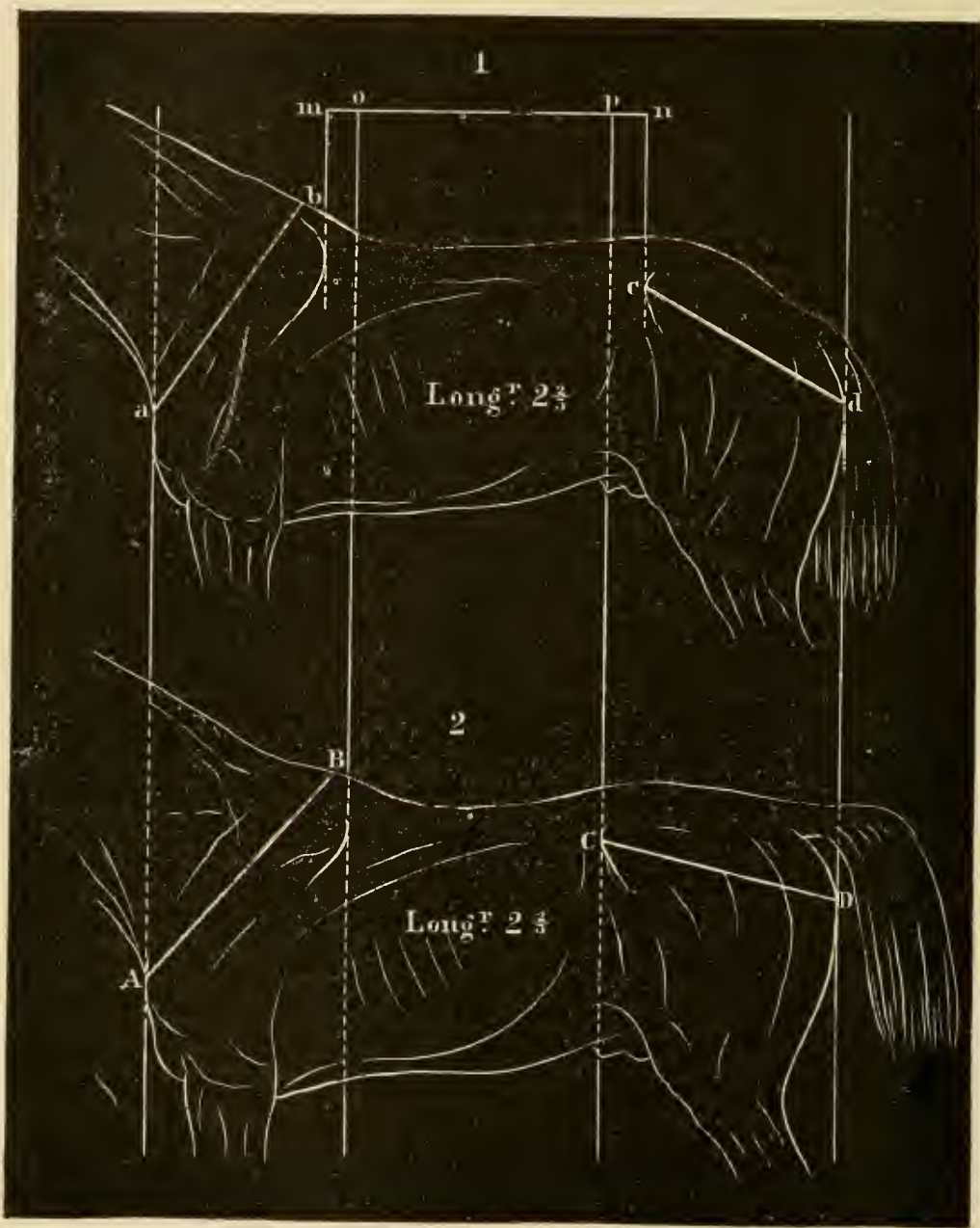

FIG 142.

without contradiction, upon the position of $A B$ and $C D$, regions which, without a longer interval between them, are more separated at their extremes by becoming more horizontal, therefore covering a larger extent of the body, and acquiring more favorable dimensions and inclinations. Here the separation of the points $A$ and $D$ is not then due, as in subject No. 1, to an excess in the length of the dorso-lumbar 
columm, but rather to the strengthening of the points of the shoulder and the buttock, two points which compensate what the total length $A D$ at first sight appears to be defective in, since it measures two and two-thirds heads.

The normal length, two heads and a half, on the contrary, is not always constant when the animal is short and compactly built. The back and the loins of many horses meeting these general requirements are weak, on account of a want of development of the croup, vertical direction of the shoulder, and often also on account of the prominence of the spine, poorly covered by these parts. Again, this defect is judged of by the value of the scapulo-iliac distance, of which we have already spoken.

Finally, the excess of length, when it is not exaggerated, cannot only be compensated, as is seen in Fig. 142, but it is to be preferred to the classic length of two heads and a half,-even supposing the seapulo-iliac separation to be normal, - if it is due to the disposition of the shoulder and croup, and if it coincides with a long chest and a short flank. In this case, in fact, the dorso-lumbar column is in good proportion and strongly supported; it supports a spacions thoracic cavity; the animal has brilliant and extensive action, endurance, and a harmonious form. This may be seen in Fig. 143, in which subject No. 2 is one-sixth of a head longer than subject No. 1, which possesses normal conditions, but whose shoulder and croup are wanting in length and inclination.

From all that has been said, it is seen that we cannot investigate too carefully the value of the different elements which compose the length of the body. A superficial estimation of this dimension is insufficient, even when it appears to be in the condition indicated above. The relative condition of the back and the loins on the one part, the shoulders and the croup on the other, must also be appreciated; the apparent excess of length should not be considered, $a$ priori, as resulting from the spinc, nor regarded as implying always the length of the chest. We should be in danger of committing errors. When assigning two heads and a half to the length, we meant to imply at the same time a proper scapulo-iliac distance, a well-formed shoulder and croup. The particular cases which we have analyzed positively prove that it is impossible to determinc absolute figures.

Relations between the Height and the Length. - What we have said in regard to these proportions naturally foreshadows that, with Bourgelat, we give preference to the square (camé) horse, one in whirh the height at the withers is sensibly equal to his length, and 
which therefore might be inscribed within a perfect square. But how many prejudices exist upon this particular point! Not to lose time, we will not consider them. Some prefer the long horse, others the short; most people reject the square,- - the only one, perhaps, which realizes in the best way a beautiful conformation.

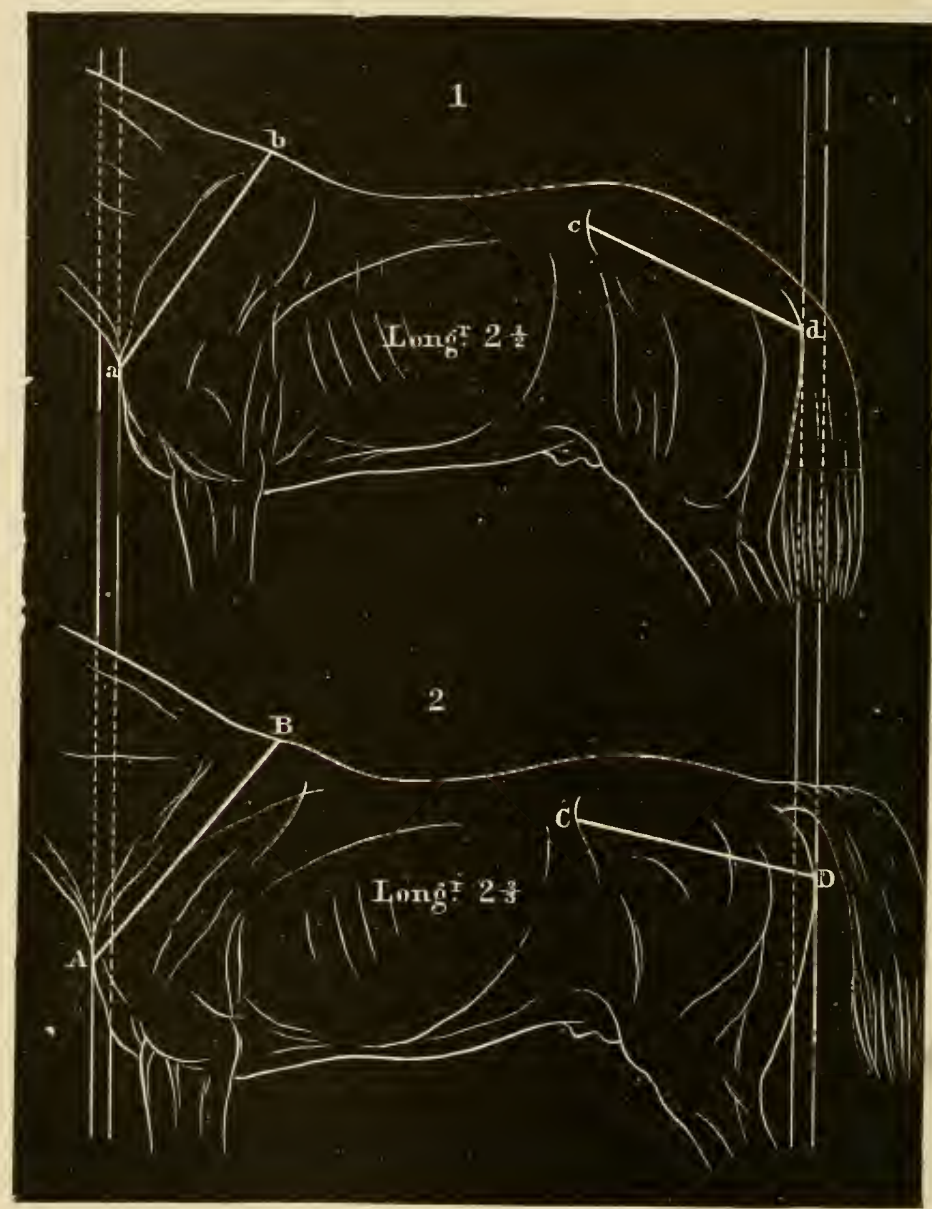

FIG, 143 ,

Why these differences of opinion? We hardly know. It seems, in this ease, that observers have judged much more from their ideas than from their researches. Still, it will be acknowledged that it would have been easy to proced differently. Howerer this may be, let us see what are the consequences if height or length be increased separately beyond its normal limits. 
Suppose, for a moment, that a well-formed horse be made taller without changing, in any respect, the relations existing between his different regions; in other words, let us vary only his height without modifying the relations previously existing between the body and the members. As Bourgelat has expressed it, we shall have determined a defect of proportion comparable to that which is observed when the animal is too short. The centre of gravity will have been raised without the base of support being enlarged; the trunk will have acquired greater weight without the columns of support becoming stronger; finally, the members will have become longer without increasing the speed, since the posterior members will not be able to move freely under the body without the risk of striking the anterior. We will have before us a locomotor unstable in its equilibrium, feeble in its parts, made taller so that he might go faster, but prevented from doing so by the imperfect adjustment of its mechanism. Our horse will be narrow, tall, liable to fall, to forge, to interfere, without power or speed, - a true string, aceording to the vulgar expression.

The results will not be better if we attempt the contrary experiment,-that is to say, if we diminish the height while allowing the other parts to remain in the condition in which they were previously. In such a case, the defeet will be the same as if the subject were too long. We will have lowered the centre of gravity, rendered the base of support relatively wider, the equilibrium more stable, and the members shorter. These will not in any way be disturbed in their action, or liable to meet each other; but their movements will be wanting in extent and also in power. The motor will appear heary, massive, and slow; he will not be able to display any speed with his shortened members, save by multiplying their movements, and that, be it well understood, to the prejudice of the museular apparatus which moves them and the nervous system which commands their displacements.

Identical conclusions would be reached if, instead of varying the height, we changed the normal relations of length in relation to the height.

The excess of length, for example, would produce the same effect as if the body were too close to the ground. 'To this, however, would be superadded the complication that the vertebral column, being longer and more movable, would become feeble, vacillating, predisposed to become sway-backed, and more fatiguing to support. The subject wonld be unfit for the saddle, his movements would lose their precision; he would go eross-ways rather than walk straight. 
As to the defect in length, would not the same inconveniences exist as if the horse were too tall? Over and above the faet that the animal wonld acquire a tendency to forge and interfere, his gait would be hard, unsightly, and high, for the spinal column, although more solid, would be shorter and less supple.

Such are the results to which extremes lead! Let us seek for the just mean by inspiring ourselves with beautiful nature. Beginning with the idea that in order to produce speed long members are neeessary, and that these, to be properly developed, should act upon a long body, many persons imagine that fast horses, trotters or others, are longer than they are high, and they give to the length a quarter of a head, or even a third, more than to the height. What reply will they give us when we tell them that they have made a suggestion in direet opposition to the reality?

M. Duhousset" says that "out of fifty African horses, twenty-six were shorter than they were high; in fourteen the height and the length were equal ; and in ten the excess was in length." Farther on, the same author records his observations on horses of fine breeding: Out of forty rumers examined, there were twenty-eight in which the height was equal to the length, nine in which it was more considerable, finally, three in which it was less (Dick, Monarque, and Ralph).

It would be fastidions to insist further upon this point. Our measurements upon the handsomest running-horses, steeple-chasers, Orloff trotters, Anglo-Norman and Arabian, Barb, Andalusian, some Hungarian, and American horses enable us to affirm that the excess in length, scarcely amounting to $1,2,4$, or 5 centimetres, is the exception, the equality or excess in height permitting variations of the same value being the rule.

For fast work, Bourgelat was right in considering the equality between height and length as the just mean to be sought. In this respect, again, he was not influeneed by purely theoretical views; he had sought for and had actually seen what he had indieated.

For slow services this just mean remains, a fortiori, the same. Still, we hasten to affirm that horses of this class are very often longer than tall, very probably because their production has received less care. Hence, sway-backs are common among them. But let those be measured which have won the prizes in expositions and in competitions, those which the government or breeding associations recommend for that very reason to the public choice; we will find that they are 
nearly in accord with the eonditions stated by the founder of veterinary schools.

Width.-We designate by this term, width, ampleness, the transverse development of the body, particularly at the level of the chest, the breast, and the croup. It results in great part from the muscular development of the parts, and is best appreciated by viewing the horse in front or behind. We determine it also by an oblique inspection, either in front or behind, or, finally, by looking at the subject from above, when he is harnessed or mounted.

When the ampleness is considerable, the animal is vulgarly said to have bulk, to be stont, a state which is indicated by the width of the chest, the prominence of the shoulders, their muscularity, the roundness of the ribs, the width of the croup and the volume of its muscles. This conformation is characteristic of the heary dranght-horse, to which it communicates at the same time bulk and power. It is songht for also, although in a less degree, for some services of luxury, principally in the coach-horse.

For fast services, on the contrary, too great a width would be prejudicial. It wonld increase the weight of the body, already proportionately high, diminish the stability of the equilibrium without being of advantage for speed, and wonld soon wear out the members, which would be too weak as columns of support. A larger osseous skeleton, especially behind, a longer chest, muscles which are more dense and firm, are to be preferred. "From behind forward," De Curnieu ${ }^{1}$ sars, "the horse must be wedge-shaped,- -that is to say", have a wide croup and narrow chest; he will all the better cleave the air before him, and if he is a little too high over the withers, the power of the hind-quarters will diminish this defeet, which, besides, often facilitates the quickness and increases the force."

The lack of ampleness is a principal fault for all kinds of work, for it is the necessary consequence of the narrowness of the thorax and the insufficiency of the muscular apparatus. It may be characterized by qualifying the animal as being étriqué, lanky.

Body and Members.-The body and the members are the two elements which compose the height. But, as they do not bear the same proportions in all subjects, it is important to know in what conditions they vary through excess or deficiency, still giving to the whole a sum of height in harmony with the length.

In ordinary language, when the body is spoken of in opposition to

1 De Curnieu, Leçons de science hippique générale, première partie, p. 278, Paris, 1855. 
the members, reference is made, by the first of these expressions, to the height of the chest and the abdomen, whilst by the second is understood only the part of the members completely detached from the trunk,that is to say, comting from the elbow or stifle. Taking this view, it will be understood how the body is also called the upper part, in relation with the members, which then assume the name the lover part, although these expressions are sometimes employed to designate the lines by whieh the trunk shows itself in profile above and below.

The relations existing between the body and the members vary according to the types considered, which, to simplify, we divide into two categories: the motors with a view to speed and the motors with a view to force. In a general way, it must be known, first, that in the former the lower part is always, equal size considered, much longer than in the latter, which are compact and near the earth. In this respect, the differences are all the greater as the services which they perform differ the more from each other.

The body, containing the organs which are most essential to life, such as the heart, the lungs, and the digestive apparatus, cannot be deficient from excess of development, since these organs are precisely those from which the animal machine draws its power and resistance. If disproportion seems to exist in the upper part compared to the lower part, then the latter is not properly constructed to support the former. But generally, although excess may not be objectionable, the same cannot be said of the deficiency of development. Our machine, having a weak chest, a small abdomen, will be without energy, without wind, capable of very little exertion. Such an animal will be a poor feeder and will not last long. All these are great imperfeetions if he is called upon to perform laborions service.

What, then, is the method of appreciating the beauty of the body? We already know it. In fact, we know that the xiphoid region (pit of the stomach) should descend several fingers'-breadth below the elbow, that the ribs should be round, the chest widened behind and a head wide in its middle part (ampleness), the abdomen full, quite cylindrical, and a head thick from its inferior line to the middle of the back.

As to the members, they cannot be too beantiful. As soon as such seems to be the ease, the reason of it is that the upper part is not in proportion. Strong columns under too light a structure are not defeetive, they are simply useless. Large wheels moved by a strong crank are neither of advantage to a locomotive nor hinder it much if its boiler and its piston are unable to make use of them. But it is entirely different if the supports, the wheels of the motor, are 
slender, weak, too long, ill adjusted, in a word, disproportionate in relation with the weight which they have to displace. In this case the most irreproachable body will be powerless; the machine will be without force, withont solidity, without speed, and destined to wear out soon. How many horses are thus constructed, which are said to be defective, wiry, mounted upon inatch-sticks, perched high, which have fine breeding, vivacity, energy, conrage, but which-veritable stran-firesonly last an instant, for want of ability to utilize the mechanism which they possess!

They will be recognized by the exaggeraterl length of their members, the narrowness and thinness of their forearms, their legs, their knees, their hocks, and their fetlocks, the slimness of their shanks, the weakness of their tendons, and the small volume of their muscles. One way to ascertain their disproportion consists in measuring the distance comprised between the passage of the girth and the pasternjoint. It is known that in a beautiful conformation this distance is equal to a head in horses of ordinary size, a little longer in large horses, and a little less in small ones. (See Relations between the Dimensions of the Regions, page 359.) At the same time we should not forget always to take into account the greater length of the locomotory eolumns in fast horses.

\section{D.-Relations of the Organism with the Nervous System; the "Blood;" the Temperament.}

Opinion of the Laity upon the "Blood."-Most horsemen still speak of the blood ${ }^{1}$ as a kind of immaterial principle endowing the subject inheriting it with a combination of physical and moral qualities of a superior order. This principle, transmissible by heredity, would be the appanage of the noble races, the English thoroughbred and the Arabian ; again, we are asked to believe that it has been precionsly preserved in all its purity, without deteriolation, through a number of centuries, thanks to the care which man has taken to preserve these races from all contamination with those called common, in which it (amnot be observed.

"The pure blood [sang]," writes M. Eug. Gavot, " "a living, artive,

1 This is a somewhat ambiguous term. Among the partisans of the theory of erossing, the ancient jea is prevalent that the races of the horse are continually degenerating, and that the Aryan (Arabian) race is of pure blood (pur sang) and superior to all the others, which it regenerate. by crossing. Hence the term "blood," as here used, indicates the degree of relationship with this race, as shown by certain qualities, both external and intermal, possessed by the aninals.

2. Moll el Eug. (iayot, La connaissance genérale du cheval, I. 313, Paris, 185-. 
and conservative power, a force inherent to the species, should be considered apart from the animal which possesses it. The latter may vary and have very different external characters without the principle which animates him ceasing to be perfectly identical, beeause it possesses in this connection an admirable scope of adaptation; this is its property. In it are all the perfections; it is the source of all the special qualities. It is through this that it governs the species and is their prototype."

It is difficult to be more metaphysical and therefore less scientific! Physiologists exact more at the present time. This spiritualistic conception deserves mention only from simple curiosity ; it is, in fact, more than a century behind modern ideas; there is therefore no reason to consider it.

Other horsemen, notably Magne, ${ }^{1}$ consider the blood (sang) as a combination of external character's proper to better-finer-races, equally transmissible by heredity.

We are mistaken as to the very essence of the question itself if we believe that English or Arabian reproducers are capable of transmitting only their conformation to the exclusion of all other qualities. The blood is no more the conformation than it is the immaterial principle spoken of above.

A determined external form is of itself incapable of constitnting the blood; it is only its substratum, its receptacle, and, for this reason, may become its index. Now, as a horse cannot inherit noble qualities without at the same time possessing the features which indicate them, we see how it is that some have taken the containing part instead of the thing contained, and mismderstood the true nature of blood.

Origin of the Word "Blood."-Whence does such an expression originate? Very probably from the ideas formerly entertained upon fecundation.

Hippocrates ${ }^{2}$ (to go back no farther) was of the opinion that the male and female each extracted from their own hmors, during copulation, stronger parts, a kind of particular production of the organs, which met each other in the genital female passage and constituted the seeds, in each of which were found male and female germs. The sexuality of the product depended upon the predominance of the one over the other. As the strong parts were produced by the agitation of the hmmors of the body, as these fluids were endowed with the

I J. H. Magne, Races chevaliues, 3e éd., p. 351.

2 Hippocrate, Traité de la génération. 
quintessence of the faculties and aptitudes of the procreators, the laity were easily led to the firm belief that children were really the very blood of their parents.

At the beginning, the word blood could then be considered as almost synonymous with the word heredity. At the present time it is nothing more than a corruption of it, in this sense, that it is not applied incliscriminately to all hereditary characters, but only to a few of them, to those which refer especially to the moral qualities of the parents.

We understand, then, what is meant when a horse is said to have blood, to be well bred. The idea intended to be conveyed is that the horse has been more or less subjected to métissage, breeding animals of different races in earlier times. The animal of a ligh lineage, descended from a noble race, and whose ancestors were entirely free from all contamination, is qualified as being of pure blood. Lastly; the horse deprived of all the qualities inherent to blood is styled a common horse, while, a fortiori, one deseended from parents that have never been mixed with pure-blooded animals is the low plebeian of the species.

But the aptitudes of the better races of the horse are not always a constant result of direct heredity, - that is to say, the immediate result of the sire's or dam's influence; sometimes they pass over one or more generations to reappear in the succeeding ones. Indeed, these aptitudes before being definitely established in the better races must have been developed slowly under the combined and incessant aetion of a thousand different eauses; they must, therefore, have shown themselves at a given time in the individual before being transmissible to the descendants, and then constituting the appanage of a determined type.

On the other hand, subjects of the same family, whatever may be their resemblance, do not always possess identical qualities; the numerous and different attributes of the species are not uniformly inherited by them; the qualities which each one possesses at birth are neither the same in nature, nor equal in intensity, nor similar in value. In any case, it is, first of all, an ancestral inheritance, the special, unconscious accumulation of (qualities resulting from the ehoice of the male and female for centuries. It may proceed, hesides, from a more or less intelligent selection on the part of the breeder, who endeavors to work in the same mannel' as Nature, and in concert with her aids her by his practical knowleclere. That is what constitutes inbormess, which is nothing else, as may be seen, than a kind of indirect heredity.

The organism, therefore, inherits from selective arecumulation and the application of zootechnic methods by man, certain qualities which, 
so to speak, establish its individuality, and which, in the species, also coneur in enclowing it with those faculties which constitute the blood.

Definition and Nature of the "Blood."-This being laicl down, we are in a position of giving-having the same opinion upon this point as Messrs. Sanson ${ }^{1}$ and Baron ${ }^{2}$ - the anatomo-physiological interpretation of the metaphysical conception of the worl blood, which until now had searedy been understood but as the expression of a distinet foree, an immaterial essence, isolated from and independent of the body which it governed.

If it ean be said of man that he is an intelligence server by organs, with better reason may it be added of the horse that he is a nervous system served also by instruments, generators of force and of speed. Without the nervous organism the latter are nothing; without them it is reduced to the most utter powerlessness; with them it is everything. These two parts of the living being are indispensable to each other for action; the nervous srstem could not command if its servants did not obey and act. Now, every command, in order to be heeded and earried out, supposes an agreement and a previous understanding between those who are intrusted with its excrcise. It supposes, moreover, a veritable correlation of action between the agents which command the action and those which excente it. In the same manner in the organism, if there is a harmonions concord between the different parts (the spinal cord and the brain) of the central nervous system which presides over the action of the organs (between the powers whose function it is to properly direet the machine),-if, besides, there is a correlation between the nervons system and the organs themselves upon which it depends (between the directing powers of the machine and its machinery), - there will result a kind of all-pervading and regulating harmony, a perfeet equilibrimm between those pieces of the economy and the forees which set them in action.

It is to this state of equilibrium-the result of a perfect nervous system, considered with regard to its functional activity or its dynamic intervention-that the name blood is given.

But in what especially does this perfection consist? In the intensity of the reflex power, - that is to say, in the property which the nerve-centres possess of transforming more or less quickly the impressions which they receive from the external world through the intervention of the senses into motor reactions.

1 A. Sanson, Traité de zootechnie, 2e éd., t. ili. p. 197.

2 R. Baron, La lynamometrie biologique, in Archives vétérinaires, année $18 \%$. p. 70 . 
It is evident that this reflective power in order to be utilized must be served by organs not only well conformed, but also well adapted to the special method of its manifestations. For example, an orchestra may possess instruments of exeellent quality when con-idered separately; its performers may be artists of the first rank, and yet the combined effect of all these musieal factors will be full of diseord if he upon whom devolves the eare of employing and directing them does not know how to manage them, or speaks in a language they do not understand. However removed from our subjeet this comparison may appear, it is none the less applicable here. The nervous system, whatever may be its value as a reflective power, and the organs, whatever may be their mechanical perfection as locomotory agents, are of little value without the harmonions relations of which we are speaking.

Whence is the "Blood" derived? - The blood is hereditary, as we have already seen; it is also inborn in certain subjects belonging to races which do not habitnally possess it. And this innateness is the consequence of the great probability that the hereditary qualities of the species are mequally distributed to their deseendants. This results from the slow and dearly-bought triumph of the organism over the surrounding medium. Even thus, the handful of wheat which is promiscuonsly cast upon a fertile soil, and the grains of which are not uniformly seattered on the soil, will produce in the future field places more or less rich in sheaves; so, also, the descendants of the species are led by ehance to develop in climates and upon grounds where they will be able to preserve their qualities, aequire new ones, and transmit them to their offspring, while others will suecumb to the unfavorable conditions of the medium.

Every individual, therefore, is born more or less endowed, and his very aptitudes vary in number and in development. He owes them to his own parents in the case of immediate heredity; to his aneestors in that of indirect heredity.

Finally, he may develop it in himself, for it is a fact equally demonstrated that blood moy be acquired. Magne" says, "It being the direet product of food and air, it changes with the influences to which the animals are exposed."

It is inereased by a special regimen and a particular education, as the Arabians have done from antiquity, as the English still do at the present day for their race-horses. The different and many methods 
employed for training the hippodrome horse; the conditions of nourishment, stabling, and temperature to which he is submitted; the sweatings, the tests of all kinds which he undergoes; the dressing, the massage, the dry friction upon the members, which are given to him every day ; is not all this preparation-so extensive and so carefuladapted to communicate to him, in the highest degree, the sangninonervous temperament and the brilliant qualities which characterize him? Is not the Arab:an horse in reality trained in the same way? The different eireumstances to which he is obliged to conform himself on account of the rough life of his master; the medium so propitious for the development of all the faculties inherent to his nature, -are they not essentially calculated to produce and to establish in him the highest aptitude of the speeies? Have not these aptitudes also germinated in several of the old French races, for example, the Nararrine, the Limousine, under the effeet of the same influences? Dowc not at the present time see them manifested in ecrtain families, notably the large Boulonnais horse, which has never been subjected to métissage with the races called pure-blooded?

Artificial Transmissibility of the "Blood."-If, now that the production of the "blood" is recognized as being derived from the power of adaptation of some isolated specific units, we obtain their individuality, with the qualities, howerer poor they may be, by which this individuality is manifested, we will be able, by the judicious use of zootechnical methods, to condense and establish it in a family or race of which it will become in some way the quid proprium. This is the practice pursued by the Arabs and the English with their horses. The care which they have taken to preserve them from all contamination has made them animals of the riehest blood; they have so thoroughly sueceded in becoming masters of this individuality, that they infuse it and transmit it with a rare facility to the varieties in which it was before absent.

This demonstrative experiment is of great interest from an cconomial point of view. From it we obtain the indieation that this endensed individuality which is ealled the blood may be made use of to communicate the speeial feature or quality to other individuals or other races less well endowed, and in whom selection will act in the same way as it has done for the parent stock. The great diffienlty of the problem is to know under what cireumstances and to what extent the operation should be attempted; but, however great this difficulty may be, the principle we have just given is not the less perfectly true.

Index of the "Blood."-Finally, a last question presents 
itself. How ean we judge of the amount of good breeding possessed by a given horse?

Two sonres of indications enable us to do so: one of them refers to characters drawn from the general conformation; the other to the external manifestations of the activity of the nervons system.

The first is fomded upon this fact, that the English and the Alabian horses are constantly infusing better breeding into our common races. Whence it results that these agents of amelioration shonld transmit to their descendants the principal features of their conformation as well as their "blood."

The second results from this other consideration, that the "blood" and the temperament, consisting in the intensity of the reflective power, will be seen by the different external states of the organs of the senses, - sight, hearing, smell, taste, and touch. This last source of information is sometimes the only one,-for example, when it is a question of a common race, free from all mixed breeding, in which the "blood" sprang into existence under the influence of the external conditions only. Our own restrictions being made upon this point, and the cases in question being, moreover, rather infrequent, we would say that the qualities proper to the blood will be recognized by :

A slender body of a stature generally tall; a slender figure, long members, firm and long muscles, projecting, developed osscons prominenees; a neat, light, square head; a wide forehead; movable ear's and nostrils; quiek, expressive eyes; thin lips; a long, straight, prramidal neck; prominent withers; short back and loins; long and horizontal croup; well-attached tail; high and long chest; slightly-developed belly; long and oblique shoulder; thigh and buttock low; leg and forearm long; straight hock; short canon; elean and well-detached tendons; feet rather small ; great nervons excitability ; thin and sensitive skin; seareness of all the hairy productions; the appearance of the superficial venous system moler the influence of the least excreise; the facility of reacting before all external excitement, even the slightest; finally, a remarkable development of the intellectnal faculties.

These are the attributes of suljects descended from noble races, and the proportion in which they will be observed in their metises (halfbrecds) will also indicate the part which reverts to the ancestor in their production.

It may now be understood withont difficulty what is meant when a horse is said to have ruec, nobility (elegance, urace, pride); figure (distinction with fine lines); quelity, breerling, fire, churueter (density and compactness of the museles, enerers, vivacity, vigor); heart (ardor 
and resistance to fatigne), ete. All these expressions serve to characterize such or such a feature of the conformation or the moral qualities of well-bred animals; they are frequently employed, and it is important to know them in order that they may be used and understood in the acceptation which custom has given them.

\section{CH A P T ER I I.}

ISOLATED EFFECTS OF BEAUTIFUL PHOPORTIONS UPON THE ANIMAL MACHINE.

Is the preceding chapter we have passed in review the four prineipal aspects under which it is important to study the proportions. We have analyzed, in a static state or repose, the details, the locomotory machinery, the machine as a whole, as well as the animating principle which regulates its aetion. Now, we have to study the same machine with regard to the individual effects which it is susceptible of producing, aceording to the partienlar combination of the clements which enters into its organization.

In this respect Professor Sanson ${ }^{1}$ says, "The actual work which it aceomplishes is utilized according to two general modes. The displacement of mass which performs this work is effected either at the slow gait of the walk or the fast gaits of the trot and the gallop. To abbreviate, we will name the first work en mode de masse, or force, and the second work en mode de vitesse, or speed. In the one as in the other of these two modes, the burden to be transported may be a mass disposed indifferently upon the back of the motor, or upon a vehiele to which this motor is attached and which he pulls."

We must therefore determine what charaeters of the external eonformation should be songht for to choose in the best conclitions the horse destined to work either in the mode of force or in the mode of speed, or in these two modes at the same time. We shall also have to say a few words concerning the mamner in which the nervous foree, the excitability, is clistributed in each of these motors, and of its useful or harmful influence upon the final result, according to its degree of richness. 


\section{A.-Conditions of the Motor en Mode de Masse, or of Force.}

The subjects intended for this kind of work are vulgarly known by the names heary dreught-horses, horses of force. Their value is proportional to the burden which they are capable of displacing, at the slowest gait, by the contraction of their muscles. Let us see upon what depends the intensity of this contraction, and what exterual signs denote it.

A muscle is a particular group of red fibres, collected in bundles ordinarily parallel, decomposable by histological analysis into very fine fibres endowed with special irritability and contractility. In the physiological state this property acts under the influence of a stimulation proceeding from the nervous centres; it shows itself by a more or less marked, energetic, and rapid diminution of the length of the primitive fibrilli. Comnective tissue isolates and at the same time conjoins the elementary parts of the muscle; abundant vessels (arteries) carry to it materials for its mutrition and its activity; others (veins and lymphatics) carry away the wastes of its functional activity; finally, whitish cords (nerves), terminating in its mass by numerous filaments, veritable conductors, connect it with the nervous centres, and transmit to it the motor stimuli from the will. These last reach the organ in sucls a way that all its elements contract simultaneously, producing, by this very means, a total shortening of variable extent.

The weight susceptible of neutralizing the movement which results from this gives the measure of what is vulgarly called the contractile force of the muscle. Whence it follows that the force of a horse, in relation with a determined effort, would be also approximatively indicated by the total or the sum of the individual actions of the agents which accomplish this effort. In other words, it would be the weight which he is apt to more in conditions when the speed appears insignificant, although, rationally speaking, it is never thus.

In this case, we see, force is created at the expense of speed; in fact, we do not regard as important the quantity of the space passed over; it is sufficient for us that the animal moves the obstacle.

Now, the manifestation of this phenomenon obeys the two following conditions:

1st. The number of the contractile elements, and the particular nature of their incidences upon the locomotory levers.

2d. The intensity of the nervous stimulation.

All things being equal, it is plain that, of two muscles whose fibres have the same force, the one which has them in donble quantity will be twice as strong as the other. It is none the less evident that if, by some mechanical disposition, one of these muscles is placed in a condition to act in a more perpendicular direction, it will do its work casily or will be able to overcome a greater resistance.

As to nerve stimulation, physiology taches that it reaches the 
contractile organ by fractional portions, at equal intervals, and in very close succession. But it is certain that the intensity of these portions and the rapidity of their succession have an influence upon the value of the effort to be produced. With regard to this, every one knows the preponderance of the will over the energy of physical exercise. We will see further on, in speaking of endurence, that the individual differences bearing upon this influence are extremely variable. For the present, we will confine ourselves to proving the necessity of an intense nerve stimulation in those motors which have to work en mode de masse, or perform force labor.

This being said, how shall we appreciate the two preceding data in the examination of the external form? This is casily answered: by the mass of the muscles, or, if preferred, by the approximative estimation of the weight, which is generally proportional to the former; afterwards by the quantity of blood possessed by the animal examined. When speaking of the mass of the muscles, we mean the surface of their transversal section, which is the more extended as the number of elementary fibres is itself greater.

These are the two requisites which must first of all be found in the motor en mode de masse.

There are still others, which are, however, only the necessary consequence of the latter. Thus, we will seek more particularly an ample, short, cylindrical body, close to the ground, and with strong loins; solid, thick, and wide members; a base of support a little wide, to give more stability to the equilibrium; developed extensors, for it is by the extension of the locomotory columns, vigorously propped upon the ground, that the animal moves his burden; such are the cervieal, dorso-lumbar, scapular, peetoral, olecranon, antibrachial, gluteal, crural, and tibial muscles. We must make sure of their compactness and their density, the width and the thickness of the articulations; the approximative length and foree of all the osseous prominenees: the trochiter, olecranon, trochanter, calcanens, ete.; the perpendicularity of the muscular insertions, from a suitable inclination of the locomotory segments; the delicaey of the skin; the expression and vivacity of the plysiognomy; finally, the ease, the energy, and the power with which the subject will accomplish his work, will bear his collar, as it is expressed in ordinary language. 


\section{B.-Conditions of the Motor en Mode de Vitesse, or of Velocity, Speed.}

We include in the category of motors suited especially for speed all saddle-horses, carriage-horses, and light dranght-horses, whose habitual gait is the trot or the gallop. Here the object to be aceomplished consists in the distance which the animal, burdened with a slight weight, is eapable of travelling during a mit of time. As to the quantity of movenent, $m e$, it remains the same as in the case of working lyy the weight of the mass, only the factor $m$, mass, is reduced as much as possible, while the factor $r$, velocity, which we wish espeeially to utilize, is thereby correspondingly increased.

Now, the rapid moving of the centre of gravity over the surface of the soil is absolutely dependent upon the two following conditions:

1st. The length of the strides.

2d. The number of strides taken during a unit of time.

The extent of each step is itself the consequence of several secondary mechanical dispositions already known, and upon which it would be useless to insist. It is, primarily, the absolute length of the columns of locomotion which renders them more apt to span over much ground; it is, secondarily, the considerable length of the muscles belonging to the superior regions of these colmmns and commanding their displacements; finally, it is the particular orientation of the articular angles, permitting the osseons segments to pass more freely over the space in the direction of the movement without losing force in raising the body.

As to the number of steps, it depends exclusively upon the rapidity of the muscular contractions, - that is to say, upon the energy possessed by the animal, upon the intensity of his nervous stimulation, and upon the time during which he ean renew them.

But one feature which it is important to take into consideration when speaking of the conformation of fast motors, is the light weight of the borly. M. Sanson ${ }^{1}$ says that "heyond a certain werght they ean no longer be ntilizable, since the strength which they dispose of is just sufficient to move their own mass about. ... It is, then, no wonder that the heary French cavalry horse has nerer been able to endure the hardships of a campaign if at all prolonged, and that cren when in garrison their mortality is 50.57 per thousand, whilst that of the light eavalry horse is only 23.39. . . . The smaller and lighter saddle- 
horses are the greater will be the ratio of their actual work. The light cavalry of Africa has for a long time furnished us with a practical proof of this. Cavalrymen, chasseurs, or spahis do not weigh, as a rule, less than the dragoons; a large number of them weigh as much ats the cuirassiers. In all the campaigns in which they have taken a part with the dragoons and the cuirassiers, in the Crimea, Italy, and France, the ehasseurs' horses have always borne the fatigues of warfare better than the others, whilst being employed in a longer and more severe service. . . . It is therefore very injudicious, in the selection of eavalry horses, not to lower the minimum of size now exaeted to the limit of that which is necessary so that the horseman may retain his seat, even though the latter has to be raised by some such device as that practised by the Arabians, the Cossacks, the Hungarians, ete. The cavalry of these people has always been the most durable and the most indefatigable of all, preeisely because it is eomposed of very small horses.

"The large and heavy saddle-horses, besides being so difficult to obtain sound and well formed, render the poorest service in the eavalry. They should be reserved as pleasure-horses, which have to perform but very little work. In such service they are well nourished and surrounded with the best care, and their prineipal function is to satisfy the self-pride of the wealthy who use them."

The race-horse (the English thoroughbred) has been, until the present time, the most successful variety which human industry has developed with reference to speed as the main quality. The principal characters of his conformation are useful to us in distinguishing our rapid motors from among all others. They shonld, in fact, have high chests and members; short and well-supported body and loins; neck, shouleler, croup, thigh, buttoek, leg, and forearm long; without too much bulk to the body; strong, dry, and clean members; wide and thick artieulations; they must be closed in their superior angles, open in their inferior; have a deep ehest; a small abdomen; skin, hairs, and mane thin; an intelligent, expressive physiognomy; must be graceful, active, excitable (blood), energetic, impetuous, and of an inexhaustible endurance.

\section{C.-Conditions of the Mixed Motor. (Combination of Force and Speed Realized.)}

The improvement of roads, the construction of railroads, the faeility of travelling, and the industrial and eommereial activity of our epoch have rendered the use of draught-horses, capable of 
moving at a certain rate of speed, more and more possible and necessary. It is rightly said, at the present day, that time is money. It is preferable to lessen the weight and multiply the number of animal motors to effect large transportations, and compensate, by the distance travelled over, the expense and maintenance of a larger number of animals. Heavy horses whose weight reaches 900 and 1000 kilogrammes will very soon be a rarity; they are reserved for hanling those heavy burdens which can be moved only at a walk; their high price, besides, bears witness to the difficulty of their production and to the competition carried on against them by the lighter varieties. Among the latter it has been attempted to establish a sort of happy medium by the combination of the principal elements of the heary dranght-horse with those of horses which possess considerable speed. The two factors of the quantity of movement, mv, supposing that they be comparable at all, have been practically calculated in such a manner that one of them should not, in the product, predominate over the other. This problem, so complicated in its material realization, has been resolved with much sagacity by our French breeders; we have as evidence those magnificent specimens of our Percheron race, of the Breton race along the coast, and even the Boulonnais horse, which large manufacturing concerns use so extensively all over the country.

The principal distinction between the mixed motor and the two preceding is a mass relatively large, supported by a strong and almost slender set of members; the furmer is the elements of strength (volume of muscles) acting upon the machinery of speed (length and direction of the bony segments). The body, less voluminous, less close to the ground than that of the slow, heavy draught-horse, is more powerful and more muscular than that of the race-horse; the members, longer and their bones more inclined than those of the first, are, on the contrary, shorter, less oblique than those of the second.

Strictly speaking, two types of conformation may be recognized in the category of mixed motors: the one, light draught-horses, finer, more energetic, and more active, especially resemble coach-horses; the other, fast, heavy draught-horses, which are more common, heavier, and slower, would, on the contrary, have more affinity with the slow draught-horse. In cach of these cases the habitual gait is the ordinaly trot, but the short trot of a speed almost below the mean for animals whose weight approaches 700 kilogrammes; it is a little more elongated for those whose weight is close to 500 kilogrammes.

We cannot indicate in a precise manner the conformation of the mixed motors on account of the numerous varieties which they present. 
In the study of the regions, we have taken care to insist upon the disposition of the angular openings and upon the proportions of some of their parts, principally of the neck, the shoulder, the arm, the eroup, and the thigh. We therefore refer the reader to them. But there is a danger against which we desire to warn him: it is in endeavoring to lighten and improve these animals by erossing injudieiously with races which are too distinguished, too fine; a certain number of subjects have been produeed which are lauky, defieient, especially in the length of their loins, the slight amplitude of their ehest, and the weakness of their members. Of course, this defect is not of a nature to cause them to be entirely rejected, sinee, for their intended utilization, they are not called upon to arry heavy loads. However, they none the less become sway-backed; as they are used on the paved streets of large eities, their locomotory apparatus will very quickly manifest its weakness by the appearance of numerous blemishes, and by an early ruin of their hocks and their fetlocks. For these reasons, the purchaser shonld give preference to those motors which are short, more compact, and closer to the ground; with the same speed as the others, they possess superior endurance, will do more work and at less expense.

\section{D.-Excitability ; Impressionability ; Irritability.}

The normal relations which exist between the living matter and its animating principle, between the physical bulk and the blood, as it is expressed in vulgar language, are not equally balanced in all subjects.

Excitability-that is to say, that faculty which the organism has of showing to the desired degree its activity under the influence of the internal stimulant, the nervous system-is of primary importance as the indispensable complement of its mechanism, however perfect it may be, for this faculty render's it eminently adapted to all the exigencies of the external world. The animal which possesses marked excitability ean at once be recognized by his intelligent physiognomy; his affectionate character ; his expressive head ; his delicate, supple, and vaseular skin; his hard hoof; his silky, not overabundant, mane; his slender, harmonious form; his powerful chest; his firm, dense, well-outlined muscles; his neat, clean, strong, solid members ; his small, proportioned feet; his easy, lengthened, brilliant gaits. Gentle and quiet when at rest and during work; active, energetie, even impetuons, if necessary, always docile; of a robust constitution, well nourished, adapting himself without diffieulty to the most diverse conditions of existence, he is prompt to begin his task, able to keep up, and ready to resume again on the morrow the work of the day before. 
But nervous excitation is not constantly distributed throughout the living machine in such a way that its manifestations are in exact equilibrium with the resistance of its machincry. Two opposite defects, equally prejudicial to the proper action of the motor, result from this, for they both restrict the play of the means at its disposal.

If it is the blood which predominates over the common element; if, as it is also said, the animal has too much bloorl, the effect exceeds the aim; the physiological excitability is too intense, too active; it becomes impressionability to a more marked degree, iritability, or, in other words, an extreme suseeptibility, an excessive reaction, sometimes dangerous in the presence of even the slightest external impressions. "This great nervous excitability," M. Sanson ${ }^{1}$ says, "has none but practical disadvantages, contrary to the opinion entertained by horsemen, who, through their ignorance of physiology, believe too easily that courage can take the place of strength, or that the latter has its sourec in the nervous system. No doubt, for a short time, the manifestation of this conrage is brilliant and may be seductive; but the brave animal wears himself out with it; he soon exhausts the true source, poorly sustained, of his strength and wears out his insuffieient mechanism. It would be better for a useful employment of his power, for an cconomical utilization of the capital which he represents, that he should be saving of both,-be less courageous, and render less brilliant but more lasting services.

"Among horses descended directly or indirectly from race-stallions of thoroughbred blood, there are by far too many subjects of which it is said that the activity of the nervous system is too great for that of the body."

Vallon adds ${ }^{2}$ that "in such a case the forms are angular; the members long and slender; the articulations narrow; the muscles well separated from each other, but sparingly developed; the tendons dense but of little volume; the horn dry and brittle; the skin delicate; the ribs flat; the head expressive, ete. When coming ont of the stable the horse performs disorderly movements, jumps, skips, is all excitement. In the drill and in the parade he tries to pass his neighbors. He is of a delicate disposition, requires choice food, water of good quality, ete. For all these reasons the horse beeomes quickly tired, exhansted. Often, after a day's march, where he has toiled a great deal, he is quite brok'n down, and should he be needed he can be of no use. After a day's work some of these animals lie

1 A. Sanson, Traité de zootechnie, 2e éd., t. iii, p. 197.

2 Vallon, Cours d'hippologie, t. i. p. 457. 
down, refuse to partake of their ration, and for several days are not in a condition to resume their service." If, on the contrary, the common clement predominates over the blood, there is a lack of physiological excitability. The setting-up of the machine may still be good, its substance of an excellent quality, its meehanical arrangement harmonious, but the stimulant is defective. Although endowed with a certain stamp of fineness and some appearance of energy and vigor, the subject, according to a vulgar expression, is a good-looking swindler; he is the picture-horse of the dealers. If he be more common still, his form, although regular, is heavy, fleshy; his muscles voluminous but flabby, containing a large quantity of connective tissue or fat; his skin is thick; his hoof soft; his temperament lymphatic; his gait indolent; his physiognomy withont expression; his extremities are common; his hairs and mane abundant, stiff, coarse; his feet voluminous, badly conformed; he is without reaction, without ardor; at each moment he must be urged on by words, whip, or spur; finally, he endures fatigue and privations poorly; he is a wretehed servant, eating much, often sick, and on the whole, renders a service, entirely unsatisfactory.

\section{CHA PTER III.}

RESULT OF BEAUTIFUL PROPORTIONS UPON THE ANIMAL MACHINE.

Resistance to fatigue: endurance. Every animated motor, from the artion of its machinery and its organs, is capable of producing certain effects, developing force, speed, or both at the same time, and of manifesting its activity more or less easily according to the nature and arrangement of its principal parts. But it is important that its effects be combined in such a way that man may be able to employ them economically, - that is to say, in all their intensity and for the longest time possible. In a word, it is necessary that they terminate, through their reciprocal concordance, in a useful and durable mechanical result: to the latter has been given the name endurance.

Opinion of the Laity upon Endurance. - In ordinary language, endurance, like the temperament and the blood, is that, in a manner, mysterious, concealed, hidden faculty which one animal seems to have in reserve, and by the aid of which he resists fatigue better than another horse. This occult power arms him for the 
fight, endows him with his most essential qualities, and manifests extemally his power and his vital equilibrium; it is this accumulated, inappreciable quality of which we can judge only by the greatness of his abilities and the superiority of his attitudes. It is therefore constantly opposed to the form, even as fitness is contrasted with beanty, the contents with the container, the true with the false, the solid with the brilliant, certainty with illusion, talent with knowledge. Form and appearances are often deceptive; without endurance they are always so; the horse becomes tired all the sooner as he possesses less of it, and works all the better as he has more, precisely like the daylaborer, limited against his will in his enterprises, if he be compared to a capitalist, whose greater power of action is due to his possessing a greater number of available resources.

Such is the notion possessed by the mass of people upon this subject. It is reduced, as we see, to the pure and simple statement of a result without any attempt to examine its nature. We feel that the question is a difficult one, that its data are numerous, complex, delicate, and profound; but, through the ignorance existing at the present time, a primary cause has been substituted for the secondary ones, and, as in many other embarrassing questions, in default of being able to surmount the difficulty inherent to the determination even of this primary cause, we lave been satisfied with a word in which truth, prejudice, errors, everything has been snmmed up: cndurance! This word no more interprets the phenomena which it aims at conveying than the conception of the soul explains psychical facts; that of force, movement; that of life, living organisms; and no more than, within our own domain, the conception of blood explains energy and ardor. The time has, however, come for exacting more, and penetrating decper, by a methodical analysis, into the very essence itself of things.

Work.-First, what is work?

To work is, essentially, to overcome a resistance, an action which is defined in two ways, either as a force acting over a certain space, $F$; or as mass moving at a certain veloeity,

$$
W^{\prime}=\frac{1}{2} m v^{2} .
$$

In animal mechanies, the first of these two formule, $F s$, is generally not very conveniently employed, because it is always very difficult to estimate practically one of the factor's of this product, the force $F$, or muscular contraction.

The second formula, on the contrary, much more precise, shows us, 
in fact, that work increases in proportion to the mass, whilst it angments as the square of the velocity. This is equivalent to saying that if the mass be increased 2, 3, 4, 5 times, the work is rendered 2, $: 3,4,5$ times greater, whilst if the velocity be modified in the same degree, the motor would accomplish a work 4, 9, 16, and 2.5 times greater; an important idea, already foreshadowing the fact that an animal employed at speed will be alsle to endure the frequent repetition of the effort only during a relatively limited period of time.

Fatigue.-On the other hand, what is fatigue? Littré ${ }^{3}$ defines it a painful sensation aceompanied by a diffenlty of exertion, and eaused by execsive work. Now, as this feeling is manifested by a cessation of locomotory activity, which, as is known, is the immediate consequence of the eontraction of the muscles, it follows that to obtain a correct conception of the nature of fatigue we must previonsly reall, in a few words, the physiological conditions of muscular contraction.

Muscular Contraction.-The fundamental property of a muscle, as we have seen, is the power of contracting under the infuence of certain stimnli. In the organism, it is the nervous system which presides over every contraction; but its rôle is facilitated or retarded according to different conditions. Thus, it is proved that contractility is increased by an active circulation of the blood, by the presence of oxygen, a moderate temperature, a proper rest, ete. It is slackened or diminished by diametrically opposite causes, an arrest of circulation, carbonic acid, lactie acid, cold, prolonged inactivity, excessive functional activity, etc. During the physiological contraction the nervous impulses are communicated to a muscle intermptedly, but, at the same time, to all its elements, in such a manner that the organ is shortened proportionally to its length, and with a power which depends upon the number of its primitive filsres. But under the influence of fatigue the contraction becomes slower and less energetic. Similar effects are produced by cold and all interferences with a free circulation. Whilst the muscle is contracted it hecomes acid, consumes oxygen, hydrocarbon principles, and, in defuult of these, albuminous substances; its circulation increases, and the renous blood is much darker. Its chemical composition is also very different from that of the inactive muscle. There are formed carbonic acid, lactic acid, urea, creatine, as well as other azotic and non-azotic waste products; all of them results either of oxidation, or of a particular fermentation, or, finally, of a pure and simple disassociation of the elements which the muscle had assimilated and which constitute the complete aliment.

However this may be, the products of respiration and muscular contraction have to be reabsorbed by the veins and the lymphatics, without which the organ becomes overloadecl and loses its contractility.

Muscnlar contraction, to he produced, requires, then, a supply of blood and an excitation; to he continued, it implies a free, active circulation, and a sufficient amount of the exciting principle. As the proportion of waste is proportionate to the rapidity, the intensity, the duration, and the repetition of the con- 
traction; and as, on the other hand, the work of depurating the muscular system devolves upon the circulatory apparatus, the economy must be provided with the special organs through which the blood can eliminate with facility the products of tissue-change with which it is burdened.

These are the organs which Professor Baron ${ }^{1}$ calls automatic cleansers. By their intervention the living machine is cleared, without its knowledge, of what its functional activity would clog it with. Such are the lungs, the external and internal tegumentary surface, the different cutaneous glands, and the kidneys.

From what has been said it results that prolonged exereise is always aecompanied by an expenditure of food, of blood, and of nervetissue, by an increased circulation, by an acceleration of respiration, by a rise in temperature, and, finally; by a greater activity of the lifferent emunctory surfaces, principally the sudorific glands and the kidneys.

Cessation of Locomotory Activity.-The above principle being admitted, it is plain that the cessation of locomotory activity will be due to the indirect influence of one of the two following causes: the animal will stop either from nervous exhaustion or from an excessive accumulation of waste proluets in the muscles (as was said above, by the clogging of his muscles).

Nervous exhaustion evidently varies according to the quality and the abundance of force-accumulation of the cerebro-spinal srstem and the way in which the nerrous foree is expended. All subjects, as we know, are not equally gifted in this respect; but, as to equality of blood, it is certain that the more the contraction is sudden, intense, prolonged, and repeated, the more will the exeiting principle of the organism diminish and the quicker will it reach its last limit. As to muscular aceumulation of waste products, it is cansed by the insufficieney of the emunctories, the circulatory, respiratory, urinary, and sudorific apparatus. Sometimes the blood does not carry away the cxcretions as rapidly as they are formed; sometimes it is not thoroughly purified in the lungs, the kidneys, the sudorific glands; sometimes, finally, it is not rich enough in primary constituents. Then one of two things will ocenr: either it returns to the muscle still loaded with waste materials, - - that is to say, with products which cause the latter to lose its eontractility, - or it reaches it not properly provided with the substances (oxygen and other musculair aliments) withont which this quality cannot be put into action. In each of these cases locomotory activity is diminished and prevented, even by the fact of the functional unfitness of the organs whose co-operation it necessarily requires. 


\section{Conditions of the Economical Production of Work.-} Let us attempt now to determine what must be exacted from the motor, in order that he may produce, in the best conditions, the greatest amount of work with the least possible fatigue. In other words, let us sec under what eireumstances the work will be the least onerous for the animal, and therefore the most economical.

Professor Baron' has well explained this important question. In his opinion resistance to fatigue is more or less a function of the following conditions:

a. A powerful faculty of dynamic accumulation of the nerro-muscular system, -blood.

b. Innate or acquired ability of the muscular fibre to make use at once of the nervous or plastic elements (excitable, firm, dense muscles; rapid reflex action).

c. A good construction of the members and beautiful proportions (perfection of the mechanism rendering it fit to act with force, ease, precision).

d. Innate or acquired ability of the organism to rid itself quickly and thoroughly of the waste materials through its emunctories (spacious, active lings ; surface of the body relatively extensive).

e. Facility of the locomotory apparatus to execute easily cortain movements (training of the horse; cconony of force and time for the excention of a determined work).

$f$. The quality of the food and that of the tissues, both of which tend to lessen the formation of the waste matters or permit the organism to rid itself of them at shorter intervals (substantial food of little bulk; a good assimilation).

The horse which will answer best to all these conditions will also be able to perform the greatest work and resist for the longest time the fatigue which results from it.

Endurance in Different Kinds of Animal Motors.-Does endurance offer the same interest in horses of force as in those of speed? Incontestably it does not, and it is not difficult to understand this. In animals which are utilized only as force factors the muscular contractions are slow, inextensive, not frequent, and of an intensity rarely excessive. Their work increasing in proportion to the weight to be displaced, their speed is always very ordinary. Consequently, their expenditure is never very great in ordinary circumstances. When it becomes so,- for example, when they have to ascend an acclivity or 
to pull upon soft ground,- their muscles have time to depurate themselves and their lungs to oxygenate the blood which flows throngh them, withont the difficulty of breathing being exaggerated. Hence it requires a long time to produce fatigne in them, and their work can continue for a considerable time, - ten, fifteen, and even eighteen hours a day,-provided they are properly nourished. Nervous exhanstion is almost the only thing that requires a certain amount of reparative rest; besides, the necessities of daily labor oblige both animals and people to interrupt their work at certain hours, principally during the night. Hence it is very seldom necessary to work the draught-horse to the utmost extent of his powers of endurance. However, this does not always imply, as De Curnieu humorously says, ${ }^{1}$ that it is foolishness to speak of the inexhaustible endurance of horses which have no speed, or which go long distances at a slow pace. On the contrary, it is important to know exactly what these animals are capable of doing at a certain moment in view of unforeseen circumstances which may happen at any instant. Where is the teamster who has not become stuck in the mud after a rain-storm, brought to a stand-still by a slippery pavement, an accidental snow-storm, a frost, a rather steep and slippery slope? Which of them has never been left on the road, discouraged, obliged to go for additional horses, despairing of overcoming the obstacle with his own team? Who, finally, being confident of his team and convinced of their vigor, has not come out victoriously from the trial by suddenly imposing upon them an excessive labor? These facts are too common and too well known to dwell upon. Let us proceed.

But in the horse which is employed as a factor of speed endurance is of the greatest importance, for the work is more considerable, the expenditure of tissne, and therefore the fatigue, greater. The muscular contraction is always extensive, intense, sudden, and repeated; the muscles need much blood, exact a rapid absorption, are quickly exhansted; the lungs should double their activity in order to aroid congestion, effect their interchange with the air, eject their waste products, and absorb the oxygen in sufficient quantity. As to nerve foree, when quickly exhansted, it very soon renders the mechanism unable to perform its work.

"It is the pace that kills!" say the English, those judicious connoissenrs, thus expressing the enormous losses which this kind of work eauses. As the animal can sustain his gait only when endowed with,

1 De Curnieu, Leçons de science hippique générale, 3e partie, p. 82. 
so to sprak, inexhaustible endurance, it is not astonishing to see this quality considered only in fast hor'ses, sinee this is the sine quâ non condition of their utility, therefore of their value.

The External Form as an Index of Endurance.-We have studied the question under most of its aspects; let us now return to the extcrnal form and try to analyze it in so far as it is an indicator of endurance, in order to call the attention of the beginner to the features which will permit him at first sight to recognize that essential quality in the animals submitted to his examination.

We must first consider the muscles. Firm, dense, compact muscles will be sought for; dearly-defined outlines; deep interstices, not filled with fat or conncetive tissue. In draught-horses especially, eare will be taken not to mistake for a genuine development of the muscular system at large that excessive corpulence which results from an aliment that is little nutritive, little exciting, or, again, from that especial preparation which precerles the sale. Small faith must be placed in those thick, clumsy, rounded forms which so often please inexperienced persons, and give rise to an idea of vigor, energy, and power. At the end of a few days all these beautiful appearances disappear, and then, but too late, the error committed is pereeived.

Then the chest, in its length, its height, and its width, as well as the other parts of the respiratory apparatus, will be considered. The horse runs as much with his lungs as with his members, let it not be forgotten. Without good wind he is incapable of accomplishing the least laborious work, for his muscular system, although well disposed, will be quickly overloaded with effete material and soon rendered inert.

Then we must appreciate in what proportions the blood and the coctrse elements exist in the animal, - that is to say, that part of the influence which is exerted by the nervons system, the condenser of that energy which the muscles discharge little by little. Thinness of the skin, the hair, and the mane; bright, expressive physiognomy; cnergetic countenance, mobility of the ears and the nostrils; general sensitiveness, doeility, attention, intelligence, prompt and easy reactions: such are the principal characteristics of distinction, without which he cannot possess great power or endure severe trials.

Finally, the perfection of the mechanism from the point of view of the harmony of the details and of the whole must be ascertaincd. If the muscles, the lungs, and the blood are the active clements of power, they can manifest it externally only through the harmony and the energy of the maehinery of locomotion; one of these elements is of no value without the others, and vice verses. Beantiful proportions 
also furnish us with the degree of functional and reciprocal relation of the parts. By them we judge of the precision of action, the entire utilization of the force, and the longevity of the machine; they imply a resultant which, without them, all isolated effects could not attain.

Sometimes, however, everything seems to be woll adjusted in the horse; vigor, good wind, and energy appear fortunately combined with the elements of form, grace, and elegance; the animal is brilliant, impetuous, all excitement when taken out; in his stepping, his movements, force, and speed he is second to none; and yet, we distinctly state, these fine qualities are only the vain appearances of a fictitions ardor, the eye-deceiver of an imaginary power of endurance.

Similar to a Leyden jar slightly charged, he differs in no way from the subject which possesses true endurance. He is no doubt deficient in something; only this lack is not seen externally, and, on that account, will lead the most skilful into crror. He possesses all the materials of power; their fault consists in not being of a superior quality. The organism has not the fine composition indispensable for the constitution of dynamical or vital equilibrium; here it has too little, there too much, elsewhere none at all. In reality, the statical conditions are good; there is sufficient material, whilst there is an absence of certain properties. Lever's, muscles, nerves, blood, and wind exist in sufficient quantity, but not with the necessary qualitics. There is a larmony of forms, there is no harmony of forces, no free outlet for their manifestation. The muscle is irritable, but its contractility is perhaps too exacting; the temperament is sanguine, but is too poor in quality; its composition is wanting in something; the nervous system is well constructed, lut it is not trained for long action; the lung is spacious, but its fundamental elements are poorly adapted for the interchange of oxygen and carbon dioxide, ete. We might go on with such suppositions almost ad infinitum.

Whatever interpretations there may be, no mystery, nothing extraordinary or oceult, should be imagined to exist in this problem. All these effects have their causes, but all enter into the domain of infinitely small factors, as yet unknown to modern science, which judges of them, on the whole, only by their manner of existenee.

To return to our first comparison. Let us again take our Leyden jar. If we touch it, it will be discharged. The moment afterwards it appears the same as it was before, and ret it no longer contains this imponderable electrical fluid, this particular vibratory movement which it is impossible for our senses to take cognizance of otherwise than by its effeets. It is by a fresh electrical shock that we can now distinguish 
it from another charged jar, and thus appreciate the difference of their internal condition ; the simple examination of the external form will be no criterion to us.

The same conditions exist for endurance. Until now, we have considered it only as a total or a product. The study of the conformation may, of course, cause us to suspect its existence; experiment alone is cupable of proving it. Now, among horses (pardon this metaphor) there are so many empty Leyden jars that one is of necessity compelled to touch and to test them, in order to avoid the inconveniences resulting from purchasing them.

Practical Determination of Endurance.-In what way shall we make a practical determination of endurance? Evidently, by suddenly increasing the expenditure and pushing the animal's work as much as possible. In the draught-horse, for example, it can be proved by making the animal pull a heavy load up a hill at a fist walk. In the fast horse, by obliging him to pull or carry a somewhat heavy weight at an unusually fast gait, the trot or the gallop.

It is well understood that these kinds of experiments should never be carried to the point of becoming prejudicial to the animals. Hence, in order to render the experiment less severe, without making it, on that account, less decisive, it is important to examine the condition of the respiration. What takes place in the muscles and, for still greater reason, the nervous centres camnot be seen ; but, as the contraction supposes a proportionate excitation and circulation; as, besides, the blood before returning to the muscles is obliged to pass through the lungs and to absorb from them as much material as it gives off, the result of this is that the activity of the thoracic bellous is in close correlation with the amount of the work, the quantity of tissue-waste, and the degree of fatigue. It follows from this that difficult breathing shows to the observer the state of exhanstion, and gives him a knowledge of the reserve strength which the animal still has at his disposal. It is true, then, that the flank is to the horse as the manometer is to the steam-cngine, since it indicates the tension of the functional activity of the horse, as the manometer indicates that of the steam.

As to the nerve conductibility, its feebleness or its disappearance is seen in unequivocal signs on the locomotory apparatus: the muscular contractions are weaker and slower; the efforts diminish in intensity and rapidity; the intervals between the steps are no longer equal and in co-ordination ; the members meet and strike each other ; the gait, at first uncertain, becomes tottering; the head hangs low; the subject becomes more and more insensible to the surroundings; soon he falls in a heap 
and dies at his task. But, before reaching this point, his steps are less frec, heavy, and uncertain; he forges. All these signs should be sufficicnt, and their appearance demands an immediate cessation of the experiment.

\section{Performances or Examples of Endurance.-Veterinary} annals are full of examples showing the feats accomplished by certain horses. It is interesting to become acquainted with some of them, so as to know about how much an animal is capable of accomplishing in certain exceptional circumstances.

We know that at a walk the work can be continued almost indefinitely without exhaustion; we have given the physiological reason for this. However, this gait is sometimes maintained with a remarkable velocity.

De Curnieu has seen, especially, two horses travel 8 kilometres in 64 minutes, and he eonsiders the distance of two leagues in an hour as almost impossible. ${ }^{1}$ This is also our opinion.

Still, Yonatt ${ }^{2}$ relates that in 1793 a hackney mare, named Sloven, travelled at a walk the distance of 22 miles (35 kilometres, 398 metres) in 3 hours and 52 seconds, which represents a speed of 11 kilometres per hour! In the face of such a ease, we may well wonder whether the unsuspecting nature of this estimable author has not been imposed upon, or whether the gait employed was indeed truly the normal walk.

At the trot, De Curnicu considers that 4 kilometres in 7 minutes is the maximum distance which a horse can realize. He asserts that in France a trotter of the first rank alone is capable of travelling over a distance of 7 kilometres in 8 minutes.

We have noted several instances of speed superior to these. Verny, an Orloff trotter, of the Chambaudoin (Loiret) stud, has trotted in harness at the Bois de Boulogne a distance of 4 kilometres in 6 minutes and 14 seconds.

Bedouin, of the same stud, has trotted at Vincennes, October 10, 1881, a distance of 5500 metres in 8 minutes and 41 seconds.

De Curnieu says that " 4 leagues per hour ( 16 kilometres, 10 miles) should be done quite easily, upon flat ground, by any horse of a certain value. . . . To travel 3 leagues an hour on smooth roads, and maintain this speed for 2, 3, or 4 consccutive hours, demands a very good, an excellent horse." ${ }^{3}$

In 1822 , $\mathrm{M}$. Bernard rode on a trot, with his mare, 9 miles (14 kilometres, 481 metres) in 27 minutes and 40 seconds. (Youatt.)

Some years previous, Phenomenon, twelve years old, trotted 16 miles (25 kilometres, 744 metres) in 53 minutes. (Youatt.)

1 De Curnieu, loc. cit., 2e partie, p. 379.

2 William Youatt, History of the Thoroughbred llorse.

${ }^{3}$ De Curnieu, loc. cit, 2 e partie, p. $37 \%$. 
In 1827, General Oudinot rode on a trot at Saumur, on his mare, 28 kilometres in 65 minutes. (De Curnieu.)

Two years later, Rattler, an American horse, was engaged to trot over a distance of 10 miles (16 kilometres, 90 metres), which he accomplished in 30 minutes and 40 seconds. (Youatt.)

Tom Thumb, harnessed to a sulky of 50 kilogrammes, with a driver weighing about 60 kilogrammes, trotted the distance of 100 miles (160 kilometres, 900 metres) in 10 hours and 3 minutes, which is more than 40 leagues! The time taken for feeding having been about 37 minutes, the 100 miles were actually travelled in 92 hours. (Youatt.)

At the gallop, if the distance has reached 6 kilometres, and the speed is very great, the test may be considered one of distance, of endurance. Sometimes the trials are made sucessively with several horses, and then the distance is long; sometimes one horse aceomplishes the whole distance alone, and this is the most common. Here are some remarkable examples :

In 1755, Bay-Malton ran 4 miles (6437 metres) in 7 minutes and 43 seconds. (Youatt.)

Flying-Childers, the fastest horse of his time, had a few years previous run 6761 metres in 7 minutes and 30 seconds. (Youatt.)

A similar speed was shown by Ten Broeck, an American lorse, which ran in 1876, in Louisville, Kentucky, 4 miles (6437 metres) in 7 minutes and 15 seconds.

In 1847 , Renard, 11 years old, and earrying 64.500 kilogrammes, ran over a distance of 9000 metres in 15 minutes and 35 seconds, at Arles.

In December, 1786, Hull's Quibler ran 23 miles, which is a little more than 37 kilometres, in 57 minutes and 10 seconds, upon the circular race-course at Newmarket. (Youatt.)

In 1771, Wilde, in Ireland, with ten horses, rode in the saddle the distance of 127 miles (207 kilometres, 743 metres) in 6 hours and 21 minutes. (Youatt.)

In 1745 , Thornhill accomplished more than this: he rode with several horses 230 miles, more than 370 kilometres (92 leagues), in 6 hours and 21 minutes. (Youatt.)

In 1762 , Shaftne rode on ten horses, five of which were mounted twice, a distance of $50 \frac{1}{1}$ miles ( 80 kilometres, 874 metres) in 1 hour and 49 minutes.

The following year, in 1763 , he wagered to ride on horseback 100 miles a day (more than 160 kilometres) for 29 days, with twenty-nine horses of his own choice. He won this bet by using only fourteen horses, and one day he was obliged to ride 160 miles (more than 250 kilometres) on account of the exlatustion of his first horse. (Youatt.)

Exotic won at Peterloorough a race of four successive trials of 4 miles each, or 16 miles in all (25.74t kilometres).

Finally, to end this enumeration, we will also mention a few more extraordinary foats performed by exceptional subjects, and in which the gait employed has been alteruately the gallop, the trot, or the walk. 
De Curnieu reports the case of a mare of three-quarters blood which travelled a distance of 24 kilometres per hour for $3 \frac{1}{2}$ hours.

The same author grives the account of Schaklari Amdan, an Arabian stallion, which came, it is said, to Alep, from a distance of 600 kilometres, in 40 hours, $\geq 7$ hours of actual travelling.

One of the most severe performances that have ever, perhaps, been recorded conscientiously is that of Sharper, which may be read in volume iii. p. 151 of the English "Stud-Book." This lorse had to travel at st. Petersburg, on A ugust 4 , 1825 , a distance of 75 rersts $(80,100$ metres), a little more than 20 leagues, against Cossack horses from the Don, the Black Sea, and the Ural. He alone finished the race in 2 hours and 48 minutes! And yet the horses he ran against were famous competitors.

Verny, a Russian trotter of which we have already spoken, won, in 1879, a famous race against an English horse; harnessed to a carriage, and mounted by two persons, he made the distance from Paris to Rouen, 128 kilometres, in 9 hours and 5 minutes. His competitor died on the road; he himself, from want of eare, died the next day.

Youatt relates that a hackney-horse travelled the enormous distance from London to York-that is to say, 196 miles (more than 315 kilometres)-in 40 hours and 33 minutes.

He relates, also, that a man, in 1827 , made a small Hungarian horse travel the distance of 95 miles (more than 152 kilometres) while keeping up with the Limerick stage.

Another man is said to have started at the same time as the Exeter mailcoach, upon a Galloway horse 1.40 metres high, and to have reached Exeter a quarter of an hour before the mail, having travelled 172 miles (more than 276 kilometres) at a rate of more than 7 miles (11 kilometres, 263 metres) an hour.

A Galloway horse also travelled, in 1754,100 miles a day (160 kilometres, 900 metres) for three consecutive days. (Youatt.)

It wats also a Galloway horse which accomplished, at Carlisle, the extraordinary feat of going 1000 miles (1609 kilometres, or 402 leagues) in 1000 hours ( 41 days and 16 hours). (Youatt.)

Finally, recently M. Prienr de la Comble, left Lunéville on the $3 d$ of April, 1S82, upon a Hungarian mare, the Mascotte, and reached Paris three days after, having gone over 385 kilometres, which is the distance between the two cities, in 72 hours. Our friend, M. Bizard, who knew this mare, assured us that her owner could certainly have made the distance in 50 hours if he had wished to do so, the Mascotte sustaining with the greatest ease periods of trotting of 30 to 40 kilometres.

These instances are sufficient to show what feats the horse is capable of performing when he is endowed with those incomparable qualities which constitute endurance. But, however marvellous these examples may be, they do not equal those which man, as a pedestrion by profession, has already given.

The weekly journal, The Field, which is published every saturday at London, and which is an anthority on such matters, has given us the three following facts:

1st. Mr. Rohert Vint, of American origin, accomplished, in 18\&1, a journey of 578 miles and 605 yards (about 930 kilometres, 721 metres) in 144 consecutive hours, - that is to say, in 6 days. 
2d. Another American, Mr. Fitzgerald, travelled 582 miles (about 936 kilometres, $6 I 2$ metres) in the same time (1+4 hours).

3d. Finally, an Englishman, Mr. Hazael, established a new record, February 27, 1882, in New York, travelling the prodigious distance of 600 miles and one lap (about 965 kilometres, 580 metres) in 144 consecutive hours, which corresponds to a distance of more than 100 miles per day, continued during six days, at a medium speed of 6 kilometres, 706 metres per hour!

It is useless to detail any more instances to prove the superiority of the endurance of man To formulate the problem otherwise: no horse could go, for example, from Amiens to Marseilles, passing through Paris and Dijon (or 994 kilometres) in the six consecutive days. This, however, is about the distance realized by Mr. Haziel; upon a tan-bark track, it is true, and uncler special circumstances, but this does not prevent it from being a very astonishing performance.

\section{Its Aggregation acting as Mechanical Individuality.-} Endurance of a Troop in Campaign.-Until now, we have examined endurance in a single individual. It would seem interesting to us to speak of this precions faculty as seen in a certain number of subjects, whose synergetic actions should result in a general determined movement. We will consider, in other words, its aggregation or its sum total, in a certain number of animals, acting as a mechanical individuality, to formulate the conditions which are the most unfavorable for the production of fatigne, and therefore the most advantigeous for an economical aehievement of the work of the mass.

This particular point of view finds its application in the question of knowing how to proceed in order to obtain from a troop in (ampaign the greatest amount of effort on the part of those which compose it.

General Bonie ${ }^{1}$ has treated the subject practically, and with numerous experiments for its support. As most of his statements constitute very wise general indications, we consider it our duty to give a resumé of them.

This worthy officer estimates that the eavalry horse should move at a walk at the rate of 1 kilometre in 10 minutes, and can thus traval 48 kilometres in 10 hours, interrupted by 2 hours of rest.

The trot should he made at the moderate rate of a kilometre in about 4 minntes and 15 seconds, if the mard is to be continued for a long time. All the horses follow in this manner, proviled, nevertheless, that they be walked in ascending or descending steep hills, so as to avoid womnds and falls. But it is evident that this gait eannot be

1 T. Bonie, Fond et ritesse d'une troupe de cuvulerie en campagne, Paris, 1872, chez Amyot rue de la Paix. 
prolonged beyond a certain limit, for all effective companies, more or less incongruous with regard to their composition, scarcely comprise more than one-fourth of good subjects.

It is important, then, to combine the walk and the trot in such a way that the animals may recover their breath.

Experience demonstrates, in this respect, that few horses forge before having travelled a distance of 1500 metres at a trot; if this pace is pushed farther, the number of those which make this noise will increase without cessation. The result will be that the walk must be resumed at this moment. Let us, then, examine the lungs; we will see that 5 minutes will be necessary for the respiration to become calm, normal, and again permit the horse to trot. A distance of 1500 metres, followed by a walk of 500 metres, alternately repeated, is, then, the combination which will furnish the most prudent pace.

The number of halts is also to be taken into very serious consideration. We know that their object is to rest the horse by unloading him of a part of the weight which he carries (the rider) and by the cessation of all work. They permit also a readjustment of the harness.

General Bonie says that in times of peace the horses should be walked at the first start 1500 to 2000 metres, in order to train the animal and prepare his organs for more rapid movements. Then a trot of 1 kilometre will be made. The walk will be resumed for 5 minutes, to be followed by a second kilometre at a trot. A five-minutes' walk will now re-establish the normal respiration. This will be the time for the first halt. At the end of 5 minutes, the walk will be resumed for from 500 to 600 metres, after which the trot will be used. If the ride does not exceed 28 kilometres, two halts will be sufficient: one at 5 or 6 kilometres from the place of starting, the other at 10 kilometres from the place of arrival. Above 28 kilometres and up to 50 , almost the extreme limit of our rides between the two halts spoken of, a third one will be made midway, and the riders dismount for a quarter of an hour to allow the horses to rest. The horses should not be allowed to trot within 2 or 3 kilometres of their destination, in order that they may be calm and dry on their arrival. The velocity of the march will thus be 8 kilometres per hour, including the halts.

In times of war the distance travelled over should be:

\begin{tabular}{|c|c|c|c|}
\hline \multicolumn{4}{|c|}{12 kilometres in 1 hour. } \\
\hline 22 & " & " 2 & ours. \\
\hline 32 & " & " 3 & " \\
\hline 40 & $" 4$ & " 4 & "6 \\
\hline 45 & “ & “ 5 & “ \\
\hline 54 & " & "6 & "6 \\
\hline 60 & "4 & " 7 & $"$ \\
\hline
\end{tabular}

1 hour and 20 minutes of rest, divided into six halts.

Then a rest of 4 or 5 hours will be taken, after which a march of 60 kilometres could be completed in 10 hours, at a walk, with 50 minutes for five halts made every 12 kilometres.

Concerning the gallop, the troop being supposed to rim upon smooth and firm ground, and not to have done any work on that day ; under these cireumstances, the following is what it is able to accomplish : 
For a distance of 1000 metres and less, they can travel very fast from the starting-place. For longer distances, it will be indispensable that the charging gallop be run only in the following proportions :

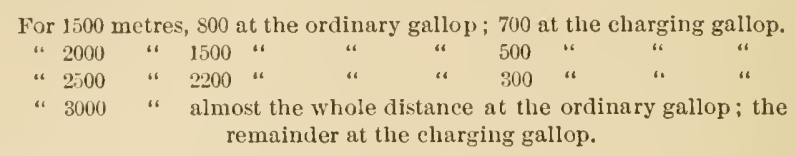

For 3500 metres, an ordinary gallop for 2000 metres; the remainder at a gallop of 500 metres per minute. The rate camnot increase just before the arrival.

For 5000 metres, the gallop is slackened for the whole distance. No charge is possible upon the arrival.

"After 1000 metres of charging, it will be necessary to stop or resume the walk, because the lungs are engorged, but the muscles still have enough vigor to act. From 20 to 25 minutes will be required for the respiration to return to its normal state, but, after 10 minutes' rest the animals can start again and with still enough freedom of respiration to go a distance of 400 to 500 metres with great speed; or, if the ordinary gallop is sufficient, 1200 to 1500 metres, since the charge exacts a triple expenditure of strength. After 10 minutes' rest, a third charge may be made of from 300 to 400 metres.

"After a journey of 3500 metres at a gallop (medium speed 7 minutes), the museles and the lungs are tired out. The animal is, however, very capable of galloping again, but he will feel it the following days. Fifteen minutes after this journey the animal is calm and in normal condition.'

"During a journey of 5000 metres at a gallop the maximum power of the horse has been called into activity. It is the work of a whole day. Nevertheless, whatever the fatigne, a cavalry troop can always continue to march at a walk. Twenty minutes after the arrival calm is restored.

"Such is the power of the cavalry horse when at a gallop. As may be seen, it is immense. But we must emphasize the fact that it is often necessary.

"In a campaign we seldom travel over ground which allows great speed, but the divisionary eavalry may be called upon to go long distances at a gallop. As a matter of fact, it should be sheltered as much as possible so long as its eooperation is not needed; it should be 500 or 600 metres from its infantry, which itself is 700 or 800 metres from the enemy.

"If the latter retreat, the interval increases from 300 to 400 metres. At this moment there will be 1700 or 1800 metres between the body of the eavalry and the troops who flee. But to produce a great effect, instead of approaching these troops in front, they should be attacked from behind, and a turn made from 500 to 600 metres at a gallop, making a total of 2500 metres, for two-thirds of the horses will not be able to follow at a trot. These 2500 metres will be gone over as much through the fields as the roads, which is equivalent to a gallop of 3500 metres upon level ground."

General Bonie estimates the power which still remains available upon the arrival of the troop, according to the distanees travelled, in the following manner :

He considers that a company of cavalry ean mareh seven hours, 
without any rest other than the halts, at the rate of 8 kilometres, 600 metres per hour. He estimates, in round numbers, that each hour of work represents 7 kilometres at a trot, 1900 metres at a gallop, or 450 metres at a charge. One or other of these distances may be travelled, at the corresponding gait, as many times as there remain hours in which to perfor'm the work. The following is therefore the a vailable power at the end of each ride:

\begin{tabular}{|c|c|c|c|}
\hline \multirow[b]{2}{*}{ Distance. } & \multicolumn{3}{|c|}{ EACH REPRESENTING } \\
\hline & the 'trot. & the Gallop. & $\begin{array}{c}\text { At } \\
\text { the Charge. }\end{array}$ \\
\hline 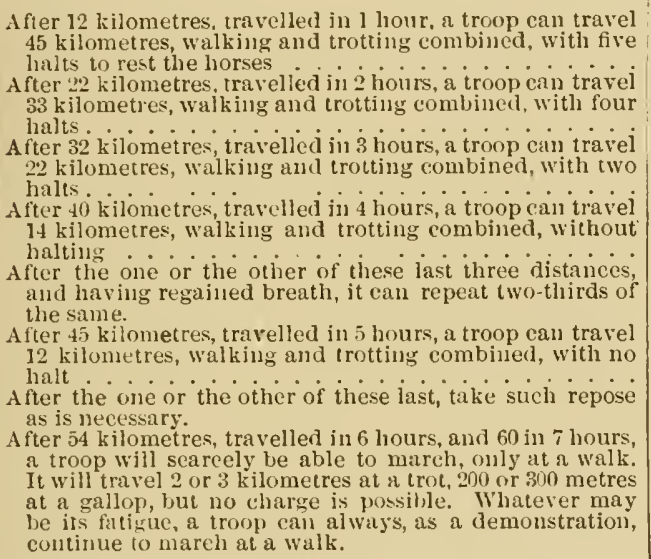 & $\begin{array}{c}\text { Kiłometres. } \\
7\end{array}$ & $\begin{array}{c}\text { Metres. } \\
1900\end{array}$ & $\begin{array}{c}\text { Metres. } \\
450\end{array}$ \\
\hline
\end{tabular}

Finally, the weight carried is extremely burdensome to the troophorse. Under ordinary circumstances, the charge does not sensibly modify the speed, but it greatly augments the fatigne and, consequently, the waste of endurance. The proof of the latter is furnished by a study of the respiration. After trotting a certain number of kilometres, the respirations, in loorses not on a charge, rise to a mean of 60 per minute; in the same subjects, when charging, they attain 74 . Whence it follows that this time of trotting has winded these lorses as much as the same distance wonld have done at a gallop.

General Bonie adds, "In the face of such a diminution of endurance, hesitation is no longer allowable, and the horses should at once be disburdened of their campaign traps. This question is so little appreciated that custom prescribes such a weight that, by considering the undressed rider ats weighing 65 kilogrammes, which is certainly not an exaggeration, and alling the harness, clothing, arms, ammunition, and provisions, it aggregates 152 kilogrammes. 
If the rain increases the weight 10 kilogrammes, an astonishing total of 162 kilogrammes is obtained. How can we make horses run that are loaded twice as heavily as the mules, which only walk? It seems impossible that this rule should not be revised.

"In foreign countries four wagons are assigned to each regiment, and one to each squadron of cavalry, to carry the accessories; why not follow this example? The objection will be made that the wagons cannot always follow; but whilst admitting that they do not immediately rejoin them, cannot the rider, sheltered by his cloak if the weather be inclement, be deprived for two or three days of this supplementary stock of elothing which crushes the horse?

"The increase of power which results from this diminution of weight is really prodigious. With the routine campaign burden a horse expends as much force as does one without such load and moving at a gallop. By relieving him of this difference of weight his power is tripled." 1

Such are General Bonie's general indications. On the whole, in their ensemble, they are perfectly founded. To cite an example, we will say that we have seen, during the Franco-German war (1870-1871), the first squadron of the Eighth Hussars, mounted on Arabian horses, who were ordered into the environs of Chateaurenault, start in the morning at half-past six o'clock and return in the evening at half-past four, having accomplished in ten hours a distance of 95 kilometres without leaving behind a single horse. At the same time, the first platoon of the same squadron accomplished with like success a distance of about 106 kilometres, calculated as accurately as possible.

The preceding indications need not be taken à la lettre as an invariable line of conduct; they are only nearly so, nothing more. The commanding officer should especially adapt himself to circumstances in order to ward off the most pressing difficulties. We therefore give him this information only as a pocket-book jotting; it is his place to appreciate in what degree he may deviate from the statements which it contains, in one sense or the other, according to the nature of the ground, the state of the temperature, its dryness, its dampness, etc.

Endurance considered as an Innate, Acquired, or Lost Aptitude.-A final question prescnts itself, that of the endurance examined as an innate, acquired, or lost aptitude.

If we remember what has already been said above, we cannot at first deny that this aptitude is a resultant whose many effects proceed fron three different sources: the first consists directly of ancestral heredity; the second is the conscquence of training; the third comes from the external medium.

The horse inherits from his ancestors the temperament, the form, 
the constitution, the mechanism, the primary material of the tissues, the blood, and the reflex power of the nervous system.

By training (fumetional grmmasties) he aequires the habit and the ability to work, to economize strength and use it with all its intensity.

Finally, from the medium conditions he borrows the nutriment for his activity and the repairing materials for his incessant losses, as well as that continual influence which blunts the too great suseeptibility of his organism and permits him, already strong and adlapted to resist external modifying causes, to struggle victorionsly against fatigue and privations.

Endurance is composed, then, of two kinds of qualities: the one imnate, more permanent, and stronger, is bequeathed by aneestors; the other acquired, less constant, and also less durable, is the result of that special gymnastics, training.

Now, the horse may lose this prineipal faculty. First, his own reserve stock will disappear, then will come the turn of what he has inherited from his ancestors. And even though the elements of the latter, less transitory, should still remain with him in substanee, we may readily understand how the negleet of eertain elementary precautions might depreciate them or deprive them entirely of their value, in the same manner as those objects of art which are allowed to spoil, or those monuments which are not preserved against the injuries of time.

This is why, throngh want of exereise and partieular care, by an ill-regulated hygiene, the animal becomes weakened, the tissues lose their properties, the artieulations their suppleness, the nerves their excitability, the museles their vigor, and the chest its wind. The horse is now but the shadow of his former self; foree, energy, enduranee, ardor, nobility, distinetion, all those brilliant faculties which he possessed at first, disappear, little by little, never more to returu.

\section{CH A PTER I V.}

\section{DEFINITIVE SYNTHESIS.}

LitTLE remains to be said abont the proportions of the horse. We have indicated in what they consist, and what their isolated or their eombined effects upon the living machine are; we have analyzed with care the details and the whole, shown the importance of each fact in 
particular, initiaterl the reader into the difficulties which the will meet with, and established the principles which it is indispensable to know. Now, we must complete this study by some general reflections upon the method to be pursued in order to properly utilize the ideas which we have presented in the preceling chapters.

Balance of the Good and of the Bad.-Whilst insisting, as we have done, npon a search for beanty, we did not mean to advise the beginner to pursue absolute perfection, ideal becuty. This wonld have been launching him upon a path without issue, and leading him into error from a practical point of view, for that kind of perfection is imaginary. In fact, there is no horse which combines all qualities, for the latter are, so to speak, infinite. But we meet subjects which have many of them, and are therefore relatively more perfect than others. And again, this superiority is a rarity which we must not delay too long in seeking; for we would often run the risk of not attaining it, which would mean a sheer loss of time and money. It is useful, however, to be acquainted with ideal beanty; he who has no knowledge of it allows to pass before his cyes some of the very features by which it shows itself, and this at his expense; since another person, better informed than he, may discorer them.

In every horse we find some good qualities and some faults. In whaterer proportion they are mixed, the animal is never worthless: He always has a value based upon the existence of the good qualities and upon the depreciation which the faults cause in him. It is neecsary, from an economical point of view, to establish this value. By what means can we accomplish this? By weighing the good and the bad. This weighing must not consist in the pure and simple ascertaining of the one and of the other, but in a meehanical and physiological balancing of the two ; it must be the result not of obscrvation alone, but of a careful analysis, a judicious and thorough comparison.

The purchaser camnot be too deeply impressed with this principle, that the fitness of the whole is derived, above all else, from the degree of equilibrinm of its details. If the latter does not exist, the motor is only capable of disconnected efforts ; the greatest part of his force is lost, producing a result injurious to himself and prejudicial and burdensome to those who employ him; it means his more or less immediate ruin, and, in all cases, incompetency.

Compensations. - In order to appreciate the vital and dynamical equilibrium, it is not sufficient to make a simple subtraction, to reckon up separately the beauties on the one hand and the defects on the other, to see which total is in excess, and to judge by the amount of the 
difference. It is necessary, on the contrary, to endeavor to ascertain whether the defects are not compensated by the good qualities, and if so, to what degree this compensation exists.

It is known that, in a locomotive, for example, the velocity depends upon the diameter of the wheels and the number of strokes of the piston in a given unit of time. Now, we ean conceive a machine quite as fast, with sualler wheels, provided the latter are construeted in such a manner that the number of their revolutions redeems what they lose by the smallness of their circumference. It is known, also, that the diameter of the wheels diminishes the conditions of stability. Nevertheless, we can construct a locomotive quite as large and as stable by lessening this inconvenience by a device of some kind which will augment the bulk withont rendering it excessive, or which will bring the centre of gravity nearer to the soil. The piston, whose fore is in relation with the extent of its surface and the intensity of the pressure which is exerted npon it, will be of equal power, although smaller, provided we have a boiler in which the steam ran be raised to a higher tension. In each of these circumstances we have compensations which render the mechanism, if not perfect from a theoretical point of view, at least very useful, economically speaking, since we have snceeded in adapting its wheels, somewhat defective, to the kind of service for which they were at first insufficient.

Likewise, in the horse, it frequently happens that a good quality annuls a defect, or that one defeet may be counterlalanced by another whose influence is diametrically opposite. Let us explain this by some examples. For the sake of brevity, we will present them in tabular form, placing on one side the defects, on the other the principal corresponding compensations. The reader must now be sufficiently familiar with all these facts to spare us the necessity of cntering into details which would lead us too far away. Besides, he always has the opportunity to refer to our descriptions of the regions, in aise he should not be able readily to grasp the value of these compensations.

EXAMPLES OF COMPENSATIONS.

DEFECTS.

Correspondisg CoMpexsations.

Too voluminous hend . . . . . . . Neck rather short, well muscled.

llead too common ........ Ears well placed, eyes expressive, physiognomy bright.

Neck too short .......... Heal light, well attached; withers prominent, shoulder bealutiful.

Withers thick and fleshy ...... High in front, beantiful shoulder and good axes in front. Withers low ............ . IInd-quarters powerful, fore-quarters light, good equilibrium, members strong. 


\section{EXAMPLES OF COMPENSATIONS-Continued.}

DEFECTS.

Back long and sway.backed

Back sliort and narrow ......... Chest high and long

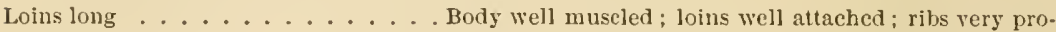
jecting behind: croup oblique; shoulder beautiful : hind-quarters powerful ; fore-quarters light.

Chest marrow ............. . . . . . . . . . . loug, very projectiug backward; intercostal spaces wide.

Chest scarcely low enough ...... Chest wide and long.

Abdomen very voluminous . . . . . Body short and strong, well supported; flanks short, chest spacious, members strong.

Greyhound abdomen ........ Good condition, good appetite, firm, dense muscles, but not too nervous a temperament.

Breast rather narrow ....... . Chest spacions, muscles dense, energetic; good anterior equilibrium.

Breast somewhat wide ....... . Body of rather small volume, gaits easy, not rocking, strong members.

Shoulder short ........... High in frout, withers prominent, neck long, shoulder oblique and muscular, arm long.

Shoulder straight . . . . . . . Body short, hind-quarters powerful, withers prolonged backward and high, neck long and straight.

Arm short and too straight ....... Shoulder loug, oblique, muscular; beautiful neck and withers, good equilibrium.

Forearm a little short ........ Beantiful shoulder, arm long, humero-radial angle large, forearm muscular.

Forearm slender ............ Shoulder and arm muscular, canon short, tendons well detached, good anterior axes.

Canon long and slender, tendous weak. Forearm wide, thick, muscular; members solid, muscular, good axcs; neck well carricd, head light, high in front.

Croup a little short ......... Thigh rather low down, muscular, rather straight; loins short, supported, well attached, fore-quarters light, looks good.

Croup a little oblique......... Iscluium straightened, thigh inclined, hocks good, axes regular, tail well attached, croup long.

Croup a little narrow ......... Croup long, with sides inclined, muscular; loins well attaclied.

Croup too horizontal ......... Thigh long, little inclined, muscular; leg long, good axes, body a little long to avoid forging.

Thigh too straight ........ Croup horizontal, leg long, inclined; good equilibrium.

Thigh thin and short ......... Croup and leg long, powerful; body short, wcll supported, fore-quarters light.

Leg short and too oblique ...... Thigh long, straiglit, muscular, hocks strong, good axes.

Leg too straight .......... Thigh oblique, hocks wide, good axes, body a little long to aroid forging.

Hock weak ............. Leg, thigh, and croup muscular; loins strong, well attached; fore-quarters light, a little low, but of good equilibrium. 


\section{EXAMPLES OF COMPENSATIONS-Continued.}

DEFECTS.

Pastern long
CORRESPONDING COMPENSATIONS.

Ileels high, tendons well detached, good axes, fore-quarters light, withers high, fetlocks wide.

Pastern short ......... Heels low, axes regular, withers high, fore-quarters light.

Heels too low . . . . . . . Pasteru straight, horn good, frog large, sole concave.

Body somewhat long . . . . . . . Chest decp, flank short, body well supported, croup and shoulders long, oblique, muscular.

Body rather short . . . . . . . Members short, Jocomotory angles convenient, gaits easy.

A little low in front.......... Head light, neck long, straight, well at tached; withers prominent, shoulder oblique, arm straight, articulations wide, thick, tendons well detached, good axes, hind-quarters powerful.

Too low behind.................. quarters light, eroup, thigh, and leg powerful: hocks strong, loins strong, good posterior axes.

Members too long . . . . . . . . Body light, chest developed; tendons detached, muscular development good.

Horse under himself in front. . . . . . Neck straight, well attached; shoulder oblique, forequarters powerful, and elevated in relation to the hind-quarters; articulations thick, wide, tendons well detached.

Horse knee-sprung . . . . . . . . Powerful muscles of the shoulder, the arm, the forearm; neek straight, withers prominent, body well supported.

Horse under himself behind . . . . . Fore-quarters light, rather low than high; hind-quarters very muscular, loins powerful, hocks wide, thick, clean.

Shortened gaits . . . . . . . Energy, vigor, rather nervous temperament.

We conld, without difficulty, have extended the list of these eompensations. Nearly every defect may be amcliorated, either wholly or in part, by a better or inverse disposition of another region. There are, nevertheless, some which it is impussible to remedy, on acconnt of their influence upon the very essence of the motor apparatus or upon the most essential qualities which it should possess. How can we make good, indeed, a defect of absolute development of the respiratory apparatus or the musenlar system, a lad quality of the hoof, a want of endurance, energy, and vigor, too great excitability, certain vices of character, ete.? Can a horse breathe snffieiently, move, react, feed, obey, and work, if he is not provided with good lungs, good muscles, large blood-ressels, an excitable nervous ș̣stem, a spacions digestive apparatus, a docile character, or a good temperament? Evidently not. There are fundamental conditions without which the animal is, so to speak, nseless; and if they do not exist in him from the first, it is useless to attempt to find a compensation ; we must palss on and reject him as improper for service.

By the side of these essential requirements there are seendary ones whose absence does not make the motor absolntely inefficient, lut 
simply diminishes his mechanical aptitudes, and, for this reason, his value. It is in the latter ease that the system of compensations can be a valuable aid, for it enables us to appreciate arcurately the degree of adaptation of the horse to the ent for which he is clestined.

Eye and Judgment.-But those who must decide upon the qualitics or doferts of the horse have not always the necessary qualifiations for the solution of this problem. As a matter of fact, they must he endowed with eertain natural aptitndes in order to preceive readily the relations of the parts and of the whole, and to discern and recognize them promptly; they needs must have the faculty to appreciate, withont previous preparation, the good or the bad, the beanty or the ugliness of the form which strikes their eyes. This, in teehnical langnage, is called the eye. It results, more especially, from an innate, peculiar, exceptional acnteness of their senses, which enables them to see exactly that which others would require a much longer time to fincl, and perhaps would never distinguish.

The eye is not only a special gift of a delieate nature; it also results from edneation and experience, and on this aceonnt it may be acquired, like all other attributes of the kind. We would therefore suggest to those who desire to acquire a thorough knowledge of the horse, that they perfeet their senses and exercise them by intelligent and patient observation, and examine the same types over and over again until the mind preserves a clear, perfeet image of the very variable combinations which characterize them.

But the aptitude to see vividly the external conformation is in itself powerless, perfect as it may be, to constitute the true connoisseur. The latter must, besides, possess a keen and sure judgment in order to duly appreciate the degrees, the shades, to avoid the variations of too exeitable a temperament, to weigh, in a snitable mamner, without an unguarded impulse or without excessive reserve, the influcnce of the good qualities and of the defects. One is not born a man of tact, one becomes sueh; for the faculty of judging rightly and accurately, of expressing our mind upon the snitableness or the unsuitableness of things, implies comparisen, attention, reflection, labit, intelligenee, and a well-balanced mind.

Taste, Prejudice, Fashion.-Everybody does not judge of a horse in the same mamer, and the opinions of some are neither as reliable nor as judicious as those of other's. Whence arise differences, the principal reason of which depends upon the causes which influence the judgment. Among these we will eite more particularly taste, prejudice, and fashion. 
Taste is the faculty which urges us to seek after the beautiful. The glance of the eye simply teaches us to perceive that which is right, good, better, beantiful, in preference to that which is ugly. "It is, in some manner," says J. J. Rousseau, exquisitely, "the microscope of our judgment; it places small details within the reach of judgment, and its work commences where that of the latter ends." 'This is a very happy figure of speech, which explains well the róle of taste in all the manifestations by which reason, tact, and intelligence are shown. As an infallible guide it enlightens them by placing them, $\therefore$ to speak, right in the focus of truth, in order that they may be preserved from error. For this very reason it must naturally precede them.

Taste not only implies an intense perception, it also requires an admiration for the beautiful, with a more or less clear consciousness of the qualities which must have been combined and of the difficulties which the breeder must have overeome in order to realize the beantiful materially. When we see a beautiful horse, it is not only his form, his gracefulness, his elegance, his vigor, etc., which arrest our attention ; it is the scarcity of the model, the skilled labor of the man who produced it or found it. The connoisseur possesses this advantage over the layman, that he appreciates with greater competence the result both of natural aptitude and of study, the details, the technical points which make little or no impression upon the latter. Why? Because his taste has been better trained. Hence his judgment is more aceurate and less liable to error. And this superiority is far from being always the result of solid theoretical studies. How many horsemen and horse-dealer's surprise us by their good selections! Go into their stables, you will find none but good horses, and yet from what books have they learned, by what teachers have they been instructed? 'The truth is, they have good taste, they "take in" a horse and understand him at a glance; the surroundings amid which they have lived have developed their special aptitudes and corrected their mistakes; they have unknowingly aequired an idea of the beantiful, this rare aris, and have applied their efforts to discover and enltivate it.

A person's judgment may be misleading when his taste becomes depraved or is influenced by prejudice and fashion; it is as though it were guided by a wrong light, and then sees everything under a color which is not the true one. It is therefore of great inportance to develop taste, to cultivate it by the ever-renewed spectarle of the beanties of nature. In this connection especially is the guidance of a 
teacher useful, and frequent association with horsemen, whoever they may be, is likely to render signal service to the beginner.

"Prejudice," says Littré, "is an opinion, a belief, aequired without examination." I In most cases it rests upon a pure coincidence or upon a simple probability, never upon a demonstrated truth, and varies aceording to persons, places, and times. The result of routine and ignorance, it encumbers the advancement of seience, and shomld be regarded as the greatest obstacle to progress. "It wages war against any bold spirit that declines to bow before it, and men whose taste is most delicate and best trained are unable to shake off the tyranny of a preconceived idea." 2

Prejudices abound in respect to the external form of the horse. What has not been said about the forms of the head, the withers, the shoulder, the croup, the tail, the ehest, the flank, the blemishes, the dress, the white-foot, the horse-hairs, etc.? What an accumulation of errors, the more difficult to eradicate as they are based on the unknown, always so full of attraction for the laity!

Prejudice is the most redoubtable foe of reason. Hence we must battle against it to the last, but without allowing ourselves to be too deeply moved by the opposition of our contemporaries. "It is in reality," adds Eug. V'éron, "only a question of a momentary disturbance, which is explained by the very effort necessary for any innovation we undertake in order to establish the general concordance of our ideas, exactly in the same way as a current of air passing over a stream is sufficient to make the water lose its transparency." 3

Nevertheless, this does not mean that we must delude ourselves into the belief that all is prejudice. It would be wrong to rejeet an opinion point-blank moler the pretence that it lacks probability or certainty, or for the sole satisfaction of creating something new, for this opinion may prove true as well as erroneous. Hence the advisability of verifying everything, of examining everything, in order to ascertain the worth of this opinion and profit by it, if we may.

Fashion is a transient custom prompted by fancy and eaprice (Littlé). It is the symptom of a sort of wandering of the imagination, this " madap of the house," stimulated by vanity and emmi much more frequently than by the expression of a true asthetic sentiment. Its characteristic, in truth, is to change for fear of monotony and not for the sake of discovering something better. Rarely are its innova-

1 Littré, Dictionnaire de la langue francaise.

2 Eug. Véron, L'esthétique, p. 73, Yaris, 1878.

${ }^{3}$ Loc. cit., p. 74. 
tions happy, and, should they be so, it would be imprudent to consirler them even as accidental signs of beanty, for that beanty is not of the kind which satisfies the eye of the competent man, which indieates the perfect adaptation of the thing to the end for which it is intended.

And still, how many people become the victims of this fancy and sacrifice everything to pride and to appearance! It is in good style, for example, to have a team composed of horses of the same form and of the same color. You go to select them from a horse-dealer. He is ever so ready to satisfy your wishes, but especially the above, since you have begun by laying great stress upon them. What happens then? It happens that, in most instances, as it is almost impossible to find two subjects absolutely identical in other respects than the two you have mentioned, he will supply you with horses which will be a mateh neither in the gait nor vigor, energy, solidity, dressing, etc. And for the sake of being able to display a team exactly uniform in relation to color and size, you will have ignored defects, vices of character, or some other grave imperfection!

Tery fortunately, it is the people of means, consequently the very small minority, who thus make themselves slaves to the fancies and whims of their period. Indeed, there is perhaps no great harm in their doing so; all horses must needs be utilized, and it is better, on the whole, that the bad ones should fall to the lot of those who only use them for public display.

Concerning horses, fashion, like prejudice, has tendencies which we must struggle against, for it only gives to the horse superficial qualities, of quite a transient kind, sought after to-day and condemnerl to-morrow, according to the arbitrary conventionalities of the moment. All such practices should be deprecated, were it but to save the horse from the senseless tastes of a few renowned ladies of the demi-monde or of pretentious and ignorant idlers! 


\title{
SECTION FOURTH.
}

THE HORSE IN RELATION TO LOCOMOTION.

\author{
PART I. \\ ATTITUDES AND MOVEMENTS UPON PLACE.
}

\section{CHA P T ER I.}

\section{ATTITUDES.}

In the exterior we designate under the name attitudes the diverse positions which the horse assumes when at rest, either standing or recumbent. They eomprise, consequently, standing, up, or station, and lying down, or decubitus.

\section{A.--Station.}

Definition; Divisions.-Station is the attitude of the animal standing almost motionless, and touching the ground with his four members or with three of them only.

It has been divided into free and forced, aceording to the number of the members which effectually support the body.

Free station is the attitude of the horse when left entirely to himself: The trunk is usually supported by three nembers; the fourth, which is always a posterior, remains semi-flexed, touches simply with its toe, and preserves this position until its congener, tired ont, then assumes a semi-flexed position itself, thus performing the function which devolved upon it in propping "n the body.

The posterior foot which is not in full contact with the ground is slightly displaced forward and inward. The hameh of this side is lower than that on the opposite side. The hase of support, in such 438 
cases, is reduced to a triangle, which renders the equilibrium less stable. Nevertheless, if the body remain immobile and the members change their relative positions alternately, it is possible for the horse to preserve this attitude for a long time, and even to sleep without heing obliged to lie down.

The anterior members do not alternate with each other in their position. Nevertheless, if the fatigue be great, they are alternately lifted up and replaced in position by a sort of slow and regular stamping movement, which eases the museles and gives intermittence to their eontraction, that intermittence withont which it conld not contimue.

As soon as a member beeomes tired out, or is the seat of some pathological alteration, it will take longer and more frequent rests, and ehanges its ordinary direetion. It is thus that the posterior limbs are displaced forward, with the foot generally flat upon the gromnd and the fetlock strongly projected forward, knuckled, as if the muscular system were powerless to maintain the osseous segments in their normal relations (see page 295). The fore-limbs, on their part, seek to deviate from the centre of gravity ; they also incline forward, and sometimes a little outward, in a semi-flexed state, which is vulgarly cxpressed by saying that the horse points, stands like a dancing-master.

In forced station, on the contrary, the fou members are obliged to support the body, and are symmetrieally disposed in each biped in order to receive a proportional share of the body-weight. The hase of support is no longer triangular ; it becomes an elongated or shortened parallelogram, according to the direction of the locomotory colmm in relation to the vertieal axis. The distance comprised between the anterior and posterior bipeds is, in this case, equal to three-fourths of the height of the horse.

As the separation of the two fore-feet is sensibly greater than that of the hind-feet, it follows from this that the polygon constituted by the base of support is, in reality, a trapezoid and not a rectangle, which M. Duhousset has demonstrated. This is a fortmate disposition, the effect of which is to maintain the equilibrium in front, - that is to say, at the place where the natural supports of the trunk are more burdened and more liable, on aecount of their proximity to the cervicocephalic regions, to allow the line of gravitation to fall outside of the base of support.

Foreed standing is always fatigning, althongh the hody may not exeente any apparent movement, becanse this attitude implics that the museular contraction is continued without the necessary intermissions. 
Hence the animal, as soon as he is left to himself, will resume the attitude of frce station in order to case his muscles.

Three different conditions may present themselves:

1. Either the members approach the centre of gravity two by two, and thus converge more or less by their hoofs.

2. Or they deviate from this centre,- that is to say, are inclined in an inverse sense, converge above and diverge below.

3. Or, finally, their direct axis is parallel to the vertical line.

These threc situations constitute the attitudes in which the horse has been said, respectively, to "rassembler," or gather up ; to " eamper," or stretch out ; and to "placer," or stand right up. Let us rapidly pass them in review.

In the rassembler (Fig. 144), or "gathering up," the four feet are brought towards the centre of the base of support, whose length is

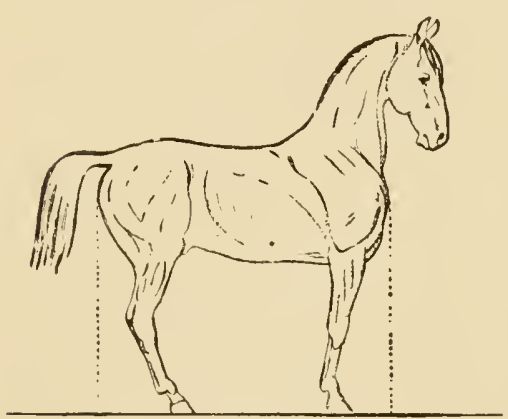

FIG. 144.-The rassembler.

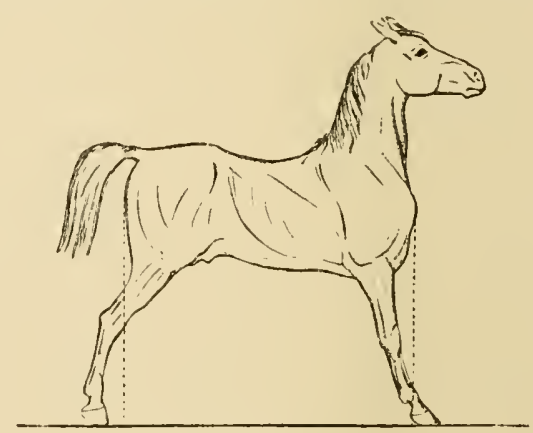

Fig. 145,-The camper.

less than three-fourths of the height of the horse. Hence there results a elosing of most of the articular angles, as well as a lessened stability of the equilibrium : two eauses of fatigne which soon oblige the animal to assume the attitude of free station. When thus "gathered up" he is ready to execute easily the principal movements,_-jumping, moving to the right, to the left, forward, or backward. In the riding-school the animal is made to assume this attitude by combined actions of the hands and the legs.

In the camper, or "stretching out," on the contrary (Fig. 145), the members are respeetively lengthened forward and backward from the body, which augments the extent of the base of support. The length of the latter then exceeds three-fourths of the height of the horse. The dorso-lumbar region, in this case, is coneave, sway-baeked, and progression becomes diffienlt. The posterior members are ineapable of communicating to the trunk an efficacions impulse, beeause they 
have almost reached their limit of extension. As to the anterior, they cannot take as long a step, heing likewise in a state of extreme extension. In order to be ahle to walk, therefore, the horse must shorten his base of support, draw the feet towards one another, and return, to a certain degree, to the preceding attitude, the attitude really preparatory to all movenrents.

To recapitulate, the comper, very fatigning to the hack and the loins, is detrimental to the horse only in the eve of the acute observer, for it gives neither grace nor elegance to the suljeet. Still, dealers have brought this particular attitude into vogue either to show to the purchaser that the animal will thus eover much ground and should, consequently, take long stricles, or to take the attention away from the defect of the axis, to mask some other vices, to give greater prominence to the obliquity of the shoulder, the horizontality of the croup, the strength of the loins, or, finally, to modify the appearance of a trunk which is not irreproachable. At first intended only as a simple preparation for the sale, this eustom, which we have for a long time opposed, ${ }^{1}$ is at present very fashionable in pleasure-horses,- the coachhorse, for example. The evil would not be great if its only consequence were to render the horse ungraceful; hut what is of greater importance in this attitude is that it inflicts a useless torture upon the animal, even if it be not prejudicial to him.

The placer (Fig. 146), or " "upright stand," is the station in which the direct axis of the members has a direction intermediary between the preceding two, and more or less approaches the vertical.

We will eall the direct axis, or line of direction of the member, the line which joins the point of suspension of the trunk upon this member (centre of movement) to the midlle of the foot. The angular displacement of this axis in front of the vertieal, when the animal walks or trots, is equal to a half-step).

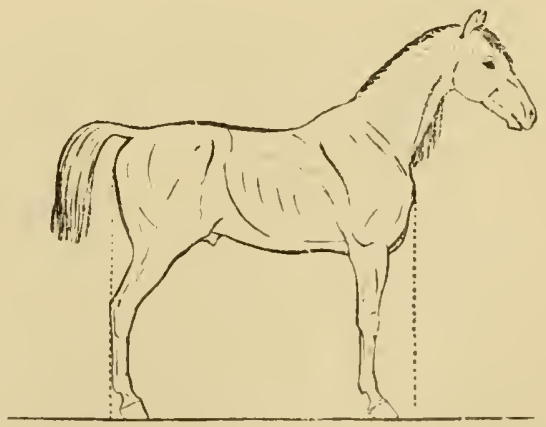

FIG. 116.-The placer.

We should endeavor to make the columns of support take this direction, which is more favorable to

1 Arm. Gombaux, De l'enrênement des elievaux, in Bulletin de la société protectrice des animaux, aunce 1572, p. 125 . 
the equal distribution of the weight, in order to judge of the soundness of the animal and his locomotory aptitudes. The part of the exterior which includes the study of the axes is therefore full of practical interest. We will treat of them in the following paragraphs.

\section{Axes, Equilibrium.}

The axes of a lorse are nothing else than the direetion of the axes of his members in relation to the ground.

It is necessary, in order to appreciate this direction, to place the subject previonsly, - that is to say, to make him stand in such a manner that the feet of each biped, anterior or posterior, are on a transverse line perpendieular to the axis of the body, and oecupy the four angles of the trapezium represented by the hase of support. Besides, the plane of the base of support should be perfectly horizontal.

The axes are called regular when the lines of direction of the members fall perpendicularly and oscillate in planes parallel to the median plane. "The trunk being a weight to be supported," says MI. Sanson, "it is a fact that the members will sustain this weight in a manner all the more effieacious and the more proportionate with the preservation of their integrity, as this same weight is always exerted upon them, in station, in the normal direction of its own gravitation,that is to say, as the different pieces which compose the columns of support are arranged in such a manner that the diverse component forces will be resolved into a single resultant invariably parallel to the plumb-line."

The axcs are styled irregular, on the contrary, when the lines of direction of the members deviate from the rertical and effect other displacements in the planes than those of which we have spoken.

The line of axis of a member is, theoretically, the vertical line which passes through the point of suspension, - that is, the centre of movement of the trunk upon this member. If this vertical line meet the opposite extremity of the locomotory column, here altogether comparable to an ordinary column, it may be supposed that the latter is well placed under the hody to fulfil with efficacy its role of support.

On the other hand, it is evident that this condition is dependent upon two principal factors: the length of the osseous segments and the value of their articular angles. The points of origin and of termination of the ideal broken line which represents each member should,

A. Sanson, Nouveau Dietionnaire de múdecine, de chirurgie et d'hygiène vétérinaires, t. i. p. 669 . 
in fact, exist upon the same vertical line (the angles not varying) (nnly on condition that the segments maintain certain determined lengths, or that the angles (the segments remaining the same) have an equally determined opening.

But, as the variations of the two factors of which we have spoken are always simultaneous and not independent, it follows that two horses provided with good axes are not necessarily identical in relation to the extent of the articular angles and the length of the boncs, because deviations in the one are properly compensated by contrary modifications of the other.

\section{a. Axes of the Anterior Members.}

Axes viewed in Profile.-It is particularly difficult to locate the line of direction of the anterior member on account of the more or less diffuse points of attachment of this member. What is, indeed, the exact centre of the combined actions of the trapezius, the rhomboideus, the angularis, the great serratus, the peetorals, and the mastoido-humeralis, which fix the shonlder and the arm ayainst the sides of the thorax, and ahmost make them integral parts of the trunk: While we know with sufficient precision the insertion of each of these muscles, and while we are able to determine in an approximate manner the directions in which they act, we are still ignorant of the role which each one plays in supporting the trunk. We are therefore obliged to depend alone in this respect upon empirical data.

Consequently, let us choose that horse which is recognized by universal practice as having beautiful axes (Fig. 147). Thus, as we have said above, it is to be supposed that the inferior extremity of his foremembers will be situated in the vertical line which passes through the corresponding centre of movement of the body. Through the midlle, $b$, of the anterior foot let us diaw this line. We will see that it meets the scapular segment at a point, a, which is often located at the same time with remarkable accuraey upon the horizontal line ac, which passes preeisely through the exo-femoral articulation, the known centre of movement of the posterior column ujon the trunk.

It is therefore probable that the centre of movement, $a$, of the shouliler, whose situation otherwise varies aceording to the inclination of the latter. accupies, in a beautiful conformation, a height equal to that of the centre of novement of the haunch.

If such really be the case, the plane of suspension of the body upen the members will be a horizontal plane. We except, of comse, those particular cases in which the withers are low and the fore part of the trunk larger or smaller than the hind part. We know that there is, in the latter eases, an irregular 
distribution of the weight and an elevation of the plane of suspension, according to the nature of the given defect.

Since the alppearance of our first edition, two distinguished veterinary surgeons, Messrs. Ralabe and Bonnal, ${ }^{1}$ have published their personal observations upon this special subject. Accorling to these authors, we have placed the centre of scapular suspension too low; they fix it empirically at the superior third of the shoulder. If this determination is exact, the plane of suspension of the body will therefore be slightly oblique, from before to behind.

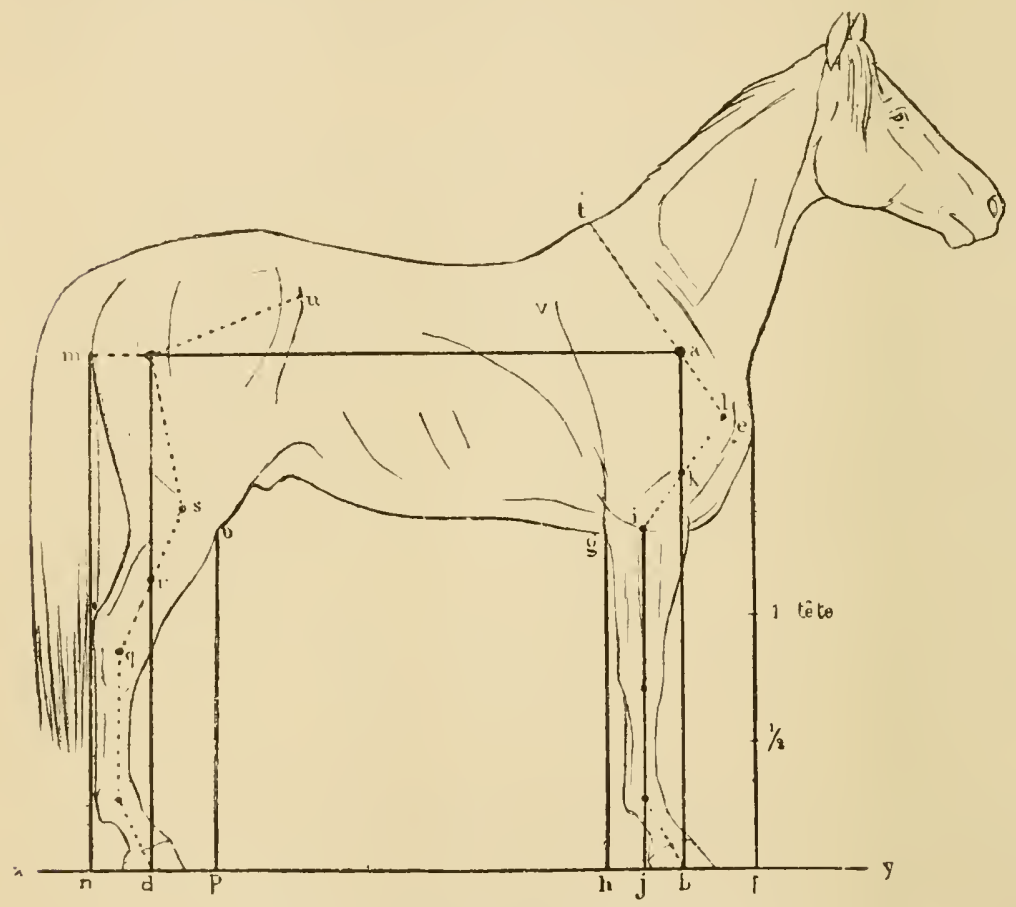

FIG. 147.-Lines of equilibrium of the horse viewed in profile.

(Reproduced from a photograph of M. Delton.)

All this is possible. It is very difficult to choose between these two opinions, because the centre of movement of the shoulder is not an anatomical point, but rather a surface which itself moves upon the thoracic parietes at the same time that the axis of the scapula rotates around it.

Besides, the direction of the plane of suspension of the body upon the members, whether it be horizontal or slightly oblique in a normal state, only offers interest from a point of view of its deviations in one sense or the other. As we have treated of these latter in connection with the centre of gravity, the withers, and the height of the fore-quarters, we will not return to them here.

1 Raabe et Bonnal, Détermination des lignes de gravité du cheval, eu station régulière monté et non monté; in Archives vétérinaires, 1883, p. 535. 
The other deductions to be made from the vertical ab lead to results of more practical value:

This line is, in fact (Fig. 148), equidistant from the two perpendiculars to the ground, ef, $g h$, which can also be demonstrated by observations on animals selected as the types of good conformation. It is also equidistant from $r s$ and $t u$, the thickness of the articulations at these points being equal.

It follows from this that $a b$ intersects $e g$ (the humerus) in its middle, as well as $r t$; for eghf and rtus are trapeziums in which $a b$ is parallel to and equidistant from their bases.

It is also seen that if ge (radiometacarpal segment) remain vertical, $f h$ (a horizontal projection from the humerus) equals $f b$ (projection of $a e$ ) plus $b h$ (projection of $b c$ ). And as $b h$ equals $f b$, it can be said that the horizontal projection from the humerus is double the horizontal projection of the phalangal segment.

Let us remark, finally, that all the conclusions drawn from these typical axes are always applicable, with the sole condition that the articular angles maintain their summits upon the lines $e f$ and $g h$.

This proves that any articular angles whatsoever can be compatible with good axes. Here, also, the theory of General Morris, which has been advanced ${ }^{1}$ as an excellent criterion to judge of the regularity of the axes, is evidently defective.

The knowledge of the fact that the vertical line $a b$ divides the humerus as well as the distance rt into two equal parts already constitutes a factor which simplifies the appreciation of the mode of equilibrium of the fore part of the body ; for

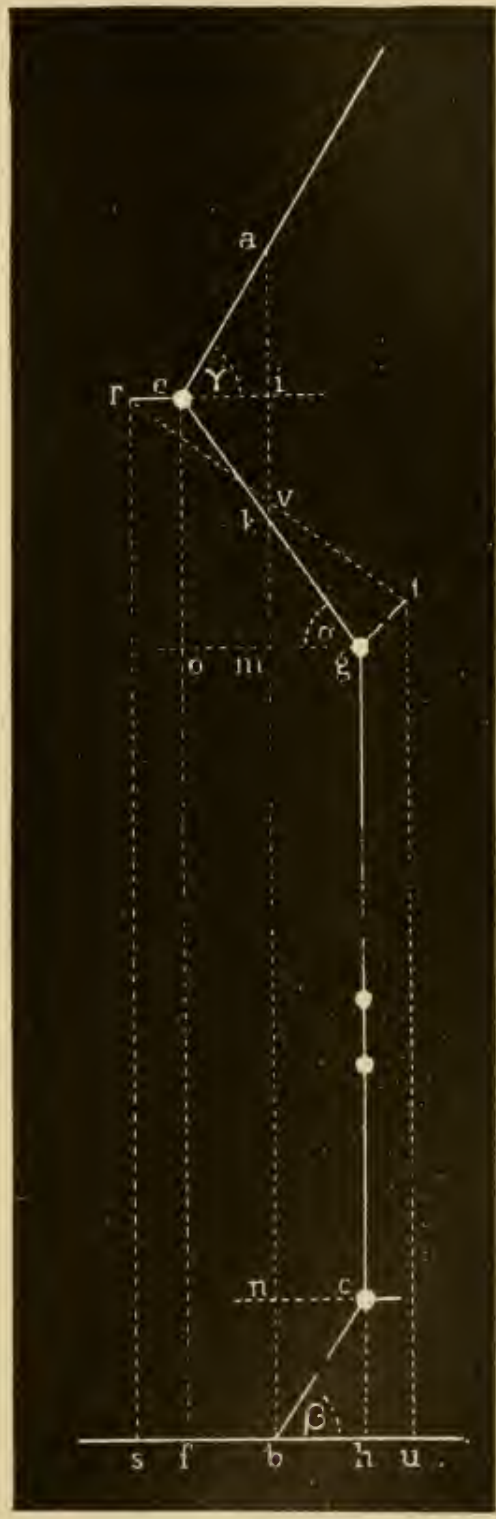

FI(i. 148. instead of lowering, from the points $e$ and $g$ or $r$ and $t$, two perpendic- 
nlars, and observing if the point $b$ (centre of the foot) is midway between $f$ and $h$ or $s$ and $u$, it suffices to fix the point $k$, middle of the humerus, or the point $v$, middle of the distance eomprised between the points of the shoulder and of the elbow, and then draw a vertical line which should fall npon the same foot.

Now that we have established the rational prineiples which indicate the location of the axes of the anterior members, we can formulate from them practical rules in the following manner. Our lines differ somewhat from those of other authors, but in principle they are equally as simple, and have, besides, the advantage of being based upon positive facts.

1st. A vertical line, ab (Fig. 149 [1]), lowered from the middle, $\mathrm{k}$, of the arm, should pass, above, through the centre of anterior suspension,

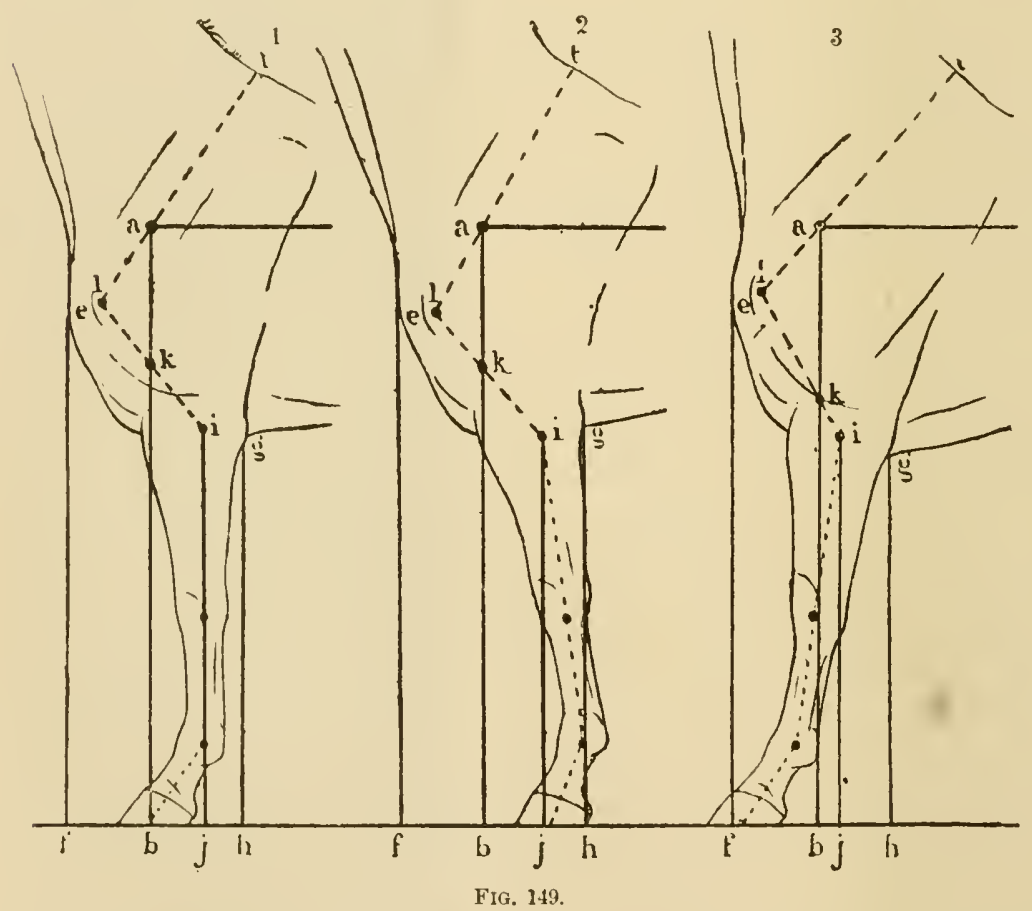

a, intersect, below, the middle of the hoof, $\mathrm{b}$, and be located equidistant from the verticals ef, gh, coming from the point of the shoulder and the summit of the elbow.

If this line falls in front of the hoof, the horse is said to be under himself in front (Fig. 149 [2]). 
If, on the contrary, this line fulls behinel, it is said that the horse is comped in fiont (Fig. 149 [:3]).

Let us observe the inconveniences which follow from these two conformations.

The Horse Under Himself in Front.-The direct axis of the member, in this ase too much inclined downward and batekwarel, is too close to the centre of gravity, which diminishes the aptitudes of the columu as a support. There results from this an evident overloading, tending to flex the segments one upon the other and to close the angle of the fetlock, two eauses which compel the museles to contract more strongly, and the tendons and the ligaments to sustain more violent tractions. Besides, the base of support being shortened, the hind-feet, during locomotion, have a tendency to meet the forefeet, whence results forging; the equilibrium is less stable and the body continually tends to swing forward, another reason which explains why this defect of the axis renders the animal liable to fall upon his knees.

In addition, the locomotory movements are less extensive, not because the step is not capable of the same amplitude, but becanse the direction of the member at rest approaches more that direction which it assumes just before the limb is raised from the ground; this will more quickly overburden the member which is still on the ground, and precipitate the movement of the one in the air. If the speed be accelerated, the horse has not sufficient time to extend the member and move the different segments one upon the other to their normal limit, whatever may otherwise be the nature of his articular angles, the dimensions and energy of his muscles, the beauty of their insertion, and the length of their lever-arm. His steps are therefore low, elose to the ground, and frequently repeated; he carries the toe close to the soil, stumbles on rough roads, and so much the more easily when he is used on an inclined plane and carries more weight on his back. Hence such a horse is unfit for saddle-work and likewise for the shafts, for, in descending slopes, he is not able to support his burden, the resistance exerted against the collar being here insufficient.

Thus, excessive wear and fatigue of the bones, the ligaments, and the tendons, rapid wearing out, diminution of speed, instability of equilibrim, inseeurity of the foothold, and tendeney towards filling, -such are the inherent defects of this vice of the axis.

This does not mean that we should, for this rason, if no better one (an be found, discomrage the purchase of such a horse. He can, without doubt, still be employed for light-or heary-dranght services; with many preantions, it is even possible to mount him. We should, 
however, not forget that he has lost a notable part of his value, in consequence of the slight solidity of the members and the feebleness of their parts.

The Horse Camped in Front.-Here, the direct axis of the member is inclined forward and downward instead of being vertical. This is a defect which authors consider congenital or acquired, according to the proint of view they take.

Some, including Bourgelat and Leeoq, refer the discases of the foot which are observed in sueh cases to the primitively bad direction of the locomotory column; others, including M. Sanson, who has been the chief upholder of this opinion, think, on the contrary, that the lesions of the digital extremity exist first, and give origin little by little to the deviation of which we speak.

Whieh of these two hypotheses is the most rational? This it is not so easy to answer, for both are plansible and supported by facts. Yet neither the one nor the other is positively established. Nevertheless, the opinion of M. Sanson appears to us to be the one which verifies itself the more frequently. Rarely is the camper in front observed in young horses, while it is very common in adults, and particularly in those which are affected with some ehronic disease of the foot. "In an instinctive manner, the object of which is so easily recognizable in the case of founder, for example, the horse imposes upon the posterior limbs a portion of the weight of the fore part of the body, and diminishes thus far the pressure supported by his fore-feet." 1

Whatever may be the point of origin of comping, whether it is regarded as the cansc or the effect of snperficial or of deep alterations of the digital region, it is well known that animals thus formed are used every day. And as this defect does not render the horse unable to perform his work, it is interesting to point out to those who wish to purchase him the principal disadvantages which follow from such a conformation.

It is seen, first of all, that the foot is placed in advance of the vertical axes; but as these lines are nothing more than the isolated directions of the components of the weight, - that part which is supported ly the anterior columns, - it follows that their resultant, which acts in the direction $a b$, will fall upon the posterior part of the hoof. The more the deviation is marked the greater will be the strain on the tendons.

Besides, the fore-members deviating from the line of gravitation, 
the hind-members are overburdened by that portion of the weight of which the former are relieved. Hence we frequently see the fetlocks and the hocks of such horses prematurely blemished and unable to communicate sufficient impulsion to the body.

Finally, the anterior feet touching the ground principally by the heels, and not almost uniformly the whole extent of the plantar border of the wall, it follows that these feet, already surcharged behind from their defeetive situation, will also be more exposed to wounds and bruises of the heels.

The last and most important consequence of ecemping is the marked slowness which it gives to the gaits. It lengthens, in fact, the base of support, diminishes by so much the length of the lever-arm which is constituted by the neck in front of the centre of anterior suspension, renders the equilibrium more stable, and all this to the detriment of the speed. On the other hand, as the angular displacement of the member, dependent upon the length of its museles, implies especially a limited position beyond which it would be very unfavorably direeted in order to take its foothold on the ground, it follows from this that a member whose free extremity is already carried forward will be much closer to the point of extreme extension, less apt to utilize the long muscles, and more disposed to take small steps.

The most serious cause of slowness of the gait consists in the pain experienced in placing the foot upon the ground. Whether the lesions indieated above are primary or secondary, it is none the less true, as II. Sanson ${ }^{1}$ said, that the violence of the concussion and the intensity of the pain are in direct ratio with the altered position of the member and the force of the impulsion. But, however feeble the morbid sensibility which is manifested in such a case be considered, the animal always endeavors to protcet these parts in proportion to the suffering which he experiences; whence a hesitation in stepping and a shortening of the gait.

To recapitulate, fatigue of the anterior members, overloading of the posterior, premature ruin of their apparatus of impulsion and dispersion (hocks and fetlocks), bruising of the heels, painful and uncertiin contact of the foot with the ground, slowness of the gait,-liere are the prineipal inconvenienees of horses camper in front. If the vice be acquired, it can be remedied by rational care and treatment of the anterior feet, but even this result is doubtful in many cases. However this may be, the subjects can only be utilized at al walk and upon 
partieular soil ; they will be, on the contrary, albsolutely unsuitable for the saddle or other service requiring speed.

2d. A vertical line, lowered from the artialation of the elbow, should divide the knee, the canon, and the fetlock in their centre and fall a little posterior to the heels (ij, Fig. 147, and Fig. 149 [1]).

This classical line, spoken of by all authors, shows the direction of the inferior part of the member, and bespeaks in some manner the axis of the knee and of the fetlock.

If the knee projects in front of this vertical line, the horse is said to be knee-sprung, over in the knees (Fig. 150).

If, on the contrary, the knee is carried backward, it is qualified hollow, effaced, or sheep-like (Fig. 151).

If, on the other hand, this line falls too far from the heels, the horse is long- or low-jointed (Fig. 153).

If, finally, it meets the hecls or the anterior parts of the foot, he is called short- or struight-jointed (Fig. 152).

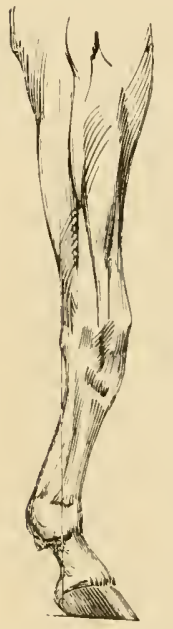

FIG. 150.

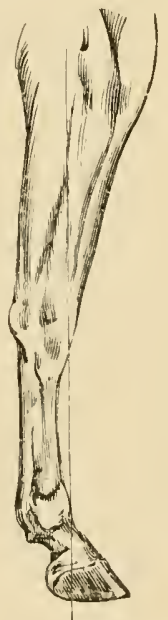

FIG. 151

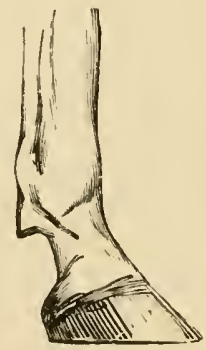

FIG, 152 .

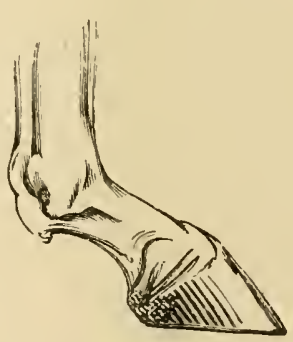

FIG. 153.

In the articles on the knee, fetlock, and pastern we have examined in detail all these vices of conformation and will not repeat them here.

Let us only say that the straightness of the anterior column, from the knee to the fetlock, is a condition of strength indispensable in all cases, especially in horses which are destined for saddle-work. Any other direction having for its effect the formation of a broken column of support which, in a physiological state, is disposed to act normally between two opposing forces that tend to incurvate it, is necessarily 
defective, for such direction favors the influence of these forees instead of resisting them.

The muscles or the ligaments, according to the nature of the deviation, are therefore required, in such cases, to supply the insufficiency of the support given by the arrangement of the bones of the member; whence more fatigue and more chances of damaging the locomotory apparatus.

Let us recall, finally, that the prominence or the effacement of the angle of the fetlock learls to consequences of the same order, by throwing upon the supporting tendons or the bones a large portion of the weight of the body, which, in the ease of regular axes, -that is to say, of a proper opening of the articular angle,-these agents of dispersion should distribute almost equally among themselves. We will say the same of the excess or deficiency of the length of the phalangal lever, so often accompanying long and low pasterns. The details, which we have already given in their proper place, allow us to dispense with any further remarks here.

Axes viewed in Front.-In order that the horse may be regular in the axes of his anterior members, the directing axis of the latter must blend, as we have seen, with the vertical line which passes through each centre of anterior suspension. But to judge of this it is not sufficient to regard these members in profile, for we would be unable to perceive the outward or the inward deviations of this axis which might readily take place. Hence we should, by all means, complete our examination hy the consideration of the animal upon his anterior face.

A single line suffices, in this position,

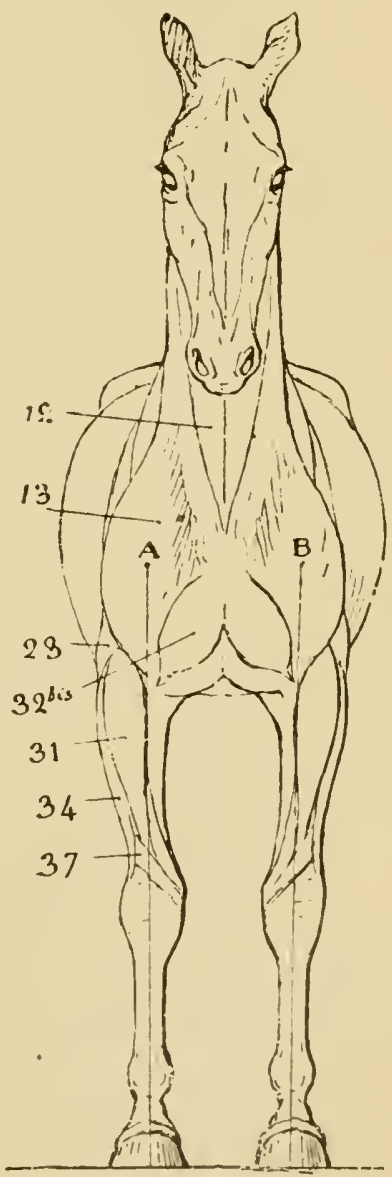

FIG, 154. to show the regularity of the axis:

A vertical line drawn doun from the point of the shoulder should divide the knee, the canon, the fetlock, and the foot into two cqual parts (Figr. 154). 
Besides, it should answer to this other requisite, that the interval comprised between the tro feet be equal to the width of the hoof measured from one quarter to the other.

It is easy to see that this line falls on the one which most anthors draw from the narrowest portion of the anterior face of the forearm (Fig. 155).

Such is the reason why we have not adopted this latter.

"Ihen the member, as a whole, is ontside of the vertical, or when

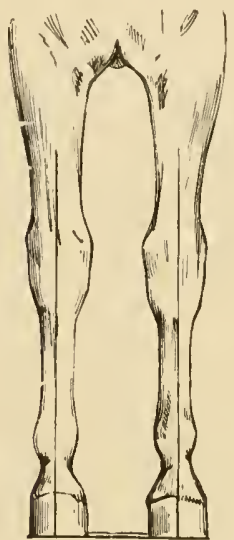

FIG. 155.

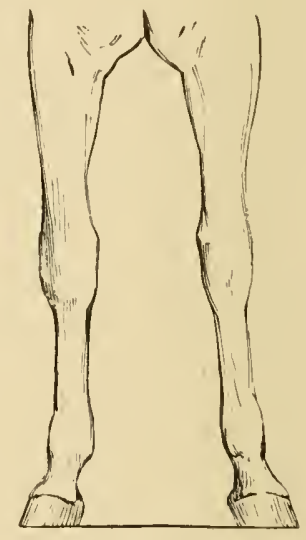

FIG. 156.

the interval between the hoofs is more considerable, the horse is said to be too open in front.

If it is the region of the knee alone which deviates, the horse is called bou-legged.

If it is the toc, the subject is crooked-legged, outbow-footed.

Reversely :

When the member, as a whole, is situated inwardly to the vertical, or when the interval between the two hoofs is too small, the animal is called closed in front.

If it is the region of the knce alone, the horse is ox-kneed.

Finally, if it is that of the toe, the animal becomes parrot-toed, cross-footerl in front.

Horse too Open in Front.-This defeet of the axis may depend upon two opposite canses. It should most ordinarily be attributed to the large development of the pectoral muscles, and it is observed more especially in heavy draught-horses. Here the interval comprised between the two hoof's is simply more considerable than is 
usual, but the vertical line still crosses the middle of the knee, the canon, the fetlock, and the foot (Fig. 156).

In other cases this conformation is due, on the contrary, to the narrowness of the cliest and the small volume of the pectoral muscles, two defects which diminish the separation of the points of the shoulders and render the members convergent towards their superior part, their opposite extremity being in reality normally placed, and appearing divergent only in eonsequence of the abnormal relation of the former.

It will be readily understood that when too large a space between the fore-members coexists with a large muscular development and great width of the thorax, the defect is of little import. If the transverse diameter of the base of support is increased, if the stability of the equilibrim augments, if the walk is heary and likewise accompanied by a more or less marked rocking of the body, from the fact of this conformation, it is apparent that the animal will be unfit to display speed, but that lie will be in good condition for the development of force. His aptitudes alone are changed. Hence he will lose scarcely any of his value for light-draught services, especially if his feet are good.

It is different, however, with the horse in which the separation of the fore-members depends upon narrowness of the ehest and flatness of the ribs. Such a horse will always be without xind and withont energy, and will not be more favorably disposed in relation to speed: first, on account of the smallness of his lungs and the weakness of his muscles; secondly, because the lateral displacement of his centre of gravity will occasion a loss of time and of force prejudicial to the veloeity of the gaits. We may add that here, as in the preceding ease, the two sides of the hoof will no longer bear their normal pressure. The internal quarter, already overburdened, will become the more so as the member deviates the more from its line of axis; whence the predisposition of the wall to crack and of the sole to become bruised, accidents that are so common in these subjects when they are used for fast work.

Knee arched Outward-Bow-legged Horse (Fig. 15i).This outward deviation of the nember, somewhat rare, is associated in most instances with a convergence of the two hoofs, but does not always imply it. As we have seen (page 2:33), this mode of conformation of the anterior member produces an unequal contact of the foot with the ground, as well as a strain on the ligaments; it renders, besides, the horse nngraceful.

Horse Outbow-footed (Fig. 158). - This defect of axis, technically called tulipes volyus, also crooked-legged, we have alieady exam- 
ined. Let us recall that it is ordinarily aceompanied by an inward deviation of the knee and of the elbow, but that it may also be due

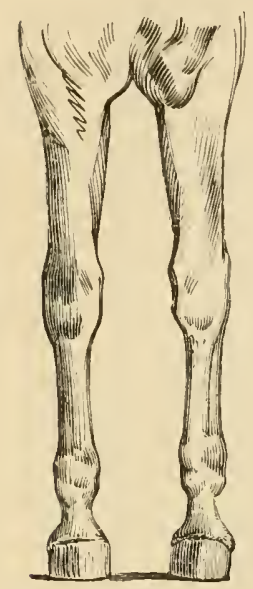

FIG. 157.

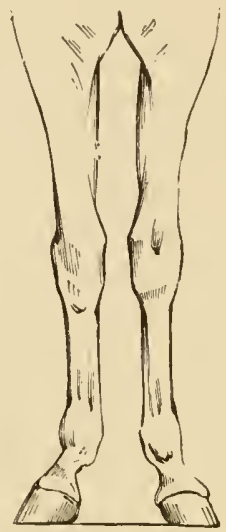

FIG. 158.

tracts from the beauty of the gait. to a simple change in the direction of the foot alone. However it may be, the foot is not slow in becoming modified; the internal quarter, bearing more pressure, has a tendency to un(lerlap the external and become contracted. The horse is, besides, liable to interfere with this quarter: Finally, during flexion of the knee, the metacarpus is thrown outward much more than in a normal state, which means a loss of time prejudicial to the speed, as well as the throwing outward of the foot, which de-

Horse Closed in Front (Fig. 159). - The closeness of the foremembers, as well as their too great separation, may result from two opposite causes : exeess or deficiency in the width of the chest. This condition is vulgarly called knock-kneed.

The objections in the first case are less than in the second, for the divergence of the members towards their superior extrenity is often due only to the development of the chest or to that of the peetoral muscles. Nevertheless, the approximation of their inferior extrenities diminishes the stability of the equilibrim, on accomt of the narrowing of the base of support in front; it also exposes the animal to interfering, cutting, and to the other aceidents which may result therefrom.

This vice of the axis is, however, much more grave when it depends upon a narrow chest and a feeble volume of the muscles. Besides the preceding faults, such a horse must also be regarded as being deficient in wind and without endurance, which renders him altogether incapable of performing the least laborious service.

Ox-Knee (Fig. 160).-The ox-knee, convex internally, is not compatible (see page 2:32) with a regular distribution of the bodyweight upon the metacarpal bones. With the member on the ground, the external concavity tends to become greater, which makes more pressure upon the external side of the carpal bones and increases the tension on the internal lateral ligament of the articulation. 
Finally, during flexion the horse displaces the eanon ontwardly, uses it in an ungraceful manner, and loses time in bringing it back

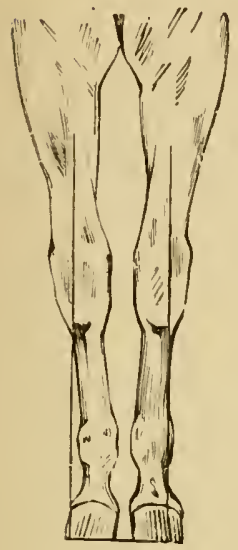

FIG, 159.

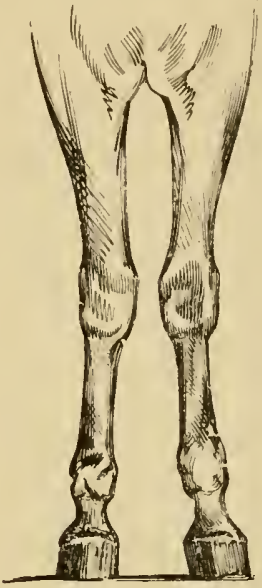

FIG. 160 .

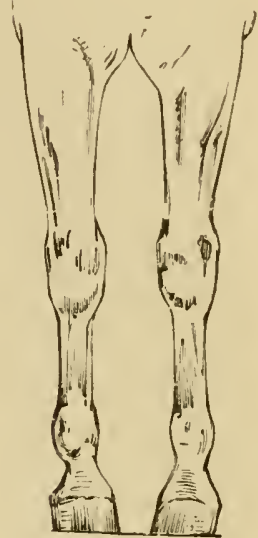

FIG. 161 .

into its proper position. Let us add that this malformation ordinarily implies an outward deviation of the toe, another disadrantage which aggravates this vice of the axis and constitutes a more important cause of depreciation.

Horse Cross-footed in Front (Fig. 161). - This defective conformation, characterized (sce page 332) by the convergence of the two hoofs, is due to too great a separation of the elbows, or to an outward arching of the knees or of the fetlocks. It is easy to understand the evil results from this conformation by the new relations which each half of the foot assumes with the line of gravitation of the member: the external mamma is closer to this line and the internal is more distant; whence an apparent overburdening of the outer side of the foot and a corresponding easing of the inner side.

The cross-footed or parrot-toed horse does not wear the inner side of the shoc, and interferes, in a manner inverse to that of the erooked-legged horse, with the internal mamma. The wounds which are thus produced, although often insignificant in appearance, constitute none the less, in the long run, some scrions lesions by their continned repetition. Even when the farrier can remedy it, even when the inferior part of the member can be protected by means of special leather boots against the knocking of the hoofs, it is still troublesome to nse the animal, by reason of the care which he requires and the expense which he necessitates. If he is destined for the saddle, his 
employment is still more lifficult, for, not having perfeet freedon in the use of his fore-limbs, and being predisposed to stumble, he exposes

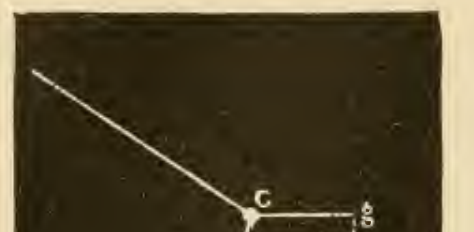
his rider to falls which may prove serious on rough and uneven roads.

\section{b. Axes of the Posterior Members.}

Axes viewed in Profile.-The principle which we have employed to estahlish the axes of the anterior member admit of a much simpler application when referred to the posterior member. The centre of suspension of the latter upon the trunk is known to us with sufficient accuracy; it is the coxo-femoral articulation. We may therefore eonclude that the direct axis of the posterior eolumn will be in a good position if the digital extrenity of this column is stationed at the bottom, $d$ (Fig. 162), of the rertical line which passes through the artienlar centre, c. In fact, it is this which observation demonstrates in horses of good equilibrium of the posterior quarters; a plumb-line placed at the level of the joint in question divides the hoof into two equal parts.

As in the anterior member, and for the same reasons, the vertical line, $c d$, is also equidistant from the perpendiculars to the ground, of and $s p$, or also of and $j h$. It intersects the leg, $o s$, as well as $e j$, at its middle. If the tarso-metatarsal segment remain vertical, the horizontal projection, $t p$, of the leg is double the horizontal projection, $d p$, of the phalangal segment. Finally, any degree of opening of the angles will be compatible witl good axes, on condition that the articular angles maintain their summits upon the vertical lines of and $s p$.

The axes of the hind-limbs are based, as is seen, upon the same principles as those of the fore-limbs. The four locomotory columns, in 
station, fulfil a rôle, if not equal, at least identical,- - that of supporting the body-weight; it is therefore but logieal that they obey the same principles of equilibrium.

Let us pass in review, now, the vices of the axes of the posterior nembers.

A vertical line, ed (Fig. 163 [1]), passing through the middle, r, of the leg, should pass, above, through the centre of posterior suspension, c (coxo-femoral articulation), intersect, below, the middle of the hoof, $\mathrm{d}$,

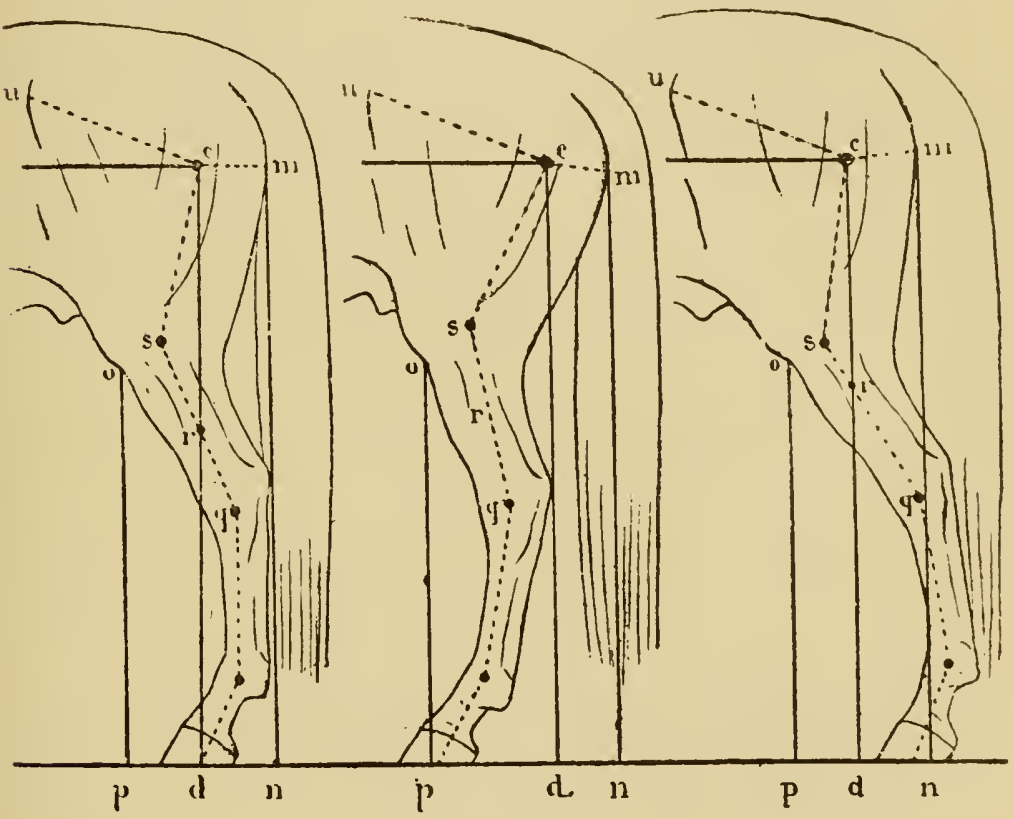

FIG. 163 .

and remain equidistant from the vertical lines op, $\mathrm{mn}$, lowered from the patella and the angle of the buttock, the latter tangent to the point of the hock and to the fetlock.

If the member, as a whole, is placed in front of this line cd, the horse is said to be under himself behind (Fig. 163 [2]).

If, on the contrary, it is situated behind, the horse is said to be camped behind (Fig. 163 [3]).

Finally, if the deviation only takes place from the fetlock down, the subject is called:

Long-and low-jointed when the middle of the foot, d, approaches the vertical line op. 
Short-and streight-jointed when it approaches the vertical line $m n$.

Having studied the last two defects in connection with the pastem, we will not return to them here. We will speak only of the inconveniences which follow from the first two conformations.

Horse Under Himself Behind (Fig. 163 [2]). - The direet axis of the member in this ease is oblique downward and forward, instead of being vertical. This disposition diminishes the aptitudes of the column as a support and favors its falling backward, borne down as it is by the force of the body-weight acting upon the point $c$ in the direction $\mathrm{cd}$. There follows from this a weakened equilibrium, causing the horse to slip forward, to be hesitating in his steps, and the bony segments to be flexed, two causes which increase the strain on the extensor muscles, the tendons, and the ligaments from greater efforts.

Besides, the metatarsus being situated obliquely under the tibia, the tibio-tarsal angle acquires a state of defective closing, characterized by the angular, elbored hock, which renders this articnlation liable, as we have seen (page 266), to show the effects of use the earlier and more seriously in proportion as the canon is more inclined under the body.

The foot also coming nearer to the centre of gravity, the base of support is shortened to the detriment of the stability, while the overburdened posterior limb has not the same freedom of movement, which augments its work and favors its chances of being blemished.

Finally, this vicions direction is also detrimental to the speed of the gaits, in consequence of the two following reasons:

The first is dependent on the shortness of the stride, becanse the member, advanced for a smaller distance than in the normal state of the extreme limit of its forward oscillation, is incapable of passing over much ground.

The second consists in the loss of time determined at each step by the vertical displacements of the croup, the member being able to communicate an efficacions impulsion only on condition of having attained that particular degree of extension which makes it underpropped against the trunk and not inclined inversely to the direction of movement.

We may add, in passing, a new cause of fatigue and wear for the hock and the fetlock, resulting from overburdening these agents of impulsion, which must here elevate the body before projecting it horizontally, the only propulsive line favorable to speed.

It follows from the preceding statements that a horse under himself is hardly capable of doing good service; but the objections vary 
according to the nature of the work which he is ealled upon to perform. Still utilizable for light-draught work which, ordinarily, exarts but little effort and speed, he becomes, on the contrary, unsuitable for the saddle, the riding-sehool, the hunt, and the race-course, on account of the relative weakness of his hind-members and the early development of blemishes which the bad direction of the latter will soon cause. Even if he be employed for heavy-draught work, his hocks and his fetlocks will not long endure the great efforts which traction on uneven ground necessitates. Henee he will lose, from this vice of axis so prejudicial to the integrity of his locomotory columns, a great deal of his value, and he should be absolutely rejected when the deviation in his posterior quarters is altogether too well marked.

Horse Camped Behind (Fig. 163 [3]).-The evil consequences of this defect are far from being as serious for the posterior members as for the anterior.

Here the axis of the member is separated from the vertical and is the reverse of that in the precerling conformation. In other words, it is oblique downward and backward, which predisposes the animal to slip backward and carry a portion of the weight upon the anterior bipeds; whence greater exertion for the latter to fulfil their function during station as well as locomotion, especially if the weight of the rider is added to that of the fore-quarters, and if the subject, low in front, is obliged to go fast down-hill, an event which takes place daily.

The deviation of the posterior feet from the centre of gravity also leads to other effects upon the vertebral column; it imposes upon the latter a portion of the weight which the hind-limbs would support by their resistance were they properly direeted under the trunk. Hence it will soon manifest the fatigne of the extensor muscles of the back by the latter becoming more or less decidedly sucu-backed, which condition is opposed, as we have seen (page 117), to the integral transmission of the impulsion from behind.

The calcaneus of the camped horse is not, as M. Sanson' believes, necessarily less developed than in the case of a limb with a normal direction; it is simply more parallel with the tibia, which makes the hock appear less wide and liminishes the perpendicular ineidence of the muscles which produce its extension. Also, as the vicious insertions of these muscles only become exaggerated during extreme extension of the canon, it follows from this that the latter will lose a 
portion of that power of which it would he capable if the tibio-taral angle, less open, had placed the calcanens in the best direction for the development of force.

Finally, the gaits will lack action and speed, because the abdominal supports of the trunk, nearer to their limit of extension than in their normal axis, will consequently rotate through a smaller space by their

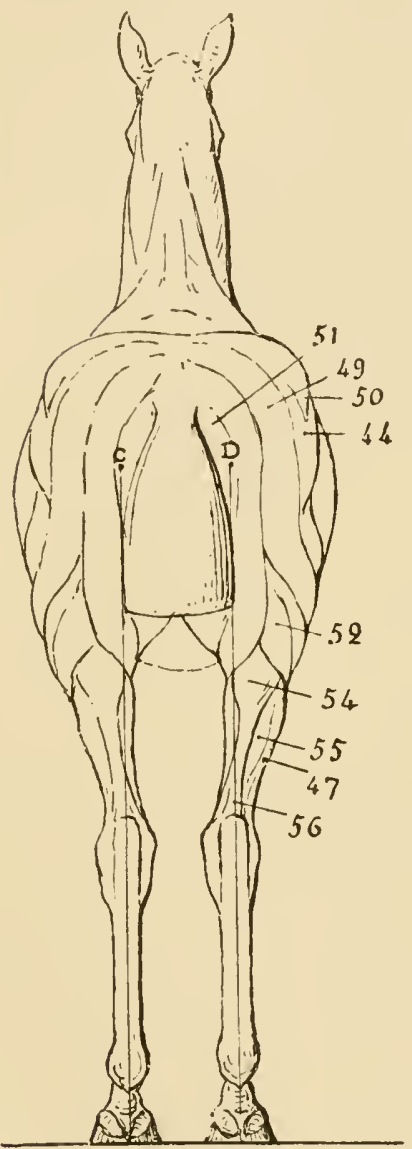

FiG. 164. superior extremity, during which they propel the body, and possess less propulsive force. If they are well situated to pass over mueh ground, they are nuable to profit from this advantage, since the impulsion really only becomes efficacious when the direct axis of the member has just passed the vertical to become oblique downward and backward. Now, this latter direction being precisely that in which the posterior column in this case arrives on the ground, it follows that this position will deprive the limb of all the angular distance which previously separates its direet axis from the normal.

Axes viewed from Behind.-In order to determine whether the direct axes of the posterior members are well situated in the plane of the vertical line which passes through their centre of suspension, it is necessary to observe the animal from behind. In these conditions the following line suffices to show the regularity of the axis :

A vertical line drawn down from the point of the buttock should divide equally the inferior part of the member, firom the point of the hock doun, and leare between the hoofs an interral almost equal to the width of the fetlock (Fig. 164).

If the member, as a whole, is situated outside of this line, or if the separation of the hoofs alone be too great, the horse is said to be too open behind.

If this only involves the region of the hock, the subject is styled bow-legged. 
If it is that of the toe, he becomes crooked-legged behind.

Conversely:

When the member, as a whole, is deviated inuard from the vertical, or if the separation of the hoofs alone is too small, the animal is called closed behind.

If it is simply the hoek, the latter is strled close, close-hammed, cow-hocked.

Finally, if it is the region of the toe, the horse becomes cross-footed behind.

Horse too Open Behind (Fig. 165). - Two different trpes of conformation may give rise to this defeet, for the direct axes of the posterior members, in order to be properly situated under the body, should not only follow the vertical, but also maintain between them a proper degree of separation. In some horses the line of axis divides the hock, the canon, the fetlock, and the foot, as in the normal conformation; the interval comprised between the two hoofs is, alone, greater than the width of the fetlock. There are others, on the contrary, whose members are deviated to the outer side of the vertical line and in which the distance between the two hoofs is too great. It is this disposition which is represented in the figure.

In the first case, the injurious effects

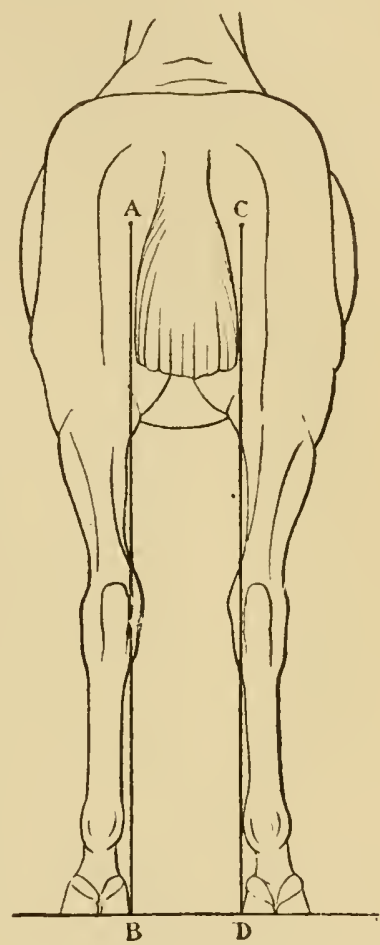

FIG, 165. are of little importance and only depreciate horses used for speed, by augnienting to excess the base of posterior support and producing a rocking motion behind, detrimental to the speed of the gait, but without any unfavorable influence upon the other services. The wide opening behind is due, ordinarily, to the width of the thorax and the croup, as well as to the development of the muscles. There is nothing very unfortunate in this, as Merche has remarked, in heary draught-horses and colts of the common races. It should, under the circumstances, even be considered as a point of beauty, if it can be demonstraterl that it is compatible with the existence of a regular axis. And as the latter does not exclude it, this is 
our only reason for giving the preference to such a conformation as the one in question.

In the second ase, the excessive separation of the members is very decidedly objectionable in the animal : first, because the members no longer support the weight in the direction capable of completely destroying its effects; secondly, because the in ferior divergence depends too often upon a narrowness of the pelvis at the level of the cotyloid carities and upon the mode of defective articulation of the posterior osseons segments. Besides the rocking, the lack of power, the diminished

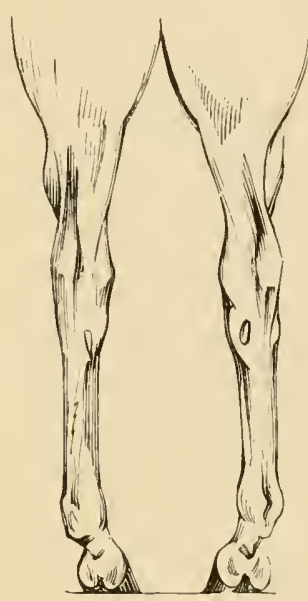

FIG. 166. velocity of the gait, and the unpleasant aspect in locomotion, the animal is also predisposed to become affected prematurely with diseases of the hock, of the fetlock, and of the foot, whose internal parts are more overburdened than when in a normal state. It is for these reasons that he becontes less serviceable, a fact which of itself means a notable diminution in his value.

Hock arched Outward-Bow-legged Horse (Fig. 166).-This defect is characterized by a curvature of the region of the hock external to the line of axis, as well as by a considerable separation of the calcanea. It is sometimes found in.horses too open behind, and is accompanied in most instances by a convergence of the hoofs in front, a conformation which renders the horse cross-footed as well as bow-legged. Hence the hock thus arched is defective in the first degree, on account of the numerous deviations which result from it and which deprive the posterior limb of a part of its aptitude to support the trunk. Besides, it is rotating when the foot is on the groumd. (See Defects of the Gaits.) Finally, it renders the gait ungraceful and sometimes induces rocking.

Horse Crooked-legged, Outbow-footed Behind (Fig. 168). - Wre will not detail here this vicions direction of the foot, which exposes the inferior regions of the hind-members to the same accidents as those which we have indicated in the fore-members. Let us only recall that it is often the conserquence of hocks too close together, which corresponds, as we know, to the close or cow-hock.

Horse Closed Behind (Fig. 167).-The closeness behind, like the same condition in front, presents two distinct cases, althongh differing little in relation to their gravity. In the one, the axis of the members remains normal, but it is too close to the median line. 
In the other, the direct axis of the members deviates internally to the vertical, and the space between the two hoofs is too small. It is this which is represented in the figure.

Whatever may be its form, this defect of the axis is to be taken

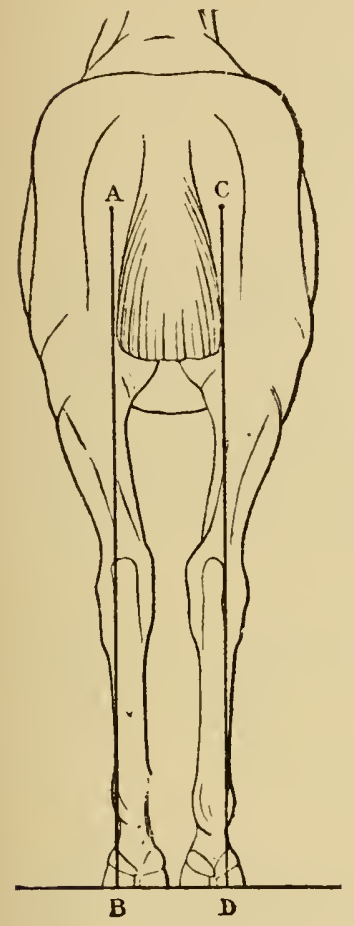

FIG. 167. into very serious consideration. It is invariably observed in subjects with narrow chest, croup, and loins, with feeble muscular development, without action, without vigor, and without energy, lacking stability, disposed to interfering, awkward in locomotion, and, especially, unable to trot on uneven roads.

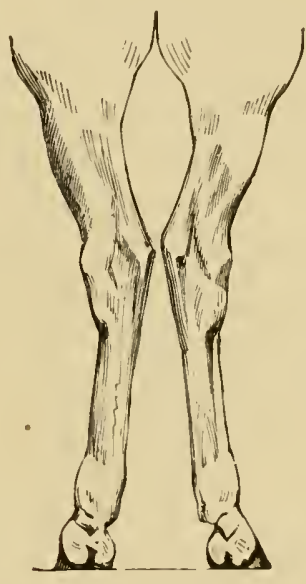

FIG. 168.

Hocks Close, or Hooked-Horse Cow-hocked (Fig. 168). -The greatest disadvantage of the cow-hocked, close-hammed horse, which, according to the vulgar expression, has the legs en pieds de banc (or is "bench-legged"), is his being ungraceful in his gaits, at the same time that he is outbow-footed behind. The normal movement of alddnction of the canon is here exaggerated when this region is flexed. I sort of rocking is also produced from the fact of the too great separation of the posterior feet. Finally, the impulsion communicated by these members is less direct, less powerful, less rapid, than when the osseons levers move in a plane ahmost parallel to the median plane.

Vallon says, with reason, ${ }^{1}$ that this conformation is common to 
many of the loorses in mountainous comtries, especially remarkable for their aptitude for resisting fatigne and privations. It seems to exist likewise in the Barl, horses and in those of Central France. If this remark is well founded, we should not, however, imagine that there is a relation of eanse and effect between this disposition of the hock and the qualities to which allusion has been made. The robustness and the energy of which Vallon speaks pertain especially to the race, to the blood, to the conditions of existence, and to the manner of rearing. These qualities would not in any manner be less if the hock, instead of being hooked, were well directed.

Horse Cross-footed Behind (Fig. 166).--The convergence of the hoofs by their anterior part is usually the conseguence of the deviation of the hock externally to the vertical line. It gives rise to the same accidents and disadvantages as in the forc-members. The contact of the foot with the ground is uneven; it takes place more especially upon the external mamma, and the animal, awkward in walking on uneven ground, frequently strikes himself with the internal mamma. His movements are ungraceful and lack the precision necessary to an energetic and rapid impulsion from behind.

Following the example of several authors, especially Vallon, ${ }^{1}$ we will here give the synoptic table of the axes, their defects and their principal inconveniences.

\section{ANTERIOR MEMBER.}

Member viewed in Profile.

\section{REGUlar AXES.}

A vertical line lowered from themiddle of the arm should intersect the middle of the hoof and remain equidistant from the vertical lines drawn from the point of the shoulder and from the sum. mit of the elbow.

A rertical line drawn from the articulation of the elbow should pass through the middle of the knee, the canon, and the fetlock and fall a short dis. tance behind the heels.

\section{IRREGULAR AXES.}

If this line falls in front of the hoof, the horse is under himself.

(Bruising of the heels: excess of If it falls behind the hoof, weight on aud wear of the hocks and the horse is camped. in standing and uncertainty of the

fore-feet; slow gaits.

Excessive wear and strain of the bones, the tendons, and the ligaments: slowness of the gaits: insecure foothold on the ground; tendency to fall; forging.

If the knee projects in (Index of use and weakness of the front of this line, the horse $\{$ fore-members: fatigne; nucertain conis arqué or knee-sprung.

If the knee is carried be- $\int$ Strain of the lateral and posterior lighind this line it is said to aments of the knee; preniature blembe hollow, effaced, a sheep's ishes of this region; lack of firmness knee. of the anterior nembers.

If the vertical line falls too $\int$ Strain of the ligaments of the fetlock far behind the heels, the $\{$ and of the flexor tendons; predisposi. subject is long- or low-jointed. (tion to overreaching; easy reactions.

If it meets the heels or the anterior parts of the foot, the horse is short- or straightjointed.

Surcharging of the phalanges; predisposition to knuckling and contraction of the heels: reactions hard. 


\section{ANTERIOR MEMBER-Continued.}

\section{Member viewed in Front.}

REGULAR AXES.

A vertical line drawn from the point of the shoulder should divide equally the knee, the eanon, and the foot, and leave between the two feet an interval equal to the width of the hoof, taken from one quarter to the other.

IRREGULAP AXES.

If the member, as a whole is situater outside of this line, or it the interval between the hoofs is too great, the horse is too open.

If the knee be deviated outward the horse is said to be bow-legged.

Conversely:

When the member, as a whole, is situated inside of the vertieal line, or when the interval between the two hoofs is too small, the horse
A rertical line inter secting the middle of the leg should pass, above, through the coxo-femoral articulation, eross, below, the initlde of the hoof and remain equidistant from the vertical lines drawn from the stifle and the angle of the buttock, the latter being tangent to the point of the hock and to the fetlock.

\section{DISA DVANTAGES.}

If it be the toe alone, the body; standing upon internal quarter subjeet is crooked-legged. slow and ungracetul gait. The horse stow and ungracetul gait. The horse of the shoe. is close or narrow.

Diminution of the base of support instability of the equilibrium; predisposition to ealking. Frequent indications of a want of endurance, defeetive development of the breast, narrowness of the chest, and feeble volume of the museles.

Loss of firmness of the step and of

If it is the region of the knee alone, the latter is ealled an ox's knee.

Finally, if it is that of the toe, the horse becomes cross( footed, parrot-toed.

eed: strain on the internal ligaments of the knee; overburdening and wear of the external parts; outwarl deviation of the foot; ungraceful gaits.

Standing upon the external quarter elbows separated: overburdening of the phalanges and the external side of the artienlations; ungraceful movements of the eanon: slow gaits; the horse stumbles and interferes with the internal mamma.

POSTERIOR MEMBER.

\section{Member viewed in Profile.}

If the member, as a whole is placed in advance of this line, the horse is under himself.

If, on the contrary, it is plaeed behind this line, the animal is camped.

If onky the parts below the fetloek are deviated, so as to earry the midale of the foot in advance of this line, the horse is long-or low-jointed.

If, in the same eonditions. the middle of the hoof is placel behind this line, the horse is shorl- or straightl jointed.
Shortening of the base of support crooked hocks; predisposition to slipping forward; fatigue of the extenisor museles, the ligaments, and the tendons: sureharging of the posterior nembers; slow gaits; premature blemishes of the hoeks and of the fetlocks: forging.

Lengthening of the base of support: tendeney to slip backward: sur charcint of the fore-limbs: strain on the back and holls: sway-back; feeble impulsion: slow gaits.

Same evil consequences as in the anterior member; predisposition to windgalls.

Same, but less serious, consequences as in the anterior member. 
POSTERIOR MEMBER-Contimued.

Member viewed Behind.

REgUlar AXES.

A vertical line drawn from the point of the buttock should pass through the median plane of the inferior part of the member from the point of the hock to the foot, and leave between the two hoofs an interval almost equal to the width of the fetlock, taken from one lateral face to the other.
IRREGULAR AXES.

\section{DISADVANTAGES.}

If the member, as a whole, is situated on the onter side of this line, or if simply the separation of the hoofs is too great, the horse is too open.

If it concerns the region of the hock alone, the horse is bow-legged.

If it is that of the toe, the subject is outbow-footed.

Conversely :

When the member, as a whole, is situated inside of the vertical line, or when the separation between the two hoofs is too small, the animal is elose or narrow.

If this is true of the hock alone, the latter is close, con hocked, and the subject is close-himmed

If it is the region of the $\{$ Same disadvantages us in the ante-

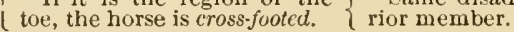

Width of the base of support and stability of the equilibrium: trequently ontward deviation of the hock and the heels; slow and ungraceful gaits in consequence of the rocking; standing on the internal quarter of the hoofs. Sometimes, indicative of the width of the cliest, of the loins, of the croup, and of the development of the museles; at other times, indieative of a narrow ( pelvis and feebly-developed muscles.

Strain of the external ligaments of the hock; overloading of the internal parts; inward deviation of the toe: standing upon the external quarter: gaits ungraceful ; impulsion less direct.

Same evil consequences as in the anterior member.

Narrow base 'of support; unstable equilibrium; indications of narrow: ness of the ehest, of the loins, and of the croup: feeble development of the muscular system ; members unsteady weakened foothold. The horse is dis. posed to interfere.

Ontward deviation of the foot: un graceful flexion of the caunon: impulsion less direct and less powerful; slow gaits.

\section{B.-Lying Down or Decubitus.}

These names are given to the attitude which the animal takes when he rests, and in which the trunk is placed direetly in relation with the ground.

We often see horses sleep while standing, even when harnessed. They usually stand in such a manner that either one foot, or the two of the same diagonal biped, are rested, or bear less weight, and remain in this position until the supporting columns are replaced by those which previously supported the body.

In general, horses do not lie down much, unless they are very tired. Yet, we have known a mare with very flat feet which laid down before eating as soon as she entered the stable.

A certain preparation is necessary for the horse to execute the decubitus: It consists in drawing together the four feet under the body in such a manner as to diminish the extent of the base of support. Then the animal lowers the head, flexes the knees mutil they touch the ground, and gently allows himself to fall over upon the side, the right or the left. 
The subject will now assume one or other of the two following positions :

Thus, in the sterno-costal decubitus, the body, leaning towards the right, for example, rests upon the sternum and the abdomen, while the four members, all semi-flexed, are directed towards the opposite side, the right being under the trunk. The head and the neck, being a counterpoise, are inclined towards the left, although elevated and supported by the resistance of the elastic nuchal ligament.

In the lateral decubitus, the head, the neck, the trunk, and the members of the corresponding side are stretehed out on the ground. This variety of attitude, more rare than the former, is, in general, only observed in colts and in debilitated or diseased horses.

Concerning the dorsal decubitus, it is very difficult in the horse, on account of the narrowness of the neck, the withers, the back, the loins, and the croup. Nevertheless, it is seen in cireus horses and in those which are especially dressed for it, but which are unable to maintain it for a long time. In all other circumstances, it should be considered that a horse which takes this position is suffering from serious colic,principally from hernia.

After a more or less prolonged rest, the animal rises. 'To accomplish this, he extends the neck and the head for the purpose of extending and carrying forward his fore-members, first the upper and then that which lies under the body: this is a sort of preparatory action. By a new effort, these members place the body, as M. Colin ${ }^{1}$ has elearly proved, in the position which a dog assumes when sitting upon his thighs. Finally, the abdominal members, in their turn, by their extension, raise the body.

Almost immediately the spine is extended and the hind-limbs stretch themselves one after the other ; sometimes the animals gape, and everything then returns to its normal state.

It is not practicable to see the horse lie down at the time of purchase; nevertheless, important indications could be drawn from its examination. Certain horses have the vicious habit of lying down like a cow, - that is to say, of having too great a flexion of the feet upon the forcarm, and thus eontusing the inferior part of the elbows with the internal heel of the shoe. There results from this, after a time, the formation of tumors, to which we have already ealled the attention of the reader. (See page 221.) 


\section{CH A P T ER II. \\ MOVEMENTS UPON PLACE.}

\section{A.-Rearing.}

REARING is an attitude in which the fore-part of the body, raised above the soil, is maintained in equilibrium upon the posterior members. It is perceived that, as a rule, it can be preserved only during a very

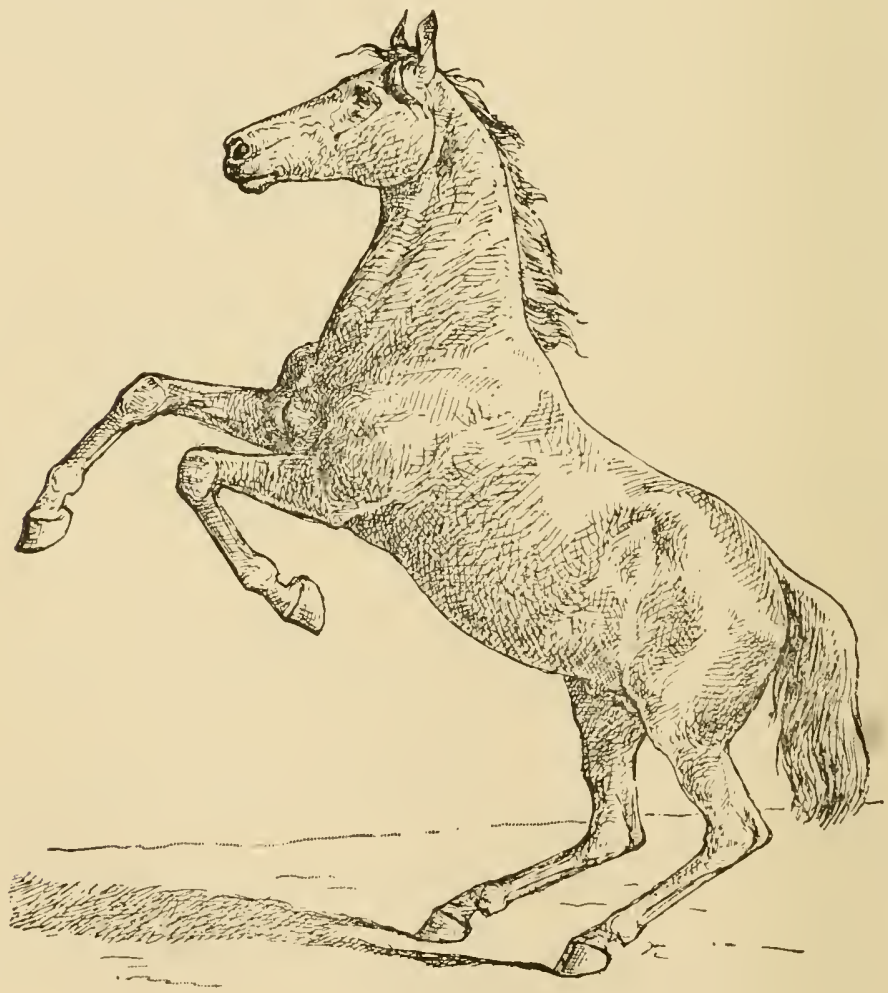

FIG. 169,-Rearing.

short space of time, on account of the small base of support represented by the contact of the two hind-feet with the ground (Fig. 169).

The horse rears under different circumstances, indicative of his 
good spirits, of impatience to act, or of restiveness ; to defend himself, attack, leap, or, finally, to mount the mare.

Its accomplishment is preceded by a very short preparation, during which the members are drawn together and the head quickly lowered, often severul times repeated. Then the time of execution is manifested by the sudden and successive extension of the head, the neck, and the trunk, and, finally, by the energetic contraction of the extensor muscles of the fore-limbs, which are at first semi-flexed. The extensors of the head, of the spine, and of the anterior members, the gluteal and the ischio-tibial muscles, are the principal agents in this sort of rotation of the fore-quarters upon the hind-quarters.

As soor as rearing is effected, the foothold exists only on the posterior bipeds, whose segments, more or less flexed, are maintained in situation by the contraction of their extensors. We can thus see the amount of the resistance which the animal must overcome and the length of the lever upon which it acts; we can also easily understand the readiness with which the line of gravitation tends to fall outside of so narrow a base of support. All this explains the shortness of the duration of rearing. Soon after it is accomplished, the fore-part of the body is lowered and the fore-feet fall upon the ground.

Nevertheless, there are some very vigorous horses capable of maintaining this attitude for a much longer time than others. This is true on condition, as Borelli ${ }^{1}$ says, that the base of support be frequently displaced. H. Bouley ${ }^{2}$ adds, that it is due to another fact, that their hocks are wide, their lumbar, croupal, and ischio-tibial muscles well developed, and that the fore-part of the body may be relatively light. Those which are weak in the hock and in the loins only accomplish it by the energy of their will; but no sooner have they raised themselves upon their hind-limbs than they will recover the quadrupedal station or else fall over sideways or backward. The easy, natural rearing is, therefore, a sign of force and of energy. The English hunter and the Arabian horse execute it with great ease; if these animals liad not this aptitude they would be incapable of lannching themselves into space with the marvellous agility which is peculiar to them, and could not clear with so much ease the obstacles which they meet in the steeple-chasce.

The facts mentioned above are not very rarely observed; the following are some examples:

A stallion, called Le Commode, some twenty years of ange, and placed

1 Borelli, De motu animalium, 173. (See Proposition CLXVII., Tab. 13, Fig. 11).

2 II. Bouley, Nouveau Dictiomnaire de médecine, de ehirurgie et d'hygiène vétérinaires, t. ii. p. 655 . 
at the school at Alfort for the stud in 1817, balanced himself upon his hocks as soon as he saw the mare on the ground, and walked to her in this bipedal position. ${ }^{1}$

Vallon ${ }^{2}$ mentions that there was, at a certain period, a stallion, named Molok, which walked upon his hind-feet for almost a minute before momting the mare. He has seen at Paris a horse, ridden by a woman, walk over quite a long space upon his posterior members.

Concerning our own experience, we have known a small stallion, of Spanish origin, which was exhibited at a eircus in Paris, and which, having reared, walked across the ring, ascended a flight of stairs consisting of fourteen steps, described a circle upon a platform, descended the stairease, and walked across the ring withont falling upon his fore-members.

A repetition of rearing is very fatigning, espeeially to the loins, the hocks, and the fetlocks. It is also common to see in sueh horses, particularly stallions, sway-backedness as well as premature blemishes of the articulations of the lind-limbs.

The horses which rear without any purpose are the most dangerons; we will speak of this when treating of vicions horses.

\section{B.-Kicking.}

Kicking is an action opposite to that of rearing. The horse which kicks suddenly elevates his hind-quarters upon the fore-quarters, and forcibly throws the two posterior members backward for the purpose of attacking or defending himself, or of dismounting his rider, sometimes from simple impatience to act or from playfulness. It is allied to certain progressive movements, such as leaping, galloping, ete.

Kieking, like rearing, is execnted in two periods: the preparation and the action (Fig. 170).

First Period.-There is first a very rapid drawing together of the bipeds with a view of shortening the base of sipport when the kick is to be low; a separation, on the contrary, by drawing the anterior members forward, if the animal intends to kick very high ; withont the latter precaution he will be liable to fall upon his knees in the latter act.

At the same time, the head and the neek are suddenly lowered in such a manner as to project the eentre of gravity forward and earry a large portion of the weight of the trunk upon the anterior bipeds, in 
order to free the hind-quarters and facilitate their movement of rotation upon the fore-quarters.

Second Period.-By the sudden impulsion from the posterior members and the contraction of the dorso-lumbar muscles, the elevation of the croup now takes place, which is a movement in some

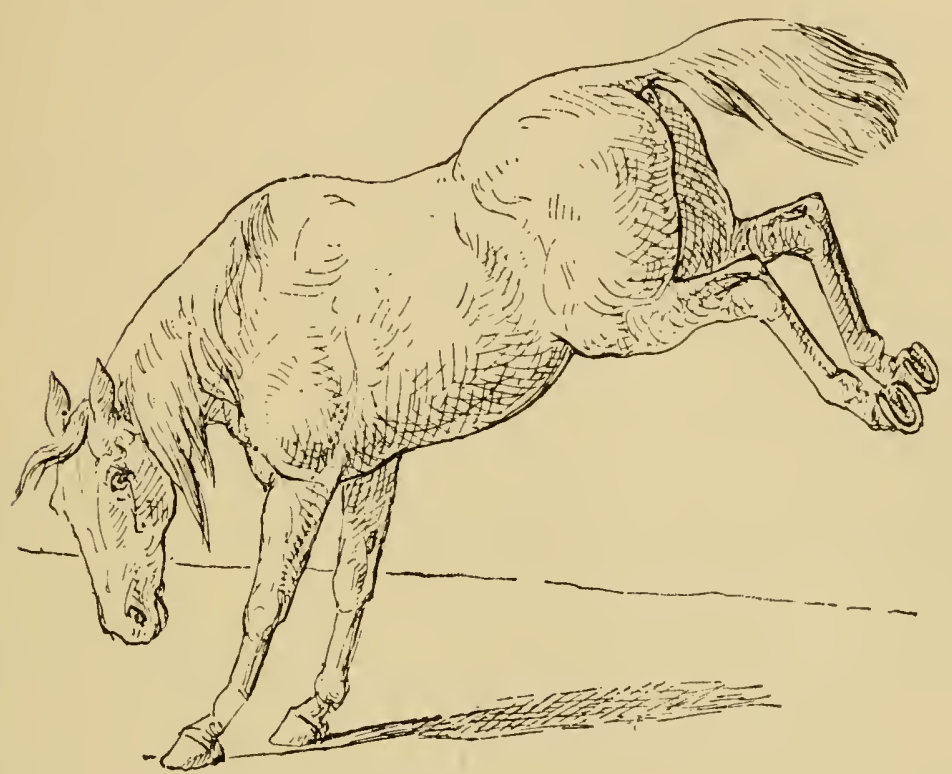

FIG. 170.-Kicking.

manner complemental to the previons lowering of the head and the neck. The extension of the thigh, of the leg, and of the canon follows almost immediately, and determines a vigorous retropulsion of the hind-feet, from the sudden and simultaneous contraction of the gluteal, the anterior femoral, and the gastrocnemius muscles.

The details into which we have entered when speaking of the rôle of the cord of the hock (see page 258) sufficiently explain the power of the hind-limbs, comparable, in this respect, to an elastic spring which recoils in an almost instantaneous manner, in consequence of the synergetic and sudden co-operation of the agents charged with the accomplishment of this action.

The kick has only a very short duration; the posterior nembers return to the ground almost immediately. Certain horses can repeat it frequently and without great fatigne, like the ass; they are short, wide, and powerful in the back and the loins, long in the croup, the 
thigh, and the leg, strong and wide in the hocks, well muscled, but relatively light in the hind-quarters.

When we come to speak of vicious horses, we will complete the other details which it is necessary to know concerning kicking.

\section{PART II.}

\section{MODE OF PROGRESSION, OR THE GAITS OF THE HORSE.}

\section{CHA P'T ER I. \\ GENERALITIES OF THE GAITS.}

Definition.-The name gaits (allures, from the French aller, to go) is given to the diverse modes in which progression is accomplished by the play of the locomotory members.

Applied to the horse, their study is of great interest. It enables one to appreciate the force which the animal expends, the speed which he employs, and the regularity with which he executes these movements. Equestrianism draws from it rational principles for dressing the horse; the artist deduces important facts for the true representation of the attitudes and the movements ; the horseman is taught to recognize his beanties and defects ; the veterinarian, finally, from a thorough knowledge of their mechanism, their irregularities, and their pathological modifications, is assisted in his diagnosis, and can deduce from them important therapentic indications.

Divisions.-The gaits are divided into:

Natural, when they are executed in a spontaneous and instinctive manner without any special education. Example, the walk, the trot, the gallop, at times the amble, and the rmning walk.

Acquired or artificial, when they result, on the contrary, from a special dressing. Example, the amble, broken amble, running walk, trot, and racing gallop.

Both may be either marched or lectped.

They are called marched, when the body does not cease to be in contact with the ground during their execution; leaped, when it leaves 
the ground entirely at certain moments, either during the same step or between two suecessive steps.

The styles of horsemanship is a name giren to a certain number of rhythmieal movements, comparable to dancing as performed by man, and acquired by the same elucation, which develop in the horse harmony of figure and suppleness of body; they communicate to him elegance, grace, and a good physiognomy. The principal movements are termed by the French the passage, the piaffer (pawing), the croupade, the ballottade, and the courbette.

Their study belongs to the domain of the high school, a superior equestrianism which teaches how to poise (to place without fatigue) the mounted horse in all the attitudes which his conformation renders possible. The number of exereises of the high school belongs more strietly to a treatise on riding and horsemanship, and will be omitted here.

A mounted horse is called poised or in equilibrium when he is capable, through the dressing, of obeying the aids of the rider (hands and legs) without unnecessary efforts and with the absolute freedom of those muscular groups whose action is neeessary to produce the desired effect. The animal, in such eases, preserves during his work what horsemen call suppleness of the movements; he beeomes, then, from his free and easy motions, altogether eomparable to the gymmast, master of his body.

\section{Diverse Qualifications applicable to the Gaits.-Accord-} ing to the forms which they assume the gaits are ealled:

Diagonal, when the members, in executing them, move or suceed one another in diagonal bipeds. Example, the trot, the walk, the gallop.

Lateral, when they evolve themselves, on the contrary, by lateral bipeds. Example, ambling, racking.

Beautiful, when they are energetic, extended, regular, harmonions, elegant.

Defective, when they produce weakness and require great exertion. Example, racking.

Long, elongated, when their strides are as cxtensive as possible.

Small, short, in the opposite case.

Reacting, high, when they impress the centre of gravity with strong vertieal displacements, which at each step very sensibly separate the body firm the gromud.

Low, when the distance of the displacements of the body from the soil is small. 
High-strained, when the members are greatly flexed without passing over much distance.

Repeated, if the movements follow each other with excessive rapidity, with or without the production of speed.

Hord, when they fatigue the rider by the violence of their reactions.

Eusy, in reverse conditions.

Light, if the percussion of the feet upon the soil produces little sonnd.

Heavy, if these percussions are violent and resounding.

Strong, rapid, when the locomotory action is quick, easy, energetic, high, extended, and rhythmical.

Free, when it is accomplished withont undue effort.

Regular, when the evolution of the members and their mode of association obey, for each gait, the principles of scientific analysis or of experience.

Uniform, when the speed is miform in consequence of the equal length of the steps.

General Considerations relative to the Play of the Members during the Gaits.-We recognize:

The beat, the sound produced by a foot or a biped when coming in contact with the soil.

The time, the period between two snceessive beats.

The contact, the time during which a member or a biped remains in contact with the soil. Example, first, second contact of the gallop.

The imprint, the trace left upon the ground after the contact by the foot which is rising.

The track, the succession of imprints indicating the character and direction of the gait of the horse.

The trail is rectilinear, if the progression takes place in a straight line; curvilinear, when it describes a curve; transverse, if the horse moves sideways to the right or to the left; single or double, aceording as the imprints of the hind-fect are or are not superposed upon those of the fore-feet.

When the imprints of the hind-feet are superposed on those of the fore-fect (se juge), which many horsemen, notably the school of Raabe, term the normal gait, the horse is said to "cover" his steps, to "check" his steps (se juger, se couvir)." When the hind imprints fall short of the fore, which, according to this school, is an unduly short gait, he is said to "ill-check" or "ill-cover" himself" (se découvrir, se 
déjuger). Lastly, when the hind are in front of the fore (a gait they style unduly lengthened), the animal is said to "overeheck," to "overcover" his steps (se mécouvrir, se méjuger).

They say also that the liorse trails himself (se piste), when one of the posterior bipeds marks its imprint npon the same transverse line as the anterior foot which is diagonally opposite to it ; again, the imprint of the posterior foot in question may be made in front or behind that of the diagonal anterior foot, and then the horse mistrails himself (se dépiste). These terms are only used for the gallop.

Since the time of Solleysel ${ }^{1}$ there have been distinguished in the evolution of a member two principal phases or periods, the contact with the ground and the elevation, luring which this member supports a part of the weight of the body or, on the contrary, is completely lifted from the ground. We have seen (page 195) that as soon as a member has passed successively through the two phases, the body has passed over a distance designated under the name of complete step. The two bipeds (anterior and posterior) are, in fact, conjointly concerned in its execution; and, even as an anterior member, for example, is incapable of taking two steps in succession without the intervention

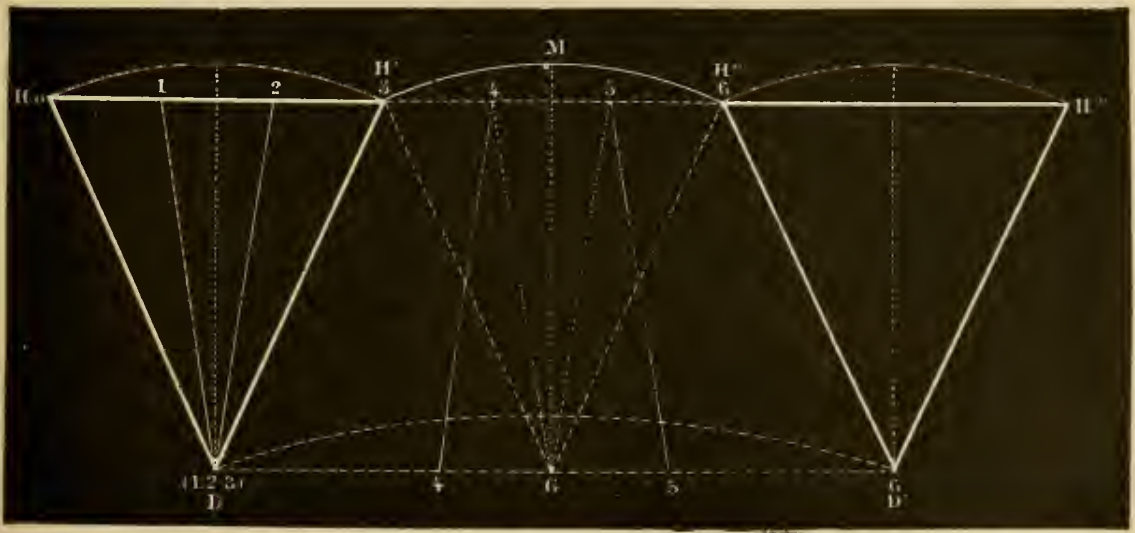

FIG, 171.-Scheme of the movement of a member during the phases of contact and elevation.

of its congener; even so, also, the anterior biped is unable to carry itself a certain distance in advance of its primitive position unless the posterior biped accomplishes exactly the same movement. ${ }^{2}$

On the other hand, it is known that during the evolution of any member (Fig. 171), the centre of movement, $H$, of this member, and, in consequence, the centre of gravity, progresses from $H^{\circ}$ to $H^{\prime \prime}$,-

1 De Solleysel, Parfait mareselıal, ed. de 1693, 2e partie, D. 66.

2 C. Bourgelat, Traité de la conformation extérieure du cheval, p. 24. 
that is to say, the distance $D D^{\prime}$, equal to the distance deseribed by one of the feet, the distance comprised between two attitudes, $H^{\circ} D$ and $H^{\prime \prime} D^{\prime}$, identical and successive in this member. (Sce Generulities of the Nembers, page 194.)

The length of the step is therefore measured by the distance separating the two points of contact, $D I)^{\prime}$, successive of the same foot. If the axis is regular, the vertical line which passes through the centre of suspension or of useillation of the member necessarily divides this intervening distance into two equal parts, each one equivalent to a semi-step.

Finally, we have also seen that the two prineipal phases, contact and elevation, insufficient for the needs of an exhaustive analysis, must be subdivided into equal secondary phases, ealled periods, six in number, as follows:

Phase of contact with soil. $\left\{\begin{array}{l}\text { 1st period, from } 0 \text { to } 1 \text {, commencement of the contact. } \\ 2 \mathrm{~d} \text { period, from } 1 \text { to } 2 \text {, middle of the contact. } \\ 3 \mathrm{~d} \text { period, from } 2 \text { to } 3 \text {, end of the contact. }\end{array}\right.$

Phase of elevation or advancement. $\left\{\begin{array}{l}4 \text { th period, from } 3 \text { to } 4 \text {, raising. } \\ 5 \text { th period, from } 4 \text { to } 5 \text {, middle of elevation. } \\ 6 \text { th period, from } 5 \text { to } 6 \text {, rest. }\end{array}\right.$

Periods of Exchange of Contact.-If, after the example of M. Lenoble du Teil, we study more attentively the evolution of the members of the same biped, anterior or posterior, during the marched gaits, we notice two moments when the weight of the body passes from one foot to the other, and vice versa.

Thus (Fig. 172), when the posterior right foot is placed on the ground, the left is not being lifted, as might be believed, but is really

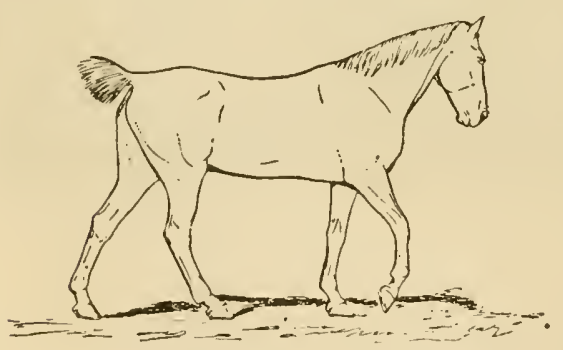

Fig. 172.-Exchange of contact upon the posterior bipeds in the walk.

(From an instantaneous photograph.) at the end of its period of contact; in the same way, it is only when the right foot commences its contact that its congener rises. In other words, in these gaits the commencement of the contact of one member does not wait until that of the other has been completed; it precedes the latter a short time. But for this the body would have no support during the interval between the successive movements. The consequence of this fact is that the duration of the contact of the foot with the ground is always longer than that of its elevation, contrary to the opinions of Vincent and Goiffon, 
Colin, and Raabe and his disciples, who admit the absolute equality of the two phases of contact and of elevation.

These two periods of the walk, well explained by M. Lenoble du Teil, ${ }^{1}$ have been called by him periods of exchange of the contact. In the middle of each of them there evidently exists a moment during which the body is equally supported by the two members at the same time. This anthor has also had reason to make three gromps of the preeeding six periods of the complete step: two of advancement, two of complete contact, and two of change of contact.

It is easy to understand that the change of the eontact with the soil, in the walk, for example, is all the longer and easier to ascertain as the gait is slower. As soon as the latter is aceelerated so as to simulate leaping, it is then seen to diminish eorrespondingly. Finally, it disappears immediately as soon as leaping is manifested. We will explain the particnlar details of this in discussing the gallop.

It is therefore throngh error that Messrs. Marey and Pagès ${ }^{2}$ elaim to have diseovered, in the marched gaits, the periods of double contact, the importanee of which they have besides enhanced, by saying that their existence permits the step of these quadrupeds to assimilate completely that of man, in whom these periods are very evident.

The speed, $V$, of a gait is valned by the distance passed over during a unit of time; naturally, it is proportional to the length, $L$, and the number, $N$, of the steps. The predominance of one of these factor's variess with the other in an inverse sense. Thus is dedueed the empirical formula $V^{r}=L N$. With equal speed, if $N^{r}$ angments (as in small horses), it follows neessarily that $L$ diminishes, and rice versa (as in large horses).

In gaits in which the body is always in eontact with the ground, the body and the feet are not advanced with the same velocity. This is dne to the fact that the centre of gravity tends to move in a uniform manner. Hence it is necessary that the feet progress more rapilly than the body to recover the time which they have lost in contact with the ground. The longer their eontact the greater will be their velocity compared to that of the body. This interesting fact has been well establisherl, as early as 1873, by M. Lenoble du Teil, who has republished it

${ }^{1}$ Lenoble du Teil, Étude sur la loeomotion de l'homme et des quadrupèdes en général, Paris, 187, p. 14.

This expression has also been employed by $\mathbf{M}$. Raabe in his work entitled Iléthode de haute école d'équitation (p. 29 el seq.), edited at Marseilles in 1863. This author, however, appears not to have deduced the results which follow from it.

2 Yarey et Pagès, Mouvement du membre pelvien ehez l'houme, l'éléphant et le cheval, in Comptes-Rendus de l'Aeadémie des seiences, is Juillet, $1 \varepsilon^{\prime}$. 
since ${ }^{1}$ M. Raabe ${ }^{2}$ attaches great importance to this and deduces from it this principle: "The relative velocity of the fect is proportional to the duration of their contact."

Time of Preparation.-The horse, before taking a step in any gait, first prepares himself by assuming an attitude which corresponds to the point of departure of this gait.

To use a familiar illustration, a man who, at the beginning of the walk, wishes to make the initial step with the left foot, must first carry the weight of his body on the right foot. This displacement of the centre of gravity varies with each particular gait; changing the situation of the head and a slight flexion of the members produce it, but these movements always have for their result the greatest possible disburdening of the member which is about to be carried forward. This principle is often applied in equestrianism. Bringing the head and neck of the horse to the right side, for example, facilitates the initial movement by the left.

Displacements of the Centre of Gravity.--The movements of the body over the ground implies displacements of the centre of gravity, and, consequently, a destruction of the initial equilibrium, which incessantly eompels the members to form new bases of support. Hence the members, each in their turn, come and prop it in front according to the ingenious comparison of Richerand, ${ }^{3}$ in the manner of the spokes of a wheel in relation to the weight of the hub which they sustain; the rapidity with which they succeed each other is so much more frequent as the imminence of a fall is greater. Here is the reason of the correctness of the expression, that the instability of the equilibrium, in these gaits, gives the measure of the velocity.

As Lecon ${ }^{*}$ has easily recognized, the displacements of the centre of gravity may take place either in a transverse sense, in consequence of the alternate support by the right and the left members, or in a vertical sense, from the successive degrees of the obliquity of the columns of support. The vertical displacements at times acquire a remarkable importance, as when the body is raised from the ground by the energetic impulsion of the hind-limb. The name of period of suspension is given to this phase of the leaping gaits.

The diseiples of the sehool of Raabe ${ }^{5}$ (all the displacement simple

1 Lenoble du Teil, Note communiquée, et loc. cit., p. 107.

2 C. Raabe, Régles du mécanisme des allures du cheral, in Spectateur militaire, année $1 s \$ 3$.

${ }^{3}$ Le Baron Richerand, Nouveaux eléments de physiologie, 10e é., Paris, 1833, t. iii. p. 148.

4 Lecoq, Extérieur du cheval, 5e éd., p. 346.

5 E. Barruil, liart équestre, p. 20, Paris, 1857. 
when there is perfect superposition of the imprints of the fore- and hind-feet (normal trot), or when those of the diagonal bipeds are in the same transverse line (normal gallop); projectile, when the imprint of a posterior biperl is in front of that of the corresponding (elongated trot) or the diagonal (fast gallop) anterior biped. The knowledge of the upuard and the lateral oscillations of the centre of gravity permits us to understand how each particular gait gives to the rider as well as to his mount more or less fatigue and exertion than any other.

Reactions.-This term designates the more or less strong concussions or tossings which the horse in motion experiences or communicates to the rider. In a general manner, they are proportionate to the height of the displacement of the centre of gravity, and, consequently, to the energy of the propulsive force, the speed employed, and, all things being equal, also to the length of the step, since the latter angments the initial and final obliquity of the members in their contact with the soil.

A gait is sufficiently defined when in it can be recognized the following characters :

1st. The number, the intervals, and the mode of association of the beats.

$2 d$. The duration of the contact and of the elevation.

3d. The trajectory of the members in the air.

4th. The ticill.

5th. The speed.

6 th. The displacements of the centre of gravity.

Let us see how each one of these diverse factors is deduced:

\section{Analysis of the Gaits.}

1st. Direct Observation.-We must not lose sight of the fact that it is by attentive, judicious, and patient observation of the horse in motion that the largest number of data concerning his gaits has been collected. The veterinarians and horsemen of the last century had already, without recourse to any instruments of precision, discovered most of the facts which the new methods have since only verified. They recognized, for each gait, the order of raising and resting the feet, the mode of association of the members, the number, succession, and rhythm of the beats, the form of the trails, the length of the step, and the nature, the extent, and the direction of the base of support. Some of them even had endeavored to establish a relation between the dimensions of the animal and the length of his strides.

Unfortunately, our external senses being unable to jerceive phenomena of so short a duration as those which take place in the rapid gaits, the first observers were unluckily led to commit errors and to leave blanks, doubts, and obscurities in their writings, whence have originated some processes for more thorough investigations. 
2d. Graphic Method.-It is to M. Marey, the learned professor of the Collége de France, that the merits of the greatest progress realizerl in this new direction must revert. In applying his method, ealled the graphic, to the study of the locomotion of the lorse, he has determined in an alnost definite manner most of the principles previously doubtful. ${ }^{1}$

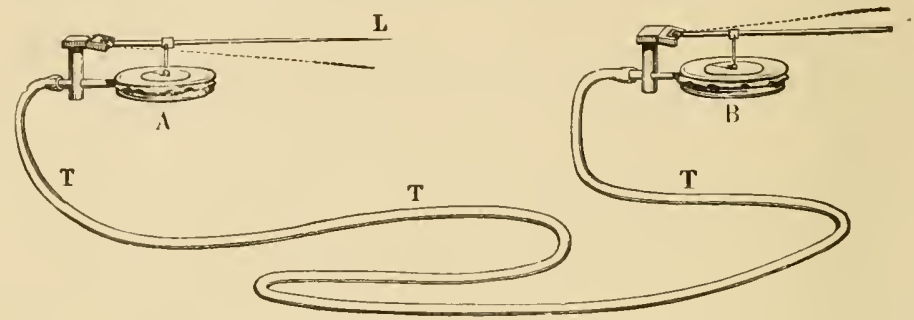

FIG. 173.-Two drums with a lever and tubing to carry the compressed air. (Marey.)

Process with Compressed Air.-Let us suppose two drums, $A$ and $B$ (Fig. 173), each one formed of a metallic case closed above by an India-rubber

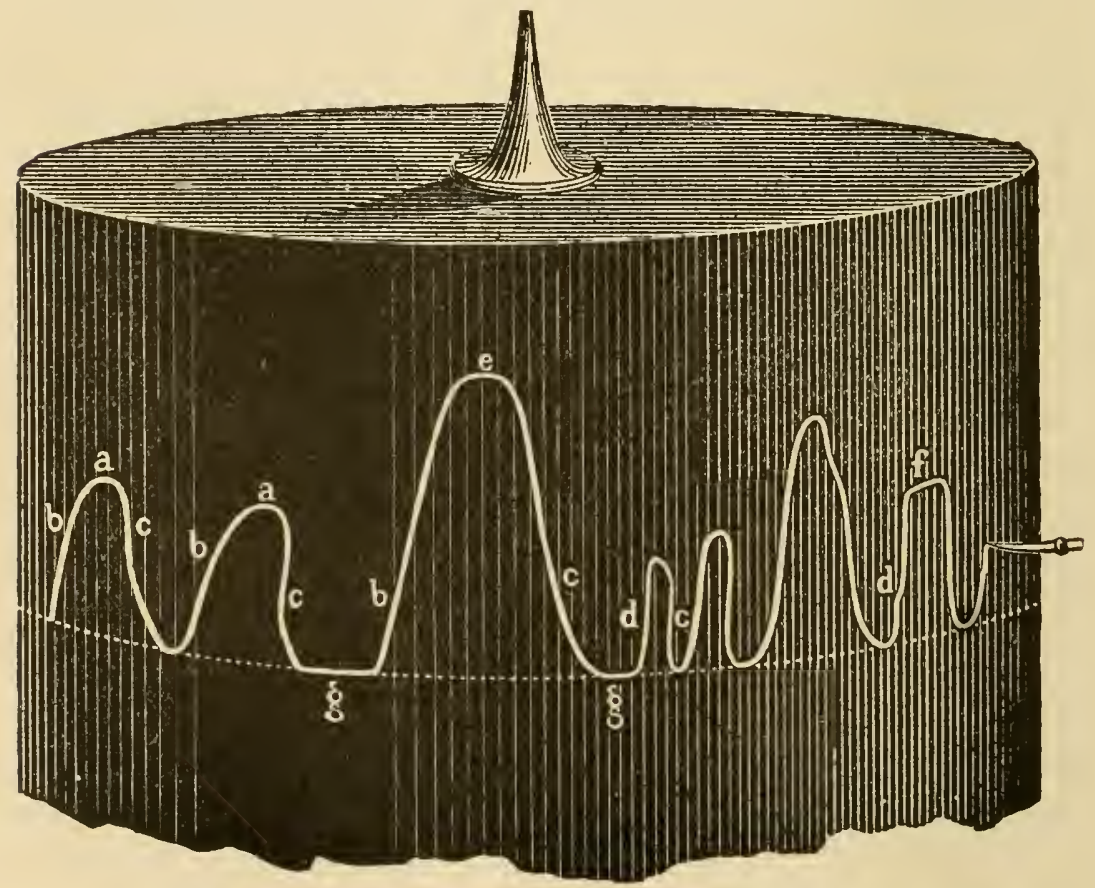

FIG. 174.

membrane. Upon this membrane is fixed an articulated lever, $L$, capable of executing to-and-fio vertical movements.

1 Marey, La machine animale, p. 146, et suiv. 
Finally, the two drums are connected with each other by means of a rubber tube, $T, T, T$. The apparatus being closed and full of air, it is apparent that all pressure exercised upon the drum $A$, for example, will force the air through the tube $T T$ into the drum $B$, whose membrane, as well as its lever, it will elevate. As soon as the pressure ceases, the two levers will naturally return to their initial position. From this unity of action of the two drums any movement whatever can therefore be transmitted from a distance, and even amplify itself if the length of the lever be augmented.

Moreover, let us imagine a cylinder (Fig. 174) covered by a layer of smoked paper, turning circularly in a uniform movement, by a sort of clock-work, opposite to one of the levers transformed into a registering needle.

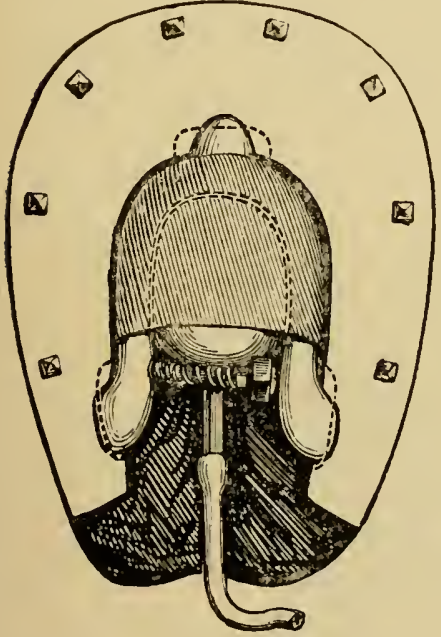

FIG. 175.-Chaussure exploratrice, or pneu. matie foot-bulb of Marey, for the registration of the gaits by eompressed air.

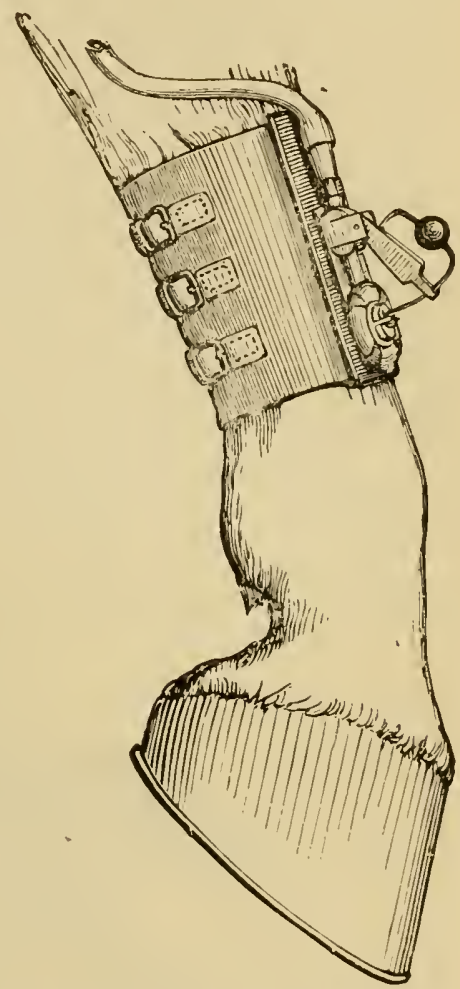

Fig. 176.-Bracelet explorateur, or pneumatic bracelet of Marey, for the registration of the gaits by compressed air.

It is easy to understand that the least displacement of the latter will leave its trace upon the paper. All pressure will produce a more or less marked deviation of the point of the needle; if there is no pressure the line traced will be straight from the point of its origin to its termination.

The figure of the tracing of a gait (Fig. 174) is therefore a eurve offering a series of vertieal undulations, $a, a$, whieh correspond to the pressure transmitted to the registering apparatus by the coneussion and the eontret of the hoofs upon the ground.

The traeing reads from left to right. The aseent, $b, b, b$, of each undulation iulieates an inerease of pressure, a contact of the member; the descent, $c, c, c$, signifies, on the eontrary, a diminution, an elevation of the member. For the same veloeity of the revolving eylinder, the more vertical the ascent is the more sudden the pereussion with the soil has been; the higher it is, $e$, the stronger the percussion has been. When the curve, $f$, at the summit of the undulation becomes parallel to the horizontal, it is a sign that the pressure is uniform; when it is parallel 
to the horizontal at the base of the undulation, $g, g$, it shows that the diminution of pressure remains stationary.

Four inseribing ueedles, corresponding to the four feet of the horse, and perpendicular to the axis of the cylinder, trace upon the latter the contacts and the elevations of the members.

Each foot is provided (Fig. 175) with a pneumatic bulb (chaussure exploratrice), composed of an India-rubber bulb stuffel with hairs and maintained under the hoof by three claws or catches whieh fasten it to the shoe. Each time the foot is placed on the ground, the bulb, strongly compressed, forees a portion of the air which it contains into the registering drum. When the foot is raised, it again becomes filled with the air which was expelled, and resumes its form.

This apparatus not being utilizable on the bard ground of ordinary roads, M. Narey has invented another very ingenious instrument which registers the morements of the feet on any kind of soil.

It consists (Fig. 176) of a sort of leather bracelet, attached by means of leather straps to the eanon of the horse. In front, this bracelet earries a flat rubber bulb, communicating through the tube of transmission with the registering drum. Upon this bulb is laid a piece of copper inelined at about 45 degrees and artieulated at its superior extremity. Finally, upon a rod parallel to the plate of eopper glides a leaden ball wlose variable position permits an augmentation or a diminution of the pressure whieh this articulated apparatus is capable of exereising upon the rubber bulb.

When the foot touehes the ground, the ball tends to continue its eourse and suddenly com. presses the bulb; when the foot is elerated, the inertia of the ball, in its turu, produces a new compression.

Tubes of transmission (Fig. 177), with a thiek wall in order to resist twisting, and main tained along the members by bands of flannel, are connected with the registering drums, themselves

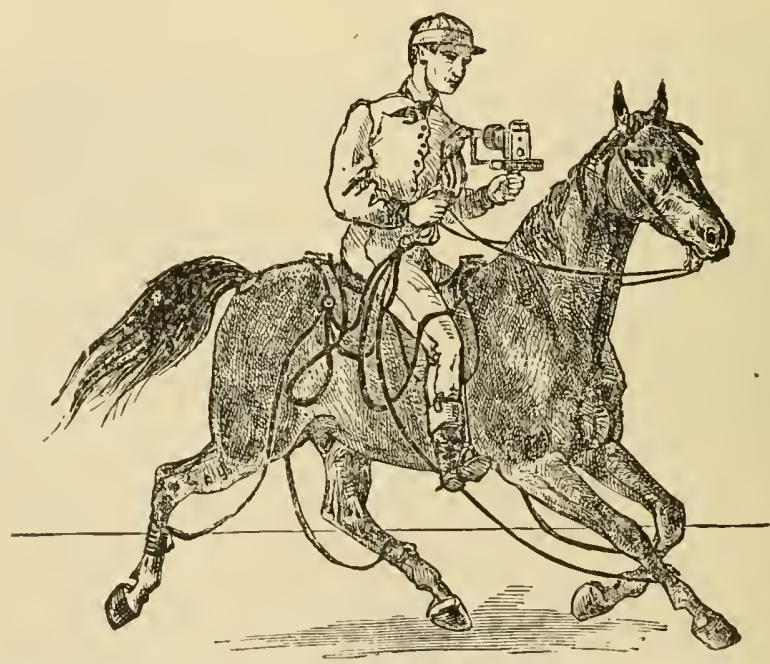

FIG. 177.-Registering apparatus of Marey applied upon the horse at the trot.

fixed to the eylinder which the rider holds. A ball of rubber, plaeed in one of his hands, enables him, when it is compressed, to bring the ncedles in eontact with the paper. In this manner the tracing can eommenee or terminate at the will of the experimenter as soon as the gait of the horse has been regulated.

Process with the Electric Current.- Since his first publications, M. Marey, always in search of improvement, has written the following on this subject: ${ }^{1}$

1 Marey, La méthode graphique dans les sciences expérimentales, et particulièrement en physiologie et en médeeine, Paris, 1878, p. 160. 
"If I were to commence again, at the present day, experiments of this nature, I would give up the compressed-air process and adopt the light electrical needles, like those of M. Marcel Deprez. Thin conducting wires would be more easily arranged along the members of the horse than the rubber tubes, and it would be more easy, I believe, to attach under the hoof an apparatus which closes and opens an electric current during the contacts and elevations of the foot than to apply the preumatic foot-bulb. . . The notation of the gait would thus be obtained directly, in a more precise and simpler manner than in my first experiments."

This registration of the gaits of the horse by means of electriaity has just been achieved by one of $u s^{1}$

Our apparatus is composed : 1st, of four chaussures exploratrices; $2 \mathrm{~d}$, four dry piles of chloride of silver carried by the rider or placed in the vehicle drawn by the horse; 3 , four electricat needles of Mareel Deprez; 4 th, a portable registering cylinder revolving at a uniform and known velocity.

Thin conducting wires, all well isolated, place the piles in communication with the chaussurcs exploratrices and the latter with the needles of Marcel Deprez; they follow the tract of the members against whieh they are maintained.

Our exploratory shoe consists essentially (Figs. 178 and 179) of a pedal, $P$, moval,le around an axis, $V$, attaehed to the frame $G$, whieh is solidly fixed to the shoe by means of two screws, $E$. A spring, $k$, kecps the pedal separated whenever the foot is in the air. In front, the latter is prolonged by a piece, $P^{\prime}$, which is slightly curved in front of the wall, while at its posterior extremity it is provided with a pont of contact, $C$, whieh is placed in relation with anotler point of contact, well isolated, adapted to the frame, and united to the knob $B$. A second kuob, $B^{\prime}$, receives the other condueting wire. Finally, a rubber membrane, $M$, preserves the points of contact from mud or dust.

It ean be seen that, in front and on the side, the pedal forms a box to prevent the entrance of foreign bodies between it and the frame, a disposition which assures the liberty of jts movements. 2

So long as the foot is in the air the two points of contact touch each other and complete the current; but as soon as the hoof touches the ground they are separated and interrupt it. At each raising and resting of the foot it is again closed and broken. The closing and breaking being instantaneous, and, moreover, the force of the spring and the projection of the pedal being capable of modification at will, it is easy to give to this apparatus great strength with all the precision and sensibility desirable.

Although we have not yet had the opportunity to employ it in our researches, its construction being but just completed, we have nevertheless been able to assure ourselves of its accuracy, in all the gaits, upon such a resisting surface as that of our macadamized roarls. By its aid we expect to register with more accuracy than has heretofore been aceomplished the periods of the change of contact, the rhythm of the beats, the number, the nature, and the liverse bases of support which may exist during the accomplishment of the complete step of any gait, normal or pathological.

Hydrostatic Method.-M. L. Hoffmamn, of Berlin, has conceived the idlea of applying to the analysis of the gaits of the horse the method alled the hydrostatic, invented by H. Vierordt for the study of the gaits in man. ${ }^{3}$

${ }^{1}$ G. Barrier, Explorateur élcetrique pour l'enregistrement des allures du cheval, in Bulletin de la Société centrale de médecine vétérinaire; séance du 28 . Iars, $185 \%$.

2 Since the construction of this figure, we have given to the posterior part of the pedal an analogous disposition, whieh dispenses with the rubber membrane, if needs be.

${ }^{3}$ L. Hoffmann, Das Exterieur des l’ferdes, p. 308, el sey., Berlin, 1887. 
To this end, he places some thirty metres of whitc paper along the ground over which the horse is to travel. Besides, he attaches to the external side of each hoof a brass tube directed

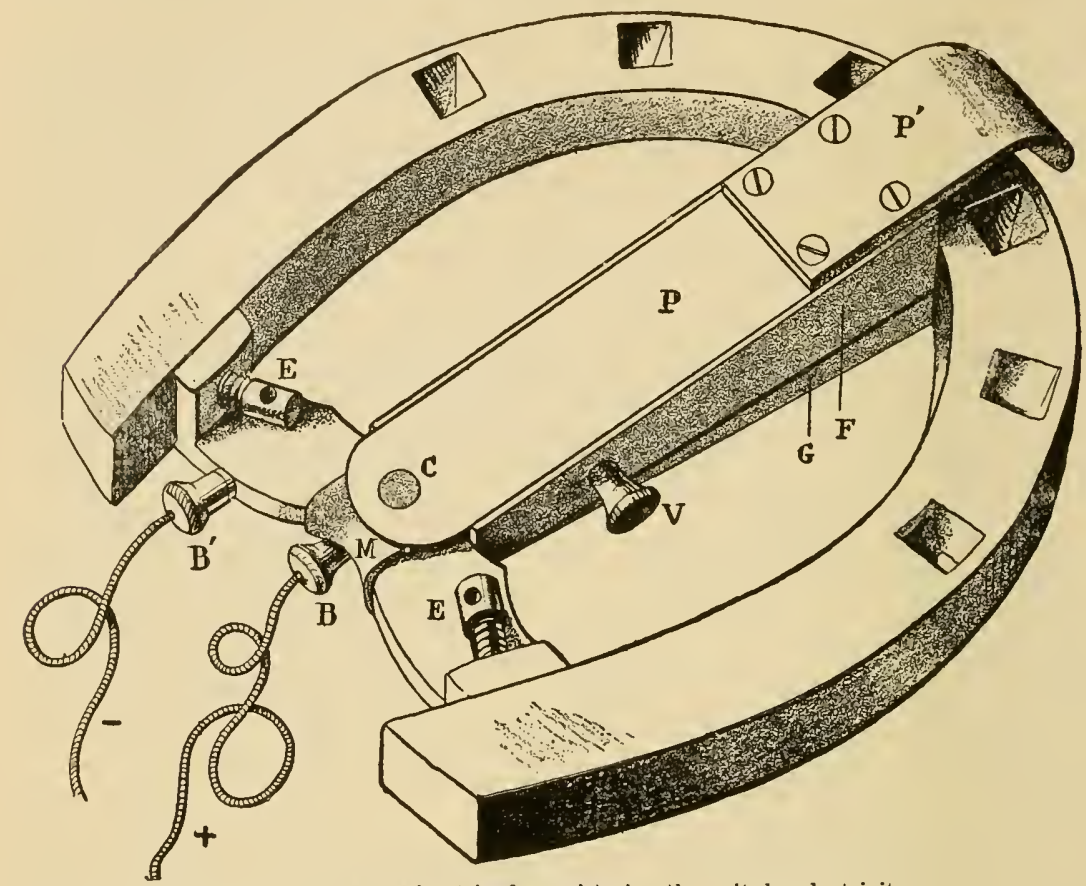

FIG. 178.-Chaussure exploratrice for registering the gaits by electricity.

$P P^{\prime}$, pedal with spring.

$V$, axis of the latter, unserewing for cleaning. $G$, frame for the pedal.

$E E^{\prime}$, serews fixing it to the shoe.
$F$, parietes of pedal forming a box.

$C$, one of the points of contact.

$B B^{\prime}$, knobs for attaching the conducting wires.

$M$, India-rubber membrane.

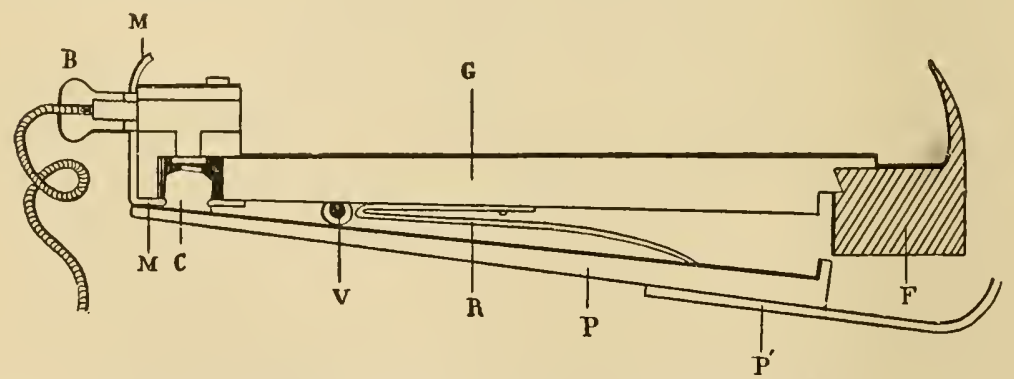

FIG. 179.-Longitudinal and median section of the chaussure exploratrice.

(Same letters as in Fig. 178, except $F$, which represents the section of the shoe at the toe.)

vertically and tapering at its extremity turned towards the ground. This tube, by its other extremity, is conmected with a reservoir containing a colored liquid, by means of an India-rubber tube attached along the members. The reservoir destiued to feed the tubes of the anterior feet is placed upon the withers; that for those of the posterior is lodged upon the croup behind the rider. 
When all is in readiness, the animal is made to walk over the white paper, at the same time that the diversely-colored liquids of the receptacles are emitted through the pointed end of the brass tube. The points where the hoof touches the paper are indieated by small pools, while the elevations are marked lines of a variable configuration connecting the pools. These lines are regarded as representing the horizontal projection of the trajectories deseribed by the feet in motion. This method is completed by the photographing of the animal in motion, to obtain the position of the members in the air.

The hydrostatic method, applied to the horse, does not seem likely to remain in use. The tracings which it furnishes are complicated, very difficult of interpretation, and often dissimilar even for the same gaits; they do not exactly reproduce the horizontal projection of the trajectory of the hoofs, from the fact that during the evolution of the members the liquid jets are not always perpendicular to the soil, the inferior face of the feet looking sometimes behind, sometimes inwardly, at other times forward. As to the trail, it is possible to note it directly in a much more simple and exact manner.

Data furnished by the Graphic Method.-The graphic notations, which can be obtained by the process of the air needles or that of the electrical needles, give us important results. They enable us to recognize:

1st. The precise moment of the elevation and the contact of each member.

$2 d$. The duration of each of these phases, by the interval which exists between the instant of the resting and the raising of each foot.

$3 \mathrm{~d}$. The rhythm of the beats, - that is to say, the measure of the cadence of the gait.

4th. The number of feet in the air and on the ground at a given moment, or the nature, the succession, and the number of the bases of support formed during the execution of a complete step.

5tl. The duration of each period of suspension in the leaping gaits.

6 th. Finally, the velocity of the feet in relation to that of the body. This velocity is proportional to the duration of their contact with the soil.

It is possible, by calculation, to deduce from this last principle the position of the feet in the air at any moment during the progression. This was known long ago to M. Lenoble du Teil, ${ }^{1}$ M. Raabe, ${ }^{2}$ and their disciples. But let there be no mistake here: if the situation or, better, the relative distances of the feet in space can be determined, it does not follow that the attitude of the members in movement is recognizable. Photography alone is capable of instructing us on this point, as we will soon see. The graphic method, registering only the duration of the contact, the rhythm of the beats, and the number of the feet which participate in supporting the body, is naturally powerless to teach us the amount of space passed over during the evolution of a complete step. It tells us the nature and the duration of the bases of support, but leaves us ignorant of the extent of these bases and their direction; it shows us in the leaping gaits a phase of suspension when the body altogether leaves the ground; but, at the moment when the contact is re-established, we do not know whether the body falls upon the same place or, on the contrary, has progressed while it was in the air.

Its indications, for example, will be identical for the trot and the trot upon place, for the ordinary gallop and the gallop upon place; it will be the same for

1 Lenoble du Teil, loc. cit., 1877.

2 E. Barroil, Lart équestre, p. 92, et sujv., Paris, 1587. 
a man who walks and one who, without advancing, "marks the stej" with the same carlence.

Finally, the graphic method tells us nothing as to the position of the members in space, an important omission for those whom the analysis of the play of the articular segments interests, either from a point of view of animal mechanics or of the artistic representation of the horse in motion.

3d. Photography.-Photography has filled up this omission. The extreme sensibility of the plates of gelatino-bromicle of silver, the perfections of the objectives and of other modern improvements, have placed this process above all those difficnlties which but lately retarded its use in the reproduction of bodies during locomotion. It is capable of representing, in fact, the vertical projection of all the attitudes taken by the animal which moves in front of the instrument, according to a plane perpendicular to the axis of the latter. As the moving object can move along a graduated scale situated below it, nothing is more easy than to ascertain the space it travels over during a unit of time,-that is to say, the velocity with which it is animated.

The photographic methods furnish two kinds of registrations:

a. They simply give the image of one or more successive attitudes effected by the animal in motion; or

$b$. They notate a series of successive attitudes with equal intervals of time.

This latter method, which registers simultaneously the time, the space described, as well as the diverse phases of the movement, is due also to the wonderful ingenuity of M. Marey, who has given to it the name of chrono-photography.

a. Instantaneous Photography.-In 1879, Mr. E. L. Muybridge, of San Francisco, effected a veritable revolution in the world of plyysiologists and artists by sending to Paris a collection of photographs taken instantaneously from horses moving at the walk, the trot, the gallop, and even from race-horses going at full speerl. ${ }^{1}$

Mr. Muybridge, in order to arrive at this remarkable result, has arranged twenty-four photographic apparatus side by side, all provided with a system of peculiar clicks. Each apparatus was provided with a very fine thread, which stretched across the trail of the horse and was attached to a fixed point situated on the opposite sicle. The mounted horse, in this manner, successively met and broke each thread, producing thus the unlatching of the corresponding apparatus, which opened and closed ahmost instantaneously.

We can understand from this how Mr. Muybridge was able to obtain the truly surprising situations of the members, which it would have been impossible to acquire under ordinary conditions on account of the, at times, prodigious speed of the extremities in certain gaits. In the gallop, for example, contacts are here placed in evidence (Fig. 180) which wonld readily be doubted if we did not find exactly, by following the series of photographs in the order in which they have been taken, the principal periods of this gait, already known.

These photographs, however, instructive thongh they were, failed to be quite satisfactory on account of their small size. In spite of their subsequent

1 These photographs have been reproduced in several publications, notably: L'Illustration, no. du 22 Janvier, 1879.

La Nature, 1879, ler semestre, p. 83.

Le Cheval, de E. Duhousset, p. 24. 


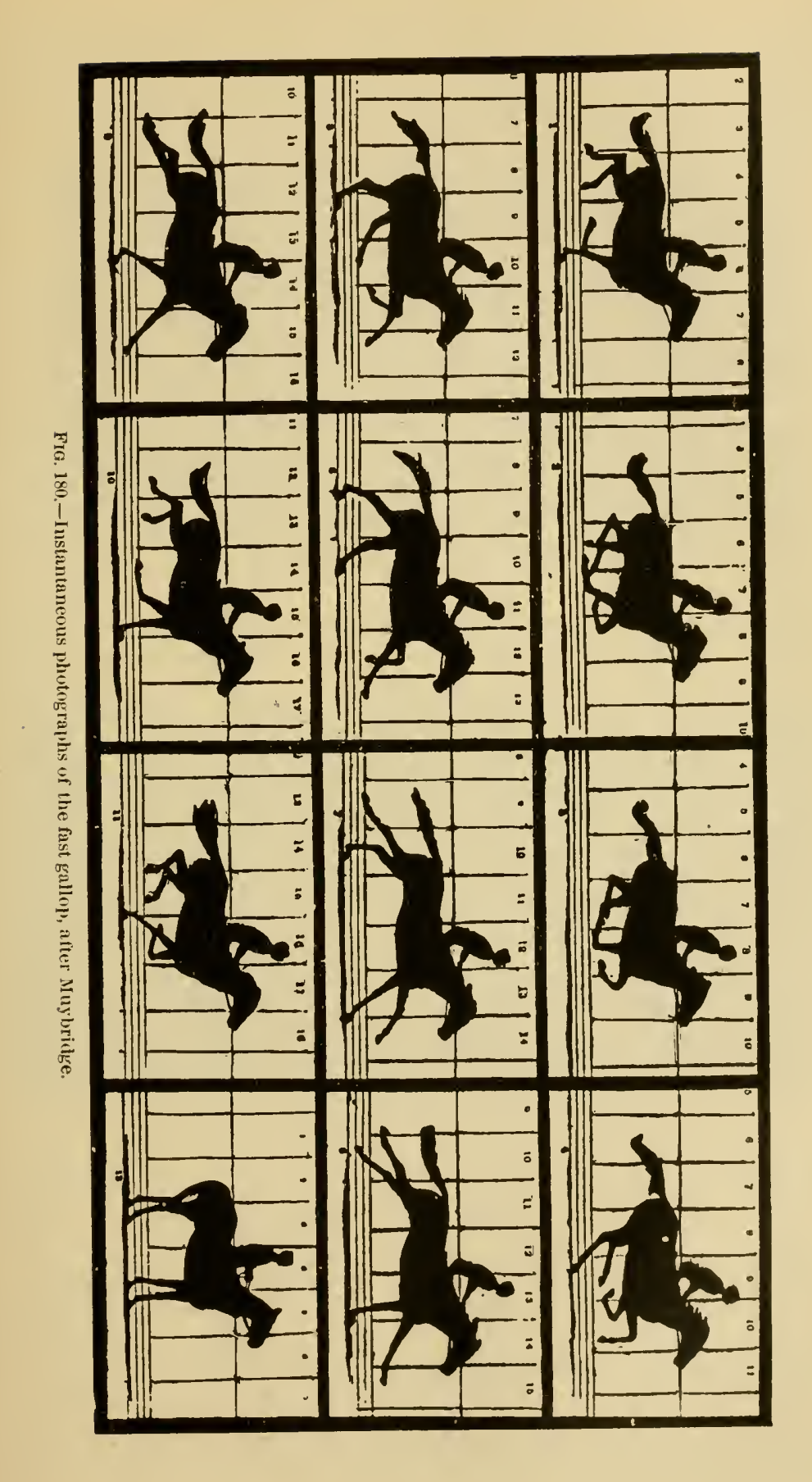


enlargement, they were always wanting in details and form, resembling more a Chinese chromo than a true portrait.

To-day the improvements made in the apparatus enable us to take larger photographs; many amateurs have produced excellent, well-formed, very distinct, and precise proofs for the scientific man as well as for the artist.

But these portraits, however well they may have been executed, only show the isolated attitudes, and not the succession of all the phases of the gait passed through by the animal.

In this respect the labors of Muybridge had not yet been surpassed, when, quite recently, ${ }^{1}$ II. Ottomar Anschïtz, of Lissa (Germany), announced new results. He sent to Paris, towards the end of the year 1888, a series of beautiful instantaneous photographs reproducing the fast walk, the trot, the slow gallop, the fast gallop, and leaping. Each of these gaits is here represented by twenty successive positions, taken at very short and probably equal intervals of time, although, according to the author, the intervals between the various photographs were not exactly measured. A scale, graduated in metres and decimetres, placed along the trail described by the animal, allows the appreciation of the length of the diverse bases of support, the separation and the position of the members in the air, the total length of the step, and, finally, the space embraced by each of the members.

The Lissa photographs, to which we will make numerous references in the course of this work, show a considerable improvement over those from San Francisco, although M. Anschïtz has not yet divulged the secret of his process. We would find them absolutely irreproachable if the intervals between the photographs were known. Unfortunately, this important omission prevents the deduction from them of a certain number of interesting scientific facts. Nevertheless, such as they are, artists will consult them with advantage.

The instantaneous photographs, when multiplied and seattered abroad, will soon appear less fantastical ; painters and sculptors will in the long run draw from them those ideas which will give their works that stamp of accuracy and truth which is but too often conspicuous by its absence. The attentive observation of animals in motion, now that we have been warned of those phenomena which the eye was at first unable to seize, will become incontestably more perfect. Little by little animal painters will abandon the fictitions and fantastic attitudes to which they have accustomed us, and will show us more and more animated Nature as she is, and not as the imagination or our inexperience leads us to conceive.

b. Chrono-photographs.-M. Marey has gone a step farther in this direction. By means of an extremely ingenious experimental process, he has been able to take upon the same immobile plate, and at equal intervals of time, a series of photographs representing the different positions which an animal in movement has occupied in space during a series of known instants.

"Let us suppose," say's he. ${ }^{2}$ "that an apparatus be turued towards the path of a man walking, and that we take a first image in a very short time. If the plate preserve its sensibility. we would be able at the end of an instant to take another image which would show the walker in a

1 For more details see G. Barrier, Présentation de nouvelles photographies instantanées relatives aux allures du cheval, in Bulletin de la Société centrale de médecine vétérinaire, 14 Février, 1889.

2 Marey, Comptes-Rendus de l'Académie des sciences, 3 Juillet, 1882. Id., Développement de la méthode graphique par l'emploi de la photographie, Paris, 1584. 
different attitude and in another place of the space; this second image, compared to the first, would indicate exactly all the displacements which were effected at this second instant. By inereasing thus the images at very short intervals of time, we would obtain, with perfect aceuracy, the succession of the phases of locomotion. Now, in order to preserve in the photographic glass plate the

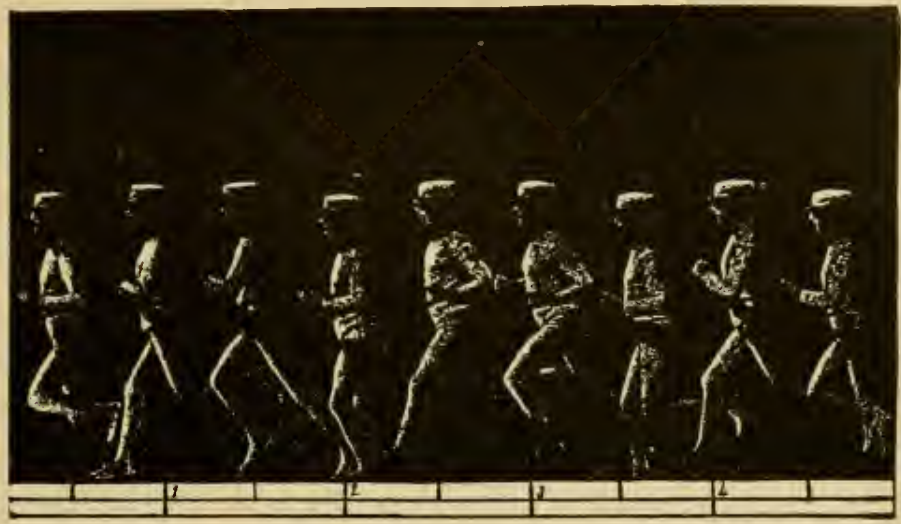

Fig. 181.-Chrono-photograph of the walk of a man. (M. Marey.)

sensibility necessary to receive the successive impressions, the space in front of the apparatus must be absolutely dark and the man or the animal passing before it must stand out in white upon a black ground.

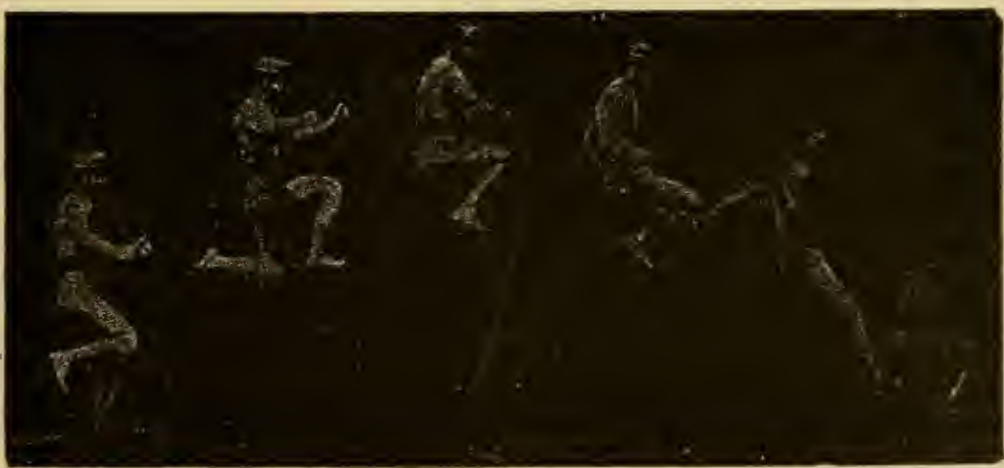

Fig. 182.-Chrono-photograph of the leap of a mall. (M. Marey.)

"My sereen is a cavity whose walls are black. A man enturely clothed in white, with the light of the sun shining brightly upon him. passes, walking, rmuning [Fig. 181], or leaping [Fig. 182], while the photographie apparatus, provided with an oval window rotating more or less rapidly, takes his image at more or less elose intervals."

"This method can be applied to the study of the different types of locomotion; a white horse or a white bird will in the same manner give the series of their attitudes."

This process has been recently attempted upon the horse by Messrs. Marey and Pagès. ${ }^{1}$

1 Marey et Pagès, Mouvement du membre pelvien chez l'homme, l'éléphant et le cheval, in Comptes-Rendus de l'Académie des sciences, 18 Juillet, 1887. 
With the aid of distinguishing marks applied upon the body over the articular centres, and united afterwards on the proof by straight lines, they have succeeded in obtaining the images of the diverse positions of the locomotory segments during the evolution of the members, as well as the exact trajectory of the centres of movement (Fig. 183).

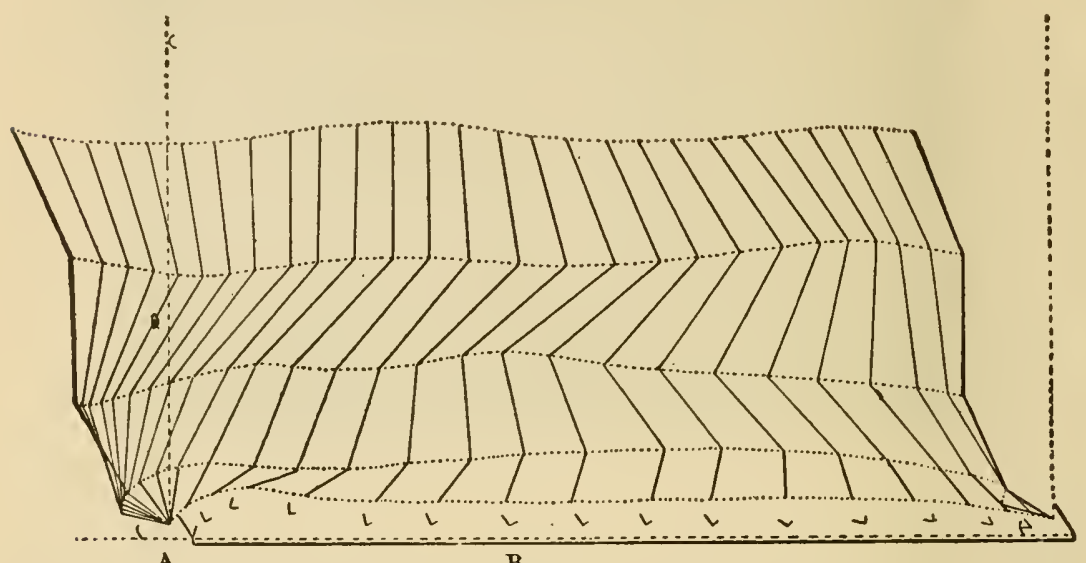

Fig. 183.-Movement of the anterior member of the horse.

(Obtained by means of chrono-photography.)

$A$. Phase of contact. | B. Phase of elevation.

This achievement is significant. It not only permits us to determine with great accuracy the limitary positions of flexion and extension and the field of oscillation of the osseous levers in the rapid motors, but it also opens the way to the discovery in the future of the scientific theory of locomotion, which has been so ably treated in the splendid works of the Weber brothers. All the investigations undertaken in this direction will be rich in facts of inestimable value to those who pursue the rational study of animal mechanics.

For ordinary requirements, however, chrono-photography can be greatly simplified, and thereby rendered intelligible and accessible to the greatest number of individuals. All that this method need do is to record, always at equal intervals of time, the principal attitudes characteristic of a given gait. The images, in this manner, being less numerous, the ultimate results will be less confused. Instead of remaining contented with the axes of movements of the bony segments, we shall be enabled to obtain true portraits, as true to nature as those of Anschïtz, and quite as valuable to the scientific man as to the artist.

\section{Systems of Notation of the Gaits.}

In order to interpret in a clear and simple manner the indications, at times very complicated, furnished by the registering apparatus, we make use of conventional symbols which represent the rhythm of the beats, the duration of the contact with the ground, the mode of association of the members, etc. These symbols, altogether comparable to those which are employed in music to represent the sounds and their intervals, constitute, by their mode of combination, what is conventionally called the notation. 
The systems of notation are not very numerous, nor are they equally satisfactory. Let us rapidly pass them in review.

1st. Method of Lecoq.-We will do no more than place it on record here, for it does not merit to be preserved.

Upon two series of vertical columns (Fig. 184) the contacts are indicated by black ovals and the elerations by blank ovals. Each series corresponds to a lateral biped; the contact of the anterior member is noted above, that of the posterior below. The number of columns in each series is equal to that of the times of the gait necessary to complete one step. Thus there nust be four in the wo (of which the figure reproduces the notation), two only in the trot, ete., beeause the times in these gaits are of different numbers.

But as all these columns are of the same width,--that is to say, of the same value in relation to the duration of the phenomena which they are destined to indicate,-tlie method is inapplicable to the gaits whose times are of unequal lengths. The method, in such cases, is inadequate, and necessitates the addition of a number of columns or a width proportional to the duration which they represent. This complicates much the reading and thesimplicity of the notation.

\section{2d. Hodochronometric Scale of Vincent} and Goiffon. ${ }^{1}$-Two former professors at the Alfort Veterinary School, Vincent and Goiffon, have conceived the ingenious idea of applying the musical notation to the schematic representation of the gaits of the horse.

They have invented for this purpose a scale called the hodochronometric, ${ }^{2}$ which is nothing more than a

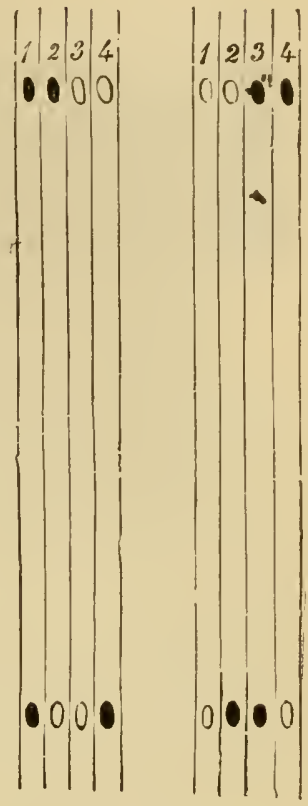

FIG. 184. stave of four horizontal lines, $A D, P G, A G, P D$, similar to those which carry the notes in music, and intersected at equal distances by vertical lines, $I, I I, I I I, I V$, which mark the time like, we might say, so many bars in music. Each time or bar is again subdivided into three spaces, making altogether twelve spaces for the whole length of the stave.

This measure corresponds to a complete step. The ordinary step, for example, is executed by the horse in four bars, whose beginning is indicated by the beats of the feet; the latter are shown by means of four notes, which are: $A D$, the anterior right member; $P G$, the posterior left; $A G$, the anterior left; and $P D$, the posterior right.

Each one of these notes will be written on the corresponding line of the stave in the order in which it will be given out, it being understood that the phases of eontact will be represented by continuous lines, and the phases of elevation or projection of the member by dotted lines. The length of these lines will be equivalent to the time during which each foot keeps up its note (rests upon the ground), or, on the contrary, does not keep it (is maintained in the air).

Let us now interpret some of the points of the notation of the walk, as reproduced in Fig. 185:

1 V'incent et Goiffon, Mémoire artificielle des principes relatifs à la fidèle représentation des animaux. In-folio, Paris, 1779, t. i. p. 87.

2 From odos, path; Xpóvos, time; and Métpov, measure. This word is improperly applied, for the scale in question does not measure the path described by the members. Moreover, it should be written hodochronomctric and not odochronometric, as Vincent and Goiflon have stated. 
1st. During the first bar, the first sound or beat is given by the anterior right member, $A D$, which commences its contact; the posterior right, $P D$, accomplishes the second half of its rest: the anterior left, $A G$, commences its elevation; the posterior left, $P G$, terminates the second half of its elevation.

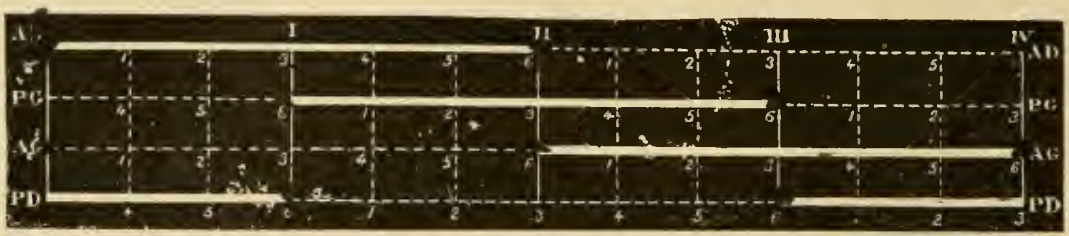

Fig. 185.

2d. During the second bar, the second beat is given by the posterior left, $P G$, which commences its contact; the anterior right, $A D$, finishes its contact; the posterior right, $P D$, commences its elevation; as to the anterior left. $A G$, it terminates its elevation.

3d. During the third bar, the third beat is given by the anterior left, $A G$, which commences its contact; the posterior left, $P G$, finishes its contact; the anterior right, $A D$, commences its elevation, while that of the posterior right, $P D$, is terminated.

Finally, during the fourth bar, the fourth beat is given by the posterior right, $P D$, which commences its contact, and that of the anterior left, $A G$, is terminated; the posterior left, $P G$, commences its rising, while the anterior right, $A D$, is reaching the end of this phase.

The step is completed; the whole stave is played. Each momber has given its note, has kept it up during two bars, and has been silent during the other two.

During each bar, also, the body has rested on two members: upon the right lateral bipeds, $A D \mid P D$ (the first bar); upon the right diagonal, $A D / P G$ (the second bar); upon the left lateral bipeds, $A G \mid P G$ (the third bar); upon the left diagonal, $A G \mid P D$ (the fourth bar).

The beats or sounds of the members have succeded each other in the following order: $A D$, $P G, A G, P D,-$ that is to say, diagonally, etc.

All these characters are those of the ordinary walk. A glance over the scheme of its notation suffices to comprehend them.

Whatever may be the combinations of the rhythm of the beats, the duration of the relations and the elevations, the mode of association or succession of the members, this scale will at a glance indicate them in all their modifications, and in a manner elearer and more rapid than can be depicted in ordinary language or writing. In this consists the great superiority of this system orer that of Leeoq.

3d. Notation of M. Marey. ${ }^{1}$-The method employed by Professor Marey is based upon the same principle as the preceding, although slightly modified in its details.

First, the notations of the anterior members are placed one below the other; those of the posterior members are treated in the same manner. This method allows an easier comparison of the bipedal locomotion of man with that of quarlruped animals.

The contacts or periods of the foot touching the ground are represented by the wide lines: the white for the right members and the gray for the left. The phases of elevation, during which the body is entirely in the air, are, on the contrary, represented by simple intervals. Thus confusion is aroided and the reading and interpretation of the phenomena are much simplified.

Finally, whenever it is possible, the tracings obtained with the registering needles are annexed and superposed to the corresponding notations.

1 Marey, La machine animale, p. 147. 
Let us represent, for example, the running of a man by using the tracing of this gait, as it was obtained by M. Marey (Fig. 186).

The continuous line, $D$, corresponds to the curve furnished by the contacts of the right foot; the interrupted line, $G$, to that of the eontacts of the left foot. The registering surface presents only iwo horizontal lines, 1 and 2, since here only two members are in question.

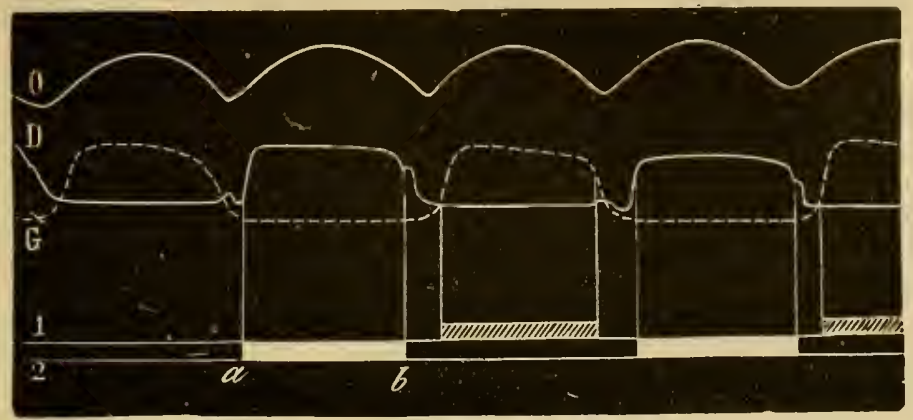

FIG. 186.

This being said, let us draw a perpendieular, $a$, upon the plane, beginning at the point where the curve of the right foot ascends; this indieates the commencennent of the eontact of this foot. Draw another perpendicular, $b$, from the point where this eurve descends, which shows when the foot is raised from the ground. Now let us join the bases of the two perpendiculars by a heary white line; this line, $a b$, will evidently have a length proportional to the duration of the contact of the right foot.

By making a similar diagram with the curve of the left foot, we will obtain the same rotation for its contacts. The same operation is practised upon succeeding curves of the right or the left foot.

The intervals between the white lines correspond to the duration of the elevations of the right foot; those bctween the gray indicate the elevations of the left.

As to the intervals comprised between the gray and the white lines, during which each member is raised, they represent the duration of the periods of suspension of the body.

This notation, applied to the horse, is equally simple. The only difference is that the registering plane contains four lines instead of two, becalse the phases of four members are to be noted.

Dugès ' has very appropriately eompared the walking quadruped to two men walking and placed one in front of the other: the one in front corresponds to the anterior biped, the one behind to the posterior. Hence the notation of the gaits of the quadruped should be similar to that which the two men furnish, if they walk with the same rhythm and make the same number of steps. In order to establish this, it will suffice to superpose the notations of the one in front to those of the one behind, keeping in view the proper rhythm and the relations which will exist between the movements of the one and the other.

Let us select, for example, the amble, a gait in which, says M. Marey,? the two pedestrians (anterior and posterior), going at a walk, both execute the same movements with perfect concordance. It is apparent that the notation will furnish us that in Fig. 187, whence it is proved that the beats of the right foot and those of the left foot, producel in the same time by the man in front and the one behind, are recorded by similar lines exactly superposed and of equal length.

1 Dugès, Traité de physiologie comparée de l'homme ct des animaux, t. ii. pp. 170 and 174, Montpellier, 1838 .

2 Jlarey, loe. cit., p. 146. 
The notation of M. Marey, although almost identical with that of Vincent and Goiffon, has, nevertheless, the preference over the latter in being clearer and more explicit.

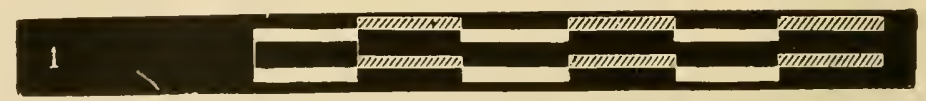

Fig. 187.

4th. Notation of M. Lenoble du Teil.'-The method of Professor Lenoble du Teil, of the School of the Stud of Pin, is without doubt the most perfect from a point of view of the intelligence which it imparts from mere ocular inspection. Its principle is always that of the musical notation invented by Vincent and Goiffon, but it adds a new idea: that of the path described by the feet. Hence the name of hodochronometric seale is much more applicable to it than to any other, and we would give to it the preference, had not its author designated it under that of method of the planes of the ground surface.

It consists as follows (Fig. 188):

Upon a sheet of paper are traced a certain number of vertical columns representing equal fractions of time. To the left of these columns is indicated the trail of the gait, by marking in a known scale the intervals which separate the imprints.

The line $X Y$ indicates the direction of movement.

We will suppose, for example, that the two feet of the anterior bipeds have left upon the ground the imprints $D D^{\prime}$ (for the right) and $G G^{\prime}$ (for the left).

Suppose, now, that this surface begins to glide from right to left at the moment when the foot $G_{r}^{r}$ commences its contact; this foot, instead of leaving a simple imprint of its shoe mpon the gromud, will trace a line, $P l^{\prime}$, so much longer as the contact is prolonged.

During this period of contact, what has the opposite foot done? We know that it was advanced after a short period of exchange of contact. As the surface, however, continues to glide during this action, the foot $D$, which should rest at $D^{\prime}$, will rest at $P^{\prime}$ at the instant of the end of the contact $\left(l^{\prime}\right)$ of $G$.

Consequently, the horizontal projection of each of the points described by the foot $D$, through the air, instead of being a straight line parallel to the axis of the trail, will be an oblique line, $l P^{\prime}$.

There a new transverse line, $P^{\prime} \ell^{\prime \prime}$, will represent the duration of the contact of $D^{\prime}$ with the ground.

During the period of contact of $D^{\prime}$, the foot $G$, beginning at the point $l^{\prime}$, will execute its period of projection and tonch at $P^{\prime \prime}$, the moment corresponding to the termination of the contact of $D^{\prime}$, etc.

It only remains now to trace through any point a vertical line, $K L$, to be immediately informed as to the respective positions of the two feet with the place where this line intersects the lines of contact and those of projection.

If to the notation of the anterior members alone were added that of the posterior, the phenomena would not be more complicated. Likewise the construction of the diagram would be quite as simple in cases in which the number of

I J. Lenoble du Teil, Locomotion quadrupède étudiée sur le cheval in Journal des Haras, année 1857, p. 224 . 
the feet was increased. It would be sufficient to have a larger surface for notation; this is always indispensable when it concerns the representation of the leaping or the elongated gaits, the obliquity and length of the notation augmenting with the amplitude of the steps and the projection of the feet.

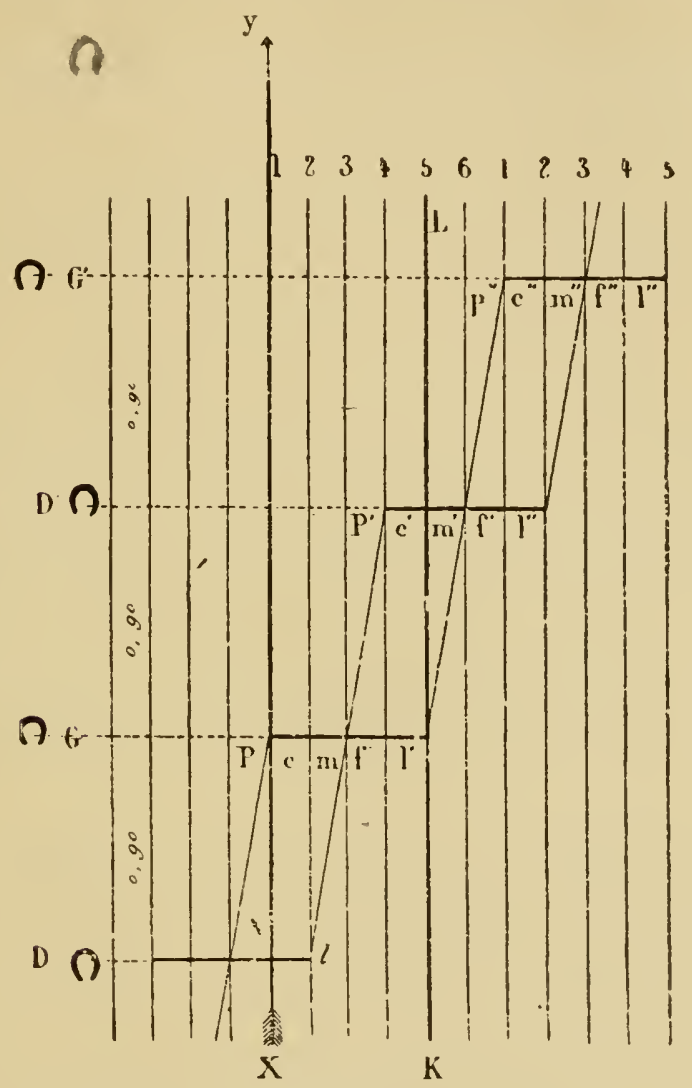

FIG. 188.

Such is the principle of the ingenious method of M. Lenoble du Teil. It has the advantage of recording all the data relative to the cluration and the space passed over which the registering apparatus or elrono-photography can collect from a given gait. When the diagram is once constructed, all desirable information relative to a complete analysis of the phenomena can be oltained at a glance in a coneise form and compared the one with the other, which is nut to be overlooked.

Unfortunately, the scheme which it furnishes has the disadvantage of requiring a large area. Besides, the notations of the anterior members are intermingled with those of the posterior in the same manner as the imprints of the trail. The reading of it is also less clear than in the method of Marey. and it is less easy to compare, as in Dugès's method, the particular characters 
of the walk of two bipers, in order to determine the general relation which they maintain as a whole. Nevertheless, it is possible to ameliorate, in a great measure, these defeets. Nothing prevents, for example, the representation of the contacts and the elevations of the right members by the continuous or the heavy lines, and those of the left by the dotted lines. In addition, it is easy to differentiate the notations of the fore- and the hind-bipeds by simply modifying the width of the tracings or lines which eorrespond to then. This is precisely the procedure which MI. Marey has employed with success to facilitate the reading of the tracing of the mode of progression.

As to the smallness of the diagram, it eannot pass beyond certain limits without danger of resulting in confusion of the imprints of the trail, especially when those of the hind-foot are in front of or behind those of the fore-foot. This, however, is more a typographical defeet, and of little importance as regards the eorrectness of the theory itself or its originators.

\section{Synthetic Study of the Mode of Progression.}

The generalization of the materials collected by the diverse analytical methods which we have passed in review, their reconstrnction into a mnit, their relations, and the reproduction of these facts into a material form in a manner to give to the mind, at first greatly confused, the actual reality,-such is the difficult problem which constitutes the synthesis of the modes of progression or the gaits.

Each analytical process offers its corresponding synthetical process.

To the results of direct observation are contrasted, first, the efforts made by artists to represent the horse by design, painting, and sculpture; also those whose ohject is to simulate experimentally the rhythm of the beats; finally, those which propose to retrace, with the eye, the imprints left upon the ground by the feet.

With the results furnished by instantaneous photographs are combined the diverse forms of animators, in which are placed the photographs themselves or simply the designs which are reproduced from them.

Finally, to the results given by the registering apparatus correspond special instruments, demonstrating the notations of the gaits or the series of transitions which show the passage from one to another.

Let us examine each of these processes in particular.

1st. Artistic Processes: Design; Painting ; Sculpture.-It suffices to pass through museums and expositions to assure ourselves of the errors of ancient as well as modern artists in the exact representation of the movements of the horse. This animal is nearly always posed in false attitudes and in conditions of impossible equilibrimm. If he is depieted moving at a walk, the members are placed in the position which they assume in the amble or the trot; if he is represented at the gallop, the artist only sueceeds in producing a spurious attitude which is neither rearing nor leaping. If he is stopped on two members, the chances are it will be on two lateral bipeds, on which station cannot exist, rather than upon a diagonal biped, which is the more accurate. Finally, even when the general movement is correct, the fault in reality lies in the details: thus, one foot is so placed that it cannot be elevated in time; another is too slow in arriving on the ground; again, it is the axis of the body which conflicts with the direction of the members; finally, it is that of the neck or of the head. We should never come to the end if we passed in review the long series of errors of 
painters and sculptors, among whom so few have abandoned the precedents inculcated by the classical routine. To this end, we owe tribute to Colonel Duhousset for the persevering efforts with which he led the new school to a more correct interpretation of animated nature. Little by little the eause of equine realism will triumph over the conventional art, which censures with disdain the innovators who assume the liberty of announcing its errors to the public.'

2d. Reproduction of the Rhythm of the Beats.-One of the most prominent of the phenomena in the gaits is the succession of the sounds which are audible. This succession does not deceive the trained ear, and permits it not only to judge of the variety of the gait which it hears, but also to recognize if this progression is accomplished with its normal characters.

With the purpose of demonstrating, in our course of lectures, the cadence of each particular gait without having recourse to the living animal, which might be, at times, not altogether free from danger to the hearers, we have conceived the idea of constructing the following small apparatus:

It is composed of a horizontal cylinder, turning upon its own axis in front of two pieces of resounding board, placed the one upon the other in such a manner as to form a spring, as is seen in the instrument called the signal, and employed by school-teachers to call their classes to silence. Small paddles or float-boards are fixed in succession in a vertical series upon the circumference of the cylinder, whose number and interval are calculated in such a manner that when passing by the signal they produce sounds according to the rhythm desired. To olstain the beats of a different gait, it suffices to slide the cylinder towards the right or the left, and fasten it by means of a cog on the surface of the axis of the crank. A new series of paddles can thus be passcd over the signal, and so on.

With the aid of this instrument, the construction of which we have been obliged to postpone for pecuniary reasons, we should have been able to reproduce rery distinctly the normal and the defective rhythms of the walk, the trot, the ordinary gallop, the fast gallop, the amble, the running walk, racking, etc.

It would have been capable of rendering efficient service in the study of this part of the exterior, for it is difficult to procure, on a given day, a horse capable of executing all the gaits. It, besides, would have enabled us to study the varieties of' each gait and to make the ear distinguish the mode of transition from the one to the other. Our instrument, in this relation, would have partaken of some of the advantages of the model for notation of M. Marey, which we will examine farther on.

3d. Artiflcial Representation of the Trails.-By differentiating with care the imprints left upon the ground by the feet of a horse in motion, and transcribing these imprints upon paper in the required scale, we easily succeed in giving an exact idea of the manner of their succession.

But, in order to avoid the encumbrance resulting from the accumulation of a large number of plates, as well as the expense of their preparation, we have invented a species of vertical, portable table (Fig. 189), with the aid of which any trail whatsoever can be represented immediately by means of small shoes, which it suffices to hang at proper intervals. By changing the respective positions of the shoes, it also becomes easy to show the diverse transitions presented by the trails of such or such a normal or defective gait.

The apparatus is composed of a black-board about $2.50 \mathrm{~m}$. in height, resting upon a pedestal provided with three drawers, $A, B, C$. In the left, $A$, are six nickel-plated shoes, three fore and three hind; in the right, $C$, are six similar shoes, but for the opposite side. The middle is

1 For more details see E. Duhousset, Le cheval, chap. i., ix., and x. 


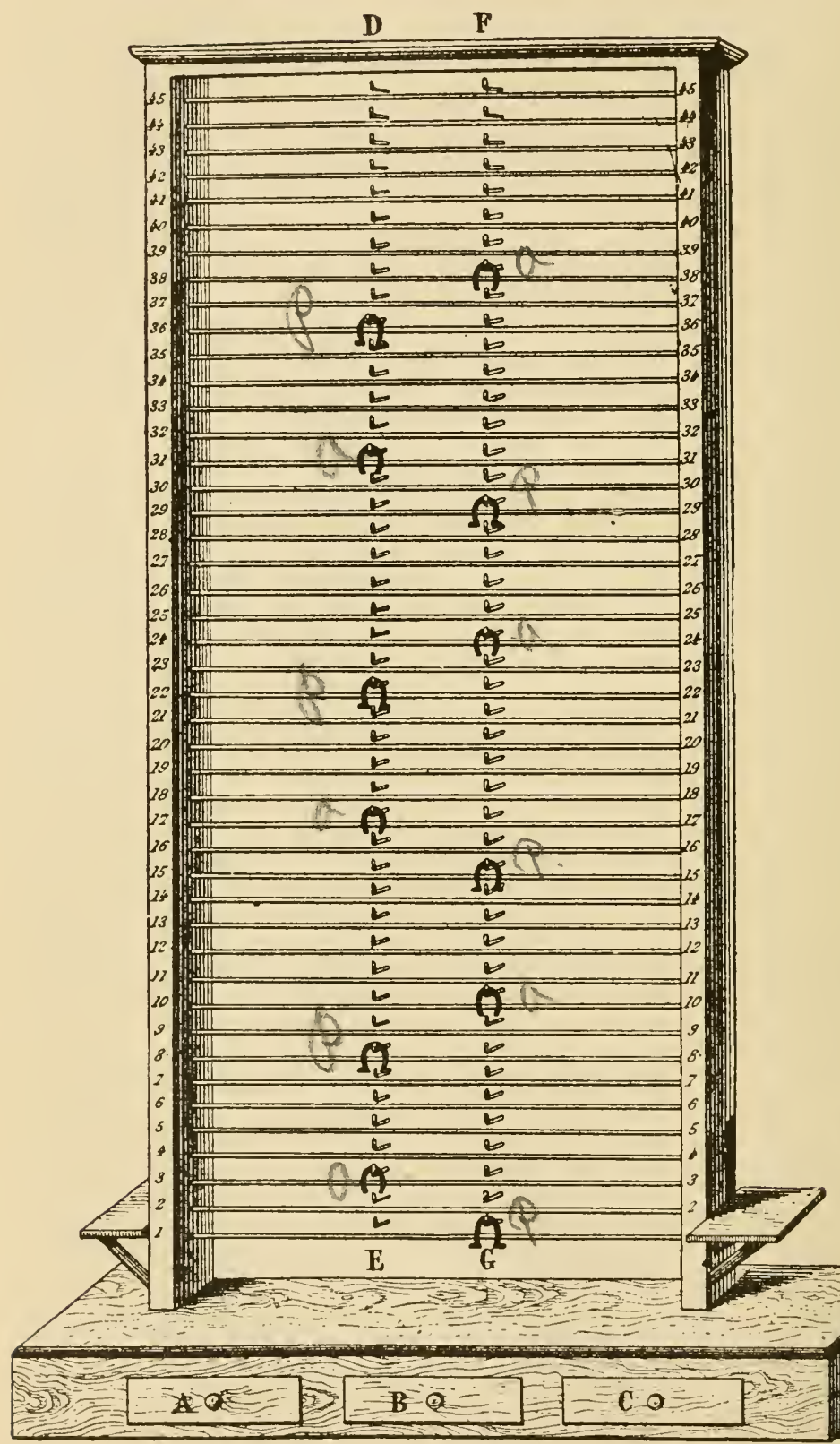

FIG. 189. 
reserved for a certain number of cards, upon which are written all the indications for the rapid construction of the trail of eaeh gait.

The anterior face of the boarl contains forty-five lines, indicated by numbers along the edges. Fiually, upon the middle of this face also exist two vertical series of hooks, $D E, F G$, the one indicating the trail of the left feet, the other that of the right. The shoes, whose light color contrasts with the black ground of the board, are hung on these hooks. We will compose the trail of the amble, for example. From the middle drawer is selected the memorandum card of the gait upon which the necessary instructions are given, as follows:

ORDINARY AMBLE.

\begin{tabular}{|l|c||c|c|}
\hline \multicolumn{2}{|c||}{ Shoes of Left Drawer. } & \multicolumn{2}{|c|}{ Shoks of Right Drawer. } \\
\hline Anterior Shoes. & Posterior Shoes. & Anterior Shoes. & Posterior Shoes. \\
\hline Nos. 3,17,31. & Nos. 8, 22, 36. & Nos. 10, 24, 38. & Nos. 1, 15, 29. \\
\hline
\end{tabular}

It suffiees to hang each shoe to the number indicated in order to obtain immediately the desired trail.

4th. Artificial Reproduction of the Locomotory Movements; Animators for Instantaneous Photographs or Drawings taken from them.-Physiology teaches that the impressions received by the retina last for some instants after the luminous body which has produced them has disappeared. It is thus that the rapid displacement of an incandeseent coal appears to the eye in the form of a stream of fire; the descent of a rain-drop, under that of streaks passing from the clouds to the earth, etc.

Basing his observations upon this fact, Plateau, in 1832, constructed an apparatus, the phenakislicope, in which are placed a series of pictures, each representing a special phase of a determined movement, the gallop of a horse, for example. A proper rotation being given to these images, there will be reproduced with surprising exactness the complete movements of which we have, in reality, only the different periods.

The zootrope is an instrument based upon the same prineiple. It is composed of a cylindrical box, in the interior of which is a strip of paper with the portraits of an animal in different positions of his gait. A certain number of vertical openings or windows expose the interior of the box and allow the observer to view the series of images on the inside. The whole pivots on a vertical axis and ean be rotated at will more or less rapidly.

It is with the zootrope that we ean demonstrate the absolute truth of the instantaneous photographs. It is even possible to render the movements resulting from the succession of these images tangible to a whole audience, as we have witnessed with M. Marey, by placing the animator in front of an apparatus on which the images are projected. The effect is then complete: the displacements of the neek, the heal, the members, the tail, the inflection of the body,-all, even the movements of the jockey, give to the speetator the sense of reality.

5th. Schematic Figures of M. Mathias Duval.-Knowing, as we will verify farther on, that the differences existing between the gaits are assoeiated with a more or less marked quiekness of the movements of the posterior members in relation with those of the anterior, Professor Mathias Duval has conceived the idea of reproducing a gait in all its details, by constructing a series of designs capable of gliding one upon the other, and thus realizing the quickness in question. 
All the marched gaits being related to the amble, M. Duval first designed sixteen horses (this number suffices) in the different phases of the latter. These reproductions are disposed in two superposed sheets of paper. The upper is fenestrated in such a manner that one-half of each horse is visible on this sheet and the other half on the lower. The hind-quarters, for example, being on the upper sheet, the fore-quarters are placed upon the lower, and are visible through the openings made in the latter. Suppose, now. that the superior sheet be noved so that an interval separates two figures of the horse, and we will have a series of images in which the anterior members are tarly in point of time upon the posterior, as takes place in the broken amble. If the gliding of the sheet be increased, we have the series of attitudes of the $w a l k$; a still further gliding will give those of the trot.

6th. Reproduction of the Notations.-Estimating that the marched gaits of the horse can be classed in a natural series whose first term is the amble, and in which the difference between a given gait and the following consists in a quickness or a slowness of the posterior members, according ats he accelerates or slackens his movement, M. Marey has invented a model, valuable both for artists and demonstrators, by means of which it is easy to construct the notation of such or such a variation of gait, even to reproduce voluntarily the forms of locomotion now unknown, which are perhaps employed by certain savage species whose mode of progression has not been analyzed.

The model for notation of the gaits ${ }^{2}$ consists of a small black-board (Fig. 190) along which can glide four small flat reglets, alternately black and white or gray and black, and placed two by two.

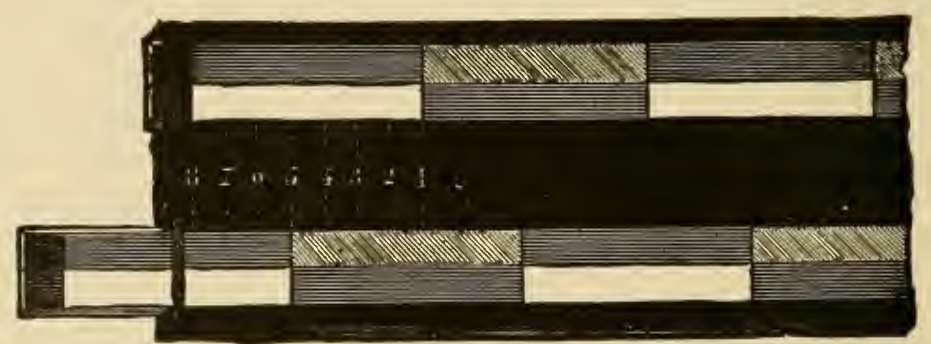

FIG. 190.

As each of these blocks is independent, it is easy to juxtaposit or alternate in several ways the white segments (contacts) and the dark segments (elevations). The notation of any marched gait whatever can thus be constructed very rapidly.

In Fig. 190, for example, have been arranged alternately the light blocks and the black blocks in both the superior and the inferior reglets. Then the latter have been moved towards the left without changing their relations. In this manner one variety of walk can be obtained. If the posterior left beat is produced opposite to the numbers $1,2,3,4$, etc., so many different varieties will thus be the result.

In Fig. 191 the blank blocks are semi-superposed in each series of reglets. The inferior series is so disposed as to make the beat of the anterior right coincide with the posterior left. The result is a notation corresponding to one variety of gallop.

But the model, thus constructed, is not applicable to the notations of the leaping gaits, in which intervene the phases of suspension during which no foot touches the ground. 
With a view of remedying this defect, we have constructed a model slightly different from the preceding. The reglets are replaced by clear, independent blocks, but gliding freely in grooves with a black surface. It becomes easy, with this modification, to represent the notation of any gait whatever.

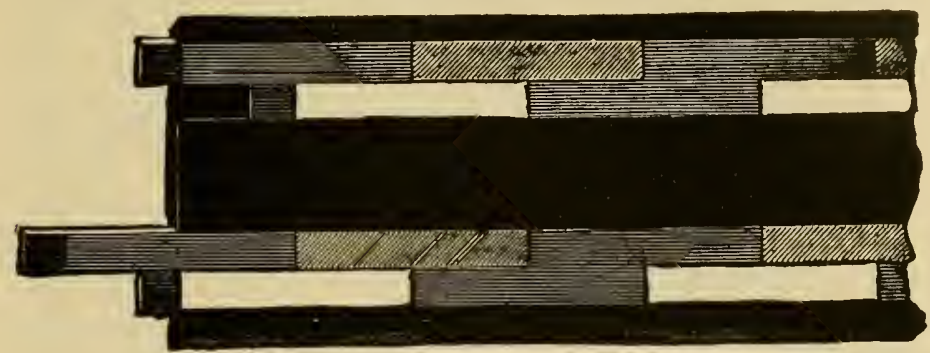

FIG. 191.

After these general considerations upon the gaits, we will resume their study in particular. Before doing so, it is indispensable to give (Fig. 192), in a table which we borrowed from M. Marey, ${ }^{1}$ a synopsis of their notations, such as most anthors admit. Except the amble and the trot, upon which all are in accord, all the others are defined in different manners.

"The variation," M. Marey very wisely remarks, "explains itself sufficiently : first, beeause the observation of these movements is very diffieult, and, secondly, because, in nature, the walk may, aceording to eircumstances, present the different forms which each author has arbitrarily taken as the type of the normal walk. Each man, in this ease, allowed himself to be guided by theoretical conditions. Those who admit equal intervals between the four heats thought they saw more clearness in this kind of rhythm and a better-marked distinetion between it and the amble and the trot.

"Others have sought, in the walk which served as their type, the realization of a certain ideal. For Raabe this ideal was the maximum stability which is obtained, aceording to theory, when the body rests longer upon the diagonal than on the lateral bipeds, hence his selection of the type represented by notation No. 6 . Lecoq, thinking, on the contrary, that the best step is the swiftest, chose as his type that in which the body rests longer upon the lateral biped than upon the diagonal (notation No. 4)."

The reader will therefore not be surprised now that our own views differ from those of the authors who have preceded ns. I cet him not for an instant lose sight of the fact that the gaits, as a whole, constitute 


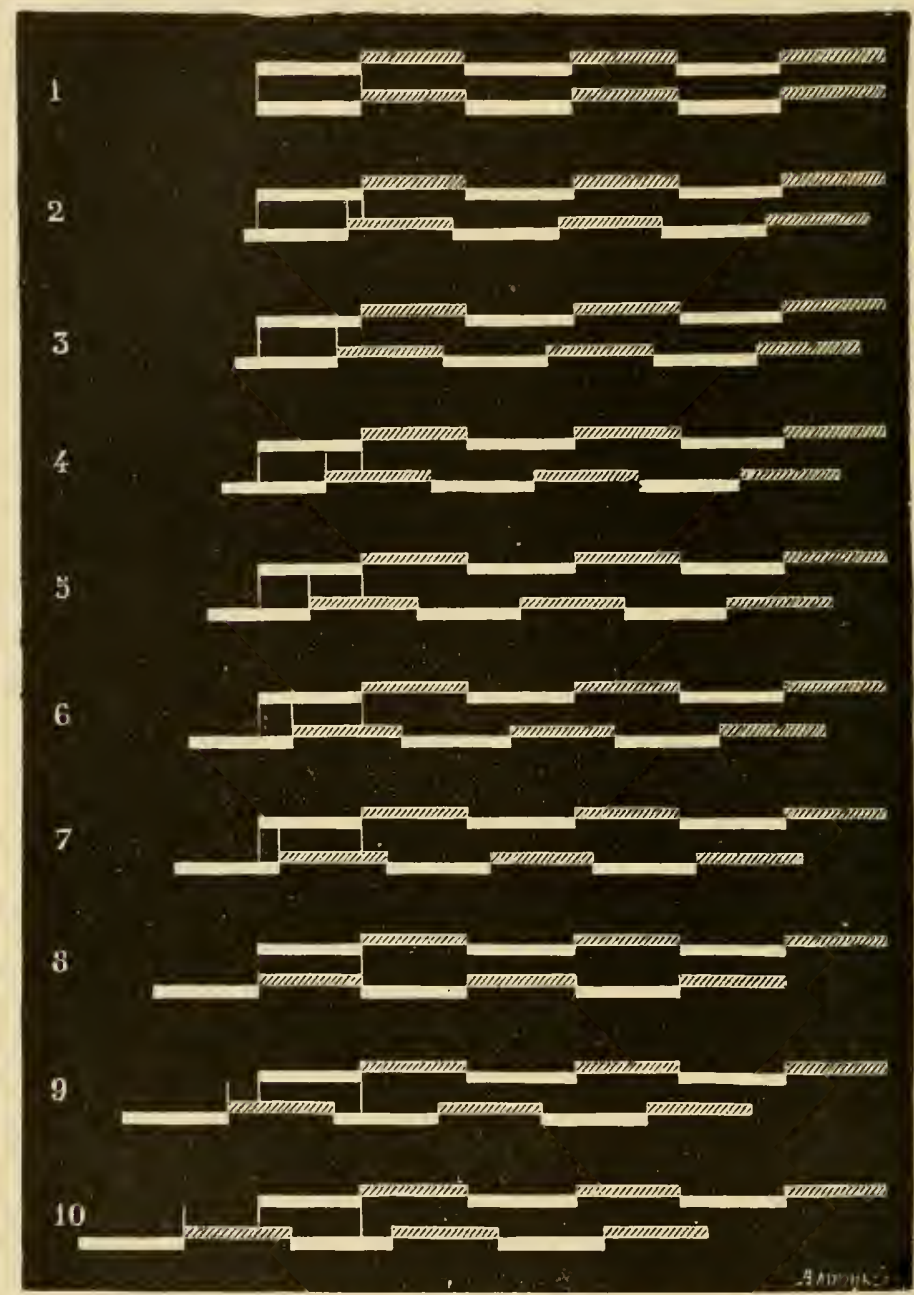

FIG. 192.-Synopsis of the notations of the gaits of the horse, ufter the authors.

No. 1. Amble, by all authors.

(Broken amble, according to Merche,

No. 2. $\left\{\begin{array}{c}\text { Vallon. } \\ \text { Running walk, Bouley. }\end{array}\right.$

Ordinary pace of gaited horse, Hazure.

No. 3. $\left\{\begin{array}{l}\text { Broken amble, Bouley. } \\ \text { Ratching, Bourgelat, Lecoq. }\end{array}\right.$

No. 4. Normal walk, Lecoq.

(Normal walk, Solleysel, Bourgelat, VinNo. 5. $\left\{\begin{array}{l}\text { Normal walk, Solleysel, Bourgelat, Vin- } \\ \text { cent and Goiffon, Colin, Bouley, } \\ \text { Merche. } \\ \text { Running walk, Vallon. }\end{array}\right.$
No. 6. $\{$ Normal walk, Raabe, Vallon, Lenoble du Teil.

No. 7. Broken trot; racking.

No. 8. \{ Ordinary trot. (The time of projec-

No, 9. $\{$ Normandy gait, Lecoq.

Nacking, Vallon.

No. 10. Racking, Merche. 
a series $\left(a_{1} \ldots, a_{2} \ldots, a_{4} \ldots, a_{7} \ldots, a_{8} \ldots, a_{\mathrm{m}}\right)$ whose terms are not all named or even known; that these terms, nevertheless, exist and presumably constitute particular forms of adaptation of a gait to such or such service; finally, that their list can increase only by the employment of more delicate and more accurate processes of analysis than our senses are. It is with the aid of the graphic method and chrono-photography, which are never inaccurate in their results, that we should pursue the long and difficult researches yet to be made on this subject.

\section{CHA PTER II.}

THE GAITS IN PARTICULAR.

THE horse, strictly speaking, employs in a state of nature only four gaits, which are-the walk, the amble, the trot, and the gallop. Domestication has modified these primitive gaits, as it has changed his external form and his aptitudes; it has originated modes of progression which are, in reality, mere varicties of the preceding.

Their study being most difficult, we will commence with the simplest, and deseribe simultaneously their corresponding varieties.

First, we will establish two great categories according to the manner of association or succession of the members : the lateral gaits and the diagonal gaits.

Among the first we include:

1st. The amble, a fast gait, marched with two times, and characterized by the simultaneous raising and resting of the lateral bipeds.

The broken amble, a variety of the preceding, with four times, consisting in the disassociation of the lateral bipeds.

Among the second we class :

2d. The trot, a fast gait with two times, characterized by the simultaneous raising and resting of the diagonal bipeds.

Ordinarily it is masched, when the posterior imprints remain behind the anterior of the same side; leaped, when the posterior imprints cover or surpass the anterior.

The broken trot is a variety of the preeeding, which consists in a disassociation of the diagonal beats. Aecording to the length of the step, the posterior imprints surpass or fall short of the anterior ; it may therefore be leaped or marched. 
The canter is an unusual or defective gait, in which the heterochronous beats of one of the bipeds, anterior or posterior, effect a rhythm different from the isochronous beats of the opposite biped. It is said, in this case, that the horse gallops in front and trots behind, and vice versa. The canter can also be defined as a trot in which the beats of one of the diagonal biperls is disassociated instead of remaining simultaneous.

The running walk, or high step, a gait establishing a transition between the marched broken trot and the walk, in which the diagonal beats follow in close succession and the posterior imprints are always but a short distance behind the anterior.

3d. The walk, a still slower gait, with four times, in which the members, associated in diagonal bipeds, are elevated and rested successively.

According as the beats are closer laterally or diagonally, it furnishes varieties which tend to simulate either the amble or the trot.

Backing, or the walli executed backward.

4th. The gallop, a fast gait, with three beats, and leaped, in which the synchronous beats of a diagonal biped are interposed between the successive beats of the opposite diagonal biped, which begins the step by its posterior nember.

The simultaneous beats of the second contact with the ground (second biped) have the greatest tendency to become disassociated when the horse moves almost without advancing, when the equilibrium is bad, or when the speed is very great. In this case the ear can perceive four distinct beats.

On the race-course the gallop is an extremely fast gait in which this separation of the diagonal beats is driven to its utmost limits.

\section{A.- The Amble, Pacing.}

The amble is a natural or an acquired gait, in which the members of each lateral biped rise and reach the ground simultaneously (Fig. 193). Two beats only are therefore heard in the complete step of the ambling horse.

It is thought that these expressions are derived from the Latin ambulare, to go about, doubtless because horses which have this gait were formerly employed for quiet riding. De Curnieu says that this gait was in great vogue at the time when the horse and saddle were the only means of transport for travellers of all ages and all sexes. ${ }^{1}$

Many anthors affirm that horses which amble naturally have better

De Curnieu, loc. cit., t. i. p. 161. 
qualities and are more sought after than those which have acquired this gait by education. The explanation for this preference, as Baron $\mathrm{d}^{\prime}$ Eisemberg ${ }^{1}$ expressed a long time ago, is that in the latter the members are raised higher from the ground, and thus the reactions of the

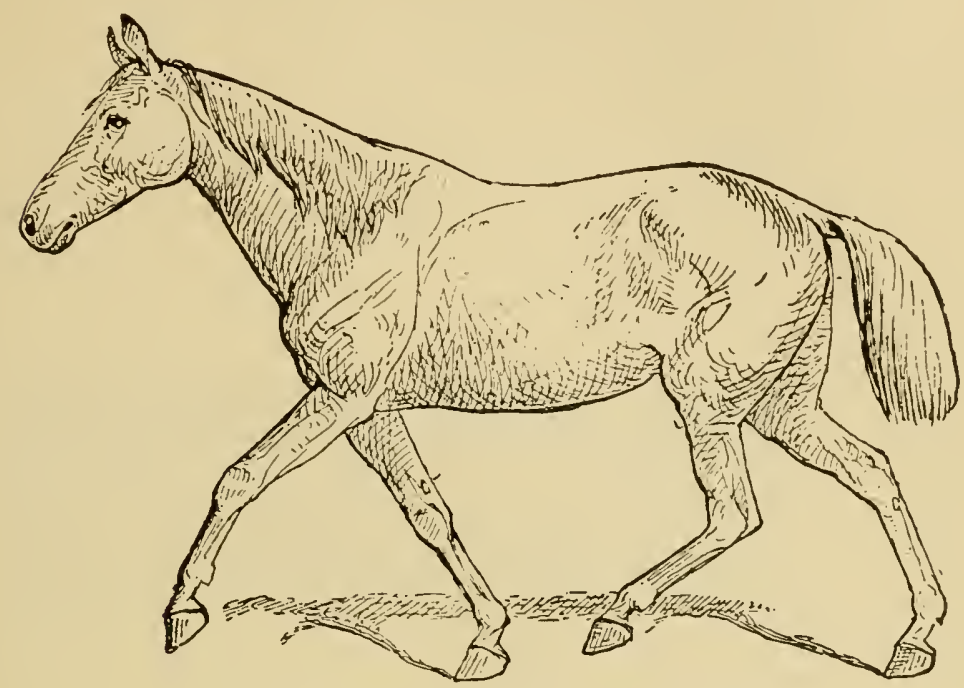

FIG. 193.-The amble: contact of right lateral biped.

body are less gentle. The former have, besides, the advantage of executing the gait from the fact of an innate aptitude, a circunstance which places them at once in better condition to profit by the benefits resulting from their training and dressing. Amblers or pacers are seldom found nowadays but in countries in which the bad state of the roads, the length of the journeys, the distance between the villages or public taverns, and the want of other means of transport, render their use necessary. They are excluded from the services of the army and from the riding-school on account of the difficulty they experience in passing from this gait into another.

The English called them geldings, or guilledins, and excelled in the art of dressing them. Baron d'Eisemberg ${ }^{2}$ relates that he saw some which maintained their gait during a whole day with so much ease and speed that they were accompanied with diffieulty by other horses at a gallop. The gelding was emasculated; he was dressed, it is said, by fastening together the members of the same side. This practice is still p, 161.)

1 Baron d'Eisemberg, Art de monter à cheval, 1747, p. 13. (Quoted from De C'urnieu, t. i.

2 Baron d'Eisemberg, loc. eit., p. 12. 
employed in Brittany and in Algeria. The movements of the members of each lateral biped are associated by means of a cord attached above the knee and the hock. This gelding does not exist in our day ; the name remains simply to designate a caștrated horse.

According to De Curnieu, Napoleon I. preferred amblers in a campaign for long and quick reconnoitrings.

Painters and sculptors have sometimes represented the amble instead of the walk, which is not extraordinary, considering the large number of horses which employed the former instead of the latter. As an example of this we may eite the equestrian statue of Lonis XII., placed at the entrance to the palace of Blois.

Let us say, finally, that certain colts, at first anblers, will at a later period learn to trot. Reversely, some horses, primarily good trotters, amble towards the decline of life, through fatigne and usage. ${ }^{1}$ But this gait is not peenliar to the horse; other animals, as the camel, dromedary, and giraffe, employ it naturally. We have also observed it in exceptional cases in the ox and the $\operatorname{dog}$ [it is common in the $\log$ ].

A complete step of the amble has two equal, snceessive times, during each of which the members of the same lateral biped are raised and reach the ground simultaneously. Leeoq was therefore quite right in comparing this succession and association of the members to the walk of two men, one placed a certain distance behind the other. ${ }^{2}$

If we represent, says M. Marey, ${ }^{3}$ the movements of these two men by placing above the notations of those of the anterior and below the notations of those of the posterior, the following figure (Fig. 194) will

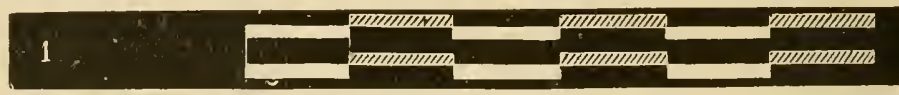

FIG. 194.

be obtained, in which the right feet correspond to the white lines and the left to the gray. It is seen here that the car can hear only two beats to each step, the two members on the same side striking the soil at the same instant.

But is this gait marched or leaped? All authors are not in accord upon this point. Most of them, however, maintain the first view, and we coincide with them. There are exceptions; some amblers leave the

1 H. Bouley, Nouveau dictionnaire de médecine, de chirurgie, et d'hygiène vétérinaires, t. i. p. 402.

2 Lecoq, loc, cit., p. 416.

3 Marey, Machine animale, p. 148. 
soil at the end of each of the lateral contacts. M. Lenoble du Teil ${ }^{1}$ has observed several examples.

It is none the less, however, a fact that if the amble is in the vast majority of eases a marched gait, there must be, between its two times, a very short period during which the four members remain on the ground. This oeeurs when the body is shifted from one lateral biped to the other. At this instant, difficult to pereeive, so short is it, the period of exchange of eontact is manifested. Hence the true notation of this gait should be like that represented in Fig. 195, and not like that which M. Marey has given, as reproduced above (Fig. 194).

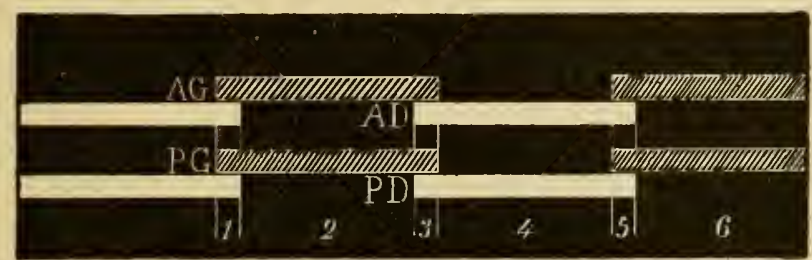

FIG. 195.-Notation of the marched amble.

There are seen, in fact, short quadrupedal bases, 1, 3, 5 ...., interposed between the fundamental bases 2,4 , 6 . ., which were alone admitted hitherto, save by M. Lenoble du Teil, who was the first to observe and formulate the facts in question. ${ }^{2}$ We expect to register these bases, as well as their duration, by the aid of our electric shoe (chanssure exploratrice).

The trail shows (Fig. 196) the imprints of the posterior feet always surpassing considerably those of the corresponding anterior, because the space embraced by each posterior member is about one-third longer than the length of the lateral base.

The length of the step of the ambling horse, according to M. Lenoble du Teil ${ }^{3}$ would be equal to that of the ordinary walk, say $1.80 \mathrm{~m}$. for a lorse of $1.60 \mathrm{~m}$. at the withers.

1 Lenoble du Teil, note communiquée.

2 Lenoble du Teil, Locomotion quadrupède étudiée sur le cheval; ze éd., p. 53, pl. v., Paris, 1877.

${ }^{3}$ Lenoble du Teil, loc. cit., p. 58. 
The displacements of the centre of gravity oceur in a transverse and an antero-posterior sense.

1st. In the transverse displacement, this centre is carried, during each time, alternately from left to right and right to left, from $E, F$, $G$, upon the lines $A B, C D, A^{\prime} B^{\prime}$, ete. (Fig. 197), which unite the two

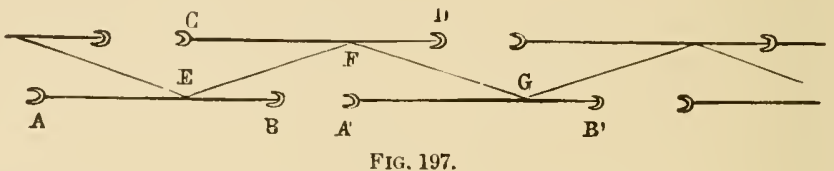

lateral bipeds on the ground. This movement produces a sort of rocking, which, when exaggerated, may oceasion a fall sideways.

$2 d$. The vertical displacements take place during each period of contact, and can be represented by the ares $E F, F G$ (Fig. 198), whose

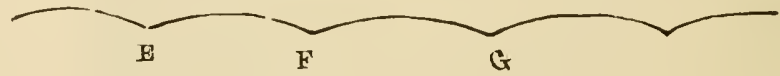

FIG. 198.

height is always small, since the gait, being very unstable, is low and quiek. This is the reason why the ambler is an easy and pleasant mount, so appreciated by persons who object to the stronger reactions of the gallop or the trot.

The great speed of this gait is explained by the eccentric position of the base of support, which inereases the instability of the equilibrium, and, consequently, the speed.

According to M. Lenoble du 'Teil,' the velocity should be $2.40 \mathrm{~m}$. per second, as in the ordinary walk, for a horse $1.60 \mathrm{~m}$. high. The veloeity of this gait, it is pereeived, varies in a great measure aceording to the conformation, the energy, and the endurance of the animals. In 1844 and 1845, in coneert with H. Bouley, we observed a mare, known in Paris by the name of Americaine, which several times, and with the same success on each occasion, ambled the whole distance from Paris to Fontainchlean against thoroughbred horses going at a gallop.

The amble, in this instance, was leaped, as, indeed, it appears to be whenever its speed attains that of the fast trot. According to M. Lenoble du Teil, ${ }^{2}$ this particular form of ambling is well known to the Germans, who call it the flying cmble. 
Disadvantages.-On the other hand, however, if the ambling horse is fast, lis step lacks sureness and safety. Obliged to advance the members close to the ground, he is liable to knoek against the inequalities of the soil ; as a consequence, he frequently stumbles, and it requires the continual attention of the rider to select the road and to support him when he makes a false step.

Conformation.-A strong and muscular frame, a wide chest, short loins, strong articulations, irreproachable axes, and perfectness of action of the members will counterbalance the inconveniences accruing from the instability of his equilibrium and the lowness of his gait.

\section{Broken Amble.}

We will call, with Vallon and Merehe, the broken amble that variety of the amble in which the members, still associated in lateral bipeds, reach the soil successively, the posterior a little before the anterior, producing thus four beats and leaving also four imprints on the ground. The only difference between this gait and the ordinary amble is that in the latter the lateral lifting and resting of the feet are simnltaneous, while in the former they are effected separately with a short interval. It follows, then, that the posterior imprints, in position, surpass mueh less the anterior, since the hind-foot is arrested behind the point where it would go if it met the soil at the same time as the fore-foot.

Fig. 199 represents the trail of the broken amble, according to M. Lenoble du Teil, ${ }^{1}$ who, in his classification, calls the latter broken walk.

The disassociation of the lateral beats, $A D, P I)$ and $A G, P G$ (Fig. 200), gives origin to complex supplementary bases $(2,3,4$ and $6,7,8)$, which are interposed between the ordinary lateral bases $(1,5,9 \ldots$ ), always of long duration. Instruments will probally demonstrate among these supplementary bases a diagonal base $(3,7 \ldots)$ placed between two very short tripedal bases $(2$ and 4,6 and 8). If the periods of exchange of contact $(2,4,6,8 \ldots)$ are longer than we have supposed, the supplementary bases will simply be tripedal.

A


Be it as it may, it results from these farcts that the variety under consideration is more stable than the normal amble; the horse can therefore take a longer step withont increasing, for this reason, the rapidity of his movements. Hence the ambler breaks his gait only when an

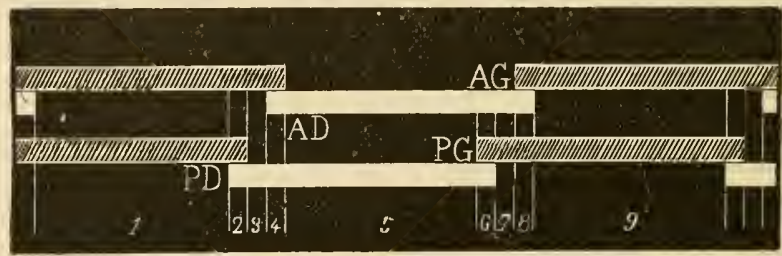

FIG. 200.-Notation of the broken amble.

increase of speed ineompatible with the synchronous play of the anterior and posterior member is demanded of him. In this case the latter is obliged to precipitate its action, to anticipate that of the former and to respond to the required acceleration.

The interposition of the three supplementary bases between the two lateral suceessive bases explains also the smallness of the transverse displacements of the centre of gravity and, in consequence, the great ease of the reactions of the broken amble. If, however, such a horse is restrained from moving his members with suffieient rapidity, so as to advance them elose to the ground without great reactions to the rider, he eonstitutes a mount hardly surer or more stable than the ordinary ambler. Like the latter, he serapes the ground, stumbles, and even falls when he is ridden hard on rough roads.

The broken amble, says Vallon, ${ }^{1}$ is usual to certain varieties of horses, such as the small horses of Normandy and those of the Hagne. It is common in Algeria, and the Arabs produce it artificially by chaining, in the pastures, their horses in lateral bipeds; then, when mounted, they urge them with the spur or the angle of their wide stirrup. But as soon as the training ceases they reassume the normal amble or the walk, and the whole series of these training. exercises must be recommeneed. Properly-dressed Barb horses can easily travel two and onehalf leagues per hour at this gait, completing thus twenty-five to thirty leagues per day.

\section{B.-The Trot.}

The trot is a natural gait, with two times, more or less fast, in which the members rise and reach the ground simultaneously in diagonal 
bipeds. As in the amble, the complete step, therefore, emits two beats.

Trails and Varieties of the Trot. ${ }^{1}$-According to the relation of the imprints left by an animal which trots, three particular varieties can be observed: sometimes the pusterior remain behind the anterior (Fig. 201); sometimes they are superposed upon each other (Fig. 202); sometimes, finally, the posterior surpass the anterior (Fig. 203).

In other words, the horse se déjuge (ill-checks his steps), se juge (checks them), or se méjuge (overchecks them), according to the length of his strides. (See page 474.)

The ordinary trot is that in which the superposition of the imprints exists, which is indicated in figures by means of a shoe provided with a single crampon. The trail is then simple, right and left.

The short trot is that in which the posterior imprints do not quite reach the anterior.

Finally, we call long

1 All the trails of the trot are after the same scale, and therefore comparable to one another.

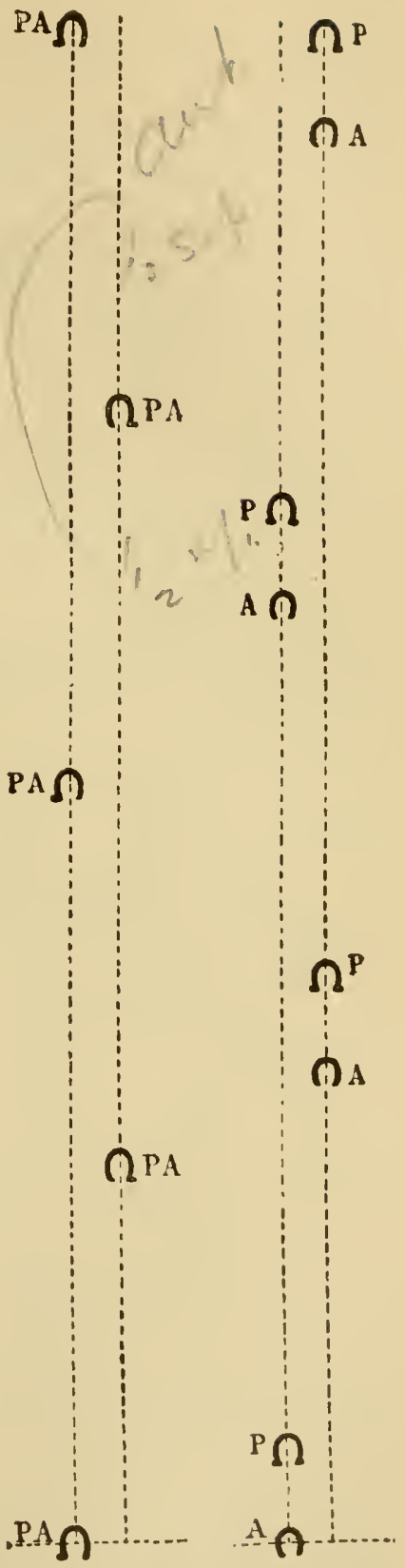

FIG, 202. - Trail FIG, 203,-Trail of the ordinary of the long trot. trot. (Lenoble du (Lenoble du Teil.) 
trot that in which the posterior imprints surpass the corresponding anterior.

In the last two eases the trail is double on both sides.

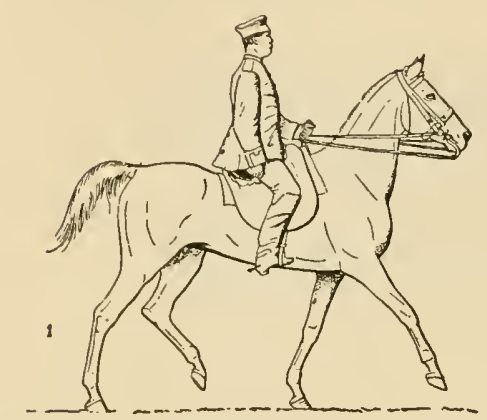

FIG. 204.-The leaped trot; left diagonal contact.

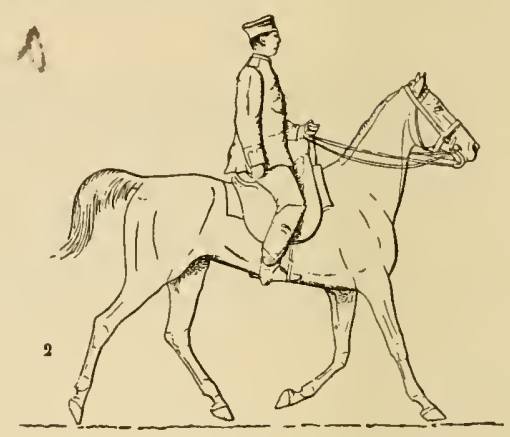

FIG. 205.-The leaped trot; projection.

The gait, however, assumes a peeuliar disposition aceording as the body, in the course of the complete evolution of the step, remains in

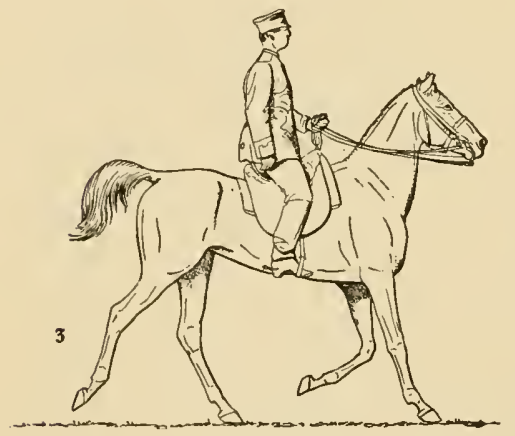

FIG. 206.-The leaped trot; right diagonal contact. contact with the soil or is separated a little before each diagonal contaet. It then takes the character of marched or leaped. In general, the short trot is marched, particularly when the animal is in harness. Nevertheless, it may be leaped, as when the horse, urged by the voice, the whip, or the legs, is prevented from producing the acceleration of speed thus indicated. It is often observed at the riding-school in horses held in the "gathered-up" attitude; also in very ardent and nervous draught-horses that are too fiery at starting and are held back.

Figs. 204, 205, and 206 represent precisely the three prineipal phases of this modification of the short trot, from instantaneous photographs by M. Ottomar Ansehïtz, of Lissa.

The ordinary and the long trots are always leaped. This is due to the fact that the fore-foot must necessarily be raised before the corresponding hind-foot tonches the ground, under penalty of wounds from the latter, and to permit the latter to eover or to pass over the imprints of the former. As at this moment the diagonal members are in the air, the body remains without contact for an instant. 
The phase of suspension of these trots coincides with a more or less lengthy and elevated projection of the body, which gives to them varying aspects. It is greatest in the long trot, medium in the ordinary, and very little marked in the short. Aceording to the height to which the body is raised, it renders the gait high or low. It is, in general, proportional to the speed employed and the vigor of the animal.

When the velocity of the trot is earried to the extreme, the synehronism of the diagonal beats is seen to disappear; the latter are slightly disassociated, and this all the more as the hind-foot reaches farther beyond the fore-foot of the same side. The amplitude of the steps then reaches its highest limits. This is the beginning of a new variety, the broken trot, trot of the hippodrome or the rece-course, which the English, on account of its velocity, eall the flying trot. We will study it presently.

Kinematic Analysis of the Play of the Members in the Trot.1st. Anterior Member.-The period of dispersion of forces, 0 to 2, very marked, is manifested, above all, during the contact with the ground, as deduced

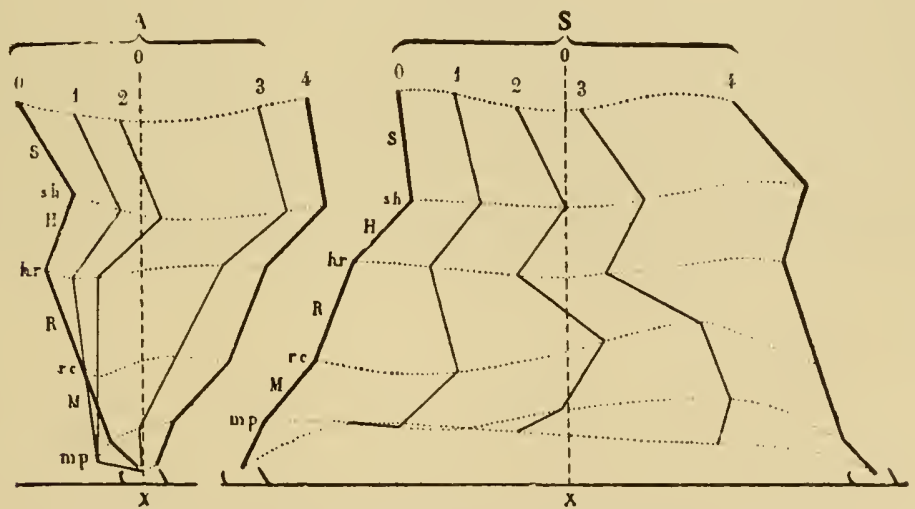

FIG. 207.-Kinematic analysis of the play of the anterior member in the ordinary trot (Messrs. Marey and Pagès.)

A. Phase of contact.

S. Phase of elevation.

from the researches of Messrs. Marey and Pagès (Fig 207, A), by the sudden and forcible descent of the fetlock, which is also perceived by the carpus and the elbow, although less sensibly by the latter. The curve of the withers is greatly depressed in its middle, in consequence of the flexion of the angle of the shoulder.

During the elevation, $S$, the trajectory of the withers also offers a curve in its middle, a markerl inflection, due to the shortening of the opposite member, now in its contact, which weakens, in its turn, the concussion of the body upon the ground.

The trajectories of the fetlock and the knee, sensibly parallel, forcibly 
ascend (the fetlock first) during the shortening of the member, to descend simultaneonsly when the latter elongates and prepares to rest again.

As to the trajectory of the foot, inversely disposerl, convex at the beginning of the elevation and oblique downward at the end, it crosses that of the fetlock under the effect of strong Hexion of the pastern at the instant when the foot leaves the ground.

2d. Posterior Member.-Phase of Contact, A (Fig. 208).--In a general manner, all the articular trajectories are lowered during the period of disper-

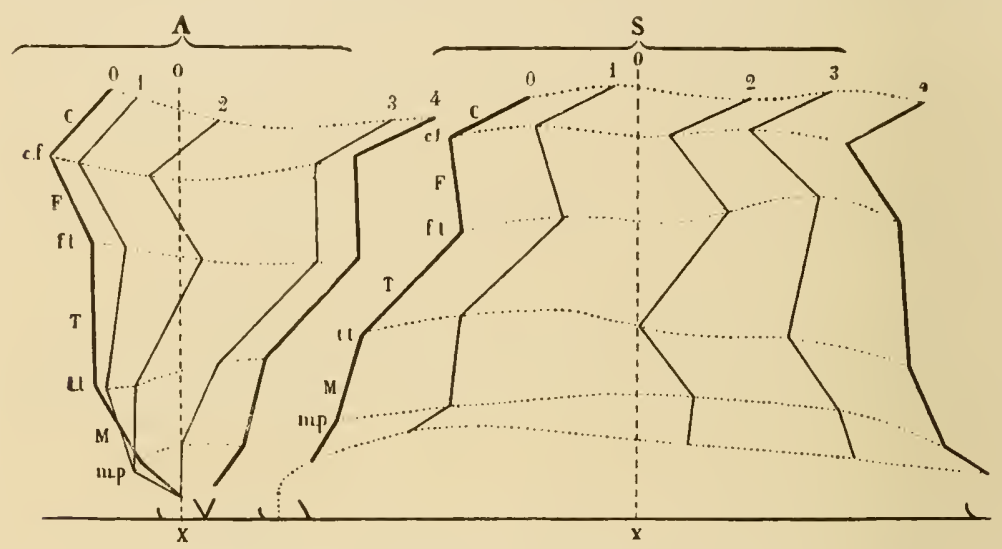

FIG. 208.-Kinematic analysis of the play of the posterior member in the ordinary trot. (Messrs. Marey and Pagès.)
A. Phase of eontact.
1
S. Phase of elevation.

sion, the inferior much more than the superior. The curves then rise gradually, as in the anterior columns, during the period of extension. These trajectories are convex, save that of the stifle, which remains concave and low, from the forward notation of the tibia.

During the elevation, $S$, a depression exists in the middle of the trajectories, except upon those of the fetlock and the foot; it corresponds to the phase of dispersion, 0 to 2 , of the opposite member. It is preceded and followed by a slight ascension, due to a greater or less raising of the body at the moment of the periods of suspension. The trajectories of the fetlock and the foot resemble those of the anterior member, only that of the foot approaches the former less, on account of the more feeble flexion of the pastern.

\section{Rhythm of the Beats; Time of Projection; Tracing} and Notation.-When the trot is regular, and its speed not excessive, only two sounds, or two synchronous beats of equal intensity, are heard. Tired and overdriven horses do not travel at this gait long without irregularities, which must be considered as defects. We will study these under the names racking, saut de pie, and canter.

The duration of the time of projection ${ }^{1}$ has been differently appre-

1 Let us recall that in the leaped trot there is a simple suspension when the lateral imprints are superposed, and a projeclion when the posterior imprints surpass the anterior. 
ciated by most authors who only had recourse to direct observation. The means of investigation employed by M. Marey has enabled him to harmonize these views. Having established this divergence of opinion by eiting $\mathrm{H}$. Bouley, ${ }^{1}$ aceording to whom the period of projection is shorter than that of the contaet, contrary to Raabe, ${ }^{2}$ who elaims the reverse, this learned experimenter expressed himself in the following terms : ${ }^{3}$

"An old and very docile horse has furnished the tracing represented in Fig. 209. In this figure are indicated the traeings of the

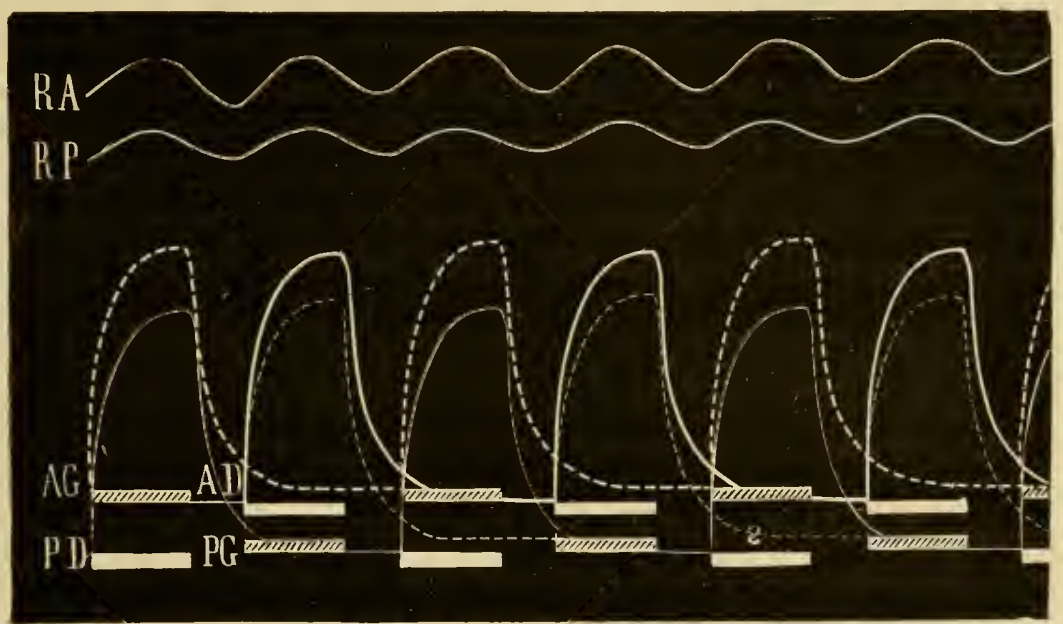

FIG. 209.-Tracing, notation, and reactions of the trot.

$A G$, beginning of the contact of the anterior $\mid P D$, beginning of the contact of the posterior left foot.

$A D$, beginning of the contact of the anterior right foot. right foot.

$P G$, beginning of the contact of the posterior left foot.

eontact with the soil of the four members, with their notation, and, besides, the reactions given by this gait to the horse.

"Here it is observed that the eurves of the contacts of the four feet reach two different levels: the higher are the curves of the anterior members; the lower, those of the posterior. In each of these series the eurves of the left foot are represented by dotted lines; those of the right by the continuous lines.

"The ascent of each curve expresses the commencement of the contaet of the foot upon the ground; the descent indicates the moment when the foot is raised." It is seen, from these tracings, that the feet

1 H. Bouley, loc. cit., t. i. p. 391.

2 Raabe, Locomotion du cheval (Examen des allures), p. 39.

3 . Narey, La machine animale, p. 150.

4 "The duration of the contact should be indicated by a horizontal line, but we have given to the tube a narrowness destined to weaken the sudden impulse impressed upon the registering 
$A G$ and $P D$, anterior left and posterior right, strike the ground at the same time. The simultaneous lowering of the eurres of these two feet shows that their elevations are also made simultaneously. Below these eurves is the notation which expresses the duration of the contact of the left diagonal biped.

"The seend beat is produced by the feet $A D$ and $P G$, right diagonal bipeds, and so on over the whole length of the tracing.

"It is seen in the notation of this tracing that the eontacts (full lines) are double the length of the time during which the body is suspended above the ground (intervals between the full lines). This suspension therefore coincides with the theory of Bouley, and is contrary to that of Raabe; but it seems to us that there is a great variation in the relative duration of these two phenomena in the trot. Thus, eertain horses, trotting in harness, have furnished tracings in which the phase of suspension was seareely pereeptible (Fig. 210), in such a

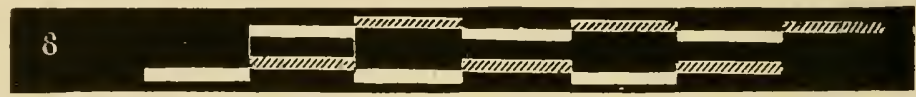

FIG. 210.-Notation of an ordinary trot in which the phase of suspension is not perceptible.

manner that this form of the trot here approaches the low gaits, but still preserving the perfect synchronism of the diagonal beats. We have not yet been able to study them in the fast trotters; in them, perhaps, there is an inverse tendency, the time of suspension inereasing at the expense of the duration of the contact."

This is the result of our own observations also. When the movements are high and extended the body remains longer in the air than in contact with the soil ; it seems as if the horse displaces himself by diagonal jumps. The strides, in this case, are very long. It may be the same in eireumstances exactly the reverse, when, for example, the horse, taking small steps, balunces himself, as it were, in the air during the projection, and carrying the feet low (Lenoble dn Teil).

At other times the speed is still eonsiderable, but the time of contact and elevation of the members appears sensibly equal; the projection is then not very extended. This is due to the fact that the movements are more rapid ; the trail then shows the imprints in eloser relation, the beats are more precipitated, and the body moves more closely to the ground.

needle; the effect of this narrowness is a slight deformity of the curve, which, however, does not interfere with the study of the rhythms." 
Finally, when the trot is marched, as is seen most frequently in that which is termed short, the phase of simple suspension is entirely absent. The body never leaves the ground altogether, and the period of exchange of contact gives rise to short quadrupedal bases, 1, 3, 5 (Fig. 211), which are interposed between the principal bases, 2, 4, 6, formed by the diagonal feet.

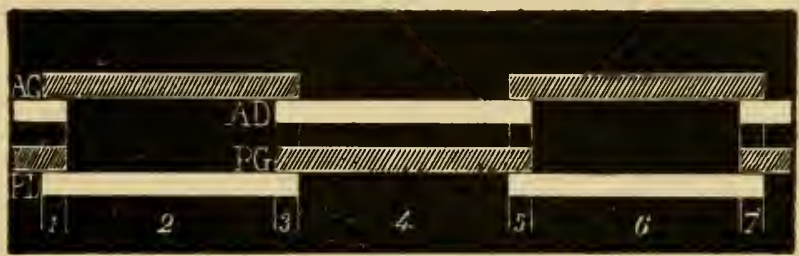

FIG. 211.-Notation of the marched trot.

\section{Displacements of the Centre of Gravity and Reac-} tions.-The centre of gravity, in the trot as in the amble, undergoes two sorts of displacements, from side to side and from behind to before. The latter give origin to reactions so much more forcible as the gait is higher and more elongated.

Concerning the lateral or transverse displacements, "sinee the body," as Lecoq ${ }^{1}$ properly says, "is successively supported by the diagonal bipeds, the centre of gravity should always lie upon a point of the line

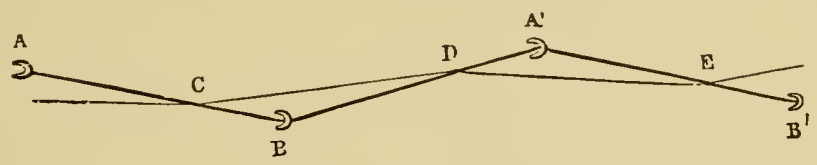

FIG. 212.

which unites the two members. If we suppose it to be at the point $C$ (Fig. 212) of the diagonal $A B$, we will find it at $D$ upon the diagonal $B A^{\prime}$, when the left diagonal biped is on the ground, and it will advance to $E$, upon the diagonal $A^{\prime} B^{\prime}$, when the right diagonal biped will have completed the step. We see, therefore, that in the complete step of the trot the line described by the centre of gravity, longer than in the amble, forms less acute angles and approaches less the borders of the rectangle of the members; and that, consequently, a more favorable condition for the equilibrium coincides with less energetic muscular effort for an equal distance, since the expenditure of 
the contraction is all the greater as the centre of gravity tends to deviate farther from the median line of the body.

"The vertical or longitudinal displacements cannot be represented," adds Lecoq, "by the two uniform curves which exist in the amble. As the body is elevated by the effort of the members and fatls in consequence, the centre of gravity should of necessity describe two parabolic curves, such as $C D$ and $D E$ (Fig. 213), the body falling with

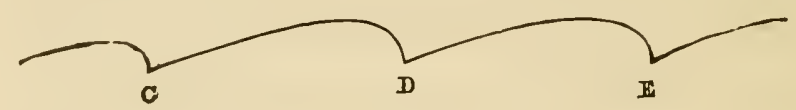

FIG. 213.

greater velocity than that with which it is raised, although the effort of propulsion may ahways be uniform."

Finally, M. Marey ${ }^{1}$ has been able, with the aid of registering instruments, to note the reaction,- - that is to say, the displacements of the withers and the croup at the period of contact of each of the members upon the ground. Thus he has obtained the curves $R A$ and $R P$, seen in the upper part of Fig. 209. The reactions of the anterior members have given the line $R A$; those of the posterior, the line $R P$. "Here we see," says he, "that the moment in which the body reaches the lowest limits of its vertical oscillation coincides precisely with that in which the feet are not in contact with the ground. Thus, the period of suspension of the body is not due to the body of the horse being projected in the air, but to the flexion of all four members for a short period. $^{2}$ The maximum height of the rise of the body corresponds, on the contrary, to the termination of the contact of the members with the ground. It seems, from the tracings, that the rising of the body only commences a little after each double beat, and continues during the whole of the contact.

"Finally, we see, in the same figure, that the reactions of the anterior members are greater than those of the posterior. This fact has to us appeared constant; besides, the inequality of the reactions is more exaggerated in the walk, in which the instrument placed upon the withers nearly always shows appreciable reactions, while upon the croup it shows scarcely any."

Upon the instantaneous photographs from Lissa it is easy to prove

1 Marey, La machine animale, p. 162.

2 Some exceptions in this respect should be made. Instantaneous photographs have given different results, more in harmony with observation of the movements of the rider upon the saddle. 
that the rider falls upon the saddle a little after each diagonal biped rests, when the axis of the members passes beyond its vertical direction. He is raised, on the contrary, at the moment when each diagonal biped leaves the ground, and remains in the air during the whole duration of the phase of suspension.

Length of the Step of the Trot.-It is extremely difficult to formulate, or even to determine approximately, the absolute facts on this point, for the experimental results obtained to elucidate this question are only comparable when the researches are made upon subjects identical and perfectly uniform in their gaits. When such is the case, the suceessive steps are sensibly equal.

But are the height, on the one part, and the length of the base of support, on the other, in simple and constant relation with the length of the strides? In other words, is it the horse highest at the withers, or that one whose base of support is the most extensive, which takes the longest steps?

The man would be liable to commit an error who would answer these questions a priori, because observation of the data in this respect leads to results apparently contradictory. The problem is, indeed, so complex, in consequence of its numerous factors, that its solution is necessarily false, if we base it only upon some phenomena without taking into account all the elements eapable of influeneing it.

The length of the space embraced at each step by the play of the members is related, above all, to the length of the locomotory columns, the degree of openness and mode of action of the articular angles, the extent of the muscular contraction, the proper relations betreen the height of the body, its largeness and its width, to the particular development of certain regions, ete. All these points have already been treated a propos of the regions, the proportions, and the axes, to which the reader is referred.

But, to speak more definitely, let us state that the mean length of a step in the ordinary trot is about $2.40 \mathrm{~m}$. for a horse $1.60 \mathrm{~m}$. in height. The eavalry regulation of 1829 makes it only $2.20 \mathrm{~m}$., which seems to us rather short.

Velocity of the Trot.-The mean velocity of this gait is about 240 metres per minute, as it has been fixed by the cavalry regulation. This gives approximately a kilometre in a little more than four minutes, and 4 kilometres in a little less than seventeen minutes. The distance traversed at the trot in a given time varies aceording to several conditions which must be recognized.

In comparative experiments made with horses of unequal height, 
we have seen that, in the same time, they can accomplish equal distances. What is the explanation of this fact? Evidently that the smallest horse compensates the shortness of the steps by an augmentation in their number. One is therefore correct in the conclusion that, all things being equal otherwise, for the same course, the same surface, the same energy, the speed of the trot is, above all, subservient to two causes: the length of the steps and the firequency of their repetition.

To these must be added another important element, training, the effect of which is so well known.

Most observers have cited examples relative to the great speed employed in the trot; a certain number are given in the following table: ${ }^{1}$

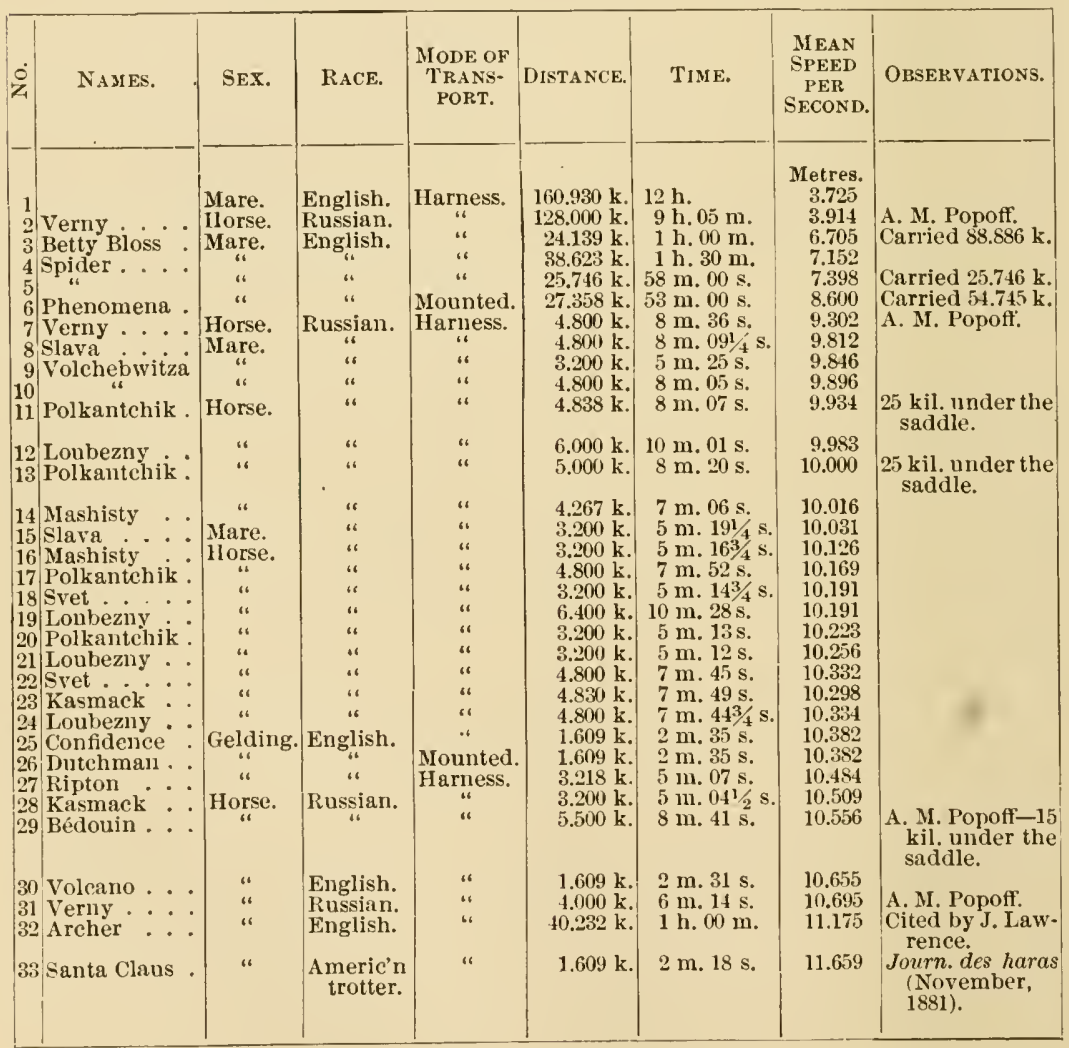

1 For more details, see Charles du Hays, The Trotters (Brussels, Paris, and Leipsic, 8vo, without date). This book treats of the trotting races which had taken place in France from 1827 to 1863 , and refers to the speed of the flying trot,- -that is to say, the broken trot. 
It is seen from this table, arranged according to the degree of speed, that the latter augments, in general, in an inverse ratio with the distance. This conclusion is, however, not applicable to all cases, because certain trotters occupy in this table a position different from that which they would have obtained had the severity of the task effected been considered. ${ }^{1}$

Beauties and Defects of the Trot.-The beauties of the gait of the trot consist in its regularity, gracefulness, height, and speed. It is extremely rare to meet all of these combined in the same subject.

Its regularity is indicated by the synchronism of the beats and the uniformity of the step.

Its gracefulness consists in its lightness, ease, and suppleness, as well as in the parallelism of the planes of oscillation of the members in relation to the median plane.

Its height is associated with the energy of propulsion and the length of the projection.

The speed depends, as we have seen, upon the length of the steps and the frequency of their repetition in a given time.

Observation can easily distinguish a good trotter.

We will summarize the principal features of his conformation, such as H. Bouley ${ }^{2}$ has, in general, so accurately outlined:

Amplitude of the chest, expressed externally by long and wellarched ribs; abdominal development proportional to the mass of the body; back and loins straight, full, muscular, situated upon the same level as the croup, neither too long nor too short; croup long, muscular, not too horizontal, inclined 30 to 35 degrees; haunches wide and well detached; head light, supported by a neck long, straight, and pyramidal ; withers high, neat, not too thin, and prolonged backward; shoulder long and oblique; arm little inclined; elbows separated; forearm long, wide antero-posteriorly, furnished with muscles large and well outlined under the skin; knee flat in front, salient behind, and, above all, articulated vertically ; canons short, strong, wide, vertical ; tendons voluminous, clean, well detached, parallel to the canon ; fetlock wide; pasterns short, little inclined; thigh long, musenlar,

1 We have purposely not included in the preceding observations this passage from Cardini : "Jack, a celebrated trotting-horse which, in 1834, trotted two English miles in three minutes and seven seconds, is cited." This horse wonld thcrefore have travelled in the time indicated. $3 \mathrm{k}$., 218 metres. By making the calculation, it is found that the speed would have been 17.208 $\mathrm{m}$. per second. We belicve that there is an error in the correctness of the time, for the most remarkable trotters are too much below the specd attributed to Jack.

2 H. Bouley, Noureau Dictionnaire, etc., t. i. p. 394. 
very mobile; stifle projecting outward; buttock and leg long, wide, muscular; hock fine, clean, wide, thick, well directed. Finally, regular axes; muscles dense, compact, prominent; skin fine and mane little abundant.

In France there are no equine races whereof the individuals are exchusively trotters, as in Russia, England, and America, for example. ${ }^{1}$ But we meet, among our Anglo-Normans, many horses which, in races to harness and under the saddle, vie with the preeding.

All horses do not trot in the same manner. There are some in which the extension of the whole anterior member is earried to such an extreme that the contact of the foot with the ground, after a short time of arrest, almost seems to be effected upon the heels. The movements of the posterior members are equally very extended, whence an energetic effort of propulsion, much more action, as we are in the habit of saying.

Again, there are some, light trotters, which emit but faint beats when trotted upon a hard road or a pavement; others, on the contrary, emit heary sounds under these cirenmstances. Some rock themselves from the fact of very great corpulence or a vicions axis of the members.

Some raise their members insufficiently from the ground, scrape the floor; others elevate them excessively, trot from the knees, which is so much loss of foree.

Others, again, lack harmony between the movements of the foreand those of the hind-limbs, or have some anatomieal defect of certain regions which detracts from the grace and ease of the gait, and even exposes them to many accidents to be described farther on; such are horses which forge, have string-halt, pegged shoulders, rotating hocks, ete.

Finally, some show their shoes, from excessive flexion of the pastern upon the fetlock.

Most of these defects are not peculiar to the trot, but are common to all the other gaits. We will examine them in a special chapter.

Nevertheless, there are some defeets whose study cannot be separated from that of the trot; they become manifest when the horse is overdriven, fatigued, or exhansted. We will immediately pass them in review.

\section{The Broken Trot; Flying Trot; Racking.}

All these expressions are symonymons in that they are applied to characterize the same phenomenon, modifying the rhythm of the trot

1 This expression is scarcely correct, for the trotter does not constitute a race. but only a variety of a race. (Harger.) 
and giving to it a peculiar appearance. We refer to the disassociation of the diagonal beats. The terms are, however, employed differently according to the conditions under which this disassociation manifests itself.

Sometimes the synchronism of the diagonal contacts disappear's when the speed of the trot, already great, is carried to the extreme, as is observed in the fast trot or flying trot.

At other times this takes place if the ordinary trot be forced ever so little. It is in this event that the word racking is to-day employed. The latter, therefore, should express more especially a disunion of the trot, which may have as its eauses fatigue, weakness, or wear and tear. ${ }^{1}$

Be that as it may, it will be found on serious consideration that it is an effort of an identical nature which induces the horse, whatever he may be, vigorous or exhausted, to break, disunite, disconnect his diagonal beats. He endeavors, in all cases, to accelerate his speed by longer strides without passing into the gallop; and he would surely pass into the latter if he were not held back, or if the urging with the voice, the whip, or the leg were continued. Hence, in our opinion, this variety of trot is a transition, a mode of ehanging from the normal trot to the gallop. As it accompanies a variable degree of velocity, it must be interpreted favorably or unfavorably according to circumstances.

Thus, it is not inadmissible in a trotting-horse, if it serves as a means of acceleration to excel his eompetitors; but this horse would be considered as being inferior to his rivals, if the disunion of the gait did not make him superior to them in point of speed. Likewise a horse which racks after a slower trot is much inferior to one which only changes to this gait after moving at greater speed.

It is seen that, in the presence of the broken trot, numerous distinctions must be made relative to the qualities of the animals. The important point is to determine at what rate of speed the change takes place, so as to ascertain whether it is or is not a sign of fitigne and exhaustion. Young horses which are little acenstomed to work frequently rack, but training and exereise will usually eause the disappearance of this defect. It is, on the contrary, irremediable in those in which excessive labor or old age has deteriorated the forces and exhansted the mechanism.

The flying trot or fast trot is in most instances a broken trot, which

${ }^{1}$ It is impossible to formulate the general trail of racking, beeause it treessarily varies with the speed. It resembles ordinarily that of the broken trot. 
the majority of horses employ either during the entire duration of a race or only when nearing the winning-post.

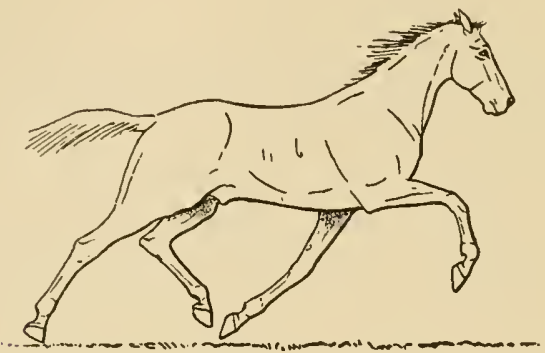

FIG. 214.-The flying trot of the horse Abe Edington: end of the left diagonal contact.

Exceptionally good subjects give way to it less frequently and for shorter periods of time than others; but, in the

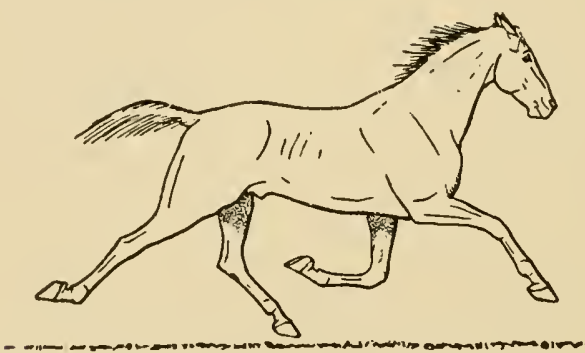

FIG. 215.-The fying trot of the horse Abe Edington: projection.

absence of more conclusive evidence, we may doubt if any horse exists that never indulges in the practice.

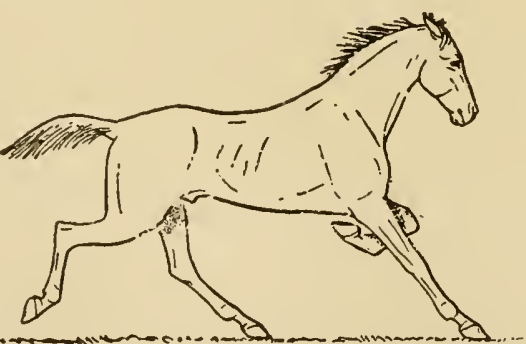

FIG. 216.-The flying trot of the horse Abe Edington: commencement of the right diagonal contact.

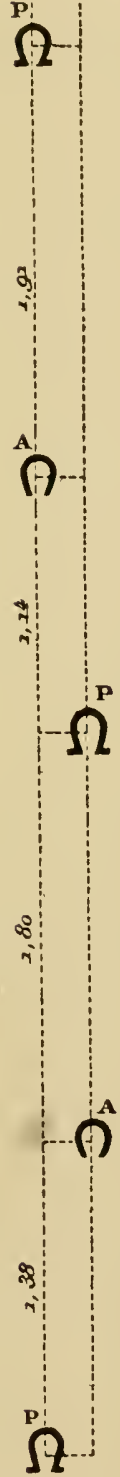

Frg. 217.-Trail of the flying trot of the horse Abe Edington. 
years opposed to the tendency which certain trainers have of training their horses in this direction. According to M. Ephrem Honel, ${ }^{1}$ it should even be strictly proseribed on all the race-courses. We are in accord with this opinion, and believe that, by the fatigue which it occasions, it exposes the members to premature ruin.

M. Lenoble du Teil has carefully studied the flying trot from the instantaneous photographs of M. Muybridge, published in the journal La Nature, in 1879 . He has, at our request, formulated the trail and the notation of this gait furnished by the American horse Abe Edington, moving at the rate of $11.90 \mathrm{~m}$. per second.

We have reproduced very accurately, in Figs. 214, 215, and 216, three successive phases of the trot of this horse, to give an idea of the attitude of the members and the very great length of the strides. These figures will explain themselves.

The trail (Fig. 217) shows that the posterior imprints are situated almost 2 metres in front of the corresponding anterior. This peculiarity is due to the distance of the projection. Here will be remarked, besides, the relative smalhess of the diagonal base, which at times does not attain $1.20 \mathrm{~m}$., - that is to say, three-quarters of the height of the horse, as is observed in the ordinary trot. Hence there results less stability and, in consequence, more precipitated movements and greater velocity.

The stride, measured between the successive imprints of the anterior right foot, is $6.04 \mathrm{~m}$.; it oceupied about half a second. That of the posterior, measured from the left imprint, is a little longer ; it, indeed, attains $6.23 \mathrm{~m}$.

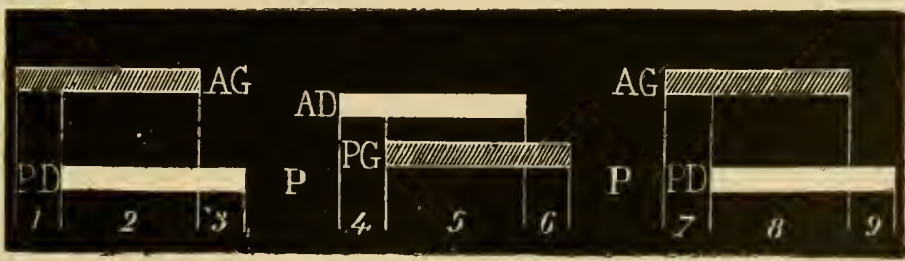

FIG. 218.-Notation of the flying trot furnished by the horse Abe Edington. (From instantaneous photographs of Muybridge.)

The notation is also most interesting. The disassociation of the diagonal beats is very evident (Fig. 218). The anterior member arrives first on the ground. It follows from this that the body is first supported by this member (1), then by a diagonal biped (2), finally by the poste- 
rior member (3) belonging to this biped. After the posterior unipedal contact the body is raised from the soil, $P$, to touch it again and complete a half-step.

II. Lenoble du Teil has caleulated that the duration of each foot on the soil lasted about fourteen-hundredths of a second, or threeelevenths of the total duration of the step, while the unipedal contacts, much shorter, equal each only one-ninth of the time of the contact of the feet. One understands then the impossibility of appreciating clearly this analysis of the diagonal beats under such velocity.

As to the phases of projection, they are equal to two-thirds of the duration of the contact, - that is to say, relatively long in relation to what they are in the perfectly synchronous trot.

In the absence of more numerous data, the preceding facts lave only the value of a simple indication, upon which it wonld, no doubt, be premature to establish the definite theory of the fast trot. Nevertheless, they are a step in the course of its mechanism.

The conclusion which can be deduced from them is that, at certain moments, four times in the same step, the body is supported only by one nember. The anterior limbs have individually to sustain the effeet of the fall of the body at great speed, while the posterior are likewise by turns severally taxed with the communicating of the impulsion. The apparatus of impulsion of the latter and the apparatus of amortissement (dispersion of coneussion) of the former are therefore frequently exposed to exertions from which they would be spared were not the synchronism of the diagonal beats more or less destroyed. Hence it is that the habitual employment of the flying trot contributes to the premature ruin of the fetlocks and the hoeks, partienlarly in young horses.

But in the broken trot is it always an anterior member which arrives first in contact? Is it not sometimes a posterior? It is possible that these two modes of disassociation of the diagonal beats (an exist, although seience only possesses presumptions npon this point.

Mr. Lenoble du Teil ${ }^{1}$ thinks that the hind-feet rest first whenever the diagonal base notably exceeds three-fourths of the height, and the head and neck of the horse, slightly elevated, displace the weight upon the posterior quarters. These conditions of equilibrium are realized when the jockey pulls the horse's head violently with the reins, in mediocre trotters, in young horses which have had no training, and in 
full-grown animals whose strength has become exhausted from excessive exertion, or which have been overdriven.

Whatever may be the process of disassociation employed by the animal, and the aceuracy of the interpretation which can be given to it, the fact remains that the disturbance of the isochronism of the diagonal beats results in the formation of unipedal bases, which increase the exertion of the extremities. Whether the broken trot is the flying trot of subjects endowed with great action, or racking of those fatigned and inapt, its consequenees upon the locomotory apparatus remain the sime : premature or positive ruin, according to cireunstances.

On the other hand, trotting-horses which disassociate their diagonal beats by the initial rest of the posterior foot are less pleasant as saddlehorses than others, the rapidity of the pace being taken ont of consideration. If they do not give very hard reactions to the rider, they communicate to him light and sudden shoeks which displace his seat transversely, a kind of movement expressed by saying that they roll upon their haunches. With them one cannot ride à l'Anglaise, an inconvenience of a certain importance to persons who are in the habit of doing so and who wish to save themselves from the umnecessary fatigue of a long journey.

\section{Saut de Pie (Skipping).}

When the disunion of the trot beeomes excessive, and when this gait is on the point of passing into the gallop, the horse, in order to preserve it, effeets a sort of leap behind, to which is given the name of saut de pie (foot-jerk).

This movement, of very short duration, and analogous to that of a pedestrian who endeavors to aequire the step of a companion whose speed is greater, has not yet been analyzed by chrono-photography or by the graphic method. (See Canter.) It is therefore impossible, in the actual state, to recognize the mechanism. Hence we will not dwell on this.

\section{The Canter.}

(The canter is a gait of transition which the trotter assumes temporarily, and in which he gallops on one of his bipeds (anterior or posterior), while he continues to trot on the other.

It could be defined as a semi-broken trot, - that is to say, with diagonal beats synchronous in one moiety of the stride, disissociated in the other.

From a peculiar resemblanee which is easily understood, althongh 
it may not be altogether accurately founded, the laity have compared the ordinary walk of a man to the walk of the quadrupeds; his manner of running to the trot, and a certain variety of the latter, which children imitate in their plays, to the gallop. The only error in this comparison is that the quadrupedal locomotion resembles, as Dugès las described, that of two men following each other, and not that of one alone.

In the gallop of the infant, instcad of emitting the sounds at equal intervals of time, the contacts of the feet are precipitated, one slightly preceding the other; the body is then projected to fall upon the foot which was first rested, and thus continued.

The anterior and posterior members of a galloping-horse behave themselves as those of the two men should who follow each other at the gallop. There is no difference in the rhythm in either case. The association of the feet of the two pedestrians may alone differ from the mode of combination of the two bipeds of the horse, but there is nothing to prevent it from being identical.

If the fore pedestrian now assmmes this gait (Fig. 219) while the hind preserves the trot, we will have the defect known under the name

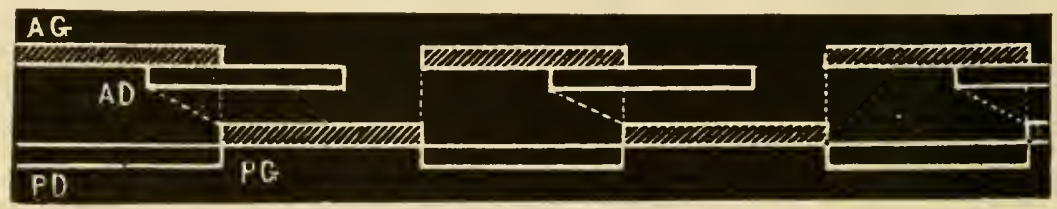

FIG. 219.- Notation of the canter in fronl. 1

The irregular beats, $A G, A D$, of the anterior biped have a different rhythm from that of the isochronous beats of the posterior biped, $P D, P G$.

the canter in front. If, on the contrary, the hind pedestrian gallops while the other trots, we produce the canter behind. The saut de pie, still so obscure, is perhaps only a single stride of the latter.

Finally, let us advance further and suppose that the horse canters at the same time upon the two bipeds, and we will gradually realize the normal gallop.

This manner of regarding the canter as a form of transition between the trot and the gallop leads ns to say that this gait is much less defective than was hitherto believed. Certain indolent, thongh perfectly sound, horses employ it with great facility, and would willingly preserve it if those who drive them did not choose to make them

In order to simplify the figure, the periods of suspension, which exist here as in the ordinary trot, have not been regarded. 
take the gallop by urging them on. Iikewise, horses very ardent and of a good conformation are often seen to eanter for some distance before passing into the gallop, despite the efforts of their riders to prevent them (Lenoble du Teil).

Nevertheless, the horse which canters ordinarily suffers in some region of the nembers of the eantering biped, most often the feet. Under other circumstances, it is an index of weakness, of indolence, or of exhaustion. Certainly we must suspect such conditions, as this gait alone may be able to betray ; in itself, it is not defective, for, bordering on the gallop, it causes, like the latter, less fatigue and furnishes a little more speed than the trot.

\section{Running Walk.}

This gait, in our study, should be placed between the many varieties of the trot and those of the walk, because it establishes very well the transition or the passage from the one to the other.

It resembles the trot (Fig. 220) in that the members are successively moved in diagonal bipeds $(A G, P D-A D, P G)$ and unites its beats in this order; it simulates the walk, on the contrary, by its slowness, its

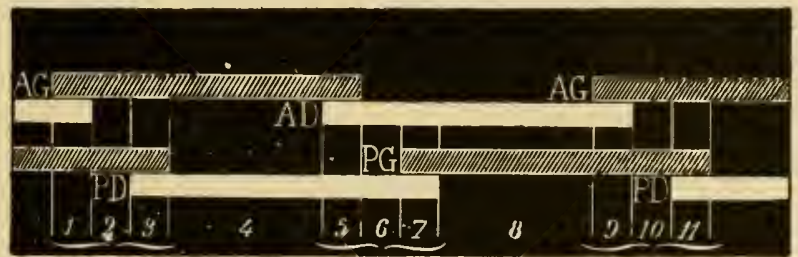

FIG. 220.-Running walk: notation and nature of the bases.

marched character, the mode of succession, and the number of the beats. It is, consequently, a short broken trot in the last degree, as well as a very accelerated walk in which the horse is at the point of passing into the trot.

The disassociation of the diagonal beats, like the marched character of this gait, gives rise to complex supplementary bases $(1,2,3-5,6$, 7), which are interposed between the ordinary diagonal bases $(4,8 \ldots$.$) ,$ always of long duration. Among these supplementary bases is found one that is unilateral $(2,6,10)$, placed between two very short tripedal bases ( 1 and 3,5 and 7,9 and 11 ).

It follows from this that the ruming walk is low, by no means leaped, and always very easy for the rider. Horses which move thus are supposed to clevate the members but little and scrape the floor. Nevertheless, this assertion has yet to be verified. These horses, called 


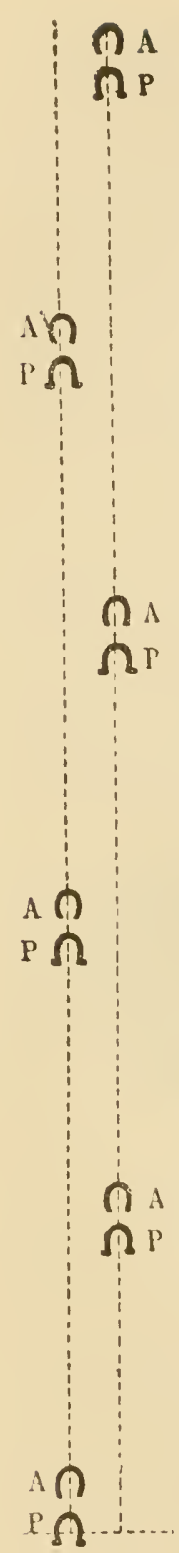

Fig. 221. - Trail of the running walk, from Lenoble du Teil.

bidets d'allure or de hent pas, are at present somewhat scarec; but before the construction of railroads they were prized by horse-dealer's, and, in general, by all persons who had to travel very long distances. They were sought for on account of their pleasant gait, the rapiclity of which almost equalled that of the ordinary trot.

Mazure ${ }^{1}$ has indicated their conformation, if indeed such a word is appropriate; for in truth a great muscular development, a somewhat large head, a powerful neek, rather horizontal than erect, loins short and strong, above all, a thigh thick, long, and descended, do not constitute a particular conformation allied to this special gait.

The trail (Fig. 221) shows, as in the atse of the short trot, the posterior imprints placed behind the anterior; the difference resides entirely in the diminished length of the step.

This gait may be natural or artificial; in the latter case the horse is dressed by trammelling him in diagonal bipeds by means of a strap attached to the pasterns, and urging him as much as possible without passing into the trot, which is not without difficulty.

It would seem that all horses do not execute this gait in the same manner. According to Lecod, there were some in Normandy which were called slaters (patineurs), and in which the beats, almost equally separated, differed only from those of the normal walk by their rapidity and a lesser elevation of the members. These animals fatigne the rider much more than those with the ordinary running walk, by the rocking which they occasion.

\section{C.-The Walk.}

Definition.-The walk is a slow, marched gait, in which the four members suceed each other diagonally, rise and touch the ground separately, and produce four equally-spaced beats.

Kinematic Analysis of the Play of the Members.The body resting always upon the ground in the walk, there is not, during the contart, a period of dispersion as energetic as in 
the trot. It is manifested, nevertheless, by a depression in the trajectories of the fetlock and the knee or the hock (Figs. 222 and 223, 1).

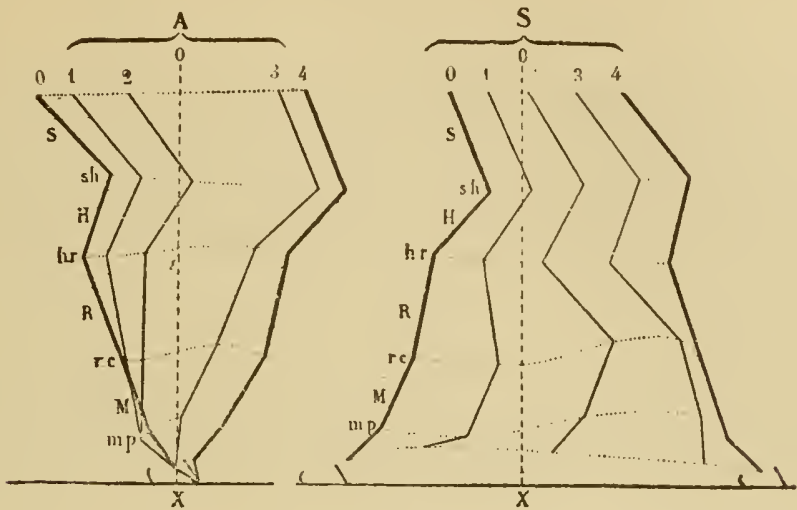

FIG. 222.-Kinematic analysis of the play of the anterior member in the walk. (From Messrs. Marey and Pagès.)
A. Phase of contact.
S. Phase of elevation.

During the phase of contact, the curves of the articulations of the fore-members become progressively eonvex, in consequence of the rotation of the phalangal lever whieh raises the articular centres, particularly the two inferior, fetlock

A

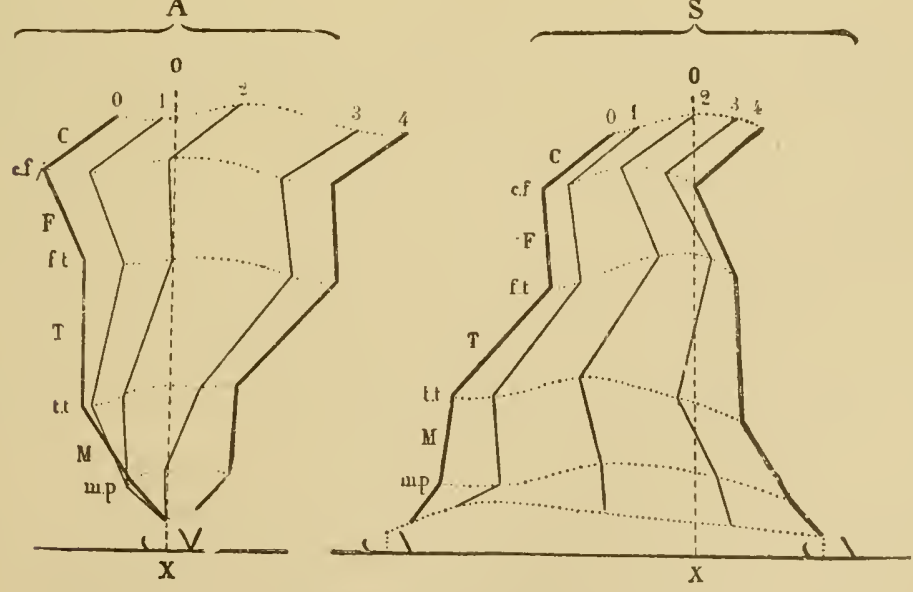

FIG. 223.-Kinematie analysis of the play of the posterior member in the walk.

(From Messrs. Marey and Pages.)

A. Phase of contact. | S. Phase of elevation.

and carpus. Towards its termination, the curves descent igain under the influence of a slight flexion of the knee. In the posterior members, they undergu almost analogrous modifications. 
During the elcution, $s$, the trajectories are sensibly of the same nature as in the trot, although farther separated from one another on account of the less flexion of the articular angles. Yet those of the withers and the shoulder, and even that of the elbow, remain almost horizontal. In the posterior member, the coxo-femoral centre and the angle of the haunch describe a curve with the convexity superior corresponding to the extension of the member before leaving the soil. This is demonstrated by the chrono-photographs of Messis. Marey and Pagès.

Order of the Beats.-It is most frequently the anterior member which commences the step. The beats in such a case follow each other in the following order, supposing the horse to step with the right foot :

Right Diagonal Biped.

1st beat : anterior right. $2 \mathrm{~d}$ beat: posterior left.

\section{Left Diagonal Biped.}

$3 d$ beat: anterior left.

4th beat: posterior right.

When the animal leaves station in a position more or less camped, it is sometimes a hind-member which moves first. If it be the left, for example, the mode of succession of the beats remains the same, but the fore-foot of the same side is brought down to the ground immediately afterwards. The step is then completed, as we have just said ; the extremities then strike the soil in the following manner : left posterior, left anterior, right posterior, right anterior, left posterior, etc., and so on, as long as the gait remains regular. Dugès ${ }^{1}$ is eonsequently correct in stating that the "four legs of the horse may be representect to the mind as two lateral pairs, acting the one after the other, and in each of which the movement of the anterior member is always immeriately preceded by that of the posterior."

Tracing and Notation.-These facts, observed by ancient investigators on equine matters, have heen registered automatically by the apparatus of M. Marey. ${ }^{2}$ We will reproduce (Fig. 224) the tracing which he has obtained and the notation which corresponds to it. The reader will in this figure find all the explanations necessary to comprehend its details.

The following principal conclusions can be deduced from it:

1st. The order of the beats, 1, 2, 3, 4, takes place after the mode indicated above.

2d. When one member is in the mirldle of its contact, that of the one which follows it commences.

$3 d$. When one member is in the middle of its elevation, that of the one which follows it commences. 
4th. In each biped, anterior or posterior, when one nember is on the ground its congener is in the air, and vice versa.

5th. If vertical lines corresponding to each one of the beats be drawn downward, commencing with that of the anterior right foot, which bears the

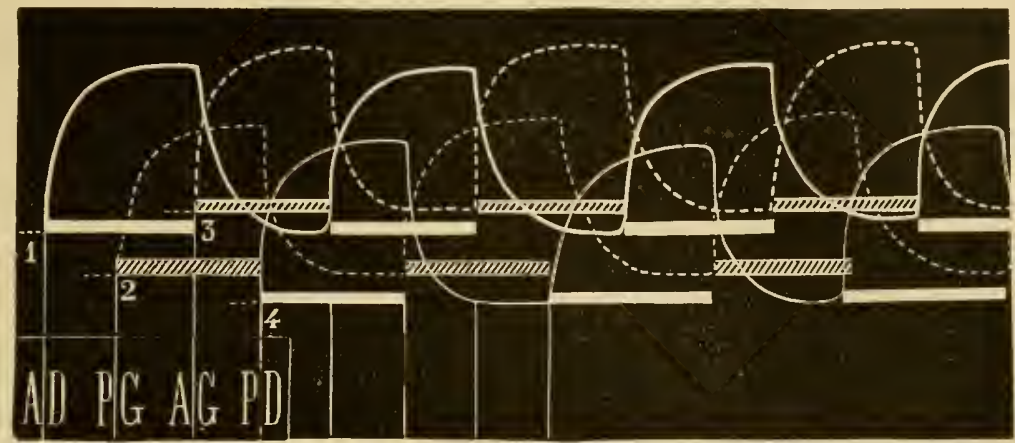

Fic. 2-24.-Tracing and notation of the wulk with equality of the lateral and diagonal contacts.

$A D$, anterior right beat.

$P G$, posterior left beat.

$A G$, anterior left beat.

$P D$, posterior right beat.

$1,2,3,4$, order of succession of the beats. Full white lincs, curves given by the contact of the right feer; dotted white lines, curves of the contact of the left fect. The curves of the posterior feet are below those of the correspouding anterior. The ascenting part of eaeh curve corresponds to a contact; the descending part to an elevation. The length of the lines of the notation, situated below the tracing, indieates the duration of the contact. The interval between two white tines represents the duration of the elevation of a right member; the interval between two gray lines represents the duration of the clevation of a left member.

number 1 , the figure will be divided into suceessive spaces, in which will be found in contact (with the soil) sometimes two members of the same sille (lateral biped), sometimes two members situated diagonally. Thus, from 1 to 2 the horse would rest upon the right lateral biped; from 2 to 3 , upon the right diagonal; from 3 to 4 , upon the lateral left; from 4 to 5 , upon the diagonal left; finally, from 5 to 6 , he would rest, as at the beginning, upon the lateral right (Marey).

The contact of the body is therefore twice lateral and twice diagonal during the duration of the same step.

6th. When the animal rests upon a lateral biped, the members of the opposite biped are very close together, for the anterior is raised white the posterior arrives on the ground. It is under these conditions that the hind-foot ean meet the forefoot, if the latter be not raised quickly enough. (See instantaneous photographs.)

7th. When the animal rests upon a diagonal base, the members of the biped in contact are widely separated, since the anterior is about reaching the ground and the posterior is in the act of rising. Never will the horse, in this ease, be exposed to forging or overreaching. (See instantaneous photographs.)

Sth. The lateral base is always very long, the members which form it showing themselves, by turns, in a camper attitude. According to M. Lenoble du Teil, it should be $1.65 \mathrm{~m}$. for a horse of $1.60 \mathrm{~m}$.

9th. The diagonal base is always small, the members which form it being drawn towards each other. According to M. Lenoble du Teil, it should be $0.75 \mathrm{~m}$. for a horse of $1.60 \mathrm{~m}$. 
The eonclusions which we have just drawn from the tracings of M. Marey are in aceord with the facts observed by all anthors, ancient and molern. We must, however, confess that they are slightly erroneous in that which concerns the number of bases which support the body successively during the aceomplishment of a complete step.

By viewing the horse obliquely in front or behind, when the gait is slow, it is not very diffieult to ascertain for ourselves that the body is not exelusively sustained by diagonal or lateral bases.

At certain moments there appear tripedal supplementary bases, reeognized by our distinguished eolleague, M. Chénier, ${ }^{t}$ and before him by M. Lenoble du Teil, ${ }^{2}$ who described in the marched gaits the remarkable periods of exchange of contact, a statement identical to that recently made by Messrs. Marey and Pagès, ${ }^{3}$ when they spoke of the period of double contact recognized by them in these same gaits.

A horse which ascends a hill, pulls a heavy load, or walks slowly, shows tripedal bases very plainly.

The instantaneous photographs, notably those of M. Ottomar Anschït, of Lissa, attest this in a forcible manner. Figs. 225, 226,

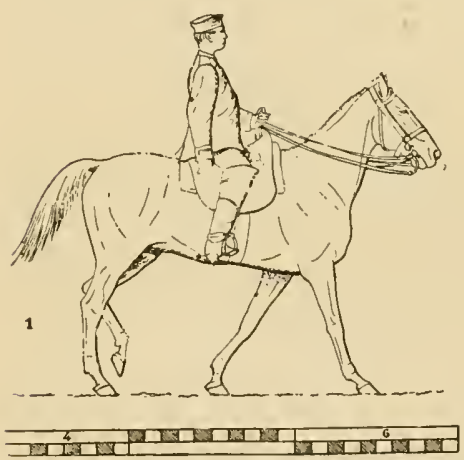

Fig. 225.-The walk : posterior right tripedal contaet

(From the instantaneous photographs of Ijssil.)

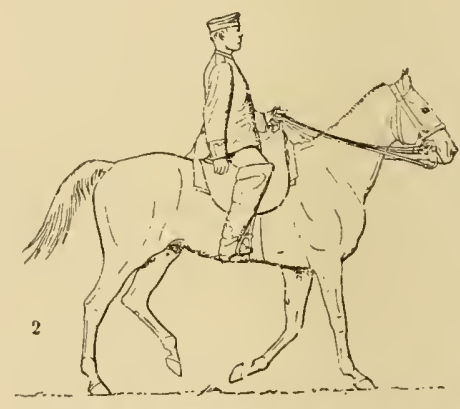

FIG. 226.-The walk: lateral right contact. (From the instantaneous photographs of Lissa.)

227 , and 228 , reproduced from these photographs, explain the suecession of the diverse bases which appear in the comrse of a semi-step, and which are repeated in the same order in the other moiety of the stride. The tripedal bases of support there are evident.

${ }^{1}$ G. Chênier, Analyse du présent ouvrage, in Ėcho des Sociétés et associations vétérinaires, année 1854.

2 Lenoble du Teil, Étude sur la locomotion de l'homme el des quadrupèdes en général, p. 14, Paris, 1887

a Marey et Pagès, Comptes-Rendus de l'Académie des sciences, 18 Juillet, 1887. 
It is also with absolute aceuracy that MI. Chénier advances that these bases alternate very regrularly with the fundamental bases already known.
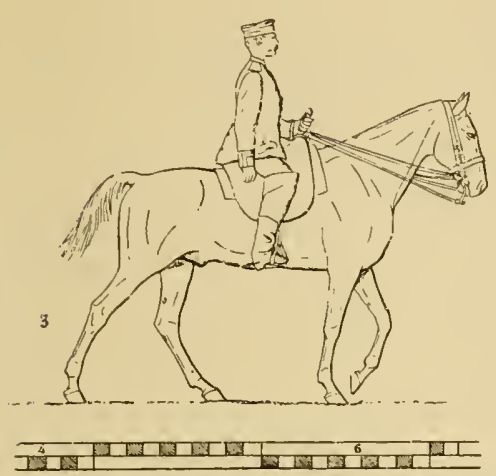

FIG. 227,-The walk: anterior right tripedal eontact.

(From the instantaneous photographs of Lissa.)
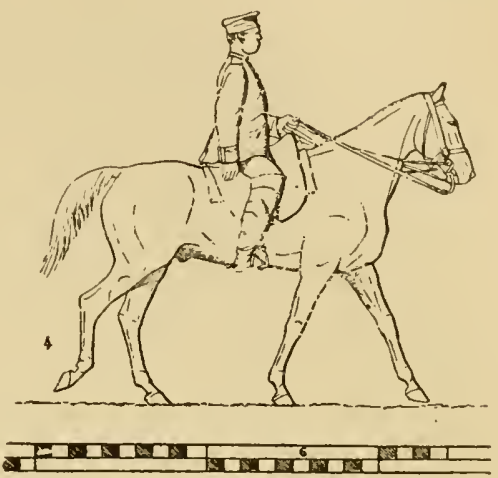

FIG. 228.-The walk: right diagonal contaet.

(From the iustantaneous photographs of Lissa.)

Fig. 229 is the exact notation of the walk with equidistant beats, which has been photographed by M. Anschïtz.

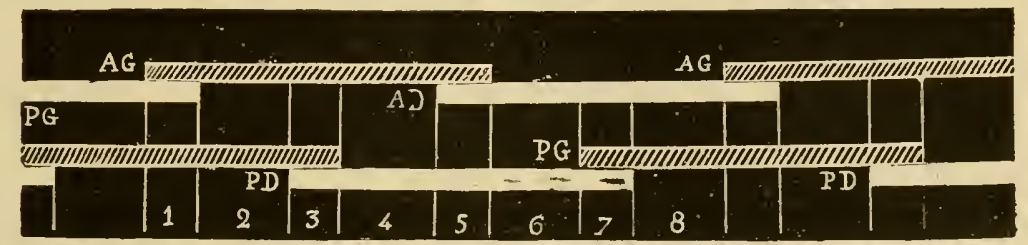

FIG. 229.-Notation of the ordinary walk.

(From the instantaneous photographs of Lissa.)

$1,3,5,7$, tripedal bases ; 2,6 , lateral bases ; 4,8 , diagonal bases.

The duration of the fundamental bases is twice that of the supplementary, which equals oneseventh of the total contact of each foot.

Evidently the periods of contact upon three members are so much shorter and less appreciable as the rhythm of the gait is more precipitated. They oceur at the time of each change of contact, and, as there are four of these ehanges, two for each biped, anterior and posterior, there should also be fonr supplementary tripedal hases. ${ }^{1}$

If M. Marey's instruments, delieate as they are, have not registered them, it is becanse they ocenl at the instant of the raising and resting

1 Like markings on the extremities, the tripedal bases are designated by the mame of the isolaled member (anterior or posterior) which contributes to form them. Example, the base $P G$, $P D-A G$, will be called tripedal anterior left. 
of the hoofs or the canoms, which are thins in an attitude ill suited to excreise sufficient pressure on the pnenmatic foot-bulb. We expect to obtain them and appreciate their duration in all the varicties of the walk by means of our electrical shoe.

Varieties of the Rhythm. - The remarks which precele apply to a particular variety of the walk, that in which the four beats ocenr at equal distances from each other, a circumstance which implies a jerfeet equality between the diagonal and lateral contacts. All authors do not admit this sprecial rhythm. Some, with Lecog, say that the beats are drawn nearer in lateral bipeds; others, with Raabe, elaim, on the contrary, that they are brought eloser in diagonal bipeds.

It follows, then, that for the former the body should be supported longer upon the lateral than upon the diagonal base. If, in fact, the interval which exists between the beat of the posterior left, $P G$ (Fig. 230), ${ }^{1}$ and the anterior

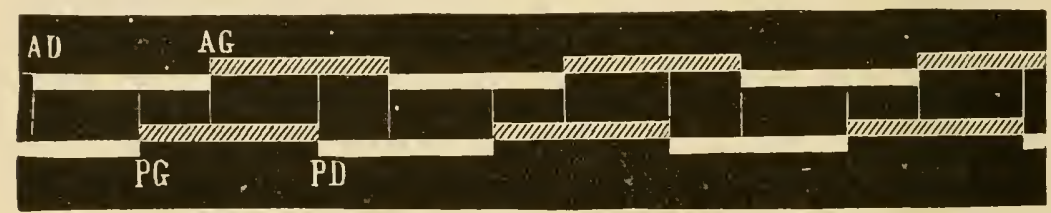

FIG. 230.-Walk, with predominance of the Iateral contacts

beat of the same side, $A G$, is shorter than that which elapses hetween the latter, $A G$, and the posterior right, $P D$, it necessarily follows that the distances from $P G$ to $A G$ (diagonal base) will be less than that from $A G$ to $P D$ (lateral base).

Besides, if the inferior line of the notation be displaced to the left so as to bring $P D$ nearer to $A G$ and remove $P G$ from $A G$, the opposite hypothesis will be represented, in which the lateral contacts will be shorter than the diagonal.

In the first case, the gait will approach the broken amble; in the second, it will be more analogous with the rumning walk.

How is this divergence of opinion explained ? The answer is casy' and, above all, conciliatory : All parties are right. As Merche properly remarked, ${ }^{2}$ it is almost impossible to find two horses walking in an identical manner. Is the walk of the race-horse like that of the driving-horse or the trained sadclle-horse? Is that of the heavy draughthorse the same as that of the light dranght- or the coach-horse? Besides, cannot a multitude of conditions modify this gait? The hereditary influences of the animals, their service, the manner in which they are driven or ridden, their state of exeitability, the weight which they

1 In order to simplify the figure, the supplementary bases, due to the exchange of contact, have been ignored.

2 Merche, Nouveau Traité des formes extérieures du cheval, p. 596. 
carry, the nature and direction of the soil on which they move, and, finally, the speed which they have,-all these influences, in our opinion, explain the modifications of the rhythm which arise in each instance, and which should be considered as definite adaptations of the animals to such or such a requirement of their utilization.

That is the reason why we have, at the beginning of our study, assumed the ordinary, the meen walk, that in which all the fundamental bases are equal and the beats equidistant. The absolutely symmetrical walk does not tend towards the amble more than towards the trot, but it may lead to them by a series of modifications inherent to the mode of relation of the beats. Then its rhythm changes, its symmetry disappears, and, at the same time, one of the fundamental bases, the diagonal or the lateral, according as the gait inclines towards the trot or the amble.

Trails of the Walk and their Varieties. ${ }^{1}$-If the rhythm of the walk offers almost innumerable individual types, it is very evident that these should also convey their influence to the trail and give to the latter, according to the case, the forms which tend to bring them nearer the amble or the trot, two modes of progression whose tracings over the ground differ essentially, as we know. It must also be admitted that between the trail of the amble and that of the slow trot there are as many particular variations as between the two extremes of the rhythms of the walk.

Without entering into the special study of these differenees, we will say that it is easy to relate them to one of the three forms of trails, as follows :

1. Sometimes, in fact, the posterior imprints are superposed upon the anterior of the same side (Fig. 231), which causes them to be styled jugé or covered.

2. Sometimes the posterior imprints are situated in front of the anterior for a variable distanee (Fig. 232), and are then called mejugés or orer-cocered.

3. In other instances, finally, the reverse eondition exists, the posterior being located behind the anterior (Fig. 233), ${ }^{2}$ which may be designated as déjugée or ill-covered.

${ }^{1}$ Lenoble du Teil, Cours théorique d'équitation, de dressage et d'attelage, p. 51 et suiv., Paris, 1 s, id. See, also, Revue des haras, Aoùt Lis, 1889.

2 The expressions elongated walk, ordinary walk, and shortened walk, by which many authors characterize also the walk as represented respectively in Figs. 231, 232, anil 233, should only be applied to the absolute length of the steps which the same subject can take when his pace is augmented or slackened, and not to the particular form of the trail.

For example, a horse which deseribes the trail in Fig. 231 can rocr easily, according to the manner in which he is led, take longer or shorter strides-that is to say, the elongated or the 


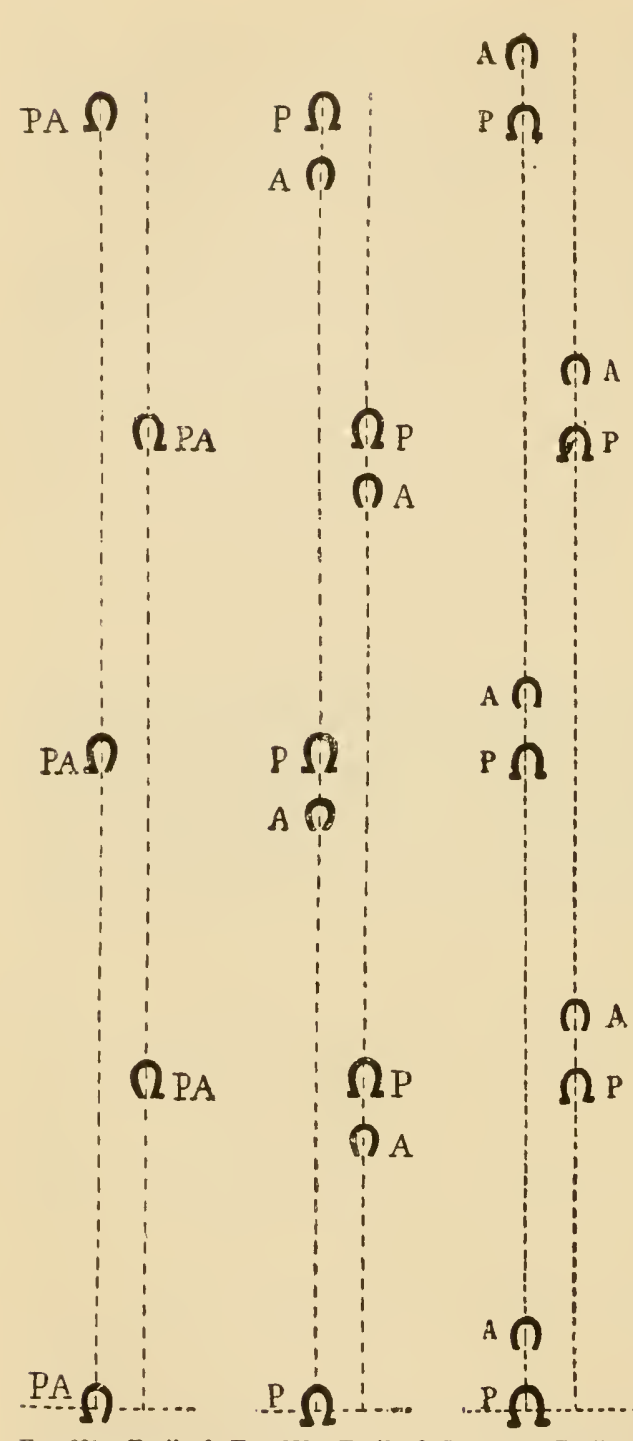

FIG. 231.-Trail of FIG. 232.-Trail of FIG. 233.-Trail of the walk, im. the walk, posprints super- terior imprints posed (pas jugé). in front of the anterior (pas méjugé).

the walk, posterior imprints behind the an. terior (pas déjugé).
Snch, it can be seen, are the predominant phenomena which may be observel in respect to the relation of the imprints. The nore the gait approaches the amble-that is to say, the synchronism of the lateral beats-the more the postcrior imprints will be in front of the anterior ; conversely, the more it tends towards the slow trot, in which the diagonal beats are synclironous, the more will the relation of the imprints be reversed (Fig. 233).

Observation teaches us that these modifications depend entirely upon the conditions in which the animal is placed, upon the matural or acquired preference of such or such a rhythm; in a word, upon the kind of equilibrium which he assumes spontaneously, or to which he is submitted by those who direct him. This is a point which M. Lenoble du Teil has clearly elucidated. ${ }^{1}$ Iet us give an example.

A horse walking in perfect freedom carries the neck relatively low, pro-

shortened walk-without the imprints ceasing to be superposed. All that is required for this is not to change his primitive state of equilibrinm.

1 Lenoble du Teil, Cours théorique d'équitation, de dressage et d'attelage, p. 51 et suiv., Paris, 1889, id. See, also, Revue des haras, Août $15,1889$. 
duces isochronous beats, and more or less places the hind-imprints anterior to the fore-imprints ; it is this which several authors have called the ordinary walk, because it is that of all horses walking at liberty. It is the same with the horse which is mounted, whose rider leaves the reins hang loose. In both eases the gait is slow.

If, however, the horse no longer has the free play of his neek; if the rider progressively raises the latter by the action of the reins, being careful to increase the traction regularly, this disposition of the lateral imprints will gradually diminish, then disappear at the moment when they are superposed; and, finally, their relation will be reversed if the raising of the neck be continued and the horse remain unexcited. The gait then takes the character of the slow, marched trot; besides, its rhythm becomes entirely different. The beats, at first equidistant, follow each other in rapid sucession diagonally, and finally become confounded.

If the horse whose lateral imprints are superposed be forced to accelerate his speed by increasing his action and giving freedom to the movements of his neck, the walk does not pass indifferently into the diagonal form or the lateral form; in other words, into the trot or the amble. The subject always modifies the rhythm in the sense of his aequired or natural aptitudes. Thus, the trotter acquires a walk tending rather towards the slow trot, while the ambler preeipitates lis beats laterally to pass into the amble, and the trails are modified in consequence.

It is the relative position of the head and neek that are the essential but not exelusive agents in these modifications of the rhythms. In addition to the muscular action, the head and neck surcharge the anterior or the posterior members, and favor the particular movements of such or such a biped, either by hastening the action of the one or retarding that of the other. When the change of the rhythm is onee produced, the gait is executed with a new cadence, and the respective distances of the members and the imprints of the trail remain the same until a new change is produced.

External influences over the horse may also oecasion remarkable modifications of the rhythm, and, consequently, determine correlative variations in the trail.

If for example, the horse atsends an inclined plane, the centre of gravity is displaced backward upon the posterior limbs and preventtheir advancing far under the trunk; their imprints then renain behind those of the anterior.

A similar result is obtained if the animal is attached to a velicle heavily loaded : the intensity of the resistance diminishes the amplitude 
of the step, and permits each foot to leave the ground only after a wellbalaneed position of the one which has preecled in the action, the body being supported after each elevation by the other three members. ${ }^{1}$

In descending an inelined plane the centre of gravity, on the contrary, draws nearer to the fore-limbs and hinders their free displacement forward, while the posterior, less burdened, have a tendeney to take longer steps. It liappens, then, that the latter mark their imprints well in front of the former. If the load be heary, however, the animal endeavors to fix himself to hold the burden, and the base remains constantly tripedal, to give more stability to the equilibrimm. The steps, in this case, are short and the posterior imprints by no means eover the anterior.

Length.-The absolute length of the step camnot be indicated with precision, on account of the individual differences and also the numerous variations of this gait, according as it is slow, ordinary, or acelerated. Nevertheless, it oscillates within mean limits which it is proper to recognize.

Aceording to Vineent and Goiffon, the length of the step should be equal to the height of the body measured fiom the withers to the groumd. The cavalry regulation of 1829 places it at $1.66 \mathrm{~m}$. Vallon, Messrs. Raabe and Barroil, and M. Lenoble du Teil estimate it at 1.80 $\mathrm{m}$. for a horse $1.60 \mathrm{~m}$. high, or one and a half times the length of the base of support. Finally, M. Duhousset considers it equal to the length of the body measured from the point of the arm to that of the buttoek.

This difference of opinion is due to the fact that these anthor's have studied neither the same variety of the walk nor suljects of the same height, the same raee, the same temperament, and the same conformation. Besides, the steps in the same animal are not absolutely equal. They vary, acording to Professor Colin, ${ }^{2}$ within the limits of 11 to 13 centimetres for the short walk, 17 for the ordinary walk, and 20 for the long walk; the horses upon which our learned colleague has experimented had a mean height of $1.5 .5 \mathrm{~m}$. and a base of support of $1.20 \mathrm{~m}$.

Speed.-The absolute speed of this gait is almost as diffieult of appreciation, for analogons reasons. At the sime time it is possible to adjust it to an almost uniform standard.

The cavalry regulation of 1829 relegates it to 100 metres per

1 G. Colin, Physiologie comparée des animaux, 3e.éd., t. i. p. 471.

2 G. Colin, loc. cit., 3e Ed., t. i. p. 472. 
minute, or 6 kilometres per hour. M. Raabe fixed it at 122 metres per minute for a horse of $1.60 \mathrm{~m}$., or 6 kilometres, 720 metres per hour. Vallon made it 111 metres per minute for a horse of $1.60 \mathrm{~m}$., or $6.600 \mathrm{k}$. per hour. Finally, M. Lenoble du Teil estimated it at $108.33 \mathrm{~m}$. per minute for a horse of $1.60 \mathrm{~m}$., which gives $6.500 \mathrm{k}$. per hour.

Displacements of the Centre of Gravity.-The displacements of the centre of gravity are never very extensive.

The support of the body upon the lateral bases constitutes the extreme limits of the lateral or transcerse displacements. The line of gravitation, as in the amble, oscillates alternately from right to left and left to right. What contributes to make these displacements much less extensive than in the latter gait, is that a diagonal base and two tripedal bases are constantly interposed between two successive lateral bases. It is understood, then, that the lateral oscillations of the body will be the less marked as the animal remains the longer upon the diagonal bipeds. This is the variety of the walk which M. Raabe extolled as always having more speed and being more pleasant to the rider than that which Lecoq preferred.

The longitudinal or vertical displacements are scarcely apparent, since the body is never elevated above the soil.

Reactions.-The reactions of the anterior quarters alone are of any consequence. "It would seem," says M. Marey, "from the extreme feebleness of the movements of the croup, that the action of the posterior members consists principally in a propulsion forward, with very little impulsion in the rertical sense."

Conformation.-A special conformation, strictly speaking, is not a necessary requirement for the proper execution of the walk. Nevertheless, all horses are far from progressing with the same elegance, the same regularity, the same velocity, the same ease, and the same vigor. The becuties of this gait will be reegnized by the following characteristics :

The head and the neck will be carried rather high than low; the anterior member will be extended freely and directly forward, withont exaggerated elevation of the forearm and the knee; viewed from behind, the bright surface of the shoe will be visible; the posterior member will move in a plane parallel to that of the anterior ; its oscillation should have a large amplitude consequent upon the strong projection of the femmr and the tibia; the flexion of the hock will be moderate. 
In both member's the fetlocks will be flexed with suppleness, but without exagreration; the contact of the feet will take place unifomly npom the plantar surface when once rested, the hoof will remain immolile until it is raised, and will rotate neither outward nor inward. The hats will be equidistant, light, and of equal intensity ; the posterior imprints will be located in firont of the anterior of the same side, and hence, in this case, forging must be looked after; they will be of the same form as the feet, cleam, entire, and marked from the toe to the heel externally and internally; their direction will be parallel to the axis of the trail ; finally, the intervals between those of the left sicle will be equal to the same intervals between those of the right side, which will indicate that the movements of the members are of the same extent.

\section{Backing.}

Backing, properly speaking, is only walking backward, and it is erroneous on the part of most anthors to classify it among the movements upon place. It is best to study it after the trot and the walk; the reason of this will be obvious presently.

Retrogression is difficult and fatiguing for the horse, in consequence of the inversion of the functions of the members which it implies; but some exeente it better than others, and even with dangerons rapidity.

Backing may be effected by the horse in three different conditions: he may be free, mounted, or harressed to a vehicle.

1.st. Free or abandoned to himself (Fig. 2:34), he performs it in almost the same manner as when he is momnted, only his step is easier and more secure. The order in which the members suceed each other is similar to that which we have indicated in the walk, the great difference being that the initial morement is made br a hind-limb. If this be the posterior right, it will be followed by the anterior left, then the posterior left, and, finally, the anterior right.

If the horse were to back at a trot, the members wonld be displaced simultaneonsly, as in this gait, by diagonal bipels in two suecessive times.

With a particnlar dressing, backing may be effected with the same regularity and the same speed as the trot forward. Comnt Lancosme de Brève publicly demonstrated this, and one of us was a witness of the performance in the riding-school in Paris of which he was director. It is not indispensable, moler these conditions, that the head and the neck be raised and drawn backward. These regions may remain in their ordinary situation and the horse back of his own accord. 
As Lecoq ' has remarked, the posterior member is earried backward before the posterior quarters can be surcharged by the displacement of the centre of gravity. The impulsion is then communicated to the

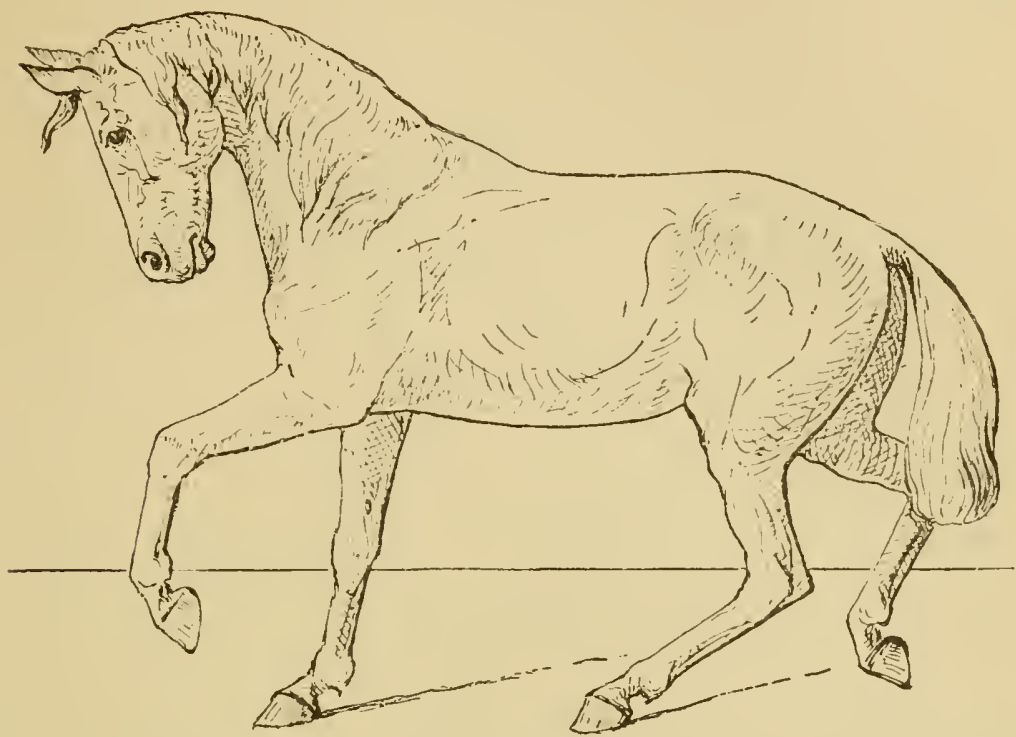

Fig. 234.-Backing.

trunk by the anterior members as well as by the posterior, whose obliquity downward and forward favors this action.

2d. The phenomena are different when the horse is attached to a rehicle, particularly if he moves a heary load orer soft or unequal ground. Tot only is he, in this case, obliged to surmount the difficulties arising from the inability to place his members in a position inverse to the normal, but he has also to overeome the resistance formed, on the one part, by the weight of the load, and, on the other, by the nature of the soil. He then backs prineipally through the breeching of the larness, and only displaces the members slowly and with difficulty (Fig. 235).

It results therefrom, says Lecoq, ${ }^{2}$ that the hind-foot supports, hesides the weight of the posterior quarters, already angmented, all the resistance opposed by the burden, and the slipping forward, rendered so frequent by this donble canse, deprives the horse of a large part of his force and exposes him to strains of the articulations. 
It is pereeived at once that backing is very tiresome, particularly to the regions of the loins and the hocks. Nevertheless, all horses should be able to execute it, at least under ordinary conditions, and it is indispensable to assure ourselves of this at the time of their purchase.

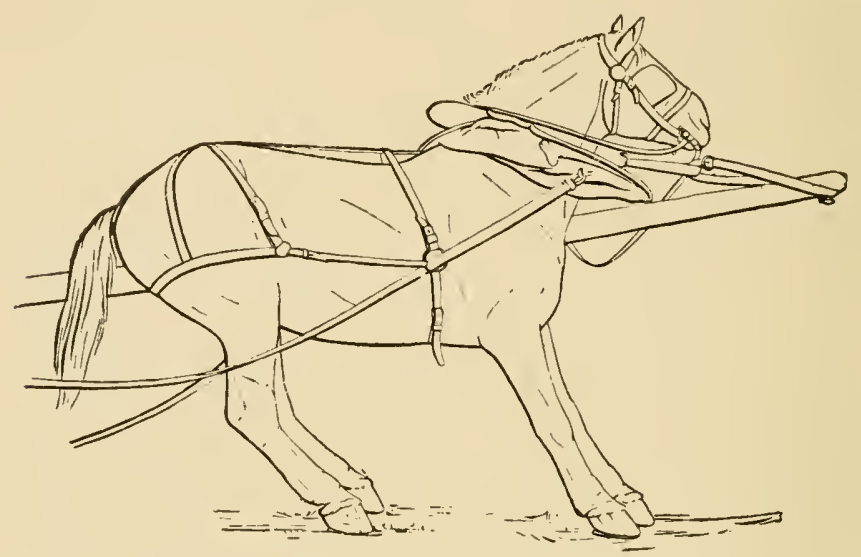

FIG. 235.-Backing, in the horse attached to a load.

(From an instantaneous photograph by the authors.)

In general, those which back badly have lesions of the bars, the dorso-lumbar vertebral column, or the hock. As to those which refuse entirely, they are affected with immobility, which is much more grave.

If, in such cases, continuous traction be exercised upon the reins, the horse leans to one side, elevates the head, arches the neck, holds the anterior members extended, and remains in loco. If more force be applied without jerking and without violence, he will twist from side to side, dig the feet into the ground, or, finally, rear and throw himself down, should the traction on the bridle be continued.

These facts which we have enumerated are sometimes more decided in the animal whose head has been turned towards the sun. Without tarrying here, we will say that immobility is a disease enumerated in Article II. of the law of August 2, 1884, coneerning the redhibitory defects.

\section{D.-The Gallop.}

General Definition of this Gait.-It is necessary, in order to understand well the phenomena of this mode of progression, to recall the comparison of Dugès, and imagine two pedestrians following each other by combining and associating the placing of their feet on the ground according to a particular rhythm. 
In the types of locomotion already studied, the canter excepted, the beats of each one of the pedestrians were always isochronous, - that is to say, separated by equal intervals of time, whether the gait was marched or leaped, lateral or diagonal. The member in contact fulfilled by itself the double role of dispersion and impulsion, althongh in a different degree according to its position in relation to the centre of gravity.

The rhythm in the gallop is entirely different. Each biped precipitates its falling on the ground in snch a manner as to render the beats irregular, heterochronous, and then it rises to be projected forward, two phenomena which give to this mode of progression a jerking and leaping character which we have so far not met.

Here, the member in contact with the soil is far from having terminated this phase when its congener begins to assume the same phase. Hence there exists a somewhat long period in which both feet rest simultaneously, exerting this action against the centre of gravity, either to deaden the concussion or to propel the body forward. It will be understood that, in this case, the motor power is increased in considerable proportions, and that the animal becomes capable of taking longer strides and acquiring greater speed.

The Gallop to the Right and the Gallop to the Left.-A biped is said to gallop upon the right foot or upon the left foot according to the foot which strikes the ground last.

True Gallop and False Gallop.-It matters little, if the trail be rectilinear, whether the gallop is effected upon the one foot or upon the other. The members are even seen, from time to time, to reverse their order of succession, in order to rest themselves better. The nember which reaches the soil first, being a destroyer of the reactions rather than a propeller, takes, at a certain moment, the place of its congener, which was principally the propeller. The changing of the feet relieves the biped by equalizing the work of its constitnent parts.

It is quite different, however, when the trail is curvilinear. We know then that a centrifugal foree is developed, which is so much stronger as the velocity of the gait is greater and the curve shorter. The animal is therefore obliged to incline himself towards the inner side of the trail to counteract this force, an attitude which consequently predisposes him to fall inside of the tract described. Hence, in view of a fall which is always imminent, he must steady his equilibrium on that side by the foothold of the corresponding propelling member, the right if the trail turn to the right, the left if it turn to the left.

The gallop is called true when it is effeeted upon the right foot, for 
example, when the horse turns to the right. It is styled false in reverie conditions; falling upon the side is then to be feared.

Diagonal and Lateral Gallop.-In the large quadrupeds the movements of the posterior biped always prevede those of the anterior

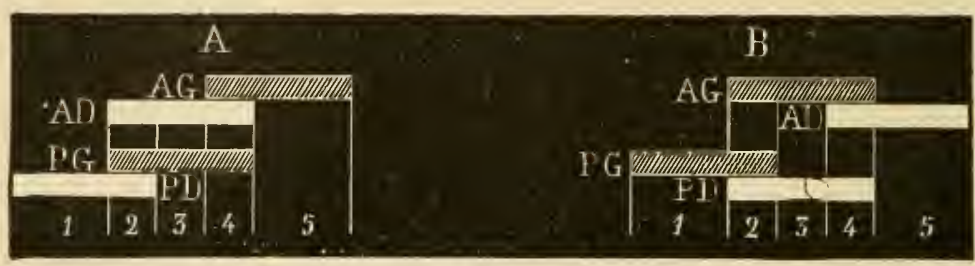

Fif. 236.-Diagonal or uniled gallop.

The two bipeds gallop upon the same foot.
A. Upon the left foot.
$B$. Upon the right foot.

in such a manner that the second beat of the former coincides with the first beat of the latter (Figs. 236 and 237).

It follows from this mode of association that instead of hearing four beats during the duration of a complete step, as if each foot was placed on the ground separately, only three are heard, in consequence of the synchronism of the beats of the second contact.

The anterior and the posterior members may combine their novements after two different types:

1 st. When the anterior biped gallops in the same manner as the posterior (Fig. 236), the second period of contact is produced by the simultaneous diagonal beats which are interposed between the two other diagonal disassociated beats. We propose to designate this type, in order to distinguish it from the following, under the name of diagonal

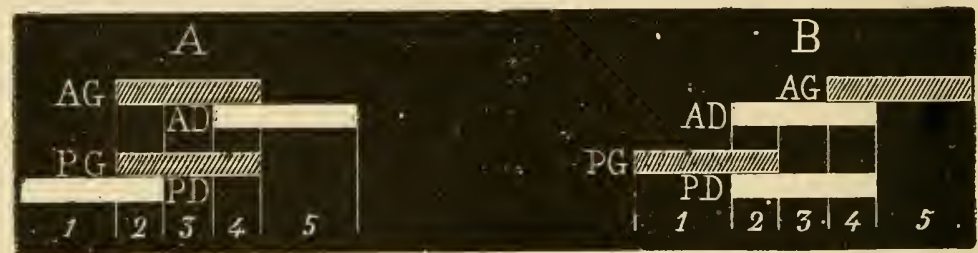

FIg. 237.-Lateral or disuniled gallop. (The horse is supposed to move towards the left.) The two bipeds do not gallop upon the same foot.
A. In front.
B. Behind.

gallop. It is that which is natural to the horse and other large domestic quadrupeds.

2d. If, conversely, the anterior biped gallops in a manner inverse to that of the posterior (Fig. 237), there are two lateral simultaneous beats, 
which form the second period of contact, and which are interposed between the other two lateral disassociated beats. In opposition to the preceding, we propose to call this gallop lateral. It has been for a long time known to veterinarians as the disunited gullop. The horse executes it rarely and with difficulty, for this quadruped uses especially diagonal gaits. Other animals, such as the dog, practise it rather fiequently, and we shonld not be surprised if the tromedary and the giratfe, which take so easily the lateral type of locomotion, use it without difficnlty under certain eiremmstances.

Be this as it may, the term disunited suits well for the lateral gallop, because it expresses the defect in the harmony of the movements of the two bipeds.

As long as the horse progresses at the lateral gallop upon a straight line, it is not necessary to employ a special expression to characterize his gait; the word disunited suffices. If, on the contrary, he describes a curvilinear trail, it is called disunited in front when, moring touctrds the left, for example, his anterior biped gallops to the right (Fig. 237, A), and disunited behind when his posterior biped does not gallop to the left (Fig. 237, B).

Definition of the Normal Gallop of the Horse.-We now possess all the elements necessary to an understanding of the definition of the normal (diagonal) gallop, the only one with which we will hereafter occupy ourselves.

It is a fast, leaped gait, with three times, in which the simultaneous beats of a diagonal biped oceur between the two suecessive beats of the opposite diagonal biped which commences the stride with the corresponding posterior member.

Each stride is separated from the following by an interval of time called projection, during which the body is in the air.

Kinematic Analysis of the Play of the Members.-Messrs. Marey and Pagès ${ }^{1}$ rightly attribute, in the gallop, a different rôle to the posterior members. The one which touches the ground first, receiving the entire body, constitutes a powerful agent of dispersion at the beginning of its contact, while the other fulfils the office of a propelling agent.

This remark being made, let us see the relative peculiarities of the articular trajectories.

1st. Anterior Member (Fig. 238).-1. Phase of Contact.-The articular trajectories are very analogous to those of the trot in the inflection of the curves during the period of dispersion, hut their rising is more marked on account of the more intense fall of the body and the greater elongation of the member at the end of this phase.

1 Marey et Pagès, Mouvement du membre postérieur, note communiquée. 
S. Phase of Elevation.-It also much resembles that of the trot, but the convexities of the trajectories are more salient because the member, as a whole, is shortened more. The foot, as well as the knee, is well separated from the

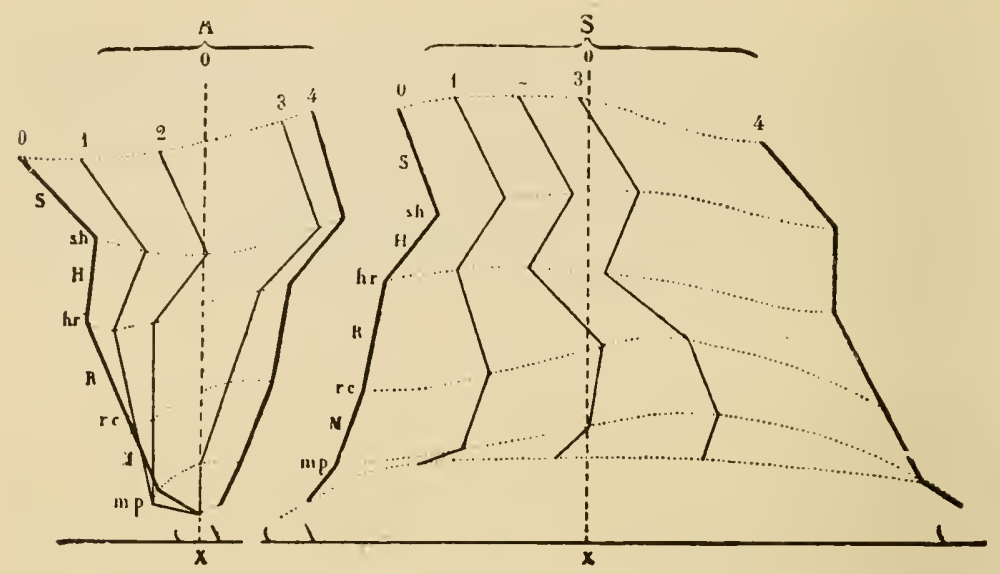

FIG. 238.-Kinematic analysis of the play of the anterior member in the gallop. (From Messrs. Marey and Pagès.)

A. Phase of contact. $\quad$ S. Phase of elevation.

ground. The curves of the withers and of the shoulder-joint are not depressed in their middle as is seen in the trot.

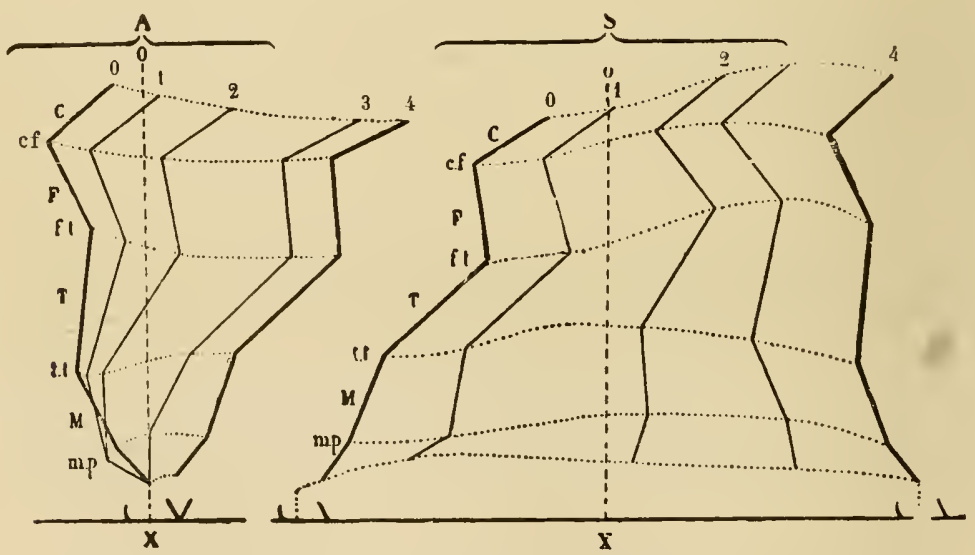

FIG. 239.-Kinematic analysis of the play of the posterior member in the gallop. (From Messrs. Marey and Pagès.)

A. Phase of contact. $\quad$ S. I'hase of eleration.

2d. Posterior Member (Fig. 239). - Nothing particular characterizes this member in the phase of contact excepting, as we have said at the commeneement of the subject, that it is an agent of dispersion and propulsion. As to the trajee- 
tories of the phase of elevution, they are equally comparable to those of the trot. Only, those of the coxo-femoral articulation and the angle of the haunch, at first concave, soon become greatly convex superiorly.

These two curves, considered during the two phases of contact and of elevation, are very incurvated in their middle in the gallop, while in the trot, on the contrary, they are more convex.

Number, Nature, Succession, and Duration of the Bases of Support; Duration of the Contacts of the Feet and of the Projection.-The members, in this gait, succeed each other with such rapidity that it is impossible, with the eye, to analyze their contacts with accuracy. Experiments making use of the graphic method, or chrono-photography alone, can give us definite information in this respect. Although the actual investigations are not numerous, never-

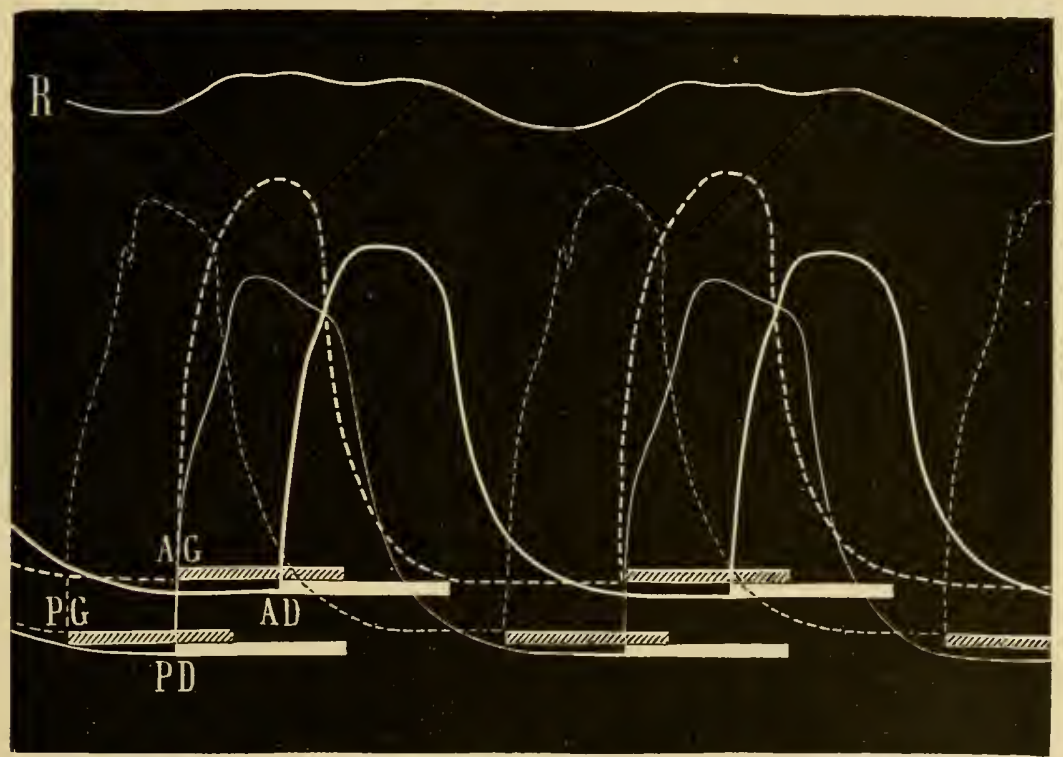

FIG. 240.-Tracings, notation, and reactions of the gallop of the trained horse. (From M. Marey.)

$P G$, curve and notation of the posterior left foot. $P D$, curve and notation of the posterior right foot. $A G$, curve and notation of the anterior left foot. $A D$, curve and notation of the anterior right foot. $R$, curve of the rcactions of the withers.

theless they permit us to establish a certain number of facts, which we will present.

Fig. 240, which we borrow from M. Marey, ${ }^{1}$ represents, by con. 
tinuous and dotted lines of different widths, the tracings furnished by the four members of a trained horse whose gait was regular and harmonions; below these curves are found the notation of the contacts.

At the beginning of the figure the horse is in the phase of projection; then eomes the beat $P G$, which is produced by the contact of the posterior left foot.

Between this beat and that of the opposite diagonal member, $A D$, and almost in the middle of the interval which separates them, the simultaneous beats of the two feet, $A G, P D$, of the left diagonal biped take place, a synchronism which is rendered very evident by the superposition of the notations $A G, P D$.

Finally, between the third beat, $A I$ ), and the first of the following step reigns a silence of a duration almost equal to that of the three beats combined.

The projection is indicated in the notation by the interval which exists between the end of the contact of the anterior right member, $A D$, and the commencement of the contact of the posterior left, when the latter has commenced a new step. The duration of this projection, according to the tracings, equals almost one-ninth of the duration of the complete step. However, it evidently varies with each form of gallop. M. Lenoble du Teil ${ }^{1}$ claims it to be longer, for he considers it as being equal, on the average, to one-fifth of that of the entire stride.

In this succession of movements the ear has therefore perceived three sounds, almost equidistant: the first produced by a hind-foot, the second by a diagonal biped, the third by a fore-foot (Fig. $241, A)$.

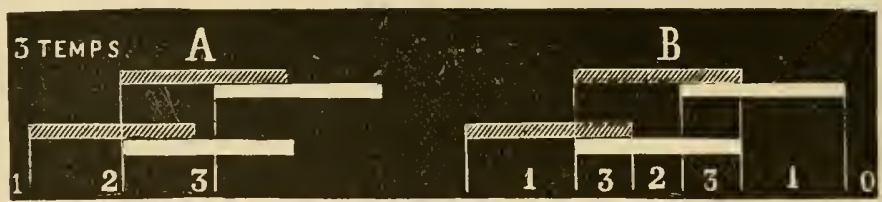

FIg. 24l.-Notation of the gallop with three times.

(From M. Marey.)

A. Representation of the three times. B. Representation of the number of feet which form the contaet of the body at each moment of the complete step.

If now the successive bases which support the body during each step are to be determined, it suffices to divide the notation (Fig. 241, B) by means of lowering perpendiculars tangent to the beginning and the termination of each contact. It is proved, then, that at the com-

1 Lenoble du 'Teil, Etude sur le galop et la conrse, broch. in- $8^{\circ}$, p. 15, Argentan, $18 s 0$. 
mencement and the end of the step the body rests upon one foot only (1 and 1); that in its middle the base is diagonal (2), and during the intermediary periods, tripectul (3 and :3).

The instantaneous photographs of Lissa, ${ }^{1}$ taken fiom a cavalry horse going at a full gallop, confirm in all respects the principal results obtained by M. Marey. As they are descriptive of a much greater speed of the gait, and as the horse which furnished them was less held in cheek and less trained than the preceding, they give rise to some differences worthy of note. We have recorded them with the greatest care in the notation of Fig. 242, which furnishes the necessary information.

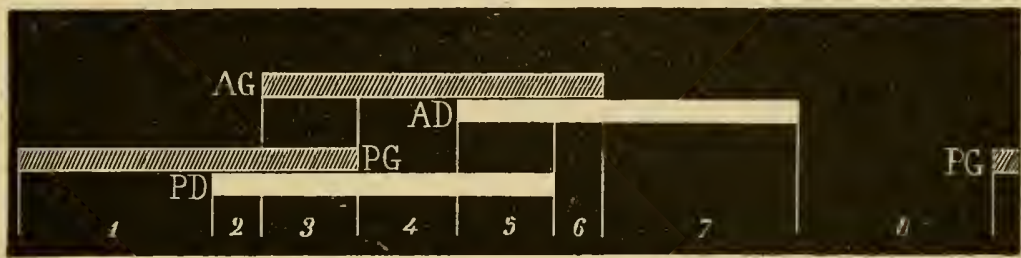

FIG, 242.-Notation of the full gailop.

(From the instantaneous photograplus of Lissa.)

The duration of the stricle is divided into twenty equal periods: the unipedal contacts ( 1 and 7), as well as the projection (\$), each equal four; the tripedal (3 and 5) and the diagonal (4) each equal two; as to the bipedal (posterior, 2, and anterior. 6), they each equal one.

Each foot remains in contact during seven periods, while its oscillation occupies thirteen.

The most prominent factor of this gallop, when it is compared to that which we have analyzed above, is that the beats $A G, P D$ of the second contact are no longer synchronous; the posterior slightly precedes the anterior. In fact, the step is executed with four times. This disassociation, which we will again find much nore perceptible on the rece-course, and which presents a great analogy with that which is manifested in the flying trot, is the result of the acceleration of the speed as well as of new conditions of equilibrium. In the gallop of the specially-dressed horse, the head and neck are more raised ; the general attitude is higher; the weight is thrown upon the posterior members. Here, on the contrary, the two bipeds have a tendeney to share the weight of the body in an inverse manner, which horsenen express by saying that the horse is upon his shoulders ; ${ }^{2}$ a certain independence of action is established between the anterior and posterio: biperds, which seem to gallop each on its own accord, the hind increasing its propelling force, the fore serving for the reception of the weight. 1889.

1 G. Barrier, in Bulletin de la Société centrale de médecine vétérinaire, séance du 11 Février,

2 Lenoble du Teil, Revue des haras, Aotit 15, 1859. 
The disassociation of the beats of the second contact gives rise to very short tripedal bases, a posterior (3) and an anterior (5). As to the angmentation of the speed, it is the consequence of a greater duration of the phase of projection.

Effort of the Members in the Gallop.-A glance of the eye upon the notations suffices to demonstrate the inequality of the effort of the members in this gait.

So far, we have found their work identical in the amble, the trot, and the walk, in consequence of the regular alternation of the members of each biped, anterior or posterior. The canter alone, a combination of the trot and the gallop, has presented an exception, in which this alternation is faulty in one of the bipeds.

In the gallop this is doubly marked, for it exists in both bipeds. In the fore as well as in the hind, one of its members is obliged to support the weight of the body alone for a longer or shorter time. It is easy to perceive that this augmentation of work relates only to the diagonal biped whose contacts are disassociated: the right when the horse gallops upon the right; the left in the contrary case.

Besides, each extremity of this biped does not overcome eqnal resistances; the posterior, on which the body falls, evidently has to sustain more than the anterior, which only supports it before the phase of projection.

It follows from these proofs that the gallop imposes a considerable inerease of fatigue upon the diagonal biped whose beats are disassociated, and in particular upon the posterior member which is one of its constituent parts.

Hence a well-understood management of the horse at this gait demands that the rider take the precaution to alternate from time to time the play of the two bipeds in order to assist his mount in the equal distribution upon the members of the efforts which he must make.

\footnotetext{
Association of the Members and Attitudes of the Body during the Evolution of a Complete Step.-In Figs. 243 and the succeeding seven we will represent the eight successive phases of a stride of the full gallop indicated by the notation of Fig. 242. These diagrams are the true reproduction of eight instantaneous photographs chosen from the twenty proofs of the beantiful collection of M. Ottomar Anschiitz. The order, succession, and nature of the beats, and the diverse bases of support, can be followed there by simply consulting the explanatory reading placed below each one.

What angments the importance of these figures, particularly for
} 
the artist, is that they prove the falseness of the old classieal doctrine, that during the entire evolution of a stride of the gullop the members of one lateral biped are always in advance of those of the opposite lateral biped. This assertion is no more eorrect of the inferior parts of the members than of the superior. Each shoulder remains, in its turn, in front of or behind its congener for a certain period of time, and the thighs behave likewise, the one in relation to the other. Despite the spasmodic rhythm in the gallop, when a member reaches the latter part of its evolution, its homologue must of necessity more or less approach the commencement of its transmission, - that is to say, be oblique in an inverse direction. When, for example, the horse, galloping upon the right, is shown detached from the soil (Fig. 250), his posterior left, upon which he will fall, is of necessity bound to pass in front of the posterior right, which will only tonch the soil afterwards. For the same reason, the anterior right, whose eontact oecurs last, should also, at a given moment, be found not very far behind the anterior left, which will take its contact with the ground before the right.

M. Lenoble du Teil ${ }^{1}$ was the first one to disprove elearly this theory of the advance of one lateral biped upon the other, which cannot be verified by an attentive observation of the facts, and which is flatly contradicted by all the instantaneous photographs, notably those of Lissa.

These true representations of the galloping-horse are precious also from another point of view. They show us, with great exactness, the changes of the direction of the body during the successive phases of the entire stride.

At the beginning (Fig. 243), at the time of the fall upon the posterior left, the withers are more elevated than the croup; the rider, who has just been projected, is seen still above the saddle and leans forward. The body then becomes horizontal when the left diagonal biped touches the ground (Fig. 246); the members of the right diagonal biped now attain their maximum separation, while the rider commences to fall back. The hind-quarters now give their impulsion, become raised and detached from the ground, while the fore-quarters, very low, touch the soil with the anterior right foot (Fig. 248). During this phase the rider bears heavily on the thighs, particularly the right; his seat is displaced baekward. But the impulsion from behind immediately changes his position; he is pushed forward and raised from the saddle. His mount at this moment (Fig. 249) prepares to leave the

1 Lenoble du Teil, Cours théorique d'équitation, de dressage et d'attelage, p. 207, Paris, 1889. 


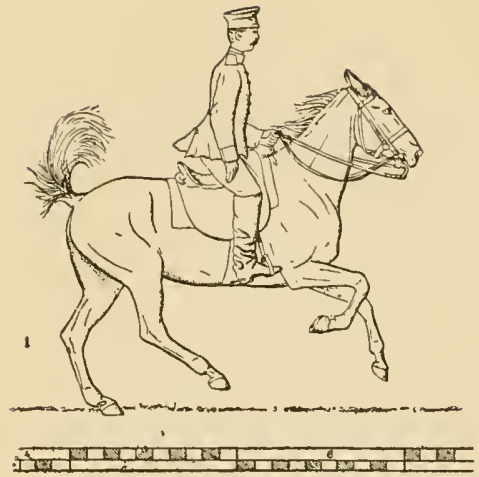

FIG. 243.-The full gallop (1st beat; posterior left unipedal base).
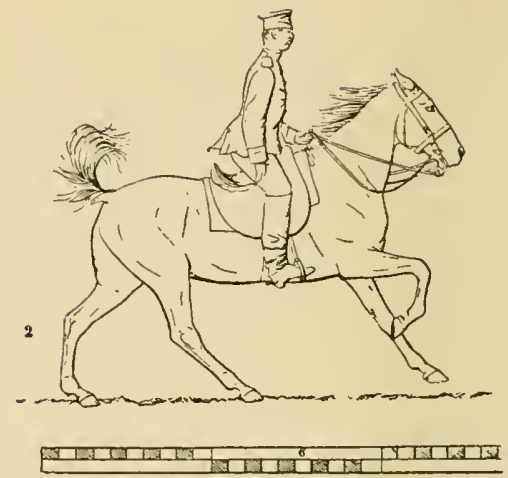

FIG. 244.-The full gallop (2d beat; posterior bipedal base).
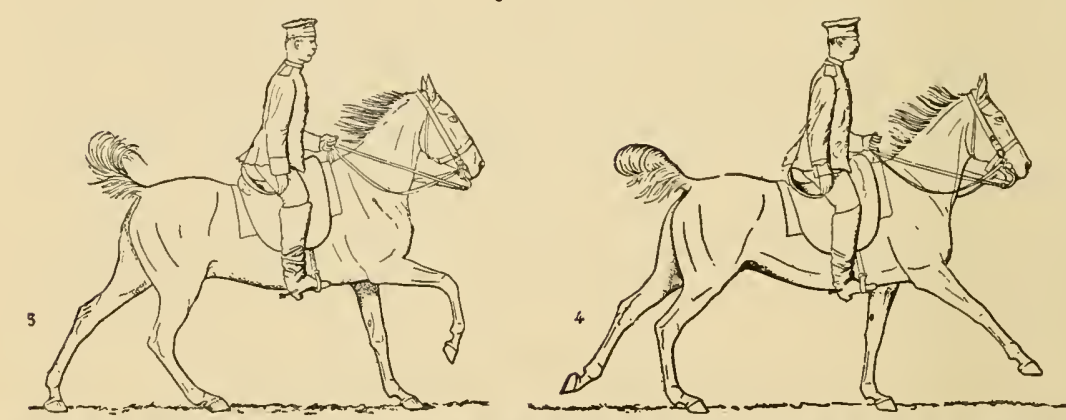

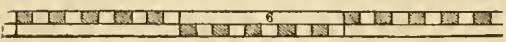

FIG. 245.-The full gallop (3d beat; anterior left tripedal base).

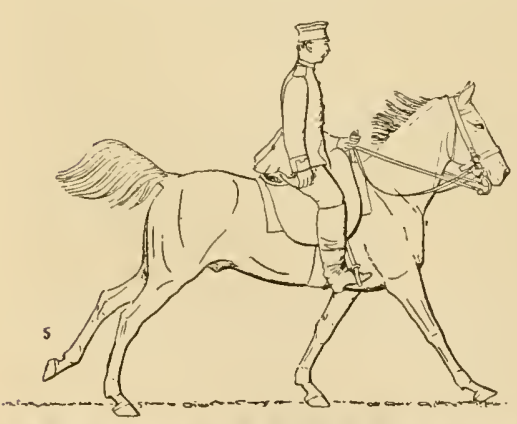

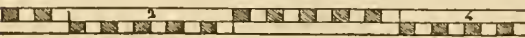

FIG. 247. $\rightarrow$ The full gallop (4th beat; formation of the posferior right tripedal base).

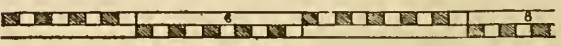

Fig. 246.-The full gallop (left diagonal base).

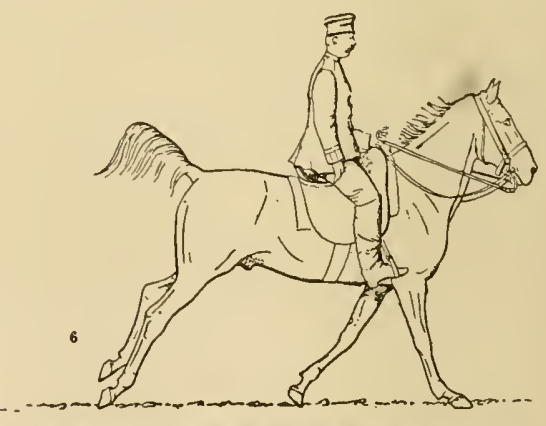

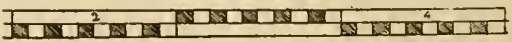

FIs. 248.-The full gallop (end of the posterior right tripedal base). 
soil and to gather (irassembler) the members under the body, the left in front of the right (Fig. 250). It is then that the projection takes place; the horse and the rider alike feel the effects; both are more or less raised and projected forward.
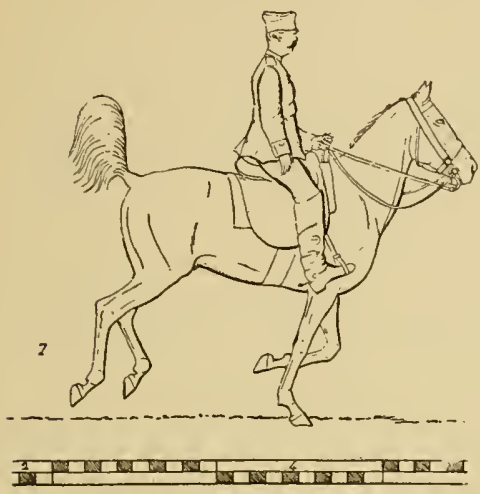

FIG. 249.-The full gallop (anterior right unipedal base).
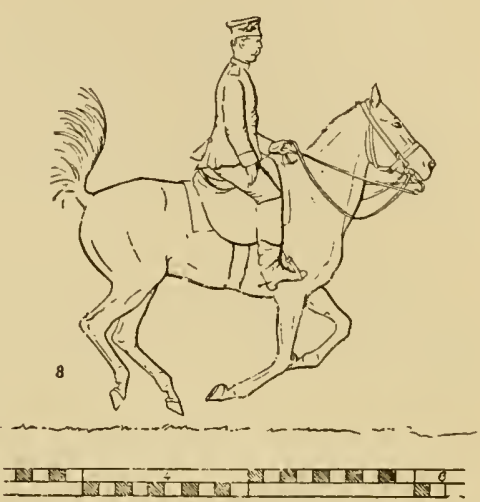

FIG. 250.-The full gallop (projection).

During the total duration of the contacts on the ground of a complete step of the gallop, the body assumes, therefore, three successive and different attitudes: it is first oblique upward and forward, then almost horizontal, and, finally, oblique downward and forward.

Sudden Passage from Station, from the Walk, and from the Trot into the Gallop.-Inverse Order of Transition.The facts recorded above enable us to comprehend the mechanism of these changes of gait.

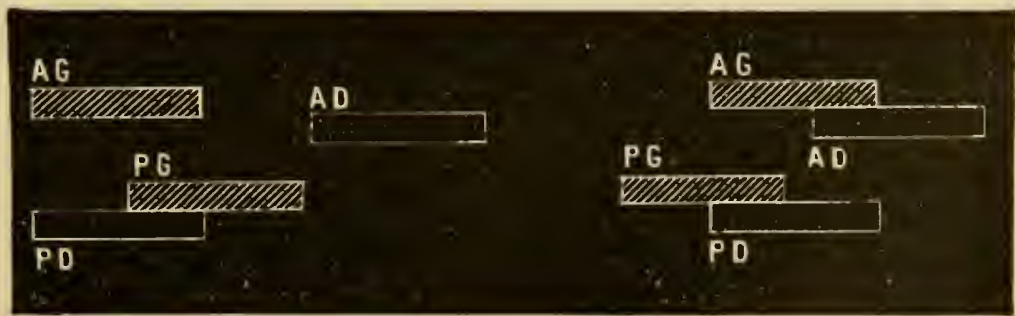

FIG. 251.-Passage from station into the gallop, the horse being at liberty.

Passage from Station into the Gallop.-In order to elucidate this phenomenon, we have made a series of experiments in which the horses, previously placed, have been abandoned to themselves and then suddenly induced to start off at the gallop.

Below are our results (Fig. 251). 
In order to start on the right foot, for example, the horse first elevates the right diagonal biped, and brings it almost instantly in contact again, at the same time disassociating the beats so as to allow the other biped to interpose simultaneously its beats in the following step, during the interval comprised between the first two.

If, instead of being at liberty, the animal were mounted, the phenomena would be different: the hind-members would be placed under the trunk, especially the left. After this preparation the other feet should be successively raised thus: 1st, anterior right; 2d, anterior left; 3d, posterior right. The posterior left, alone in contact, would commence to pusb the body forward (1st period); immediately the left diagonal would effect its contact (2d period); last of all would come the contact of the anterior right ( $3 \mathrm{~d}$ period). The gallop should commence and continue as usual. (Lenoble du Teil.)

Passage from the Walk into the Gallop. ${ }^{1}$-This can be accomplished when the contact exists upon a right diagonal base: 1st, elevation of the anterior right and impulsion by the posterior left (1st period); $2 \mathrm{~d}$, the posterior right and the anterior left, already elevated, strike the ground simultaneously ( $2 \mathrm{~d}$ period); 3 d, extension and contact of the anterior right ( $3 \mathrm{~d}$ period). (Lenoble du Teil.)

Passage from the Trot into the Gallop.-It is possible at the commencement of the contact or during the contact of the right diagonal : 1st, elevation of the anterior right and impulsion of the body by the posterior left (1st period); $2 \mathrm{~d}$, contact of the left diagonal; 3d, contact of the anterior right (2d and $3 d$ periods). (Lenoble du Teil.)

Passage from the Gallop and the Trot into the Walk or Station.-It is when the horse rests upon a diagonal biped that he is capable of effecting these changes. (Lenoble du Teil.)

Varieties of the Normal Gallop and their Corresponding Trails.-The horse, in a state of nature, employs the gallop to reach with speed any spot to which he may be strongly attracted; he also uses it to flee from any danger which may threaten him. The straight line, or a direction similar to it, is preferred by him as producing less fatigne and offering more safety. The gait in these conditions is easy, sure, and generally fast. As to the imprints left upon the ground, they give rise to a trail more or less analogous to that of Fig. 252, $A$, in which are seen the traces associated in pairs (anterior and posterior), each pair being separated diagonally. Moreover, between two snecessive strides there always exists quite a long interval, indicating not only a prolonged suspension, but also an extensive projection, whose value augments with the speed, without, however, being absolutely proportional to it.

All the domestic horses which have not been influenced by training furnish a similar gallop and trails when they are induced to move at this gait. As they decidedly form the major portion of our equine 
population, it seems logical to consider this gallop as the ordinary type, since it is the most natural and the easiest to execute spontaneously by the largest number.

These animals, in this state, are little adapted to the service of the saddle, notably of the riding-school. They lack that suppleness which is sought for by horsemen, and without which a mount is unable to obey the rider's wishes; the different groups of muscles have not yet acquired the functional independence necessary to the required efforts; the distribution of the weight upon the anterior and posterior quarters exists in such proportions that the lateral displacements are difficult and at times dangerous.

Hence it is necessary to submit them to a particular dressing in order to modify their conditions of equilibrium. By educating them so as to diminish the base of support and displace the centre of gravity backward; by giving an elevated attitude to the neck; by drawing the head backward, we are enabled to endow them with case and suppleness, and make them perform the most varied movements. When thus educated, they execute a very different gallop from the preceding, its primitive type being changed as to rhythm, cadence, and mode of association of the members. Even if the speed be less, this gallop possesses a very superior grace and elegance.

The trails, under these conditions, become at times very dissimilar; with a little attention, however, the characters of an evident uniformity of construction can be recognized, and, being given the common cause of their modification, it is easy to discover the transitions which unite the diverse terms of the series which the trails constitute.

It is the projection which first diminishes and renders its distance less, as well as the diagonal base (Fig. 252, $B$ and $C$ ); finally, the posterior foot marking the first contact is less separated from its anterior diagonal, which makes the last beat.

Then the projection disappears and is replaced by a simple suspension. The distance of projection (mépister) is null (Fig. 252, D); the fore and lind imprints are arranged side by side; the posterior foot marking the first contact, falls upon the same transverse line as its diagonal anterior; the length of the step is exactly equal to the distance passed over during the three contacts.

If the animal be more restrained (Fig. 252, E), he falls behind the imprint of the anterior right foot, which marks the third contact; the trail shows a succession of steps which overlap each other in consequence of a more or less considerable scparation (dépister); the step, in this case, is somcwhat shorter than the space of ground covered.

In a still higher degree of restraint (Fig. 252, $F$ ), the posterior foot marking the first imprint is superposed upon the imprint of the corresponding anterior; the trail, double on one side, then becomes single on the other; the space covered exceeds much the length of the stride. 


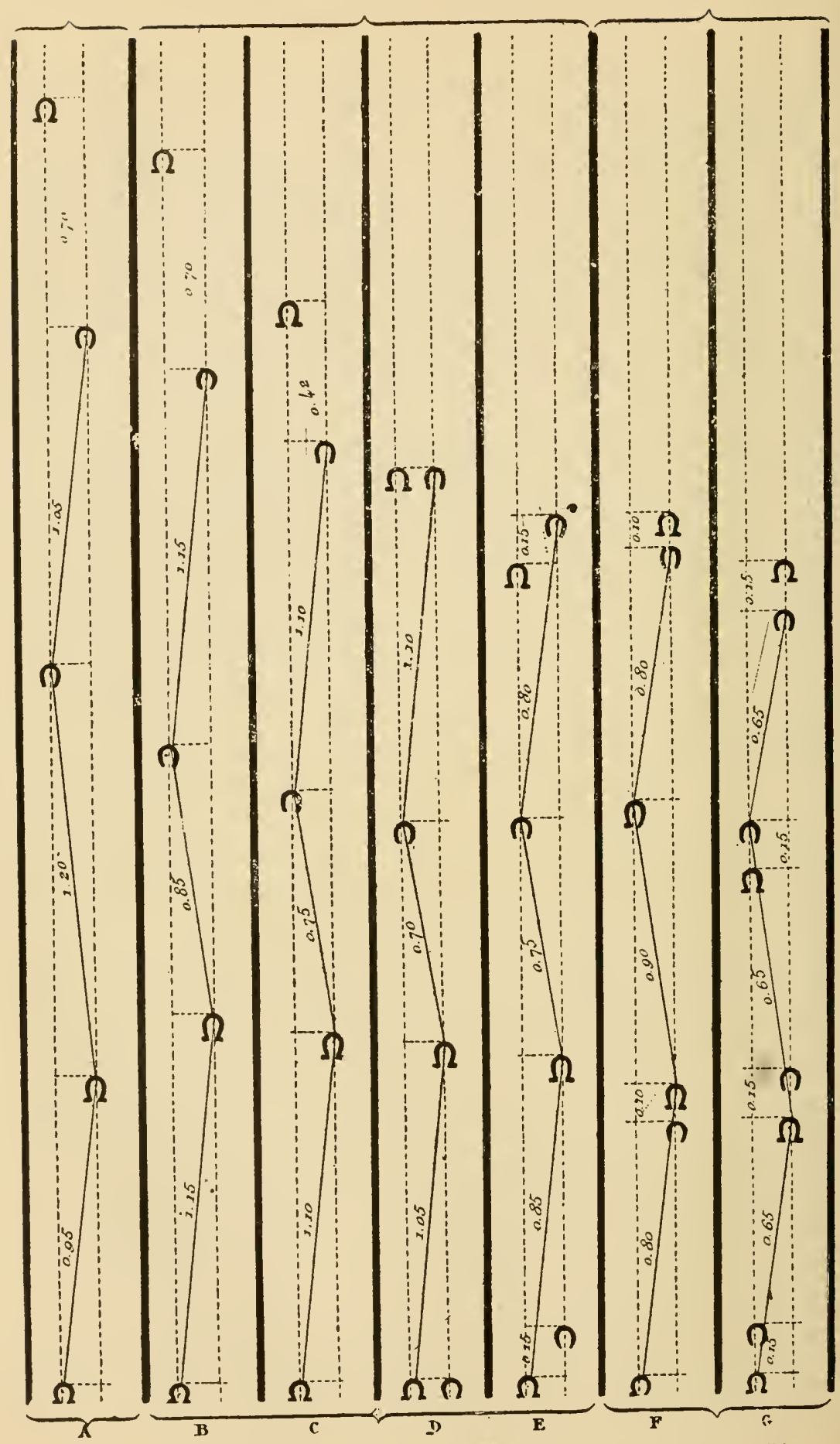

FIG. 252,-Principal trails of the gallop. (From Messrs. Barrier and Lenoble du Teil.)

A. The full gallop, from the instantaneous photographs of Lissa. $B, C, D, E$. Series of gallops gradually shortencl, furnished by the same horse, progressively restrained. F, G. Very short gallops, furnished by another horse, well dressed and well balanced. 
Finally, when the restraint is pusher to its utmost limits, the posterior foot marking the first imprint touches the ground behind the corresponding anterior; their separation (dépister) is so great (Fig. 252, $G$ ) and the stride is so short that the trail is double on both sirles; the horse gallops almost upon place, and the stride is less than half the length of the space covered.

Between these principal types of the gallop there exist, it is perceived, numerons intermediary forms which the skilful horseman can realize by the manner in which his mount is dressed. Masters of ridingschools are nevertheless unable to understand, even at the present time, the indications which are best adapted for the production of this or that one; this is to be regretted, for language renders the explanation of the facts still less intelligible. We are not able to explain these differences and fix their terminology. Suffice it for us to recognize the most important varieties and the dominant part of education in their production.

Length of the Stride.-The absolute length of the stride of the gallop cannot be established, since it varies with the speed, the form of the horse, the lengtl of his members, his dressing, the manner in which he is held by the rider, ete.

The trails of Fig. 252 suffice to give an idea of the differences which can be obtained with a horse $1.59 \mathrm{~m}$. to $1.60 \mathrm{~m}$. in height, by the sole influence of restraint, the position of the head, and the velocity of the gait, without the dressing being a very important factor, except in the last two:

In the trail $A$ the stride is $3.90 \mathrm{~m}$. In the trail $D$ the stride is $2.85 \mathrm{~m}$.

\begin{tabular}{llll|llll} 
" & $B$ & " & $3.85 \mathrm{~m}$. & " & $E$ & " & $2.70 \mathrm{~m}$.
\end{tabular}

In the trail $G$ the stride is $1.60 \mathrm{~m}$.

Nevertheless, if its length is not uniform, it oscillates aromd certain mean figures which should be recognized:

The cavalry regulation of 1829 fixed it at $3.25 \mathrm{~m}$. According to Captain Raabe, it should be equal to three times that of the base of support, or $3.60 \mathrm{~m}$. for a horse $1.60 \mathrm{~m}$. at the withers.

Speed.-The speed of the gallop is quite as variable as the length of the stride. All things being equal, it depends upon the variety of the gait studied. It varies from 300 metres per minute, or 5 metres per second (cavalry regulation), to 362 metres per minute, or $5.44 \mathrm{~m}$. per second (Raabe and Vallon).

Displacements of the Centre of Gravity.-As I Lecoq ${ }^{1}$ has 
indicated, the horizontal or transverse displacements of the centre of gravity have not here, by reason of the irregularity of the play of the members, the regular rhythm which they give in the trot, the amble, and the walk.

The interposition of the tripedal bases ( 3 and 3 ) during the duration of the diagonal base of the second period (Fig. $241, B$ ) is not, by any means, of a nature to ameliorate sensibly the lateral displacements.

At first supported by the posterior left member, $A$, for example (Fig. 253), the centre of gravity is displaced to $E$ in the line $C B$, representing the left

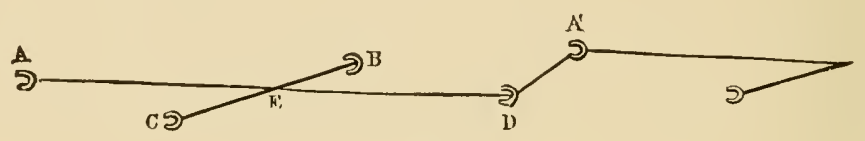

FIG, 253.

diagonal base, and thence to $D$, upon the anterior right member. During the period of projection, $D A^{\prime}$, it is carried to $A^{\prime}$, upon the posterior left member, and so on.

To recapitulate, these oscillations, very feeble in a lateral sense, do not render the gait tiresome for the rider. In addition, they are so much less extensive as the velocity is greater, the imprints of the right feet tending then to approach, on the median line, those of the left.

It is different with the longitudinal or vertical displacements. The direction of the body, primitively oblique forward and upward, now becomes, at the time of the descent upon the posterior left, oblique in an inverse sense,- - that is to say, forward and downward at the end of the contact of the anterior right. There result from this upon the right diagonal biped, in galloping upon the right, alternate rotatory movements which are in direct ratio with the shortness of the gait.

When the gallop is false, the line of gravitation has a greater disposition to fall outside of the base of support, in consequence of the inclination of the body towards the centre of the curve described. It can be said that falls are then inevitable, if the turning be sudden and the speed great. The animal preserves his equilibrium only by modifying the direction of his axis in relation to that of the trail, so as to be oblique instead of parallel to the latter, as it should be. If the horse gallops upon the right in turning to the left, besides lessening his speed, he also places himself transversely to the trail and turns the haunches inward in order to draw the posterior left foot to the side on which the borly is more liable to fall when a new stride is taken. 
When the gallop is true, the line of gravitation, as Raabe' has truly observed, is always nearer to the concentric lateral biped than to the other, on aceount of the inclined position of the body. Hence this biped is more fatigued, becaluse it must support during the whole time the excess of weight of which its congener is relieved. This fact becomes very apparent in ring-horses, which perform always in the same style in circuses in rings only 14 metres in clianeter.

When the gallop is broken, the horizontal displacements of the centre of gravity are more extensive than under ordinary contitions. This follows from the fact that the members, in striking the ground, succeed each other alternately in lateral instead of diagonal bipeds. (See the notation of Fig. 237.) As to the longitudinal displacement, it is effected laterally,- - that is to say, from a pusterior member to the anterior of the same side. These two peruliarities render the gait more tiresome to the rider and destroy the stability of his position in the saddle.

Reactions.-It suffices to glance over Figs. 238 and $2: 39$ to ascertain that the pressure of the feet upon the ground must be much more energetic in the gallop than in the walk or the trot. The descent of the fetlock and the closing of the superior angles during each phase of dispersion of concussion is here much greater. As M. Marey ${ }^{2}$ has observed, the horse is obliged not only to support the weight of his body, but also to propel himself by violent impulsions. The greatest effort seems to appertain to the first beat. The body, raised an instant, again falls, and one foot only sustains this shock.

The reactions which are produced at the withers are represented in Fig. 240 (upper line $R$ ) by an undulating eurve, which continues during the whole of the contacts of the feet with the ground.

Marey considers that the minimum elevation of the curve corresponds to the moment when the feet are in the air, and therefore he concludes that the so-called phase of projection is in reality only a simple suspension, without any ascending movement of the body.

We regret to entertain a different opinion, for these statements are not in aceord with the daily olsservations of all riders, or with those which can be made upon instantaneous photographs, notably those of Muybridge and Anschïtz. From the latter, which remove all doubt, it is easy to prove that the distance of the back above the ground

1 Raabe, Fxamen des allures, l'uris, 1857, p. 53.

2 Slarey, loc. cit., p. 174. 
attains its maximum when the body is entirely in the air. The phase of projection in the gallop is therefore quite real.

Conformation. - The horse which is destined to the service of the gallop should be casily gnided by the hand; he should have a long and supple neck, short back and loins, muscular croup and thigh, high withers, long shonlders, muscular leg and forearm, wide and strong hocks and fetlocks, flexible pasterns, strong body and strong limbs, spacious chest, should be nimble, easy, and sure on the feet, docile, and well dressed.

Uses.-The gallop which we have examined, also ealled the hunting gallop (galop de chasse), is particularly adapted for the saddle, the riding-school, long journeys, races, eavalry manœuvres, etc.

\section{The Slow Gallop with Four Times.}

M. Lenoble du Teil ${ }^{1}$ has clearly established the variations which are produced in the order of the contacts aceording to the conditions of the equilibrium of the galloping-horse. The beats of the second contact, primitively synchronons, become more or less separated, so as to emit four distinct somds during a complete step.

This dismion, however, can manifest itself in two different ways:

A.- In horses characterized as being upon their shoulders (whose weight is thrown upon the anterior quarters), such as those of the racecourse, the cirens, and the trained saddle-horse, the anterior biped hastens its contacts. Their beats sueced cach other as follows, supposing that they gallop upon the right:

\section{1st beat: posterior left.}

$2 \mathrm{~d}$ bert: anterior left.
$3 \mathrm{~d}$ beat : posterior right. 4th beat: anterior right.

The gait, in such cases, is but slow and quite rhythmical.

B.-In horses designated as being upon their haunehes, closely gathered $u$ in consequence of an exaggerated rassembler (members under the body), the order of placing the feet beeomes, on the contrary, as follows:

1st beat: posterior left.

$2 \mathrm{~d}$ beat: posterior right. 3d beat: anterior left.

4th beat : anterior right.

This is the gallop with four times of ancient horsemanship, but completely rejected to-day. It implied one foot always on the gromnd, 1889.

${ }^{1}$ Lenoble du Teil, Le galop et la course, p. 12, Argentan, 1880. Id., Revue des haras, Aout 15, 
and was exeented almost upon place, being more like a riding-school parade than a true gait.

\section{Gallop of the Race-Course (Running Gallop).}

As soon as the ordinary gallop exceeds a cortain relocity the simultaneons beats of the second contact commence to be disassociated, and, at the same time, the diagonal base angments progressively in length.

This gait insensibly passes into a new one, which has received the name ruming gallop, and in which the members appear to act separately in pairs (anterior and posterior).

It is this very character of apparent independence between the anterior and the posterior members that led ancient horsemen to believe that this variety of gallop was effeeted wiih two times.

We know to-day that such is not the case. It is a gallop with four times, mequal and very rapid, which presents great analogies with that of the photographs from Lissa, of which Fig. 242 reproduces the notation.

The honor of having demonstrated in a positive manner the existence of the disassociation of the diagonal beats in this gait, in consequence of the reality of its four times, reverts to M. Marey. ${ }^{1}$

But here the violence of the pedal percussion in this gait is so great that the experimental apparatus had to be modified so as to become more durable. Unfortunately, there resulted from this modifieation less acute sensitiveness of the instrument, which makes the representation of the order of the contacts scarcely accurate. In this connection it is evident that great and numerous improvements have yet to be made in the graphic method.

The thorough analysis of the instantaneous photographs of M. Muybridge, taken from the American race-horse Sallie Gardner, which was moving at a velocity of 1142 metres per minute, has permitted M. Lenoble dn Teil to make the verification of the faets more exact and more eomplete. ${ }^{2}$

Fig. 254 is a true reproduction of these photographs.

Upon the notation which corresponds to them (Fig. 255) it can be seen :

1st. That the contacts of the right members take place respectively at the commencement of the last third of the contarts of the corresponding left members.

2d. That in the dismited diagonal biped, $P D, A G$, the anterior left

1 Marey La machine animale, p. 177.

${ }^{2}$ Lenoble du Teil, Le galop et la course, p. 9, et suiv., Argentan, 1880. 

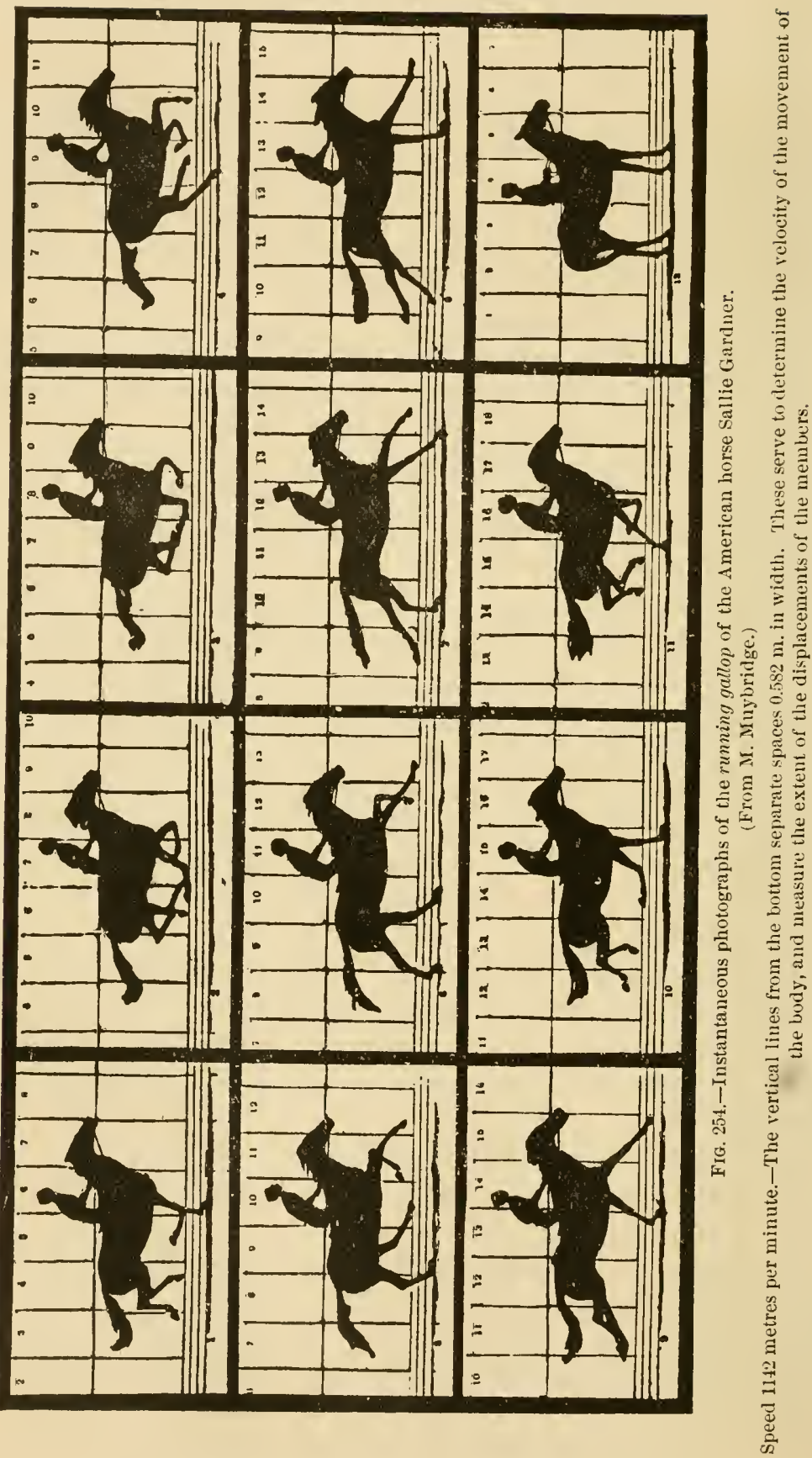
beat, $A G$, is heard at the end of the first third of the eontact of the posterior right.

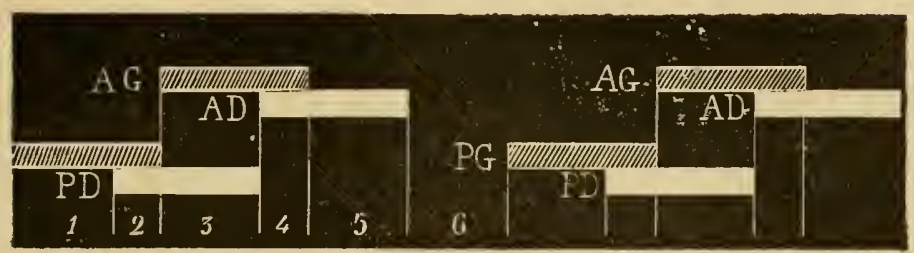

FIG. 255.-Notation of the running gallop, furnished by the instantaneous photographs of the American horse Sallie Gardner.

(From M. Lenoble du Teil.)

The result of this rhythm is to render the times unequal, for the heats $\left.P^{\prime} I\right)$ and $A G$ occur in more rapid sucession than the others.

After the contact of the anterior right member follow's the phase of projection (6), which M. Lenoble dn Teil has valued at one-fifth of the total duration of the complete step; then a new stride is accomplished, and so on. As to the successive bases of support, they differ somewhat from those of the ordinary gallop. Excepting the first (1) and the last (5), which are unipedal, the other three are bipedal, and it is the diagonal upon which the body is sustained for the longest time.

Finally, as in the gallop with three times, it is the members of the diagonal biped, which cause the first and the fourth beat, that are the most fatigned.

The facts which we have just presented differ in a measure from those which M. Marey has observed. Althongh the differences concern principally the details, it is nevertheless necessary to collect more numerous data in order to remove all doulits as to the truth of these facts.

The trail of this gallop is characterized loy the great length of the projection, as well as that of the diagomal hase, which is always much in excess of three-fourths of the height of the horse. Fig. 256 reproduces from the estimates of M. Lenoble du Tril the distance between the imprints furnished by the instantaneous photographs of Sallic Gardner.

The length of the step, measured between the two successive imprints of the posterior left, is equal to $4.41 \mathrm{~m}$. 
Deducting from this quantity the distance of the projection $(1.60 \mathrm{~m}$.), it is proved that the space covered by the animal was $2.814 \mathrm{~m}$., with a diagonal base of $1.92 \mathrm{~m}$.

We will, nevertheless, remark, with M. Lenoble dı Teil, that nothing is so variable as the step of this gallop. By comparing the different associations of the imprints left upon the ground by horses of an identical external appearance, one is surprised at the differences which exist among them. Not only have their trails but little analogy, but even two successive strides of the same subject appear completely dissimilar. It follows from this that, in order to understand how the trail of the race-horse is produced in its details, it becomes necessary to analyze the complete scries of each one of his steps.

This is the reason that not even an approximate length of these steps ean be given : they vary, in fact, from 4 to 7 metres, a very wide range.

Be this as it may, the posterior imprints are always considerably in front of the corresponding anterior. It is necessary, therefore, that the anterior members be raised very promptly to avoid their being struck by the posterior. Hence the race-horse, not considering his conformation, frequently overreaches when his speed is pushed to its extreme and when his training has been ineomplete. The examination of the instantaneous photographs, for this purpose, verifies this statement.

Another important fact worthy of mention in this commection is that the imprints left upon the ground by a rumning-horse follow each other upon the same straight line as if made by the spokes of a wheel deprived of its felloe (Lenoble du Teil). This indicates a mininum size, in a transverse sense, of the base of support, and, consequently, great instability as well as enormous speed.

M. Lenoble du Teil estimated that the velocity of the trunk is equal to $\frac{7}{10}$ of that of the feet, and as Sallie Gardner, npon which he made his study, travelled about 19 metres per second, it ('an be inferred how difficult it is for the eye to analyze the phases of such a rapid movement.

It is, eonsequently, not astonishing that nearly all artists have represented the ordinary gallop and the running gallop incorrectly. The horse suspended in the air with the four members pointed in opposite directions, as is shown by all the classical reproductions, is in a false attitude, which is contradicted by the instantaneons photographs nowadlays becoming more and more numerous. The members, during the projection, are not extended, but in reality flexed, gathered under the 
trunk; it is at this moment that interfering takes place. Incapable as we are of perceiving clearly with the eye the silhouctte of the rumning gallop, we might just as well reproduce it truly, as photographic apparatus take it; for, in truth, our eye does not see the members of a race-horse lengthened out any more than it sees them gathered in, and it wonld be more logical if we were to agree on substituting for a conventional attitude one which is (to be sure) equally undiscernible by our insufficiently-trained senses, but which is at least more real.

We have given in the following table some examples of speed displayed upon various French and foreign race-courses by some remarkable horses. Most of the data are drawn from the Joumul des haras and from Le Sport; some eoneerning Ameriean horses have been communicated to us by our associate, Professor Huidekoper.

\begin{tabular}{|c|c|c|c|c|c|c|c|c|c|c|}
\hline$\stackrel{\circ}{Z}$ & 国 & $\begin{array}{c}\text { Place } \\
\text { OF } \\
\text { Course. }\end{array}$ & $\begin{array}{c}\text { NAME } \\
\text { UF } \\
\text { ANIMAL. }\end{array}$ & SEX. & AGE. & $\begin{array}{l}\text { WEIGHT } \\
\text { ('A RRILD } \\
\text { BY THE }\end{array}$ & 它 & TIMF. & \multicolumn{2}{|c|}{$\begin{array}{l}\text { SPEED PER } \\
\text { SECOND. }\end{array}$} \\
\hline & & & & & Yrs. & Kilog. & Metres. & II. S. & Met. & Mill. \\
\hline$\frac{1}{2}$ & $\begin{array}{l}1817 \\
1842\end{array}$ & $\begin{array}{l}\text { Arles. } \\
\text { Paris. }\end{array}$ & $\begin{array}{l}\text { Renard. } \\
\text { Tragédie. }\end{array}$ & $\begin{array}{l}\text { Horse. } \\
\text { Mure. }\end{array}$ & $\begin{array}{r}11 \\
4\end{array}$ & $\begin{array}{l}64.5 \\
56.0\end{array}$ & $\begin{array}{l}9000 \\
4000\end{array}$ & $\begin{array}{r}1535 \\
458\end{array}$ & $\begin{array}{r}9 \\
13\end{array}$ & $\begin{array}{l}625 \\
422\end{array}$ \\
\hline 3 & 1816 & 4 & Fitz-Emilius. & Horse. & 4 & 60.0 & 4000 & 455 & 13 & 559 \\
\hline 4 & 1841 & 4 & Cavatine. & Mare. & 4 & 56.5 & 4000 & 449 & 13 & 810 \\
\hline 5 & 1839 & 4 & Roqueneourt. & Horse. & 3 & 51.5 & 2000 & 2.24 & 13 & 888 \\
\hline 6 & 1842 & $" 4$ & Nautilus. & $\because$ & 7 & 62.5 & 4000 & 447 & 13 & 937 \\
\hline 7 & 1847 & Nantes. & Philip Shah. & $"$ " & 4 & 60.0 & 4000 & 447 & 13 & 987 \\
\hline 8 & $184]$ & Chantilly. & Roquenconrt. & $\because \because$ & 5 & 59.5 & 4000 & 447 & 13 & 937 \\
\hline 9 & 1848 & Toulouse. & Eden. & $"$ & 5 & 62.5 & 4000 & 446 & 13 & 986 \\
\hline 10 & 1846 & Paris. & Le Chonrineur & " & 3 & 51.0 & 2000 & 222 & 14 & 084 \\
\hline 11 & 1847 & " & Wirtsehofl. & Mare. & 3 & 49.5 & 4000 & 444 & 14 & 084 \\
\hline 12 & 1811 & Versailles. & Oak Stick. & Horse. & 6 & 60.5 & 3900 & 436 & 14 & 130 \\
\hline 13 & 1845 & Paris. & Fitz. Enilius. & $" 1$ & 3 & 51.0 & 2000 & 221 & 14 & 184 \\
\hline 14 & 1816 & "6 & Miss Waggs. & Mare. & 3 & 49.5 & 2000 & 221 & 14 & 184 \\
\hline 15 & 1847 & " & Prédestinée. & $\because$ & 5 & 61.0 & 4000 & 441 & 14 & 234 \\
\hline 16 & 1845 & " & Impasse. & " & 3 & 34.5 & 2000 & 220 & 14 & 285 \\
\hline 17 & 1840 & $"$ & Quoniam. & Horse. & 3 & 54.0 & 2000 & 220 & 14 & 285 \\
\hline 18 & 1842 & " & Annette. & Mare. & 3 & 52.0 & 2000 & 220 & 14 & 285 \\
\hline 19 & 1845 & " & Prédestince. & ". & 3 & 47.5 & 2000 & 219 & 14 & 388 \\
\hline 20 & 1840 & Clantilly. & Jenny. & " & 3 & 47.5 & 2000 & 219 & 14 & 388 \\
\hline 21 & 1847 & Tarbes. & Premier Aout. & Horse. & 4 & 64.5 & 2000 & 218 & 14 & 492 \\
\hline 22 & 1840 & ('llantilly. & Fortunatus. & $\because$ & 4 & 63.0 & 2000 & 218 & 14 & 492 \\
\hline 23 & 1879 & Paris. & Nubienne. & Mare. & 3 & 53.5 & 3000 & 327 & 14 & 492 \\
\hline 24 & 1868 & $" 6$ & The Earl. & Horse. & 3 & 55.0 & 3000 & $3 \longdiv { 2 7 }$ & 14 & 492 \\
\hline 25 & 1876 & $"$ & Kisber. & " & 3 & 55.0 & 3000 & 326 & 14 & 563 \\
\hline 26 & 1877 & " & St. Christophe. & " & 3 & 55.0 & 3000 & 324 & 14 & 705 \\
\hline 27 & 1876 & Jonisville. & Ten Broeek. & 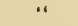 & 3 & 55.0 & 6437 & 7153 & 14 & 797 \\
\hline 28 & 1847 & Arles. & Gouleuse. & Mare. & 4 & 62.5 & 3000 & 317 & 15 & 228 \\
\hline 29 & 1840 & Paris. & Nautilus. & Horse. & 5 & 60.0 & 2500 & $2+3$ & 15 & 337 \\
\hline 30 & 1877 & I,ouisville. & Ten Broeck. & $\cdots$ & 4 & 60.0 & 1609 & $139 \% / 4$ & 16 & 252 \\
\hline
\end{tabular}

It follows from this table, in which the subjects have heen arranged in the order of speed, that the velocity of the gait is inversely proportional to the distance travelled.

We refer the reader to what we have said eoneerning the conditions of the motor in relation to speed (page 408) for all that has reference to the eonformation of the race-hurse. 


\section{Transitions between the Different Gaits.}

"It is very difficult," says M. Marey, "for an observer to understand how the passage from one gait to another is accomplished. The graphic method furnishes a very easy metns to follow these transitions; this will, perhaps, not be one of the
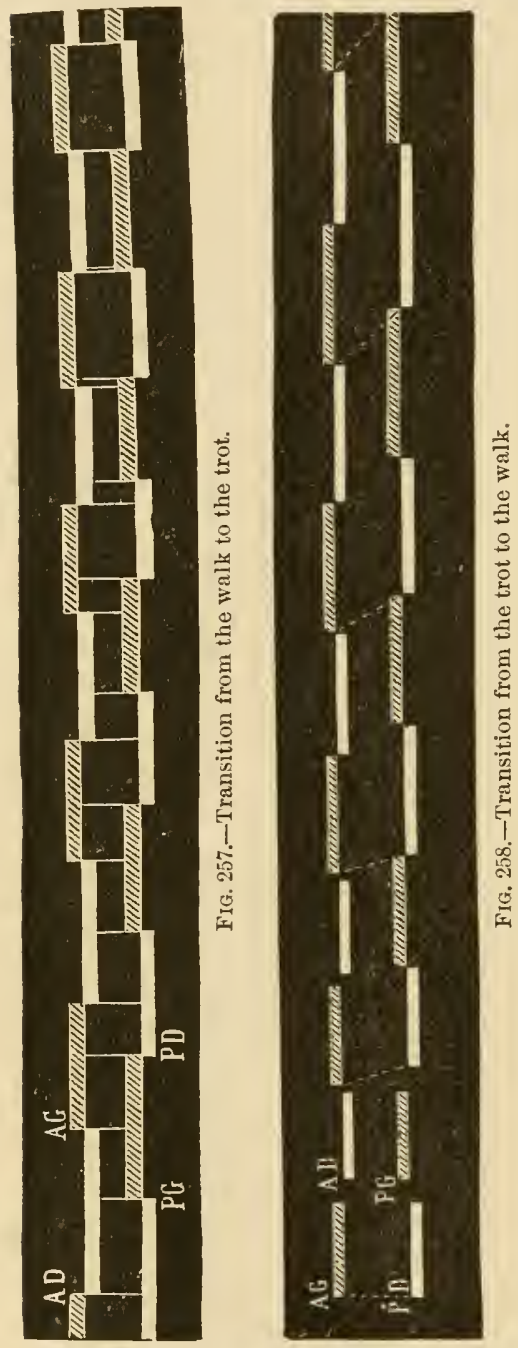
least benefits derived from the application of this method to the study of the gaits of the horse.

"In order to comprehend well what takes place in the transitions, it is necessary to revert to the comparison of Dugès, and to concejve two pedestrians who follow each other at the walk, the trot, or the gallop. They present, in the continued gaits, a constant rhythm in the relation of their movements, while, in the transitions, the one behind or the one in front, according to the case, hastens or slackens his movements so as to change the rhythm of the beats. Some examples will render the explanation clearer.

"Fig. 257 is the notation of a transition from the walk to the trot.

"The dominant character of this transition, independently of the augmentation of the rapidity of the movements, consists in the fact that the movements of the posterior members gradually gain in speed upon those of the anterior, so that the posterior left beat, $P G$, for example, which, during the walk, took place in the middle of the duration of the contact of the anterior right nember, $A D$, gradually approaches the beginning of the contact of $A D$, and finally coincides with this beat itself when the trot is produced.

"Fig. 258 indicates, on the contrary, the transition from the trot to the walk.

"It is seen, by inverse phenomena, that the diagonal beats, at first synchronous, disassociate themselves more and more. A dotted line which unites the left diagonal beats, is vertical at the commencement of the figure, in the part which corresponds to the trot; little by little this line becomes oblique, showing that the synchronism disalppears. 
The direction of the obliquity of this line denotes that it is the anterior nembers which slacken in speed in the passage from the trot to the walk.

"The transition in the passage from the trot to the gallop is very peculiar; it is represented in the notation of Fig. 259. It is seen there, in the beginning of the figure, that the trot is slightly broken; the dotted line which unites the left diagonal beats, $A G$ and $P D$, is already somewhat oblique and marks a slight tardiness of the posterior foot. This obliquity continues to augment, but in the left diagonal biped alone; the right diagonal biped, $A D, P G$, remains united, even after the establishment of the gallop. The transition from the trot to the gallop is made not only by the slowness of the movements of the posterior foot, but also by the advance of the anterior foot, so that the two diagonal beats, which in the trot were synchronous, are now separated by a long interval: this, in the ordinary gallop, constitutes the long silence.

"An inverse change produces the transition from the gallop to the trot, as can be seen in Fig. 260."

\section{E.-Leaping.}

Definition.-Leaping is a progressive movement in which the body is completely separated from the ground to be projected forward and upward by the sudden impulsion given by the four members. The latter act, according to the case, simultaneously, in pairs, or separately. This mode of progression, exacting a large amount of force, is not accomplished by all horses with equal facility. It takes
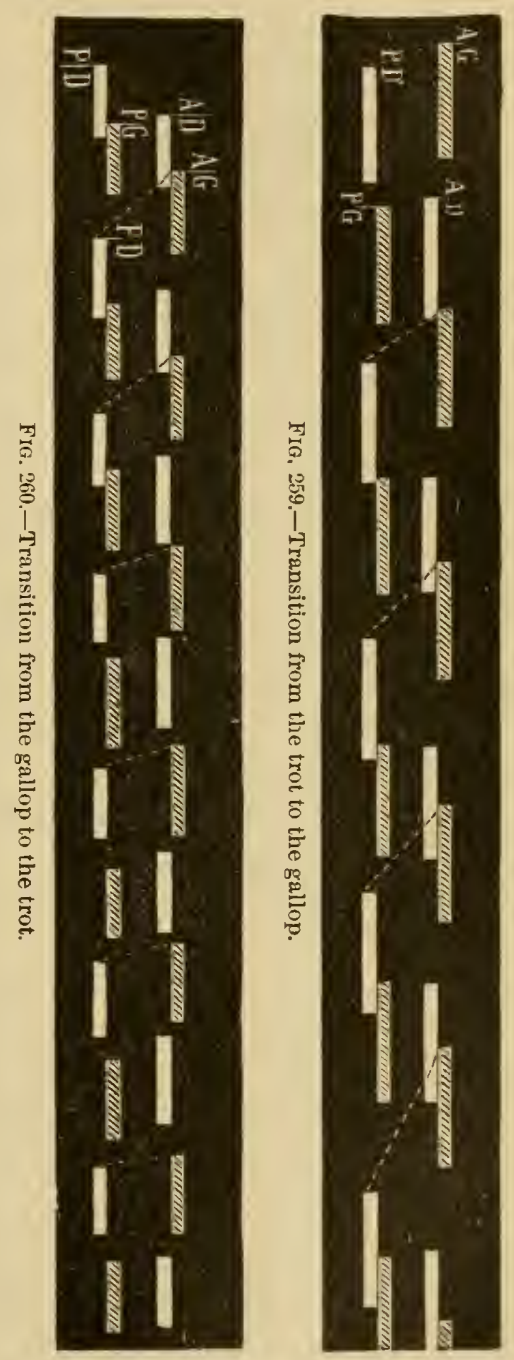
part, at times, in some gaits, particnlarly the trot and the gallop, but is exceuted by the animal speeially under many cireumstances.

Divisions.-Leaping, property so called, may be (Fig. 261) ascending, longitudinal, and, finally, descending. All other divisions 
appear useless to us, for leaping is produced in the horse neither vertieally nor in a retrograde manner, as it is seen in some other animals.

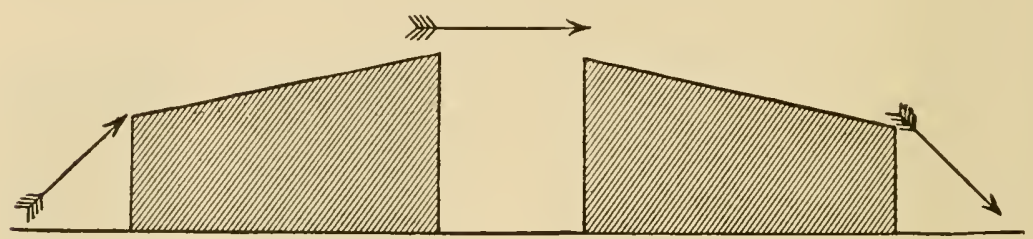

FIG. 261.-Seheme of the three prineipal varieties of leaps.

As to leaping to one side, it is only a variety of one of those which we have enumerated above; it, therefore, need not oceny our attention.

1st. The Ascending Leap, or the Leap over a Barrier.-It is this variety which we will take for a type. Steeple-chasers and hunters, which have to clear ditches, fences, and walls, as in England and America in the popular fox-hunts, execute it most frequently, either without modifying their speed if the barrier is not too high, or, on the contrary, with a certain fixation of the feet during a momentary period of arrest, permitting them to recognize the nature and the height of the obstacle. In certain cases the body does not fall to the same level as that of its point of departure, when, for example, the horse, in traversing a meadow, leaps over ditches and embankments which lie along the route, and then continues his course upon this ronte.

However it may be, the action in all cases comprises three more or less rapid phases: one of preparation, one of execution, and one of descent.

M. Ottomar Anschiitz has recorded all the successive attitudes by means of instantaneous photographs. We will reproduce, from his series of twenty portraits, the five principal positions which it appears useful to us to study ${ }^{1}$ (Figs. 262 to 266).

The animal during the first period (preparation) approximates his four members under the trunk, suddenly elevates the head and the neck, and forcibly carries them backward. The anterior columns, at the same time, become rigid and straightened, and raise the anterior quarters (Fig. 262), as if the horse intended to rear.

During the second period (execution) the posterior members extend, in the manner of a bow in the act of unbending, and propel the body upward and forward (Fig. 263). The next instant the body is sent up

1 For more details, see G. Barrier, Société centrale de aédecine vétérinaire (séance du 14 Février, 1859). 

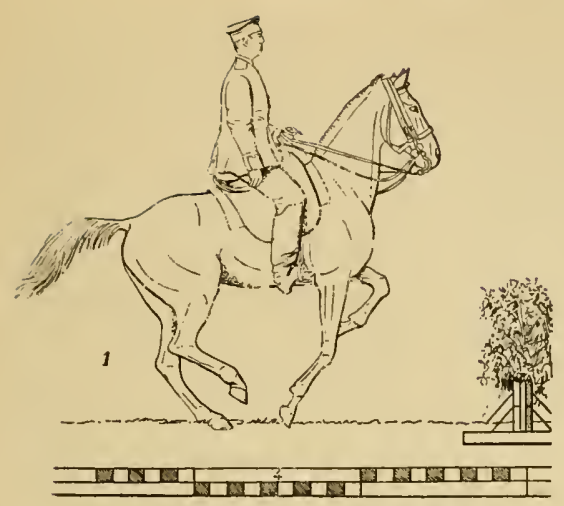

FIG. 262.-The leap. (Preparation.)

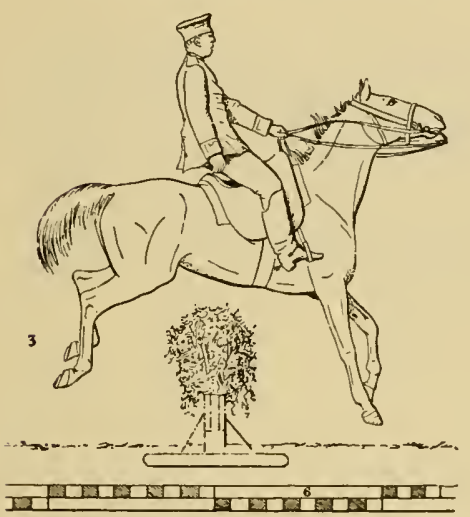

FIg. 264.-The leap. (Passing the obstacle.)

altogether in the air (Fig. 264) with an energetic impulsion which will cnable it to clear the obstacle placed before him.

Finally, the descent is effeeted first by that of the anterior biped (Fig. 265), followed by that of the posterior (Fig. 266).

All authors are not in aceord as to the manner in which the body alights on the gromd after having cleared the obstacle. To solve this question, we have experimented upon steeple-chase lorses in training at Vincennes.

Our observations are in absolute conformity with those of De
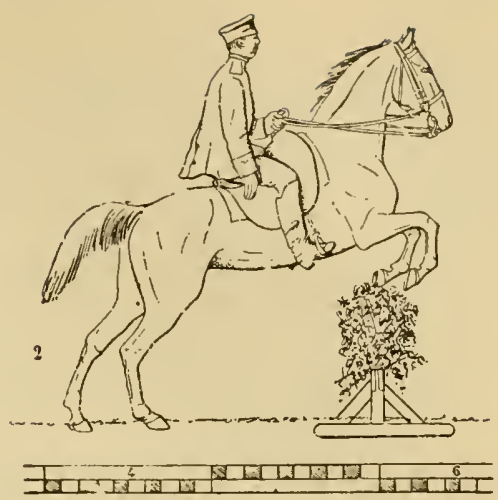

Fig. 263.-The leap. (Impulsion.)

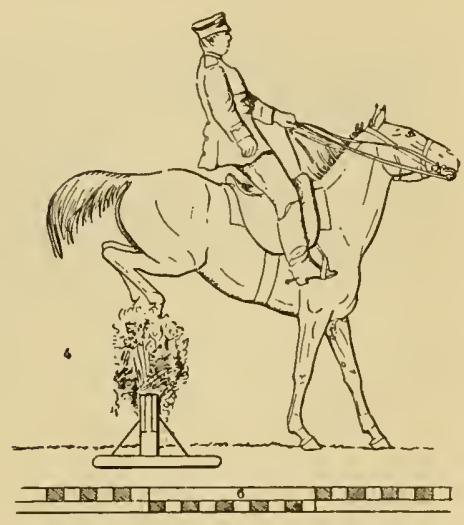

FIG. 265.-The leap. (Descent in front.)
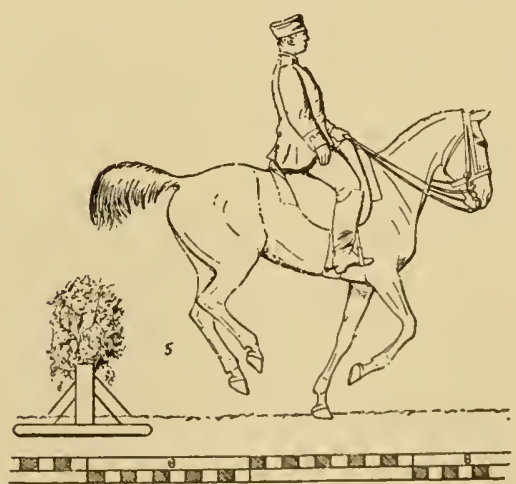

FIr, 266.-The leap. (Descent behind.) 


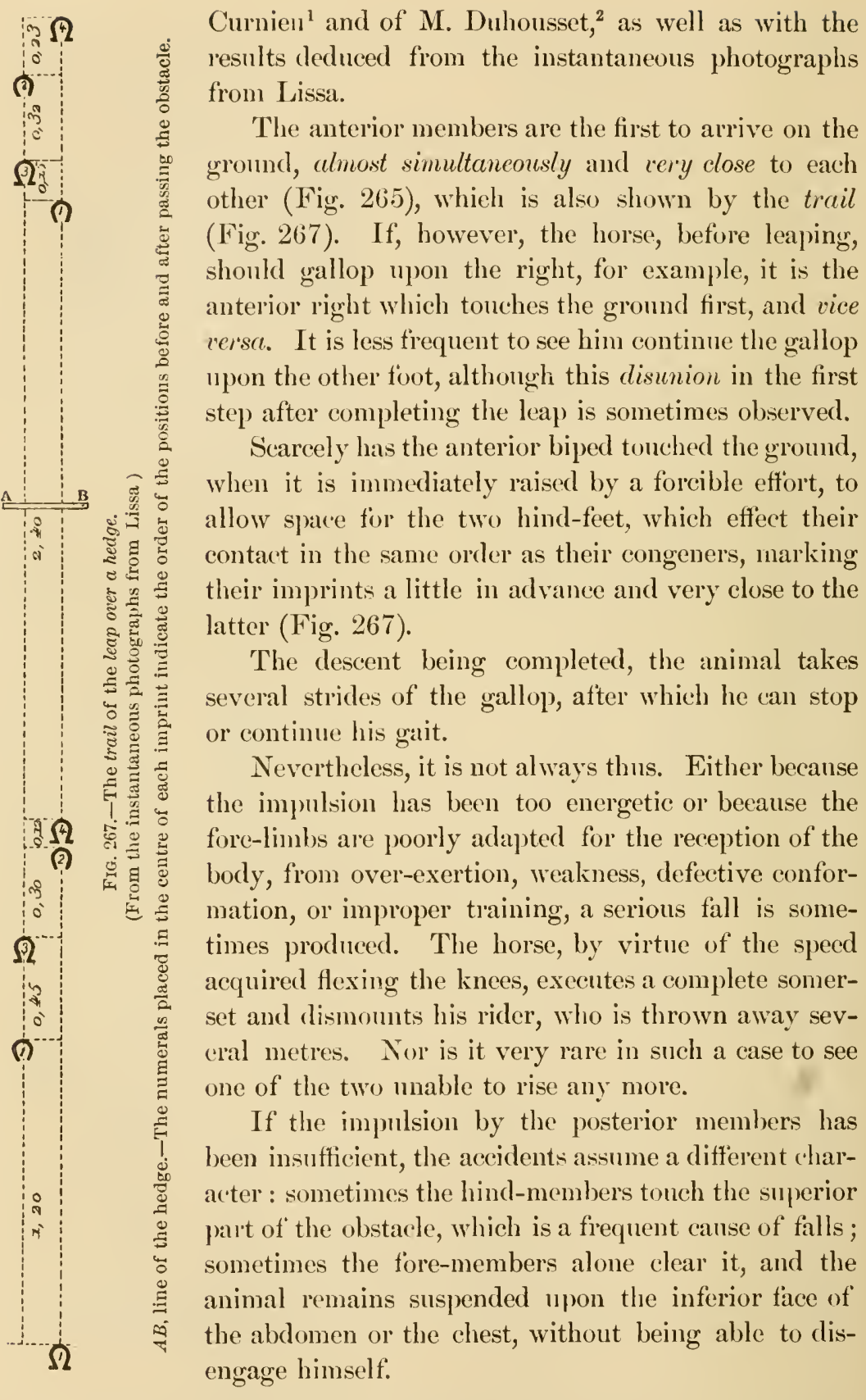

1 De Curnieu, Leçons de seience hippique, t. i. p. 166.

2 Juhousset, Le cheval, p. 33. 
Fig. 268 gives the notation of a leap over a hedge, after the photographs from Lissa; the annexed explanatory legend simplifies its comprehension. This notation enables us to follow the series of the phenomena as to their times, while the trail represents them to us as to their distance.

At the commencement of the figure, the horse, which was trotting, disassociates the elevations of $A G$ and $P D$, during which he hastens the contact of the anterior right. In phise 4 he prepares to support himself immediately (5) upon the posterior member. The two hind-limbs, in contact with the ground, remain there during the whole duration of phase 6 , and effect simultaneously in energetic impulsion; the body, under this influence, is projected upward and forward to clear the barrier (8); it then falls successively upon the anterior members, the right first.

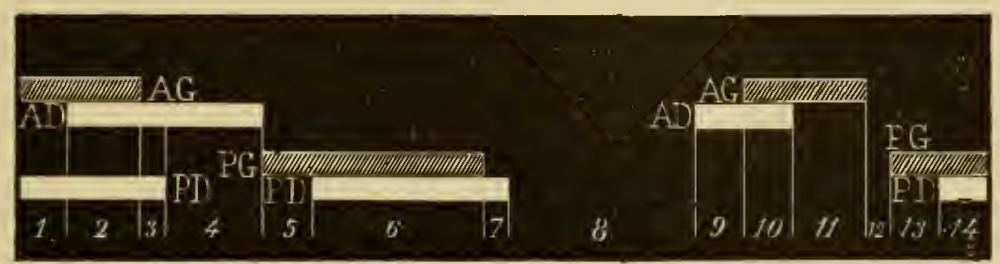

FIG. 268.-Notation of the leap over a hedge.

(From the photographs from Lissa.)

At 4 , the preparation: 5 , elevation of the anterior part of the trunk: 6 , the impulsion; 7 , the body suspended: 8 , passage over the obstacle; 9 , descent; 10 , clearing by the hind-limbs; 13 , descent of the hind-limbs.

The anterior biped, however, is immediately raised (11), and, as the posterior has not yet come into contac $t$ with the ground, there results a new and very short suspension (12), after which the posterior members are rested. The leap is accomplished; the horse starts afresh in a broken gallop. (See above, page 571.)

It is not without interest to eite here some examples of remarkable leaps.

We have seen in the school at Alfort a horse that jumped out of a box-stall $3.80 \mathrm{~m}$. in length, and enclosed by a railing $1.20 \mathrm{~m}$. in height.

According to Youatt, ${ }^{1}$ a horse, which had been cauterized in three nembers, was placed at liberty in a box closed by a door $1.80 \mathrm{~m}$. high, above which wats a space of 1 square metre; his height was $1.60 \mathrm{~m}$. This animal, on hearing at a great distance the shonts of the hunters and the yells of the dogs, leaped with one bound over the door of his box, without showing under his chest, his neck, or his sides the least evidence of an abrasion or a wound.

De Curnieu " relates the following feats :

"In 1792, for a wager of 500 guineas, an Irish horse was brought into Hyde Park, to leap over the wall of Park Lane, $2.22 \mathrm{~m}$. high on one side and only $2.08 \mathrm{~m}$.

1 Youatt. History of the English Thoroughbred.

${ }^{2}$ De Curuieu, Lesons de science hippique gẻmèrale, Paris, 1857, t. ii. p. 413. 
on the other. He cleared the lower side easily, but touched slightly on the opposite side. It appears that he was at liberty.

"Another Irish horse also leaped over the same wall.

"There are also some rare examples of horses leaping over walls 2 metres high for wiagers.

"A humter of Kent County, in endeavoring to follow a fox into a closed field, is reported to have leaped over a wall of 2 metres without difficulty.

"We rarely see a leap of 1 metre under a heavy man ; one of $1.46 \mathrm{~m}$. is not often witnessed, even in hurdle-races, because what I call a leap is the leap clear and free over a movable bar which falls from the least touch or over a wall which does not bend or give way. The hurdles of the race-courses are nearly always struck by the feet at 18 or 22 centimetres from their superior extremity.

"A leap of $1.46 \mathrm{~m}$. is worth one's while to go 100 kilometres in order to see it, and a leap of $1.62 \mathrm{~m}$. is seen but once or twice in the life of a sportsman."

2d. The Longitudinal Leap.-This is also ealled the leap in width by De Curnieu. It is that which a horse executes in jumping over a ditch or a stream of water, but it ean be made in a vertical and a longitudinal sense at the same time.

Thus Flora, a celebrated hunting mare of the English thoroughbred variety, leaped over a hedge of $1.46 \mathrm{~m}$. with a ditch of 7 metres close behind it. ${ }^{1}$

"The Sporting Magazine" speaks of a wager in which it was proposed to leap, with 66 kilogrammes, the canal of Mar Dyke, in Corez, at a place where it was 25 English feet wide."

The longitudinal leap is not always solitary ; it is frequently associated with a progressive movement, the trot or the gallop, when the body of the horse is altogether in the air.

\section{3d. The Descending Leap.-This form of progression must not} be confounded with the fall, properly so called, nor again with the third period of the ascending leap,-that is to say, the descent. In each case the exeeution has as its principal agent the weight of the body, and, very secondarily, the fraction of the initial impulsion not yet exhausted, which counteracts a fall and lessens the concussion.

The horse, in the descending leap, is, on the contrary, not obliged to raise himself previous to clearing the obstacle; he must simply leave the ground in order to reach a point on the latter situated beyond and at a greater or less distance from the place where the surface changes its level. At this moment he collects the members under the body during a very short period, and then springs obliquely downward and forward, from the energetic extension of his hind-members.

The parabolic curve described by the body under such circumstances is produced by the weight of the body and the impulsive force from

1 De Curnieu, loc. cit., t. ii. p. 139.

2 Octobre, 1829. Citation de $\mathrm{Ml}$. de Curnieu, loc. cit., t. ii. p. 414. 
behind which is added integrally. It is appreciated from this how violent must be the reaction to the rider and to the horse. If the anterior members of the latter are not constructed strongly and solidly, if their vertical axes and equilibrinm are defective and his training incomplete, a fall becomes inevitable.

The three varieties of leap of which we have spoken are sometimes combined on the hunting-field or the race-course. The Irish banquette is only an obstacle similar to the one of which Fig. 261 represents the scheme. Very variable in its disposition, it often has a trench in front of the ascent and a second one behind the descent, which render the leap still more dangerous.

Conformation of Leapers.-The horse which is destined to leap frequently, requires, of necessity, an irreproachable conformation, as well as energy, force, and vigor, in order to be able to withstand the great fatigue that results from this act.

A light head, long neck, beautiful withers, strong and compact body, powerful loins and croup, wide articulations, regular axes, and equilibrium of the anterior members, as well as energy, are the essential beauties to be desired in him.

Besides a strong muscular development, adds M. Sanson, ${ }^{1}$ the horse must have an intelligence developed and improved by education and training. It is very disadvantageous not to have, in this kind of service, a horse that possesses the intellectual faculty which is called judgment, and which implies, on his part, close observation, appreciation, and, finally, decision, with which he measures his efforts by the severity of the task imposed upon him.

\section{Bounding and Bucking.}

The bounding or skipping is effected upon place, with two times, and consists of a complete elevation of the body above the ground by the successive and alternate raising of the anterior and posterior parts of the body. The movements of the posterior quarters, however, are ordinarily not that of kicking. This act can be repeated screral times in succession. The horse most often practises it from mere playfulness in the parade or in the riding-school, but sometimes also for the purpose of dismounting his rider.

Bucking, or the goat-leap, is almost identical with the preceding. It only differs from the latter in that the animal appears to 
elevate simultaneously the four members, and tonches the ground again in the same manner.

There are some horses which are specially trained, in ridingschools, to buck and bound: these are the leapers between posts ${ }^{1}$ and the leapers at liberty. ${ }^{2}$ In general they are compart, elose to the ground, wide over the back and loins, very muscular, powerfully constructed, and have wide and strong hoeks. A similar conformation is required for kicking, a service which is sometimes exacted from them. They become, in some instances, breathless and covered with profinse perspiration. It is, at times, extremely difficult to mount them and to remain on their backs even after having mounted them. They should possess, besides these external claracters, intelligence and good moral qualities; some are indoeile, vicions, and dangerous; finally, they shonld be endowed with great energy, endurance, and good breeding.

\section{CHA PTER III.}

\section{DEFECTS IN THE GAITS,}

WE will examine in this chapter the defeets which, in a general mamner, may manifest themselves more or less distinetly in all the gaits. To this end, we will arrange them under five different elasses:

A. Defects existing in the anterior members alone.

$B$. Defects existing in the posterior nembers alone.

C. Defects dependent upon the mode of association in raising the anterior feet and resting the posterior feet. 1st. Dragging the toe.

2d. Excessive knee-action.

3d. Immobilized, cold, pegged shoulders.

1st. String-halt.

2d. Rotating hocks.

Forging.

1 The leaper between posts is one that is attached, in the riding-school, between two pillars in order to oblige him to leap upon place and in a certain manner.

2 The leaper at tiberty is one which, mounted at liberiy, describes a trail like any other horse, with this difference, that he executes the goat-leap or buck at the will of the horseman who gives the lesson. 
D. Defects existing simultaneously or separately in the anterior quarters or in the posterior quarters. 1st. Rocking.

2d. Strain of the loins.

$E$. Defects existing indiscriminately
$\quad$ in the four members. $\left\{\begin{array}{l}1 \text { st. Billarder. } \\ 2 \text { d. Interfering. } \\ 3 \text { d. Lameness. }\end{array}\right.$

Having thus classified the defects, we will study each one in particular.

\section{A.-Defects existing in the Anterior Members Alone.}

When, during locomotion, the anterior members move too close along the ground or rise excessively; when their segments are not extended and flexed with the quickness and to the extent which their mode of association requires, the gaits assume some particular forms which render them ungraceful, slow, uncertain, and even dangerous to the animal, his driver, or his rider.

1st. Dragging the Toe.-It is said that the horse drags his toe, scrapes the floor, when his anterior feet are raised with difficulty during the evolution of the step. Horses which have pegged (cold) shoulders and stiffened members; those which are worn out or exhausted ; finally, young animals (colts), during the first period of their life, present more especially this defect. It predisposes them to strike the roughnesses

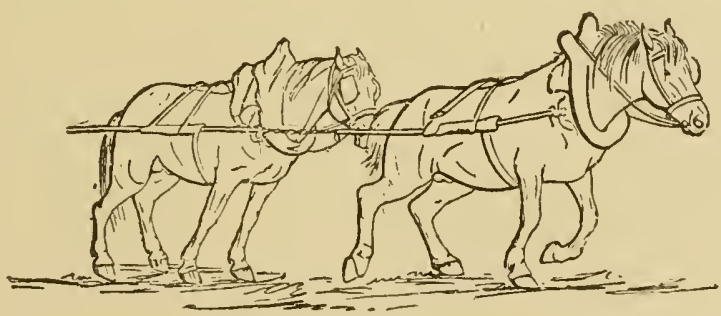

FIG. 269.-Instantaneous photograph of draught-horses moving a heary load.

of the ground, and, consequently, to stumble, make false steps, or fall. It may be caused to disappear by proper dressing, but not, however, if it be the result of hard work.

It is particularly in the trot, the walk, the amble, and the broken amble that this defect is apparent. Horsemen, nevertheless, apply this expression to horses which gallop close to the ground. It seems that the same disadrantages result in all instances. This defect is ordinarily all the more grave as the gait in which it appears has 
more speed. Certain conformations-that of the thoroughbred horse, for example, or, again, certain methods of training at great speedseem to predispose to it. It is, on the contrary, much more rare in dranght-horses, which always raise their feet high during work (Fig. 269).

2d. Excessive Knee-Action.-This action, also called high lnee-action, is especially marked in the trot, and more particnlarly in German and Dutch horses. It is characterized by exaggerated flexion of the canon and the forearm. It is far from constituting a beauty, as many persons think, nor is it graceful either; it is not in favor at the present day. It is well known that this manner of progression involves a loss of time and force which are prejudicial to both the velocity of the gait and its duration.

According to some authors, it is more common in horses with arehed necks and in those with angnlar (cow) hocks. ${ }^{1}$

We know of no means of remedying it.

Let us remark, in passing, that blind horses imitate this action considerably when they trot, endeavoring thus to avoid obstacles; but in this case the action is not identieal, properly speaking, with the one under consideration.

3d. Immobilized or Pegged Shoulders.-When the shoulders, although normal in appearance, seem to be restrained from acting with entire freedom, and only shortened movements of the members are allowed, they are said to be immobilized, cold, or pegged.

These expressions are incorrect, for, as $\mathrm{H}$. Bouley remarks, ${ }^{2}$ it is less in the shoulder than in the inferior regions of the members that the impediment resides. The animal, in most instances, suffers in the feet, and shortens his steps to diminish the intensity of the percussion against the ground. As a proof that this is so, the destruction of the sensibility in the region of the surgical foot, by the operation of neurotomy, will, in most instances, restore the natural nobility to the shoulders.

The immobility of the shonlders is not always an index of a lesion of the members; it may depend simply upon a want of energy, the coldness and lymphatic type of the temperament, compatible sometimes with the most perfect regularity of form. The picture-horse of the lealers, a model to offer to artists, is a case in point. With an irre-

1 Similar to string-halt, this action may be due to an excess of elastic fibres in the antibrachial aponeurosis and in the tendon which extends from the biceps musele to the tendon of the extensor of the metacarpus. (1Iarger.)

${ }^{2}$ H. Bouley, Nouveau dictionnaire de médecine, de chirurgie et d'hygiène vétérinaires, t. vi. p. 155 . 
proachable conformation, the horse has neither gait nor energy, and trots under himself, because he lacks that qualification without which the best-arranged mechanism loses all its value,- - the breeding, the blood.

Let us add, finally, that such restrained movements of the shoulders are sometimes only temporary; it is thus when the defect results from extreme youth, insufficient training, weakness from certain pathological alterations, etc. Under these circumstances, it is possible, with good hygiene, abundant alimentation, and daily exercise judiciously practised, to cause the disappearance of the defect.

\section{B.-Defects existing in the Posterior Members Alone.}

1st. String-halt.-String-halt, or dry spavin, is characterized by a sudden jerking and somewhat convulsive flexion of the canon upon the leg, to such a degree in some subjects that the anterior face of the fetlock touches the inferior face of the abdomen.

This sudden and exaggerated flexion of the hock affects sometimes only one and sometimes both members. If, in the latter case, the action of string-halt is very intense, locomotion, when the amimal first starts off, is very singular.

The horse suffering from this affection presents absolutely no external lesion which will reveal its existence. It is only in the walk more especially and in the trot that this symptom manifests itself. More or less pronounced, and always more visible after a prolonged rest, it sometimes disappears altogether during and immediately after exercise. It may therefore be said to be of an intermittent nature, since it may appear and disappear according to circumstances. Hence H. Bouley has thought that this defect should be considered as a variety of chronic intermittent lameness, and for this reason redhibitory, according to the terms of Article II. of the law of August 2, 1884. We share this opinion, but we know of no legal opinion that las been given on the subject.

What is the cause of this affection?

"The true cause of this flexion of the hock, more frequent in well-bred horses than in those of the conmon races," says Lecoq, ${ }^{1}$ "has not yet been recognized. To attribute it invariably to a disease of the hock is to forget that the osseons levers camnot be moved isolatcly, and that the spasmodic flexion of one articulation suffices to excite that of all the others. If the flexion of the look is more apparent to the eyes than that of the superior articulations, is this a 
reason why the former should be the point of origin of the abnormal morement of the member?"

These remarks are not without reason and foundation, for the lesions of string-halt are not always located in the tibio-tarsal articulation. The facts which we will eite fumish evidence of this, and will also serve to direet investigators in their researches upon this subject.

1st. Rigot attributes the abrupt movements of perfect ginglymoid (hinge) articulations to the ulcerated lines which their articular surfaces present. According to him, alterations of this nature are found in the humero-radial articulation when the horse is string-halty in front, and in the tibio-tarsal when he is affected in the hind-limb. ${ }^{2}$

2d. Pastureau, veterinarian at Esclates (Lot-et-Garonne), has advanced the opinion, without any proof to support it, that string-halt is due to the accidental fastening or catching of the internal femoro-patellar ligament upon the superior extremity of the femoral trochlea. ${ }^{2}$

3d. II. Watrin, ex-army veterinarian, thinks, on the contrary, that it is produced by the complementary fibrn-cartilages of the third phalanx, which, slightly modified in their structure and relations, press against the second phalanx (coronary bone) at the time of the raising of the member.

This hypothesis, revived by MIessrs. Chénier and Weber, has induced M. E. Bizard to employ anesthetic injections in the fold of the pastern to relieve the pain which horses affected with string-halt seem to experience. These injections have given negative results. ${ }^{3}$

4th. M. Orillarl, veterinarian of Châtellerault, has also published several interesting facts. According to his views, the action of string-halt is due to muscular laceration in the posterior part of the tibial region and of the thigh, or to a partial rupture of the tendons and aponeuroses of the cord of the hock. ${ }^{4}$

Concerning our opinion, we will say that, like Rigot, we have seen horses which were string-halty in the anterior members, and which have presented at the autopsy ulcerated fissures of the lumero-radial articulation; these subjects are, however, extremely rare.

As to those which are affected behind, they have shown rery diverse lesions: sometimes they existed only in the femoro-tibial articulation, in the form of nlcerations, foreign bodies, simple or rheumatoid arthritis; sometimes they exist, with almost the same characters, in the femoro-patellar articulation only; sometimes in the tibio-astragaloid joint exclusively ; at other times we have found all the articulations in the posterior member diseased except the coxo-femoral; finally, there were instances in which nothing abnomal could be perceived, no more in the bones and the cartilages than in the muscles, the tendons, the aponeuroses, the synovial membranes, the vessels, and the nerves. ${ }^{5}$

${ }^{1}$ Rigot, Traité complet de l'anatomie des prineipaux animaux domestiques. (Syndesmolo. gie, p. 19.)

2 Pasturenu, Journal des vétérinaires du Midi, année 1819, p. S71: Quelques réflexions sur l'éparvin et la crampe.

3 Bulletin de la Société eentrale de médecine vétérinaire, séance du 25 Février, 1882, in Reeueil de médecine vétérinaire, année 1882, p. 373.

4 Orillard, Quełques rensejgnements sur la mature et l'étiologic de l'éparvin sec, in Archives vétérinaires, 6e amnée, 18s1, p. 161.

5 Arm. Goubaux, Comptes-Rendus de la Société de biologie, année 1S5̃3, pp. 19 et 92. 
In two instances our attention was arrested by the degree of openness of the articular angles. Besides the various forms of chronic arthritis, we bave, in other instances, found the tibio-tarsal angles so large that their branches, in their maximum state of separation, formed almost a straight line. This disposition has appeared to us to have for its effect the augmentation of the spring-like action of the hock. This action, seen in the freshly-dissected articulation, when it is flexed or extended, is the more intensified as the constituting bones of the articulation are closer to their limit of separation. As no definite lesion can be discovered in horses which are affected with dry spavin, it might be that the sudden and abrupt movement which accompanies, in such cases, flexion and extension of the metatarsus las its sole catse in the mode of coaptation and union of the bones of the leg and of the caunn. ${ }^{1}$

It is also possible, as Pastureau has supposed, that the accidental suspension of the internal patellar ligament upon the femoral trochlea, whose internal lip is at times very salient, opposes at first a certain resistance to the movement of flexion of the member, and, as this obstruction suddenly disappears, the flexion is then spasmodically completed. ${ }^{2}$

These are, of course, only hypotheses, but the study of the nature and cause of this condition will receive ample reward and are well worth one's undertaking.

All these facts demonstrate that science does not know the exact cause of this remarkable symptom. Be this as it may, the horse which is so affeeted is not easily relieved; ${ }^{3}$ he has, consequently, lost much of his value, although this does not render him unable to perform his work, even the most laborious kind.

2d. Rotating Hocks.-Horses of the lieavy-draught or the lighter types quite frequently present this outward rotation of the hocks, for which there is no remedy; they are, as a rule, animals degenerated from hard labor.

During the walk, and more particularly when the foot is placed on the ground, the point of the lock describes a sort of rotation outward, making the toes converge forward and inward. It is said, in this case, that the horse has rotating hocks. He is not prevented from rendering

1 f. Barrier, Bulletin de la Société centrale de médecine vétérinaire, in Recueil de snédecine vêtérinaire, annúe 1882, p. 372.

2 Anotlier very beautiful as well as plausible theory of the nature of string-halt is that of the excessive claticity of the tibial aponcurosis, particularly of its triangular fuseiculus, whieh extends from the anterior face of the hoek-joint to be altached to the tendon of the anterior cxtensor of the phalanges. When the foot is on the grotund, the aponenrosis is tenserl when the foot is raised, it will reeoil, like a piece of India-rubber, and impart a sudden movement to the limb. This disposition is more common in well-bred horses, in which string-halt is, as we have remarked, more frequent. The treatment eonsists in section of the apoueurosis at the superior extremity of the canon, where this structure ean be outlined from the exterior.

In the camel and the elephant this aponeurosis is composel almost exclusirely of elastie fibres, and hence the sudden elevation of the members of these animals. (Harger.)

${ }^{3}$ Boccar has proposed to make section of the tendon of the lateral extensor muscle of the phalanges close to its termination upon that of the anterior extensor. (Journal vitérinairc et agricole de Belgique, anu(e 1815, p. 273.) We have had occasion to perform this operation once, but without result. 
good service, but his action is ungraceful and diminishes, in part, the firmness of the members.

\section{C.-Defects Dependent upon the Mode of Association in raising the Anterior $F$ eet and resting the Posterior.}

Forging.-We sometimes observe horses which, in the walk or the trot, produce an abnormal sonnd, more or less loud and frequently repeated, which has been compared to that of the hammer upon the anvil. It is produced by striking the toe of the hind-foot against the fore-foot of the same side, in consequence of the want of harmony between the anterior elevations and the posterior contacts, whether through too great a rapidity of the movements of the hindlimbs or an exaggerated slowness of those of the fore-limbs. It is said, in ordinary language, that such horses forge. The points of striking, varying according to the degree of advance of the hind-foot in relation to the fore-foot, are marked on the shoe by the grooves or seratches which exist upon its branches, at the heels or at the quarter.

This fault of forging has serious inconveniences: first, its sound is disagreeable and tiresome; besides, the horse may pull his shoe, throw himself, break his knees, calk himself, contuse the heels, the phalanges, the tendons, or, finally, injure himself somewhat seriously, and suffer from diverse complications, such as overreaching and quitters.

The causes of this defect it is important to recognize. They are dependent upon the general state of the subject and the faults of conformation.

The general causes result in most cases from weakness, fatigue, excessive use, improper training, or some diseased state. Some of these are persistent and irremediable; other's are only temporary, and for this very reason, under the influence of good hygiene, nutritious alimentation, judieious exereise, and proper attention, forging may disappear. Young horses which are worked too early, full-grown horses which are overdriven, finally, those which are not accustomed to work at speed, may be corrected of this fanlt if they are placed in proper conditions, while it is entirely different with those in which it becomes a symptom of weakness consequent upon old age.

The faults of conformation capable of producing forging are rather numerous. We will cite the prineipal :

1st. The volume and weight of the head.

2l. The shortness of the neek, its museular development, as well as that of the shonlders. 
3d. The vicious axis of the members, which renders the horse under himself and low in front.

4th. The excessive length of the posterior members in relation to that of the anterior.

5th. The deficient length of the body relative to its height.

6th. The excessive length of the back and loins, implying too great flexibility of the spinal column, and permitting the posterior members to reach the anterior more easily.

The action of all these it is easy to comprehend:

First, it must be noticed that, in the first three conditions, the surcharge of the anterior members determines a longer contact of the anterior feet with the ground, in consequence of an appreciable tardiness in being raised. As a consequence of this delay, if the gait be lengthened, the posterior feet, not finding the place free which they should oceupy, strike against their corresponding homologues, whence the particular sound which announces that the horse forges. The same result is produced, and for identical reasons, if the rider, badly seated too far in front, surcharges the anterior limbs of his mount.

In other cases, it is because the forward displacement of the posterior member is greater than in ordinary conditions, or that its play cannot be entirely accomplished, from the insufficient extent of the field of oscillation under the body. It will then reach the anterior member at the end of its contact or the commencement of its elevation.

There are horses which, in the trot, forge almost at each step. We have known several which had to be put to another kind of work, and could only be employed at a walk. Fortunately, this extreme measure need not always be resorted to.

There are, in fact, some means of remedying this defect when it results from a bad conformation.

Thus, the elevation of the head and the neck, either directly, through proper intervention of the rider, or indirectly, by making the rein shorter, ean relieve the anterior members and displace upon the posterior a portion of the weight which overburdened the former. This, however, is not the only remedy. Special shocing, applied rationally, is often the most efficacions treatment. The principal object, as H. Bouley has so well expressed, will be to diminish as much as possible the volume of the parts concerned at the points where they strike each other. It willocousist, in the hind-foot, in the diminution of its antero-posterior diameter at the expense of the toe, and, at times, in incrusting the shoe in the horn, which then projects in front; in the fore-foot, in shortening the branches of the shoe, 
making them narrower, or even in applying a tip. Bourgelat, from purely theoretical considerations, had advised a method of shoeing different from that in question. H. Bouley opposed them, and demonstrated that they are not in accord with the facts of practice. ${ }^{1}$

\section{D.-Defects existing Separately or Simultaneously in the Anterior or the Posterior Members.}

1st. Rocking.-Rocking consists in a lateral balancing of the body, comparable to the to-and-fro movements of a cradle, which is apparent particularly in the trot or the walk.

The horse can rock in front, behind, or in both extremities at the same time. These lateral oseillations always consume a portion of the force destined for propulsion, and, as Lecoq has said, the more apparent they are the less the animal machine becomes adapted to the fast gaits.

This defeet, sometimes due to weakness and exhaustion, is seen preferably in horses having an excessive width of the chest, of the eroup, and of the base of support. It is observed, besides, in horses with crooked legs and bovine knees. Finally, let us add that, according to our observation, horses, at first very regular in their gait, will rock themselves when their obesity bceomes excessive; conversely, we have seen the defect disappear under the influence of emaciation.

It can be understood, from the causes mentioned, that slow and weakened animals may be affected with this balancing only temporarily, for with age, moderate work, and sufficient nourishment they may acquire the energy and strength which they lack. As to those whose rocking is due to irregularities in the axes of the limbs, they can never be corrected, and there exist no means of palliation.

It is to be observed that eertain trotters rock in the walk or the slow trot, but show nothing abnormal when their gait aequires a greater velocity.

Rocking never takes place in the gallop, on account of the great speed employed, the feebleness of the transverse displacements of the centre of gravity, and the narrowness of the base of support. We know that, in such cases, the imprints of the left members tend to approach those of the opposite side, and we have even seen that the trail in race-horses is represented only by a single line of imprints.

This defect is therefore more or less grave according to the nature of the work.

1 For more details, see the excellent article by II. Bouley upon forging, in Nouveau Dictionnaire de médecine, de ehirurgie et d'hygiène vétérinaires, t. vii. p. 214. 
2d. Strain of the Loins.-Strain of the loins, a symptom of diverse diseases of the dorso-lumbar region, most frequently a strain of the vertebral column, is manifested by a want of rigidity of the spine, a defect of harmony between the movements of the anterior and posterior quarters, as well as lateral swinging and great weakness of the latter.

Saddle- and shaft-horses are most predisposed to it; at other times, the affection is a simple aecident and has no relation with the work performed.

The animal affected with this alteration has no firmness in his posterior members, which maintain him in equilibrium with difficulty. It suffices to push against the haunches or pull on the tail to make him totter from side to side. He lies down, rises, and backs with great difficulty, and is incapable of carrying the least weight on his back. During locomotion he oscillates alternately from one side to the other. The plane of movement of the posterior members is not parallel to the axis of the body; the members are moved inward, outward, and knock against each other awkwardly; their contact is not firm, and their hoofs pivot upon themselves so as to make the toes converging; finally, their imprints are marked without symmetry, and their gait has lost its normal rhythm. All these facts are more exaggerated in turning and in trotting; falling upon the side is quite frequent.

It is evident that the horse in this state cannot render good service; when the symptoms are very severe, it is even impossible to employ him at any kind of work. Nevertheless, there are some inattentive buyers, notably contractors, who buy the horse under such eonditions. $\mathrm{He}$ is presented for sale in the shafts of the cart, where he is more supported, and is constantly more or less excited by the application of the dealer's whip. They perceive the irregularities in the movement the following day, but it is too late, the defect not being redhibitory.

Strain of the loins, known also under the names winding of the loins, dorso-lumbar strain, is always grave, and results most frequently from a fall or from earrying too heavy a weight on the back. There is little encouragement for the cure of the animal, which has now lost the greater part of his value. At present he is abandoned to the slaughter-house or to the knacker to save the expense of treatment, in most instances ineffectual, which, from its duration, may exceed his intrinsic ralue. ${ }^{1}$

\footnotetext{
1 For more details, see Arm. Goubaux, De l'entorse dorso-lombaire considérée chez le cheval, in Reeneil de médecine vétérinaire, année 1851, pp. 414 et 498.

H. Bouley, Nouveau Dictiommaire; etc., t. v. p. 362 .
} 


\section{E.-Defects existing Indiscriminately in the Four Members.}

1st. Billarder.-Billarder (rowing, paddling) is the action of the horse in whieh, during locomotion, he throws his feet outside of the plane of movement of his members. Usually, all the regions from the eanon to the foot participate in this deviation; at other times, only the regions from the fetloek down are involved. In either cirenunstance, this peeuliarity of loeomotion is observed in the postevior as well as in the anterior members, and it is ineorreet, in our opinion, for authors to consider it as being exelusively confined to the latter.

As there exists no teehnical word to characterize this irregularity in the hind-limbs, we propose to designate it by the word paddling in both bipeds indiscriminately.

The animals which paddle in front are those whose axis of movement of the anterior members is deviated, at the level of the knee, outside of the vertieal line, or whose feet are turned outward; such are horses with crooked legs or with ox-knees.

Horses which paddle behind are affected with an analogous vice of conformation. They include such as are close-hocked, bow-legged, and erooked-legged.

According to Lecoq, " ${ }^{1}$ horses whose feet are wide and flat are more subject to this defeet, beeanse they are forced to separate their feet from each other to avoid interfering."

It is in the walk and in the trot that the defeet is especially apparent. Besides rendering these gaits ungraceful, it oeeasions a waste of time and foree, and is therefore a serious canse of fatigne and slowness of the gait. Horses thus formed and still capable of speed, owe the latter, if our observations are correct, only to the frequent repetition of their movements; but it is certain, all things being equal, that they waste more energy.

2d. Interfering.-Interfering is that irregularity in the horse's aetion in which one of the feet strikes the inferior part of one of the other members.

This defeet, says H. Bouley, ${ }^{2}$ has particular degrees and modes, which are designated by different expressions.

Relative to its degrees, it is said that the horse brushes when the faulty member simply touches the skin, always in the same place, and

1 Lecoq, Traité de l'extérieur du cheval, etc., 5e éd., p. 383.

${ }^{2}$ H. Bouley, Nouveau Dictionnaire, etc., t. iv. p. 442. 
leaves no other mark than the forward deviation of the hairs and a deposit of mud or dirt or of coloring matter with which the hoofs may have been coated.

If the defect be more severe and the contact of the moving member produces pain, but without abrading the epidermis, it is expressed by saying that the animal touches himself.

He strikes or cuts himself when the injury is so intense as to make a wound ; finally, when each member of the same biped, during progression, alternately gives and receives a blow which is always upon the same place, we have the phenomena which essentially characterize the vice interfering. The blows may be inflieted sometimes in one place, sometimes in another, as happens in the race-horse during the projection; it is then said that the horse overreaches.

Horses interfere more often behind than in front; this is owing to the fact that the separation between the hind-feet is generally less marked than that between the fore-feet.

These contusions may be situated in various places: the coronet, the internal face of the fetlock or of the eanon, and, more rarely, the internal face of the knee and the inferior extremity of the forearm, of which we have seen several instances.

The wounds do not always present the same characters. If recent, they are covered with blood; if they have existed for some days, they are covered by a seab. If, however, the contusions which produce these lesions are frequently repeated, the latter will be cireumseribed by hard, thick, and indurated borders. Finally, they are situated, in certain cases, over osseous tumors; we have found this condition upon the two anterior members of a horse which interfered at the inferior extremity of both forearms.

Their gravity depends upon their depth, their seat, the frequency of their repetition, and the nature of the parts involved.

They are not accompanied by lameness, excepting sometimes, at the moment of their production; they always blemish the animal more or less, aceording to the various causes which oceasion them, and which we will arrange into six principal classes:

1st. Weakness, resulting from old age, privation, fatigne, exeessive work, and, in young horses, from poor nourishment and want of training. There is every hope, in the latter case, that the fault will disappear under the influence of a better regimen and more judicious care, which observation has demonstrated.

2d. The faulty conformation in horses close behind, with long members, too short a croup, wide and disproportionate feet, in those that 
are parrot-toed or crooked-legged, and, in general, in those with defective axes of the members.

The extremities, under each of these conditions, approach each other inordinately, either in the anterior or in the posterior biped, or the hind-members do not find suffieient space under the body to move freely.

3d. The irregular play of the articulations, which prevents the bony levers from being flexed and extended in planes parallel to the median line, as is seen when the subject has excessive knee-action and the knees and the hocks are arehed ontward.

4th. Enlargements of the inferior and internal parts of the members, whatever may be their nature.

5th. Improper shoeing, when the foot is not level, lias a defective axis, or the shoe and the hoof are too wide.

6 th. Finally, fatigue, which has the same effect as weakness, and diminishes, in the horse, the facility of moving the members with the proper precision, regularity, extent, and direction. The defect, in this instance, disappears with rest and moderate exercise; it must therefore be considered as aceidental and temporary.

All horses do not interfere with the same part of the shoe; it is sometimes the mamma and sometimes the quarter which strikes and wounds the member on the ground. It is important to ascertain this fact in order to apply intelligent treatment concerning the shoeing.

It wonld extend beyond our plan to enter more minutely into the details of this defect of the gaits; hence we refer the reader to works which deal specially with this condition. ${ }^{1}$

Concerning the treatment, we will limit onrselves simply to the following principal indications:

In weak and exhausted horses a good regimen, moderate work, and rational shoeing give, as a rule, satisfactory results. In those which have a bad conformation, as irregular axes of the members, it is entirely different, and the treatment is very often unsatisfactory. Interfering-boots, shin-boots, etc., are employed to protect the affected parts. Finally, a particular mode of shoeing is practised, especially that called the Turkish.

3d. Lameness.- This name is given, says H. Bouley," "to an irregularity of the gait, determined by an inequality or a diminution of the action of one or several of the locomotory columns."

IH. Bouley, Nouveau Dictionnaire, etc., t. iv. p. 441.

2 We borrow the details which follow from the exccllent work on Lameness, which H. Bouley has published in the Nouveau Dictionnaire, etc., t, ii. p. 503. 
This irregularity should always be considered as the symptom of a local or a general disease. The diseased member, in such cases, makes a less strong beat, and its contact is less prolonged than that of the sound member; its step, besides, is longer. It is then said that the horse is lame, that the horse limps; he is called sound, on the contrary, when the gait is normal.

Lameness, on account of its frequency and its variable gravity, may temporarily prevent the animal from working or diminish his services for an indefinite period and even permanently. We will limit ourselves in this study, and will only examine here the interesting points relative to the exterior.

Its degree of intensity is indicated by diverse symptoms : the horse is called sore when the irregularity in his gait is very slight; he limps when it is quite apparent; he hobbles on all-fours when he hardly leans at all on the diseased member; finally, he hobbles on three members when this member supports no weight at all. ${ }^{1}$

A lameness may affect one, two, three, and even the four members, but the last cases are rare, the scrvices of a veterinarian being called in before this stage has been reached.

H. Bouley correctly states that the diagnosis of a lameness is a triple problem, which resolves itself thus: Recognition, 1st, of the affected member; $2 \mathrm{~d}$, the seat of the lameness ; $3 \mathrm{~d}$, finally, the nature of the latter.

The first point alone interests us in relation to the exterior; the others, involving a special profound knowledge of diseases, belong to other treatises.

Recognition of the Lame Member.-To arrive at this result necessitates an examination of the subject at rest, in the walk, and in the trot. In each instance he must be led by the hand with a strap, or be mounted.

a. At rest, we notice if the position of the members is regular or irregular. Sometimes the diseased member is carried in advance of its vertical axis, which is expressed by saying that the horse points; sometimes it is placed under the centre of gravity, or, again, is abducted from its vertical axis. Sometimes it rests upon the ground with the toe, or is held altogether in the air. At other times it mndergoes isochronous movements, being incessantly rested and elevated, especially if the pain is great; the litter is then pawed back and trampled into

1 We say, in ordinary language, to limp on thrcelegs. This is technically an improper expres. sion, which results from confounding the members of the animal with his legs (tibial region). Quadrupeds have two legs and not four, but they have four members. 
a heap; the corresponding shoe, in certain cases, presents a polish which is not seen in that of the other members.

$b$. It is necessary now to observe the horse in action. In this proeess he is led at a walk by the hand, with the precaution of not giving him too much liberty, and, at the same time, without furnishing any support to the movements of the heal. The veterinarian stations himself in such a manner as to see the movements successively from in front, from behind, and in profile from the two sides. If the lameness is slight the walk is insufficient to show it, and the animal must be trotted.

The irregularity of locomotion, in the latter gait, is rendered more evident on account of the stronger conenssion against the soil. It is for this reason that a lameness which was not visible in the walk becomes apparent in the trot.

Having seen the animal trot in a straight line, it is sonetimes well to turn him around a eirele, with a view of surcharging the particular lateral biped. Finally, he is rapidly turned from side to side, in such a manner as to see whether the elevation of the diseased member is more rapid and its contaet with the ground more painful than that of the healthy member. ${ }^{1}$

c. The choice of the surface over which the horse is moved must be considered. A horse which appears sound may, at times, limp if he suddenly passes from a dirt road to a hard pavement. Likewise, it is not rare to see the lameness angment in intensity if the test takes place upon a ploughed field or some other soft surface. The horse, in this case, is obliged to use greater musenlar efforts, which means more pain, in elevating his members and disengaging them from the soil into which the feet bury themselves.

\section{The Manner of Manifestation of the Lameness.}

1st. Lameness in an Anterior Nember.-In the case of the anterior left member, for example, the contact will have a shorter duration than that of the anterior right; the beat will also be less strong. This is not all: at each step the head will be elevated and inclined to the right, to ease, in a certain proportion, the diseased member and render its concussion more feeble.

Concerning the sound member, its step will be shorter, the beat stronger and louder, and the contact, more prolonged, coincides with the lowering of the head.

2d. Lameness in a Posterior Nember.-As in the preceding instance, the beat of the diseased member is less strong than that of its homologue; likewise, the duration of the contact is shorter and the step less long. There are, in the trot, other symptoms to which it is necessary to direct the attention. According to 
the judicious remark of $\mathrm{H}$. Bouley, the nodding of the head, characteristic of lameness, takes place upon the side of the lame member in posterior lameness, while in anterior lameness this is the reverse.

The croup, like the head, also shows an unequal movement of equilibrium under the influence of the nuequal action of the lame member; but, less marked than that of the head, it furnishes a less certain index. It consists ordinarily of an exaggerated lowering of this region at the moment when the healthy member, upon which the body takes its principal point of support, touches the ground, while it is almost imperceptible when the diseased member tonches the ground.

An error rather frequent among laymen consists in believing that the animal is lame in the foot upon which he falls. This results from a false interpretation of the objective phenomena, which are so well known to practitioners that it is not necessary to give the proof of its illogical foundation; we merely mention it here because the veterinarian has frequently to argue this idea out of his elient's mind.

3d. Lameness in Two Nembers. - There are eases in which the horse is lame in two members at one time,--in the anterior, the posterior, the lateral, or the diagonal biped.

"The symptoms proper to a lameness of the anterior or the posterior biped give rise to an irregularity or an impediment of action in general as intense in the right as in the left member. The movements of the biped are modified to the same degree on both sides, making thus a contrast with those of the other biped, which acts normally.

"As to lamenesses of the lateral bipeds they are characterized by the combined symptoms of anterior and posterior lameness, but much more increased on account of the greater difficulty of progression.

"Let us suppose, for example, a horse lame in the right diagonal biped; at each step the nodding of the head and the lowering of the croup will be very decided at the moment when the left diagonal pair touches the soil.

"At first sight there is a want of harmony in the movements which is not easily explained, but by directing one's attention exclusively to the anterior biped on the one part and the posterior on the other, the double cause which produces it is soon discerned.

"The irregularity in the progressive movements is still more decided when the animal is lame in a lateral biped. In this instance it is difficult for him to move in a straight line; if he limps on the left, for example, the centre of gravity being displaced upon the right, the body of the animal will be earried in this direction, and progression will be affected on that side."

4th. Lameness in Four Members.-The irregularity of the locomotory function, here, is such that the lameness is very apparent to the eyes of the least experienced persons. It is therefore useless to dwell further on this point.

We must discuss two points more: the duration and the type of the lameness.

In relation to the first factor, a lameness is aeute, recent, or chronic. This can be established from the history of the lame animal, and a 
logical inference based upon the symptoms and alterations which he presents. In spite of the interest bearing upon this question, we cannot go into details without passing beyond our domain.

As to the type, a lameness is continued or intermittent. The animal, in the first case, is lame at all times : after rest, during exereise, at the beginning as well as at the termination of the latter.

The characters of an intermittent lameness are entirely different. It becomes apparent only under special circumstances : sometimes only when leaving the stable, cold lameness; sometimes at the end of a certain period of exercise, warm lameness. This variety of lameness is included in the list of redhibitory vices and diseases, with nine days of warranty, which is mentioned in Article II. of the law of August 2,1884 , where they are designated under the generic name of chronic intermittent lamenesses.

Fraudulent Methods.-Unscrupulous horse-dealers sometimes attempt to deceive purchasers by knowingly offering for sale a horse which suffers from an intermittent lameness. For this purpose they intentionally make a wound which renders him lame from a simple and apparent cause and for a duration which always exceeds that of the guarantee according to law. We must be on our guard against such malpractice. In general, a lame horse should never be bought unless his price is notably reduced. It is especially in this particular case that it is necessary to consult the veterinarian, in order to be informed as to the gravity of the lesion and the cause of the lameness. If, however, it be determined to buy a lame horse having a recent wound, it is well to require from the seller an appropriate bill of warranty, as a matter of precaution in case, the wound having entirely healed, the characters of a chronic intermittent lameness should afterwards manifest themselves. 


\section{SECTION FIFTH.}

\section{AGE OF THE HORSE.}

BY the word age is generally understood, in speaking of the horse, the time which has elapsed since his birth. It must not be confounded with ages, or periods, a paronymous expression by means of which the different periods of life are designated.

Physiology teaches us, in fact, that the evolution of one same organism passes through three very distinct periods of development:

The first, during which it increases, grows, and accuires, little by little, possession of its functional activities.

The second, stationary or adult period, in which it has acquired its complete development, possesses all the attributes of its species, all its aptitudes, and remains stationary.

The third, finally, of decline, in which it manifests more and more the effects of organic deterioration and insensibly approaches decay and death.

These three periods of life, which characterize all beings whose evolution is normal and complete, are, as will be understood, intimately related to the time during which the organism has already lived.

From an industrial point of view, the adult period is by far the most important as it concerns our domestic animals. Characterized by the regular and harmonious development of all his parts, this is the time, says H. Bouley, in which the horse enjoys the fulness of all his functions and is in a position to furnish, as a motor, the largest share of useful services. ${ }^{1}$

It is of special interest to those who desire to reproduce and inprove him, prepare him for the sale, and develop his aptitudes, to know exactly when he reaches or passes beyond this period in which he acquires his greatest value.

1H. Bouley, Nouveau Dietionnaire pratique de médecine, de ehirurgie et d'hygiène vétérl naires, t. i. p. 200. 
The general aspect of the body, the state of the organization, and his particular mode of functional activity furnish, in most instances, the indications that cannot deceive a practised eye, but they are not infallible in practice, and are subject to variation according to the rational or abusire employment which has been given to the animals.

It is necessary, therefore, to have reeourse to other sourees to establish the basis of a preeise determination of the characters indicative of the age of the horse.

Now, of all the organs which receive and preserve with the greatest accuracy the marks of time, the teeth of solipeds are, without doubt, those which register them, so to speak, in ineffaceable signs. Admirably adapted to the needs of the organism, instruments constructed in view of the mode of alimentation, and presenting a series of landmarks whose snecessive disappearance marks the trace of the years, the teeth appear, develop, wear off, change their external form, are shed, and succeed each other with a regularity which veterinarians have learned to recognize and determine seientifieally.

Hence we will commenee the study of the age of the horse by a minute description of the dental apparatus, in order to place the reader in a situation to understand fully the characteristies upon which it is based.

\section{PART I.}

\section{THE TEETH.}

Definition; Number; Distribution.—"The teeth are meehanieal instruments, harder than bone, placed, in vertebrate animals, at the entrance of the alimentary canal, to seize, cut, tear, and bruise the nutritive substances before their transmission from the month into the nesophagus. They ean also serve the animal as weapons of defence and offence." 1

In the adult animal of the equine speeies the teeth number from thirty-six to forty, ${ }^{2}$ and are designated by names which reeall their use (Fig. 270) :

1 G. Cuvier, Leçons d'anatomie comparée, t. iv., 1 re partie, p. 197.

2 This number should be considered as absolute, but we will call attention to some variatious which it presents, according to the individual. 


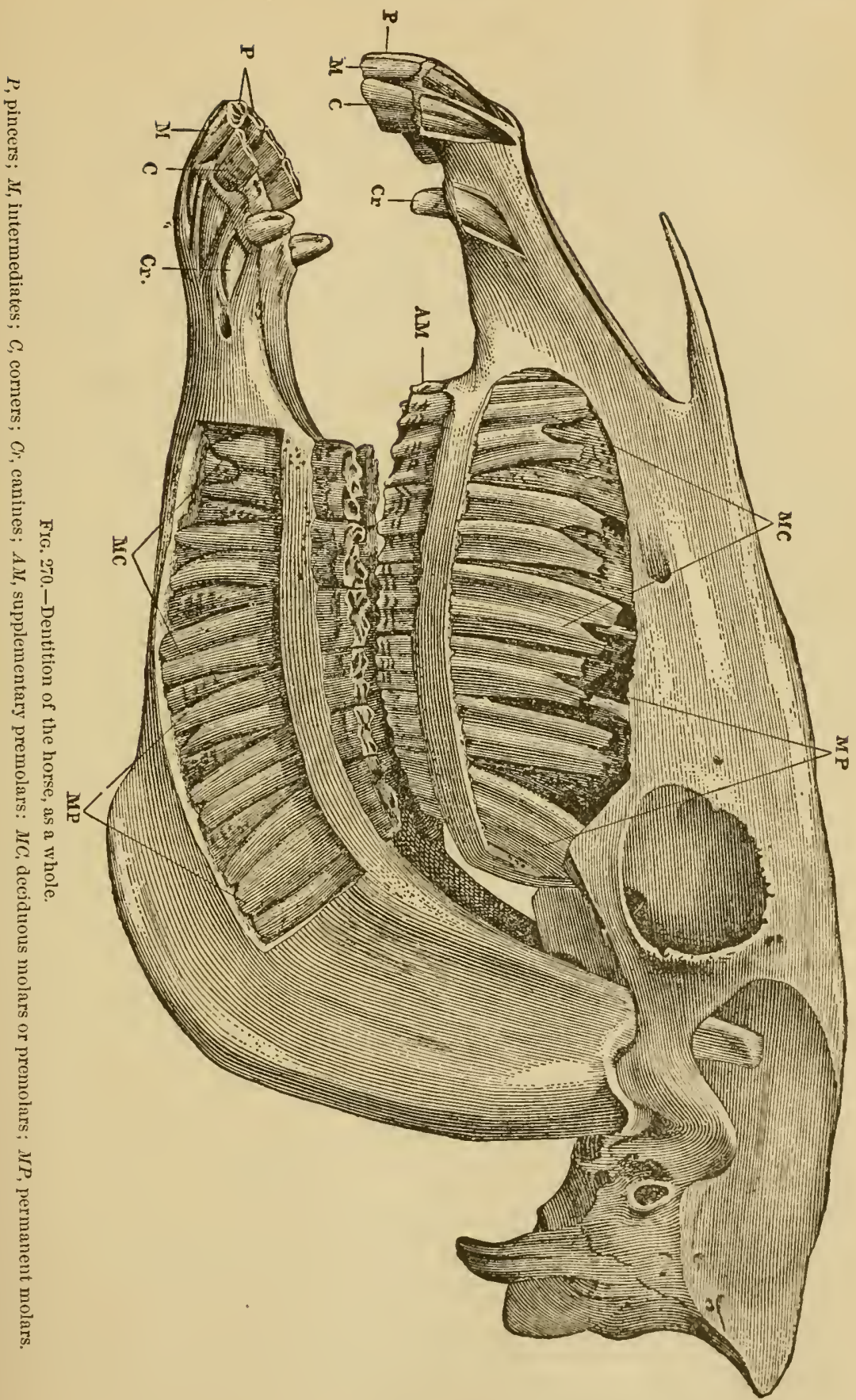


The most anterior are called incisors, $P, M, C$, destined to seize, tear, and ent the aliment.

Then come the tusks, canine teeth, or fangs, $C r$, whose rôle is to tear.

Finally, those which ocenpy the posterior part of the mouth are the molars, $I I C, M P$, which serve to crush, in the manner of a millstone.

Concerning their disposition in the jaws, the teeth form a parabolic curve designated under the name dental areade. The dental areades, two in number and distinguished as superior and inferior, are composed of three parts: one anterior and two lateral.

The incisor's, six in number in each jaw, occupy the anterior part, and describe, as a whole, a transverse semicircle convex in front.

The molars, situated behind and upon the lateral parts, are twelve in number in each jaw: six on the right side and six on the left side.

But immediately behind the ineisive areade, between it and the molar's, exists on each jaw an asymmetrieal interval called the interdental space, upon the course of which the canines or tusks are situated. The bar, as we already understand it, is the name given to the region of the interdental space situated behind the inferior eanine tooth. In the mare, in which the eanines are more or less aborted, the interdental space is commonly minterrupted; the bar is eonsequently longer than in the male.

We count, eonsequently, in the adult, in each jaw and on each side, 3 ineisors, 1 canine, and 6 molars, making in all 40 or 36 permanent tecth, according to the sex.

During the first period of life the teeth are not quite so numerous: only three molars exist on each side, in each jaw, and the tusks are usually wanting. The dentition of the colt, therefore, eomprises 12 incisors and 12 molars, or a total of 24 teeth, whose duration is altogether transient.

Let us ald that Daubenton, Lafosse, Tenon, and Girard ${ }^{1}$ have said that the teeth are sometimes 44 in number; in this ease there are supernumerary premolars; we will again revert to these.

1 Daubenton, see Histoire naturelle générale et particulière avec la dcscription du cabinet du Roi, par Buffon. Edition in-4o de l'imprimerie royale, t. iv., I'aris, 1763, p. 334.

Lafosse, Cours d'hippiatrique ou traité complet de la médecine des chevaux, in-folio, Paris, 1772 , P. 2.1.

Tenon, sccond essai d'étude, par époques, des dents molaires du eheval. Read and deposited with the secretary of the Institute the 16th day of the fourth month in the fifth year (French calendar). This essay has been published in the Memoirs of the Nitional Institute of Sciences and Arts for the fourth year of the Republic (Sciences mathématiques et pliysiques), p. 60 .

J. Girard, Traité de l'âge du cheval, 3e éd., Paris, 1834, p. 35. 


\section{CHA P TER I.}

\section{THE INCISORS.}

\section{A.-Incisors of the First Dentition.}

THEse teeth, also called foctal, milk, deciduous, are twelve in number: six in each jaw, three on each side (Figs. 271 and 272).

They have received the particular names pincers, intermediates, and corners.

The pincers are placed almost on the median line, the one to the right, the other to the left; the intermediates, external to the pincers ; finally, the corners, external to the intermediates.

Collectively they form a regular parabolic curve. By their free portion they present distinctive characters which depend upon their situation, their widtl, and their degree of curvature.

Compared with those of the second dentition, their width is much less, and there exists a well-marked constriction or neck between their free portion or crown, projecting above the gums, and their incased portion, root, embedded in the alveolus. The presence of the neck allows these teeth, in all cases, to be distinguished from the former at a glance (Fig. 273). Finally, their color is of a dull milky-, or yellowish-white; besides, they are curved in the direction of their length.

They present for study two faces, two borders, and two extremities.

Faces.-Each of the faces diminishes gradually from the free extremity to the end of the root.

The anterior, convex in every sense, shows longitudinal striæ more or less marked, which consist of small grooves separated from one another by small longitudinal lines in relief. As the animal grows older, this fuce becomes whiter and more polished under the influence of the friction; a semicireular enlargement of the gums shows its separation from the neck.

The posterior, eoncave longitudinally, is slightly convex transversely. It presents nothing of special importance, and the neck is here less apparent.

Borders.-The internal border is thicker than the external.

Extremities.-In the virgin tooth (one that does not sliow any use) the free extremity (Fig. 274) is flattened from before to behind, and limited by two borders: one anterior, $a$, the other posterior, $b$, and, finally, by two sides: one external, the other internal.

The two borders cireumscribe a cavity, the external dental curity, occupying nearly the whole of the free extremity of the tooth. The anterior, $a$, is the more elevated and longer from side to side. Sharp and convex transversely, it is the first to pierce the gums; the posterior, $b$, penetrates the gums later, and, from the effects of wear, comes on a level with the preceding.

The external dental eavity, $c$, which we will examine in detail farther on, diminishes in depth for the same reason, little by little, and finally disappears. The tooth is then levelled.

As these teeth must be replaced, at a certain epoch of life, by those of the 

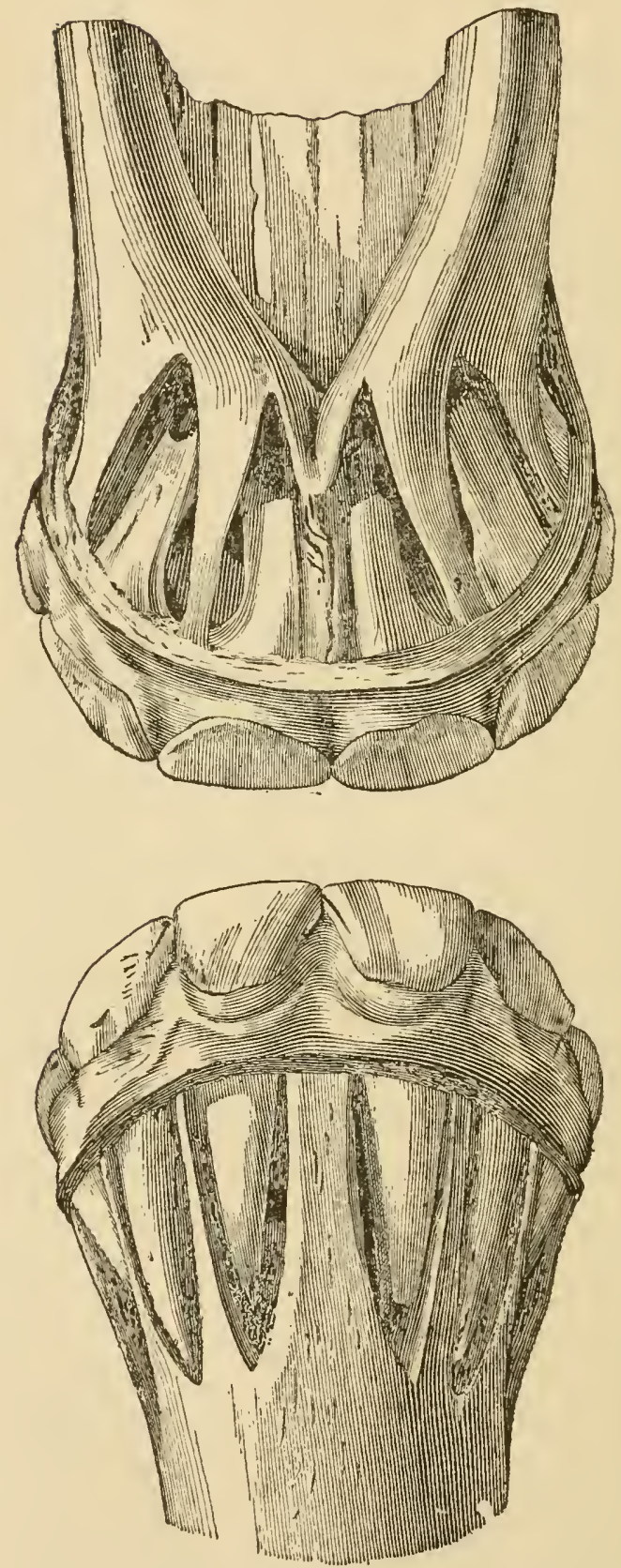

FIG. 271,-Deciduous incisors viewed on their anterior face. 

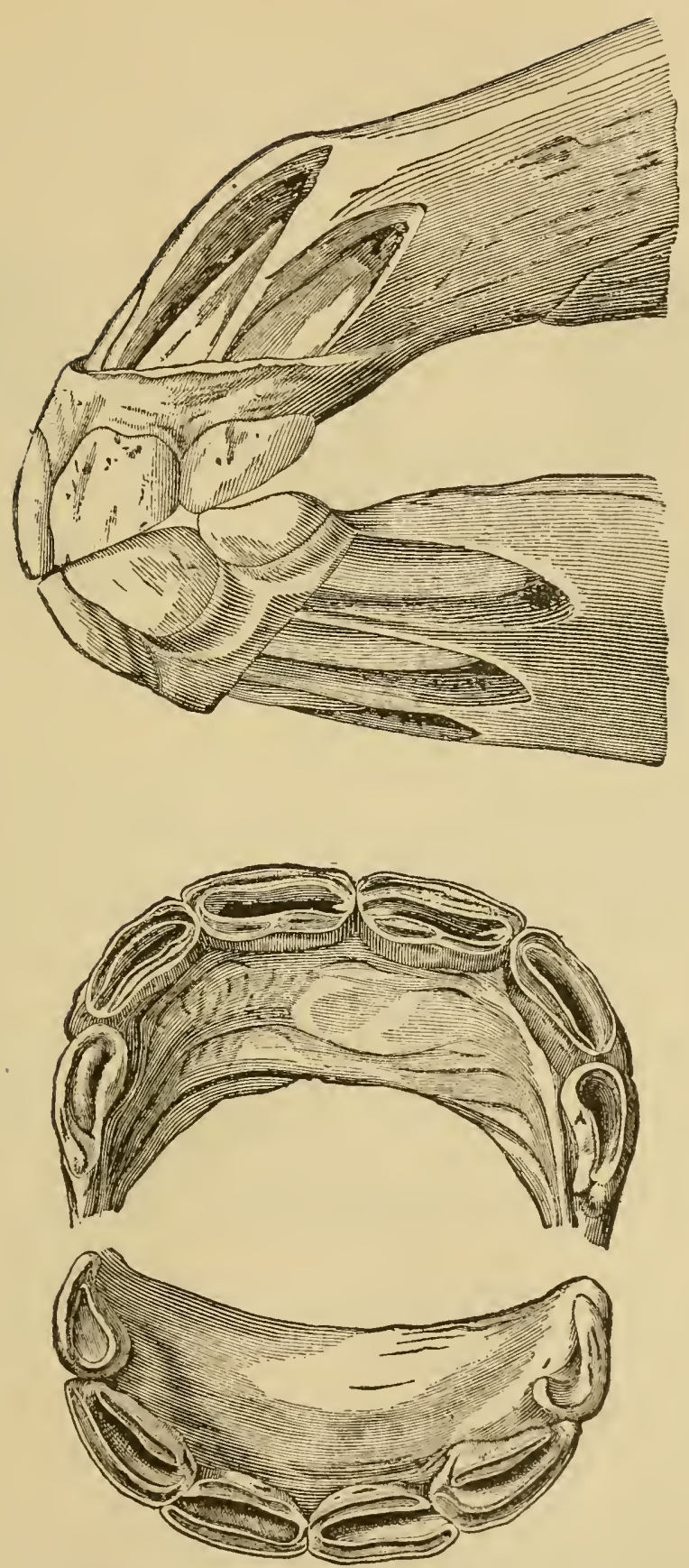

FIG. 272.-Deciduous incisors. (Profile and dental tables.) 
second dentition, we will study with the latter the modifications in the dental table from wear.

As to the embelded extremity, it is provided with an opening, the orifice of the internal dental or pulp cavity, $d$, in which the papilla or pulp of the toath is contained.

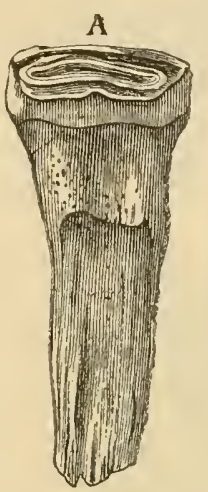

A. Posterior face.
B

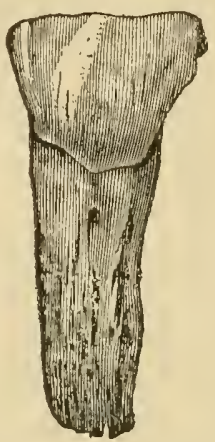

FIG. 273.-A deciduous pìnecr.

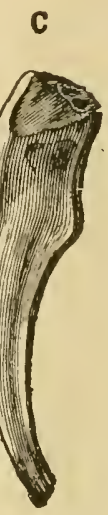

C. Profile.

But, as the young animal advances in age, the milk-teeth increase in length by growth at their roots, while their pulp cavities diminish in size in a great

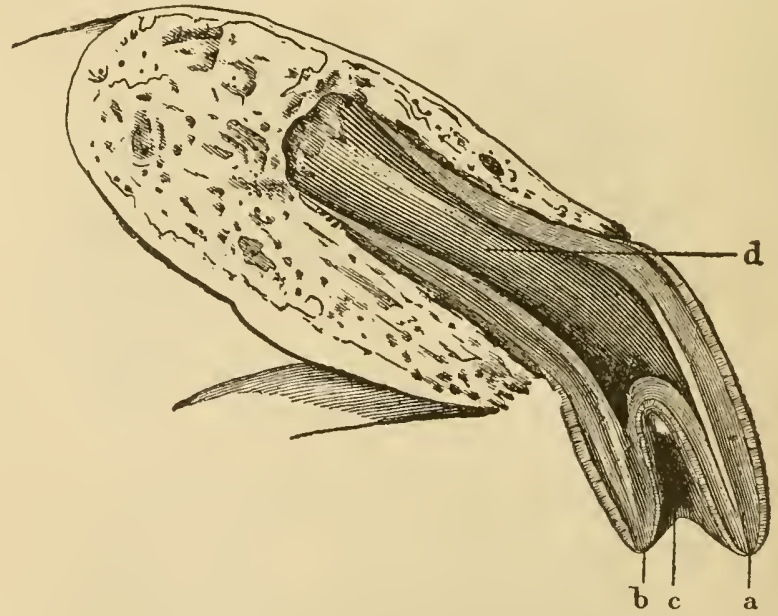

FIG. 274.-Magnified longitudinal section of a superior virgin pincer of the first dentition, seen in its alveolus.

measure. The maxillary bones at the same time become thicker and the permanent incisors are being formed in their thickness. The latter are situated behind and within the deciduous teeth, from which they are at first separated by the 
alveolar partitions. These partitions then become absorbed in such a manner that at a given moment the two teeth are found to lie in contact (Fig. 275).

There results, in ordinary cases, from the relation which is established between the posterior face of the deciduous tooth and the crown of the replacing tooth, a direct compression of the one upon the other, the effect of which is a

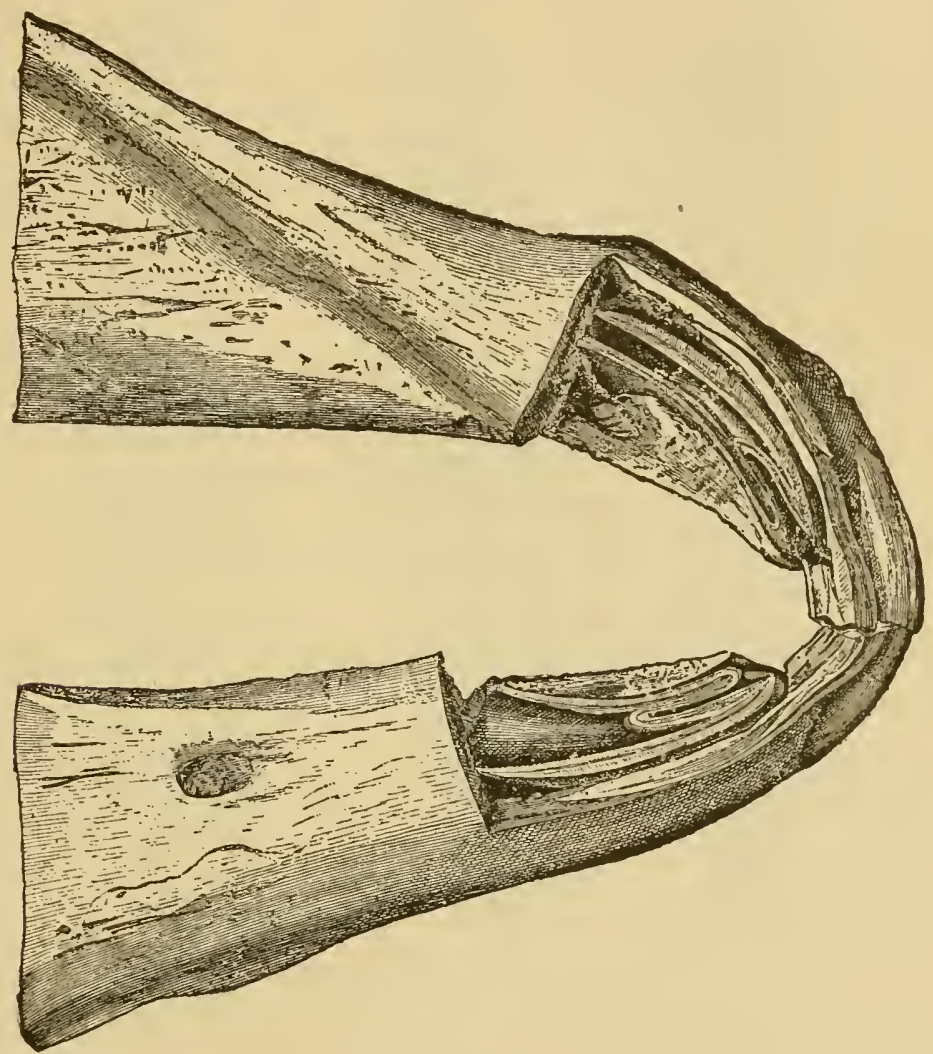

FIG. 275.-Longitudinal section of the jaws showing the relative situation of milk and permanent incisors.

flattening and atrophy of the root of the first dentition. The permanent teeth, nevertheless, are sometimes placed at the level of the others, without compress: ing or pushing from their sockets, but simply remain situated behind them.

\section{B.-Incisors of the Second Dentition.}

These teeth, known under the name permanent or adult incisors, incisors of replacement, number the same as the preceding, which they succeel. There are, therefore, in each jaw two pincers, two intermediates, and two corners.

They are distinguished particularly from the milk incisors in that they are 
longer, larger, not so white, deprived of a neck between the root and the crown, and have a wide gutter on their anterior face.

Form.-Their general form, always more regular in the pincers than in the intermediates, and in the latter more so than in the corners, is that of an irregular cone, whose base, flattened from before to behind, corresponds to the free extremity of the tooth, while the summit, depressed from side to side, corresponds to the root.

This double flattening of the two extremities of the tooth necessarily implies an intermediary zone more or less trifacial.

The incisor tooth is, besides, curved in the direction of its length, which is most marked in the pincers and least in the corners; its long axis appears more or less twisted upon itself from side to side, particularly at the level of the root. This is most apparent in the intermediates and the corners. In order to facilitate the description we will recognize in each incisor (Fig. 276) :
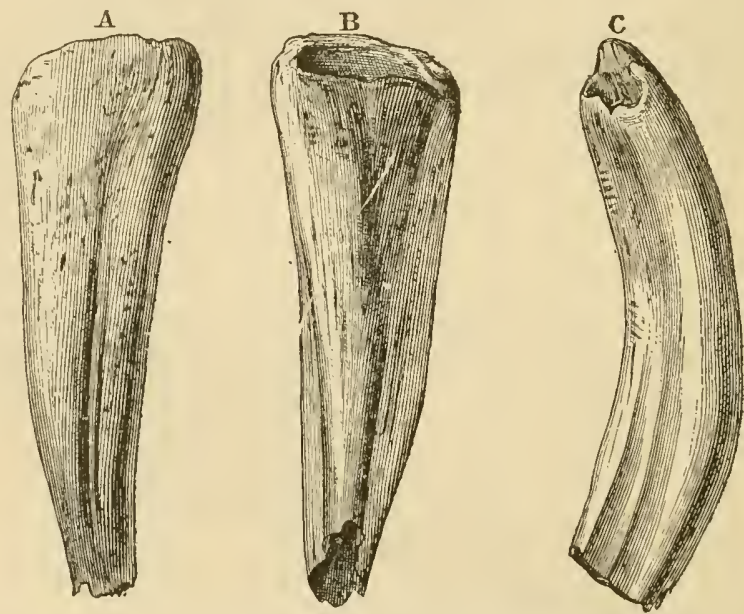

FIG. 276.-Unworn inferior pincer of the second dentition.
A. Posterior face.
$B$. Anterior face.
C. Profile.

Two faces : the one anterior, the other posterior.

Two borders: external and internal.

Finally, two extremities : the crown, or free portion, and the root, or incased portion.

1st. Faces.-The anterior face, wider at the crown than at the root, is almost flat transversely and convex in the direction of its length. It contains a longitudinal gutter, which is more marked on the crown than on the root.

The superior incisors (Fig. 277), always wider and more curved, sometimes have two grooves on the anterior face instead of one.

The posterior face, rounded transversely, is concave from the summit to the base; its width and its curvature are more pronounced in the superior incisors.

2d. Borders.-The internal border is thicker than the external; each of them, separating the two faces, augments in width from the base to the summit 
of the tooth, in consequence of the double flattening of the latter. They are similar in the incisors of both jaws.

3d. Extremities.-The free extremity is opposed to the corresponding tooth of the other jaw, and should be examined first in the virgin tooth.
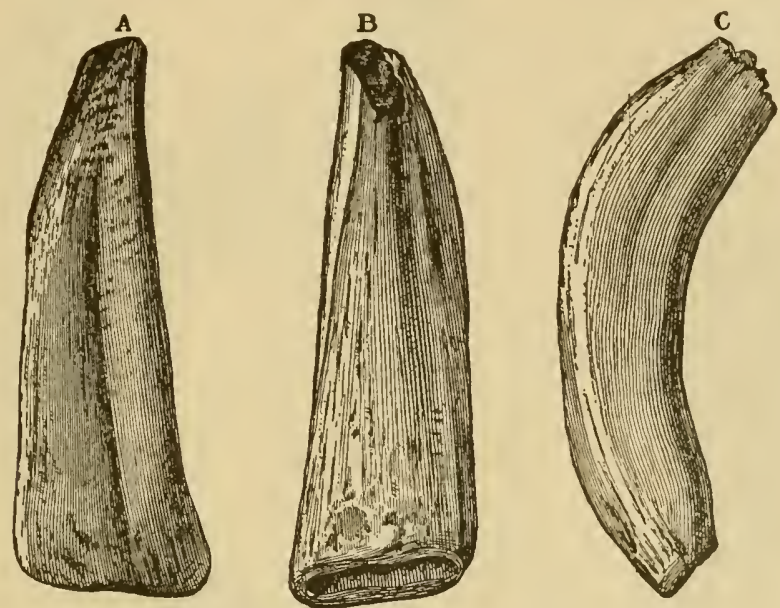

Fig. 277.-Superior virgin incisor of the second dentition (pincer).
A. Anterior face.
B. Posterior face.
C. Profile.

It is flattened from before to behind, and, consequently, elongated from side to side.

This extremity (Fig. 278) is occupied by a cavity called the external dental cavity, $c$, which separates two borders, an anterior and a posterior; two sides, an external and an internal.

These two borders are unequal. The anterior, $a$, is more prolonged and more salient than the posterior; it is thin, quite sharp, slightly convex transversely, and is the first to appear in the eruption of the tooth from its alveolus; its pressure causes absorption and perforation of the gums.

The posterior border, $b$, less salient than the anterior, sometimes has a notch in its middle part, which renders the external dental cavity much less regular.

As to the sides, they constitute the commissures of the two borders; the external is thinner than the internal and presents a small notch.

The external dental cavity or infundibulum, $c$, circumseribed by the central enamel, $d$, has an irregularly conic form. Wider at its entrance than at its bottom, and partially filled with cement, $e$, according to the subjects (sce Structure of the Teeth), it is curved upon itself in its length, which draws its summit towards the posterior face of the tooth.

According to Girard, whose remarks we have consulted, in horses six years of age the external dental cavity of the inferior pincers has a depth of 0.016 to $0.018 \mathrm{~m}$; ; that of the intermediates, $0.020 \mathrm{~m}$.; and that of the corners, 0.011 to $0.013 \mathrm{~m}$. In the superior jaw its depth in the pincers is 0.025 to $0.027 \mathrm{~m}$.; in the intermediates, 0.027 to $0.028 \mathrm{~m}$.; in the corvers, 0.018 to $0.020 \mathrm{~m}$. 
Whence it follows that the external dental eavity is deeper, all things being equal, in the superior ineisors, and that, in each jaw, its depth is greatest in the intermediates. It may also be added, as a differential characteristic relative to this cavity, that this part of the tooth extends closer to the posterior face of the incisors of the inferior jaw.

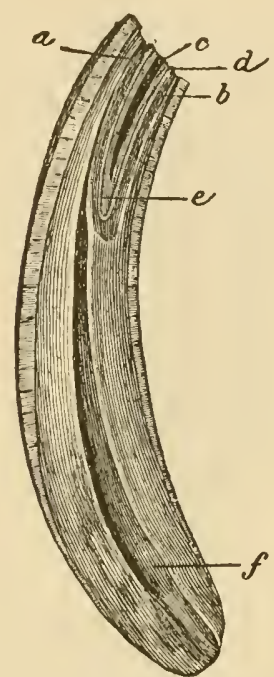

FIG. 278.-Longitudinal section of a permanent incisor that has been used.

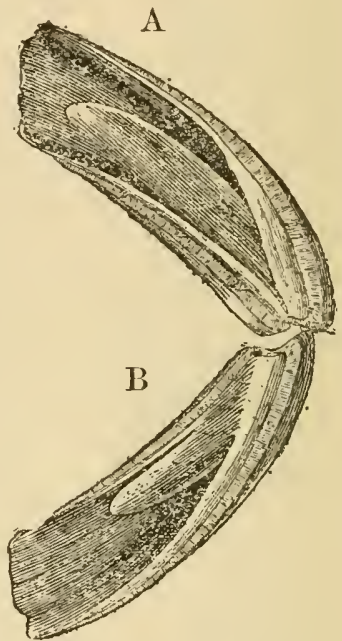

FIG. 279.-Eccentric and longitndinal section of the superior and inferior intermediates of the adult, showing the different characters of the external dental cavity.

The incased extremity or root presents a large opening which leads into a cavity in the interior of the tooth, in which the dental pulp is lodged. This is the internal dental or pulp cavity.

The preceding details apply in a general manner to all the incisor teeth. They nevertheless present some slight modifications if each individual tooth be examined in particular. Hence we have presented in Fig. 280 antero-posterior longitudinal sections of three superior and inferior incisors of the same side, obtained from the jaws of a five-year-old horse, in order that the reader may view for himself the modifications of which we speak.

Successive Forms of the Dental Table.-From the continual friction and rubbing against cach other, the incisors progressively level their crowns, which gives to the extremity of the latter the aspect of a plane surface, known under the name of dental table. The form of this table, which changes more and more as we approach the root of the tooth, necessarily varies with the age of the animal. This can be proved by following, in the horse, its successive modifications during several years. 
It is, huwever, more convenient and much less complicated to
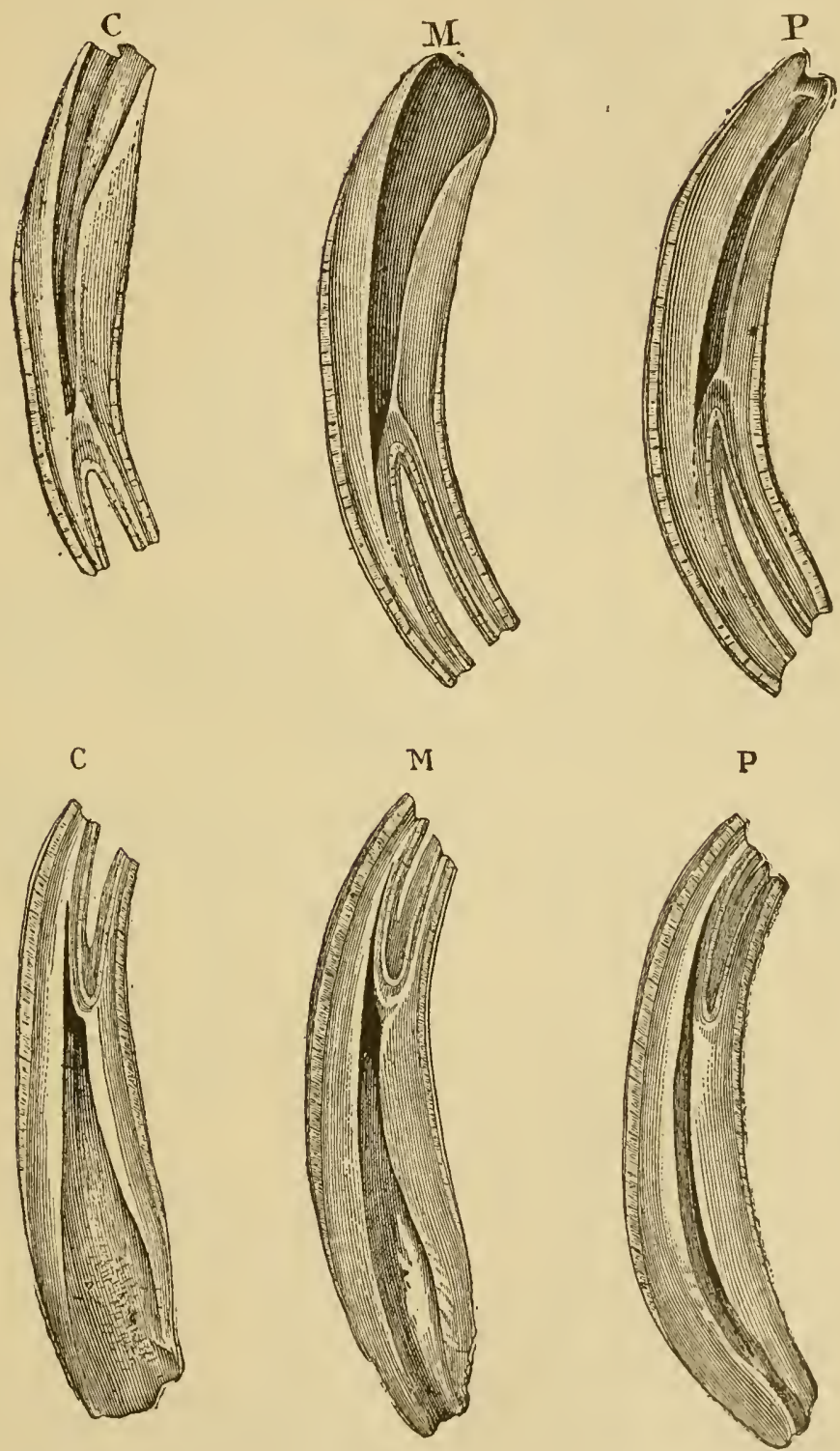

FIG. 280.-Longitudinal and median sections of the pincer, intermediate, and corner in each of the jaws.
P. Pincers.
M. Intermediates.
C. Corners.

arrive at the same results by making with a saw, upon a five-year-old 
pincer, for example, a series of transverse sections three or four millimetres in thicknesss. We can, in this manner, obtain artificially the sucessive forms of all the tables which are furnished by the natural usage. The forms which are best defined may be arranged sucessively in the following manner (Fig. 281):

1st. The dental table is at first fluttened from before to behind,- - that is to say, its transverse diameter is more extensive than the antero-posterior (sections 1 and 2).

2d. The dental table becomes oval; here there is less difference between the extent of the two diameters, although the transverse is still greater than the antero-posterior (sections 3 to 5 ).

3d. It takes a rounded form, and its two diameters are almost equal (sections 6 and 7 ).

4th. It becomes trianguler, and is limited by three horders, an anterior and two lateral. The summit of the triangle looks backward (sections 8 to 11 ).

5th. Finally, the wearing surface is fattence from side to side (sections 12 to 16). This last form characterizes old age, and persists, whatever may be the duration of the life of the animal. Girard designated it by the metaphoric expression, bianguler.

These configurations of the dental table are much more regular in the pincers than in the intermediates, and in the latter more so than in the corners. They are almost identical in the incisors of the superior jaw, but, in general, the latter are not examined in this relation.

\section{C.-Structure of the Incisors.}

The study of the structure of the incisors furnishes important indications for the determination of the age. In conjunction with what we have already said, it enables us to understand fully the peculiarities which the tooth presents, according to the age, at its free extremity.

We will choose, as the type for description, an inferior incisor; the reader can easily apply the details into which we shall now enter to the superior incisors.

The sac or follicle in which all the incisors are developed presents for consideration two papillary prolongations or papillæe, one superior, $a$, the other inferior, $b$ (Fig. 282), which penetrate each other mutually. The former, or enamel germ, conical in form, is lodged in the external dental eavity; the second, or dentine germ, bifid, cup-shaped at its summit, and flattened antero-posteriorly, fills the pulp cavity in the interior. The one is endowed with the formation of a substance called enamel; the other, secreting the dentine or ivory, alone persists, under the name of pulp, until a very advaneed period of life, and it is from this structure that the tooth receives its nourishment. In the very old tooth it may become almost entirely absorbed. 
THE INCISORS.

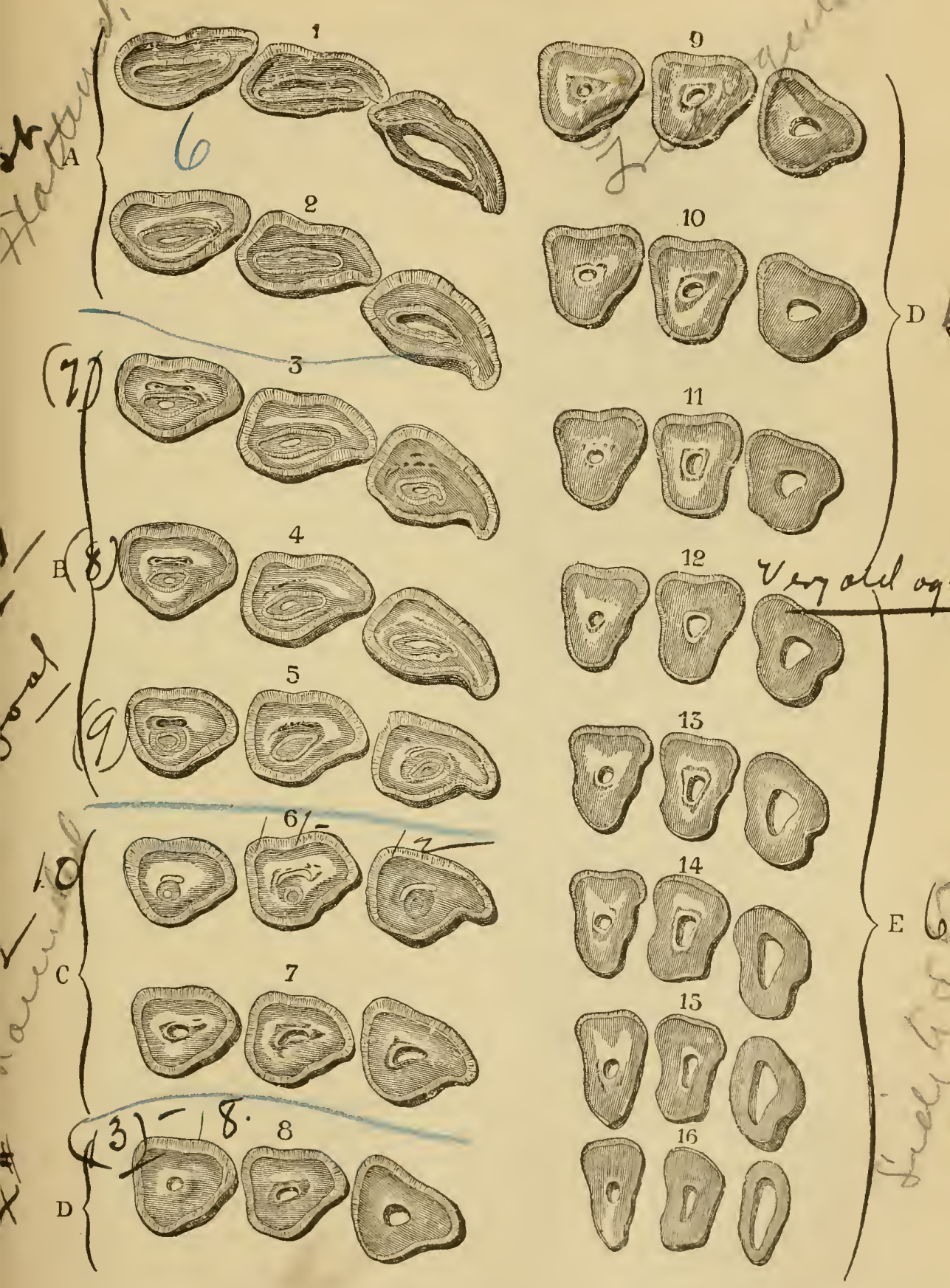

FIG. 2S1.-Series of longitudinal sections of the right inferior incisors of a fire-year-old horse. $A$. Forms flattened from before to behind. B. Oval forms. C. Rounded forms. D. Triangular

$$
\text { Cub wear of } 13 \text { - }
$$


It is between these two papillary systems that the constituent parts, $d$, of the tooth are deposited. They are represented at first by a thin lamella, hollowed

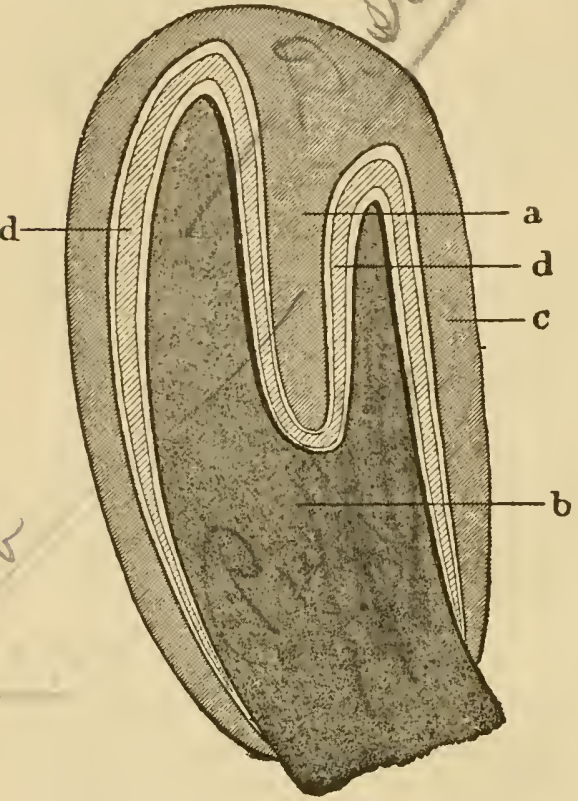

Fig. 282.-Schematic section of the dental follicle of an inferior incisor of a horse.

$a$, superior papilla, enamel germ; $b$, ilferior papilla, dentine germ or dental pulp; $c$, parietes of folliele; $d$, dentine.

internally and deeply depressed at the level of its free extremity. Later, the parietes of the dental follicle, $c$, are transformed into the alveolar periosteum. This much being said, let us view the incisor at a more advanced period of its development.

A longitudinal section of a tooth still enclosed in its alveolus shows us the relations which exist between the two eavities (Fig. 279). It is there seen that the point of the enamel sheath which surrounds the external dental cavity approaches the posterior face, but is not confounded with it. Whence it follows that the internal cavity is prolonged around the periphery of this sheath and leaves the latter absolutely free. The case is different in the aged tooth : the pulp cavity at a later period becomes filled up behind this projection and remains only in front, as is seen in Fig. 283.

Three substances enter into the construction of an incisor tooth: one fundamental and two enveloping. They differ in situation, thickness, position, hardness, and microscopical structure. Let us rapidly examine them.

Of the two enveloping substances, the most superficial has received the name cement; the other is the enamel.

1st. The Cement, $C$, (Fig. 283), forms a superficial coating directly applied upon the enamel. It envelops the entire periphery of the tooth and is reflected into the external dental cavity, at the bottom of which it forms a more or less thick nucleus, according to the subjects and the teeth which are examined. There are eases in which this layer is only 2 or 3 millimetres in thickness; in others it reaches 10,15 , and even 20 millimetres. Generally, it is less thick in the superior incisors. This fact has been determined, but it is not very long since that Messrs. Chauveau and Arloing, ${ }^{1}$ in France, and Mr. Mayhew, in England, ${ }^{2}$ have recognized its practical importance concerning the determination of the age, to whose works the reader is referred. It is pereeived that the depth of the unfilled portion of

1 Chauveau et Arloing, Traité d'anatomie comparée des animaux domestiques, 3e éd., Paris, 1879, p. 404.

2 Maylhew, The Horse's Mouth, showing the Age by the Teeth, p. 32.

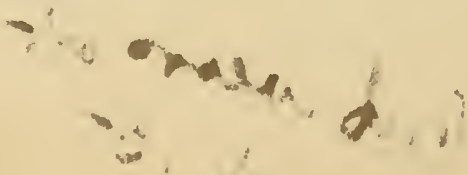


the external dental cavity depends, in a great measure, upon the thickness of the cementous deposit. It is much more rare to find it due to an exaggerated length of the enamel diverticulum, as most authors have written.

The cement, which gives bulk and strength to the teeth, does not offer, by a great deal, the same resistance to wear which the other substances possess. It is spread over the faces of the tooth in the form of a very thin layer, and gradually disappears by reason of the friction of the aliment, the lips, and the tongue. It persists, on the contrary, at the bottom of the external dental cavity, while the free portion of the latter exists upon the dental table, in the form of a blackish spot or " mark," more and more confined and surrounded by a round band of enamel.

The cement is very similar to bone, as its microscopic examination demonstrates. It is formed by the alveolar periosteum, principally at the limit between the root and the crown of the tooth, and is not the result, as Simonds has advanced, of the transformation of the dentine into bone. In very old teetl (Fig. 284) it exists in great abundance around the roots, and the following appears to us to be the mechanism of this new cementous formation. As the maxillary bones, little by little, push the greater part of the tooth from its alveolus as age advances, the root which then constitutes the wearing surface is no longer attached with sufficient soliclity to resist the energetic actions of the jaws, particularly of the inferior, which rubs against the superior; it therefore becomes, little by little, dis-

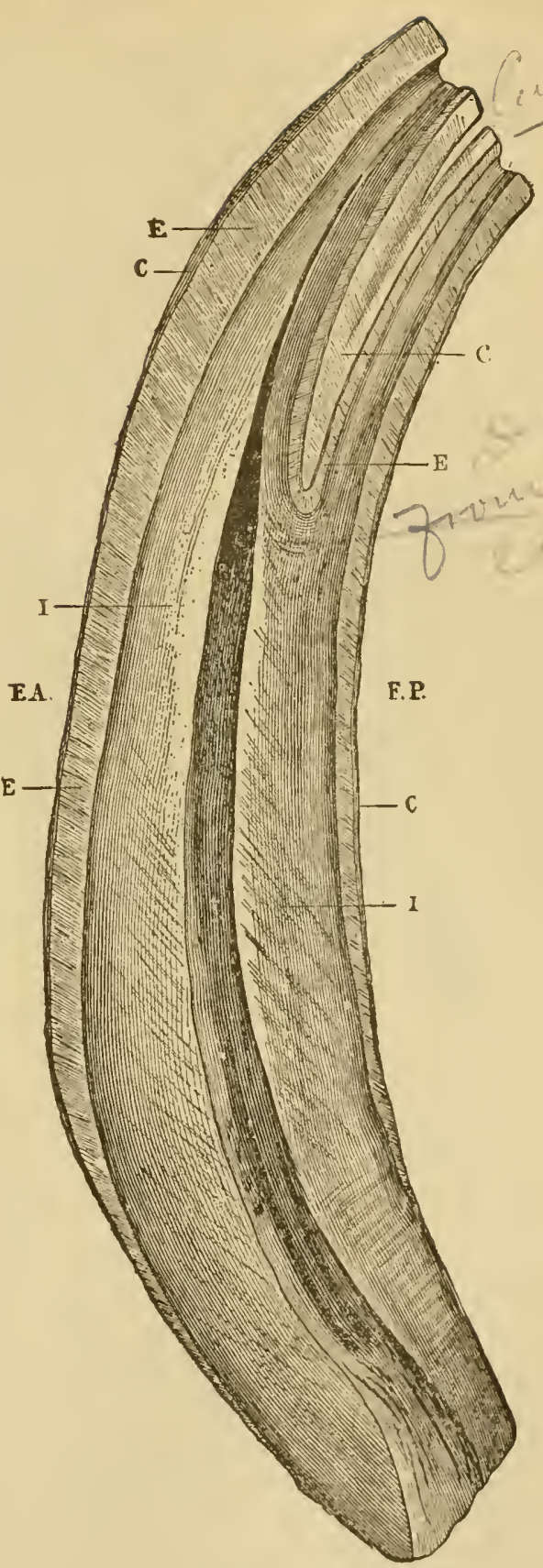

FIG. 283.-Longitudinal and median section of a permanent inferior pinecr (enlarged).

$F A$, anterior face; $F P$. posterior face: $C$, cement; $39 \quad E$, enamel; I, ivory. 
turbed in its cavity of reception, and so much the more as the surface of friction is less extensive, for the animal is obliged to increase the frequency of the movements to compensate for the imperfections of its instruments of mastication.
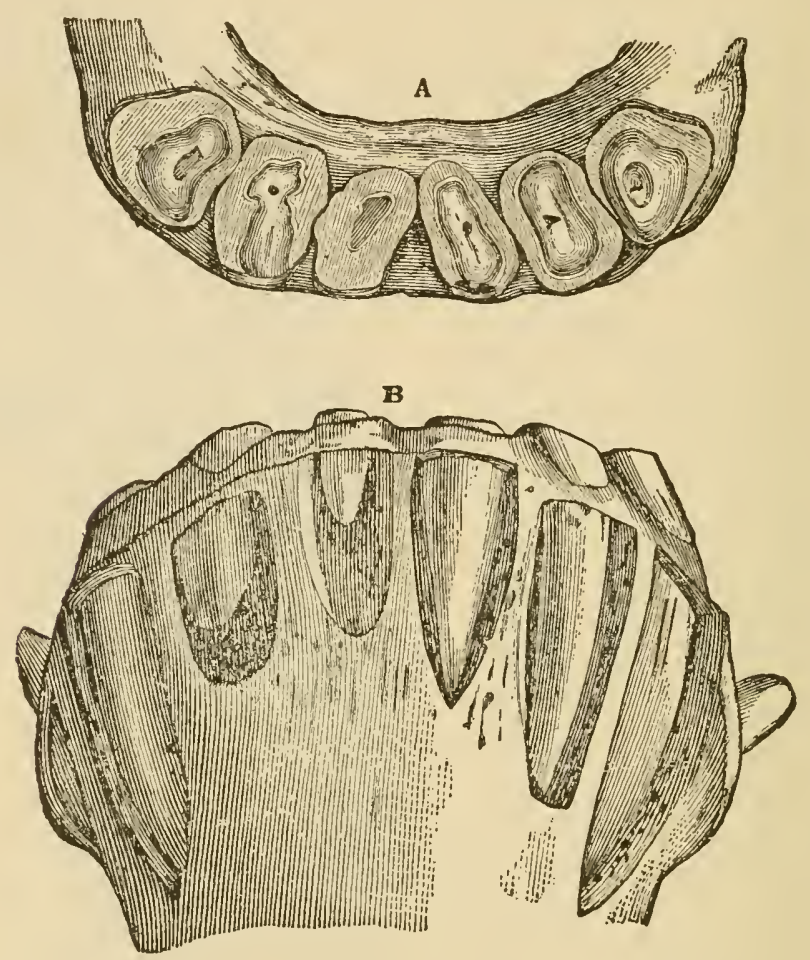

FIG, 284.-Radical cementation of the incisors of the horse.

A. Dental tables, $\quad \mid \quad B$. View of the same teeth in their alveoli.

These continual displacements to which the dental stumps are submitted stimulate the action of the alvcolar periosteum, whose irritation is manifested by the production of very dense osseous layers which are deposited in proportion to the intensity of the dental displacements, and solidly seal the tooth in its alveolus at the same time that they increase the area of its surface of friction.

It is perceived that this cementation is the more active as the dental stump is shorter, narrower, and the aliment coarser; in a word, as it offers less resistance to the diverse causes tending to break its adherence with the living parts. Thus, in the horse, it is the teeth of the inferior jaw, those which occupy the centre of the incisor and molar arcades, which present the greatest thickness of radical cement. The violent and brutal tractions exercised upon the bit often lead to similar formations around the corner teeth. The same results are observed, finally, after surgical operations in which a tooth is accidentally disturbed or partially dislocated in its alveolar cavity.

It is easy to comprehend the utility, to the organism, of such a new formation. The nature of the aliment on which our large herbivora subsist would 
render it impossible for the teeth to fulfil their functions, and would determine their early shedding, were it not for this fortunate restoration, in advanced age, to preserve their properties for a still long time. ${ }^{1}$

If, as Simonds ${ }^{2}$ thinks, this radical cement be the consequence of the transformation of the ivory into bone, the teeth upon which it is deposited should not augment in volume in consequence of its appearance; in the centre of the dental table is always found, in such cases, an area of dentine the dimensions of which are exactly the same as those of the normal root. The peripheral cement is therefore superadded to the tooth, and is not formed at the expense of the latter.

2 d. The enamel, $E$, is the true protective layer of the teetl. Situated underneath the cement, it represents a sort of polished coating covering the whole of the surface of the dentine and forming the parietes of the external dental cavity; it does not extend into the pulp cavity. As Lecoq has indicated, "its thickness is greater upon the anterior than upon the posterior face of the tooth, and it also extends lower down upon the former." It becomes quite thin towards the extremity of the root.

These facts, to which no importance has been attributed, nevertheless deserve to arrest our attention. It is well known that there exist, upon the dental table, a certain number of intermediary phases between the commencing triangular form and the lateral flattening, or that which Girard has called biangular. Nothing is more difficult, then, than to determine whether a certain triangular form is more recent than another which may differ but little in shape. This is, nevertheless, a problem which an attentive examination can solve, since we know that the enamel will disappear earlier upon the surface of friction behind than in front. It will suffice, then, to ascertain its relative thickness upon the periphery of the table; or, again, to prove its absence or its presence upon the posterior border of the tooth. The degree of wear of the latter can thus, with practice, be easily determined.

An error rather irequently committed in France, and

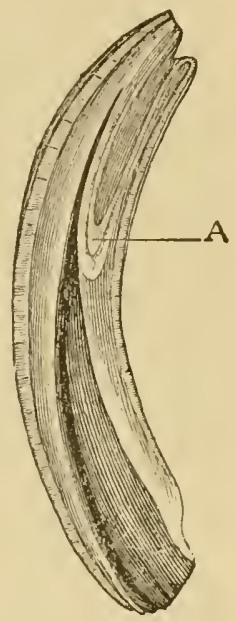

FIG. 285.-Longitudinal antero-posterior section of an inferior pincer, showing the enamel sheath, $A$, prolonged into the external dental eavity. which Messrs. Chauvean and Arloing have corrected, consists in believing that the layer of enamel which forms the wall of the external dental cavity (contral enamel) is prolonged in the form of a cone or enamel horn well beyond the bottom of the external cavity properly so called. We have demonstrated ${ }^{3}$ that the sections upon which such a disposition is observed are not marle exactly according to the axis of the tooth, but pass to one side of the latter. There results thus a more or less oblique section of the parietes of this eone, which may deceive a superficial observer. Fig. 285, $A$, represents precisely such a section, and shows that similar ones can be obtained at

1 Goubaux et Barrier, loe. cit.

2 James Beart Simonds, The Age of the Ox, Sheep, and Pig, London, 1854, p. 34.

8 Goubaux et Barrier, loc. cit. 
will whenever the observation is made in the defective manner that we have indicated.

If, however, the section be made so as to divide the point of this cul-de-sac into two moieties absolutely equal, its disposition will be different; at its summit the layer of enamel does not present any thickening, and in certain cases it is even somewhat thinner than anywliere else.

These facts are demonstrated, besides, in the transverse sections (Fig. 281). After the external cavity has disappeared, the central cement, which fills its bottom, still persists in the form of a white spot bordered by a thin band of enamel. This spot then diminishes in size, alproaches the posterior border of the dental table, and is finally effaced at the same time as the zone of enamel which surrounds it.

In relation to its hardness, the enamel is certainly the most remarkable layer of the teeth. When the latter are still enclosed by the gums in their alveoli, it can be easily cut by a sharp instrument, and its histological elements, disposed almost perpendicularly to the surface which it covers, disassociate themselves readily. But as soon as this substance has been submitted to the contact of the air it becomes hard, even to the extent of striking fire with steel. It is also much more resistant to wear than the dentine, and shows itself constantly in relief upon the surface of friction.

The enamel is a tissue of epithelial origin formed by the supcrior papilla of the primitive dental follicle. It is composed, microscopically, of an infinite number of small hexagonal prisms (enamel jrisms), solidly united and directed obliquely in relation to the subjacent surfaces; it is, by its deep surface, applied upon the peripheral lacunar spaces of the dentine.

It does not cover the extremity of the root of very old teeth; but, as soon as it has disappeared on their table, it is replaced by the cement in the manner which we have already described. (See the longitudinal sections of Fig. 286.)

Of a milky-white color more or less clear according to the lustre of the tooth, but always very brilliant and slightly striated longitudinally, the enamel preserves the same thickness when once it is formed, and does not repair its losses.

34. The fundamental substance, the eburnated substance, the dentine or the ivory, $I$ (Fig. 283), constitutes the greater portion of the tooth. Produced by the inferior papilla of the dental follicle, and strongly depressed at its superior extremity for the reception of the central enamel, it is everywhere covered by the enamel. It forms the parietes of the pulp-cavity and surrounds the point of the central enamel, at first projecting into its interior.

Primitively not abundant, it does not delay to fill the cavity which it contains in its interior by the addition of new layers which are deposited on the surface of the old ones. This leads to a progressive atrophy of the pulp, which extends gradually from the crown to the root.

The more recent layers have a deeper coloration; the tint of the obliterated parts also allows, in transverse and longitudinal sections, the recognition of the outlines of the internal cavity at the beginning. This eavity is obliterated at first behind the central enamel, the distance which separates the latter from the posterior face being less considerable than that which separates it from the anterior. Then the obliteration takes place in front. It is these layers of this new 
THE INCISORS.

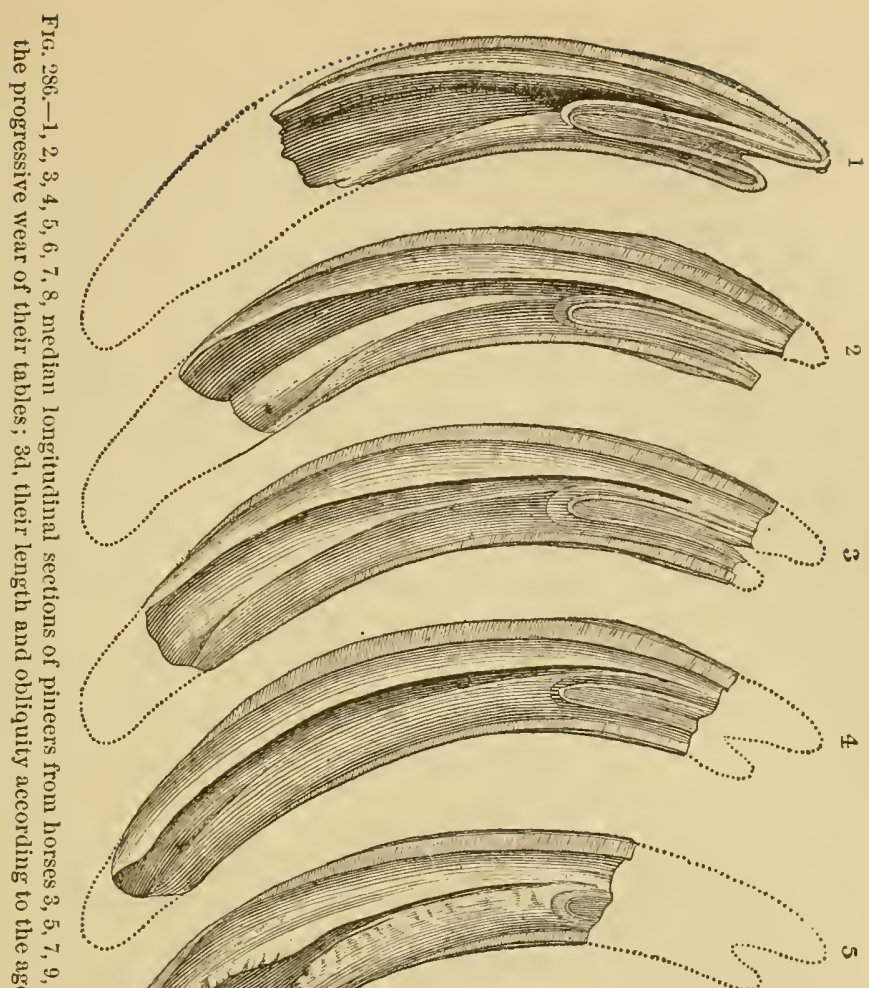

$\therefore$

है

돈
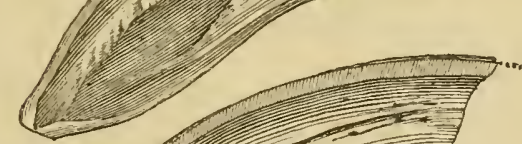

si

है

옹요

로ำ

品

.

胥

:

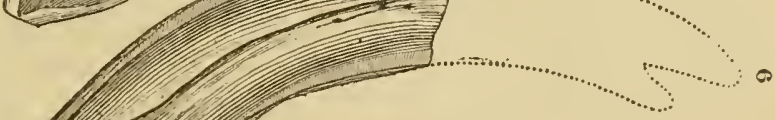

.

1

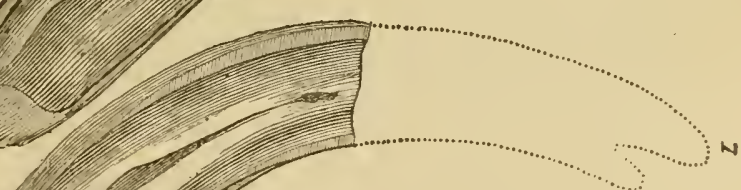

er

$\Xi$

ह

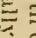

.

Е

7

气ุ․ำ

है

อ

อ

冚

is 
formation which, appearing upon the table at a given period in the form of a transverse yellowish band in front of and behind the central enamel, constitute what is called the dental star.

To speak accurately, there are two of these dental stars, but the posterior, always less distinct, most frequently passes unperceived. Nevertheless, in certain teeth it is seen quite plainly.

Fig. 286 represents the median longitudinal sections of pincers from lorses of different ages, which show the gradual diminution of the internal dental cavity. It will be seen, too, in the very old teeth, that the extremity of the root is covered by an abundant formation of radical cement directly applied upon the surface of the ivory, from the fact of the disappearance of the enamel. On that account these teeth, when the wear has reached this level, never display the whiteness which they did primitively.

The dentine is a substance less hard than the enamel, but much more resistant to wear than the bone or the cement. A microscopic examination of desiccated or macerated teeth shows that it is penetrated by a multitude of extremely fine canaliculi, which extend in a radiating manner from the internal cavity of the pulp to terminate, after anastomosing with one another, under the deep surface of the enamel in the lacunar spaces, called the interglobular spaees of Czermak.

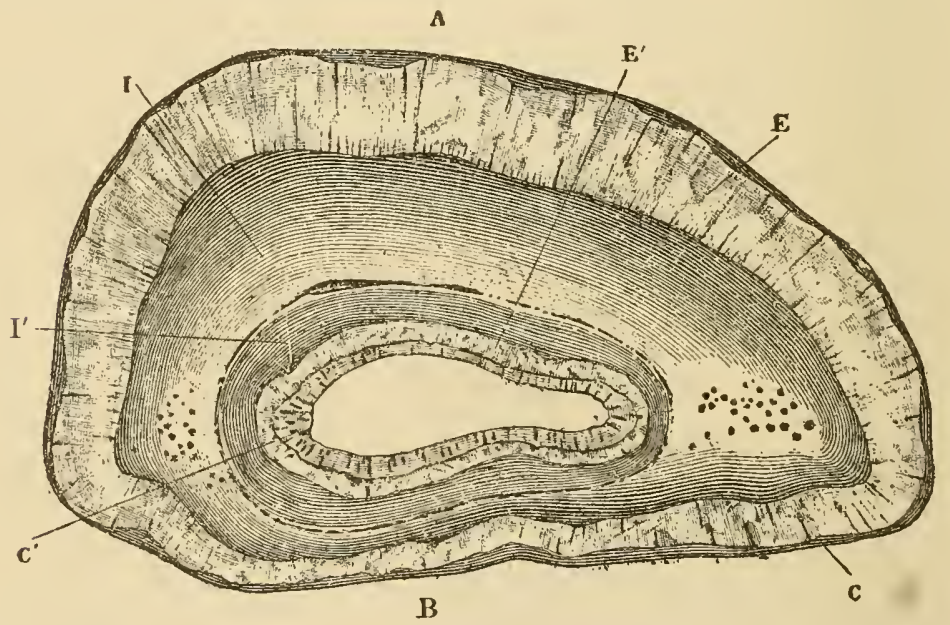

FIG. 287.-Transverse section of an inferior right pincer, showing the different layers constituting the tooth, with their relative thickness. (Magnified five diameters.)

$A$, anterior face.

$B$, posterior face.

C, peripheral cement.

$C^{\prime}$, central cement.

$E$, peripheral enamel.
$E^{\prime}$, central enamel.

$I$, jory (external layers); $I^{\prime}$, ivory darker in color surrounding the central enamel (internal layers).

Such are the principal details which it is essential to understand before proceeding farther. They may also be examined in transverse sections analogous to those of Fig. 287.

Let us now see what molifications the free extremity of the permanent incisors undergo under the influence of wear and tear. 


\section{D.-Details of the Dental Table according to the Age.}

These details are dependent, in an intimate manner, upon the form and the structure of the incisors. We will study them from the period of the eruption of the tecth until very advanced age.

1st. Primitively the free extremity is ocenpied by the external dental cavity, circumseribed by the central enamel, almost conical in form, oblique from before to behind, terminating in a cul-de-sac, and containing the central cement, which, however, does not completely fill it.

The border which limits it anteriorly is higher than the posterior.

2d. At the end of a certain time the two borders of the central enamel are placed on a level with each other from the effects of wear. The external cavity, less deep, no longer occupies, as it did before, the whole of the free extremity; it appears more removed from the anterior border on account of the direction of its great axis, which is oblique backward.

The layers of enamel, in consequence of this modification, present a new disposition, for the enamel now forms two distinct parts (Fig. $287)$ : the one, $E$, which always circumscribes the external surface of the tooth, receives the name peripheral cnamel; the other, $E^{\prime}$, which surrounds what remains of the external cavity, is called central enamel. The latter is the less thick of the two; it, as well as the peripheral enamel, stands in relief above the dentine and in relation with the cement which fills the external dental cavity.

3d. When this eavity has entirely disappeared, there only remains a small "island" of cement, limited by the central enamel. But the configuration and location of this island do not remain invariable. It diminishes little by little in area, tends to become round, and approaches more and more the posterior border of the table, in consequence of the disposition, the direction, and the length of this cone of enamel.

A levelled incisor tooth is characterized by the disappearance of its external cavity.

All are agreed in this respect. However, after what has been said concerning the structure, when the war has reached this point, there still exists a more or less considerable part of the external enamel cup, whose bottom, filled with cement, does not present, as is believer, a solid point prolonged far beyond into the thickness of the dentine. (See Fig. 285.) The presence of the central cnamel, after the tooth is levelled, furnishes an important indication for the determination of the age.

Abont the same time a spot of a deeper yellow appears in the middle of the dentine, between the anterior border of the table and the 
central enamel; it has been ealled the dental star by Girard, who was the first to observe it. We know that a seeond one exists close to the posterior border of the dental table, but it is so little marked that it does not concern us.

The dental star is at first narrow and elongated transversely ; afterwards its situation, dimensions, and form change in a notable degree, in proportion to the age of the animal. It progressively gains the central part of the dental table, diminishes in length transversely and increases in thickness antero-posteriorly, and, finally, becomes triangular and round. It never stands in relief above the surface of friction, and can therefore never be confounded with the central enamel. It is constituted by the dentine of more recent formation, which is deposited by sucessive layers in the internal eavity of the tooth.

4th. Save a few modifications, the preceling details are maintained during many years; then the central enamel disappears, and with it the nueleus of eement which it enclosed.

From this period until extreme old age nothing but the dental star and the dentine are found upon the surface of friction. The peripheral enamel diminishes in thickness; it is effaced very late, at first behind, and afterwards in front; finally, there appears, upon many tecth, the radical cementation of which we have already spoken when on the subject of the structure.

\section{E.-Direction of the Incisors.}

The incisors must be viewed in two principal directions: the one, relative to the plane of meeting of the areades, is judged by inspecting the jaws in profile; the other, relative to the median plane, is appreciated by viewing the latter from in front. Both furnish important data for the determination of the age.

\section{1st. Direction in Relation to the Plane of Meeting of} the Jaws.-If the teeth of a young horse be exposed by removing the bone with a chisel (Fig. 288), it will be found that they are greatly convex upon the anterior face. It follows therefrom that, viewed in profile, they project in the manner of a vertical are, at first almost regularly semicircular. At this moment each of the moieties of this are is therefore opposed to the other, like two semi-cireumferences that are placed in eontact by their diameter in such a manner that a tangent to the point of contact of the jaws will be perpendieular to their plane of apposition. But as the table of friction, in consequence of the progress of wear, approaches more and more the region of the root, the aforesaid semicircle becomes altered and resembles an ogive 
more and more acute in proportion as the plane of meeting of the jaws, which is being displaced above and below parallel to itself, is gradually separated from the primitive diameter. Consequently, the

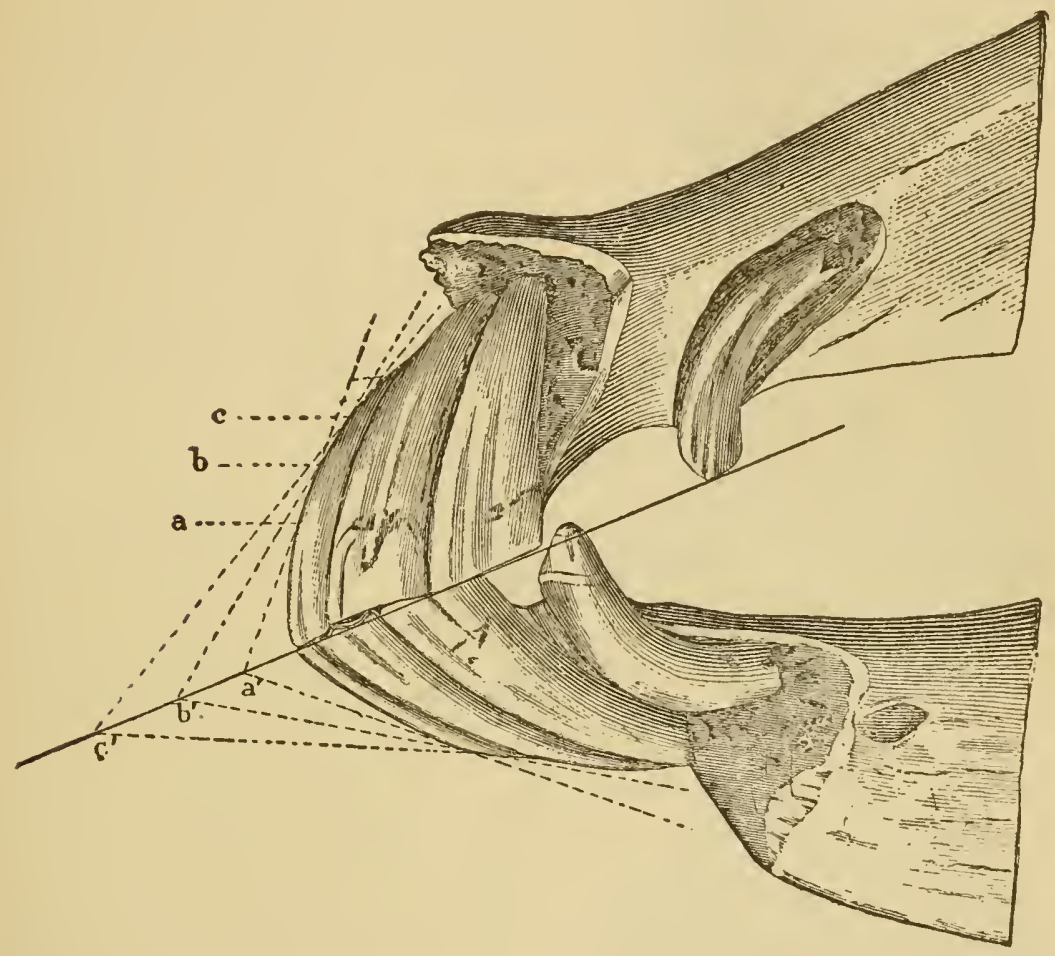

FIG. 288.-Incisive arcades exposed to show the progressive inclination of the teeth in relation to the plane of meeting of the jaws.

tangents $a a^{\prime}, b b^{\prime}, c c^{\prime}$, drawn through the new points, $a, b$, c, of contact of the arcades, will no longer be perpendicular to this plane, but will tend, on the contrary, to be more and more parallel to it.

This permits the conclusion that the incidence of the incisors angments in obliquity with age, and that the horizontality of the arcades indicates fairly the age, save, of coursc, in certain cxceptional eases which are sometimes met.

Consequent on this change of direction there are eertain modifications which appear at the inferior extremity of the head. The latter, voluminous and rounded in young animals, becomes thin and pointed in the old, whose teeth, often very long, project so much that the lips can scarcely meet and occlude the buccal opening. 

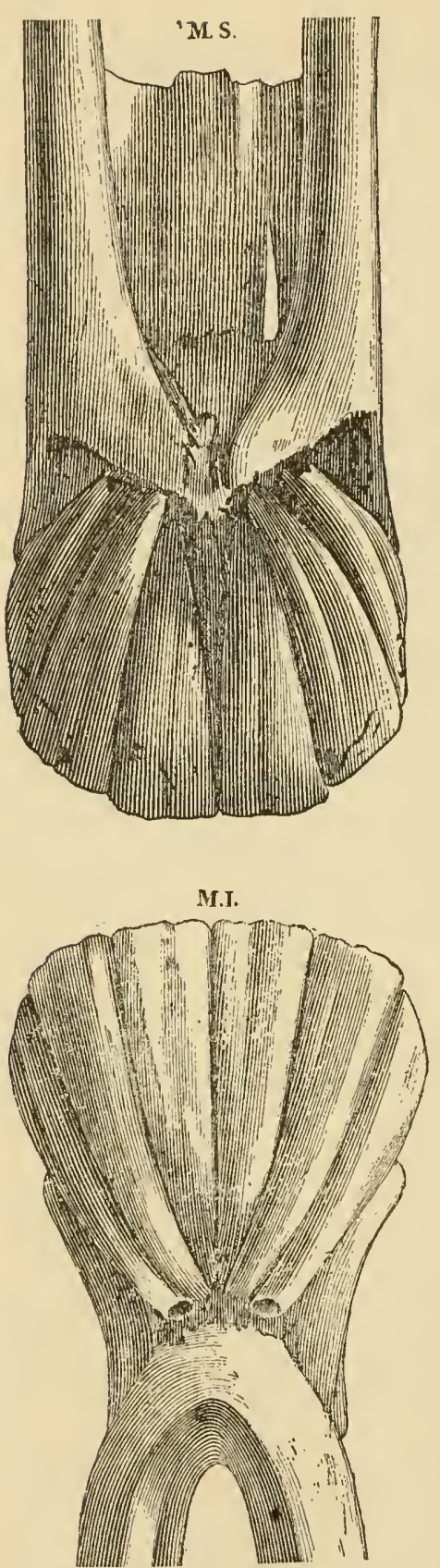

FIG. 299.-Incisors exposed by their anterior face to slow their relative inclination towards the median line. 2d. Direction in Relation to the Median Plane.-In the young animal (Fig. 289), in consequence of the greater extent of the areades formed by the surfaces of friction elongated transversely, and also on account of the lateral flattening of the roots, the incisor's all appear to be convergent at the level of their roots. They, however, do not remain so. With the progress of age the crown of the tooth is little by little worn off, at the same time that the maxillary bones push them out farther and farther from their alveolar cavities. Under the combined influence of these two causes the roots, which at first were almost contiguous, are gradually separated from each other, and draw towards the entrance of the alveolus, while the tables diminish in width transversely.

The evolution of these facts has for its result a modification of the primitive direction of the incisors: their axis is slowly separated from the median line, so much so that at a given moment it becomes altogether parallel to it (Fig. 284).

Finally, the phenomenon of the gradual expulsion of the teeth from their alveoli continuing to manifest itself in concert with the transverse narrowing of the arcade, there comes a time when the teeth are found converging by their free extremity and diverging by their opposite extremity,- that is to say, inversely disposed in relation to the axis of the jaws. In this case, the intervals separating the pincers from the in- 
termediates, and the latter from the corners, are well marked, and enable us to ascertain with the greatest ease the changes which have taken place. To observe this, it suffices to separate the lips of the animal and to examine the mouth from in front.

The following facts resnlt from the preeding phenomenon, concerning the general direction of the teeth :

1st. That the incidence of the areades increases in obliquity with the age.

2d. That their curvature and their transverse diameter diminish.

3d. Finally, that the roots, at first converging, become parallel, then diverging, while the free extremitics approath each other and leave between themselves, at their base, a triangular space occupied by the gum, so much the more exaggerated as the animal increases in age.

\section{The Tusks or Canine Teeth.}

Four in number in the adult horse, and situated between the incisor's and the molars, the tusks are absent or but little developed in the mare, as a rule. Formerly, those which were provided with canines, called bréhaignes, were wrongly considered as being sterile.

Does cach one of the two dentitions present canines?

It is rather difficult to answer this question with precise accuracy. Girard mentions that Rigot and Forthomme have observed deciluous canines. The latter showed him jaws which, independently of these deciduous teeth, presented behind the latter their two replacing teeth stripped of their alveolus. Rigot said that this fact was not rare, and that he had seen it not infiequently in colts three or four years old. As to Girard, he had never witnessed it.

If the teeth of colts be examined, there is constantly found in the two sexes, in the place of the canines, very small tecth which are exceedingly thin and needle-like. Are these the deciduous canines? This is probable; but it is certain that if these tecth simulate them in position, they do not at all possess their particular form. The facts of Rigot and Forthomme should therefore be regarded as very exceptional. In the absence of a detailed deseription, it is not ont of place to ask if these were not abnormal instances of double canines. We are rather inclined to adopt this latter opinion, having witnessed a case of this kind in an old ass, of which we will represent the inferior jaw (Fig. 290).

A short time after their eruption the canines have the general form of a cone, and are curved upon themselves in the direction of their length. There is no well-defined limit between the crown and the 
root. Almost similar in the two jaws, the inferior are, nevertheless, a little longer and more porous and roughened at the level of their free

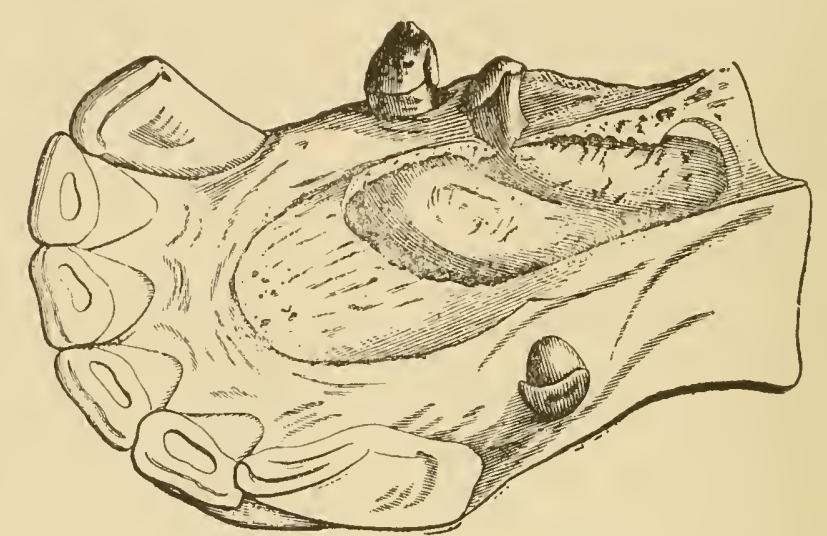

Fig. 290.-Double inferior right canine tooth in the ass.

part. They present for study two faces, two borders, and two extremities.

Faces.-The external or labial face (Fig. 291, A) is convex in both its diameters, - that is to say, from above to below and from before to behind. Its free portion shows very fine strix, which eventually disappear under the effects of friction.

The internal or lingual face (Fig. 291, B) is less convex than the preceding. It presents, on the crown, two well-marked grooves, the one anterior, the other posterior, which follow the corresponding borders of the tooth. Between the two is found a triangular eminence whose base is confounded with the remainder of the same face.

Borders.-The anterior border is convex, the posterior concave; both angment in thickness from the free extremity towards the incased extremity.

Extremities.-The free extremity or crown of the virgin canine tooth (Fig. 292) terminates in a blunt point, flattened transversely, while the embedded extremity, much more voluminous, is occupied by a round opening, which leads into a cavity in the interior of the tooth, terminating in a cul-de-sac. This cavity, of a conical form, contains the pulp. At first spacions, it is gradually obliterated, until it is constituted only by a short and narrow canal. The tusk elongates from its root, which becomes pointed, while the opposite end becomes rounded and blunt from the effects of wear.

But as the canines are not placed in definite relation to each other 
at any period of life, the inferior being always more anterior than the superior, ${ }^{1}$ this wear is caused by the lips, the tongue, and the aliment.

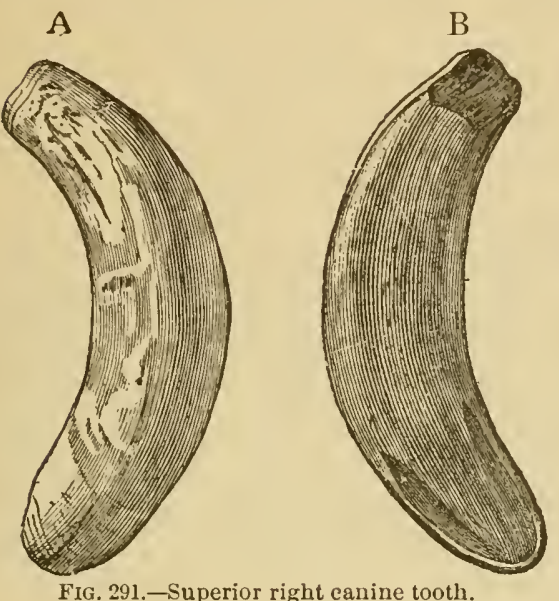

A. External face. | $B$. Internal face.
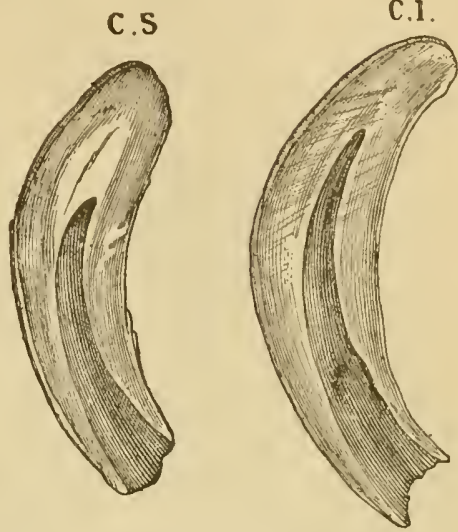

FIG. 292.-Longitudinal and median section of the canines.

CS. Superior canine. | CI. Inferior caniue.

The dental table ultimately shows, in its central portion, a dental star having the form of a round spot. The configuration of the internal face likewise becomes effaced.

In proportion as these modifications are produced, the free part diminishes ordinarily in length; sometimes, however, it remains very salient above the gums, even in very old horses.

\section{CHA P T ER I I.}

\section{THE MOIAARS.}

\section{Supplementary Premolars.}

THEsE teeth (Fig. 270), first recognized by Daubenton, ${ }^{2}$ do not exist always. They are present more frequently in the superior than in the inferior jaw, and rarely do they exist in both simultaneonsly. Girard says that they appear at about the age of ten months, and that their shedding is usually simultaneous

I It is very rare to observe these teeth rubbing against each other, but we have, nevertheless, witnessed an example.

2 Daubenton, Histoire naturelle générale et partjculière, avec la description du Cabiuet du roi, édition in-4o de l'Imprimerie royale, t. iv. p. 314. 
with the eruption of the first permanent molars. Their alveoli are, in fact, placed immediately in front of these teeth; we have, nevertheless, seen examples in the inferior jaw in which the supplementary teeth and the first permanent molars were separated by a space of three centimetres. Finally, they persist sometimes in very aged horses.

Their presence renders the dental formula somewhat variable.

Elongated and slightly curved upon itself in the direction of its length, the supplementary premolar resembles, by the form of its free part, the incisor of a carnirorous animal. It is for this reason that certain anthors have given it the name wolf tooth. Its incased extremity is unicuspid. One of these teeth, measured in a horse six years old, had a length of $0.025 \mathrm{~m}$.

As to the posterior supplementury molars, which Girard has simply mentioned, we have never seen them; it is probable that he has mistaken certain anomalies for such teeth. We will further refer to these anomalies.

\section{The Molars Proper.}

They form the lateral parts of the dental arcades, and are distinguished, like the incisors, according to their epoch of eruption, into molars of the first and of the second dentition.

We will commence our study with the former.

\section{A.-Molars of the First Dentition.}

There are twelve deciduous milk molars, or molars of the first dentition : six in each jaw and three on each side. It was believed for a long time, upon the authority of Ruini, ${ }^{1}$ that they were only eight in number; Tenon has demonstrated that this is an error. ${ }^{2}$

These teeth, strong and short, have the general form of a quadrangular prism, save the first, which has only three faces.

They present four faces and two extremities.

Faces.-The anterior and posterior faces, almost plane, show nothing remarkable; but in the first tooth, above as well as below, the anterior face is replaced by a border of no great thickness; it is the same for the posterior face of the third inferior molar.

In the superior jaw, the external face, $F E$, has three grooves in the first and two in the second and third (Fig. 293).

The internal face, $F I$, irregular, very slightly concave in the direction of its length, presents gutters much less distinct.

In the inferior jaw (Fig. 294), the exterual face, FE, shows, in the middle of its length, a groove which augments in depth and diminishes in width from the first to the third molar.

The internal face, $F I$, almost plane, is irregularly grooved.

Each of the deciduous molars is provided, at the level of its root, with a constriction or neck rather well marked and completely encircling the tooth.

Extremities.-1st. Incased Extremity.-The inferior molars bave two roots, the one anterior, the other posterior. They are strong, convex externally, and

1 Anatomia del Cavallo, by Carlo Ruini, Venice, 1598.

2 Tenon, loc. cit., p. 60. 
concave internally. Each is penetrated by an opening which leads into the interior of the tooth. These roots, sometimes divided into several somewhat narrow points, when they are examined at a period approaching that when they are shed, leave between themselves a mammillated surface which is moulded upon the corresponding extremity of the replacing tooth.
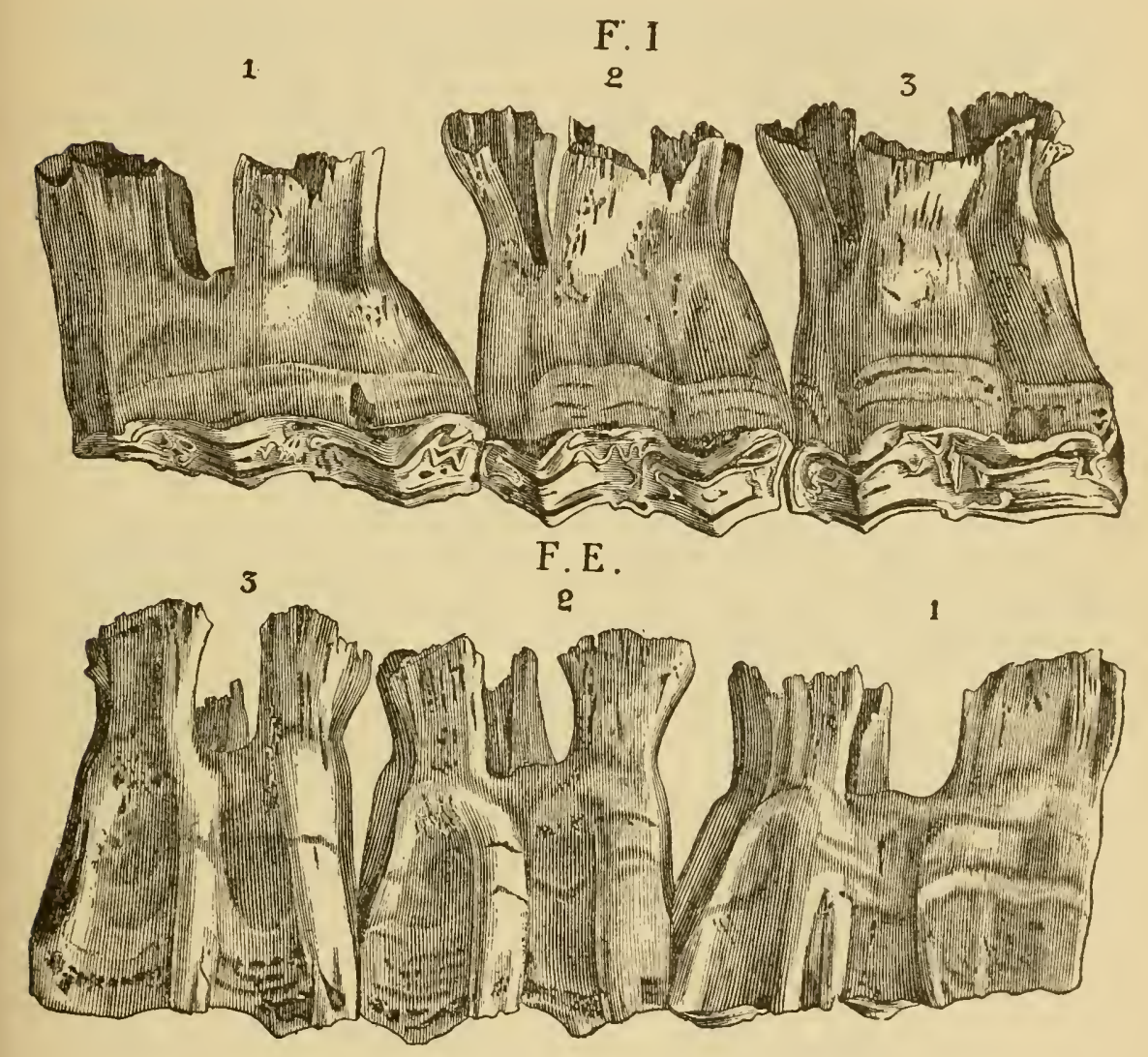

FiG. 293,-The three superior deciduous molars (right side).

FI. Internal face. i FE. External face.

All the molars of the superior jaw have three roots: one anterior and two posterior iu the first; two external and one internal in the last two. These roots are slightly diverging in such a manner that the tooth oceupies more space in the direction of this extremity than in the other.

2 d. Free Extremity.-The free extremity, in the virgin teeth of both jaws, is irregular, eovered with eminences and hollow eavities; but the exterual border is always more salient than the internal in the superior, while it is the contrary in the inferior.

This extremity changes its aspeet under the influence of the friction, and ultimately constitutes a surface formed of planes alternately oblique in different 
directions, and upon which are outlined in relief the zones of enamel of which we have spoken in connection with the strueture of the teeth.

F.I.

1

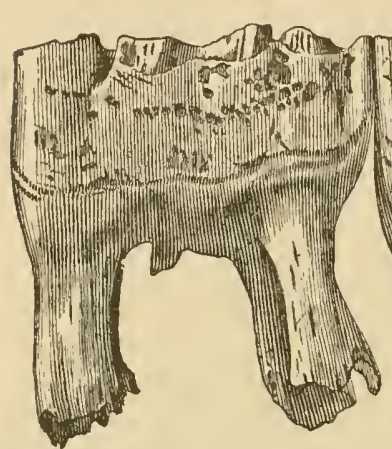

3
2

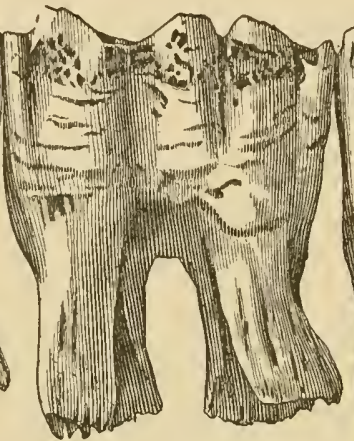

F.E.
3

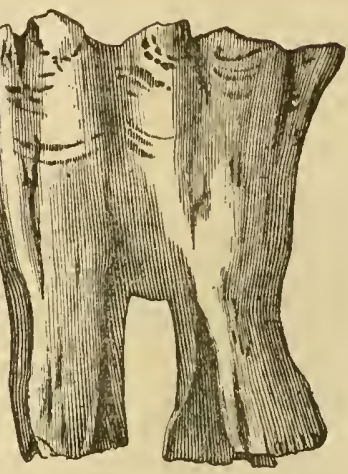

2

1

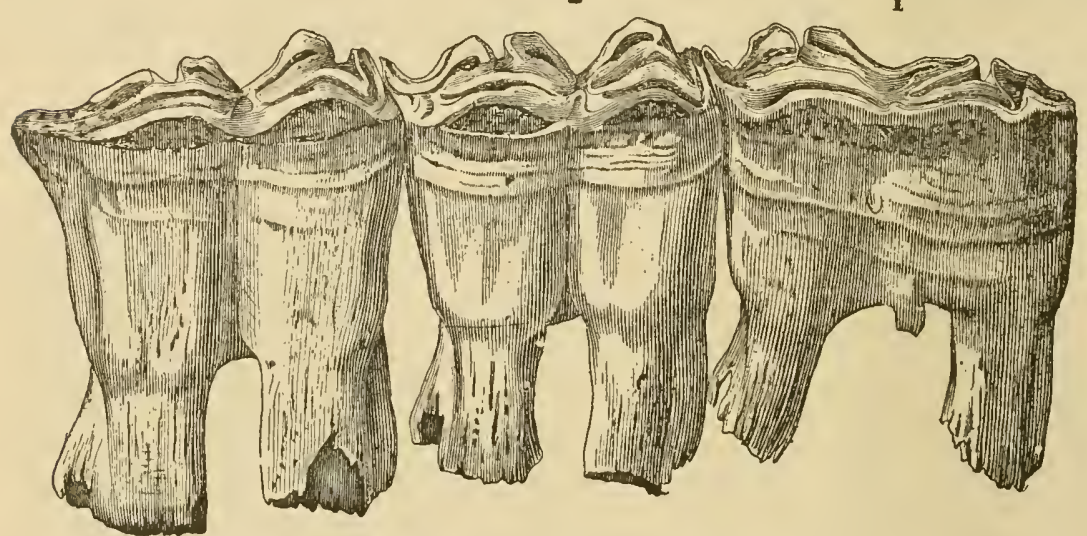

FIG. 291.-The three inferior deciduous molars (right side).

FI. Internal face. | FE. External face.

The following are the dimensions of the molars of the first dentition: ${ }^{\mathrm{I}}$

(a) Thickness from without to within, measured in the middle portion :

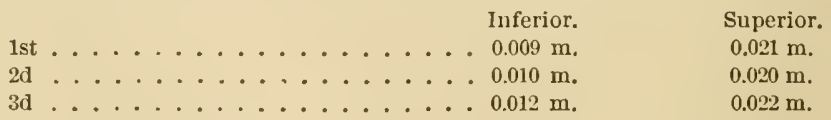

(b) Length from before to behind:
Inferior.
1 st .................. $0.035 \mathrm{~m}$.
$2 \mathrm{~d} \ldots \ldots . \ldots . . . . . . . . . .0032 \mathrm{~m}$.

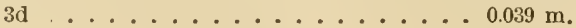
Superior.
$0.043 \mathrm{~m}$.
$0.033 \mathrm{~m}$.
$0.035 \mathrm{~m}$.

1 We only eite these dimensions to give a general idea of them. It is evident that they are subject to variation; but as all our figures are taken from the same animal, it will be known what relations exist among the teeth themselves. 
(c) Total length from above to below, measured through the centre:

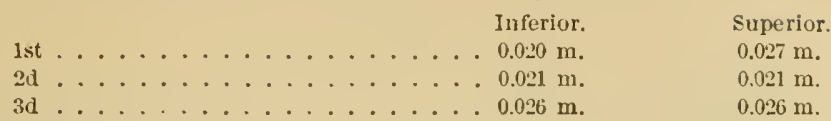

(d) Length of the roots:

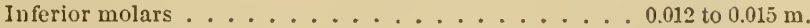

Superior molars . . . . . . . . . . . . 0.010 to $0.013 \mathrm{~m}$.
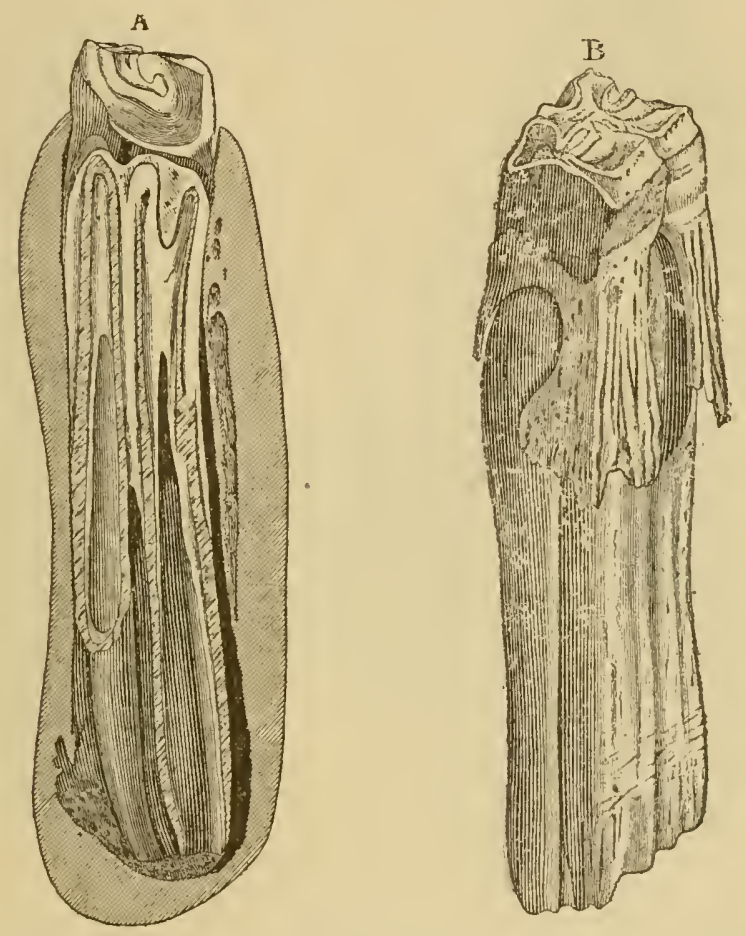

FIG. 295.

A. Transverse seetion of the inferior jaw, showing the third molar of the first dentition and its replaeing one, with the relations which they affect in the alveolus at the moment of eruption.

$B$. Third inferior molar of the second dentition eovered by its milk-tooth.

The free part of the molars, in proportion as the animal advances in age, diminishes in length until finally it becomes a small shell or plate which is moulderl exactly upon the extremity of the replacing tootli; the latter is thus, as it were, crownerl. The deciduous molars are always expelled regularly at the period of eruption of the permanent molars.

\section{B.-Molars of the Second Dentition.}

The permanent molars, twenty-four in number (twelve in each jaw and six on each side), are (lesignated numerically, proceeding from before to behind, under the names first, second, etc. The first three, called premolars, always suc- 
ceed the milk molars; the last three are also called hind-nolars, or persisting molars.

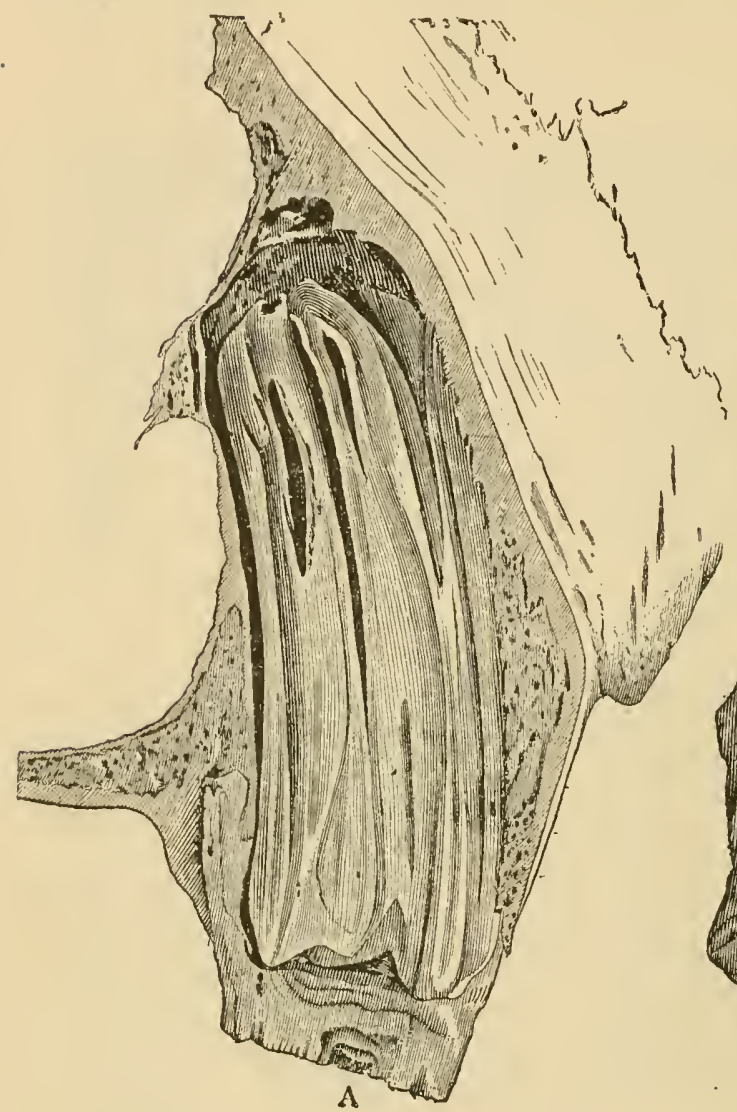

Fig. 296.

A. Transverse section of the superior jaw, showing the third molar of the first dentition and its replacing one, with the relations which they affect in the alveolus at the moment of eruption.

$B$. Thurd superior molar of the second dentition covered by its milk-tooth.

This set forms the branches of the dental arcade, which describe a line slightly convex externally in the superior jaw, but straight in the inferior. The superior molar areade, a little wider than the inferior, surpasses the sides of the latter.

General Characters. - $A$ molar of the second dentition resembles, in general, a quadrangular prism flattened from within to without, save the first and the sixth, which have only three sides. We can recognize four fices and two extremities.

It presents, in situ, a free part or crown and an incased part or root: the former projects above the level of the gums; the second is deeply implanted in the alveolus. As there is no line of demarcation between these two parts, it is useless to describe them separately. 


\section{a. Superior Jaw.}

Faces.-Each of the molars has its posterior face almost plane.

In the sixth, however, the face is constituted by a thick border, concave above and behind.

The anterior face presents the same general configuration, excepting in the first molar, in which it is constituted by an almost rectilinear border, extending from one extremity of the tooth to the other.

The external face, $E$ (Fig. 297), has two deep longitudinal grooves, separated

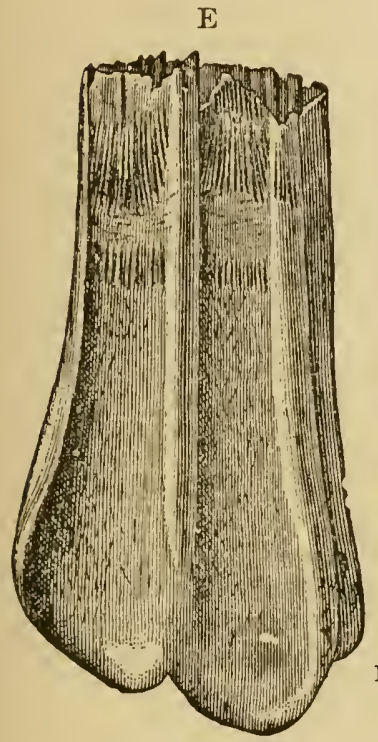

E. External face.

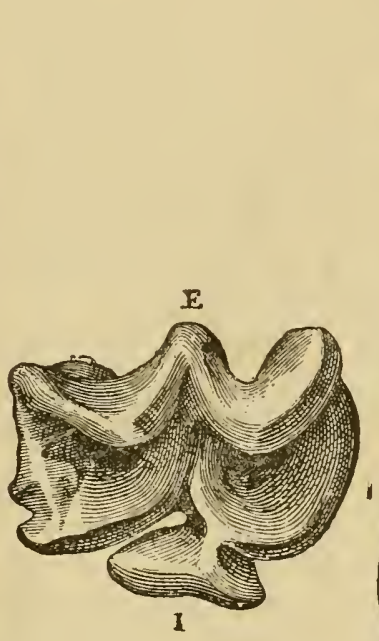

Fig. 297.-Superior molar of replacement.

(Right side. Virgin tooth.)

$I$. Internal face. $\quad E, I$. Surface of friction.

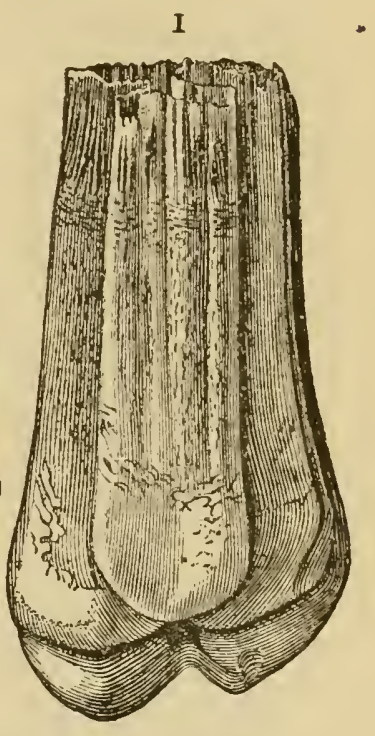

from each other by a salient ridge. That of the first molar has three of these grooves, separated by two intermediary ridges.

The internal face, $I$, is traversed by two grooves on the first molar and only one for all the others. In the last five this groove is nearer to the posterior face of the tooth.

Extremities.-Of the two extremities, the one is free, the other incased. The latter corresponds, properly speaking, to the roots of the teeth.

The free extremity, or crown, EI, quadrilateral in general, is triangular in the first and the sixth molars. It does not show the same disposition at all periods of life.

If the unworn tooth be first considered, there is seen an irregular surface, somewhat resembling a Gothic $\mathfrak{B}$, whose "branches," turned inward, would circumscribe two deep cavities, more or less filled with cement, according to the subject. To the anterior of these branches is found annexed a secondary loop, which is attached to it by a narrow pedicle. The external border of this surface of friction, al ways more salient than the internal, is soon worn off, and the primitive 
nence on the third molar to the corresponding part of the opposite tooth, $0.108 \mathrm{~m}$.

3d. Finally, behind: from the middle of the posterior border of the sixth molar to the corresponding part of the opposite tooth, $0.097 \mathrm{~m}$.

Direction.-All the superior molars have not the same direction. (See Fig. 270.) If the head be placed horizontally, the first is almost vertical, while the others are curved from below upward and from before to behind in a degree which varies somewhat according to the subjects. Howerer it may be, this clirection is always more pronounced in the last than in those which precede it.

Relations.-The superior molars are implanted in their alveoli of a quadrangular form, moulded exactly upon the former, and separated from each other by thin osseous septa, whose thickness augments from below upward. The bottoms of the last three alveoli alone project into the maxillary sinus; ${ }^{1}$ those of the first three are, on the contrary, placed in the thickness of the bone. It is for the above reasons that diseases of these teeth sometimes extend to the mucous membrane which lines these sinuses; that the face, upon its lateral planes, appears convex in young horses and coneave in old, whose molars are much shorter; finally, that perforation of the superficial table of the superior maxillary bone is produced in the young by the roots of one or other of the first three molars.

Length.-The following table shows the data which we have obtained in this respect from the heal of a horse over six years old, whose teetl have been measured from the midlle of their external border to the notch which separates the two roots on this side, roots that are sensibly of the same dimensions:

1st . . . . . $0.054 \mathrm{~m}$, plus the antero-external root, $=0.018 \mathrm{~m} .=0.072 \mathrm{~m}$.
$2 \mathrm{~d} . . . .0 .068 \mathrm{~m} .$,

It might almost be said, from the results of these measurements, that the length of the superior molars augments gradually from the first to the third, and then diminishes from the latter to the sixth. This conclusion is, nevertheless, not altogether accurate, for, as the table will show, the fifth is slightly longer than the fourth.

\section{b. Inferior Jaw.}

In orler to avoid repetitions, the descriptions of the inferior molars will be as concise as possible. These teeth, as we already know, of the same number as in the superior jaw, are also designated by numbers.

They have the same general form, but are less voluminous and, particularly, less thick in their transverse diameter.

Faces.-The anterior and posterior faces, almost plane, present nothing particular. The anterior face of the first and the posterior face of the sixth are repliced by a slightly-thickened borkler.

The extemal face, $E$ (Fig. 299), is traversed by a longitudinal groove in the first five; the sixth his two grooves on this face. All are limited in front and behind by a more or less rounded ridge.

In oll horses we have seen the inferior maxillary sinus extend beyond the root oi the second molar. 
On the internal face, $I$, the grooves are more numerous: in the first and sixth three are observed; in the other molars several grooves of variable length and depth are seen.

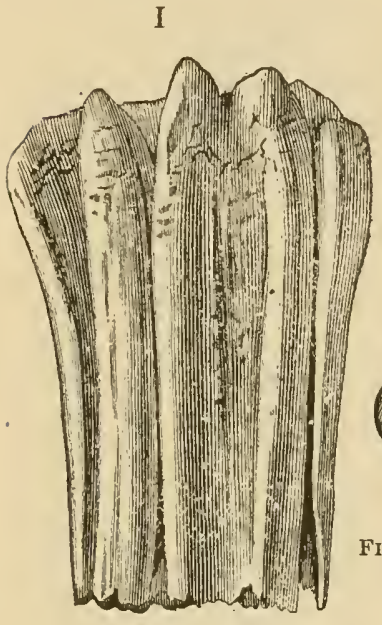

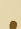

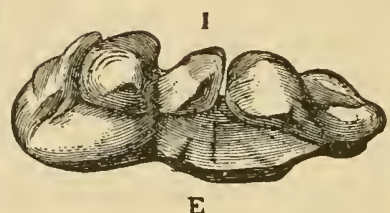

FIG. 299.-Inferior molar of the second dentition.

(Left side. Virgin tooth.)

I. Internal face. $\quad \mid \quad E, I$. Surface of friction.

Extremities.-The free extremity, EI, triangular in the first and sixth, and quadrilateral in all the others, is less extensive transversely than from before to behind. Irregularly mammillated, elevated at some points and hollow at others, it is always bevelled obliquely from within to without. The branches of the Gothic $B$ are turned outward.

The incased extremity, bieuspid in the first five, is unicuspid in the sixth. The divisions of the root are divergent, and each contains an opening which penetrates the interior of the tooth where the dental pulp is lodged.

Length.-The length increases from the first to the third, and diminishes from the latter to the sixth. Below are the measurements which we have obtained from the teeth of the head previously mentioned:

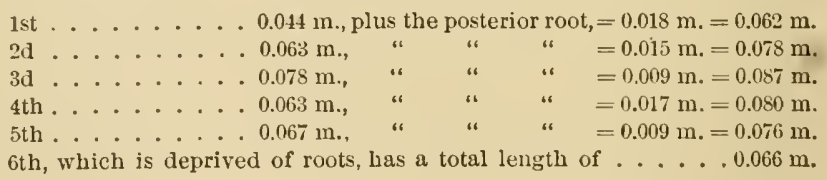

Direction.-After removing the external table of the inferior maxilla in order to expose the teeth, it is easy to recognize that all have not the same clirection. Placing the head upon a horizontal plane, the first and sixth are vertical, while the others are more oblique, particularly in the incased extremity, as they are examined more posteriorly.

Relations.-The alveoli, which contain the teeth, have a corresponding form, and are separated from each other by osseous septa (interalveolar septa), quite thick, which become thinner towards the entrance of these cavities. 
Their bottoms, as well as the dental canal, are at first in close proximity with the inferior border of the maxillary bones; but as the teeth are shortened and pushed from their sockets by the progress of age, the alveoli diminish in depth and the aforesaid canal is elerated in almost the same proportion. This fact is particularly obscrvable in the first three or four molars. It can be understood, from this, that the border of the inferior maxillary bone will be thicker as the animal is younger, or as the teeth are more deeply implanted in their cavities of reception, and, conversely, thinner as the animal grows older.

Separation of the Two Inferior Molar Arcades. -The inferior molar arcades, considered as a whole, are rectilinear and divergent behind. The following measurements can be easily compared with those which have already been given for the superior arcades of the same horse:

1st. The separation of the anterior border of the first molar from the corresponding border of the opposite tooth was $0.043 \mathrm{~m}$.

2d. The separation on a level with the middle part of the third molar (measured from the outside) was found to be $0.072 \mathrm{~m}$.

3d. Finally, at the level of the posterior border of the last molar it measured $0.077 \mathrm{~m}$.

Extent of the Table of the Six Inferior Molars in the Antero-Posterior Sense.-The total length of the arcade, in the horse in question, was $0.164 \mathrm{~m}$., which was shared by each tooth in particular, as follows:

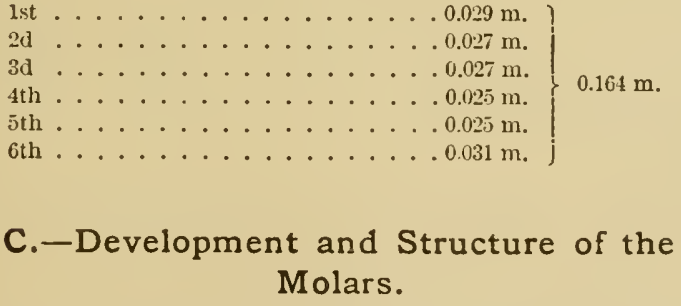

These teeth have the same general organization as the incisors, but the substances constituting them have a very complex arrangement, which must be examined in the molars of both jaws.

\section{Development.}

Superior Molars.-If a superior molar be viewed in the interior of the sac in which it appears, it is observed that prominent papilla, two in number, penetrate the thickness of its free extremity, while at the incased extremity only one is found, but which is much more com-

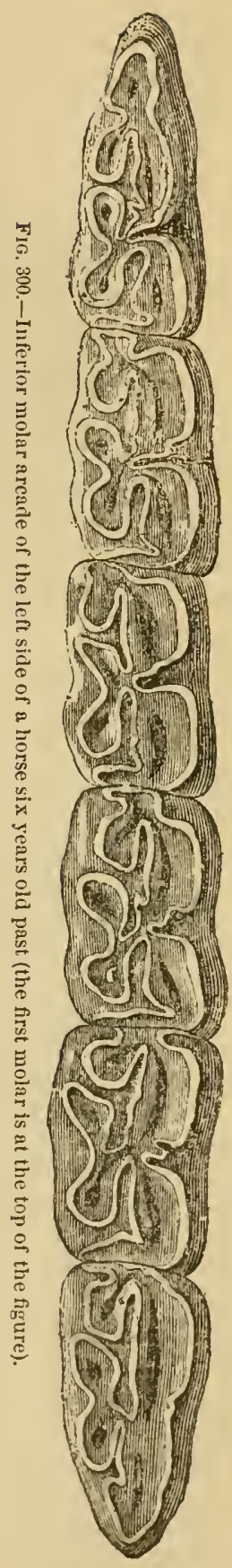


plicated. Besides, the dental sac sends forth into the grooves or notches of the faces, as prolongations, longitudinal folds which continue without interruption with the external papillary system (Fig. 301).

A

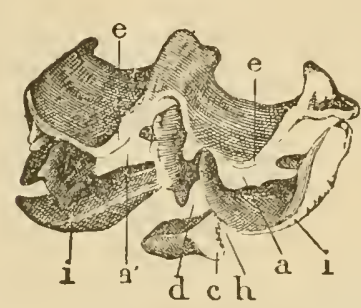

B

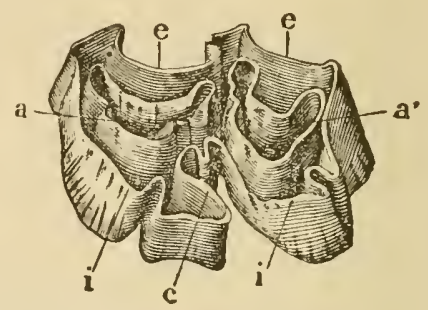

FIG. 301.-Superior right molar removed from its dental follicle.

A. Vicwed by its free part: $a$, :uterior infundibulum. $a^{\prime}$, posterior infundibulum. $e$, external border of the infundibula.

$i$, internal border of the infundibula. $c$, accessory eolumn of the anterior infundibulum.

$B$. Viewed by its incased extremity (same letters).

Each exterual papilla penetrates, from below upward, into the thickness of the tooth, in the same manner as that which forms the central enamel of an incisor tooth. It fills thus a cavity, a veritable infundibulum, at first open at its bottom, and afterwards terminating in a cul-de-sac, when it is completely developed (Fig. 301, $A: a, a^{\prime}$ ).

There are two infundibula on the table: an anterior, $a$, and a posterior, $a^{\prime}$, absolutely distinct from each other. The cavity of each, almost elliptical, wider from before to behind, is limited by two borders, $e, i$, of which the external is the more salient. The internal, $i$, presents, as a singular peculiarity, a sort of columı, $c$, flattened or depressed, but rather thick, situated towards the middle part of this border, and annexed to the anterior infundibulum. This column is limited by two grooves, $d, h$; the posterior, $d$, forms a sort of re-entering angle forward, and is deeper than the anterior.

The incased extrenity (Fig. 301, B) does not resemble that which we have deseribed. It presents a number of folds whose disposition appears at first sight complicated, and which have been compared with much correctness, by Bracy Clark, to a Gothie B. $^{1}$

On careful examination, there can be clearly distinguished : first, the bottom of the infundibula, $a, a^{\prime}$, which we mentioned above, and, around these, an irregular cavity folded upon itself. The latter opens at the incased extremity, but, terminating in a cul-de-sae towards the free extremity, is continued into the accessory column, $c$, of the anterior infundibulum, $a . \Lambda$ superficial observer might be led to believe in the presence of five cavities, - namely, two close to the external border, $e, e$, two close to the internal border, $i, i$, and, finally, one for the accessory eolunm, $c$, on the internal face. This would be an error; in fatet, there

1 Bracy Clark, On the Knowledge of the Age of the Horse by his Teeth, 4to, London, 1826. (See Fig. 8.) 
is only a single cavity, very diverticulated, in the interior of which the dental pulp is contained.

It will be understood from this that the infundibula of the free extremity correspond to two somewhat conical reflections which are situated one in front of the other and surrounded, outwardly as well as inwardly, by the internal cavity.

Inferior Molars.-The development of the inferior molars is much more simple. In fact, if the free extremity be first examined (Fig. 302, A), it is seen
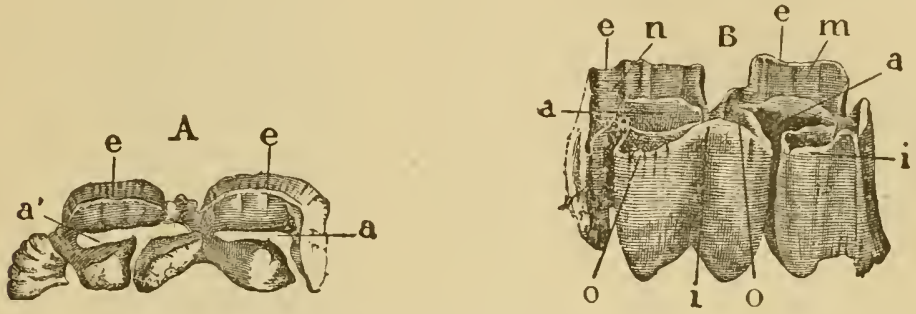

Fig. 302.-Inferior left molar removed from its dental follicle.

$A$. Viewed by its free extremity :

$a$, anterior infundibulum.

$a^{\prime}$, posterior infundibulum.

$e$, external border of the infundibula.

$i$, internal border of the infundibula.

$B$. Viewed by its incased extremity:

$m, n, o$, pulp cavity. Other letters same as in $A$.

that the infundibula, $a$ and $a^{\prime}$, are produced by two reflections of the enamel from the internal face towards the centre of the tooth. They are also cleft outwardly throughout their whole length. The cleft of the posterior infundibulum, $a^{\prime}$, occupies the middle part of this cavity, while that of the anterior, $a$, is situated much more in front. An inferior left molar can thus at a glance be recognized from its homologne of the right side.

The mode of formation of the infundibula of the inferior molars is therefore different from that of the superior. Both result from the penetration of the papille, but, in the former, it is through one of its lateral faces that a longitudinal papilla enters the tooth; in the latter, on the contrary, a conical papilla enters through the summit.

Concerning the opposite extremity of the inferior molar (Fig. 302, $B$ ), there is found a spacious cavity, $m, n, o$, very much diverticulated, surrounding the periphery of the infundibula, $a$ and $a^{\prime}$, isolating the one from the other, and separating them from the external face, $m, n$. The three diverticula, $m, n, o$, of this cavity, conmunicating with one another, lodge three prolongations of the internal papilla or the pulp; all terminate in cul-de-sacs at the free extremity of the tooth.

\section{Structure.}

The molars, like the incisors, are composed of a fundamental substance and two protecting envelopes.

a. The enamel constitutes the only element in the tooth when the latter is first developed. Having formed the four faces, it is reflected upon the free extremity (superior molars) to circumscribe the infundibula. 
If the table of a superior molar which has already been used be examined, the enamel presents itself in the form of more or less sinuous lines, which have not everywhere the same thickness (Fig. 303, $S G)$. These bands are
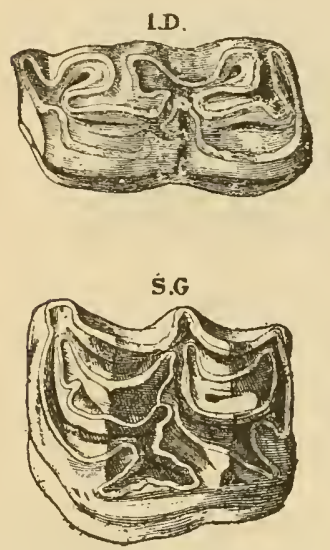

Fig. 303,-ID. Table of inferior right molar. $S G$. Table of fric. tion of a superior left molar.

thicker in the tract of two transverse lines which pass through the middle part of the branches of the $\mathfrak{B}$, and it is at the points corresponding to these that they stand slightly in relief above the other points. In the inferior molars, it is the parietes of the infundibula which possesses the least thickness (Fig. 303, ID).

However it may be, the enamel layer is always relatively rather thin, and undergoes no modifications under the influence of age when once the teeth have acquired their full development.

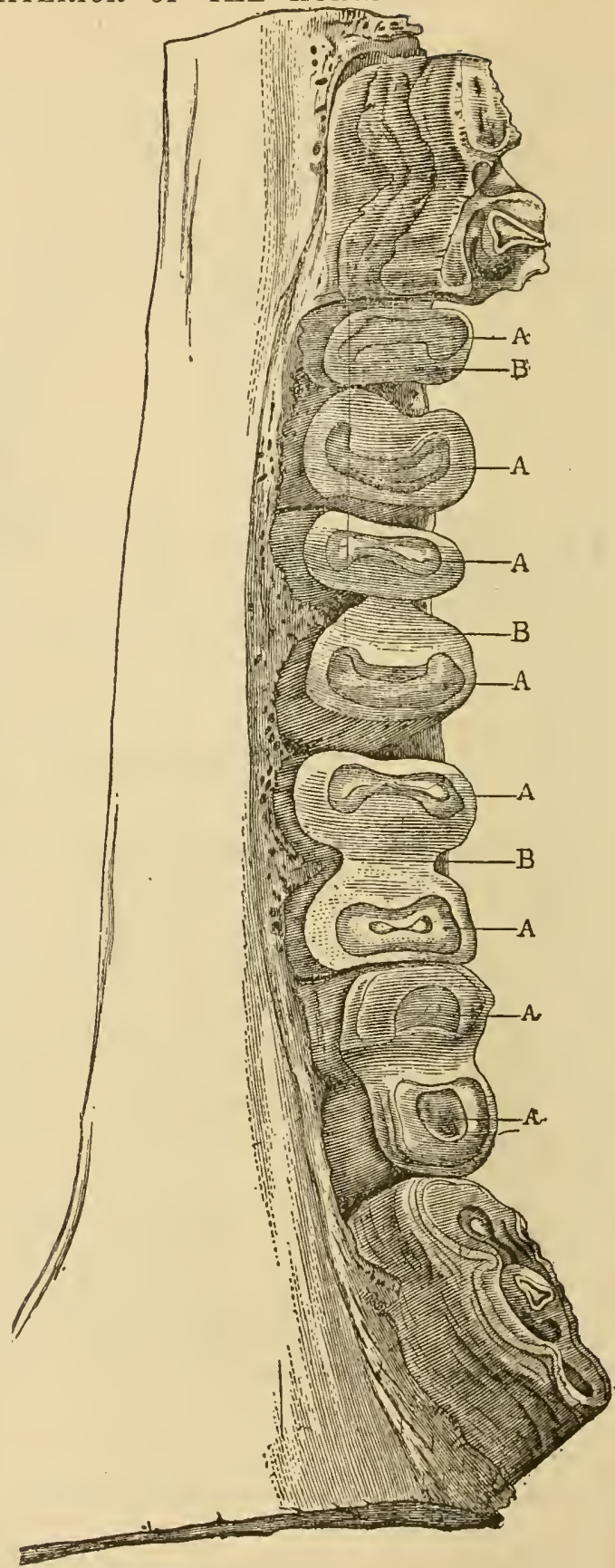

FIG. 304.-Inferior left molar arcade of a very old horse, showing the radical cementation of the middle teeth.

$A, A, A$, restiges of the roots; $B, B, B$, radical cement. The enamel has disappeared. 
b. The ivory or dentine is deposited little by little upon the internal face of the enamel, and soon fills, from the crown to the roots, the diverticula of the pulp cavity. At first covered by the enamel, it soon becomes, under the influence of wear, an integral part of the dental table. It is seen, in the superior molars, to surround the periphery of the two infundibula and to constitute the basis of the 13 which their table resembles; upon wany of these teeth this comparison is so exact that it is ontlined by brown lines, sometimes very dark. In the inferior molars, the dentine is found, so to speak, only upon the outer side of the infundibula; its central parts also have a brown coloration in a large number of subjects.

$c$. The cement is extremely abundant upon the molars. It is this which is directly applied upon the enamel, covers the faces, penetrates the notches, and fills the infundibula. The tooth seems to become covered with it in proportion as it is expelled from its socket, and at the level of its free extremity particularly, for the radicular extremity only carries a thin layer; but when the latter becomes the surface of friction, in very old horses, it excites an abundant secretion of radical cement, which consolidates it into its cavity of reception and considerably angments the area of the dental table, as we have already seen $a$ propos of the structure of the incisors (Fig. 304).

It is easy to account for the relations of the different layers which enter into the composition of a molar, by making transverse sections of the latter parallel

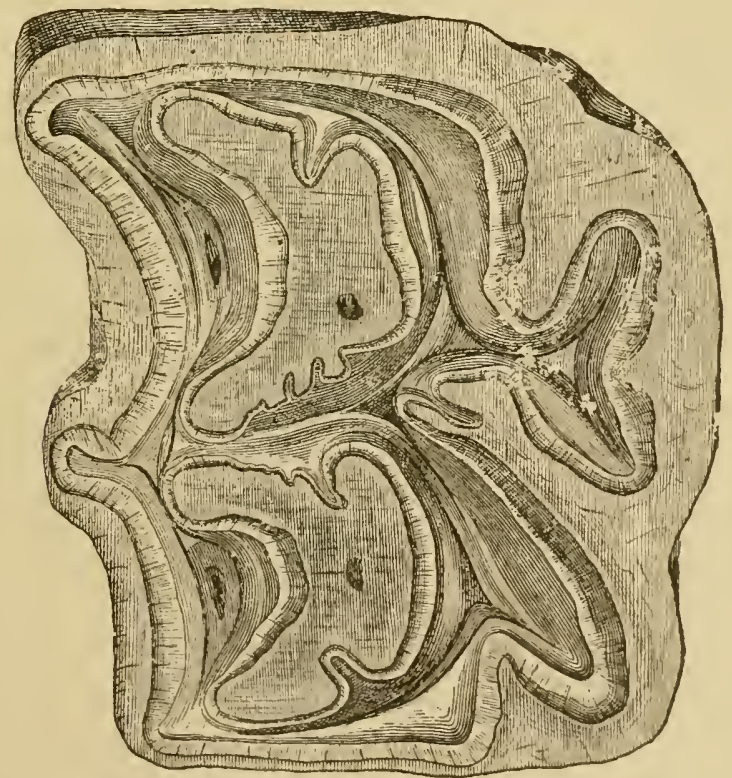

FiG. 305.-Transverse section of a superior left molar (enlarged).

to the surface of friction. The enamel is there ontlined by porcelain-white, sometimes vitreous, bands, the ecment by very clear coffee-and-milk color, the dentine, finally, by darker coffee-and-milk color, always veined with darker lines.

The accessory branch or loop, in the superior molars (Fig. 298), is always 
attached to the anterior branch of the $B$ by a narrow pediele of ivory. In this respect there is no exception in the horse. In the hipparion, on the contrary, which some evolutionists consider as the ancestor of the preceding, this loop is constantly isolated on the dental table (Fig. 306).

Numerous differences concerning the disposition of the folding of the enamel are also found. They form at times, in certain animals, remarkable wavy or sinuous folds, analogons to those on the tooth of the hipparion. Some anatomists have considered these characteristics as sufficient reasons for the establishment, among equine fossils, of an intermediary species between the hipparion and our actual horse, the Equus plicidens (plio-hippus). Whether this distinction is justified or not, the truth is that these enamel plications still exist in many horses of to-day.

In the inferior molars, the configuration of the surface of friction differs slightly from that of the superior; Fig. 307 gives a sufficiently accurate idea of this.

Let us recall, in conclusion, that the three substances, enamel, dentine, and cement, are not equally

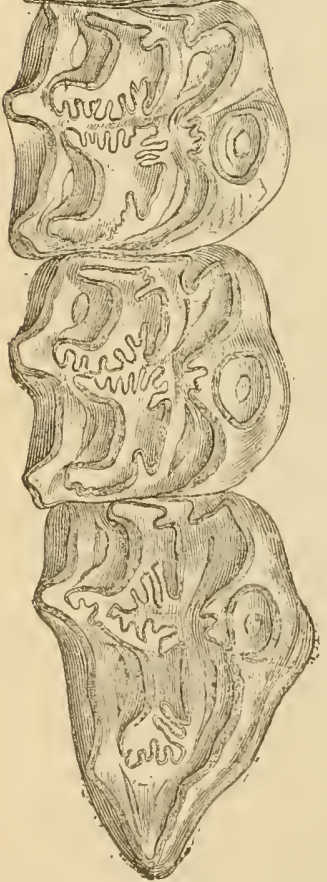

FIG. 306. - Superior left molar arcade of tle hipparion.

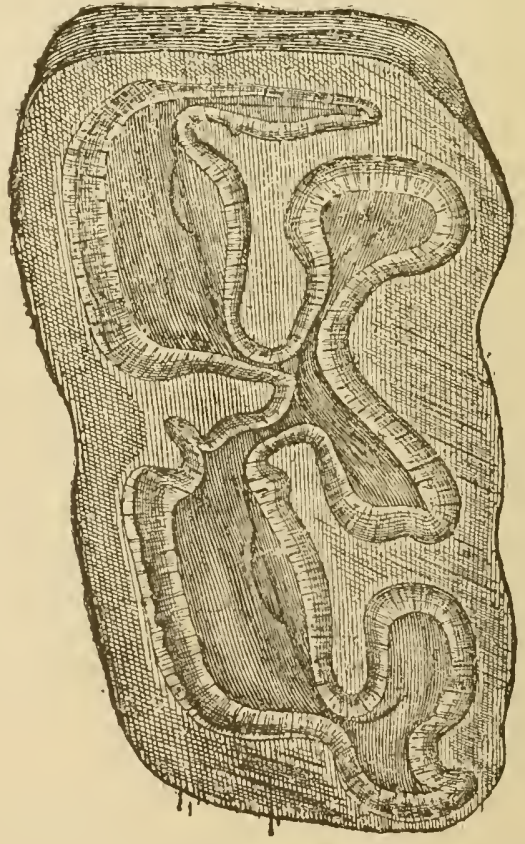

Fig. 307.-Transverse section of an inferior right molar (enlarged). 
resistant to wear. Hence the first is always in relief above the second, and the latter above the third. In consideration of this fact, Cuvier rightly said that the molars of the horse were comparable to millstones, which incessantly rub against each other. These asperities of the surface of friction, in fitet, render the crushing of the alimentary substances much more complete. In old horses, when the enamel bands have disappeared, these substances can without doubt be bruised or broken, but no longer crushed as before. It is for this reason that digestion is less perfect, and that many of the cereal grains, having resisted the action of the teeth and the digestive juices, still preserve all their germinating properties after having traversed the entire length of the alimentiry canal.

\section{CHA PTER III.}

\section{ERUPTION OF THE TEETI.}

\section{A.-Eruption of the Incisors.}

ThE eruption of the milk incisors determines, in general, no partieular phenomenon susceptible of attracting the attention of persons who care for the young animal, though it is probable that it sometimes occasions depression and inappetency. For this reason these teeth will not especially concern us here.

In proportion as the colt approaches the period in which the second dentition begins to appear, certain peculiarities, which it is important to recognize, take place. Thus the head augments in volume and becomes more prominent upon the sides of the region of the face. This aspect of the face is due to the development of the molars, which are enclosed in the alveoli of the superior maxillary bones.

The effects of this dentition generally seem to pervade the whole organism; the first attacks of periodic fuxion, strangles, and other diseases manifest themselves at this epoch, as Profeseor Dupuy and other authors have stated. But if these facts are frequent, it does not follow that they can be extended to the generality of young horses.

When the colt arrives at the age at which the adult incisors shonld make their eruption, it is observed that the milk-teeth have already been shed, leaving vacant the place for the permanent tecth, or they may still remain in place. Let us examine the two cases:

1st. The Milk-Teeth being shed.-The spaces which they ocenpied then present a swelling, tumefaction, and redness, having an exaggerated sensibility, which goes so far as to be painful when the 
gum is touched. Soon after, the anterior border of the replaeing tooth, which has compressed, thinned, worn out, so to speak, the gum from its deep to its superficial face, gradually appears and perforates the latter by commencing at its internal moiety. 'This border is not always directed transversely to the median line; it is sometimes oblique from before to behind and from within to without. Little by little the tooth disengages itself from the alveolus, arrives on a level with its neighbors, and, finally, opposes itself to that of the other jaw.

2d. The Milk-Tecth still in Place.-The phenomena in this case are less visible. It is not sufficient to make an examination of the ineisive areades by their anterior faces; it is also necessary to separate the two jaws to see if there is any particular evidence showing that the eruption of the permanent teeth is about to take place. It happens, even, in certain eases, that this has already been accomplished for the pincers, as we have observed in the English horse Vade-Mecum. After separating the lips of the horse, only the milk-teeth were perceived, but on opening the mouth, the superior permanent pineers, well developed, and even slightly used, were diseovered, while the inferior still remained covered by the gums.

We will remark, in conclusion, that nearly aluays the eruption of the superior ineisors is earlier than that of the inferior. In both jaws it takes place by pairs, commeneing with the pincers and terminating with the corners.

Causes which may hasten or retard the Eruption of the Incisors of the Second Dentition.-We cannot take under consideration here the extraction of the deciduous teeth, a fraudulent practice which we will, however, study separately ; but will speak only of the physiological causes which may lasten or retard the eruption of the permanent teeth.

According to Girard, ${ }^{1}$ the precocity of the race, the vigor of the temperament, and abundant assimilation are eapable of hastening the eruption of the incisors of the second dentition, and of advancing it three or four months.

According to Traeger, ${ }^{2}$ pregnancy can retard this eruption for a year, notably that of the corners:

All the pregnant mares, born in 1841 , were no more advanced in relation to the dentition than the mimpregnated ones which were foaled in 1842 ; while other mares, also born in 1841 , but which were

\footnotetext{
1 Girard, loc. cit., p. 58.

2 Traeger, Magazin für die gesammte Thierheilkunde, 1846 , in Recueil de médecine vétérinaire, 1849, p. 136.
} 
not impregnated, presented, without exception, the teeth of a fiveyear-old.

One of our confrères in the army, Mr. Bizard, has communicated to us an observation of the same nature: a half-bred mare, foaled on the 26th of May, 1875, and served on the Sth of May, 1880, when five years of age, was still provided with her four corner milk-teeth; the latter were only shed from the 18th to the 30th of July, 1881, -that is to say, at the age of six years and two months.

Facts of this nature are undoubtedly more frequent than is believed, in conseruence of the difficulty which is experienced in obtaining exact information as to the age of the subjects. If these facts were to be made a criterion in this connection they would tend to increase rather than diminish the age of pregnant mares.

Girard ${ }^{1}$ has equally noticed the action of the climate. The horses of Southern France, raised in their native country, are more precocious than those of the North; in them the eruption of the permancnt teeth takes place sometimes in the early part of September, and most often at the beginning of October ; they are always entirely through the gums by the middle of December.

In the cold climates of the North, in Normandy, for example, it takes place normally only at the beginning of January, February, March, and even April. In the Limousin district, it is rarely terminated before the month of January. These variations depend so much upon the climate that the transportation of colts from cold into warm countries hastens the eruption; it is retarded in a contrary case, and this so much the more as the difference in the temperature is greater.

Finally, Bernard, ${ }^{2}$ Magne, ${ }^{3}$ and MI. Sanson ${ }^{4}$ have adranced the opinion that the race-horse, always very strongly nourished, constitutes an exception to the principles of Girard. Our noted colleague, M. Tonssaint, ${ }^{5}$ has furnished the proof that the thoroughbred horse is, in this respect, not different from the common draught-horse. Our observations fully confirm his.

That there are subjects presenting exceptions to these general

1 Girard, loc. cit., p. 60.

2 Bernard, Guide des acheteurs et des vendeurs d'animaux domestiques, Toulouse, 1845, p. 175.

${ }^{3}$ Magne, Mémoire sur l'allaitement et le sevrage des jeunes animaux. See Bulletln de l'Académie de mérlecine, annéc 1876, p. 965.

4. Sanson, Le cheval de Solutré; memoir read at the Soc. anthropologique, dans sa scance d12 15 Octobre, 187 .

5 Toussaint, De l'âge de chevaux de course, an point de vue de la doctrine de la précocité. See Recueil de médecine vétérinaire, année 1872, p. 992. 
laws, that the eruption of the incisors of the adult is premature in some and slow in others, we will willingly admit. Nevertheless, this does not appear to us to be exclusively the result of the fact that they belong to such or such a race, possess such or such a temperament, or, finally, that they are abundantly or poorly nomished. We will cite, in this connection, the example which Jules Goubanx, veterinarian at the depot of stallions at Blois, showed us in 1857 : it was a small horse of a common rece, which had placed all the incisors of the second dentition in the course of the same year. This early eruption, extremely rare in the horse, occurs less seldom in the bovine and in the ovine species. It must depend upon very diverse eauses, which, in our opinion, still remain to be determined.

\section{B.-Eruption of the Canines.}

The eruption of the canine teeth is of little utility in the determination of the age: first, because it is very variable; secondly, because these are absent in the majority of mares.

The eruption of the tusks is preceded, accompanied, and followed by the same inflammatory phenomena as those which concern the incisors. According to Girard, there is nothing regular about it. Sometimes these teeth exist at three years; at other times they only appear at six ; in general they appear at four years. The indications which can be drawn from their state are therefore very uncertain.

\section{C.-Eruption of the Molars.}

In proportion as the animal advances in age the molars of the first dentition, as a result of wear, become shorter and shorter, reduced somewhat to the state of small, loosened plates, which envelop, as we have seen, the corresponding extremity of those of the second dentition, and are held only very imperfectly in their alveoli. Their asperities, wounding the internal face of the check, sometimes canse abnormal movements of the jaws. The animal does not eat in the ordinary manner: this is what attracts the attention and leads to an examination of the interior of the mouth.

It is good practice, under such circumstances, to extract these teeth so as to favor the eruption of the replacing ones; an easy operation, and one which veterinarians in breeding districts practise very often.

The last three molars of each jaw, or the hind-molars, also appear one after the other; but, situated very deeply in the interior of the mouth, it is difficult to observe well their eruption. 
Eruption of the Molars in Particular.-We knew already that the opinions of Girard concerning the period of this cruption were contested by those veterinarians who had had oceasion to examine them ; hence we applied to one of our collaborators, Lecellier the elder, veterinarian at $Y$ vetot. 'This distinguished practitioner, who for a long time las directed his attention to the dental apparatus of the horse, has succeeded in ascertaining some facts of great importance.

1st. Molar's of the First Dentition.-According to Girard, the first two deciduous molars have generally pierced the gums at birth, or, at the latest, from three to four days after; as to the third, it should always appear at the end of the first month.

Lecellier ${ }^{1}$ and Mayhew ${ }^{2}$ assert, on the contrary, that these teeth all exist at birth, and that they can serve for mastication at the end of thirty or forty days.

2d. Molars of Replacement and Persistent Molars.-The observations of Girard, Lecellier, and Maylew are not in accord upon this point; they differ especially as to the period of eruption of the sixth molar. We have presented them in the following table:

\begin{tabular}{|c|c|c|c|c|c|}
\hline \multirow{2}{*}{$\begin{array}{l}\text { DESIGNATION } \\
\text { OF THE } \\
\text { TEETH. }\end{array}$} & \multicolumn{2}{|c|}{ Peried of Eruption. } & \multicolumn{2}{|c|}{$\begin{array}{c}\text { DESIGNATION OF THE } \\
\text { TEETH. }\end{array}$} & \multirow{2}{*}{$\begin{array}{l}\text { PERIOD OF } \\
\text { ERUPTION, } \\
\text { AFTER } \\
\text { LECELLIER. }\end{array}$} \\
\hline & After Girard. & After Mayhew. & $\begin{array}{l}\text { Inferior } \\
\text { Molars. }\end{array}$ & $\begin{array}{l}\text { Superior } \\
\text { Mlolars. }\end{array}$ & \\
\hline $\begin{array}{l}\text { 4th. } \\
5 \text { th. } \\
\text { Ist. } \\
\text { 1st and } 2 \mathrm{~d} \text {. } \\
2 \mathrm{~d} \text { and } 3 \mathrm{~d} \text {. } \\
\text { 6th. } \\
\text { 6th and } 3 \mathrm{~d} .\end{array}$ & $\begin{array}{c}10 \text { months. } \\
20 \text { " } \\
30 \text { to } 32 \text { months. } \\
36 \text { months. } \\
4 \text { to } 6 \text { years. }\end{array}$ & $\begin{array}{l}12 \text { months. } \\
18 \text { to } 24 \text { months. } \\
36 \text { months. } \\
60 \text { months. }\end{array}$ & $\begin{array}{l}\text { 4th. } \\
5 \text { th. } \\
\text { 1st and } 2 \mathrm{~d} . \\
6 \text { th. } \\
\text { 3d. } \\
\text { 3d }\end{array}$ & $\begin{array}{l}\text { 4th. } \\
\text { 5th. } \\
\text { Ist. } \\
6 \text { th. } \\
\text { 2d. } \\
\text { 3d. }\end{array}$ & $\begin{array}{l}10 \text { to } 12 \text { months. } \\
20 \text { to } 24 \\
30 \text { to } 36 \\
32 \text { to } 36 \\
40 \text { to } 42 \\
44 \text { to } 48\end{array}$ \\
\hline
\end{tabular}

According to Lecellier, the inferior deciduous molars are constantly shed before the superior, while the erruption of the permanent molars takes place in both jaws at the same time.

1 Lecellier père, note communiquéc.

2 Mayhew, loc. cit., pp. 69, 70, 71, 72, and 82 . 


\section{P A R TII. \\ DETERMINATION OF THE AGE.}

\section{CHA P T E R I. \\ DURATION OF LIFE IN THE HORSE.}

According to Buffon, "the duration of the life of horses is, as in all the other species of domestic animals, proportional to the duration of their period of growth or increase. A man, in whom this period is fourteen years, can live six or seven times this space of time,- that is to say, ninety or a hundred years; the horse, whose period of increase continues throughout four years, can live six or seven times as long,- that is to say, twenty-five or thirty years."

According to Bourgelat," "one can suppose the ordinary life of a horse to continue eighteen or twenty years, the number of those which surpass this time being very small. Aristotle observed that horses kept in stables live a much shorter time than those which run at large; the state of stabulation and domestication are well calculated to produce some differences. Athenæus and Pliny claimed that horses have been known to live sixty-five and even seventy years. Augustus Nipheus also speaks of the horse of Fcrdinand I. as a septuagenarian horse, but these last observations are ouly exceptions, similar in the equine species to those which sometimes take place in the human species. ...."

"The life of mares," says Hartmann, " "is ordinarily longer than that of the males. This obscrvation, already made by Aristotle (Hist. Animal., vol. v.), corresponds to that made at different periods upon the human species, in which the females generally live longer than the males.

"It is an indubitable sign that it stud-horse is of a good race, or at

1 Buffou, IIistoire naturelle générale et particulière, t. iv. p. 226.

2 Bourgelat, Traité de la conformation extérieure du cheval, 2e éd., Paris, 175, p. 286.

${ }^{3}$ Hartmann, Traité des haras, ete., translated from the German, l'aris, 1788, p. 32. 
least that he is healthy, if he be slow in attaining his maturity. One that only eeases to grow at six or seven years of age will, barring particular accidents, be of good service for twenty years or more, and can even live forty years and longer. On the contrary, one which reaches full growth in four years, will live at most only twenty or twenty-five. Heavy and lymphatic horses, which attain their full growth in still less time, are also shorter lived, and are already old at the age of six or seven years.

"Instances of an age of thirty or forty years would not be so rare among these animals if the brutality of men did not shorten their lives, if they were less abused, and if they were better cared for. Commonly, one has not the least regard for a horse after he has attained a certain age; one endeavors to dispose of him in order to save the expense of his keep; and his ordinary recompense, after having rendered the best services for a fair length of time, is to be worked to a cart and reserved for the most severe labor, or to be sent to the knacker."

This passage, written in Germany, is equally applicable in France: it proves that men act everywhere the same towards the animals, auxiliaries in their work.

Among the principal causes which modify the longevity we will cite the slowness of the development, the size, the service, and the care.

We believe that there are precocious individuals and not precocions races. Nevertheless, agreeing with the opinion of some authors, we will admit that certain races live longer, and that the duration of life is in proportion to the time which the animal requires to reach his maturity, although until the present no one has furnished proof of it.

However it may be, $\mathrm{H}$. Bouley has endeavored to demonstrate the foundation of this opinion. "There are," says he, "tardy races and precocions races. In the latter, the precocity results from the combined action of heredity and of the alimentary regimen, so that the organic formation is effected in a hurried manner, so to speak, in the subjects which eompose them, which causes an carlier maturity; whence it follows that the duration of the first period is shortencel, and, as a fatal consequence, that of their life, for the more rapid processes of growth impressed upon their organism have no other effect, in view of the industry which produces them, than to hasten the moment of their death." 1

1 See Nouveau Dietionnaire pratique de médecine, de chirurgie et d'hygiène vétérinaires, t. i., ammée 1856, art. "Ages," p. 189. 
Concerning the size, it appears to us that the life of small horses is longer than that of large ones, but it would be very perplexing to give the explanation of this fact.

The scrvice produces its principal effects throngh the more or less intense fatigue and wear which it oceasions. Certain subjects have such a quiet existence and such good hygienie surroundings that they often attain a very advanced age. Those which inhabit the large industrial centres live under entirely different conditions. There, more than anywhere else, the services at a fast gait, which exact frequently-repeated violent efforts, the prolonged duration of the daily work, the inclemencies of the weather, ete., exhaust the vitality, predispose the system to diseases, and cause premature death. Hence, for opposite reasons, horses kept in the country attain a more advaneed age than those in cities.

The care received from man has likewise a great influence. Bad treatment, privation of nourishment, insuffieiency of the latter and its poor quality, do not permit the necessary reparation of the incessant losses due to the work, and shorten the duration of the services.

To recapitulate, it will be understood that this question, eannot be determined in a very precise manner: the causes which tend to complicate the subject are too numerous, and yet it is necessary to take cognizance of them. One horse is old, worn ont, at the age of twelve years; another still performs his work at twenty or twenty-two.

Be this as it may, the following are some remarkable examples of longevity :

One of our friends, M. Laurent, has sent us the jaws obtained from horses which had lived forty-two, forty-three, and forty-nine years. We have known several which had passed thirty-five years. Finally, we have seen, in 1845, at the Petite-Villette, a horse which had served in a regiment of cuirassiers during the Russian campaign in 1813. If, at the beginning of the campaign, this animal was six years of age, he must, therefore, have been thirty-eight at the time when we saw him.

It is rare to observe such advaneed age, because owners generally dispose of the subjects whose work becomes insufficient. Rather than deliver them to the slaughter-house, the proprietor sells them ordinarily for a low price, and it is then that they enter upon the most pitiable existence which can be imagined. Financial interest and sentiment are not always in aecord! 


\section{CHA P'TER II.}

\section{AHE PARTS TO BE ExAMINED FOR THE DETERMINATION OF THF AGE.}

However little one may be aceustomed to the handling of horses, it is not difficult to distinguish the young from the old. In the very aged white hairs appear upon the region of the temples, around the eyes, the nostrils, ete, when the robe is dark-colored; the inferior extremity of the head is more pointed; the lateral parietes of the face are depressed. Besides, a roach-back, alterations of the axes of the members, and blemishes of the members also denote a variable degree of wear, often in a certain relation with the duration of this degenerated existenee. Every one is able to observe these facts; but there are persons who flatter themselves that they are able to estimate the age of the horse by the sole examination of the jaws, or by other procedures of equally trifling importance. It is upon these pretended means that our attention will be arrested for an instant, to dispose of them once for all, and warn the reader against those individuals who put them in practice.

1. Examination of the Jaws. - We know that the teeth are so much the more deeply incased in their alveoli as the animals are younger. The teeth, in fact, are little by little pushed from their sockets in order to compensate for the losses oceasioned by the friction of mastication, at the same time that the two tables of the maxillary bone are drawn towards each other. It results from this that the free border of the jaws becomes thinner with the progress of age. Nevertheless, the recognition of this fact is incapable of furnishing the least precise indication. With prolonged practice, we can thus distinguish young horses from old horses, but we doubt whether such an examination does not ordinarily expose one to error.

2. Raising of the Skin of the Forehead or of the Cheek. - "One of the signs by which a horse that is old can be recognized consists in pinching, between the index finger and the thumb, the skin of the forehead, raising it with the fingers from the parts below, and then suddenly letting go; if this skin then quickly returns to its place and presents a very smooth surface, as it clid before, the animal will be very good to serve as a stallion, etc." I

1 Ibn-el-Awamm, Le livre de l'Agriculture, translated from the Arabian by J. J. Clement Mullet, Paris, 1867, t. ii.. 2e partic, pp. 27 et 58. (This book appears to have been written in the twelfh century of the Christian era.) 
Aristotle recommended this same procedure, but he preferred the skin of the lips to that of the forehead." "If," says he, "in raising the skin from the lips, it is promptly retracted, the animal is young; if it remains wrinkled for a long timc, he is old."

3. Examination of the Nodes of the Tail.-The practice of this ancient procedure, upon which Minot, one of our associates, has particularly insisted, is no more positive than the preceling.

What Minot ${ }^{2}$ called nodes or knots are nothing more than the prominences formed upon the lateral surface of this appendage by the transverse processes of the first eoceygeal vertebre. The first of these nodes shonld appear between thirteen and fourteen years, should be altogether distinet at fourteen and one-half years, and shonld show a depression behind at fifteen years. The second should be distinet between seventeen and eighteen years, and the third at twenty-one years.

These lateral projections of the eoecygeal vertebræ are, perhaps, most marked in very emaciated subjects, but their prominence only appears to indicate this to us. We likewise consider the caudal examination as being useless.

4. Examination of the Teeth.-This is the only positive examination. It comprises two steps:

1st. The examination of the incisors upon their anterior surface.

2d. That of their tables, of the tusks, and of the molars.

First Step.-The observer stations himself on the left side; the two lips, seized with the open hand, are separated from each other. If the animal offer any resistance, the right foot is raised without being given a point of support, and, if necessary, he is subdued by the application of a twitch to the ear.

It is then easy to recognize :

a. If the incisive arcade is composed of teeth of the first or of the second dentition, or of those belonging to both.

$b$. If the teeth are normal in number.

c. If they have the normal situation, direetion, and dimensions.

d. If they correspond with one another reeiprocally.

$e$. If their anterior face and their free border are intact.

$f$. If, finally, they have not been subjected to fraudulent practices.

Aristotle, Hist. anim., t. i. p. 401.

2 J. Minot, Appréciation des chevaux d'après les caractères du pouls et l'exameu des formes extérieures, Paris, 1850 , p. 244. 
The existence of these facts having been ascertained, the observer releases the lips and prepares for the second step.

Second Step.-The left hand is applied upon the nose to prevent the horse from advancing; the right is introduced into the mouth and seizes the tongue in the manner already indicated (Fig. 25). This procedure must be executed with gentleness, as before stated, for the brutal tractions exereised upon this organ are painful and often ineite resistance from the animal.

It suffices, in most instances, to insert the index and middle finger's into the interdental space and separate these two digits in order to cause the animal to open his mouth; the inferior lip is lowered with the thumb; as to the left hand, it is kept in position upon the nose.

The observer must then fix his attention :

Upon the incisors of the two jaws.

Upon the canines.

Upon the molars.

Relatively to the incisors he will observe:

a. Their form and the details of their dental table.

$b$. Their direction and their length.

c. The state of freshness of the corners.

Concerning the canines, he will examine :

a. Their freshness.

$b$. Their degree of wear.

c. Their direction and their length.

Finally, the examination of the molars must be made upon the two sides, the tongue being grasped by the left hand and the right hand successively, to expose the corresponding areades. With the hand which remains free one or other commissure will be separated outwardly. If the horse offers any resistance, he should be backed into a corner and the head kept in an elevated attitude by an assistant.

This examination is important, for an abnormal condition of the molars prevents the animal from masticating properly, which diminishes his vitality and his resistance to fatigne. It will reveal, therefore :

1st. The number of the molars and the dentition to which they pertain.

2d. The state of their surface of friction.

3d. Their length and their direction.

4th. Finally, the integrity of their substance, the state of the gums and of the cheeks. 


\section{CH A P TER III.}

\section{THE CHARACTERS FURNISHED BY THE TEETH.}

At the point at which we have now arrived, is not the reader justified in asking why we have led him into the details of so minute an anatomical description? Would it not be better, after a summary exposition of the construction of a tooth, to enter immediately upon what we appropriately call the characters of the age? Evidently not, as he will hereafter comprehend.

The effects of the friction, pertaining to the dental apparatus, are slow, insensible, and variable, three factors which render the wear difficult of appreciation. Incessantly clcansed, rubbed, polished, worn, and displaced by the action of the saliva, the lips, the cheeks, the tongne, the aliment, and the muscles of mastication, the teeth, which always seem to the eyes of the superficial observer to have the same appearance, nevertheless modify their form at every movement. It is for this reason that we have thoronghly studied the configuration, the structure, the mode of eruption, and, in a word, the manner of existence. The wear resulting from these diverse influences is so fecble, when we end avor to trace it during a short interval, that it necessarily implies, in order to be intelligently recognized, a profound anatomical knowledge. The theoretical details, which have been the theme of the preceding ehapters, are consequently justified.

Restrictions to be made.-Does this mean that we shall necessarily obtain invariable indications for the determination of the age? By no means, for the variety of the conditions of existence of the animal is an influence which the tissues, apparently the most unchangeable, obey like the organism itself. If, for example, the alimentary substances are different in nature, texture, origin, and physico-chemical properties, the functional activity of the tooth will be proportionally inereased or diminished, and its resistance to the deteriorating agents will be more considerable or more feeble. Besides, identical results will manifest themselves if the tooth does not possess, in all subjects, the same configuration, hardness, inclination, volume, and dimensions. Moreover, the horses of the North do not mark their teeth like those of the South, East, and West; those of the mountainous countries like those of the plains; those of the finer races like those of the common races, etc. As these two sorts of variations, in fact, always exist face 
to face, it follows that the churacters of the age can never be formulated upon absolute principles. To endeavor to establish, upon this point, some invariable prineiples would be systematizing beyond all rational bounds and in defiance of the most elementary observation.

We will therefore give the reader nothing more than altogether general indications, and he will have to interpret them, saying to himself that the wear of the dental apparates is manifested rather in this manner than otherwise. His theoretical knowledge and his practical sense, his pereeption, and his good judgment will do the rest. Called upon to excreise his judgment in certain localities in purelasing for himself or for others horses differing as to their intended service, it will be his duty to examine, at the beginning, some particular types of jaws; thus he will be cnabled, at the end of a relatively short time, to recognize the age with an accuracy sometimes surprising. Passing into other localities, he will be obliged to complete his technical education and adapt himself to new months and to new types of wear.

In the remarks which follow, we will first review the actual state of the science, and add thereto our own views and observations; then we will present for the consideration of the reader a series of plates, chosen from the numerous authentic mouths of our collection, and as to whieh we will furnish some explanatory information.

In France, all foals, save those which are thoroughbred, are supposed to be born in spring-time, - that is to say, in the season of the year when pasturage is abundant and affords a convenient nourishment for the young animals. There are, nevertheless, some exceptions in this respect, and it is on account of the varialole periods of the dressing and the sale of the animals that it is necessary to employ certain variations in the terminology by the use of the following expressions :

It is said that a horse is coming or rising to a certain age when his month is at the point of presenting the elassical cliaracters of the age to which reference is made; for example, a rising six-yectr-ole. He las a eertain age when all these characters really exist. Finally, he is past a certain age when these characters, morc marked, commence to disappear, to be replaced by those of the age which immediately follows that which was previonsly indieated ; for example, a six-yecer-old pest.

The knowledge of the age of horses is based npon the observations

1 It is not the same in England, at least for thoroughbred horses, whose age is always estimated from the 1st of January. 
as a whole, which it is necessary to classify methodically, in order to render its study more simple. We should mention once for all that this knowledge does not include that of the canines or the molars: the former, because they do not exist in all subjects, and because their wear is too irregular ; the latter, because they are practically not very accessible in the examination, and because they have already been discussed.

A division which naturally presents itself consists in distinguishing, on the one part, the phenomena that pertain to the milk-teeth, and, on the other, those which relate to the permanent teeth; but the following subdivisions must also be made :

1st. The period of eruption of the incisors of the first dentition.

21. The period of their levelling, their progressive wear, and their expulsion fiom the alveolus.

3d. The period of shedding of the deciduous incisors and their replacement by those of the sccoml dentition.

4th. The period of lecelling of the latter.

5th. The period of the successive forms which their table of friction presents, and the details that are observed there.

Whence it follows that there are five prineipal periods from birth to extreme old age.

First Period.-Eruption of the Incisors of the First Dentition.-At the moment of birth none of the incisors have penetrated through the gums; the anterior border of the pincers alone is outlined underneath the mucous membrane, which is red and congested in both jaws. (Plate I.)

About One Week.-The pincers generally appear in from six to eight days, and the eruption of the superior precedes that of the inferior. (Plate II.)

It is of very little importance to examine the teeth at this epoch of life, for the general aspect of the foal,-its gait, which is not yet defined, the state of the hairs and of the mane,-all, in a word, indicate at a glance that the animal is still young.

About One Month.-The intermediates emerge through the grums in from thirty to forty days, and the anterior border of the pincers shows the effects of wear. (Plate III.)

About Three Months.-The jaws now present four teeth above and below, which have emerged through the gums; the pincers commence to wear on their posterior border. (Plate IV.)

About Four Months.-The incisive arcade is wider transversely; the inferior intermediates have emerged still more through 
the gums; their anterior border commences to wear, but only on its intemal part, which alone comes in contaet with the corresponding superior teeth. (Plate $\mathrm{T}$.)

About Five Months.-The eruption of the pincers is complete ; the intermediates touch by the whole extent of their anterior border; the mueous membrane behind these teeth is sometimes sensitive, in consequence of the presenee of the eorner tooth, which is at the point of piereing the gums. (Plate VI.)

About Six Months. - The intermediates are more prominent; their posterior border commenees to wear. The mucous membrane, in the region of the corner, is tumeficd and vascular ; sometimes, even, the anterior border of this tooth has pierced it very close to and behind the intermediate.

Eight to Ten Months.-The corner is ordinarily visible by its anterior border only, but more or less slowly according to the subjects. As to the intermediates, they are well emerged from the gums, which are at the level of their necks. The inferior incisive arcade forms an almost regular semicircle. (Plate VII.)

It is impossible to pass, with precision, deeper into the details, diverse causes being susceptible of influencing the eruption of the teeth and their wear. Some subjects are strong and vigorous, others are delicate. The nourishment also may have been more or less abundant. Finally, it is certain, although it may not always be possible to appreciate the reason, that, all things being equal, there are some animals more precocious than others.

At the commencement of the first period of life the foal is nourished by the milk of its mother; the wear of its teeth, but little marked, is due only to their simple apposition,- to their contact with the superiors; it is only at a later period that the animal commences to consume the fibrous and resisting aliments, and that its incisors become more blunt. However this may be, the wear will be more pronounced upon the pincers, whose eruption took place first. It will be the same, in each tooth, with the anterior border as eompared with the posterior.

Besides, after the supposed epoch of birth, it is not very difficult to judge, almost exactly, the age of the young subjeet, which, in most instances, is still suekling its mother. It is at the end of this time, which continues eight, nine, or ten months, that the animal, in eertain localities, is sold, as we have seen in Brittany, and taken into distriets where the food is more abundant, and where, especially, he is reared with a view of utilizing him for work and preparing him for sale. 
Second Period.-Levelling and Progressive Wear of the Incisors of the First Dentition.-About One Year.-The corners are well emerged through the gums, but the inferiors have not yet come in contact with the superiors. The inferior pincers, if not levelled, are much worn upon their two borders; the incisive arcade commences to be slightly depressed at their level. The superior pincers and the intermediates are scarcely worn through upon their posterior border. (Plate VIII.)

About Sixteen Months.-CThe superior corners are in apposition with the inferior, and have commenced to wear, in both jaws, by their anterior border which touches the intermediates; their necks are quite visible above the gums. The inferior pincers are often, at this time, completely levelled, but in the intermediates this is much more rare. In the upper jaw the table of the two sorts of teeth is completely formed ; the depression of the incisive arch is present. (Plate IX.)

About Twenty Months. - The inferior corners are much worn over the whole extent of their anterior border; the superior corners show the wrear a little less. The inferior pincers become more constricted at their base and are completely levelled; the intermediates are often levelled. Ordinarily, the incisive arch is still less convex. (Plate X.)

About Two Years.-The inferior dental areade is completely worn down to the level of the pincers and the intermediate teeth; the superior arcadc is less worn. The neck of the superior pincers is above the level of the gums. Pressure on the palatine arch posterior to these teeth shows a sensitiveness of the gums, and reveals the presence of the permanent incisor underneath the mucous membrane. The intermediate teeth commence to show their necks, above and below. Finally, the incisive areade becomes wider transversely, and is much flattened in its central portion. (Plate XI.)

It can be seen from the preceding characters that the levelling of the milk-teeth does not furnish as precise an index as Girard would seem to indicate. According to this author, in fact, "the pincers should always be levelled at ten months, the intermediate teeth at one year, and the corners at from fifteen to twenty-four months." Unfortunately, there are too many allowances to be made in this respect, for these changes follow each other with much less regularity. Some variations result, as we know, from the thickness of the nucleus of cement which occupies the bottom of the external dental cavity ; they depend also upon the character of the food and the manner of existence of the animals. 
It is especially at the end of this period that the observer must exercise his pereeption and judgment in giving to all the variations of the wear their proper value, particularly that of the corners and the superior incisors. He will see, little by little, the free portion of the pincers diminishing in length, their neeks insensibly protruding above the gums, and their color assuming a brownish hue. As they are pushed out they become loose, movable, break off in fragments, and naturally fall out, preparatory to being replaced by the permanent tecth. This falling out will mark the third period of the life of the horse.

Third Period.-Eruption of the Permanent or Adult Incisors.-The eruption of these teeth commences at the age of two and one-half years and terminates at that of five years.

About Two and One-half Years.-The successive sliedding of the milk pincers, the tumefaction of the gums at their level, and the appearance of the anterior border of the one or the other permanent pincers usually begin in the superior jaw ; in six weeks or two months their evolution is completed.

Rising Three Years.-This expression indicates that the colt has not yet attained its third year, but that it is elosely approaching this age.

In the superior jaw the adult pincers have perforated the gums - and are at the point of reaching the level of the milk intermediates; in the inferior jaw their borders and sometimes a variable portion of the crown emerge from the gums. In all cases these teeth are unworn. The milk intermediates appear constricted at their base and much worn off; as to the corners, the wear involves their external borcler. (Plate XII.)

Three Years.-The animal has now completed his third year, and his jaws present four permanent pincers well emerged through the gums, whose surface of friction is found at the same level as that of the neighboring teeth. By carefully examining the mouth, the presence of the incisors of the second dentition can now be immediately recognized. By their greater volume, their slightly-square form, their deeper color, and the groove on their anterior face they eam be clearly differentiated from the others, always constrieted at their base, smaller, more convex, whiter, and not grooved in front. We must also take cognizance of the time of the year and the race in fixing the age of three years. Thoroughbred colts attain it in the month of Jannary, while those of the common races, whose birth takes place later,- " in the spring-time, in the grass," as it is called,-will reach this age only in the months of March, April, or May. 
Three Years Past. - The colt has passed his third year by two, three, or four months. The four permanent pincers show wear on their two border's (anterior and posterior), which are on the same level, but the external dental cavity is not yet cireumseribed by the circle of central enamel. The milk intermediates are much worn and pushed ont, so as to show their bases, and are more or less broken; one of them is sometimes almost ready to fall out; the table of the corners is sensibly enlarged and prolonged towards its exterual border. (Plate XIII.)

Rising Four Years.-Eruption of the adult intermediates and progressive falling out of the milk intermediates. The latter are at times replaced in the two jaws. The newly-erupted teeth are altogether virgin and have not attained the level of the corners; they show no trace of wear. The central enamel, in the pineers, cireumscribes the external dental cavity, flattened from before to behind and already greatly diminished. The milk eorners appear much pushed out from the gums and bare at their bases. (Plate XIV.)

Four Years.-Each jaw shows four permanent teeth whose tables have all reached the same level. The intermediates are worn upon both of their borders (anterior and posterior), but the central enamel is not yet completely separated from the peripheral enamel. Often the inferior pincers are levelled, especially in thoroughbred horses. Finally, the corners of the first dentition are constricted at their bases, pushed ont, and much levelled. (Plate XV.)

Four Years Past.-Loosening and successive shedding of the deciduons corners, which look like stmmps barely able to retain their places. Sometimes one of the superior falls ont, and leaves the permanent incisor in its place, ready to penetrate through the gums; at other times the superior jaw already presents, on one side, the free part of the corner of the sceond dentition. Pronounced wear of the pincers and the intermediates, anomalies in the eruption, also frequently takes place at this period. It is not rare, in fact, to see the eruption of the intermediates and the corners occurring at the same time. The animal is then only four and one-half years old, sometimes only four, although the tecth may actually mark five. ${ }^{1}$ (Plate XVI.)

Rising Five Years.-The four milk corners have fallen out and are replaced by those of the adult teeth. The latter, not having reached the same level as the intermediates, do not show the least trace of wear. The pineers show ennsiderable wear; their central enamel, elongated transversely, is separated from the anterior border of the dental table. 
The surface of frietion of the intermediates is completely formed. (Plate X VII.)

Five Years.-The mouth is made, full; the ineisive arch is a regular semicircle. All the permanent teeth have reached the same level in both jaws. The anterior border of the corners tonches and begins to wear; the posterior is not worn. (Plate XVIII.)

Five Years Past._The preceding characters on the pincers and the intermediates are more marked. It is especially from the full development and the freshness of the corners that this age is determined. The posterior border of these teeth in the superior incisive areade is only commeneing to wear. The jaws form a regular semicircle, convex in front and from above to below, when examined in profile from the side.

Fourth Period.-Levelling of the Permanent Incisors. The signs furnished during this period by the dental apparatus already become more difficult to reeognize. The determination of the age also now becomes more uncertain than in the preceding period. The prineipal points to be examined are the degice of wear of the corners, the form and transverse diameter of the ineisor teeth, and the form and situation of the central enamel in relation to the posterior border of the tables of friction. Finally, too much stress should not be laid upon the indications, often fallacions, of the levelling of the teeth, the disappearance of the so-called "mark," which is nothing more than the external portion of the external dental cavity colored black, and filled sometimes with alimentary matter.

Six Years. - Very marked levelling of the pincers, whose table tends to assume the oval form. Wearing of the posterior border of the corners, and the formation of a complete circle of central enamel around the external dental cavity. The latter, in the intermediates, is almost worn away to its bottom, and sometimes even these teeth are completely levelled. The eement is now commeneing to disappear from the anterior face of the pincers, especially towards the anterior border, which makes them appcar whiter than at five years. (Plate XIX.) [The corner incisor is very often a shell tooth, its posterior border being entirely absent. In such a case, a six-year-old can be reeognized by the fact that not only the anterior border but also its external extremity are decidedly worn.]

Seven Years.-The layer of ecment which covers the anterior face of the ineisors is worn off, so as to show the pearly tint of the enamel. The inferior corner, narrower from in front to behind than the superior, wears off the table of the latter, so as to form on it a noteh towards its posterior part, more or less visible according to the 
subject. This notch may sometimes be absent, and, in some eáses, is rasped off" with fiaudulent intent before selling the horse. [This notch commences to form at six yeurs.] The table of the inferior intermediates is ordinarily levelled, or at the point of becoming so, and begins to issume the oval form. The central enamel, in the pincers, is smaller, and becomes convex behind. Viewed in profile, the jaws form a semicircle which is less regular than at six years. (Plate XX.)

Eight Years.- The incisors have a yellowish tint; all the lower ones are levelled; their areade, quite regular, is narrower transversely than at five years. The pincers are becoming round ; the intermediates are oval; the corners are beeoming oval. The dental star is shown upon the tables in the form of a yellowish transverse line; it is most marked in the pincers, and often indistinct in the remaining incisors. The central enamel, still less extensive in the pincers, is more angular behind and nearer to their posterior border. According to Mayhew, ${ }^{1}$ the base of the corner is ent squarely by the gums, which gives to the free part of this tooth a square form. Besides, the mucous membrane is harder, less delicate, and the mouth now seems to have aequired its full strength. The inferior border of the maxillary bone is comparatively thinner; the cheeks are flat. Viewed in profile, the opposed superior and inferior dental areades no longer form a regular semicirele. Their are seems to be broken at the level of the place where the tables meet, and it acquires little by little the curve of an ogive. This results, as we know, from the change in the direction of the teeth, which are now opposed obliquely instead of perpendieularly, as at five years. (Plate XXI.)

Fifth Period.-Disappearance of the Central Enamel and the Successive Forms of the Dental Tables.-This period, in which it is said by laymen that the horse is old, or marks no more, extends from nine years to extreme old age, and is based upon characters less and less reliable. The greater the number of years, says Mayhew, ${ }^{2}$ with good practical judgment, the more difficult it is to arrive at an exact determination of the age. After the twelfth year there is but little probability of judging it accurately; after the sixteenth all is confusion, for there are no positive signs that will enable us to give a definite opinion upon this point, and it is better now to be cantious or remain silent.

Certain indications are, without doubt, capable of giving rise to the p. 104 .

1 Edw. Mayhew, The Horse's Mouth showing the Age by the Teeth, London, 3d edition,

2 Mayhew, loc. cit., p. 107. 
opinion that the horse is over fifteen or sixteen years. We concede that such an opinion from an experienced and sagacious man may at times become a certainty. Nevertheless, we do not think that any one is justified in saying positively how much older than sixteen years the animal is. Those who make this pretension have perhaps sueceeded in a few isolated cases; but, if it were possible to know each time their absolute reasons and their success, their numerous errors would prove that in most instances they are not guided by any positive principle: it is the absence of proof which saves them. In a case of adcanced age, prudence will prompt the observer or the expert to do no more than hazard conjectures. All those who, like oursclves, undertake the task of studying the age from authentic mouths of the horse, will soon be convinced of the necessity of eaution in making their estimates. We have seen some jaws thirty-five, forty, fortytwo, and forty-seven years of age which evidently presented the definite signs of old age. But by examination it was impossible to tell at what age the subjects from which they had been obtained had arrived.

The characters of this period are:

1. The successive forms of the free extremity of the incisors.

2. The disposition of the cul-de-sac of the central enamel in the two jaws.

3. The form and situation of the dental star upon the tables of friction.

4. The obliquity or the degree of incidence of the incisive arcades.

5. The convergence of the teeth by their free part, and the small transverse diameter of the same areades.

6. The degree of thickness of the peripheral enamel bordering the dental table in front and behind.

7. The appearance of the radical cement.

8. The external state of the tooth.

Nine Years. - The pincers are round ; their central enamel takes a triangular form, and their dental star, narrower but more marked, occupies almost the middle of their tables. The intermediates are becoming round, and the corners are oval. The superior pincers are often levelled. The noteh of the superior corners sometimes disalppears at this age. In profile, the jaws form an ogive, more marked than at eight years. (Plate XXII.)

Ten Years.-The pineers are still more rounl; their central enamel is smaller, distinctly triangular, and approaches more towards their posterior border. 
The intermediates are round, and the corners tend to assume this form. The dental star, more alplarent in all the tecth, is situated rather in the middle of their tables. The incidence in profile is still more oblique. (Plate XXIII.)

Eleven Years.-Romndness of the corners and of the intermediates. The central enimel forms a more or less small island, placed very ' 'lose to the posterior borker of the teeth. The dental star, narmower transversely, is found on the middle of the surfice of friction. The inferior corners, viewed in profile, are more narrow and almost as wide at their base as at their free extremity ; the gum extends squarely across their basc. The supcrior corners, more oblique, show a new notch; they are levelled or at the point of becoming so. (Plate XXIV.)

Twelve Years.-All the teeth are round, and at times the central enamel has disappeared. Frequently, however, a slight trace of the latter still exists in some of then. The tables in which this enamel does not exist present in their centre a yellowish spot, rather small, which is the dental star. In the superior corners the central enamel is very small. The two incisive areades are much narrower from side to side, and less convex on their anterior face. The tongue projects bevond the bars; the inferior border of the maxillary bone is becoming sharp ; the cheeks are flattened and the face hollowed upon its lateral surfaces. The incidence of the incisive areade has augmented in inclination, especially when the teeth have acquired considerable length. (Plate XXV.)

Thirteen Years.-The signs of the preceding age are more marked. The superior corners are ordinarily completely levelled or at the point of becoming so ; they have a well-defined notch when examined in profile. The central enamel is absent in the inferior incisors; in the superior pincers it has a rounded form. (Plate XXVI.)

Fourteen Years. - The pincers tend to assume the triangular form. The incisive areade appear's greatly depressed in profile and narrowed transversely.

Fifteen Years.-Triangular form of the pincers; this is only beginning in the intermediates. The dental star is very distinct and round in all the lower incisors. The central enamel on the superior pincers is much smaller. (Plate XXVII.)

Sixteen Years.-The characters of the preceding age more marked. Triangular form of the intermediates.

Seventeen Years. - All the inferior incisors are triangular; their dental star is round ; the central enamel of the superior pincers has 
almost disappeared; the inferior incisive areade is narrow and but slightly convex; an interspace now forms between these teeth. The tongue overhangs the bars more, and the saliva rums from the mouth when the jaws are separated. Viewed in profile, the latter form an ogive more or less acute. The obliquity of the corner's is more marked than that of the intermediates. Viewed in front, the teeth of each areade are very convergent by their erown. (Plate XXVIII.)

Eighteen Years.-The dental tables become elongated from before to behind. The central enamel of the superior pincers is absent.

Nineteen Years.-The tables of the pincers and the intermediates are longer from before to behind than transversely,-bianguldu; besides, these tables, by their lateral borders, converge behind and diverge in front. Central enamel absent in the superior intermediates. Viewing the jaws in front, the convergence of the corners is very decided. The teeth are more horizontal, often too long. (Plate XXIX.)

Twenty-one Years. - In profile, the two arcades meet each other at a very acute incidence. The superior teeth are convergent in fiont, and conceal the greater part of the inferior. The inferior incisive areade is, so to speak, no longer eonvex, and the teeth here become more separated from each other ; their tables are becoming flattened from side to side; finally, their posterior border is covered by a layer of enamel which gradually becomes thinner. A layer of radical cement often surrounds the base of the teeth. (Plate XXX.)

Thirty Years.-Beyond twenty years of age the horse is considered as having reached the limit of his life. The characters of the month are then those of extreme old age. Sometimes the teeth are too long and too horizontal; at other times, on the contrary, they are altogether too short and wom down to a level with the gums. In all eases, only a small portion of the root remains in the alveolar cavity. When the lips are separated, the maxillary bones, at the level of the palatine areh and the symphysis of the inferior jawbone, are very thin. Viewed in profile, the dental areades scarcely show more than the corners and the intermediates; the pincers remain hidden by the latter. Viewed in front, the teeth are so straight and prominent that, in order to see the inferior ineisors, the head must be raised. The superior converge towards the median line by their free extrenity, whilst they are very divergent at their base; wide triangular interspaces, into which pointed prolongations of the mucous membrane as well as brownish alimentary matter are prolonged, separate the pincers from the intermediates and the latter firom the corners.

The tables of friction become more and more flattened upon their 
lateral surfaces; the dental star shows itself here by a white spot, or in some very old horses by a small cavity, which oceupies their centre; the incisive arcades are almost effaced, rectilinear, and very narrow in the transverse sense.

The peripheral enamel is incomplete; it is often wanting behind; at other times no traces of it are found in front. When it has totally disappeared, the radical cementation takes its place (Fig. 286), surrounds and consolidates the incisive stumps into their cavities, at the same time that it increases the surface of the dental tables. As this layer of enamel wears off, there are seen through its thickness the strix of the subjacent dentine, provided always that there is no superficial cementous formation.

The canines, either the superior or the inferior alone, or both simultaneously, are always very much worn. As to the molars, they are ordinarily very irregular.

Finally, the tongue protrudes beyond the bars; the narrowness of the lingual canal causes a flow of saliva when the jaws are separated; the mucous membrane is wrinkled, less vaseular, and adherent to the bone; the inferior border of the maxillary bone is altogether sharp and the lateral sides of the face hollowed.

The general aspect of the horse also furnishes other signs: the temples and the supra-orbital arches are gray; the hairs of the mane and the tail have fallen out; the head and the body are emaciated; the axes of the members lose their regularity, the articulations their neatness and their mobility, the movements their ease; in a word, the practised observer recognizes quite easily upon the organism which he views the signs of degeneration, fatigue, and wear. It is by an intelligent deliberation and comparison of these numerous characters that one ean form an opinion relatively near the truth.

The fact remains, without contradiction, that numerous researches have yet to be made upon all questions which pertain to a more exact determination of the age of the horse. Those of our professional brethren who are able to conduct them will have deserved well of science if they are willing to publish their results.

Before passing on to the study of the irregularities of the dental system, we will request the reader to read the explanatory legends of the plates to which we have referred him in this chapter, and which, ly reason of their dimensions, we have not been able to insert completely into the text. If he familiarizes himself thoroughly with the characters which lie should recognize, it will be more easy afterwards for him to apply them upon the living animal. 
PLATES. 


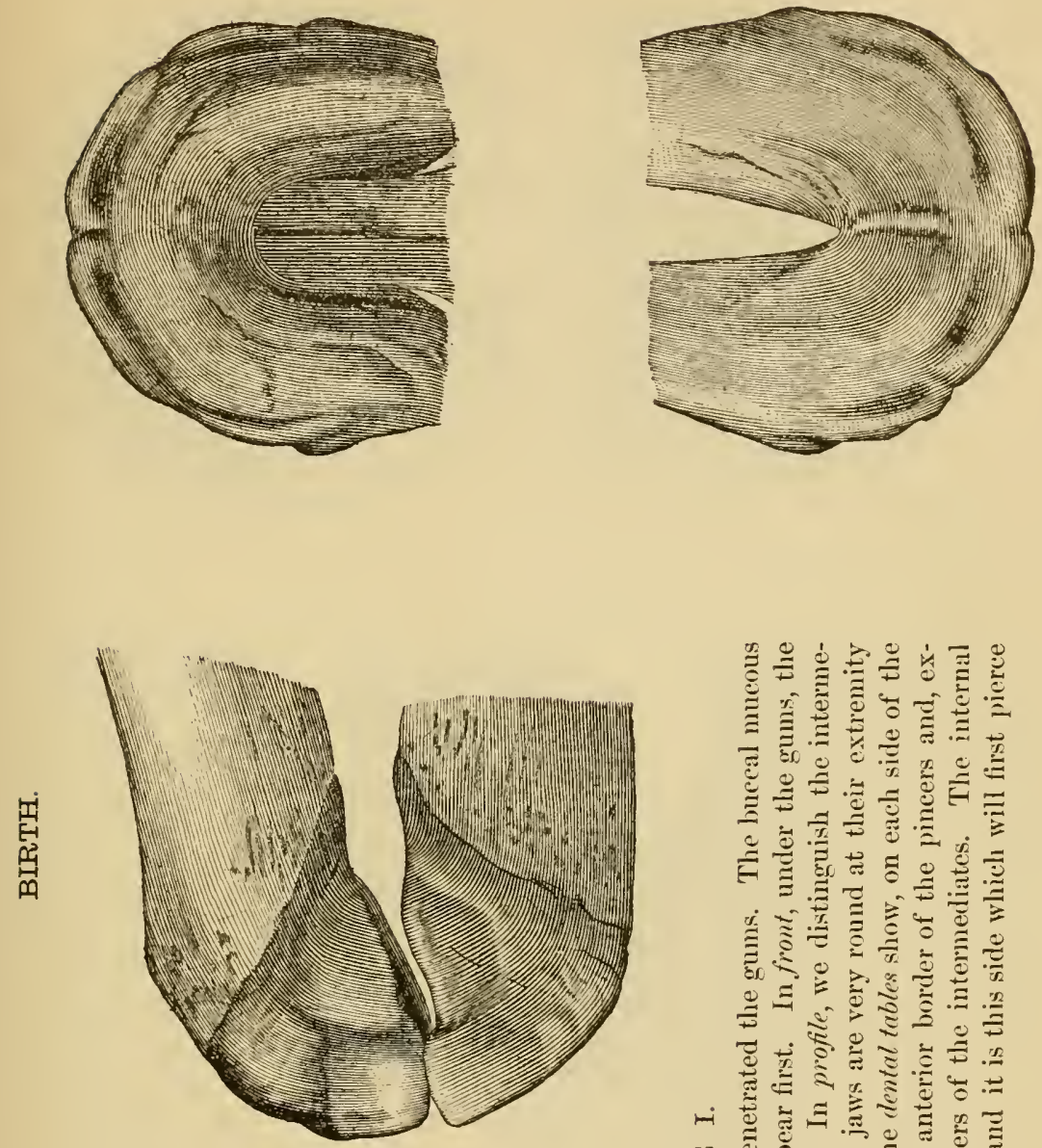

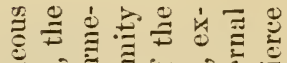

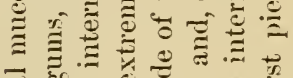

马

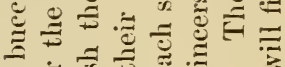

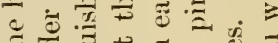

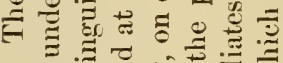

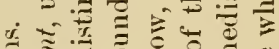

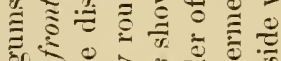

क $=2$

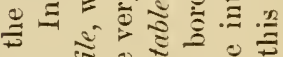

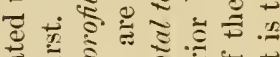

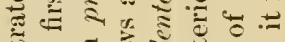

-

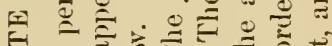

플

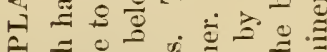

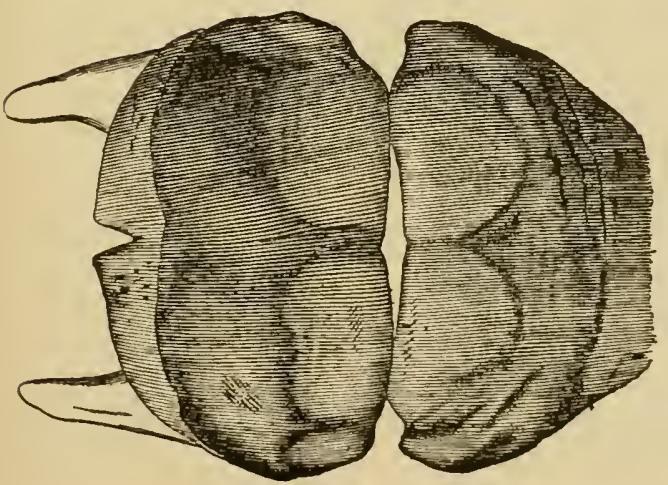

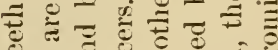

의

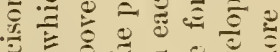

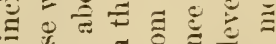

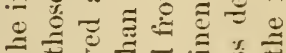

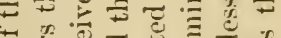

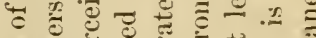

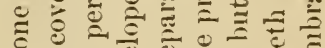

$\bar{\gamma}_{1} \equiv$ ए

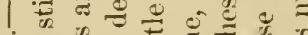

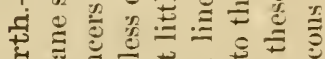

ติ

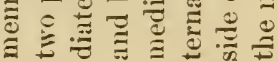



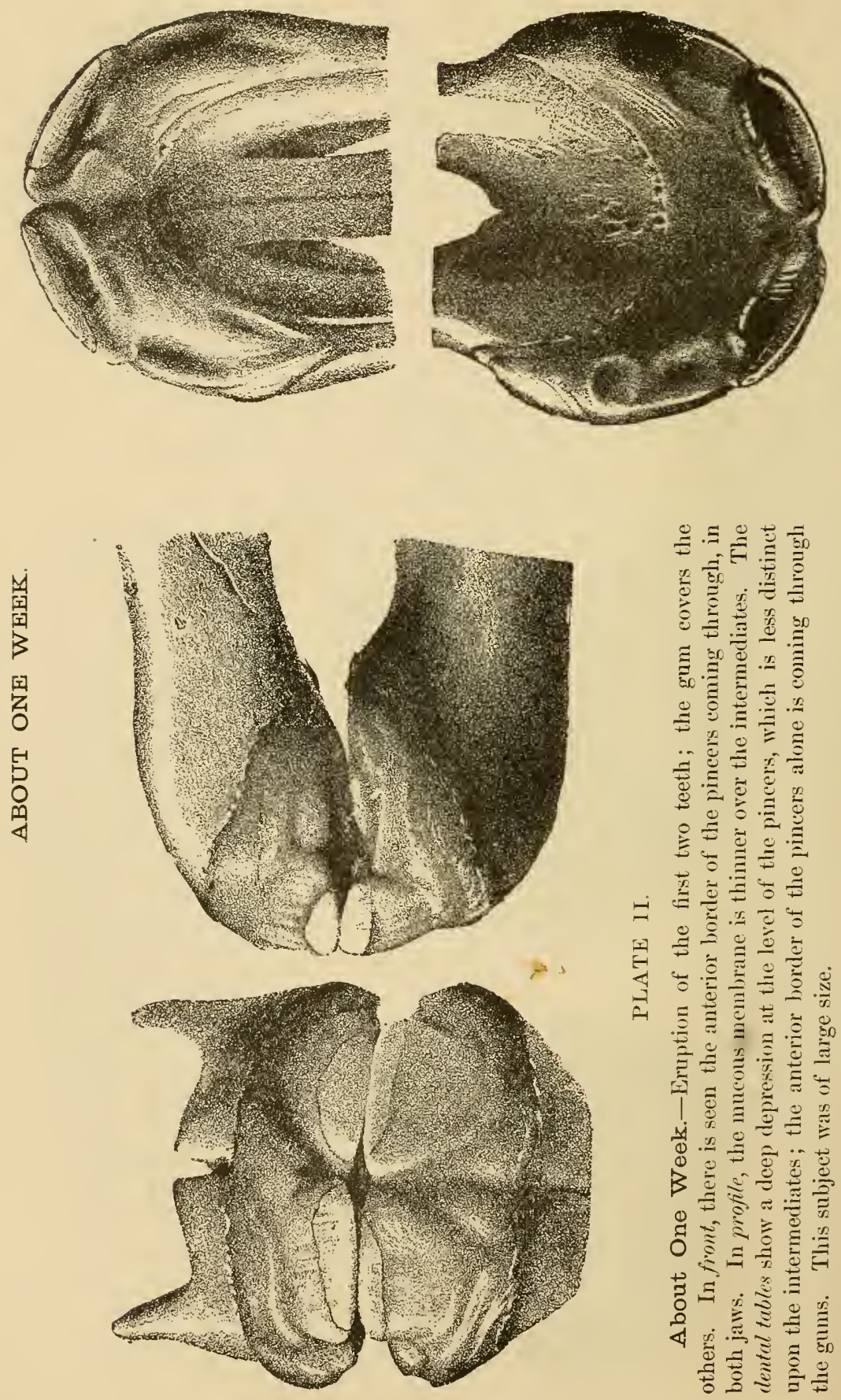

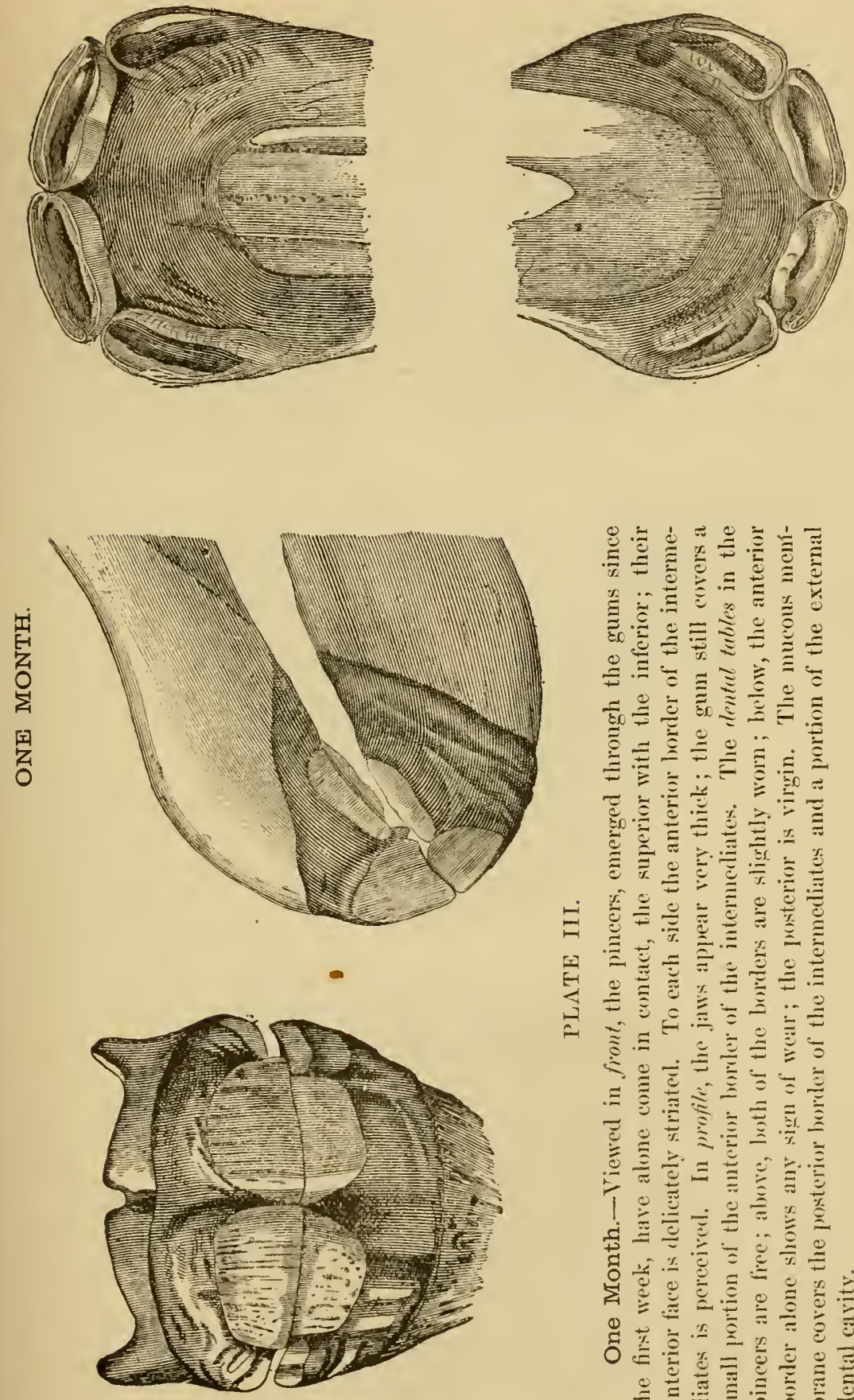

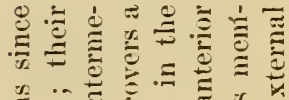

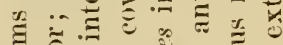

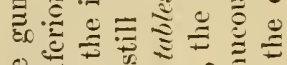

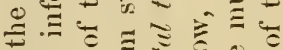

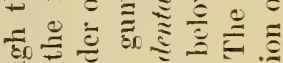

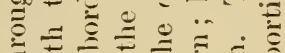

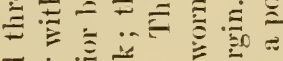
¿

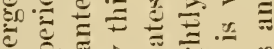

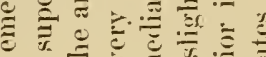
-

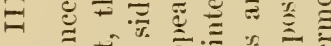

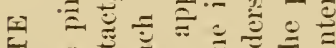
E $\cong$

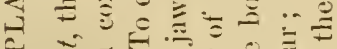

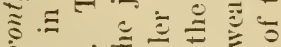

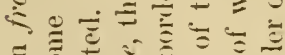

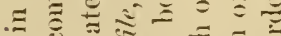
च

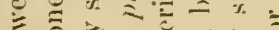

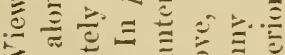

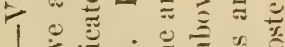

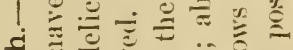

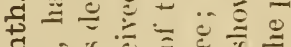
ดี

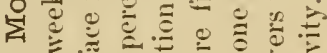
๑ $\cong$

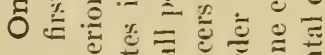

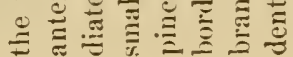




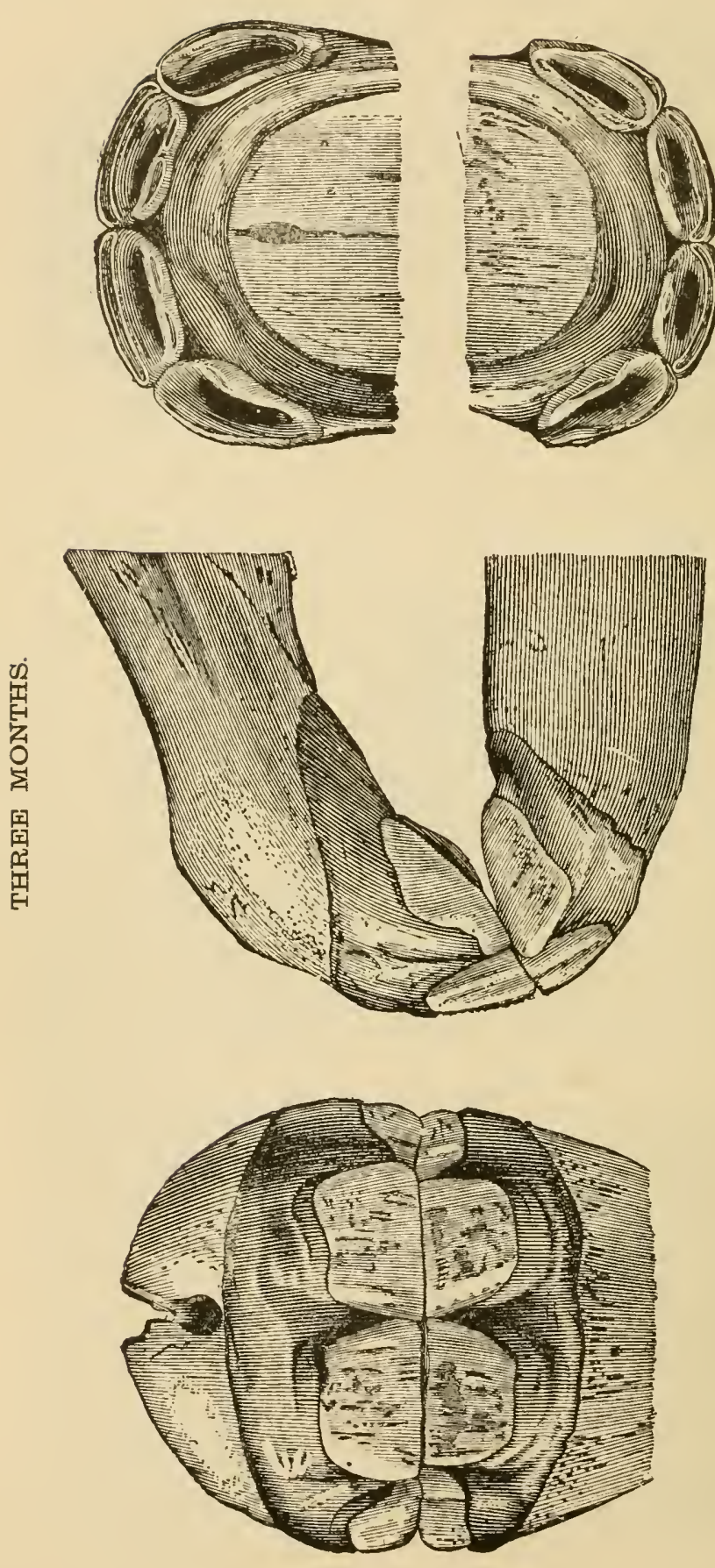

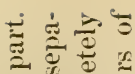

巳 :

$\because 38$

$\stackrel{0}{\Xi}$

ए马

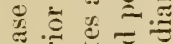

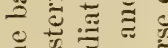

$\cong$

$\ddot{\overline{0}} \because \overline{0}$

\& $\Xi \Xi$

$\ddot{\Xi} \cong \stackrel{\Xi}{=}$

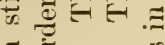

.气

ว

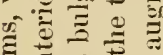

है

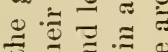

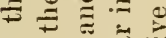

क्ष०

อ

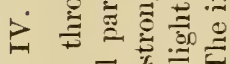

$\Rightarrow \quad \vec{z} \%$

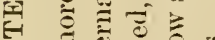

〈

Q

馬苛苛

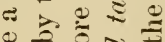

苟苛

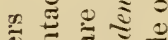

ङ

$\Xi \Xi$ E

$\cong \cong$

๘0

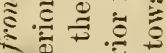

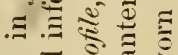

¿

हैं 20

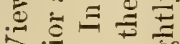

ᄀ范

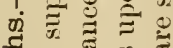

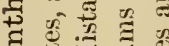

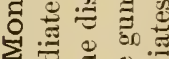

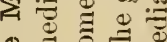

ه

范 总

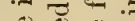

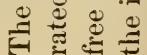



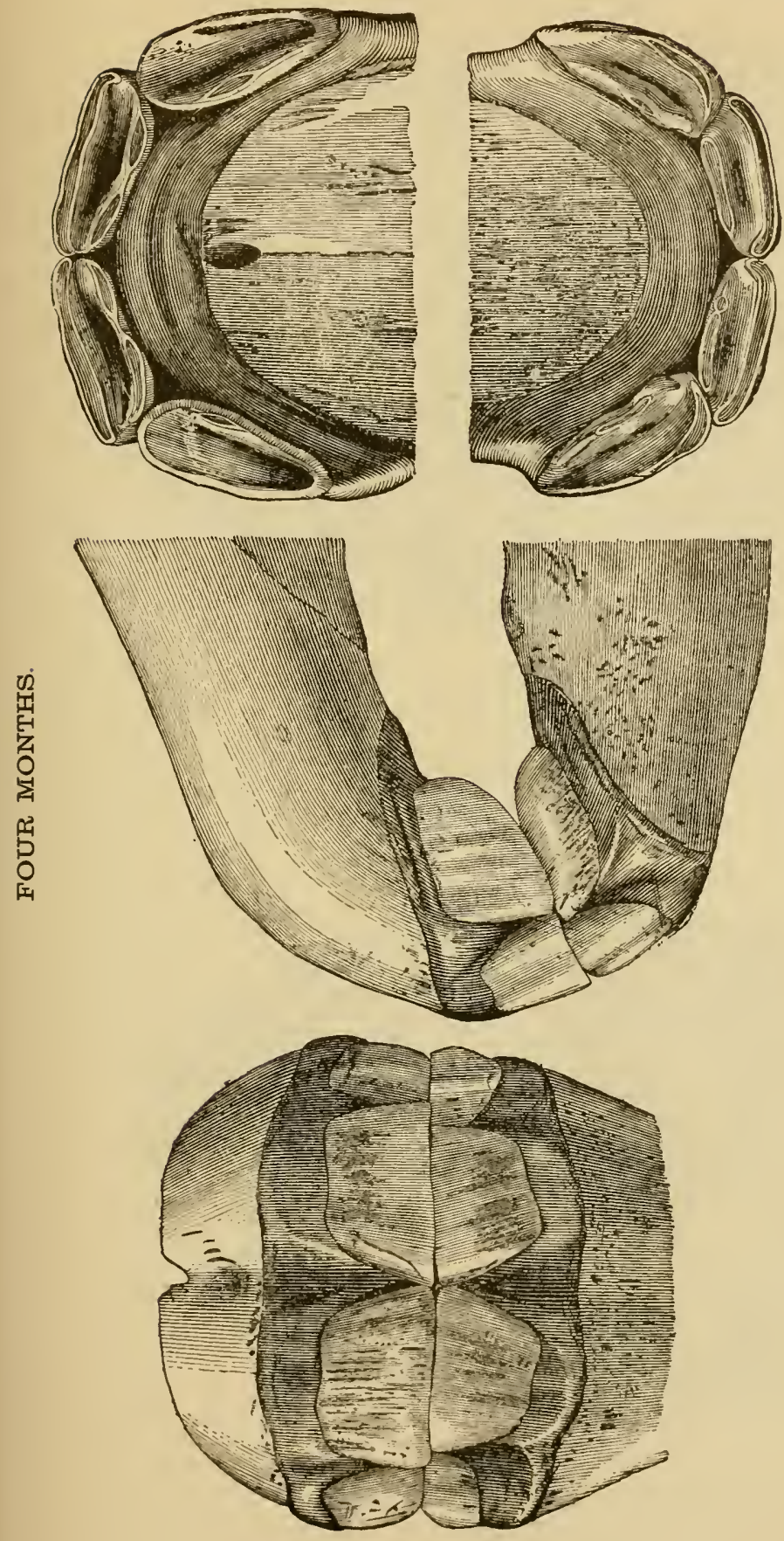

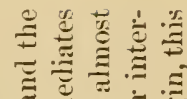

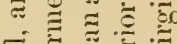

ट्ट

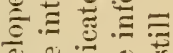

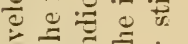

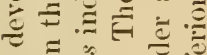

ธ.

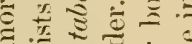

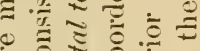

ฮ

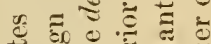

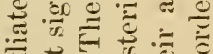

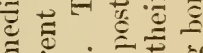

छ

Ð

( $\overrightarrow{7} \cong \overrightarrow{0}$

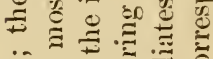

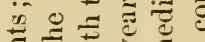

Ð

$\Xi 5 \div \overline{0}$

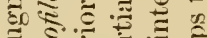

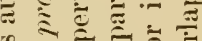

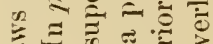

$>\sum \Xi$ क

‘过䓃命

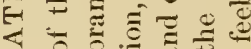

उ०

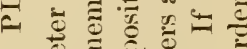

छ

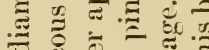

\&

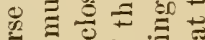

¿ $\div$

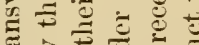

ㄴ.

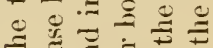

$\nsubseteq \stackrel{\Xi}{\Xi} \pm \Xi$

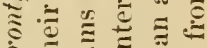

- $\Rightarrow$ हो $¥ 0$

$\Xi \forall \cong \cong$

एँ

है

$\therefore \div$

广光跣

○次

व $\approx$

: $=\approx$

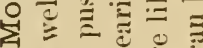

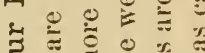

० $\cong$ है

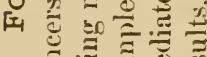

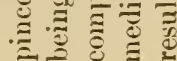




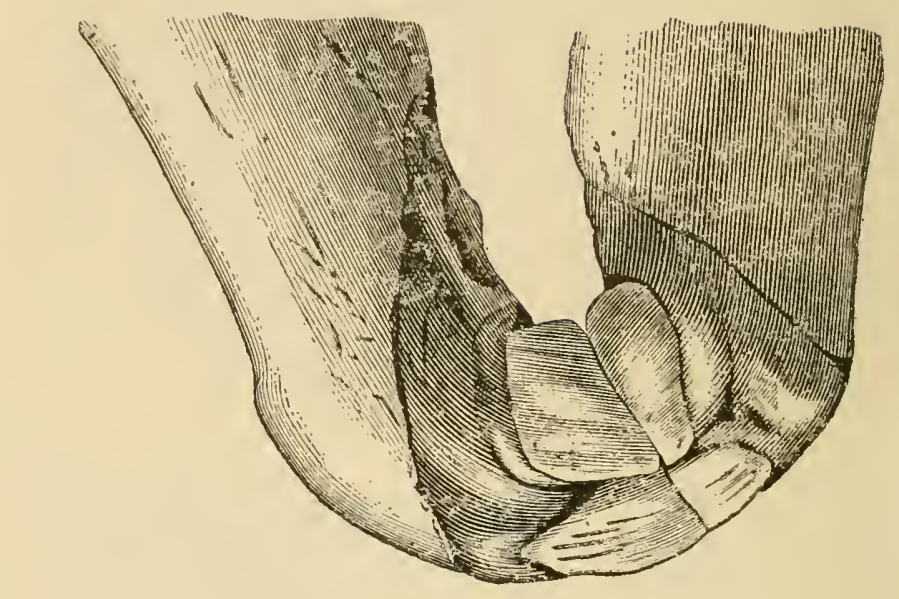

空

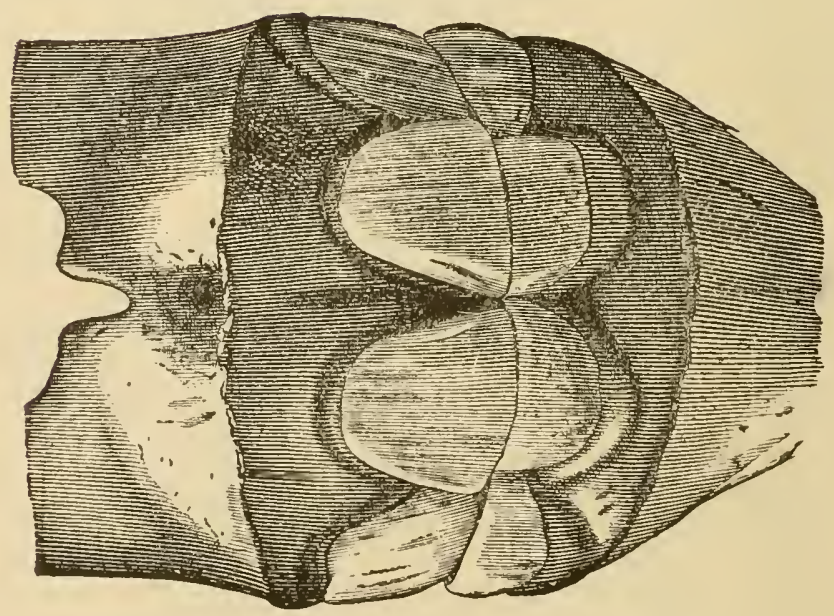



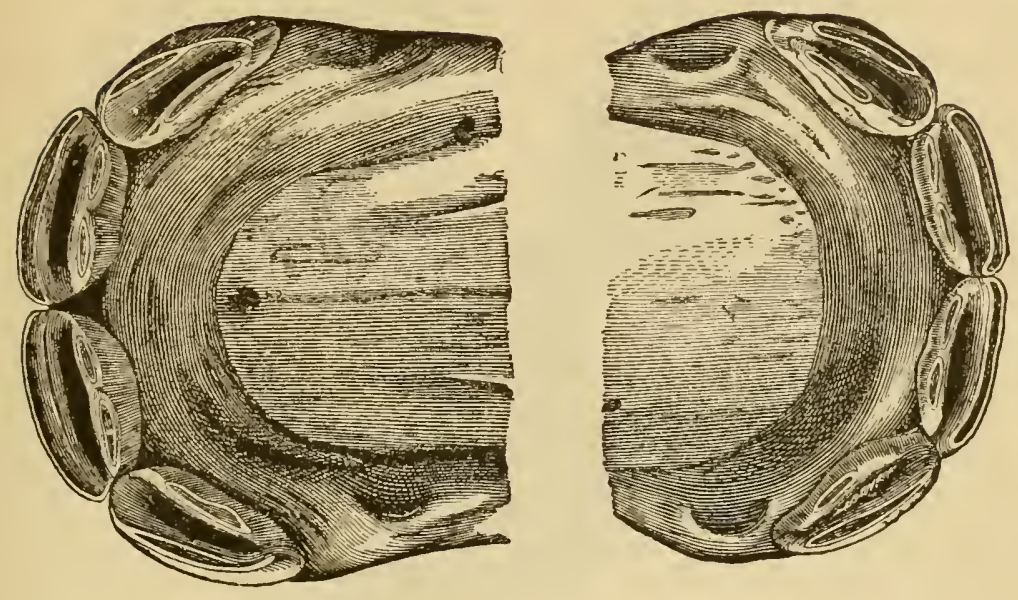

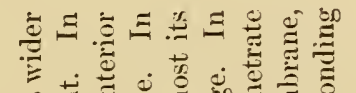

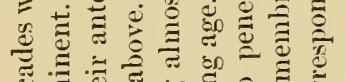

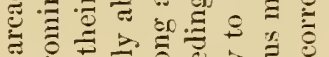

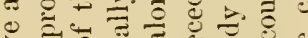

$$
\begin{aligned}
& \text { : }
\end{aligned}
$$

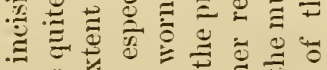

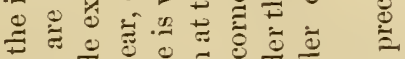

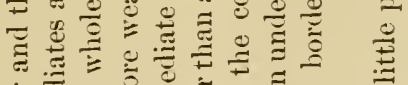

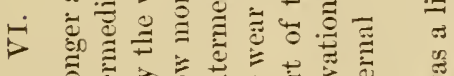

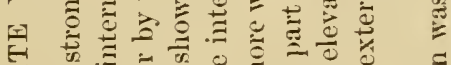

$$
\begin{aligned}
& \text { A } \\
& \text {. }
\end{aligned}
$$

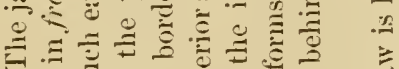

$$
\begin{aligned}
& \text { । }
\end{aligned}
$$

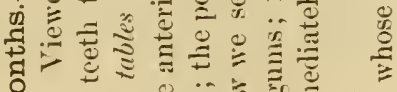

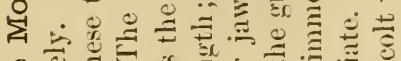

$$
\begin{aligned}
& \text { o } \bar{r}_{0} \equiv
\end{aligned}
$$

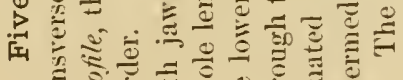

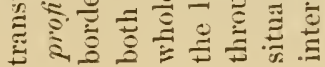




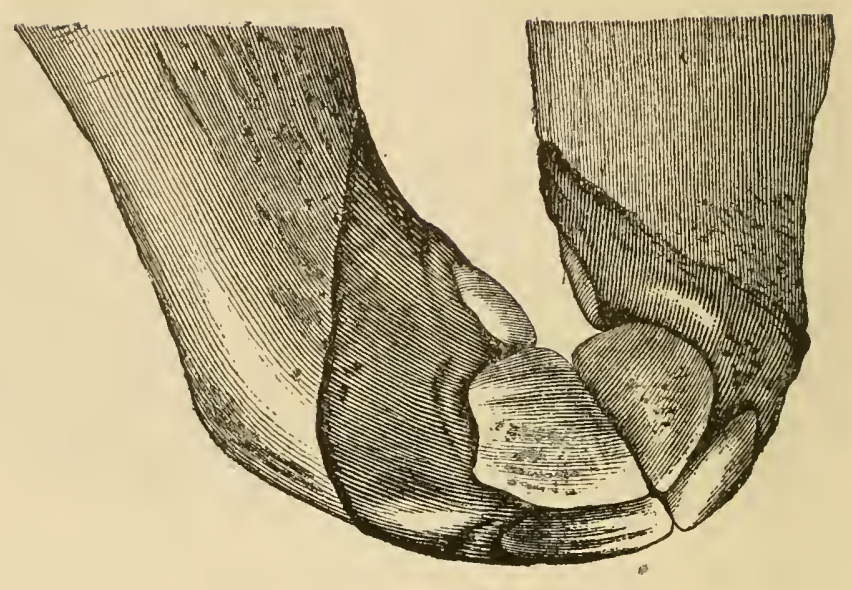

号

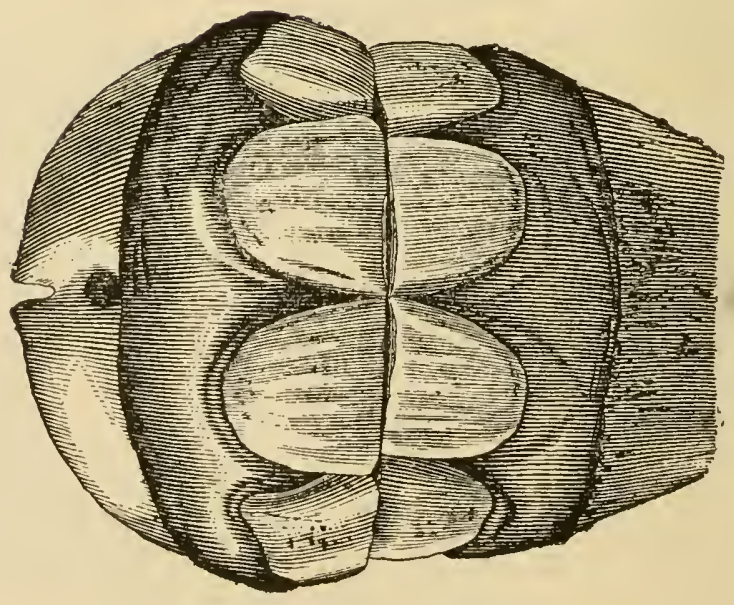



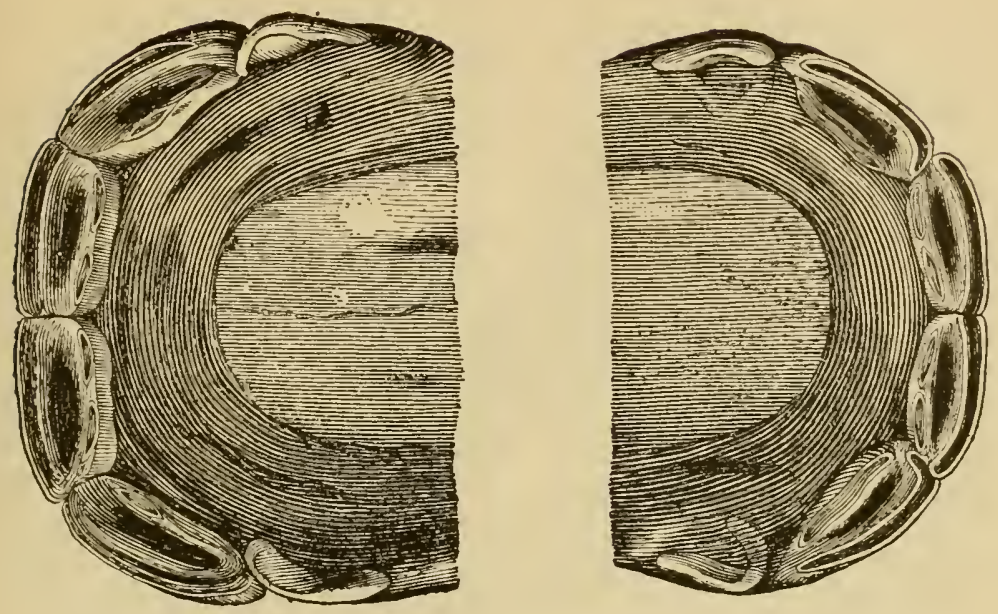

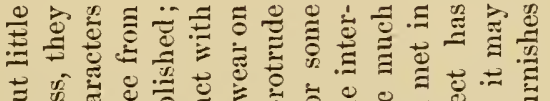

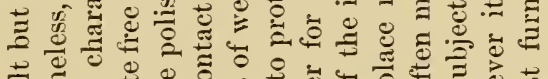

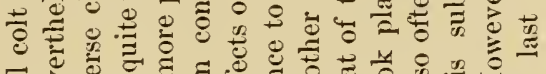

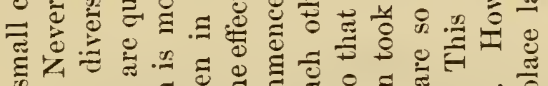
घ

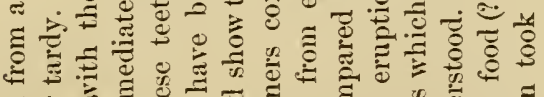

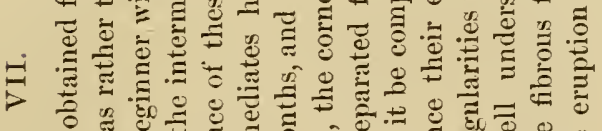

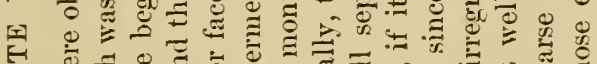

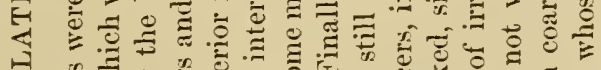
A

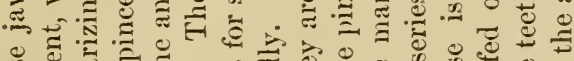

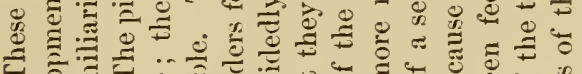

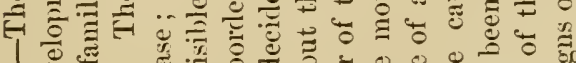

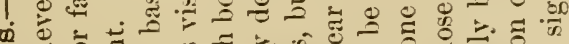

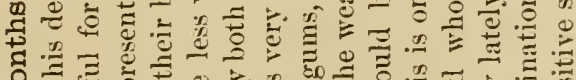

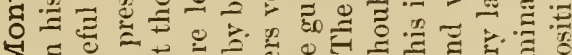

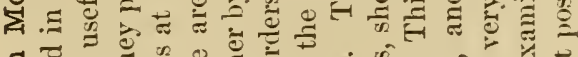

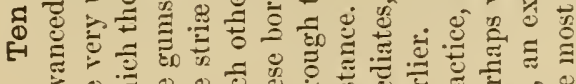

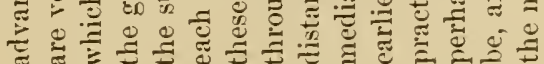




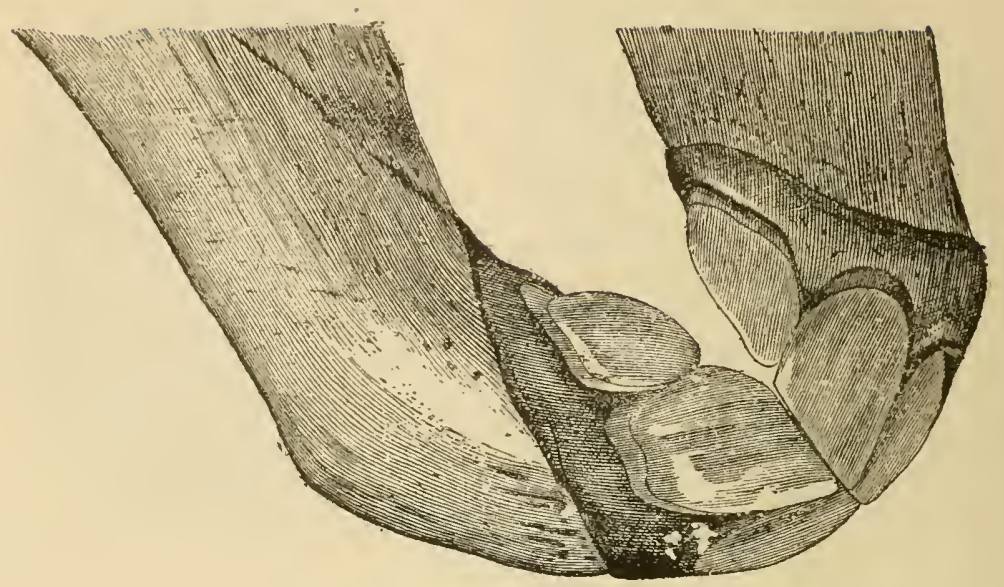

帒

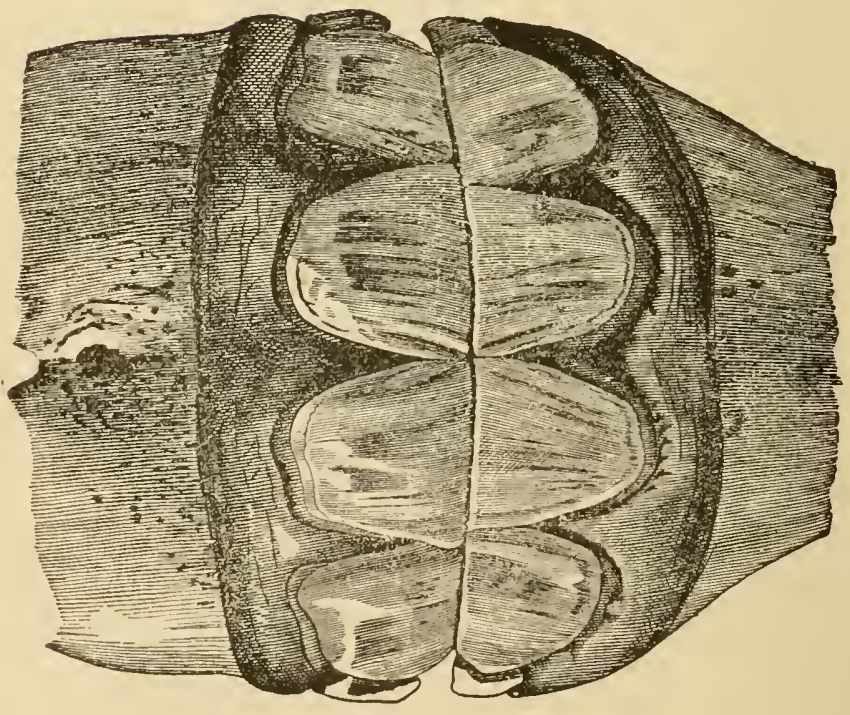



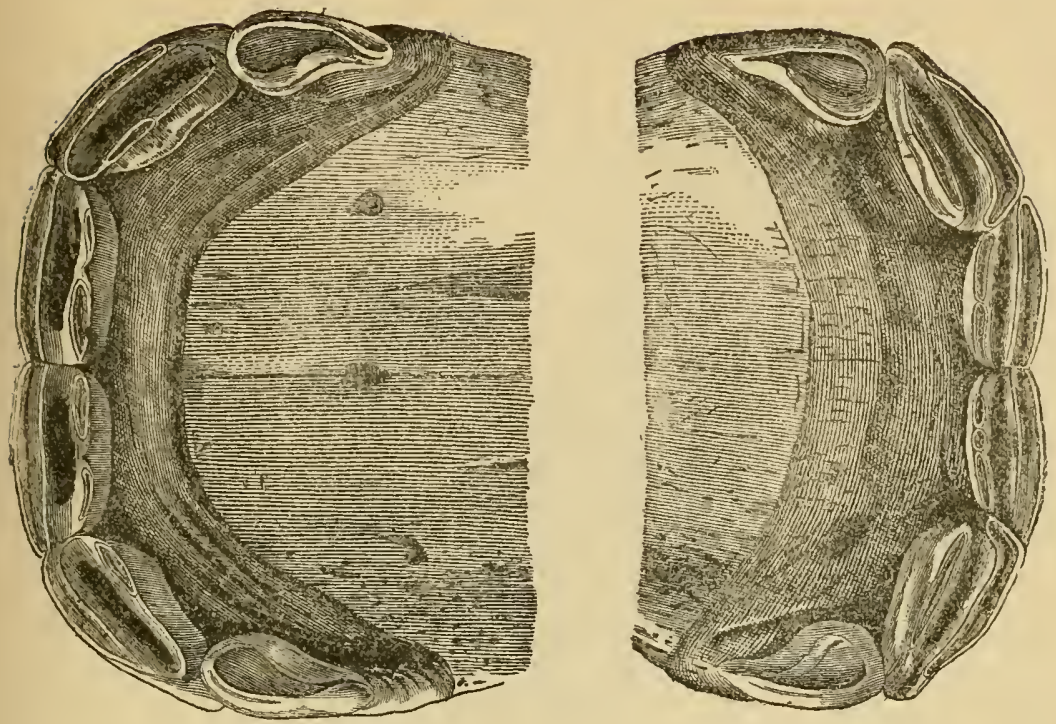

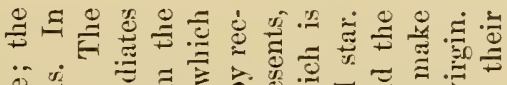

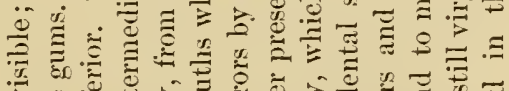

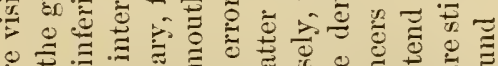

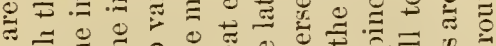
\% $\cong$

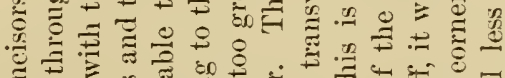

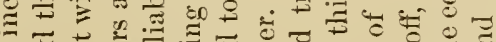

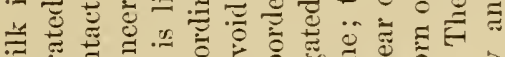

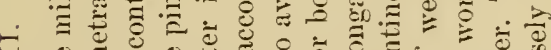

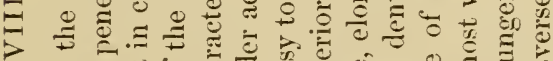
도류

$E x=\overrightarrow{0}$

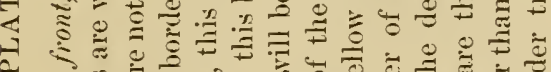
$\approx \mathscr{J}$

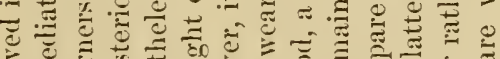
एँ Е

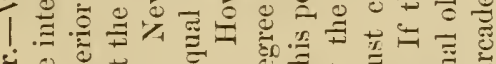

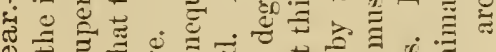

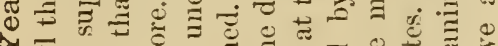

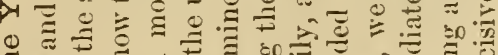

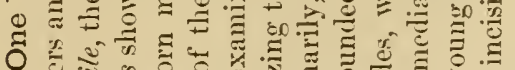
टँ

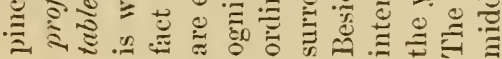




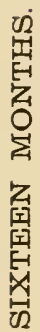
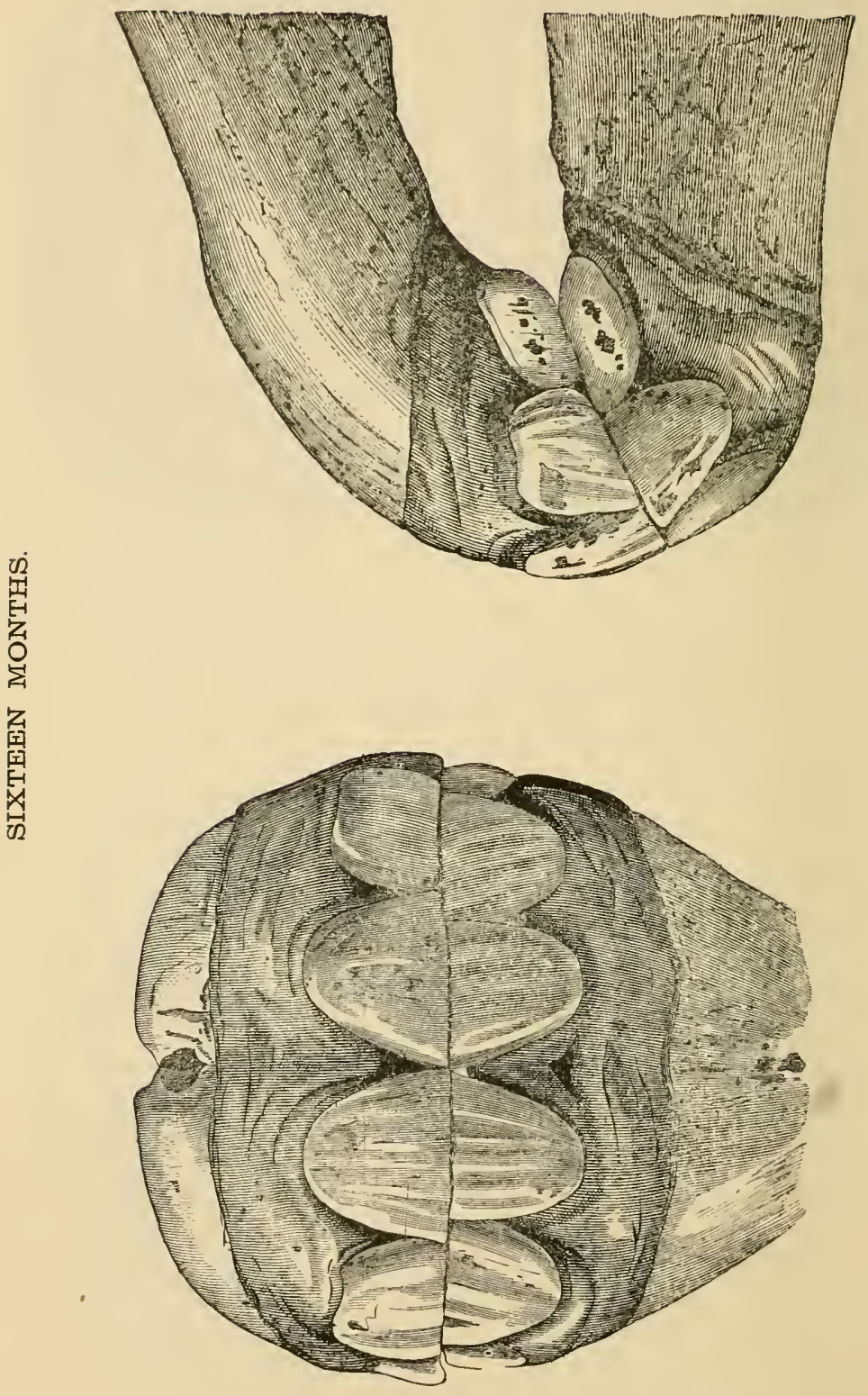

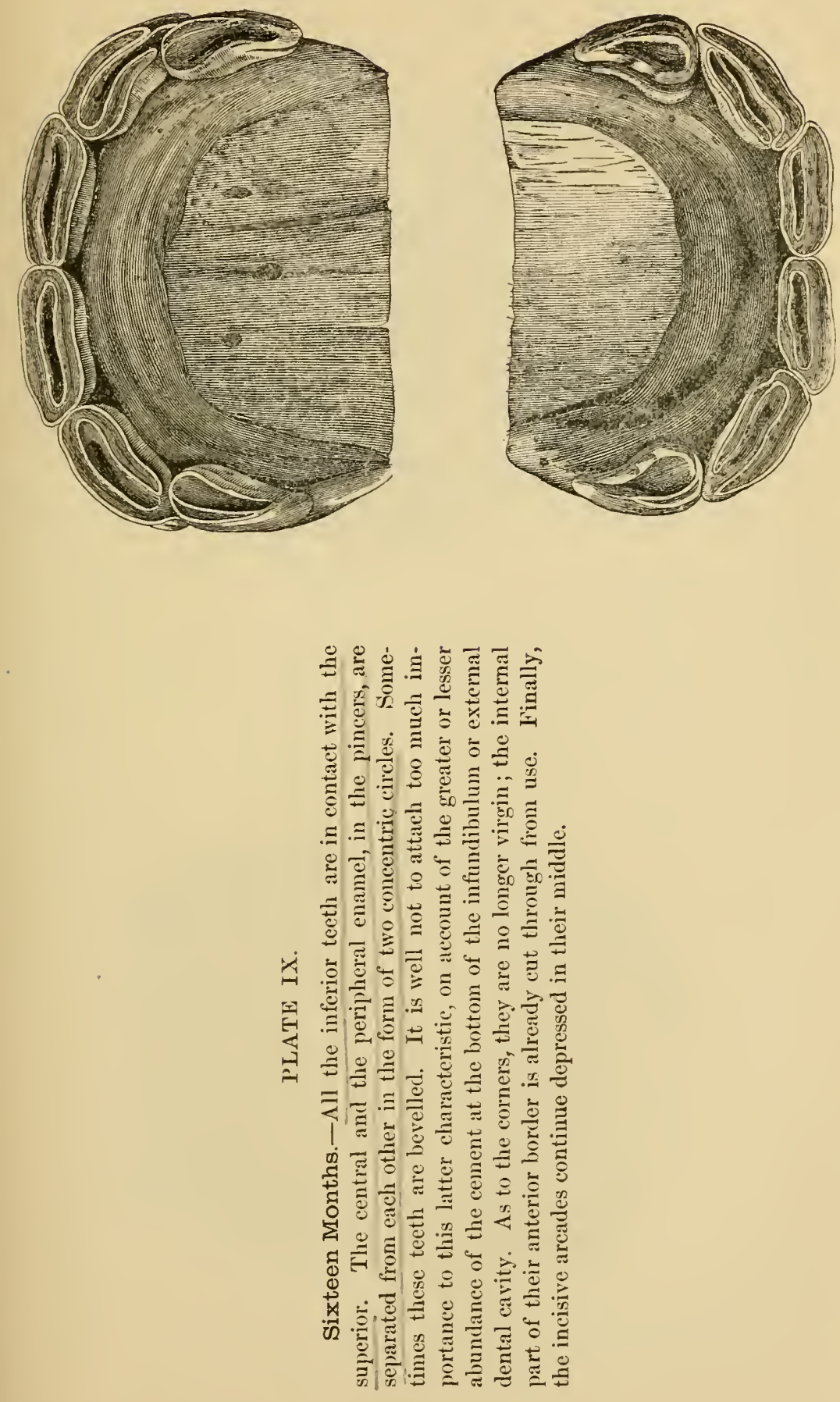


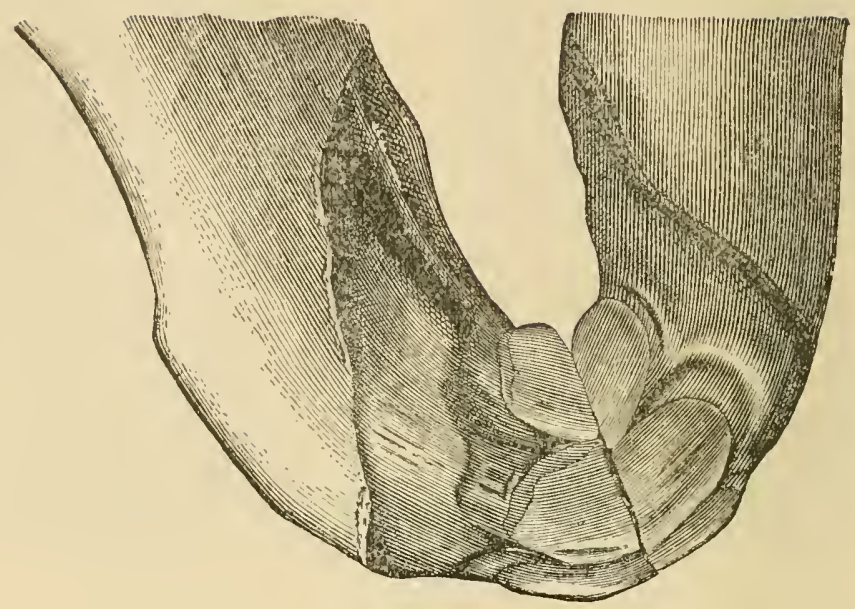

号

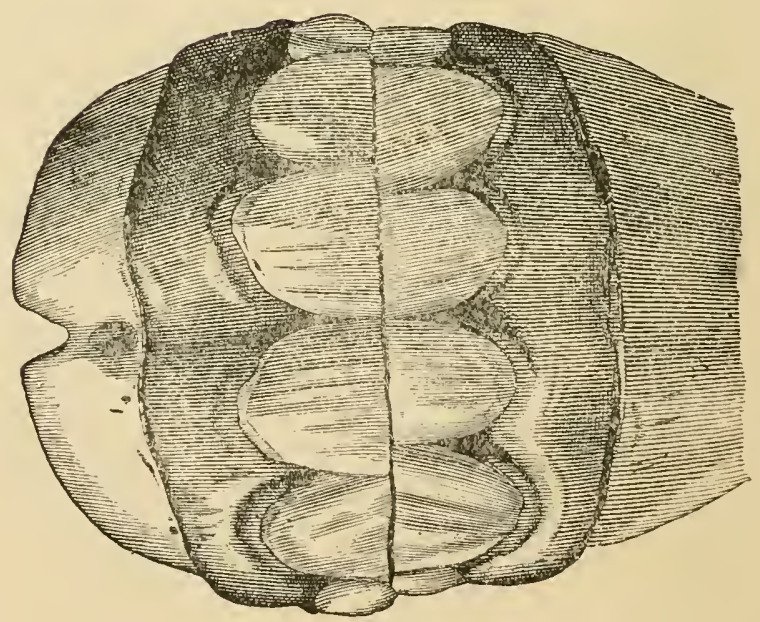



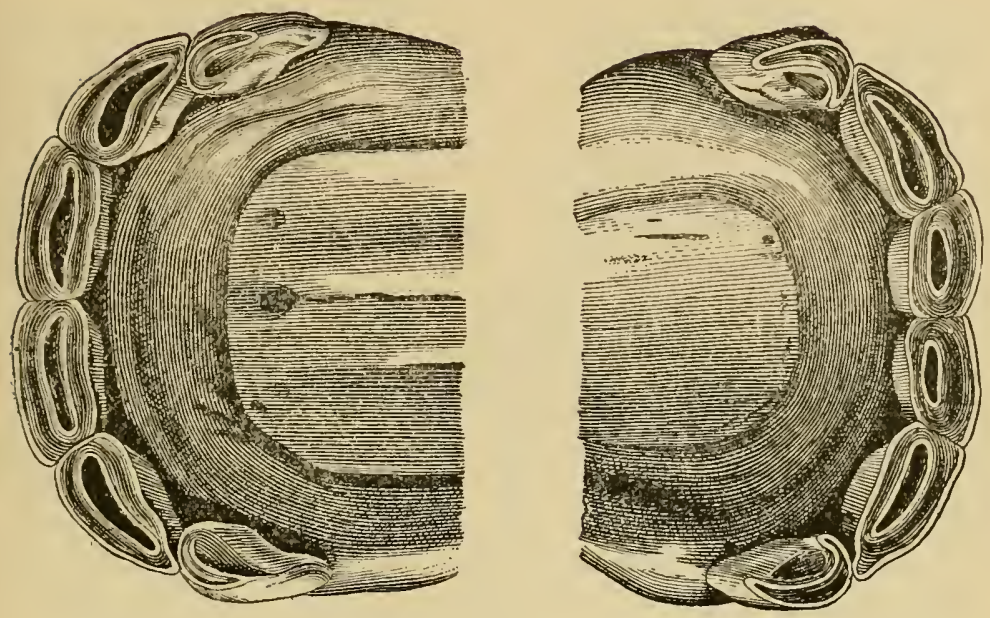

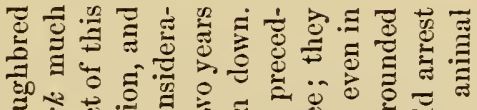
है

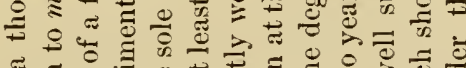

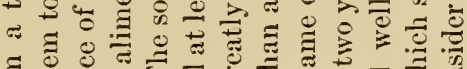

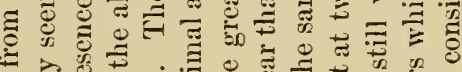

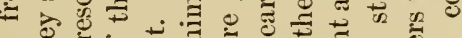

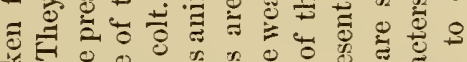

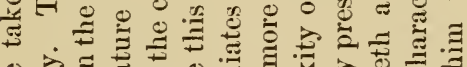
४⿻ ज小

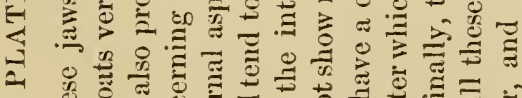

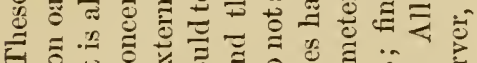

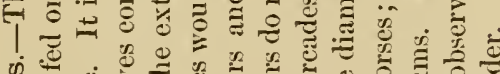
की

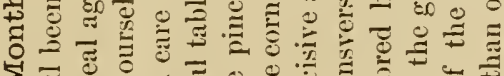

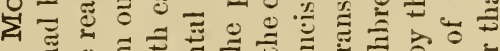

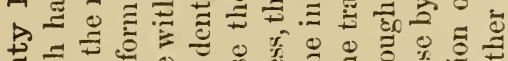

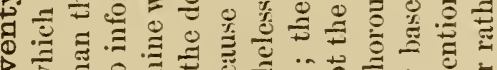

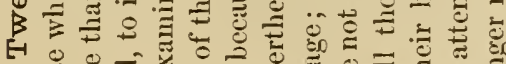

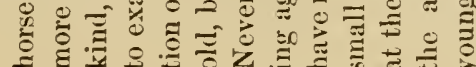




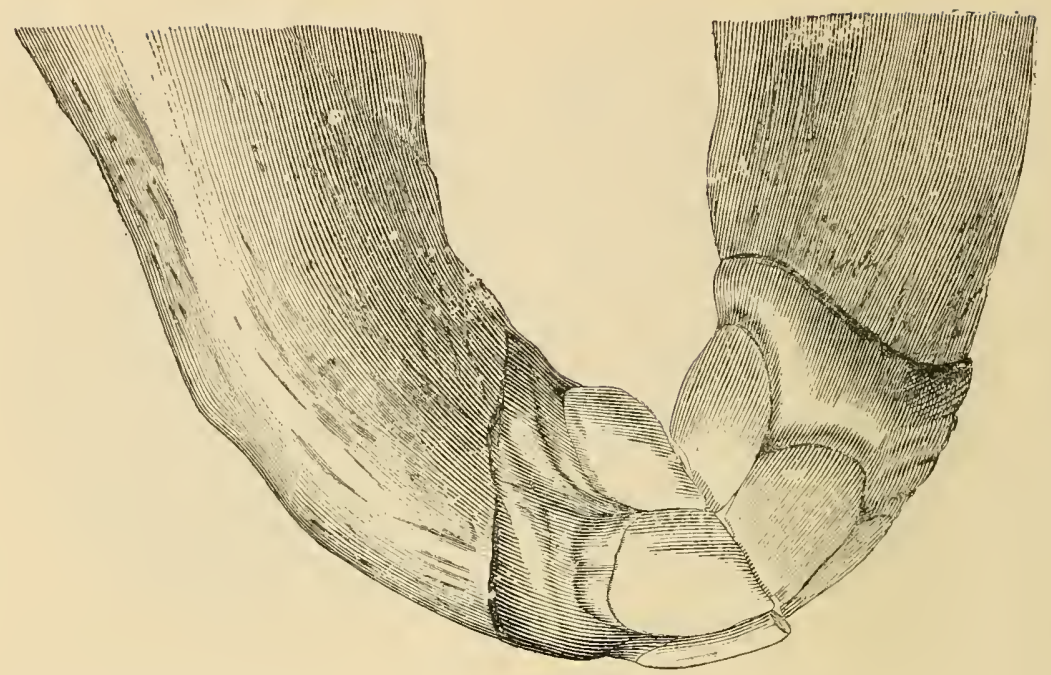

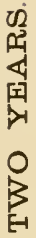

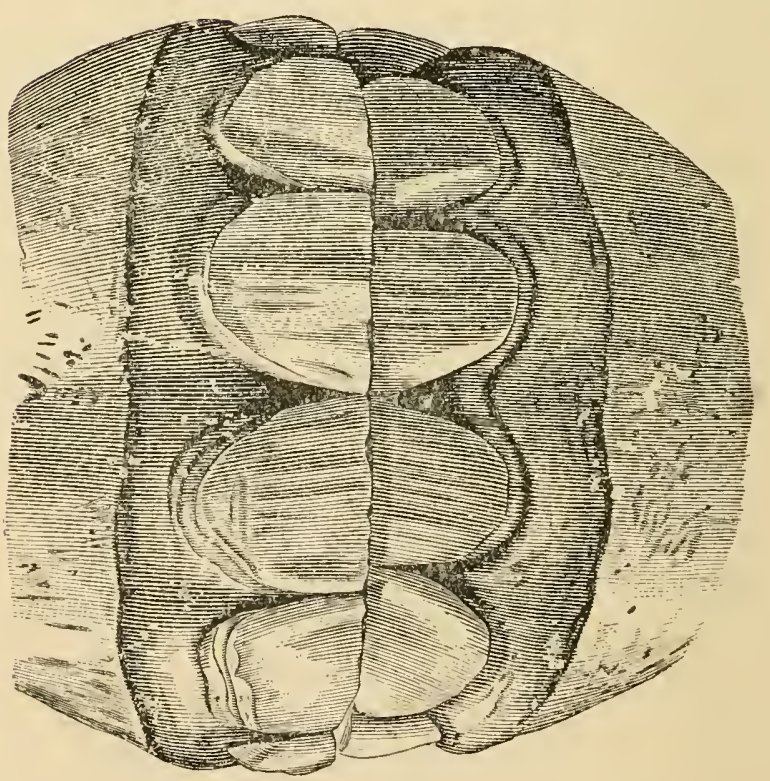



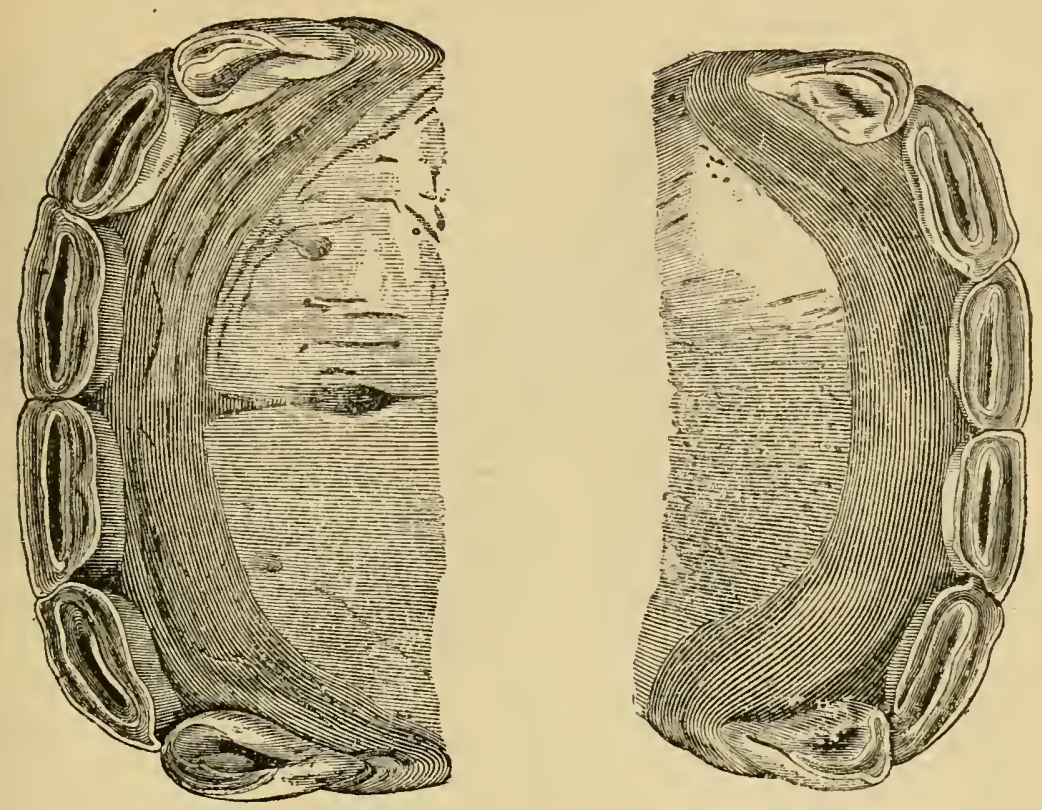

¿

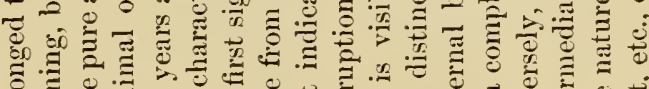

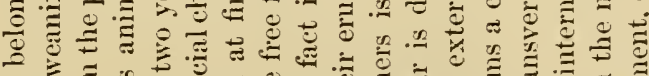

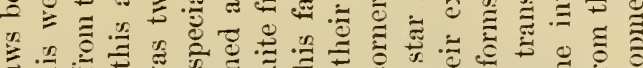
.气 \%

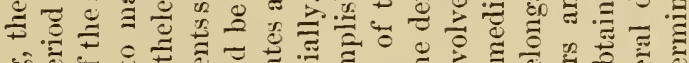
कi .. 平

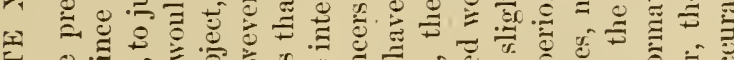

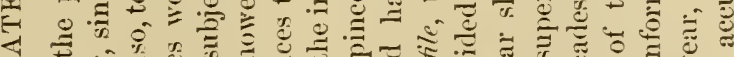
马 0 \&

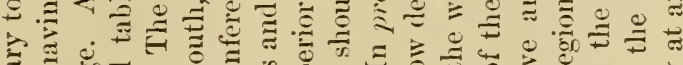

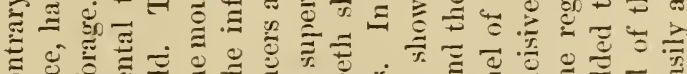

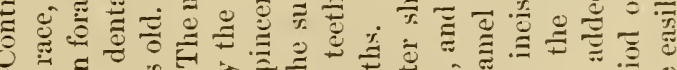

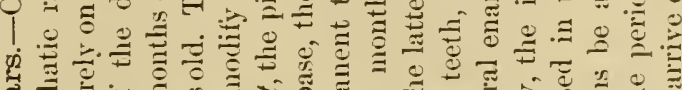

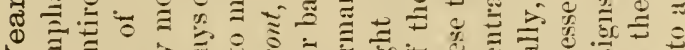

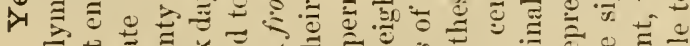

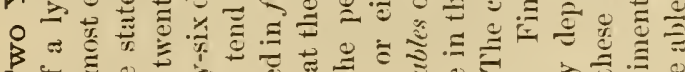

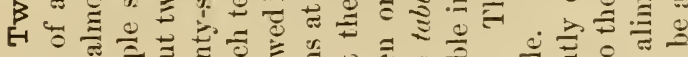

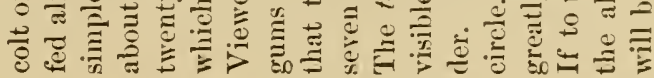




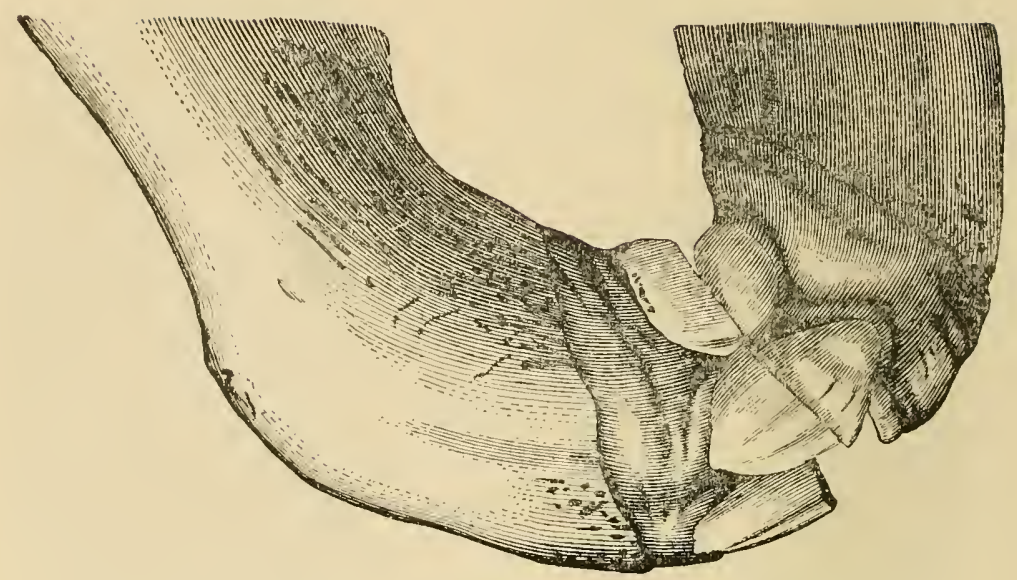

䠁

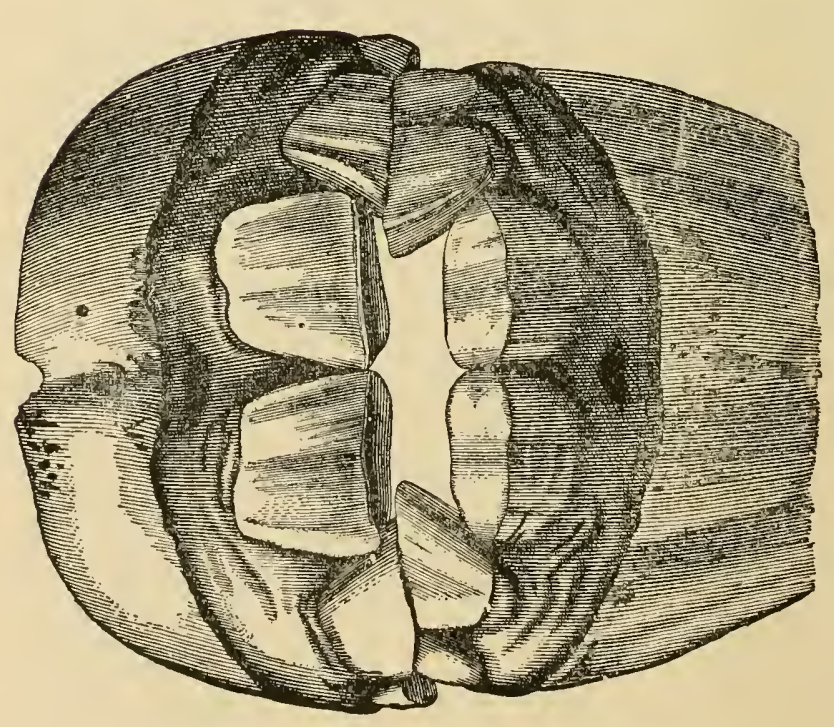



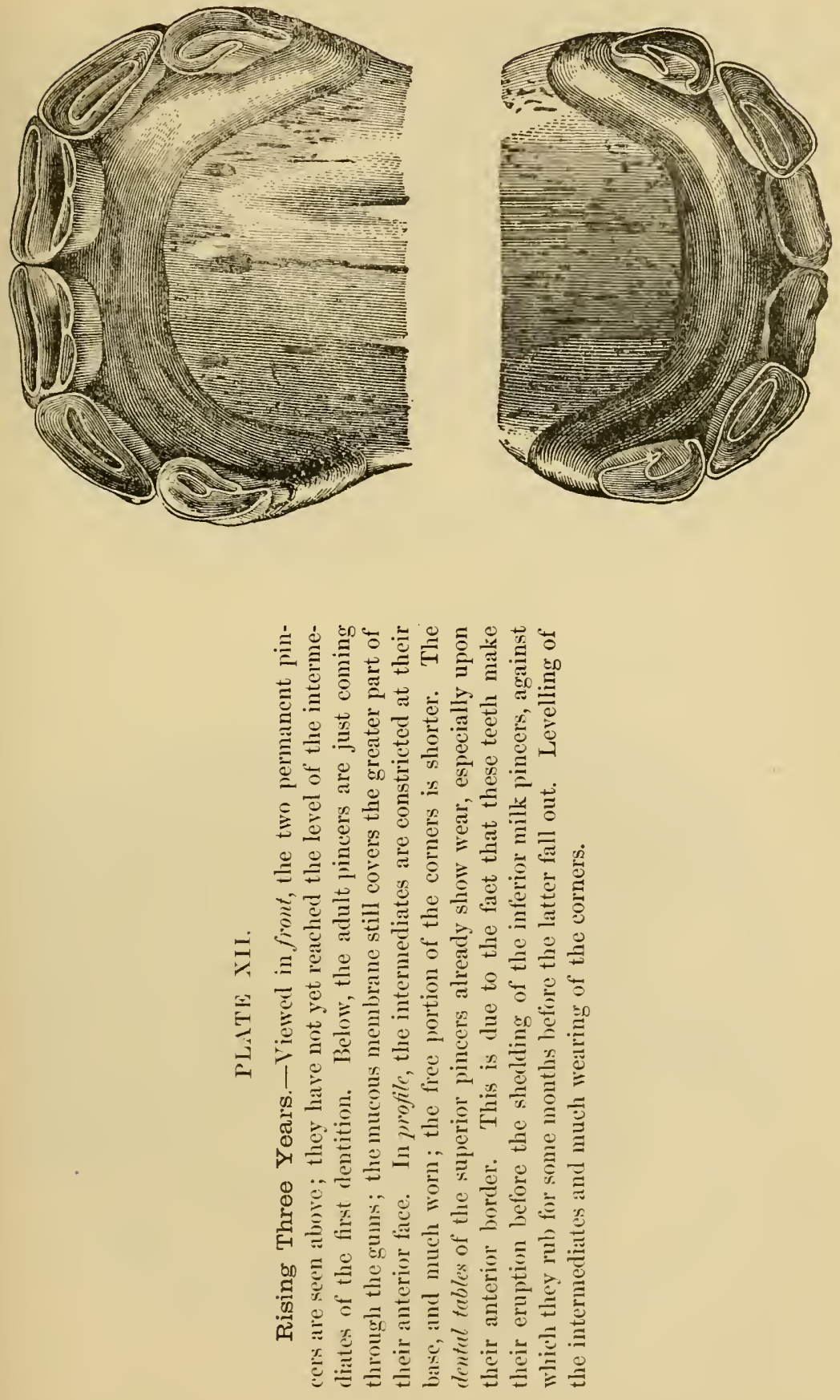
年

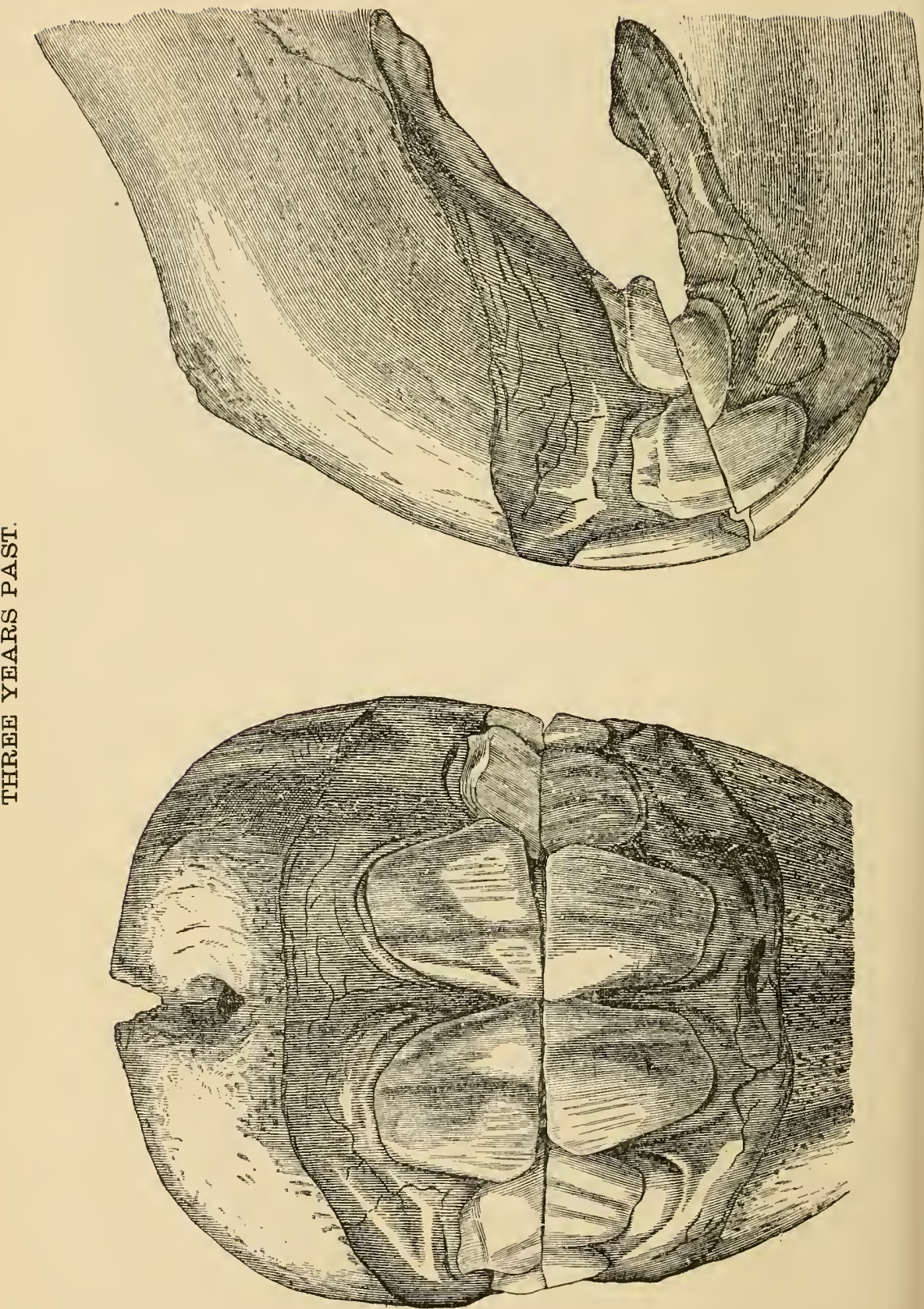



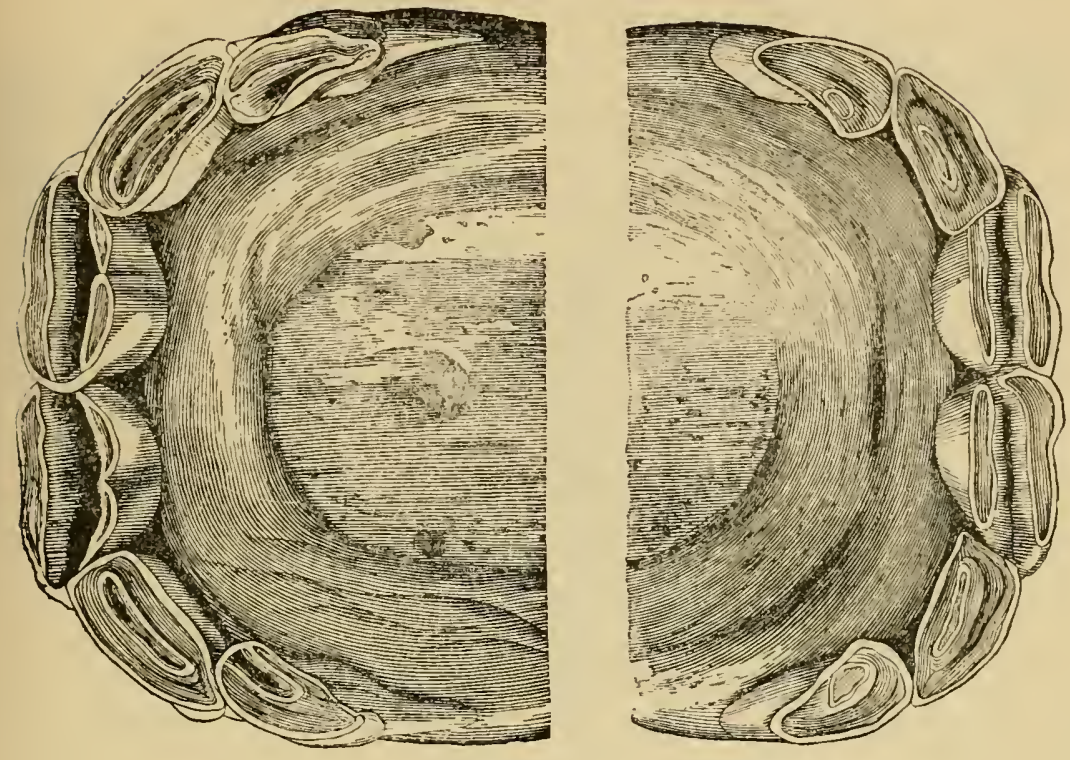

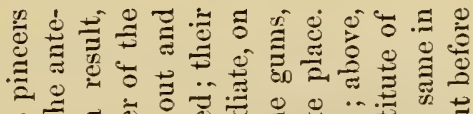

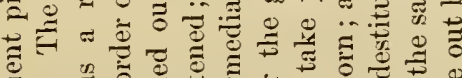
节

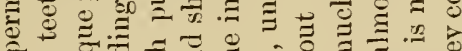

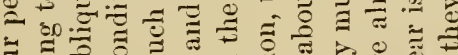

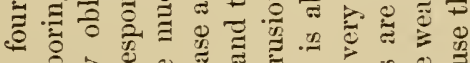

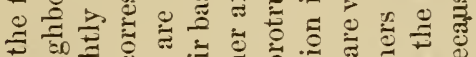

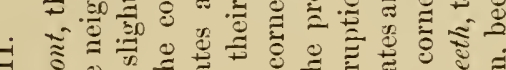

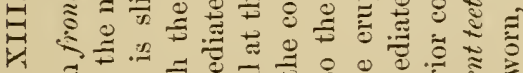

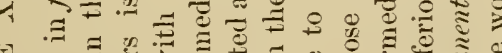

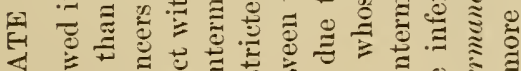

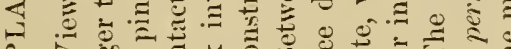
A 1.

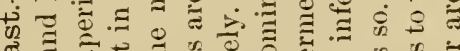

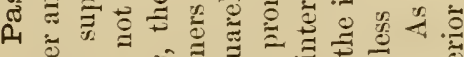

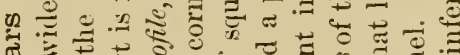
ॠ

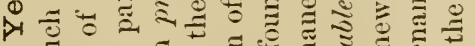
๑范

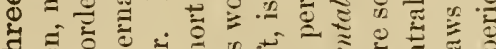

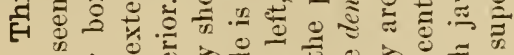
光. 
告
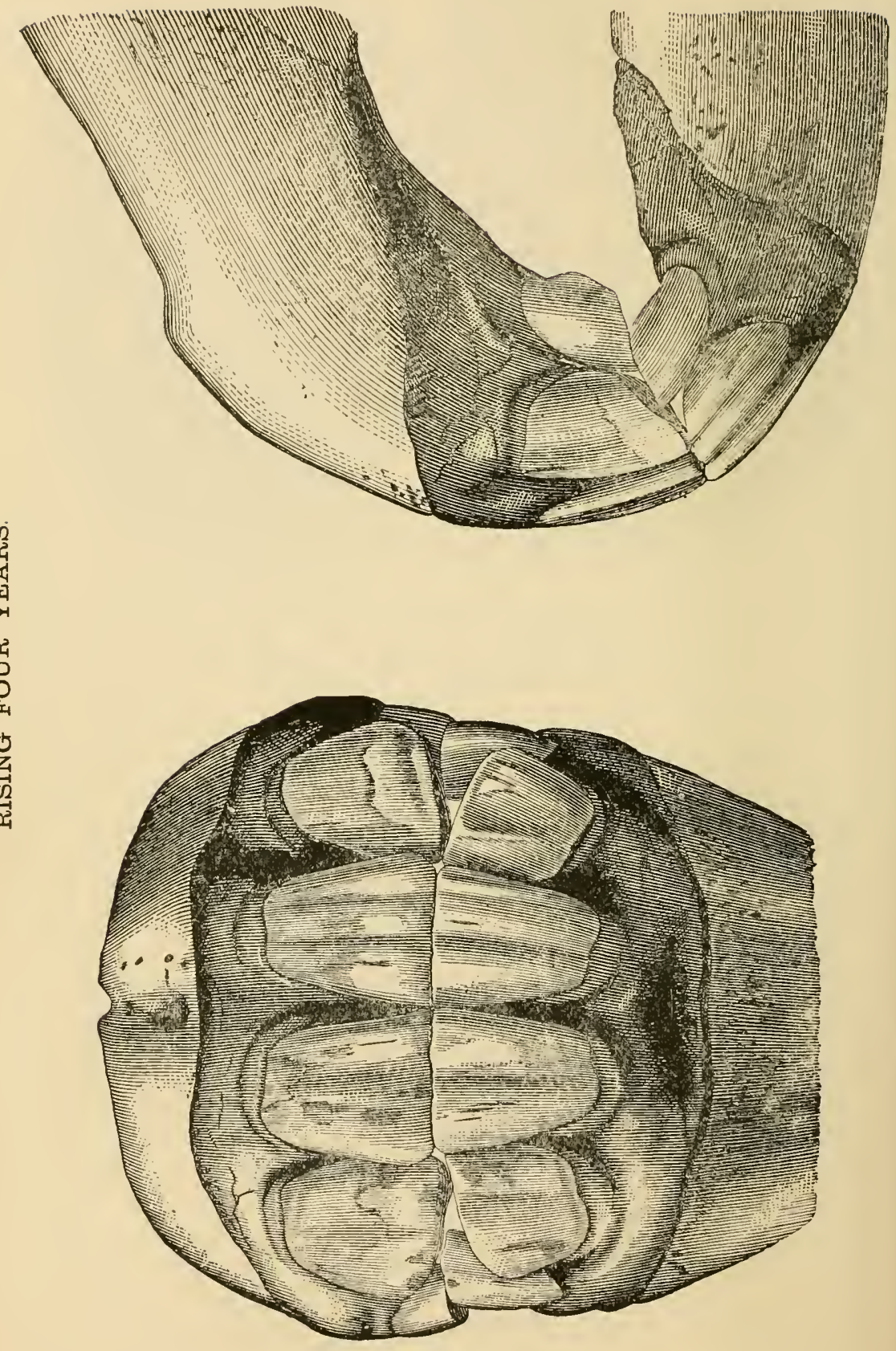

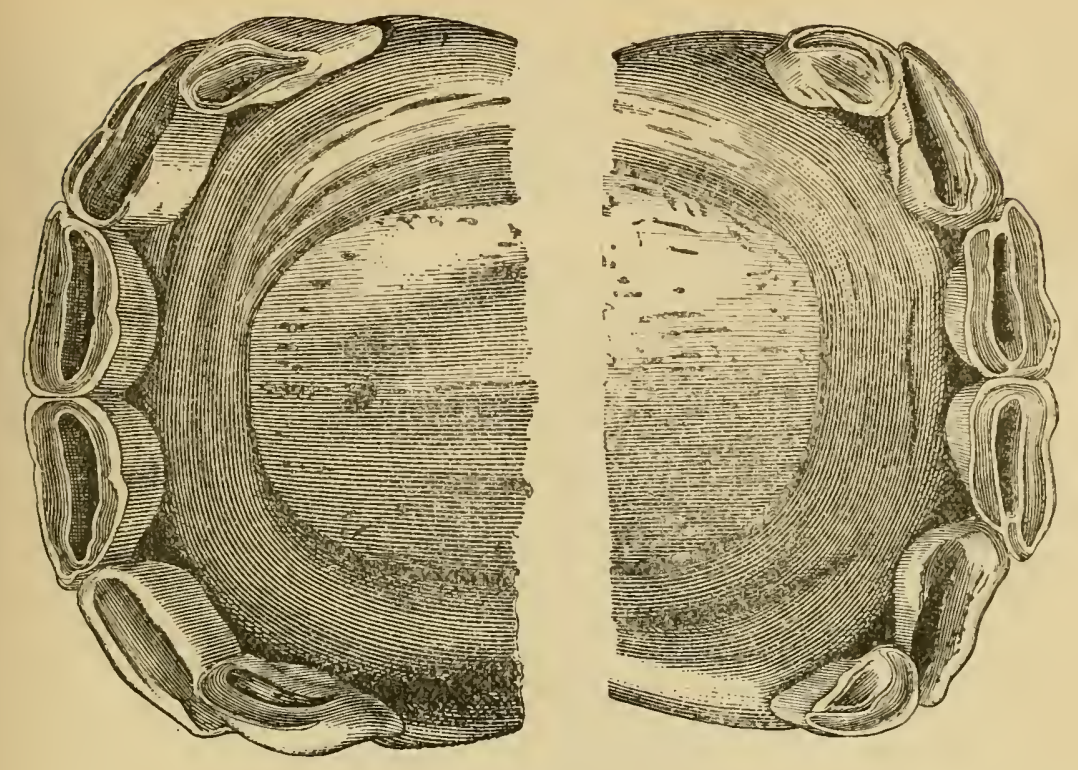

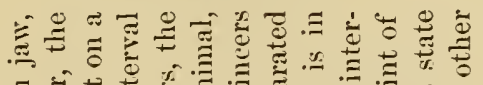

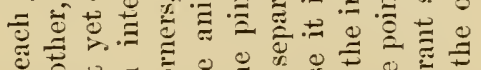

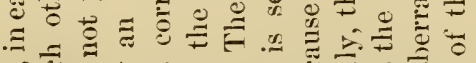

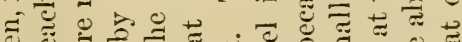

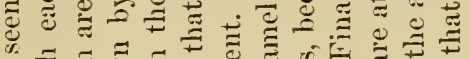

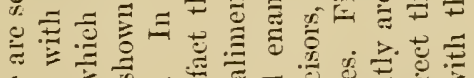
पे

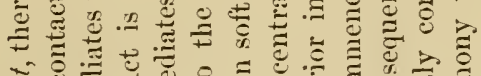

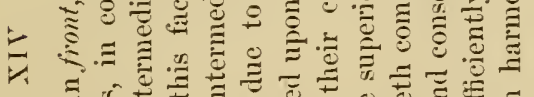

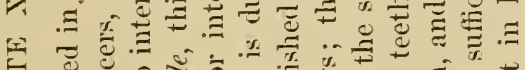

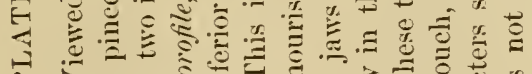

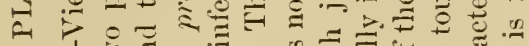
।

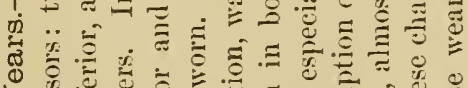

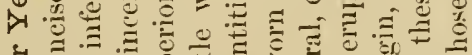

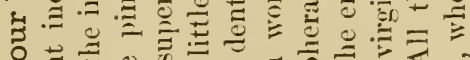

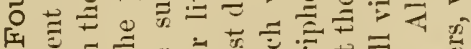

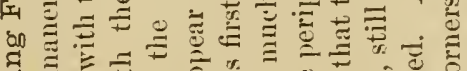

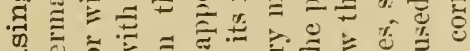

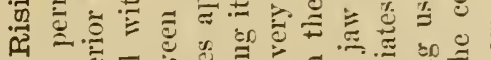

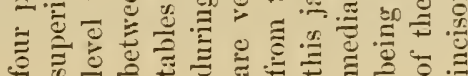




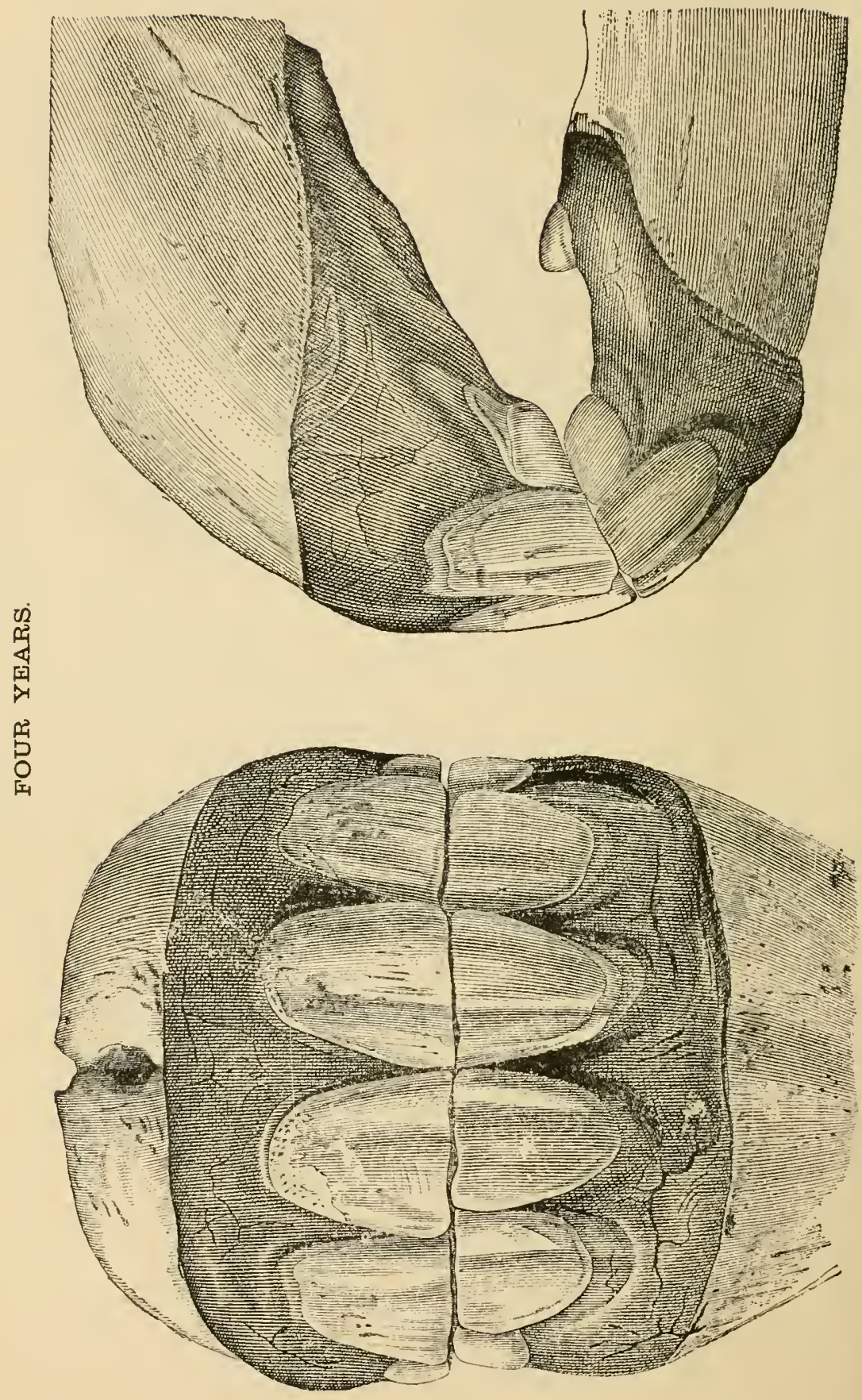



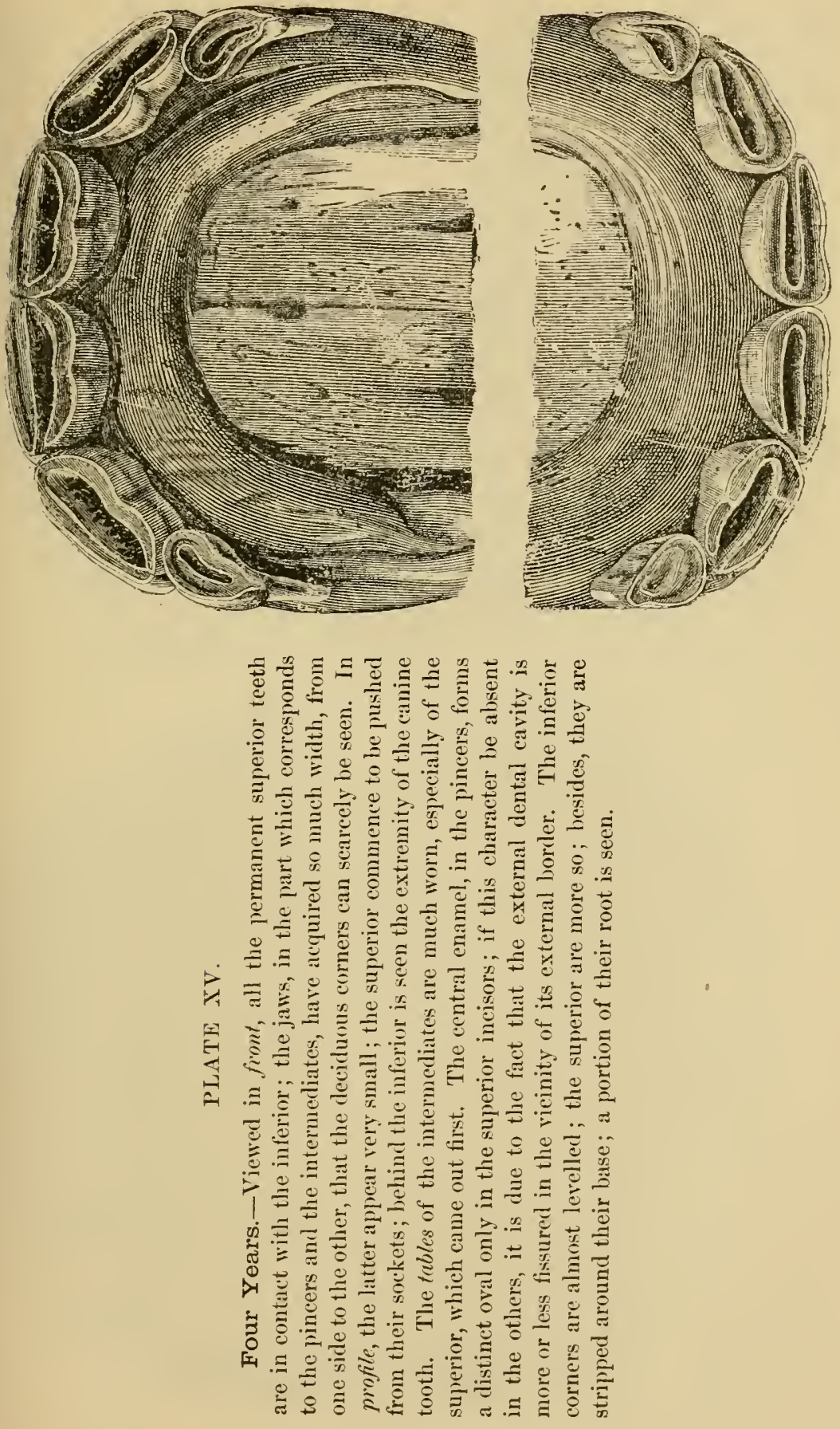


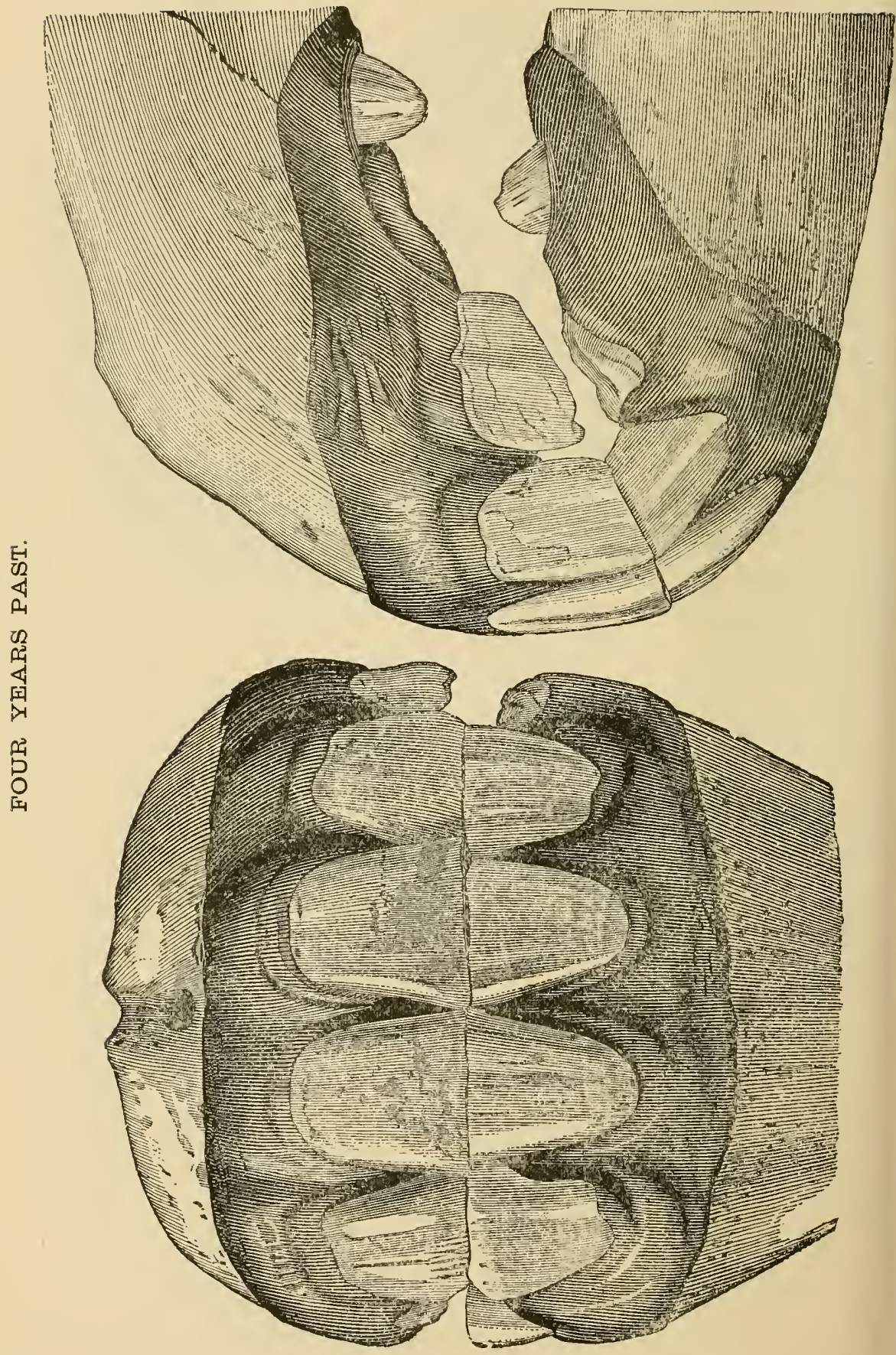



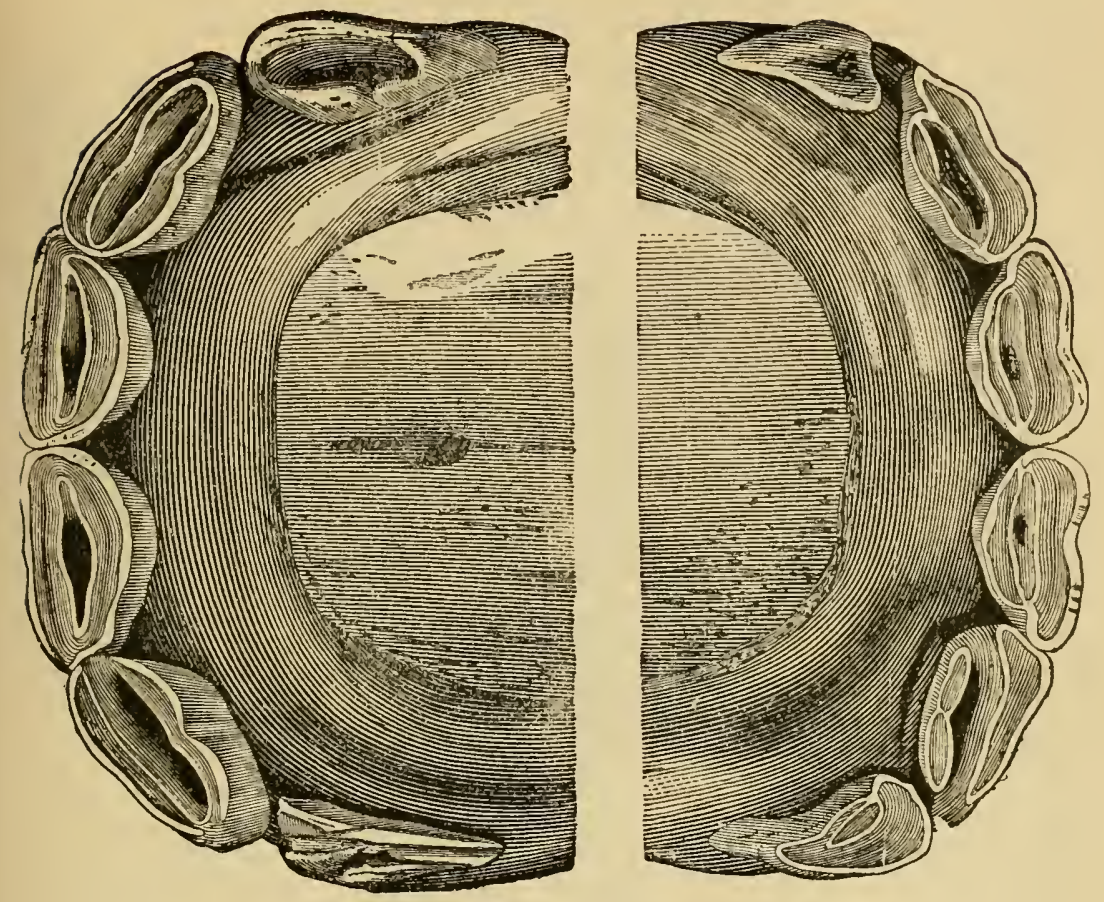

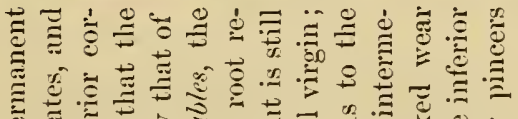

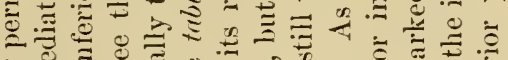

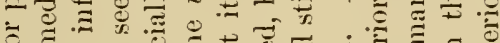

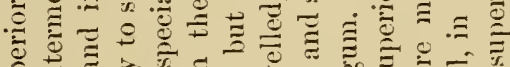

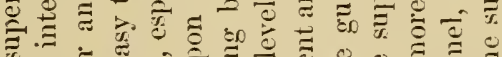

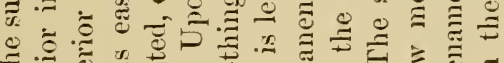

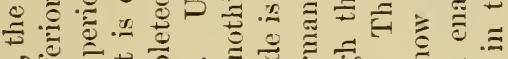

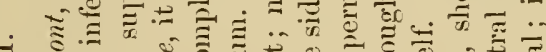

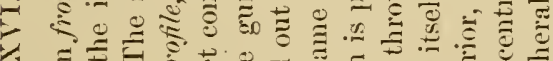

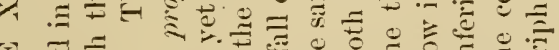

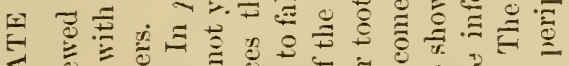

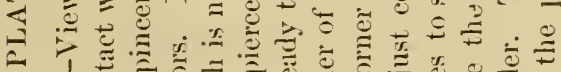

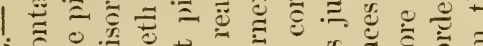

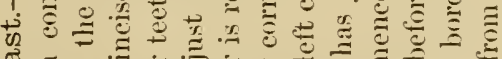

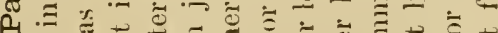

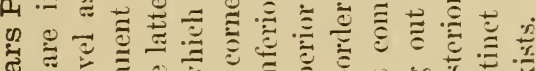

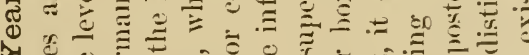

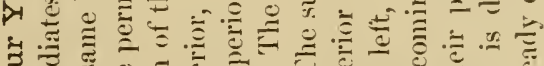

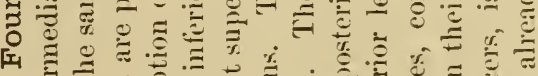

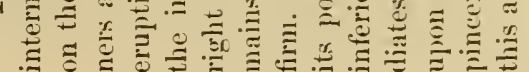




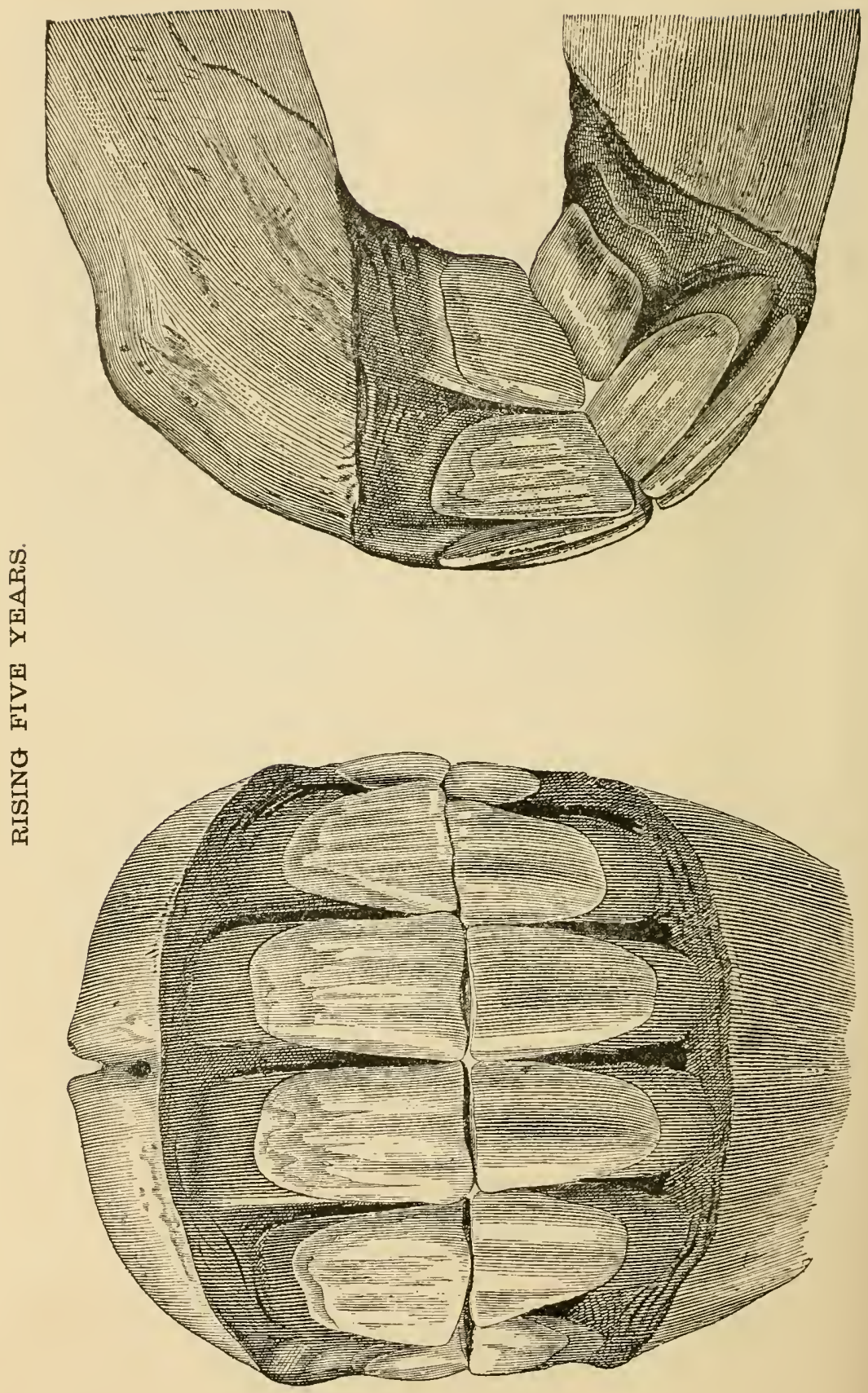



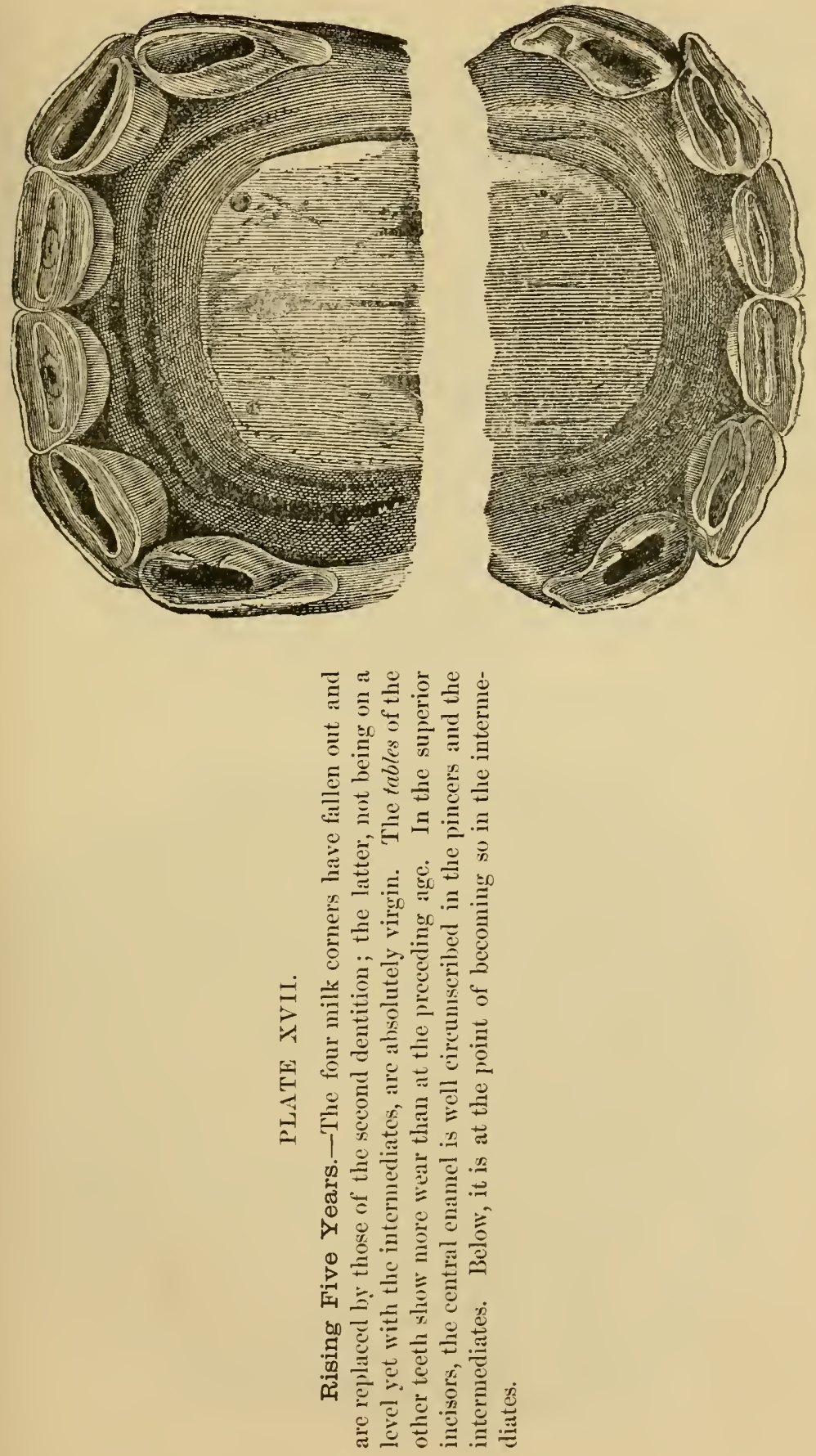


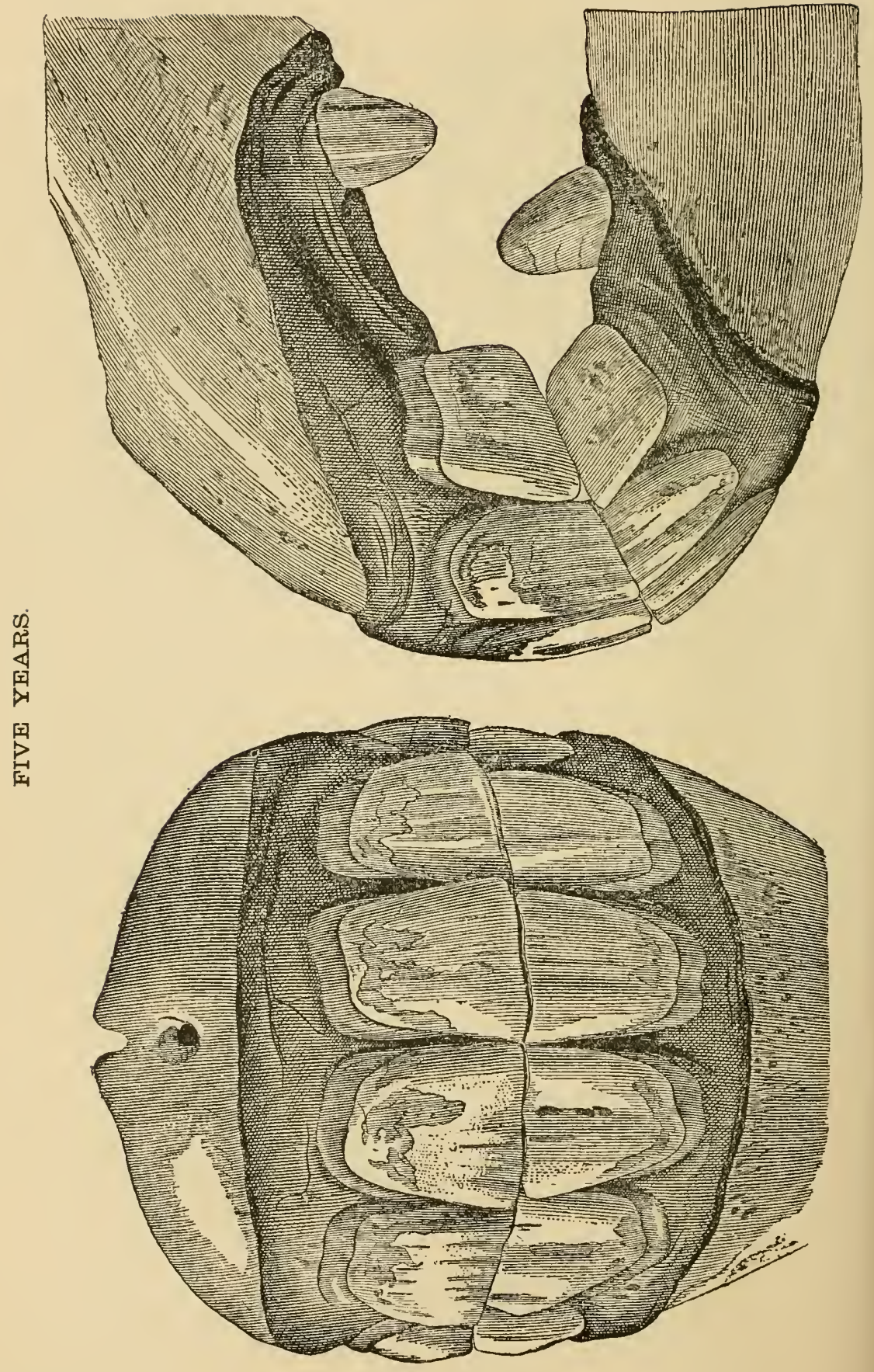



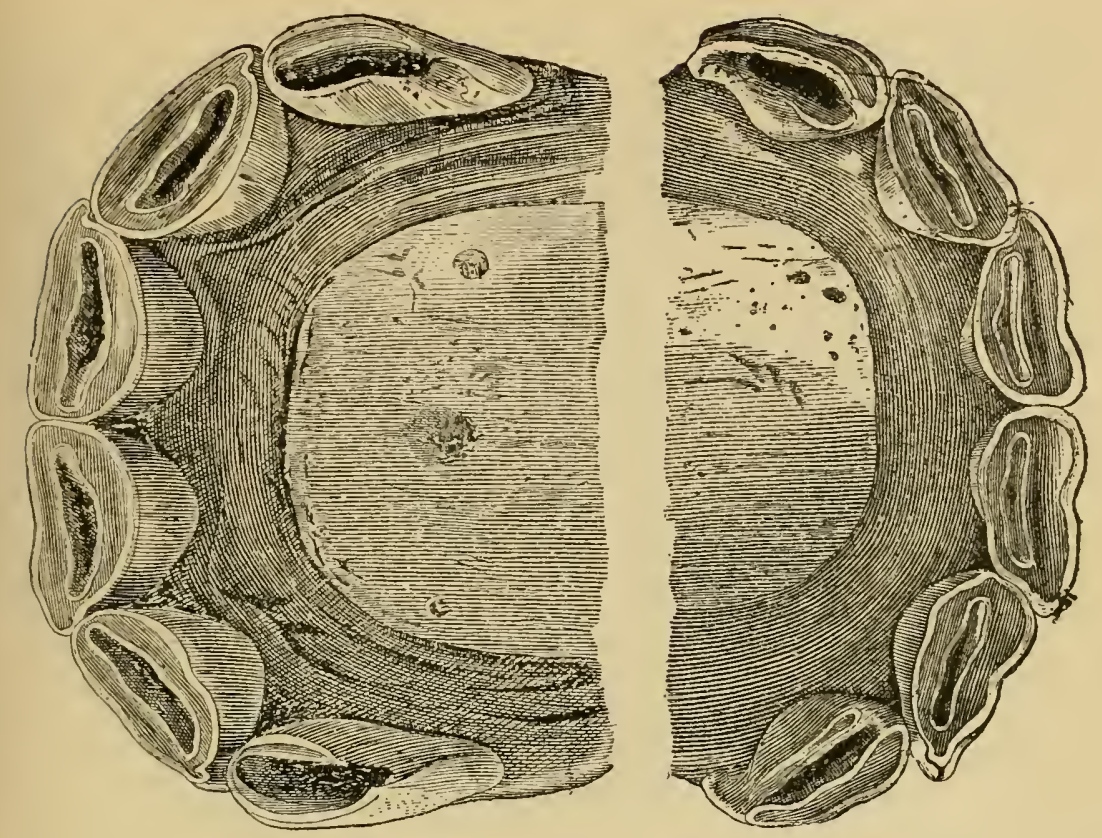

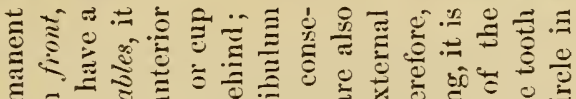
ఏ.

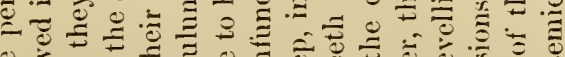

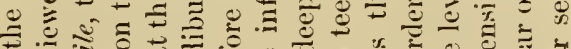

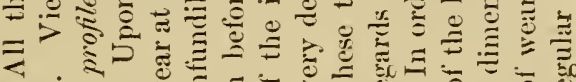

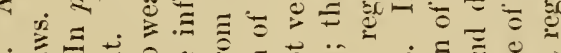

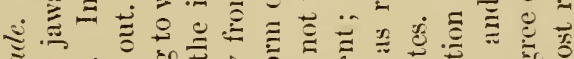

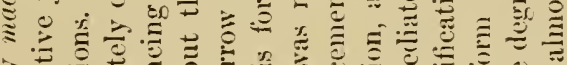

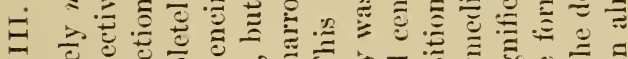
5 巳

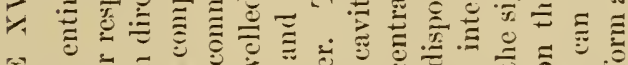

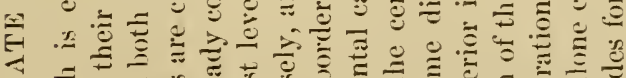

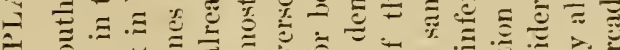

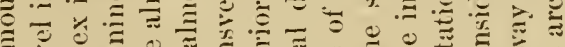

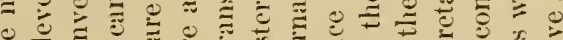
$\cong \frac{0}{0} 0 \%$

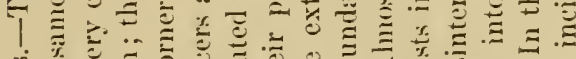
\%

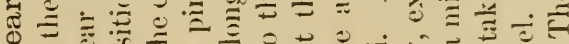
入 ه

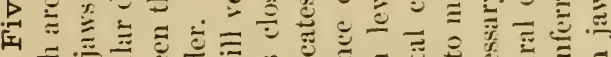

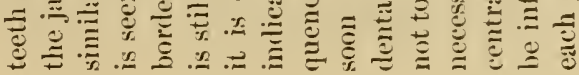


望
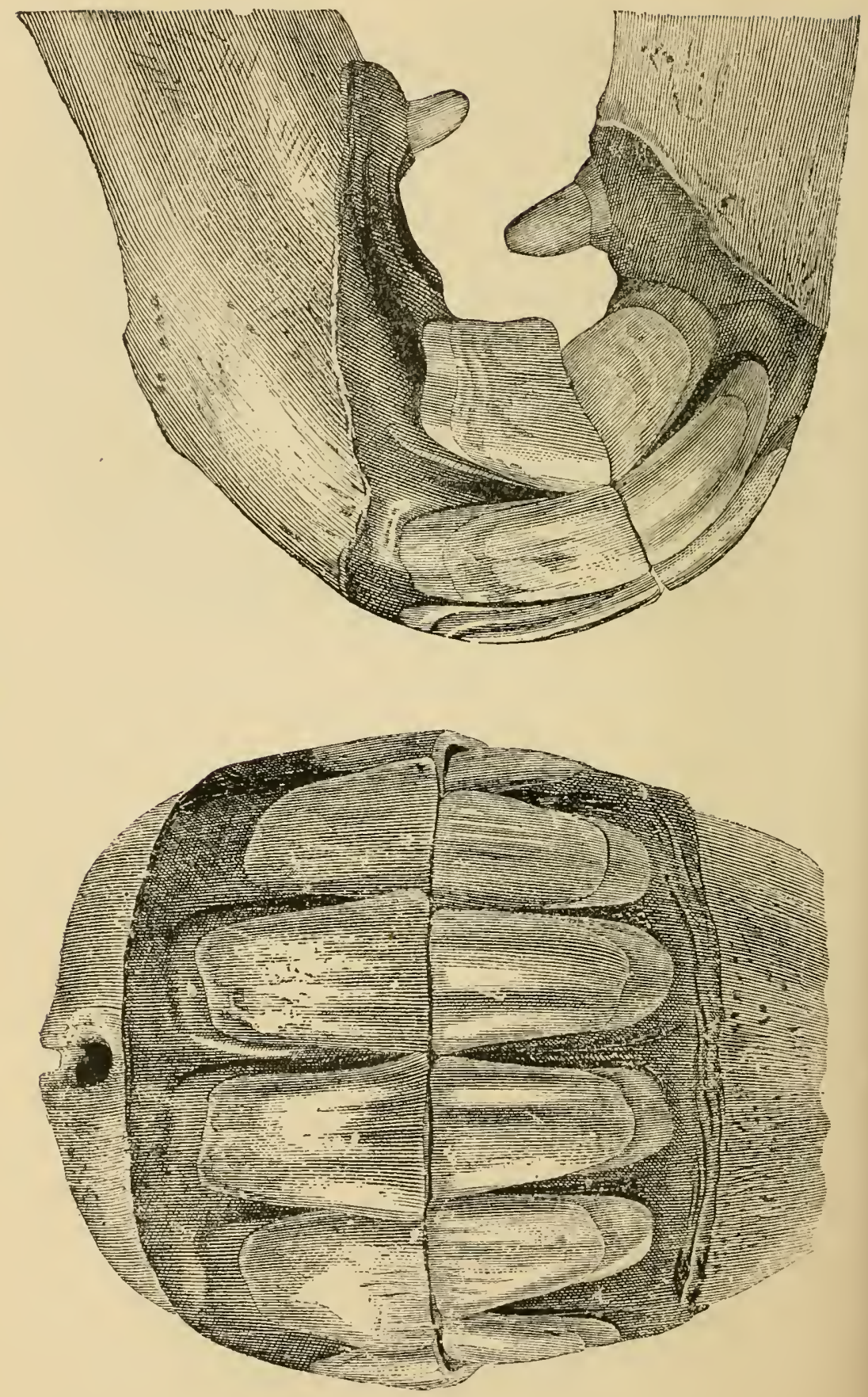

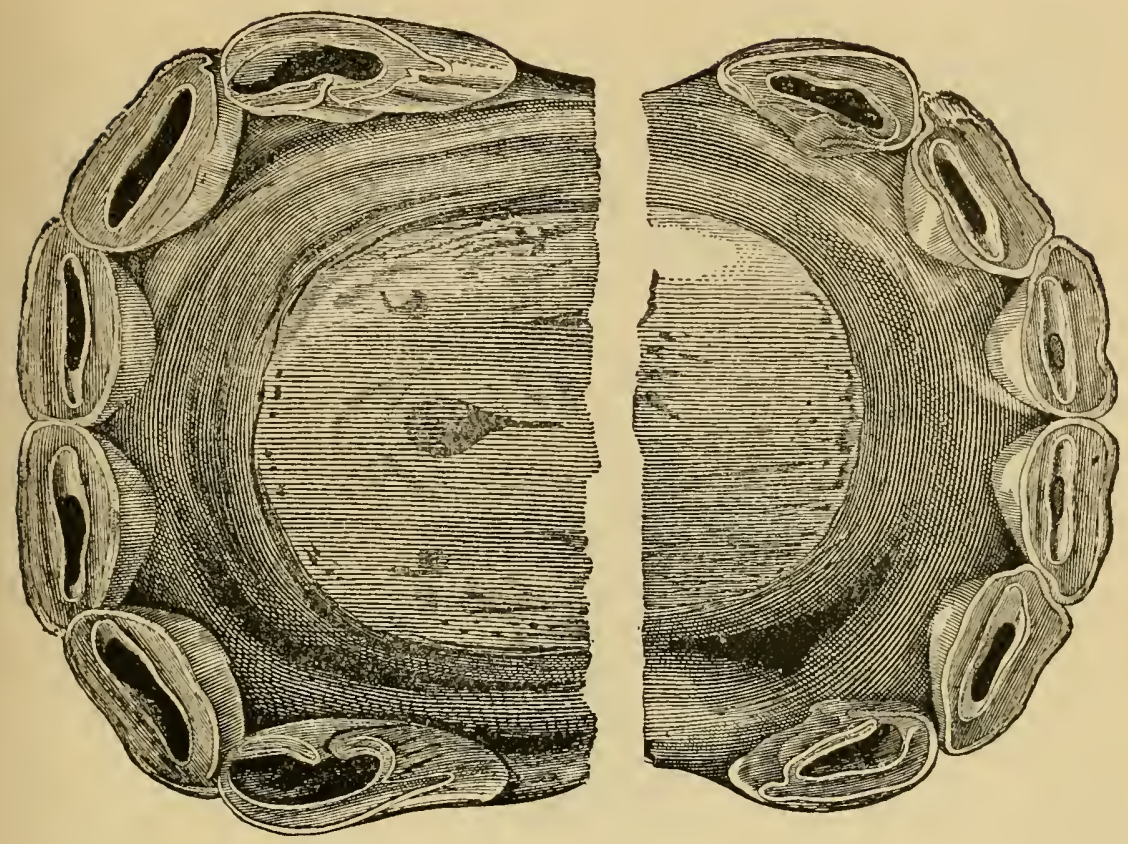

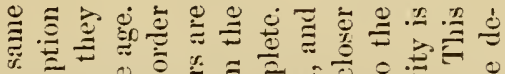

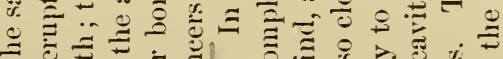

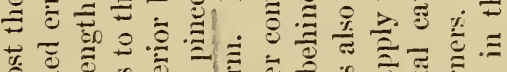

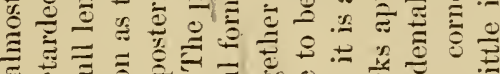

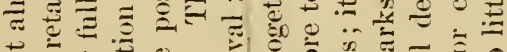

¿

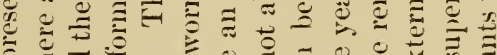

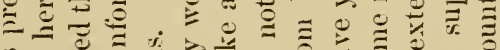

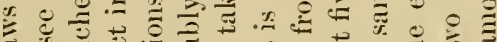

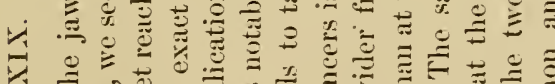

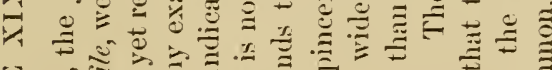

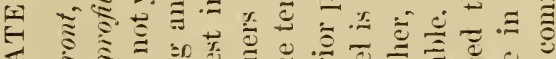

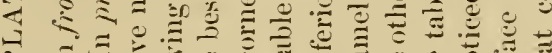

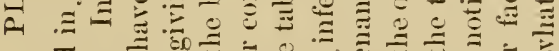

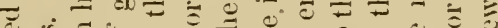

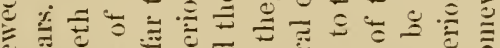

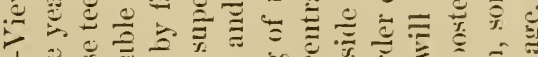

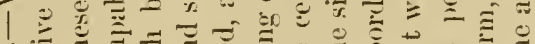

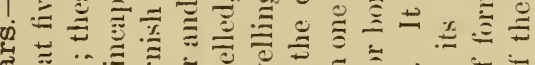

สำ

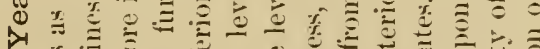

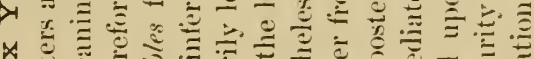

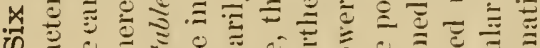

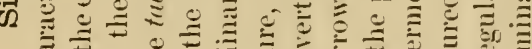

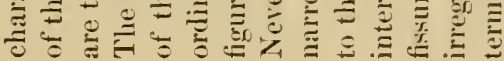




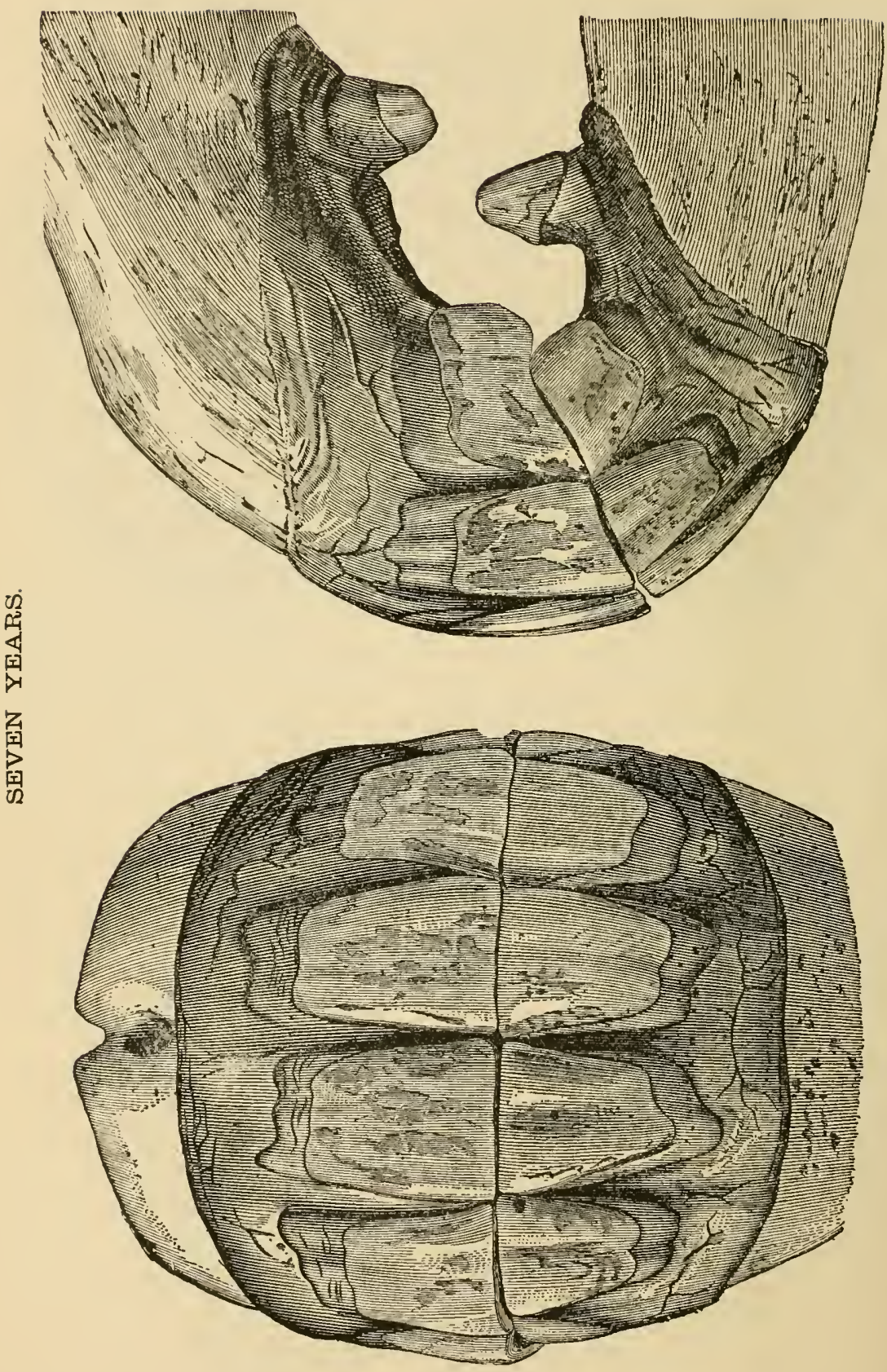



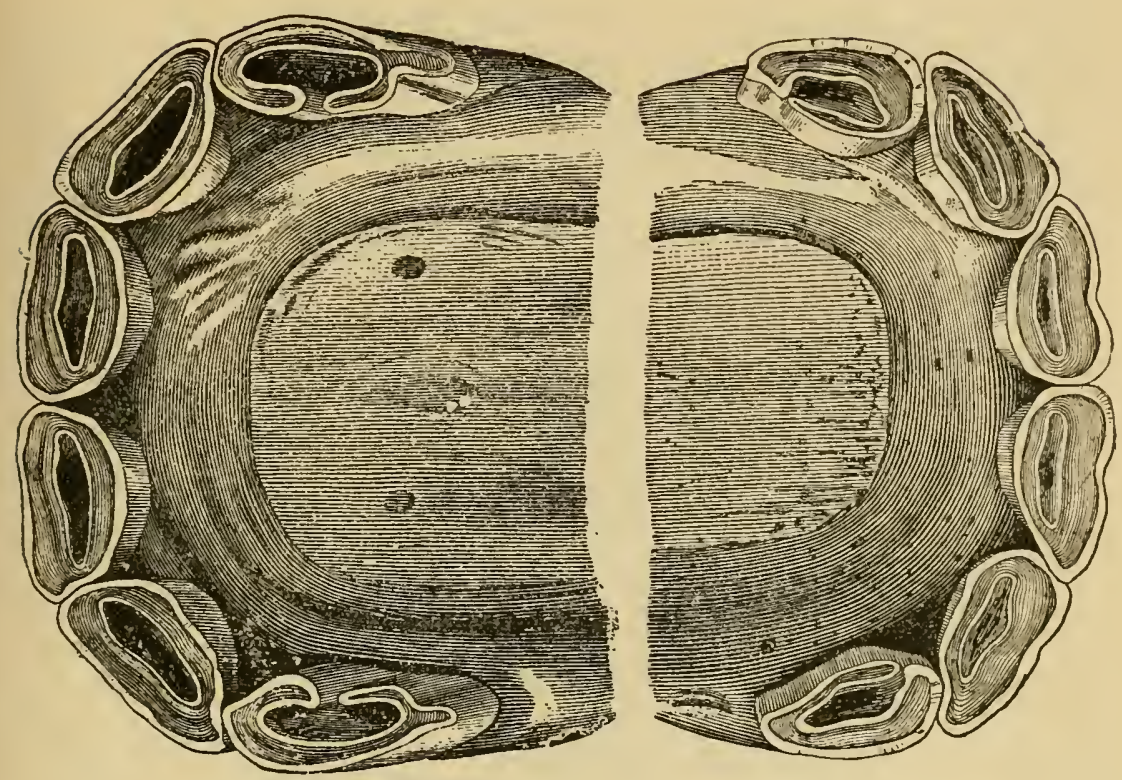

戸

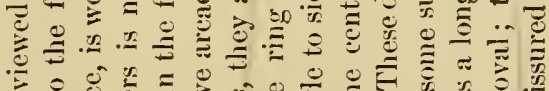

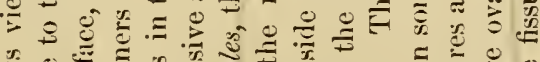

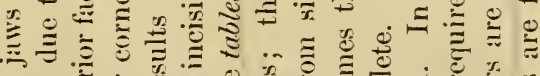

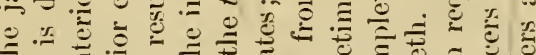

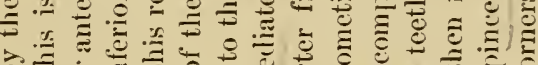

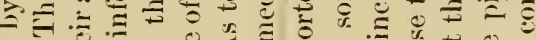
Е.

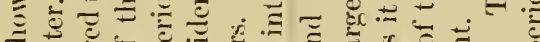
ن

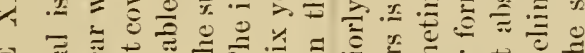

(1)

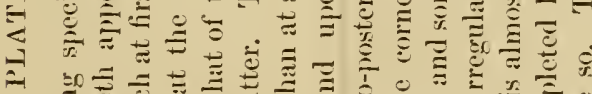

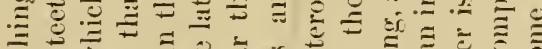

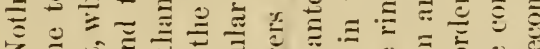

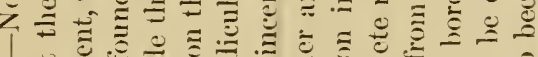

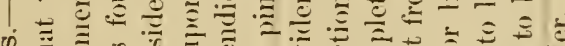

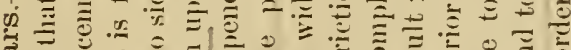

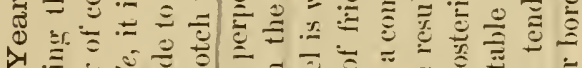

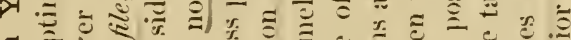
ฮี

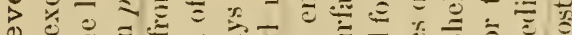

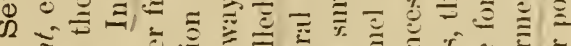

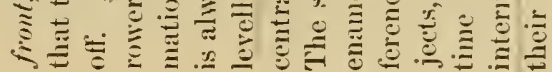




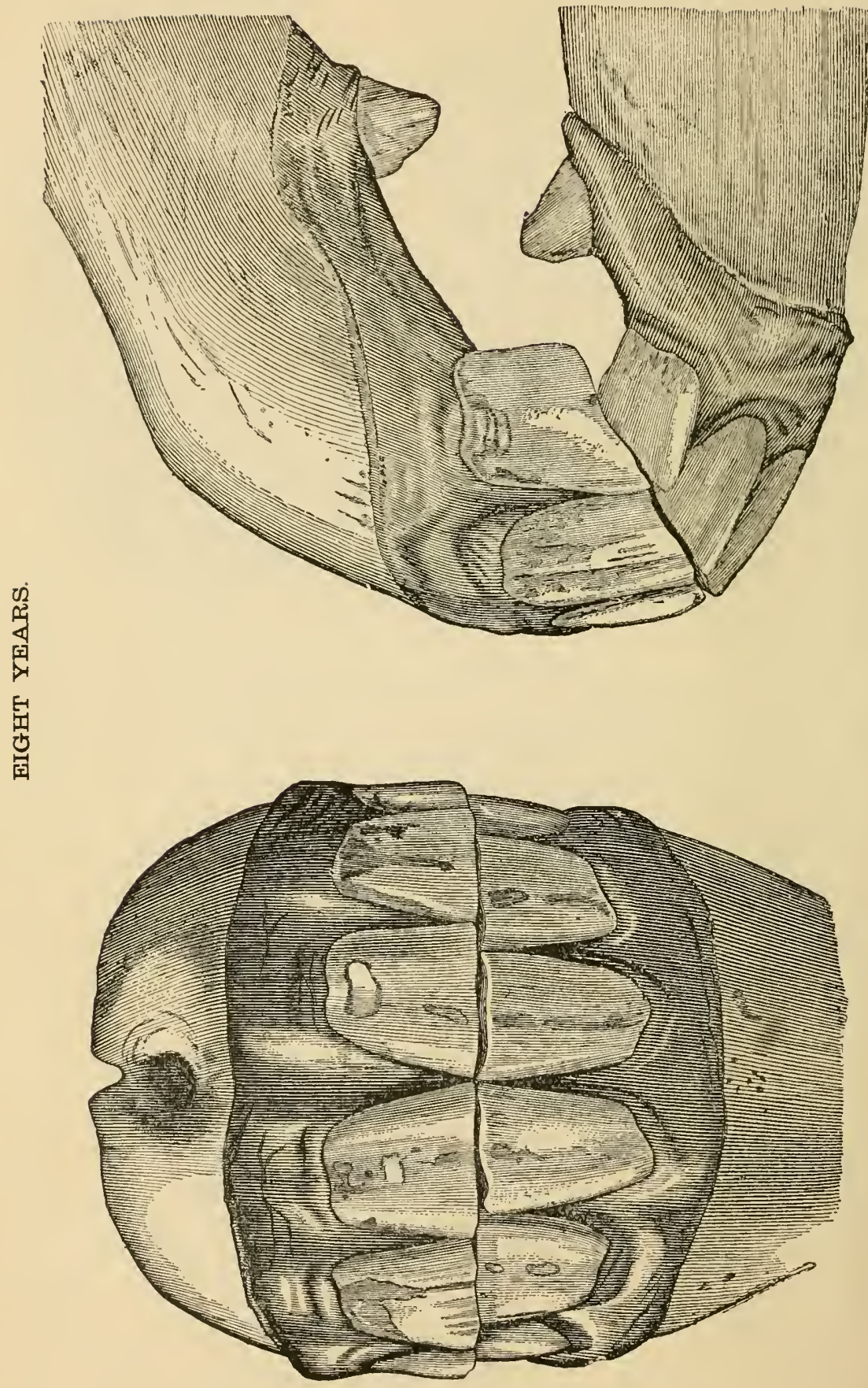



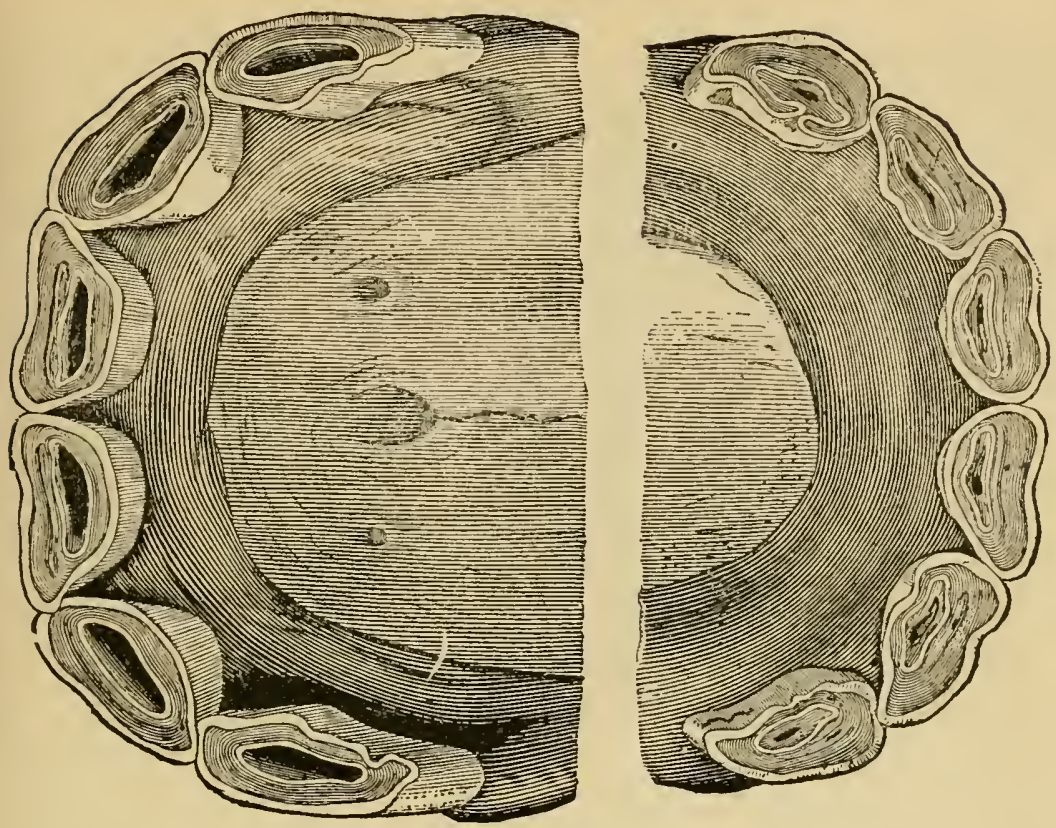

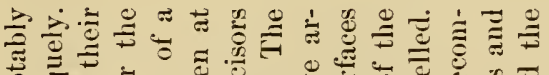

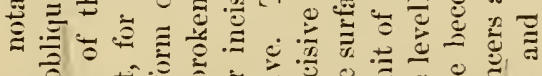
$\therefore \stackrel{0}{0}$ w

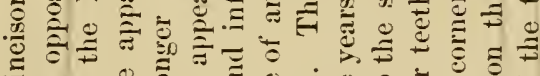
$\approx$ ○ $\cong$ ¿ -

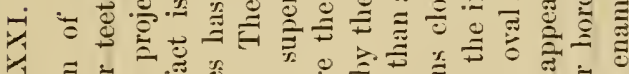

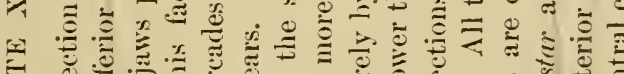

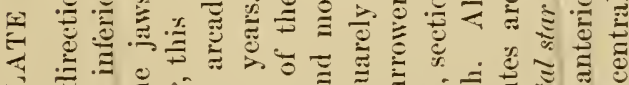

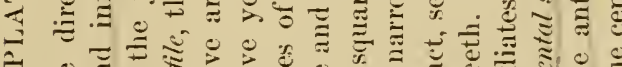

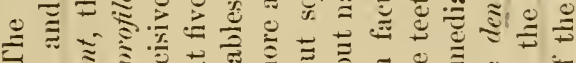
।

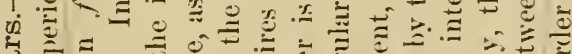

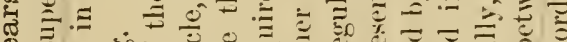
¿्र $\cong=$

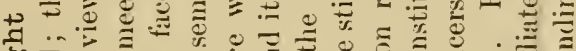
\% - \%

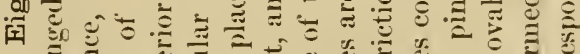

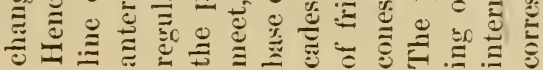




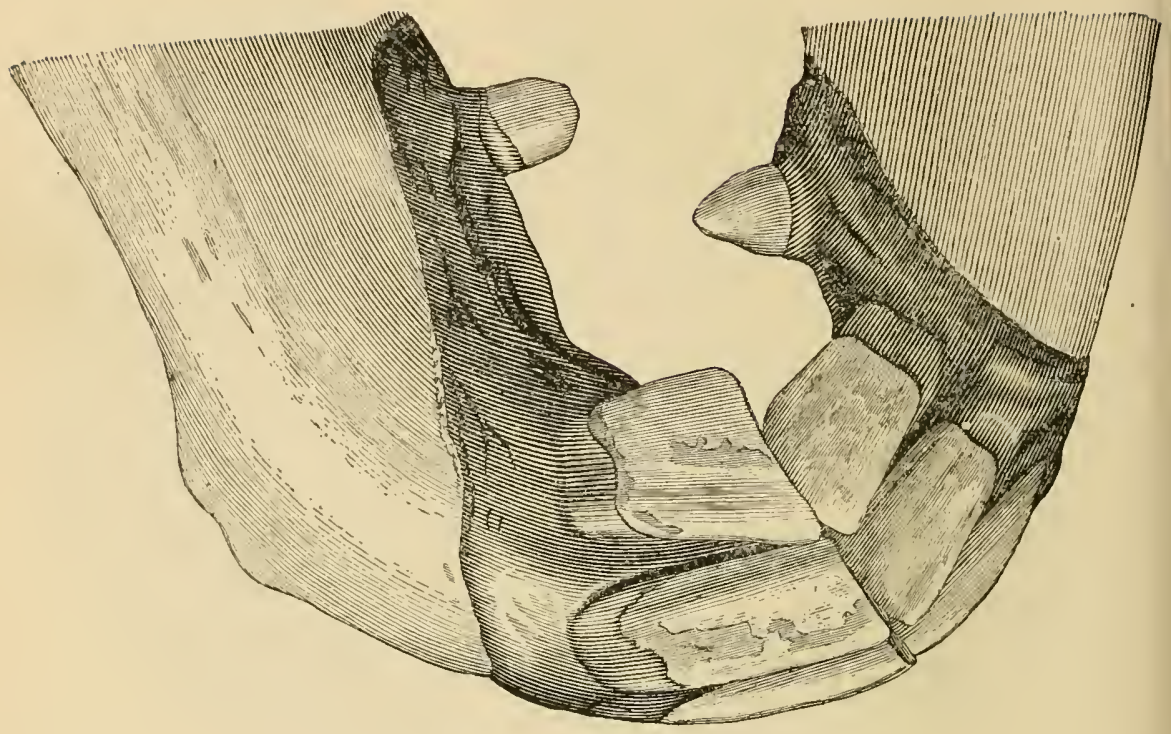

望

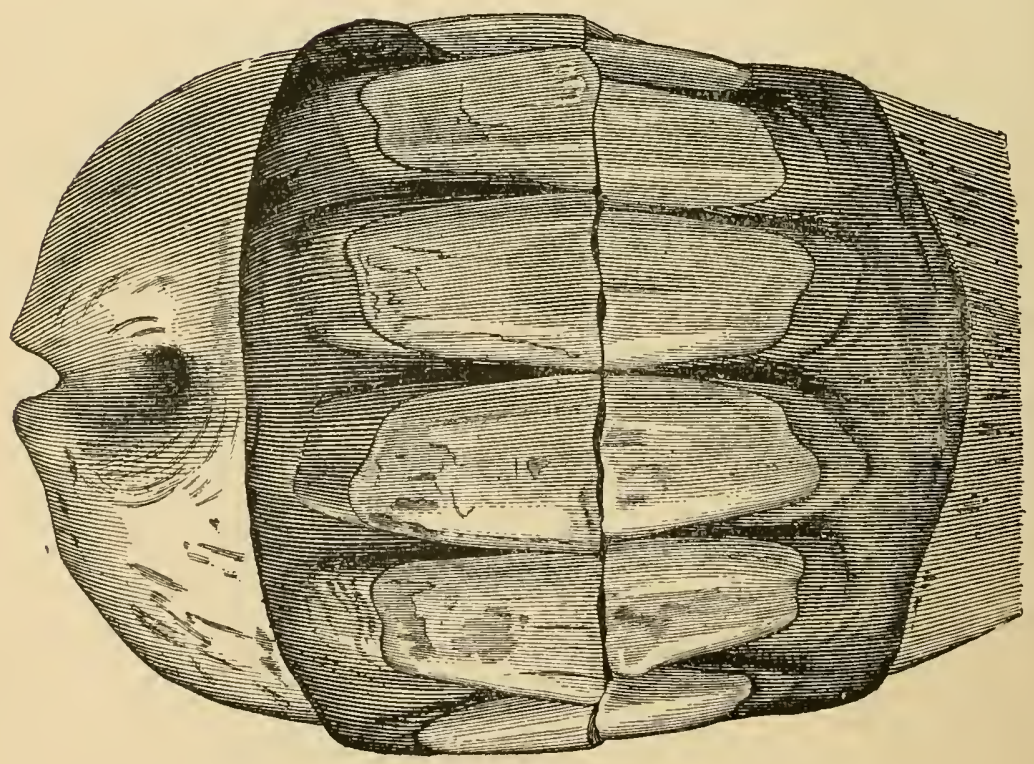



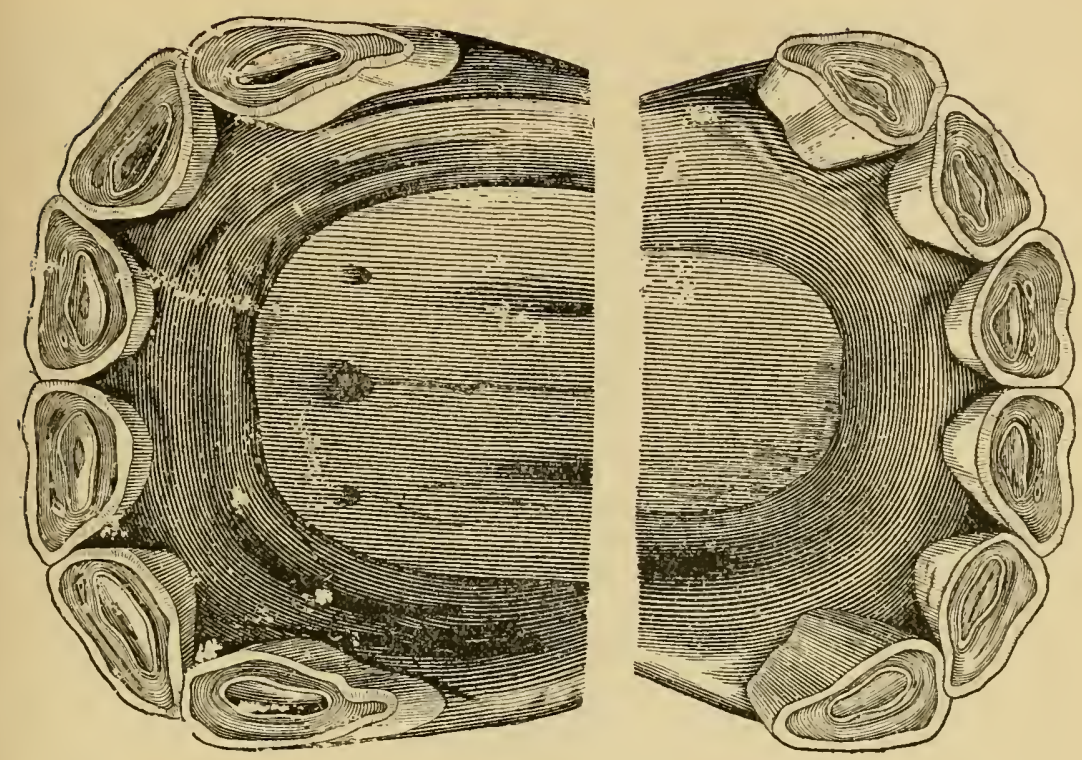

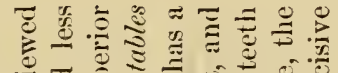

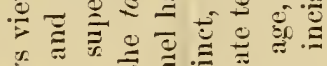

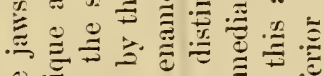

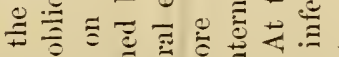

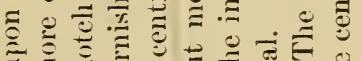

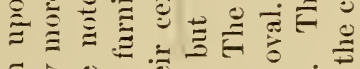

$$
\begin{aligned}
& \text { ¿ } \\
& \text { U. }
\end{aligned}
$$

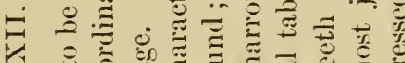

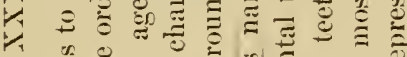

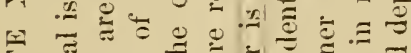

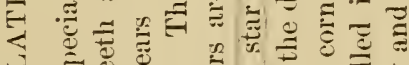

$$
\begin{aligned}
& \text { क क }
\end{aligned}
$$

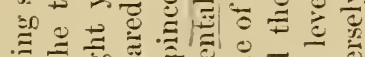

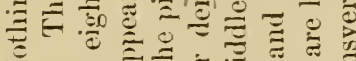

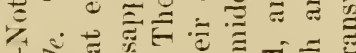

$$
\begin{aligned}
& \text { 1. } \\
& \text { 记完 }
\end{aligned}
$$

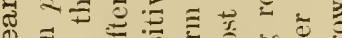

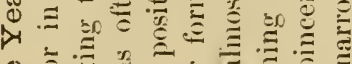

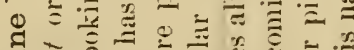

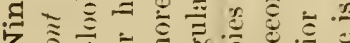

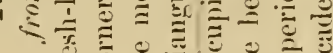

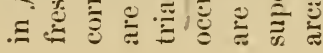




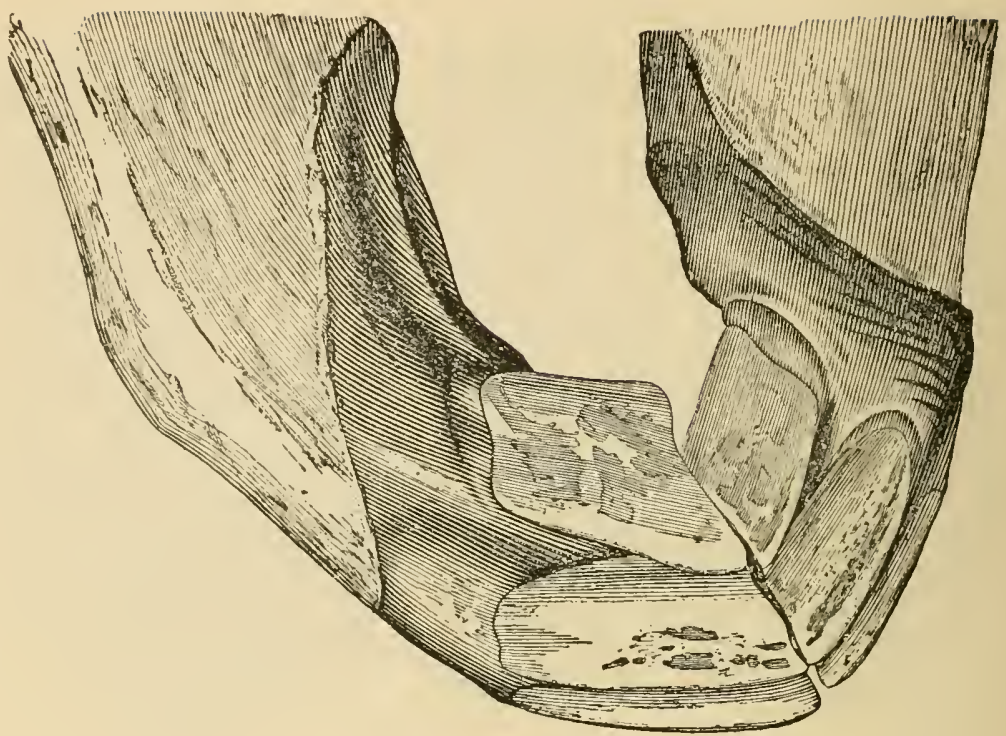

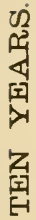

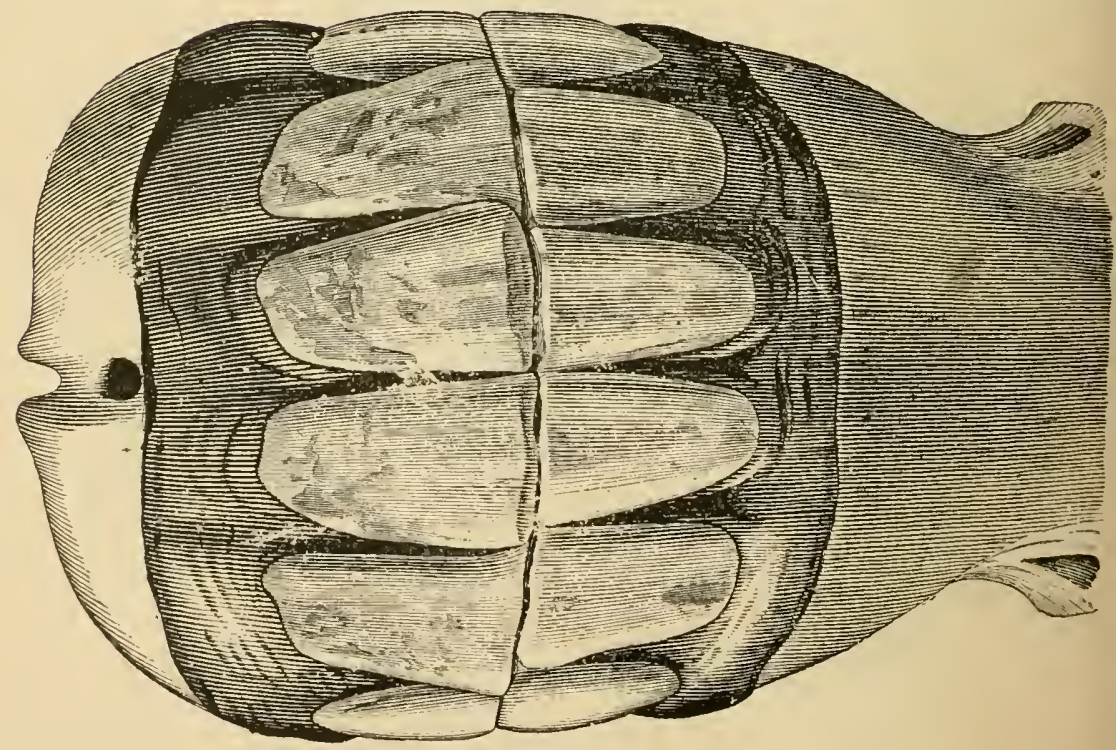



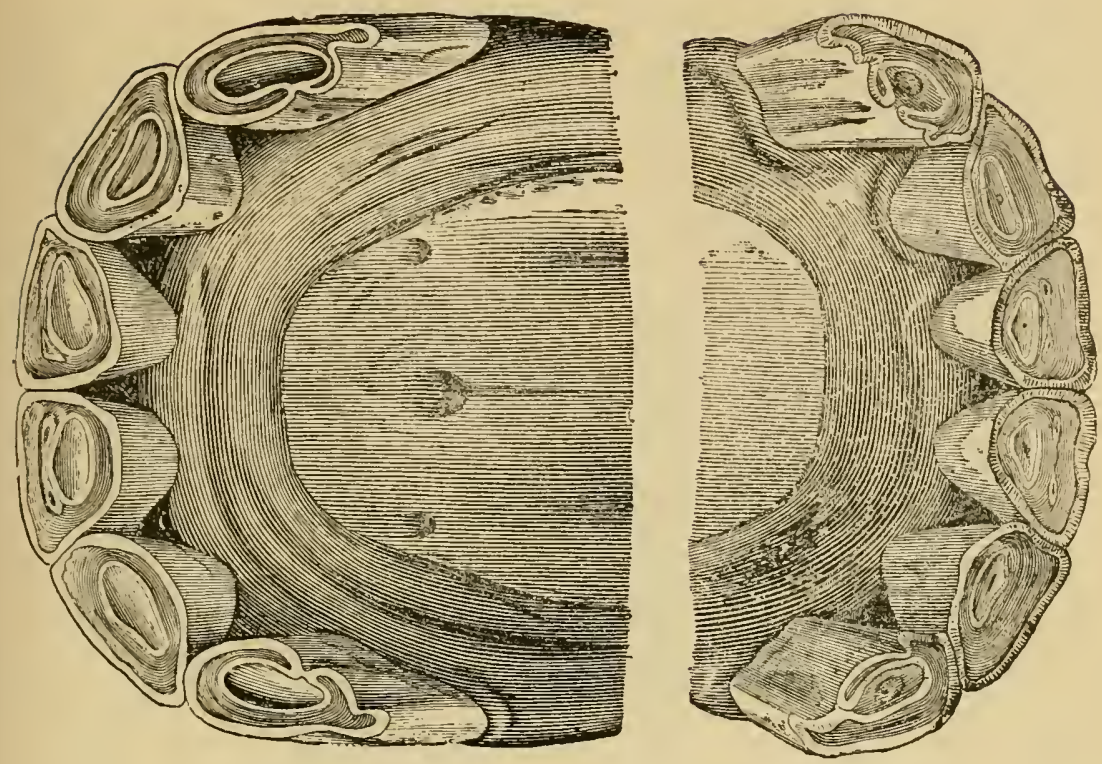

$\cong$

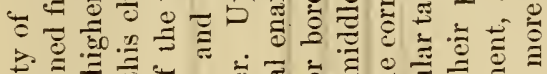

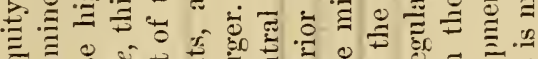

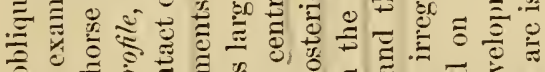

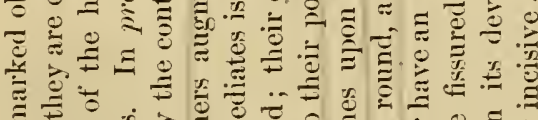
苛 $=$

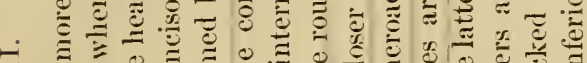
$\Xi$ छ

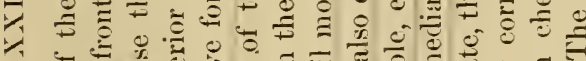
,

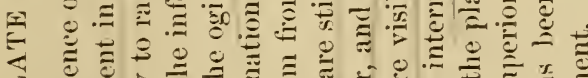

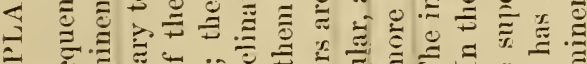

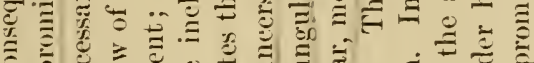

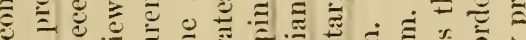

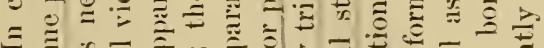

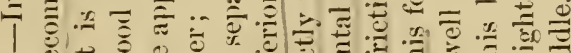
क力口

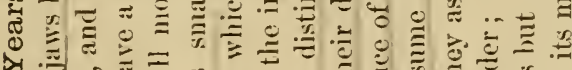

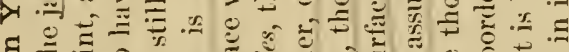
वี HE

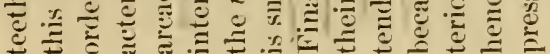




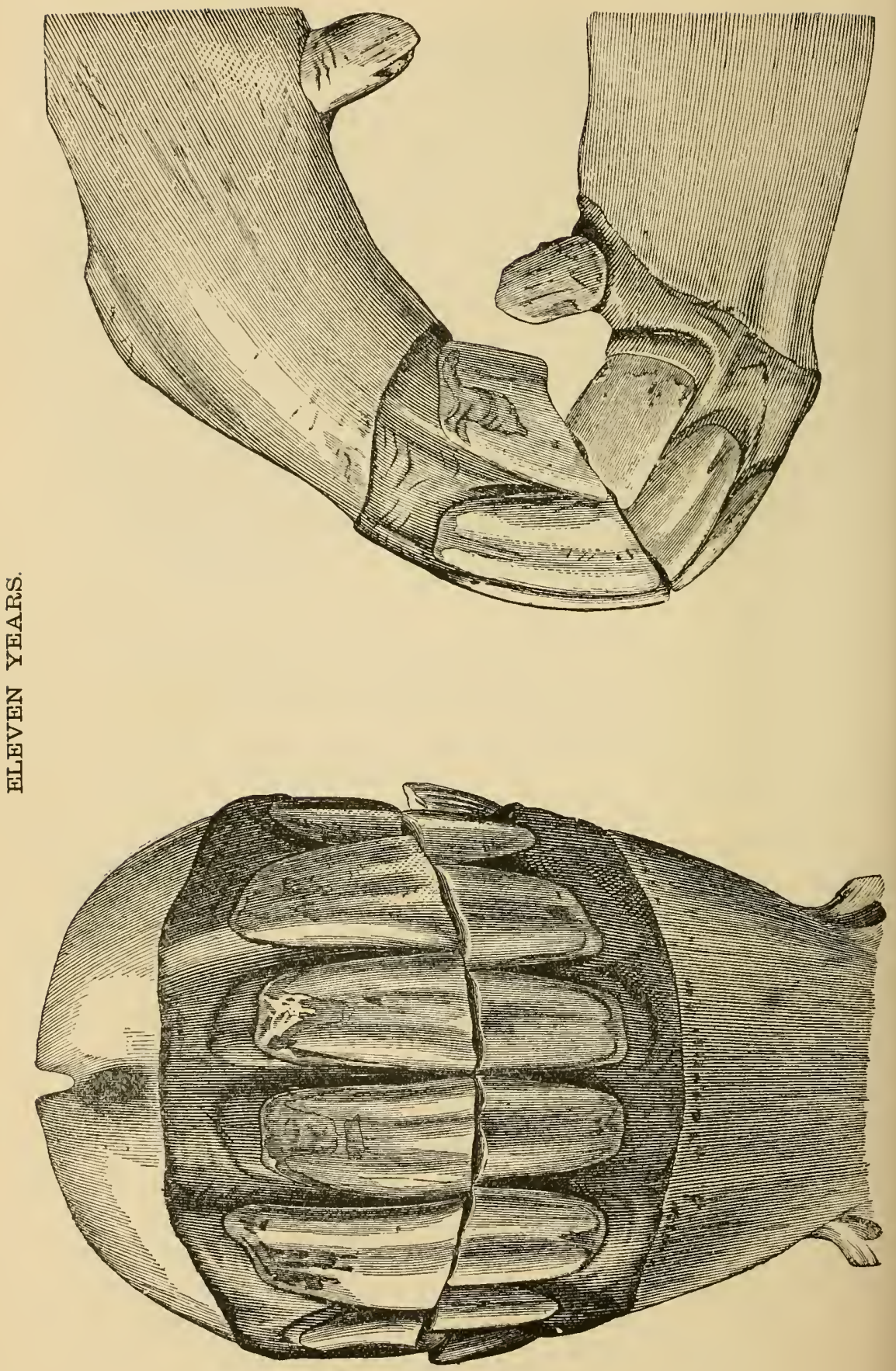



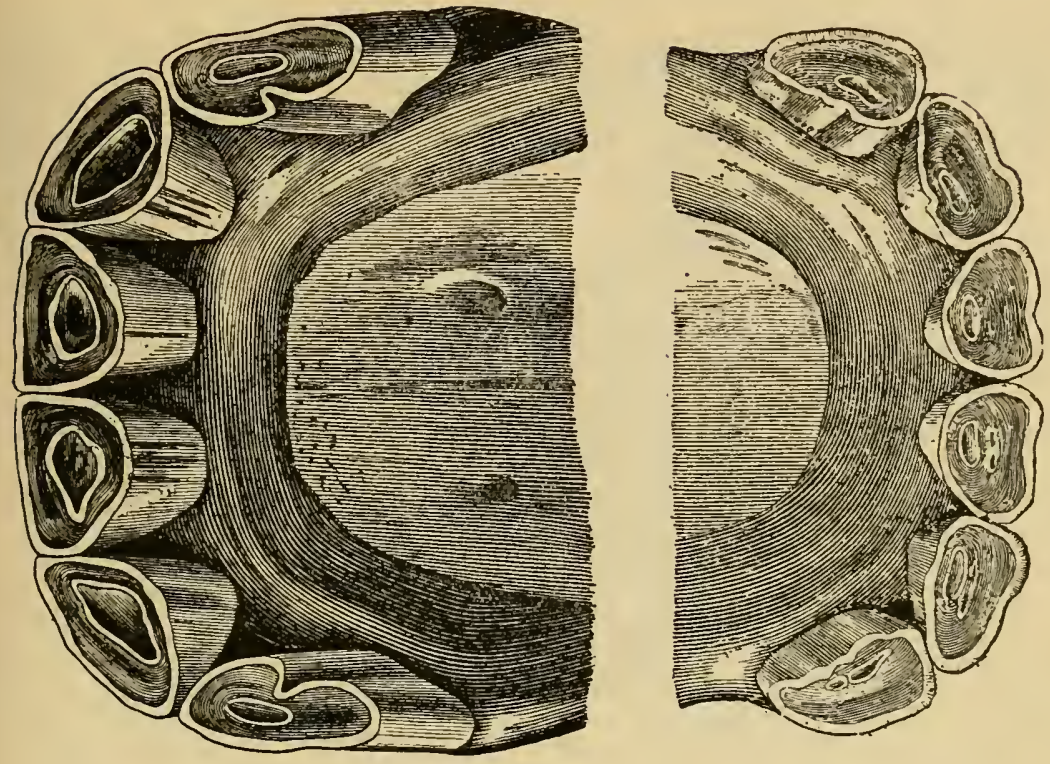

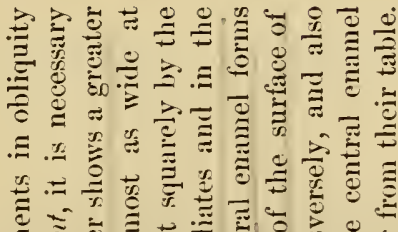

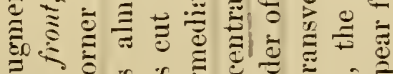

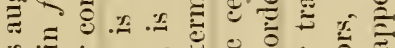

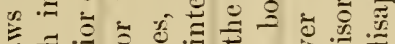

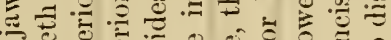

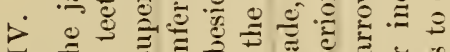

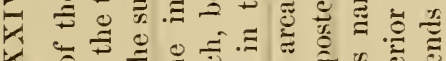

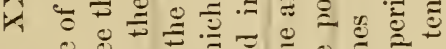
E

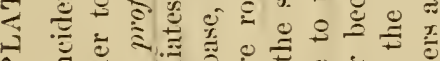

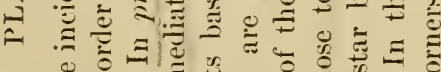

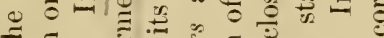
Е.引. | สี่

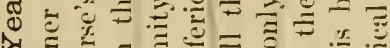

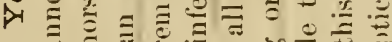
몷

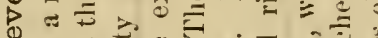

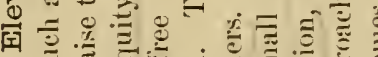

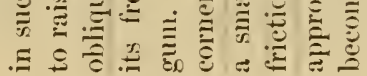




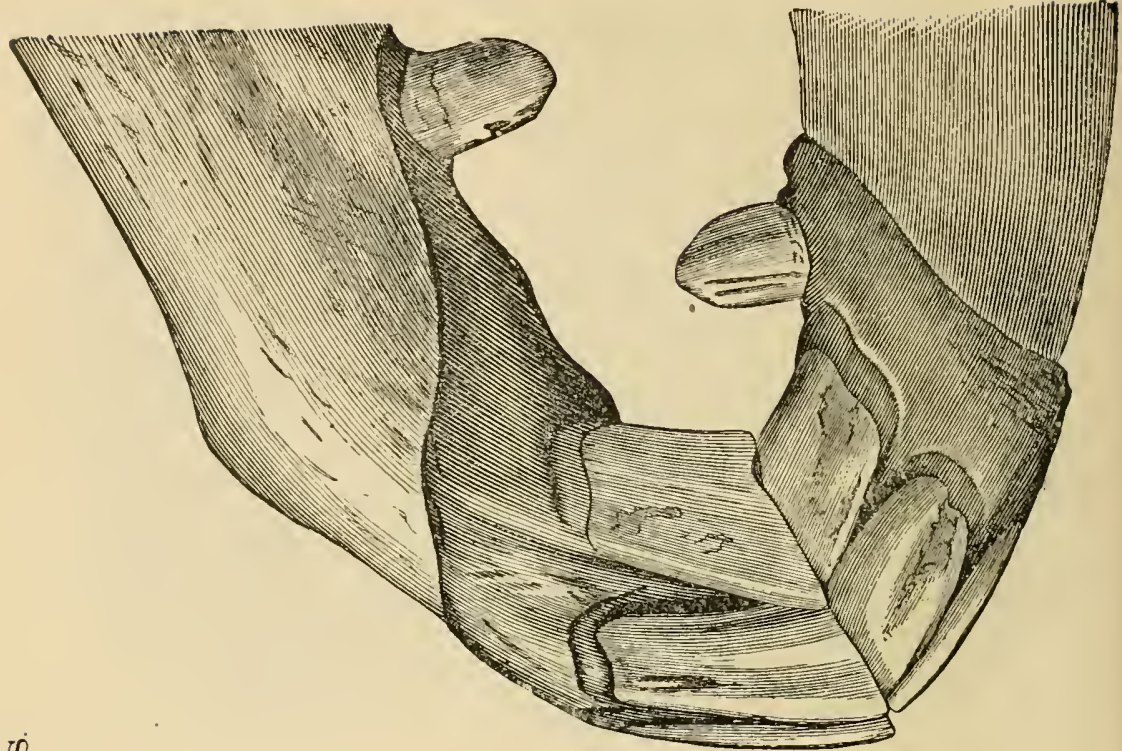

恣

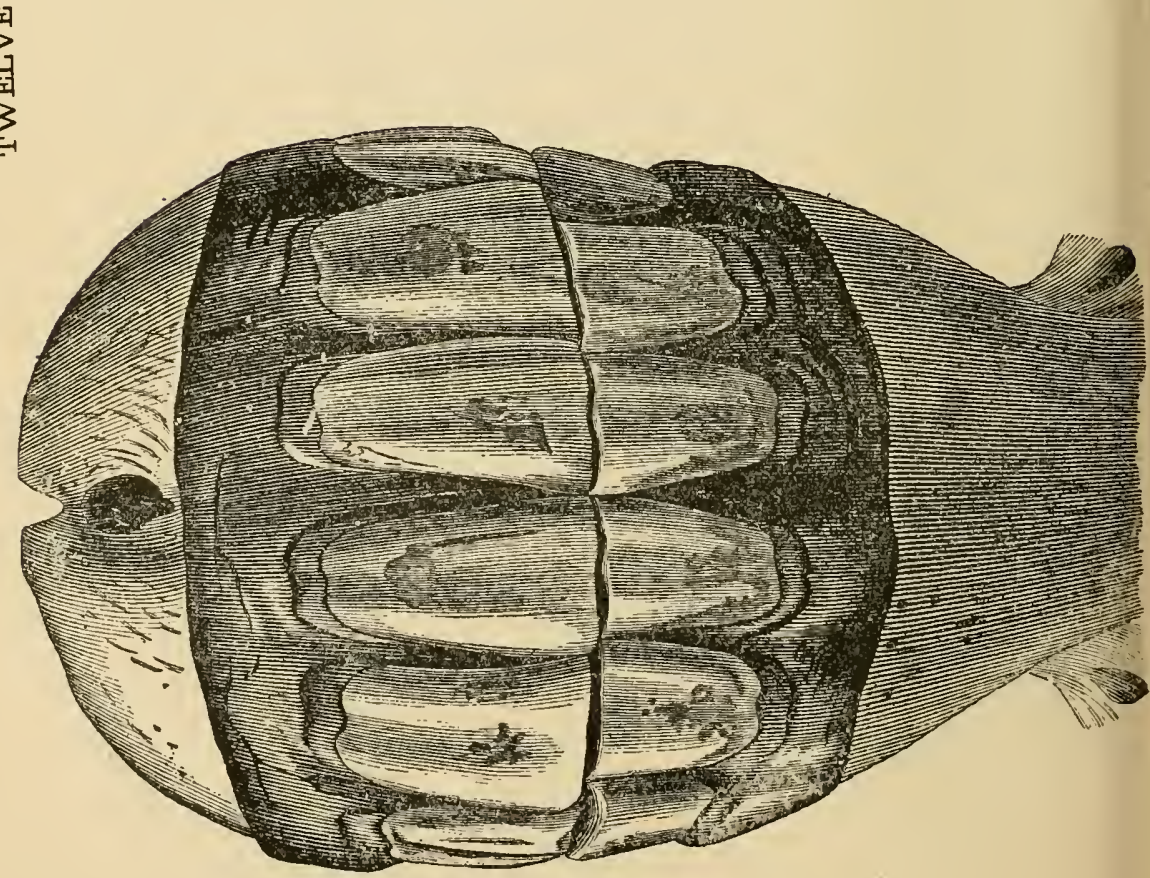


$\begin{array}{llllll}\text { THE CHARACTERS FURMISHED BY THE TEETH. } & 707\end{array}$
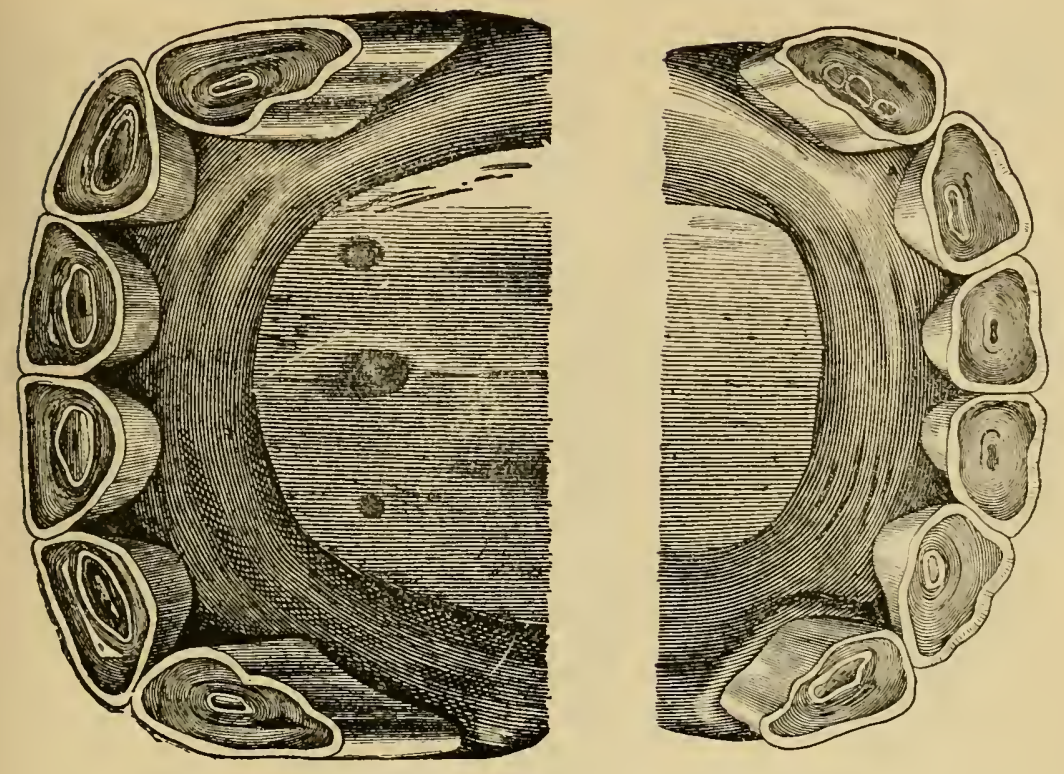

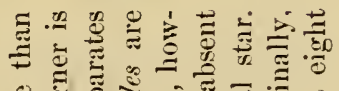

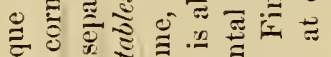

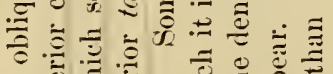

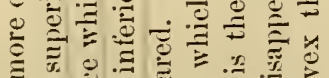

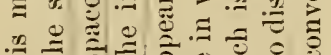

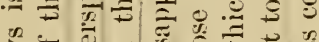

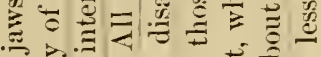

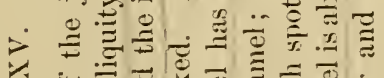

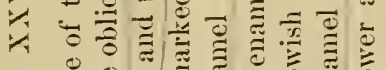

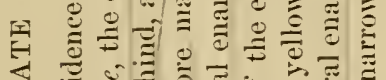

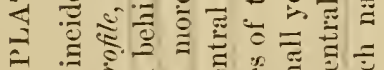

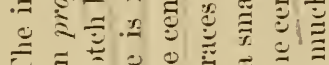

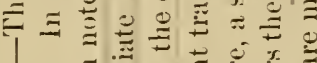

$$
\begin{aligned}
& \text { ণิ }
\end{aligned}
$$

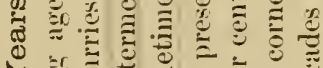

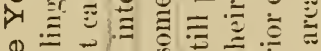

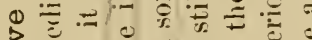

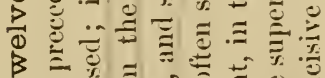

$$
\begin{aligned}
& \text { B }
\end{aligned}
$$

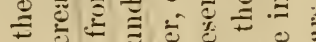

$$
\begin{aligned}
& \text { ᄃ. }
\end{aligned}
$$




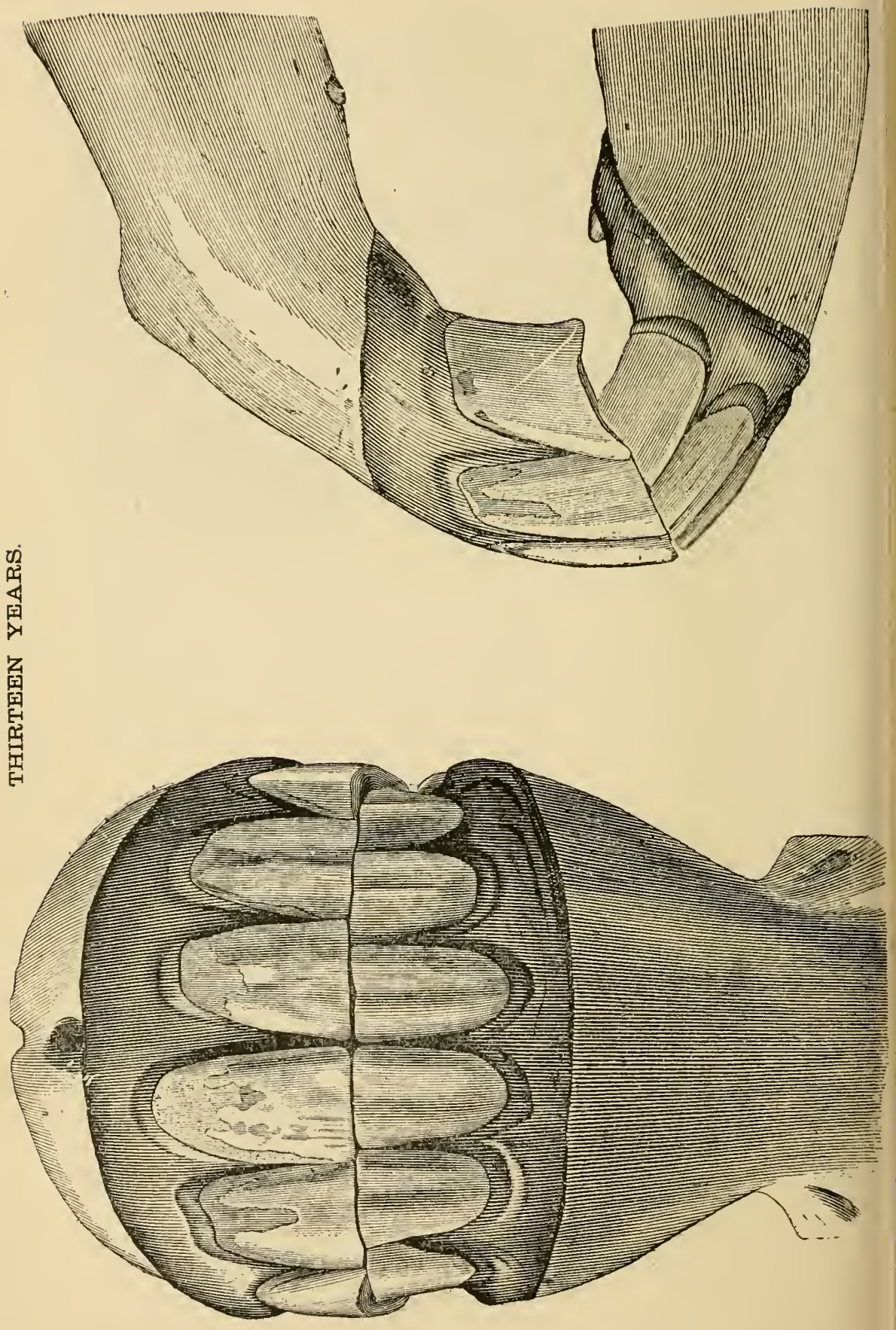



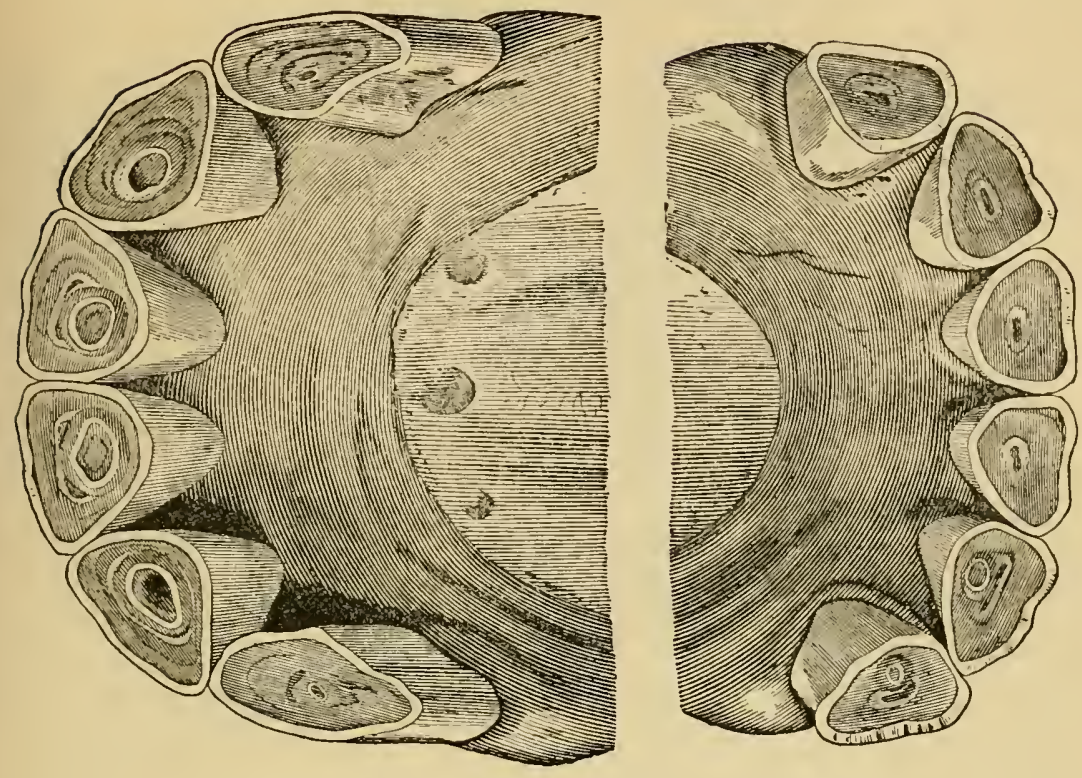

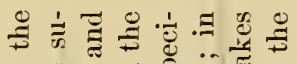

$\overrightarrow{0} \ddot{\Xi} \Xi$ क

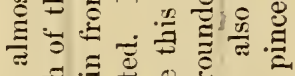

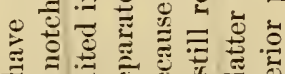

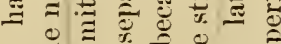

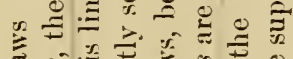

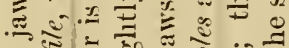

น.

$\cong$ ซ

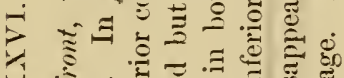

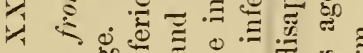

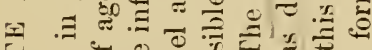

=

\记

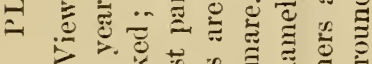

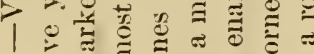

का $\Xi \Xi \Xi$

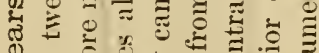

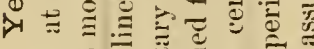

व 2.0 出.

○े

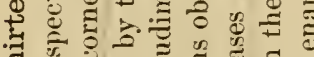

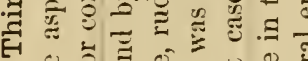

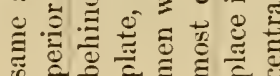



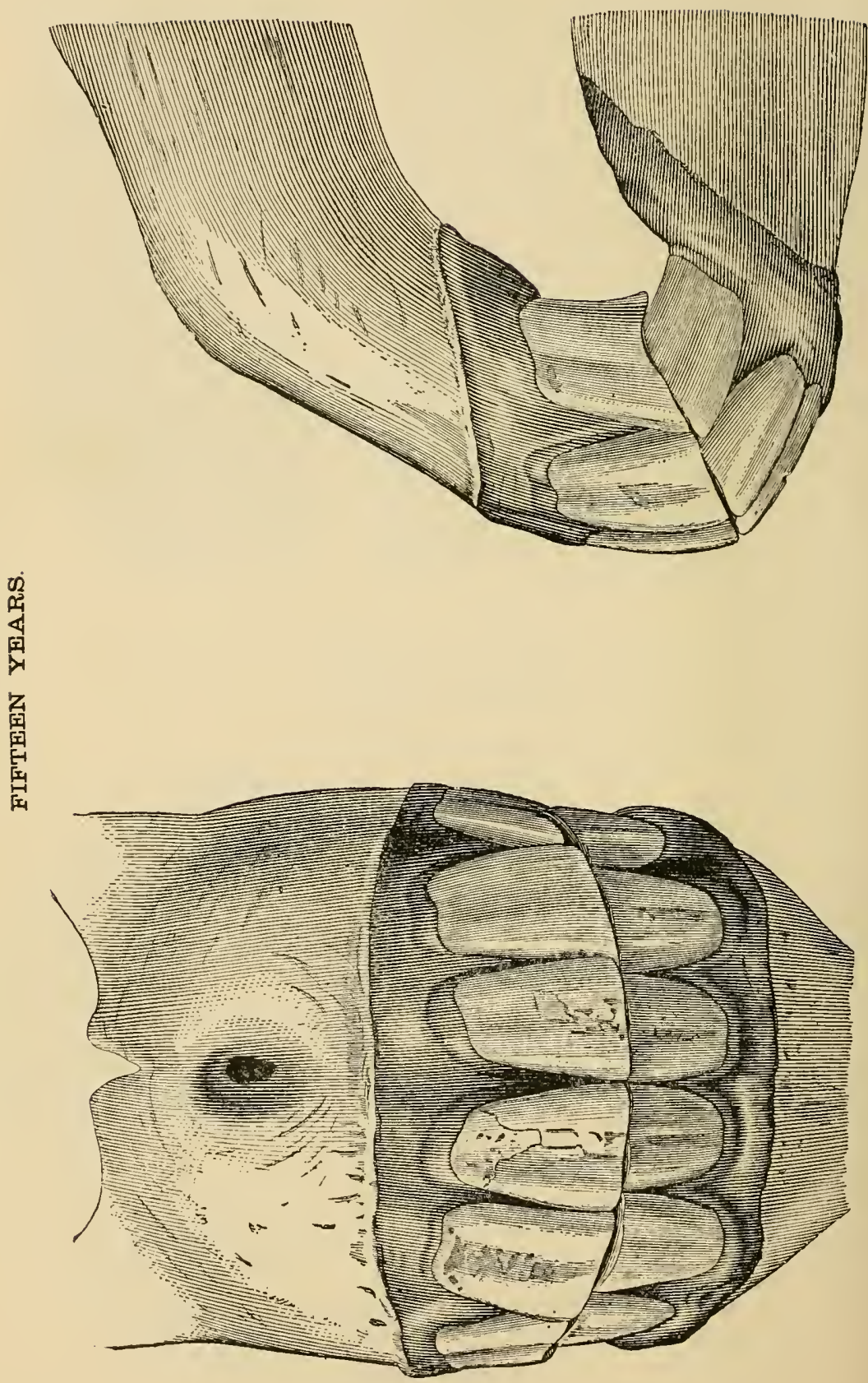

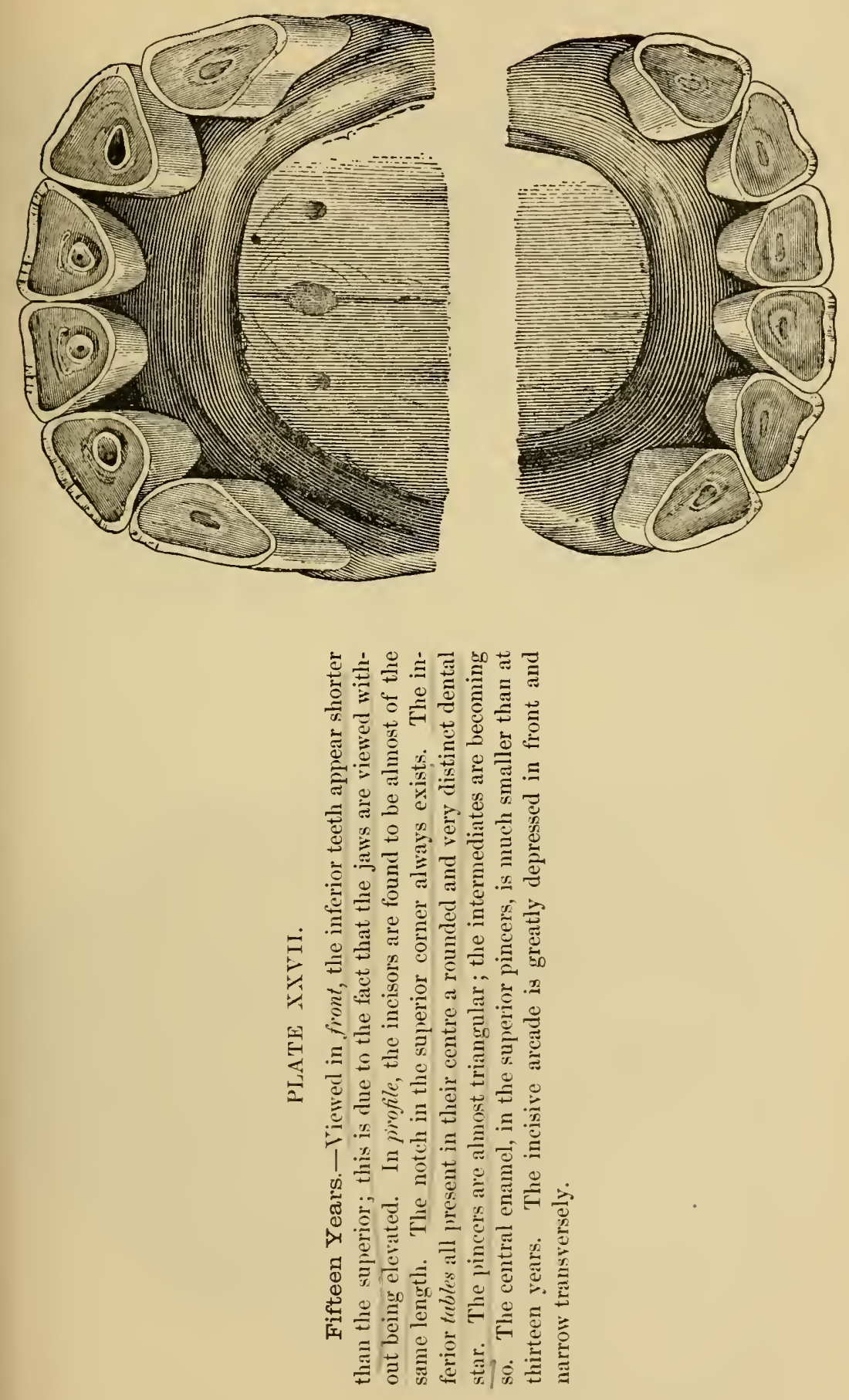
望
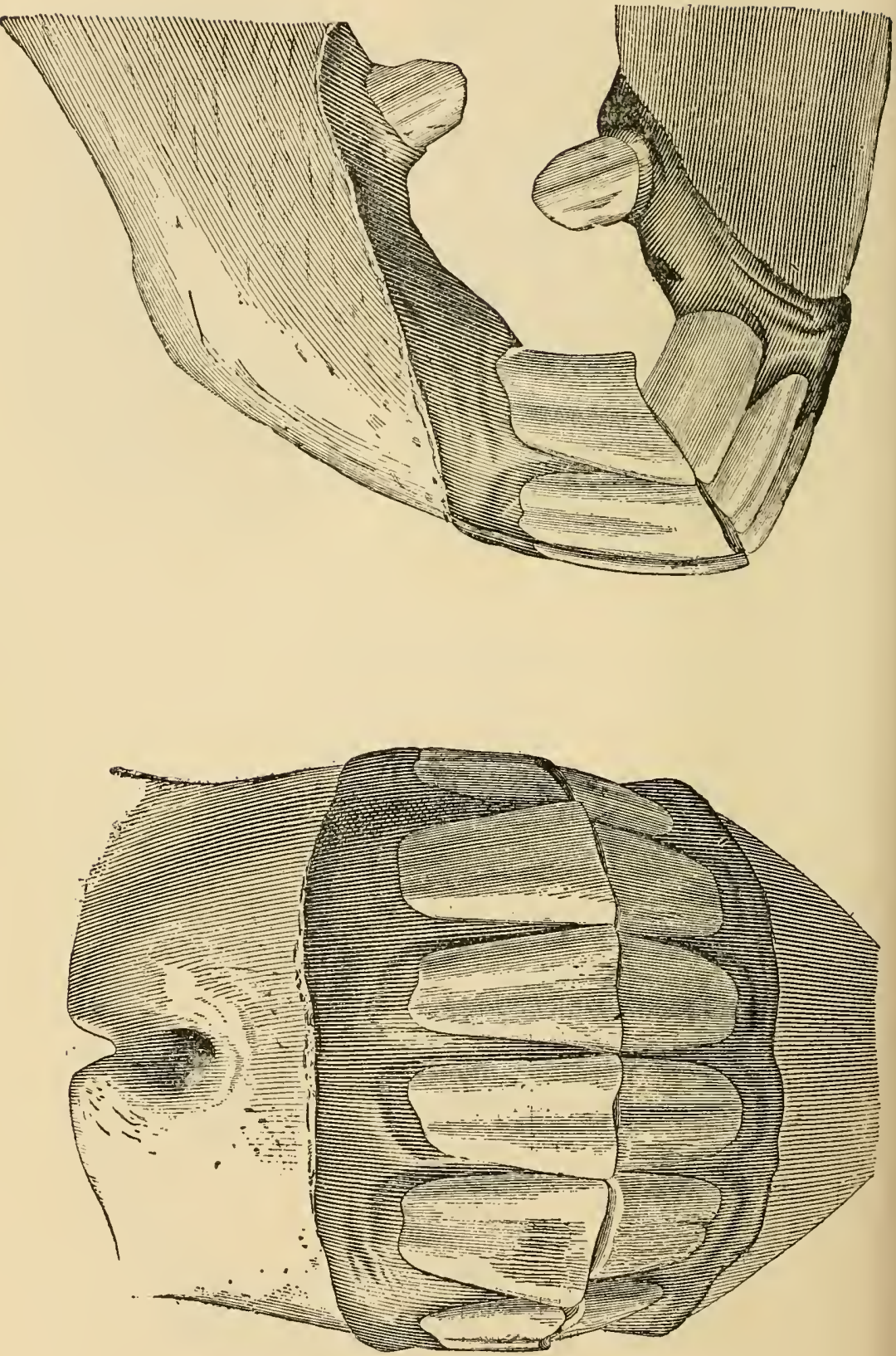

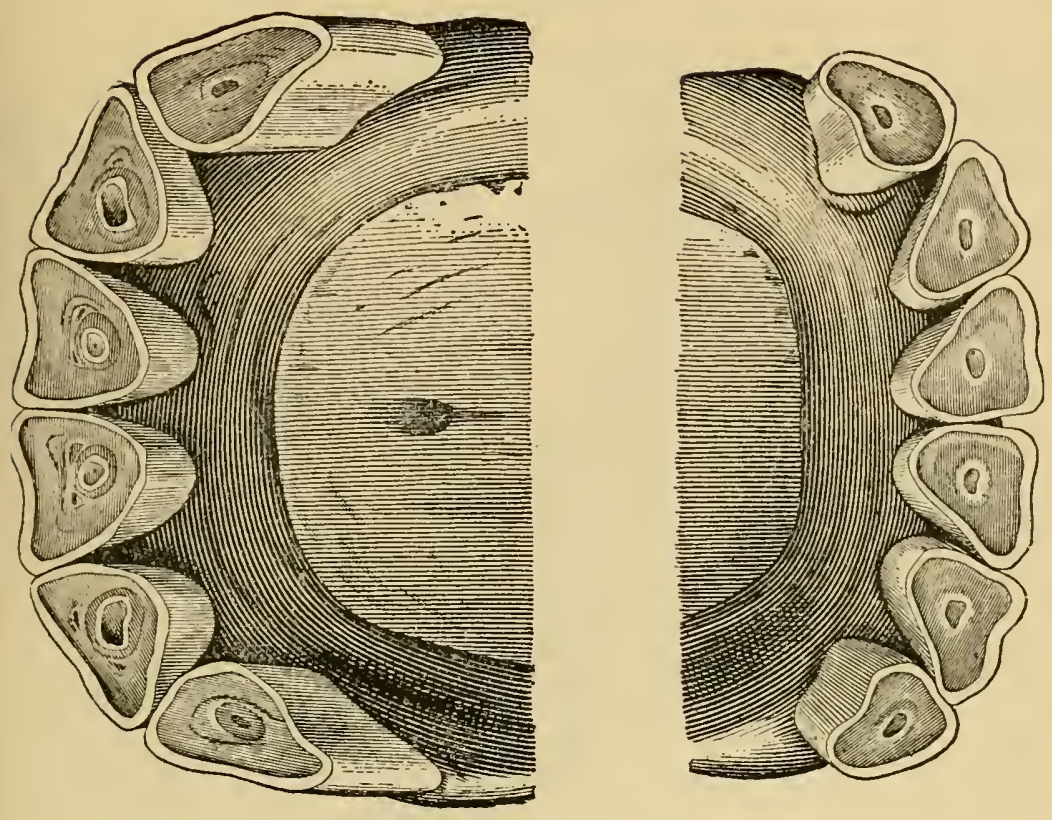

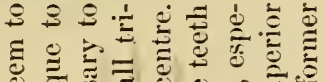

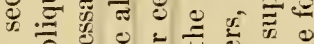

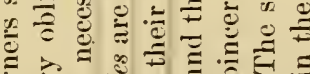

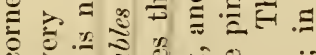

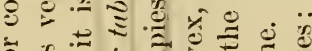

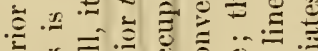

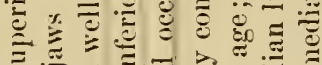

$$
\begin{aligned}
& \bar{x} \because \Xi \Xi \geq
\end{aligned}
$$

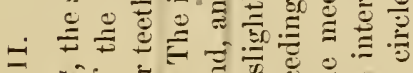

$$
\begin{aligned}
& \Xi \text { ‡宁. }
\end{aligned}
$$

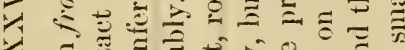

$$
\begin{aligned}
& \text { ᄀ. }
\end{aligned}
$$

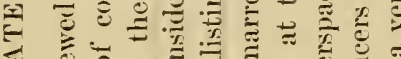

$$
\begin{aligned}
& \text { J }
\end{aligned}
$$

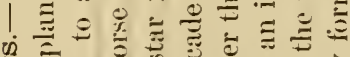

$$
\begin{aligned}
& \text { 为- } \\
& \text { ๙ีڤ }
\end{aligned}
$$

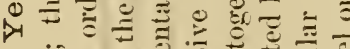

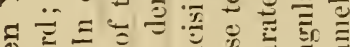

$$
\begin{aligned}
& \text { Ф }
\end{aligned}
$$

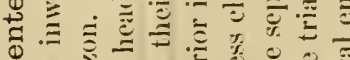

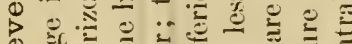

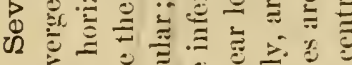

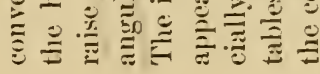




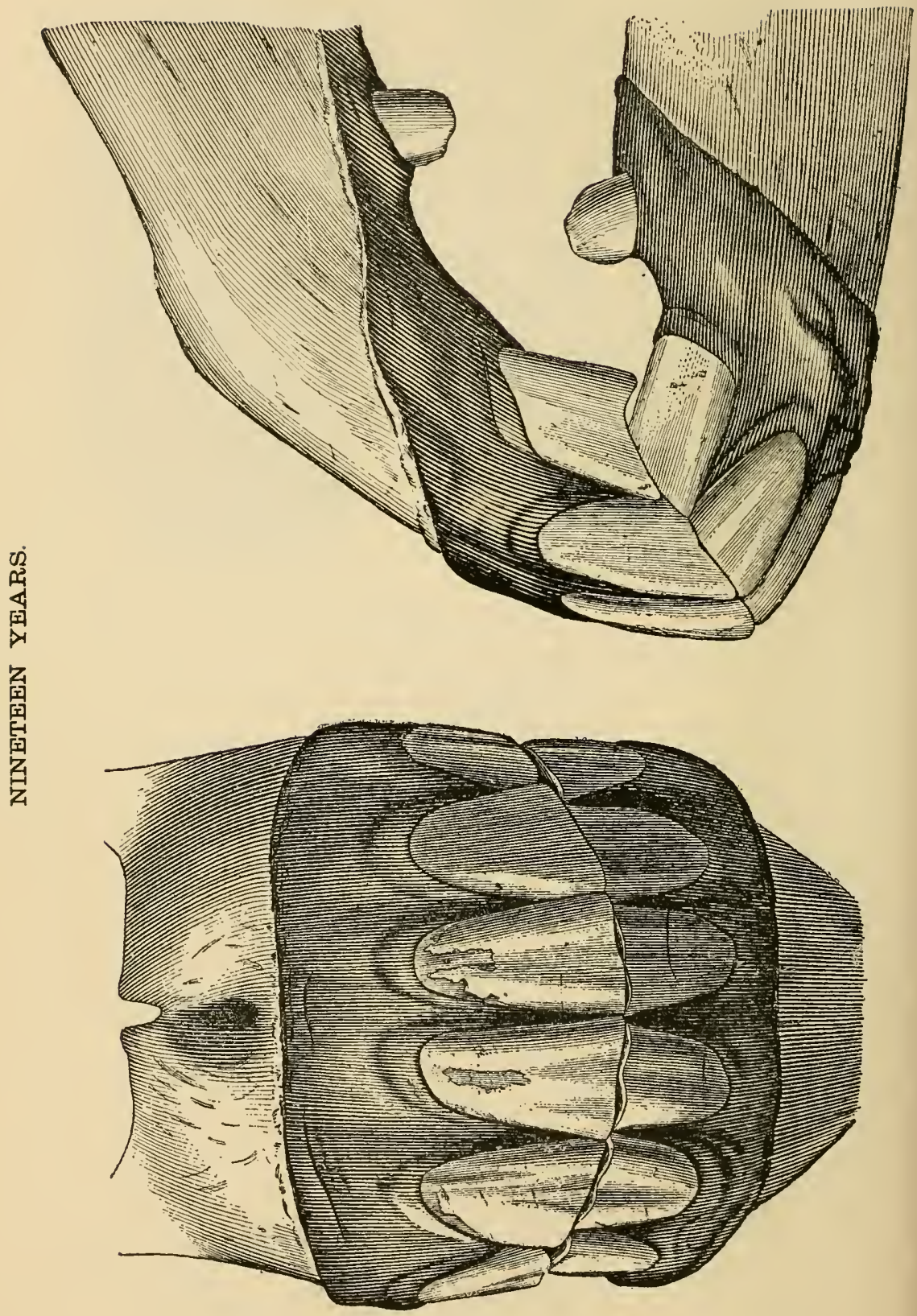



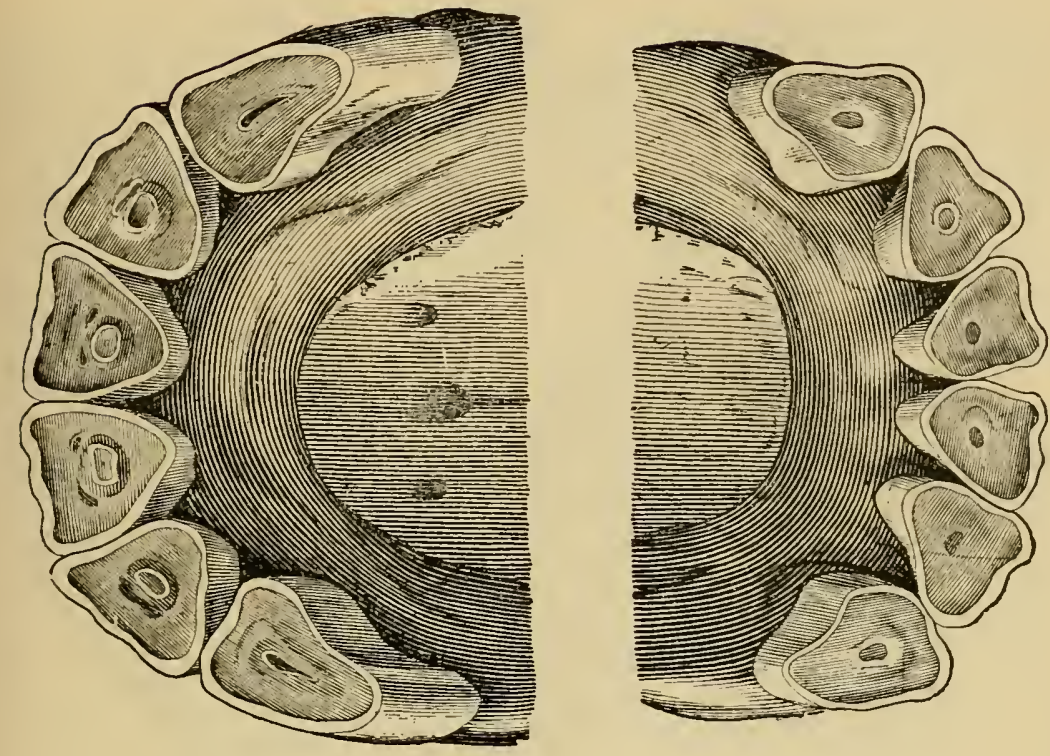

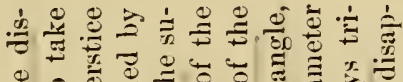

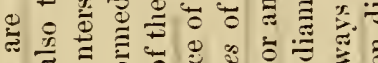

क

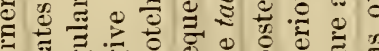

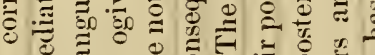

เ

苛证

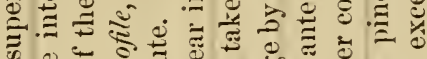

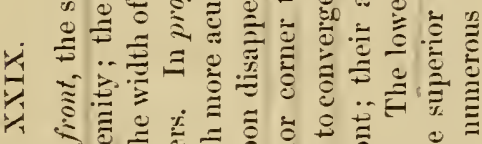

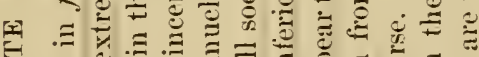

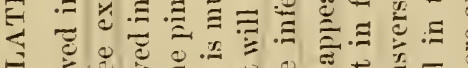

$\hat{A}$.

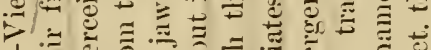

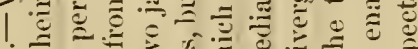
क ฮㄹ

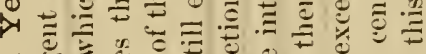
ฮี

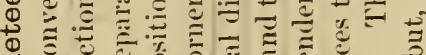

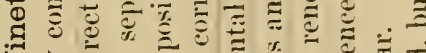

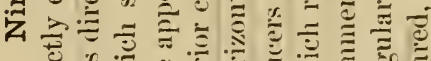

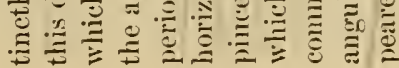




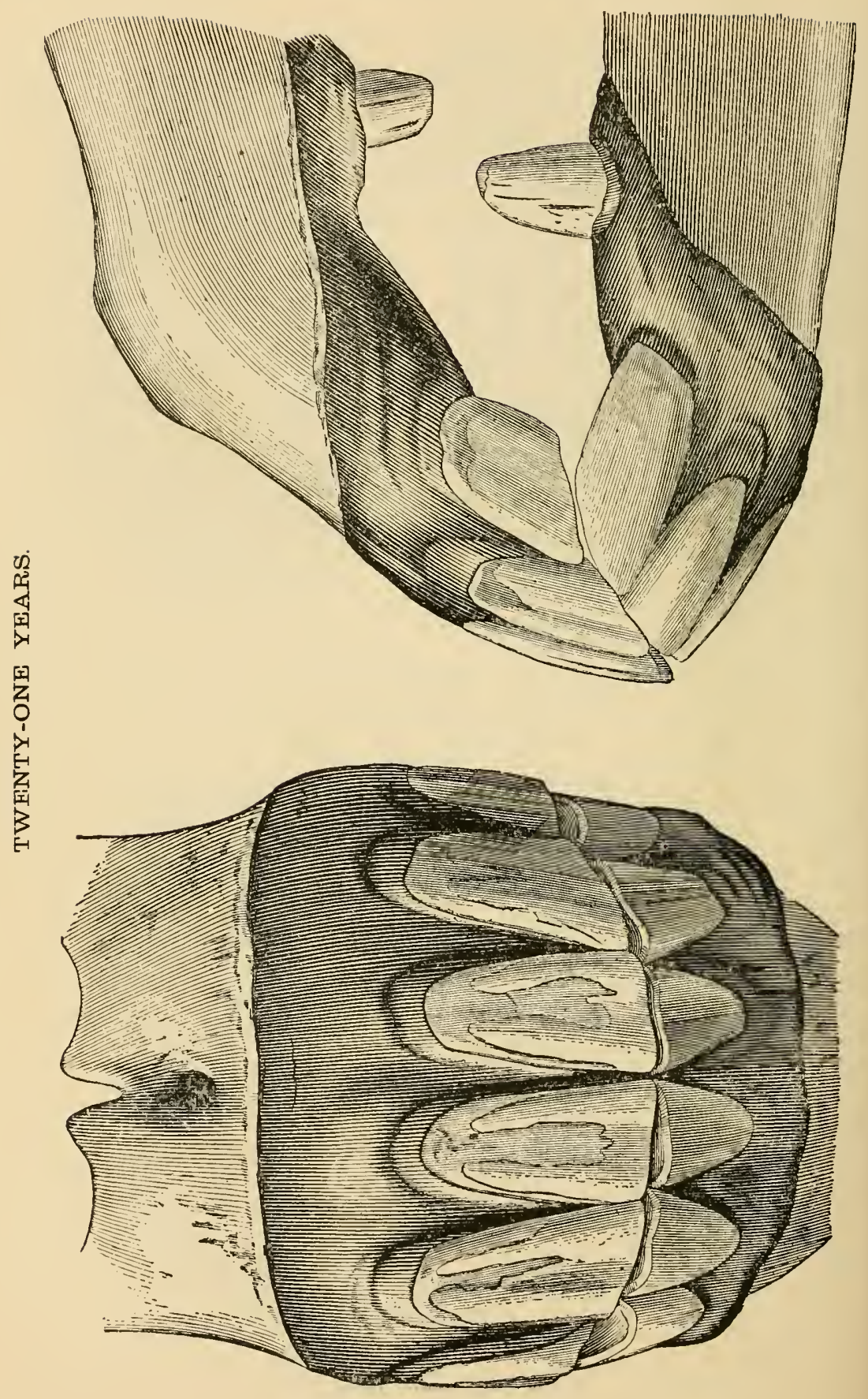



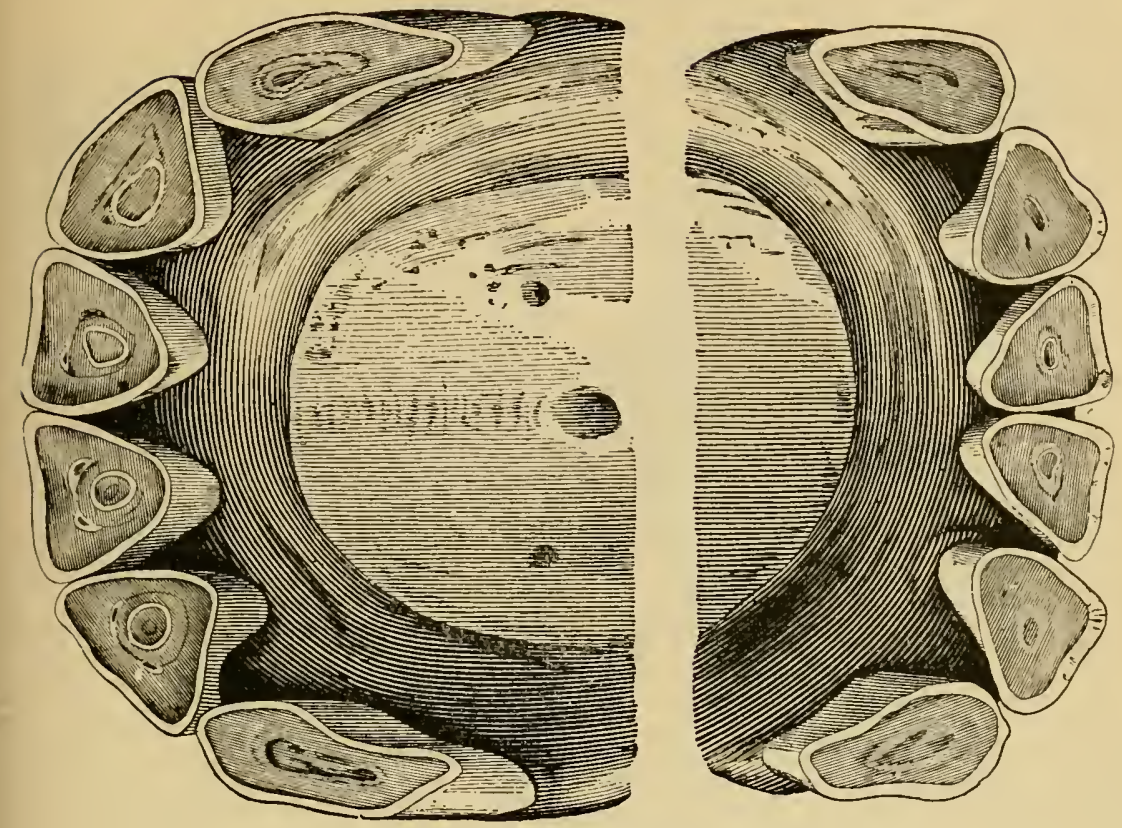

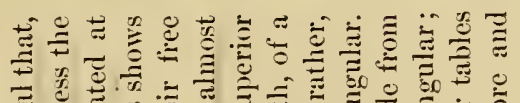

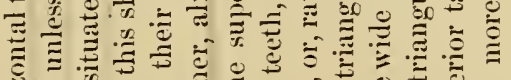

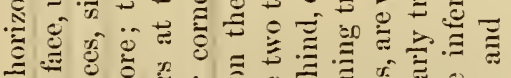
ช. Ð

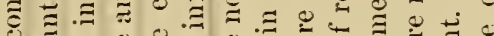

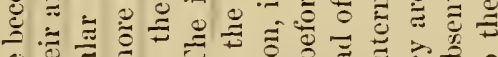
,

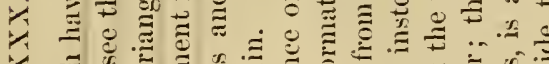

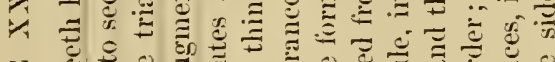

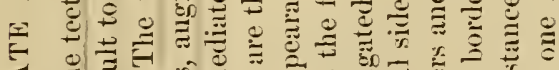

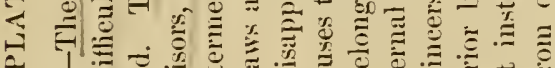
ค

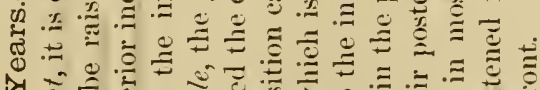

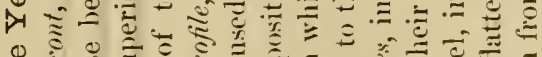

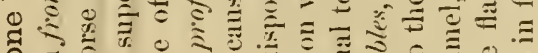

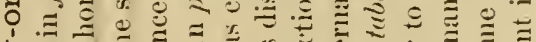
bこ

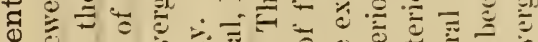

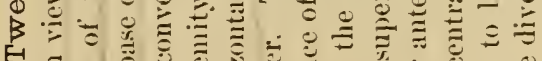

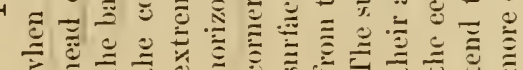


空

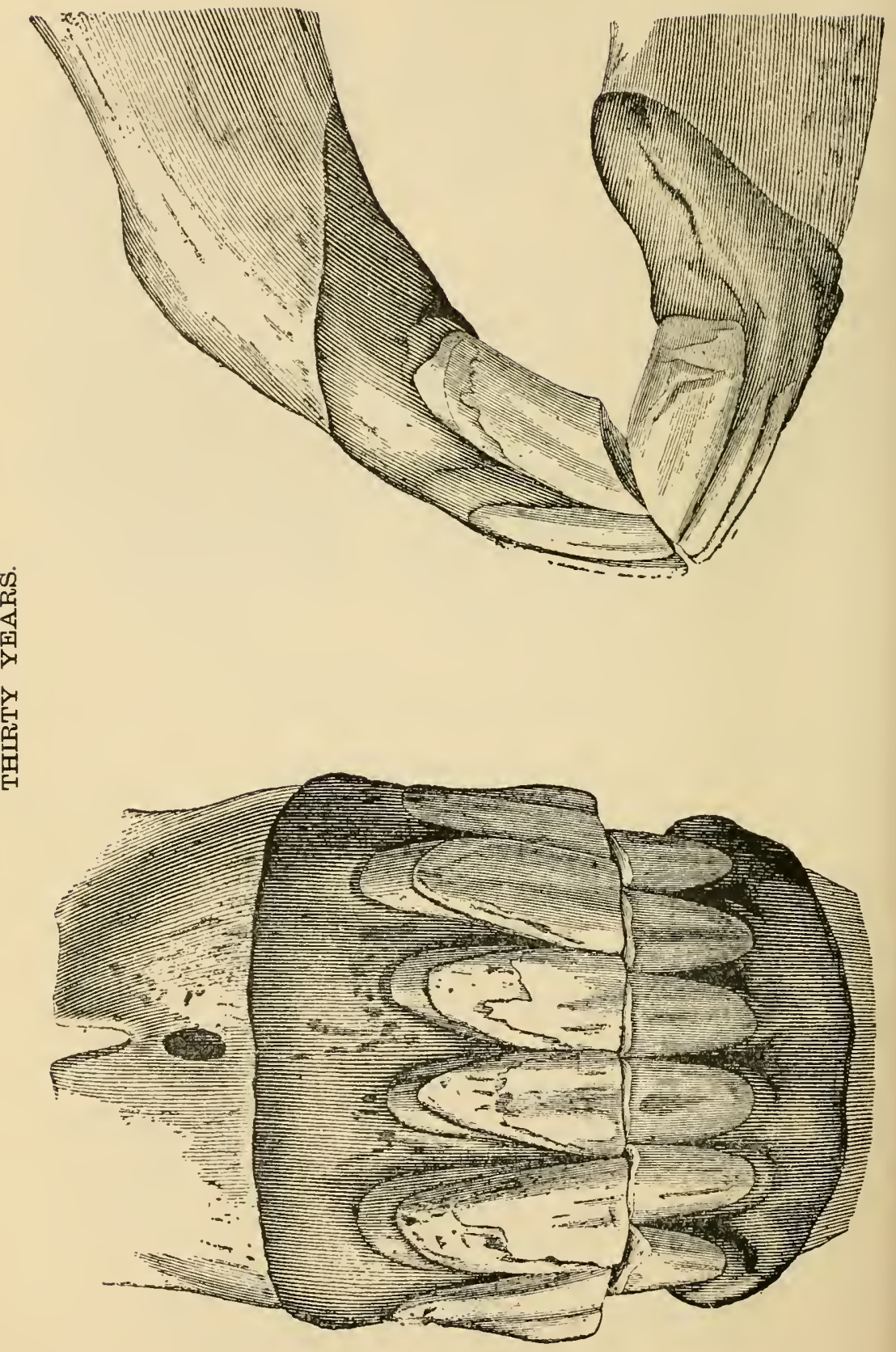



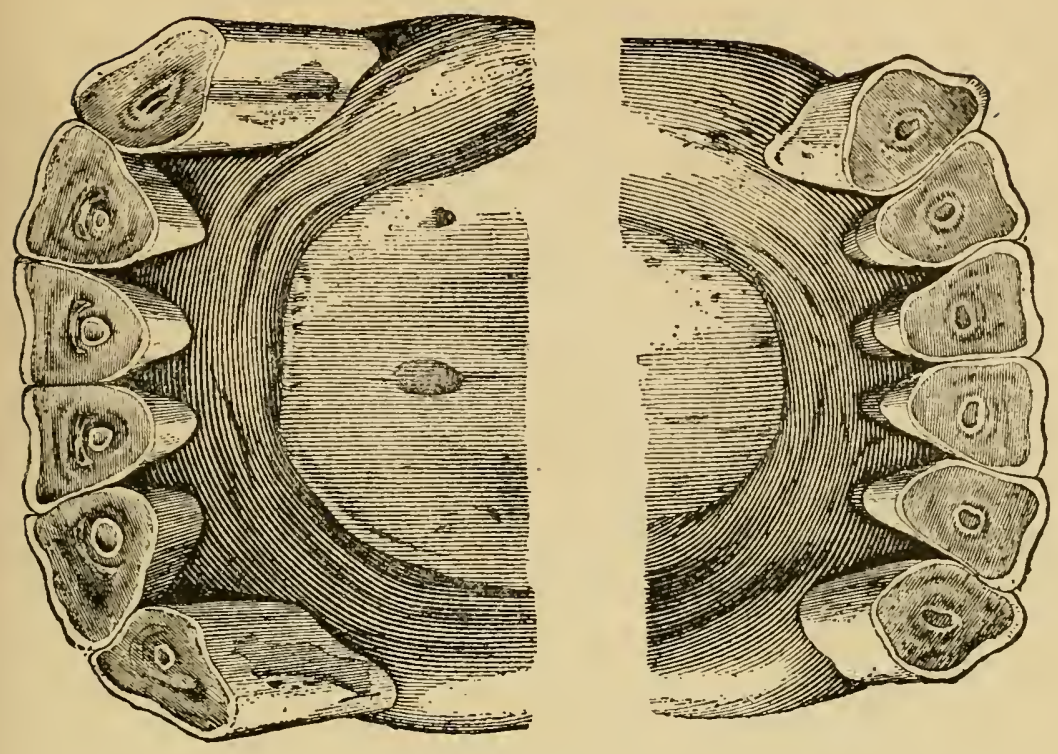

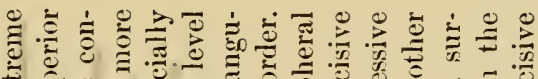

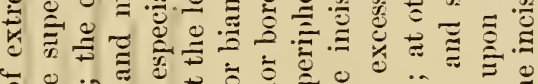

б

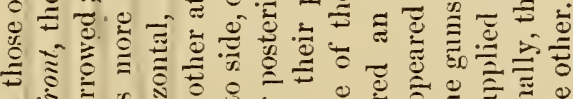

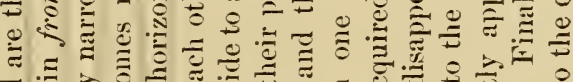

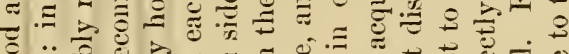

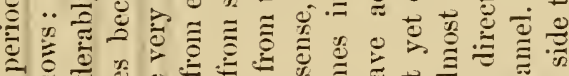

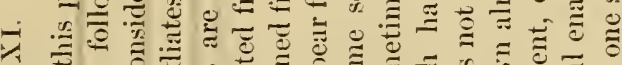

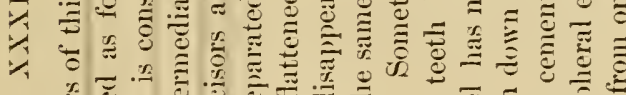

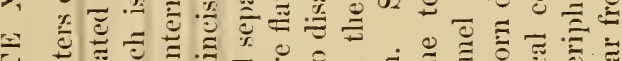

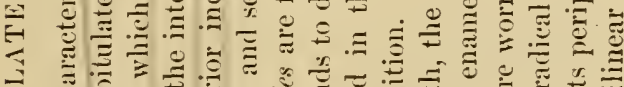

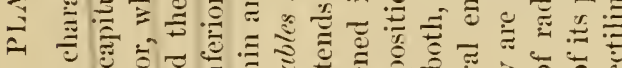

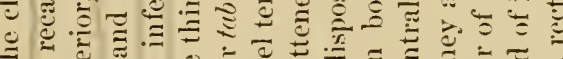

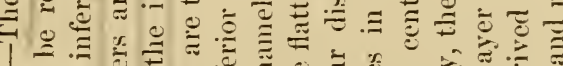

1

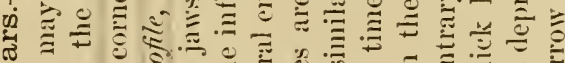

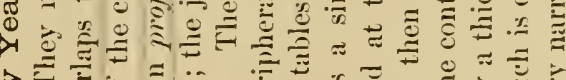

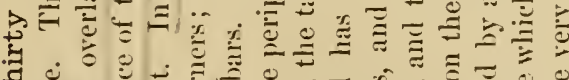

突

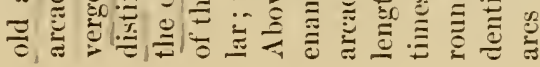





\section{PART III.}

IRREGULARITIES OF THE DENTAL APPARATUS.

THE irregularities of the dental apparatus are numerous and interesting. When they exist, the lorse is said to be falsely marked, or to have a folse mouth. While many of them are without importance, there are others which should be taken into serious consideration, as much in their physiological relations as in the determination of the age. We will enumerate the more remarkable in the following synoptical table :

Irregularities.

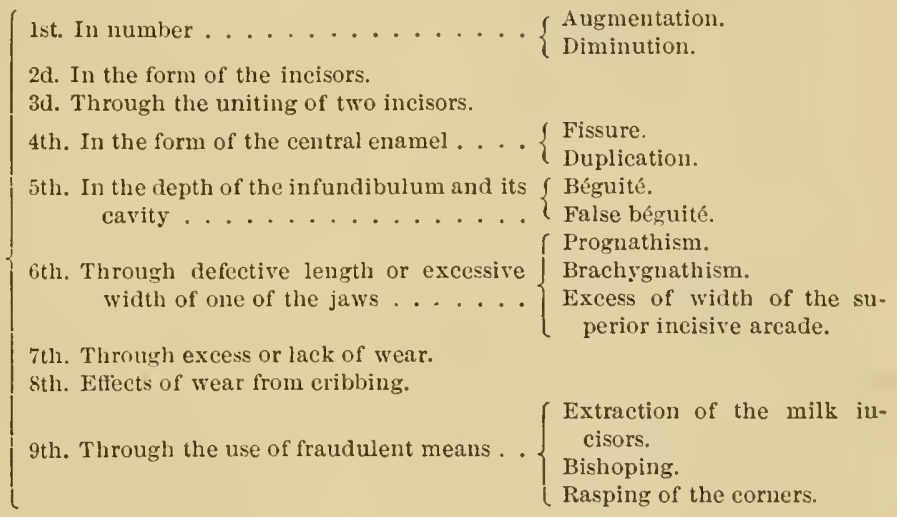

We will study the irregularities of the dental system in the order given in this table.

\section{Irregularities in the Number.}

\section{a. Augmentation.}

Incisors. -The most extraordinary example of this anomaly is that which has been reported for the first time by Lafosse." "There are some horses," says he, "which have a double row of incisors. This condition cannot exist without obstructing the other teeth, disturbing their support in the socket, and altering the germ of the tooth."

1 Lafosse, Cours d'hippiatrique ou Traité complet de la médecine des chevaux, Paris, in-folio, 172, p. 32. 
We have made a similar observation upon a horse brought to the elinic of the Alfort School in 1842. ${ }^{1}$ His mouth presenterl a double row of incisors of the second dentition in each jaw,-in other words, he had twenty-four in all.

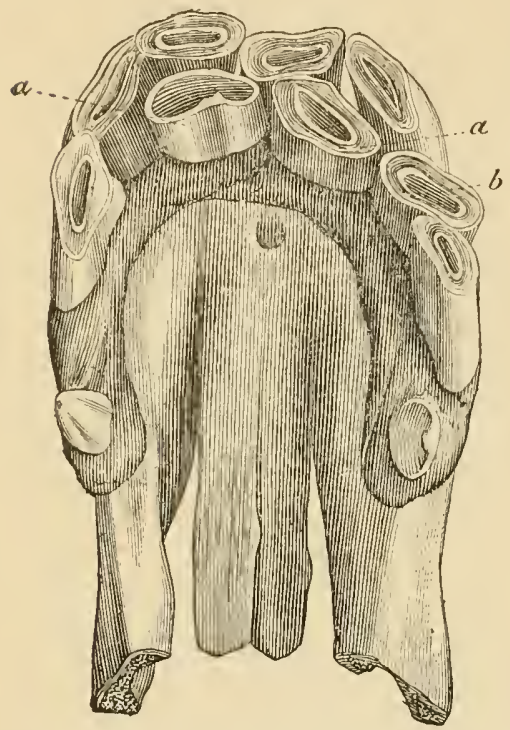

FIG. 308.-Two supernumerary pincers, $a, a$, and one intermediate, of the second dentition.

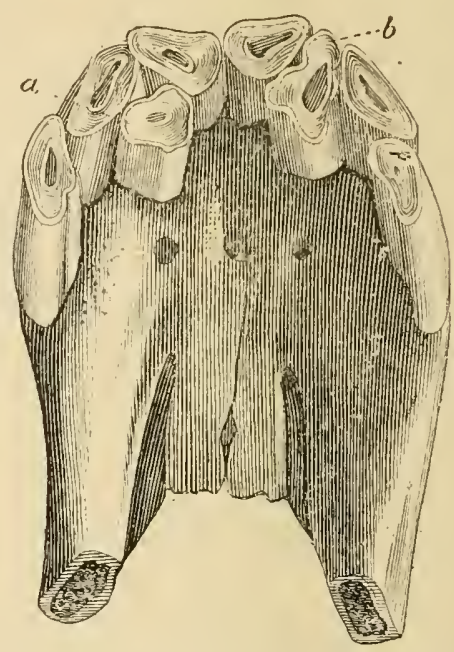

FIG. 309.-Two supernumerary intermediates, $a$ and $b$, of the second dentition.

Such remarkable examples as these are very rare, but there are others relatively more frequent: those of augmentation of number, which involve the teeth of one or of both jaws, or consist in a doubling of these incisors. We have several times had the opportunity of witnessing these anomalies, more especially in the superior jaw.

Superior Jaw.-We have handerl to Dr. Magitot ${ }^{2}$ several specimens, which he reproduced in his beantiful treatise upon the "Anomalies du Système Dentaire." We will limit ourselves here to a few examples.

In one case (Fig. 308) there existed two supernumerary pincers, $a, a$, and one intermediate, $b$.

In another (Fig. 309) the supernumerary teeth were two intermediates, $a$ and $b$.

In a third horse (Fig. 310) the anomaly consisted of one supernumerary intermediate, $a$, lying transversely and kept in position against the incisive arch by a small bridge of bone.

Finally, in a fourth (Fig. 311), a pincer, a, equally displaced, was found.

All these incisors were of the second dentition. ${ }^{3}$

${ }^{1}$ Arm. Goubaux, Des aberrations dentaires chez les animaux domestiques, in Recueil de médecine vétérinaire, année 1854, p. 70.

2 Magitot, Traité des anomalies du système dentaire chez l'homme et les mammifères, in-40, Paris, $18 \pi 7$.

${ }^{3}$ See, also, Ch. Morot, Incisive supplémentaire caniniforme à la mâchoire supérieure d'un cheval hougre de douze ans, in Recueil (Bulletin de la Société centrale de médecine vétérinaire), Mars, 1885, p. 138. 
Inferior Jaw.-The augmentation in the number of incisor teeth in the lower jaw appears to us, all things considered, less common than in the upper jaw. We will cite, nevertheless, the doubling of a left permanent intermediate, which we have observed.

The supernumerary teeth, which, to our knowledge, are always of the second dentition, do not seriously modify the characters of the age; they are more or less solidly implanted into the alveolus, nearly always displaced, and influence in a variable manner the regularity of the incisive arcade.

It is important to remark that they differ from irregular teeth or from stumps, vestiges of deciduous milk-teeth broken by the animal or during a surgical operation.

Canines.-Our colleague, M. Ch. IIorot, reports ${ }^{1}$ having seen an adult horse with seven canines; the three supernumerary (two above and one below) were situated behind and very close to the normal canines.

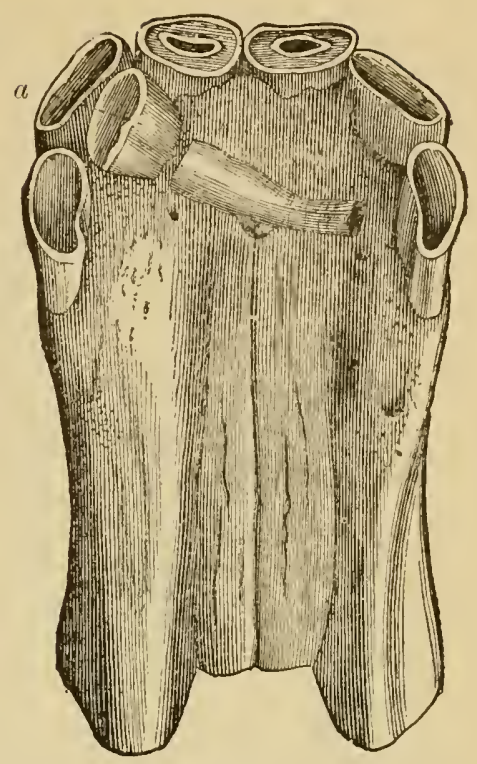

FIG. 310,-One right supernumerary inter. mediate, $a$, of the second dentition.
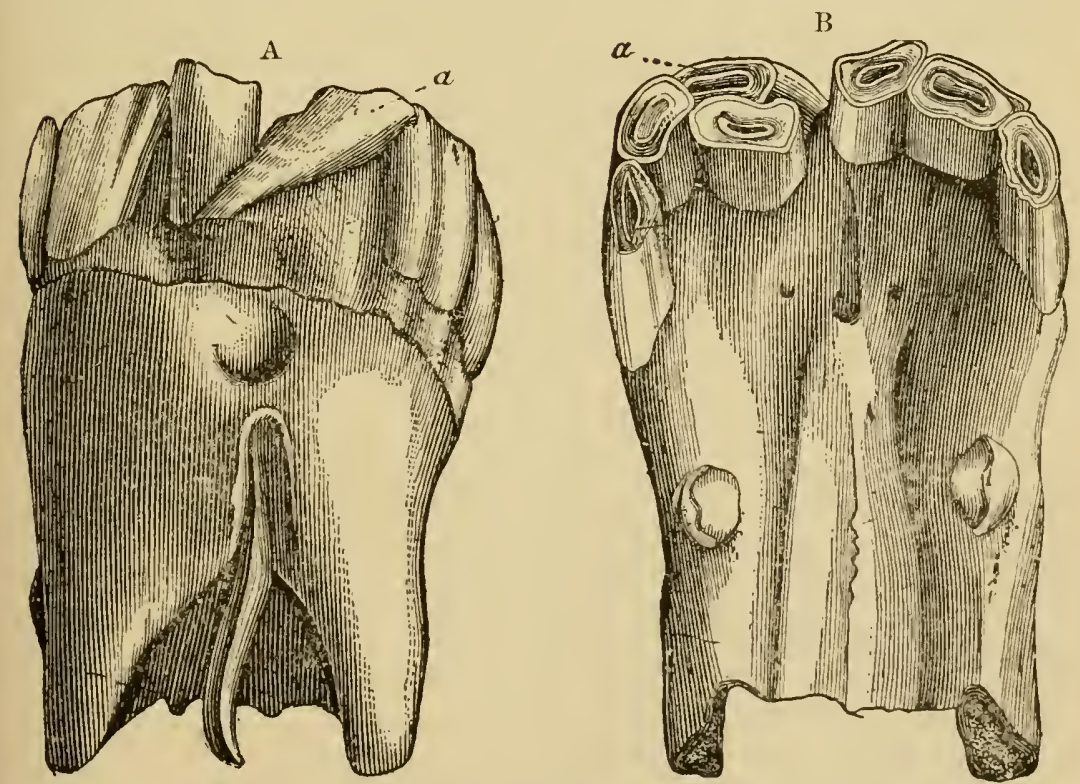

FIG. 311.-A supernumerary intermediate, $a$, of the second dentition, viewed on its anterior face, $A$, and on its dental table, $B$.

${ }^{3}$ Ch. Morot, Recueil de médecine vêtérinaire (Bulletin de la Société centrale de médeciue vétérinaire), 1888, p. 139. 
Conceming our own experience, we have seen only one example in the ass (Fig. 312).

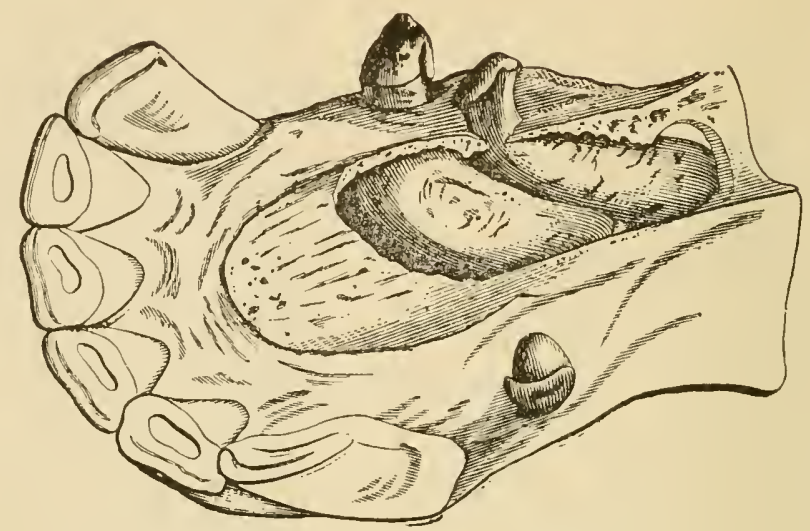

FIG. 312.-Double right in ferior canine in the ass.

Molars.-Sinpernumerary molars in the horse and the ass have been observed for a long time by Lafosse, ${ }^{1}$ Girard, ${ }^{2}$ M. Thomas, ${ }^{3}$ M. Chuchu, ${ }^{4}$ M. Morot, ${ }^{5}$ and ourselves. ${ }^{6}$

They exist nearly always in the superior jaw, either in the axis of the normal arcade or on the external side; in the latter case, they may produce wounds of the cheeks, a fact which has been observed by M. Chuchu.

In the inferior jaw they are considered very exceptional. M. Morot has, notwithstanding, related the case of a mare which presented a superior right supplementary molar, and, at the same time, two inferior, one right and one left.

Until the present time, the only facts known relate to the presence of $a$ single supernumerary molar in each jaw ; this tooth is most often situated behind the others, next to the sixth.

[We have in our possession a skull obtained from a Clydesdale mare, which has seven molars in each arcade. The first molar is evidently supernumerary, and very probably the first one of the seven molars in each arcade of the skull of the hipparion,-a reversion of an ancestral form; in other words, it is an excessive development of the volf-tooth.]

It is not within our domain to speak of the irregularities of locality, of which science has collected several examples, in which the supernumerary teeth were situated in the zygomatic process, or at the base of the ear, projecting sometimes into the interior of the cranial cavity. These are heterotopic facts whose study pertains especially to teratology.

1 Lafosse, loc. cit, p. 32.

2 Girard, Traité de l'âge du cheval, 3e éd., p. 35.

3 Thomas, Journal de médecine vétérinaire militaire, t. xiv., 1876-1877, p. 687.

${ }^{4}$ Chuchu, Recueil de médecine vétérinaire, annce 1877, p. 637.

5 Ch. Morot, Bulletin de la Société centrale de médecine vétérinaire, p. 434, in Recueil de médecine vétérinaire, 1888.

6 Arm. Guubaux, loc, eit., p. 71. 


\section{b. Diminution.}

Irregularities from diminution in the number of the teeth are perhaps less common than the preceding; they must not be confounded with the phenomena of a tardy eruption, with those of arrest of development, in which the tecth remain enclosed in their alveoli without ever piereing the gums, or, finally, with those of fractures and of extraction, which are quite often met in old horses. They can only result, in their true sense, from an arrest of development of the dental follieles; they entail no evil consequences, and may exist in the incisors, the canines, and the molars.

1st. Incisors.-Rudolphi ${ }^{1}$ has noted the absence of one of these teeth in the horse, but gives no specifie description.

MI. Mégnin ${ }^{2}$ has observer the absence of a left pincer in the adult horse.

In our experience, we have noter, in a horse fifteen years of age, the absence of the left intermediate and corner.

Absence of the corners, of which we possess some specimens (Fig. 313), has been eited.

In June, 1887, a horse was presented to us in which the four corners and the four tusks were wanting.

Relative to the diminution of the number of incisors of the first dentition, M. Bizard ${ }^{3}$ has succeeded in obtaining the jaws of a colt twenty-eight months of age, in which the inferior pincer of the left side did not exist.

Hore recently. our colleagues, Messis. Lainé and Joly, have mentioned the absence

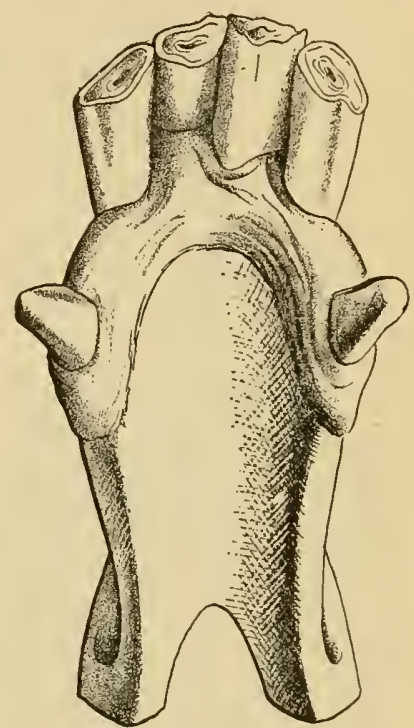

FIG. 313.-Absence of the inferior corners. of the inferior pincers of the first and second dentition in a subject which they have been able to observe during a sufficient length of time.

II. Ch. Morot ${ }^{5}$ has also presented to the Central Society of Veterinary Medicine two analogous eases, but involving the superior comers. Besides, he has demonstrated that this numerical reduction of the teeth is in obedience to the laws of heredity. He has also shown that the non-existence of the milkteeth means a suppression of the corresponding permanent teeth; at other times, on the contrary, the eruption of the latter was not in the least hindered.

2d. Canines.-The absence of the superior canines, either on one side or on both, is more frequent than that of the inferior. But it is very excep-

1 Rurolphi, eité par Isidore freofroy saint-Hilaire, in Histoire générale ct particulière des anomalies de l'organisution, t. j. p. 658 .

2 Mégnin, cité par le Dr. Magitot, loe. cit., p. 103, et suiv.

3 Bizard, note communiquée.

4 Lainé et Joly, note communiquie, 1887.

5 Ch. Morot, in Bulletin de la Société centrale de médecine rétérinaire, Séance du 23 Novembre, 1882. 
tional to find these teeth altogether absent, as in the horse of which we have spoken.

3d. Molars.-As to the molars, we have seen only two examples of this anomaly in the superior jaw.

\section{Irregularities of Form.}

"In certain subjects," says Girard, "the incisors of the superior jaw present, at the age of six years, a well-marked triangular form, almost the same an is observed at fourteen or fifteen years of age." This premature triangular form, which we have often noticed, even at five years of age, cannot lead us into error, on account of the presence of the central enanel in all the teeth which have this form.

\section{Irregularities caused by the Union of Two Teeth.}

Isidore Geoffroy Saint-Hilaire ${ }^{2}$ a long time ago mentioned this variety of irregularities, which is without importance in determining the age, but which

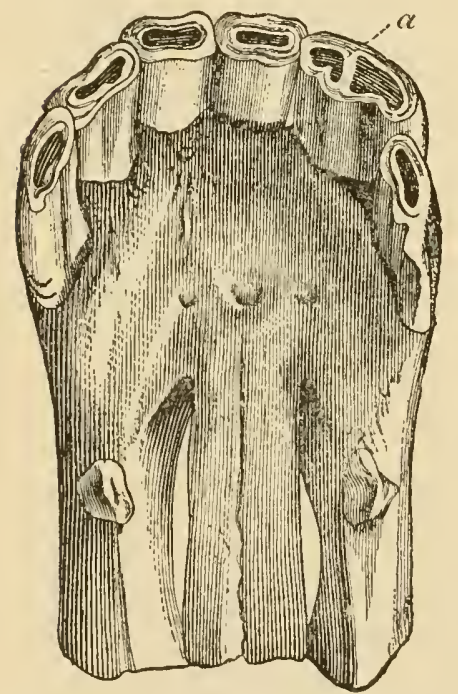

FIg. 314-['nion, at $a$, of two superior ineisors, one of which is superummerury. should be considered as very rare, and resulting from the fusion of two neighboring dental follicles. They consist in an intimate fusion of two teeth, sometimes more or less distinct, at other times entirely confounded.

We possess a specimen of the latter kind (Fig. 314); the superior intermediate was double, which could be easily recognized by its large volume, the presence of a groove corresponding to the line of fusion, and the existence of two perfectly-distinct external dental cavities.

Messrs. Chauveau and Arloing ${ }^{3}$ have observed, in the clinic of the Veterinary School at Lyons, an ass in which the pincers and the intermediates were soldered together in the inferior jaw. The incisor teeth were only four in number instead of six, the irregularity existing on both the right and left sides.

M. Cl. Morot ${ }^{4}$ has reported a very remarkable case of this kind in a gelding six years old. The double tooth was supernumerary and situated in the inferior jaw, external to and behind the corner, which it tollched. The two pieces which composed it were seven centimetres in length and separated for the greater part of their extent, save at the level of the

Girard, loc. cit., p. 66.

2 Isidore Geoffroy Saint.Hilaire, loc. cit., t. i. p. 516.

${ }^{3}$ Chauveau et Arloing, Anatomie comparée des animaux domestiques, 4e éd., p. 413.

${ }^{4} \mathrm{Ch}$. Morot, Bulletin de la Société centrale de médecine vétérinaire, p. 140 , in Recueil de médecine vétérinaire, année 1588. 
roots, which were united at their points for a distance of one and one-half centimetres. The nerves and blood-vessels penetrated through the roots into the two pulp cavities by means of a single orifice; the alveolus was single.

\section{Irregularities in the Form of the Central Enamel.}

a. Fissure.-We know that the central enamel circumscribes the parietes of a conical cavity, depressed from before to behind, which is entirely isolated
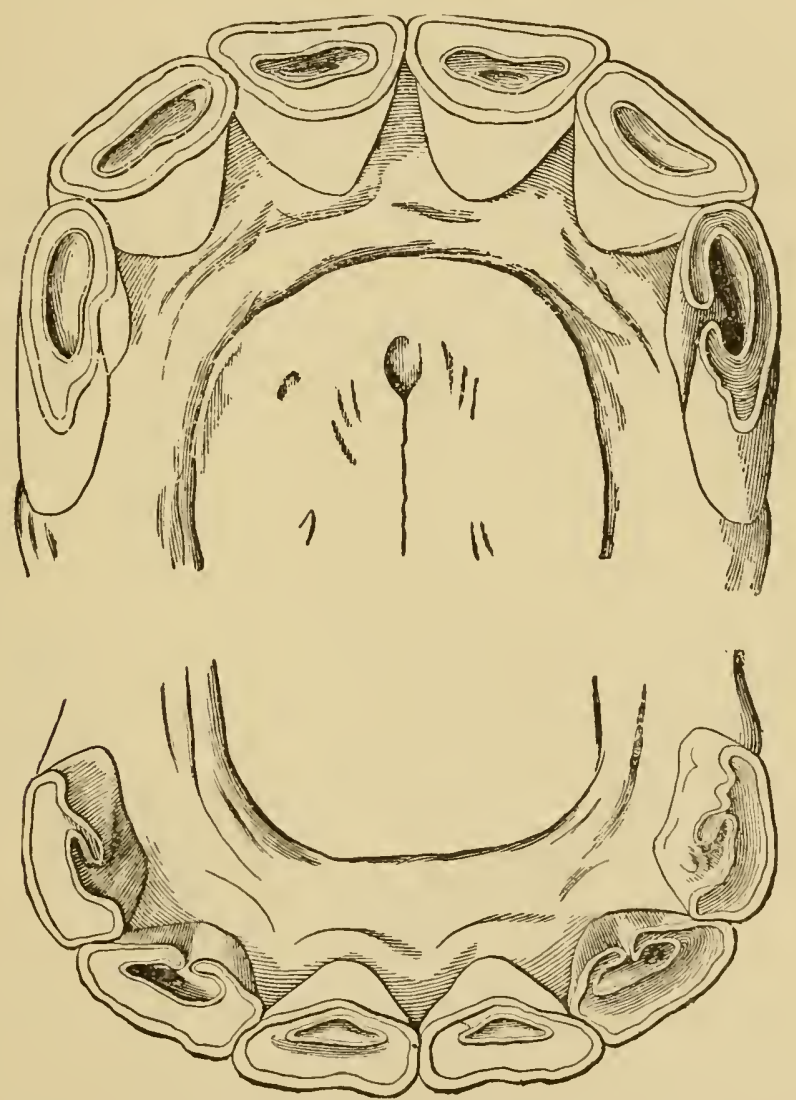

FIG. 315.-Fissure of the infundibulum of the inferior intermediates and eorners, as well as of the left superior eorner (horse).

from the peripheral enamel upon the surface of friction. This is not always so, as we have verified by observation a large number of times, but more ofter in the ass and mule than in the horse.

It happens, in fact, that the posterior horder of the incisor, less developed than usual, fails to elose the external dental eavity hehind; whence it follows that the free extremity of this tooth, beginning at its anterior border, simulates a hollow surface, oblique downward and backward (inferior incisors), which can, to 
a certain extent, be compared to the lingual surface (arale) of the tooth of a ruminant animal (Fig. 315).

This more or less deep variety of fissure of the infundibulum, which canses a total or partial absence of a true external dental cavity, is more common in the inferior than in the superior incisors, and sometimes renders difficult the determination of the animal's age. The surface of friction, as soon as it is formed, besides being very irregular, does not present in a distinct manner the two circles known under the names peripheral encmel and central enomel. The latter
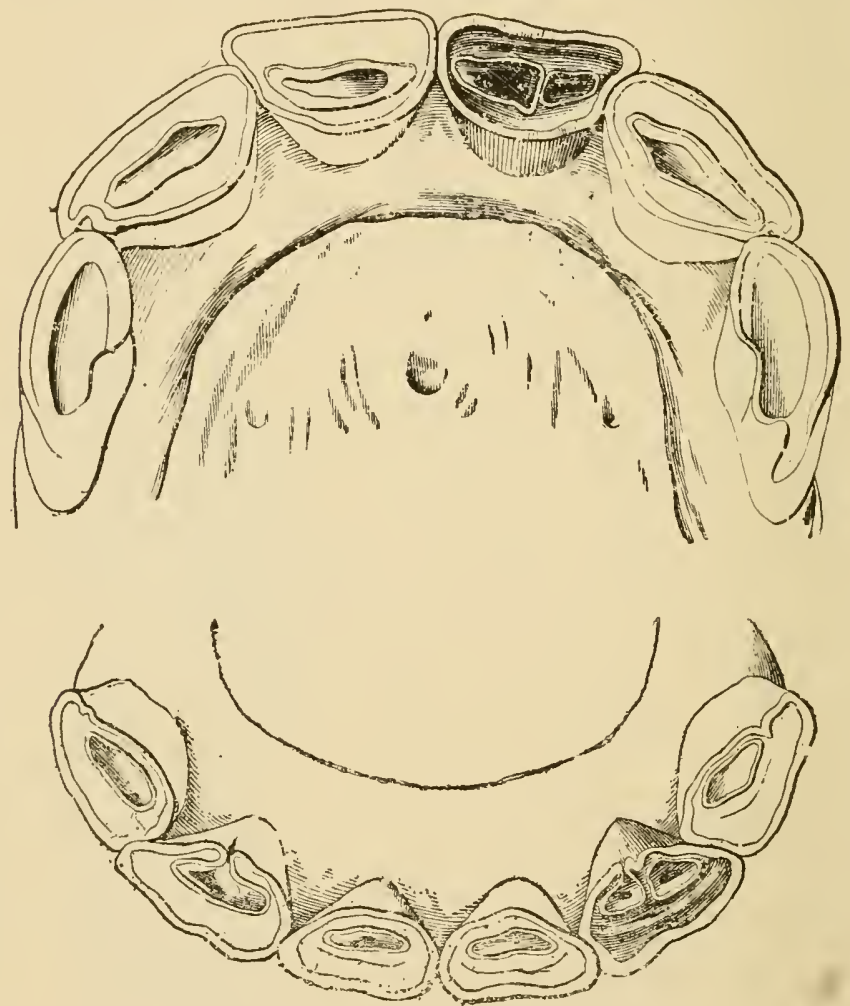

FIG. 3I6.-A superior pineer and an inferior intermediate provided with two infundibula.

is cleft behind, in a proportion which varies with the width of the fissure, and its extremities become continuous on each side with the peripheral enamel.

It is, without doubt, this type of tooth which Joham Schlechter, of Vienna, has taken for a type of development of the incisors of the horse. ${ }^{1}$ It is only a question here of a malformation of the reflection of the enamel, otherwise somewhat rarely observed upon the whole of the arcade, but more common on the

Johann Schlechter, Ueber Bau und Form der Zihne bei dem Pferde und seinen Vorfahren, in Esterreichilche Monatschrift für Thierheilkunde, ete. (January, February, and Mareh numbers, 1851). 
corners than on the intermediates, and on the latter than on the pincers. The teeth which are normally constructed will always act as landmarks in determining the wear.

3. Duplication.-A much less frequent malformation is the duplication or cloubling of the infundibula formed by the central enamel, resulting, consequently, in the presence of two exterual dental cavities upon the same surface of friction (Fig. 316). This fact, which we have pointed out for the first time, ${ }^{1}$ and of which we possess some examples, has no importance as regards the determination of the age. These anomalies must not be confounded with those of fusion or soldering of two teeth, of which we have spoken; for, in the former case, the teeth are no larger than when in a normal state, and show, besides, no external trace of a previous lusion. It is probable that this anatomical disposition is the result of the bifurcation of the external papilla, or germ of enamel. In certain subjects, one of these two eavities is eleft behind and opens upon the posterior face of the tooth, instead of being entirely isolated, like the other one, upon the central part of the dental table.

\section{Irregularities in the Depth of the Infundibulum and its External Dental Cavity.}

a. Béguité.-When the external dental cavity or dental (up persists upon the dental table at a period when it should have disappeared, the animal is called bégu, and does not mark his teeth properly, which is designated béguité. (Plate XXXII.)

We know alrealy that the bottom of the infundibulum is filled by a deposit of cement whose thickness can modify the depth of the external cavity of the tooth. Besides, the eruption of the incisors having taken place snceessively in pairs, from the pincers to the corners, the successive disappearance of these cavities is effected first upon the teeth which complete their eruption first, and which, for this reason, have been used the longer. It is this which constitutes regular levelling.

But this levelling can only take place in its normal snccession, and with such regularity, on condition that the external dental eavity has almost the same depth in all the incisor teeth; or, in other words, that the cementous deposit of the infundibulum takes place in a layer of uniform thickness. But as this is far from being the ease in many instances, since in certain pincers the cementous nucleus is two centimetres in thickness, while in others it scareely attains a few millimetres, it can be very easily understond that an infundibulum almost void of cement means a tardy levelling, and that an infundibuhm filled with cement means an early levelling. 


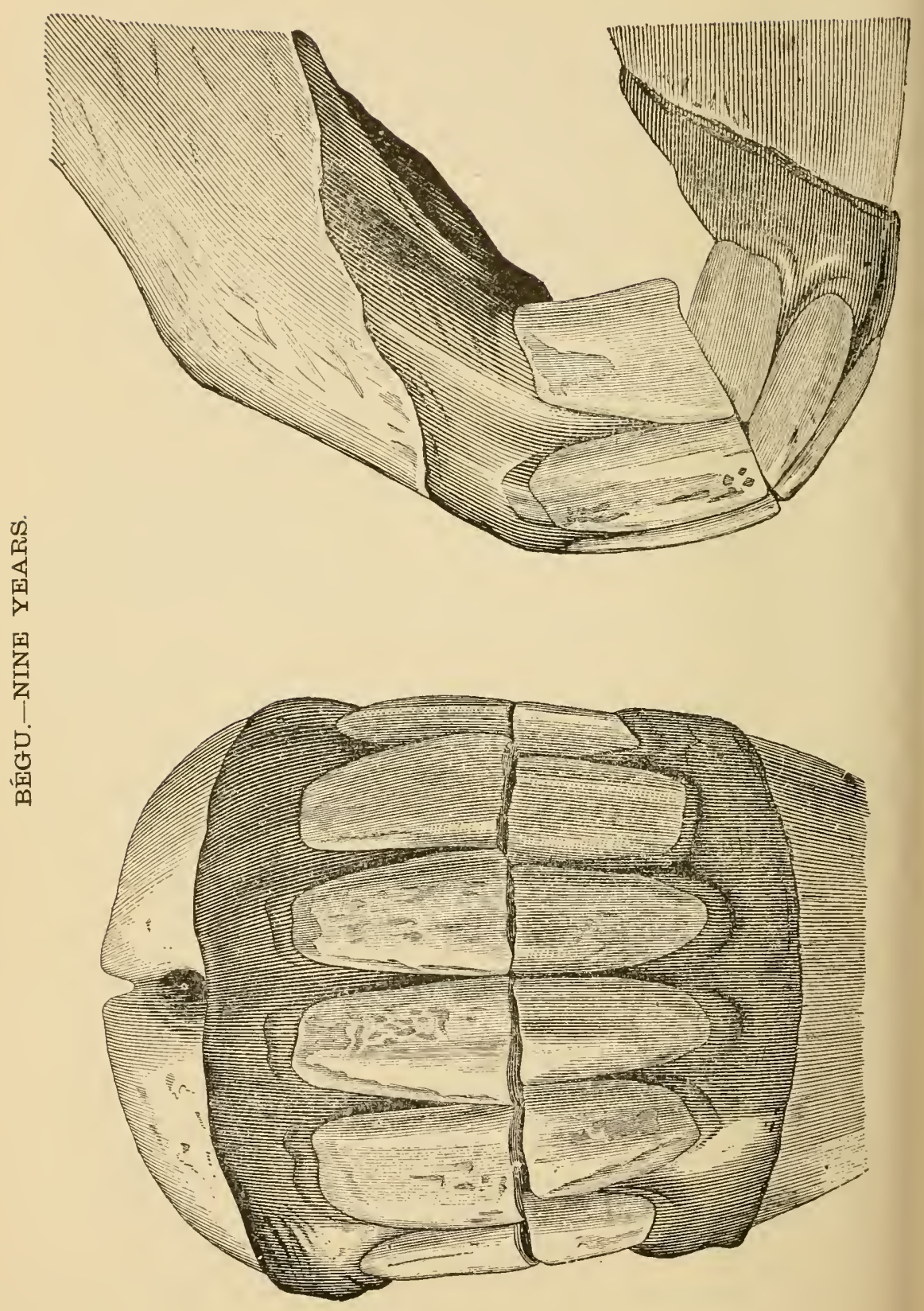



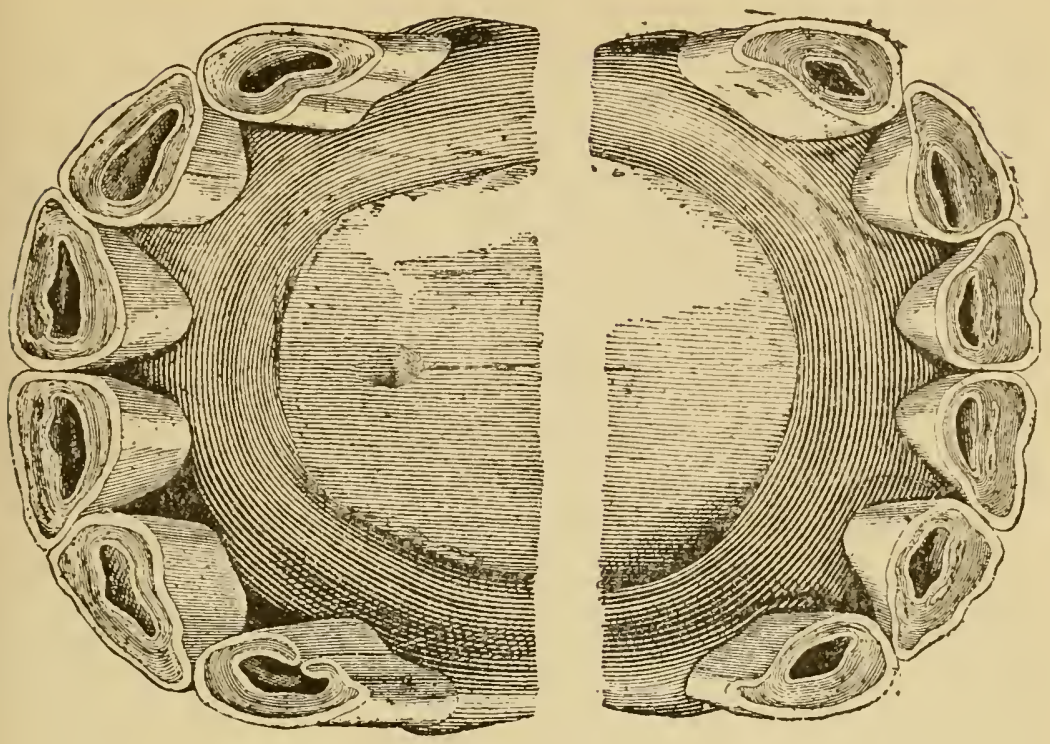

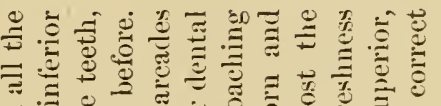

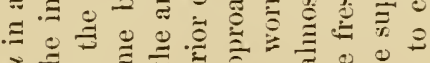

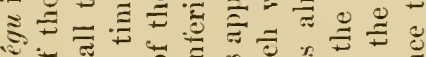
$\lesssim$ 万人

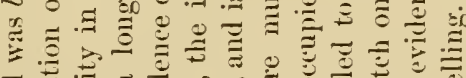
उับ

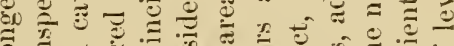

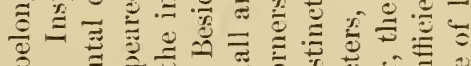
๒

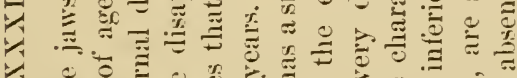

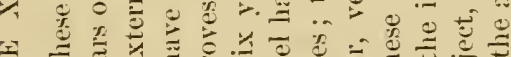

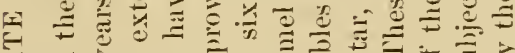
द

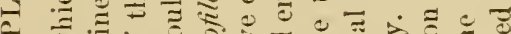

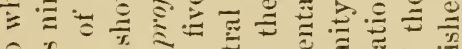

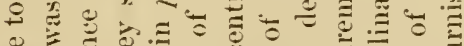
\%

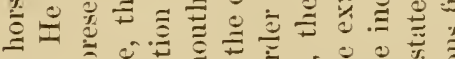

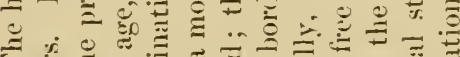
$\exists$ 일 1.

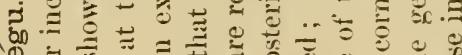

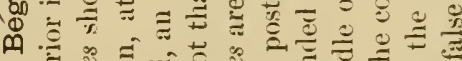

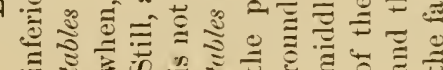


A deep external dental cavity means nothing else than the persistence of the eavity, "the mark," at a period when it should exist no longer, and its principal cause resides in the thinness of the layer of cement which fills its bottom.

Besides, the hardness of the dental tissnes, the nature of the food, and the conditions of health of the teeth, are also so many causes capable of explaining this irregularity; but the differences of wear which they imply are not well recognized, and have not been, so far as we know, determined experimentally.

It is known that the dental cups should not be present after the age of eight years, for it is at this period that all the inferior ineisor teeth are levelled.

The observer, however, will be very much mistaken if he accords an absolute value to this assertion. In many horses the external dental eavity, in the inferior incisors, has not disappeared at six years in the pincers, and frequently persists in the intermediates up to seven years. On the contrary, it is not rare to witness a too early levelling of the former or of the latter.

However this may be, béguité is not known to have the least influence upon the value of the services rendered by the horse. This reminds us of an acquaintance of ours at the Paris Tattersall, who never purchased a horse, however suitable he might have been in all other respects, if he was bégu.

According to MI. de Curnieu, the bégut horse is a fable. "In fact, if the 'marks' on the dental table indieate six years, the length and the inclination of the teeth will contradiet the first evidence, and should prevent us from being deceived. In these horses, the wearing away of the tecth takes place more slowly than in the generality of cases. Therefore the tooth is harder; therefore the general constitution of the animal is stronger; therefore the animal is more durable; therefore he really has for the service the age which he appears to have. For the age of a horse is not so much the number of years he has lived as of the years during which he will yet be able to live and to work." 1

Of this there can be no donbt. Still there is no positive proof: 1st, that the anomaly in question is due to the hardness of the dental tissues; $2 \mathrm{~d}$, that the resistance of one organ to wear and tear necessarily implies that of the organism as a whole.

There are some mouths in which the dental enps are more hollow 
than in others, but this disposition of the latter, not having any influence upon the qualities of the animal, becomes unimportant as to its practical application. It is so irregular that it may exist in one or in several incisors, on one side only, or on both at the same time; it is so frequent that it may be seen in almost all horses at some period or other of their life.

Hence we have the best reason for saying ${ }^{1}$ that the levelling of the incisors has much less value, from a practical point of view, than the form of the central enamel, since the infundibulum is so irregularly filled with cement, according to the subjects. The successive configurations of its central enamel, as the tooth wears off', enables the practised eye to determine with enough precision to what phase of wear it belongs. Its absolute depth secms to us more constant in the same teeth than is generally believed. On the other hand, admitting that its length may become excessive, there are other characteristics drawn from the form of the tooth, its direction, and its coloration, which indicate more. These, in themselves, would be sufficient in nearly all cases to justify an opinion, but there is another one which, by its presence, should remove all doubts: it is the dental star, a yellowish, narrow, transverse line, which ordinarily becomes visible, at eight years of age, "1) the dental table between the anterior border of the tooth and the ring of central enamel surrounding the exterual dental cavity, or its cul-de-sac, when the external carity no longer exists.

6. False Béguité.-The persistence of the cul-de-sac of the central enamel at a period when it should no longer exist eonstitutes false béguité, and causes the horse to be designated false bégu. (Plate XXXIII.) This cul-de-sae, it is known, is filled with cement, and appears on the table as a circular ring of enamel standing out in relief.

It appears thus first in the pincers, then in the intermediates, and, finally, in the corners, as soon as their levelling has been eompleted. If the wear is normal, and if the external cavity has the ordinary depth, it should assume this disposition at eight years in all the inferior incisors, and its disappearance takes place only at the age of twelve or thirteen years.

It is hardly possible to explain this tardy disappearance of the central enamel or the fulse béguité by admitting an excessive length of its external carity, all things being equal otherwise. It may he surmised, nevertheless, that this anomaly may be due also to a greater 


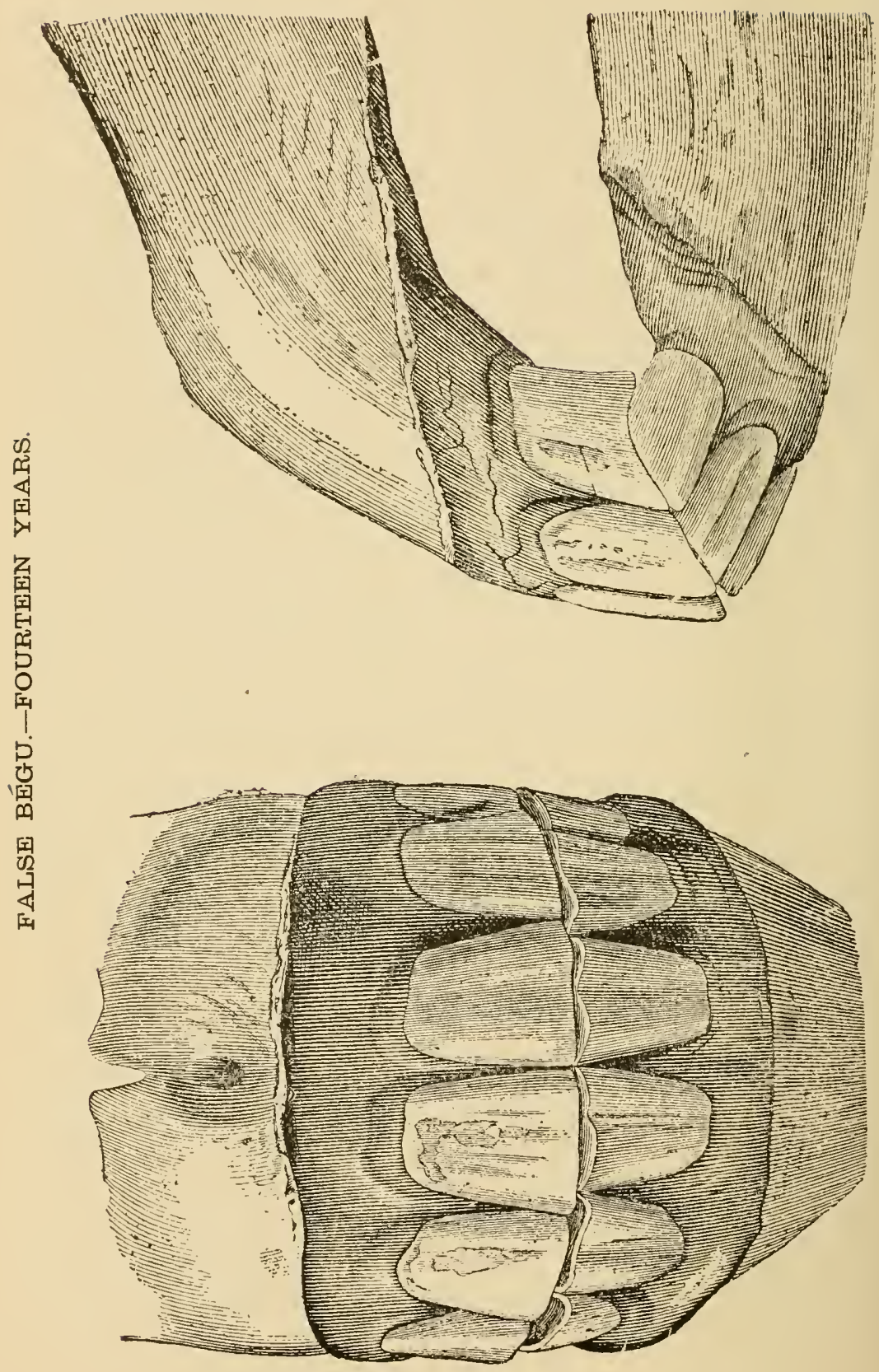



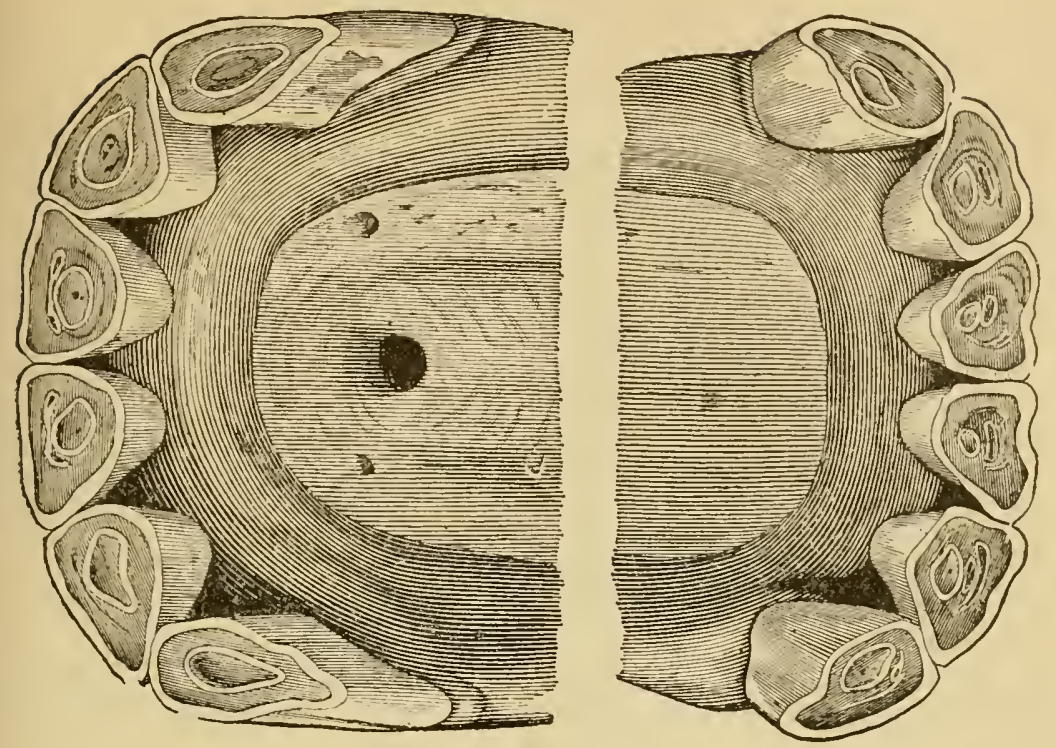

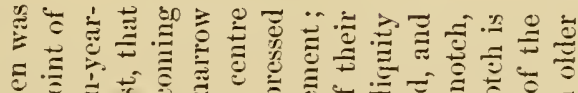

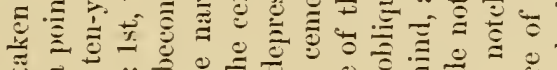

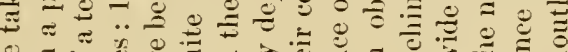

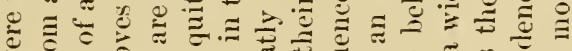
I

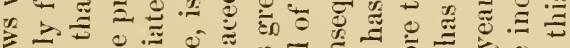

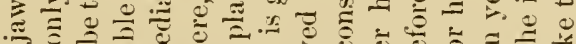

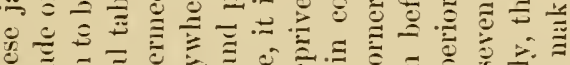

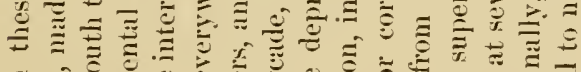

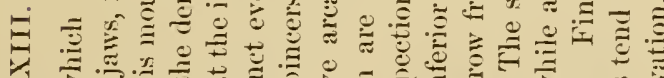

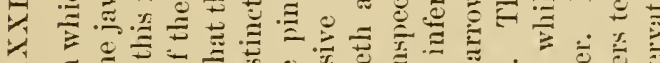
H 由 E

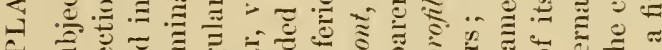

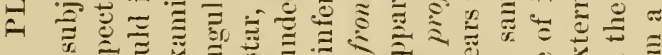

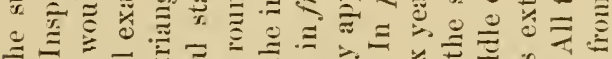

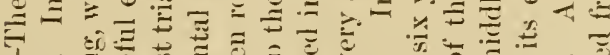
|

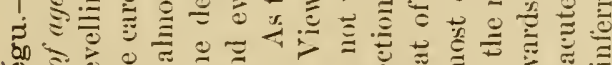
10

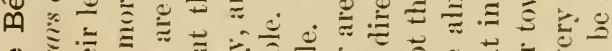

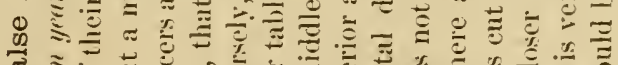
๙

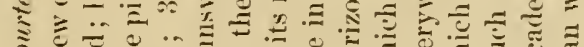

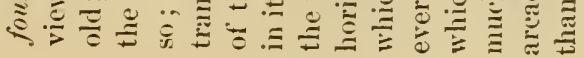


hardness of the dental tissues, to the nature of the aliment, or, again, to their state of somndness; but the first of these causes is by far the most common.

Like the béguite, it is frequently observed and in a rery irregular manner. Sometimes it exists only upon a few of the teeth, at other times in all, on one side of the incisive areade only, or in both at the same time.

Whatever may be its forms, it is never a serious obstacle to the determination of the age. While its presence, at first sight, would indicate the horse to be younger, an attentive examination of the dental tableits particular form, the configuration and the situation of the dental star, the state of the superior incisors, the direction of the teeth, their length, their coloration, ete.-will furnish many signs, easily appreciable, and which will prevent us from committing a grave error.

\section{Irregularities through Defect of Length or Excess of Width of one of the Jaws.}

A.-Defect of Length of one of the Jaws.-We have seen and also possess some specimens of this very rare anomaly. Their variable degrees permit us to establish some important distinctions as respects their gravity.

In the mildest cases there is found a slight diminution of length of the superior jaw, which occasions a prominence of the inferior incisors and simulates somewhat the prognathism of man, in which the inferior jaw appears longer than the superior. The only unfavorable effect of this form of jaw is an abnormal wear, rendering the determination of the age more difficult.

In all the more serious cases (Figs. 317 and 318 ), on the contrary, it depends upon an arrest of development of one of the jaws, to which can be applied the name brachygnathism ${ }^{1}$ (superior and inferior), because, in fact, the jaw which is affected is shorter than the other. ${ }^{2}$

Sucl a disproportion of length has a definite importance in that which concerns: 1st, the deformity of the opposite jaw, which is curved more or less forward than normal; $2 d$, great difficulty in the prehension of food, especially in lorses feeding on pasture; $3 \mathrm{~d}$, finally, an absolnte obstacle to the determination of the age.

Brachygnathism is superior (Fig. 317) or inferior (Fig. 318); the former is more rare than the latter. The incisors, in both cases, are of great length. As to the molar areades, they are normal. The nulformation, therefore, only alters the dimensions of the superior or inferior interdental spaces.

When the incisors still touch each other, the wear due to the friction involves their contiguous faces, and produces here, ordinarily, a very oblique bevelling.

\footnotetext{
1 From $\beta \rho a \chi v i s$, short, and $\gamma \nu \alpha \dot{\theta} 0$ s, jaw.

2 It will be remarked that superior brachygnathism, for example, is accompanied by inferior prognathism, more or less marked, and vice versa.
} 

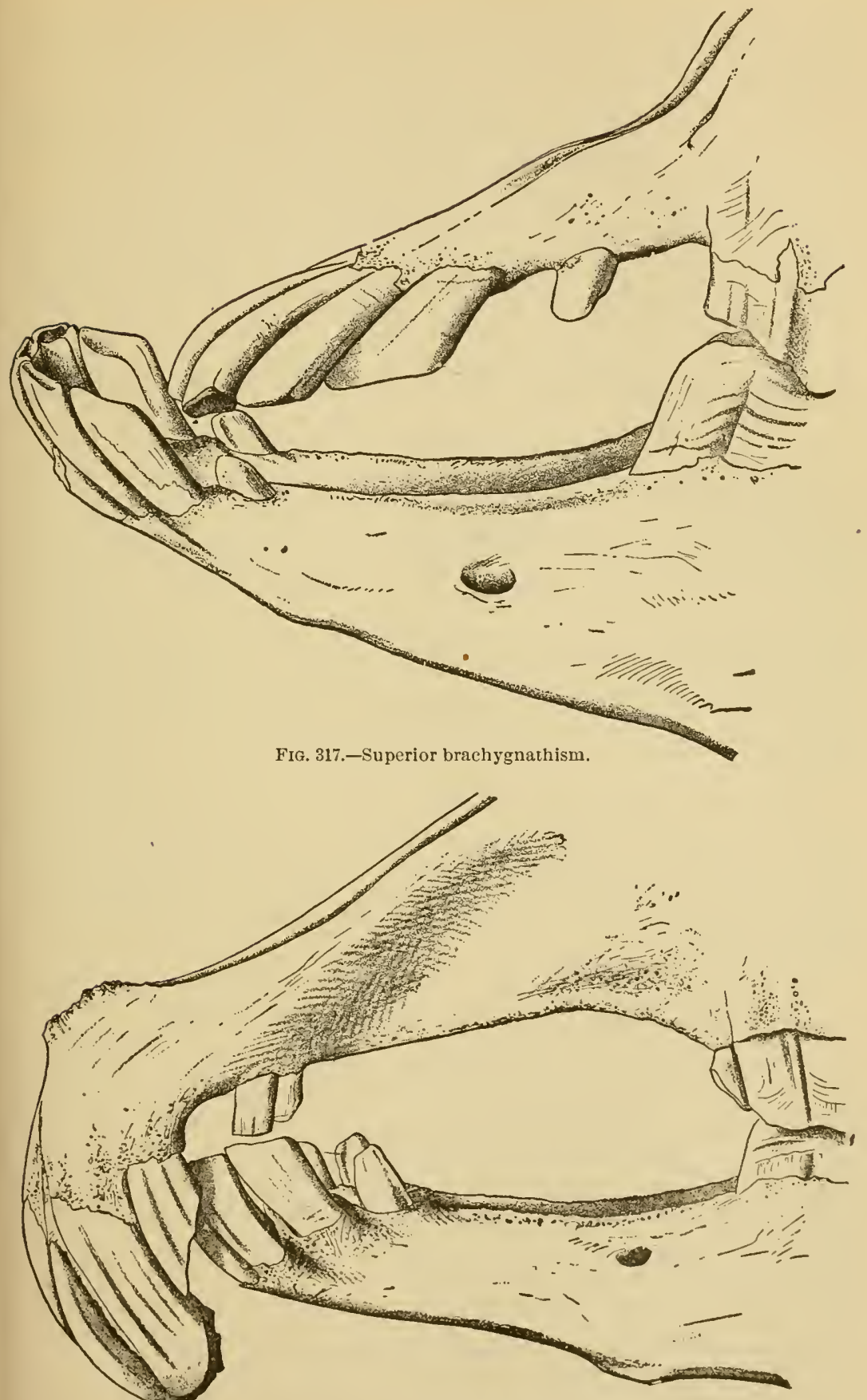

FIG, 318.-Inferior brachygnathism. 
Let us add that the teeth of the shorter jaw, by increasing excessively in length, are at times capable of injuring the corresponding parts of the opposite jaw, the region of the barbs or the hard palate, according to the case.

Our colleagues, Messrs. W Weber and Mitaut, ${ }^{1}$ have each observed an example of inferior brachygnathism in which pressure was made on the hard palate almost to the point of perforation.

B.-Excess of Width of the Superior Incisive Arcade.-An excess of width of the superior incisive arcade is quite frequently met. When the jaws are closed, the latter overlaps the inferior arcade in front and upon the sides, over its whole periphery. This is probably the beginning of what we will study a little farther on under the name parrot mouth.

\section{Irregularities through Excess or from Insufficient Wear.}

\section{§. Incisor Teerth.}

In gencral, the incisors always preserve the same length of their free part, although they diminish each year under the influence of the friction which takes place upon their table. This is due to the fact that the teeth are being constantly pushed out of their alveoli; whence it follows that what is at first a portion of the root will, in time, be pushed out so as to constitute a part of the crown. Transverse markings, those of a rasp, for example, made at different heights on the anterior face of these teeth, will ultimately disappear one after the other.

By experiments of this nature, Pessina ${ }^{2}$ has demonstrated an annual wearing away of four millimetres of the tooth in common horses, and only three millimetres in those that are well bred. $\mathrm{H}$. Bonley has verificd the accuracy of these results in animals which belonged to him.

But there are some horses in which the teeth are too long, others in which they are too short. How ean this be determined?

Nothing is more easy, since it is known, from the observations of Girard, that the free part of the ineisors, from the gum to the table, has a mean length of fifteen millimetres. There are certain subjects, nevertheless, in which this length varies according to the teeth examined. The same author has recognized that it is about eighteen millimetres for the pincers, fifteen millimetres for the intermediates, and thirteen millimetres for the corners. All these facts, which we must remember, we will use presently.

1 Weber et Mitaut, Bulletin de la Société eentrale de médecine rêtérinaire, in Recueil de médecine vétérinaire, année 1876, p. 768.

2 Pessina, Sul modo di conoscere dai denti l'etì dei cavelli. Translated from the German by Luiggi Ferreri and revised by Giuseppe Antonio Cross, Milan, 1831, p. 24 and Pl. ix. 
As we have already stated, the variations of length are of two orders: the excess and the insufficiency. We will first study the former.

\section{a. Excess of Length of the Crown.}

This anomaly presents the following variations:

a. Incisors too Long in both Jaws.-In specimens deposited by us in the museum of the Alfort School, we have found an excess of length of nineteen to twenty-two millimetres for the superior tecth and fifteen to eightecn millimetres for the inferior.

The direction of such tecth, as a rule, closely approaches the horizontal, for, were it otherwise, the superior molar arcade could no longer be brought in contact with the inferior. Their free extremities are a little divergent, and, on this account, the arcades are somewhat funshaped. The surface of friction still resembles that of early years; flattened from before to behind, it tends to assume an oval form; as to the central enamel, it occupies a large area upon the dental table, and a small external dental cavity on the inferior corners often still exists.

The excessive length of the crown, in such conditions, is not in relation with that of the root; the teeth, less firmly implanted, are much more liable to break. Besides, they do not mark the real age, and might deceive the observer who only makes his inferences from the dental tables, without having recourse to the procedure indicated by Pessina and Girard.

To determine the correct age of the horse it suffices to shorten, in imagination, the teeth which are too long. This means, easy of employment if the successive forms of the dental table at the different periods be recalled, enables one to arrive at an estimate, if not exact, at least very approximative.

Sawing or rasping off the incisors which, in old horses, have acquired an excessive length, a procedure often practised by horsedealers, with a view of making them appear younger than they really are, does not deceive the expert. An attentive purchaser should not thus be deceived, since, by this means, he is spared the mental operation of shortening the teeth, which we have just recommended. But the layman may be influenced by this trick, for he is imbned with the idea, very correct otherwise, that the exaggerated length of the tecth coincides, to a certain extent, with the animal's age.

b. Incisors too Long in the Superior Jaw alone.-This anomaly constitutes what is vulgarly called parrot mouth, or crow mouth, bec de perroquet (Fig. 319), by reason of the resemblance of the 


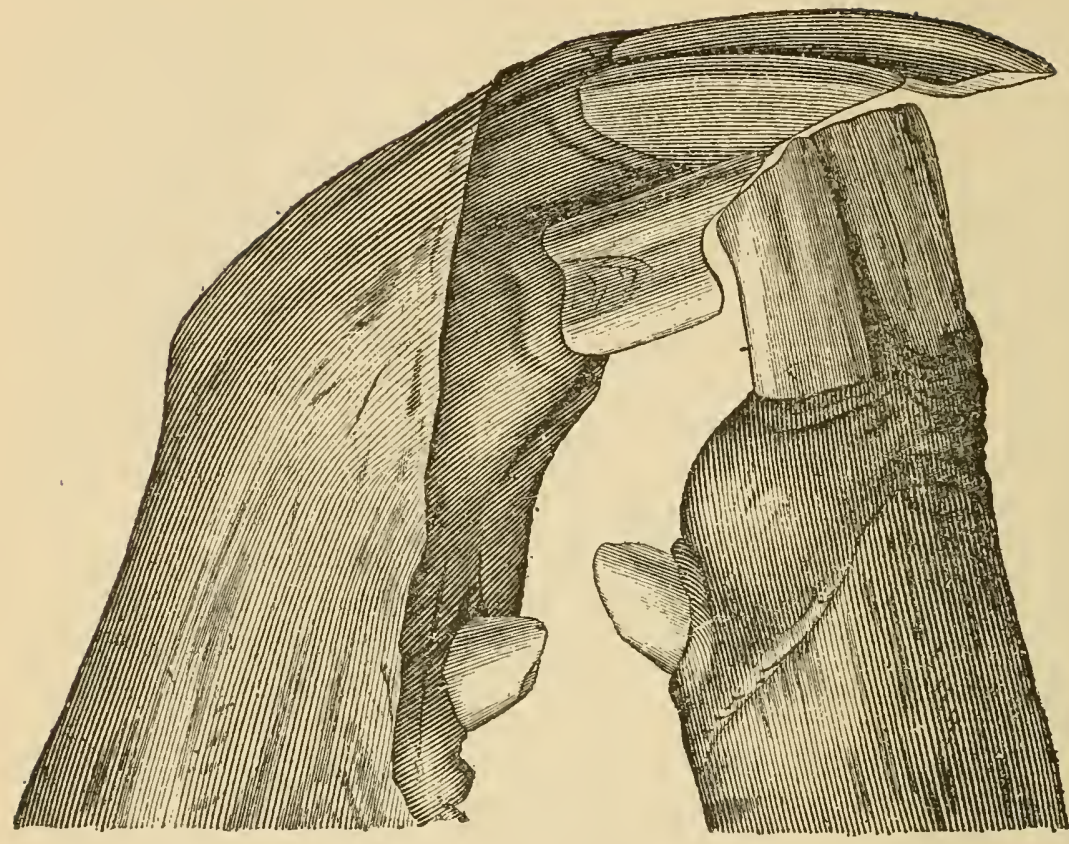

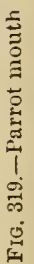

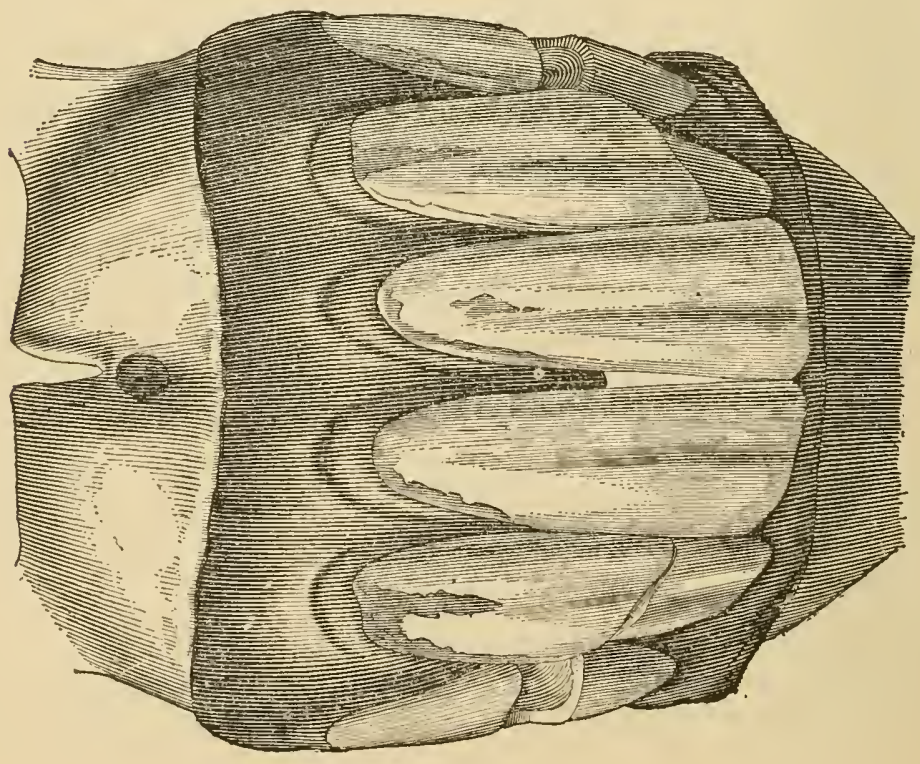


superior jaw to the corresponding mandible of the parrot or the erow.

The teeth, in this case, not only have aequired an excessive length, which may reach ten centimetres, but they are greatly curved forward and downward, while their posterior face is cut by a sharp bevel from the friction of the inferior incisors.

The latter are generally shorter than in a normal state, and the "parrot beak" is formed almost regularly by the pincers and the intermediates on both sides of the arcade, the corners participating much less in this respect than their neighbors. Nevertheless, it may happen, as is seen in the jaw represented in the figure, that the irregularity is more marked on one side than on the other. In this case, the inferior teeth, which do not correspond to the projection formed by the superior, are longer than in ordinary conditions.

In certain horses five years of age, the superior jaw overlaps, for a few millimetres, the inferior, while behind the surfaces of friction correspond at their whole extent. The wear, therefore, spares the anterior border of all the superior incisors, especially the pincers and the intermediates. We think that there results from this, in time, first a more decided prominence of this border, then a more or less elongated bevel, and, finally, a true parrot mouth. Those who have had the opportunity of observing such horses during a number of ycars could easily throw some light upon this interesting point.

However this may be as to its varieties of form and its genesis, the parrot month is observed only in very old horses. It interferes more or less, according to its degree, with the prehension of food, especially that of the grains, for its prominence considerably hinders the action of the lips. The jaws become comparable, in a mamner, to a pair of pincers or tongs whose branches overlap each other. Besides, their maximum separation has no longer the same proportion. While the buccal opening, in a normal state, is ten to eleven centimetres, we lave found only two centimetres between the pincers of the two areades, in the jaws represented above.

In such a state the determination of the age is almost impossible. We must depend mainly upon the characters relative to the direction, the color, and the width of the teeth, or, finally, shorten the latter, in imagination, to their ordinary length. When the bee de perroquet is too long and too inconvenient, it may be necessary to resort to mechanical means to shorten the superior areade. This operation, which is done by means of a saw, is not very difficult when practised upon the living subject. Besides the immediate advantage which it 
possesses of easing the animal, it also makes him show his real age, two reasons which should prevent its being considered as a frandulent procedure.

c. Incisors too Long in the Inferior Jaw alone.-The inferior pincers and intermediates are equally capable of lengthening beyond measure and curving upward and backward in such a manner as to present, in the inferior jaw, an irregularity analogous to the preceding (Fig. 320). We have proposed, when describing the first speeimen, to

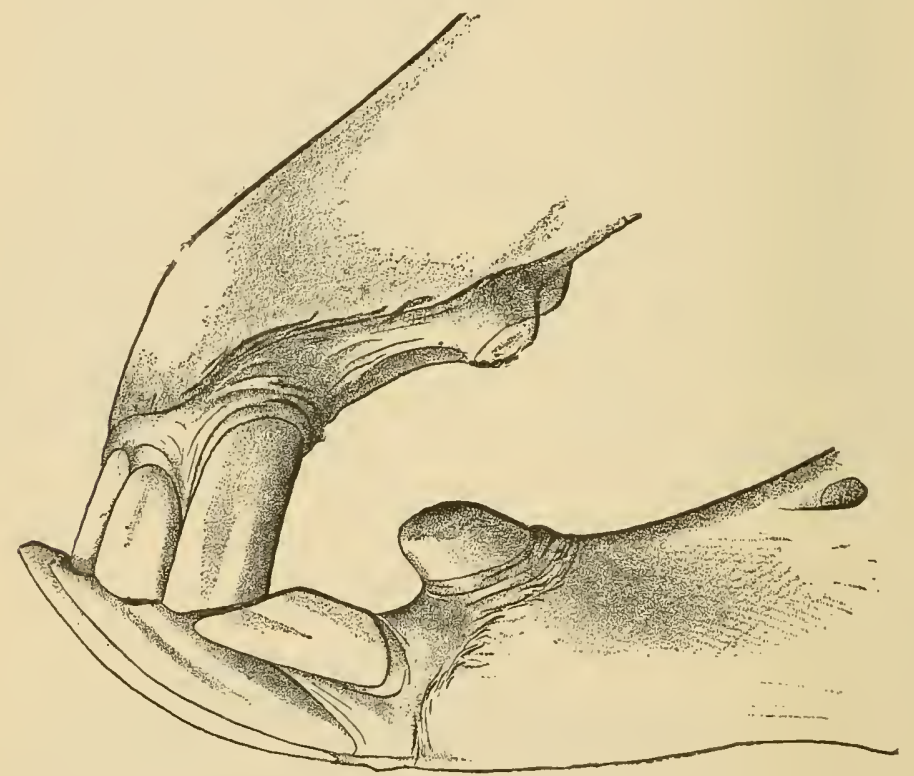

FIG. 320.-Reversed parrot mouth.

give it, for this reason, the name reversed parrot mouth. ${ }^{1}$ It appears to be rather frequent in the mules in the department of the Gers, where our colleagne, M. Faulon ${ }^{2}$ has recently noticed it, and where the subjects which present it are called beffes. M. Brissot, ${ }^{3}$ veterinarian at Suippes, has also noticed a very remarkable example.

Reversed parrot month seems to be duc to a slight prognathism of the inferior jaw, or, again, to the absence of the superior pincers. The

1 G. Barrier, Sur le bec de perroquet renversé, in Bulletin de la Société centrale de médecine vétérinaire, p. 134 ; Recueil de médecine vétérinaire, année 1855.

2 Faulon, Bulletin de la Société centrale de mélecine vétérinaire, p. 47, in Reeueil de médecine vétérinaire, année 1858 . Rapport de M. Chuchu.

צ Brissot, Recueil de médecine vétérinaire, 1885 ; Bulletin de la Société centrale de médecine vétérinaire, p. 192. 
characters of the wear are the opposite of those of an ordinary parrot mouth. Here it is the posterior face of the lower pincers which becomes bevelled as a conscquence of the prolonged friction against the upper ineisors. The difficulty in the prehension of food and in the determination of the age are of the same order as in the opposite anomaly; the discrepancy, in this case, is also remedied by the same operation.

d. Excess of Length of some Teeth alone in both Jaws. -This disposition is, so to speak, only a necessary consequence of the preceding. It will suffice to mention it.

In certain horses the inferior pincers, intermediates, and corners on the left side, for example, are very short, while the corresponding teeth of the superior jaw are very long. In the right half of the incisive arcade there is a contrary disposition. Whatever may be the seat and nature of this anomaly, the wear of the teeth in both jaws is always inversely proportional. If such a horse be examined with a view of determining his age, it is found that one side evidently appears older than the other. To make a proper estimate, it suffices to take the mean of the signs furnished by each side separately.

\section{$\beta$. Insufficient Length of the Crown.}

The irregularities due to this cause also involve both jaws; such examples, somewhat rare, are pecnliar exclusively to old horses. In such deformities, save in horses that are cribbers, the tecth of the opposing arcade are always too long.

In specimens which we have before us while writing these lines, the superior pincers measure only $0.004 \mathrm{~m}$., the intermediates $0.005 \mathrm{~m}$, and the corners $0.009 \mathrm{~m}$. from their anterior border to the gums; while in the inferior jaw we estimate in the same order $0.032 \mathrm{~m}$., $0.030 \mathrm{~m}$., and $0.028 \mathrm{~m}$.

In the jaws belonging to another subject, but in which the defect of length existed in the teeth of the inferior jaw, we found (Fig. 321):
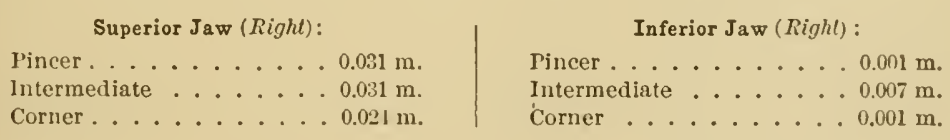

Very often the defect in the length of the free part coincides with that of the incased part, as can be seen in the figure. However this may be, the state of the dental table-by its form flattened from one side to the other, and by the abundince of the radical cementation-always 
indicates that the animal has reached extreme old age. One should not purchase such a horse with the expectation that his service will still
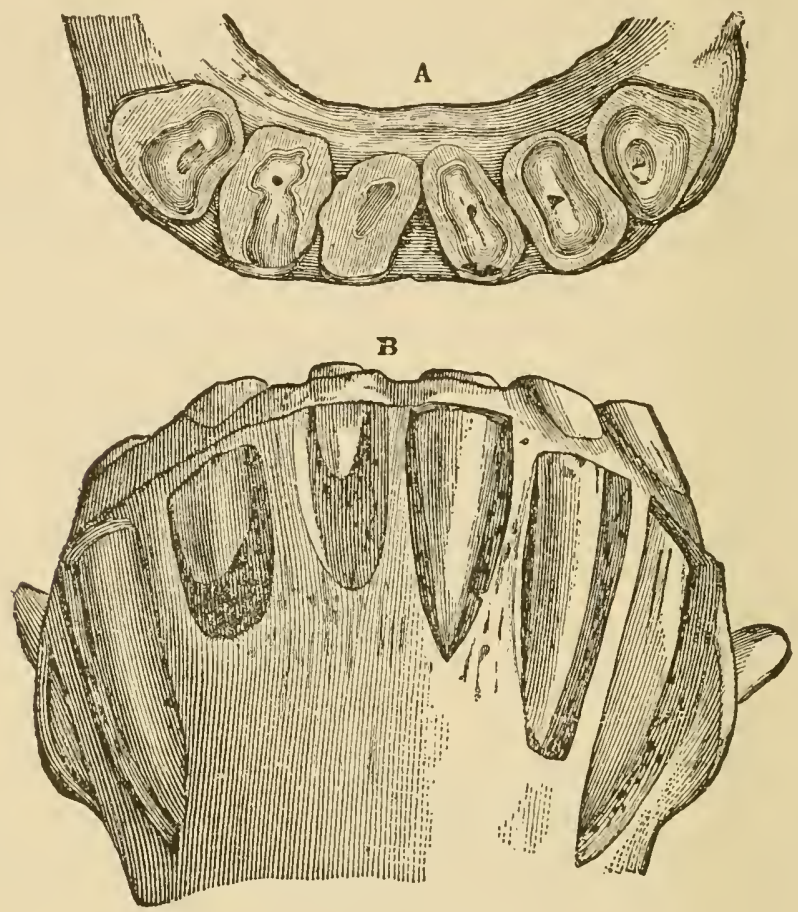

FIG. 321.-Incisors of the inferior jaw too short.

$A$. Dental tables. | B. Roots exposed in their alveoli.

be of long duration, a circumstance which, in such a case, removes all special interest from the determination of the age.

\section{§ 2. Molar Teeth.}

As in the case of the incisors, the irregularities of the molars are due to an excess or an insufficiency of wear. They may be seen only on one side, or on both sides at the same time; upon all the teeth of the same arcade, or only upon some of them.

Their recognition, at the time of purchase, is of extreme importance, by reason of the disturbances which they may cause in mastication and in nutrition.

\section{a. Defect of Length of the Crown.}

We have often found instances of this kind in subjects in the dissecting-room. 


\section{a. Inferior Jaw.-}

It is rare that the abnormal wear affects all the molars on the same side. Sometimes those of the middle are the shortest (Fig. 322), and then the areade describes, as a whole, a somewhat regular curve, concave from before to behind, in which are placed the superior teeth. Sometimes, on the contrary, those of the extremities, the anterior or the posterior indifferently, are deformed, and then the middle part of the areade becomes more or less convex, according to the degree of the anomaly (Fig. 323). Here, also, the length of the crown in the two jaws is always inversely proportional.

Another peculiarity is remarked, which consists in the separation of the roots in the advanced degrees of wear. They form then so many distinct teeth, and it almost seems that the number of molar's is greater than in ordinary conditions. In the speeimen presented in Fig. 322, eight teeth can, apparently, be counted; in that of

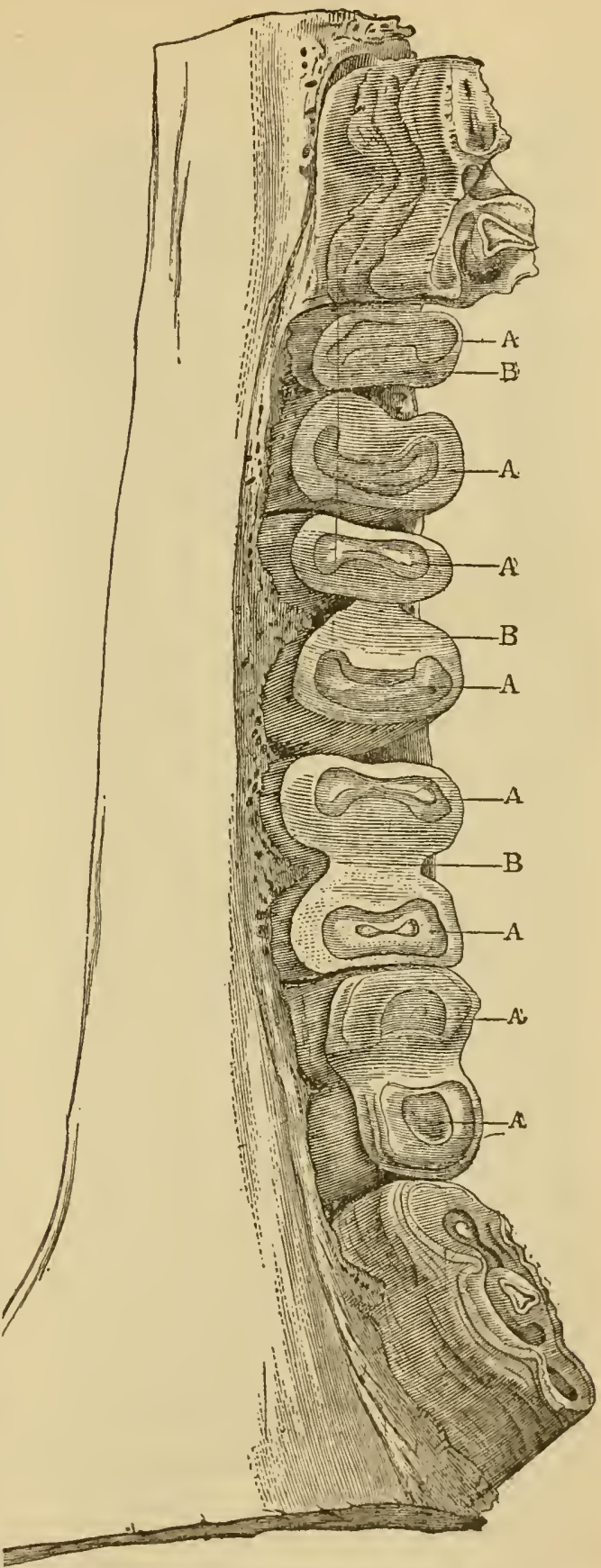

Fif. 322,-Inferior molar areade of a very old horse, show. ing the radical cementation, as well as the old horse, showof the middle teeth.

$A, A$, vestiges of the roots; $B, B$, cement. The enamel has disappeared. 


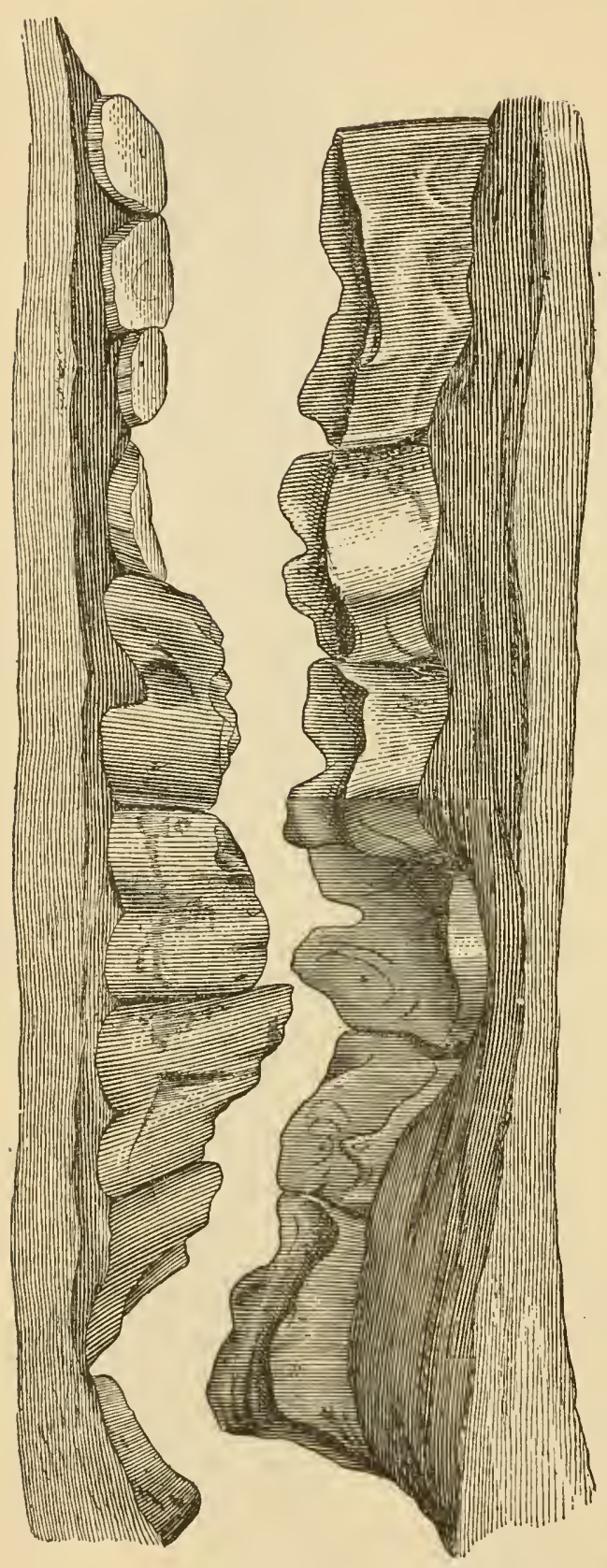

FIc. 323.-Right molar arcades of a very old horse.

(The inferior jaw is to the left of the figure.)
Fig. 323 there are nine. Thus, as we have said $\grave{\imath}$ propos of their structure, when the wear has reached this point there is formed around the dental stumps a thick layer of cement, which, by consolidating them into the alveoli and angmenting the area of the dental tables, permits them still to fulfil their functions.

However, we would make a great mistake were we to believe that these functions are performed with the same perfection as when the animal is young. The surfaces of friction, having lost their bands of enamel, are smooth, round, and deprived of all roughnesses. Mastieation becomes ineomplete, irregular, and the alimentary substances pass through most of the digestive apparatus without yielding anything like the sum total of their nutritive principles. Hence nutrition is impaired; the animal beeomes languid, emaciated, and, little by little, ineajable of working.

\section{b. Superior Jaw.-} What we have just now said can, in all respeets, be applied to the teeth of the 
superior jaw when an excess of wear has made them too short. Instances of this kind are more rare. We present one in Fig. 323. The separation of the roots here is also less common, and the bands of enamel persist longer. It would be superfluous to go into fuller details.

\section{$\beta$. Excess of Length of the Crown.}

The irregularities from excessive length of the molars are as common as the preceding. As they may exist in both jaws, and as they give rise to the same considerations, we will examine them in a general manner.

\section{a. Sharp Spiculæ of the External and Internal Borders} of the Molar Arcades.-The excess of length, but slightly marked in the simpler eases, alters only the external or the internal borders of the surfaces of friction. It is then manifested by asperities in the form of sharp spiculo or points appearing upon the external border of the tables of the superior molars, and the intermal border, on the contrary, of those of the inferior molars. These roughnesses, by their prominence, lacerate the internal face of the cheeks and cut the lateral surface of the tongue; they cause, for this reason, severe pain, which interferes with the regular mastication and necessitates dressing of the teeth.

The presenee of these irregularities may prove to be an obstacle to the normal lateral movements (diduction) which the jaws deseribe. This impediment is nearly always due, as has been pointed out by $\mathrm{H}$. Bouley, ${ }^{1}$ to the gluttony of the subjects or to their ravenous appetite. Mastication in them is hasty, and is aceomplished simply by an up-and-down or chopping movement of the jaws. This is all the more decided as the aliment on which the animal feeds is less diffienlt of trituration. The superior molar tables, which are wider, and normally overlap the inferior, no longer rub against the latter at their whole extent, and become eovered with sharp points at the level of the part not worn,- their external border. The impediment of which we speak can be remedied, in most instances, by the tooth-rasp or a few cuts of the tooth-plane.

\section{b. Bevelling of the Molars.-Molaires en Ciseaux.-The} molar teeth are subject to irregularities much more grave, and already pointed out by Girard, ${ }^{2}$ by H. Bouley, ${ }^{3}$ and by us. $^{4}$

II. Bouley, Nouveau Dictionnaire de médecine, de chirurgie et d'hygiène vétérinaires, t. iv. p. 622 , Paris, $18 ; 8$.

2 Girard, Traité de l'âge du cheval, p. 49.

4 G. Barrier, Sur les molaires en ciseaux, in Bulletin de la Société centrale de médecinc vétérinaire, p. 82 ; Recueil de médecine vétérinaire, année 1887. 
The tables of the molars, instead of meeting each other on an almost horizontal plane, are sometimes worn down so obliquely that they become almost parallel to the median plane and overlap each other like the blades of a pair of shears (Fig. 324).
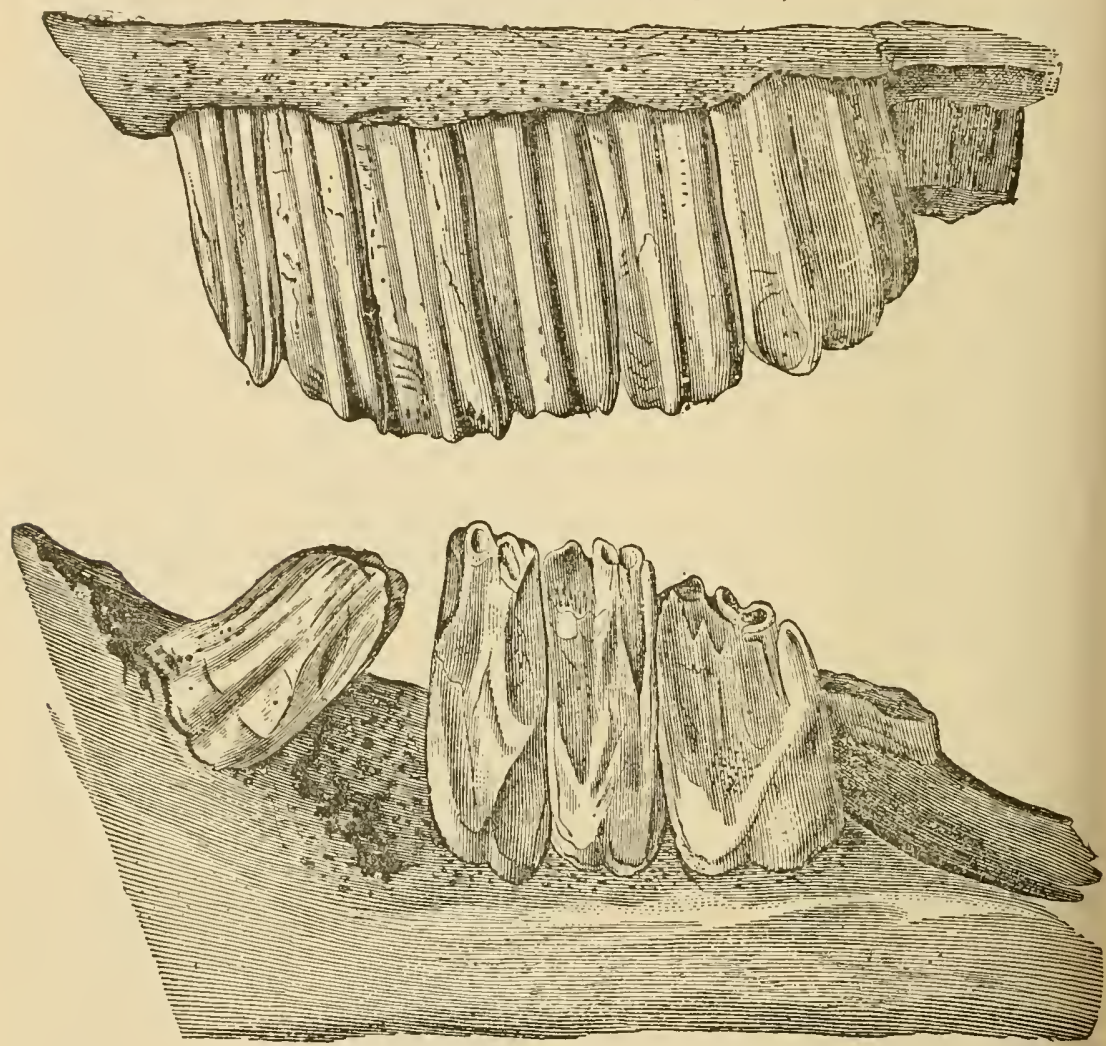

FiG. 324.-Bevelled molars from irregular wear.

This obliquity of the surfaces of friction enables the external side of the superior molars and the internal of the inferior to frequently acquire an enormous length, even to the extent of injuring the parts around the erowns, either the hard palate above (inferior molars), or, below, the bottom of the ponch of the cheek (superior molars).

French authors designate the teeth worn in this manner molaires en cisenux, from their resemblance to a pair of shears.

Their mode of formation is easy to comprehend:

If a horse masticates on the right side, for example, it will be understood that the left molar areades no longer rub against each other; the inferior is displaced inward from the superior, and it is only by its 
external border that it can bruise the aliment against the internal border of the superior areade, when the jaws are tightly closed. These two regions of the left areades will therefore be the only ones exposed to wear, while the opposite parts of these same areades, not exposed to friction, will eontinue to increase in length. Suppose, now, any permanent cause whatsoever (periostitis, caries, fistula, lesions of the check, the tongue, ete.) prevents, by the pain which acconupanies it, mastication on the left side, and we will have the conditions for the production of the irregularity in question. The tables, being no longer worn outwardly for the superior molars and inwardly for the inferior, will acquire an excessive length at these points, and will become more and more obliquely bevelled ontward and downward. The effect, becoming a canse in its turn, will be superadded to the action of the primitive lesion; the tables on the right side will remain normal, while those on the left will eross each other like the blades of a pair of shears.

The gravity of these bevelled molars depends upon the nature of the diffieulties which the dental irregularity opposes to mastication, and which may even extend to lesions of the hard palate.

They may pass unperceived at the time of purchasing the horse, if the buyer neglects to examine the mouth. The state of the incisors will, nevertheless, arouse suspicions, the plane of meeting of these arcades not being regular; in fact, these teeth always appear short on one side and long on the other. This characteristic, of itself, is sufficient to direct attention to the molar arcades.

\section{c. Irregularities on the Surface of the Molar Dental}

Tables.-For some obscure reasons, probably the absence of the normal movements of propulsion and retropulsion of the jaws, the molar arcades, no longer gliding against each other in the longitudinal direction, become covered with prominenees more or less extensive and elevated, which are lodged in corresponding cavities on the opposite molar tables.

These irregularities of the surfaces of friction are generally attributable to a ravenous appetite, swallowing the food without mastication, and the slight consistence of the food. Under the influences of all these causes mastication is very rapicl, the jaws make a simple up-anddown movement, and the tables are not worn smooth by the action of the two sets of teeth glicling against each other.

The softer constituents of the tecth are worn away and become hollow, while the harder parts preserve their length and even continue to increase. The effect, eventually becoming a cause, contributes more and more to augment the primitive inequalities, so that at a certain period 
the projections on the dental tables will penetrate the gum of the opposite jaw, and finally the bone, whenee an intolerable pain which render's mastication very difficult, and makes it almost impossible for the animal to feed himself.

Ordinarily, it is the superior molar arcades which present these prominences at the level of their middle portion, more rarely at their extremities; conversely, the inferior arcades are most often concave in their midlle and elevated at their extremities. But great differences may occur in the wearing out of these teeth which cannot be comprised in this general deseription.

It may be said, in this connection, that whatever shortening or breaking, partial or total, exists at one point of the molar arcade,
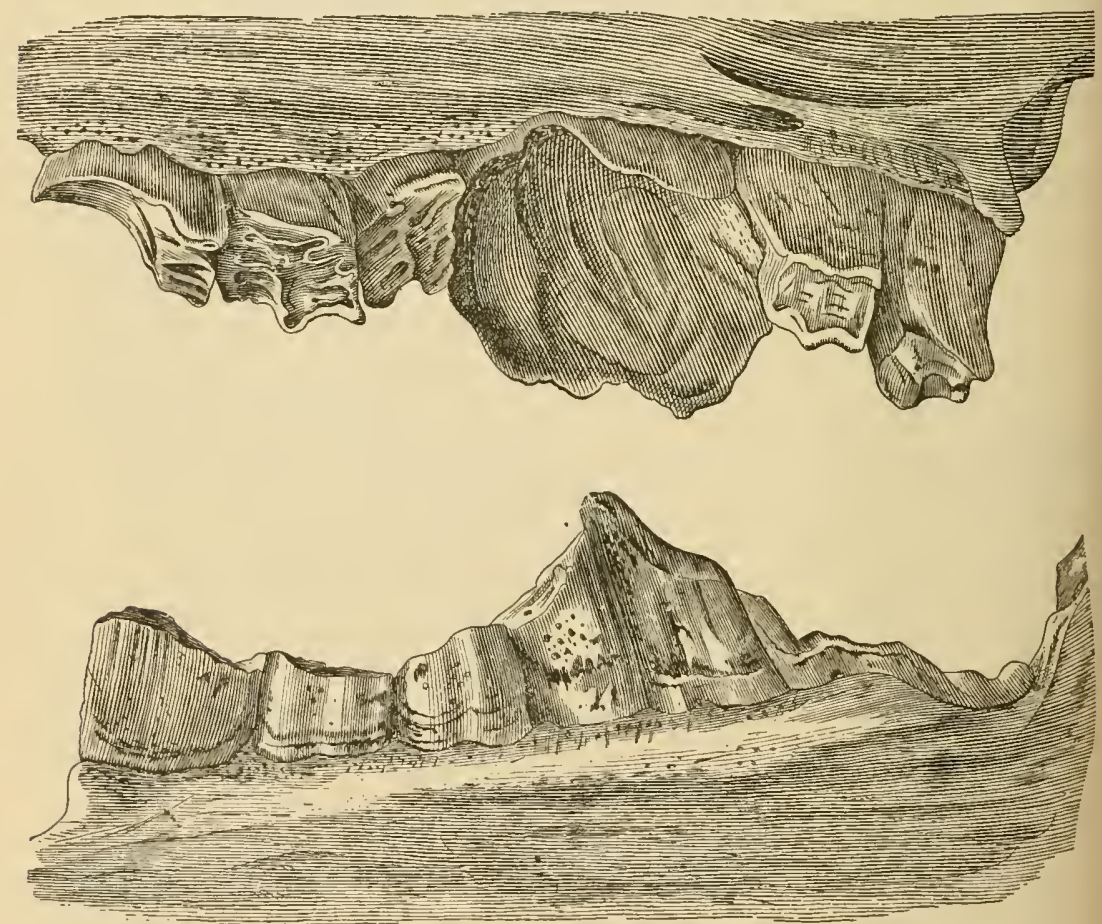

F16. 325.-1lypertrophy of the fourth right superior molar. The cavity receiver the curresponding prominence on the inferior tooth.

results in a proportional elongation of the tooth opposite this place. This is especially observed in cases of fracture, extraction, caries, ete., so frequent, even in animals quite young.

We present (Fig. 325) a very remarkable example of an irregnlarity of this kind. The fourth superior molar shows upon its table a 
cavity capable of lodging a hen's egg, and in which is received a very elevated conical eminence on the fourth inferior molar. It will be noticed that, in this ease, the superior tooth is almost twice its normal size, and is not square. This hypertrophy has not the eharacters of an anomaly through fusion, as we have shown in the ease of the incisors. It is more probable that it is the result of a dental eyst, an opinion which, if it were demonstrated, would also at the same time account for the excessive volume of the tooth and the slight resistance of its tissues to wear.

"To recapitulate," says H. Bouley, "an important fact follows from the preceding statements: when, from one cause or another, the grinders of herbivora do not rub against each other regularly, on each side, and over the whole extent of length and width of the surface of the dental tables, the unequal wear, as a necessary and inevitable consequence, causes, first, the deformity of the molars, and, later on, the irregularity, the imperfection, and, finally, the insufficiency of their function. This result is explained by the eontinual pushing out of the teeth : in order that the latter phenomenon (poussée) may remain a physiological faet it must be counterbalaneed by a proportional wear; then will the dental organs be preserved in their proper conditions of form and length, in order that mastieation may be performed regularly.

"But if this wear is unequal or less than what it should be, at one point or another, either at the level of an isolated tooth, upon the borders of the dental row, or upon the whole extent of the grinding surface of this row, then the continued growth of the dental organs, or of that part of them which is not worn off, will inevitably cause an excess of their length. This being once aceomplished, it cannot fail to be exaggerated progressively, because mastication becoming so much the more difficult as the masticatory apparatus is more imperfect, the friction of the grinders against each other diminishes proportionally to the degree of this abnormality.

"Thus the tooth which is abnormally lengthened because a primary cause prevented its regular wear, finding the condition of a new abnormal increase in the same excess of length which hinders the regular action of the molars, one against the other, the effect produced becomes a couse in its turn, and continues to produce similar effects; whence these deformities, often excessive, of the apparatus of mastication of which we have just given a description."

All this shows us that an examination of the molar tecth should 
never be negleeted at the time of purchasing a horse; in this respect it is of the greatest importance in relation to the exterior.

\section{Irregularities of Wear resulting from Cribbing.}

If the incisors of a horse be examined, we sometimes find irregularities of their borders, their faces, or their tables. 'They are due to diverse causes, concerning which it is neccssary to make some important differentiation.

Many irritable and nervous horses have, in fact, the bad habit of biting their fastenings or some surrounding olject when they are approached, when they are caressed, or when they are groomed by the attendant. There results from this, in time, a sort of breaking off of the free border of their teeth, which makes them irregular, and which must not be confounded with the abnormal wear produced by cribbing. [In such a case the border is generally roughened and broken off in small particles; in cribbing, as we shall see farther on, the dental border is perfectly smooth.] Although these modifications of the dental apparatus may already be of a nature to complicate the determination of the age, they nevertheless do not alter the form of the incisors so profoundly that the observer cannot, without difficulty, deduce sufficient signs to this effect, should he be called "pon to pass his opinion upon the animal submitted to him for examination.

The incisors likewise do not show any wear in that varicty of cribbing which consists most ordinarily in swallowing air without fixing the teeth on a foreign body, and which, for this reason, we proposed, in 1866 , to designate ceropinic, to distinguish it from the other varieties. ${ }^{1} \quad$ The French law of May 20, 1838, included cribbing in the number of redhibitory vices, but on condition that it did not imply the marking of the tecth.

In order to avoid the numerous eases of litigation which arose from the defective wording of this law, the legislature in 1884 judiciously substituted for the words cribbing without marking of the teeth those of cribbing properly so ealled, with or without marking of the tecth. Henceforth experts will no longer have to discuss the nature of the vicious habit in question or the characters of the wear of the tooth ; it will suffice for them to ascertain the existence of cribbing properly so called, as to the signs of which all are agreed; this alone is of a nature to lead to a nullification of the sale, according to the terms of Article II. of the French law of August 2, 1884.

${ }^{1}$ Arm. Goubaux, Journal de médecine vétérinaire publié a l’École de Lyon; année 1866, p. 349 . 
The horse does not always place himself in the same conditions in order to erib: he takes or does not take a point of contact. In the latter case, it is said that he cribs in the air, or that he is a rind-rucker. We will not oceupy ourselves with this here. (See Vicious IIabits.)

When the horse cribs by taking a point of contuct with his teeth, it is evident that the latter should present abnormal characters which vary in a very great degree, according to the mode of eribbing and the nature and form of the bodies which are seized between the jaws.

Sometimes, in fact, the animal chooses the bottom of the trough, the free border of the manger, the internal edge of this border, the lower eross-piece of the hay-rick, the strai or rope to which he is fastened; at other times it is the window-sill, the border of the stall, if he be loose in the stable; the end of the shafts, that of the pole of the wagon, the harness of a neighboring horse, or any other body in his reach, if he be harnessed to a wagon.

More rarely, he cribs upon himself, upon one of his nembers, for example; or, again, he cribs by contact and in the air alternately; finally, sometimes, the point of contact is simply taken by the lips or by the tift of the ehin; in this case the teeth will, of course, not show any abnornal wear.

But, whatever may be the mode of eontact, or the incisors upon which it is effected, this wear is constant in all cases in which the jaws are in contact with bodies of wood, leather, metals, stone, ete., capable of cutting them in consequenee of the repeated frictions.

After laving fixed the jaws, the animal makes a guttural "clucking" sound more or less strong, which many persons liken to that caused by belching, but which to us appears to be exclusively a grunt or sound oceasioned by effort: immediately after this the air descends towards the stomach. Our researches upon this point, as well as the analyses of the gas in the digestive apparatus, induce us to believe that, in the generality of cases, the subjects actually swallow the air. Many persons, on the contrary, think that there is an eructation of gas through the month, eonsequently true belching. We have not been able to verify this latter fact, although we have spent entire days with cribbing horses.

However this may be, it follows from our special observations of eribbing, ${ }^{1}$ that the varieties of wear which result from it can be classed in one of the five following eategories:

' Goubaux et Barrier. Des irrégularités dentaires résultant de l'usure produite par le tic ; in Bulletin de la Société centrale de médecine vétérinaire, séance du 10 Novembre, 1ssi, et Arehives rétérinaires, $1882, \mathrm{p} 13$. 
1st. The abnormal wear only involves the anterior face of the incisors.

2d. It bears upon their posterior face.

3d. It exists upon their anterior and posterior faces at the same time.

4th. It affects the dental tables.

5th. It takes place upon the lateral surfaces.

In four of these cases, a bevel is formed at the expense of the faces; in the fifth, there is a simple shortening of the tooth, which leaves the form of the dental tables absolutely intact.

1st. The Abnormal Wear only involves the Anterior Face of the Incisors (Fig. 326:A, $B, C, D$ ).-The pincers and the intermediates are, as a rule, worn at the same time; more rarely only the corners are affected. The wear is ordinarily more pronounced in the middle portion of the arcades, and often more extensive from one side to the other. The bevel which results from it may become two centimetres in length, and may even go so far as to open the external dental cavity; this always diminishes to a great extent the surface of the dental table.

We have observed in this category the four following varieties :

a. The bevel exists only upon the superior jaw $(A)$.

b. It is observed only on the inferior $(B)$.

c. It is seen in both jaws $(C)$.

In the first two cases, the contact takes place by the anterior part of the dental table upon the foreign body; in the third case, the horse seizes a round border or a sharp edge, each jaw setting itself or cutting against one of the adjacent faces of the foreign body.

d. The two bevels are upon the same plane instead of being convergent towards the interior of the mouth, $D$. This form results when the animal cribs on a wide, flat surface, as the bottom of the manger, for example, by making toand-fro movements with the jaws alternately from before to behind or from one side to the other.

2d. The Abnormal Wear only interests the Posterior Face of the Incisors (Fig. 327, $A, B, C$ ).-This category is one of the most singular. If the observer confines himself to a simple separation of the lips for the purpose of examining the anterior face of the teeth, it is evident that nothing abnormal can be seen; if, on the contrary, he opens the mouth, it may happen that he still may not recognize the accidental use, or that, even if recognized, it may not be attributed to cribbing, but be considered simply as a dental anomaly.

This wear is manifested in this variety by a bevel converging towards the side of the lips, whose obliquity is directed in the same sense as the curve of the posterior face of the incisors, while in the preceding cases the berel was directed in an inverse sense, which rendered it much more apparent. Nevertheless, the observer who has been forewarned will never fail to perceive very easily the posterior bevel of which we speak, but he will not forget that it is always less apparent below than above, in consequence of the greater curvature of the superior incisors.

It may be added that this sort of wear is more commonly observed in 

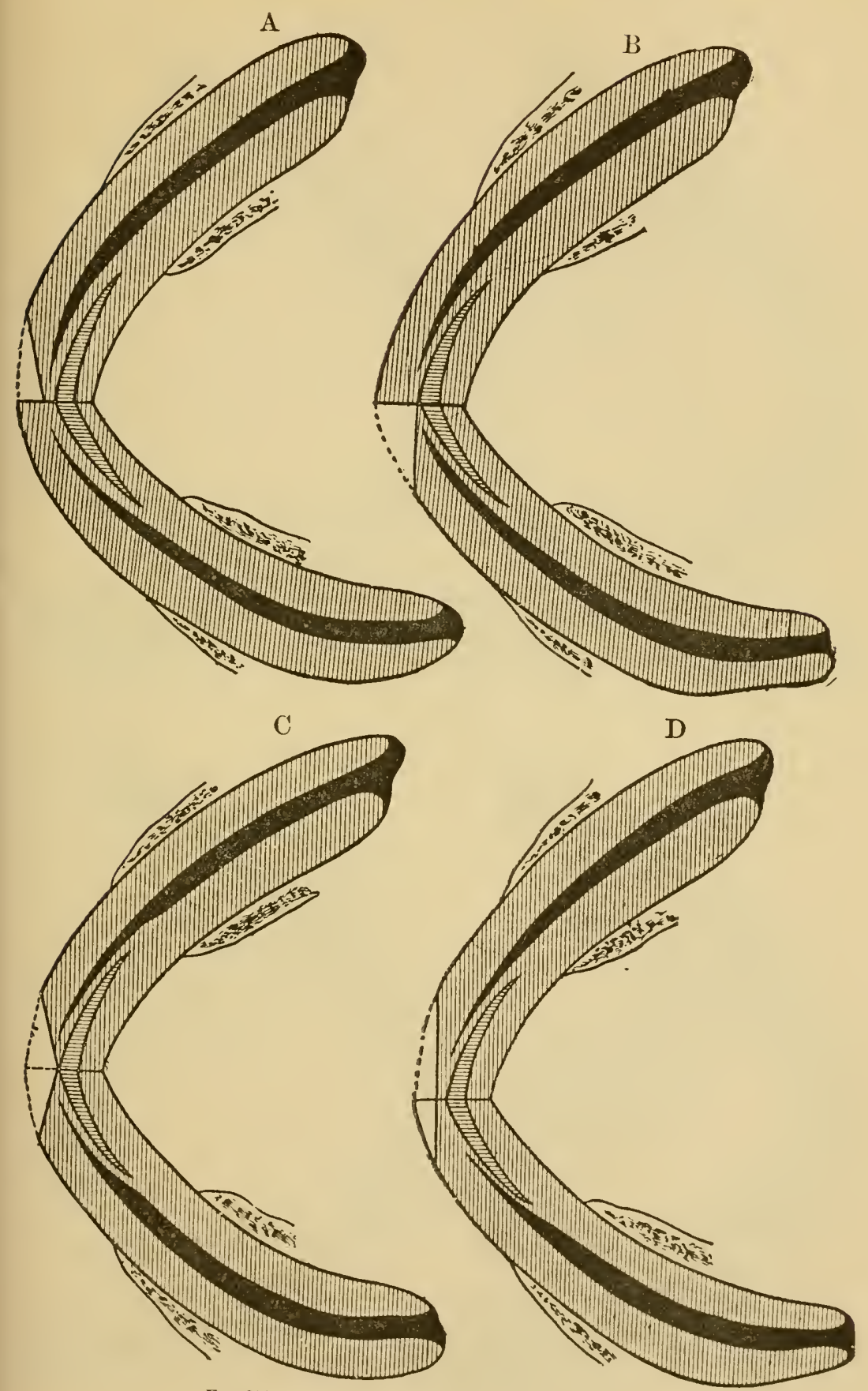

Fig. 326.-Abnormal wear produced by cribbing. 

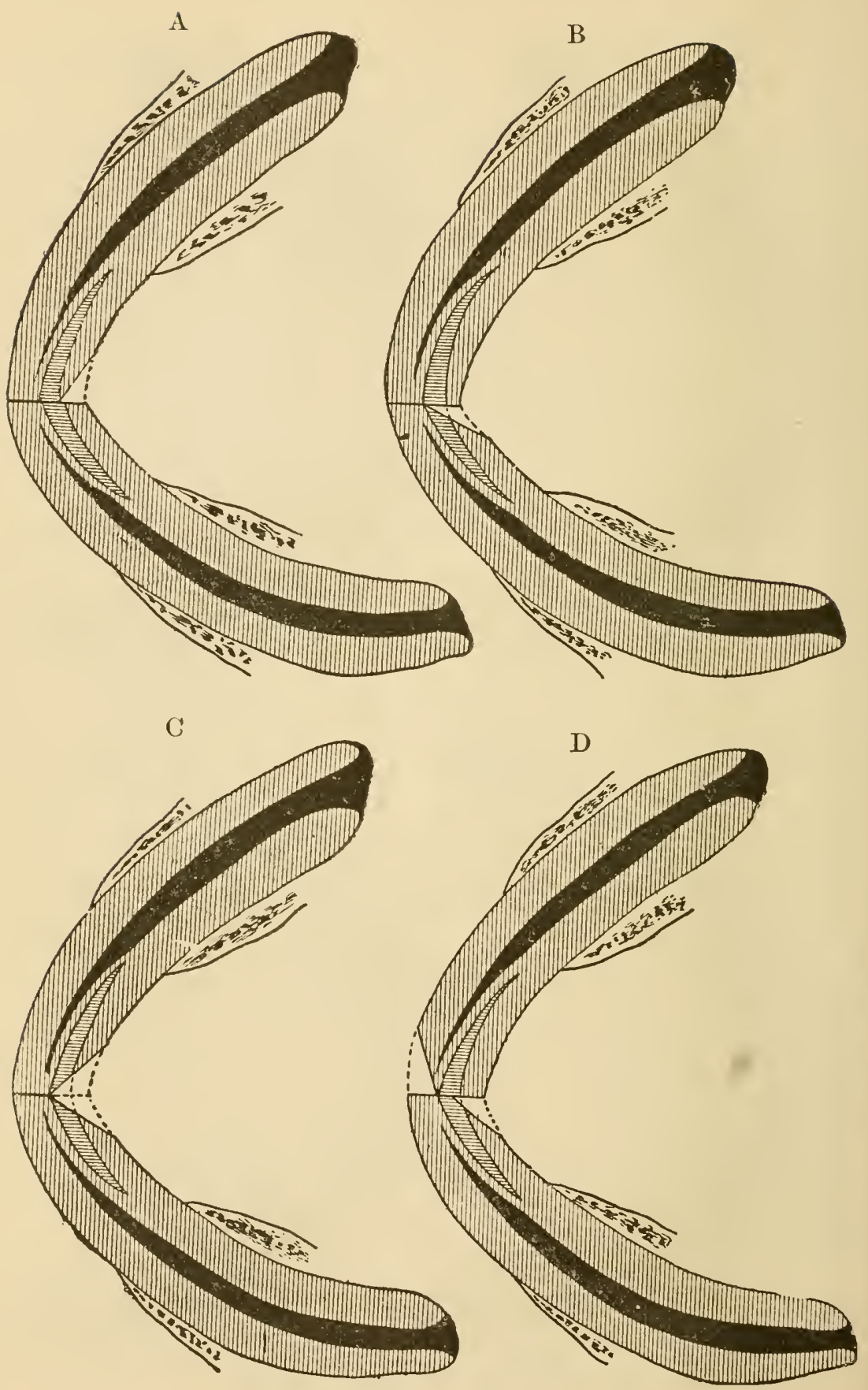

FIG. $327,-A$ bnormal wear produced by eribbing. 

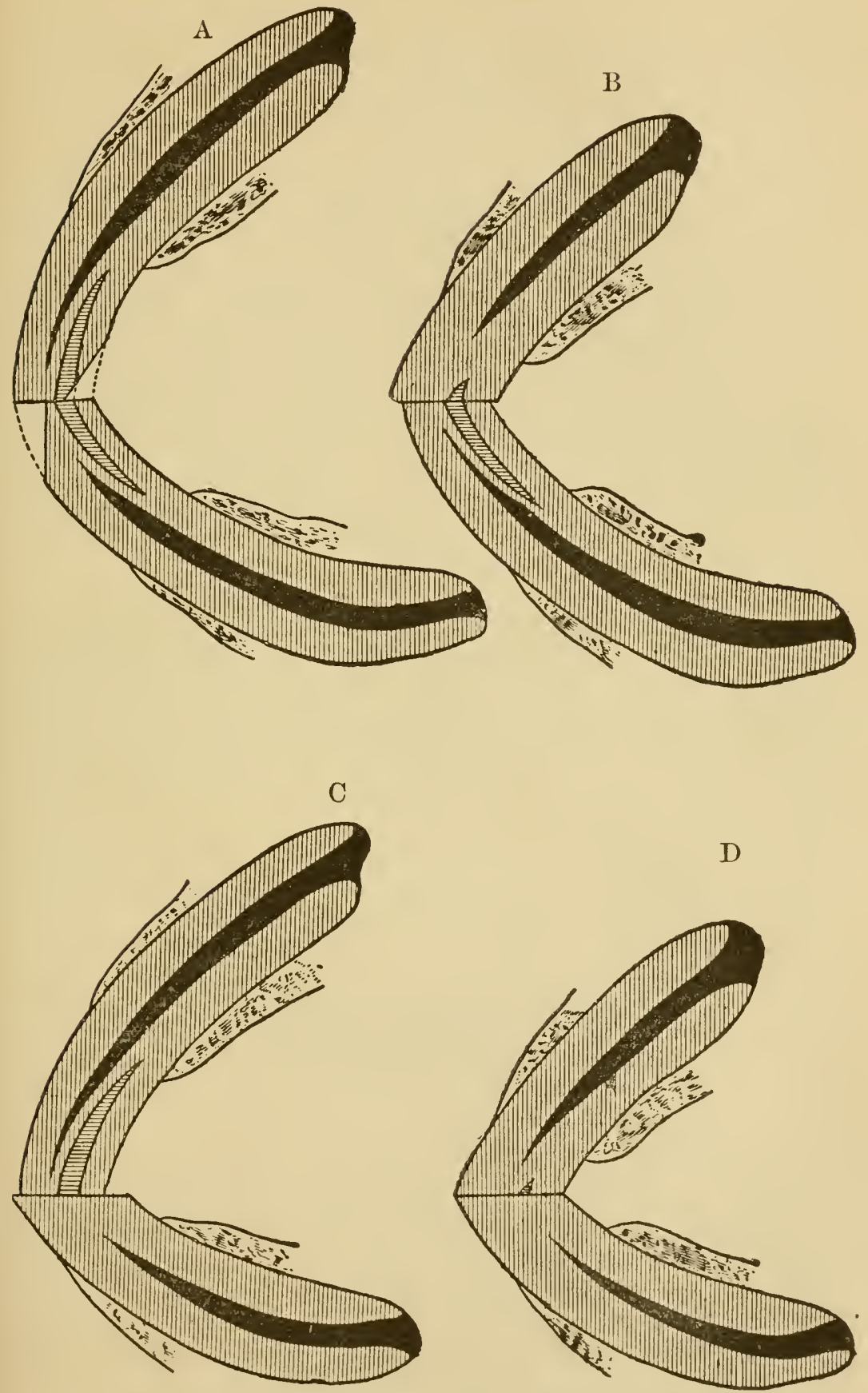

Fic. 328.-Abuormal wear produced by cribbing. 
oblique teeth that have a tendency to become horizontal; they are all the more liable to this, as the subjeets which present it are in the habit of eribbing most often upon a manger whose free border has its two edges very rounded.

a. The posterior bevel only exists above $(A)$.

b. It only exists below ( $\left.B^{\prime}\right)$.

c. It exists in both jaws $(C)$.

Whatever may be its seat, it makes the teeth of the horse to a certain extent analogous with those of cattle; they are no longer in apposition, excepting by the more or less small portion of the anterior part of their tables.

3d. The Abnormal Wear exists at the same time upon the Anterior Face of the Incisors of one Jaw and upon the Posterior Face of those of the other (Fig. $327, D$, and Fig. $328, A$ ).-The varieties which are met in this eategory interfere more particularly with the proper determination of the age, for they show themselves, both above and below, by a diminution in extent of the tables, and on opposite sides. It is necessary, therefore, to replace, in imagination, the portion removed by the wear, first in one jaw and then in the other, which doubles its diffieulties; while in the preceding categories the portions to be replaced were of the same nature in each arcade. There are, therefore, and in the same subject, a combination of two forms which we will pass in review.

Two varieties may be observed:

a. The Anterior Bevel above and the Posterior below (Fig. 327, $D$ ).-This variety is seen, for example, in horses which crib upon a manger whose free border presents upon its external edge a sort of round iron moulding projecting from the sides, and turned outward and downward. The surface of this moulding gives the point of contact to the upper teeth, whilst the lower glide along its edge by a retropulsive movement of the inferior jaw at the moment of the performance of the act. There are also circumstances in which cribbing is accomplished by the previous contact of the superior jaw. It is then only (when it has been once executed) that the animal, incited by a singular mania, rubs his inferior incisors across the edge in question, from one side to the other, and repeats the act several times during a few moments.

b. The Anterior Bevel below and the Posterior above (Fig. 328, A). -It is seen that, in this case, the marking is completely the reverse of the preceding. It is produced by seizing a round body with the jaws, as the border of a window, the extremity of the shafts, for example. This variety, however, is less common, because it necessitates a position of the head more uncomfortable for the animal. The latter, in fact, should approach the vertical direction, in order to allow the superior teeth to eut with their posterior face, an attitude which the subjects do not always find it possible to assume.

4th. The Abnormal Wear only affects the Dental Tables (Fig. 32S, $B, C, D)$.- This variety of wear is the most singular, for its only abnormal condition consists in a simple shortening of the teeth. But, as all horses which have the incisors ton short are not necessarily cribbers, and as, besides, in all cribbers they are not invariably shorter than is necessary, it follows that the unprejudiced observer cannot well recognize the eharacter of this particular shortening of which we now speak. In 1842, M. Mignon remarked ${ }^{1}$ that it 
would be interesting and useful to prove by observation whether horses which, without being very aged, have the incisor teeth very short may not have abandoned the habit of cribbing. M. Zundel' has related some facts confirming the opinion; we ourselves also know of several examples of this nature.

Horses which crib in this manner seize the foreign body with the whole extent of their dental table, most ordinarily the plane surfaces, external or internal, of a manger whose free border is too thick to be lodged between the two arcades at the moment of the effort. There is then a regular but excessive wear over the whole surface of friction of the teeth which bear against the foreign body.

The pincers and intermediates are nearly always the seat of the diminution of length. This fact is quite evident when the jaws are closed, for there exists a more or less wide interval between these incisors, the corners having preserved their normal length and contact.

At other times, the shortening may affect all the teeth of the same areade, and then it may, even if perceived, at least fail to be attributed to cribbing, if we are ignorant of the relations of cause and effect which connect this variety of wear with the vicious habit as to the character of which we may be consulted.

The following are the three possible cases which we have noticed:

a. The shortening affects only the teeth of the superior jaw $(B)$.

b. It affects only those of the inferior jaw $(C)$.

c. Finally, it is seen on both jaws simultaneously $(D)$.

In the last example the free border of the manger is narrow enough for the animal to be able to grasp it easily between the teeth.

5th. The Abnormal Wear takes Place on the Lateral or Adjoining Faces of the Incisors (Fig. 329).-The varieties of this category are very numerous and remarkably complicate the determination of the age. All are,

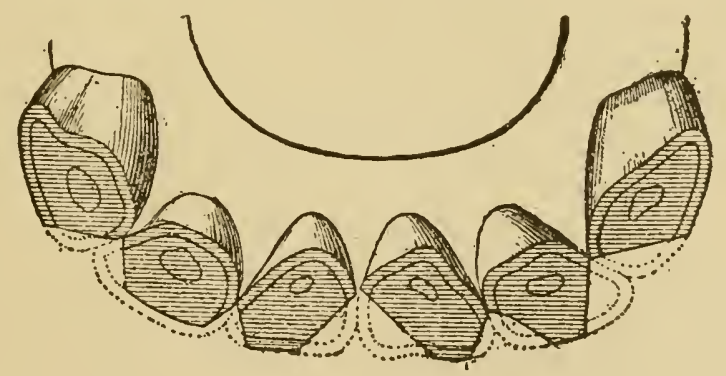

Frg. 329.-Abnormal wear produced by cribbing.

however, characterized by the formation of a double bevel at the expense of the lateral or contiguous faces of the teeth, converging towards the centre of the mouth. There results from this upon the anterior face of the incisive areades, and when the jaws are elosed, a series of vertical gutters or grooves whose bottom occupies the interstice comprised between two adjacent teeth. The tables at these places are deeply notched upon their anterior and lateral borders, by reason of the situation and the mode of convergence of the bevels. 
Here the abnormal wear is produced by the contact and friction of the dental areades upon the halter-strap by which the animal is fistened. The latter stands back in the stall to stretch the halter-strap to its full length, eribs upon the latter, and afterwards rubs his teeth over it alternately from above to below and from before to behind. The convex form of the incisive arcades renders these movements at first difficult and uncertain; but soon the strap strikes more particularly the interstice of two teeth and enlarges it by reason of the repeated friction. The vertical gutter, becoming more and more hollowed, extends to the posterior face. The result is that the gum becomes irritated, and then, in order to avoid the pain which results, he cribs on the other side. Analogous phenomena taking place, he will then crib at another point of the arcade, where a new gutter will soon be worn out, and so on.

This abnormal wear usually takes place on both jaws, although it may sometimes affect only one, the superior or the inferior. In all cases, and although the number of gutters may not be multiple, the dental tables scarcely furnish any index of a nature to assist in the recognition of the age. It is necessary, therefore, to depend upon the length, the direction, and the freshness of the incisors, the characters of the tushes, those of the molars, and, finally, upon all the external signs, which we will study presently.

Such are the varieties of wear, as numerons as remarkable, witnessed on the tecth of eribbing horses.

A number of them may often be combined; the teeth may be bevelled off at the anterior border of their tables and at the same time be very much shortened; it is the same as regards the posterior bevels.

But what we have not observed yet is an abnormal wear of the anterior and posterior borders rupon the teeth of the same areade, either in the upper or lower jaw. In order that such wear may be produced, the subject should be capable of changing his manner of cribling, - that is to say, of correcting himself spontanconsly of a bar luabit while he still has the power to indulge in it (which is almost illusory); or, again, the animal slould be in some manner forced into this change by reason of his master altering the position of the surrounding objects on which he previously plactised this habit. But, in such eases, it is more common to sec eribbing cease altogether for a variahle period of time, only to reappear as soon as eireumstanees are again favorable, ratler than to olserve a change in the horse's manner of eribbing. The subject does his best to find other objects and to overeome the restraint which is placed upon him, and he frequently sueceeds in this, but he will always erib in the same manner. Nevertheless, it is well known that the cribbing horse, prevented from touching an external object, will, for this reason, not lose the habit, becausc he will learn to crib in the air, become a wind-sucker. 
The seller may, in certain cases, find it to his interest to manipulate the teeth of a horse so that they show an artificial wear, capable of simulating that of cribbing properly so called.

How can we recognize the employment of this fraudulent practice?

This is ordinarily very casy.

If the abnormal wear has been produced by a file, the marks of the latter can be seen on the teeth. If, after having made a surface of friction artificially, the latter be polished to remove these marks, the fraud can be detected by the fact that the enamel is perfectly on a level with the dentine, and not (as when the wear is natural) in relief upon it, as we have already mentioned. ${ }^{1}$

Besides, those who perform these trieks do not always take the precaution or have not the ability to make upon the incisor's a surface of wear in accordance with the nature of the oljject on which it was produced. Hence it seems to us insufficient that the prosecutor should place in evidence only the reality of this wear ; it is, moreover, necessary that he should furnish the proof that it is certainly due to cribbing. This is what the expert should not forget.

The determination of the age is particularly difficult in cribbing horses, beeanse the dental tables are in most cases partly destroyed by the friction which they have sustained. But in many instances the experienced observer gets over the difficulty by reconstituting, in imagination, the normal length and the normal form of the incisors. By considering the portions still present, it is possible to reconstruct the teeth such as they would have been if all the conditions had remained normal. It is this sort of dental restoration which we have endeavored to represent in the drawings that aceompany our description; it is a great aid to those who are but little experienced.

Other indirect methods also lead to a recognition of the age of cribbers: we refer to the careful examination of the tectil least affected by the habit, especially the corners, which are less frequently abnormally worn by reason of their situation upon the lateral parts of the areades; the superior incisors, the molars, and the buceal mucons membrane; the characters to be drawn from the direction, the length, the width, and the coloration of the teeth; the general aspect of the subject, the form of his bead, the thickness of his jaws, the state of his temples, of his supra-orbits, etc.; in a word, all the characters, however wak they may be, capable of elucidating the question as to whether the animal is young or old. 


\section{Irregularities from the Employment of Fraudulent Means.}

All salesmen endeavor to present their goods in such a condition as will enable them to dispose of them to the greatest advantage, and breeders and horse-dealers are not wanting in this respect. Concerning the age, they strive to give to the mouth the eharacters of that period of life in which the animals have their greatest value, endeavoring to make the young appear old and those that are too old young (at least in appearance). Two particular cases should be studied under this heading.

\section{$\S 1$. Extracting the Incisons to make the Horses appear Older.}

"In breeding distriets," says Girard, "especially in Normandy, breeders rather frequently extract the milk intermediates, particularly in horses which are retarded in their development. This causes the eruption of the permanent teeth several months earlier than usual. Those who gain possession of these same horses very soon practise a similar operation upon the milk corners. In this manner, a horse which is not yet four and one-half years old is already provided with all the permanent incisors. . . .

"Certain subjeets whose dentition has been hastened by the extraction of the milk-tecth will mark the age of five years, whilst they have really only attained four years.

"In order to reeognize such a fraud, we must make every comparison capable of furnishing positive inductions and leaching to the truth. The absence or the freshmess of the tushes is no criterion by which to form an opinion, since these teeth, which come out most ordinarily at four years, may be advaneed or retarded a year, and even appear only at six years. If we examine with care the state of the dental arcade, it can be verified that, thongh one has discovered a means of hastening the eruption of the incisors, he is still umable to make these teeth assume the position in the jaw which they should have and give to the dental areade which they form the disposition that is proper to it. When the permanent teeth make their eruption naturally after having atrophied and expelled the milk-teeth, they arrange themselves symmetrieally in the same order alongside of each other, and constitute at the age of five years a regular arcade. In the contrary case, when their eruption has been hastened by the extraction of the milk incisors, they are placed somewhat erosswise and render the areade irregular. The gums and the alveolar border, at this period more or less red 
and swollen, seem to push the dental row backward; these parts are so much the more seusitive as the extraction has taken place more recently. Sometimes particles of the teetl, incompletely extracted and still remaining in the maxillary bone, show themselves in front of the adult teeth; nevertheless, the incisive arcade presents an musual aspect which the experienced eye can easily recognize. When the foetal teeth have been extracted recently, the places which they occupied are inflamed, contused, and excoriated ; for this reason it is always more easy to recognize fraudulent means from the beginning.

"Often the teeth of the inferior jaw alone are extracted; this is the true cause why, in a large number of horses, their eruption precedes that of the superior incisors; and this case is too simple not to be properly recognized." "

Many authors have spoken in the same strain. Séon Rochas, ${ }^{2}$ who has fully described the mode of procedure in the extraction of the deciduous incisors, says that a horse three years of age, at the time of the operation, would appear three months later as a four-year-old, because the intermediates of the second dentition are commencing to appear.

All this, at first sight, seems very clear, but does the pulling of the milk-teeth really result in an earlier eruption of the permanent teeth? The question is worthy of a careful examination.

Everybody is not of the same opinion in this respect. De Curnien, for example, expresses himself unmistakably against the success of the practice. $^{3}$

"First," says he, "I do not believe in colts being advanced by the premature extraction of the milk-teeth.

"One day I bought a draught filly at the market of Chamy, without horse-teeth (without adult teeth) in the superior jaw and with four milk-teeth in the inferior.

"The place of the pincer's was unoceupied, the gums healthy", clean, and without any appearance of a wound or eicatrix.

"When the superior pincers came out, the lower pincers were just ready to penetrate the gums. Evidently, some one intended to advanee the dentition of the mare. Was it advanced? No; the teeth were extracted and that was all. ${ }^{4}$

1 Girard, loc. cit., p. 81 , et suiv.

2. Séon Rochas, Histoire d'un cheval de troupe, Paris, 1839, p. 26.

3 De Curnieu, loc. cit., t. iii. p. 527.

4 It is only proper to remark that De Curnieu has not proved that the pincers had been pulled. It is a simple presumption on his part, which adds nothing to the proof of his conclusion. 
"If, in extracting the milk-tooth, we do not wait until the permanent tooth has atrophied its root and prepared it to fall out, the gum will contract, and it will then be more diffieult for its successor to penetrate naturally:"

Maylew, ${ }^{1}$ on the other hand, has devoted a long chapter to the diverse frandulent means which are employed in England to hasten the eruption of the permanent incisors. He speaks of canterization of the gums with the hot iron, of scarifications of the gums, and, finally, of the extraction of the milk-teeth. But he considers all these means barbarons, and claims that the extraction of the milk incisors at times hinders the eruption of the adult incisors.

In the face of such contradictory opinions, we have applied directly to several of our honorable colleagues living in districts where extraetion of the deciduons teeth is practised. Here are the answers given to our questions :

1st. Who are the persons that practise extraction of the incisors of the first dentition?

They are breeders, empirics, and dealers in horses. Veterinarians consider it, with good reason, as a fraudulent procedure with which they are unwilling to be associated.

$2 \mathrm{~d}$. Method of the operation.-Immediate results.

The animal is held in a standing position, with a twiteh placed on his upper lip.

Special instruments are employed : pliers, foreeps, or even the key of Garengeot. It appears that the latter instrument is preferable, because it permits the extraction of a single tooth without disturbing or breaking the adjacent ones.

The difficulty of the operation augments in proportion as the time is more in advance of the period when the tooth should have fallen out of itself. In the latter ease, it is very simple. It is neeessary, nevertheless, to operate with caution, because the incisor may happen to break immediately below its neek.

The pain which is a consequence of the operation is often rather severe, and sometimes hinders the animal from continuing to feed in pasture. It is then advisable to feed him in the stable, at least during a certain length of time, on a particular diet, such as oats, rye, or barley which have been previously boiled.

The animal sometimes, as a consequence, becomes vicious or difficult to bridle.

${ }^{4}$ Edward Mayhew, The Horse's Mouth, showing the Age by the Teeth, 3d ed., London, p. 123. 
3d. At what age is the operation practised? How many teeth are extracted at one time?

This varies. Sometimes the pineers alone are extracted towards the end of the seeond year; sometimes at a later period only the intermediates are extracted; or, finally, at a still later period the corners alone may be removed. But there are some horses in which the pineers, the intermediates, and the corners are removed at suceessive periods. It appears that the operation is sometimes performed only upon the teeth of the upper jaw.

In this respeet there are no fixed procedures. The principle of the stock-breeder who has colts to raise is to dispose of them at the earliest possible moment to avoid the expense of feeding, the chances of loss or of deterioration, or, finally, to realize in the shortest time the amount which their sale will produce.

This trick is practised at from three to three and one-half years of age, if it be desired to sell the horse as a four-year-old, and from four to four and one-half if he is to be represented as a five-year-old past. It is understood, of course, that in the first ease the four intermediates are extracted; in the latter ease the four eorners.

4th. Does the ertraction of the deciduous incisors hasten the eruption of the adult teeth?

Nearly all our colleagues have given an affirmative answer to this question; one alone claims that not only does it not lasten, but that it even retards the eruption of the permanent teeth, aceording as it has been practised six, eight, or ten months before the natural period of their replacement. The others declare that the eruption is quiekened, if the operation has been properly performed; that is to say, if the whole of the milk-tooth has been removed.

M. Ivon ${ }^{1}$ has, in this respect, eommunicated to us some interesting observations.

"This operation," says he, "hastens the evolution of the tooth but little. In the vieinity of Bayeux, and especially in the district of Caen, where extraction of the incisors of horses is frequently performed to make the animals apparently older and to dispose of them more promptly, it is practised only, at furthest, six months before the period when the teeth would naturally fall out. More often, howerer, it is done two months and even only one month before this period, in order to dispose of them more easily to the remounts or sell them to dealers. In the first case the eruption of the permanent teeth is lastened two 
months at the most, and sometimes not at all ; in the second case, from fifteen to thirty days.

"It would be a grave error to believe that by pulling the intermediates at the time of the natural shedding of the pincers the former would, at the end of some days, be pushed out on a level with the latter. The wound resulting from the operation on these teeth would, on the contrary, cicatrize very promptly, and form, at these places, a strong and quite persistent pad.

"As I have said above," adds M. Y von, "I think that the extraction of the teeth advances the dental evolution but little. On the posterior" face of each milk-tooth which is shed it is easy to notice a deep concavity, a veritable imprint made by the permanent tooth, which inerusts itself here by pushing the former out of its alveolus. It is evident that it is not the milk-tooth, which must fall out, that prevents the eruption of the permanent one, but rather this latter which pushes out the other one in proportion as it is developed.

"Our Norman colts, with a few exceptions, are born from the 15th of February to the 15th of June. There is therefore a difference of four months between these two extreme periods. In the month of Jamuary, five years after their birth, the colts born in February may have all their incisors, while in the others the evolution of the corners will not have taken place until the month of May. Nevertheless, all these colts will be considered as five years old, although those born in May or in Jume may not have all their teeth. To do away with the dental differences from this variation in time, breeders very often extract at four and a half years the eorners of colts born in June, in order to make them mark five years, like those of February of the same year.

"Under other conditions, breeders extract at four and one-half years the corners of horses foaled at the commeneement of the year, and their permanent corners having gradually aequired their normal length in Jannary and February after their fifth year, they may pass them on ignorant persons for horses six years old."

The remoral of the milk incisors has no infuenee upon the general development of the animal on which the operation is performed.

Finally, it must be concluded, after all the information given, that the extraction of these teeth quickens in a certain proportion the ermption of the permanent ones, and apparently makes the animal older, especially if the operation has been done a short time before the natural fall of the milk-teetl. In this case a horse which marks five years has, therefore, really not acquired this age. 


\section{§2. Bishoping, Countermarking.}

The fraudulent trick known under the names bishoping, countermarking, is performed to make the horse appear younger than he in reality is; it, however, can only deceive ignorant and careless observers, as we will demonstrate immediately.

We know that in young horses the transverse diameter of the free extremity of the tooth is greater than the antero-posterior diameter. We know also that the dental table becomes modified and aequires a form successively oval, round, triangular, ete. We have seen, finally, that the external dental cavity occupies at first the whole of the surface of friction; that it gradually diminishes in depth, draws nearer and nearer to the posterior border of the table, disalppears, and is then replaced by the central eement, ciremimseribed by the circle of central enamel, whose extremity, in its turn, finally completely disappears.

The jobber (for an honest horse-dealer would not indulge in such methods), in order to the better gain his end, will choose in preference a horse rather vigorous, still well preserved, and having good members. Let us take a subject twelve years of age, for example: the inferior incisors, at this period of life, are round, and the central enamel has disappeared, or almost so, from their tables. Suppose, also, now, that we desire to give to these teeth the characters of seven years.

Certain men in Paris have the reputation of practising this fraud very artistically, and we have had them perform it on two horses expressly for the purpose of showing it aftervards to our students. We have observed numerous speeimens of this kind in horses recently purehased.

The following is the modus operandi: a strong halter is placed on the horse's head; the halter-strap is fastened close to the ground, so that the head is conveniently placed within the reach of the operator. Then a thick block of wood is placed in the month, to keep it open, so that the inferior incisive areade may be altogether free.

Some operators, before commeneing the $u$ ork, level the dental tables in both jaws with the rasp; then, with a narrow gouge, a small transrerse cavity is seooped out upon the intermediates and the corners. This operation is somewhat difficult on account of the lardness of the eentral enamel. These carities are never made in the superior incisor's, because there they still exist. At other times, also, the tushes are rasped off, especially on their inner side, to refreshen their free extremity by rendering it a little more pointed. The latter precaution is, however, not practised upon all bishoped mouths. 


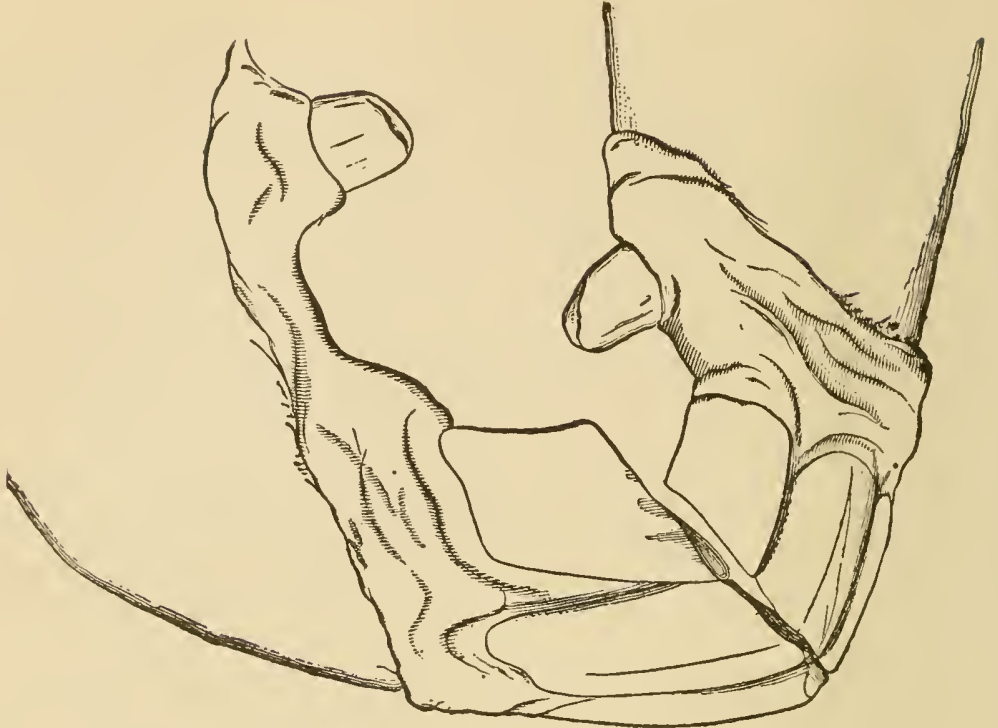

它

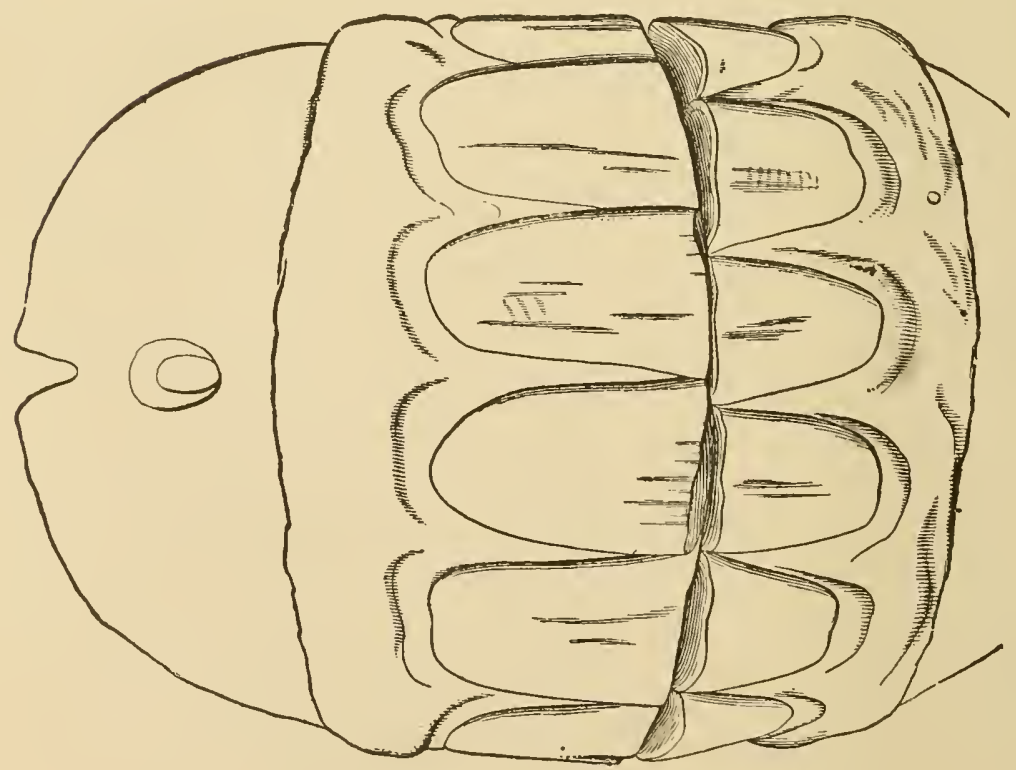



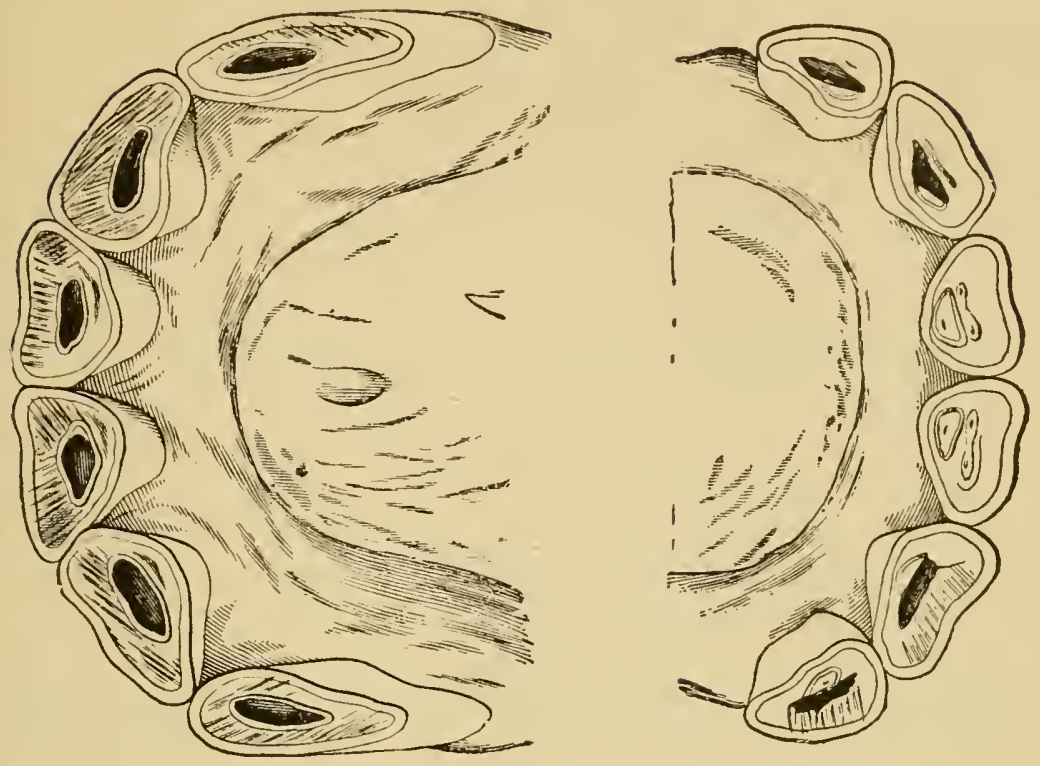

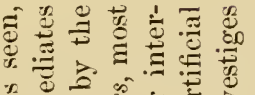

$\therefore \stackrel{0}{2}$

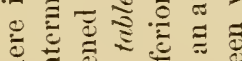

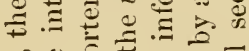

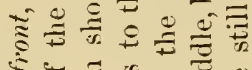

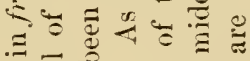

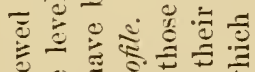

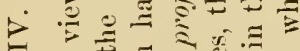

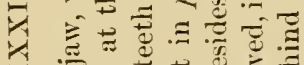

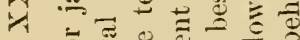

国

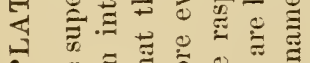

A

$\exists$ है

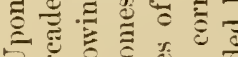

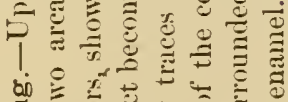

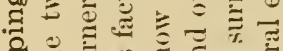

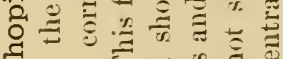

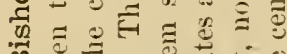

ติ

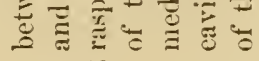


The artificial cavity is then generally eolored black by the application of nitrate of silver, so as to give to it the appearance of what in the adult tooth is alled the been, the mark.

But if we take the precaution to wipe the alumdant saliva from the dental tables when the horse is offered for sale, it will be easy to detect this imitation. The following are its characteristics (Plate XXXIV.):

1st. If, after having separated one lip from the other, it is secn that the incisors of the two jaws do not exactly correspond, it is evident that their surface of friction has been rasped without shortening the molars in the same proportion.

2d. If, after having seized the tongue in order to separate the inferior jaw from the superior, eavities are observed upon the dental tables, it is necessary to ascertain if their presence is in relation with the form of the table; finally, it must be determined whether they are natural or artifieial. We must be ecrtain as to the latter point.

a. When the cavity is nutural, it is surrounded by a border of enamel which is in relief above the dental table. This relief results from the fact that the two substances which essentially compose the tooth (the enamel and the dentine) do not offer the same resistance to wear.

b. On the contrary, when the cavity is artificial, its periphery is not surromed by enamel, and the line which surromds its opening or entrance is not in relief upon the table. Thus it can be very easily recognized by sight as well as by touch.

\section{§ 3. Rasping of the Corner of the Superior Jaw.}

We know that often at the age of six years the superior corners present a well-defined notch on their table, due to the fact that the whole of their table is not worn against that of the inferior. Nany persons recognize the notch, and horse-dealers especially are well aware that if this notch be removed while the teeth are still fresh, the horse will seem younger than he really is. They remove it with the rasp. This trick, which is not very often practised, and of which we have seen some examples, is of no great importance; such manipulation may be easily discovered by finding the marks of the rasp upon the tables of the superior corners. 


\section{SECTION SIXTH.}

\section{CONSIDERATIONS RELATIVE TO THE DESCRIPTION AND IDENTIFICATION OF THE HORSE.}

WE propose to treat in this section on the ideas which the reader should possess in order to be able to describe a particular horse, - that is to say, to distinguish him from other horses. Among these items of knowledge there are some of which we have already treated and which we shall now only have to apply. The others we will study in detail ; they have reference to the coats and their peculiarities, the height, and the formulation of that doement called a description, which can also be employed as a model for a certificate of soundness.

\section{CHA PTER I.}

THE COATS.

\section{Coats properly so called.}

Ix the exterior, the word cout is synonymons with robe, and refers especially to the color of the hairs. It denotes the whole of the hairs which eover the surface of the body.

These hairs, produced by particular organs of secretion annexed to the skin (hair-lulbs), present a remarkable variety of colors. This is especially true of animals which live in a state of domestication. In wild animals, such as the tiger, leopard, deer, cte., the color of the hairs is 11 iniform.

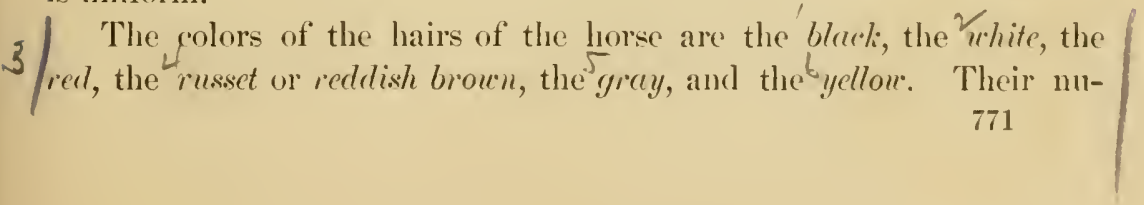


merous shades and diverse intermixing render the study of the coat somewhat complicated.

Nearly all writers on the horse have described these latter after classifications of their own, which they have considered simpler, more explicit, and more complete than those of their predecessors.

The history of these classifications and the examination of the principles upon which they are based would be irksome and would lead us too far away. It may be said to their credit that they are all tolerably satisfactory in relation to the facts mentioned, but not one of them is free from serious objections. The reason of this fact is the extreme complexity of the details of the subject. While most of the varieties can be identified and easily arranged into one of the divisions adopted, there are a certain number of them which defy all such attempts, and to deseribe which on language should extend its vocabnlary. In our opinion, the invention of new terms would add fresh complieations instear of easting a new light on these already confused descriptions. In practice it is wisest to make special mention of the exceptions-rare exceptions they are, in truth-which we are liable to meet.

Basing our argument upon the fact that ordinarily foals are never born either white or having pure white in their coat, and that this eoat only appears more or less late, ${ }^{1}$ we will at once establish, after the example of our noted colleague, Professor G. Nemmann, three great categories: the primitive couts, the derived coats, and the comjugate couts. birth.

By primitive coats, we understand those which the foal has at

By derived coats, those which appear some time after birth, and are due to the introduction of white into a primitive coat.

By conjugate coats, those which are characterized by the presence, upon the same animal, of two primitive or two derived eoats.

We will begin with the study of the first.

1 We should, nevertheless, mention the following passage from De Curnieu relative to white foals: "Often," says he, "the white cont charaeterizes a raee. Mention is made of the small white horses of the Duke of Montrose, in England, derived from Spanish or Barb horses. . . In Hanover and Denmark white horses somewhat similar to the latter have been preserved for a long time. They still exist there, and are ealled weissyeboren (while-born). (In De Curnien, Lecons de seience hippiq̨ue génçrale, lre partie, p. 174, Paris, 1855.) 


\section{$\S 1$. Primitive Conts.}

We will divide these eoats into three groups:

a. The simple coats, formed by hairs of a single color.

Examples: black, sorrel.

$b$. The composite coats, formed by hairs of two colors: the one, black, for the mane, tail, and extremities; the others, yellow, red, or gray, for the body.

Examples: Iscabella, bay, mouse-color.

c. The mixed coats, formed in great part by dark hairs, upon each of which are found two different colors, the yellow more or less light at the base, and the black at the summit.

Example: fox-color.

\section{A.-Simple Coats.}

We will class among the simple coats all those which are constituted by hairs of the same color. They comprise the black and the sorrel. If we do not include the white here, as nearly all anthors have done, it is becanse this color does not belong to the primitive coats. Besides, the true white, that which, in the strict sense of the word, presents no dark-colored hairs, is so rare that many doubt its existence. The horses which are described white are, in reality, only very light grays, upon which some dark hairs of the coat are discovered in the mane or tail, if they are carefully examined. Moreover, we apprise the reader of a different opinion, according to which it will be easy for him to classify this coat in the various groups of which we will speak presently.

1st. The black coat needs no definition. It is the darkest of all the coats. Its varieties are two in number, as follows:

a. The true or ordinary black, dark, dull, uniform, and without any reflection.

b. The rusty black, dull, reddish in the sun, with a gradation of tints, less dark, and sometimes almost washed, at the elbows, the axillex, the flanks, the abdomen, the thighs, and the buttocks. It is often difficult to distinguish it from the brown, especially in summer; we will, nevertheless, show how to differentiate between them in speaking of the latter coat.

The black may possess a brilliant reflection which is proper to it. This is designated by the names roal black, jet black, extremely black, on account of its brilliant aspect analogous to that of sprarkling 
jewels. It will be deseribed more in detail in discussing the peculiarities of the coat.

2d. The sorrel coat consists of golden, fawn, and reddish-brown hairs, and recalls, more or less, the color of einnamon bark.

We will add to this type that which most anthors call coffece-andmilk: or crean-color, for it appears to us to be only one of the varieties.

This sorrel coat comprises:

a. The coffee-and-milk sorrel is of a tint resembling that of a mixture of eoffee and milk. Aceording to its shate it is ealled light, ordinary, and dark. When very light it is more especially called crectm-color.

b. The light or fawn sorrel has a yellowish tint which is similar to the eoat of the decr. The ordinary sorrel will sometimes assume this aspect if the horse runs at liberty for a month or six weeks.

c. The ordinary sorrel recalls the color of cinnamon, not only for the burly, but also for the mane, the tail, and the extremities.

d. The bovine or washed sorrel has a degraded fawn tint, but the mane, the tail, and the extremities are pale, rushed, or almost white.

e. The dark or dull sorrel is of a cinnamon color, bortering upon brown.

$f$. The cherry sorrel has the reddish tint of a cherry.

$g$. The chestnut sorrel is of a clear, reddish-brown, and uniform color, like that of a ripe chestnut.

$h$. The maroon sorrel has the same general tint as the preceding, but shows, here and there, darker spots, analogons to the veins of the maroon of the West Indies.

$i$. The burnt sorrel has exactly the same shade of eolor as that of roasted coffee. It is not rare to see this tint with mane and tail almost entirely white. It should then be described with white mane and tail.

Several of these varieties are aceompanied by peculiar reflections. Thus the light or fawn sorrel may be golden; the ordinary and the cherry sorrel copper-colored; the chestnut and the maroon bronzed, according to the manner in which they reflect the light.

We will add that the white markings of the head and members, as well as the leprous spots around the lips and nostrils, are extremely common in sorrel horses.

Finally, with De Curnien, ${ }^{1}$ we will say that we have olscrved several subjects of this color absolutely deprived of white hairs. 


\section{B.-Composite Coats.} distinct kinds of hair, the one yellow, red, or gray, for the body, the other always black, for the mane, tail, and extremitics.

They comprise the Isabella, the bay, and the mouse-color.

1st. The Isabella or Isabella coat is characterized by hairs of two distinct colors: those of the body are yellow or yellowish; those of the extremities, from the knee and the hock down, as well as the mane and tail, are black. This color of the horse is also called the dun.

According to its shade, it is light, ordinary, and dark.

It is common, but not invariable, to find a narrow, longitudinal black stripe (mule stripe) upon the median line of the back, the loins, and the croup of Isabella horses, as well as blackish stripes across their forearms and legs (zebra stripes); their ears are also often bordered by a band of dark hairs. Although these peeuliarities undonbtedly modify the aspect of the eoat, they do not change its nature. The essential characteristics necessary to identify this coat are the yellow hairs and black mane and tail or black extremities. When the mule stripe, the zebra stripes, or the auricular border exist, we simply mention their presenee, for these markings may at times be found upon bay, sorrel, and mouse-eolored horses.

This distinction, already accepted by several veterinary writers, has the advantage of elearly distinguishing the Isabella from the ereamcolor, whose hairs are often very analogons in color to the preceding. Hence the variety of Isabella with black mane and tail is no longer preserved as a definition; as to that which was formerly designated Isabella with white mene and tail, we could not admit it either. When the extremities are of the same color as the body, the animal should be considered as heing a cream-colored sorrel. It will be remarked that here we consider the white or washed mane and tail as a peculicurity and not as a rariety.

It wonld perhaps have been more simple, more natural, and more logieal to classify the Isabella among the bars, to some of which it often bears a striking resemblance, and to make it a bay Iselbella, in aceordance with the principle which has guided us for the cream-color in relation to the sorrel. Nevertheless, with all due respect to traditions and technical langnage, we have preferred to allow our idea to be matured by time before proposing its absolute introduction into practice. 
A humorous legend conceming the origin of the name Isabella relates that the Archduchess Isabella of Austria, daughter of Philip II. of Spain, and wife of the Governor of the Netherlands, made a vow at the time of the siege of Ostend not to change her linen before the surrender of the place. The siege having continued for three years (1601 to 1604 ), the chemise of the princess had acquired a peculiar fawn shade, to which has since been given the name Isabclla. ${ }^{1}$

2d. The bay or bay coat differs from the Isabella only in so far that the yellow hairs are replaced by red hairs. The latter are of an ill-defined tint, similar to mahoginy, ripe cherry, fractured red cinchona, ete, but varying from light to dark, from fawn yellow to maroon and brown.

The bay could not be confounded with the sorrel, first, becanse the mane, tail, and lower part of the members are black in nearly every case; sceondly, on account of its deeper color, its brighter shade, and its more brilliant reflection.

We, nevertheless, meet horses of this color in which the members, over their whole extent, are of the same color as the main shade of the coat ; upon others, only the coronets are black; finally, there are some in which black hairs exist only along the course of the tendons and upon the phalanges.

The varieties of the bay are as follows:

a. The light bay, whose red color is very light, bordering somewhat upon yellow. It often resembles the dark Isabella, and, like the latter, sometimes has the mule and zebra stripes, which lead ns, in such cases, to classify it without hesitation with the latter type, in which these peculiarities are so common.

$b$. The ordinary bay is of a distinetly red color.

c. The cherry bay, blood bay, and mahogany bay are a little darker and almost identical. The names by which they are designated suffice to point ont the differences as well as their particular shades.

d. The chestnut bay, of a uniform light brown, is similar to that of a ripened chestnut.

$e$. The maroon bay reproduces quite accurately the color of the maroon of the West Indies, with deeper and fresher shades upon the upper part of the body.

$f$. The dark bay is of a dark color bordering upon brown.

1 Bouillet, Dictionnaire d'histoire et de géographie éd. de 1860 ; Littré, Dictionmaire de la langue trançaise. 
g. The brown bay, finally, is almost black. It might even be mistaken for the rusty black, especially in winter, were it not for the reddish colorations around the nostrils, the axillæ, the elbows, the abdomen, the flanks, or the buttocks, which always distinguish the former from the latter.

Bay horses, like the sorrel, often show white markings upon the head; nevertheless, such marks are less conmon in them. The same may be said of their reflections. In the vigorous and well-groomed subjects, and in a bright light, the light colors frequently appear golden, the red copper-colored, and the brown bionzed.

3d. The mouse or mouse-colored coat is also formed by an assemblage of two distinct colors : the body is covered with hairs of an ashy gray analogous to those of the mouse; as to the members, they are black from the knee and hock down, as in the Isabella and the bay.

According to the case, the monse-eolor is light, ordinary, or derk. Sometimes the head is a little darker, and the mule stripe upon the back and the zebra stripes upon the arm and forearm are present; at other times, the members are of the same color as the body. The existenee of these peculiarities should be mentioned.

\section{C.-Mixed Coats.}

In the preceding groups, we have seen that the coat is formed by hairs of but one or two colors, but the body, in all cases, is provided with hairs of the same shade; the extremities alone have a different color. In the mixed coat, the elements are of a diverse nature and ordinarily intimately mixed; besides, this mixing takes place in the individual hairs themselves: the latter show two distinct, loealized shades, the one at their base and the other at their extremity.

For the reason that these coats, as a whole and in detail, show more or less of a combination of the eharacters of the other groups, we have named them mixed.

Only one variety of this coat has been, until the present time, recognized upon the horse: the fox-color; but there are others in certain domestie or wild animals, such ats the collie dog, the at, the badger, the wolf, the roe, the deer, the hare, the rabbit, ete. Each of them has some part of the integument, notably the superior face of the borly, covered by hairs of two or three colors, associated in very different manners and eombinel in very variable proportions. To deseribe them would be outside the seope of this book. 
The fox-color, or fox-colored coat, called in French louret, resembles, as it: English name indieates, the color of the fox ; formerly, it was ralled color of the deer, for similar reasons.

Vallon, whose observations we have carefully analyzed, has, in our opinion, given the most aceurate definition of this coat. "The foxcolor (louret)" says he, "is formed of two shades, the black and the vellow, sometimes separated upon different hairs, but most often united upon the same hair, whose base is yellow and the extremity black." We will add that the mane and tail are ordinarily dark like those of the burnt sorrel; it is the sane with the extremities; in such eases the latter peenliarity should always be mentioned.

Aceording to the predominance of the one or the other of these colors this coat presents the following varicties:

It is called light, when the rellow, more or less vasherl, predominates; ordinary, when the yellow and black are distributed almost in equal proportions; dark, finally, when the black is in excess over the yellow, itself quite intense. Horses of this color are rare. It is to be remarked that after moulting they become lighter, approaching the Isabella, the eream-color, and are at times almost white. Onr colleague, M. Saint-Yves Ménard, has shown us one of them, belonging to the Japanese variety of horses, which could scarcely be recognized after having been elipped, becanse the base of the hairs was almost white.

The nsual reflections of this color are the golden and the bronze.

\section{§. Deriven Coats.}

We have defined these coats: those which appear after birth and result from the introduction of white hairs into a primitive coat.

They are fonr in number: the gray, the white, the flea-bitten, and the rocen.

1st. The gray is, in our estimation, much less easily distinguished than is generally supposed. Classically, it is regarded as a mixture of white and black hairs. Praetically, this is far from being the rase. All that is needed in order to convince one's self that this definition is insufficient is to select at hap-hazard ten gray horses. The dark hairs, first of all, are not alurey. black; far from it. The latter are often replaced by brown, maroon, chestnut, bay, sorrel, and, more rarely, yellow hairs. As to the white hairs, they are at times only the yellow 
very thoroughly washed. This is why the grays are so difficult to specify. If they are, in fiut, only a mixture of black and white, whence, then, come the bluish, the purplish, the reddish, or the yellowish shades which are found in the slate-colored, the wine-colored, the reddish, the roan, the Isabella, the dirty, and the flea-bitten gray: To reply that these shades are not so many varieties, but only peconliarities, does not solve the diffieulty, for a peculiarity is a detail which changes the aspect of one region alone; it is not disseminated everywhere, and for the same reason does not modify the general color of the coat.

It appears to us more logieal and exact to say that the gray is sonetimes a mixture of black and white, sometimes of white hairs and those of a darker color, the latter consisting of the lighter colors, such as the bay, the sorrel, or the Isabella. The extremities, the mane, and the tail are always of the same nature as the coat of the body.

Brivet was quite conseions of the want of conformity of the varieties contained in the classical definition of this coat when he wrote, "The gray coat is excessively varied in its degrees; it is a sort of chaos, so many different shades of hairs are there; it is composed of all varieties: we mean to say that it borrows a little from all the colors." 1

To recapitulate, two constant elements intimately mixed espercially characterize the gray : white hairs and hairs of a derk color. It will be remarked that we intentionally use the word atak in order to indicate that this shade may valy from the true black to the brown.

To these elements are often added others, such as the bay, the sorrel, and the Isabella, which variegate the coat, but without taking away the characteristics and the aspeet which are proper to it.

From the preceding statements, the gray coat is therefore the black, the bay, the Isabella, or the sorrel, mixed with the white to a clegree more or less marked aroording to the case. This, consequently, justifies the place which we have given it among the dericed coats.

In relation to its degree-that is to say, its darkness and brilliancy-we will recognize the following principal varieties:

«. The very light gray, which greatly resembles the whitc, and shows very few black or dark hairs.

$b$. The light gray, not so white as the preceding and with more black or dark hairs. 
c. The ordinary gray, which presents an almost equal mixture of white and dark or black hairs.

๙. The dark gray, characterized by the predominance of dark or black hairs.

Relative to its particular tint or color, the gray is also called:

$e$. Iron gray, when it has the bluish shade of a piece of iron recently broken. This horse is vulgarly called blue or grayish-blue.

f. Slate-colored gray, when it resembles the dull blue of slate. It is a shade darker than the preceding, and varies from light to dark, according to circumstances.

g. Clayey gray, when it has a very light yellowish tint. It much resembles the clayey white.

h. Isabella gray, when it is constituted by a mixture of white, yellow, and dark hairs. Aceording to the intensity of the yellow and the relative abundance of the dark and the black, it beeomes light or dark; but its general tint always recalls that of the Isabella.

$i$. Roan gray when it is constituted by an intimate mixture of white, dark, red, or reddish hairs, the latter ordinarily less abundant. It may be light or dark. When the red or reddish hairs predominate over the others, and particularly over the dark, it acquires a more marked red tint; it is then called wine gray.

$k$. Gray, called " thrush gray," when it has the aspect of a light roan gray, upon which are disseminated small patches of whitish or yellowish hair's (Brivet).

l. Flea-bitten gray, when it is constituted by a dark roan gray intermixed with small patches of whitish hairs (Brivet).

The last two varieties are very rare.

Gray horses have darker extremities, and become more and more light as they advance in age. They even change from year to year, which necessitates a frequent modification in their description. Finally, they are subject to numerons and special peculiarities, which we will study farther on.

2d. The white or white coat, being a color so universally recognized, needs no definition.

This coat exists, with very rare exceptions, only at a more or less advanced period of life. Hence we will consider it, essentially, as being derived from the gray, or again as a primitive color, such as the black, the sorrel, the Isabella, or the bay, in which the primary black, blond, yellow, or red hairs have almost totally disappeared. But in examining such horses, we find, in most instances, some of these 
colored hairs upon the body, the mane, and the tail, or upon the extremities. The knowledge of this fact has led certain author's to say that white horses do not exist. Lecoq ${ }^{1}$ has condemned this opinion as being too absolute. The determination of the coat is not arrived at with one eye alone. The whole, and not the detail, rules the diagnosis. The varieties of the color are as follows:

a. The dull, milk, or pigeon white is withont reflection, opaque, of a milky aspect, and resembles somewlat that of a white pigeon.

$b$. The porcelain white has the tint of porcelain china, in consequence of the black coloration of the skin which is visible under the hairs.

c. The dirty white is of a slightly yellowish tint. It is derived sometimes from coffee-and-milk, aream-colored, or even from very light washed hairs. More frequently it results from uncleanliness.

d. The rosy white presents in some places more or less large rosy spots, which are due to the absence of the cutaneous pigment and to the thinness of the hairs, learing the discolored parts of the skin visible.

The reflection of the white is the silcer, in the same manner as the coal or jet is that of the black.

3d. The flea-bitten coat is formed upon the body by red and white hairs mixed, while the mane, tail, and extremities are of the same color as the coat proper, and often lighter.

It will be seen from this that the flea-bitten is nothing more than the sorrel more or less freely intermingled with the white.

It is differentiated from the gray with a rosy or reddish shade in that it never presents very dark hairs, - that is to say, black, blackish, or brown ; but as it becomes more and more white with age, it will eventually terminate in a clear wine gray.

Acerding to the abundance and intensity of the red, this coat is designated light, ordinary, or dark.

When the mixing of the two kinds of hairs is not miform, it receives particular designations.

Thus the flea-bitten is called all-flower, when the white hairs are collected in small patches and disseminated over the gromndwork of the coat.

It is called perch-blossom, when composed of patehes of red or rosy hairs which are strewn over the lighter groundwork of the coat. 
4 th. The roan or roan coat is composed of three kinds of hairs: red, white, and black. The red and white hairs are mixed npon the body, the black form the mane, the tail, and are also found on the extremities.

This eoat is therefore only a bay, modified more or less by the admixture of white.

Accorling to the relative abundance and intensity of the red, this coat is called-

Light, when the white predominates.

Ordinary, when the red and white exist in almost equal abundance.

Wine, blood, or strawberry, when the red predominates.

Dark, finally, when the brownish red predominates.

In roan horses the members are not always black. In this respect the same remarks are true as in the case of bay horses.

With old age these horses become more white, and are then only roan grays.

\section{§3. Conjugate Conts.}

We designate by this name the coats which are characterized by the presence, upon the same animal, of two primitive or distinct derived coats, and, more rarely, of two varieties of the same coat.

Until the present time only two types have been described.

1st. The piebald or pied coat is nothing more than a union, and not an intermixture, of the white coat with one or other of those which we have deseribed. As a result the animal presents a singular appearance: he is covered with large white patches, irregular, unequal in extent, and variously situated, which are associated and conjugate, so to speak, but do not blend with the colored areas, giving him a fantastic appearance.

In the strict sense of the word, the true piebald should consist only of the white and the black, like the plumage of the bird from which it borrows its name. Nevertheless, custom has decreed that the black color may be replaced by any one of the others. Hence to designate the couts of this type we employ a compound expression, in which the word pied always refers to the white, while the other term indicates the color with which the latter is associated.

Examples : pied black, pied bay, pied roan, pied sorrel, ete.

Besides, in order to make the description more exact, it is preferable to arrange the two terms of this expression in such a mamer as to prefix the name of the color which eovers the largest area of surface. 
Thus we eall it bay pied, gray pied, roan pied, ete., when the bay, the gray, or the roan covers a larger area than the white; and pied bay, pied graly, pied roun in the contrary disposition.

Finally, in order to be more precise, even the variety of the white or colored eoat ean be mentioner, as may be seen in the following examples: rusty black pied, daik for-color pied, flect-bitten rosy pied, burnt sor'el porcelain pied, ete. Ordinarily, however, the varieties of the white color are not mentioned.

When the four extremities of a piebald horse are white, they are designated as having stockings, or as being uhite-footed.

When the mane, tail, and extremities of the pied bay, pied Isabella, and pied roan are white instead of black, one may be easily deceived, and confound these coats with the pied sorrel, cream-color, and fleabitten. In such a case, there remain no other points to guide us excepting the shade of the hairs; but there are found at times in the forelock, the mane, the tail, or upon the extremities some dark, black, or eolored hairs, which enable us to avoid this error. However this may be, if the exact determination of the colored hairs be impossible, it is well to indicate, for want of a more accurate expression, that the subject has a white mane, tail, and extremities.

The rarieties of the picbald are as numerous as there are types of coats, exeepting the white. We will consequently recognize-

The pied black, the pied cream-color, the pied bay, the pied mouse, the pied fox-color, the pied gray, the pied flea-bitten, and the pied roan.

2d. The conjugate gray and Isabella is an extremely rare coat, of which one of us ${ }^{1}$ has observed but two examples. We have aldded to it the epithet conjugate, to distinguish it from the ordinary Isabella gray (which is mixed), and to fully establish its relation and its analogy with the piebalds.

In the case under consideration there existed, upon the body of the horke, two distinct conts: one was the gray, and the other the Isabella.

We are not aware that instances of this kind, identical and analogons, have been observed previously. In any case they might he very logically classified along with the latter and be lesignated according to the same principle.

We will also mention here another observation which we had the opportunity to make during the month of July, 1883 , and which we brought under the notice of our pupils, as well as of $\mathrm{H}$. Bouley and some others of our colleagues.

It concerned a mare in the army, used for the saddle, whose coat was rherry bay, and presented large, irregular patches of dark meroon bay. The latter were almost blended upon the left side of the body and members; upon the right side, disseminated and well delinented.

The officer who described this animal had entered her as a cherry bay 
aud maroon bay, "en forme de pie." As a matter of fact, these two varieties of the bay were as well marked and distinct as the two coats of the piebald. If we had to give the description at present, we would saly. "Cout conjugate cherry bay and muroon bry color," ete. This qualification would recall at the same time the disposition of the two sorts of bairs, as well as the affinities of this singular coat with those of which we have just spoken.

De Curnieu' classifies in a special 'ategory the coats which, upon a base of white or trout-color, present nuequal spots of an almost round form and disseminated over nearly the entire surface of the body. These spots, ordinarily dark or red, are more especially found upon white, gray, bay, and sorrel coats. When they are localized in one region they simply constitute a peculiarity, but when they are genenalized they altogether change the color and aspect of the coat, and render it more or less fantastic.

Horses of this color are vulgarly called spotted or marbled horses. According to De Curnieu, these animals are most frequently found in Denmark, Hanover, and along the borders of the Damube. Formerly they were very much sought after and sold at high prices. To-day they are scarcely used except in the circus ring or for advertising wagons.

SYNOPTICAL TABLE OF THE COATS.

\begin{tabular}{|c|c|c|c|}
\hline \multicolumn{4}{|c|}{$\begin{array}{l}\text { PRIMITIVE COATS. } \\
\text { (Already formed a short time after birtl..) }\end{array}$} \\
\hline CATEgORIES. & $\begin{array}{c}\text { Color OF THE } \\
\text { HAIRS. }\end{array}$ & $\begin{array}{l}\text { Primitive } \\
\text { TyPes. }\end{array}$ & CORRESPONDING VARIETIES, \\
\hline $\begin{array}{l}\text { A. } \\
\text { Simple coats. } \\
\text { Hairs of a single color. }\end{array}$ & $\begin{array}{l}\text { Black. } \\
\text { Red or red- } \\
\text { dish. }\end{array}$ & $\begin{array}{l}\text { Black. } \\
\text { Sorrel. }\end{array}$ & $\begin{array}{l}\text { Ordinary, rusty. } \\
\text { Cream-color, light, ordi- } \\
\text { nary, washed, dark, cherry, } \\
\text { ehestmut, maroon, burnt. }\end{array}$ \\
\hline $\begin{array}{l}\text { B. } \\
\text { Composite coats. } \\
\text { Hairs of two varieties: } \\
\text { some black, for the mane, } \\
\text { the tail, and the ex- } \\
\text { tremities; other' yellow, } \\
\text { red, or gray, for the } \\
\text { body. }\end{array}$ & $\begin{array}{l}\text { Yellow. } \\
\text { Red or red- } \\
\text { dish. } \\
\text { Gray. }\end{array}$ & $\begin{array}{l}\text { Isabella. } \\
\text { Bay. } \\
\text { Mouse. }\end{array}$ & $\begin{array}{l}\text { Light, ordinary, dark. } \\
\text { Light, ordinciny, cherry, } \\
\text { blood, mahogany, ehestmut, } \\
\text { maroon, dark, brown. } \\
\text { Light, ordinamy, dark. }\end{array}$ \\
\hline $\begin{array}{l}\text { C. } \\
\text { Mixed coats. } \\
\text { Several colors upon the } \\
\text { same hair. }\end{array}$ & $\begin{array}{l}\text { Yellow at } \\
\text { the base, } \\
\text { black at } \\
\text { the point. }\end{array}$ & $\begin{array}{l}\text { Louvet. } \\
\text { (Fox-color.) }\end{array}$ & Light, ordinary, dark. \\
\hline
\end{tabular}


SYNOPTICAL TABLE OF THE COATS-Continued.

\section{DERIVED COATS.}

(Appearing at a remote period of life, and due to the introduction of white into the primitive coit.)

\begin{tabular}{|c|c|c|c|}
\hline PRLMITIVE CoATS-Elements. & $\begin{array}{l}\text { COLOR OF THE } \\
\text { HAIRS ASRO- } \\
\text { CIATEI, WITH } \\
\text { THE WHTTE. }\end{array}$ & $\begin{array}{l}\text { DERIVED } \\
\text { TYPES. }\end{array}$ & CORRESPONDING VARIETIES. \\
\hline $\begin{array}{l}\text { Bluck, sorrel, bay, Isa- } \\
\text { bella. }\end{array}$ & $\begin{array}{l}\text { Black, } \\
\text { brown, } \\
\text { blood-red, } \\
\text { red, or yel- } \\
\text { low. }\end{array}$ & Gray. & $\begin{array}{l}\text { Very light, light, ordinary, } \\
\text { dark, iron, slaty, elayey, } \\
\text { Isubclla, roan, wine, tour- } \\
\text { dille (dirty), fleu-bitten. }\end{array}$ \\
\hline $\begin{array}{l}\text { Those which form the } \\
\text { gray. }\end{array}$ & White. & White. & Dull, poreelain, clayey, rosy. \\
\hline Sorrel. & Reddish. & Flea-bitten. & $\begin{array}{l}\text { Light, ordinary, dark, all- } \\
\text { flower, peach-blussom. }\end{array}$ \\
\hline Bay. & Red. & Roan. & Light, ordinary, wine, dark. \\
\hline
\end{tabular}

\section{CONJUGATE COATS.}

(Union of two primitive or distinct clerived coats, and, more rarely, of two varieties of the same coat.

\begin{tabular}{|c|c|c|}
\hline $\begin{array}{c}\text { COATS OR VARIETIES-ELE- } \\
\text { MENTS. }\end{array}$ & $\begin{array}{c}\text { CORRESPOXDING CONJUGATE } \\
\text { TYPES. }\end{array}$ & CORRESPONDING VARIETIES. \\
\hline $\begin{array}{l}\text { The white coat and one } \\
\text { other. }\end{array}$ & Pied. & $\begin{array}{l}\text { Black, sorrel. Isabella, bay, } \\
\text { mouse, fox-color, gray, flea- } \\
\text { bitten, roam. }\end{array}$ \\
\hline $\begin{array}{l}\text { The gray coat and the } \\
\text { Isabella coat. }\end{array}$ & $\begin{array}{l}\text { Conjugate gray and Isa- } \\
\text { bella. }\end{array}$ & \\
\hline $\begin{array}{l}\text { Yarieties: cherry bay and } \\
\text { maroon bay. }\end{array}$ & $\begin{array}{l}\text { Conjugate cherry bay and } \\
\text { maroon bay. }\end{array}$ & \\
\hline
\end{tabular}

\section{Peculiarities of the Coats.}

Aside from the kind of eoat and its variety, it is necessary to indicate, in a ecrtificate of description, certain details or marked peculiarities, which are due to brilliant reflections, to the presence of hairs different from the other's, either in color or in direetion, or, finally, to a discoloration of the skin as well as of the hairs themselves. These 
diverse markings, very varial,le in their situation, their form, their extent, and their nature, have received the general name peculiarities of the enat or the markings. They are of great importance for distinguishing subjects often identical as regards the color of the hairs and their special tint or shade.

We will divide them into fonr principal groups:

1st. General peculiarities, found indiseriminately npon the different parts of the animal.

2d. Peculiurities special to the head.

3d. Peculiurities special to the body.

4th. Peculiarities special to the members.

As to the peculiarities independent of the coat, we will make mention of them is propos of the certificate of description.

\section{A.-General Peculiarities.}

These markings, without any fixed location, are arranged under the following seven principal headings, according to their manner of formation :

1st, the brilliant reflections; $2 \mathrm{~d}$, the shade of the hairs; $3 \mathrm{~d}$, the white hairs ; th, the black hairs ; 5th, the red hairs ; 6 th, the different directions of the hairs; 7 th, finally, the diseolorations of the skin and of the hairs.

\section{Brilliant Reflections.}

They comprise the jet black, the silver, the golden, the copper, the bronze, and the uruy (moiré).

Jet Black.-This is the reflection proper to the black. It is identical with that of jet jewelry.

Silver.-By this term is designated the reflection of the white, the very light gray, and the very pale cream-color.

Examples: silvery porcelnin white; silvery light gray; silvery creamcolor.

Golden.-This term is applied to the sorrels, the bays, the Isabellas, and the cream-colors, whose shade is yellowish with a reflection recalling that of metallie gold.

Examples: golden fancn-colored sorrel; golden light bay; golden ordinary Isubella; golden dark cream-color.

Copper.-This reflection resembles the preceding, but is brighter and of a reddish tint, like that of copper utensils. It is found on the sorrel and the bay.

Examples: copper cherry bay; copper mahogany bay. 
Bronze.-The bronze is more brown than the copper. It is seen more especially upon the burnt sored, the maroon bay, the dark bay, the daik Isabella, and the louvet.

Wavy.-This is a bright, changeable lustre, of an undulating aspect, which the preceding reflections acquire upon different parts of the body, when the hairs, instead of being smooth, present in places slight undulations, giving to the coat the appearance of wavy cloth or galranized tin plate.

Examples: silvery white, wary upon the sides of the neck; jet black, wary upon the croup and flenkis; dark sorrel, bronzed and wary upon the thighs and forearms; copper chestnut bay, wary upon the cheelis and thighs; golden Isabella, way upon the ribs and shoulders, etc.

\section{Shaded Hairs.}

The peculiarities due to shuded hairs comprise, upon the base of the coat, round spots, sometimes lighter, sometimes darker, resulting from a more or less intense tint of the general color.

It inchudes the peculiarity which is ordinarily called dapple.

A dapple coat is one which presents spots of the form and diameter of a fire-franc piece, lighter or darker than the base of the coat, but of the same greneral color. They are observed upon bay, sorrel, Isabella, mouse- and fox-colored horses.

It is well to mention their presence, their abundance, and their seat.

When they exist on the coat of gray horses, French anthors designate this peculiarity by the term pommelé.

When they are generalized, the coat is simply ealled dappled, without any other mention.

Examples: dark Isabella, slightly dappled; burnt sorrel, greatly alappled upon the rioup and thighs; mahogany bay, dappled upon the cheeks, meck, and sides; ordinury gray, greatly dappled upon the baek and loins; dark dapple gray.

\section{White Hairs.}

The peculiarities due to the absence or variable abundance of white hairs upon different parts of the body are whole-or solid-colored, mbican, snow-flake, flect-bitten, growing gray, and bordered. We will add to these the aeridental white markings.

Solid Color. - We all by the terms zain or solid-colored the bay, black, sorrel, dark Isabella, and monse-colored horse, whose coat has no white hairs.

Example: solid jet black. 
Rubican.-This expression is applied to horses of a bay, black, sorrel, mouse, Isabella, and dark fox-color, which present, disseminated here and there in variable quantity, isolated white hairs, but never sufficiently numerous to change the nature of the groundwork of the eoat.

It is important to mention their abundance and their seat.

Examples: rubican chestnut sorrel; ordinary black, very rubican; cherry bay, slightly rubican upon the checks, neck, and sides; dark Isabella, very rubican upon the head and fanks.

Snow-flaky (Neigé)._-The suow-flakes, or neigeures, are small white spots strewn over a dark or colored coat, ordinarily the black, the sorrel, and the bay, and resembling snow-flakes which have fallen upon the body of the animal.

The terms light or heavy are used to designate these spots, aceording to the area of the base of the coat which is visible between them. ${ }^{1}$ We have in one case seen a large number upon a sorrel horse which had been previously affeeted with herpes tonsurans.

The neigeveres, instead of being isolated, are at times confluent; in such cases they form patehes or spots, which we propose to name snowballs or snow-spots.

Examples : jet black, slightly snow-flaky upon the croup; brown bay, very snow-flaky upon the back and loins ; cherry sorrel, with light snowflakes upon the shoulders and sides; maroon bay, with large snouballs upon the loins and flanks.

Flea-bitten.-This is found upon the sorrel and the bay, whose red parts are invaded by white hairs, which are mixed with the red in such a manner as to eonstitute flea-bitten areas upon the body or the head.

Examples: cherry bay, flea-bitten upon the left cheek; chestnut sorrel, flea-bitten at the tail firom birth.

Grisonné, or Grayish.- These terms are often employed șrnonymonsly with the preceding, althongh in reality they have an entirely different signification. They indicate, in fact, the presence of white hairs mixed at one point or another with the black coat or the black parts of the body, such as the extremities, the mane, and the tail of the bay, the Isabella, and the monse-color.

The grayish and the flea-bitten differ from the rubiean, in that the white hairs which form these markings are sufficiently numerons to change, loeally, the nature of the base of the coat.

1 We need only mention the ligh snow-flake; the heary is the snow-flake properly so callect. 
Examples: black, grayish upon the temples; brown bay, grayish upon the right haunch; light Isabella, grayish upon the anterior face of the left canon.

Bordered.-This word is applied to a mixture of white and colored hairs disposed in the form of a border aronnd any white margin whatever, but always well outlined.

Examples: bordered blaze, bordered stocking, bordered leprous spot, ete.

Accidental White Markings.-We designate by this term the white markings which are the consequence of wounds produced by the harness, the hobbles, falling upon the knees, injuries, ete. Their number, their extent, and their location should be indicated in a certificate of description or of soundness.

Examples: dapple light bay, aceidental white marking on the withers and on the point of the right hock; rusty black, two small arcirdental white markis upon the face and a larger one at the base of the tail.

\section{Black Hairs.}

The peenliarities formed by the black hairs are called speckled, trout-spotted, ermined, leopard-spotted, spurious brand-iron mark, wharbonné, louveté.

Speckled.-This condition, designated by French authors mou cheté, is caused by small black spots, similar to those prodneed by flies thickly seattered over the surface of the body. These spots are common upon horses of a white or gray coat.

Examples: dull uhite, much speckled; light gray, slightly speckled upon the croup; iron grouy, speckled.

When the dark-colored spots are not entirely composed of black hairs, but contain some that are brown, maroon, or red, the coat is said to be moucheté-truité.

Same examples as the preecling.

Ermined.-The ermine spots (herminures) are black markings larger and more elongated than the preceding two. They always imply a white or very light gray base, and are arranged so as to simulate the spots on the fur of the crmine.

Examples: burnt soriel, blaze on herol, neck ermined; muhogany bray, with large snou-flake spots, ermined upon the left wide of the (roul).

Leopard-spotted.-The leopard spots (tignures) are black or very dark patehes whose disposition recalls that which is observed upon 
the panther and the leopard. They are generally spread over the whole extent of the coat, while the preceding are usmally smaller and lowalized upon an isolated white mark, sneh as a snow-flake pateh, a blaze, a white face, white foot, or again, upon the white areas of the piebald coat.

Example: pied chestnut bay, leopard-spotterl upon the loins and right flank:

Be this as it may, when the herminures are very abundant, they no longer preserve the character of a peculiarity; the aspect of the coat is then so modified that the latter is elassified among those which, with De Curnien, we have designated muder the names spotted, leopard, or mabled coats.

The herminure is always a black marking upon a white base; the tigrure, or tiger-marking, is of the same character, but always larger, more round, and may be indiseriminately located upon a white or a colored base.

When these markings are formed by colored hairs, such as the bay, the sorrel, the Isabella, or the monse, upon a white or very light gray base, the coat is called marbled. Nowadays the marbled and the leopardspotted coats are considered identical.

Spurious Brand-iron Mark. - This is an irregular elongated black marking, appearing as if made by a stroke of the branding-iron or fire-poker upon a gray, sorrel, bay, Isabella, monse, roan, or fleabitten coat.

Examples : iron gray, spurious brand-iron mark upon the left cheek; dark bay, spurious brand-iron mark upon the croup.

There is still another black marking, the charbonnure, which is wider and more elearly outlined than the preceding. Otherwise, most authors consider these two as identical.

Louveture.-We propose to designate under the name louveture mixed, blackish spots, poorly ontlined and of variable extent and configruration, proper to the light or fawn varieties of the Isabella, the bay, and the sorrel. They are formed by black hairs mixed with the red or yellow of the coat, giving to the latter, in these places, an appearance resembling that of the wolf. It looks as if soot latd been sprinkled over the regions which present this peenliarity. We have seen it upon the head, the sides of the neck, the shoulders, the back, the ribs, the thighs, the stifles, the elbows, the arms, the forearms, the legs, ete.

Examples: louveture Isabella; light bay, louveture in front of and behind the shoulders; fawn sorrel, deep louvetwre on the cheeks, neck, elbows, and forearms. 


\section{Red Hairs.}

We will mention in this group trout-spotted, truité-moucheté, marbled, wine-colored, and rusty.

Truité, or Trout-spotted.-The truitures, so named on account of their resemblance to the spots which are found on the trout, are small red or reddish patches, formed of bay and sorrel hairs upon a base of white or gray. They differ from those of the ordinary speckled surface only by their color.

Examples: silver white, slightly trout-spotted; light gray, very much trout-spotted upon the head, the sides, and the eroup.

Truité-moucheté.-This is only the trout-spotted peculiarity in which a certain number of truitures, or spots, are composed of hairs of a reddish-brown or almost black color, which causes them to resemble the monchetures, or fly-marks.

Same examples.

Marbled.-From the above it will be seen that we have called marble spots those analogous with the leopard spots, excepting that they are composed of colored hairs (bay, sorrel, Isabella, or mouse) upon a white or light-gray base.

Examples: dirty gray, marbled upon the croup; light silver gray, marbled upon the loins; pied rusty black, marbled upon the left shoulder and the right side of the neck.

Wine-colored.-The wine-color is characterized by the presence of red hairs mixed with those of a gray or white eoat, upon any part of the body. Upon the white, the wine-colored points form spots ordinarily well circumscribed, well defined, and more or less extensive; upon the gray, these points are less clearly outlined, their color not contrasting so well with the gray. When the wine-tint is generalized over the body the borse is designated wine gray.

Examples : very light gray, with large wine-colored spot over the back, sides, and abdomen; ordinary gray, wine-colored over the thighs.

Rusty.-We thus designate the bright-red or yellowish-red coloration which the hairs of eertain regions take, such as around the eyes, the alie of the nose, the axilla, the breast, the elbows, the stifles, and the flanks, in bay and sorrel horses of a dark tint.

Examples: maroon bay, rusty around the nostrils and eyes; burnt sorrel, rusty at the elbow's and stifles.

\section{Hairs of Different Directions.}

The hairs of a certain region do not always have the same direction; at times there are some which take a direction inverse to the 
others, which canses, on their neeting with the former, a turning back or a more or less circular direction, to which has been given the names épi, courlick, and tuft.

Tufts, or cowlicks, may be distinguished as concentric and cecentric, or, again, as concerging and direrging, according as the hairs composing them curl up and converge towards a centre, or, on the contrary, radliate and diverge from a centre.

Some are constant and, consequently, exist upon all horses; these are met with on the middle of the forehead, on the breast, the axilla, and the superior and inferior parts of the flank; it is useless to mention their presence.

The other's exist only on some animals, and constitute peculiarities which are orlinarily specified in a complete certificate of description as to their form, their extent, and their seat. We will eite as examples the épi which exists upon the lateral faces of the neck (Roman surorl), that which is found along its inferior border, that which is between the two ears, those of the checks, of the withers, of the sternal region, the internal face of the thigh, the point of the buttock, etc.

One of our collaborators, M. Ledoyen, ${ }^{1}$ has endeavored to give the physiological reason of the constant tufts.

According to him, they are designed to collect the perspiration upon special parts of the body in such a manner as to form drops, which then fall directly to the ground instead of accumulating in certain places exposed to friction, and where the skin soon becomes irritated and inflamed. We can only eite this interpretation, for any proof, experimental or otherwise, inclines us rather to admit the theory, not to deny it.

In France, and indeed thronghout Europe, no importance is attached to the presence or absence of cowlicks, but it is quite different with the people of the Orient, who attribute to them great influence, aa being so many good or bad omens. It would be childish to dwell longer on this point. For more details we refer the reader to the book of General Daumas, ${ }^{2}$ or to that which has been published by one of our collaborators, Minot, of Lisy-sur-Oureq. ${ }^{3}$

Curliness or Frizzles. - We will classify with the tufts a peenliarity as to the nature of which our colleague, M. Blane, the Paris reterinarian, has had the kindness to direct our attention. It is found

I Ledoyen, Démonstration de la valeur des épis et des eauses de cette valeur ehez les herbivores, in IIémoires de la Société vétérinaire du Calvados et de la Manehe, 1851-1852. p. 193.

2 (rénéral Daumas, Les chevaux du Saluara et les mceurs du désert. 13. 143, Paris, 1 s.j8.

${ }^{3}$ Minot, Appréciation du cheval et des qualités intriusèques de eet animal pour le travail et la reproduction, p. 232, Paris, 1853. 
in certain horses whose hairs have the curly aspect of astracen. The Hackney Cab Company has had several such horses in their service. 'They were of Danish origin. zled.

This peculiarity an be indicated by the expression eurly or friz-

Example: with chestmut sorrel hair, frizzled.

\section{Discoloration of the Hairs or of the Skin.}

The hairs and the integument itself are in certain cases the seat of discolorations which it is important to note. They include the urashed hairs and the leprous spots.

Washed Hairs.- This expression signifies a general or partial discoloration of the coat, as if the hairs had been subjected to the artion of water in order to make its primitive color disappear.

Examples : dappled burnt sorrel, washed at the elbons and the stifles; brown bay, washed at the axilla, the flank, and the buttocks; light sorrel, washed.

Leprous Spots (Ladre).-These terms, used to deseribe the integumentary lesions in lepers, are applied, in the exterior, to the parts of the integument which are destitute of their normal coloration in consequence of the absence of the cutaneous pigment in these places. The skin in these locations is of a pale or rosy color, which greatly contrasts with the surrounding black surface. Irregular spots, ordinarily denuded, thus result, which can be eompared to the surfice, at times rariously colored, of the leprous skin.

The discolorations are most often met around and in the interior of the natural openings (mouth, nostrils, eves, sheath, anus, vulva), or upon the testicles, the mamme, the internal face of the thighs, the perineum, and the trunk of the tail; at times they are disseminated over the body in the different regions, and then the presence of the hairs renders them less visible. It is interesting to knew that they are eapable of increasing both in extent and in number, as well as of disappearing, although the causes of these singular phenomena cannot be explained.

Leprous spots are named-

Mixed, when the skin, which is their seat, is still provided with hairs.

Bordered, when, hairless in its centre, it is prolonged meler the peripheral hairs and forms with them a sert of border around the given spot.

Marbled, when it presents here and there black spots or very dark points, at the level of which the skin is not discolored. 
Absence of Hairs.-All horses are not born with the same quantity of hairs; in certain foals their diminution may even amount to a complete absence, called alopecia. These circumstances are extremely rare, and science mentions but a very small number of them. I. Geoffroy-Saint-Hilaire only mentions this anomaly ; ${ }^{1}$ De Curnien reports several examples, ${ }^{2}$ and one of $u$ s has also had a case of this kind, in 1832, in a menagerie.

\section{B.-Peculiarities of the Head.}

The peculiarities proper to the head are the following: white mark of the head, fort-nosed, moustaches, Moor-headed, Moor-faced, wall-eye, and forn-eye.

White Mark of the Head.-We term by this expression the whole of the white coloration located upon the forehead or npon the face. It should be examined in relation to its extent, its form, its situation, its direction, its composition, and its termination. Let us review the expressions which characterize its diverse conditions:

1st. When the mark is located upon the forehead we say :

a. Relative to its extent:

Some hairs on the head, when the horse has here very few white hairs.

Scattered, if it presents a large number.

Medium, when there exists a spot of ordinary dimensions.

Prolonged, in cascs where the mark is prolonged upon the face.

Interrupted, when it is intersected by a place deprived of white hairs.

Large, in cases where the mark is extensive.

$b$. Relative to its form, it is also designated-

Irregular, when the white has no recognized form.

Blaze, if the mark is round.

Star, when it presents prolongations analogous to the rays of a star.

List, whenever it is elongated towards the nostrils.

Crescent, when it simulates the are of a circle. We then indicate whether the concavity or opening of this crescent is in relation to the right, the left, abore or belor.

Flame, when it has the form of the flame of a candle. Heart, if it has the form of the heart on a playing-card.

1 I. Genffroy-Saint-Hilaire, Histoire générale et particulière des anomalies de l'organisation, t. i. p. 702 , Paris, 1832 .

2 De Curnieu, loc, cit., 1 re partie, p. 196. 
Bifurcated, when it presents two prolongations separating at an aeute angle.

Pointed, when it terminates in a point abore, belou, to the right, or to the left.

c. Relative to its situation :

High, when it is situated high up on the forehead.

Low, in the opposite case.

To the left, when it approaches the left eyelid.

To the right, when it is nearer to the right.

d. Relative to its direction:

Oblique, if it is elongated obliquely.

Transverse, if it extends transversely.

e. Relative to its composition, this mark is said to be-

Mixed, when the base of the coat appears to be mixed with the white hairs which eompose it.

Bordered, when it is eircumseribed by a mixed border.

Trout-spotted, when it is interspersed by red points.

Speckled, when it is mixed with black points.

Ermined, in cases where it is provided with larger black points.

2d. When the mark is located upon the face it is a list, and is designated :

a. In relation to its width:

Small list, when it is narrow.

List, if it has a mean width.

Wide list, when it occupies the whole width of the middle part of the face.

Semi-white-faced, when it also extends upon one of the lateral surfaces.

White-faced, when it extends upon the two lateral surfaces of the fare.

$b$. In relation to its length, the list is-

Complete, if it extends the whole length of the face.

Incomplete, when it is not prolonged, bolow, to the extremity of the nose, or when it does not extend, above, to the forehcad. It should then be mentioned on which side it is incomplete.

Interrupted, if it is intersected by hairs of the same color as the base of the enat.

When it is prolonged to the upper or the lower lip, involving them wholly or in part, it deserves particular mention.

c. In relation to its termination, the list is- 
Pointed, when it converges towards the extremity of the nasal spine by forming a point analogous to the latter.

Dentated, when it terminates by indentations or tecth.

Terminated in leprous spots, when it is mixed inferiorly with some leprous spots.

d. In relation to its direction, it is-

Deviated to the right, when it passes upon the right lateral surfice.

Deviated to the left, in the contrary case.

c. Finally, in relation to its composition, it may be-

Mixed, bordered, trout-spotted, spotted, and ermined, identical with the white mark on the forehead.

Fox-nosed. - We designate by this expression the rusty coloration,--that is to say, the red or yellow hairs which horses of a dark color (brown bays, burnt sorrels) have upon the alae of the nostrils and around the lijs.

Moustaches.-The moustaches are tnfts of long hairs, white or colored, which the superior lip presents on each side. This peeuliarity is rarely (though incorrectly) noted.

Moor-headed.-The horse is Moor-headed, cap de Maure, when the head is black or much darker than the rest of the body, as is seen in the iron gray, the mouse, the roan, the Isabellat, and the fox-color.

Moor-faced.-The animal is Moor-faced when the inferior part of the head or the face is of a black or very dark color.

Wall-eye.-The eye whose iris is of an ashy or bluish color, instead of being brown, is ealled wall-cye ; the horse is also said to be silver-eyed. This discoloration often exists in a single eye as well as in both ; more rarely it is seen only in a portion of one or other of these organs. It is said that horses which are thus marked have less clear vision in darkness (Brivet). ${ }^{1}$

Fawn-eye.—"The color of the iris sometimes takes a fawn or lees-of-wine tint; to this eye we preferably give the name faun, becanse this tint is most usual. We shond mention this peculiarity, althongh it has not yet been described by anthors" (Brivet ${ }^{2}$ ).

\section{C.-Peculiarities of the Body.}

The peculiarities whose exclusive seat is npon the body are the mule ray, the cross upon the withers, the rocbuek abdomen, the uhite or washed mane and tail, and the mixed mane and tail. 
Mule Ray.-The mule roy or stripe is a dark or black stripe, formed of black or red hairs, of a maroon or brown tint, which extends, npon the median line, from the withers to the base of the tail.

It is observed upon Isabella, bay, sorrel, monse-colored, gray, and fawn-eolored horses, but not in all, which constitutes it an oceasional peculiurity of these coats.

Cross upon the Withers.-This expression is used to designate a dark stripe which passes transversely across the withers upon the sides of the shonlders. It is found upon the same coats as the preceding marking, although more rarely.

Sometimes it extends upon one shoulder only, which should always be mentioned.

Examples: light Isabella, mule ray and cross; ordinary mouse, mule ray and cross to the right; fawn sorrel, cross; chestmut bay, mule ray.

Roebuck Abdomen.-This is only a yellowish washed coloration of the inferior face of the abdomen, which often extends to the hairs of the sheath, the testieles, the mamme, the internal face of the thigh, and the perineum. It is especially marked in the Isabella, the bay, the sorrel, and the fox coats.

This expression, because of its inaecuracy, is no longer used. It is simpler and more exact, in fact, to specify the parts which are the seat of this peculiar color.

White or Washed Mane and Tail.-When the mane and tail are white in black, bay, Isabella, sorrel, mouse, and fawn horses, instead of being black or dark, we designate them white or washed; also if they are completely or only partially so.

Examples: burnt sorrel, white mane and tail; dark bay, washed mane and tail; ordinary black, base of tail white; dark Isabella, middle portion of mane washed.

Mixed Mane and Tail.-The mane and tail are called mixed when they eontain some white hairs which do not enter into the composition of the eat cousidered, such as the black, the sorrel, the bay, the Isabella, the mouse, and the fox. Ordinarily the mixing is only partial.

Examples: mahogany bay, tail mixed; rusty black, base of mane mixed; Isabella, mane and tail mixed.

\section{D.-Peculiarities of the Members.}

The pereuliarities which eoncern the members are the white-foot, the zebre stripes, and the arborizations. To these should be added the diverse colorations of the horn of the hoof. 
White-feet. - White-feet consist of white marks on the inferior part of the members. They are very common and are seen in nearly all the coats, even the gray, where they are, however, less striking.

They must be examined in relation to their number, their extent, their form, and their composition.

a. In relation to their number, the horse may have-

One white-foot, and then the member which is involved should be mentioned.

Example: uhite-foot, anterior left.

Two white-feet, in which case they are necessarily anterior, posterior, lateral, or diagonal.

Examples: white-fect right lateral biped, left diagonal biped, ete.

Three white-feet.-Here it will suffice to specify the one which is isolated. Example: three white-feet, posterior left. This signifies that the right posterior alone is not white.

Four white-feet.-This needs no further explanation. It suffices to mention the elaracter of these markings.

Old veterinarians named arzel the subject whose posterior right foot alone was white. The legend narrates that such a marking was considered as a very bad omen. In support of this, it is related ${ }^{1}$ that the mount of a certain Sejanus, a Roman eonsul and favorite of Tiberins, was thus marked, and as this horse killed in sucession each of its five owners, it became the fashion to say of a man who seemed threatened with an unfortmate end, "IIe has the horse of Sejanus." 2

Let us add that horse-dealer's also call magpie the bay horse with four white feet. They also give the same name to pied horses.

b. In relation to its extent, the white-foot is designated-

Incomplete, if it does not completely circumseribe the member.

Interrupted, if its course is broken by black or colored hairs, or if it is not eontinued to the extremity of the member.

Trace of white-foot, when it ocenpies only a small portion of the coronet.

Beginning of white-foot, when it only involves the region of the coronet, which it completely surrounds.

- Small white-foot, when it surrounds the coronet and the pastern.

White-foot, when it extends to the fetlock.

1 De Lafont-Pouloti, Nouveau régime pour les haras, p. 23, Paris, 1787

2 See, for more details, Solleysel, Le parfait marescha\}, Paris, 1693, t. ii. p. 129. 
Large white-foot, or half-stocking, when it reaches the middle of the camon.

Stocking, when it extends to the knee or the hock.

High stocking, when it reaches still higher and extends npon the forearm and the leg.

Finally, very high stocking, when it reaches the vicinity of the body.

c. In relation to its composition, it is similar to the markings of the head:

Bordered, speckled, ermined, trout-spotted, mixed, marbled, ete.

We should mention the white-feet of gray horses only in cases where these markings are perfectly apparent.

[In a certificate of soundness, it suffices to speeify the name of the region which is white, it being understood that the white coloration exists. As to the head, it is only necessary to mention the character of the marking without stating that it is on the head.

Examples: light bay, star, off hind pastem; bumt sorrel, blaze, three half-stockings near. hind.]

Zebra Marks.-The zebic marks are black or blackish sinuous lines directed transversely upon the regions of the forearm, the leg, the knee, the hoek, and the canon, which recall somewhat the disposition of those seen upon the zebra. They are observed more fiequently upon the Isabella, the mouse, the sorrel, and the farm bay.

Arborizations. - The arborizations are peculiarities analogons to the preeeding, but differ from the latter in that they are formed of white hairs. They are located upon the external fare of the forearm, the leg, and the back of the ears, in horses exclusively gray. ()ur observations, extending over a long period, have tanght us that these markings follow very aceurately the direetion of the corresponding subcutaneots arterial branches (anterior radial, anterior tibial, and posterior auricular arteries).

Color of the Horn.-The color of the skin of the coronary band determines that of the horn of the hoof in the parts situated below. It is frequently modified by white markings in the region of the foot, and may, in fact, be rhite, black, or mixed.

\section{Causes of the Modifications of the Coats.}

In general, coats of the same eolor and even the sime shade have not, at all times, identical characters. This is due to diverse intlu- 
SYNOPTICAL TABLE OF THE PECULIARITIES OF THE COATS.

General Peculiarities.

(Without Fixed Location.)

\begin{tabular}{|c|c|}
\hline $\begin{array}{l}\text { 1. Brilliant } \\
\text { reflections. }\end{array}$ & $\begin{array}{l}\text { Jet black. } \\
\text { Silver. } \\
\text { Golden. } \\
\text { Copper. } \\
\text { Bronze. } \\
\text { Wavy. }\end{array}$ \\
\hline $\begin{array}{l}\text { 2. Shaded } \\
\text { hairs. }\end{array}$ & Dappled. \\
\hline $\begin{array}{l}\text { 3. White } \\
\text { hairs. }\end{array}$ & $\begin{array}{l}\text { Solid-colored. } \\
\text { Pubican. } \\
\text { Snow-flaky. } \\
\text { Flea-bitten. } \\
\text { Grayish. } \\
\text { Bordered. } \\
\text { Accidental } \\
\text { markings. }\end{array}$ \\
\hline $\begin{array}{l}\text { 4. Black } \\
\text { liairs. }\end{array}$ & $\begin{array}{l}\text { Speckled. } \\
\text { Iloucheté- } \\
\text { truité. } \\
\text { Ermined. } \\
\text { Leopard- } \\
\text { spotted. } \\
\text { Spurious brand- } \\
\text { iron mark. } \\
\text { Louveture. }\end{array}$ \\
\hline $\begin{array}{l}\text { 5. Red } \\
\text { hairs. }\end{array}$ & $\begin{array}{l}\text { Trout-spotted. } \\
\text { Truité-nou- } \\
\text { cheté. } \\
\text { Marbled. } \\
\text { Wine-colored. } \\
\text { Rusty. }\end{array}$ \\
\hline
\end{tabular}

$\left.\begin{array}{l}\text { 6. Hairs of } \\ \text { different } \\ \text { directions. }\end{array}\right\} \begin{aligned} & \text { Tufts, } \\ & \text { curly. }\end{aligned}\left\{\begin{array}{c}\text { Concen- } \\ \text { tric. } \\ \text { Eccen- } \\ \text { tric. }\end{array}\right.$

\section{Discolorations:}

Of the coat. I $\mathrm{W}$ a-hed.

$\left.\begin{array}{c}\text { Of the } \\ \text { skin. }\end{array}\right\} \begin{gathered}\text { Leprons } \\ \text { spots. }\end{gathered} \quad\left\{\begin{array}{l}\text { Mixed } \\ \text { Bordered. } \\ \text { Marbled. }\end{array}\right.$
Absence of hairs. $\left\{\begin{array}{l}\text { General. } \\ \text { Partial. }\end{array}\right.$

\section{Special Peouliarities.}

1. White Wark of the BODY AND MEMBERS.

\section{I.-Body.}

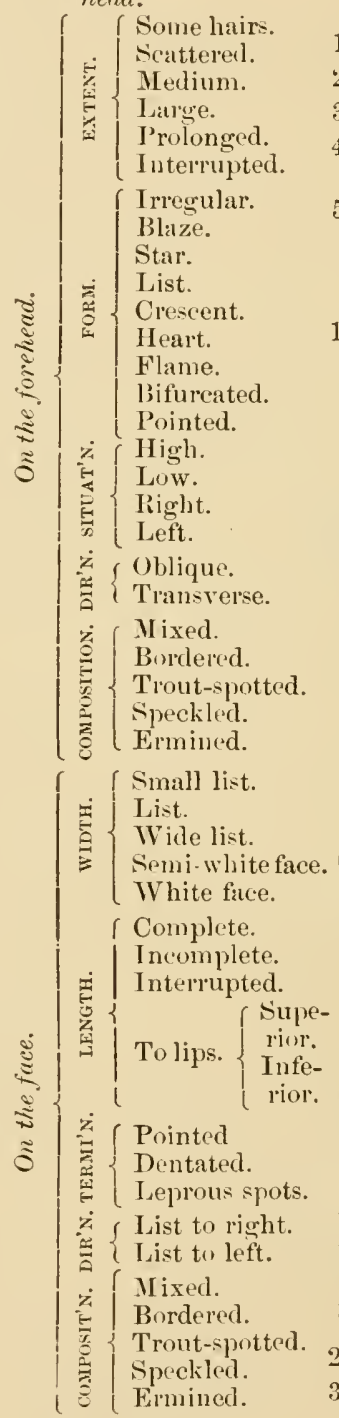

1. Mule ray.

2. Cross upon the wither's.

3. Roebuck abelomen.

4. White or washed mane and tail.

5. Mixed mane and tail.

\section{II.-Members.}

1. White-feet.

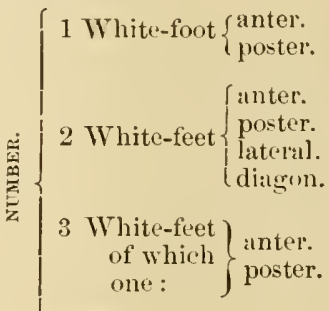

4 White-feet.

Incomplete.

Interrupted.

Trace.

Coronet.

Pastern.

Fetlock.

Middle of canon.

Stocking (knee or hock).

Forearm or leg.

To body.

- Irregular.

2. Regular.

Dentated.

ż Mixed.

Bordered.

Trout-spotted.

Sipeckled.

8 Ermined.

2. Zebra marks.

3. Arborrzations

4. Horn of hoofs. $\left\{\begin{array}{l}\text { White. } \\ \text { Black. } \\ \text { Mixed. }\end{array}\right.$

3. Fox-nosed.

4. Moor-headed.

5. Moor-faced.

6. IVall-exye.

7. Fawn-eye. 
ences, the principal of which are the following: the age, the sex, the cleanliness of the slin, the nowrishment, the condition and the health, the atmospherie action, the humidity of the air, the sunlight, the sectson, the climate, the moulting, and the tinctorial action of certain substances.

Age.-The foal is covered, at birth, with fine, short, woolly hairs of a dark color, which, towards the middle of the first year, are replaced by those of the distinctive or adult coat. Hence it is extremely difficult to foretell at this period what the latter will be. The head and the extremities are somctimes an index, but are frequently uncertain. "Thus," says De Curnien," "the gray is always born very dark, and sometimes absolutely black; the black, on the contrary, is at first reddish or mouse-colored, and now and then even ashy gray. The bay and the sorrel are sometimes darker at birth and sometimes lighter than at the adnlt age, and in all ases the legs are of a fawn-color, which becomes so light towards the region of the foot that it is often necessary to use care to distinguish them from white-feet. At this age the coat leads us into frequent crors and doubts."

In proportion as the animal grows older the coat, even when it appears made, is modified by the more or less early appearance of white hairs. I et us reeall, in passing, that it is the knowledge of this fact which has led us to arlopt the gromping established by Professor Neumann, - that is to say, to divide the coats into primitive and derived.

Sometimes the white hairs appear at an early period, especially around the eyes, the temples, and the cars, in horses which later will become gray, white, Hea-bitten, or roan. The last two are always sorrel or bay at hirth; then they become rubiean, and at the end of a variable period the white hairs are so numerous that the coat must be classed as roan or flea-bitten. Generally, they do not remain thus: the white in them always inereases more and more. These remarks apply equally well to the black destined to become wray afterwards.

Sex.-The influence of sex is ordinarily combined with several other causes of which we will speak. Nevertheless, it is commonly observed that in stallions the hairs are darker, of a brighter shade, and fresher-looking than in geldings and males. The sane is true of thoir diverse reflections.

Cleanliness of the Skin.-The deanliness of the slin and the hairs, obtained by gool groomine, lotions, baths, and loeal lathering, 
lathering, gives to the coat a lustre and a brilliancy which are not seen in those of horses improperly cared for. The latter are always dull; the white and light gray are dull and ordinarily soiled by the litter in the regions of the thighs, the buttocks, the sides, the elbows, the knees, the hocks, and the fetlocks.

Nourishment, Condition, Health.-A good alimentation, especially a grain regimen, a satisfactory degree of corpulence, and a good state of health render the hair's smooth, fine, brilliant, the sharle of the coat more bright, and the skin supple. On the contrary, in poorlynourished, thin, emaciated, or diseased horses the hairs are rough and staring and have a dead color.

Atmospheric Action.-Animals which are always exposed to the action of the open air and the sun, and those which run in pasture day and night, for example, are soon sunburnt or tanned, and are covered with long, dry, dead, staring hairs of lighter tint. It is different with those which are constantly kept in the stable, protected from the atmospherie inclemencies, the dust, or the cold by eoverings or blankets, under which the coat loses nothing of its lustre and its brilliancy.

Humidity of the Air.-Dampness makes the eat darker, by moistening the hairs, causing them to alhere to one another, and modifying their reflections; mist or fog simply deadens it, in the manner of a brilliantly-polished object which is placed in an atmosphere charged with watery vapor.

Sunlight.-The direct action of sumlight altogether changes the aspect of the coat, especially in well-groomed horses. It then communicates to the hairs incomparably bright shades and brilliant reflections. Under these conditions the white, the light gray, the black, the bay, the sorrel, and the Isabella become, according to eircumstances, silver, jet, golden, eopper, bronze, and sometimes rainbow-colored. In the shade all these peculiarities disappear.

Season and Climate.-The influence of the seasons and the climates seems to be dependent upon the sunlight and the hygrometric state of the air. Thus the hairs are shorter, smoother, more shiny, and darker in summer than in winter, when they lose their reflection, become longer, coarser, paler, and washed. Besides, in warm climates the coat is more brilliant and its shades brighter than in cold and moist climates. However, these characters change as soon as the atmosphere becomes doudy and damp. This is due to the less intense light and to the moisture, two anses which contribute to render the coat dull and sombre.

Moulting.-In general, moulting or shedding the coat gives to 
it a lighter color, because the hairs are always paler at their base than at their point; it beeomes, on the contrary, slightly darker in the white and light gray, because it allows us to perecive the black color of the skin. Let us cite some examples: the ordinary black beromes rusty; the burnt sorrel, maroon; the cherry bay, light; the dark Isabella, ordinary ; the ordinary mouse, light; the roan, fleabitten (upon the body only); finally, the louret, Isabella and sometimes almost white. But in proportion as the hairs grow the horse regains little by little his primitive shade.

Tinctorial Action of Certain Substances.--Garsault ${ }^{1}$ has spoken of horses dyed bay, bay brown, or black, in order to prevent their recognition, or to arrange them better with reference to the convenience of the owner. Unfortunately, at the next moulting-time the horse will recover his old coat, sometimes even fifteen days afterwarls, if the eolor has been sparingly used! This fraudulent practice is no longer employed ; there are, however, a few dyers who use it in order to conceal the imperfections in the colors of doges.

The application of certain medicaments to the skin produces for a short time an abnormal coloration of the eoat. Such are the tincture of iodine, which stains it more or less yellow; nitrate of silver, black; Villate's solution, pale green; ointment of the biniodide of mercury, which colors it red; mereurial ointment, slaty gray ; unguentum populeum, vegetable green, ete. It suffices to call attention to these artificial peeuliarities, in order that they may not be confounded with the natural; they are of but temporary duration.

\section{Indices furnished by the Coats and their Peculiarities as to the Qualities of Horses.}

What is more diffienlt to overeome than prejudiees and superstitions ideas? Often a simple examination would suffice to overthrow them, but, nevertheless, they always find here and there minds disposed to give them a lind weleome and to propagate them.

This is shown very plainly by all that has been said and written upon the seleeting of horses according, exclusively, to their "oat or their peculiar markings.

The eolor of the hairs, their shade, the form of the white marking on the head, the nmmber and extent of the white fect, the presence, the form, and the situation of the tufts, etr., liave all served at the basis of a theory, and the theorists have committed the error of arguing from a particular premise to the gencral. A brown bay horse, for ex- 
ample, which has shown himself endowed with great qualities, has a star on the forchead; this has been sufficient, in many (ases, to give this eat and this marking a premimm over all others.

Here, as in all preconceived ideas, coineidences have been noticed withont taking into consideration the contrary facts, interpreted as exceptions, although more numerous. Thus, black horses are but slightly esteemed, becanse they are used in hearses; white horses and those whose enat is pale or washed are rejected, under the pretence that they are slow, lymphatie, and deficient in energy ; sorrel horses are in disrepute, becanse they are believed to be of a vicious temperament, etc.

In other cases, there is not even the shadow of a reasom in favor of the judgment formed. Taste, faney, caprice, and fushion alone determine the choice. "It is even improssible," writes De Curnien, keen connoissenr though he be, "for a man with much experience among horses not to have certain whimsical preferences for such or such a coat, or such or such a mark. Thus, I never like to buy a cherry bay horse with four white feet, while a brown bay with these markings pleases me, provided he has a white mark on the head. I prefer the Isabella to be solid-eolored, and the black to have at least a star on the forehcad. Two hind white feet and a list appear to me good signs in a black, a bay, and, especially, a sorrel horse. The proverb, ' Cheral de trois, cheral de roi,' intending to express that a horse with three white feet often has more brillianey than endurance, is frequently true. Two fore white feet and one or none behind, and, in general, more white in front than behind, diminishes greatly, to my mind, the value of a horse. Finally, althongh with all the coats there are found horses extraordinarily good as well as bad, I always much prefer the burnt or goklen sorrel, the bay, and the trout-spotted."

These opinions, which vary with the observers, the times, and the places, being credited to-day, disbelieved to-morrow, and revived later on,- - will they not, like the belief of the ignorant in the mysterious, be banished by a more rigorous observation and a more eareful jutgment of facts?

In this respect, it is interesting to real the works of the old horsedoctors and horsemen. In most ases they abound in the strangest kind of superstitions, which Solleysel ${ }^{2}$ and Garsanlt, ${ }^{3}$ especially, have reprinted too indulgently.

Strietly speaking, all persons do not manifest the same credulity

1 De curnieu, loc, cit., Ire partie, p. 194.

¿ Solleysel, Le parlait mareschal, 2e partie, p. 126, et suiv. éd. de I698.

${ }^{3}$ De Garsault, loc. cit., p. 15. 
eoncerning the indices furnished by the coats and their peenliarities. Thus, Gaspard de Samnier ${ }^{1}$ does not lesitate to speak of these remarks as "pure fiddle-faddle and imagination!" The old proverb, which says that "there are good howses under all colors," was not unknown to lim, and he leaves us to suppose that the prejudice against white, pale, washed, sorrel, black, and white-footed horses, leprous spots, cte, had, even at that time, numerous opponents.

We do not intend to examine these strange and ineongruous opinions. We will, neverthcless, mention some speeial requirements and peculiar facts worthy of interest.

In general, in pleasure-horses, the darker coats, especially the black and the sorrel, are sought after, on account of their great lustre, their more brilliant reflections, and the ease with which they may be groomed. Nevertheless, the choice of the coat has at times another guide than faney and style. Thus, in the hunter the gray is preferred, becanse this color contrasts more sharply with the red costume of the huntsman.

At other times the purchaser desires a particular coat for the reason that it is, as it were, a race characteristic. Percheron and Brittany horscs, for example, being nearly always gray, are not in great demand, either in France or other countrics, if they have a color which shows that they have been contaminated with some inferior races.

In the French army it is known that at the remount depots gray and white horses are condemned on aceount of their eolor, which can be too easily distinguished on the battle-field.

Moreover, the white and the gray eoats are objectionable in other respects, which justify in part the slight esteem in which they are lreld. They are soiled rery asily by the litter and mud, and become very nnpleasant, at the time of monlting, to the rider and the driver on acconnt of the white hairs which freely fly about; finally, they predispose the animal to the formation at some time of molanotic tumors, cither internally or upon the exterior of the body, which may oceasion considerable inconvenience and may even canse the death of the animal in some rare cases.

We recall, on this subject, the appropriate remark of our collearue Mercier (of Evreux), that subjects affected with internal or external melanosis always have a curly or frizzled mane and tail, a character which should attract attention if it be very prominent.

From a zootechnical point of view, the white markings on the head, the body, and the members deserve to be taken into consideration. 
As Hartmann affirms, " These markings are transmitted by heredity, and always become larger in the descendants, so much so that finally pied horses will be produced."

The same anthor establishes a connection, the accuracy of which is far from being demonstrated, between the disagreable odor which emanates at times from certain horses and the color of their coat. Aecording to him, in fact, "the perspiration of rubican, bay, and sorrel subjects, like that of some florid and blond persons, has an extremely strong and disagreeable odor." Althongh we have had two opportnnities of verifying this fact, one upon a light sorrel and the other upon a dark gray, we see in these exceptions only, and, indeed, very rare coincidences, which it would be absolutely erroneous to establish as a rule.

\section{CHA PTER II.}

THE HEIGH'T.

Definition; Importance.-The height of the horse is the distance from the summit of the wither's to the ground. It varies in very large proportion according to the race and the subject. The extreme measurements which we have obtained are the following:

$$
\begin{aligned}
& \text { Small Spanish horse . . . . . . . . . . } 0.98 \mathrm{~m} \text {. } \\
& \text { Heavy-draught Flemish horse . . . . . . . } 1.83 \mathrm{~m} \text {. }
\end{aligned}
$$

Nevertheless, we may meet subjects which are smaller, and likewise others which are much larger. The celebrated American horse-trainer, Carter, publicly exhibited in London, it is said, ${ }^{2}$ a very remarkable giant of the equine speeies. Born at Northampton, six years of age, and of a heavy-draught type, this gigantic animal was six feet nine inches in height (English measure), or 2.057 metres, and weighed 2500 pounds, or 11:33, kilogrammes and $5: 37$ grammes. His proportions were regular, and he was active on his feet. To make a more striking contrast, a Scotch pony was placed alongside of him, which conld pass under him without touching his abdomen.

The reader will see, a propos of the services, the importance of the height when it is a question of determining the category in which the horse should be classed. Whence the necessity of approximating as elosely as possible to it, inasmuch as it constitutes, in relation to a

1 Ilartmann, Traité des haras, p. 75.

2 Recueil de médecine vétérinaire, amnée 1847, p. 790. 
technical description, a factor whose ordinary precision and fixity are very great aids in distinguishing, in pratice, animals otherwise almost alike.

Experienced persons judge the height of a horse quite accurately by a simple glance, scarcely misjudging it even by one centimetre. However, it is preferable to employ an instrument which gives positive information and constant results, if it be well constructed and properly manipulated.

Sometimes, however, we meet with certain very irritable subjects which object to being tonched, and can only be approached with difficulty. "Sucl cases are frequently found," says Captain Rivet," "among the horses in the swamps of the Poitou and the Tendée, which have never been shod, and which are haltered for the first time when they are brought before the committee on remounts." Be this as it may, we must always act with gentleness and care to avoid accidents; the height must be judged by the eye alone whenever it is impossible to take it by other means.

Instruments employed for determining the Height.-An instrument formerly in rogue was the chain, of which some persons still speak, but often withont being acquainted with it. The most recent description of it which has been given dates back to 1770 ; we will repeat it here simply on account of its historical interest.

"The chain," writes De Garsault," "is made of small links of iron or brass, is six feet long, and is marked foot by foot by a twisted brass wire; from the fourth to the sixth foot other small iron or brass wires mark the inches; at the lower end of the chain is a plumb. In measuring the horse, the chain is so held that the plumb hangs opposite to the hoof of the fore-foot; then, placing the chain along the side of the shoulder to the point of the withers, the corresponding point on the chain is noted; then the number of feet and inches on the chain is determined, and the height of the horse obtained according to this measurement. This measurement is not exactly accurate, because it can be modified by the shoulder, more or less fleshy, in different horses of equal height, which may sometimes amount to a difference of two and one-half inches or more."

\section{The same author adds farther on :}

"Some persons, in the absence of the graduated chain, measure upon a cord with the fist. The fist measures three inches, which is called a hand. Thus, nineteen hands are equal to about four feet nine inches. More rarely the elbow is used to measure the horse ; one elbow equals one foot and a half."

Modern horsemen, much more correctly, measure the height of the 


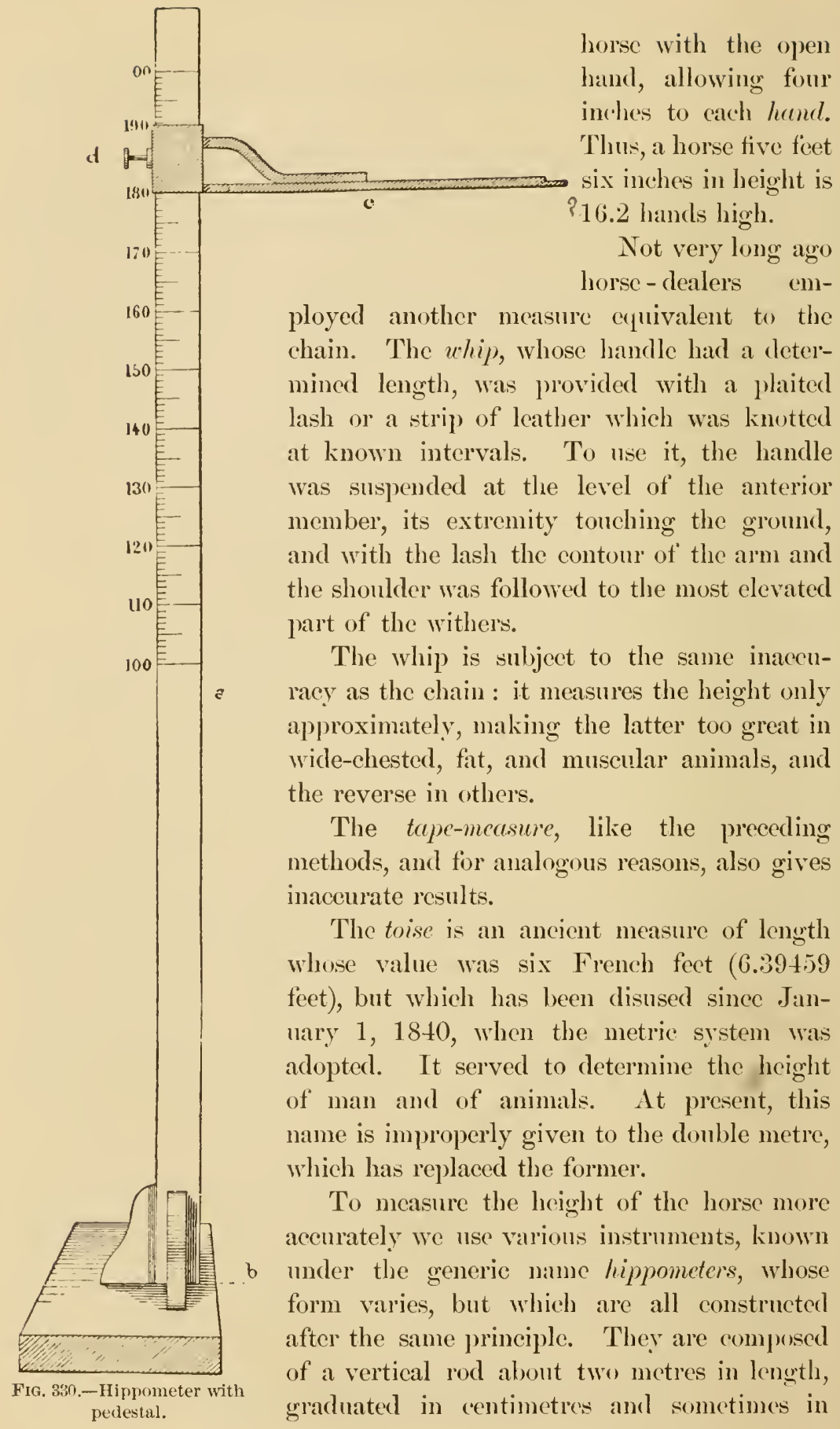


millimetres, to which is attached another, but horizontal, rod that can be lowered or raised at will upon the former, and is fastened by means of a serew.

The simplest of the hippometers is the standurd. It consists of a flattened rod, graduated upward and downward, upon which freely glides a horizontal bar or gauge, that is, consequently, always perpendicular to it. A pressure-serew serves to fix the gliding bar upon the vertical rod, when the former has been gradually lowered upon the latter to the level of the withers. The standard would be an aecurate instrument were it not for the inconvenience of always placing it in the perfectly vertical position.

For the standard, therefore, the hippometer with a pedestal has been substituted. In the latter (Fig. 3:30), the vertical rod, $a$, is thick, quadrangular, and inflexible, and rests upon a small pedestal, $b$. The horizontal arm, $c$, glides upon the former, and is supported there by a pressure-screw, $d$, which can fix it upon any point of the seale.

The graduation is expressed in centimetres, and at times in millimetres. We may mention that the proclamation of the French Minister of War, dated June 10, 1847 , requires that the height be taken in centimetres and not in millimetres. When the number of millimetres is above five, it is counted as a centimetre; if the number of millimetres is below five, they are entirely disregarded, and only the even centimetres are counted.

This hippometer can scarcely be employed except in large establishments, such ats remomint depots, schools, large sales-stables, ete. It is too cumbersome,

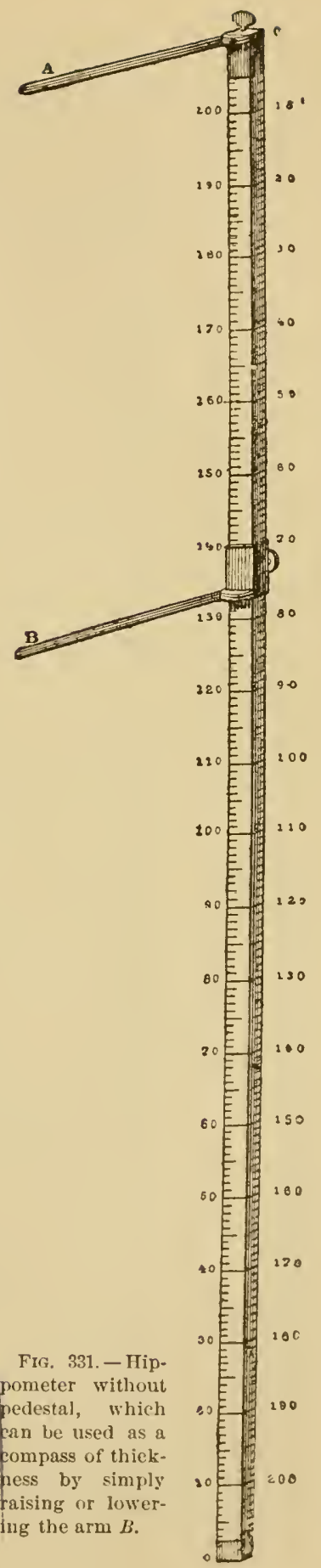




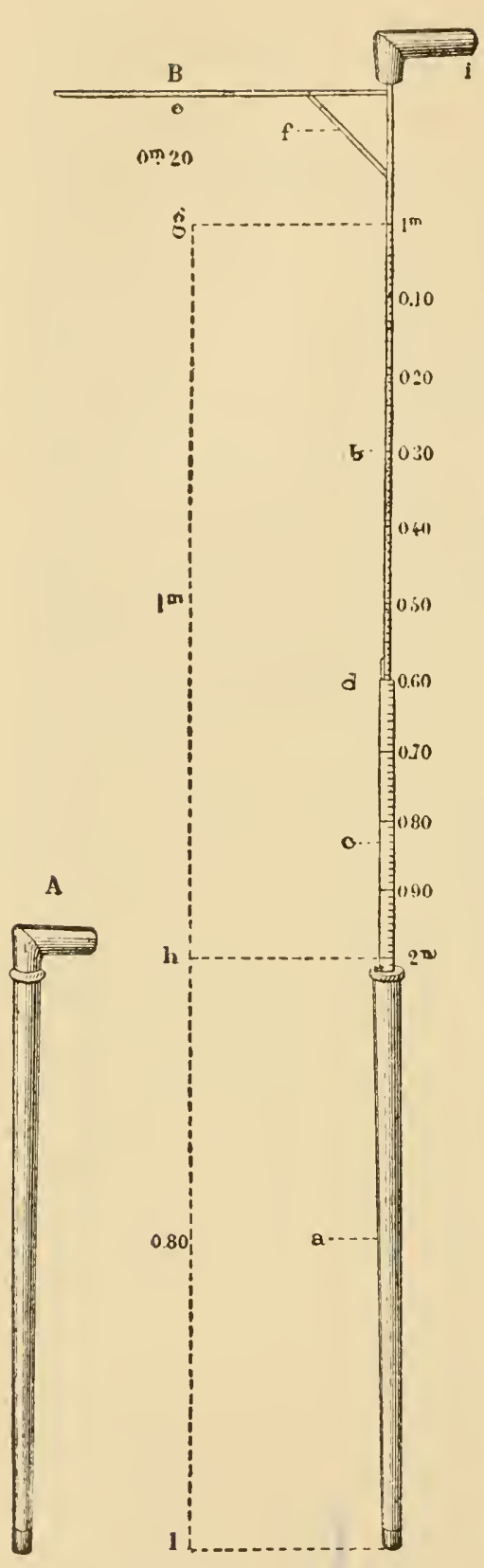

Frs. 332.-Hippometric cane.

A. Closed, serving as a cane.

$B$. Unfolded, forming a standard. and wonld be inconvenient of application in the horse-market, at the cattle-show, or in the farmyard, unless a large number of animals were to be measured. Besicles, it gives erroneous results whenever the ground mpon which the measurement is made is not perfectly horizontal.

For these reasons we much prefer the hippometer without a pedestal (Fig. 3:31), which we have had constructed for our particular use, and which possesses the advantage of being very easily changed into a compass of thickness, as, for example, in measuring the length of the body or that of the base of support.

But when the expert is ealled away from home, the hippometric cane (Fig. 332) may be used; this is more portable, and, on the whole, very satisfactory, in spite of its flexibility. It consists of an ordinary Nalacea or rattan eane, $B$, which is hollowed internally, and contains a quadrangular metallic graduated rod, formed of two pices, $b$ and $c$, the one gliding within the other when they are not in use. Superiorly this rod is hollowed by a longitudinal slot designed to lodge a horizontal branch, $e$, which the support, $f$, constantly keeps perpendicular to the rod in question.

Both pieces are graduated so as to form a continnous sale when fully drawn out, beginning 
at the point $g$, whose situation varies aecording to the leight of the cane itself. The distunce, $r g$, is always calculated in such a manner that it makes the length of the cane equal to one metre. This amomnts to the same thing as though the cane itself had this length, and, it being inconvenient to carry a cane of this size, the inventor conceived the ingenious idea of giving to the distance, eg, the required length of which we speak.

To use this instrument, the handle, $i$, must be forribly pulled to draw out the whole length of the superior segment, $b$. A catch placed at the lower end of this segment fixes it here, $d$, and prevents it from being pushed baek into the lower segment when pressure is made upon the handle. It is necessary to take this precaution in order to avoid the errors whieh would otherwise follow. The horizontal bar, $e$, is then placed in position, supported by $f$, and the animal is measured, as in the preceding eases, by gradually pushing the graduated segment into the eane, $a$. When the segment, $c$, has been entirely pushed back, we meet with a resistance at $d$ : the instrument will now shorten no more. It is then necessary to press upon the cateh, $d$, to allow the segment, $b$, to deseend in its turn. As soon as the horizontal arm touches the summit of the withers, the figures corresponding to the extremity of the cane, $h$, are read, and it only remains now to add this number to one metre to determine the accurate height of the horse.

When purchasing a hippometrie eane, it is important to verify its acenracy with care, for the metallie eap at the extremity, $l$, is sometimes too short or too long, and the eombined distances $t h$ and $e g$ are then no longer equal to one metre. It is necessary, besides, that the arm, $e$, should form a right angle, move easily, and, with its support, $f$, be easily lodged in the groove which is exeavated for it upon the segment $b$. It is indispensable also that the segments $b$ and $c$ shonld glide one within the other, and both within the sheath of the eane, without excessive friction. Finally, the play of the spring $d$ should be exact.

Precautions to be taken.-In order to measure a horse certain precantions must be taken, without which the measurement would be of no value. The animal should first be taken npon a horizontal surfice and placed in the position of regular station. An assistant, standing in front, holds the head and neck in their ordinary position; then he covers with one of his hands, especially from behind, the eye on the side towards the operator, in order that the animal may not berome frightened or unmanageable. Besides, the operator should be eareful to touch the animal very gently. Is to the hippometer, it is nealless to say that it must be held reertically. If it be inclined or inemerated 
towards the horse, it loses its horizontal position and, consequently, makes the height too great; curved in the opposite direction, the result obtained is too small.

One means of verifying the rertical direction of the instrument is to examine with it, from in front and from the side, the corner of a building, the moulding on a wall, a door-post, etc.; in a word, some vertical object which is elose by. Differences in certain results are rery often occasioned by neglect of this fundamental test. In this respect, the hippometer with a pedestal is as uncertain as the others; it deserves even less eonfidenee when it is employed upon soil not perfectly horizontal and uniform; the least unevenness of the gromnd will canse a deviation of the horizontal arm, the extent of which is directly proportional with the height of the instrument. It is therefore necessary to verify its horizontal direction at each examination ; the small pedestal upon which it is mounted has, in our opinion, no other use than to enable the operator to get rid of it easily when it is in his way.

With the hippometric cane we must take eare that its extremity be not lower than the shoe of the horse. This may take place if the horse be measured upon meven pavements or stable floors. In such cases the extremity of the cane sometimes rests in a depression or an interstice, whose depth and wilth, however, are not sufficient to change the equilibrim of the hoof.

Finally, we must take notice of the height of the anterior heels, the thickness of the shoes and their heels, as well as the quantity of adipose tissue, which, in stallions, is often excessive upon the superior border of the neck and more or less eonceals the summit of the withers.

Concerning army horses, Captain Rivet' states that, "when the horse is fice yerts old or older, the maximum limit of the height ean be exceeted by two centimetres, but never more, in order to have a standard of uniformity among army horses."

Fraudulent Methods.-Fraudnlent methods to increase the height are employed rather frequently, especially in cases where two horses are presented as mates, or, again, in horses offered at the army remounts which are not up to the required height.

Under these conditions the seller endeavors to place them in such a position that the hind-quarters are relatively lower than the fore-quarters. In the stable, as well as on the exhibition-ground, everything is so arranged that this trick (an be easily enough accomplished. When it camnot be done in this mamer, the seller augments the height of the 
heck, the thickness of the shoes and their heels, obliges the animal to lower his head, which stretehes the nuchal ligament and raises the withers; finally, if needs be, he pinches him under the sternum or irritates and excites him with the whip to make the animal restless and render the operation of measuring less exact.

\section{CHA P'T ER I I I.}

\section{CERTIFICATE OF DESCRIPTION.}

Definition; Divisions ; Importance.-A certifieate of deseription is a written doeument comprising a short, precise, clear, methodical, and more or less complete enumeration of the external characteristies which enable one to distinguish a certain horse from all others.

It is summary or detailed, aceording to the number of items which it contains.

In some eases it is limited to a simple indication of the external characters. Some authors alio include elements which, strictly speaking, are not essential to it. We refer to the pedigree and the performances, of which we will speak farther on.

Whatever may be its form, a certificate of deseription is a docment which, in many instances, may become one of very great importance, either in disputes relative to some of the redhibitory vices or when there is a question of theft, substitutions, and exchanges in relation to legal proceedings, etc. It then becomes an official instrument by the aid of which one shonld always be able to establish the identity of the animal in litigation.

Order to be followed.-The order adopted in the enumeration of the characters which should be included in a complete deseription of the horse varies somewhat acording to the eiremustances and the purpose in riew. In general, it is adapted to the nature of the information which it is neessary to know. The only pule which shomlel invariably be followed is to proceed in a uniform nanner with all animals belonging to the same series, so that we may go forwarl methodically and rapidly without omitting any important details. The following is the oreler nsinally adopted :

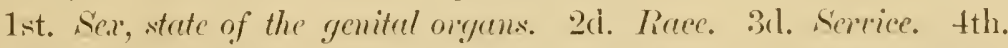
Coat, its earieties and its peculiarities. 5th. state of the mane and tail. 6th. Age. Tth. Mright. Sth. Blemishes and peenliar marlings. 9th. Direrse peculiarities forcign to the cout. 10th. Date. 
Here may also be inserted-

The name and registration number of the horse, his price, his pedigree, his performences, and the name and address of the proprietor.

In the army, in breeding establishments, and in livery, omnibus, and street-ar stables the order of this outline may be a little different from the preceding. We will give some examples farther on.

The preceding headings require some explanatory remarks as to details, which we will give below.

1st. Sex, State of the Genital Organs.-The words mrere, horse or entive horse, and gelding explain sufficiently this first phrase. Nevertheless, it is neeessary to note gelding bistoumé, and not entire, a horse which has been emasculated by subcutaneous torsion of the testieular cord. (See Bistournage, page 178.) Likewise, we should designate by the terms cryptorchid or monorchid a subject whose two testicles, or only one of them, have not descended into the scrotum. On the other hand, we designate entire the horse provided with only one testicle, and in which the other has been removed for a therapeutic purpose, as, for example, in the cure of strangulated hernia. In such cases this detail should be indicated under the heading diverse peculiarities foreign to the rout. The presence of a cicatrix of a special character at the place of the absent testicle always enables us to distinguish an animal of this kind from a true monorchid.

There are instances (very rare) in which it is at first embarrassing to name the sex of the animal under examination. We refer to the so-called hermaphrodite horses, of which science has already furnished quite a large number of examples. ${ }^{1} \quad$ These subjects are nothing more than complicated cryptorchids with grave malformation and atrophy of the external genital organs, in most instances having a simple fissure of the perineum or of the sheath, to which is sometimes added a median fissure of the canal of the urethra; the latter malformation is known under the name hypospadia. We need, conse(quently, not hesitate as to the sex; all observations agree in regarding them as males, and not as females, nor as real hermaphrodites. Besides, on autopsy, we constantly find the testicles either external to the inferior inguinal ring, in the ingninal canal, or in the abdomen;

\footnotetext{
I See, for more details, De Garsanlt, Le nouveau parfait maréchal, eh. ix. pl, xxviii., Paris, 1770 .

J. B. Gohier, Mémoires et observations sur la médecine et la chirurgie vètérinaires, t. i. p. 27, Paris, 1813.

A. Rey, Deux exemples d'hermaphrodisme dans le cheval, in Journal de médecine vétérinaire publié à l'École de Lyon, année 1 s46, p. 230.

I. Geoffroy-Saint-Hilaire, Histoire générale et particulière des anomalies de l'organisation. t. ii. $\mathrm{p} .87$.
} 
the testicles are soft, flabby, and without spermatozoa, like those of cryptorchids. To these glands are annexed the normal deforent canal, which terminates in the urethra after following its ordinary course upon the superior surface of the bladder. Neither a uterus nor ovaries have ever been found.

It is none the less true that the external resemblance of these animals with the mare is rather striking. They have, in fact, two perforated inguinal glands well developed; the borders of their perineal fissure almost simulate the lips of a vulva; as to their penis,-atrophied, curved like an $\mathbf{S}$, and always direeted backward,-its free extremity is lorged in the inferior commissure of the entaneous opening, like the clitoris of the female. But these animals are distinguished by other external and unequivocal characters. First, their mouth is provided with tusks like that of ordinary males; besides, their psendo-elitoris is enstomarily piereed by an orifice through which the mine flows, unless there be a hypospadia, in which case the urethral fissure terminates directly in the bladder and not in the vagina ; finally, they show masculine signs, neigh, and have an ereetion of the penis at the approach of a mare in heat, and at times endeavor to mount her. In the presence of such undeniable proofs of masculinity there is, therefore, no possible doubt. Such a horse should, in our opinion, be designated cryptorchid horse, affected with a fiswre (median or lateral) of the perineum, the sheath, or the urethra, etc, according to the seat and the nature of the parts interested.

2d. Race.-Save in the races whose characters are very striking, there are instances in which it is not alwars possible to tell the race. This fact is due to the numerous crossings which have been practised for a long time upon the various types, formerly much more easily reeognized. At present the mixture often becomes so ronfusing that one is almost tempted to imitate the example of Buffon relative to the dog, by establishing, also, for a number of subjects withont any estahlished origin, the large group of street horses (cheranx de rue). In practice, these animals are usually termed common horses, horses of a common rece, a volgar and improper expression, which, literally, by no means conveys the idea of bastardy, but to which, neverthelest, it is intended to make allusion. In such eases, it is hetter to omit mention of the race when it is not very clearly characterized, rather than expose one's self to error in the diagnosis.

3d. Service.-The sevie for which the animal "an be employed is indiated hy these works: "groper to the servier of . ." It is then specified if the aninal in question is a sirlelle-horse, a driving-horse, a 
running-horse, a trotting-horse, a steeple-ehaser, a light- or heavydraught horse, mixed, ete. In general, this factor in the description ean be deeided without diffieulty. When the same subjeet ean be used under the saddle, for driving, as well as for light-dranght purposes, it is said to be for saddle and hurness. We will show, in speaking of the pleasure-services, that motors of this kind are somewhat frequently employed to-rlay, as, for example, the pony and the col.

4th. Coat, its Varieties and its Peculiarities.-The order to be followed here is indieated exactly by the title of this paragraph. We usually say, "color sorrel, bay," ete. Finally, this expression can be simplified by omitting the word coat.

Example: light bay, etc.

The term designating the variety should be placed immediately before it.

Examples: Coat, burnt sorrel ; coat, rusty black; dark roan gray.

Finally, it is necessary to speeify the peculiarities of the eoat by commencing with those which have no fixed loeality, and then mentioning those of the head, of the body, and of the menbers.

Example: brown bay, very rubican, large blaze, leprous spot at the end of the nose and the superior lip, mane and tail mixed, small accidental mark behind the wither's, three white feet irregular and dentated, one of uhich (the onterior right) is smaller.

5th. State of the Mane and Tail.-The tail may be entire or may be shortened by amputation. In the first case, the horse is designated with full mane and tail; in the sceond, docked.

At the present day, many horses have their tails docked, and many persons still tem the subject uith full mane and tail whose hairs have not been shortened, whatever may be the state of the trunk of his tail. But it is evident that it would be more exact to employ the term tail docked, hairs full, for horses whose hairs have been preserved at their full length after the amputation of a part of the trunk. Likewise, we should say tail entire, hairs banged, in all cases in which the trunk is intact and the hairs alone have been shortened, as is observed in the race-liorse.

If this appendage has been sulmitted to an operation after the English style, it suffices to use the word docked. It is understood that in this ease the hairs are always benged. But when the amputation of - the tail has not been done in this manner, the deseription should make , mention of it: . . docked, with full hains. After having given the state of the trunk, the condition of the hairs is indicated.

Example: Tail docked, club-shaped, brush-shaped, etc. 
6th. Age and Peculiarities of the Teeth.-The reader has seen that, from three to six years, the various degrees of the dental wear are indicated by special expressions : rising such age, haring such age, or past such age. These expressions are used in the description when the lrorse has not yet reached his seventh year. When he has passed this age, the facts are far from being as positive. On the other hand, we should not fall into the contrary error by saying that the horse is old or aged. As the determination of the age is no longer absolutely certain, we always make use of the word about as a prefix.

Examples: rising four years, five years, about eighteen or twenty years old, about fifteen years old, nine years old, ete.

In this connection it is also necessary to mention the peculiarities and the anomalies of the teeth; to recognize, for example, if the dental cup is too deep or too shallow; if the horse has supernumerary, double, or badly-direeted teeth, wolf-teeth, ete. ; if any teeth are missing; if those which he has are too long or too short, irregularly worn, etc.; finally, if some of them are worn abnormally from cribbing. These peculiarities or anomalies constitute, nearly always, excellent signs of identification. It is therefore necessary to note them with care.

7th. Height. - The height should be expressed in metres and centimetres, or, what is more preferable and more eustomary, in hands, allowing four inches to the hand. It is also necessary to say in what manner it has been estimated.

Example: height, sixteen and a half hands with standard or with chain.

When a certificate reads that a horse is "about . . . liands high," it is evident proof that it has been impossible for the operator to measure the height with accuracy.

8th. Blemishes and Peculiar Markings.-It may happen in many cases that there are no special remarks to be entered in this paragraph. Be this as it may, we should here enumerate the various blemishes, such as splints, ring-bones, spavin, curb, thoronghpin, windgalls, cicatrices on the shoulders and withers, on the knees, ete.; in a word, all the permanent blemishes. The same applies to the peculiar markings of horses on breeding farms, those of certain public corporations, ete.

9th. Diverse Peculiarities Foreign to the Coat.-Frequently, likewise, it might be advisable to mention in a certifieate of description that the horse has a tendeney to walk in such or such a gait,-the amble, the rumning walk, for example; that he has such or 
such a defect in his equilibrimm (parrot-toed, crooked-legged, bowlegged, eow-locked, under himself, etc.); that he is lame in one of his members when warm or eold ; that he has heaves, rear's, kicks, bites, ete. This information is sometimes of great use, especially in gray horses, which are so diffieult to distinguish from one another. Needless to say, these details are useful in legal documents.

10th. Date of the Certificate.-If a horse always retained the same appearance, it would not be necessary to date the certificate. But this preeaution shonld never be neglected; otherwise, it becomes impossible, at a later period, to verify the age, the height, the shade of the coat, its peculiarities, ete. Besides, it enables us to ascertain the ehanges which have taken place during the time intervening between two successive certificates, and prevents us from erring as to the authenticity of the first one.

We have said at the commencement of this chapter that other facts are sometimes mentioned in the certificate, such as the nume of the horse, his registration number, his price, as well as the name and address of his owner. These four points needing no further explanation, we will confine ourselves to their simple enumeration. The case is different, however, with the pedigree and the performances.

Pedigree.-The term pedigree is synonymous with origin and geneulogy. In stallions, trotters, and rmmers it is especially important to know the pedigree or genealogy. Farther on we will give some examples of certifieates to which are added these particular facts.

The horse whose genealogy lias been entered in the stud-Book is ealled traced; in the contrary case he is marked not traced. This expression is especially applicable to thoroughbred and trotting-horses.

Performances.-This word is employed on the turf to indicate the work which the race-horse is capable of accomplishing. We can easily understand the importanee which is attached to a knowledge of these performances when it concerns animals designed for breeding purposes or for the race-course. There is no public sale of rumningor trotting-horses in which the performances of each subject are not given in a more or less explicit manner.

In general, these certificates are rarely as detailed, and, to speak candidly, it is useless to complieate them execpt when they are liable to figure in legal procecdings, or in the ease of animals designed for breeding purposes.

Most often they are very coneise, and are eonfined to a simple enu- 
meration of the principal distinctive characters : sex, state of the genital organs, service, coat (its varieties and its peenliarities), age, height, and dete.

In the French army all the horses are marked by a number burnt upon the left anterior hoof; the anterior right, on the eontrary, is reserved for a mark indicating the branch of the service and the regiment to which the animal belongs. Finally, each subject bears a particular name; the place where purchased and the price paid for him are always known. These are the various elements whieh enter into a military eertificate, and which should be enumerated in the following order :

1st, registration number ; 2d, nume; $3 \mathrm{~d}$, sex; 4th, age; 5th, height; 6th, color and its varieties; 7th, peculiarities; 8th, where purchased; 9 th, price; 10th, regiment.

On breeding farms the order followed is almost the same. Here, also, the pedigree is added to the certificate, and sometimes the prineipal performances of the subject.

In large transportation companies the order adopted is similar to that of the army, but differing somewhat with each establishment, and for which there seems to be no uniform formula.

In the Compagnie génerale des omnibuts, of Paris, for example, each horse corresponds to a descriptive account, upon which are recorded the following elements: registration number (narked with the liot iron upon the left side of the neck), name of seller, date of purchase, sex, age, height, coat, its varieties and its peculiarities.

Models of Certificates. - IVe will here give a certain number of examples of eertificates in which the principles previonsly mentioned will be applied.

Civil Certificate, very Complete.-Philadelphia, September 28, 1891. No. 243. Harry, gelding, Norman race, proper to light-draught service; coat dark chestnut bay, dappled upon the shouklers and croup, very rubican npon the cheeks, the neck, and the back; head, star prolonged by a small bordered list, deviated to the right, terminated by a marbled leprous spot between and in the nostrils, and prolonged to the superior and inferior lips; three accidental marks, one upon the left side of the withers, the other two upon the right and behind; grayish at the base of the tail; abdomen, axilla, and stifle washed; diagonal left fetloeks, the posterior irregular, dentated, and ermined; pastem, anterior right, bordered, speekled; tail docked and banged; age six years; one supernumerary left superior intermediate; absence of superior right canine; $16 \frac{1}{2}$ hands high with standard. Small spavin on left hock, with tratces of actual cautery in points in same place; outbow-foot anterior right ; interfering 
mark left anterior fetlock. Bought for $\$ 500$, in 1880 , of $\mathrm{X}-$, horse-dealer in Philadelphia.

The same, less Complete.-Philadelphia, September 23, 1891. No. 243. Norman gelding, light draught; dark chestnut bay, dappled, rubican ; hearl, star prolonged by small list, deviated, terminated by leprous spot at the nostrils and at the inferior lip; three accidental marks upon withers; grayish at the base of the tail; three white feet, one of which, the anterior right is but slightly marked; tail docked; age six years; $16 \frac{1}{2}$ hands high, standard; bought for $\$ 500$, at Philadelphia.

The same, more Concise.-Gelding, ehestnut bay, dappled, rubican ; head, star prolonged by list, terminated by leprous spot at the nostrils and at the inferior lip; tail docked; three accidental spots upon the sides of the withers; three white feet; six years; $16 \frac{1}{2}$ hands high; price $\$ 500$. Philadelphia, September 23,1891 .

The same, too Incomplete.-Gelding, chestnut bay; star prolonged by a small list, terminated by leprous spot; three white feet; tail docked; six years; $16 \frac{1}{2}$ hands high.

[The following is a convenient formula of a certificate which I have used in examinations for somndness, and which gives entire satisfaction. (Harger.)

No.

Philadelphia,

Mo. 189

EXAMINATION FOR SOUNDNESS.

This Certifies that I have this day examined, at the request of

$M$

Animal, _._. Height,

Markings,

NOTES :

From above notes, in my judgment, said Animal is

Above examination does not include such obscure diseases as Staggers (Epilepsy and Immobility), Moon-blindness, Cribbing, without marking teeth, etc.]

It will be seen from the preceding examples that the details of the coat and its peculiarities, as well as most of the other secondary matter, are gradually omitted. The animal is conseqnently more and more easily confounded with the others, especially if the latter comprise a large number and belong to a troop in which the horses are almost uniform as to the coat and its shade and as to their height.

The expression simple, by which is designated a certificate in which the details are very summary, is not to be encomraged. The de- 
seription is either complete or incomplete, detuiled or summary. The horse alone which is described may be simple or complicated in his characters, and then the certificate will be more or less complete according as it is detailed or summary. It is not possible to be brief and at the same time complete in deseribing a thing which is complieatecl. It is proper to be relatively concise, and it is always well to pass upon the value or the worthlessness of certain observable facts. It is evident that if we propose to give simply the data of a clinical observation of a given horse, the enumeration of his registration number, his name, the peenliarities of his eaat, ete., will be of no interest in the case. If, on the contrary, it refers to an animal concerning which there is some difference, for example, we should note all the facts without fear of making it too detailed.

\section{Examples of Military Certificates.}

a. "No. 1212. Jupiter, gelding, four years; $1.60 \mathrm{~m}$.; eherry bay, snow-flaky upon the croup; head crescent to the right; mule stripe; three white feet, of which one, the anterior left, is bordered and trout-spotted." (Vallon.)

b. "No. 15. Cornelins, stallion, four years; $1.40 \mathrm{~m}$. ; golden sorrel ; posterior stockings, dentated and ermined around coronet." (Merche.)

c. "243. Alcide, gelding, six years; $1.54 \mathrm{~m}$.; golden sorrel ; head mixed; list bordered upon forehead, terminating in leprous spot between the nostrils and the lips; lateral right white feet, the posterior small. Bought at Angers, January 3, 1873, 600 francs. Traced. Trace, of blisters on the thighs." (Commission d'hỵgiène hippique.)

d. "Regulus. Barb horse, entire; foaled at the stud of Bòne (Alélick) in 1846 ; height $1.49 \mathrm{~m}$. with standard; light gray, much trout-spotted, especially upon the cheeks and around the eyes; black monstaches; traces of actual cautery in points on a spavin of left hock and string-halt on same side; sold as a stallion, 1500 francs, April 1, 1852." (Merche.)

The last example is given as a model for a detailed ecrtificate.

\section{Examples of Certificates for Breeding Establishments.-} As we have said, we add, on the stock-farm, the pedigree, the performances, and the get of such or such a stallion, also the place and date of birth.

a. "Thoroughbred colt, by Royal Oak and Carisandre, foaled March 8, 1847 , and entered in the French Stud-Book under the name Fianetta ; coat light bay, bordered list prolonged to the extremity of the nose; trace of white foot posterior right, ermined ; high stocking anterior right, bordered and irregular." (Riclaard, du Cantal.)

b. "Thoroughbred brondmare, entered in the French Stud-Book under the name Josephine; by Napoleon and Agar; foaled in 1840 . Height $1.66 \mathrm{~m}$. Burnt sorrel, rubican upon the croup and the base of the tail; traces of white feet left diagonal biped ; blaze prolonged by a sinall list, bordered upon the forehead ; grayish upon the right cheek." (Richard, du Cintal.) 
c. "Agar, English thoroughbred mare; $1.58 \mathrm{~m}$; sorrel; flame; white foot posterior right; foaled at the stock-farm of Pin in 1837; sire Eastham, dam Danaé.

$$
\begin{aligned}
& \text { "Eastham : sire, Sir Oliver; dam, Cowslip. } \\
& \text { "1840. Imbroglio, by Paradox. } \\
& \text { "18+1. Ben Agar, by Lottery. } \\
& \text { "18+2. Reine-de-Chypre, by Eylau." (Vallon.) }
\end{aligned}
$$

In certain cases the pedigree is more complete. The following is an example taken from the Journal des haras. ${ }^{1}$
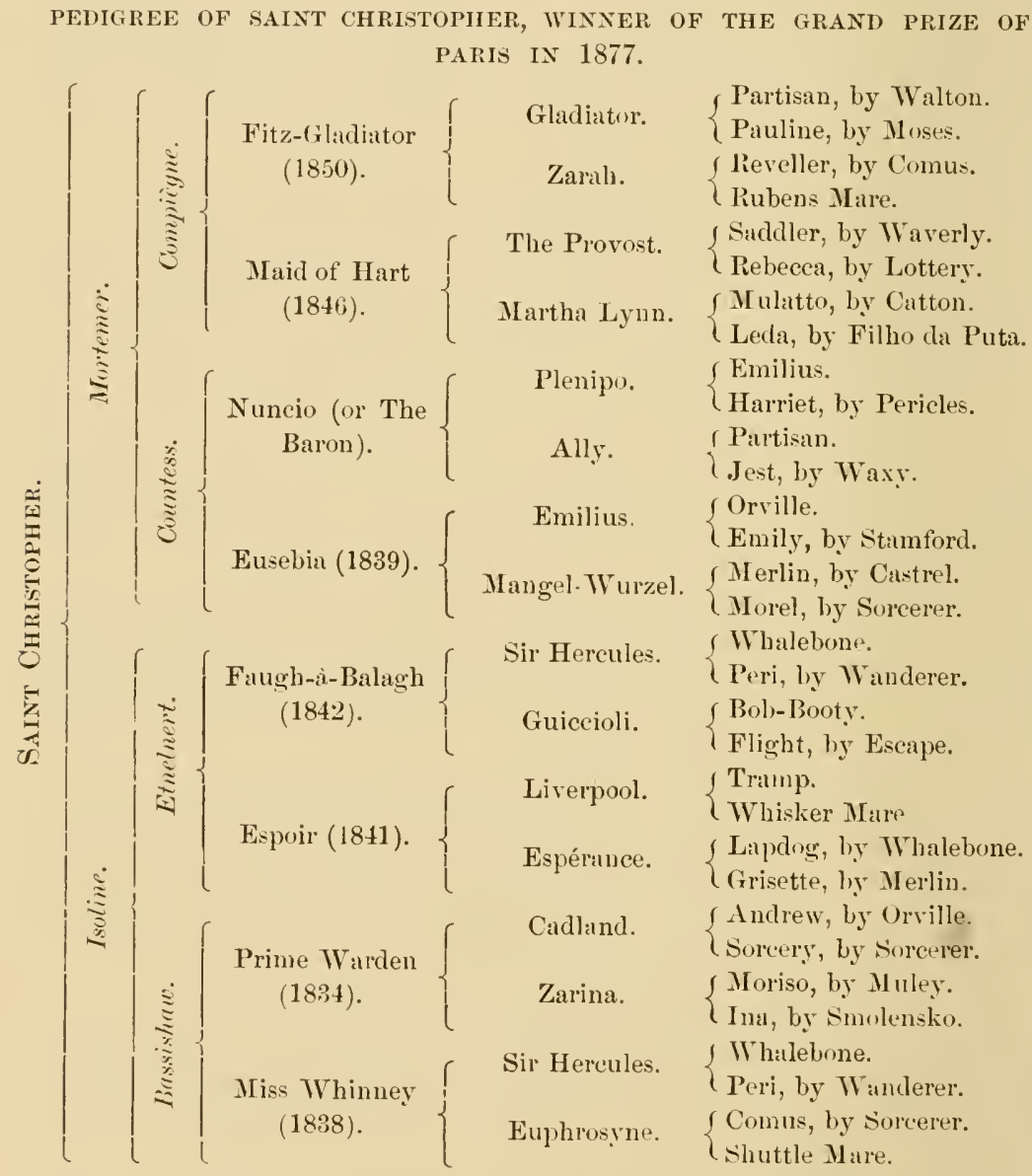

The pedigree only contains so many minute details when it concerns a celelorated horse. If Saint Christopher had not won the 
Grand Prix de Paris, his pedigree would have been indieated in the following manner :

Saint Christopher: sire, Mortemer ; dam, Isoline.

Mortemer: sire, Compiègne; clam, Countess.

Isoline: sire, Etnelnert; dam, Bassishaw.

Compiègne: sire, Fitz-Gladiator; dam, Maid of Hart.

Comtess: sire, Nuncio; dam, Eusebia.

Etnelnert: sire, Faugh-à-Balagh; dam, Espoir.

Bassishaw: sire, Prime Warden; dam, Miss Whinney.

Sometimes we prefer to recognize more espeeially the direct genealogy of the two progenitors. The pedigree is then formulated as follows:

\section{Saint Christopher.}

Sire, Mortemer.

G. s., Compiègne.

G. g. s., Fitz-Gladiator.

G. g. g. s., Gladiator.

G. g. g. g. s., Partisan.
Dam, Isoline.

G. d., Bassishaw.

G. g. k., Miss Whinney.

G. g. g. d., Euphrosyne.

G. g. g. g. d., Shuttle Mare.

In eonnection with the pedigree a list of the animal's performances is enumerated, if he be a celebrated one. It should be remembered, nevertheless, that in order to operate with rapidity and precision it is neeessary to have mueh practice, a methodical proeedure, and quick perception. All certifieates that are intended for public use shonld be previously revised and correeted with care. 


\section{SECTION SEVENTH.}

\section{THE APTITUDES OR THE SERVICES.}

The horse's strength is employed in moving burdens placed upon his back through the agency of the saddle or the paek-saddle, or dragged along the ground, either directly or by means of particular vehicles on wheels, or hauled on the surface of the water.

In other words, he camies or he pulls; exceptionally, he does both at the same time. In both eases the effort to be made depends in great measure upon the weight of the burden, the velocity with which it is moved, and the consistency and inclination of the surface upon which it rests.

From this point of view, we should primarily establish two principal categories: saddle-horses and hamess-horses. Practically, however, these would be insufficient, and would confound aptitudes which it is important to distinguish. The special exigencies of luxury, the army, commerce, industry, and agrieulture evidently require some degree of specialization ; again, we must not lose sight of those requirements which relate to the reproduction of the species.

Therefore we will divide the services into four prineipal chapters. In the first we will study the race-horse, whose pecuniary value is the most considerable; in the second we will treat of horses of huxury; in the third, cavalry horses ; finally, in the fourth, horses for industrial and commercial purposes, whose average value is generally inferior to that of the preceding.

We will add that, aceording to his eategory, the horse is constantly utilized as an animal of force or of speed and, more rarely, as a mixed motor. All things being equal, it follows that his height and bulk should, before all other attributes, constitute the principal elements by which to class him in such or such a group, because these elements, united to the bulk and elevation of the vehieles, are in direet relation with the extent or intensity of the muscular contraction, the greatness 
or power of the effort to be made. Afterwards will follow, as a secondary although very important consideration, the examination of his conformation, his breeding, his gaits, his origin, and his performances, if there be any, his dressing, his training, his coat, ete. Under these different aspects we will briefly investigate each service. The information given concerning prices is not absolute, in this seuse, that they are subject to variation according to circumstances, but they are drawn from a good soure and represent with sufficient accuracy the actual value of the horses in the place under consideration.

\section{CHA P T E R I.}

RACE-HORSES.

IT is not our intention to give an opinion here upon the utility and value of races, tests by the aid of which it is sought to ascertain the qualities of speed and endurance of a certain number of subjects which are designed for breeding purposes, in order to ameliorate the equine species. We simply wish to recall that animals which undergo these trials may aequire considerable value on account of the possibilities hoped for in them either as reproducers or as machines destined to win prizes.

Thus considered, these animals constitute a category with welldetermined limits, concerning which we should say a few words.

Wre will divide race-horses, according to their specialization, into running-horses, steeple-chusers, and trotting-horses.

\section{A.--Running-Horse.}

Mode of Utilization.-As his name indieates, the rumuing-horse is always ridden upon the race-course at a fast gallop,-that is to say, upon chosen ground, almost flat, and never presenting obstacles to be leaped over. The jockey who mounts him uses every effort to make him travel over the ground with the greatest speed possible.

Height.-His height varies from 1.5.5 metres to 1.6 .5 metres, lout the highest is sought for, since it places the animal in the best conditions to take long stricles.

Conformation.-Wre have indicated on page 406 the prineipal features of this conformation. The rumning-loorse (Fig. 3333) should 
have a high chest and long members; a short body and strong loins; the neck, shoulder, croup, thigh, buttock, leg, and forearm should be long, without being too heary in the upper part; the members strong, clean, and free from blemishes; he should have wide and thick articu-

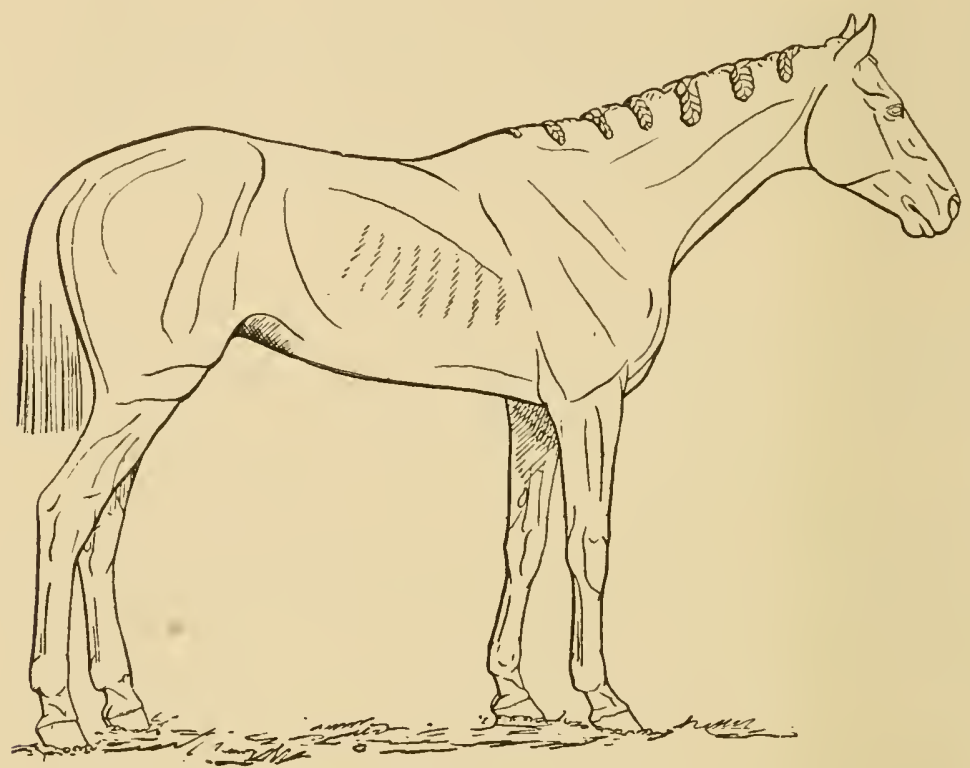

FIG. 333.-Running-horse.

Vermout, winner of the great prize of Paris in 186t. (Reproduced from a photograph belonging to M. Delton.)

lations, closed in the superior angles, open in the inferior; a deep chest, abdomen slightly full ; fine skin, hair, mane, and tail ; an animated and expressive physiognomy; he should be graceful, nimble, elegant, excitable, energetic, impetuous, and of great endurance.

Preferred Coats. - The two coats which are the most common are the bay and the sorrel, sometimes the roan, and more rarely the roan gray; the black is but little esteemed, the qualities of the horse being, of course, taken into consideration.

Price.-The price of a ruming-horse is as variable as that of a work of art. It is determined, for the eighteen montls' colt, or the yearling, which has not yet appeared upon the turf, aceording to his genealogy and his conformation. At that time the greatest value is attached to the qualities of the parents and even of the grandparents, especially when they are combined, in their descendant, with great perfection of form. In such cases, the value of the young subject 
remains always contingent, since he has not yet shown what he is capable of accomplishing. Speculations have no other base than the succession of trials undergone during the training. Under these conditions the price may vary from $\$ 200$ to $\$ 6000$.

Begiming at the age of two years, as soon as the colt appears upon the race-course, his value increases in proportion to the number and nature of the prizes which he has won. His value as a stallion may then be $\$ 2000, \$ 6000, \$ 10,000, \$ 20,000, \$ 40,000$, and even $\$ 60,000$, when his conformation is perfect. On the contrary, if he has not been successful, his owner can scarcely dispose of him for a few hundred dollars. With such variations, it is impossible to determine anything. Horses which have been purchased for $\$ 20,000$, by reason of the hopes arising from a victory too easily won, have been known, after a few easy defeats, to depreciate in value to $\$ 1000$ or even to $\$ 600$ !

Origin.-The rumning-horse is always of the so-called thoroughbred blood. His pedigree is inseribed either in the English or French Stud-Book. It is therefore very easy to become accurately informed as to the qualities of his ancestors by consulting one or other of the aforesaid records.

\section{B.-The Steeple-Chaser.}

Mode of Utilization.-This name is given to a variety of horses which only appear in races in which obstacles are to be leaped over. Here, again, the horse is mounted and always ridden at a rapid gallop. The trial takes place upon the race-course, as in the preceding case, but a series of artificial obstacles are intentionally placed upon the track, snch as hedges, walls, ditehes, brooks, Irish benches, ete, over which the animal must leap successively before reaching the end. This lind of race, being much more exciting, delights the public infinitely more than the ordinary race, on account of the incessant dangers threatening, at cach new obstacle, the jockey and his mount.

Height.-The medinm height is comprised within the sime limits as that of the preceding,- - that is to say, between 1.5.5 metres and 1.65 metres. The intrinsic value being equal, preference is given to the tallest subjects, because they are able to leap orer higher obstacles without loss of speed.

Conformation.-The conformation does not differ much from that of the rumning-horse, for only horses which have not performed well on the race-course are risked in the stepple-chase. High withers, a short and straight dorso-lumbar region, a strong and beatiful attach- 
ment of the loins; large and strong museles of the hind-rquarters, partienlarly of the eronp (which, withont ineonvenienee, may be a little inclined), the thigh, the buttock, and the leg; development of the articulations, especially of the hocks and the pasterns; strength and beauty of equilibrim of the anterior members; finally, a rather short body,-such are the principali qualities to be sought for. It is evident that training constitutes an essential element of this condition. If the subject is not trained with the special purpose to jump high, freely, and with skill, it is nseless to enter him in this kind of race, whatever may be the perfection of his form.

The horse which we have chosen (Fig. 334) as a type is BoisRoussel, which won the French Derby in 1864. Although he never

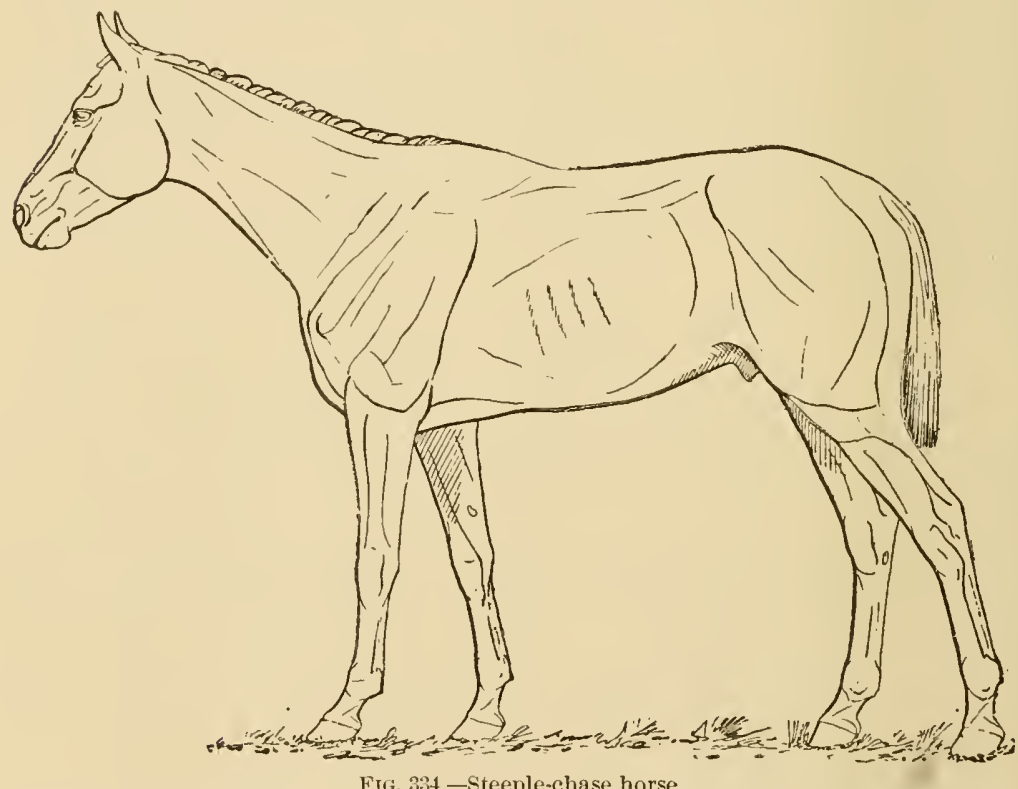

Bois-Roussel, winner of the French Derby in 1864. (Reproduced from a photograph belonging to $\mathrm{Ml}$. Delton.)

ran in a steeple-ehase, his whole conformation indieates how great would have been his fitness for this service had he been trained with a view to it. It is, then, quite intentionally that we here recommend his portrait to the reader's attention, in spite of the different use to which he has been put by his owner.

Preferred Coats.-Most subjects in this category are bay, sorrel, or roan, but excellent ones are found among the other color's. 
Price.-The price of the steeple-chaser is as variable as that of any other race-horse. It is determined according to the perligree and the conformation in the colt which has not yet performed; on the other hand, accorting to the performances and the suceesses obtained when he has already appeared upon the turf.

Ordinarily, it is inferior to that of the preceding, because the animals which are entered in steeple-rhases are neither as beantiful nor as serviceable. It is evident that if their chances of winning a prize on the race-course were good, it wonld be to the advantage of their owners to utilize them in this way, for aecidents are much less common. For these reasons we give, based upon very gencral indications, the figures $\$ 200$ to $\$ 12,000$ as representing the approximate value of this variety of horse.

In a large number of hippodromes it is rather common to meet among steeple-chascr's running-horses which have met with some accident in a former race, a laceration or rupture of the tendons, for example. They are then said to be broken down. In this case, they are castrated with a view of modifying somewhat their conformation, and are then fired that they may regain their strength. However, their price is diminished in proportion to the blemishes of which they still bear the traces.

Origin.-Formerly the half-thoroughbred horse was employed for the stecple-chase, being foaled and raised exchusively with a view to this end. Little by little the trainers eoneeived the idea of making use of the thoroughbred horse, which experience has always shown to be superior in speed and endurance. For this reason we no longer sce the half-breed at the present time.

\section{C.-Trotters.}

On a parallel with the running races are placed the trotting races, in harness or under the saddle, for which purpose a particular variety of horses is produced. We must then distinguish at once in this group trotters in hamess and trotters under the saddle.

\section{Trotters in Harness.}

Mode of Utilization.-As their name indicates, these animals are always driven upon the race-track harnessed to very light vehicles called sulkies or skeletons.

"The sulky is composed of a small seat, without covering, for a single person. The driver has his legs separated, and his feet rest upon two bars fistened to the shaft:; besides, the horse is harnessed so short that his hind-quarters are placed between the two lougs of the 
driver. This vehicle is not suspended; a pair of very large light wheels, an axle, and two shafts form the whole, which does not weigh more than twenty-five kilogrammes."

In construction and lightness the skeleton resembles the sulky very much, but it has four wheels and is not very high.

In Russia and in England the trotters in harness are often utilized with the vehicles of which we have just spoken; in America, principally in the United States, a skeleton a little modified, known under the name of buggy, is used, which the French vulgarly call araignee (spider), because of its aspect, or mort-subite (sudden death), on aceount of the dangers to which it exposes the driver when rounding the turns. In Norway, the Norwegians employ it; in cold countries, in general, the sleigh is used.

Height.-The ordinary height of these horses varies from 1.52 metres to 1.65 metres.

Conformation.-The animal should be harmonious, unblemished, well constructed in the body and in the members. Wither's rather low and loins slightly weak may be overlooked, but a powerful croup, thighs, buttocks, legs, and hocks are essential ; also, long neck, shoulders, and forearms; not too horizontal in the croup ; normal inclinations of the superior segments of the members; width, height, and depth of the chest; wide, thick, neat, and elean articulations; in a word, all the characters of a beantiful conformation. It is especially when in motion that a trotter can be judged. By his actions, lengthened, close to the ground, and regular, by the extent and complete projection of the anterior members, and by the energetic action of the hind members, he will manifest in the best way his aptitude as a trotter.

We give as an example of this variety (Fig. 335) the portrait of Fazan, a Russian stallion of great value, presented to the Emperor Napoleon III. by Czar Alexander II. at the time of the Universal Exposition in 1867.

Finally, with respect to edneation or training, he should be aecustomed to preserve the trotting gait during the whole duration of the race. The rules specify formally that every horse which breaks (runs) is obliged to resume the trot immediately. This change from a fast gait into another less fast always causes loss of time and a considerable slackening of speed. Subjects of the first rank are not wanting in number, which have the greatest difficulty in wimning a prize, because

\footnotetext{
1 Belvalette et Quenay, Rapport du jury international de l'Exposition universelle de 1878 (section de la carrosserie et du charromnage), p. 46, Paris, Imp. nat., 1880.
} 
they are too ardent, too excited, from the moment they appear on the track until the end of the race.

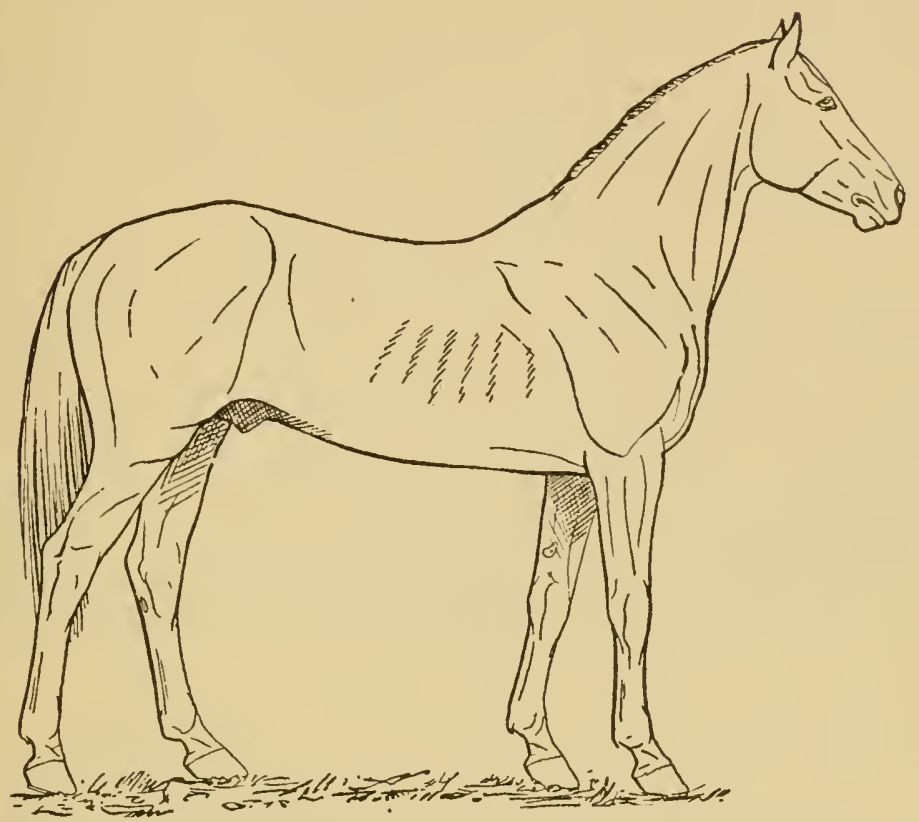

FIG. 335.-Trotter in harness.

Fazan, Russian stallion of the Orloff variety. (Reproduced from a photograph belonging to M. Delton.)

Preferred Coats.-Properly speaking, there are not, anong trotters under harness, any preferable coats. It may simply be said that the dark colors, bay or sorrel, are always the most estecmed.

Price.-The price of geldings and mares varies from $\$ 600$ to $\$ 2000$ and even $\$ 40,000$. Stallions are much more expensive; to our knowledge there are some which have brought as much as $\$ 105,000$ in America. Here, again, the differences of price result from causes of the same nature as those which influence the value of race-horses in general; such are the pedigree (genealogy), the conformation, the gaits, the performances (trials undergone), races won, ete. We will dwell no further upon these.

Origin.- Several countries are renowned for their trotting-liorses. The United States, England, Russia, and France furnish the most remarkable examples. The American trotter has only lately been imported into Europe; the English is lreed mostly in Norfolk and also in Yorkshire; the Russian is found in the stud of Orloft"; as to the French, he comes especially from Normandy, more rarely, from the Ardennes. 
These animals all possess great speed and endurance. However, if we wish to classify them with regard to speed, the Ameriean and Russian ordinarily come first, whilst the Norman and English only hold the second place. As regards endurance, the Norman and English exeel the American and Russian. We will find these last two excitable; their chest would be improved were it a little higher, like that of the English horse, for example.

\section{Trotters under the Saddle.}

Mode of Utilization.-Trotters under the saddle appear on the race-course always momted, like the rumning-horse or the steeplechaser; it is useless to add that they never have any obstacles to leap over.

Height.-Their height, slightly inferior to that of the preceding, varies between 1.50 metres and 1.62 metres.

Conformation.-CTheir conformation is the same, although still greater perfection is sought, particnlarly with regard to the fore-quarters,

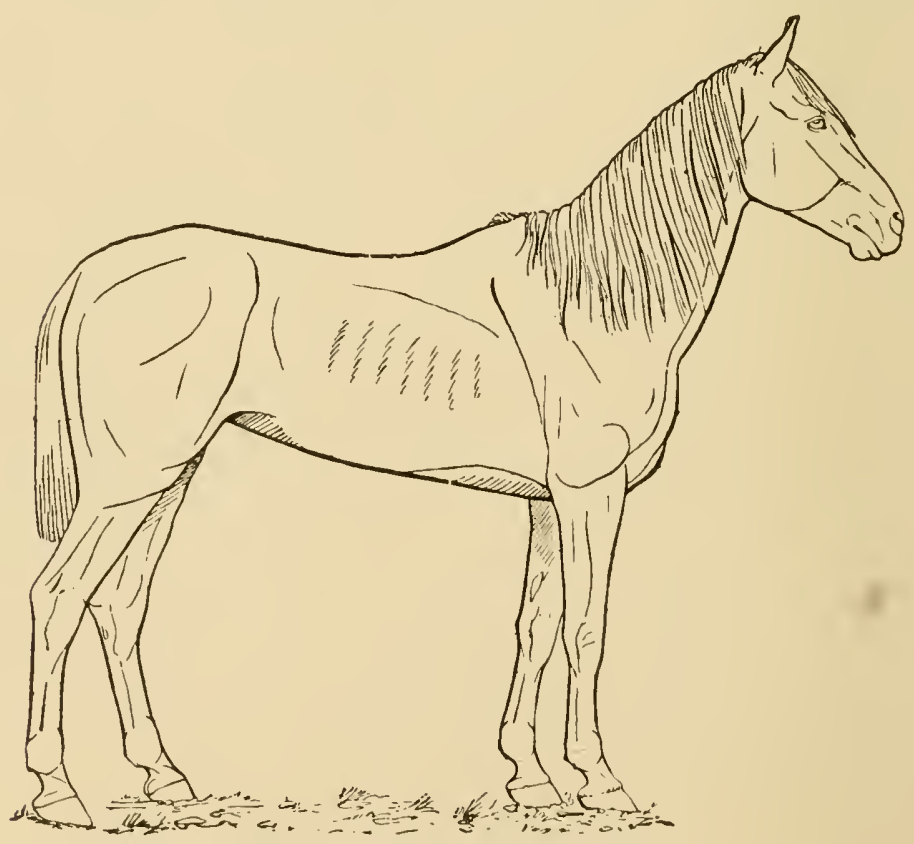

FIG. 336.-Trotter under the saddle.

Bayadère, Anglo-Norman mare. (Reproduced from a photograph belonging to M. Delton.)

already burdened with the weight of the rider. For the trotter in harness, withers somewhat low, a back slightly hollow, loins rather 
weak, and anterior equilibrium somewhat defective, mar be overlooked; but such defeets are mupardonable in the trotter under the saddle.

We grive as an example the portrait of Bayadère (Fig. 336), a celebrated Norman trotter, never beaten, and foaled in 185.3 by Phenomenon and Bayadère (by Ramsay), victor in twenty-two trotting races at the expositions of 1862 and $186 \%$.

Preferred Coats.- Taste and fashion have established nothing in particular in this respect; there are no coats of special value; the darker ones are preferred, bowever, to the others.

Price. - The prices here are lower than those of the preeding category, becanse horses trotting under the saddle are less common and less in demand than those trotting in harness. These prices vary from $\$ 400$ to $\$ 2000$ and eren $\$ 2500$ for geldings and mares. For stallions four years of age as much as $\$ 5000$ have been paid.

Origin.- Nearly all these animals originally came from Normandy and Norfolk, and result from erossing practised for a long time between the local races of these comntries and the thoroughbred horse.

\section{CH A P'T ER I I.}

\section{HORSES OF LUXURY.}

In this group we place horses used for the trot and the gallop, but never appearing upon the turf. These are exclusively animals of display ; they are mounted or hamessed ; more rarely they are adapted for horseback riding and for driving. Their service, which is not fatiguing, consists of a single drive of two or three hours at the most, during which they move at moderate speed.

They constitute an important commercial element, which recommends itself both by the number of its representatives and the high prices which they reach.

We will divide them into two eategories with respect to their destination: coach-horses and saddle-horses. The former having a much greater value than the latter, will be examined first.

\section{A.-Coach-Horses.}

Coach-horses are so called from the name of the vehicles with which they were formerly used. These horses are harnessed at the 
present time to all carriages of luxury, in pairs or single, according to cireumstanees.

With respect to height and bulk, they are again subdivided into large coach-horses and small coctch-hoises.

\section{Large Coach-Horses.}

Mode of Utilization.-The large coach-horses are nearly always driven in pairs, two or four at a time, to large carriages of luxury of various kinds.

Height._-The average height of these horses varies from 1.63 metres to 1.70 metres; exceptionally, some of 1.78 and even 1.80 metres are found.

Preferred Coats.-The coat, in this eategory, has an importance which must not be neglected. The ordinary bay, the brown bay, and the burnt or golden sorrel are the colors most highly prized.

In certain cases two subjects of different coats are harnessed together: a brown bay and a beautiful dappled gray or a white horse, for example. This variegation is, however, no longer fashionable; it attracts the eyc and has a pretentious appearance, and at the present time, at least, is not often seen among the aristocracy.

Formerly, two dark horses, alternating with two light ones, were driven in pairs to a mail-coach or a Daumont earriage. They are then disposed like a checker-board, according to the common expression : a dark and a light at the pole, and a light and a dark in tront. The result is that coats of the same color are placed diagonally. This is, be it understood, a purcly fantastic or eapricious blending of shades.

The black coats are but little esteemed; they are only made use of as evidences of mourning. In such cases, the carriage and harness, as well as the dress of the coachman and footman, are black. Unless the owner be in mourning, a black team is no longer fashionable. Hence a black coat should be, to the buyer who is above questions of fashion, a forcible pretext for depreciation.

Conformation.-The large coach-horse, being the horse of display par excellence, should have a perfect conformation and gaits as brilliant as possible. His intrinsic value is of secondary importance, for he has always enough endurance to perform the service required of him, which is not laborious. The horse thus chosen should have a square head, rather light, neat, and expressive; a long, supple, and well-attached neek; beautiful withers; oblique and muscular shoulders; a good dorso-lumbar line; a horizontal croup with a tail well attached and well carried; a round and descending rib; a full and 
short flank, a muscular thigh, a descending buttock; strong, elean members without defeet; small feet, etc. If slender, he does not properly fill the harness and appears disproportionate with the vehicle to

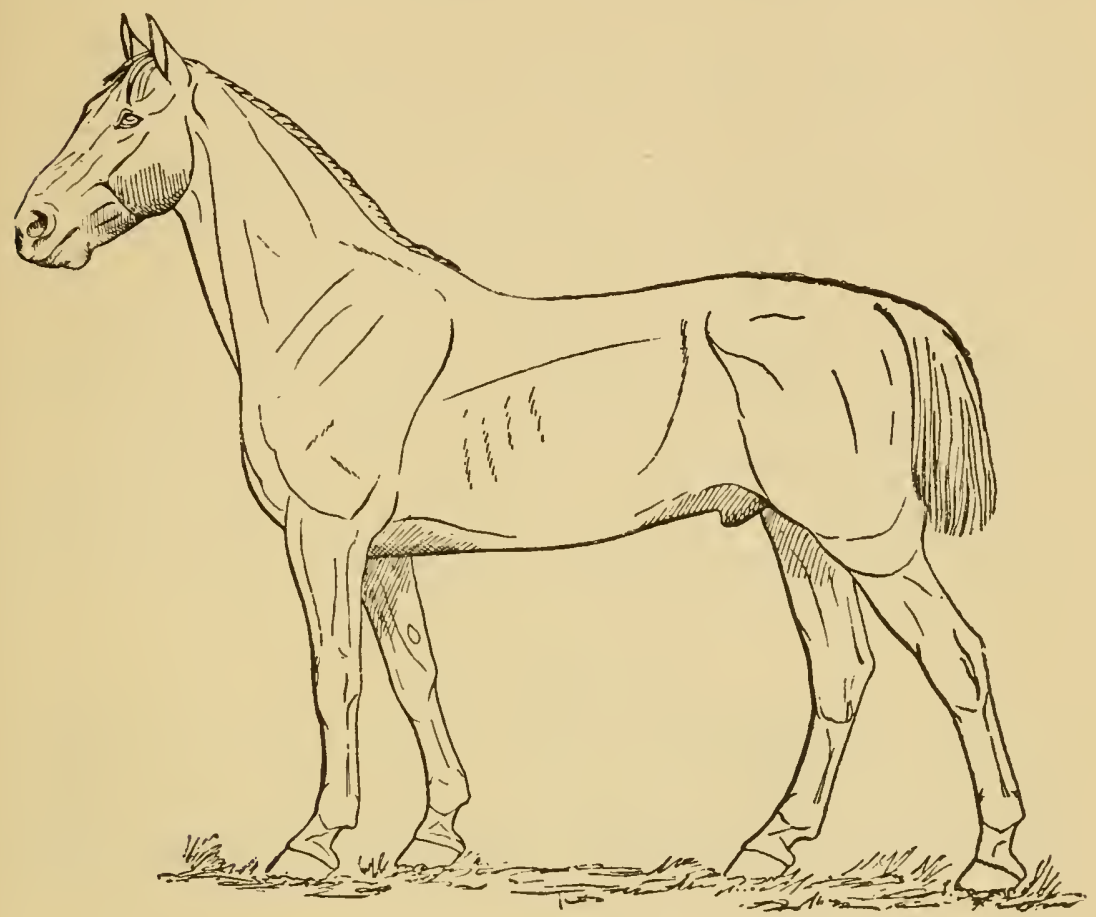

FIG. 337.-Large coach-horse.

Lahore, half-thoroughbred Anglo-Norman, belonging to the Marquis d'Aligre. Grand prize at the horse exposition of 1868 . (Reproduced from a photograph belonging to M. Delton,)

which he is harnessed ; too stout, he becomes heavy, massive, wanting in suppleness and grace; he must be fine and well proportioned (Fig. 3337).

Origin.-WThe most valuable large coach-horses are half-breeds (métises) more or less resembling the horses which come from England, particnlarly from Yorkshire and Lincolnshire; the largest among them are bred in Suffolk. Normandy, especially the plain of Caen, furnishes some very handsome ones, but they are second to the English. Then eome the German and the Dutch coach-horses, the former raised principally in Hanover and Mecklenburg, the latter in Friesland. Both are very mumerous in the Paris market. They are brilliant, have considerable style, and are sometimes from very goorl ancestry. However, their conformation is sometimes inferior to the English and the Norman coach-horses; they often lack something to be desired. 
Among these horses the defects are seen in their long, narrow head, which is but slightly arched and poorly attached; their eyes, which are placed high ; their slender neek, flat ehest, weak baek, long and poorlyattached loins, hollow flanks, prominent haunches, slender members, coarse mane and tail, and large and flat feet. Their movements, it is true, have a certain clegance, but they are excitable. These subjects trot from the knee (knee-action) and are wanting in speed and in activity.

Price.-The price varies according to the size of the animals, their conformation, breeding, pedigree, coat, and especially according to the dressing, the mating, and the brilliancy of their gaits. It varies, for a pair of fine coach-horses, firom $\$ 2000$ to $\$ 3000$ and even $\$ 4000$.

But this price increases very much when two pairs of horses, very similar and well mated in all respects, are selected, for they are obtained with difficulty. Under these conditions, there are examples of two matched pairs which have eost as much as $\$ 12,000$ and $\$ 15,000$.

On the other hand, it is possible to buy a pair of Hanoverian, Mecklenburg, or Friesland horses for $\$ 1000, \$ 1500$, or $\$ 1800$ at the most, but they are never coach-horses of the highest grade.

\section{Small Coach-Horses.}

Mode of Utilization.-The small coach-horse is harnessed single or double to carriages of less weight, such as the landau, threequarter coupés, ordinary coupés, ote. Less wealthy people drive them sometimes to the landau and the calèche as they would a large evachhorse, which wonld, however, be much more in aceord with this lind of vehicle were his price not so high.

Height.-As its name indieates, this horse is of inferior size to that of the preceding; it varies from 1.56 metres to 1.62 metres.

Preferred Coats.-The whims of fashion are licre as exacting as for the large coach-horsc. If the light eoats, principally the gray, are preferred, it is on condition that the subjects have some exceptional qualities.

Conformation.-The conformation of this horse always implies elegance, style, firmness, brilliant and striding gaits. Nevertheless, he should be more bulky, more stocky, and closer to the ground than the large coacher. Busides, proportionally, his work is more considerable, since he is generally driven alone to carriages almost as heary. Among other beauties, he must have a neat head, long neek, good withers and shoulders, strong body, strong members, without defect and with good equilibrium, good action, and enongh bulk to fill the hamess woll (Fig. 338). 
Origin.-The finest small coach-horses come from England and Normandy ; the latter are produced in Merlerault (Orne); the Hanoverian, the Mecklenburg, and the Dutch oceupy a second rank.

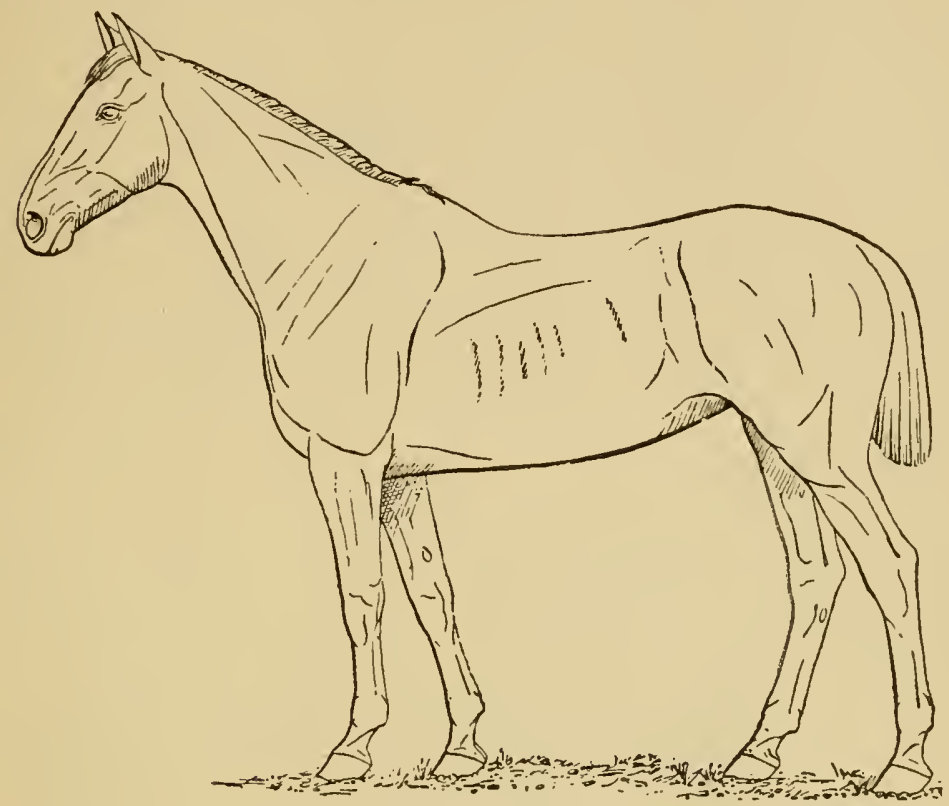

FIG. 338.-Small coach-horse.

Shang-Haï, half-thoroughbred Anglo-Norman. Grand prize at the horse exposition of 1868. (Reproduced from a photograph belonging to M. Delton.)

Price.-This horse is necessarily inferior in value to that of the large coach-horse. In the first place, he is smaller; again, his mating need not be taken so much into consideration, since he is oftener driven single; finally, when driven double, he is mated more casily, because there are more from which to choose and less to be exacted.

Besides, his price is subject to the same variations, inherent principally to the size, conformation, breeding, coat, and brilliancy of the gaits. It varies from $\$ 500$ to $\$ 1200$. The pair has an average value of from $\$ 1400$ to $\$ 1600$; exceptionally, from $\$ 2000$ to $\$ 2400$

\section{B.-Saddle-Horses.}

All horses of this catecrory may be ntilized for the service of the saddle, some exclusively, others accessorily, they being fitted for a double purpose. If we have joined these latter to the former, it is as much to avoid making a division as to call attention to the fact, that they are harnessed perhaps less often than they are mounted. 
We will adopt here, as in the preceding groups, the distinctions established in commerce.

\section{The Hackney.}

Adaptation. - The saddle-horse of pure luxury, which is reserved for the promenade and for display, and which is put to no other use, is the hackney. He ocenpies, in the list of saddle-horses, the same place as the large coach-horse among the coach-horses, - that is to say, the first rank. He is chosen for gentlemen or for ladies and young men. In the first case, he is generally larger, more nervons, better bred, higher, and has a longer gait; his price is also higher.

Height.-For a man, a hackney of 1.55 metres to 1.62 metres is needed; for ladies and young men, he may be smaller, since he is

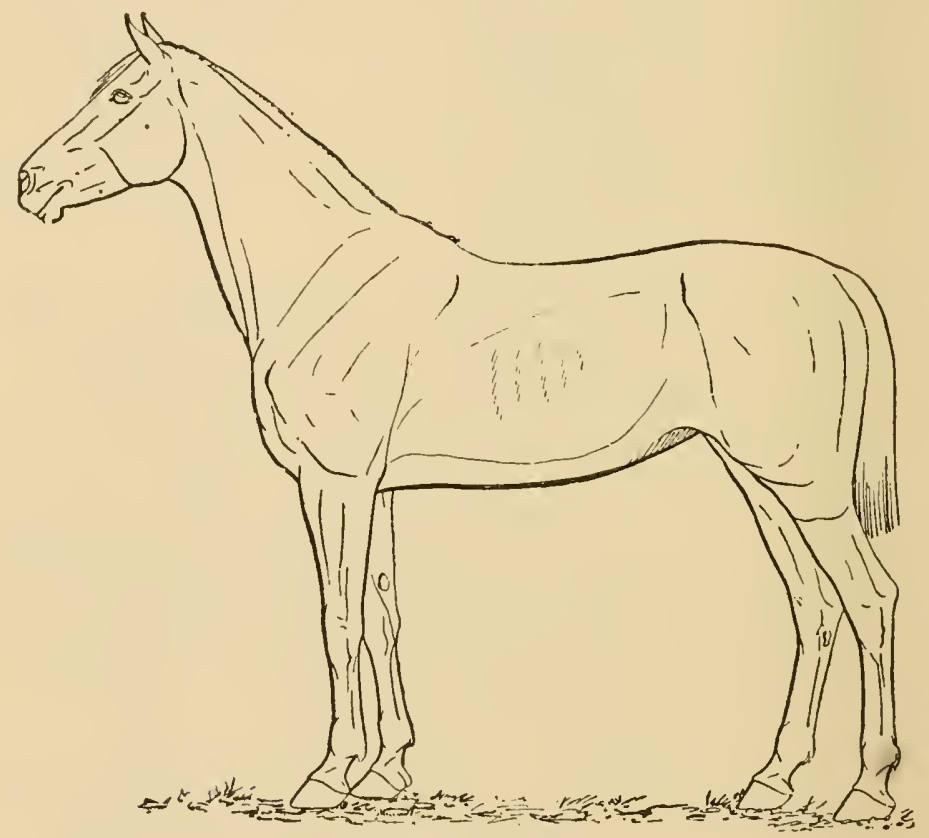

FiG. 339.-Hackney.

Gelding belonging to the Princess of Metternich. (Reproduced from a photograph belouging to II. Delton.)

intended to carry less weight; his height also varies from 1.54 metres to 1.60 metres.

Preferred Coats.-These are, indisputably, the dark sharles: the bay, brown bay, golden or burnt sorrel. The gray coats, on accomt of their resemblance to those of common horses, are but little valued. 
Conformation.-The purity of the anatomical outlines approaches perfection; the harmony of the form and the fine proportions of the body give to the connoissenr an impression of plastic beauty; the thinness of the integument, the neatness of the members, and the beauty of the whole are carried almost to extremes; the ease and suppleness of the movements, the gracefulness of the attitudes, the nobleness of the walk, the expression of the physiognomy, the pride and intelligence of the look, the elegance and brilliancy of the gaits, united to breeding, docility, impetuosity, and ardor, - such are the qualities which this horse should possess, the animal chosen by every sportsman really worthy of the name (Fig. 339).

Origin.-The finest hackneys are often of pure English breeding, sometimes Irish very nearly thoroughbred. Eastern Prussia also furnishes some; they are known in commerce by the name trakens, becanse they are produced principally in the stud of Trakehnen. Some, also, come from Würtemberg, in the neighborhood of Stuttgart. Finally, Normandy possesses some that are quite handsome, principally in that part of the department of Orne which is ealled Merlerault.

The hackney lightest in weight, that which is preferred for ladies and young men, is found among horses of all origins, many of them, however, being small thoroughbreds and horses from Southern France, principally from the vieinity of Tarbes.

Price.-The price of these animals varies much according to size, conformation, fineness, breeding, gaits, coats, ete. The largest ones cost from $\$ 600$ to $\$ 1400$ or $\$ 1600$; the smaller ones from $\$ 200$ to $\$ 1000$ or $\$ 1200$.

\section{The Cob.}

Mode of Utilization.-The cob is a horse of luxury for driving or riding, which is used as a saddle-horse for old persons and those of heavy weight, and whieh may, besides, be employed as a driving-liorse for light earriages, such as phatons, buggies, dog-carts, ete.

Height.-The expression cob has been abused by being applied to all rather powerful small horses. In England the average height of the eob is 1.40 metres; in France he is larger, his height varying from 1.50 metres to 1.58 metres.

Preferred Coats.--The present fashion rather favors the roan and the iron gray, but we find all kinds of coats.

Conformation.-This horse, a very pleasant sort to use, is short, stubby, muscular, regular and round in form, elose to the ground; he has an expressive head, a rather strong neek, a wille chest, strong members, eompact eonformation, and a calm and docile temperament. 
Notwithstanding some appearance of clumsiness and indifference, he has, nevertheless, style, clegance, distinetion, beautiful gaits, and ardor when necessary (Fig. 340).

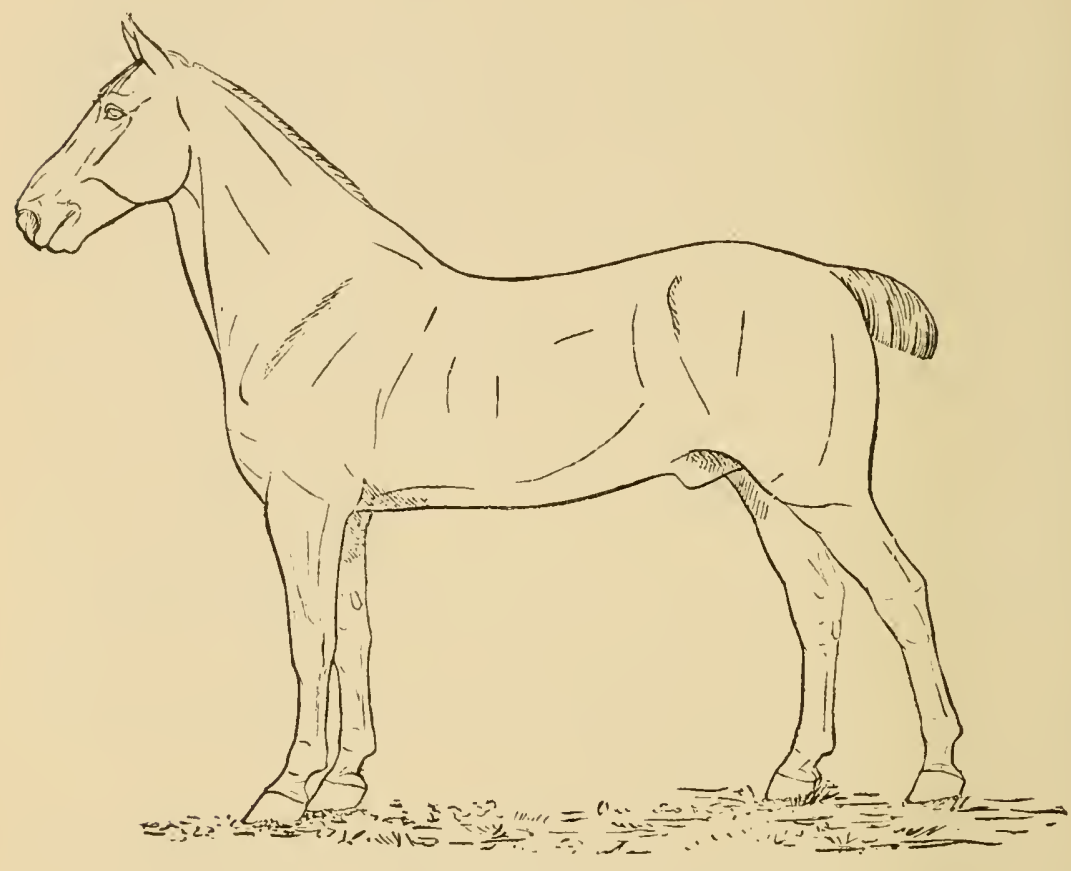

Fig. 340.--Cob.

(Reproduced from a photograph belonging to M. Delton.)

Origin.-The English cobs are by far the most valuable. They come from Norfolk. Ireland also produces some. The French variety is less numerous; some are found in the market of Niort, which are brought from Poitou and Saintonge.

Price.-When the pedigree is good, their value ranges from $\$ 400$ to $\$ 1600$.

\section{The Hunter.}

Mode of Utilization.-As the name indicates, this horse is exclusively designed for hunting. He must not be confounded with the steeple-chaser, which is one variety of race-horse. His principal characteristics are those of galloping and leaping over obstacles.

Height.-His average height ranges from 1.54 metres to 1.62 metres. It is never less, but sometimes more; the huntsman chooses his mount with reference to his own size and weight. Thus, certain hunters attain a height of 1.75 metres. 
Preferred Coats.-Little importance is placed upon the color of the coats of these horses. However, light coats, such as the gray and the pied particularly, are rery much in favor, as they contrast agreeably with the red coat of the rider.

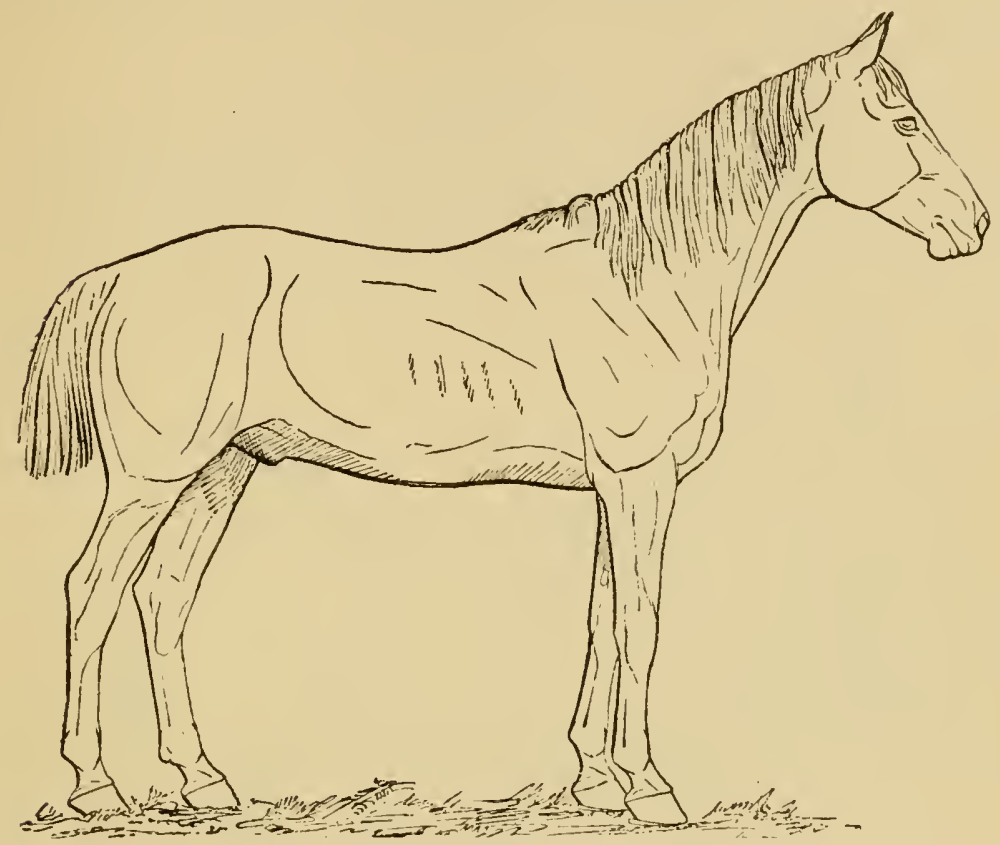

FIG. 341.-Hunter.

(Reproduced from a photograph belonging to M. Delton.)

Conformation.-A beautiful hunter should have a long, high neek, never arched ; beantiful shoulders, high chest, prominent withers, strongly-built body, muscular loins, well attached, a powerful croup, thigh, and buttock, and, finally, strong members of good equilibrium. To these qualities must be added energy, good breeding, endurance, and speed, for hunting is very laborious and difficult, and exacts a special training (Fig. 341).

But all horses which are used for this service by no means possess all these eonditions, especially in France. Many of them are blemished and have a very defective conformation; hence they are not serviceable very long.

Origin.-The best hunting-horses are half-breeds, bred in England and in greater numbers in Ireland. Those which are used in France are usually half-ruined thoroughbred and some Norman horses.

Price.-Their valne is not uniform, owing to the varicty of their 
breeding, their state of preservation, the absenee of blemishes on their members, and their degree of training. In France, their price varies from $\$ 160$ to $\$ 500$; in exceptional eases they are worth from $\$ 800$ to $\$ 1000$. But in England, "a hunter known to have performed brilliastly with the county hounds may reach a price ranging from 600 to 750 guineas." 1

\section{Double Pony.}

Mode of Utilization.-The double pony is smaller, more common, less fine, and less speedy than the cob. Like the latter, he can be mounted or driven to harness, according to circumstances.

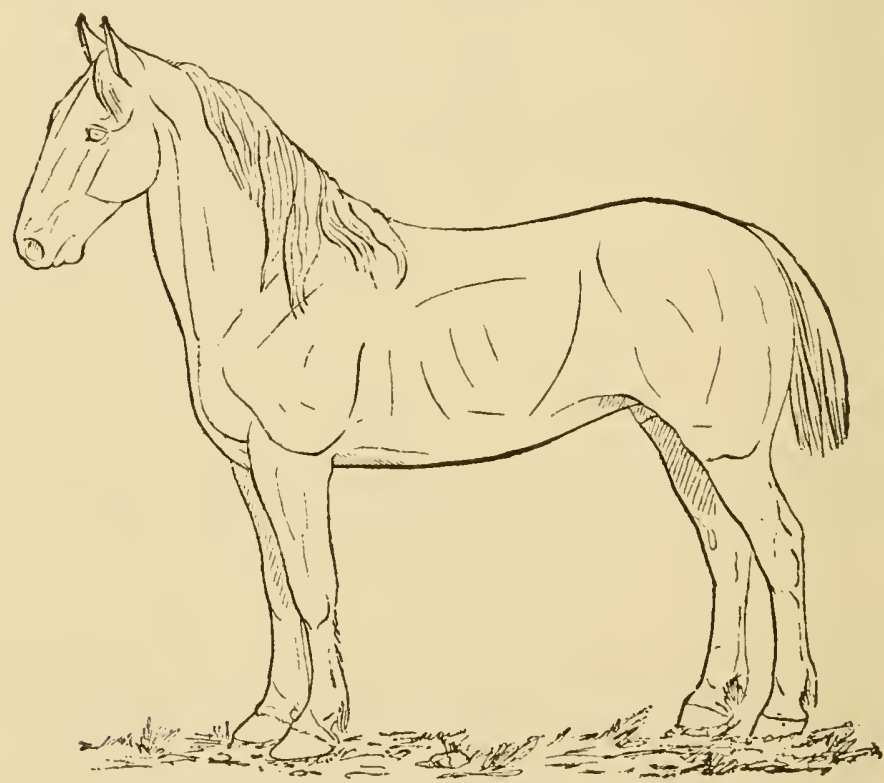

FIG. 312.-Double pony.

(Reproduced from a photograph belonging to M. Delton.

Height.-His average height is from 1.45 metres to 1.53 metres.

Preferred Coats.-They are of all colors, which are of equal value.

Conformation.-This horse is close to the ground, broad-backed, muscular, of a strong conformation and rounded form; his head is coarse, his members strong, but not very fine; he is often sluggish and indolent (Fig. 342). 
Origin.-He has no special centres of production, but is found scattered over Denmark, Poland, Ireland, Wales, and in France, in Brittany, along the English Channel, the Ardennes, ete.

Price.-His price raries from $\$ 100$ to $\$ 300$; when of exceptional form and aptitude, his value may even rise to $\$ 350$.

\section{Pony.}

Mode of Utilization.-The pony is the smallest horse of luxury, and is especially adapted to children's use. When, harnessed, he is driven to all sorts of small vehicles.

Height. - The height of ponies is very variable ; it ranges from 1.30 metres to 1.45 metres; but there are some in which it is no more than one metre.

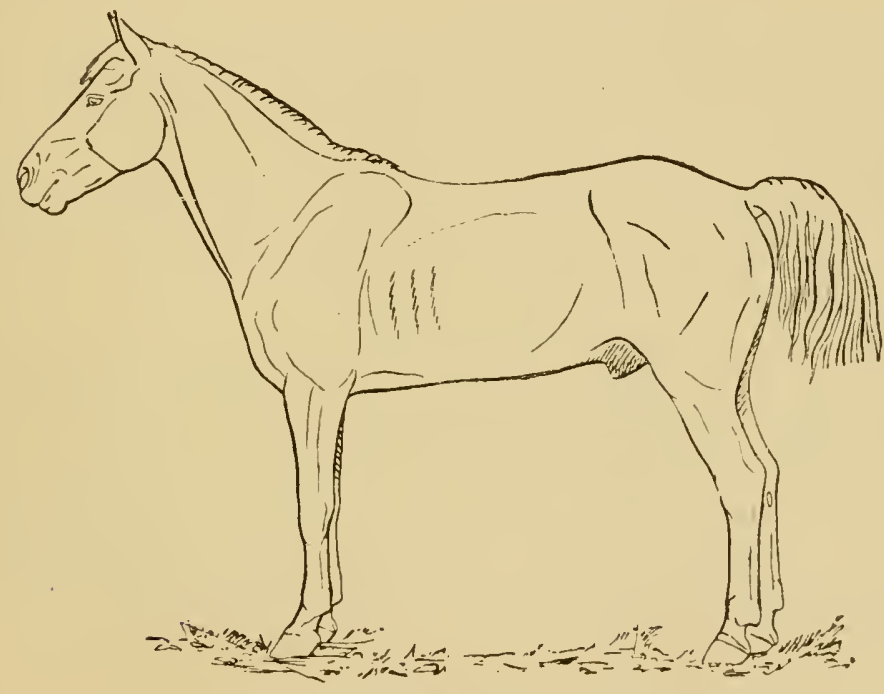

Fig. 343.-Pony.

(Reproduced from a photograph belonging to M. Delton.)

Preferred Coats. - We have nothing particular to say in this respect. In England, odd coats are the most sought after, the piebald, for example.

Conformation.--The body is elose to the ground, compact, and muscular; the head often concave over the forehead and nose, and expressive; the neek a little heary, but earried high; the nember's fine and neat; the mane, the forelock, the tail, and the hairs of the extremities are long, coarse, and abmulant; in trotting, the step is high and frequently repeated ; finally, they possess speed, energy, endurance, and a robust constitution (Fig. :343). 
Origin. - The most remarkable ponies come from England, Scotland, Irelaud, Iceland, the Shetland Islands, Wales, Corsica, the Crau d'Arles, the Landes, and, generally, from all mountainous and poor comutries.

Price.-In France, the price of a pony varies from $\$ 60$ to $\$ 300$. "In England, when the animal is exceptional, it may increase to $\$ 1000$ or $\$ 1200$ and even more." 1

\section{CH A P T E R I I I.}

\section{CAVALRY HORSES.}

The horses intended for the army are, in France and other continental countries, bought in the breeding districts by speeial committees, which act under instructions from the Minister of War.

For the present, we will limit ourselves to indicating the divisions established by the remounts, the requirements which the animals bought by them must meet, and, finally, the prices which are paid for them.

Army horses are divided into three great eategories, according to their scrvice: the horses de carriere, employed in the equestrian schools of the army; staff horses, reserver for the remount of the eorps of officers; finally, troop horses, which constitute the prineipal part of the cavalry. Staff and troop horses are, besides, classed aceording to that part of the army to which they are suited: reserve, line, light cavalry, and artillery (sarddle or hamess). Again, in each of these subdivisions they are distinguished, aceording to their qualities, as rery good, good, or passable.

Each year the price of the cavaly horse is established by the Budget Committee, but it generally remains about the same.

This schedule price is neither a minimum nor a maxinum one; it is looked upon as representing the valne of a good horse in each eategory.

It is always understood that a suffieiently large margin is left to the officials of the remount depots, for the practice of economy, either by encouraging the production of horses of such or such a category by paying more for them, or in order to give a proper value to the animals that are difficult to obtain, as the cavalry-school and the reserve horses, for example, which are in great private demand by the wealthy. It is the 
duty of the presidents of the commissions on purchasing to see that the latter do not exceed the limits of price allowed to them.

Category. Scimeduled

Cacalry-School Horses. . . . 360 dollars. Staff Horses.

Reserve . . . . . . . . 280 "
Line . . . . . . . . 272 " 2728
Vanguard . . . . . . . 228 “

Troop Horses.

Reserve “ 232 “

Line . . . . . . . 206 "

Light eavalyy . . . . . 182 "

Artillery (saddle). . . . 200 " .

Artillery (hamess) . . . 200 "
REAL PRICE

PAID AT THE REMOUNT.

300 to 410 dollars.

260 to 320
240 to 280
210 to 280

210 to 280 "

180 to 220 " 6

150 to 200 " "

200 to 220 " "

160 to 190 "

We give in the above table the scheduled figures which were established by the French government in 1889, and we place opposite the prices which the remount really pay. ${ }^{1}$

We will now quote from Captain Rivet, ${ }^{2}$ whose competency in this direction is well known. The lines below are full of precious information for purchasing officiais and officers of the army.

\section{A.-Staff Horses.}

"They may be classed as follows:

"1st. Ordinary.-Regular conformation, medium neck, sufficient power and speed. Those which have a rather large head, a white color, washed mane and tail or coat, and slight blemishes are also included in this class.

"2d. Good.-Those which have sufficient breeding, good neck and lines, regular conformation, strong body and members, and good gaits.

"3d. Very Good.-Those which possess a good conformation and good breeding, a fine, expressive head, strength, beantiful chest, good members, prominent tendons, long and brilliant gaits.

"The price of the ordinary horse is from 75 to 150 francs less than that of the goorl horse, with a range of 50 francs alove or below.

"The value of the very good horse is 100,150 , and in rare instances 200 franes more than the arerage.

"The price of the gray horse is one-eighth less than that of the class in which he may be plated.

"The standard line horse ranks between the rexerve corps horse

1 Wiart, Vétérinaire en Ier an dépôt de remonte de Caen. (Note communiquée.)

2 A. Rivet, Guile pratique de l'acheteur de chevaux, p. 19, et suiv, Caen, 1877. 
and the light cavaling horse; the average scheduled price of the staff horse may be applied to him. The price of the reserve horse will be 100 francs more, and that of the light cavalry 150 francs less.

"These data convey nothing absolute, and are only points of referenee which may be utilized specially in countries which furnish the majority of reserve and line horses."

\section{B.--Troop Horses.}

"The troop horses may also be grouped into three prineipal classes :

"1st. Passable.-Either by reason of their conformation, their defects of equilibrium, their want of ampleness of the chest, or their blemishes.

" $2 \mathrm{~d}$. Good.-These may be subdivided into three categories: $a$, if there are white markings, if the coat, the mane, and the tail are washed, the head large, the neck short, ete.; $b$, good, properly so called, if they have enough neek, strong body and members, sufficient weight, harmonious conformation, and good action ; $c$, if they have, besides, a fair physiognomy, a solid coat, and energy.

"3d. Very Good. - Those that have a good physiognomy, a neck well attached, a very good body, beautiful chest, good members, fine coat, power, and long gaits.

"The passable horse, of which no more than a certain number should be willingly bought, commands one-fifth less than the scheduled price.

"The price of a good horse of the first degree is about 60 franes less than the average; that of the second degree, or properly called good, is the mean sum ; and, finally, that of the third degree is 50 franes more.

"The very good horse costs from 75 to 100 franes more than the average price.

"The price of the gray horse is one-eighth less than that of the eategory in which it may be classed, and the passable gray should never be bought, so as not to encourage that coat, which is known to be unsuitable for war service.

"Every horse that is one-fifth less in value than the average, should be condemned.

"In order to operate with quickness and certainty, if it be possible, it is well to draw up a table of the different prices based upon these statements, and to consult it when necessary. (See pages 747 and 848.)

"It is important to make marked differences in the prices, according to the quality of the horses, so as not to be always confined to the average prices for the very good and the passable horse.

"The breeder and the horse-dealer should be convineed that the 
committee judges impartially and as accurately as possible the horses which are presented to them, and that they pay for a horse what he is worth from a military point of view.

"A horse may, in fact, have considerable eommercial value for a heavy team, or as a coach-horse, and still not be suitable for the cavalry, or only be a very ordinary saddle-horse. Again, a beautiful saddlehorse may be more valuable for the remount than for eommeree. These differences are of importance, and, while seeking to approximate to the mercantile value of the animal, we should not forget the use for which he is reserved. ...

\section{Schedule of Prices}

ACCORDING TO THE AVERAGES PAID AT THE REMOUNT.

1. Cavalry-Sehool Horses.

Beautiful lines, much expression, irreproachable bolly, good breeding, energy, good temper, easy and long gaits.

\begin{tabular}{|c|c|c|c|}
\hline & ORDINARY. & GOOD. & VERY GOOD. \\
\hline HEIGHT. & $\begin{array}{l}\text { Head somewhat } \\
\text { common, white } \\
\text { coat a jittle } \\
\text { washed, slight } \\
\text { blemishes. }\end{array}$ & $\begin{array}{l}\text { Good head, solid } \\
\text { coat, without } \\
\text { blemishes. }\end{array}$ & $\begin{array}{l}\text { Good physiognomy, beau- } \\
\text { tifil coat, brilliant gaits. }\end{array}$ \\
\hline $1.56 \mathrm{~m}$. to $1.62 \mathrm{~m}$. . & 320 to 340 dollars. & 360 to 380 dollars. & 400 to 410 dollars and \\
\hline
\end{tabular}

Gray Horses.

$1.56 \mathrm{~m}$. to $1.62 \mathrm{~m}$. . . . . 280 to 298 dollars.| 315 to 332 dollars.| 350 to 394 dollars and more.

2. Staff Horses.

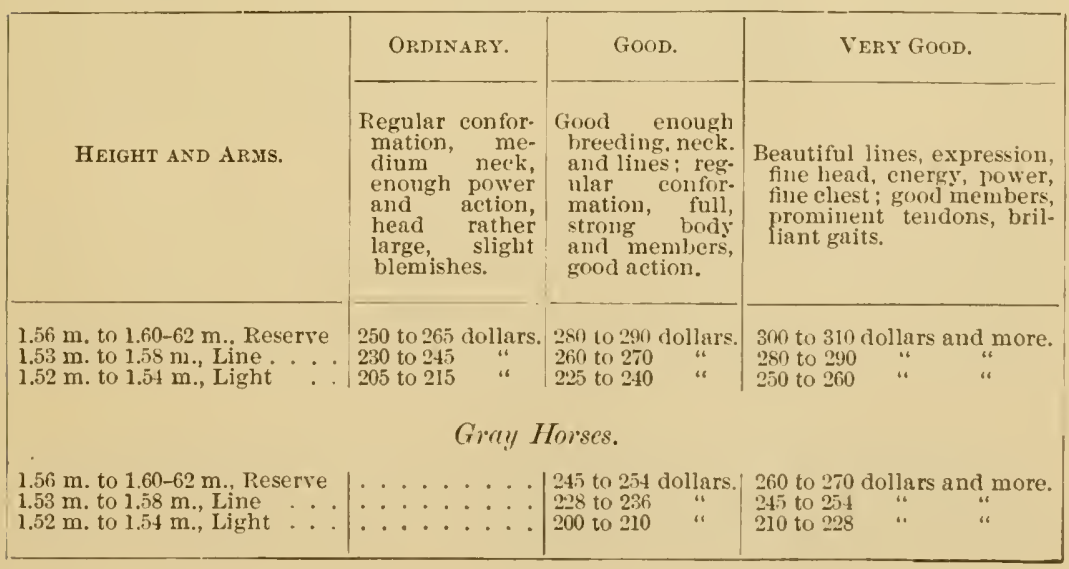




\section{Schedule of Prices}

ACCORdiNg to THE AVERAgEs PAID AT THE REMOUNT-(Continued).

\section{Troop Horses.}

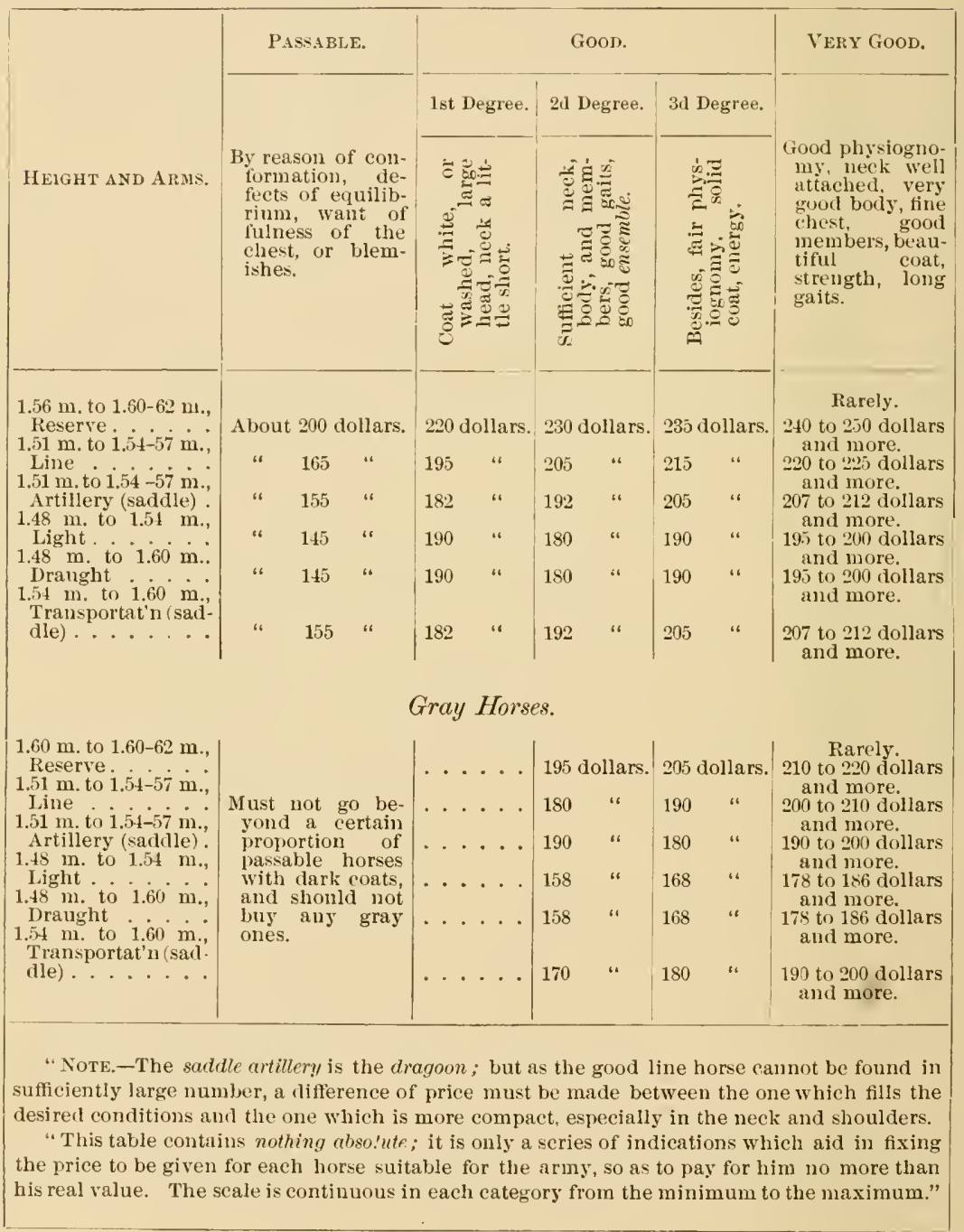

"The hollow back is generally the cause of the greatest rariations; it depreciates the horse for the saddle to a great extent; too much exaggerated, it even renders him altogether unfit for this service, whilst 
under the saddle his neek projects as well as his head, which gives a certain grace to the gaits.

"It must not be forgotten, however, that a slightly hollow-backed horse with a narrow chest, and seareely four years old, will be strong and broad enough at six years old. Proper consideration is not always given to the difference existing between the four-year-old and the fiveor six-year-old horse. With the four-year-old horse everything is chumsily bundled up; his fiture condition must be guessed at; he will certainly gain. The six-year-old horse, on the contrary, will remain about the same. Still, the horse and especially the mare six years of age, which have never had anything but grass, are like those of four years old.

"Whilst confining ourselves to the regular limits of height, we must not class a horse to the centimetre; our judgment must be founded upon his construction, his ampleness, his expression, his degree of thoroughbred descent, and his gaits. A certain horse of $1.5+$ metres will make a good cuirassier if he has a strong build; another of the same height can only make an ordinary dragoon if he possesses a medium development ; another of 1.60 metres is good for nothing if he is leggy, lanky, and weedy.

"Only the horse which is really worthy of the name should be classed as an officer's horse; we should not yield to simply apparent qualities which are not backed by strength and endurance. Rcasoning thus, it would often happen that the officers' horses would be inferior to the troop horses.

"The principal centres of production and amelioration in France are Normandy, Brittany, Vendée, Poitou, Limousin, Bigorre, and Morvan, which produce horses suitable for the saddle. The FrancheComté, Lorraine, Ardennes, Bonlonnais, Perche, and the Pays de Caux are, in geographical order, the countries where draught-horses are especially predominant."

\section{CHA PTER I V.}

HORSES OF INDUSTRY AND COMMERCE.

WE will consider in this chapter all dranght-horses, by far the most numerous elass, including as it does the animals employed in commeree and agriculture, in the service of workshops and manufietories, in farm-labor, in omnibuses and tramways, and in all sorts of 
heavy transportation, in the retail deliveries of large stores, for hackney cabs and coaches,-which, in a word, are used for all the special requirements, so numerous and so varions, of the ordinary eity and country life.

The very diversity of these requirements renders impossible a detailed classification of the horses thus employed. As a general rule, they are nsed either at a walk or at a trot. In the first case, of course, the burden is always considerable as compared with that in the second. The conformation must therefore be proportionally different.

This fact permits us to establish two large divisions in this category : heavy-draught horses and light-diaught horses. But among heavydraught subjects there are some whose work is alternately accomplished at a walk or at a trot, and which resemble very much the slow heavydraught variety by their large size and the bulk of the weight which they earry, but are distinguished from the light-draught horses by an inferior speed and less slender forms. We have previously given them the name fast heary-draught horses (see page 409).

Such are the three tolerably well-defined gromps into which horses of service, properly so called, may be divided. Difficulties arise as som as we undertake to establish secondary divisions. The reason of this is that the three principal factors of the general form, height, bulk, and the gaits, vary only within scareely appreciable limits, according to the destinations.

It is less the whole conformation than the education imparted with a view to the adaptation desired which principally specializes a particular aptitude in a given category, like that of the heavy-dranght, for example.

Thus, the shaft-horse, the heavy cart-horse, the tow-horse, the drayhorse, the horse that unloads wood npon the wharf, the horse that is employed to hold the cart back when going down a descent, or to help to draw it when going up a sharp incline, all these are dranght-horses that are recognizable as such at first sight, but which edueation, training, and habit have rendered peculiarly fit for some special service. No doubt the qualities which make special motors of them imply some physical modifications; but these are imperecptible, owing to the part played by the moral modifications. Now, we must be careful not to confound, among these changes in the form of the body, those which result from actual adaptation and those which proceed from usage. The first are incomparably weaker than the second, and cannot be considered as capable of realizing distinct types of conformation unless these changes 
have been produced and transmitted during numerons generations. For this reason, we shall confine ourselves to generalities in what concerns the great divisions of the horses of industry and commerce.

\section{A.-Slow Heavy-Draught Horses.}

These animals are always employed at a walk. We will take as a type the dray-horses, which are usually employed for hauling building materials, wood, stones, and iron, and which are harnessed to those

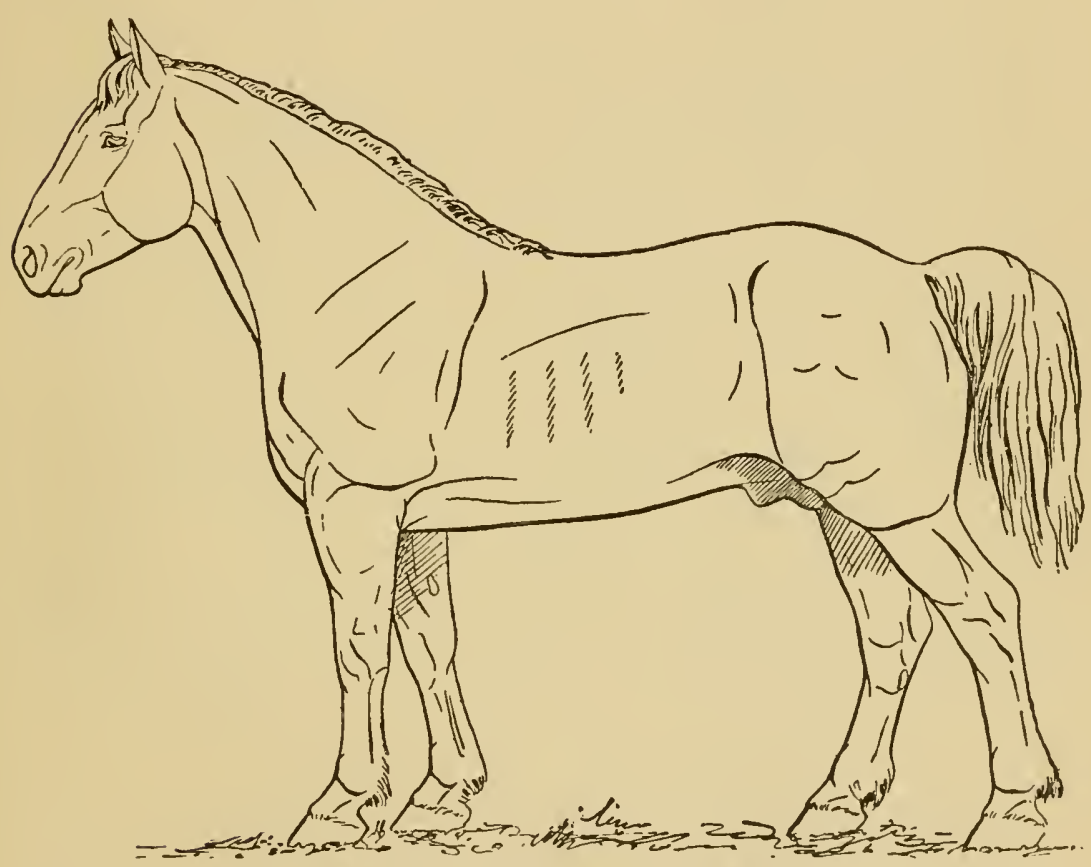

FrG. 341.-Slow heavy-draught horse (dray-horse).

(Reproduced from a photograph belonging to M. Delton.)

vehieles known as drays, loaded with enormous weights, also to heary wagons, carts, ete.; in a word, to all two- or four-wheeled vehicles intended for heavy traetion. The dray-horse is rarely harnessed alone ; generally four or five horses similar to him, but sometimes smaller, are driven in the same team.

With regard to conformation, preference is for a body that is massive, low-set, ample, very musenlar, short-flanked, cylindrieal, with solid, large, and broad limbs, good feet, good physiognomy, ardor, and endurance (Fig. 344). He is preferred entire, as he is then more vigor- 
ons. In this connection those horses are reserved as shaft-horses which are nearest to perfection; their loins are short and very straight, their eroups well made, their members very strong, of good quality and perfect equilibrinm. Unfortunately, owners are far from always attending to these requirements; they too often employ as a shaft-horse their tallest horse, wrongly imagining that muscular power and other qualities necessary for this work are directly and exelusively in proportion to the height.

The height is very great, on account of the volume and weight of the loads to be movel. It varies from 1.55 metres to 1.75 metres; exceptionally, it exceeds the last figure; in this case, the horse is in most instances badly conformed and defective.

As to the coat, little importance is attached to it ; however, enstom favors the dapple and the dark gray more than the coats called colorerl, - that is to say, the bay, chestnut, roan, black, ete.

As to prices, they vary greatly, aceording as the animals are destined for industry and commerce or are bought for breeding purposes. On an average, geldings, mares, and non-produeing stallions cost from $\$ 300$ to $\$ 500$; stallions from $\$ 600$ to $\$ 1000$. Shaft-horses, all things being equal, bring twenty-five per cent. more than the others, but it is daily becoming more and more diffieult to obtain them, on account of the enormons competition of the Americans on the French market. It is no exaggeration to say that every year the breeders of the Perehe and the Beance export to the United States from twelve to fifteen hundred of their handsomest gray horses, which the American purchasers buy for stallions, at from $\$ 1200$ to $\$ 1600$.

\section{B. -Fast Heavy-Draught Horses.}

As we have said, the horses of this eategory differ from those of the preceding in that they alternate the trot with the walk, the loads which they pull heing much less heary. In Paris, they are specially used for brewers' and milkmen's wagons, and for omnibuses and tramways.

They are of smaller stature, and the body is less massive, less ample, and less muscular; on the other hand, they have longer, lighter, and more slender members, longer necks, and a more rapid gait.

Brewers' Horses (Fig. 345) are from 1.62 metres to 1.65 metres high. They are harnessed singly to small two-wheeled wagons called brasseuses, also in pairs to light drays. They trot almost invariably. Most of them come from Perehe, Beauce, and Normandy (Eure and 
Seine-Inférieure). Small Boulonnais and some coarse Breton horses are found among them. Their average price varies from $\$ 300$ to

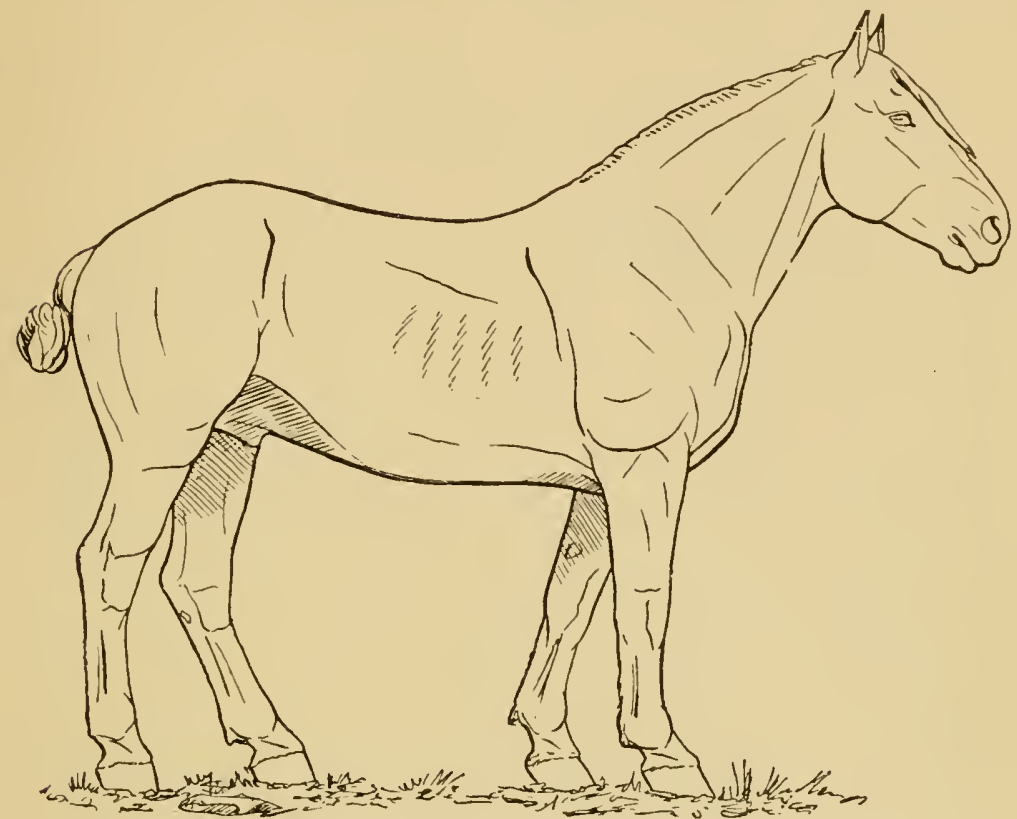

FIG. 345.-Fast heavy-draught horse (brewers').

(Reproduced from a photograph belonging to M. Delton.)

$\$ 350$; but it is never very high, for they are not in demand as stallions; they are not bulky enough for this service.

The milkmen's horses are a little smaller; their height is only 1.60 metres. In France, they are driven to two-wheeled wagons called laitieres. They come from the same localities as the preceding, but they are lighter in weight, more slender, and more active. Their price varies firm $\$ 300$ to $\$ 320$.

The subjects which we deseribe under the names of stage-coach, omnibus, and tramway horses, more bulky and heavier, altlongh not so tall, mark well the transition between the types of the fast heary-dranght, of which we have just spoken, and those of lightdraught, which follow immediately afterwards. They are worked in twos and in threes in railroad trucks, in omnibuses which are used by large transportation companies, and in the strect-cars, which, in spite of their considerable volume, have a very weak coefficient of traction, allowing the use of lighter motors, and therefore lessening the expense of purchase and of kecp. 
The largest of these horses are those used by the French express companies; their height is from 1.62 metres to 1.65 metres; then

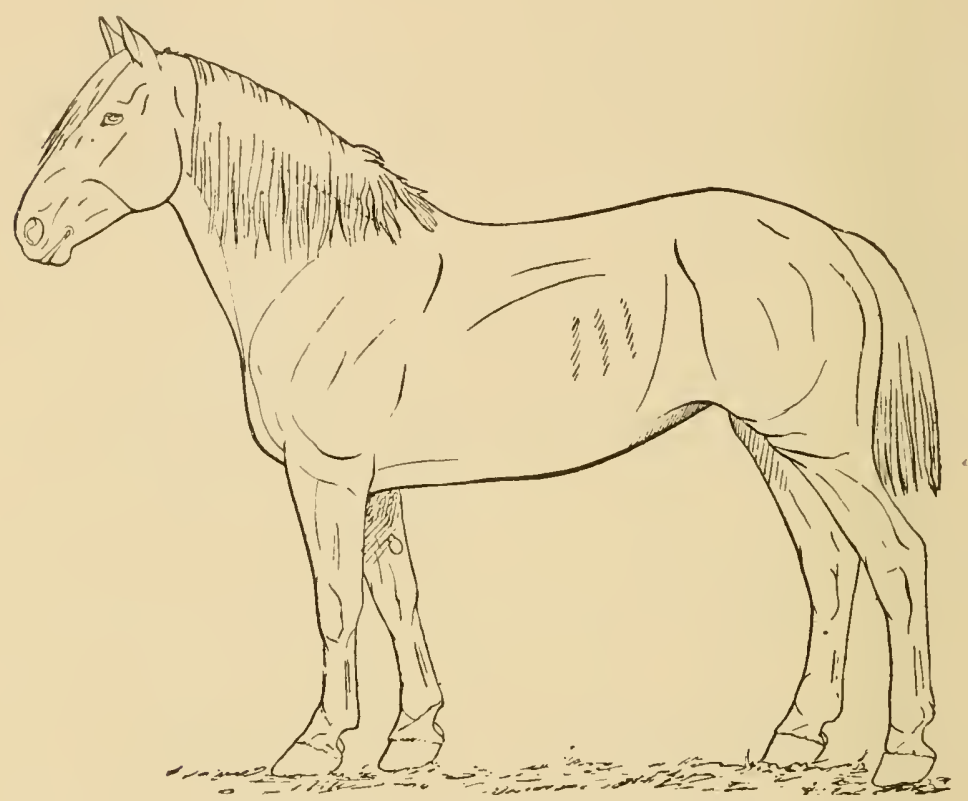

Fig. 346.-Vélocité, Percheron mare of the Compagnie générale des omnibus. Grand prize of the Universal Exposition of 1878 .

(Reproduced from a photograph belonging to M. Delton.)

come those of the three-horse omnibus, and of the street-cars, which are 1.60 metres to 1.62 metres; those of the tramways rank last; their height varies from 1.58 metres to 1.60 metres.

It is impossible to indicate by words the differences of conformation which distinguish these animals from the preceding. We refer the reader to what we have already said on page 40\%. They are of abont the same type, with more or less bulk and speed according to the height and the purpose of use. But the rolume remains considerable in proportion to the members, which, without losing any of their strength, beconre longer and more slender to give more extent to the movements and increase the rapidity of the steps (Fig. :346).

The Perche, Beance, Brittany, Normandy, and the Ardennes are the sections which furnish these horses for commeree. Those of Normandy come from Eure, Seine-Inférieure, and Orne, particularly from the vicinity of Mortagne.

The express horses and the street-railroad horses-that is to say, 
the largest division of the group-are worth from $\$ 280$ to $\$ 350$. The average price of those of the Compagnie générale des omnibus et tramways of Paris is $\$ 250$; a little more or a little less, according to circumstances.

\section{C.-Light-Draught Horses.}

In this category we have placed the horses whose habitual step is the fast trot.

The true type which formerly represented it was the post-horse, now somewhat scarce, but still reserved for certain services of luxury. Teams of post-horses are in fact rather in vogue in châteaux, country residences, and villas during the hunting, the racing, or the bathing season, for visits among relatives, friends, or guests.

The post-horse may be considered, from his conformation and breeding, as the intermediate between the small coach-horse and the fast heary-dranght horse. He should be low-set, rather plump, with good members, regular body, with a fine neck, a horizontal croup, and long gaits. His height varies from 1.56 metres to 1.58 metres. These characters make him resemble very closely the cob, whose finer and more brilliant qualities he does not, however, possess. He is driven in twos or in fours in mail-coaches and family carriages. A few years ago the dark gray was the color preferred for this kind of horses; now the bay and the black are preferred. Most of these horses come from the vicinity of Mortagne (Orne), Côtes-du-Nord, and, especially, Finistère, where they are found in the Conquet, in the neighborhood of St. Renan and Trélabu. Their average price is from \$300 to \$350.

Secondary to these animals, but more common, less elegant, and of less regular form, we place the geldings and mares of commerce, which are used for all sorts of professions and industries.

Their height varies from 1.58 metres to 1.65 metres, according to the weight of the vehicles which they are to draw ; it is rarely as high as 1.70 metres; in such cases they are nearly always thin, lanky, longlegged, and delicate. They are constantly worked alune, their load being seldom heary. They come principally from the Pays de Caux (arrondissements of Havre, Dieppe, and Yvetot), the Ardemes, Mayenne, Sarthe, and Côtes-du-Nord. Their price varies from $\$ 200$ to $\$ 400$.

In the series of light-draught subjects are found many small common horses, suitable for fast individual or public services. They are often designated (e-pecially in Brittany and Normandy) by the name bidets, or nags, but they have nothing in common with the 
animals which were formerly ealled bidets d'allure, whose gait was a rumning-walk, which were nsed under the saddle, and disappeared with the custom of travelling on horseback, since the improvement of the roads and the use of railroads. In large cities they are represented by horses for hire. Energetic, very robust, inured to fatigue and privations, of a somewhat regular conformation, light, and quick, they are harnessed alone or in pairs to small carriages, such as small breaks, small upholstery wagons, pleasure-carts, tilburies, cabriolets, etc. For public service they are used in the varions kinds of coaches (eoupés, victorias, cabs), and also, in some provincial towns, on tramways.

Their medium height varies from 1.50 metres to 1.56 metres, and their cost from $\$ 160$ to $\$ 180$.

They have no special centre of production, but are ordinarily furnished by the less fertile distriets. 


\title{
SECTION EIGHTH.
}

\author{
VICIOUS HORSES.
}

Up to this point we have occupied ourselves only with the external conformation of the horse, and the reader should by this time be in possession of the elements necessary to appreeiate it thoroughly. Still, this will not be sufficient for him. It may in fact happen that the animal has an irreproachable form, superb actions, energy, and ardor, and yet is deficient in the moral qualities necessary to utilize, for the benefit of those who use him, all the advantages which the perfection of his mechanism confers upon him. Poorly endowed in this respect, he will expend his forces at a loss, under the influence of the bad habits which he has contracted; or he will be harmful, dangerous, unserviceable, on account of his vices, which is a much more serious matter, especially so far as the public interest is eoncerned. A rapid examination of his moral imperfections, whether slight or grave, becomes an indispensable complement of the preceding sections. We will divide this subject into two chapters:

In the first we will study the vices or vicious habits, 一that is to say, the dispositions contracted by frequent repetition of injurious actions, which, however, involve no very bad consequences, implying no evil natural inclinations, and neser entirely preventing the utilization of the horse.

In the second we will pass in review the rices properly so called,that is to say, the serious defects, showing an indocile, stubborn, or timorous nature, a bad education, an indomitable aggressive character, defeets which, in a word, render the animal dangerous or almost useless.

The question to be solved is this: given a vicious horse, how we we to recognize him? 


\section{CHAPTER I.}

WHIMS AND VICIOUS HABITS.

WE designate as whims, bad or vicious habits, a certain number of acts, resulting in most instances from idleness, which the horse free from restraint incessantly repeats, without any other motive, in reality, than the gratification of desires which at length become imperative, but which always more or less interfere with his complete ntilization. The subjects of these whims may be classified as follows:

+1 st. Horses which loll the tongue, double it up, or eontinually protrude it from the month.

2d. Horses which strike the lower lip against the upper.

f 3 d. Horses which rub the lower extremity of the head against the manger, or the tail against surrounding objects.

th. Horses which shake the head up and down or jerk the reins.

5 th. Horses which grasp the நranches of the bit with the lower lip.

6th. Horses which tear their blankets with the teeth.

7 th. Horses which rest one hind-foot upon the other.

8th. Horses which lie down cow-fashion.

9th. Horses which strip their halters.

10th. Horses which roll as soon as they are harnessed, or upon entering the stable after working.

11 th. Horses which trot in the stable.

12th. Horses which paw in the stable.

13th. Horses which weare like a bear.

14 th. Horses which eat carth.

15 th. Horses which erib or suck wind.

We pass over divers other vices of too little importance to deserve mention here. They consist most frequently of a kind of sudden, convulsive, and involuntary movement of eertain regions, which the animal has inadvertently contracted by degrees, and which has no other effect than that of rendering him mingraceful. Ordinarily, this contraction has its seat in the face, in some of the nasal muscles, the lips, the cheeks, or the cyelids. At other times it takes place in one or other of the muscles of the head ; the latter then shakes by slight jerks, more or less marked and more or less frequently repeated according to cireumstances. Finally, there are cases in which the same phenomenon is observed in the muscles of the neck, which determines 
a more excessive displacement, and is therefore more disagreeable to the eye.

\section{1st. Horses which loll the Tongue, double it up, or con-} tinually protrude it from the Mouth.-When deseribing the region of the tongue, we had occasion to say a few words about these vicious habits. It is known that certain horses during work protrude the tongue from the buecal cavity, usually either to the left or to the right, sometimes in front. This defeet constitutes what is called lolling the tongue, or having a pendulous tongue, but it is not, as one might suppose, always the result of a paralysis of the lingual muscles.

On other occasions, a horse will altemately protrude his tongne from his mouth and retract it somewhat as serpents do: he is then said to have a snake's tongue.

Sometimes the animal doubles up the tongue,- - that is to say, folds the free part backward and underneath, without its being visible, however, on the exterior.

Finally, there are horses which displace the tongue in such a manner that, instead of supporting the bit, it lies on top of the latter. The inconveniences which result from these four different lingual displacements are not identical. The lolling tongue, besides giving a stupid expression to the face, is exposed to cuts, often deep, which hinder the prehension of food, its mastication, insalivation, and deglutition.

The serpentine tongue is a less important defect : the most serious fault to be found with it is the great loss of saliva which it oceasions, for it is drawn back into the mouth only after it has become dried in order to become moistened again. Besides, it becomes filthy and soils the parts of the harness which it touches.

As to the other habits, they injure the bitting by preventing the bit from having its ordinary point of support. They are remedied by tightening the curb.

\section{2d. Horses which strike the Lower Lip against the} Upper.-Certain horses, harnessed, mounted, at rest, or during exercise, in the stable or outside, have the bad habit of continually moving their lower lip, by sudden and rapid to-and-fro movements, which canse it to strike, sometimes with a noise, against the upper lip. This singular vice is nothing worse than unpleasant. In the language of horsemen, it is called cracking muts. It is prevented either by adapting to the bit a lip-strap, or by fastening to the lower part of its two branches a sort of metallic eross-piece, conforning with the shape of 
the tuft of the chin and limiting the descending movements of the lower lip.

\section{3d. Horses which rub the Lower Extremity of the Head against the Manger, or the Tail against surrounding Ob-} jects.-In the stable we sometimes see a horse rubbing the end of his nose against the side of the manger, or the tuft of his chin against the bottom of the latter. He then moves his head alternately from one side to the other, or from before to behind, with provoking persistence, as if he experienced from these mancenves a pleasant tickling sensation. This habit is indulged in during the intervals between meals, when the animal has no food with which to ocenpy himself. To remedy this is very difficult, if not impossible; fortunately, it has no serious drawback.

It is different, however, with horses which rub the base of the tail against surrounding objects, as the sides of the stall. The hairs of the tail soon become dishevelled, tangled, break, and fall off, under the influence of repeated rubbings. This disfigures the part very much. No doubt uneleanliness, or disease of the skin, ordinarily eanses intense itching in this region. Often, however, this symptom results from the presence of worms in the intestine. Attention shonld be especially paid to this. An appropriate treatment will remove the eanse and its effect at the same time.

4th. Horses which shake the Head or jerk the Reins.In either of these cases the horse gives his head alternate movements of extension and flexion when he is in harness or mounted. With the driving-horse or the dranght-horse, the reins, constantly drawn forward or backward, may be canght by the extremity of the shaft or the pole, and annoy the driver. With saddle-horses, besides the difficulty in keeping a proper hold of the reins, the movements of the head, when they are extensive, jerk the arms and the body of the rider with great violenee, and sometimes may even unseat him. On the other hand, the horse that is given to this habit pays no attention to the ground upon which he moves, and hence is liable to stumble and fall.

Ontside of the dressing and the combined action of the reins, there is but one remedy for this habit, and that is the employment of a martingale of suitable length.

We do not allude here to horses which practise the habit on aceount of an exaggerater sensibility of the bars, or to those whose dressing has not yet been completed, horses to whom the pressure of the bit is 
disagreeable, annoying, or painful. Under these circumstances, it is evident that the pressure should be diminished, either by modifying the form of the bit, or by making the traction of the reins proportional to the degree of sensibility of the month.

\section{5th. Horses which grasp the Branches of the Bit with} the Lower Lip.-This habit, a very common one, shows itself during work, in walking, in trotting, and more rarely in galloping. Usually it is with the lower lip that the animal seizes one of the branches of the bit. Sometimes he sneceeds in seizing it between his tecth, especially if the bit is of the kind called pelham, or if the bar is broken. In such cases, the defect may become serious at any moment,- - for example, in places where it is important to drive with care to avoid obstacles in the road. Usually a light jerk of the reins will compel the horse to let go and take his attention away from it. But when this is inefficacious, the false curb must be applied, or even a bit having its branches curved backward.

\section{6th. Horses which tear their Blankets with the Teeth.-} There are horses which have the labit of biting and tearing their blankets. Perhaps the salty taste which is found in woollen fabrics impregnated with sweat or other excrementitions productions of the skin, leads them at first to lick the blanket, and then to tear it; but never, as is thought by some, do they eat it. The inconvenience is more serious to the owner than to the animal, since it occasions expensive repairs. This can be avoided by using a bar attached at one end to the halter and at the other to the surcingle, which prevents the lateral inclination of the head and neek. Another means is often employed which, in our opinion, is more efficacions. It is a kind of bib, made of a piece of woollen choth or of leather, fastened at one extremity to the posterior part and the sides of the nose-band of the halter, the other extremity hanging free a certain distance below the lips. This bib interposes between the teeth and the blanket every time the horse attempts to bite the latter. He never succeeds in doing more than biting the leather without being able to tear it, since it offers no resistance to his efforts. On the other hand, however, the bib soon becomes soiled by the saliva and the food, so that it aequires a disagrecable odor, and soon wears out, rendering its frequent renewal necessary, which is expensive.

7th. Horses which rest one Hind-Foot upon the other.It is not a rare thing to see a horse when he is tired rest himself by 
placing the plantar surface of one hind-foot, semi-flexed, upon the anterior face of the other. Some subjects acquire this habit under the influence of certain causes apart from fatigne, but as yet insufficiently ascertained. Perhaps the merenness of the stable floor, as we have observed, makes it difficult for him to stand upright, and may bring about this result.

However this may be, the prolonged and frequently-repeated contact of the shoe oceasions wounds of the coronet and contusions of the coronary band. Sometimes even, as a consequence of these latter, the superior border of the wall becomes thiekenerl, entirely changing the direction of its anterior face and tending to render it more or less perpendieular to the ground.

The only means of preventing this defeet consists in protecting the parts exposed to wounds by a leather pad or boot.

8th. Horses which lie down Cow-Fashion.-The cause of this habit has thus far eluded obserration. The horses which manifest it assume the decubitus peculiar to ruminants, - that is to say, they hold their anterior members flexed under the chest. The result of this is that the extremity of the branches of the shoe, the heels (always on the inner side), presses against the elbow. From its prolonged contact and frietion there results at first an irritation of the skin, then sometimes a wound, but more nsually an indolent tumor capable of acquiring a considerable volume, and ealled a shoe-boil, on account of the cause which gives rise to it. In treating of the elbor (page 221), we said that during several years we kept trace of a horse which was actively worked and which had at each ellow an enlargement of this kind, of the size of a man's head. Gencrally, the tumor is annoring and ungraceful rather than harmful. However, it may become so painful as to necessitate suspension of work. As soon as an excoriation or evidence of friction is seen on the surface of this region, it is important to ascertain the animal's usual mode of deenbitus. If he lies down like a cow, it will be advisable to remedy the habit either by protecting the foot with a boot, or, preferably, by shortening the inside heel of the shoe to prevent it from rubbing against the elbow.

9th. Horses which strip their Halters.-This expression is used in horse language to indieate that a horse is in the habit of extrieating his head from the halter.

The inconvenience of such a habit is often of no consequence, especially when the horse is alone in the stable. However, if there is 
fodder in the stable, or if the oat-box has been left open, a greedy, gluttonous horse is apt to contract a fatal indigestion. In other cases he goes and scents around his neighbors, attempts to fight, teases the mares and perhaps monnts them if he be a stallion, and is liable to injuries from bites and kicks, as well ats to falls, wounds, contusions, fractures, and accidents of all kinds.

A plain strap around the neck, instead of the halter, would often be sufficient to keep the horse in his place, if it did not leave too much liberty to the head. Hence it is better to employ at the same time both neek-strap and halter, each fastened separately to the manger. But it would be erroneous to believe that a throat-latch added to the halter will always be sufficient to check this practice, as certain authors thought, particularly Cardini. ${ }^{1}$ We have from personal knowledge numerons proofs to the contrary.

10th. Horses which roll as soon as they are harnessed or when they return to the Stable after working.-Another very disagreeable habit is that of rolling upon entering the stable after work, or on being harnessed. Some horses experience this desire to such an extent that they seek its gratification at every opportunity. After an insignificant exercise, with a harness perfect in regard to its adjustment, under conditions, therefore, when the horse can be neither tired nor inconvenienced, he will commence to roll as soon as he is not watehed. The eonsequenees of this vice are much more serious for the owner than for the animal himself. The latter only runs the risk of getting soiled; he is rarely injured. But it often happens that he breaks the saddle, tears his blankets, and ruins the harness. Under these conditions, the expenses of repairing beeome onerous. Fortunately, the vice is easily prevented by tying the horse, so that he eannot lie down until the harness has been either put on or removed.

11th. Horses which trot in the Stable.-This habit is rare; however, several horses have furnished us eximples of it. In the stable, in front of the manger, they move suceessively upon their diagonal bipeds with considerable rapidity, thus acomplishing a sort of stationary trot, but more or less irregular and interrupted. We think that regnlar exercise instead of a prolonged stay in the stable would overcome this viee. The result of the habit, when it exist- in an exaggerated degree, is to fatigne the animal to no purpose whatever. In this case, his anterior members must be fettered or hobbled. 
12th. Horses which paw in the Stable.-Certain subjects contract the habit of persistently pawing the floor of their stable with one of their fore-feet. In cases of colic the horse frequently manifests, in this manner, the uneasiness and pain which he suffers. We do not allude here to this symptom. We wish to speak more especially of an analogous habit, which has no morbid cause, but which evidences the restlessness the animal feels when alone in the stable, when he has insufficient exercise. This is a most disagreeable vice. Besides useless fatigne and loss of energy, it causes a rapid wearing out of the shoe, necessitating its more frequent renewal, and gives rise to incessant noise, well-nigh unbearable, especially at night-time, an inconvenience of no trifling nature when the stable occupies the first floor of a dwelling-house. The means of remedying this habit consists in giving the horse proper daily work, and, if need be, from time to time fettering the two anterior members.

13th. Horses which weave.-This habit, similar to that of the bear, consists in lateral oscillations of the head and neck, accompanied by an analogous and alternate movement of the body upon the anterior members. Sometimes these members retain the same position, at other times one foot is slightly raised, the left, for example, when the movement takes place to the right, and vice versa. The subjects which especially contract this habit are those which stand too long in the stable, and whose fore-feet rest upon an uneven stable floor. Generally being of an irritable temperament, they assume a particular attitude in order to execute it; their anterior feet, separated from each other, diverge ; their toes are turned outward like the ontbow-footed horse. The habit is indulged in with more or less frequency, but especially during the intervals between meals. Its principal effect is a useless fatigne, and it is with much difficulty that the habit can be prevented. This may be effected, however, by attaching the animal with two straps of such a length that the head ean still be raised and lowered, but cannot be turned to the right or the left.

14th. Horses which eat Earth. - This vice is a depravation of the appetite, which is by no means rare in some localities. Perhaps the saline taste of certain soils canses the animals in some cases to contract the habit. But, ordinarily, the insoluble and insipid minerals thus swallowed are not capalole of stimulating the taste. Thus, examples have been recorded of horses which eat chalk; we have seen several of them in Champagne. They had at first fallen into the habit of 
licking the plastering on the walls of their stables, then they had bitten it with the tecth, and finally had eaten it.

At any rate, the facts of which we speak are exact and are, besides, familiar to physiologists and pathologists. Are they always the result of a vieions habit and bad education, or are they rather the expression of a need of the organism which does not find a sufficient quantity of earthy salts in the ordinary aliments? This has not yet been demonstrated. The truth resides, in all probability, in both of these hypotheses.

Of itself, the rice of eating earth may give rise to very serions consequences. Subjects which suffer from it are exposed, among other things, to frequent colics, and even to irremediable intestinal obstructions. Their purchase, therefore, is not to be recommended, but, in Franee, this vice is not considered as belonging to the list of redhibitory vices. We shall see that the case is entirely different with the following viee, which consists in sucullouing air.

15th. Horses which have the Vice of "Wind-Sucking," or swallowing Air. - The varions modes of swallowing air are vulgarly known by the names cribbing and wind-sucking. In the great majority of cases, this habit is accompanied with a guttural noise very much resembling an eructation; exceptionally, this noise is not made.

Authors are far from agreeing upon the true nature of eribbing. Nearly all consider it as proceeding from a simple eructation of gas throngh the mouth. Others consider it as resulting from a reglutition of air. Notwithstanding the number and anthority of those who express an opinion contrary to ours, we hold firmly to our view, for it rests upon physiologieal and experimental facts to which no serious objection has yet been offered. ${ }^{1}$

In the first place, the guttural noise has not the eharacters of that of belching, but is rather an effort having its seat in the larynx. ¿pon a horse which eribbed with a loud sound, we practised tracheotomy and divided the two recurrent laryngeal nerves.

The animal eontinued to erib; but the sound disappeared on account of the paralysis of the larynx and the opening made in the trachea.

1 See, for further details:

Liautarl, Du tie à l'appui, in Jourual de médecine vétérinaire publié à l'Éeole de Lyon, 1861. pp. 552 et 600 .

Furges, Du tie et de ses diverses espèees tans le eheval, in Recueil de múrlecine vétérinaire. 186, , p. 5.

Arm. Goubaux, Communication sur le tie proprement dit, in Journal de médecine vétirinaire publić à l'Éeole de Lỵon, 1866, p. 249. 
Besides, to suppose that it is produced by an cructation would make it neessary to admit that horses which crib have the power of ejecting into the resophagus the gats contained in their stomach. Sueh is not the ease ; for we have never seen, at the antopsr, any abnormal dilatation of the cardiac end of the stomarh; a stomach inflated through the pylorns will not allow any escape of air from the osophagus, free from ligature, no matter what pressure may be employed.

We will add that if the guttural air were an eruetation, as is believed, we could not understand why such horses suffer from abdominal tympanites still more when they crib persistently, whilst we know that their meteorism disappears promptly as soon as the gas is ejected through the anus. H. Bouley affirms, however, that he saw a horse beleh and pereeived the grassy odor of the gases ejeeted by the animal. An observation of the same kind has been made by one of our pupils, which case we published in the Journal de l'École véterinaire de Lyon. $\mathrm{By}$ no means disputing the exactness of these facts, we simply consider them to be pure eoineidences, very rare and altogether exceptional.

What we maintain is that horses which crib sucllow air.

To demonstrate this, it suffiees to expose the resophagus and slightly raise it, as in performing œopophagotomy. We shall then see, after each effort, a monthful of air descending through this passage in the direetion of the stomach.

Another and even more palpable proof eonsists in colleeting, immediately after death, the gases contained in the stomach and the first portions of the intestine, and submitting them to a chemical analysis. Clément, at our request, undertook these researehes, when he was prineipal of the chemical laboratory in the veterinary sehool of Alfort. In the stomach, always more or less distender, he found pure air ; in the small intestine he also found air, but it was modified on aecount of its mixture with the gaseons produets of digestion.

These experiments, therefore, show that the essential character of this vice is a deglutition of air, frequently laborious and at such times accompanied by a noise resulting from an effort having its seat in the larynx.

The horse does not always perform this air-swallowing in the same manner. Sometimes he does not take any point of support; sometimes, on the contrary, the inferior extremity of his head is supported upon a resisting body in order to render the act easier. From these different methods come the distinctions of cribbing in the air, or wind-sucking, and cribbing with support, aecording to the method employed by the animal. 
The old French law upon the redllibitory ricess ranked cribbing in the air, withont support or withont wear of the teeth, among the vices capalble of cansing a nullification of the sale. At present, according to the new law of 1884 , cribbing properly so called, whatever its form, with or without werer of the teeth, is to be considered as redllibitory.

The vice manifests itself usually as follows: To crib in the air, the animal begins by agitating his lips by frequent, rapid, and slight upand-down movements of these organs; then he suddenly lowers his head, sometimes to a level with his knees, and then swallows a monthful of air, with or without the production of the guttural sound which has wrongly been compared to an eructation. Often this effort is not successful; in this case it is confined to a simple deglutition of saliva, which, however, does not appear to give the desired satisfaction, since the attempts are renewed until the desire is satisfied.

Cribbing with support differs from the preceding only in this, - that in order to execute it the inferior extremity of the head is supported upon a resisting body of some kind. Horses which are prevented from cribbing in this mamner sometimes learn to crib in the air, and rice rersa. We have seen (page 753) that the body chosen as the point of support is very variable. Sometimes it is the bottom of the manger, the border of the manger, the internal or the external edge of this border, the lower crosi-piece of the hay-rack, the halter-strap; sometimes it is the window-sill, the side of a stall, the end of the shatt, that of the pole, the harness of his mate, ete. ; more rarely the animal cribs upon himself. In most instances, the teeth effect the support; in other cases it is the lips, the tuft of the chin, the inferior border of the jaw. The subject often previonsly moves his lips over the body which he is going to seize, or he lieks it and wets it with saliva. Then he presses forcibly on it, arches his neek if this body is somewhat low, and, finally, energetically contracts his inferior cervical muscles, especially the sternomaxillaries, ${ }^{1}$ and at that moment produces the guttural noise of which we have spoken.

When the teeth rest on the point of support, there is an abnormal wear of the incisors. As the reader already knows the varions characters of this wear (see page 75.3), we shall not refer to it again. We need only bear in mind that in cases of expert testimony it is useful to prove its existence, and to show clearly that it is the necessary consequence of the manner in which the support is etfected. Horses

1 At antopsies, we have frequently moticed, as M. Berthe has done, that these muscles are much more voluminous than under ordinary eonditions. 
indulge in this vice during meals or during the intervals between meals, and repeat it with more or less firequency and persistence. Some desist from the practice in the presence of strangers; others do it only when they are alone in the stable; the greater number, however, indulge in it whenever they experience the desire; and there are some in which the alcidental arrival of some one in their stable provokes the desire to crib. This vice is not always equally easy to detect. Certain subjects must be carefully watehed for a long time; in some cases the observer is even obliged to conceal himself to tetect them. The expert should never neglect this precaution when he has any dortbts as to the case.

Long periods of intermittence in the manifestation of this act have been recorded. Bellanger tells ns of a cribber which, during the Italian campaign of 1858, had never cribbed, but which resumed this habit upon his return to his stable in Paris. The same observation may be made every day. Very often the removal or change of the body which acts as a support will be sufficient to cause the disappearance of this defect. Unfortunately, this remedial measure is only temporary in its effect; the animal soon manages to find a new place, and the habit is recommencel.

Many remedies for eribbing have been devised. The one which seems to give the best results is a leather strap placed more or less tightly around the neck at the level of the throat. In conjunction with work, it produces good effects npon vigorous horses which become restless through a too prolonged standing in the stable. We have performed tenotomy upon the two sterno-maxillary muscles, but without success. Cribbing horses are subject to flatulence of the intestines, as has been said. The quantity of air which they swallow is sometimes so enormous that it causes a distention of the intestines accompanied by colicky pains. Fortumately, the latter are not of a serious character. Brisk exereise and the oceasional applieation of the whip, if necesary, forcing the animal to rm, jump, and kick, will soon caise the expulsion of the gas. But it escapes throngh the anus and not through the nosophagus.

Cribbers are, moreover, a source of useless expense to their owners, becanse they mutilate the hay-rack, the manger, the harness, etc., upon which they apply their teeth. Besides, the wear of their teeth is sometimes so marked that they experience inconveniences from it, prineipally when their incisors are shortened to a level with the gums. Horses that crib have been supposel to require a longer time to eat their oats, and to lose a portion during feeding, which led to their 
being fed from nose lags instead of from a manger. We are not of this opinion. Often have we taken note of the time required by cribbers to consume their ration. When they have an ordinary appetite it takes them about fourteen minutes to eat two litres of oats; if they drop a certain quantity of the feed, they will afterwards pick it up again from the ground. The loss of time and food is insignificant.

\section{CHA P T ER II.}

\section{VICES PROPERLY SO CALLED.}

UNDER the above heading we class those serious moral defects which indicate an indocile, stubborn, or irritable nature, a bad education, an ungovernable temperament, an inclination to be aggressive, or to resist, - vices which, in a word, render the animal dangerous or almost useless.

Generally, horses which have these imperfections are called ricious; they are further designated in various ways, according to the vice with which they are affected. Thus, the balky horse is one which disobeys the command of his driver or refuses to go in the desired direction; the biter, one which attacks or defends himself with his teeth; the kicker, one which uses his hind-feet under similar ciremmstances; the rearing horse, one which raises the fore part of the body to strike or to dismount his rider; the shyer, one which is easily firghtened by acicilental things or cireumstances for which he cannot aceount.

Sometimes vicions horses are qualified as ricked, and at other times as stubborn. There are some, however, for which specific names wonld be impossible. We will rapidly pass them in review.

\section{§1. External Manifestations Proper to each Vice.}

1st. Balky Horses.-The balky horse, as already said, refuses to obey his rider or his driver.

Balkiness, one of the most common equine yices, is as frequently found in the saddle-horse as in the driving-horse. Sometimes the animal obstinately goes in a direction different from that in which he is desired to go ; sometimes he refuses to go along certain roadk, to pass by certain objects or certain houses; in other anser, he stops, notwithstanding the most energetic efforts of the rider or driver' or he will insist on going to the right, to the left, forward, lackwarl, or will refuse to arlvance, to turn, to back, to jump, ete. It is not from fear, but from 
stubbornness; not from a spirit of resistance, but from a determination to have his own way. It will be readily understood that such horses are the source of serious danger to those who drive them, since one has to eontend constantly with them, and sometimes it becomes impossible to handle them by the ordinary means. Numerous accidents are thus occasioned in large eities, where the streets are always erowded. We have seen balky horses allow themselves to be belabored with blows rather than move one step; many will remain in the same spot, without offering any other resistance than a determined obstinacy. These are the least dangerons. Generally they make this vice still worse by striking with their fore-feet or by biting; in such eases, the best course to pursue is to await their pleasure ; the wisest plan, however, would have been not to purchase them at all.

2d. Horses difficult to Approach or to Groom.-We inehde among ricious horses those which it is difficult to approach. As soon as such horses see any one coming near them, they set back their ears, stamp with their feet, strike or kick, show their teeth and try to bite. When loose in their stalls, they turn around and commence to kick. If they be placed in a single stall, it is often diffienlt to avoid their attacks. When they do not snceed in biting or striking, they press the attendant who approaches them against the side of the stall, even leaning down to squeeze him with still more force. Many of them, when monnted, have the habit of pressing the leg of the rider against trees, walls, and other objects. It is with a view to avoid accidents of this kind that all riding academies are provided with a wall inclined towards the track.

All these animals are skittish and irritable. We should approach them boldly, speak to them, and avoid raising the arms, and especially tonching or stroking their hind-quarters. Gentleness, caresses, some little dainty, in a word, kind treatment, will have the happiest effect upon their disposition; while lond words, threats, and the use of the whip will nearly always render them intractable.

Certain subjects have, besides this vice, that of being diffienlt to groom. They bite their halter-strap when they are ctrried, snort, areh their back, try to lic down, press the groom against the stall, stamp, strike with the hind-feet, set back the ears, and show in a thonsand ways their distaste for the grooming. When they are only skittish or ticklish, they are not very dangerons. If they are badly treated, however, they will soon become aggressive. They should therefore not be dressed with the curry-comb, nor should they be treated harshly ; it 
would also be well to tie the head to the hay-rack to protect one's self from bites and kicks.

When these simple means are not efficacious, others must be improvised according to circumstances. Recourse may be had, for example, to the muzzle, a side-line, a rope forming a loop around the neck, passed throngh the mouth, then around the hind pastern, and forward again through the halter, where it is tied or held by an assistant, ete. The important point is to secure the head and keep it in place; the proceedings, in this respect, vary according to the disposition of the localities, but it would be out of our scope to describe them in detail.

3d. Horses difficult to Harness or to Mount.-In most cases, a horse allows himself to be harnessed without any difficulty, especially if the harness canses him no pain by rubbing over sore places and is applied with care and gentleness.

Sometimes, however, he offers a most determined resistance. $\mathrm{He}$ kicks, strikes in front, rears, squeals, bites, and tries to lie down. Under these conditions, he becomes all the more dangerons according as the man who approaches him is loaded with the harness or blanket with which he wishes to cover him. Certain animals refuse to receive the bit; they turn their heads from side to side, rear, or try to run away or to bite. Others puff up and resist when an attempt is made to tighten the girth, or to place them between the shafts, or to mount them. In the latter case, the animal often rears, plunges forward, and jumps as soon as the rider's foot is put in the stirrup. Some arail themselves. of this moment to bite their rider; others rear and kick as soon as he is in the saddle; the more vicious try to dismount their rider, then to lie down and trample upon him.

Nothing could be more varied than the ways in which this vice is manifested. It may be modified, but it is impossible to overcome it altogether. The most frequent means used consists in fastening the horse's head very short to the hay-rack before harnessing him, in order to prevent him from kicking and biting; two of his diagonal members are hobbled if he attempts to rear. In some cases recourse must be had to the twitch in order to bridle him. Lastly, it often becomes necessary, to get him between the shafts, to cover his head with an apron. But it is only by a methodical dressing that he can be accustomed to receive the rider.

th. Horses difficult to Shoe.-It is very important, when purchasing a horse, to make him lift his feet one after the other, and to 
strike each foot with a hammer, in order to make sure that he lets himself be shorl without difficulty. The neglect of this precaution may result in rely serious consequences; for animals which are difficult to shoe are always a great inconvenience to their owners, and too often the canse of aecidents to blacksmiths and other persons. When the horse is merely lazy, the inconvenience is comparatively trifling; he gets himself corriced, as the saying is, and the farrier can relieve himself of a portion of the weight by means of a rope fastened to the pastern and passed around the thorax. But when the animal absolutely refuses to allow his feet to be manipulated, his shoeing beemes difficult and dangerous. In fart, it is then necessary to place him in a stocks or tracis, and sometimes to throw him down upon a soft bed of straw, to snceed in the attempt. We see, then, to what inconveniences one is subjected at each successive shoeing of the horse. The risk of personal injuries, and of wounds inflieted by the horse upon himself, and the dangers to which one is exposed when it becomes necessary to employ violent means, make it judicious to reject him, or, should the vice not have been perceived at the time of purchase, to get rid of him.

5th. Biters.-We designate by this term horses which use their teeth against persons who approach them, groom them, monnt or lead them, as well as those which use them as weapons of defence against other animals. This rice is undoubtedly most common in stallions, which often show around their lips, nostrils, sides, and upper border of the neck, and the withers, evident traces of the struggles they have hat with their neighbors and rivals. In whatever direction they gratify their vicious propensity, they all eventually become very dangerons. Some have been seen to plunge ferocionsly upon their victim, trample him underfoot, bruise him, and rend him, as if impelled by a firrions rage. Is a rule, dealers do not hesitate to put them up for sale, especially when the vice is not very marked. Hence purchasers should leave no means untried to recognize them. They usually set back their ears, pucker their nostrils, curl up their lips, streteh out their heads, and show their teeth when any one passes within reach of them. Somctimes, however, they appear very docile, accustomed as they are to the grooms; at other times their apparent gentleness is due only to their being cowed down by the remembrance of past punishments or their dread of future ones. As soon as they change masters their vicious and aggressive nature quickly reasserts itself. It is then important that the new owner should approarh them himself, and caress and stroke them gently, so as to avoid startling them. Such animals 
are not useless. Were not their vice a grave one, they would be as good as other horses, for they are neither indocile nor lazy. On the contrary, fatigue, privations, and bad treatment are of little concern to them. That is why there is but little hesitation to use them. Many of them perform the most laborious work. It is customary to work them on the lead, or to place them between horses with which they have no desire to fight. But they must always be watehed. The simplest way to protect one's self' against their attacks is to muzzle them; in the stable, they can be seeured by means of the neeklet or neck-cradle, or by tying them on both sides of the stall, or with the side-rod fastened to the sureingle, a nose-band, a muzzle, a rope passing through the mouth and the hind pastern. When they are very troublesome, it is well to make use of the muzzle.

\section{6th. Horses which rear and strike with the Fore-Feet.}

-There are some horses which only rear; others rear and at the same time strike with the fore-feet; still others strike withont rearing. The first, or rearers, raise themselves suddenly upon their hind-feet for the purpose of defence or attack, by a sudden impulsion of the anterior members. This act, which is often only the result of excessive playfulness or restlessness, may unfortunately also assume the character of a very dangerous vice. The saddle-horse, when rearing, sometimes strikes the rider with his head and injures him either in the face or on the chest. The blow is in some cases so violent that the rider is dismomnted and under the horse's feet. Besides, the animal himsdf often loses his balance and falls over backward, crushing the rider under his body and causing serious fractures of the ribs, the pelvis, or the limbs.

Some rearers, as soon as they are standing 11 , avail themsclyes of this attitude to strike out with their fore members at neighboring persons or horses. Some have been seen, after throwing off" their rider, to kneel down upon him and erush him in the most horrible manner. Under similar ciremstances, there are some which attack the groom with their teeth, a habit which is popularly characterized in a singular way by the expression, they are in love with the men! Are not these actions rather the result of a premeditated vengeance directed against those who have been violent and brutal in their treatment of the animals intrusted to their care?

This vice is tolerably easily remedied. When in the stable the horse may be prevented firom rearing by a short halter-strap; in the shafts or mounted, by the use of the martingale. When he simply strikes in front, this habit is sometimes corrected by the manger being 
made very slanting in front; it then becomes impossible for him to raise his forearms very ligh without striking his knces against the bottom of the manger.

7th. Horses which back. - The importance of this vice has been recognized for a long time past, for Gabriel Meunier, ${ }^{1}$ in the midst of an enumeration of very different matters, exclaims, "Du cheval qui recule. . . . Libera nos, Domine!"

Although more difficult than ordinary progression, backing is an act which every horse properly dressed shonld be able to perform when required. There are some, however, which back without any apparent motive; others do it as soon as they are touched with the whip, or when they are in the hands of unskilful drivers or inexperienced riders. A similar result is produced when the animal inclining his head to one side, in the endearor to rid himself of flies, for example, hooks the inferior eross-bar, which unites the two branches of the bit, against the end of one of the shafts. We have also seen it oceur in ases of turning a four-wheeled carriage by holding the horse by the bricle, when the lines have remained attached to the dasher ; finally, it is often the conseqnence of fear or of pain occasioned to the bars by brutal tractions upon the reins.

Whatever the canse which produces it, horses having this habit are always very dangerons, espeeially in large eities, where they may back through shop-windows, knock against other vehicles, injure the passersby, etc. Outside of good training and careful driving we know of no practical mans to remedy this evil. It is important, then, at the time of purchasing an animal, to ascertain that he is free from the habit.

8th. Kickers._- A cheval rueur d'avant passe," says a proverb of the sixteenth century, ${ }^{2}$ which may be translated, "With a kicking horse, pass in front."

This vice consists in kicking as a means of attack or of defence. All horses, however, do not kick in the same manner. Some kick at the riding-boot, when they endeavor to strike, with one of their posterior members, the leg of the rider as he is about to mount. Others kick eow-fashion, gice a lick like a cow, forcibly projecting one hindfoot forward and ontward, like a cow, to reach a person standing near their corresponding anterior member. Again, there are some which kick backward with only a single posterior member. But generally it 
is kicking properly so called which is witnessed. It often takes place in the stable, without any good reason. In snch eases, the injuries sustained by the points of the hock produce small swellings, cappedhock, which should be taken into consideration in purchasing a horse. Frequently it oceurs during work, from contact of the leg, the spur, the riding-whip, or the whip-lash, from the touch of the lines upon the croup, or of certain parts of the harness, as the traces, or from some unexpected ocenrence stimulating the hind members and surprising the animal. The subjects worked in single-file at times kick the shaft-horse with violence upon the head, the chest, and the internal face of the forearm. The same is true of saddle-horses with reference to those who follow them, or to their neighbors in the parade, in the riding-sehool, and in cavalry manœurres. Mares, especially those which continually evert the elitoris, are very irritable when people approach them too closely. Too low a dash-board sometimes permits the driving-horse to eateh the lines under his tail and retain them there. Should the attempt be made to pull them out foreibly, it is by no means rare for the horse to kick. We cannot too strongly condemn the bad practice which some drivers have of correcting a horse for this or any other habit by the free use from behind of a long whip, the lash of which in a manner encircles the animal's shoulder, ribs, back, loins, and a part of the croup. This so-ealled girdle-whipping is often dangerons. The animal, surprised by so violent and so sudden a punishment, ordinarily responds to it by a shower of kieks, and it is very fortunate if he does not run away.

Under all these eireumstanees, kickers can inflict upon their neighbors more or less serious injuries, such as contused wounds of the chest, the ribs, or the abdomen, or fractures of the bones of the head, the forearms, or the legs. Too often, also, these aecidents befall the persons who drive, mount, approach, or groom the aninals in question.

The kicking-strap, passing across the croup from one side to the other, and fastened to the shafts, is a fairly practieal method to prevent kicking during work when the animal is in harness. In the stable, the rope throngh the month and around the fetlock, as before described, should be fixed to the halter. With this appliance a horse will seldom kick more than once. Finally, when they are used under the siddlle, the rider must bring good horsemanship into play to prevent theu from lowering their heads, and be very careful at the time of mominting.

We will also consider with kickers those horses which switeh their tails,-that is to say, which shake their tails like dogs when their hind-quarter's are approached. "Don't buy a horse that switches his 
tail" is the advice of an old proverb." This advice is to be remembereel, for these animals, among which are found especially ticklish subjects and pissy mares, are inclined to kiek and show their evil intentions. They expose persons to all the dangers we have enmmerated.

9th. Timid Horses, Shyers._Fear, says Littré, ${ }^{2}$ is a painful passion which is excited in us by that which alpears dingerous, threatening, and supernatural. Fright, according to the same authority, is fear carried to a high degree, a great fear. In horse language, timid or easily-frightened horses are known by different names. The horse which is afraid of his shadow or of an object which surprises him is also called skittish. The timid horse is one which is easily frightened; the horse which is said to be vatchiful, or a little watchiful, is more or less timid.

Fear, in the horse, does not scem to be ever the effect of a simple moral influence, sueh as is observed in some circumstances in man. In most cases the causes are entirely external ; their action is sudden,one may say instantaneous. Some act upon sight, others upon hearing; most of them affect simultaneously the apparatus of vision and hearing, and sometimes even that of olfaction. Who has not seen it horse, that has often been maltreated by his driver, prick his ears upon the approach of the latter, open his eyes widely, and pull back or swerve to one side, to avoid the blows with which he magines he is threatened? Another one, at the sight of clothing lung out on elothes-lines, flapping to and fro, and blown up by the wind, will plunge to one side and start to run away. Still another will suddenly stop, rear, and turn aronnd on the road, alarmed by a pool of water refleeting the rays of the moon, a velocipede wheeling along rapidly and silently, a field laborer suddenly rising from a stooping attitude, a dog running out of a house into the street, a railroad train suddenly coming out of a tunnel, the bright light emanating from a sky-rocket sent up in the dark by a child, etc. How many horses tied at the door of a blacksmith-shop are frightened by the sparks which fly from the iron hammered on the anvil, prick their ears, dilate their nostrils, snort, pull at the tyingstrap, break their bridle, run away, or throw themselves down! How many, also, unbridled and quietly eating their oats as they stand by the sidewalk, while the driver is taking his repast, are suddenly seized with fear on seeing the flashes of light reflected from the freshly-rar-

1 Bouilli, Proverbes, sixteenth century.

${ }^{2}$ Littré, Dictionnaire de Ja laugue française. 
nished wheels of passing vehicles, a flock of pigeons flying to roost upon the roof of a neighboring house, a drove of sheep approaching in a huddled mass along the dusty road, ete.

The exciting causes of fear which act upon the sense of hearing are perhaps even more numerons and more operative than those which aet upon the sense of sight, because it is harder for the horse to understand their nature. We may mention among them a sudden noise, such as the report of a fire-arm or of a cannon, the explosion of a piece of fireworks, the whistle of a locomotive, the barking of a dog, the accidental resonance of the ground over which the horse is travelling, the transition from a dirt road to a parement, or to a wooden or an iron bridge, the shaking of the ground and the noise produced by the passing of a railroad train, the swift arrival of a earriage, the beating of a drum, the sound of a bugle, etc. "A good bugler's horse is not frightened by noises." 1

The odor of wild beasts, certain pungent emanations which the animal pereeives suddenly when passing before a menagerie or a knacker's establishment, ete., may also frighten him and eause him to run to one side. But influences of this kind are more rare than those mentioned in the preceding paragraph. Such horses at every moment expose to great dangers those who drive them. Good horsemanship alone is capable of inspiring them with confidence and boldness.

10th. Aversion to Special Objects. - We purposely take up this vice immediately after the preceding, on account of the diffieulties which are sometimes experienced in distinguishing the one from the other. It is characterized by the extreme repugnance, mingled with hatred and aggressiveness, which some horses manifest for certain colors, or towards certain animals. J.-B. Rodet ${ }^{2}$ has given three remarkable examples, and we also have observed some. The following are cited from Rorlet:

"In 1806, during the campaign of Austerlitz, a Piedmontese officer possessed a beautiful mare, a very good animal in all respects with the exception of a vice which rendered her excessively dangerous as a sattlle-mare. This animal had a very decided aversion for paper, completely losing her senses not only as soon as she saw it, hut also whenerer, even in darkness, she hearil the rustle produced by it. This effect was always so prompt and so violent that in several instances, taken by surprise as it were, she ran away or dismounted her rider, and even at one time, the foot of the latter remaining caught in the stirrup,

J Leroux, lictionmaire eomique, t. i. p. 162.

2 J.-B. Rodet, Doctrine physiologique appliquée à la médecine vétérinaire, p. 272 , et suiv. In- $8^{\circ}$, Paris, 1828. 
she dragged him for some distance over the stony ground. A remarkable fact was that this same mare was very gentle otherwise, and, exrepting this one object of her special terror, she would ignore all the causes which ordinarily frighten most horses: the noise of a cannon, the beating of drums, military music, the whizzing of balls and bullets, the sight of camp-fires, the smoke and fire of small-arms or artillery, the sight of troops in battle, the waving of plumes and flash of brilliant arms,-none of these would give her the least fear. And, as was several times observed, she did not show the same fear for other white objects as that which she experienced at the sight or the noise of paper. Every means employed for the cure of this defect proved unsuccessful, and her owner was forced to sell her, not being able to use her as his mount.

"Déicon, a brown bay horse, belonging to the old French army, was very gentle to man, to other animals, and to all horses, except those with a more or less brilliant light-gruy coat. In fact, he had for the latter, and for them only, so great a hatred that as soon as he saw one he would make every effort to get to him; when he sueceeded in this he would assail him with great violence. He behaved in the same way at all times and in all places,-free or when mounted, on the drives, the roads, on the march, or during the mannuvres or the halts: his animosity was such that it was dangerous to put not only a stallion but even a mare of a gray or white coat in his stable or at any distance away from this, so long as he could see them. He was not satisfied until he had broken loose, and when he succeded in this he would plunge upon these animals, kicking and biting them with the greatest fury, usually seizing them by the head, often even by the throat, and might have choked them had not some one promptly come to their assistance. As he grew older (he was eighteen years old when he was sent out of the army), this furious temper only slightly abated. In 1818 it was so strong that he could not be turned ont to grass with the other horses of the regiment which, like himself, were in need of this diet. For other white brodies he did not have the same aversion as for horses whose coat approached this color.

"Dague, a sorrel mare, of the Norman variety, was, on the contrary, very much afraid of all inanimate white bodies, - that is to say, bodies motionless of themselves, such as white cloaks, shirt-sleeves, cross-belts, paper, but especially white plumes. When these white bodies, set in motion by any cause whatsoever, mexpectedly met her gaze, if they were of a certain size, and if the movement was somewhat rapid, she was extremely frightened and would endeavor to run away. But if the white objects were small and had but a slight degree of movement, she would plunge angrily upon them and endeavor to bite them and strike them with her fore-feet. No other rolor and no other bodies produced this effect upon her. A still more singular circumstance was that she manifested neither fright nor anger in the presence of white horses and white dogs, whilst she was always irritated at the sight of a sheet of paper or a white plume set in motion by the air or any other cause."

We, on our part, saw several times during the existence of the post at Iffort, relays of gray horses attack relays of bay horses, striking them with their anterior members and biting them, uttering at the same time the most ferocions cries.

One day, a gray stallion. having broken his halter-strap, eseaped 
from the hospital yard of the school of Alfort, and with his teeth and feet attacked a bay horse harnessed to the wagon of a grocer who supplied the establishment. It was with great diffieulty that the two animals were separated; the aggressor had seriously wounded the other horse and almost demolished one of the shafts. ${ }^{1}$

We have known horses which hatd the greatest horror for hogs; their ears directed forward, the expression of their face, their snorts of alarm, their eftorts to run away, everything, in short, showed the fear which they felt. ${ }^{2}$

Wild animals, by the peeuliar odor which they exhale, seem to provoke identical manifestations. We saw, a few years ago, a good horse harnessed to an upholsterer's wagon stop suddenly, jump to one side, and snort londly in the presence of three very peaceable bears which some grpsies led by a rope, and which did not in any way obstruet the road. But facts of this kind are not rare; all those who have travelled in eountries where the wolf still exists have seen similar ocenrrences.

11th. Runaway Horses.-A horse is said to run away when he suddenly rushes forward blindly, impetuonsly, madly, going straight ahead, heeding nothing but the irresistible stimulus which impels him, and losing even the instinct of self-preservation. Vulgarly it is erroneously said that he takes the bit between his teeth, that he is seized with a short fit of insenity. In horse language, the same thing is expressed by saying that the animal pulls, or again, the runaway horse is called a lugger. ${ }^{3}$ Generally, this vice is more common in ardent, very sensitive, and irritable horses, and in those which have bad eyesight. It also appears to us more frequent in warm countries and during the hot seasous, judging, at least, from the reports in the press. But the usual causes are fear and pain. Any sudden noise inspiring terror, such as the report of a grim, an explosion, a clap of thunder, the beating of drums, the whistling of locomotives, an unusual resonance of the ground, passing over a bridge or under an arch, the arrival of a train, the barking and attack of a dog, the sudden appearance of white bodies in motion, sueh as clothes flapping on a clothes-line, the sight of a

1 See, also, Séon Rochas, Hygiène vétérinaire militaire, p. 505, I'aris, 1811.

2 One of the anthors has observed in a parrot the same aversion for hogs. When it saw one of these animals, it was seized with terror, gave utterance to piereing sereams, and would sometimes tumble from its perch.

3 See, for further details, A rm. Goubaux, he l'emportement chez les ehevanx et des moyens de le réprimer, in Moniteur des hôpilaux du 31 Octobre, 1855, ancl Argus des hnras el des remontes, annce 18 sis, pp. 441 et 496 . 
wild animal, or the odor emanating from it, the breaking down of a carriage, the snipping of the axle-tree, the shaft, the pole, of some part of the harness, ats the girth, the erupper, the trace, the lines, the arcidental unfastening of the collar, ete., any sudden pain, a wound, brutal traction upon the bit, a violent cut of the whip, immoderate nse of the spurs, sometimes the simple inconvenience oceasioned by a disarranged harness, etc.,-any of these circumstances, or many other analogous ones, may cause a horse to run away.

Often it results from a vicions disposition, a bad education of the horse, which, at the slightest provocation, becomes irritable, defends himself, and runs away.

Sonetimes, on the eontrary, the aet implies neither fear, pain, nor amnoyance, and occurs in animals which display in other respects extreme gentleness. High spirits, the desire to l'un, the need of exercise, a whim, or some internal impulse as yet not satisfactorily explained, lears them on, intoxicates them little by little, and the next moment they "lose their head;" they fall a prey to the mad impulse and are deaf to all restraint. Some people are imprudent enough to unbridle their horses entirely, in order to give them a drink or to feed them, along the roadside or on the strect, without keeping a watchful eve over them. In such eases accidents are not rare. Accustomed to work with a bridle and with blinds, and thus to see only what is in front of them, these animals become friglitened at the sight of objects in motion alongside of them, and will at once start to rum away. For this reason the use of blinds should be avoided as much as possible, and esperially should the bridle never be taken off upon the public road, unless extreme watchfulness is exereised upon the vehicles, or the brake applied to the wheels, and the horse's head tied to a weight or to some fixed body elose by.

Again, there are some persons who will not allow any other carriage to pass them on the road, and on that aceomnt urge and excite their horses in every possible way. The latter at first quicken their gait, become excited by degrees, redouble their speed, and often end by rmming away. In time the spirit of emulation becomes a part of the horse's disposition and develops into a veritable mania. He will no longer allow another horse to pass him on the road, and manifests this determination, if needs be, by indocility.

The animal which runs away usually breaks suddenly into a gallop and rushes forward headlong with all the speed of which he is eapable. Sometimes the inerease of speed is gradual; little by little the animal becomes unmanageable, and in a short time he is beyoud the control of 
his master. Once started, he no longer knows what he is doing, no longer sees, hears, or smells; he runs away, and this seems to be the only thing he has the desire or the ability to do. Nothing calms him ; deaf to threats, insensible to blows and tractions on the bit, he no longer realizes danger. The efforts made to stop him, the obstrnctions in his way, the eries of alarm which are raised along his ronte, serve but to increase his fright. He stops only when utterly worn out in strength and wind, or when his earcer is checked by collision with a house, a wall, or a vehicle.

During this senseless run the horse holds his head in a characteristie manner : he carries it either extended or arehed. In either ase he takes a strong point of support on the bit by the assistance of the bars, except when he is unharnessed or left to himself. It is this that has led the layman to suppose that the runaway horse has the bit between his teeth. We know, however, that this is not the ease. The bar of the bit can, at most, sarcely touch the first molars. This indeed would be sufficient to explain the twisting of the branches of the bit and the rupture of the bearing-rein, which sometimes result from the violent tractions made to restrain the animal, to avoid danger or pull him baek.

Many means have been devised to prevent runaway aecidents or to control runaway horses. When a horse is rumning away on a level, unobstructed road, all that can usually be done is to let things take their conrse; the dangers are not great; the horse will stop of his own accord when he becomes too tired to run farther. If the driver feels him start sucklenly away, pulling every instant more and more, especially if this is habitual with him, it beeomes necessary at once to sau the bit (that is, pull alternately upon each line) and try to turn the horse's head strongly around to the left or to the right, in such a way as to slacken his gait, hamper his movements, and produee a sharp pain upon the bars; when practicable, it would be well to turn him into ploughed ground. But if the horse has become entirely unmanageable, there is nothing left for the driver to do but to use every effort to keep his seat, and await the result. To leap from the wagon would be, at least, equally dangerous. No doubt there are mechanical arrangements which ace in varions ways upon the month and the eyes, and by the aid of which it is possible to prevent a horse from ruming away altogether. Unfortunately, they are not always at hand at the required moment. They onght to be permanently employed on horses difficult to manage; but, then, what eonstant attention, what expenses, what annoyanee they entail! Besides, however ingenious they may be, they 
are not applicable to animals left unbridled upon the public road. There is only one way to manage these that we know of : that is, to grasp their heads firmly and seize them by the nostrils. On the whole, the wisest thing to dygrith reference to a horse addicted to rumning away is to get rid of bim as soon as possible; the pecuniary loss that may result is not to be thought of for an instant, in view of the irreparable accighnts which might be the consequence of retaining him in one's servic

pre

Generai, Causes of Vices (Whether ascertalned, ProbABLE, OR SURMISED).

The causes of vices are as yet but little understood, on account of their extreme complexity. Their influence is either temporary or permanent; this, in our opinion, explains the relative curability of the untoward manifestations to which they give rise.

Most anthor's who have made a study of this question concur in the opinion that heredity is one of these causes.

"Every horse," says De Lafont-Pouloti," "which is indolent, indocile, timid, bal-mouthed, balky, stubborn, cowardly, skittish, or spiteful to man, is to be rejected, however perfect he may be otherwise; his get will have the same disposition."

Hartmann thinks likewise that the offspring may inherit the good qualities as woll ats the bad ones. ${ }^{2}$

Brugnone wonld exclude from reproduction all horses which are skittish, too ardent, ill-natured, indocile, kickers, or biters; also the lazy, the irascible, and the cowardly. ${ }^{3}$

Demonssy ${ }^{*}$ asserts that physical resemblance is not the only similarity transmitted to the descendants, but that the latter inherit also the moral qualities of their ancestors. For example, the shy horse would usually beget timid colts. The great-grandchildren of Cardinal and of Jaumont, and quite a number of the progeny of Curde would (according to him) be distingnished from their contemporaries by their excessive irritability and their irascible disposition.

Professor Grognier ${ }^{5}$ spealis of moral qualities which, transmitted throngh many generations, have ultimately become race-types, such are

1 De Lafont-Ponloti, Nouveaux régimes pour les luaras, p. 23, Turin, 1787.

2 Hartmann, Traite des haras, translated from the German, 2e éd., p. 74, Paris, 1785.

3 Bruguone, Traité des haras, translated from the 1talian by Barantin de Montehal. p. 53, Paris, 1807.

1 Achille Demoussy, Traité complet des haras. p. 60, Tulle, 1833.

5 L. F. Grognier, Cours de multiplieation et de perfectionnement des différents auimaux domestiques, p. 239, 3e ed., revised by Mague, Paris, 1841. 
the gentleness and docility of the coach-horse of the Cotentin and the indoeility of the camargue horse. "It is a rare thing," he adds, "to see balky and ill-tempered colts begotten by gentle and doeile stallions, whilst every day we see young hores disposed to kick and bite whose sires and dams were affected with the same vices. A stallion stationed at Alfort was very ill-tempered, and this ill temper was transmitted to the majority of his get. In England there are examples of families of horses, very superior otherwise, but vicious from sire to son, and dangerous to the lives of those whose lot it was to mount them and care for them."

De Curnieu ${ }^{1}$ recommends the use of the half-thoroughbred mare for breeding "only when she has done good service and has a good temperament. If she kicks, bites, or is difficult to harness, to shoe, or to groom, there is every reason to believe that the colt will be like her, through heredity, education, bad example. . . If you wish to produce a horse for your own use," he continues, "reject a vicious broodmare, and try to obtain some reliable information concerning the stallion, but do not let yourself be duped, especially if it be a question of a thoroughbred horse ; for the slightest indication of irritability in an ordinary mare, a shadow of an inclination to kick, laying down of the ears, all this becomes a downright vice when it is increased from the father's blood, espeeially if he has defects of the same nature. No mare should be used as a broodmare unless she is perfectly known."

All these statement- are of great importance in guiding the breeder in the choice of the stallion and the mare. All vicious stallions of studs should be banished from the breeding farm.

Excessive impressionability and innate irritability. also often give rise to serious vices, because they oceasion violent reations in the presence of the simplest methods of leading, driving, or restraining the animal, and will soon provoke indocility, anger, aggressiveness, and a spirit of revenge.

Bad education, resulting from a bad example set by the mother and, espeeially, by the attendants, has an undeniable influence. How many horses are known to be kickers, biters, rearers, runaways, irascible, or timid, which have learned these vices from their mothers or have contracted them by degrees through the provoeations and continual teasing of man himself !

Interference with already acquired habits sometimes renders the horse ill-tempered. Some horses, for example, will not toler-

1 De Curnieu, Leçons de seience hippique générale, 3e partie, p. 313, Paris, 1855. 
ate the rider's mounting on the right side or leading them from this side; others, worked in a team, will work only when they are placed on the right side or on the left side; still others will work only in the shafts or in file; some saddle-horses will not work in harness, and vice rersa ; some become indocile when the rider or driver is changed, ete.

But there is no cause more important or more common than bad treatment. It rebukes the horse, frightens him, and disposes him to resist and to attack. Carters, coachmen, grooms, blacksmiths, riders, and brutal masters are in most instances primarily culpable and responsible for the vices which follow bad treatment.

Pain, resulting from wounds on the surface of the body, from a defective fitting and application of the harness, or firm the nse of brushes and curry-combs whose stiffiness is out of proportion to the degree of sensibility of the skin, ete., produces the same effeets upon the disposition, and often render's the animal intractable. Thus, the wounds in the region of the loins oceasioned by the saddle are usually so painful that the animal cannot be used, and kicks, rears, defends hinself, and absolntely refuses to allow his rider to mount him.

During warm seasons the horse is more frequently vicious than during cold weather. The heat enervates him, the cutaneous secretions, being more abundant, irritate his skin, and the insects especially constantly annoy him. Certain insects belonging to the diptera, as the gadfly and spider-fly, for example, torment him, stinging him sometimes in the most sensitive regions; he is rery apt to become indoeile, irritable, and even ummanageable when he is not aceustomed to these annoyances.

The influence of diverse physiological states should also be mentioned. Some are connected with the finction of reproduction; such are the sexual desires and matemity. Others depend upon a defective conformation of the eyeballs.

In the entire horse the sexual desires manifest themselves especially in the spring and during the heated term of snmmer. At these two periods of the year horses which at other times are gentle and docile suddenly become exritable and stnbborn. They have frequent erections. neigh, plunge upon their grooms, and furiously kick and bite neighboring horses. Castration is often the only means of remedring this condition, which, in ecrtain casce, may have very serious consequences.

Demoussy' says that "the mare also shows, by unequirocal signs, the want of satisfying the desires of nature. The sexual organs 
beeome tmmefied; the raginal membrane is eongested; there is a copions discharge of a mucons, tenacious, whitish fluid from the vulva; the animal frequently stretehes out to urinate; the temperature of the perineal region is raised, the neighing becomess more frequent than usual, the eyes are more expressive, the physiognony more animated. When she is in the stable, she is more restless; she trembles at the slightest noise, and her uncasiness ceases when she is taken out. The saddle-mare, when she is mounted, no longer responds to the spurs. Far from considering their effect a punishment, as in other scasons of the year, their pressure upon the flanks no longer quickens her step; she stops, on the contrary, and stretches out, separating the abdominal members. Sometimes she resents the eorrection inflicted upon her; she kieks, and in the act of raising her hind-quarters discharges several jets of urine. If she is then vigoronsly spurred, she defends herself to the utmost. . . However, the most iraseible disposition and the greatest ill temper yield sometimes to the powerful influence which dominates them. I have seen the most savage mares allow themselves to be led with the greatest doeility at the time of rutting, becanse they were in hopes of being taken to the stallion, but such an oceurrence is very rare."

After parturition, many mares which until then had been very gentle, suddenly become aggressive and vieious. Always watchful that nobody should tonch their foal, they then display extreme irritability and must be approached with great caution.

An abnormal conformation of the eye, considered as a dioptrie apparatus, results especially from an aberration in its spherical shape or in the curvature of the cornea. From this there results, as we have already shown on page 71 , a defeetive vision which gives rise to presbyopia and myopia. It is a matter of common observation that myopie animals are more timid and more liable to shy than others, and, on this very aceount, dangerous to those who have eharge of them or who employ them.

Insanity has been admitted by .J.-B. Rodet ${ }^{1}$ and Pierquin ${ }^{2}$ to be a possible canse of ill temper. And, truth to say, we are, in spite of ourselves, apt to find, in sereral vieions manifestations in the horse, something analogous to, if not identical with, the fits of unreasoning passion observed in man. How can we explain, for example, the singular eondition of horses which kick at night when in the stable with-

1 J.-B. Rodet, loc. cit., p. 254.

2 Pierquin, De la folie chez les animaux. 
out any appreciable motive? How can we account for those sudden attacks of terror which are witnessed in some horses in the mirlst of the greatest external quictude, and which so elosely resemble hallucinations? To what are we to attribute the eaprices, the stubbornness, of the balky horse, and the oceasional fury of the dumminess? W'hat significance are we to attach to the last period of excitement of the runaway horse? What are we to think of the feeling of aversion or anger displayed towards the colors white and red, or towards certain speeies of inoffensive animals? Why, in a word, may not the horse, which also has intelligence, be liable to perversions of judgment, disturbances of intellectual sensibility, or other moral perturbations, resembling human mania, dementia, delirium, and insanity? In domestic animals, says Littré and Robin, ${ }^{1}$ eases of idiocy and imbecility, either congenital or consequent upon diseases of the brain or its meninges, have been observed. To say nothing of ordinary delirium, horses laboring under hallncinations and others which had lost the eonscionsness of their bodily wants have been met with. Aside from cases of aeute disease, there are well-attested instances in which the mental states of dogs were similar to those of insane persons. There are hallueinations during the whole of the hydrophobic stage.

We take this opportunity to raise the interesting question of intellectual aberrations in the horse, and propose it to our colleagues as a subject of study which up to this time has been almost unexplored, althongl very worthy of being investigated. It wonk be instructive to determine by the antopsies of balky, runaway, and other vicions horses whether there exist any alteration of the brain and its envelopes, in relation to weight, form, volume, blood-ressel supply, intimate strueture, ete. Perhaps we should find lesions like those which have been met with in the human species, and also in cases of immobility.

\section{CH A PT ER I I I.}

CHOICE OF THE HORSE.

BFFone proceeding to the choice of the horse, the reader should be aequainted with eertain facts which coneern the seller and the purehaser, in order that he may have a correet idea of the difficulties 
which the latter will experience in his transactions with the former. It is not suffieient to go to the dealer and ask him to show what he has to sell : in order to buy as a skilful connoisseur it is necessary to be well acquainted with the habits and business ways of a trader whose every interest is to deeeive and swindle the bnyer; besides, it is important to know what preeautions are needed in dealing with him. These ideas will form the sulject of the two following sub-chapters.

\section{$\S 1$. The SEller.}

The seller, as is known, is a breeder or a horse-dealer; more rarely he is a pricate gentleman. But we will lay no stress upon these distinctions, since any man who sells horses, whatever his social status, tries to present them in the best possible conditions, in order to reap the greatest profit from the sale. Trickery, frand, and deception seem in this connection to be inherent in the very nature of things. The difference between one seller and another will be merely a difference in degree. Even the most serupulous will acknowledge only certain defeets in their horses; the discovery of the other's they will leave to the sagacity of the purchaser. As to those who are less honest, they conceal everything except the qualities which they exaggerate and even improvise aceording to the requirements of the ease. To declaim against these tendencies would be a waste of time. The best thing to do is to gutard against being deceived by making one's self aequainted with the tricks resorted to by horse-dealers. These eonsist in the employment of a special diet and of certain attentions and certain hygienic conditions in the dressing, in a special toilet, in clipping, and in appropriate shoeing.

a. By diet, the horse-dealer can easily manage to inerease or diminish the size of the abdomen and render the development of this region proportional to that of the other parts of the body. Thus, by giving watery food, such as har, grass, ete, he can modify the shape of the so-ealled narrou-gutted horse; by substituting for the ration of hay a larger quantity of oats, he will eause the cow-belly to disappear, and at the same time will render the coat less coarse and more glossy.

b. By regulating the light in the stahle and slightly inereasing the temperature, the eoat will be made to assmme brighter shates and to reflect a more brilliant lustre.

c. By eovering the body with blankets, and kecping a hood upom the head, neek, shoulders, and breast, the cont is rendered cleaner, more glossy, more supple, and more smooth. But it is especially by the aid of good grooming, frequently repeated, that the coat is beantifier. By means of the curry-comb, a wisp of straw, a brush, and a sponge, 
all the exeretory products which acemmulate on the skin are removed, and the hairs are cleansed of all foreign bodies that may adhere to them.

d. A gain, training, or dressing, constitutes an important means of preparation for the sale. By gentleness, caresses, and appetizing delieacies the dealer by degrees teaches the horse to allow himself to be approached, to be harnessed, to have his members tonehed and his feet raised; thus, also, his disposition is rendered more doeile, he becomes aceustomed to his master's voice and person. The dealer leaves no means untried : patience, kind treatment, intimidation, rebukes, brutal blows, and nareoties, snceessively employed to tame him, if he be illtempered, irascible, or vieions, and to dominate him by the mere fact of his trainer's presence.

When the training is completed, the most intractable animal has, usually, beeome docile and obedient, is easily harnessed, saddled, bridled, and mounted; he no longer manifests fear of moises, people, and things, simply becanse of the fear which the sight of his master arakens in him. When he passes into other hands, however, often everything ehanges its aspeet: the defeets reappear, and are the more readily attributed to the unskilfulness of the purehaser, as the latter had not, by his own showing, suspected them at the time of the sale. Fortunately, these dishonest trieks are not resorted to by dealers who have any regard for reputation. The good effects of the training which they give to their horses are permanent, and many dealers will take back, without objection, animals whieh do not snit their enstomers. In such eases, however, it should not be forgotten that if the seller consents to take back the aninal, it is upon the well-understood condition that the purehaser shall not go to his neighbors for one that suits him better. The exchange which is offered to him always deprives him of much of the self-confidence which he felt before he made his first mistake, and it is then that he shonld be especially cautions in his selection, so that the second transaction be not unsatisfactory, for he is at the merey of the man with whom he deals.

It is by training that the pleasure-horse acquires the swan-like eurve of the neck which is so much admired in such animals. An instrument of torture, called the cauclier de bois, is employed for this purpose. It consists of two bars of wood crossed thus, $X$, consequently diverging above and below from their point of intersection, and held in place upon the back by means of an ordinary surcingle. It is so arranged that, when the animal is bridled, the reins ean be attached to a buckle, by means of which they can be shortened at will. Nothing is then 
easier than to force the neck to maintain the desired degree of Hexion. The first applications last from five to ten minutes; they would secm to be painful, from the evident fatigne which they occasion. Is the lessons increase in length, they give less fatigue to the animal, which soon becomes so aecustomed to them that every fecling of uneasiness disappears; he is walked and trotted as before the labit is acquired; the neck and head will hereafter be earried in the desired position.

With the pleasure-horse, training does not stop here. It is always supplemented by daily drives, in which he is driven on the near side of a horse already thus trained, if he is intended for a double team. During these drives he is accustomed to walk, trot, turn, back, step forward, and stop, so that he can easily execute these manceures in the hands of the dealer and under the eyes of the purchaser at the time of the sale.

$e$. The toilet is a device the object of which is to give a horse a fine and distingué look. It is practised only upon light-dranght and heavy-draught horses, and upon those of good breeding, some of whose parts are somewhat too coarse. It consists in removing or shortening, by various means, the hairs scattered over the face, around the mouth, the nostrils, the eyelids, along the lower jaw, and in the intermaxillary space; in diminishing the thickness and length of the forelock, the mane, the tail, the thickness of the eanon, the fotlocks, the pasterns, and the coronets; finally, in cutting the hairs on the inner surface of the ears.

The toilet is said to be complete when it is practised upon all the parts; it is incomplete or partial when one or several of them are thus treated. In the latter case the operation is designated by a special term.

The hairs seattered over the head in the places of which we have just spoken are removed by being cut with the scissors, extracted, or singed. Extraction is done with the hand, as in plucking a fowl, and is a somewhat painful procedure, the pain even continuing for some days after the operation. Singeing, when it is well done, is greatly preferable. It is done with a eandle, a small bundle of lighted straw, or an alcohol lamp. Care must be taken, however, not to burn the surrounding hairs or the skin. As the singeing proceeds, the dog-grass brusl is passed over the surface of the skin to remore the earbonized parts which still adhere to the hairs. The removal of the hairs of the ears, a somewhat difficult procedure, is practised only upon common horses, in order to give greater neatness and make their houds look 
lighter. First the hairs which surround the external orifice of the ear, and then those on the inner face of the aurieular cartilage, are cut with the scissors, care being taken to leave no visible traces of the cutting.

We have seen that the mane and the forelock are plaited in order to give them a good direction, and that the thickness of the hairs of the former is diminished by,means of a comb or a special cluteh, which pulls ont a certain number.

As to the arrangement of the tail, it is done in the same manner whenever it is deemed desirable to make it smaller. Very often, however, the hairs are cut transversely. They are grasped firmly with one hand near their extremity, and with the other are eut evenly with the scissors or a knife, either at the level of the point of the hocks, or higher up or a little lower down.

Light-draught horses and (in France) army horses are the only ones in which the hairs of the members are ent; in well-bred horses the hairs of the members are usually so short that such a procedure is not necessary ; in the heavy-draught horse they are arranged in a particular way, of which we will speak farther on.

To dress the hairs, a horn comb, or, better still, a comb made of brass, and a pair of curved scissors, are employed. The operator. proceeds in the same way as a barber in eutting a person's hair. He introduces the comb between the hairs firom below upward, commencing at the coronet and passing upward. The difficulty, which is considerable, consists in thus dressing the coronet, the pastern, the fetlock, and the canon withont leaving any traces of the cuts of the scissors. Care must also be taken not to womd the skin with the teeth of the comb, and it is important not to remove the hairs aromel the coronary band, nor to shorten them too much in the fold of the pastern, where they protect these parts against the irritating action of dust and mud. Dealers are not only skilful in dressing the hairs artistically and shortening them to a suitable degrec, according to the quality of the subjects, but they also excel in concealing, by cutting them obliquely, below the knee, the defect which resnlts from a feeble development of the tendons. A practised eye will readily detect this frand ; it can only deceive the inattentive or the inexperienced.

In certain heavy-dranght horses the hairs of the extremities are so abundant and of such length, thickness, and coarseness, that it is often found necessary to shorten them so as to render the inferior part of the animal's members less heavy. With this object the dealer makes use of a very sharp triangular and short knife. The member to be 
dressed being raised, the blade of the instrument is introduced into the mass of hairs and part of their length ent away. This opreration should be done quickly, and its good execution depends much ıpon the amount of practice possessed by the person who performs it. It is sometimes done with the members resting on the ground.

$f$. Clipping consists in cutting the hairs over the entire surface of the body. It has some advantages from a hygienic point of view, since by diminishing the thickness of the coat it lessens the perspiration to which the slightest exertion gives rise during the winter, in workhorses, and which often oceasions ehills leading to serious reflux of the blood into the respiratory or the digestive organs. But it is not with any intention of guarding the animals against diseases that the dealer clips his horses. Rather it is to give them an appearance of lightness and fineness and to conceal a coarse conformation, when they have an unattractive look, a lymphatic temperament, and a clumsy and commonlooking form. The instrument used everywhere at present for clipping horses is the clipper, or clipping-machine. "It is generally composed of two comb-like metallic plates which move one upon the other. The lower plate, which comes in contact with the skin, is a kind of comb, whose short teeth insert themsel ves between the hairs and thus straighten them 'up. The upper plate, set in motion by means of a handle which acts as a lever-arm, glides upon the lower plate in such a manner that its sharp teeth move from side to side in relation with the fixed lower teeth and ents the straightened hairs close to the skin. As soon as one becomes accustomed to the use of the clipper, the operation is performed without any difficulty." 1

g. Shoeing, recently and properly done, has a certain value as a means of adornment. It improves the apparance of the feet, rectifies their equilibrium, lessens their size, and corrects several of their defeets. It also often serves as a pretext for various maneuvres which be:-peak anything but honesty on the part of the seller. Is it not well linown that it is posible by shoeing, if not to prevent overreaching, at least to cause the noise resulting from the habit to disappear? Is it not well knorn, also, that the defect of interfering may be thus concealed ; that by diverse means, such as the applieation of gutta-pereha, a corn, toecracks, and quarter-eracks can be hidden; that with the rasp, a hoof which has been deformed by a chronie laminitis can be restored to its normal appearance, etc.? These are frands of which the purchaser

1 Magne et Baillet, Traité d'agrienlture pratique et d'lyggiène vétérinaire générale, te éd., t. iii. p. 587 , Y'aris, 1883 . 
should be aware, for the unscrupulous dealer will not hesitate to resort to them whenever he thinks it to his interest to do so.

$h$. When the horse is ready to be sold, he is either placed in a special stable or is taken to a pnblie market. Here the seller will spare no device of ormamentation to attract the attention of the visitor. All his animals are covered with similar blankets, more or less riehlooking, with wide colored borders, and each bearing his monogram. Every animal is provided with a variegated girth, as well as a leather halter, white, yellow, red, green, or blue, its shade contrasting strongly with that of the coat. Ribbons of glaring colors are sometimes attached to the halter or the bridle, the forelock, the mane, and the base of the tail. Bands of linen regularly rolled around the canons and the fetlocks, knee-eaps, and ear-eaps of linen or netting are also seen. It is customary, in the market or on the exhibition ground, to fasten a bunch of straw to the mane and one to the base of the tail to indieate that the horse is for sale. This display is by no means always a mere advertisement. It is much more likely to be a blind to conceal various defects and irregularities of conformation. The ear-eaps straighten the ears, the blinds of the bridle conceal the eyes, the blankets bring the shade of the coat into strong relief, hide defects of conformation, and diminish the apparent length of the body, the knee-eaps eoneeal the knces, the bands eover splints, windgalls, ete. On several oceasions we have seen, in the Paris market, intractable or vicious horses subdued and rendered docile by use of a small twitch supported behind one of the branches of the bit, or attathed to the side of the bridle or the halter. The best way to protect one's self against all these trieks is to examine the horse with the blanket and all other appurtenanees removed, and to pay no attention to the dealer's talk.

\section{§ 2. Tile Purchaser.}

The purchaser should, above all, know exactly what he wishes to buy, - that is, he should know the kind of service the horse is intended for, the animal's gaits, size, conformation, sex, age, and coat, and the price which he is willing to pay for him. It is also important that he should have been prepared for the making of his purchase, either by long practice, great alility, an old rontine or by study aided by observation, for the time has come when he must avail himself of all the special knowledge he possesses.

The most elementary prudence at once commands him to purchase only a healthy horse, or, at least, one with no liseases, either acute or 
ehronie, that are capable either of endangering his life or of impairing his usefulness.

Further, he should endearor to ascertain in this connection the following points :

1st. Does the horse answer to the service required of him :

By his conformation (ensemble, size, gencral srmmetry).

By his general physiognomy (brecding, temperament, race, eoat).

By his action (heaves, rearing)?

2d. Is he fitted for it both by treining and by disposition?

3d. Is he close to or far from the age of his full usefulness?

4th. Is he affected with disereses, vices, and defects, and, if so, how far do they interfere with his usefulness?

5th. Finally, is the price asked in accordance with his intrinsic value ?

If the purchaser does not feel himself apable of judging of these points, he should not hesitate to call in the aid of an expert. Whatever the expense of consulting a professional man, it is not to be compared with the loss which would result from a wrong selection. Veterinarians will be found the safest guides in such matters. Their special studies and their knowledge enable them more especially to give the best advice and to judge of the qualities, defects, and blemishes of the animal presented and of his state of health or of clisease.

We must not forget that the purchase of a horse is a difficnlt and delieate matter; but the trouble increases still more when one is purchasing for others. In this ease, it is important to be well informed as to the tastes and requirements of the person for whom the choice is to be made, and also as to the limits of the price to be given. A sadtle-horse is desired, for example. It is well to know if the person who employs us is a sportsman in the proper sense of the nord, or if, on the contrary, he possesses only elementary notions of horsemanship; becanse the animal chosen for the latter should not have the enerey, ardor, brecting, and action of a horse selected for the former. The true sportsman wonld find no pleasure in mounting a horse which, though well formed, was sluggish, lazy, irresponsive to the spurs, heary on the hand, and withont action, whilst anothor inclividual might appreciate these as qualities likely to add to his safety and satisfy his wishes. The same thing is true as to driving-horses and dranghthorses. The particular eonditions of their utility should be constantly kept in view, so as to adapt them as exaretly as possible to the requirements of the service as well als to those of the owner himself. 


\section{§3. Examination OF the Horse.}

The examination of the horse cannot always be made at one's leisure, although enongh time should be taken, if possible, to make the examination thorough. This depends rpon the place where the purchase is male. As a rule, purchases are made at the horse-market or at the horse-show, and very often at the dealer's stable.

We will say a few words upon the plan to be followed in each of these ciremustances.

1st. Examination of the Horse at the Horse-Market.When a horse which seems to answer the requirements has been found, he should be brought out of the stall, taken away from the other horses, and, if possible, led to a quiet place, where he can be easily observed. It will then be seen at once whether, by his size, weight, and general development he fulfils the required purpose. At the same time it will be well to determine his age and his race. Finally, his price should be asked. If these first conditions are not favorable, or if the price is too high, it is useless to proceed further with the examination. Only a general inspection of the whole animal will be made, by a glance of the eye ; either he pleases or he displeases. That should suffice.

When the impression is favorable, a more minute examination of the month, eyes, nostrils, and intermaxillary space is indispensable, and this should be made according to the rules we have indicated, so as not to omit anything that is important. Then the horse should be placed, and a careful survey made of him both in general and in details, embracing his equilibrium, his gaits, ete, all this in aceordance with the instruction which we shall now give.

2d. Examination of the Horse at the Dealer's.-At the dealer's, the purchaser ean take his time, and it is there especially that he will find what he wishes as to kind, nature, quality, and price; provided, always, that the dealer is one whose reputation is made and whose honesty is well known. The animal should be seen in the stable, and in action on the show-ground.

a. Examination in the Stable.-Passing through the stable, the purehaser will examine the horses with attention, and as soon as his choice is fixed upon one of them, he will note the manner in which the animal is tied to the manger, how he stands in the stall, the way in which he carries his head, the expression of his comtenance, and the movements of his ears; this is the time also for him to observe the conformation of the hind-quarters, the hocks, the fetlocks, etc. 
Then he will order the horse to be taken out of his stall. At once the dealer or the stable-man will take off the blanket, run the brush over the horse's coat, and comb his mane and tail. During these preparations the traditional piece of ginger is introduced into the anus, as has been seen. Then the horse is turned round in his stall, and the strap of the lalter is placed in his mouth, or a bridle is put on his head, according to circumstances. The purchaser observes the way in which the animal has turned, if he has backed easily, and what his general attitude was while being groomed. Before taking him out into the yard, an examination must be made of the eyes, the nostrils, the submaxillary glands, the pulse, the age, the mouth, and the poll, the horse being in the door-way.

b. Examination on the Show-Ground.-The show-ground is a flat patel of ground situated in front of a wall painted or papered green in such a way as to show off the animal to the best advantage; it is usually situated on a higher level than the surrounding parts, in order to give more prominence to the height of the horse. The horse having been led there, the stable-man, standing in front of him, makes him step forward or backward until his fore-feet and hind-feet are respectively on a line with each other; after which the head is kept in a fixed position.

The dealer shonld be told not to place the animal in the camped or stretched-out position, so that his equilibrium, the axis of the nembers, may be appreciated; then the animal should be examined as a whole and in detail by suecessive inspections in profile, on both sides, in front, behind, and obliquely from in front and from behind. This survey shonld be made at a distance of four or five steps, while walking around the animal slowly, stopping for an instant at each of the points which we have just enumerated.

In judging of the whole, of the ensemble, we should take into account the general harmony of the great lines, the height, the length, the size, the relative development of the upper and lower parts, - that is, of the body and the members; the equilibrium, the expression of the head, fineness, temperament, race, and breeding should all be studied

In judging of the detcils, one shonld begin with the limbs and end with the trunk. Comparing the horse to a locomotive, M. Sallson says, very appositely, that the former, like the latter, consists of a generator of force and a mechanism which is the machine properly so called. In the first place, then, we should examine the organs of locomotion or of movement, the wheels, the cranks, the rods, and the pistons, then the generator of steam, the boiler, and fireplace. It is 
evident that, however perfect this generator may be, however great the amount of steam or of heat that it produces, if the organs of the machine consume too great a part of it, or are liable to break within a short time under its impaet, the locomotive cannot be considered fit for service. The solidity and good arrangement of these motor organs, then, are essential, since without them the generator of force cannot be used, for the expansive power of steam is available only through the medium of the mechanism which it moves.

"It is the same with the animal machine, in which the motor organs are represented by the members, whilst the generator of force is represented by the trunk. The latter, in fact, contains all the organs for the nutrition of the machine, the digestive and the respiritory apparatus through which are introdueed the solid, liquid, and gaseous articles of food indispensable to the display of organie power and the manifestation of movement." 1

The advantage of this method is that one is obliged to begin the examination with the hoof, whose good integrity and conformation are of so much importance. In order that another examination nay not be necessary, one should make sure at once, by raising each of the four feet, that the animal will offer no resistance to this mancuvre, and by striking upon his shoes, that he will allow himself to be shod without diffieulty. The upper parts of the members should then undergo ocular inspection, either by comparing the analogons parts in the two anterior and the two posterior members, or by analyzing them as compared with those which are above or below them in the line of the same member. In the first case, the lorse is divided into imaginary horizontal seetions (feet, pasterns, fetlocks, canons, knees, and hocks; forearms and legs; arms and thighs; shoulder and croup), as recommended by Captain Rivet; ${ }^{2}$ in the second, we proceed vertically in such a way as to recognize the harmony of adjacent regions (canon and forearm; arm and forearm; shoulder and arm). In our opinion, the eye of the examiner should take in the animal in both of these two ways, for each will give valuable information.

The body is to be examined in the same way (neck, shoulder, withers, back, croup, ehest, abdomen, and Hank). While inspecting the flanks, the movements of which are of great importance, the genital organs should be examined, the loins pinched, and the tail raised to examine the anus.

1 A. Sanson, Traité de zootechnie, t. iii. p. 179, 2e éd., Paris, 1878.

2 A. Rivet, Guide pratique de l'acheteur de cheraux, p. 108. 
As to the head, it is to be reserved for the last, becanse the eyes, nostrils, age, mouth, and intermaxillary space should be particularly examined a second time in full daylight. While the head is being inspected, the larynx shonld be compressed with the intention of provoking a cough. The healthy condition of the two jugular veins should also be determined at this time.

The examination of which we have spoken should be made as much as possible without touching the horse. The purchaser should have sufficient experience to recognize at a glance whatever blemishes may exist. If there be any doubt in his mind, he should remove it by examining the parts with the hand. Should he suspect a splint, a sparin, ete, he has the right to make himself aequainted with the actual state of affairs by every proper means. The error once committed, it is too late to repair it; this should never be forgotten at the time of the sale.

c. Examination of the Horse in Action.-It is important, after this, to exercise the animal at the walk, the trot, and, in eertain cases, the gallop, in order to judge of the beauty of his gaits. In these exercises, except the last, he will be led by the halter, and the intending purchaser must see to it that the hand does not firnish a point of support for the head. With this object, the stable-man is to be instructed to allow considerable freedom to the hor'se's head, and as he always holds a whip in his left hand, the dealer shonld be requested to abstain from all extraneous means of excitement, such as cracking the whip, striking his hat, shonting, gestures, ete. It is indispensable that the trial should take place on a paved surface, this being the best way to detect any existence of lameness. Finally, in these manouvres, the horse shonld be examined in profile, from the left and the right, in front and from behind, either by rumning him snecessively from one side of the yard to the other, or by making him turn around in a crole. This will give an opportunity of noticing how he turns and how he backs. After this preliminary examination, the animal should be seen in the trial, mounted or harnessed, according to the service for which he is intended. Light-dranght lorses, as well as driving-horses, are, however, often momnted, in order to show better the extent of their movements, their nimbleness, and their speed.

The trial of the mounted horse should always be made with the saddle and bridle, in the ease of a sadclle-lorse. It will bo woll, indeed, for the purchaser to momnt him himself, after the boy, to jurlege of the sensitiveness of the animal's mouth, his reations, ardor, tractatbility, dressing, ete. He will see at the same time how the animal 
allows himself to be bridled and saddled, how he bears the pressure of the girth, and how he behaves when the foot is pot in the stirrup. Here, again, the horse should be seen in profile, right and left, in front and from behind.

The trial of the draught-horse cannot always be made under favorable conditions at the time of the sale, for example, at a fair or in the horse-market, because the necessary appliances are often lacking. Sometimes, however, this inconvenience is obviated by harnessing the animal to a cart, and in a few minutes blocking the wheels, so as to ascertain his energy, vigor, and strength, the ease with which he pulls, and his manner of pulling. In the Parisian market, a special track, the trial track, is reserved for this purpose, and heavy vehicles, easily stopped, as well as sets of harness, are placed at the disposal of the public. Unfortunately, these harnesses are neither so numerous nor so raried that they can be properly fitterl to any horse. Many of the animals, worried by a poorly-fitting collar, make a noise similar to that of roaring, an affection from which, in reality, they are entirely free.

As to driving-horses, they are not shown in the same way; the dealer harnesses them and drives them to various vehicles which the purchaser can mount, and where he also has the privilege of driving them, if he chooses. But before doing this, he should ascertain, by observing every detail around the stable, how the animal allows himself to be harnessed and led, how he trots, turns, stops, backs, and starts off. He shonld ascertain, also, that he is good in his wind, that he is gentle and tractable, and that he does not become frightened at unfamiliar oljects or moises.

Besides the ascertaining of the fitness and qualifications of the horse, another object of the trial is the testing of his respiratory organs. Whether the horse be harnessed or mounted, one should always, as soon as he is stopped,- - that is to say, after a sufficient amount of exercise,-listen attentively to the sound of his respirations, to see if he is a roarer, and to examine the movements of his flanks, to be sure that he is not heary and short-winded. In some countries the law allows a trial of nine days for the detection of the so-called redhibitory vices, but much trouble will be avoided by finding them ont at the time of the sale.

We recapitulate, in the following table, the order in which to proceed in the examination of the horse. After practising with this table a few times the beginner will rapidly become expert in the somewhat complicated operations which are asked of him. 


\section{SUMIIARY.}

The purchaser should examine the horse :

In the Stable :

On the Show-Ground:

In Action : 1st. In place: method of harnessing, general attitude, the eal's, grooming, gringer, turning, backing, Jocility.

2d. In the door-way: eyes, nostrils, age, mouth, inter( maxillary space, pulse, pull.

Inspect the horse: in profile, right and left; obliquely, forward and baekward; from in front and from behind. His attitude and his equilibrium then should be examined:

1st. The whole conformation: general harmony, height, bulk, body and members, physiognomy, temperament, race, and breeding.

2d. Details : the animal must be viewed from all sides, following the order given below.

a. Mombers.-Examine them separately and from below to above: foot, fetlock, canon, knee, and forearn ; hock, leg, etc.

View them together and horizontally: fore-foot and hindfoot, knee and hock, forearm and leg, arm and thigh.

b. Body.-Upper zone: neek, withers, back, loins, croup.

Lower zone: breast, shoulder, chest, abdomen, flank.

Explore the groin and the genital organs, pinch the loins, raise the tail (anus and rulva), docility.

c. Hoad.-Expression, proportions; examine again the eye, nostrils, mouth, age, intermaxillary space; excite a ( cough, inspeet the jugular veins.

View the horse in all possible aspects and take note of his gaits, speed, nimbleness, elegance, endurance. Make him stop, back, turn, etc. Respiration and flank (roaring and heaves). Dressing, docility, ete.

The trial will take place :

1st. Led by the hand: walk and trot; on hard mad and paved road. Lameness; flank.

2d. Mounted: saddle, bridle, girth, disposition, dorility, dressing, gait, trot and gallop. Respiration, flank.

3đ. Harnessed: harness, bridle, docility, disposition, dressing, force, speed, walk and trot, ete.

Taking Notes.-If only one horse is to be purchased, it is not worth while, as a rule, to determine his relatire value by concrete notes, expressing the sum total of the aptitudes he has shown. But it is rery different when a considerable number of animals are to be bought or to be compared. In such (alise, the jotting down of notes is indispensable not only to establish and fincilitate their classification, but also to enable the expert to furnish exact information conerning them. In this connection every man is at liberty to take notes, - that is to say, to group as he chooses the different elements which he has observed, after his 
own ideas, and to give them the relative importance which he considers they onght to have. The following is the scheme we use on competition committees when we deal with horses already grouped by categories, according to their height, weight, and age.

EXAMPLE OF NOTES.

Coefficients, Marks.

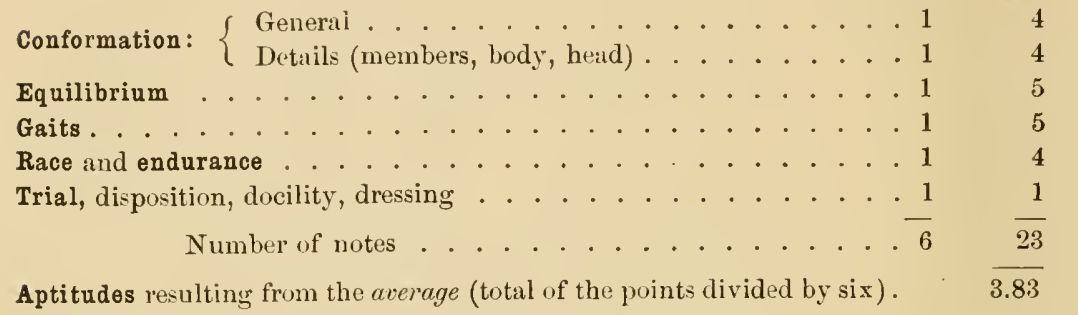

Note.-The scale of marks which we employ to note each subject is from 0 to 5 , but it can be modified at will. We reject every horse that does not obtain the average of 3 . If many horses are to be judged, it is well to take down the information in a note-book having, for example, the following formula:

MODEL OF PURCHASE MIEMORANDUMI-BOOK.

\begin{tabular}{|c|c|c|c|c|c|c|c|c|c|}
\hline \multirow{2}{*}{$\begin{array}{c}\text { NAMES OR NUMERICAL } \\
\text { ORDER. }\end{array}$} & \multicolumn{2}{|c|}{$\begin{array}{l}\text { CONFOR- } \\
\text { MATION. }\end{array}$} & \multirow{2}{*}{ 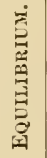 } & \multirow{2}{*}{ 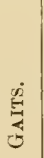 } & \multirow{2}{*}{ 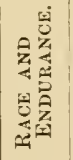 } & \multirow{2}{*}{ 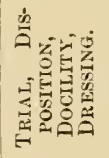 } & \multirow{2}{*}{$\underset{4}{5}$} & \multirow{2}{*}{ 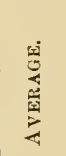 } & \multirow{2}{*}{ OBSERVATIONS. } \\
\hline & $\begin{array}{l}\text { Gen- } \\
\text { eral. }\end{array}$ & $\begin{array}{l}\text { De- } \\
\text { tails. }\end{array}$ & & & & & & & \\
\hline $\begin{array}{l}\text { Bijou. . . } \\
\text { Coco : . } \\
\text { Pompier : }\end{array}$ & $\begin{array}{l}3 \\
4 \\
3\end{array}$ & $\begin{array}{l}4 \\
4 \\
2\end{array}$ & $\begin{array}{l}4 \\
5 \\
1\end{array}$ & $\begin{array}{l}2 \\
4 \\
2\end{array}$ & $\begin{array}{l}3 \\
4 \\
3\end{array}$ & $\begin{array}{l}4 \\
5 \\
1\end{array}$ & $\begin{array}{l}20 \\
26 \\
12\end{array}$ & $\begin{array}{l}3.33 \\
4.33 \\
2.33\end{array}$ & $\begin{array}{l}\text { Ambler. } \\
\text { Weak loins. } \\
\text { Old and worn out. }\end{array}$ \\
\hline
\end{tabular}

To simplify and hasten the evaluation of any horse whatsoever, Professor Tabourin, ${ }^{1}$ in 1877 , devised for beginner's a system of notation the essential character of which was the estimating in figures of the beauties of some regions only, eonsidered as of predominant impoitance, deducing from the sum total of the marks obtained an estimate of the general value of the animal.

Professor Baron ${ }^{2}$ has recently attempted to revive the same idea, under the name method of judging by marks, but with a much more

I Tabourin, La connaissance extérieure du cheval réduite à l'étude d'un petit nombre de caractères. Méthode synthétique à l'aide de laquelle on peut juger de la valeur d'un cheval exposé en vente, pour la forme ct pour le fond; in Recueil de médecine rétérinaire, 1877, pp. 710 et 813 .

2 R. Baron, Appréciation de la vache laitière par la méthode des points, in Recueil de médecine vétérinaire, 1885, p. 797. Extension et généralisation complète de la méthode des poiuts, in Recueil de médecine vétérinaire, 1889, pp. 35, 105, 185, 262, 326, et 379. 
judicious selection of the parts upon which he bases the result of his examination. For this purpose our colleague has endeavored to formulate for each type of utilization a special table, on which the particular aptitudes to be noted are enumerated and numbered according to their relative importance.

It is eviclent that every experienced horseman will have his own way of interpreting different things. But as in such cases opinions are always divergent, we shall not enter into the details of the proposed systems, their value depending, in our opinion, on the judicious use which is made of them.

Up to the present time the methods of notation applied by beginners to a single individual do not seem to have given the results that had been hoped for.

The reason is first that they are not in vogne in our present practice, the fact of taking notes upon a horse on the show-ground being looked upon, and not without reason, as a sign of inexperience.

Finally, they are still open, for aught we know to the contrary, to one or the other of these two objections :

Either they have a tendency to limit the examination to too small a number of regions, or, on the contrary, they make it cover too complicated groups of parts or of characters.

In the first case, aiming at excessive simplification, they become manifestly insufficient, inasmuch as they expose one to neglect a certain number of important beauties or defects, and thus lead to erroneous conchusions. In the second case, they embrace too many points, and thus lose their simplifying character, learing the student as much puzzled as he was originally.

The difficulty, then, is to find a system free from these exaggerations.

But, however perfect a method of notation may be, it cannot prove a substitute for a thorough analysis of the parts. To render it useful, it is necessary to practise it often, and consequently to observe much, and to go patiently through the different operations which it implies. This, above all, should never be forgotten.

\section{§. HoRsEs MATED OR PAIRED.}

When horses are chosen with a view to forming harmonious and identical groups, at least with reference to form, height, weight and bulk, breeding, coat, and age, they are said to be mater or paired; and, as breeders and dealers experience much difficulty in obtaining horses 
that can be thus paired, the absolute price of one of these groups is always much greater than would be the total amount of the separate individual values.

In most eases horses are matched, in eouples or pairs, for pleasure teams; for heavy work one is much more easily pleased than when elegance and fashion are in question ; besides, even fashionable people are not always sufficiently fastidious to demand an absolute resemblance between the horses of the same pair, and thus the price of the pair is lowered in proportion.

From these data it will be understood that mated teams are principally sold only in those high-life centres where there is a demand for them. The purchases are usually made at the stable of the regular dealer.

On his arrival, the customer is at first invited to look at the different teams which the dealer has in his stable, and it is business for him to show what animals suit him, as to height, age, race, and eoat, aceording to the team of horses he wishes to have. His selection being made, the horses shonld be examined, their value determined, both separately and as a pair, and the question of price decided.

They are then taken out of the stable. The first point to be ascertained is whether the mating is real, for, should it not be so, it would be useless to proceed with the examination. It is easy to judge of the height, the coat, and the general proportions by placing the horses side by side, first in the usual way, and then facing in opposite directions. Afterwards they are inspected separately; they are examined in detail, at rest, at a walk, at the trot, led by hand; and even now it is possible to place them mentally side by side and thus aseertain if the differences between them are sufficiently marked to cause them to be rejected. For example, when the differenee of age amounts to several years, the purchaser should hesitate to make the bargain, for a short time afterwards, whereas one of the horses will still be vigorons and fit for service, the other will be worn out and unable to travel with his mate. The presenee of serious blemishes is a good reason for declining to purehase.

Lastly, the general examination of the animal is resumed with the utmost eare. There should be the desired degree of equality in height, length, carriage, bulk, weight, direetion of the members, temperament, energy, and coat. The two animals should be capable of being harnessed to the carriage indifferently to the right or the left, and no attention should be paid to the observations of the dealer, who may explain how they have been acenstomed to be always driven on the same side, 
and who, as a rule, will harness the better one of the two on the left side and the poorer one on the right. In this manner it will be easy to find ont if there is between them a great disproportion in vigor and in the gait, a difference which would perhaps not have been otherwise perceived. The horses are held by an assistant standing between them, who makes them, according to the orders of the purchaser, sucressively walk, back, turn to the right and to the left, after which, if the trial is satisfactory, there is nothing more to be done but to hitch the horses to the earriage. This is the most difficult and most important proeedure of all, and great attention should be paid to it. All dealers possess vehicles of various sorts intended to train and to exhibit mated horses. The purchaser makes the pair pass before him in every direetion ; finally, he gets on the seat and drives, or employs some trustworthy person to drive for lim.

The following qualifications must be found in horses that are to be mated: 1 st, identity of race, energy, and temperament; $2 \mathrm{~d}$, equality of age ; $3 d$, equality of height, form, and length ; 4th, harmony of the gait; 5th, the same quantity of force and good breeding; 6 th, the same kind of coat. The last point, which is really only a matter of fashion and taste, is at present sometimes waired. Often, not to mention little details which eannot be absolutely alike in the two horses of one pair, such as white feet, or some peeuliar mark on the head, a radical difference of the coats is accepted, and very fine coach teams are to be seen composed of a dapple-gray and a bay. Of course this combination will not give the perfection of elegance which would result from absolute similarity in the two subjects, but with respect to their value, such a pair will frequently be better mated and more easily found, and, therefore, will cost much less.

\section{§5. HoRses Which MaY BE MoUNTED OR DRIVEN AT WILL.}

There are horses which may be indifferently driven to a carriage or mounted, according to the pleasure of the owner. Let us liere remark that the advantages of this double utilization are less absolute than relative, and more imaginary than real. A good saddle-horse always loses in value by being driven much, just as the driving-horse makes an indifferent saddle-horse. In this respect, it is with horses as with hunting dogs. If the latter are indifferently employed ats bird-dogs or rabbit-logs, ete, they will soon lose their good qualities for either service, but afterwards will tend to return to the special use for which they have the greatest aptitude; the true sportsman will have none of them, and he is right. 
This ostracism which banishes from the stable of the wealthy the "donble-purpose" horse is justified by the peremptory reason that the true rider is averse to mounting an animal which has not been dressed and trained with a view to saddle-work. How, indeed, can this animal act properly and balance himself, if he has not been initiated into the means that will be nsed to guide him, if he is incapable of understanding the meaning of the indications given by the legs and hands, and if he cannot draw himself in or gather himself up readily, an attitude indispensable to most of his mancuvres? The saddle-horse which has been satisfactorily trained understands a special language, that of the hands and legs, and his conditions of equilibrimm are changed. A part of his weight is thrown upon the haunches, as the riding-master says, becanse, in his case, the centre of gravity has been displaced backward and brought nearer the posterior quarters. This result is evidently obtained by education, but it must not be forgotten that the new aptitudes acquired by a subject are transient and require a daily practice if it be desired to preserve them.

On the contrary, the driving-horse or light-dranght horse is the onteome of an entirely different training, if not, indeed, of a quite opposite training. Accustomed to bear against the collar, he soon carries his head and his neck more horizontally in order to displace the weight forward upon the harness, which relieves him very much. The animal is balanced upon the shoulders, and not upon his haunches, as in the preceding ease. Besides, the action of the driver is different; the hands no longer give the same indications, and the legs are here out of the question. In this eondition the head and the neck are always but little "drawn in ;" as to the "gather" attiturde, it no longer exists. It is therefore natural that the animal should be less supple, harder on the hand, less manageable, and that the means of utilizing him should be fewer and less diversified.

How, then, can he, if he be constantly worked in the shafts, acquire, in a lasting degree, the attitude and qualities required for the riding service? All attempts made in this direction, meaning confusion for him, will succeed only in spoiling him, so that the time will come when in all respects he will only be an ordinary horse; not only will he have learned almost nothing, but he certainly will have lost with regard to the aptitude in which he formerly gave the most satisfaction. We understand and approve the sportsman who refuses to lend his favorite horse to others, and who obliges his servant to lead him by the hand when any aceidental ocenrrence prevents his customary onting with the owner on his back. Nothing is easier than to notice, in the case of a 
well-trained horse, that a stranger has ridden him even for a short while; much worse will be the results should he be used for a different service.

For enthusiastic horsemen the "donble-purpose" horse is therefore a myth; they will not hear of him. But real horsenen are not the only people who employ the saddle-horse. The majority of riders have a very limited knowledge of horsemanship, and many are satisfied with the merest inkling. Provided that the horse which they hitch to their carriage to-day will on the next day allow himself to be mounted, walked, trotted, and galloped, if need be, and will turn to the right or the left, this is sufficient for them; they ask nothing more. Those are the people who seek, purchase, and utilize the "donble-purpose" horse; nor is the latter as common nowadays as it was formerly.

The general form of this horse is that of the saddle-horse with variations in height, weight, bulk, and breeding, aceording to the ease. A saddle-horse, if he be not vieious, may always be driven to a vehiele adapted to his conformation, whilst it is not correct to say that a drivinghorse or a light-draught horse will be sure to be suitable for the saddle. Some sperial defect might greatly detraet from his value for the latter service, while it might be of no eonsequenee in the ease of the former.

Still, if we wish to choose a subject partaking of the trpe of saddle-horses, we must not be too exacting upon this point. And in truth it would be ont of the question to seek the perfection of the type in him, since it is known that, from the very character of the proposed service, the individual chosen will never be perfect. One must be contented, therefore, with a short body, not plump, although rather ample, a head somewhat large, a shorter neck, a withers lews prominent, a eroup somewhat oblique; but the upper part of the body should be regular and well supported; the members should be strong and well poised, even though they lack fineness; there should be a celtain distingué look in the general appearance; the actions should be free and easy ; there should be more endurance than speed and more firmness of the members than brilliancy.

Large coach-horses and heavy-dranght horses are the only ones that camnot be mounted: the first because they are almost always too heavy and too long, the second becanse of their weight and their ahsolute lack of breeding. All other horses, after a short training, can be nsed either under the saddle or in harness. 



\section{N D EX.}

A.

Abdomen. Situation, limits, anatomieal base, beauties, defects, volume, $1 \pm 9$; form, 150 ; diseases and blemishes, 151; greyhound-like, dropping, pentnlous, cow's, 151 ; horse which has too much air passing underneath the, 151 .

Age. The parts to be examined for the determination of, 645 ; charaeters of the age furnished by the teeth, 648 ; rising, having, past sueb age, 649 ; marking no more, 656.

Albugo, 56 .

All-flower, $T R 1$.

Amaurosis, 56 .

Amble, 505; definition, 505; characters, 506 ; notation, trail, displacements of the eentre of gravity, length of the step, 507 , 508 ; speerl, disadvantages, eonformation, 508,509 ; broken amble, 509 .

Anorchid, 179.

Anterior quarters, 22.

Auus. Situation, limits, anatomieal base, 174 ; form, diseases, blemishes, $17 t$.

Aqueous hum or, 50 .

Arborizatious, 779 .

Arm. Situation, limits, anatomieal base, form, morements, 214 ; length, 215 ; direetion, 216 ; musenlarity, diseases, and blemislues, 219; proint of the arm, 201.

Arthrogoniometer, 375 .

Articular angles (angles formed by the union of the loeomotory segments). Orientation, 190; extent of the spaee or field of oscillation of their segments, 191 ; limit of extension and flexion, 191; measurement, 375; value, 375; photography applied to the measurement, 377 ; inflnence of the inelination of the bones upon speet, 3252.

Articular movements, limits, 190.

Artificial eye, 51 .

Attitudes, 38 .

Avalure, 339 .
Aversiou to special objects, 877 .

Axes. Regular, irregular, line of axis of a member, 442; of the anterior inembers, 443 ; of the posterior, 456 .

Axilla. Situation, limits, anatomical base, 147 ; disenses, 147 ; fraying, 147.

Axis. Of figure of a boue, 365 ; of movement of a bone, 365 ; of rotation of the bones, 371 ; direct axis of a member, 193.

B.

Back. Situation, limits, anatomieal base, 116 ; direetion, 117 ; form, 119 ; length, 120 ; width, 121; diseases and blemishes, 122; straight, convex, eoncare, roach. sway, hollow-backed, 117 ; dipped, double, 119 ; sharp, long, 120 ; short, 121.

Backing, 5.1 ; rieious habit, 874 .

Balky horses, 869 .

Bar (part of the hoof), 317 .

Bar (region of the mouth). Situation, limits, anatomieal base, form, beauties, diseases, blemishes, 74 .

Barb (barbillon), 75 .

Base, of support, 10 : form, 439 .

Bay (eoat), 776 .

Веan, 770 .

Beat, 474 .

Beating of the parotid glands, 84 ; of the lips (vieious habit), 72, 619.

Beauties. Definition, 31 ; divisions, 31 ; absolute and relative, 31 .

Bégul, 729; false, 73:.

Béguité, 729 ; false, 733 .

Bidets, 530 .

Billarder, 586 .

Hishoping, 767 .

Bistournage, 178,814 .

IB istourué, 178 .

13it. Description, use, s0: action, 82.

Biters, 872 .

Bitting, 82. 
IB lack (coat), 773 .

Blaze (mark of the head), 794.

Blinduess, blind horse, 57 .

Bliukers, 51.

Blood. Opinion of the laity, 397; origin of the word, 398 ; definition and nature, 400 ; whence derived, 401 ; artificial transmissibility, 101 ; index of the, 402 ; horse which has blood, 399 ; pure-blooded, 399; horse which has too much, 411 ; in which the common element predominates, 412.

Body, divisions of, 21 ; and members, 395 ; ciliary, 48.

Bordered, 793.

Bounding, 575 .

Bow-legged, 269, 462.

13 rachyguathism, 736 .

Brand (mark of identification), of the thigh, 243 .

Breast. Situation, limits, anatomical base, form, width, 144; blemishes, 147 ; sharp, hollow, sunken, 144.

Breeding, 403.

Broken-down, 288.

Broken trot, 522 .

Bruised sole, 388 .

Brushing, 506 .

Bucking, 575 .

Bntteris. Cuts with the butteris, 336 .

Buttock, 2.37 ; point, angle, folı, 238 ; long, well descended, short, round, salient, 242 ; sharp, well furnished, 213.

\section{c.}

Calf of the leg, 248 .

Calluses, 108.

Camper. Ilorse camped in front, 448.

Canker, 337 ; behind, 459 .

Canon. Situation, limits, anatomical base, 279 ; rôle and action, 281 ; form, direction, 283 ; length, 28. ; width, thickness, 285 ; fincness, neatness of outline, 286,287 ; diseases, blemishes, 287; meagre, narrow, round, slender, 286 ; overreaching, striking, 287 , fractures, 290 .

\section{Canter, 527 .}

Capellet, 270.

Carcinoma, 181.

Cataract, 56 .

Cavalry horse, 844 ; staff horse, 845 ; troop horse, 846.

Cavity, external dental, 597, 603 : irregnlarities of depth, 729 ; internal dental, 600.

Cement, 608; radical, 610, 635.
Centre of gravity. Determination in the horse, 3; experiments of Raabe and Bonnal, 6 ; of Morris aud Baucher, 6 ; of Morris and Bellanger, 8 ; Goubaux and Barrier, 9 ; 1 isplacements, 478.

Certificate of description, 813 ; order to be followed, 831 ; enumeration of points, $8: 31$; models, 819.

Chain, 807.

Champiguon, 181.

Character, 403 .

Cheek. Situation, limits, anatomical base; benuties, defects, 58 ; blemishes, 59 ; raising of the skin, 645 .

Chest. Definition, limits, anatomical base, function, 157 ; beauties, height, 158 ; width, 159 ; depth, defects, 161 ; well descended, 158 ; narrow, long, 161.

Chestuut, anterior, 227 ; posterior, 279.

Chin. Situation, limits, anatomical base, liseases, blemishes, 68 .

Choice of the horse, 886 .

Choroid coat of the eye, 48.

Ciliary process, 48 ; body, 48 .

Circled hock, 279.

Circles, of the hoof, 339.

Clandication, 558 .

Close hocks, 463.

Closed (horse), in front, 146, 454; behind, 462.

Coach-horses, 833 ; large, 834 ; small, 836.

Coats, division, 772 ; primitire, simple, 773 ; composite, 775 ; mixed, 777 ; derived, 778 ; conjugate, 782 ; spotted, 778 ; synoptical table, 784; peculiarities, 786 ; of the head, 794; of the body, 796 ; of the members, 797 ; synoptical table, 800 ; canses of the modifications of the coat, 799 ; index furnished by the coat, 803 .

Coffee-and-milk (coat), 774 .

Collar, application of, 214.

Commou horse, 399.

Compass of thickness, 373 .

Compensatious, 430 ; examples, 431.

Conjunctiva, 50 .

Contact, 474 ; period of exchange of, 476 , phase of, 195.

Contraction of the hoof, 337.

Coom, 182.

Cord of the testicle, 177.

Corded lymphatics, 109.

Cornea, 48.

Corners (incisor teeth), 597 ; rasping of the superior, 770 .

Corns, dry, moist, suppurating, 335 . 
Coromary baud, 315.

Coronet. Situation, limits, anatomical base, 309; wilth, fineness, absenee of blemishes, diseases, blemishes, 310 ; mange, 311.

Costal region, 152.

Cover his steps, 474 .

Cow-hocked, 268, 463.

Cowlick, 792 .

Crapaudine, 310,340 .

Creau-color, $7 \pi 4$.

Cremaster muscle, 176.

Crescent, deformity of the sole, 339 .

Cribber, 753 .

Cribbing, 752,865 ; with or without marking the teeth, 752 ; with a point of contact or in the air, 753 .

Crop-eared, 14 .

Cross-footed, in front, 455 ; behind, 464.

Cronp. Situation, limits, 123; anatomical base, 124; length, 125; thickness, 128 ; width, 129 ; direction, 130 ; forms, 140 ; diseases and blemishes, 141 ; long, short, 125 ; horizontal, 130 ; oblique, 137 ; sharp, almond-shaped, mule-like, 140 ; narrow, pointed, hen-tailed, cut-off, low, slanting, double, angular, oscillating, 141.

Crown of tooth, 597 .

Crowued, of knee and fetlock, 234.

Cryptorchid, 179.

Crystalline leus, 49.

Curb, 273.

Cutaneous envelope of foot, 314 ; podophyllous tissue, 315 ; relvety tissue, 316 ; plantar cushion, 316 .

Cutidure. (See Coronary band.)

Cutigeral cavity, 318 .

Cyst (soft tumor filled with liquid), of the false nostril, 64 ; of the testicle, 181.

\section{D.}

Dartos, 44, 169 .

Deafuess, 45 .

Decubitus, 166 .

Defects. lefinition, divisions, 32 ; absolute, relative, eongenital, acquired, 32 .

Déjuger (sc), 475 .

Dental star, 614, 616 , 6is.

Dental table, sucessive forms, 64 ; details according to age, 615 .

Dentiue, 612 .

Dépiste (se), 175 .

Discharge, of the nosc, 63 .

Docliced, 14, 169.

Docking, 169.
Double expiration, 166.

Douriue (maladic du coït), 184, 186.

Drauglt-horse, slow heary-, 851 ; fast heavy-, 852; light lieavy-, 855.

Dry spaviu. (See Stringhalt.)

\section{E.}

Ear. Situation, limits, anatomical base, length, 41 ; thickness, movements, 12 ; lefeets, blemishes, 43 ; fraudulent means employed, 44; bold, 42 ; restless, swine-ear, 43 ; erop-eared, 44.

\section{Ear-cutter, 45.}

Early eruption of the permanent teetl, causes of, 638 .

Eczena, 285 .

Elbow. Situation, limits, anatomical base, length, 219; direction, diseases, blemishes, 220 ; on the body, 220 ; turned outward or inward, 220.

Elevation (place of oscillation of a member in the air), 475.

Emplysema (infiltration of air into the connective tissue), puluonary, 166.

Ename1, 611 ; germ, 606 ; peripheral, 612 ; eentral, 615 .

Endurance. Opinion of the laity, 412 ; in different kinds of animal motions, 416 ; external form as an index, 418 ; practical determination, 420 ; examples of, 421 ; of a troop in campaign, 424 .

Ensemble (word which signifies the manner of existence of the proportions of a given animal), 385 .

Eutire horse, 178.

Equilibrium, 10, 473 .

Ergot, 297 .

Evacuator, 174.

Eventration, 151.

Examination of the horse, 894 ; at the horse-market, 891 ; examples of notes, 900 ; in the stable, 894 ; in action, 897 : trial, 897 ; molel of purchase memorandum-book, 9(30); on the show-grounl, 895; summary, 899); taking notes, 899 .

Excision of the submaxillary ganglia, 69.

Excitability, 411.

Exomplualus, 151 .

Exterior. lefinition, object, enl, utility, 2.

Eye. Situation, limits, anatomieal base, 45 ; eye-globe, 4s; media, 49; comprartments, 50 ; protective organs, 50 ; veular sheatl, 50 ; apparatus of Jubrication, 51 ; exanina- 
tion, 51 ; beanties, 53 ; defeets, 55 ; diceases, blemishes, 56 ; artifieial, 57 ; small, concealer, bovine, borlered, unequal, myopie, hypermetropie, hollow, wall-eyed, fawneyed, 55.

Eyebrows, 4\%.

Eyelids, 51; thin eyelid, 54.

\section{F.}

Face. Situation, limits, anatomieal base, 38 ; divisions, direction, width, 39 ; diseases and blemishes, 40 .

False nostril, 61 .

Fatigue. Definition, causes, 414 .

Farriery, 335.

Fanlts, 33.

Fetlock. Situation, limits, anatomical base, 290 ; mechanisin, 290; form, width, 293; thiekness, direction, fineness, 294; diseases and blemisbes, 295 ; small, round horse with light wrists, weak in the pins, 294; puffy, 295.

Fici, 295.

Figure, 403 .

Fissures, of the pastern, 309.

Fistula, of the withers, 116; of the back 122 ; of the anus, 175 ; artificial, of the anus, 175 .

Fituess, 31.

Flank. Situation, limits, anatomieal base, divisions, form, 162 ; extent, 163 ; movements, 164; examination, 165 ; diseases, blemishes, 167 ; hollow, cord, movable portion, 162; hollow, eorded, tueked up, greyhound, short, narrow, 163; horse which has two fingers' width of flank, 164.

Flea-bitten (coat), 781 .

Fly-specks, 789 .

Flying trot, 522 .

Foot. Definition, organization, 312 ; internal parts, eutancous envelope, 313 ; differences between fore and hind, right and left, 321 ; elasticity, 323 ; beauties, characters of the unshod foot, 327 ; defects of volume, proportion, 328 ; conformation, 329 ; equilibrium, 332 ; quality of horn, 335 ; accidents from shoeing, 335 ; diseases, 336 ; large, small, 328 ; narrow, unequal, flat, 329 ; full, puniced, with bunions, 330; with high heels, low heels, sloping heels, 331 ; outhowfooted, eross-footed, erooked-footed, 332 ; pinearl, elub-foot, 333 ; soft, dry, broken, 334 ; with weak beels, 335 ; accidents from pricking, 335 ; compression by the nail, by the shoe, beated sole, burnt sole, excessive paring, euts from hoof-knife and butteris, 336 : diseases of, 336.

Force, moment of a, 12; horses of, 405 ; of a hosse, 405 ; of a musele, 405.

Forearm. Situation, limits, anatomical base, form, 221 ; movements, length, 222 ; willth, 22.4; thickness, direction, 225 ; diseases, blemishes, 227 ; museularity, 224; slender, 225.

Forehead. Situation, limits, anatomieal base, width, 36 ; direetion, peculiarities, diseases, blemishes, 38.

Forelock, 110.

Forging, 582 .

Founder, 338 .

Fox-nosed, 796.

Fraying of the axilla, 147 .

Frog, 319; frog-stay, 319; median laeuna, lateral lacuna, branches, 319 ; point, glomes of, 320 .

Frosted, 63 .

Furrow of misery, 238.

\section{G.}

Gaits. Divisions, 472 ; diverse qualifieations, 473 ; play of the members, 474 ; speed, $4 \tau \tau$; displacement of the centre of gravity, 478 ; reactions, 479 ; analysis, 479 ; systems of notation, 490 ; synthetical sturly, 496 ; the gaits in particular, 503 ; transitions between the rlifferent gaits, 568 ; defects, 576 .

Gallop. Definition, 544 ; to the right, to the left, 545; true, false, diagonal, lateral, 546; disunited, 547 ; play of the members, 547 ; number, nature, succession, duration of the bases of support, 519; duration of the contacts of the feet, and the projection, 549 ; effort of the nembers, association of the members, and attitudes of the body, 552 ; transition from station and the walk, 555; varieties ant trails, 556 ; length of the stride, speed, displacement of the centre of gravity, 559 ; reactions, 561 ; conformation, uses, 562 .

Gallop, slow. Definition, notation, 563; trail, length of the stride, 565 .

Garniture (edge of the shoe projecting beyond the wall), 328 .

\section{Gelding, 178 .}

General causes, of vices, $s 82$; bad education, 883; exeessive impressionability, 883 ; interference with habits already aequired, 883 ; insanity, 885 ; pain, 884 ; phys- 
iologieal states, 884; sexual desires and maternity, 884; defective conformation of the eycball, 884 ; parturition, 885 ; warm seasons, 884.

\section{Gland in the intermaxillary space,} 168.

Glands, Meibomian, 51 ; laehrymal, 51 ; exeretory eanals, 51 .

Glaucoma, 56 .

Golden (reflection of coat), 786 .

Gontte seriene, 56 .

Granary, 58.

Grapes, 295.

Gray, 778 ; temples, 47 .

Grease, 228, 295, 310 .

Groiu. Situation, limits, anatomieal base, 167 ; examination, diseases, 167,168 .

Gums, 73.

\section{H.}

\section{Halter-cast, 308 .}

Halter-strap, 308.

Hannch. Situation, limits, anatomical base, 142 ; well detaebed, angular, low dropped, low, 142 ; long, short, narrow, wide, straight, oblique, 143 ; horse upon his baunehes, 562 .

Head. Divisions, 34; regions, 35 ; harmonious relations, 86 ; length, volume, 87 ; direetion, 88 ; forms, 92 ; attachments, movements, 95 ; fine, coarse, fleshy, plain, senile, sharp, 87, 88; horizontal, 89 ; vertieal, 91 ; straight, eonical, archerl, hare-faced, ram's head, 93 ; snub-nosed, rhinoceros, 94 ; the head as a unit of measure, 359 ; proportions, 361.

Heavy (affected with heaves), 166.

Heel of the wall, 317 .

Height of horse, at the withers, 386 ; at the croup, 386 ; relation to length, 391.

IIermaphrodite, 814 .

Herminures, 789 .

Hernia, umbilical or exomphalus, 151 ; ventral, 158, inguinal, 168, 181.

Hippiatrique (name formerly given to all that pertains to the medicine of the borse).

Iippobosca equina, 175 .

Hippometric cane, 841 .

Hip-shot (fracture of the haunch), horse, $14: 3$.

Hock. Situation, limits, anatomical base, 253 ; external conformation, 25.5; examination, 257 ; morements, 255 ; beauties, neatness of outline, 260 ; wilth, 261 ; thickness, 262 ; direction, 268 ; discases and blenishes,
269 ; extent of the tibio-tarsal angle, 263 ; fold of the, 255 ; point, cord, hollow of the, 256 ; rotating, $25 s$, 581 : fat, full, doughy, wide, narrow, sleuder, 261 ; straight, 264 ; elose, crooked, 26s, 463 ; too open behind, $26 \mathrm{~s}$; the hock as a centre of amortissement and impulsion, $25 \mathrm{~s}$.

Hood (for ears), 45, 8:3.

Hoof. Definition, form, 316 ; division, 317 ; growth and wear, 323 ; concussion, 338.

\section{I o of-kuife, 336 .}

Hooped linee, 236.

Horn. Structure, properties, origin, color, consistency, 332.

Horus, froutal, 38 .

Horse-pox. (See Variola equina.)

Horses, of industry and commeree, 849 ; difficult to approach or to groom, 870 ; difficult to harness or to mount, 871 ; mated or paired, 901; which back, 874 ; which eat earth, 864; which may be mounted or driven at will, 903 ; which paw in the stable, 864; which rear and strike with the forefeet, 873 ; whieh rest one hind-foot upon the other, 861; which rub the lower extremity of the head agrainst the manger, or the tail against surrounding objects, 860 ; which suck wind or swallow air, 865 ; which strip their halter, 862 ; which tear their blankets, 861 ; which weave, 864 .

Hunter, $s+1$.

Hydrocele, 181 .

Hydropsy, of the eye, 56 .

Hygroma (serous effusion into the connective tissue), of the knee, 235 ; of the hock, 270.

Hypospadia, 814 .

\section{I.}

Immobility, $73,8,6$.

Impressionability, $4 \mathrm{ll}$.

Imprint, of the foot, 474 .

Impulsiou, from behinul, 522 ; mechanism of, 189.

\section{Inbornuess, 309.}

Incisor teeth, of the first dentition, 597 : seeonl, 601 ; $^{7}$ structure, 606 ; direction, 616 ; eruption, 637 .

Iuclined plane. liôle, 19: application to animal meehanics, 19; of surfice and of sergment, 20.

Iuduratious, 28T.

Inferior maxillary region. Situation, linits, anatomical base, beauties, 67 ; cliseases and blemishes, llessing of the hair, 6s; examination, 645 . 
Interaxilla. Situation, limits, anatomical base, 147 .

Interfering, 586, $58 \pi$.

Intermaxillary space. Situation, limits, anatomical base, defects, 65 ; diseases and blemishes, 66 .

Iris, 48 .

Irregularities, of number, 721,722 ; form, 726 ; fusion, 726 ; excessive or insufficient wear, 738 ; cribbing, 752 ; extraction of milk-teeth, 762 .

Irritability, 411.

Isabella (coat), 775 .

Ivory, 612 ; germ, 606 .

\section{J.}

Jarde, 275.

Jet black, 786 .

Jointed, long, short, 300,450 ; straight, low, 304,450 .

Juger (se), 474 .

Jumper. (See Leaper.)

\section{K.}

Keraphyllocele (horn tumor on the internal face of the wall), 339 .

Keraphyllons tissue, 315 .

Kickers, 874 .

Kicking, 471 ; like a cow, $87+$; vicious habit, 874.

Knee. Situation, limits, anatomical base, 227 ; movements, 228 : form, 229 ; fineness, thickness, wirlth, 230 ; height, direction, 231; clearness of outline, diseases and blemishes, 234.

Knee-action (high), 22.

Knee-sprung, acquired, congenital, 231, 450 .

Kuuckling, 297,450 .

L.

Lach rymal, gland, caruneula, puneta, ducts, sac, canal, 51, 61 .

Lameness. Definition, 588; recognition of, 589 ; acute, recent, chronic, 591 ; continued intermittent, cold, warm, 592 ; horse which limps on all-fours, 589 .

Laminar tissue, 315 .

Lampas, 79 ; burning of, 791 .

Lauky, 395.

Leaper, 575 .

Leaping. Definition, livisions, 569 ; varieties, 570 ; trail, 572 ; notation, 573 ; conformation of leapers, 575 .
Leg. Situation, limits, anatomical base, form, 246 ; movements, length, 247 ; width, 248 ; thickness, 249 ; direction, 250 ; discases and blemishes, 252 ; long, 247 ; thin, lean, fat, 250 ; fracture, 252.

Length of the body, 387 .

Leprous spots, 793 .

Leucoma, 56 .

Levelling, of the incisors, 615 .

Lever. Definition, equilibrium, 11 ; leverarm, 12 ; direction of the forces, 13 ; different classes, 16 ; fixed, inter-resisting, 16 ; inter-puissant, 17.

Life. Duration of the life of the horse, 642 .

Limı, on all-fours, 583 ; at ear, 43.

Limes. (Synonyme for length and direction of the regions.) Horse which has beautiful lines is symmetrical in his lines, 343 .

Lingual canal, 75 .

Lippitude, 56 .

Loins. Situation, limits, anatomical base, wilth, length, form, direction, 122 ; examinatiou, diseases, blemishes, 123 ; low, weak, false, dipped, narrow, feeble, 123; flinching over the loins, 123 ; strain, $123,585$.

Lop-eared, 43 .

Louvet (coat), 773 .

Louveture, 790 .

Luxation of the patella, 245 .

Lymphangitis (inflammation of the lymphatic vessels), 295.

Magpie, 798 .

M.

Maladie du coit, 184.

Malanders, 235 .

Mamma (region of the wall on each sido of the toe), 317 .

Mammae (glands secreting the milk). Situation, limits, anatomical base, external characters, diseases, blemishes, 186.

Mane. Situation, limits, form, 109 ; simple, double, 109 ; cutting of, 110 ; washed, mixed, 797.

Mange, of the neck, 109.

I arbled, 791.

Mark, white mark of the head, 794 .

Martingale, 92.

Mechanics, principles of, 11 ; muscular, 14 . Mécouvrir (se) (overchecking), 475.

Meibouian glands, 51.

Melanosis, of the eyelids, 56 ; of the tail, 174 ; of the anus, 180 ; of the sheath, 182 ; of the penis, 184 ; of the mammary gland, 186. 
Members. General considerations, 186; function, 186; wechanism of impulsion, 189 ; orientation and play of the Jocomotory angles, 190 ; space of oseillation, 191 ; mode of evolution during progression, 193 ; systematic analysis of the play of the, 195 ; regions of the anterior, 200 ; the posterior, 237 ; body and nembers, 395 ; direct axis or line of direetion, 441 ; line of axis of a, 442 ; axes of the anterior, 443 ; the posterior, 456 ; horse straight in the members, 294.

Iolars. Supplementary premolars, 622 ; posterior supplementary molars, 636; first dentition, 636 ; second dentition, 625 ; premolars, 625; hind molars, 626; development, 631 ; structure, 633 ; eruption, 610 .

lloment, of a force, 12; of a musele, 15.

Monorchid (without visible testieles), 186.

Moor - faced, 796 .

Moor-headed, 796 .

Mounted npou matches, 397.

Mounting side, 22.

Iouse-color, 778 .

Moustaches, 796.

Mouth. Situation, divisions, 69 ; temperament, 81 ; bitting, action of bit, 82 ; steady, sensitive, tender, delicate, easy, strong, hard, thick, spoiled, fresh, active, 81 ; mouth made, 655 .

Mule ray, 797 .

Mule's foot, 337.

Muscle. Insertion, 14; intensity and extent of contraction, 14 ; moment, 15 ; contraction, 414.

Iuscles, superficial, 28, 29, 30.

Near side, 22.

N.

Neck, of tooth, 597 .

Neck (region of body). Situation, limits, anatomical base, divisions, 98; form, 99; direction, carriage, 100 ; volume, 102; length, 103 ; attachments, 105 ; movements, 106; diseases and blemishes, 107 ; arched, swan-necked, stag-like, ewe-neckel, reversed, 99 ; vertieal, 100 ; horizontal, 101 ; oblique, 102: supple, 100; slender, thick, 103.

Necrosis, of the poll, 83 ; of the nuchal ligament, 108.

Neurotomy (seetion of the digital nerves), 309,578 .

Nicking, of the depressor muscles of the tail, 169.

Nictitans membrane, 51 .
Nose. Extremity of, situation, limits, anatomical base, 40 : blemishes, 41 .

Nostrils. Situatiou, limits, anatomical base, form, divisions, 59 : beauty, movements, 60 ; examination, 61 ; expression, blemishes, 64 .

Notation (of the gatits), 490 ; reproduction of, 500 ; mollel for; 500 .

Nuage, 56 .

\section{O.}

Cidema (exudation of serum into the connective tissue), of the abdomen, 151 ; of the scrotum, 180 ; of the sheath, 182.

Cistrus hemorrhoidalis (insect whose larvat inhabit the digestive canal of the horse), 175 .

Off side, 22.

Olecranou (head of the elbow), 56 .

One-eyed, 57 .

Onglet, 56 .

Open (horse), in front, 146, 151 ; behind, 268, 461.

Ophthalmia, 56 .

Orbital cavity, 50 .

Orchitis (inflammation of the testicle), 181.

Osselets, of the knee, 236 ; of the fetlocks, 297 ; of the pastern, 309 .

Outbow-footed, in front, 454 ; behind, 463.

Ovariotomy, 185.

Overreaching, 587 .

Overstretching, 288 .

\section{P.}

Pacing, 504.

Paddling, 586 .

Palate. Situation, limits, anatomical base, discases, 83 .

Paries. (See Wall.)

Parotid region, 84 .

Paring, of the foot; foot too much pared, 336.

Parrot mouth, $7 \pm 0$.

Parrot-toed, in front, 455 .

Pastern. Situation, limits, anatomieal base, 295 ; movements, torm, 299 ; width, thickness, length, 300 ; direction. 303 : neatness of outline, $30 \tau$; diseases, blemishes, 308 ; fold of, 300 ; exostosis, 309.

Patella (bone of the stifle). Fractures, luxations, 245.

Patineur, 530 .

I'each-blossom, $7 \& 1$.

Pedigree, 818 .

l'egred shoulders, $203,578$. 


\section{P'endulum, 184.}

I'enis. Anatomical base, beauties, defects, 183; diseases, blemishes, 184 ; paralysis of, 184.

Perched high, 397 .

Performances, 818 .

Perineum, 175 .

Periodic fluxion, 56 .

Periople, 320 .

l'erioplic band. (See Periople.)

Phlebitis, 109.

Piebald, 782.

Pincard foot, 333.

Pissy (mare), 185 .

Pituitary membrane, 62 .

Placer (attitude of the borse), $\mathbf{1 4 2}$.

Plantar cushion, $313,316$.

Podophyllous tissue, 315 .

Point, 439, 589 .

Pointed haunch, 140.

Pointing. (See Point.)

Poll. Situation, limits, anatomical base, diseases, blemishes, 83 .

Pommelé (dapples), 787 .

Posterior quarters, 22.

Pricking of the foot, 335 .

Proguathism, 736 .

Projectile, 479.

Proportions. Definition, relation of regions, 341; harmony and diseord, proportion and disproportion, 342 ; the agreeable, the beautiful, and the good, 344 ; history, 344 ; object and utility. 357 ; points of view from which the proportions are studied, $35 \bar{r}$; relations of dimensions between the parts, 358: of the man and the horse, 364 ; angular relations of the osseous segments, 365 ; theory of the similitude of the angles and the parallelism of the bony segments, 365 ; determination of the articular angles, 371 ; influence of the inclination of the bones upon speed, 382; general relation of the whole organism, 385 ; height, 386 ; length, 387 ; width, 395 ; relations between the body and the members, 395 ; relations of the organism with the nervous system, 397 ; isolated effects of beautiful proportions upon the animal machine, 404 ; conditions of the motor en mode de masse, or of force, 405 ; en mode de vitesse, or of speed, 407 ; of the mixed motor, $40 \mathrm{~S}$; excitability, impressionability, irritability, 110 ; result of beautiful proportions upon the mechanism, endurance, 412; definitive synthesis, 429; proportions viewed in profile, 360 ; of the head, 361 .
Pulmonary emphysema, 116.

Pulp cavity, of tooth, 600 .

Pulp (dental), 600 .

Pupil, of eye, 48 .

\section{Q.}

Quarter, of hoof, 317 ; false, 339.

Quitter, 310, 339.

\section{R.}

Race, 403 .

IRace $=$ horses, $\$ 26$.

Racking, 522 .

Raising of the skin, 660 .

IRammy foot, 339 .

Rampin. (See Pincard.)

Raplié, 175 .

Rassembler (attitude), $\$ 40$.

Reactions, of the boly, 479 .

Rearing, 468 .

Regions, of the horse (table), 23 ; in profile, in front, behind, $24,25,26,27$.

Reflex power, 400 .

Retina, 49 .

Ribs, 152.

Ridgeling, 179 .

Riug-bones, 311 .

Ringed, 185 .

Roan (eoat), 782 .

Roarer (horse affected with roaring), 64

Rubican, 788 .

Ruuaway horse, 879 .

Running-horse, 826 .

Rusty, 791 .

\section{s.}

Sallenders, 270 .

Sarcocele, 181.

Sclerotic coat, of the eye, 48 .

Scrotum. Anatomical base, 176 ; beauties, 177.

Seams, of the quarter, the toe, 337 ; the bar so barred, 338.

Seat (of the rider), 553,576 .

Seedy-toe, of the wall, 339 ; of the sole, ว339.

Seller, 887 ; tricks resolted to by, elipping, 891 ; diet, 887 ; grooming, 887 ; light, 887 ; shoeing, 891 ; training or dressing, sss; toilet, 889.

Shaft-horses, 852 .

Sheath. Anatomical base, diseases, blemishes, 182; horse which urinates in his sheath, 184 . 
Shoe, 335 ; wide-webbed, 328 ; semi-covered, 329 ; covered (width of the branches of the shoc), 329 .

Shoe-boil (fibrous tumor of the elbow), 221.

Shoeing, 335 ; accidents from, 335.

Short-ivinded, 165.

Shoulder. Situation, limits, anatomical base, form, 201; movements, 202 ; length, 205 ; length in relation to the arm, 205 ; direction, 207; scapulo-lumeral angle, 209; position, muscularity or volume, 212 ; diseases, blemishes, 213; erest, point, 201 ; angle blemish, 202; pegged, 203; long, short, oblique, 204; vertical, 205 ; wel] placed, forward, 212 ; well ontlined, meagre, lean, atrophied, massive, fleshy, thick, 213 ; cold or pegged, 578 ; horse upon his shoulders, 562 .

Shyers, 876 .

Side (mounting, left side of the horse), 22 .

Sides. Situation, limits, anatomical base, form, movements, beauties, 152 ; round, flat, incurvation, 153 : length, 154; defects, diseases, blemishes, 156.

silver (reflection), 786 .

Similitude of the angles, theory of (General Morris), 365.

Skipping, 527.

Skittish, 43 .

Sneezing, 64 .

Snowballs (spots), 788 .

Snow-flakes, 788 .

sole, of the foot, 378 ; bruised, 338 ; burnt, 336 ; heated, 336.

Solid-colored, 787 .

Soot-balls, of the eye, 49 .

Sorrel (eoat), 773 .

Sound of the frog, 182 .

Spavin, 273.

Speed, condition of the motor for speed, 407 .

Splints, 288; chained, pegged, simple, spindle-shaped, 289.

Square lorse, 391 .

Standard, 809 .

Station (attitude of the horse), 438 ; foreed, camped, gathered up, 440.

Steeple-chaser, 827 .

Step, 475 ; length, 476 ; periods, 476 .

Stifle. Situation, limits, anatomical base, 244 ; neatness of outline, direction, diseases, b]emishes, 245 ; foll, 244 .

Strain, of the eoxo-femoral articulation. 141: of the loins, 585 ; of the shoulder, 214; of the tendons, $28 s$.

Striking, 587 .
String-halt, $272,579,592$; in front, behind, 580 .

Stroug-limbed, 243.

Stud-book, 818 .

Stumble, 230, 577 .

Superuumerary digits, 281.

Support, base of, 10.

Supra-orbit. Situation, limits, anatomical base, beauties, fraudulent practices upon, 47 .

Surfeit, 110.

Suspension, of the body, 478 .

Sway-backed, 117.

Swine-ear, 43 .

Switching of the tail, 173 .

Symmetry, beautiful, 343 .

Synovia (riscid fluid lubricating the articulators).

Synovial dilatations, of the hosk, $2 \pi 1$, 272 ; of the kuee, 236 ; of the stitle, 245.

\section{T.}

Tail. Situation, limits, anatomical base, divisions, attachment, carriage, 168; state of stump and hairs, 170 ; forms, 171 ; dressing, 172 ; movements, 173 ; diseases, blemishes, 174 ; frauds, 173 ; entire, with shortened hairs, 170 ; short, full, banged, 171 ; bushy, club-tail, rat-tail, 172 ; dockel, 169 ; washed, mixed, 797 ; examination of the norles, 646 .

Teeth. Definition, number, distribution, 594; incisors, 597 ; canines, 619; molars, 621 ; eruption, 637; examination, 646; characters furnished by the teeth, 648 ; irregularities, 722 ; of number, 722 : of form, 726 ; of fusion, 726 ; form of central enamel, 727 ; depth of infundibulum and its external dental carity, 729 ; defect of length or excess of width of one of the jaws, 736: excessive or insuffieient wear, 738 ; cribbing, 752 : fraudulent means, 762.

Teeth, foetal, milk, deciduous, 597 ; virgin, 60.3 ; wolf, 622 .

Temple. Situation, limits, anatomieal base, distinctness, freedom from blemishes, disenses, blemishes, 46 : gray temples, 47 .

Tendon, 283: well detached, 283; strains, 288 ; horse which has snapled a tendon, 288 ; weak tendons, 285.

Testicles, Siquation, limits, anatomical base, 176 ; examination, $17 T$; beauties, 178 ; diserses, blemishes, 180 .

Thigh. Situation, limits, anatomical basc, form, 237; movements, 238 ; direction, 239 ; length, 242; willh, thickness, peeuliar 
murkings, 243; diseases, blemishcs, 244; flat of the thigh, 238; flat, lean, froggy, shar ', 243 .

Throat. Situation, limits, anatomical base, beautics, defects, examination, diseases, blemishes, 85 .

Thrombus, 109 .

Thrush, 337.

Time, 474.

Timill horses, 876 .

Toe (of the wall), 317 .

Tongue. Situation, limits, anatomical base, examination, 76 ; beauties, defects, blemishes, 78; horses which loll the tongue, double it uj, or protrucle it frow the mouth, 859.

Trachea (windpipe), 99.

Tracheotomy, 108.

Track (suceession of footprints), 475 .

Trail. (See Track.)

'Trichiasis, 56.

Troop horses, 846 .

Trot. Trails, varieties, 571 ; play of the members, 513 ; rhythm of the beats, time, projection, tracing, and notation, 574 ; displacements of the centre of gravity, reac tions, 517: length of the stride, velocity, 579 ; beantics and defects, 521 ; horse which trots in the stable, 863 ; broken trot, flying trot, racking, 522 .

Trotter, in harness, 829 ; under the saddle, 832.

Trunk, inferior line of, 396 ; superior line of, 396.

Tuft of the chin, 68 .

\section{U.}

Under himself (horse), in front, 448 ; behind, 458 .

Urethra, 183 ; fissure of, 814 .

Urethrotomy (incision of the wrethra to remove stone (calculi) from the bladder), 175.

Uvea, 49 .

\section{V.}

Vaginal sheath, of the testicle, 177.

Varicocele, 181.

Variola equina, 186 .
Velvety tissue, 316 .

Vices of character, 857 .

Vices properly so called, 869 ; general causes of, 882 .

Vicious liabits, enumeration of, 858 .

Vicious horses, 857.

Vitreous humor, 50.

Vulva. Situation, limits, anatomical base, external charucters, 185 ; diseases, blemishes, 186 ; rupture, 186.

\section{w.}

Walk. Definition, play of the members, 530 ; order of beats, tracing, and notation, 532 ; varieties of the rhythm, 536 ; trails of the walk and their varieties, 537 ; length of the step, speed, 540 ; displacements of the centre of gravity, reactions, confirmation, 541 ; running, 529 .

Wall of the hoof, 316 .

Wall-eye, 55,796 .

Wanting in form and symmetry, 343 .

Warts, of the eyelids, of the sheath, of the vulva, 186.

Washed, 793 .

Wavy (water) (reflection of coat), 787.

Well rumped, of horse, 243.

Whip, sos.

White-feet, 798 .

White markings, of the coat, 789 .

Width of body, 395 .

Winded, 165.

Windgalls, 296.

Wiud-sucker, 753 .

Wine-colored, 791 .

Withers. Situation, limits, anatomical base, beauties, defects, form, 111; height and extent, 112; thick, low, sharp, 112 ; prominent, 113; muscular, effaced, 114; mode of suspension, 114; diseases and blemishes, 116 .

\section{X.}

Xiphoid region. Situation, limits, anatomical base, diseases, blemishes, 148 .

\section{Z.}

Zebra marks, 799 

i) 36

7asplap thom as

619.1

$G / 21 . E H$

1592 

